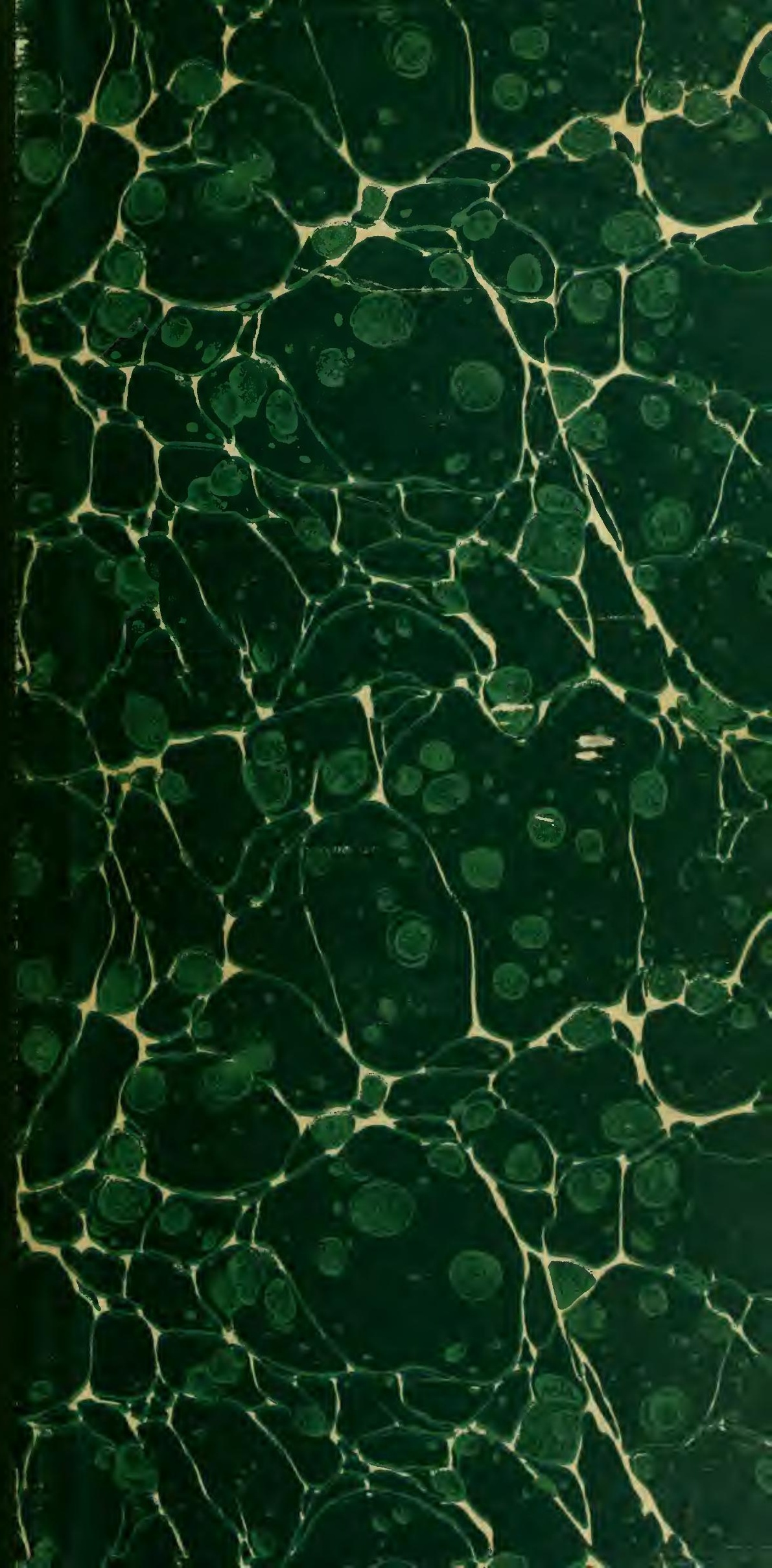




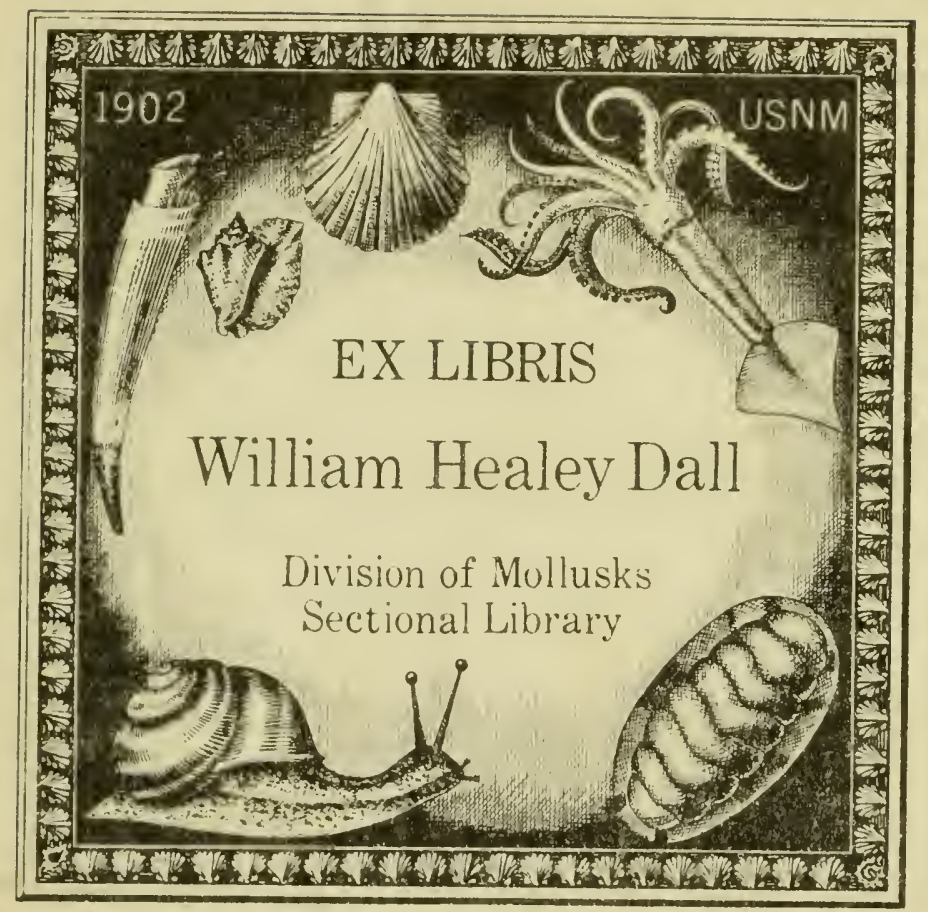




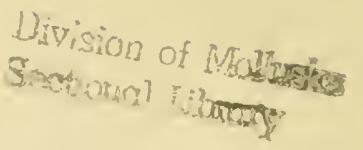








\section{Mollusca of the Southwestern States.}

I: Urocoptidæ; Helicidæ of Arizona and New Mexico.

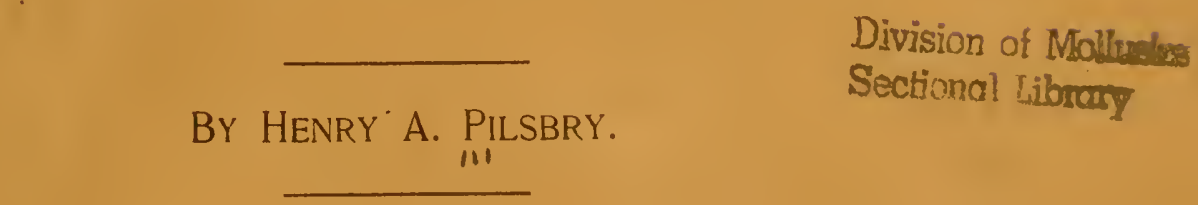

From the Proceedings of The Acudemy of Naturul Sciences

of Phaladelphin, March, 1905.

Issued May 18, 1905.

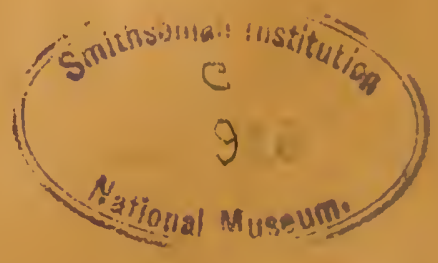



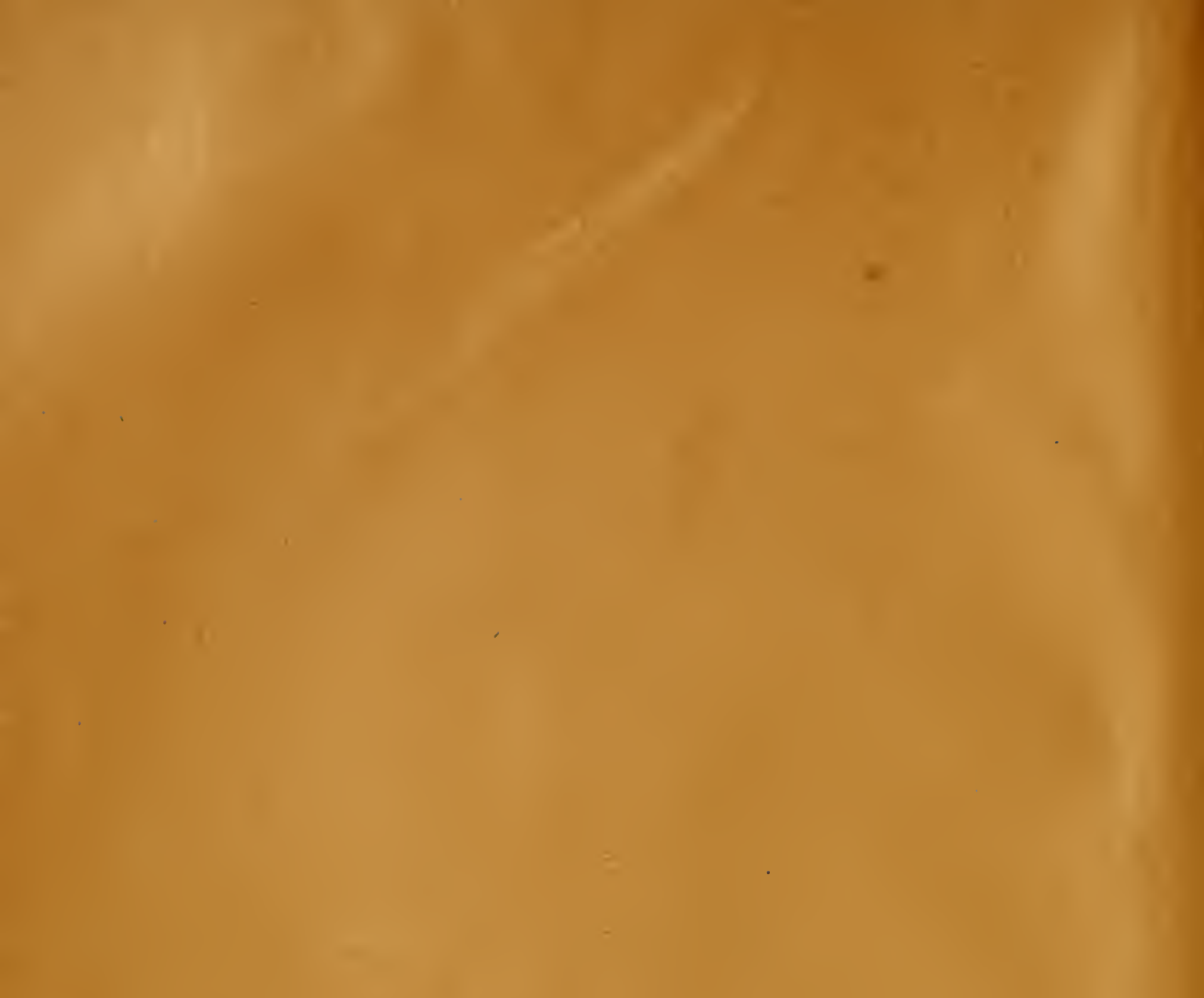

1.

, - 1
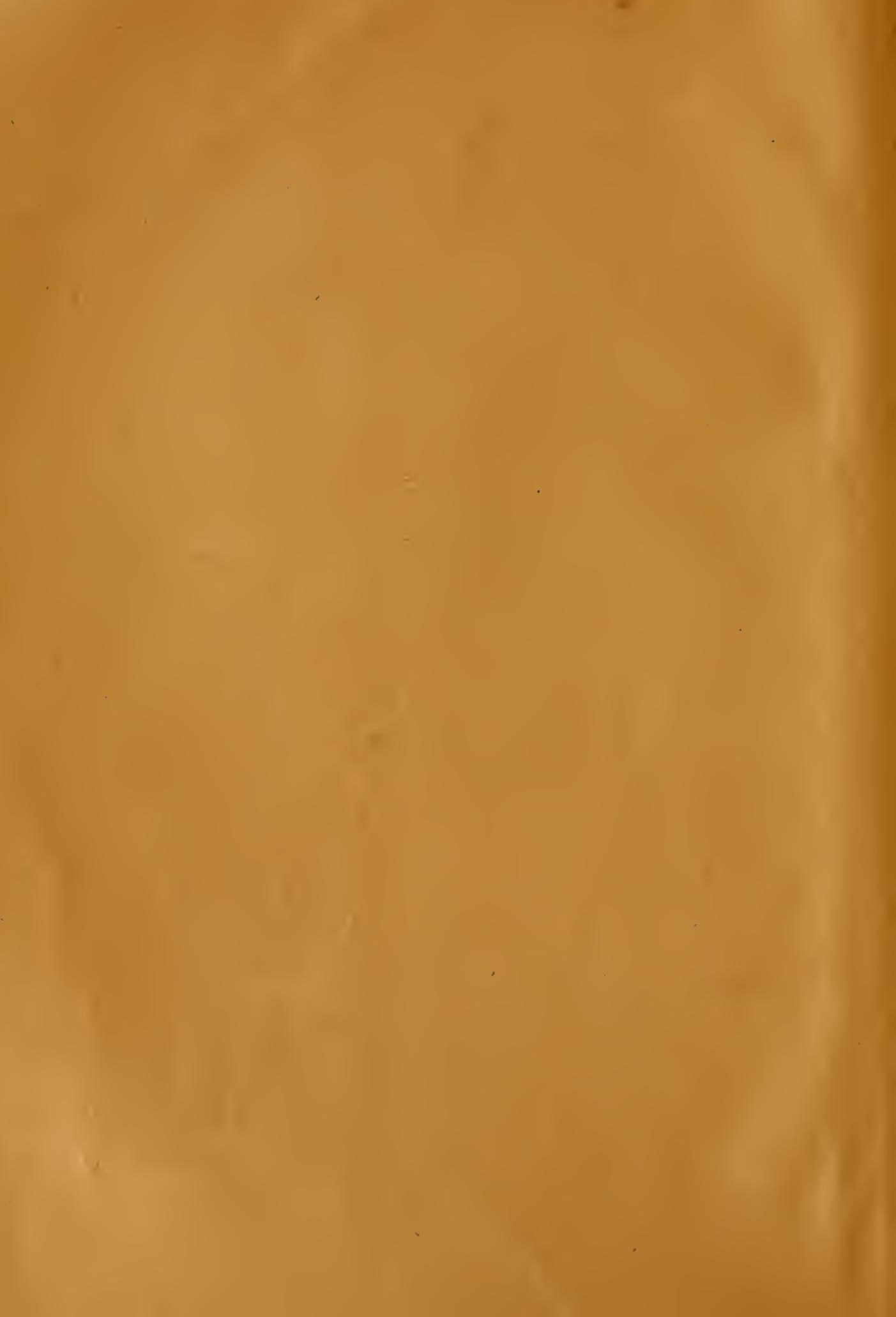


\section{MOLLUSCA OF THE SOUTHWESTERN STATES, I: Uroooptidæ; Helicidæ of Arizona and New Mexioo.}

BY HENRY A. PILSBRY.

In these papers the mollusks eollected by Mr. James H. Ferriss and the writer in the expedition made in 1903 and by Mr. Ferriss in two visits to Arizona in 1902 and 1904 will be diseussed. The present contribution deals chiefly with Mr. Ferriss' researches in Arizona, where an extraordinarily rich and varied snail fauna was found in the canyons of the Chiricahua and Huachuca Mountains. In the study of these materials I have worked over many specimens received from the late $\mathrm{E}$. $\mathrm{H}$. Ashmun, who first made known to us the richness of the Arizona snail fauna, and from Prof. T. D. A. Cockerell, whose uneeasing labors on the fauna and flora of New Mexico are familiar to all naturalists. The treatment of the genus Ashmunella has been made practically monographic.

It is unfortunate that no good topographic survey of southern Arizona has been published. It is extremely difficult at present to determine some localities given by previous naturalists, or to clearly indieate the positions of those explored by Mr. Ferriss. The aceompanying sketeh of the canyons explored in the Huachucas makes no pretensions to cartographic accuracy beyond showing the relative positions of the localities mentioned in the text. From Fort Huachuca to Ramsey Canyon is 10 miles; to Carr Canyon 14, and to Miller Canyon 20 miles. Manilla mine is 6 miles from Fort Huachuca. The range is about 30 miles long and 6 wide.

Of the Chirieahuas, it may suffice to say that Bar or Bearfoot Park is on the summit, and is believed to lie at 8,500 feet elevation. There was a sawmill there in 1904. From it toward the southwest Sawmill Canyon leads, and Cave creek flows down from the opposite side. This must not be confused with Cave Creek Canyon in the Huachueas. Fly Park, the type locality of Ashmunella chiricahuana, is on the same mountain, farther south about two(?) miles. Cave creek is 30 miles from Nine-Mile Canyon, and 20 miles from Fort Bowie. Mr. Ferriss has given notes on the general conditions of collecting and on the country in the Nautilus for September, 1904.

Some considerations of general interest to evolutionists are touched 
upon in the discussion of the composite nature of snail colonies (p. 226), since the conclusions reached from mollusean studies apply equally to communities of other comparatively sedentary animals.

Throughout the preparation of this paper I have had the coöpcra-

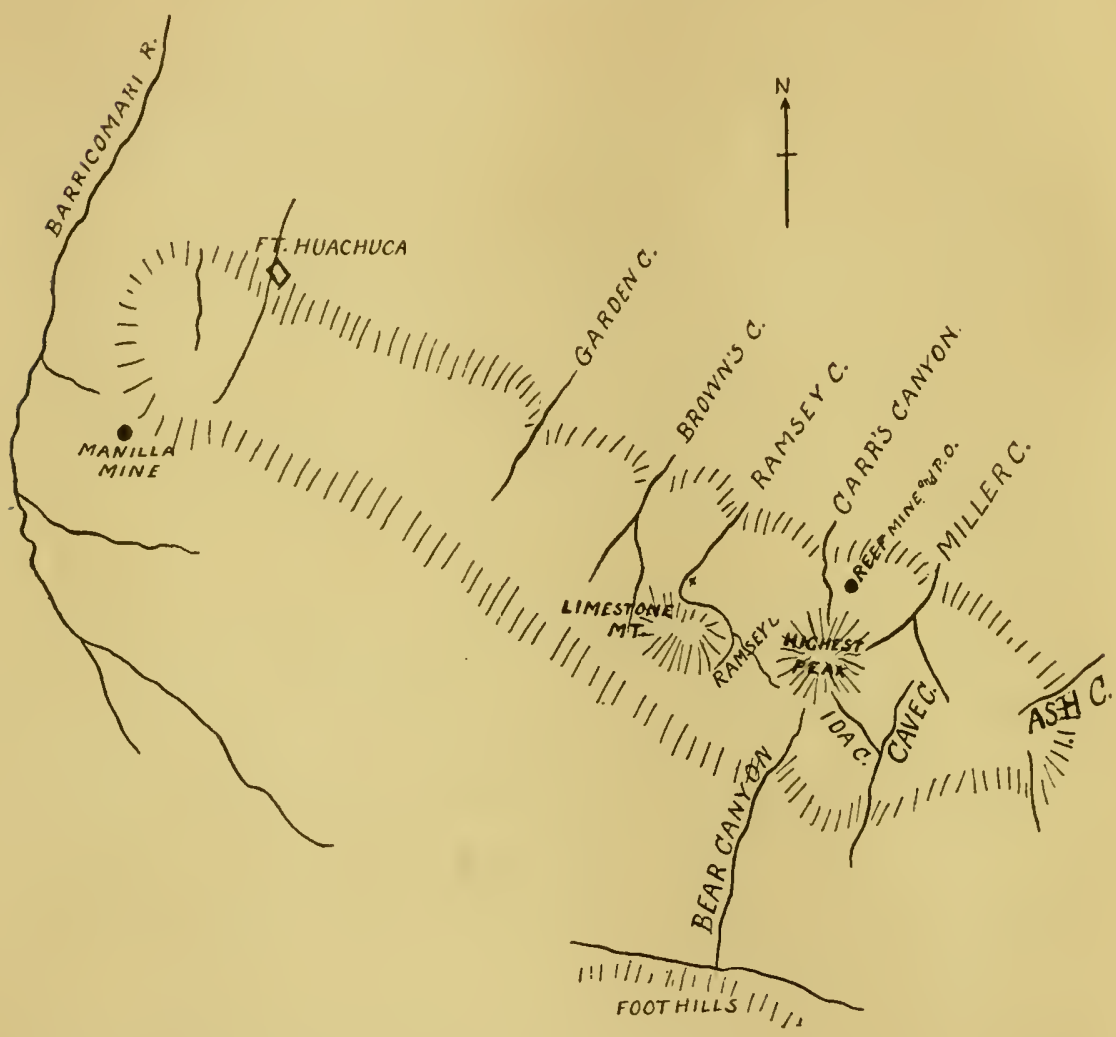

Sketch of Huachuca range, by J. H. Ferriss.

tion of Mr. J. H. Ferriss. I would also gratefully acknowledge assistance lent by Dr. Wm. H. Dall, in the comparison of various species of Holospira, etc., with those described by him.

The figures of shells were photographed and those of soft anatomy drawn by the author. 
Family UROCOPTID $\nRightarrow$ Pils.

This family is represented in the Southwest by members of two very distinet subfamilies: Eucalodinæw with the genus Holospira, and Microceramin.玉 with the genus Microceramus.

Holospira is an old genus, containing several highly specialized phyla. Our species fall into five groups as indicated below. The subgencra were formerly defined by the internal lamellw alone; but these are in some cases of less significance than the general form and seulpture.

A.-Last whorl distorted, its last half turning sinistrally.

I.-Internal column rather large, smooth throughout; last whorl sinuous, turning sinistrally. Aperture oblong, with a strong fold within the right margin and a vertical columellar callous in the throat. Metastoma Strebel. One species, $H$. roemeri.

B.- - Last half of the last whorl straightened, normal.

II.-Internal column small, smooth and simple throughout, or with a small axial lamella in the last whorl; very slender below, slightly wider above. Shell rather large, 19 to 29 $\mathrm{mm}$. long, the individual whorls comparatively high; the last one or two more coarsely sculptured than the intermediate ones. Number of whorls much less than the number of millimeters in the length of the shell. Haplocion Pils. Species, H. pasonis Dall, H. hamittoni Dall.

III.-Penultimate whorl with a short, stout lamella on the axis, and a weaker one on the basal wall. Number of whorls decidedly less than the number of millimeters in the shell's length. Distomospira Dall. Species, H. bilamellata Dall.

IV.- Internal column moderate, one-fourth to one-sixth the diameter of shell. Shell 9 to $18 \mathrm{~mm}$. long in known species, compactly coiled, ribbed or striated, the whorls short, their number about equal to the number of millimeters in the length of the shell, or exeeeding that number. A short axial lamella is present within the penult. whorl, and sometimes short basal or parietal lamellæ. Bostrichocentrum Strebel. Type $H$. tryoni.

V.-Cavity of the penultimate whorl obstructed by four strong lamellæ, axial, basal, parietal and palatal. HoLospira s. str. Speeies, H. goldfussi Mke.

In addition to the species noticed below, the following species of Holospira are known from north of the Mexican boundary:

$H$. (Bostrichocentrum) pilsbryi Dall, rather doubtfully recorded from New Mexico or Arizona, without definite locality, and known to inhabit the Mexican state Puebla.

H. (Distomospira) bilamellata Dall, from the top of Hacheta Grande Mountain, Grant county, New Mexico. 
H. (Haplocion) pasonis Dall, from Mule Canyon, El Paso county, Texas.

H. (Haplocion) hamiltoni Dall, from Rio Grande Mountains, Brewster county, Texas, at an elevation of 3,500 fect, living on Sclaginella lepidophylla, a common and conspicuous moss of western Texas.

Subgenus HOLOSPIRA (typical group).

Holospira goldfussi (Menke). Pl. XXVI, figs. 1-5.

Like $H$. roemeri, this species belongs to the hill country bordering the Lower Cretaceous area in Texas. Mr. Ferriss and the writer found it

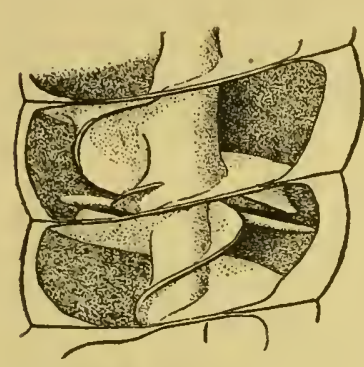

Internal structure of $H$. goldjussi. above San Marcos, Hays county, Texas, in the flood-débris of Sinking Spring, and on ledges of its bordering limestone cliff. This is farther northeast than the spccies has hitherto been found, for I have no doubt that the locality "Dallas," cited by Strebel, is an error. It is abundant under stones at the foot of the cliffs along the Guadalupe river, about six miles above New Braun-

It varies a good deal in size:

fels, Comal county. Also nearer the town, in the hills above the head of Comal creek.

Length 14, diam. 4 mm.; whorls $14 \frac{3}{4}$.

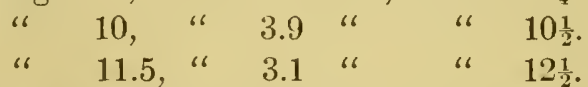

The specimens figured are from the Guadalupe. New Braunfels is probably the type locality.

At the Hondo river, two miles north of Hondo, Medina county, in the drift-débris, we also found $H$. goldfussi. This is the extreme western range of the species as far as we know. It did not occur in the Devil's river region, on the Pecos or westward.

\section{Subgenus BOSTRICHOCENTRUM Strebel.}

All of the species have a small, short lamella on the axis in the last part of the penultimate whorl, sometimes almost obsolete, and some of them have a very weak basal or parictal lamella, or both. These lamellæ are always very much smaller and lower down than those of typical Holospira (goldfussi, etc.). The variations are as follows : 
Species.

H. ferrissi:

Lamella present.

H. arizonensis: axial, parietal, .......

H. bilamellata: axial, ….... basal.

H. mcarnsi:

axial,

In $H$. crosse $i$ the axial lamella is so weak as to be readily overlooked.

Part of the species of this group have the terminal cone short, others having it very long; $H$. crossei being somewhat intermediate. Otherwise they are very similar externally. They may be grouped thus:

\section{Cone of the spire short, rapidly tapering.}

Three internal lamellæ ....ferrissi.

Two internal lamellæ ......arizonensis.

Ribbed throughout.

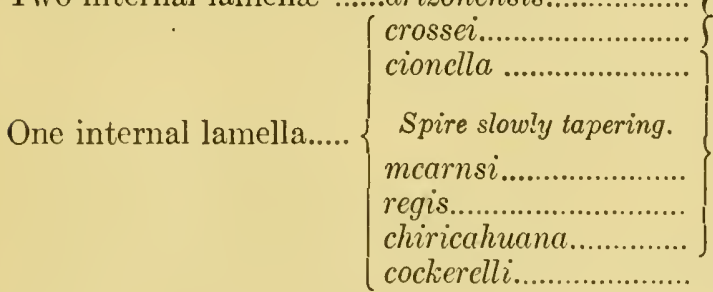

Median whorls

smoothish.

Ribbed throughout.

Median whorls smoothish.
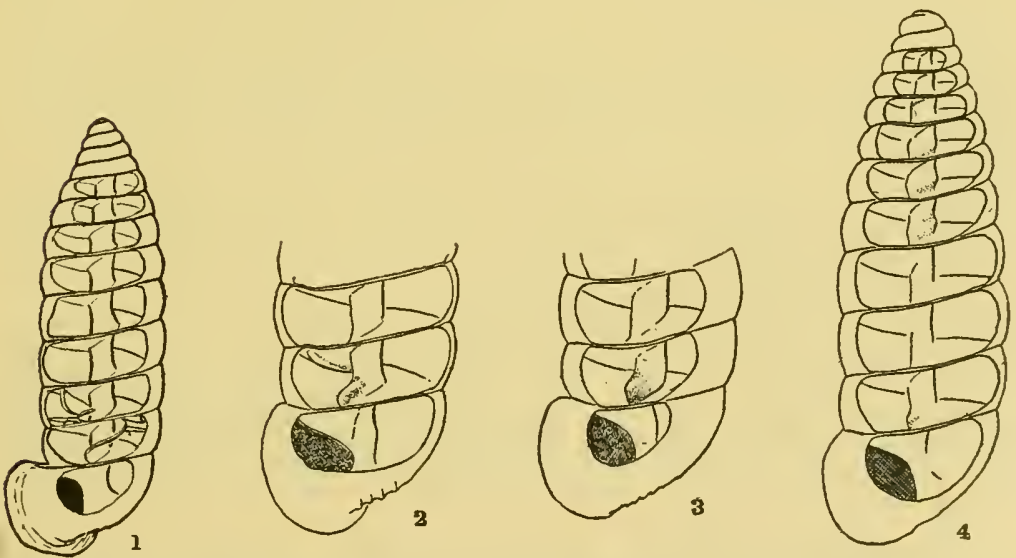

Fig. 1.-Holospira goldfussi. 2.-H. ferrissi. 3.-H. cionella. 4.--H. chiricahuana.

Holospira ferrissi n. sp. Pl. XXVII, figs. 22-25.

The shell is rimate but imperforate, short and cylindric, rather thin, and very pale brownish-corneous. Whorls $9 \frac{1}{2}$ to 11 , the first whorl wider than the second, both of them smooth; all the rest of the whorls are regularly, evenly and closely rib-striate, the riblets as wide as their 
intervals or a little narrower, except on the last whorl, where the sculpture is a little coarser and irregular. The whorls are all convex, the last 4 or 5 forming the cylindric portion, the preceding whorls forming the terminal cone, which is about one-third the total length of the shell. The last whorl is pinched or compressed laterally, but the very short straight "neck" is full again, and carries the aperture very shortly free. The aperture is rounded, but a little irregular, the upper margin being somewhat straightened. The thin peristome is narrowly expanded.

The internal pillar is rather large and of equal calibre in the cylindric portion of the shell. At the end of the penultimate and beginning of the last whorl there is a short strong and blunt lamella on the pillar below the middle, a low, short lamella on the parietal wall and another on the basal wall. There is no palatal lamella.

Length 7.5 to 9 , diam. $3 \mathrm{~mm}$.

Manilla mine, Huachuca Mountains.

This is a very short, thick-set species, unlike all others known in its internal armature. The even ribbing and short terminal cone are also characteristic. It is closely related to $H$. arizonensis Stearns, from Dos Cabezas, a place west of the Chiricahua range and not far from one of the localities of $H$. ferrissi; but besides the slight difference in internal structure, $H$. arizonensis differs in being slightly larger with more whorls, and the riblets arc subobsoletc on the cylindric portion of the shell, while in $H$. ferrissi they are even stronger there than on the terminal cone.

This species occurred also at Fort Bowie, Arizona, where the shells average a trifle larger:

Length 7.5 , diam. $3 \mathrm{~mm}$., whorls $9 \frac{1}{2}$.

Length 10 , diam. $3 \mathrm{~mm}$., whorls $11 \frac{1}{2}$.

This'species seems to partially connect typical Holospira with the sections Eudistemma and Distomospira. The lamellæ are far shorter and weaker than in the typical section, in fact, might easily be overlooked.

\section{Holospira arizonensis Stearns.}

This shell is cylindric with a short, ribbed, terminal cone. The median whorls are smoother, only obscurely sculptured, and the last whorl is ribbed. Whorls 12 or 13 .

The internal axis is moderately large, and there is a short lamella on the axis and one on the parietal wall or roof in the penultimate whorl.

Length 12.5 to 13 , diam. $4 \mathrm{~mm}$.

Southeast Arizona, at Dos Cabezas, Cochisc county. 
This species resembles $H$. ferrissi and $H$. cionella in shape, but differs by its larger size and the obsolete sculpture of the median whorls, as well as by the slightly different internal lamellæ. It is known by the original specimens only.

Holospira cionella 11 sp. Pl. XXVII, figs. 30-83.

The shell is very shortly rimate but imperforate, cylindric with a short terminal cone, corneous-white. Whorls $11 \frac{3}{4}$ to $12 \frac{1}{2}$, convex, the first $2 \frac{1}{2}$ smooth, second whorl narrow, the first wider and bulging. Subsequent whorls are sharply and closely ribbed throughout. The last whorl is compressed laterally, tapering downward, the base white, rounded and prominent; it is contracted, descends a little, and is shortly free in front. The aperture is very shortly ovate, the peristome thin and narrowly expanded. The axis is moderately large and cylindric, with a low, blunt lamella at the end of the penultimate and beginning of the last whorl.

Jength 10 to 12 , diam. $3 \mathrm{~mm}$.

Fort Bowie, Cochise county, Arizona.

The uniform ribbing throughout, the cylindric shape and short terminal cone are the prominent features of this species, which groups with $H$. mearnsi, cockerelli and chiricahuana.

\section{Holospira crossei Dall. Pl. XXVI, fig. 8.}

This species is closely related to $H$. cockerelli, but differs by its wider shorter form and much shorter terminal cone of the spire. At the end of the penultimate whorl there is a very weak prominence upon the axis near the basal wall, hardly to be called a lamella. The tapering portion of the spire is ribbed, the cylindric portion smoothish.

Length 11, diam. $3.7 \mathrm{~mm}$.

New Mexico; top of Hacheta Grande Mountain, Grant county, with $H$. mcarnsi and $H$. bilamellata.

Figured from one of the original lot for comparison with the related species. It has not again been found.

\section{Holospira mearnsi Dall.}

The spire tapers gradually and is ribbed, the ribs somewhat weaker on the intermediate whorls, stronger again at the base. Whorls 14 . The axis is small, with a short, strong lamella near the base in the penultimate whorl, as in $H$. cockerelli and $H$. regis. Length $14.5 \mathrm{~mm}$.

Southwestern New Mexico, on the top of Hacheta Grande Mountain, Grant county, with $H$. crossei, a smaller species with less projecting aperture. 
Holospira regis Pils. and Ckll., n. sp. Pl. XXVI, tig. 7.

Shell small, the lower half cylindric, upper half slowly tapering in a long cone to the obtuse apex. Whorls $12 \frac{2}{3}$, all convex, the first two smooth, the following whorls of the tapering portion of the spire rather strongly, obliquely rib-striate, the riblets slightly narrower than their interstices; the penultimate and next carlier whorls are more closcly and a little more finely sculptured, but on the last whorl the riblets become stronger again. The last half of the last whorl is compressed laterally, sloping to an almost subangulate but very obtuse base. Near the end the whorl becomes free, descends a little, and is flattened and excavated above. The aperture is obliquely piriform, its contour being compressed near the upper outer angle. The peristome is free throughout, expanded, the columellar and upper margins a little reflexed. The upper margin is a little dilated inwardly. The axis is small and slender. Near the end of the penultimate whorl there is a short, stout lamella on the axis near the basal wall.

Length 10.8 , diam. of cylindric portion $3.3 \mathrm{~mm}$.

Near Kingston, Sierra county, New Mexico. Type No. 87,208, A. N. S. P., collected by Mr. O. B. Metcalfe.

This species is about the size of $H$. chiricahuana, which, however, differs in the less projecting last whorl, contracted behind the lip, and in the smaller, differently shaped mouth. The more closely related $H$. mearns $i$ is larger with more whorls, but it is not unlikely that specimens intermediate in these respects will be found. Several broken shells of $H$. regis indicate dimensions smaller than those of the type.

Holospira cookerelli Dall. Pl. XXVI, fig. 6.

Holospira (Haplostemma) cockerelli Dall, Nautilus, XI, p. 61, October, 1897.

Shell cylindric below, the upper half tapering in a long, very slowly tapering cone to the obtuse apex. Whorls $13 \frac{2}{3}$, convex, the upper ones more so. The first $2 \frac{1}{2}$ form the smooth embryonic shell, the second of them being wider and more swollen than the following one. Post-embryonic whorls of the tapering spire rather strongly rib-striate, the riblets oblique, narrower than the rather wide intervals. On the cylindric portion the riblets weaken to irregular growth wrinkles, but the base and the last half of the last whorl are strongly ribbed again. The last whorl is well rounded below, projects forward but very shortly, and descends to the mouth. The aperture is obliquely rounded-piriform, produced at the upper outer angle. Iip well expanded, the columellar and upper margins narrowly reflexed. The axis is slcnder. There is a low weak lamella on the axis in the last part of the penultimate whorl, close to the basal wall. 
Length 12.1, diam. $3.5 \mathrm{~mm}$.

The type was found in the débris of the Rio Grande at Mesilla, New Mexico. The specimen described above is from near Kingston, Sierra county, New Mexico, collected by O. B. Metcalfe, sent by Prof. T. D. A. Cockerell.

$H$. cockerelli differs from the related $H$. regis and $H$. mearnsi chiefly by the smoothness of the intermediate whorls. It is not improbable that the original specimen found in the flood-clebris of the Rio Grande was washed down from the region around Kingston, as Prof. Cockerell suggests to me.

Holospira chiricahuana n. sp. Pl. XXVI, fig. 9; Pl. XXVII, figs. 26-29.

Shell imperforate, shortly rimate, eylindric, the upper half tapering, thin, pale brownish-corneous. Whorls 11 to 12 , all convex, the first slightly bulging and wider than the second, both smooth, the following whorls sharply sculptured with close riblets a little narrower than their intervals. The last whorl is compressed laterally, tapering downward, the base prominent and white. It is very shortly straightened and a little contracted in front, not carrying the aperture in front of the ventral plane of the shell, though the peristome is very shortly free. The aperture is shortly ovate, nearly round, the peristome very narrowly expanded.

The axis is moderately large and of nearly equal calibre throughout, and at the end of the penultimate and beginning of the last whorl there is a low, short obtuse lamella below the middle on the axis.

Length 10, diam. $3 \mathrm{~mm}$.; whorls 12.

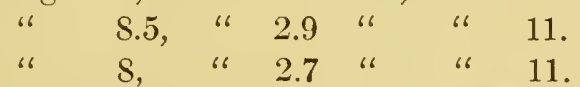

Cave Creek Canyon, Chiricahua Mountains, southeast Arizona. Also Fort Bowie, at the southeastern termination of the same range.

$H$. mearnsi Dall is a larger and smoother species. In H. cockerelli the sculpture is coarse on the early and last whorls only, the middle ones having a polished or at least smoothish surface with quite faint striation only. The spire in $H$. chiricahuana tapers more gradually than in most other species.

Some of the specimens from Fort Bowie are larger, length 13, diam. $3.25 \mathrm{~mm}$.; whorls 14; and one from Cave Creek Canyon, the type locality, measures length 13.5, diam. $3.2 \mathrm{~mm}$; whorls 14 . The riblets are strong and uniform throughout in all the specimens. 
Subgenus METASTOMA Strebel.

Holospira roemeri (Pfr.). Pl. XXVI, figs. 10-18.

This peculiar snail inhabits the hilly border of the 1,000 foot elevation which roughly defines the southeastern limit of the Lower Cretaccous area in Texas. It has not been observed northeast of New Braunfels. Thence it has been traced westward in Medina county, and near the Rio Grande, at Devil's river and the Pecos. We know nothing of its distribution northward upon the "Edwards Plateau," since only its lower scarps have been explored. Westward we have it from El Paso, where Ferriss got specimens on Franklin Mountain in 1902; and in New Mexico Rehn and Viereck found it in Alamo Canyon, near Alamogorda, Otero county, in the eastern range of the Cordillera.

The specimens from El Paso are large, like those of the Pecos. An average one measures, length 15.5 , diam. $4.5 \mathrm{~mm}$.; whorls 14 . Those from Alamo Canyon are smaller, 12 to $13 \mathrm{~mm}$. long, 4 wide. They vary but little in size.

In the canyon of the Pecos river, in Valverde county, Texas, above and below the High Bridge (figs. 16, 17, 18), the specimens are larger than at any other locality, and have more whorls for their length. The base is narrowly and deeply excavated, and the last whorl is very strongly sigmoid and projects in a longer neck than in the shells of central Texas. Most of the shells measure 15 to $16 \mathrm{~mm}$. long, 4 wide, few being larger or smaller.

Length 17, diam. $4.7 \mathrm{~mm}$; whorls $15 \frac{1}{2}$.

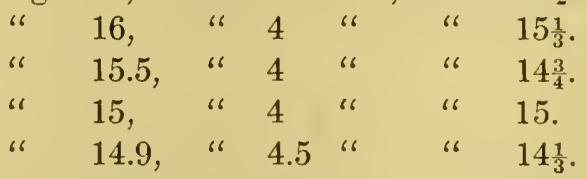

In the drift-débris of Devil's river, Valverde county, Texas, about four miles from its mouth, a large majority of the shells are 14 to 15 $\mathrm{mm}$. long, with $14 \frac{1}{2}$ to $15 \frac{1}{2}$ whorls. The base and neck are like the larger shells of the Pecos.

Length 15.2, diam. 4 mm.; whorls 16.

\begin{tabular}{|c|c|c|c|c|}
\hline 15 & "6 & 4 & "6 & "6 \\
\hline 14.9 & " & 3.9 & " & " \\
\hline 14.9, & "6 & 3.8 & " & "6 \\
\hline 14.3, & "6 & 4.2 & " & "6 \\
\hline 13.8, & "6 & 4 & " & " \\
\hline 14 , & " & 4.1 & $"$ & $" 6$ \\
\hline 12.9 , & " & 4 & $"$ & $"$ \\
\hline
\end{tabular}


Hondo river, two miles north of Hondo, Medina county, Texas (figs. 10-15). The shells are much smaller than in western Texas, usually 11 to $12 \mathrm{~mm}$. long, and the diameter is generally less than $4 \mathrm{~mm}$. A large proportion of the shells have "overhanging" upper whorls. They were picked out of river-débris, and probably came from the hill country some miles farther north. The measurements of fifty aduit shells, all the perfect ones I found, follow:

$\begin{array}{lccccccccc}\text { Length } & 15 & 13.8 & 13 & 13 & 12 & 12 & 12 & 11.7 & 13 \\ \text { Diam. } & 3.8 & 4 & 3.5 & 3.7 & 3.9 & 3.6 & 4 & 3.3 & 4 \\ \text { Whorls } & 15 & 14 \frac{1}{2} & 13 \frac{1}{3} & 13 \frac{1}{3} & 12 & 13 & 12 \frac{3}{4} & 12.5 & 13 \\ \text { Length } & 11.5 & 12 & 11.9 & 11.5 & 12.1 & 12 & 11.5 & 11.1 & 12 \\ \text { Diam. } & 3.5 & 4 & 3.9 & 4 & 4 & 4 & 3.5 & 4 & 4 \\ \text { Whorls } & 12 \frac{1}{2} & 12 \frac{3}{4} & 12 \frac{3}{4} & 12 \frac{1}{2} & 13 & 12 \frac{1}{2} & 12 \frac{3}{4} & 12 & 12 \frac{3}{4} \\ \text { Length } & 12 & 11.2 & 11.6 & 11 & 11 & 11.1 & 11.1 & 11.1 & 11 \\ \text { Diam. } & 4 & 4 & 3.9 & 3.9 & 3.8 & 3.8 & 3.9 & 4 & 3.8 \\ \text { Whorls } & 12 \frac{1}{2} & 12 \frac{1}{3} & 12 \frac{1}{2} & 12 \frac{1}{2} & 12 \frac{1}{2} & 12 \frac{1}{2} & 12 & 12 & 12 \frac{1}{3} \\ \text { Length } & 11.6 & 11 & 11 & 11 & 11.1 & 11 & 11 & 11.1 & 10.1 \\ \text { Diam. } & 3.6 & 3.8 & 3.5 & 4 & 4 & 3.9 & 3.6 & 3.9 & 3.5 \\ \text { Whorls } & 12 \frac{1}{2} & 12 & 12 \frac{1}{2} & 11 \frac{1}{2} & 12 \frac{1}{2} & 12 & 12 & 12 \frac{1}{3} & 12 \\ \text { Length } & 11 & 10.5 & 11 & 10.3 & 10.7 & 10.7 & 10 & 10 & 10 \\ \text { Diam. } & 3.9 & 3.6 & 3.5 & 3.8 & 4 & 3.8 & 3.5 & 3.8 & 3.5 \\ \text { Whorls } & 12 & 11 \frac{1}{2} & 13 & 11 \frac{3}{4} & 11 \frac{1}{2} & 11 \frac{1}{2} & 11 \frac{1}{2} & 11 \frac{1}{2} & 11 \frac{3}{4} \\ \text { Length } & 10 & 9.9 & 9.5 & 9.3 & 8.5 \mathrm{~mm} . & & & \\ \text { Diam. } & 3.6 & 3.5 & 3.3 & 4.8 & 3.9 & 6 & & & \\ \text { Whorls } & 11 \frac{1}{4} & 11 & 11 \frac{1}{4} & 10 \frac{1}{2} & 10 & & & & \end{array}$

The lengths give the following curve, which, although of no great value on account of the small number of variates, is given for what it is worth.

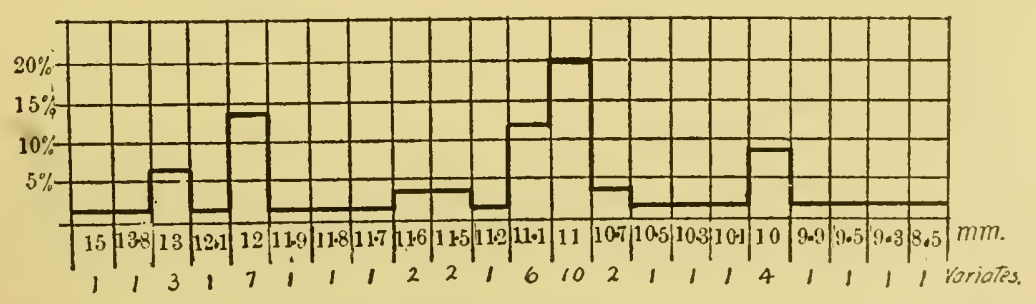

Genus MICROCERAMUS Pils. and Van.

Nautilus, XI, p. 107; Proc. Acad. Nat. Sci. Phila., 1S98, p. 281; Manual of Conchology, XVI, p. 151. 
Microceramus comprises the species formerly referred to Macroceramus in works on snails of the United States. These, with their Antillean relatives, prove to have no near relationship to true Macroceramus, which belongs to a different subfamily, the Urocoptince, very unlike the Microceramince in dentition.

Microceramus texanus (Pils.). Pl. XXVI, figs. 19-21.

A species of the hill country inhabited by Holospira goldjussi, with which it is found. It was originally described from New Braunfels, Comal county, but the range has becn extended both north and south by Mr. Ferriss and myself. Specimens were taken in the drift of the Hondo river, two miles north of Hondo, Medina county; in Comal county, on the rocky, wooded hillside above the head fountains of Comal creek, near New Braunfels, and along the Guadalupe river, some miles above (figs. 19-21). These last are the largest and best developed shells, but vary in size:

Length 10.5, diam. $3.5 \mathrm{~mm}$.

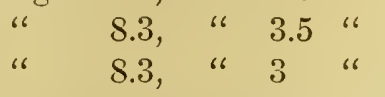

The average is about $9 \times 3.5 \mathrm{~mm}$.

In the débris of Sinking creek, near San Marcos, Hays county, they are smaller:

Length 8, diam. $3.1 \mathrm{~mm}$.

" 7.3 , " 3 "

M. texanus is closely related to $M$. mexicanus (v. Mart.), a species extending from the State of Vera Cruz to Nuevo Leon and Tamaulipas, and to $M$. floridanus of Florida. The areas of the three are now widely separated.

\section{Family HELICID 开}

The following genera of Helicidoe are represented in Arizona and New Mexico:

Ashmunella Pils. and Ckll. Thysanophora Strebel.

Sonorella Pilsbry.

Oreohelix Pilsbry.

Polygyra Say.

The first three of these, though degenerate in their reproductive organs, are believed to belong to the Belogona euadenia of my classification of Helices, and are therefore more nearly related to the Californian and Mexican Helices than to those of eastern North America.

Thysanophora is represented by two species, noticed below.

The only Polygyra yet reported from New Mexico or Arizona is Polygyra triodontoides Bld., which has been reported from South Spring 
ereek, near Roswell, in the Peeos Valley, New Mexieo (Nautitus, XIII, p. 84), but the specimens, now in my possession, proved to be a form of $P$. texasiana, near $P$. t. texasensis. This is farther west than any previous record of $P$. texasiana.

\section{ASHMUNELLA Pils. and Ckll.}

Pilsbry and Cockerell, Proc. Acad. Nat. Sci. Phila., 1899, p. 188; Nautilus, XII, p. 107; Pilsbry, Proc. Acad. Nat. Sci. Phila., 1900, p. 107; Ancey and Iurdoch, Journal of Malacology, VIII, 1901, p. 73.

Helieidæ with a Polygyra-like or Triodopsis-like shell, always umbilieate and with a reflexed or reeurved lip; aperture with 0 to 4 teeth. Genitalia with, on the $\sigma^{7}$ sicle, a short or moderate penis, an extremely long epiphallus, and an excessively short flagellum; + side with a moderately long or very long spermatheea duet, but slightly or not dilated at the distal end; other organs as usual; no dart-saek, mueous glands or other aceessory organs. Right eye-stalk retraeted between the branches of the genitalia. Penis retractor musele with a very long or double insertion near the base of the epiphallus, inserted distally on the lung-floor. Jaw ribbed. Teeth of the ordinary Helieid type, about 10 on each side being laterals.

Type A. rhyssa miorhyssa. All known species are from the mountains of New Mexieo and southeastern Arizona.

Only two of the 15 speeies and 10 subspecies now known had been reeognized prior to 1895 , and but one of these was published at the time the last treatise on Ameriean land snails was issued, Binney's Manual of American Land Shells, 1885. The literature of the group is seattered through many volumes of several periodicals, and a large majority of the speeies have not been figured. In making substantial additions to the group, it seems timely to review and systematize the data aecumulated.

The soft anatomy has proved to conform elosely to the generie eharaeters originally set forth. Ten speeies and varieties have now been disseeted by myself and one additional by Mr. Murdoeh, none of them diverging in any important respeet. The proportions of the organs vary in the several forms, showing specific variation and affording valuable elues to the affinities of the species. To utilize these data it is neeessary to give the measurements of the organs, readily obtained by pulling them out straight. ${ }^{1}$ The measurements of the genitalia of ten speeies of Ashmunella follow:

1 The comparative lengths of the organs are not materially altered by different degrees of contraction owing to different methods of preservation; and even the absolute dimensions are less affected than might be supposed. All but one of the dissections noticed herein were made from drowned specimens preserved in alcoliol, with but little contraction. 


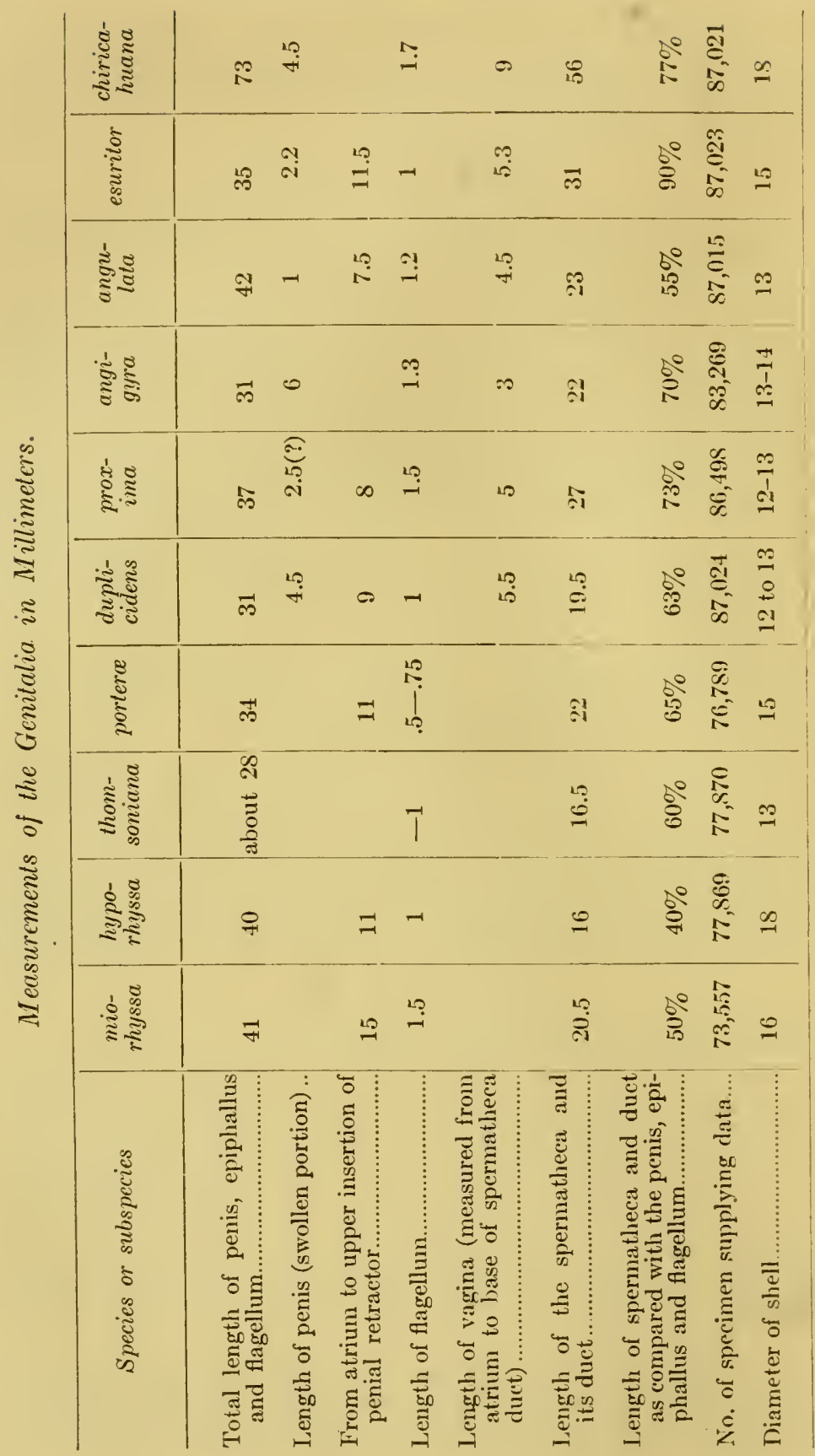


The jaw and teeth of Ashmunella do not differ from those organs in Sonorella. The jaw is ribbed, the ribs variable and irregular, as is often the case in the Californian Helices. It is less strong and the ribs are less convex than usual in the jaw of Polygyra. The radula has from 24.1.24 to about 30.1.30 tecth. There are 9 to 12 lateral teeth. In nine of the ten species examined, both mesocone and ectocone are bifid on part of the marginal tecth. In $A$. duplicidens and A. chiricahuana the ectocone is usually simple, but on occasional outer marginals of the latter they are bifid, as in the other species. The number of teeth reckoned as laterals varies somewhat on different parts of the same radula, as I have obscrved in several species; so that the inportance of variations from the counts of tecth given in the text must not be overestimated. Exeept in the ease of $A$. chiricahuana, all of my preparations of genitalia, jaws and radulx are from specimens of the type lots.

From the data now in hand, it seems in a high degree likely that the ancestral stock of all known Ashmunellas had a tridentate apcrture. There was a tendency to split the basal tooth, perhaps not expressed in the original stock, but subsequently developed orthogenetically in most of the subgroups. This tendeney euminates in the levettei group, where the original basal tooth has been divided into two distinct and often widely separated tecth. There has also been degeneration of the aperture-tecth, parallel in various stocks, and culminating in several toothless forms, astonishingly alike, though of undoubtedly diverse parentage. A. hyporhyssa Ckll., robusta Pils., chiricahuana Dall, esuritor Pils., ctc., are convergent forms of this character. The true relationships of such simplified species must be demonstrated by their internal anatomy. The idea that the toothless forms are primitive can hardly be cntertained in view of their anatomical diversity and their demonstrable relation to several groups of toothed species, the evidently homologous teeth of wnich, on this hypothesis, would have been independently evolved. This would be homoplasy on too extensive a scale to be readily believed.

The aperturc-tceth in Ashmunclla curiously imitate those of Polygyra, a genus not in the least related. In Europe, Isognomostoma and Helicodonta have evolved similar forms in still other phyla.

There has been a tendency to overload Ashmunella with subspecific names, which would logically end in naming every colony in existence. I do not minimize the importance of noting and recording local differentiation. My appreciation of its ommipresence convinces me that it cannot all be stereotyped in nomenelature, and if it were, the result would be too unwieldy for any human intellect to make use of. 
The range of individual variation in Ashmunellu among specimens from one place is (with the exeeption of $A . l$. heterodonta) not greater than in Polygyra. Among specimens I have measured or examined, I have seen no lot which would yield a markedly bimodal curve were the variations plotted. The variations between different colonies or gens are often appreciable, sometimes conspicuous; but here also the case may readily be paralleled in Polygyra, although usually not in such restricted areas, for the reason that in the Polygyra country the topographic and elimatic features are less cmphatic, and the life-zones are not erowded upon one another as in the land of the Ashmunellas, but are spread over larger areas.

The conception of species in such sedentary animals as snails is far from simple. A "species" comprises a multitude of colonics or communities which at any one time are isolated one from the other by the existing topographic and other surface features of the country. This is and always has been the ease, even with the common, widespread forms of the more level parts of the country; but the colonies there lrave always been subject to frequent mixture with their ncighboring colonics, by the ever slightly fluctuating conditions of woodland and local moisture, so that their network over the country has been here and there made practically complete within comparatively short periods. As a consequence, we have in many cases no tangible difference between individuals from colonies hundreds of miles apart.

In regions where the local physical features are more accentuated, the colonies or communities are often less subject to mixture. Moreover, the range of conditions within a limited area is far greater. Thus snails of the same original stock living in the rocky talus on opposite sides of a canyon are of ten subject to very diverse conditions of heat, moisture and consequently cryptogamic food. They are of ten wholly unable to cross from one side to the other by reason of a wide, freshetswept or arid space. Morcover, subsequent changes, such as the formation of lateral canyons and the localization of suitable stations in the talus, tend to further isolate the several colonies, and to preserve their individuality for long periods.

Thus each colony follows its own bent; and differentiation ensues, cither by the cumulation of organic changes induced by varying conditions of growth and nutrition, determined by the local environment as mentioned above, or by the occurrence of diverse "mutations" in the several colonies, or by both causes. My idea of the practical isolation of snail colonies is based upon the expericnee of many years. Similar views have been expressed by Hemphill, in the 
account of his collecting in Utah, and by Ferriss, who in speaking of the Huachucas says, "Every colony in the canyon was liable to have some distinctive mark in size, color or form. . . . . No two colonies scemed exactly alike, and they did not visit back and forth, nor travel far from the best part of their own rock pilc" (Nautilus, XVIII, p. 51).

When through some means two slightly differentiated colonies intermingle, as they occasionally must, hybridism follows, and a complex progeny issues, such as I have found in the Floridian Liguus. Who can unravel the tangled threads of affinity when the modified forms of two or more canyons reach each other across a divide! It is as complex as a modern human community, where subraces are mingling blood after centuries of pure breeding.

\section{Group of A. rhyssa.}

In specics of this group, small basal and parictal teeth arc often present, but therc is no outer lip tooth. The spermatheca and its duct are about half the length of the penis, epiphallus and flagellum, or even less. The combined length of the penis, epiphallus and flagellum is decidedly less than three times the diameter of the shell. The penis is comparatively well developed.

This group is especially characteristic of the Capitan, White and Sacramento ranges of southern-central New Mexico, east of the Rio Grande. The forms now known arrange themselves in three series, thus:

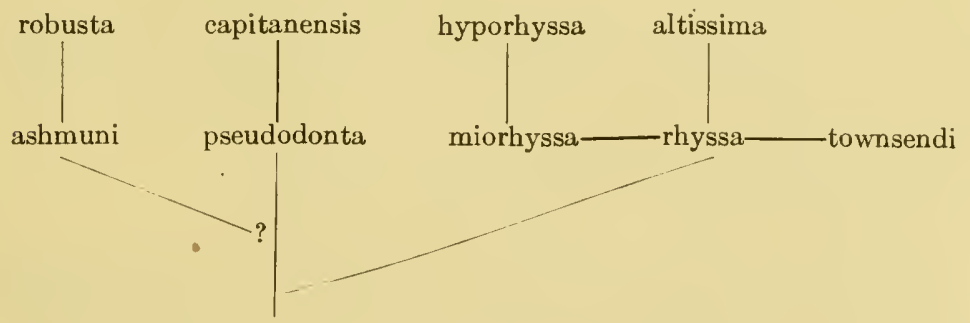

The central and right-hand groups are known to be related by the genitalia. The group on the left is separated from these geographically, and its relationships must remain wholly uncertain until the soft parts can be examined.

\section{Ashmunella rhyssa (Dall). PI. XII, figs. 1-4.}

Polygyra rhyssa Dall, Nautilus, XI, May, 1897, p. 2.

A shmunella rhyssa Dall, Pils. and Ckll., Proc. Acad. Nat. Sci. Phila., 1899, p. 192; Dall, Proc. U. S. N. Mus., XXIV, p. 500, Pl. 27, figs. 11, 14. 
This is the senior name for a member of the group of closely related forms inhabiting the Sierra Blanea and adjoining Sacramento Mountains, in middle-southern New Mcxico.

The shell is more globose than any other known Ashmunella, having about the proportions of the large Fastem Mesodons. It is dull and roughly sculptured on the last whorl with coarse, curved irregular wrinkles, between and over which fine incised spirals may be traced. The rather small aperture is eontracted by a wide, heavy lip, the outer margin of which is indistinctly thickenerl within. There is a low, indistinct basal tooth or callous, and a very small, deeply placed, oblique parictal tooth, sometimes absent. The umbilicus is narrow and deep, but slightly enlarging at the last whorl. Whorls $5 \frac{1}{2}$.

Alt. 10, diam. $17 \mathrm{~mm}$.

$$
\begin{aligned}
& \text { " } 9 \text { " " } 17 \text { " " (Dall's type). } \\
& \text { " } 10.2 \text {, " } 16 \text { " } 16 \\
& \text { " } 10.2 \text {, " } 16 \text { " " } \\
& \text { “ } 9.9 \text {, " } 15.5 \text { " } \\
& \text { " } 9.3 \text {, " } 15 \text { " } \\
& \text { " } 8, \text { " " } 14.9 \text { " }
\end{aligned}
$$

Sicrra Blanca, New Mexico, collected by Rev. E. H. Ashmun.

Ashmunella rhyssa miorhyssa (Dall). Pl. XI1. figs. 5. 6.

Polygyra miorhyssa Dall, Nautilus, XII, p. 75, November, 189 .

Ashmunella rhyssa miorhyssa (Dall), Pils and Ckll., Proc. Acad. Nat. Sci. Phila., 1899, p. 193, figs. 1-3 on p. 189 (genitalia, jaw and teeth); Pilsbry, Proc. Acad. Nat. Sci. Phila., 1900, p. 108 (anatomy).

This form differs from 4 . rhysse chicfly in being smoother, the coarse wrinkles of that being reducel to strix. The umbilicus is a little more open at the last whorl. In other respects there are no constant or even prevalent differences.

Alt. 9, diam. $16 \mathrm{~mm}$. Sicrra Blanca (Ashmun).

Alt. 9, diam. $15.5 \mathrm{~mm}$. Sicrra Blanca (Ashmun).

Alt. 10.6, diam. 16.S mm., whorls 6

Alt. 9.9 , diam. $16 \mathrm{~mm}$., whorls $5 \frac{1}{2}$.

Alt. 10.3, diam. $16 \mathrm{~mm}$, whorls $5 \frac{3}{4}$.

Near Eagle creck, Sierra Blanca (Townsend).

Sierra Blanca, Lincoln county. New Mexico (E. H. Ashmun). Near Eagle creck (C. H. T. Townsend).

Ashmunella rhyssa hyporhyssa (Ckll.). Pl. Xll, figs. 7-13.

Polygyra r. hyporhyssa Ckll., Nautilus, XII, November, 189s, p. 77.

Ashmunella hyporhyssa (Ckil.) var, edentata, with mut. rufescens and alba, Ckll., Nautilus, XIV, p. 72, October, 1900 (Cloudcroft).

A.r. hyporhyssa Ckll., Vanatta, Nautilus, XVI, p. 58, September, 1902 (Highrolls and ('louderoft): Pilsbry, Proc. Acad. Nat. Sci. Phila., 1900, p. 10S, fig. 1 (genitalia of (loudrof t specimen). 
"Like rhyssa in size and form, but umbilieus wider, exposing the penultimate whorl; sculpture fincr, consisting of striæ rather than riblets. One specimen, diam. max. 15, min. $12 \frac{2}{3}$, alt. $9 \mathrm{~mm} . "$

Lower slopes of Sierra Blanca, New Mexien, above head of Ruidoso creek, in aspen belt, about 9,500 feet altitude. (Prof. C. H. T. Townsend, August 14, 1898.)

The original description is given above. The unique type specimen was lost. Prof. Cockerell subsequently described what seems to be the same race, or one excessively similar, as A. hyporhyssa edentata, with mutations rufescens and alba, from Clouderoft, Sacramento Mountains. In the absence of any differential feature in the description or measure-

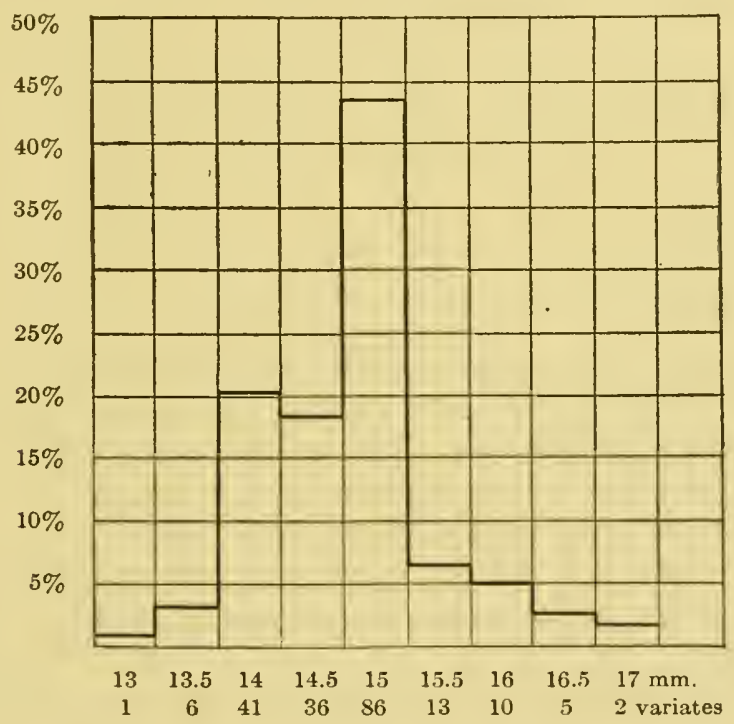

ments, I assume that the Clouderoft shells are identical with hyporhyssa.

A somewhat large series was colleeted by Mr. H. L. Viereek in James Canyon, at Cloudcroft, Saeramento Mountains, at an elevation of 9,500 feet. Two lots were taken, one of a few large specimens (PI. XII, figs. 7,8 ), the other of many smaller ones. Compared with $A$. rhyssa the shells differ in the constantly more depressed last whorl, though the spire may be equally high; the umbilicus is wider at its opening, exposing more of the penultimate whorl; the basal tooth is obsolete or very weak, and the parietal tooth is present only as an extremely small vestige in less than 5 per cent. of the specimens. Finally, the 
sculpture is less strong except just behind the lip, where the wrinkles generally are emphatic.

The lot of smaller specimens (PI. XII, figs. 9-13) consisted of about 300 shells. 200 fully adult specimens were measured. The diameter varies between 13 and $17 \mathrm{~mm}$., and gives the curve plotted on p. 229 . The major mode is at $15 \mathrm{~mm} ., 43$ per cent. of the lot being within .2 $\mathrm{mm}$. of that dimension. There is a minor mode at $14 \mathrm{~mm}$; but the lot is remarkably homogeneous, since over 80 per cent. are between 13.8 and $15.2 \mathrm{~mm}$. diameter.

The altitude bears no constant ratio to the diameter. It is individually variable within wide limits. In the first 50 individuals of $15 \mathrm{~mm}$. diameter (from my schedule of measurements of 200 specimens of all sizes) the following dimensions were found:

$\begin{array}{lllllllrc}\text { Alt. in mm., } & 8 & 8.5 & 8.6 & 8.7 & 8.8 & 8.9 & 9 & 9.2 \\ \text { No. of variates, } & 3 & 2 & 3 & 3 & 5 & 3 & 15 & 2 \\ \text { Alt. in mm., } & 9.3 & 9.4 & 9.5 & 9.6 & 9.7 & 9.8 & 10 & 10.2 \\ \text { No. of variates, } & 3 & 1 & 2 & 1 & 2 & 2 & 1 & 1\end{array}$

Alt. in mm., $\quad 10.6$

No. of variates, 1

It will be noticed that the mode is at $9 \mathrm{~mm}$., $30 \%$ of the whole number having that altitude, while the number of more depressed individuals is as nearly as possible equal to the number more elevated. Specimens of the same lot, of other diameters, give altitude curves of the same symmetrical form, and need not here be detailed.

There are 5 albinos in the 200 shells measured, though an uninterrupted series from albinos to the darkest brown specimens makes a selection difficult.

Nine shells in 200 show a very small parietal tooth, one being shown in fig. 12 .

The other lot, of larger shells (Pl. 12, figs. 7, 8), contains 2 albinos out of 14 shells. None has a parietal tooth. The measurements follow:

$\begin{array}{lllcrlllll}\text { Alt., } & 12 & 11 & 10 & 10.3 & 10.7 & 10 & 10 & 10 & 10 \\ \text { Diam., } & 19.3 & 19 & 19 & 18.5 & 18.3 & 18.3 & 18.2 & 18 & 17.5 \\ \text { Alt., } & 10 & 10 & 9.2 & 9.2 \mathrm{~mm} . & & & & \\ \text { Diam., } & 17.5 & 17 & 17 & 16.8 & \text { " } & & & & \end{array}$

A small series from Cloudcroft, 8,750 fect, collected by E. O. Wooton, received from Prof. Cockerell, contains also large and small examples, 
the diameters being, large, $18.5,18,17.3,17,16.2$, and small, 15, 15 $\mathrm{mm}$. These are part of Prof. Cockerell's original lot of $A . h$. edentata.

At Highrolls, in the Sacramento Nountains, at 6,500 feet elevation, Mr. Viereck obtained three specimens, 17.2, 17 and $16.8 \mathrm{~mm}$. diam. They have the umbilicus a trifle narrower than in the larger Cloudcroft shells.

In Alamo Canyon, 14 miles from Alamogorda, Mr. Ferriss picked up a few dead specimens. The umbilicus is decidedly narrower than in the Clouderoft shells. One of five examined has a vestigial parietal tooth. The proportions of alt. to diam. are as in Clouderoft shells. Diam. $16.2,16,15.8,13.7 \mathrm{~mm}$.

\section{Ashmunella rhyssa townsendi (Bartsch).}

Ashmunella townsendi Bartsch, Smiths. Misc. Coll., XXXXvII, p. 13, August 6, 1904.

Described from two specimens. "Nost nearly related to A. rhyssa Dall, but is much smaller than that form, and is uniformly more strongly sculptured."

Alt. 8.2, diam. $15 \mathrm{~mm}$.

Sicrra Blanca, on the slopes of the ridge on the south fork of Ruidoso river, about 5 miles above the town of Ruidoso, Lincoln county, New Mexico, at an altitude of 8,500 fect. C. H. T. Townsend.

A. rhyssa commonly varies from less than 15 to $17 \mathrm{~mm}$. in diameter, and from $\mathrm{S}$ to over $10 \mathrm{~mm}$. alt., so that the present form falls within its range of size. The coarser sculpture of "many strong sublamellar axial ribs" seems to be its chicf or only distinguishing character. It stands, apparently, between rhyssa and altissima.

\section{Ashmunella altissima (Ckll.). Pl. XII, fig. 14.}

Polygyra altissima Ckll., Nautilus, XII, p. 76, November, 1898.

Ashmunella altissima (Ckll.), Pils. and Ckll., Proc. Acad. Nat. Sci. Phila., 1899 , p. 192.

The shell is small and depressed, of $5 \frac{1}{1}$ moderately convex whorls, the inner ones enlarging slowly, the last much wider, with the periphery above the middle, very obtusely subangular in front, elsewhere well rounded. The only specimens yet found are dead, bleached and somewhat worn, having lost all of the cuticle. The embryonic $1 \frac{1}{2}$ whorls are smooth; the first neanie whorl almost equally so. Then oblique striæ set in which gradually become coarser. On the last whorl they become strong, rounded sigmoid ribs, very strong on the last half whorl. There are traces of fine spiral lines between the ribs. Bchind the lip the whorl is moderatcly contracted, and it descends a trifle to the aperture. The aperture is very oblique, lunate. The peristome is thickened within and on its convex face, narrowly reflexed throughout. 
There is a faint, hardly noticeable basal prominence, but nothing to be called a tooth. There is no parietal tooth, and the callous between the lip-ends is very thin.

Alt. 5.5, diam. $11 \mathrm{~mm}$.

Sierra Blanca, on the highest summit, three found under a rock, elevation 11,092 feet (C. H. T. Townsend).

One of the co-types of this very distinct form is figured, No. 73,558, A. N.S.P.

Ashmunella pseudodonta (Dall). Pl. XiI, figs. 15, 16, 17, 18.

Polygyra pseudodonta Dall, Proc. U. S. Nat. Mus., XIX, 1896, p. 343 (White Oaks, New Mexico).

Ashmunella pseudodonia Dall, Proc. U. S. Nat. Mus., XXIV, 1902, p. 500, Pl. 27, figs. 13,$15 ; \mathrm{Pl} .28$, figs. 7 .

Ashmunella pseudodonta Pils. and Ckll., Proc. Acad. Nat. Sci. Phila., 1899, p. 192; Murdoch, Jour, of Malac., VIII, p. 79, Pl. 7, figs. 1-7 (anatomy).

This.species differs from those of the Sierra Blanea chicfly by its more depressed shape and the bifid basal callous, which is split into two low denticles like some of the subspecies of A. thomsoniana. The comparatively short duct of the spermatheca shows $A$. pseudodonta to be much more closcly related to $A$. rhyssa than to $A$. thomsoniana. Five specimens of the original lot collected by Mr. Ashmun at White Oaks, New Mexico, measure:

$\begin{array}{lrrrrr}\text { Alt., } & 7 & 7 & 6.5 & 6.4 & 6.4 \mathrm{~mm} . \\ \text { Diam., } & 13 & 12.7 & 12.7 & 12.2 & 12 \text { “ }\end{array}$

Two spccimens found with $A . p$. capitanensis measure:

Alt. $7 \quad 6.7 \mathrm{~mm}$.

Diam., 13.913 .5 “

The internal anatomy has been well deseribed and figured by Murdoch.

Ashmunella pseudodonta oapitanensis Ashm. and Ckll. Pl. XII, figs. 21-23.

A. p. capitanensis Ashmun and Cockerell, Nautilus, XII, p. 131, March, 1899.

The shell is depressed, glossy, brown, with weak irregular growthwrinkles and fine, close ineised spirals. The spire is very low conic. Whorls $5 \frac{1}{2}$, quite convex, the last wide, rounded peripherally, swollen above benind the deep constriction behind the lip. The aperture is quite oblique, the lip either brown-tinted throughout or white. Within the basal margin there is a low, very weakly bifid callous, often hardly noticeable. There is a very small parietal tooth in four out of six specimens cxamined. The umbilieus is small and deep within, enlarging at the last whorl, rather broadly exposing the penultimate whorl.

$\begin{array}{lccrrrr}\text { Alt., } & 9 & 9.5 & 9.2 & 9 & 9 & 9 \mathrm{~mm} . \\ \text { Diam., } & 18.5 & 18 & 17.8 & 17 & 17 & 17 \text { “ }\end{array}$


Near Baldonado Springs, Capitan Mountains, Lincoln county, New Mexico, elevation S,200 feet, collected hy E. H. Ashmun.

This form is at present well separated from pseudodonta by the uniformly much larger size. The basal teeth are also less developed, and the lip comparatively narrower. It is to pseudodonta as robusta is to ashmuni. It has reached about the same stage of evolution as $A$. hyporhyssa, A. a. robusta and A. chiricahuana. In the lot of 100 specimens taken by Mr. Ashmun there is one pale greenish-corneous albino.

Ashmunella ashmuni (Dall). PI. XII, figs. 19, 20.

Polygyra ashmuni Dall, Proc. U. S. Nat. Mus., XIX, p. 342, 1896.

Ashmunella ashmuni (Dall) Pils. and Ckll., Proc. Acad. Nat. Sci. Phila., 1899, p. 192; Ancey, Jour. of Malac., VIII, p. 76; Dall, Proc. U. S. Nat. Mus., XXIV, p. 501, Pl. 28, figs. 4, 6, 9.

This species is small, much like A. pseudodonta, but there is scarcely the trace of a basal tooth. The outer lip is well thickened within, and there is no parietal tooth. The usual wrinkle-like growth-lines are present, but spiral lines are very faint, not discernible in some specimens. Five of the original lot measure:

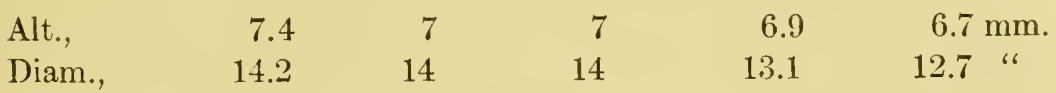

Bland, New Mexico. E. H. Ashmun.

Ashmunella ashmuni robusta n. subsp. Pl. XII, figs. 24-26.

Polygyra chiricahuana and Ashmunella chiricahuana, in part, of various authors, specimens from Jemez Mountains and at Jemez Sulphur Springs, New Mexico.

The shell is similar in size and general contour to A. p. capitanensis; chestnut or greenish-chestnut colored, glossy, sculptured with low, irregular growth-wrinkles which are strongest bolow the suture, and weaker on the base, and very fine incised spirals, close and numerous but very lightly impressed. The spire is very low conoid. Whorls $5 \frac{1}{2}$, convex, the last about double the width of the preceding, its last third decidedly swollen, inflated behind the deep constriction back of the lip. The aperture is roundly lunate, without teeth. The lip is coffee-tinted, rather narrowly reflexed, convex on the face, and a little thickened inwardly within the outer margin. There is no parictal tooth. The umbilicus is eylindric within and deep, rather broadly expanding at the last whorl, exposing the penultimate whorl.
Alt.,
9.2
8.6
S.7
$9 \mathrm{~mm}$
Diam.,
19
17.2
17.6
16.5 “

Jemez Mountains, near Bland, New Mexico, at higher elevations than A. ashmuni. E. H. Ashmun. 
This form has hitherto been referred to A. chiricahuana, from whieh it differs ehiefly in the greater inflation of the latter part of the last whorl. This is noticeable in a side view, and is scen prominently above the aperture in a front view. It differs from $A$. pseudodonta capitanensis ehiefly by wanting basal teeth.

In such simplified forms as this, it is not easy to determine the true relationships by the shell alone. When the genitalia ean be cxamined the affinities of $A$. ashmuni and $A$. a. robusta will doubtless beeome clear. There is an albino in Mr. Ashmun's eolleetion.

\section{Group of A. thomsoniana.}

Aperture of the shell with parietal, outer and basal teeth, the latter often bifid, divided into two eontiguous tubereles. Iength of the spermatheea and its duet 60 to 65 per cent. that of the penis, epiphallus and flagellum in known forms.

These forms are from northern central New Mexieo. They have been investigated ehicfly by Prof. T. D. A. Cockerell and his pupils.

By their genitalia and shells they are related to the southeastern Arizona group. Three forms are perhaps suffieiently differentiated to require names: $A . t$. porterce, $A$. thomsoniana and $A$. $t$. pecosensis.

Ashmanella thomsoniana (Ancey). P1. XIlI, figs. 27-30.

Helix levettei Bland var. thomsoniana, and var. orobcena Ancey, Conchologist's Exchange, II, p. 64 (November, 1887).

Ashmunella thomsoniana (Anc.) Pils. and Ckll., Proc. Acad. Nat. Sci. Phila., 1899, p. 192; Ancey, Jour. of Malac., VIII, p. 75, 1901; Pilsbry, Proc. Acad. Nat. Sci. Phila., 1900, p 108, fig. 2 (genitalia of specimen from Santa Fé canyon); Ckll. and Cooper, Nautilus, XV, p. 109, February, 1902, with mut. alba C. and C., l.c., p. 110 (Canyon Diablo); Ckll., Nautilus, XVI, January, 1903, p. 105 (Pecos Pueblo).

Ashmunella thomsoniana cooperce Cockerell, Nautilus, XV, p. 35, July, 1901.

A.t. antiqua Ckll. and Coop., Science, December 27, 1901, p. 1,009; Nautilus, $\mathrm{XV}$, p. 110 (Pleistocene, Las Vegas).

Specimens from J. H. Thomson, part of the original lot from Santa Fé Canyon, are before me, and two are illustrated (Pl. XIII, figs $27,28)$.

It is narrowly umbilicate, brown and glossy, finely striate, with very faint traees of ineised spirals on the last whorl. There are 5 whorls. The eharacters of the aperture are suffieiently shown by the figures, the only ones published to this time. The basal tooth is simple in all specimens I have seen from the type eanyon.

Alt. 6.9, diam. $13 \mathrm{~mm}$; whorls 5.

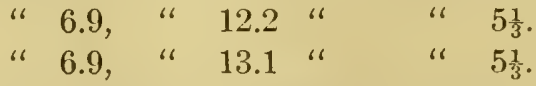

The speeimen I disseeted in 1900, eolleeted by Prof. Cockerell at 
Monument Rock, Santa Fé Canyon, at 8,000 feet above the sea (Pl. 13, fig. 29), is slightly larger with the umbilicus wider at the opening. Alt. 7.2, diam. $14 \mathrm{~mm}$; ; whorls $5 \frac{3}{4}$. The basal tooth is simple. Another like it, taken by Ashmun in the same canyon, is figured (Pl. 13, fig. 30).

In all the forms referred to $A$. thomsoniana and its subspecies no distinct internal lip-rib is formed when a resting-stage oceurred in the neanic period. Such growth-arrests are often inclicated by a darker streak on the penultimate or beginning of the last whorl, but the shell is very rarely thickened within by a white callous, and when present, the callous is very thin.

Distribution: Santa Fé Canyon (Thomson, Ashmun, Ckll.); Ias Vegas and Las Vegas Hot Springs (Miss Cooper, Prof. Ckll.); Canyon Diablo, near Rowe (Mary Cooper); Old Pecos Pueblo, near Vallé ranch, Pecos (W. C. Ckll.).

The form from Las Vegas Hot Springs, at about 7,000 feet clevation, called A.t.cooperæe, offers no tangible difference from Santa Fé thomsoniana. It is not yet evolved enough to be distinguishable from thomsoniana if the specimens were mixed. I do not think it desirable or practicable to name forms so very slightly differentiated. The umbilicus is a trifle more open than typical A. thomsoniana, like the Monument Rock shells or a little less open, being thus intermediate in size. The teeth are in the average slightly smaller. The basal tooth is quite feebly doubled in a minority of the shells seen, simple, small and tubercular in the others. The spire is, in the average, a trifle higher than in Santa Fé thomsoniana (Pl. XIII, figs. 31-34, the last a co-type of A.t. cooper(x).

\begin{tabular}{|c|c|c|c|c|c|c|c|c|c|}
\hline & \multicolumn{2}{|c|}{$\begin{array}{l}\text { Co-types of } \\
\text { cooperæ. }\end{array}$} & \multirow[b]{2}{*}{7.3} & \multirow[b]{2}{*}{7.9} & \multirow[b]{2}{*}{7} & \multirow[b]{2}{*}{7} & \multirow[b]{2}{*}{7.3} & \multirow[b]{2}{*}{7.1} & \multirow[b]{2}{*}{$6.8 \mathrm{~mm}$} \\
\hline & 8 & 7.9 & & & & & & & \\
\hline iam. & 13 & 13 & 13.8 & 13.8 & 13.5 & 13.5 & 13.3 & 13 & $12.2^{\circ}$ \\
\hline Thorls & $5+$ & $5+$ & $5+$ & $5 \frac{1}{2}$ & $5 \frac{1}{3}$ & 5 & $5 \frac{1}{3}$ & 5 & $4 \frac{3}{4}$ \\
\hline
\end{tabular}

A. antiqua Ckll. and Coop., from the Pleistocene at Las Vegas, New Mexico, is like the shells from Las Vegas Hot Springs noted above in size, but the basal tooth is a low, wide callous, slightly emarginate but not distinctly bifid. The rather heavy teeth and small umbilicus are like typical thomsoniana. A co-type measures $13.2 \mathrm{~mm}$. diam. The parietal callous has scaled off, carrying the tooth with it. I see no valid reason for believing that it represents a divergent branch of thomsoniana. Such characters as this are mercly individual. 
Specimens from Canyon Diablo, near Rowe, New Mexico (PI. XIII, figs. 35, 36, 37), are exactly like those from Las Vegas Hot Springs.

\begin{tabular}{|c|c|c|c|c|c|}
\hline Alt. & 8 & 6.8 & 6.6 & 6.4 & \\
\hline Diam. & 14 & 12.8 & 12.3 & 12.3 & 12 \\
\hline Whorls & $5 \frac{1}{3}$ & 51 & $5 \frac{1}{3}$ & $5 \frac{1}{8}$ & 5 \\
\hline
\end{tabular}

Ashmunella thomsoniana porteræ Pils, and Ckll. Pl. XIII, figs, 39-46.

A shmunella thomsoniana porterce Pils. and Ckll., Nautilus, XIII, p. 49, September, 1899; Cockerell and Cooper, Nautilus, XV, p. 109, February, 1902, with mut. alba, p. 110; Murdoch, Jour. of Malac., VIII, p. S2, Pl. 7, fig. S (genitalia); Pilsbry, Proc. Acad. Nat. Sci. Phila., 1900, p. 559, footnote 4, Pl. 21, fig. 6 (pallial complex).

A. $t$. cooperce Ckll., Nautilus, XVII, p. 36, July, 1903 (Pecos).

Shell larger than thomsoniana, light brown, glossy, a little translueent, with distinct growth-wrinkles and fine incised spiral lines. Whorls $5 \frac{1}{3}$ to 6 , convex, the last decply constricted behind the lip, swollen behind the constriction. Lip brown-tinted above. Parictal lamina moderately devcloped. Outer lip-tooth long and concave. Basal tooth bifid, the inner denticle smaller, sometimes reduced to a low callous. Umbilicus rather broadly open, exposing the penultimate whorl more than in thomsoniana.

Type locality, Upper Sapello Canyon, Beulah, New Mexico (Pl. XIII, figs. 39-42, 46, Miss Wilmattc Porter, Dr. H. Skinner and others).

Twenty-two specimens collected by Dr. Skinner measure as follows:

$\begin{array}{lccccccccc}\text { Alt. } & S & 8.5 & \& & 8.5 & 8 & 8 & 8 & 8 & 8.2 \\ \text { Diam. } & 17 & 15.3 & 15.8 & 15.3 & 15.3 & 15 & 15.6 & 14.8 & 15 \\ \text { Whorls } & 6 & 5 \frac{1}{2} & 5 \frac{3}{4} & 5 \frac{1}{2} & 5 \frac{1}{2} & 5 \frac{1}{2} & 5 \frac{1}{2} & 5 \frac{1}{2} & 5 \frac{1}{2} \\ \text { Alt. } & 8.2 & 8 & 8.5 & S . S & 7.8 & 8 & 7.7 & 8 & 7.8 \\ \text { Diam. } & 15.5 & 15 & 15 & 15.5 & 13.8 & 14 & 14.8 & 14 & 14 \\ \text { Whorls } & 5 \frac{1}{2} & 5 \frac{1}{3} & 5 \frac{1}{2} & 5 \frac{3}{4} & 5 \frac{1}{3} & 5 \frac{1}{3} & 5 \frac{1}{3} & 5 \frac{1}{2} & 5 \frac{1}{3} \\ \text { Alt. } & 7.8 & 8 & 8 & 7.6 \mathrm{~mm} . & & & & \\ \text { Diam. } & 14.1 & 14 & 14.1 & 13.9 & 6 & & & & \\ \text { Whorls } & 5 \frac{1}{3} & 5 \frac{1}{3} & 5 \frac{1}{3} & 5 \frac{1}{3} & & & & & \end{array}$

Prof. Cockerell and Miss Cooper measured 40 specimens of porterce from Beulah:

2 specimens are $14 \mathrm{~mm}$. diam.

$\begin{array}{rllll}12 & \text { " } & \text { " } 14+ & \text { " } & \text { " } \\ 17 & \text { " } & \text { " } 15 & \text { " } & \\ 6 & \text { " } & 15+ & \text { " } & \text { " } \\ 3 & \text { " } & 16 & \text { " } & \text { " }\end{array}$

There is no appreciable differenee in the comparative altitude among the specimens I have seen. 
Miss Mary Cooper collected specimens in Manzanares Valley, near Rowe, New Mexico, which have been reported on by Prof. Cockerell and Miss Cooper (Nautilus, XV, p. 109). They are in all respects like those of the type locality except that the inner basal denticle is more obsolete, as in fig. 39. The curve of diameters is the same as in the Beulah lot. The specimens I have seen are from 15 to $16 \mathrm{~mm}$. diam.

A single specimen I have seen from Cooper's Mill, near Rowe, New Mexico, measures $8.7 \times 16 \mathrm{~mm}$, with $5 \frac{3}{4}$ whorls. The inner basal denticle is low, as in Manzanares shells.

The shells from Pecos, New Mexico (Pl. XIII, figs. 43-45, collected by Cockerell), are intermediate between thomsoniana and porterce; the size being that of the former, while in 14 out of 17 specimens before me the basal tooth is double, as in porterce. In the others it is simple, as in thomsoniana. The umbilicus is rather wide, as in porterce. Prof. Cockerell refers the form to A. $t$. coopera. Its location depends upon whether size is more important than the teeth as an index of affinity; but the question of name is of minor importance in view of the intergrarlation of the whole series. Specimens measure:

$\begin{array}{lcccrcrcc}\text { Alt. } & 8.2 & S .2 & S & S .2 & S & S & 7.7 & 7.9 \\ \text { Diam. } & 15 & 14.7 & 14.6 & 14.5 & 14.3 & 14.3 & 14.3 & 14 \\ \text { Whorls } & 5 \frac{1}{2} & 5 \frac{1}{2} & 5 \frac{1}{3} & 5 \frac{1}{2} & 5 \frac{1}{2} & 5 \frac{1}{2} & 5 \frac{1}{3} & 5 \frac{1}{2} \\ \text { Alt. } & 7.8 & 7 . S & 7.6 & 7.5 & 7.6 & 7.3 & 7.2 & 7 \\ \text { Diam. } & 14 & 14 & 14 & 13.8 & 13.5 & 13.5 & 13.2 & 13.2 \\ \text { Whorls } & 5 \frac{1}{2} & 5 \frac{1}{3} & 5 \frac{1}{3} & 5 \frac{1}{3} & 5 \frac{1}{4} & 5 \frac{1}{3} & 5 \frac{1}{4} & 5 \frac{1}{3}\end{array}$

There is practically no variation in number of whorls, or in the proportion of altitude to diameter. The variation in diameter is not great, but serves to connect thomsoniana and porterce, but the skew of the curve is toward the larger size of porterce.

Ashmunella thomsoniana pecosensis Ckll. Pl. XIII, fig. 98 .

Cockerell, Nautilus, XVI, p. 105, January, 1903.

Shell like thomsoniana in shape, size, the small umbilicus and the simple basal tooth; but differing in sculpture, a coarse, lou costation being superposed upon minute growth-lines and mieroscopie spirals similar to those of A. thomsoniana. Aperture as in thomsoniana, the "lip and teeth strongly developed, the basal tooth single."

Alt. about 6.3, diam. $11.8 \mathrm{~mm}$.

Vallé ranch, Peens, New Mexico. A Pleistoecne fossil. Type No. S.4,209, A. N. S. P., collected by T. D. A. Cockerell. 
Some specimens of $A$. thomsoniana from Las Vegas Hot Springs are almost as strongly wrinkled or costulate. The subspecies cannot, therefore, be considered to be strongly differentiated.

\section{Group of A. levettei.}

The aperture has four teeth, but sometimes the two basal teeth are contiguous, partially united. The length of the spermatheca and its duct is from 55 to 73 per cent. of that of the penis, epiphallus and flagellum in known forms.

This somewhat heterogeneous group is characteristic of southwestern New Mexico and southeastern Arizona. Here are grouped about ten species and subspccies, some of them exceedingly specialized.

Ashmunella levettei (Bld.). Pl. XV, figs. 72-78.

Triodopsis levettei Bland, Annals of the New York Academy of Sciences, II, 1SS2, p. 115 (cuts); Binney, Manual of American Land Shells, p. 385; Supplement to Terrestrial Mollusks, Vol. V, p. 154, Pl. 1, fig. E, copy from Bland; Second Supplement, in Bull. Mus. Comp. Zool., XIII, No. 2, p. 36, Pl. 1, fig. 15, December, 1886.

Polygyra levettei Bld., Dall, Proc. U. S. Nat. Mus., XIX, p. 341, 1896.

A shmunella levettei Bld., Ancey, Journ. of Malac., VIII, p. 74, September, 1901.

This is a form of ample proportions, rich dark chestnut color and glossy surface. The periphery is rounded, or has a mere trace of angulation in front. The cylindric umbilicus enlarges rapidly at the last whorl. The spire, while compactly convoluted, has more rapidly widening whorls than $A$. l. angigyra. The spaces between the three lip-tceth are about equal. The parietal lamella has a "kink" or inward bend at the axial end in the type specimen, but this kink is often wanting; being a variable character in levettei and allied species. There are about $6 \frac{1}{2}$ whorls, all convex. The first $1 \frac{1}{3}$ are smooth and glossy except for short striæ racliating from the suture; on the sccond whorl these strix extend across the whorl. The following whorls are very finely, irregularly marked with faint growth-lines. On the penultimate and last whorls there is a faint, exeessively fine and close spiral striation, too minute to be visible except with a compound microscope; and a fine malleation in spiral dircetion, or spiral impressed lines, rearlily seen with the hand lens or even the naked eye. The periphery is rounded. Bland's type measured, alt. 6.5, diam. $16 \mathrm{~mm}$.; aperture, including peristome, $7 \times \mathrm{Smm}$., according to the original description. Bland evidently measured the altitude of the axis, not of the whole shell to the base of the lip. His type, which I have examined, agrees with the shells Mr. Ferriss found in Bear and Miller Canyons, in the Huachucas. Figs. 72-75 represent shclls from Bear Canyon, agrecing with type specimen in all respects. 
Huachuca Mountains, Cochise county, Arizona, in Bear, Miller and Carr Canyons (James H. Ferriss). It has been reported also from near Tueson, Arizona (Cox). I have seen no speeimens from that place.

Bland originally described levettei as from Santa Fé Canyon, New Mexico, but the researehes there of Ashmun, Cockerell and others have failed to bring it to light. Indeed, no closely related species is known to occur within hundreds of miles of that place, whereas some of the Huachuca shells agree perfectly with the type specimen of levettei which I have examined. There ean be little doubt that Dr. Levette was mistaken in the locality. It is not known that he collected the shells himself. They mav have been given him by some army offieer who had served in the Southwest. There is, aecording to Mr. C. R. Bicdermann, a Santa Fé Canyon in the San José mountains, just south of the Huachuea range, in Mexico.

A series from Bcar Canyon measures:

Alt. 9, diam. $17.8 \mathrm{~mm}$; width aperture outside $8 \mathrm{~mm}$.

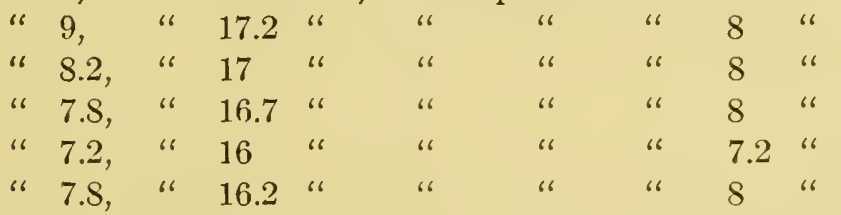

The lip is either brown or nearly white. Mr. Ferriss' largest speeimen from Bear Canyon measures $8 \times 18 \mathrm{~mm}$.

Fig. 76 represents a beautiful albino found at the head of Bear Canyon, on the southwest side of the Huachuea range, at about 7,000 feet elevation. It is bluish white under a very thin eaducious pale yellowish cuticle.

A pathologie specimen from the same place (fig. 77) has suffered extensive breakage at the aperture. A new peristome has been formed and three of the teeth regenerated, typical in shape and position. The inner basal tooth, however, is only feebly represented by a low eallous.

The shells from Miller Canyon, on the north side of the Huachucas (Pl. IIII, fig. 78), are intermediate between the Bear Canyon levettei and the slightly different race from Carr Canyon, perhaps ncarer the latter. They measure from alt. 8.5 , diam. 16.3 , aperture $7.8 \mathrm{~mm}$. to alt. 7.5, diam. 14, aperture $6.3 \mathrm{~mm}$.

In Carr Canyon, about four miles farther eastward, at about 5,000 feet elevation, a form was found resembling angigyra in its close-coiled whorls and small aperture, but differing in being usually larger, hardly angular, with a larger umbilicus and rleeper constriction back of the 
lip. It differs from levettei in the smaller mouth, larger umbilicus and deeper constriction. Specimens measure:

Alt. 7, diam. $15.2 \mathrm{~mm}$; width of mouth, outside, $7.3 \mathrm{~mm}$.

\begin{tabular}{|c|c|c|c|c|c|c|c|}
\hline « 7.2, & ، & 15.2 & " & $"$ & " & $"$ & 7 \\
\hline 7.2 , & $"$ " & 15.2 & " & " & " & " & 7 \\
\hline " 7 & $"$ & 15 & " & " & " & " & 7 \\
\hline 6.3 , & $"$ & 14 & " & " & $"$ & $"$ & 6.1 \\
\hline "6.8, & " & 13.8 & " & " & $"$ & " & 6 \\
\hline 6.8, & " & 14 & " & “ & $"$ & "6 & 6.7 \\
\hline 6.3 , & $"$ & 12.5 & $"$ & $"$ & " & " & 5.8 \\
\hline
\end{tabular}

This form is about intermediate between levettei and angigyra, but it has some slight special characters of its own. They seem harlly sufficient to require that it be named. See Pl. XV, figs. 92, 93.

Ashmunella levettei angigyra n. subsp. Pl. XIV, figs. 47-5t.

The shell is brown, smaller and more depressed than levettei obtusely but distinctly angular at the periphery. The surface of the postembryonic whorls is smoothish, under the lens seen to be very closely, irregularly marked with minute growth-lines, giving it a silky luster, and the last whorl is often finely malleate spirally, as in A. levettei. Whorls $6 \frac{1}{4}$ to 7 , very closely coiled and slowly widening, all of them convex above. The suture descends rather abruptly to the aperture. Behind the outer and basal lips the whorl is rather decply, angularly guttered. The back of the lip is creamy. Aperture very oblique, smaller than in A. levettei. The tecth are arranged as in levettei. The notch between the two basal teeth is wider than that between the outer basal and the tooth of the outer lip. The inner basal tooth is smaller than the outer. The cylindric umbilicus rapidly enlarges at the last: whorl.

Alt. 6.5, diam. $13.6 \mathrm{~mm}$.

$\begin{array}{lllll}\text { " } 6.3, & \text { " } & 13.2 & \text { " } \\ \text { " } 6, & \text { " } & 13\end{array}$

Huachuca Mountains, in Ramsey or "Conservatory" Canyon, near Fort Huachuea. Types No. \$3,269, A. N. S. P., collected by J. H. Ferriss, 1902 (figs. 47-49).

This form was also found in the drift-débris of Barbakomari creek, near Huachuca station. The same form was eollected by Mr. Mearns some years ago, and then referred to levettei.

It differs from typical $A$. levettei in being smaller, with more closely coiled whorls, the last one angular at the periphery. The aperture is smaller and therefore more filled by the teeth. It resembles $A$. angu- 
lata, but the whorls are not flattened above as in that species, and are not punctate.

With a single exeeption mentioned below, no angigyra have been found on the south side of the range. On the north side it occurs in Brown's Canyon (figs. 50, 54), varying much in size and degree of angulation, the smaller specimens being like the type lot, the larger ones less angular and approaching levettei. Five measure:

Alt. 7.3, diam. $14.8 \mathrm{~mm}$.

$\begin{array}{lllll} & 7, & \text { " } & 14.8 & \text { “ } \\ \text { " } & 6.7, & \text { “ } & 14.5 & \text { " } \\ \text { " } & 7, & \text { " } & 13.8 & \text { “ } \\ & 6, & 12 & \text { " }\end{array}$

At Ramsey Canyon, two miles east of Brown's Canyon, similar forms were found at about 6,000 feet elevation.

On the opposite side of the range, at the base of Bear Canyon, in the foothills, at about 5,000 feet, Mr. Ferriss collected a few small specimens which do not seem to differ much from typical angigyra. Two before me measure $5 \times 11$ and $4.8 \times 10 \mathrm{~mm}$., with only $5 \frac{3}{4}$ whorls (figs. $51,52,53)$.

The genital system (PI. XXI, fig. 2S) is somerwhat peculiar. The penis is quite long, but the vagina is unusually short. This is unlike $A$. angulata of the Chiricahuas, some forms of which imitate angigyra in the form of the shell.

The jaw (Pl. XXIII, fig. 14) has 8 very unequal ribs.

The radula (Pl. XXII, fig. 12) has 19.10.1.10.19 teeth. The ectocones of central and inner lateral teeth are very short. The mesocone is bifid from about the 15 th tooth out, but the ectocone only on the outer marginals. This approximates to the condition found in $A$. chiricahuana. There are more teeth and more laterals than in A. angulata.

Ashmunella levettei heterodonta n. v. Pl. XV, figs, 80-91.

In Cave Creek Canyon and the tributary Ida Canyon on the southern slope of the east end of the Huachuca range, Mr. Ferriss found an extraordinary series of Ashmunellas, in which the tceth vary from about as well developed as in $A$. levettei to completely obsolete as in $A$. chiricahuana. No other member of the genus was found in these canyons. The several stages occur together, ${ }^{2}$ and the chain of mutations is uninterrupted.

\footnotetext{
'See also Mr. Ferriss' notes on this race, Nautilus, XVIII, p. 51, below middle of page.
} 
So far as I know, such variability in a land snail among individuals living under the same conditions in one spot is elsewhere absolutely unknown.

Most of the specimens measure from 15 to $18 \mathrm{~mm}$. diam., but there is one pygmy of $12 \mathrm{~mm}$. (fig. 88). In the general shape, etc., the race does not differ from $A$. levettei. There is no trace whatever of pathologic or abnormal growth. The forms with well developed teeth and those with none were found much less numcrous than the intermediate stages. The most abundant forms (figs. 84, 85) may be considered the types of the variety.

The toothless examples have the lip slightly wider than that of $A$. chiricahuana. They constitute a race parallel to that, rather than identical with it.

The colonies of Cave and Ida Canyons are evidently undergoing rapid degeneration of the teeth, the parent form having been typical $A$. levette $i$ such as occurs in the adjacent canyon westward, and that over the ridge. Examples of such degeneration are common enough at any stage of progress; but the unique feature about it in this particular colony is that the individuals have been so unequally affected that all stages of the process are present at one time and place. It does not seem to be a case of hybridism between $A$. levettei and $A$. chiricahuana, as I at one time suspected. The results are unlike hybrid colonies in the predominance of intermediate individuals.

Figs. 80 to 87 of Pl. XV are a series from Ida Canyon, showing stages of tooth development. Figs. 89, 90,91 are from the Cave Creek Canyon series. All of these figures are photographed from fully mature shells.

Two specimens before me from Miller Canyon, or extreme head of Cave Creek Canyon, Huachucas, figured on Pl. IV, figs. 94, 95, may be toothless heterodonta, as Mr. Ferriss suggests to me; though from the narrower lip I had provisionally called them A. chiricahuana, to which they seem absolutely similar. If the latter be correct, these are the only specimens of that species I have seen from the Huachuca range. They measure 18.3 and $16 \mathrm{~mm}$, in diameter. The smaller shell is an albino.

Ashmunella levettei proxima n. subsp. Pl. XIV, figs. 65, 66, 70. 71 .

The shell is depressed, biconvex, strongly angular at the periphery, pale corneous-brown. Whorls $6 \frac{1}{2}$, none with punctate sculpture. Aperture like that of $A$. angulata, except that the two basal tecth are nearer together, the space between them being smaller than that between the outer basal and the upper lip-tooth; though the two basal teeth are not united basally as in $A$. fissidens. 
Alt. 5.3, diam. $12 \mathrm{~mm}$.

“ 5.3 " " 5.8 " 12.9 " 12.9 “

Chiricahua Mountains, Sawmill Canyon. Types No. 86,498, A. N. S. P., collected by James H. Ferriss.

Less carinated than the closely related $A$. fissidens which is apparently a member of the same serics. It is difficult to decide on the rank to be given to the members of these chains of modifications of a single type. A. proxima will probably be considered a species eventually.

There are 14.10.1.10.14 teeth. The side cusps are very short, almost subobsolete on the central teeth. The tenth to twelfth teeth are transitional. Both cusps are split on the marginal teeth.

The genitalia (Pl. XXI, fig. 24) of one of the type specimens figured has the atrium protruded. There seems to be an extremely short basal enlargement or penis in another individual opened. The retractor muscle of the penis is very weak. The proportions of the organs are given in the table on p. 224. The very short penis contrasts with $A$. $l$. angigyra, which also has more marginal teeth.

The jaw (Pl. XXIII, fig. 17) is thin, with about 5 ribs, of which only two are well developed.

Ashmunella fissidens n. sp. Pl. XIV, figs. 67-69.

Shell depressed, lens-shaped, biconvex, with acutely angular periphery; rather thin, brown. Sculptured with fine, irregular growth-lines, the penultimate and next earlier whorls more or less roughened with minute elevated points, as in $A$. angulata. Spire very low conoid. Whorls fully 6 , closely coiled, moderately convex, the last usually a little impressed above the periphery, which is angular throughout. It is convex below, and deeply guttered behind the reflexed outer and basal margins of the lip. The suture descends a little to the aperture. The aperture is very oblique, much obstructed by four teeth; an oblique parietal lamella, curved in at its axial end, with, in old specimens, a very low converging ridge outside of it, the two arranged V-like; a long, square-topped or coneave-topped tooth within the outer lip; and two contiguous teeth on the basal lip, slightly united basally the outer one thick and higher, the inner low and more spreading. Parietal callous distinct.

Alt. 5.3, diam. $12.3 \mathrm{~mm}$.

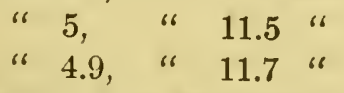

Chiricahua Mountains, in Cave Creck Canyon. Types No. 87,022, A. N. S. P., collected by James H. Ferriss, February, 1904. 
This species differs from A. angulata by its contiguous basal teeth, but is related to it by the punctate surface. It resembles $A$. duplicidens in some respects, but the basal teeth are not nearly so closely united as in that snail, the periphery is earinate, not merely angular, and the whole shell is much more depressed.

Ashmunella duplioidens n. sp. Pl. XVI, figs. 103-107.

Shell depressed, umbilicate, brown or corneous-brown, glossy and sculptured with minute growth-lines only. The spire and base are convex, the periphery obtusely subangular in front, and situated above the middle of the last whorl. There are $5 \frac{3}{4}$ to $6 \frac{1}{2}$ closely coiled, narrow and moderately convex whorls, the last one very slightly descending in front. The aperture is ear-shaped, very oblique, the lip white, well reflexed," and convex on the face. Within the outer margin there is a somewhat retracted broad tooth, prominent at its two ends, concave between them. Upon the basal lip there is a less widened, more emerging double tooth, the outer eusp larger than the inner. The parictal wall bears"an oblique, straight lamella.

Alt. 6.5, diam. $13 \mathrm{~mm}$.

" 5.9 , " 12 "

Bearfoot or "Bar" Park, Chiricahua Mountains, Arizona, at an elevation of $S, 500$ feet.

This species is an important link in the A. levettei chain, showing the origin of the two basal teeth by splitting of an original median one. It is less differentiated from the group of $A$. thomsoniana than the other known Arizona species.

The genitalia (Pl. XXI, fig. 23) also resemble those of thomsoniana. The general proportions are shown in the figure and table of measurements. The penis is comparatively long. The duct of the spermatheca is large, weakly varicose, and contracted where it joins the vagina. I did not make out any lower attachment of the penis retractor muscle.

There are about 18.10.1.10.18 teeth, nine or ten being laterals, the next three or four transitional. The cetocone is not split on the marginals, at least not on most of them.

Ashmunella angulata n. sp. Pl. XI, fig. 11 ; Pl. XIV, figs. 55-61, 63, 64 .

The shell is lens-shaped, angular peripherally, rather narrowly umbilicate, glossy, reddish-chestnut when unworn, paler and more corneous around the umbilicus and in the middle portion of the upper surface, but frequently dull throughout by slight wear of the surface. Sculpture of very fine and irregular growth-lines, and for a short space 
behind the lip there are fine, sharp strix. The embryonic whorl is glossy, with fine radial strix on the outer side of the suture; some part or parts of the third or fourth whorls are sculptured with very minute raised points in quincuncial order. The spire is low conic-convex, very obtuse above, the first two whorls being almost in a plane. Whorls $6 \frac{1}{2}$ to $6 \frac{3}{4}$, very narrow, and very slowly increasing; the first three are convex, those following being decidedly flattened, only slightly convex. The last whorl is acutely angular at the periphery, the angle more obtuse on its last third. The base is convex. The suture descends a little to the aperture. The lip is preceded by a creamy stripe, and the base is deeply guttered behind the expansion. The aperture is very oblique, narrow and lunate, obstructed by four teeth: a more or less sinuous, oblique parietal lamella, two compressed, entering teeth on the basal lip, of which the outer one is higher and more compressed, and an oblique, square-topped tooth within the outer lip. The sinus or notch between the two basal teeth is slightly wider than that between the outer basal and the outer lip tooth. The umbilicus is about one-sixth the diameter of the shell.

\begin{tabular}{|c|c|c|c|c|}
\hline Alt. & 14.3, & iam & 6.5 & $\mathrm{~nm}$. \\
\hline 66 & 13.3, & "6 & 6.3 & 6 \\
\hline " & 13.3, & “ & 6.4 & 6 \\
\hline " & 13 & " & 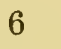 & \\
\hline " & 13 & " & 6 & \\
\hline
\end{tabular}

Two other specimens of the type lot measure 14 and $14.3 \mathrm{~mm}$. diameter respectively.

Chiricahua Mountains, Arizona, in the South Fork of Cave Creek, at the base of the mountain. Types No. 87,019 , A. N. S. P., collected by Mr. Ferriss, February, 1904.

The young shells show the characteristic punctation better than adults. At resting periods in the neanic stage of growth a callous rib is formed within the lip. When this occurs early (as in the specimen figured, Pl. XI, fig. 11, $8 \mathrm{~mm}$. diameter) the rib is much thicker in the middle. When it occurs in the last whorl it is more equally thickened.

This species is closely related by shell characters, but not by its soft anatomy, to A.levettei angigyra of the Huachuca range, agreeing with that form in the close convolution of the whorls, the angular periphery and the general arrangement of the teeth. But all fresh specimens of A. angulata show a quincuncial punctation of some part of the neanic whorls, not present in the Huachuca form, and the two especially differ in the shape of the whorls, the upper surface of which is flattened 
in angulata, convex in angigyra. Moreover, the genitalia of angigyra and angulata differ in important respeets.

As usual in Ashmunella and many other snails, the "species" is composed of a group of varying colonies, all living in Cave Creek Canyon and its branches. The largest and best developed of these has been taken as the type lot, Pl. XIV, figs. 55-57.

Another lot $(87,015)$ from the South Fork of Cave Creek, "under cliffs" (fig. 58), has smaller shells of a paler dull brown tint. The whorls after the first $1 \frac{1}{2}$ are flattened; and there is sometimes a low ridge making the parietal tooth $\mathrm{V}$-shaped.

Alt. 12.8 , diam. $6.5 \mathrm{~mm}$; ; whorls $6 \frac{1}{2}$.

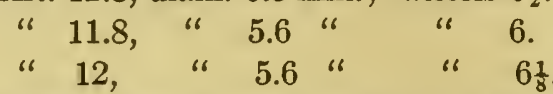

Another lot, from a different spot from the above, also consists of small shells:

Alt. 5, diam. $11 \mathrm{~mm}$; ; whorls 6 (2 specimens).

$\begin{array}{rrrrrr}\text { “ } 5.3, & \text { " } & 11 & \text { “ } & \text { “ } & 6 \frac{1}{2} . \\ \text { “ } & 5.3 \text {, “ } & 10.7 & \text { “ } & \text { " } & 6 . \\ \text { “ } & 4.8 \text {, “ } & 9.9 & \text { “ } & \text { " } & 5 \frac{3}{4} .\end{array}$

The following lots are from Cave Creek Canyon (the preceding being from its south fork):

No. 87,111 (fig. 61 ) is almost exactly like 87,015 (above).

No. 87,020 (figs. 59,60 ) varies more in size and shape, as follows:

Alt. 6.3, diam. $11.2 \mathrm{~mm}$; whorls $6 \frac{1}{2}$.

$\begin{array}{lllclll}\text { “ } 5, & \text { “ } & 11.3 & \text { “ } & \text { " } & 6 \frac{1}{2} . \\ \text { “ } 5, & \text { “ } & 11 & \text { “ } & \text { " } & 6 \frac{1}{2} . \\ & 4.8, & \text { " } & 9.9 & \text { “ } & \text { " } & 6 .\end{array}$

The punctation of the spire is well developed.

At the Falls in Cave Creek (figs. 63, 64) the shells are like the preceding lot, except that the punctation is less developed and the umbilicus frequently smaller:

Alt. 5, diam. $11 \mathrm{~mm}$; width of umbilicus $2 \mathrm{~mm}$.

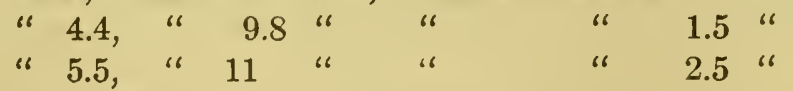

The genitalia of $A$. angulata (Pl. XXI, fig. 26) are figured from a specimen from the south fork of Cave Creek, No. 87,015, A. N. S. P. The penis is very short (long in angigyra, see fig. 28); the epiphallus, on the other hand, is very much longer than in angigyra; while the spermatheca and its duct are of about equal length in the two speeies. The vagina in A. angulata is rather long, as usual in Ashmunella, while in A. l. angigyra it is much shorter than in any other Ashmunella I have dissected. 
The jaw (Pl. XXIII, fig. 15) of the same specimen is thin, with perhaps as many as eight very weak, narrow, delicate unequal ribs.

The teeth (Pl. XXII, fig. 9, a group of lateral, transitional and marginal teeth) number 16.S.1.8.16 to 18.9.1.9.1S on different parts of the same radula. There are $S$ or 9 laterals and two or three transition teeth. Some of the outer marginals have the ectocone bifid.

Ashmunella ferrissi n. sp. Pl. XVI, figs. 108-110, 113.

The shell is biconvex and acutely carinate, narrowly umbilicate, brown, but slightly glossy, and sculptured with fine growth-wrinkles only. The spire is convex, of $6 \frac{1}{2}$ very closely coiled and slowly widening whorls, the earliest two convex, the rest flat, with a narrow keel projecting upward and outward above the suture. The last whorl is concave above and below the keel, and descends very shortly to the aperture. The aperture is very oblique and obstructed by four white teeth: a wide one slightly notched at the summit, just below the peripheral angle; two compressed teeth on the basal margin, connected by a low flange on the face of the peristome; these three teeth stand about equidistant. There is also a low prominence on the lip at the position of the keel. On the parietal wall there is a straight lamella, very obliquely placed and shortly, abruptly curved inward at the axial end.

Alt. 5.5, diam. $11.3 \mathrm{~mm}$.

" 5.2 , " 11 "

Cave Creek Canyon, Chiricahua Mountains. Types No. 89,232, A. N. S. P.

This extraordinary member of the group of $A$. levette $i$ is at once distinguished from all others known up to this time by the projecting keel above the sutures of the spire, somewhat like the Chinese Eulota tectumsinense (v. Mits.), or like Helicodonta maroccana (Morel.).

Ashmunella walkeri Ferriss. PI. XVI, figs. 111, 112, 117.

Ferriss, Nautilus, XVIII, p. 53, September, 1904.

The shell is much depressed, lens-shaped, acutcly carinate peripherally, rather thin, and pale corneous-brown. The umbilicus, narrow within; enlarges rapidly at the last whorl. Surface lightly marked with growthlines, but showing no trace of spiral striæ or lines. The upper surface is but slightly convex. The apex is sculptured like that of A. levettei. Whorls $4 \frac{1}{2}$, slightly convex, the last very shortly descending in front. Base more convex than the upper surface. The aperture is small and very oblique, the lip well reflexed, white, with an obtuse, squarish tooth in the outer margin and two compressed teeth in the basal margin, the inner one smaller; these three being nearly equally spaced, or the outer two may be nearer together. There is a rather short, straight, obliquely 
set parietal tooth, and in old shells a very low cliverging ridge between it and the outer insertion of the lip.

Alt. $4 \frac{1}{2}$, diam. $13 \frac{1}{2} \mathrm{~mm}$.

Florida Mountains, Luna county, New Mexico, in a rock talus near the top of the mountain, at an elevation of probably about 6,500 feet. Co-types in collections of J. H. Ferriss and A. N. S. P., No. 87,101.

Only a few specimens were found, and none living. While related to the carinate forms of the $A$. levettei group, and to $A$. mearnsi by the structure of the aperture, this species is flatter than any of them, and differs especially in the small number of wlrorls-less than in any other Ashmunella. It was named in honor of Mr. Bryant Walker, of Detroit.

Ashmunella mearnsi (Dall). Pl. XIV, fig. 62; Pl. XVI, fig. 116.

Polygyra mearnsi Dall, Proc. U. S. Nat. Mus., XVIII, 1895, p. 2 ("Hachita Grande and Huachuca Mountains, New Mexico"); Proc. U. S. Nat. Mus., XIX, 1896, p. 343, Pl. 32, figs. 7, 8, 11; Cockerell, Nautilus, XI, October, 1897, p. 69 (Filmore Canyon, Organ Mountains, New Mexico).

Ashmunella mearnsi Dall, Ancey, Jour. of Malac., VIII, September, 1901, p. 74.

In this species an accessory parietal lamella, incipient or rudimentary in $A$. walkeri and some forms of the levettei series, is well developed. The lip-teeth are arranged as in the $A$. levettei group. It is nearer $A$. walkeri than any other known species, but some specimens of $A$. angulata (fig. 58) have a weak upper arm of the parietal V.

The geographic range is wide for a species of this group: the Huachuea Mountains, in southeastern Cochise county, Arizona, the Hacheta Grande Mountains, Grant county, southwestern New Mexico, and the Organ Mountains, Donna Ana county, New Mexico, east of the Rio Grande. All of these localities are near the Mexican boundary.

The specimen figured is one of those collected in the Huachuca Mountains by the well-known ornithologist Edgar A. Mcarns, for whom the species was named.

The remarkable parietal armature is weakly foreshadowed in A. walkeri, some forms of $A$. $l$. angigyra, etc. The soft anatomy remains unknown.

\section{Group of A. esuritor.}

Aperture of the shell without teeth. I.ength of the spermatheca and its duct about 90 per cent. that of the penis, epiphallus and flagellum, which do not much exceed twice the diamcter of the shell.

A single species from the Chiricahua Mountains differs strikingly from the levettei and chiricahuana groups in the proportions of the genitalia, the epiphallus being as short as in the thomsoniana group, while the spermathecal duct is much longer. 
Ashmunella esuritor n. 8p. Pl. XIII, figs. 23-26.

The shell is rather solid, light brown, biconvex, angular at the periphery. The cylindric umbilicus is suddenly dilated in the last whorl. The surface is irregularly marked with slight growth-wrinkles, and on the last whorl there are impressed spiral lines, more or less irregularly developed and sometimes almost obsolete. Some intermediate whorls are indistinctly punctulate. Spire low-conic. Whorls $6 \frac{1}{3}$ to $6 \frac{1}{2}$, slowly increasing. The first three whorls are convex, the rest more or less flattened. The last whorl is distinctly but not acutely angular in front, but becomes rounded in its later half. The suture descends a little to the aperture, and the whorl is rather deeply guttered behind the lip. The aperture is very oblique, roundly lunate. The peristome is white, thickened within, and equably reflexed. In the middle of the basal margin there is a low, indistinct prominence, but there are no other traces of teeth. The parietal callous is thin except in old specimens, when it is thickened at the edge, forming a cord across the whorl.

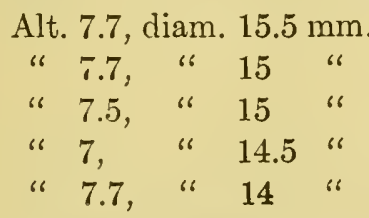

Chiricahua Mountains, in Bar (or Bearfoot) Park. Types No. 87,023, A. N. S. P., collected by James H. Ferriss, February, 1904.

At first glance this form scems to be a small angular race of $A$. chiricahuana; but upon closer study it scems far more likely that it is a terminal member of the $A$. angulata group, in which the teeth have degencrated. The slight flattening of the whorls, the shape of the mouth, and a faint punctation observable near the end of the third whorl in the freshest specimens, all indicate this relationship. Most of the fully adult and old individuals seen have lost much or all of the cuticle, and are dull flesh-tinted.

The spiral engraved lines vary a good deal in different specimens, and when slightly corroded neither spirals nor granulation are visible, even in living shells.

The smaller size, angular periphery and comparatively wider lip readily distinguish $A$. esuritor from $A$. chiricahuana..

The genital system (Pl. XXI, figs. 30,25$)$ resembles that of $A$. chiricahuana except that the ducts are very much shorter, both absolutely and in comparison with the size of the shell; and the spermatheca and its duct are nearly as long as the penis, epiphallus and flagellum. The extruded penis and atrium in another specimen are shown in fig. 25 . 
The penis has low, slowly spiral ridges. The entire length of the organs exserted is about $3.2 \mathrm{~mm}$.

The jaw has about 7 unequal ribs.

The teeth number about 16.12.1.12.16, the tenth to thirteenth being transitional. Both cusps of the marginal tecth are bifid.

Five shells taken in Sawmill Canyon, running from Bear Park, Chiricahuas, are like the types. The periphery in some is not quite so angular. The punctulation is identical. Two measure:

$\begin{array}{lcc}\text { Alt. } & 7.5 & 7 \mathrm{~mm} \text {. } \\ \text { Diam. } & 16.3 & 14 \text { " } \\ \text { Whorls } & 6 \frac{1}{3} & 6 \frac{1}{4}\end{array}$

Group of A. chiricahuana.

Aperture toothless. Epiphallus and duct of the spermatheca very much longer than in species of any of the other groups, the diameter of the shell contained four times in the length of the penis, epiphallus and flagellum.

Ashmunella ohiricahuana (Dal1). P1. XV1, figs. 96-100.

Polygyra chiricahuana Dall, Proc. U. S. Nat. Mus., XVIII, p. 2, 1895 (Fly Park, Chiricahua Mountains); Proc. U. S. Nat. Mus., XIX, p. 341, Pl. 32, figs. 9, 10, 12, 1896.

Ashmunella chiricahuana (Dall), Pils. and Ckll., Proc. Acad. Nat. Sci. Phila., 1899, p. 192; Ancey, Jour. of Malacol., VIII, September, 1901, p. 76, with var. varicifera, p. 77.

This species has the general shape and rounded periphery of $A$. levettei. It varies from chestnut to rather light greenish-brown, and shells which have lost their cuticle are dull flesh-colored. It is very glossy and smooth, marked with weak growth-wrinkles and engraved spirals, which are distinct in some, almost obsolete in other specimens. Under the compound microscope fine spiral striæ are seen to cover the surface between the spiral lines. Whorls about $5 \frac{1}{2}$, slightly convex. The last descends a trifle in front, and is somewhat constricted behind the lip. The aperture is without teeth. The lip is narrow, reflexed, brownish above and at the edge, without trace of lip-teeth. The umbilicus opens rather widely at the last whorl.

There is almost always an opaque yellow stripe on the last whorl, marked inside by a strong white rib, and indicating a place of growtharrest. Some shells have several such variceal streaks on earlier whorls also. The feature is a variable one in shells of the same lot, for reasons I have elsewhere discussed in full. In one lot of 16 specimens from Cave Creek Canyon, Chiricahuas, there are 3 specimens with a single streak on last whorl, 8 with 2 streaks on last 2 whorls, 4 with 3 streaks on last 3 whorls, and 1 with 4 streaks on last 3 whorls. 
Type locality, Chiricahua Mountains, southeastern Arizona, in Fly Park, 10,000 feet altitude (Fischer); also in Cave Creek Canyon (Ferriss, 1904). The locality "near Tueson" is also given for specimens eolleeted by a Mr. Cox, many years ago. ?Huachuea Mountains, in Miller Canyon (see below).

Dall's type measured, alt. 7.7 , diam. $18 \mathrm{~mm} .^{3}$ Three topotypes of the original lot collected by Fischer measure:

Alt. 9, diam. $18 \mathrm{~mm}$.; whorls $5 \frac{3}{4}$.

" 8.5, " 16 " " $5 \frac{1}{2}$.

Sixteen of the specimens eollected by Mr. Ferriss in Cave Creck Canyon (Pl. 16, figs. 96-100) measure:

$\begin{array}{lcrrrrrrr}\text { Alt. } & 10 & 9.5 & 10 & 9 & 10 & 8.8 & 8.5 & 9.5 \\ \text { Diam. } & 20.5 & 20 & 19 & 19 & 18.5 & 18.5 & 18.5 & 18 \\ \text { Alt. } & 9 & 9 & 9 & 8.5 & 8.3 & 8.2 & 9 & 8.5 \\ \text { Diam. } & 18 & 18 & 18 & 18 & 18 & 18 & 17.7 & 17.5\end{array}$

The diameter curve from this small series has a strongly marked mode at $18 \mathrm{~mm}$. ( $44 \%$ of the whole), with a skew toward the smaller diameter.

There is a considerable variation in the height of the spire, shown in the measurements above and in the figures, of which figs. 99 and 100 represent about the extremes of variation in this respect.

Two specimens from the head of Miller Canyon, in the Huachucas, measure $8.5 \times 18.2 \mathrm{~mm}$. and $8 \times 16 \mathrm{~mm}$. The smaller one is an albino, greenish-white. These may be referable to A. levettei heterodonta, $q . v$.

I have seen no Ashmunellas from Tueson, but no differential characters have been indicated for the variety varicifera Ancey, from that place. Nearly all the specimens from the Chiricahua range have varices.

The genital system (Pl. XXI, fig. 29) is remarkable for the great length of the epiphallus, vagina and spermatheea duet. The penis is large and well developed. The specimens examined are from Cave Creek Canyon, in the Chiricahuas.

The jaw (Pl. XXIII, fig. 13) is stronger than in most of the species, with 8 strong ribs and several weaker ones.

The radula (Pl. XXII, figs. 10, central and lateral, and 11, groups of transitional and marginal teeth) has 16.13 .1 .13 .16 or 16.14.1.14.16 teeth. The thirteenth to fourteenth or fifteenth teeth are transitional.

8 This measurement was not to the base of the lip, and hence is less than in $_{\mathbf{1}}$ the shells from the same lot measured by me. 
The fifteenth tooth has the mesocone bifid. As a rule, the marginal teeth have the cetocone simple, but I found a few teeth in some rows having a bifid ectocone.

Ashmunella ohirioahnana mogollonensis n. subsp. Pl. XVI, figs. 101, 102.

Similar to chiricahuana but slightly more tumid, dull greenish-brown, not glossy. Surface sculptured with low, irregular, coarse wrinkles of growth, and distinct, clear-cut incised spirals all over the last whorl. Spire very low, the early whorls depressed.

Alt. 9, diam. $17.5 \mathrm{~mm}$.; whorls $5 \frac{1}{2}$.

West fork of the Gila river, near Mogollon Peak, in the southwestern part of Socorro county, New Mexico, in a pine region, collected by Prof. E. O. Wooton, August 7, 1900, sent by Prof. T. D. A. Cockerell. Type No. 79,530, A. N. S. P. (fig. 102). A specimen has also been taken by Mr. O. B. Metcalfe near INingston, Sierra county, New Mexico (fig. 101).

In A.chiricahuana the spirals are very much weaker or obsolete, and the cuticle, when in unworn condition, is conspicuously glossy. 1

\section{Group of A. metamorphosa.}

Shell edentulous, similar to A. chiricahuana. Genitalia peculiar, see below.

Ashmunella metamorphosa n. sp. Pl. XVI, figs. 114, 115.

Shell similar in form and color to $A$. chiricahuana and $A$. esuritor. Surface slightly marked with growth-lines and very minutely engraved spirally when unworn, but the spirals cannot be seen on slightly corroded living shells. Whorls $5 \frac{3}{4}$ to $6 \frac{1}{2}$, convex, slowly widening, the last rounded peripherally, slightly descending in front, contracted bchind the reflexed and slightly recurved lip. Umbilicus a trifle less open than that of $A$. chiricahuana. Aperture like that of $A$. chiricahuana in shape, but in some specimens there is a low callous within the outer lip, and one or two indistinct callouses within the basal margin, while in others these are hardly noticeable.

Alt. 9, diam. $17 \mathrm{~mm}$., or slightly smaller alt. 8.9, diam. $16.5 \mathrm{~mm}$.

Bear (Bearfoot or Barfoot) Park, Chiricahua Mountains, Cochise county, Arizona. Types No. 88,885-6, A. N. S. P., collected by Mr. J. H. Ferriss, 1904.

Genitalia (Pl. XXY, fig. 27) with a very short atrium. There is no differentiated penis, the of organ being of equal calibre throughout, and evidently an epiphallus. It terminates in the usual very short flagellum. I can find no trace of a penial retractor muscle. The very long vagina consists of a vcry slender lower portion and an excessively thick, muscular 
upper part. The spermatheca is long and narrow, its duct rather short. The epiphallus and flagellum measure $22 \mathrm{~mm}$.; flagellum 2 $\mathrm{mm}$.; spermatheca and duct $20 \mathrm{~mm}$. The specimens had been placed in alcohol without drowning.

The jaw (Pl. XXIII, fig. 16) has seven ribs, grouped in the median half, the ends smooth.

The radula (Pl. XXII, fig. 8) has about 38.1.38 teeth. The ectocones are developed on central and lateral teeth. From the twentyfourth or twenty-fifth teeth outward from the middle the inner cusp is bifid. The ectocones are unsplit. A central and two lateral teeth are shown.

This snail, so far as the shell is concerned, would be referred without hesitation to A. chiricahuana; the differences bcing less than the ordinary range of individual variation in Ashmunella or Polygyra; but the genitalia are so utterly unlike in the two forms that it is obvious that they are not even nearly related. From the granulation and the weak traces of teeth it seems that $A$. metamorphosa is probably a toothless derivative of the $A$. levettei stock; I regret that I have no alcoholic specimens of $A$. levettei or A.l. heterodonta for comparison. A. esuritor differs from metamorphosa by its angular or distinctly subangular periphery, rougher surface when perfectly fresh, and perhaps somewhat wider umbilicus; but it must be admitted that the two forms are so similar that their distinction may be difficult without an examination of the soft parts. The genitalia, however, are so very different that the two species cannot even be closely related. They must be independent derivatives from toothed ancestral forms.

I dissected two of the three specimens received. They could be extracted only by breaking into the shell. Having been preserved in alcohol without drowning the specimens were much more contracted than the A. chiricahuara and A. esuritor I examined. A somewhat extensive experience with snails in all conditions of preservation has shown that beyond a moderate diminution of the absolute size, the characters of the genitalia are not altered by preservation of the animal in strong alcohol.

Genus SONORELLA Pilsbry.

Pilsbry, Proc. Acad. Nat. Sci. Phila., 1900, p. 556 (definition, anatomy); Bartsch, Smiths. Misc. Coll., Vol. 47, p. 187, 1904 (monograph).

The soft anatomy of this genus has hitherto been known in a single species. The study of numerous specimens of several species enables me to extend the generic characterization.

The shells in these Helices, while interminably modified locally in 
size and minor details of shape and sculpture, show with few exceptions no prominent specific differentiation. On the other hand, in the internal anatomy there has been a good deal of divergence. A few forms, such as S. lohrii Gahb and S. wolcottiana Bartsch, seem to be quite distinct conchologically, but in many cases the determination of specimens of the shells other than the type localities is so uncertain as to be little better than guesswork, even when types are available for comparison. In dealing with these ambiguous forms I have thought the interests of science best furthered by applying specific names only to those I am able to characterize anatomically, and thus put upon a secure basis.

An illustrated monograph of Sonorclla, dealing with the shells only, has been 'published by Mr. Paul Bartsch, who has devoted great industry to the elucidation of the numerous species and races. The work is of permanent value for its exact descriptions and excellent figures, both of which I have had occasion to test; but it deals with selected or "type" specimens only, ignoring the fact of variation, and hence fails to give a just idea of the complex of varying forms which exist, or even of the variations of size, etc., occurring in the type lots. I would here express my indebtedness to Mr. Bartsch for his invariable kindness in comparing for me various forms of $S$. hachitana with spccimens in the U. S. National Museum.

Mr. Bartsch has made the valuable observation that the embryonic shells of Sonorella are sculptured, usually with oblique forwardly descending threads, or with two sets of intersecting threads, sometimes interrupted to form papillæ at their intersections. This sculpture may, I think, be the accelerated vestige of a somewhat similar sculpture characteristic of the Californian Helices in their adult stage, and which may thus have been common to the ancestral Sonorellas.

The relationships of Sonorella are primarily with Oreohelix and Ashmunclla. It differs from Oreohelix chiefly in the different proportions of the kidney and pericardium, but also in the structure of the shell, the oviparous reproduction, the unkeeled young shell, and in the distinctly ribbed jaw.

Sonorella stands nearer Ashmunella in internal anatomy, but there is a constant difference in the male organs, the penis being well developed in Sonorella, while in Ashmunella it is more or less completely degenerate, the epiphallus being hypertrophic. The divergence between the shells of the two genera is conspicuous. So far as the shell is concerned, Sonorella stands nearer to the generally prevalent type of Belogonous Helices than do either of the other genera. 


\section{Generic Characters of Sonorella.}

The genitalia (Pl. XX) show no accessory organs on the female side. The vagina is long; the spermatheca is globular or ovate on a very long slender branchless duct. The atrium is always extremely short. The penis is a well-developed, thin-walled tube, containing a large papilla, and terminating in a well-developed epiphallus. There is always a loose sheath or wide collar enveloping the base of the penis, and attached by muscular threads to the end of the epiphallus, which is thus held loosely in a reflexed position. This sheath has been removed in most of my figures, as it obscures the parts enveloped.

The retractor muscle is attached to the epiphallus close to the penis, and is adnate to or envelops it to the apex of the latter. The flagellum is extremely short, or even absent. The details of structure are much varied in the several species as described below under each specific caption, and in the table of measurements.

The free muscles, pallial complex and digestive tract have been described in these Proceedings for 1900 , p. 558. No material differences have been observed in additional species examined.

The jaw has four to eight ribs grouped in the median part, and either strong or weak, as in the Californian Helices (Pl. XXIII, figs. 18-23).

The radula has unicuspid middle and lateral teeth, bicuspid transitional and inner marginal teeth and low, wide marginals with both cusps bifid. Exactly the same type of teeth occurs in the Californian Epiphragmophoras, in Ashmunella, Polygyra, etc.

The upper surface of the foot is densely pcbble-granose, with rather indistinct dorsal grooves; the genital furrow is undeveloped except near the mantle. The tail is depressed, rather long, and sometimes has a weak median impressed line along the top.

In my original diagnosis of Sonorella I stated that the shell was "neither malleate nor spirally striate." Mr. Bartsch has also asserted that "incised spiral lines are never present in this genus." This statement must now be withdrawn, since several forms discovered by Mr. Ferriss show impressed spiral lines; but they are inconspicuous, and visible only under the lens. ${ }^{4}$ To the eye, the shells of all known Sonorellas appear nearly smooth, the sculpture, aside from slight growthwrinkles, being microscopic. This is somewhat remarkable becausc they often live in the same rock-piles with rudely sculptured Oreohelices.

4 Mr. Bartsch has excluded Helix carpenteri Newc. from Sonorella on account of its spiral sculpture; but since I have found that this is not a diagnostic character of the genus, I am disposed, pending an examination of the sof $t$ charamy, to adhere to my former opinion that carpenteri belongs to Sonorella. 
Up to this time, no carinate or even strongly angular species have been found. Such uniformity in the shell is unusual in a Helicid genus.

The characters of the soft anatomy originally attributed to the genus have proved to prevail in the more extensive material now examined, except that in one species the flagellum is obsolete. The penis was incorrectly described in my original diagnosis, through my failure to open it, and thus ascertain the exact limits of penis and epiphallus.

Measurements of the Genitalia in Millimeters.

\begin{tabular}{|c|c|c|c|c|c|c|c|}
\hline Species & Penis & $\begin{array}{l}\text { Penis- } \\
\text { papilla }\end{array}$ & $\begin{array}{c}\text { Free epi- } \\
\text { phallus } \\
\text { and fla- } \\
\text { gellum }\end{array}$ & $\begin{array}{c}\text { Fla- } \\
\text { gellum }\end{array}$ & $\underset{\text { gina }}{\text { Va- }}$ & $\begin{array}{l}\text { Sperma- } \\
\text { theca and } \\
\text { duct }\end{array}$ & $\begin{array}{l}\text { Mu- } \\
\text { seum } \\
\text { num- } \\
\text { ber }\end{array}$ \\
\hline $\begin{array}{l}\text { S. hachitana, } \\
\text { Florida Mountains }\end{array}$ & 9 & 4 & 7 & 0.5 & 10.5 & 29 & 86,496 \\
\hline $\begin{array}{l}\text { S. h. ashmuni, } \\
\text { Purtyman's ranch }\end{array}$ & 11 & 6 & 7 & 0.7 & 9 & 29 & 79,409 \\
\hline $\begin{array}{l}\text { S. h. ashmuni, } \\
\text { Purtyman's ranch }\end{array}$ & 11 & ......... & 6.7 & 0.7 & 8 & 35 & 79,409 \\
\hline $\begin{array}{l}\text { S. h. bowiensis, } \\
\text { Bowie }\end{array}$ & 10 & 3 & 8.5 & 0.6 & 10 & .......... & 86,497 \\
\hline $\begin{array}{l}\text { S. rowelli, } \\
\text { Sanford's }\end{array}$ & 5 & 2 & 5.5 & $\begin{array}{c}\text { vesti- } \\
\text { gial }\end{array}$ & 5.3 & 20 & 83,273 \\
\hline $\begin{array}{l}\text { S. rowelli var. } \\
\text { Patagonia Mountains }\end{array}$ & 4 & ......... & .......... & $\begin{array}{l}\text { want- } \\
\text { ing }\end{array}$ & 4.5 & .......... & 83,268 \\
\hline $\begin{array}{l}\text { S. granulatissima, } \\
\text { Huachuca Mountains }\end{array}$ & 7.3 & 4.8 & 6 & 0.7 & 21 & $24-25$ & 83,257 \\
\hline $\begin{array}{l}\text { S. virilis, } \\
\text { Chiricahua Mountains }\end{array}$ & 34 & 29 & 23 & 1 & 16 & 24 & 79,622 \\
\hline S. v. circumstriatus & 24 & ...... & 21 & 0.8 & 20 & ......... & 87,026 \\
\hline
\end{tabular}

Helix remondi Tryon belongs to another genus, still uncharacterized anatomically, of the Belogona Euadenia. A living specimen sent me by mail some years ago was crushed en route, partially decayed and dried hard when it reached me. I soaked up the remains, and found that the tail has a strong scrrate keel above; there is a slender, cylindric-fusiform penis, but the rest of the genitalia were impossible to make out. The radula does not differ materially from the Epiphragmophora type. In Mexico, the genus Lysinoe and at least one species of Leptarionta have the same extremely unusual structure of the tail. 
Neither is much like $H$. remondi conchologically; but further information on both $H$. remondi and Leptarionta is needed.

Sonorella hachitana (Dall). Pl. XVII, figs. 1-8.

Epiphragmophora hachitana Dall, Proc. U. S. Nat. Mus., XVIII, p. 2, 1895 ; XIX, p. 338.

Sonorella hachitana Dall, Pilsbry, Proc. Acad. Nat. Sci. Phila., 1900, p. 557 (as type of Sonorella).

S. hachitana Dall, Bartsch, Smiths. Misc. Coll., XXXXVII, p. 190, Pl. 31 , fig. 2 (shell), and Pl. 29 (apex), 1904.

Probably includes as subspecies $S$. ashmuni Bartsch, l. c., p. 190, Pl. 31, fig. 5 ; S. nelsoni Bartsch, l. c., p. 191, Pl. 31, fig. 3, and S. goldmani Bartsch, l. c., p. 192, Pl. 32, fig. 6.

This is a wiflely distributed species in central and southeastern Arizona and southwestern New Mexico. It varies in size, degree of depression, width of umbilicus, size of aperture, and in color-tone; also in some measure in the sculpture; but so multifarious are the connecting links that I do not now see my way to support the dismemberment proposed by Mr. Bartseh. It will doubtless be found uscful to recognize by name a half-dozen or more local races.

The internal anatomy of the types, from Hacheta Grande Mountains, Grant county, New Mexico, is not known, nor have topotypes been dissected. I have been able, however, to examine several specimens from other localities, which conchologically differ very little from the original lot of hachitana, some of which are before me.

The name "hachitana" scems to be a perverted form of that of the locality, "Big Hatchet." The Spanish name, locally in use, and appearing on most maps, is "Hacheta Grande."

1. Filmore Canyon, Organ Mountains, New Mexico (PI. XVII, figs. 7, 8). A single specimen sent by Prof. Cockerell measures alt. 13.8, diam. $23.5 \mathrm{~mm}$., umbilicus $3.2 \mathrm{~mm}$. The aperture is ample, $11.8 \times 13.3$ mm., as in the large shells from Florida Mountains. This specimen has been referred by Mr. Bartsch to his S. nelsoni, which measured $25.5 \times 13.4$, umbilicus about $4 \mathrm{~mm}$., aperture $11.1 \times 12.8 \mathrm{~mm}$., and is said to differ from hachitana in being "more depressed and has a larger aperture."

The genitalia show that the specimen, while full grown, is not quite mature, the male organs especially being thread-like. The spermatheca is globular, on a very slender duct. The specimen is No. 71,413, A. N. S. P. It has been referred by Mr. Bartsch to S. nelsoni.

The jaw (Pl. XXIII, fig. 19) has eight narrow equal ribs.

2. Florida Mountains, near Deming, Luna county, New Mexico. Mr. Ferriss states that these specimens were collected in a very barren, arid locality. Very large specimens were taken measuring $28.3 \times 15.9$ 
mm., width of umbilicus $4.7 \mathrm{~mm}$., or even larger $29.5 \times 15.5 \mathrm{~mm}$. They exceed S. ashmuni Bartsch in size, and are larger than any Sonorella on record (Pl. XVII, figs. 1, 2). The aperture is ample, $12.9 \times 14.5$ mm.

Another lot (\$6,496, A. N. S. P.), figured on Pl. XVII, figs. 3-6, from the same locality, consists of smaller specimens. Some are typical hachitana in form and size except that the last whorl descends more deeply in front, making the aperture subhorizontal in some specimens (figs. 5, 6). In a few specimens the supraperipheral band is almost obsolcte, very narrow and interrupted (figs. 3,4 ), but most of them are pale reddish-brown, fading to white in the middle region of the base, and with a white or whitish band on each side of the dark supraperipheral belt.

Alt. 14.5, diam. 25.4, width of umbilieus $4 \mathrm{~mm}$.

\begin{tabular}{|c|c|c|c|c|c|}
\hline 14.3, & " & 27.7, & "6 & 6 & 4 \\
\hline 13 , & 6 & 26.7, & " & " & 3.9 \\
\hline 13.9, & " & 26 , & " & " & 4 \\
\hline 13.7, & " & 26 & " & "6 & 3.9 \\
\hline 13.3, & " & 23.5, & "6 & " & 3 \\
\hline 13.3, & “" & 23.4, & " & " & 2.9 \\
\hline 12.6, & " & 22 & $"$ & "6 & 3.9 \\
\hline 10.7, & " & 22, & " & "6 & 3.8 \\
\hline
\end{tabular}

Specimens of this lot were sent alive.

The pale sole is indistinctly tripartite, extremely weak impressed lines dividing it in some specimens, not traceable in others. The back is slate or blue-blackish, the tail brown above, paler toward the footedges. The surface is finely pebble-granulate. There is a pair of indistinct dorsal grooves, and the genital furrow is traceable only near the mantle. The tail is depressed, with a very faint median groove.

The genitalia (Pl. XX, fig. 12) show no differenees of any moment from the form of hachitana from Purtyman's ranch, Arizona, figured by me in 1900, except in the shape of the spermatheca, which, however, is not constant in the Purtyman's lot. The individuals cxamined were partly not fully developed, and possibly older specimens will show a somewhat stouter vagina and penis than that figured. The penis papilla is long and slender, not eonroluted in the specimen opened.

The jaw (Pl. XXIII, fig. 20) nas eight ribs.

The radula is somewhat unlike other Sonorellas examined in the central tooth, which is narrower than the adjacent laterals. There are 55.1.55 teeth, an ectocone appcaring on the fifteenth. Both cusps are bifid on most of the marginal teeth, the mesocone + entocone being 
very oblique and unusually long in the inner marginals. This radula differs a good deal from that of the Purtyman's raneh form, in both count of the teeth and in some details of their shape; but these features are admitted by all who have examined many radulæ to vary so widely among individuals that their value is largely discounted. The diserepancy between the forms should be eontrolled by the examination of several of each form.

Sonorella hachitana ashmuni Bartsch. Pl. XVII, figs. 9-14.

Sonorella hachitana, specimens from Oak creek, Purtyman's, Arizona, Pilsbry, Proc. Acad. Nat. Sci. Phila., 1900, p. 557, Pl. 21, figs. 1-5 (anatomy).

Sonorella ashmuni Bartsch, Smiths. Misc. Coll., Vol. 47, p. 190, Pl. 31, fig. 5 (1904).

Purtyman's ranch, on Oak creck, 40 miles from Jerome, in the eastern edge of Yavapai county, Arizona. Collected by Rev. E. H. Ashmun, 1900 (No. 79,409, A. N. S. P.).

These specimens furnished the anatomieal preparations deseribed by me (Proc. Acad. Nat. Sci. Phila., 1900, p. 557, Pl. XXI, figs. 1-5). Specimens of this lot have been examined by Mr. Bartsch and pronouneed by him to be "a small race of $S$. ashmuni. They bear the same relation to ashmuni that $S$. mearnsi bears to $S$. dalli." I would prefer to make an immaterial change in this statement. I would say that $S$. ashmuni represents a large race or eolony of $S$. hachitana, and the Oak creek lot is nearly typical hachitana.

'The specimens are well-developed shells, often larger than typical hachitana from Hacheta Grande Mountains. Nearly all are banded, whitish above and below the band; but 3 out of 350 eollected by Mr. Ashmun at this plaee lack the dark band (figs. 13, 14). Specimens measure:

\begin{tabular}{|c|c|c|c|c|c|c|c|c|c|}
\hline Specimens: & $a$ & $b$ & $c$ & \multicolumn{2}{|c|}{ (hachitana) } & $d$ & $e$ & $f$ & \\
\hline Alt. & 13 & 13.4 & 13.5 & (13.5 & $12)$ & 13.3 & 13 & 13 & \\
\hline Diam. & 23 & 22.8 & 22.5 & $(22.7$ & $22.2)$ & 22.5 & 23.3 & 22 & \\
\hline Alt. apert. & 10.7 & 10 & 10.1 & ( 9.6 & $9.9)$ & 9.9 & 10.3 & 10 & \\
\hline Diam. apert & 12.3 & 10.5 & 11.7 & $(11.9$ & $10.7)$ & 11.7 & 12 & 11.3 & \\
\hline
\end{tabular}

Compare with the measurements in parentheses of topotypes of hachitana, part of the original lot, reecived from Dall.

In general the aperture in the Purtyman raneh shells averages larger than in typieal hachitana, but no hard and fast line ean be drawn, and seleeted individual specimens of each are simply indistinguishable, either by measurements, color or any other eharaeter. The most we ean elaim for $S$, ashmuni is the rank of a weakly differentiated local raee of S. hachitana, ehiefly separable in actual practice by its geographic 
distribution. The radula has fewer teeth in a transverse row than in the hachitana from the Florida Mountains near Deming, New Mexico; but only one radula from each locality has been examined.

The color and other external features of the foot are as described for S. viritis. The internal anatomy was described and figured in iny paper of 1900, Pl. XXI. The spermatheca in another speeimen of the same lot was globular, as in other Sonorellas, not ovate with thickened duet as in the individual figured, which was stuffed with spermatophores. The penis was wrongly described in my former article. I did not then open it, and considered its upper portion to be epiphallic. When opened (Pl. XX, fig. 15) it is found to be a long, thin-walled sack, the upper half containing a long, slender, more or less convoluted papilla (p.p.). This is a little longer than in the hachitana examined from the Florida Mountains. Otherwise the genitalia are practically the same in the Florida Mountains and Purtyman's ranch snails.

Sonorella hachitana bowiensis n. subsp. Pl. XVIII, figs. 29-32.

The shell is similar to hachitana but is much smaller, with $4 \frac{1}{3}$ to $4 \frac{1}{2}$ whorls. The supraperipheral band shows on about $2 \frac{1}{2}$ whorls, above the suture on the spire; on the last whorl it has very faint, inconspicuous pale borders or none. No spiral lines are present in most specimens, but'in two they may be scen very faintly, near the periphery. Seven fully adult shells measure:

$\begin{array}{lrccccccc}\text { Alt. } & 9.9 & 9.9 & 9.8 & 10 & 9.2 & 9.7 & 8.7 \mathrm{~mm} \text {. } \\ \text { Diam. } & 17.8 & 17 & 17.5 & 17 & 17.2 & 16.6 & 15 & \text { " } \\ \text { Alt. apert. } & \text { S.2 } & 7 . S & \mathrm{~S} & \mathrm{~S} & 7.7 & 7.7 & 6.9 & \text { " } \\ \text { Diam. apert. } & 9.5 & 9 & 9.2 & 9 & 9 & 8.4 & \mathrm{~S} & \text { " }\end{array}$

Bowie, Cochise county. Types No. 86,497, A. N. S. P., collected by James H. Ferriss, 1904. Specimens were also taken by Mr. Ashmun at the same place. Mr. Ferriss writes that they were taken "in a situation exceedingly favorable for snails."

The genitalia (Pl. XX, figs. 10, 11) show externally only slight differences from hachitana. The penis and epiphallus are comparatively a little longer. Internally, however, the penis differs in having a short, obtuse papilla, only about $3 \mathrm{~mm}$. long (Pl. XX, fig. 10), while in the forms referable to hachitana the papilla is twice as long, slender and tapering. These features, which $I$ have confirmed in a number of individuals, inclicate a ecrtain amount of racial differentiation which may properly be recognized in nomenclature.

The jaw (Pl. XXIII, fig. 22) has four low, wide, unequal ribs ant some minor riblets. 
The radula is like that of Purtyman's ranch hachitana in general features. The twelfth lateral shows a small cetocone, larger on succeeding teeth.

Sonorella rowelli (Newcomb). P1. XVIII, figs. 33-35.

Helix rowelli Newc., Proc. Cal. Acad. Sci., III, p. 181 (January, 1865).

S. rowelli (Newc.), Pilsbry, Proc. Acad. Nat. Sci. Phila., 1902, p. 511.

Shell like S. hachitana, but small, with large mouth and small umbilicus. Corncous-brown, with a dark band above the periphery, indistinct pale borders above and below it; somewhat translucent, thin. Whorls nearly $4 \frac{1}{2}$, convex, the first (embryonic) $1 \frac{1}{3}$ whorls nearly smooth, sculptured with some slight radial wrinkles only; following whorl or whorl and a half showing some indistinct granulation in places; last whorl with growth-lines only, rounded peripherally, descending a little in front. The aperture is large, subcircular, oblique, the thin whitish peristome being very narrowly cxpanded, columellar margin dilated. Umbilicus comparatively narrow, partially covered by the columellar lip.

$\begin{array}{lrrr}\text { Alt. } & 9.9 & 9.6 \mathrm{~mm} \text {. } \\ \text { Diam. } & 17.1 & 16.6 \text { " } \\ \text { Umbilicus } & 2.5 & 2.1 \text { " } \\ \text { Alt. apert. } & 8.5 & 8.7 \text { " } \\ \text { Diam. apert. } & 9.5 & 9.5 \text { " }\end{array}$

Sanfords, near the eastern border of Pima county, southeastern Arizona. No. 83,273 , A. N. S. P., collected by James H. Ferriss, 1902 (figs. 33, 34).

Genitalia (Pl. XX, figs. 13, 14). The penis is short, containing a short, cylindric, obtuse papilla. The free portion of the epiphallus is about equal to the penis in length. The flagellum is reduced to a mere tubercle, being much shorter than in any other Sonorella yet dissected. The vagina is about as long as the penis, and the spermatheca and its duct are about four times as long.

The jaw has 6 or 7 narrow, unevenly spaced ribs.

The radula has 44.1 .44 tecth, like those of $S$. granulatissima. The eleventh and twelfth are transitional.

The last whorl is less deflexed than in S. h. bowiensis, the aperture is larger and the umbilicus smaller. Both penis and vagina are decidedly shorter, though their proportionate lengths do not differ materially, and both have the penis-papilla short and obtuse; but in $S$. rowelli the flagellum is reduced to a minute vestige, unlike any of the other species. The remarkable constancy of this organ in the large number of individuals of Sonorella and Ashmunella which have been 
under my scalpel, gives reason for eonsidering its modification in this species of importance.

I have identified these shells with S. rowelli (Newc.), a species said to have been collected in Arizona by Frick, many years ago. S. arizonensis (Dall), from Tueson, is more elevated, but is probably related to rowelli.

A form collected by Dr. G. H. Horn, the coleopterist, at Fort Grant, Arizona, is closely related to the shells deseribed above.

In the Patagonia Mountains, a short distance castward from the locality of $S$. rowelli, a smaller form of the species was collected by Mr. Ferriss (Pl. XVIII, fig. 35), and also by Mr. Ashmun. The umbilicus is narrower and more covered by the dilated lip than in Sanford's rowelli, and the last whorl descends more deeply in front. The shells measure:

83,268, Ferriss coll.

Alt.

Diam.

Alt. apert.

Diam. apert.
9

15.4

7.8

8.5

$S$
14
6.9
7.8

73,604, Ashmun coll.

$\begin{array}{cccc}8 & 8 & \text { S } & \\ 14 & 14 & 13.5 & \text { " } \\ 6.8 & 6.8 & \ldots \ldots . . & \text { " } \\ 7.7 & 7.5 & \ldots \ldots . . & \text { " }\end{array}$

One of Mr. Ferriss' specimens (fig. 35) was sent alive, and proves to be like the Sanford's rowelli anatomically, differing merely in the smaller size of all the organs, exeept that there is no perceptible flagellum (Pl. XX, fig. 20, the terminal duets only are drawn). The jaw (Pl. XXIII, fig. 18) has about 6 narrow equal ribs.

The type measurements of $H$. rowelli given by Neweomb are alt. .4, diam. maj. .6, min. .5 inch., about equal to $10,15,12.5 \mathrm{~mm}$. The type is in the collection of Cornell University.

Sonorella granulatissima Pils. Pl. XVII, figs. 21-23.

Nautilus, XVI, p. 32, 1902.

Bartsch, Smiths. Misc. Coll., Vol. 47, p. 193, Pl. 32, fig. 4.

The shell in the eo-types of this species is thin, pale, with a rather wide dark chestnut band without white borders, and visible above the suture on the last $2 \frac{1}{2}$ or 3 whorls. The surface is very minutely and very densely granulated over the usual low growth-wrinkles. Near the periphery some faint traces of spiral lines may be deciphered in places, but they are so slight that they would have been overlooked if not especially looked for. The umbilicus is small. The two co-types measure?

- These measurements differ slightly from those given in the original deseription, due to the fact that at that time I used only a flat millimeter rule, upon which it is, I find, impossible to read correctly the dimensions of globose shells. 


$\begin{array}{lcrc}\text { Alt. } & 10.4 & 10 & \mathrm{~mm} . \\ \text { Diam. } & 19 & 18.5 \text { " } \\ \text { Alt. apert. } & 9.5 & 8.7 \text { " } \\ \text { Diam. apert. } & 10.4 & 9.7 \text { " } \\ \text { Umbilicus } & 2.5 & 2.7 \text { " }\end{array}$

They are from "Spring Canyon," near Fort Huachuca, No. \$3,257, A. N. S. P.

The sole is indistinctly tripartite, the middle field ochraceous, the sides dusky; the colors separated by very faint lines. The upper surface is blackish-gray, cvenly pebble-granose. A subobsolete dorsal line is discernible, and a very weak line on the tail, not quite median.

The two co-types were dissected. The genitalia (Pl. XX, figs. 16, $17,18)$ are characteristic by the proportions of the penis and vagina. The penis is short, cylindric, composed of a thin-walled sack containing a large, fleshy, cylindric papilla (fig. 18). Epiphallus and flagellum (fig. 16) as usual. The vagina is large, very long and muscular, about three times the length of the penis. Its upper portion is swollen and sometimes fusiform. Other organs as usual (see table of measurements).

The jaw (Pl. XXIII, fig. 23) has four very wide, low, flat ribs.

The radula has 36.1.36 teeth. the central and inner laterals unicuspid, the eleventh showing a minute ectocone. Most of the marginal teeth have both cusps bifid.

2. Brown's Canyon. One specimen similar to those from Cave Creek, Ida and Bear Canyons, 11.8 x $19 \mathrm{~mm}$.

3. Ramsey Canyon. The shells are darker than the types, beautifully granulated, and show distinct spiral lines on the top of the last whorl. Umbilicus typical.

4. Carr Canyon (Pl. XVIII, figs. 51-54). These shells show the spiral lines more or less distinctly. They are otherwise typical, but vary a good deal in size.

5. Miller Canyon (Pl. XVIII, figs. 41, 42, 43). Of a rich dark reddish color with a wide darker band, well granulated and showing weak or excessively faint spirals. More depressed than any other granulatissi$m a$ seen; and in some specimens the umbilicus is decidedly wider, 3 $\mathrm{mm}$. in a shell $18.5 \mathrm{~mm}$. diameter.

There were also some much lighter, greenish-yellow shells taken in Miller Canyon (PI. XVIII, figs. 39, 40, 44). They are much depressed, with a wide umbilicus and very distinct spiral striation (Pl. XI, fig. 10). They photograph abnormally dark. 
Alt. 10.7

$19.9 \quad 19.5$

11.1

Diam. 19.

(Miller Canyon)
(Carr Canyon)

$\begin{array}{lll}11.8 & 10.8 & 10.2\end{array}$

Alt. $\quad 11.5 \quad 10.7 \quad 9 \quad \mathrm{~mm}$.

Diam. $20 \quad 19.6 \quad 18.5$ "

6. On the south side of the range, specimens were taken in Cave Creck Canyon, typical in form and sculpture, but larger, $12.6 \times 20.8$ mm.

7. Ida Canyon (Pl. XVIII, figs. 36, 37, 38). Typical in shape and color, but with slightly effaced granulation, very weak spirals, and variable size.

$\begin{array}{lllc}\text { Alt. } & 11.9 & 10.4 & 9.3 \mathrm{~mm} . \\ \text { Diam. } & 21.3 & 19.8 & 17.8 \text { “ }\end{array}$

S. Bear Canyon. Similar to the Cave creck form, $11 \times 19.3 \mathrm{~mm}$., or more depressed, like Miller Canyon shells, $10.7 \times 20.8 \mathrm{~mm}$; umbilicus $2.9 \mathrm{~mm}$.

Sonorella granulatissima parva n. subsp. Pl. XVIII, figs. 4j-47.

Shell with the sculpture of S. granulatissima, but much smaller, and subangular at the periphery. Whorls $4 \frac{1}{2}$, convex, parted by well-impressed sutures, the last moderately descending in front. The band is wide, without pale borders, and is visible on two or two and a half whorls.

$\begin{array}{lcccc}\text { Alt. } & 9.3 & 10 & 9 & \mathrm{~mm} \text {. } \\ \text { Diam. } & 16 & 16 & 15.2 & \text { " } \\ \text { Alt. apert. } & 7.4 & & & \text { " } \\ \text { Diam. apert. } & 8.3 & & & \text { " } \\ \text { Umbilicus } & 2.4 & & & \text { " }\end{array}$

West end of the Huachuca Mountains, between Fort Huachuca and Manilla Mine. Types No. 87,114, A. N. S. P., collected by James H. Ferriss, 1904.

Eleven specimens of this small form were obtained at the place mentioned. It is chiefly notable for the subangular periphery, very unusual in Sonorella. It is very similar to $S$. mearnsi Bartsch, differing in the wider umbilicus and more oblique aperture. S. mearnsi may prove to be a subspecies of $S$. granulatissima, but its internal anatomy is unknown.

\section{Sonorella granulatissima latior n. subsp. Pl. XVIII, figs. 24-28.}

This form is very similar to $S$. granulatissima, from which it differs in the usually larger size and the more depressed last whorl. The granu- 
lation is finer and less distinet than in typical granulatissima, and the umbilicus is slightly wider. The supraperipheral band is wide, and has no paler borders. There are $4 \frac{3}{4}$ whorls, the last rather deeply deflexed. The embryonic shell is sculptured as in S. hachitana.

$\begin{array}{lllrrr}\text { Alt. } & 12 . & 12 & 12.4 & 12 & 12 \\ \text { Diam. } & 23.6 & 23 & 22.6 & 22 & 22 \\ \text { Alt. apert. } & 11 & 10.5 & 10.8 & 9.8 & 10 \\ \text { Width apert. } & 11.7 & 12.2 & 12 & 11.4 & 12 \\ \text { Width umbilieus } & 3.2 & \ldots \ldots . . & 2.6 & 3.3 & 3 \\ \text { Alt. } & 11.7 & 11.2 & 11.7 & 12.2 \mathrm{~mm} . \\ \text { Diam. } & 22 & 21.9 & 21.3 & 20.5 \text { " } \\ \text { Alt. apert. } & 10.7 & 10 & 9.8 & 9.4 \text { " } \\ \text { Width apert. } & 11.9 & 11.5 & 11.2 & 10.9 \text { " }\end{array}$

Huachuea Mountains, in Brown's Canyon. Types No. 87,083, A. N. S. P., collected by James H. Ferriss.

The soft anatomy is unknown, but the form, while not conspieuously differentiated, is yet readily distinguishable from $S$. granulatissima. Specimens sent to Mr. Bartsch were pronounced by him to "stand half way between $S$. dalli and S. granulatissima."

Sonorella dalli Bartsch.

Smiths. Misc. Coll., Vol. 47, p. 193, Pl. 21, fig. 1 (October 10, 1904).

This form is somewhat larger and more depressed than S. g. latior. It is described as with "numerous microscopic granulations," but in one of the type lot kindly presented by Dr. Dall these are hardly appreciable. The type measurements are alt. 12, diam. 26.5, aperture $10.5 \times 11.8 \mathrm{~mm}$; and Mr. Bartsch has kindly supplied the diameters of the rest of the series in the U.S. National Museum, as follows: Type Jot, Tanner's Canyon, Huachuca Mountains, 26.5, 26.1, 25.9, 24.1, 24, the last two not quite mature. Huachuca Mountains, $25.3 \mathrm{~mm}$. Fort Huachuca, $24.6 \mathrm{~mm}$.

The smallest mature specimen of $S$. dalli slightly execeds the largest latior by $1 \mathrm{~mm}$., and the smallest adult latior measures the same as the largest granulatissima. S. mearnsi Bartsch, from the San José Mountains, 4 miles south of the Arizona boundary, measures $16 \mathrm{~mm}$. diam., being $1.5 \mathrm{~mm}$. smaller than the smallest adult granulatissima. It is quite conccivable that $S$. dalli and S. mearnsi are merely the extremes of dimensions in a continuous series of variations in size. Since $S$. granulatissima is the only form of the series known anatomically, the ultimate status of the others remains in abeyance. Some or all of them may prove to have valid anatomical specific characters. 
Mr. Ferriss dirl not find S. dalli. He thinks that Tanner's is another name for Garien Canyon of the sketeh map on p. 212.

Sonorella virilis n. sp. Pl. XVII, figs. 25,16 .

The shell is openly umbilicate; pale brown, lighter around the umbilieus, with a dark band above the periphery, and visible on about $2 \frac{1}{2}$ whorls above the suture, with borders a trifle paler than the ground color. Whorls $4 \frac{1}{2}$, the earlier $1 \frac{1}{2}$ forming a slightly rugose embryonic shell. The next 1 or $1 \frac{1}{2}$ whorls are striate, the striae appearing slightly broken into granules. The last whorl has the usual slight growth-lines, and near the end some spiral lines are visible, in the vieinity of the suture. The whorl deseends rather deeply, and is well rounded peripherally. The aperture is rather large, oblique and rounded, the upper, outer and basal margins about equally areuate. The outer and basal margins of the thin lip are slightly expanded. Alt. 11, diam. 19.5, umbilicus $3.1 \mathrm{~mm}$; aperture $9.3 \mathrm{~mm}$. high, 10 wide.

Chiricahua Mountains, at 7,500 feet elevation, collected by V. Owen. Type 79,622 , A. N. S. P.

There are no longitudinal lines on the sole. The pebbly-granose back and the eye-stalks are blackish-gray, becoming much paler dirty brownish-white on the sides and tail. Dorsal grooves are but weakly indicated, and there is no longitudinal median line on the tail.

The kidney is wedge-shaped, $15 \mathrm{~mm}$. long. Perieardium $5.5 \mathrm{~mm}$. long.

Genitalia (Pl. XX, figs. 21, 22). The penis is relatively enormous, more than double the length of the vagina, and much longer than the spermatheea and its duct. It has the usual thin wall, enclosing a fleshy "papilla" about $29 \mathrm{~mm}$. long (fig. 21). The epiphallus is also very long, slender and convoluted. The vagina is much convoluted. The spermatheea has the usual globular shape; and its slender duet, while long, is shorter than in other species of equal or greater size.

The jaw (Pl. XXIII, fig. 21) has four broad ribs grouped near the micldle.

$S$. virilis is slightly smaller than $S$. hachitana, with more rounded aperture and weak spiral lines near the suture. From the shell alone I would not separate this form more than varietally from $S$. hachitana; but the enormously developed or reproductive organs indicate one of the most distinet speeies of the genus. The jaw has few ribs, as in $S$. h. bowiensis. It is not elosely related to any other species I have dissected.

The faint spiral lines of the shell are pertaps its most important differential feature. 
Several lots collected hy Mr. Ferriss in the Chiricahua Mountains resemble $S$. virilis in size, color and sculpture, but differ in having about one-fourth of a whorl more $\left(4 \frac{3}{4}\right)$, and a noticeably smaller aperture. The spiral lines, while visible in some places on all of them, in a favorable light, are often excessively weak. None of them, unfortunately, were sent in the flesh.

In Bar (or Bearfoot) Park, at the summit of the Chiricahuas, the specimens taken show some very weak spiral lines below the last suture.

Alt. $\quad 10.7 \quad 10.7 \mathrm{~mm}$.

Diam. $18.9 \quad 18.7$ "

In Sawmill Canyon, Chiricahuas, adjacent to Bearfoot Park, similar shells, cliam. 18.7 to $19.9 \mathrm{~mm}$., were taken (Pl. XVII, figs. 17, 18, $19,20)$.

Sonorella virilis oircumstriata n. subsp. Pl. XVIII, figs. 48-50.

In Cave Creek Canyon, Chiricahuas, the shells are darker throughout, reddish-brown, with a broad very dark chestnut band with wide pale borders, sometimes not very conspicuous. The last whorl shows weak but distinct spiral engraved lines above the periphery, in ardition to the usual fine growth-striæ. The umbilicus varies from about 3.3 to $3.8 \mathrm{~mm}$. in width. A. N. S. P., No. $87,026$.

$\begin{array}{lcrrr}\text { Alt. } & 11.6 & 11.3 & 11 & 10.8 \mathrm{~mm} \text {. } \\ \text { Diam. } & 21 & 20.3 & 20 & 19.5 \text { " } \\ \text { Alt. apert. } & 9.7 & 9.2 & 9 & 8.9 \text { “ } \\ \text { Diam. apert. } & 10.7 & 10.4 & 10 & 9.5 \text { " }\end{array}$

The genitalia (Pl. XX, fig. 19) in two specimens dissected agree in having several minor differences from typical $S$. virilis. The penis, while still extraordinarily large, is only about two-thircls as long as in viritis. The vagina is a fourth longer. The epiphallus is the same as in viritis.

This form may prove to be connected with typical virilis by intermediate stages, in which case the subspecies may prove superfluous; but at present the dark color, more distinct spiral striæ, and small aperture of the shell, and the somewhat differently proportioned genitalia, scem worth recording.

Sonorella virilis huachucana n. subsp. P1. XVII, fig. 24.

Shell slightly more elerated than S. hachitana, with much smaller umbilicus; more elevated than S. virilis, which also is more widely umbilicate; glossy, thin, striate but without granulation. The top of the last whorl, near the aperture, shows numerous weak spiral inciscd 
lines. The supraperipheral band is rather wide and dark, with distinct white or whitish bands both above and bclow it. Above the upper white band the surface is pale reddish to the white sutural line. Below the lower white border the same reddish color prevails, but gradually fades on the base to whitish around the umbilical region. The dark band runs about $2 \frac{1}{2}$ whorls up the spire. Apex with sculpture like S. hachitana. Whorls $4 \frac{3}{4}$, the last rather deeply descending in front. Aperture rounded-oval, the peristome thin, expanded, the dilated columellar end partially covering the umbilicus. Alt. 12.4, diam. 20.6, alt. aperture 10, width $11.5 \mathrm{~mm}$; ; width of umbilicus $2.4 \mathrm{~mm}$.

Brown's Canyon, Huachuca Mountains. Type No. 89,225, A. N. S. P., collected by James H. Ferriss, 1904.

This beautiful snail is the only Huachuca form I have seen which seems closely related to $S$. virilis. Unfortunately, the soft parts were not preserved, and its exact relationships are thus uncertain. It is not very unlike S. hachitana, but I can see no spiral lines on some of the original lot of hachitana before me. The white bordering bands are particularly conspicuous. Only a few were taken by Mr. Ferriss.

In Bear Canyon, Huachuca Mountains, Mr. Ferriss found a few specimens similar to those from Brown's Canyon, but noticeably more depressed, with a smaller mouth and obtuse lip. One measures, alt. 11.5, diam. 20, aperture $9.8 \times 11 \mathrm{~mm}$., umbilicus $3 \mathrm{~mm}$. wide. The shell is also somewhat more solid, and the spiral lines are more distinct. In both forms they are readily seen with a hand lens.

\section{Genus OREOHELIX Pilsbry.}

Helix, Patula and Pyramidula of authors.

A new genus of Helicida, Pilsbry, Proc. Acad. Nat. Sci. Phila., 1902, p. 511. Oreohelix Pils., Nautilus, XVII, p. 131, March, 1904.

The shell is umbilicate, varying from discoidal to pyramidal, with 4 to 6 tubular or carinate whorls; earthy, with thin cuticle or none. Embryonic whorls with radial and usually spiral seulpture and carinate periphery. Aperture rounded, oval or angular, oblique, the columellar lip dilated, the outer lip blint or acute, unexpanded. The sole is undivided. Foot granulose and blackish above or smoothish tessellated with gray. A pair of dorsal grooves is present and usually a distinet genital groove. The tail is depressed above. No parapodial furrows.

The lung has thin-walled venation, chiefly on the eardiac side. The kidney is short, but little longer than the pericardium; has a large lumen with coarsely plicate walls, and the usual reflexed ureter. The secondary ureter is elosed throughout in the species examined (Pl. XIX, fig. 1, O. strigosa var., Pecos, New Mexico). 
The penis is well developed, its lower part being museular, and plicate within, the upper part thinner and densely, finely papillose inside. The epiphallus is well developed, with terminal vas deferens or with a terminal tubercle (representing the flagellum) and a sublaterally inserted vas deferens. The vagina is rather long. The globular or ovate spermatheca terminates a slender duct nearly as long as the uterus. Reproduction is viviparous.

The retractor muscle of the penis arises from the apex of the penis and base of the epiphallus, or from the cpiphallus near its base, and is inserted on the lung floor. The right ocular retractor passes between the $\sigma^{7}$ and 0 branches of the genitalia.

The jaw is strong, arcuate, its anterior face more or less distinctly striated vertically; and there are sometimes very weak traces of ribs. The radula is of the ordinary Helicid type. In some species the median area has unicuspid teeth, the cutting-edges usually overhanging the sides of the mesocone; while in others distinct ectocones are developed in all the teeth. The marginal teeth are bicuspid, the cusps unsplit as a rule, though there are exceptions where the inner of the two cusps is bifid.

Type Helix strigosa Gld. Distribution, Rocky Mountain region from the Canadian to the Mexican boundary.

This dominant type of Helicide in the area indicated above formerly extended farther east, one species occurring in the loess of Iowa, and there is one outlying species westward, O. avalonensis Hemph., on Catalina Island, California. In its present area the type has been interminably modified into local races of all grades of differentiation, more than fifty of these having reccived names. ${ }^{6}$ It is true that in some ranges every canyon-I might almost say every rock-heap-has its own race; but in a broader view it is seen that a single strain usually cxtends over an entire range with numerous minor modifications, and with increasing elevation a general diminution of size, loss of sculpture and often intensification of color. These reduced forms are probably due to the diminished food supply and especially the shorter growing season in the heights-factors subject to great local variation, even at equal

- The number of species of Oreohelix is uncertain. About fifty forms of all degrees of differentiation have been described and named. My treatment of the group in former publications (Manual of Conchology, VIII, p. 115, IX, p. 50 Catalogue of the Land Shells of America, etc., pp. 31, 32 (1S9S), was unduly influenced by the views of Binney and Hemphill, both of whom adrocated the inclusion of the entire series as varieties of $P$. strigosa. The characters of the shells, penes and teeth indicate, in my opinion, that the species are somewhat numerous; but their notorious variability cautions us to benare of multiplying them without ample materials. 
altitudes. To attain a true idea of the relationships of any given alticolous dwarf it is essential to know the forms of the lower canyons of the same region.

The first step toward a fundamental knowledge of the races and species of Oreohelix must be the study and definition of races in the broad sense above indicated. In my opinion, the minor modifications can be so overnamed that the wider distinctions become altogether lost, as in the Utah series. The field is vast, and for many years to come there will be plenty of room for work. Anybody who secures a good series of the forms of any district can materially help the cause by working them up.

The sculpture of the embryonic shells and the genitalia seem to afford the most important characters for specific classification. It would take us too far afield to discuss the entire mass of data at hand. This must be reserved for another occasion. Only forms from central and southern Arizona and New Mexico are dealt with below. ${ }^{7}$ The measurements of the genitalia in millimeters follow:

\begin{tabular}{l|c|c|c|c|c|c}
\hline \multicolumn{1}{c|}{ Species } & Penis & $\begin{array}{c}\text { Epi- } \\
\text { phallus }\end{array}$ & Vagina & $\begin{array}{c}\text { Sperma- } \\
\text { theca and } \\
\text { duct }\end{array}$ & $\begin{array}{c}\text { Diam. of } \\
\text { shell }\end{array}$ & $\begin{array}{c}\text { Mus. } \\
\text { No. }\end{array}$ \\
\hline O. strigosa, Pecos & 16.3 & 6.3 & 5 & 21 & 18.5 & 85,100 \\
O. elrodi & 17 & 6 & 8 & 19 & 22.5 & 79,475 \\
O. s. huachucana & 14 & 6.5 & 5 & 22 & 21 & 83,370 \\
O. barbata & 6 & 4 & $\ldots \ldots .$. & 13 & 13.5 & 87,011 \\
O. yarapai & 5 & 3 & $\ldots \ldots .$. & $\ldots \ldots \ldots$ & $15-16$ & 79,415 \\
O. y. neomexicana & 4 & 2.1 & $\ldots \ldots .$. & $\ldots \ldots . .$. & 15 & 80,700 \\
\hline
\end{tabular}

The species thus far dissected show considerable differences in the genitalia, chiefly in the proportions and shape of the penis, the forms falling into three groups, as follows:

${ }^{7}$ For comparison with the southern forms I have, however, figured the anatomy of $O$. elrodi (Pils.), from Montana, Pl. XIX, fig. 2. The penis is like that of $O$. strigosa, from Pecos, the lower third having thick walls, densely plicate within; above that the walls are thinner, densely lined with long papillæ, and in the upper third there are several low fleshy ridges, also papillose. There is an extremely short, conic penis-papilla in the apex. The vas deferens enters the epiphallus centrally. The vagina is much dilated and muscular above. The uterus is provided with muscular strands forming an incolierent protractor muscle (fig. 2, r.u.). The embryos were packed in like coins except the two lower ones. The dimensions are given in the table. 
1. Penis long, the distal half strongly twisted, there being two distinct kinks, resulting in convolutions variously disposed, and of course not always falling the same in the same species or varicty. O. strigosa, from Pecos, and O. clrodi (Pl. XIX, figs. 3 and 2) belong here.

2. Basal half of the penis swollen and muscular, the distal half smaller, without distinct kinks. O. s. huachucana and O. barbata (Pl. XIX, figs. 6 and 5) are of this type.

3. Penis small, short, the basal half not much larger than the distal portion, the latter not kinked. O. neomexicana and O. yarapai (Pl. XIX, figs. 7 and 9) have penes of this kind.

All the above have the penis longer than the epiphallus. In the subgenus Radiocentrum the epiphallus is as long as the penis or longer.

As yet my observations have covered only about a dozen of the numcrous species and subspecies; and until more of the forms of the central and northeru States are examined, characters of the soft anatomy cannot be fully utilized in classification.

There are two types of dentition in Oreohelix. The ordinary forms have unicuspid central and inmer lateral teeth. Here stand $O$. strigosa, cooperi, newcombiana, huachucana, yavapai, neomexicana and haydeni. In the second type of teeth ectocones are developed on all of the teeth, the centrals being thus tricuspid, the lateral and marginal teeth all bicuspid. Of this kind are $O$. idahoensis, $O$. hemphilli, O. barbata, $O$. chiricahuana and $O$. clappi, but in the last species the ectocones are not well developed.

The series of Huachuca Orcohelices shows that colonies of the same original stock vary greatly and often show parallel variations in different canyons.

Those from the greatest altitudes are smallest (Pl. XXIV, figs. 25-27, 29-32, Limestone Mountain, 8,000 feet; Pl. XXIV, fig. 28, Carr Canyon, 7,000 feet, ete.), though some large shells occur elsewhere at equal elevations.

Conspicuously banded shells were taken only at high clevations (Pl. XXIV, figs. 17, 1S, Brown Canyon, 7,000 feet), plainer ones occurring lower down in the same canyon; but not all the high altitude shells are so marked.

Gerontic or senile individuals or colonics are common, manifested by deep descent of the last whorl in front, with a tendency to form a free or solute peristome (Pl. XXV, figs. 33-35, Ida Canyon).

The carinate periphery is an ancestral character of $O$. strigosa and its allies, present invariably in the neanic stage. It will be noted that 
in most colonics there is great individual variation in the extent to which it has been replaced in the adult stage by a rounded periphery.

Oreohelix strigosa (Gld.).

Various forms referable to strigosa occur in New Mexico, such as those sent from the Red river (Ashmun), Pecos (Cockerell), Canyon Diablo, near Rowe (Miss Cooper), and Big Spring, 5 miles cast of Zuñi (H. S. Conard). They are two-banded, with the periphery of the last whorl rounded, not differing from the forms commonly found farther north, but slightly unlike the typical Northwestern strigosa. The exact affinities of these forms await further investigations now in progress.

I have examined the internal anatomy of specimens from Pecos, New Mexico. The shells are either rounded or subangular at the periphery in adults. Sculpture of sharp, irregular growth-wrinkles or strix, decussated by slightly impressed spiral lines both above and below. The color varies from yellowish Isabelline to light reddish, with paler strix, always with two narrow bands, and in one specimen a third band around the umbilicus. The embryonic shell is strongly carinate. The first whorl is convex and almost smooth; then fine, regular, obliquely radial striæ appear, and continue to the end of the embryonic shell of 2 to $2 \frac{1}{3}$ whorls; over them there is an extremely minute regular spiral striation, and on the last half whorl coarser, spaced spirals (Pl. XYV, figs. 45, 46, 47).

The specimens examined were taken August 9, 1903. The penis is very long and strongly twisted. The basal third of its length is cylindric, the rest more or less lank, partially collapsed. Internally the basal third ( $5 \mathrm{~mm}$.) is rather finely plicate longitudinally, thick-walled; the rest has larger lumen and thinner walls, which are densely papillose within, the distal half having three low fleshy internal ridges. The penial retractor is inserted upon the end of the penis and the base of the epiphallus, which is decidedly less than onc-half the length of the penis. The vagina is subcylindric. The uterus is distended with embryos, of which there are 9 , with shells 3 to $4 \mathrm{~mm}$. in diameter (Pl. $\mathrm{XI}$, figs. 14, 15). Each is enclosed in a membranous capsule, apparently the podocyst. Some of them seem to have a small ecphalic vesicle. The other o organs call for no especial notice (Pl. XIX, fig. 3).

The pallial organs have been described above. The kidney is 6.7, the pericardium $4.6 \mathrm{~mm}$. long.

The foot is slate-blackish and fincly granular above, the dorsal furrows distinct. The distinct genital furrow is duplicated on the left side.

The jaw (Pl. XXIII, fig. 25) has fine vertical striæ. 
The radula (Pl. XXII, figs. 1, 2, 3) has 29.1.29 tecth. Central and inner lateral teeth are unicuspid. An cetocone appears on the eighth or ninth teeth. The marginal teeth are all bieuspid (fig. 2).

Mr. Binney has figured the genitalia of a specimen of strigosa from Salmon river. Just what race it belongs to is not positively known. It differs from the Pecos form of strigosa by the shorter, apparently untwisted penis. The epiphallus and vagina are also shorter. He figures the teeth of strigosa with the cetocone split on an extreme marginal, and the radula had 50.1.50 tecth-a far greater number than I have eneountered in this genus. The teeth of $O$. haydeni as figured by Binney are like those of Pecos strigosa, and 33.1.33 in number. 0 . elrodi has $28.1 .2 S$ similar tecth, the tenth with an ectocone, marginals bicuspid.

Forms referable to Oreohelix cooperi have been found by Prof. Cockerell in central New Mexieo. None were turned up in the regions explored by Mr. Ferriss.

Oreohelix strigosa concentrata (Dall).

Patula strigosa var. concentrata Dall, Proc. U. S. Nat. Mus., XVIII, 1895, p. 1 ; XIX, p. 336.

This was described from a dwarf form of the mountain tops, the types from the summit of the Huachuca Mountains, Cochise county, Arizona. Through the courtesy of Dr. William H. Dall, I have one of the typical lot (No. $\$ 9,237$, A. N. S. P., from No. 129,999 , U. S. Nat. Mus.), and a scries from the top of Hacheta Grande, 9,000 fect elevation (No. 65,742, A. N. S. P.).

1. Typieal concentrata is white with two dark red-brown bands, the lower one wider, and some livid clouding on the upper surface. The 5 whorls are convex, the last rounded peripherally, with a slight and inconspicuous trace of angulation at its origin. The umbilicus is widely open, very ample within. Sculpture of low, rude, nearly effaced wrinkles, with no trace of spiral lines anywhere. The type measures alt. $\$$, diam. $16 \mathrm{~mm}$., the specimen before me $7.8 \times 14.8$ nm. with the umbilicus $4 \mathrm{~mm}$. wide.

$O$. $s$. concentrata is a relatively evolved form, having lost the lieel on the last whorl. The embryonic whorl secms to be similar to that of huachucana. There are no spirals on the last whorl. Diam. 14 to $16 \mathrm{~mm}$.

The following lots from the Huachucas seem referable to concentrata.

2. Carr Canyon, 7,000 feet (Pl. XXIV, fig. 28). Similar to typical concentrata, with the same depressed shape, very ample umbilicus and nearly effaced sculpture, but fine rarlial ripples are visible on the cm- 
bryonic whorls in the least worn shells; broadly two-banded with chestnut, blackish in places, the upper band sometimes extending to the suture.

$\begin{array}{lccl}\text { Alt. } & 9 & 8.7 & 10 \mathrm{~mm} . \\ \text { Diam. } & 15.2 & 15 & 15 \text { " }\end{array}$

3. Limestone Mountain, Huachucas, south side at 8,000 fect elevation (Pl. XXIV, figs. 29-31). The shells are whitish with some fleshy or livid streaks or dots, and with two bands, or clouded and suffused with purple-brown. Similar to typical concentrata except that the umbilicus is decidedly smaller within. The last whorl descends to the aperture. They are like O. s. huachucana, No. 3, from Brown Canyon, in miniature. They are rounded or slightly angular in front. The sculpture is subobsolete, without a trace of spirals.

$\begin{array}{lcccc}\text { Alt. } & 8.9 & 8.4 & 9.5 \mathrm{~mm} \text {. } \\ \text { Diam. } & 15.2 & 15.3 & 15 \text { "6 } \\ \text { Whorls } & 5 & 4 \frac{3}{4} & 5\end{array}$

Scalariform monsters are not rare, but the inception of that abnormal condition secms to be invariably traceable to an injury of the shell. One such is figured (Pl. XXIV, fig. 31).

4. Limestone Mountain, south side, $\mathrm{S}, 000$ feet. Like the preceding, but more elevated and fleshy white with pinkish apex. The last whorl descends rather deeply (Pl. XXIV, fig. 32).

$\begin{array}{llrr}\text { Alt. } & 10 & 9.7 & 8.7 \mathrm{~mm} \text {. } \\ \text { Diam. } & 15.3 & 15.5 & 13.7 \text { “ }\end{array}$

5. Limestone Mountain, north side, $\$, 000$ fect. Similar to the two preceding lots in size and sculpture, but broadly two-banded with purple-black, or entircly of this color (Pl. XXIV, figs. 25, 26, 27). This lot rescmbles O. s. huachucana, Nos. 11, 12, from Carr Canyon, which are also from a high altitude. No. 5 from 7,000 fect, Brown Canyon, has also similar coloring, but is much larger.

This lot, like all secn from Limestone Mountain, does not have the umbilicus so wide within as in typical concentrata.

$\begin{array}{lcrr}\text { Alt. } & 9 & 8.5 & 9.3 \mathrm{~mm} . \\ \text { Diam. } & 16.3 & 15.5 & 15.2 \text { “" }\end{array}$

6. The series of five specimens sent by Dall as $O$. s. concentrata from Hacheta Grande Mountain, Grant county, New Mexico, one of which is figured on Pl. XXV, fig. 60, shows no appreciable divergenee from the 
co-type brfore me, having the same ample umbilicus and blunted sculpture. Whether these shells are to be regarded as really identical with the Huachuca concentrata, or as a parallel dwarf race independently evolved, is a question remaining to be determined by a study of the forms from the lower canyons of the Hacheta Grande Mountains.

Oreohelix strigosa huachucana (Pils.). Pl. XXIV, figs. 5-7 (types).

"Pyramidula" strigosa huachucana Pils., Proc. Acad. Nat. Sci. Phila., 1902, p. $511 .^{8}$

1. The types are from "Conservatory Canyon," otherwise known as Ramsey Canyon, on the northeastern slope of the Huachucas between Brown and Carr Canyons.

They are depressed with a broad umbilicus, exposing more of the penultimate whorl than strigosa, ${ }^{9}$ and it is also more ample within. There are 5 whorls, of which $2 \frac{1}{2}$ arc cmbryonic. The tip is a little depressed; the first whorl is delicately striate or wrinkled in an obliquely radial direction. On the second whorl weak raised spiral lines usually set in; and the last embryonic whorl is rather coarsely, irregularly wrinkled radially, and finely striate spirally, with (in some shells) several raised threads on the last half whorl. These cease abruptly at the end of the embryonic stage. The following whorls are irregularly, obliquely wrinkled and have at most obsolete spiral lines or traces of them in places, often almost imperceptible. The base has no spiral striation as a rule, but in some spccimens from Carr Canyon there are faint spirals there. Up to the end of the fourth whorl the periphery is strongly carinatc, but in adult shells it is ncarly angular in front, the last half or more becoming rounded. The suture follows the crest of the keel, and usually descends a trifle to the aperture.

The shell is flesh-colored above, with irregular whitish streaks or maculæ; beneath, the opaque white predominates more, and there is a purplish-brown band close to the periphery (but 4 or 5 of 25 examined are equally flesh-tinted beneath, and lack the band, PI. XXIV, fig. 8). The aperture is small, very oblique, with the ends of the lip approaching. The peristome is not expanded.

Alt. 10.5, diam. 21.8, width of umbilicus $6 \mathrm{~mm}$; aperturc $8.8 \mathrm{~mm}$. wide. Types No. 83,370, A. N. S. P., collected by James H. Ferriss.

The reproductive system of one of the types is figured (Pl. XIX,

${ }^{8}$ It was evidently this race which Dr. R. E. C. Stearns reported from Fort Huachuca as Helix (Patula) hemphilli Newc. (Proc. U. S. Nat. Mus., XVI, 1893, p. 745), and Dall from the Huachuca Mountains, as P. strigosa (Proc. U. S. Nat. Mus., XIX, 1896, p. 335).

The comparisons are with typical $O$. strigosa from the extreme Northwest, which is identical with Hemphill's var. parma. 
fig. 6). It was taken in Fcbruary, during the inactive season, and the uterus is quite small. The dimensions of the organs are given in the table (p. 270). The lower half of the penis is much swollen, the upper half smaller and lank. When opened the basal narrower portion is found to have strong acute folds; these become weak in the swollen part, which contains a large fleshy process adnate to the upper side. The eontracted upper portion of the penis is papillose inside, with three low ridges.

The retractor musele and epiphallus are as in Pecos strigosa. The of organs show nothing noteworthy.

The rarlula (Pl. XXII, fig. 5, group of transitional teeth) has 30.1.30 teeth. Those of the median area are much as in Pecos strigosa, with overhanging mesocones only. The ectocone beg:ns weakly on the sixth or seventh, and is well developed on the eleventh tooth. The marginal teeth are all bieuspid, the cusps unsplit.

O. s. huachucana is wiclely distributed in the canyons of the Huachuca Mountains, and nearly every colony has some individual features. "Sometimes only one form was found in a colony, but usually they vary in color and form. They are slow travelers and hence the distinctive characteristies of the colonies. They had not encroached at all upon the ground burned over two years ago. Colonies on different sides of the divides between canyons were entirely different, even when but a hundred or two hundred feet apart' (Ferriss).

Brown Canyon, Huachuca Mountains. Numerous colonies in this canyon vary in color, but in all the periphery of the last whorl may either be rounded, as in the type lot, or the acute keel of the young may extend upon the first third or half. The color-forms of the individual colonies are as follows:

2. Solid, opaque pinkish-white, with a few fleshy streaks and scattered dots. Sculpture weak (Pl. XXIV, figs. 9, 10).

3. Similar, but with a narrow band on the upper surface and on the base a band below the periphery, as in the typical form. Frequently the upper surface is largely fleshy-brown. This is an abundant form, differing from the Conservatory Canyon race only in the frequent retention of the keel in adults (Pl. XXIV, figs. 11, 12, 16).

4. Dull brown predominates throughout. Usually there are no bands (Pl. XXI Canyon are from about 7,000 feet. Some specimens are like the following form. In one gerontic colony at 6,000 feet the peristome is contracted and continuous in old shells (Pl. XXIV, fig. 15).

5. A broad, blaclich-chestnut hand below the periphery, the rest 
of the base whitish, often dotted. Upper surface also dark brown, usually with a light line below the periphery (Pl. XXIV, figs. 17, 18). 7,000 feet elevation.

6. Ramsey Canyon, Huachuca Mountains, collected in 1904, and evidently from a different colony from the types collected in 1.902. Two specimens received are dirty whitish. The whorl descends very deeply to the aperture. They are markedly gerontic.

Alt. 9.5 , diam. $17.3 \mathrm{~mm}$.

" 10

" 16

Carr Canyon, Huachuca Mountains. In this canyon most or all colonies have the form with rounded periphery, and that with it acutely carinate on the first half of the last whorl. The spire is usually sharply striate obliquely, and the last whorl is frequently striate spirally. The special tendencies of this canyon are most strongly expressed in No. 12.

7. Carr Canyon, 5,500 feet. Similar to No. 4, Brown Canyon, except that the sutures are less impressed, nearly level, and margined very distinctly above by the keel. In some shells the last whorl is rather distinctly decussate by spirals above. In one specimen the suture is deeply deflexed above, as in the Ramsey Canyon shells. A basal band is sometimes present.

$\begin{array}{lllcl}\text { Alt. } & 12 & 10.5 & 9.8 & 10.8 \mathrm{~mm} . \\ \text { Diam. } & 21 & 19.5 & 1 \mathrm{~S} & 18 \text { “ }\end{array}$

S. Carr Canyon, 5,500 feet. One specimen is similar to No. 7; the other three, measured below, are more calcareous, resembling No. 2, but the whorl is deflexed anteriorly (Pl. XXIV, figs. 21, 22, 23). In one the keel extends to the aperture, though rather weakly.

$\begin{array}{llrr}\text { Alt. } & 10 & 9.8 & \$ .6 \mathrm{~mm} . \\ \text { Diam. } & 20 & 18.8 & 18.8 \text { “ }\end{array}$

9. Carr Canyon, 6,000 feet (figs. 19, 20). Shells like No. 3, Brown Canyon, but not so white, the ground color being light brown, and the oblique striation sharper. Two specimens show a second band on the base.

$\begin{array}{lllll}\text { Alt. } & 11 & 12 & 11 & 10 \mathrm{~mm} . \\ \text { Diam. } & 19.8 & 19 & 18.7 & 17 . \mathrm{w}^{\prime \prime}\end{array}$

10. Carr Canyon, 6,000 feet (fig. 24). Similar to the preceding, but the ground is much darker, like No. 4. Diam. 18.6 to $19.5 \mathrm{~mm}$.

11. Carr Canyon, 7,000 feet. Blackish-chestnut, the inner whorls 
paler; striation sharp; spirals well developed on the last whorl; not carinate. Alt. 8.8, diam. $14.7 \mathrm{~mm}$. (Pl. XXV', fig. 36).

This lot is dwarfed, about the size of $O$. s. concentrata.

12. Another lot from Carr Canyon, altitude not stated, contains whitish bandless shells and brownish ones, uniform or banded like No. 7. One is carinated to the aperture and all are keeled in front. The sculpture consists of fine, sharp rib-striæ on the spire, and when fresh, young shells show cuticular laminæ on the costulæ, larger at intervals and at the periphery. The base has a similar sculpture. The last whorl is spirally striate above and below. Dian. 21 mm. (Pl. XXV, figs.' 37, 38, 39, 40).

It may be noted that Dall has reported "a sharply carinated variety" from Tanner's Canyon, Huachuca Mountains (Proc. U. S. Nat. Mus., XIX, p. 335).

Mr. Ferriss notes that the young are hirsute. This form diverges quite markedly from huachucana and to some extent parallels $O$. barbata of the Chiricahuas. It was found in one small colony only (No. 79 of Mr. Ferriss' coll., S7,132, A. N. S. P.).

13. Miller Canyon, 5,000 feet. Very large, depressed shells with 0,1 or 2 bands, ground color fleshy-white or brown. Periphery rounded, or in one specimen angular in front (Pl. XXIV, figs. 1, 2, 3, 4, the last immature).

$\begin{array}{lllll}\text { Alt. } & 14 & 13.6 & 13 & 12 \mathrm{~mm} . \\ \text { Diam. } & 24.5 & 23 & 23 & 21 \text { “ }\end{array}$

14. Miller Canyon, 5,500 feet. Similar to the preceding.

On the opposite side of the range specimens were taken in Cave Creek and Ida Canyons.

15. Cave Creek Canyon, 5,500 feet. Whitish or brown-banded specimens like Nos. 3 and 4 (Pl. XXV, figs. 41, 42, 43).

16. Ida Canyon. Whitish specimens, angular or rounded in front, and with or without a band. The whorl descends more or less in front, and some gerontic forms occur. Dian. 19.8 to $22 \mathrm{~mm}$. (Pl. XXV, figs. $33,34,35$ ).

Oreohelix strigosa metcalfei Ckll. P1. XXV, figs. 44, 48, 52.

Nautilus, XVIII, p. 113, February, 1905.

The shell is calcareous, whitish with comeous and brownish streaks and dots, and a dark brown band below the periphery. The upper surface is rather rudely wrinkled obliquely, but scarcely shows spirals; but the base is closely and in most specimens rather distinctly spirally striate. Embryonic shell like that of $O$. s. huachucana. The whorls have an acute, projecting carina which continues to the aperture, and are 
flat above it, forming a straightly conic spire. Suture not impressed. The last whorl descends in front. Aperture rather small, as in $O$. s. huachucana. Umbilicus ample within, as in huachucana.

$\begin{array}{lcccc}\text { Alt. } & 12 & 10.2 & 10.6 \mathrm{~mm} . \\ \text { Diam. } & 21 & 19.5 & 20 \text { " } \\ \text { Whorls } & 4 \frac{3}{4} & 5 \frac{1}{4} & 5 \frac{1}{2}\end{array}$

Mountains near Kingston, Sierra county, New Mexico, collected by O. B. Metcalfe.

This form stands close to the huachucana series, from which it differs only in the spiral striation of the base, which is usually quite distinct though very minute,$^{10}$ and in the persistence of the peripheral keel to the aperture. In the last feature it is less evolved than huachucana. In some specimens of the latter the keel also persists, though less strongly.

Oreohelix strigosa socorroensis n. subsp. Pl. XXV, figs. 49-51.

The shell is thin, with $2 \frac{1}{2}$ embryonic whorls closely and sharply obliquely striate, with a few low, coarse, indistinct spirals on the last embryonic whorl. Whorls $4 \frac{1}{2}$ to $4 \frac{3}{4}$, convex, the later ones rudely but not coarsely wrinkled, without noticeable spirals above, but the base is very densely and distinctly striate spirally. The last whorl is quite convex above and below a cord-like peripheral keel, which extends nearly or quite to the aperture. The last whorl descends a little and slowly in front. The umbilicus is rather small, but enlarges at the opening, Aperture as usual.

$\begin{array}{lrrrr} & & & & \\ \text { Alt. } & 8 & 9.2 & 8 & 8.8 \mathrm{~mm} . \\ \text { Diam. } & 15 & 14.8 & 13.5 & 13.3 \text {. }\end{array}$

Negra Mountains, Socorro county, New Mexico. Types No. 58,128, A. N. S. P., presented by Dr. W. D. Hartman, collector unknown.

Related to $O . S$. metcalfei, its neighbor on the south, but that is a more strongly carinate shell with flat whorls and straightly conic spire. They agree in the beautiful circular striation of the base.

Oreohelix barbata n. sp. Pl. XXV, figs. 57,58 .

The shell is broadly and openly umbilicate, depressed, biconvex, carinate, pale brown, lusterless; obliquely closely lamellose costulate, the lamellæ lengthened into a cuticular fringe at the periphery, and at several places on the base, forming circular fringes there. A similar

${ }^{10}$ In some specimens of huachucana from Carr Canyon, such as Pl. XXV, fig. 36 and figs. $37-40$, the base is spirally striate, but it is not so in huachucana from other places. 
but less developed one runs in the middle of the upper surface of the last whorl. The embryonic shell of nearly two whorls is not distinctly defined from the subsequent growth; the first whorl is smoothish with some radial wrinkles only; the second is densely obliquely costulate, with cuticular lamellæ on the fine riblets in perfectly preserved examples. There are weak traces of a few coarse, low spirals. Whorls 4 , rather rapidly increasing, the last slowly descending in front, very convex beneath. The aperture is very oblique, shortly pear-shaped, the peristome simple, upper and lower margins much converging and straightened, comnected by a short and thin parietal callous.

Alt. 7, diam. $13.5 \mathrm{~mm}$, not including the cuticular processes.

Cave Creek Canyon, Chiricahua Mountains, Arizona, collected by J. H. Ferriss. Co-types No. 87,011 and 87,146 , Coll. A. N. S. P. It lives in a moist situation, in stone talus near the falls of the stream.

Cuticular processes or "hairs" are generally present on the shells of very young Oreohelices, but in this one alone their development culminates in the adult snail. Their projection at the angle of the whorls of the spire makes the lamellæ look continuous over the sutures. When denuded the shell is sharply striate, with some ill-defined spirals marking the positions of the more prominent cuticular wreaths. Besides those described above, there are some minor and variable spirals on the most perfect specimens.

The processes are very efficient as gatherers of soil, which is probably glued on by the mucous of the animal, as usual. In the general plan of ornamentation, this bearded Oreohelix is not unlike Polygyra (Stenotrema) pilsbryi Ferriss.

By its tricuspid central and bicuspid lateral teeth, as well as by the general form of the shell, $O$. barbata recalls $O$. hemphilli, especially when denuded of the "beard." The embryonic sculpture is not very unlike some forms of hemphilli, but it most resembles that of $O$. $s$. socorroensis, though a little coarser. The insertion of the penis retractor solely on the epiphallus is like Radiocentrum, and unlike any of the typical Oreohelices.

The foot of $O$. barbata is small, slate-blackish above, and finely granulated. No genital furrow is discernible, but there is a pair of dorsal grooves. The tail is flattened and pale above. The mantle edge is very thick and fleshy.

The genitalia of one of the types are figured (Pl. XIX, fig. 5). The penis resembles that of $S$. strigosa huachucana, the lower half being much swollen, the upper half smaller and cylindric. Internally the larger portion has 4 or 5 large and some smaller longitudinal folds, the 
upper part is densely papillose inside. The epiphallus bears the penisretractor muscle, some distance from its base, and the vas deferens enters centrally at the end. The duct of the spermatheea is somewhat swollen basally. The uterus contained neither eggs nor embryos, the specimens having been collected in February.

The radula (Pl. XXII, fig. 6) has 23.1.23 teeth. The mesocones are long, and all the teeth have well-developed ectocones. The marginal teeth are bicuspid as usual, the cusps unsplit.

Oreohelix yavapai n. sp. Pl. XXr, fig. 53 .

Shell thin, whitish more or less stained with brown, with a faint brown band above and another close below the periphery. The small peripheral keel extends to the aperture, but is pinched up less than in neomexicana; the last whorl elsewhere is well rounded, the earlier whorls flattened. Embryo of $2 \frac{1}{3}$ whorls, the first nearly smooth, convex, the next more flattened, finely, densely stri ate obliquely, and very strongly striate and ribbed spirally. At the end of the embryonic stage this spiral sculpture abruptly stops, and is succeeded by sharp oblique striation which becomes eut by a few spiral lines. On the last whorl there are more spirals, usually emphasized as series of granules or pits upon the oblique striæ (indicating cuticular processes in perfectly fresh shells). Whorls about $5 \frac{1}{3}$, the last hardly descending in front. The umbilicus is ample, as in $O . y$. neomexicana. Aperture oblique, rounded, with thin lip.

$\begin{array}{lrr}\text { Alt. } & 8.7 & 9.5 \mathrm{~mm} \text {. } \\ \text { Diam. } & 15.2 & 16.6 \text { “ }\end{array}$

Purtyman's ranch, on Oak creek, Yavapai county, about 40 miles from Jerome, Arizona (northwest of the center of the Territory), types No. 79,415, A. N. S. P., collected by E. H. Ashmun. Also found on the summit of Mt. Mingus, near Jerome, and fossil in a road eutting in Walnut Guleh, near Jerome (Ashmun).

Dr. R. E. C. Stearns reported a form probably identical with $O$. yavapai from Coon Mountain, a eurious erater about 10 miles south of Canyon Diablo, and about 3 days' travel from Flagstaff, Arizona (Patula strigosa Gld., Nautilus, VI, May, 1892, p. 1; Proc. U. S. Nat. Mus., XVI, p. 745).

The embryonic young shells, $2 \mathrm{~mm}$. diameter with $2 \frac{1}{2}$ whorls, are acutely carinate (Pl. XI, fig. 13).

This species cliffers from $O$. strigosa in the form of the shell, which is more like $O$. hemphilli, and by the diminutive penis, while the epiphallus is longer in proportion than in forms of strigosa I have exam- 
ined; it differs from O. y. neomexicana chiefly by the stronger spiral seulpture of the embryonic shell and the abrupt change in sculpture at the inception of the neanie growth. The same differenees and the wider umbilicus separate it from the northern $O$. hemphilli, which, moreover, differs by its dentition, as indicated below under $O . y$. neomexicana.

The penis (Pl. XIX, fig. 7 ) resembles that of $0 . y$. neomexicana except that it is larger, and the vas deferens enters the epiphallus centrally at the apex. There were 10 embryos in the uterus, each half enveloped in its podocyst.

The jaw has longitudinal and vertical striæ. The radula (Pl. XXII, figs. 7) has 26.1.26 tecth, those in the middle unicuspid; the ectocone distinctly appearing on the sixth. Marginal teeth bicuspid, the cusps unsplit.

Oreohelix yavapai neomexioana n. subsp. P.. XI, figs. 8, 9 ; Pl. XXV, fig. 59.

The shell is thin, brown, acutely keeled, pinched in above and below the peripheral keel, which extends to the aperture, the whorls elsewhere convex above and below. Embryo of 2 to $2 \frac{1}{3}$ whorls, convex except near the periphery where they are impressed; they are densely striate obliquely and rather obsoletely striate spirally. The junction with the subsequent neanic growth is often indistinct. Whorls $4 \frac{3}{4}$ to $5 \frac{1}{4}$, the later ones rudely, very obliquely wrinkled, and showing raised spiral striæ, usually rather indistinct. The umbilicus is ample within and rather widely open, exposing the penultimate whorl. Aperture small with simple lip, the whorl descending slowvly to it.
Alt.
8.5
$7.5 \mathrm{~mm}$.
Diam.
15.6
14.5 "

Canyon Diablo, near Rowe, San Miguel county, New Mexico. Types No. $\$ 4,297$, A. N. S. P., collected by Miss Mary Cooper.

This form differs from $O$. hemphilli (Newc.) by its less convex embryonic whorls, which are more impressed near the periphery, and by the more ample umbilicus; but it differs chiefly by the unicuspid teeth of the median part of the radula, those teeth in $O$. hemphilli having welldeveloped ectocones, as in $O$. barbata. It seems to be rather widely separated geographically from the range of $O$. hemphilli.

It is also before me from Beulah, in the Sapello Canyon, San Miguel county, at $\$, 000$ feet (Prof. Cockerell), small specimens only $10 \mathrm{~mm}$. diameter, with $4 \frac{1}{2}$ whorls, perhaps not quite adult. Similar small specimens come from Las Huartes Canyon, Bernalillo county, New Mexico (Miss Cooper). 
I have partially examined the internal anatomy of one of the specimens from Beulah. The penis (Pl. XIX, fig. 9) is bent in the middle, the lower half a little swollen, with muscular walls, the upper half slightly smaller, softer. There is a very small apical papilla, and the retractor muscle is inserted at the apex of the penis and root of the epiphallus. The epiphallus is large, shorter than the penis, and the vas deferens enters at the side, not the center of the apex.

The radula has 19.1.19 teeth, similar to those of 0 . yavapai. On the fifth or sixth teeth the ectocone is developed. Marginals bicuspid, as usual.

\section{Subgenus RADIOCENTRUM nov.}

Oreohelices with an embryonic shell of $1 \frac{1}{2}$ radially ribbed whorls, spiral striæ in the intervals betwcen ribs excessively weak or wanting. Penis rather short, with a hollow dilation at the distal end. Epiphallus club-shaped, as long as the penis, the retractor inserted near its base. Type O. chiricahuana Pils.

This group differs from Oreohelix by the smaller number of embryonic whorls and their different sculpture, and in the somewhat different structure of the penis. It includes at present three species: $O$. chiricahuana, O. clappi and O. avalonensis.

The genitalia are similar in the two species examined, the only difference being in the shape of the distal end of the penis, and in the absolute dimensions. The pallial organs of $O$. clappi do not differ from those described above for Orcohelix strigosa.

\section{Kcy to Specics of Radiocentrum.}

a.- Shell bluntly subangular or almost rounded at the periphery; covered with a green or olive cuticle, largely worn from old shells. Alt: 8.5 to 9.7 , diam. $15 \mathrm{~mm}$., . . . . O clappi Ferriss. $a^{\prime}$.-Shell carinated; earthy, without perceptible cuticle.

b.- "Whorls $4 \frac{1}{2}$, granulated above and below, the last one wide; aperture large. Alt. 6, diam. 11 mm." (H emphill).

$O$. avalonensis Hemphill.

$b^{\prime}$.-Whorls 5 , striated but not granulated, slowly widening; aperture small. Alt. 6.5, diam. $11 \mathrm{~mm}$.,

O. chiricahuana Pils.

Oreohelix chiricahuana n. sp. Pl. XI, figs. 1, 2, 3.

The shell is depressed, the altitude about .6 of the diameter, about equally convex above and below the peripheral keel. Umbilicus rather well-like, slowly contracting, and eontained five or six times in the diameter of the shell. Whitish, with an indistinct gray band near 
the middle of the upper surface and another immediately below the white keel, the early whorls dull brown; withont perceptible cuticle. Sculpture of elose but irregular and rather sharp growth-wrinkles, very indistinetly decussated with spiral strix. The embryonic shell consists of only $1 \frac{1}{2}$ whorls. The first half whorl is nearly smooth, the next whorl is sharply and finely but very regularly ribbed radially. With the compound microseope some very weak spiral striation may be seen indistinetly in the intervals. At the end of the embryonic period the rib seulpture abruptly gives place to a lower, less regular oblique striation. The spire is convexly eonic. Whorls 5, eonvex, impressed above the suture, where the keel projeets a trifle. At the periphery the kcel projects somewhat, the surface being a little coneave above and below it. Base eonvex. Aperture small, oblique, a little angular at the outer part. Lip simple, the ends approaching.

Alt. 6.5, diam. $11 \mathrm{~mm}$.

" 7 , " 10.5 "

Cave Creek Canyon, Chiricahua Mountains. Types No. 87,012, A. N. S. P., eollected by James H. Ferriss. "Occurred on a dry, clay hillside, under dead vegetation and stones, and was found nowhere else on the mountain."

This is a very distinct little speeies, elosely related to $O$. avalonensis Hemphill of Santa Catalina Island, California, which has an apex of the same type. O. avalonensis differs, however, by its conspieuously decussate surface, wider last whorl and larger aperture, and it has a half whorl less. It is figured for comparison, Pl. XI, figs. 4, 5, 6, 7. The umbilicus is about equal in the two species.

O. chiricahuana differs conspieuously from O. yavapai and O. $y$. neomexicana by its peculiar apical sculpture, ete.

The genitalia are figured (Pl. XIX, fig. 4). The penis is cylindric, a little flattened and protruding on one side at the distal end. The epiphallus is longer than the penis, elub-shaped, the retraetor inserted upon it not far from its base. The lower part of the spermatheea duct is enlarged and museular. The lengths of the organs are as follows: penis 4 , epiphallus 4.7 , vagina 3.5 , spermatheea and duct $7.5 \mathrm{~mm}$. The foot is scarcely granulose, the integument smoothish, tessellated in rather coarse pattern with blackish or gray spots. No genital furrow is visible. The mantle edge is thin.

The jaw (Pl. XXIII, fig. 24) is striate, somewhat less arcuate than that of $O$. clappi.

The radula (PI. XXII, figs. 10, 11) has 26.1.26 teeth. They are rather shorter than usual in Oreohelix. The ecntral and lateral teeth 
have well-developed ectocones. The marginal tecth are bicuspid, as usual in Oreohelix, but the inner cusp is split.

Oreohelix olappi Ferriss. Pl. XI, fig. 12 ; HI. XXV, figs. 5\$-56.

Nautilus, XVIII, p. 53 (September, 1904).

This is a remarkable snail, slightly resembling Pyramidula solitaria on a small scale, but very different from any other Oreohelix by its rapidly narrowing umbilicus and green or olivaceous cuticle.

The smoothish integument is blackish on the head and tail, and darker toward the foot margins, elsewhere tessellated with large polygonal gray pigment spots. Sole cream colored. There are two irregular dorsal grooves.

The kidney, $6.3 \mathrm{~mm}$. long, is a thin-walled sack, its lumen large, with strongly corrugated walls. The pericardium is fully $4 \mathrm{~mm}$. long.

The reproductive system (Pl. XIX, fig. 8) resembles that of 0 . chiricahuana. The rather slender cylindric penis is enlarged at the summit, the protuberance on the upper side (in the figure) hollow. The epiphallus enters through a very small acorn-shaped papilla. The walls of the penis are thin, with a minute oblique corrugation meeting V-like on one side. The penis measures 7 , epiphallus 7 , vagina 6 , spermatheca and duct $13 \mathrm{~mm}$. long. The penis retractor is inserted about 1.5 $\mathrm{mm}$. from the base of the epiphallus.

The jaw (Pl. XXIII, fig. 26) is areuate and striate vertically.

The radula (PI. XXII, fig. 4) has about 29.1.29 teeth, of the general form usual in Oreohelix. There are rudimentary ectocones on the central teeth, at least where they are unworn. The laterals have similar outer cutting points. The marginal teeth are bicuspid. In general, the teeth are between the unicuspid type and that with developed ectocones.

\section{Explanation of Plates XI-XXViI.}

Plate XI.-Fig 11 was drawn by the author; the others are reproduced from photographs.

Figs. 1-3-Oreohelix chiricahuana Pils. $\times 3 \frac{1}{2}$. Co-types.

Figs. 4-6.-Oreohelix aralonensis Hemph. $\times \dot{\varepsilon} \frac{1}{2}$. Santa Catalina Island, California.

Fig. 7.-O. avalonensis. Early whorls. $\times 6$.

Fig. 8.-Orcohelix yava pai neomexicana Pils. Young specimen. $\times 3$. Showing embryonic whorls and two neanic whorls.

Fig. 9.-O.y. neomexicana. Segment of base. Only the coarser spirals are visible in the half-tone cut.

Fig. 10.-Sonorella granulatissima Pils. No. 87,087. Miller Canyon. Portion of last whorl above the periphery. $\times 7$.

Fig. 11.-A shmunella angulata Pils. No. S7,113. Immature shell of $\mathrm{Smm}$. diameter showing temporary lip-rib. 
Fig. 12.-Oreohelix clappi Ferriss. Early whorls. $\times 6$. Sculpture is very imperfectly shown.

Fig. 13.-Oreohelix yavapai Pils. Young shell, showing embryonic whorls and about one-third of the first neanic whorl. $\times 6$.

Figs. 14, 15.-Oreohelix strigosa Gld. Pecos, N. M. Uterine young. $\times 6$. The very fine, even spiral striation is not sufficiently enlarged to be visible in the reproduction, though shown in the photograph; the radial ripples are also largely lost.

Plate XII, Figs. 1-4.-Ashmunella rhyssa Dall. Sierra Blanca. Nos. 73,561 and 73,575

Figs. 5, 6.-Ashmunella rhyssa miorhyssa Dall. Sierra Blanca, New Mexico. No. 73,577 .

Figs. 7, 8.-A shmunella rhyssa hyporhyssa Ckll., larger form. James Canyon, Cloudcroft, New Mexico. No. 89,201.

Figs. 9-13.-A.r. hyporhyssa Ckll. James Canyon, Cloudcroft. No. 83,345.

Fig. 14.-Ashmunella altissima Ckll. Co-type. Summit of Sierra Blanca. No. 73,558 .

Figs. 15, 16.-Ashmunella pseudodonta Dall. White Oaks, New Mexico. No. 73,589 .

Figs. 17, 18.-A. pseudodonta Dall. Capitan Mountains, New Mexico. No. 79,529 .

Figs. 19, 20.-Ashmunella ashmuni Dall. Bland, New Mexico. No. 73,599.

Figs. 21-23.-A. pseudodonta capitanensis A. and C. Capitan Mountains, New Mexico. No. 74,556.

Figs. 24-26.-A. ashmuni robusta Pils. Bland, New Mexico. No. 73,576.

Plate XIII, Figs. 23-26.-Ashmunella esuritor Pils. Types.

Figs. 27, 28.-Ashmunella thomsoniana (Ancey). Part of the original lot from J. H. Thomson. Santa Fé Canyon, New Mexico. Nos. 58,113 and 58,114 .

Fig. 29.-A. thomsoniana. Specimen from Monument Rock, Santa Fé Canyon. Prof. Cockerell and Miss Porter. No. 77,870.

Fig. 30.-A. thomsoniana. Santa Fé Canyon. E. H. Áshmun. No.76,709.

Figs. 31-34.-A. thomsoniana (Anc.). Las Vegas Hot Springs, New Mexico. Nos. $84,293,80,750$ and 83,946 . Fig. 34 is a co-type of $A . t$. coopera Ckll.

Figs. 35-37.-A thomsoniana (Anc.). Canyon Diablo, near Rowe, New Mexico. No. 84,295 .

Fig. 38.-A. t. pecosensis Ckll. Type, Vallé ranch, Pecos, New Mexico. No. 84,209 .

Figs. 39-41.-A. $t$. porteræe Pils. and Ckll. Sapello Canyon, San Miguel county, New Mexico, 8,000 feet altitude. No. 81,983.

Figs. $42,46 .-A$. $t$. porterce P. and C. Co-types. Beulah, Upper Sapello Canyon. No. 76,789.

Figs. 43-45.-A. $t$. porteræ P. and C. Pecos, New Mexico. No. 85,099.

Plate XIV, Figs. 47-49.-Ashmunella levettei angigyra Pils. Types. Conservatory Canyon, Huachuca Mountains. No. \$3,269.

Figs. 50, 54.-A. l. angigyra. Brown's Canyon. No. 87,093.

Figs. 51-53.-A. l. angigyra. Foothills, Bear Canyon. No. 89,202.

Figs. 55-57.-Ashmunella angulata Pils. Types. South fork of Cave creek, at base of mountain, Chiricahua Mountains. No. 87,019.

Fig. 58.-A. angulata. South fork of Cave creek, under cliffs; showing weak upper branch of the parietal tooth. No. 87,015 .

Figs. 59, 60.-A. angulata. Cave Creek Canyon. No. 87,020.

Fig. 61.-A. angulata. Cave Creek Canyon. No. 87,111.

Fig. 62.-Ashmunella mearnsi Dall. Huachuca Mountains. No. 65,736.

Figs. 63, 64. - Ashmunella angulata Pils. Falls of Cave Creek. No. 87,112.

Figs. 65, 66.-Ashmunella proxima Pils. Types. Sawmill Canyon, Chiricallua Mountains. No. 86,498 .

Figs. 67-69.-Ashmunella fissidens Pils. Cave Creek Canyon, Chiricahua Mountains. Types. No. 87,022.

Figs. 70, 71.-1. proxima. Topotypes. No. 87,102. 
Plate XV, Figs. 72-75, 79.-Ashmunella levettei (Bld.). Typical. Bear Canyon, Huachuca Mountains, 6,500 feet. No. $\$ 7,089$.

Figs. 76.-A. levettei. Albino. Head of Bear Canyon, 7,000 feet. No. 87,098 .

Fig. 77.-A. levettei. Pathologic monster, same locality.

Fig. 78.-A. levettei. Miller Canyon, Huachuca Mountains, 6,000 feet. No. $\$ 7,099$.

Figs. S0-88. - A. l. heterodon Pils. Ida Canyon, Huachuca Mountains. No. 89,203 .

Figs. 89-91.-A. l. heterodon. Cave Creek Canyon, Huachuca Mountains.

Figs. 92, 93.-A. levettei, var. approaching angigyra Carr Canyon, Huachuca Mountains, 5,000 feet. Nos. 87,092 and 89,204.

Figs. 94, 95.-A. l. heterodon Pils. or chiricahuana Dall(?), Miller Canyon, Huachuca Mountains. No. $\$ 7,097$.

PLATE XVI, Figs. 96-99.-Ashmunella chiricahuana (Dall). Cave Creek Canyon, Chiricahua Mountains. No. 87,096, A. N. S. P.

Fig. 100.-A. chiricahuana. An elevated specimen from the same locality. No. 87,021 .

Fig. 101.-A. c. mogollonensis. Base of a larger specimen from Kingston, Sierra county, New Mexico.

Fig. 102.-Ashmunella chiricahuana mogollonensis Pils. West fork Gila river, near Mogollon Peak, New Mexico. No. 79,530.

Figs. 103-107.-Ashmunella duplicidens Pils. Bearfoot Park, Chiricahua Mountains. No. 87,024.

Figs. 10S-110, 113.-A shmunella ferrissi Pils. Cave Creek Canyon, Chiricahua Mountains. No. $\$ 9,232$.

Figs. 111, 112, 117.-A shmunella walkeri Ferriss. Co-types. Florida Mountains, near Deming, New Mexico.

Figs. 114, 115.-Ashmunella metamorphosa Pils. Types.

Fig. 116.-A shmunella mearnsi (Dall). No. 65,736.

Plate XVII, Figs. 1, 2.-Sonorella hachitana, var. Florida Mountains, No. 87,078 .

Figs. 3-6.-Sonorella hachitana, var. Florida Mountains. No. 86,496.

Figs. 7, 8.-Sonorella hachitana, var. Organ Mountains. No. 71,413.

Figs. 9-14.-Sonorella hachitana ashmuni Bartsch. Purtyman's. Nos. 79,409 and 80,707 .

Figs. 15, 16.-Sonorella virilis Pils. Type. Chiricahua Mountains. No. 79,622 .

Figs. 17-20.- Sonorella virilis Pils., var. Sawmill Canyon, Chiricahua Mountains. No. $\$ 7,081$.

Figs. 21-23.-Sonorella granulatissima Pils. Types. No. 83,257.

Fig. 24.-Sonorella virilis huachucana Pils. Brown Canyon, Huachuca Mountains.

Plate XVIII, Figs. 24-28. - Sonorella granulatissima latior Pils. Brown's Canyon, Huachuca Mountains. No. 87,083.

Figs. 29-32.-Sonorella hachitana bowiensis Pils. Fort Bowie. No. 86,497.

Figs. 33, 34.-Sonorella rowelli (Newc.). Sanfords. No. \$3,273.

Fig. 35.-Sonorella rowelli (Newc.). Patagonia Mountains. No. \$3,268.

Figs. 36-38.- Sonorella granulatissima Pils. Ida Canyon. No. 87,088.

Figs. 39, 40, 44.-Sonorella granulatissima Pils. Miller Canyon. No. 87,087.

Figs. 41-43.-Sonorella granulatissima Pils. Miller Canyon. No. 89,227.

Figs. 45-47. - Sonorella granulatissima paria Pils. West end of Huachuca Mountains. No. $\$ 7,114$.

Figs. 48-50.-Sonorella viritis circumstriatus Pils. Types. Cave Creek Canyon, Chiricahua Mountains. No. 87,026 .

Figs. 51-54.-Sonorella granulatissima Pils. Carr Canyon, Huachuca Mountains. No. 89,226 . 
Plate XIX.-Anatomy of Oreohelix.

Fig. 1.-Oreohelix strigosa, from Pecos, New Mexico. Pallial complex.

Fig. 2.-O. clrodi (Pils.).

Fig. 3.-O. strigosa (Gld.), from Pecos, New Mexico.

Fig. 4.-O. chiricahuana Pils.

Fig. 5.-O. barbata Pils.

Fig. 6.-O. s. huachucana Pils.

Fig. 7.-O. yavapai Pils. Penis.

Fig. 8.-O. clappi Ferriss.

Fig. 9.-O. y. neomexicana Pils. Penis.

Plate XX [all figures $\times 2$ ], Fig. 10.-Sonorella hachitana bowiensis Pils. Penis opened to show papilla. Bowie, Arizona. No. 86,497.

Fig. 11.-S. h. bowiensis Pils. Genitalia of same specimen.

Fig. 12.-Sonorella hachitana (Dall). Genitalia of individual from Florida Mountains, New Mexico. No. 86,496. The penis-papilla shows faintly through.

Fig. 13.-Sonorella rowelli (Newc.). Penis opened to show papilla. Sanford's, Arizona. No. 83,273.

Fig. 14.-S. rowelli (Newe.). Genitalia of same individual.

Fig. 15.-Sonorella hachitana ashmuni (Bartsch). Opened penis of a specimen from Purtyman's ranch, Oak creek, New Mexico. No. 79,409.

Fig. 16. - Sonorella granulatissima Pils. ठ7 organs, showing epiphallus and flagellum of one of the type specimens. Spring Canyon, Huachuca Mountains.

Fig. 17. - S. granulatissima Pils. Genitalia of same individual.

Fig. 18. - S. granulatissima Pils. Opened penis of same individual.

Fig. 19.-Sonorella viritis circumstriata Pils. Genitalia of No.87,026. Cave Creek Canyon.

Fig. 20.- Sonorella rowelli (Newc.). Terminal ducts of genitalia of a small form from the Patagonia Mountains, Arizona. No. 83,268.

Fig. 21.-Sonorella virilis Pils. Opened penis of type specimen. Chiricaluua Mountains. No. 79,622 .

Fig. 22.-S. virilis Pils. Genitalia of same specimen.

Plate XXI.-Genitalia of Ashmunella.

Fig. 23. - Ashmunella duplicidens Pils. $\times 22 . \quad$ No. 87,024 .

Fig. 24.-Ashmunella proxima Pils. $\times 2 \frac{2}{3}$. No. 86,498 .

Fig. 25.-Ashmunella esuritor Pils. Exserted penis.

Fig. 26. - Ashmunella angulata Pils. $\times 2 \frac{2}{3}$. No. 87,015 .

Fig. 27. - A shmunella metamorphosa Pils. $\times 2$. No. 88,885.

Fig. 28. - Ashmunella l. angigyra Pils. $\times 2 \frac{2}{3} . \quad$ No. 83,269 .

Fig. 29.-Ashmunella chiricahuana Pils. $\times 2$. No. 87,021

Fig. 30.-Ashmunclla esuritor Pils. $\times 2 \frac{2}{3}$. No. 87,023.

Plate XXII, Figs. 1, 2, 3.-Oreohelix strigosa, variety from Pecos, New Mexico. 1. Central tooth $r$, with three laterals; 2 . Group of marginal teeth at the edge of radula; 3. Lateral and transitional teeth.

Fig. 4.-Oreohelix clappi Ferriss. Central and two lateral teetl of a co-type.

Fig. 5. Oreohelix strigosa huachucana Pils. Group of lateral and transitional teeth of a type specimen.

Fig. 6.-Oreohelix barbata Pils. Central tooth with laterals i-iii, vi and vii of a co-type.

Fig. 7. - Orcohelix yavapai Pils. Co-type. Group of lateral and transitional teeth, with a central tooth on the extreme right.

Fig. 8. - A shmunella metamorphosa Pils. Central with two adjacent lateral teeth of a type specimen.

Fig. 9.-Ashmunclla angulata Pils. No. 87,015. Group of transitional and marginal teetl.

Figs. 10, 11.-A shmunclla chiricahuana (Dall). Group of eentral and lateral teeth and two groups of marginal tecth of a typical specimen.

Fig. 12.-Ashmunella levettei angigyra Pils. Conservatory Canyon. Huachuca Mountains. Half row of teeth, some of the marginals omitted. 
Plate XXIII.-Jaws of Ashmunella, Sonorella and Oreohelix.

Fig. 13.-Ashmunella chiricahuana Dall. Cave Creek Canyon, Chirieahuas. No. 87,021 .

Fig. 14.-Ashmunella levettei angigyra Pils. Type. No. \$3,269.

Fig. 15.-Ashmunclla angulata Pils. No. 87,015.

Fig. 16.-Ashmunella metamorphosa Pils. Co-type.

Fig. 17. -Ashmunclla levettei proxima Pils. Co-type. No. $86,49 S$.

Fig. 18.-Sonorella rowclli (Newc.). Patugonia Mountains, Santa Cruz county, Arizona. No. \$3,268.

Fig. 19. - Sonorella hachitana var. Organ Mountains, New Mexico. No. 71,413 .

Fig. 20.-Sonorella hachitana (Dali). Florida Mountains, New Mexieo. No. 86,496 .

Fig. 21.-Sonorella virilis Pils. Type. No. 79,602.

Fig. 22. - Sonorclla h. bowiensis Pils. Type. No. 86,497.

Fig. 23.-Sonorella granulatissima Pils. Co-type.

Fig. 24.-Oreohelix chiricahuana Pils. Co-type.

Fig. 25.-Oreohelix strigosa GId. var. Peeos, New Mexico.

Fig. 26.-Orcohclix clappi Ferriss. Co-type.

Plate XXIV, Figs. 1-4.-Oreohelix strigosa huachucana. Hiller C'anyon, 5,000 feet. No. 87,144 .

Figs. 5-7.-Conservatory Canyon. No. 83,370. Type specinens.

Fig. S.-Uniform brown specimen. Same locality. No, \$3,371.

Figs. 9, 10.-Brown's Canyon, at 7,000 feet. No. $87,125$.

Figs. 11, 12, 16.-Brown's Canyon, at 7,000 feet. No. S7,124.

Figs. 13, 14.-Brown's Canyon, at 7,000 feet. No. 87,126.

Fig. 15.-Brown's Canyon, at 6,000 feet. No. $\$ 7,122$.

Figs. 17, 18.-Brown's Canyon, at 7,000 feet. No. $87,127$.

Figs. 19, 20.-Carr Canyon, at 6,000 feet. No. 87,135 .

Figs. 21-23.-Carr Canyon, at 5,500 feet. No. 87,134.

Fig. 24.-Carr Canyon, at 6,000 feet. No. 87,136 .

Figs. 25-27.-O. s. concentrata (Dall). Limestone Mountain, north side, at 8,000 feet. No. $\$ 7,128$.

Fig. 2s.-O. s. concentrata (Dall). Carr Canyon, 7,000 feet. No. 87,138.

Figs. 29-31.-O. s. concentrata (Dall). Limestone Mountain, south side, at 8,000 feet. No. 87,131 .

Figs. 32.-O. s. concentrata (Dill). Limestone Mountain, south side, at 8,000 feet. No. 87,131

Plate XXY, Figs. 33, 34.-Orcohclix s. huachucana Pils. Ida Canyon, Huachuca Mountains, 7,000 feet elevation. No. 87,143 .

Fig. 35.-O. s. huachucana Ida Canyon, 7,000 feet. No. $57,142$.

Fig. 36.-O. s. huachucana. Carr Canyon, 7,000 feet. No. \$7,137.

Figs. 37-40.-O. s. huachucana, keeled and hirsute form. Carr Canyon. No. 87,132 .

Figs. 41-13.-O. s. huachncana. Cave Creek Canyon, 5,500 feet. No. S7, $140,87,141$.

Figs, $4.48,52 .-0$. s. metcalfci (kll. Co-types, 44 and 48 from bleached specimens, 52 from one collected alive.

Figs. 45-47.-O. strigosa (GId.). Pecos, New Mexico. No. 85,100.

Figs. 49-51.-O strigosa socorrocnsis l'ils. Co-types. No. 58,128.

Fig. 52. - O. s. metcalfei ('kll.

Fig. 53.-O. yavanai Pils. ('o-type. No. 79,415.

Figs. 54-56.-O. clappi Ferriss. (o-types. No. S7,013.

Figs. 57, 58.-O. barbata Pils. Co-types. No. 87,011 .

Fig. 59.-O.y. neomexicana Pils. Co-type. No. $\$ 4,297$.

Fig. 60.-O. s. concentrata (Dall). Hacheta Grande Mountain, at 9,000 feet. No. 65,742 . 
Plate XXVI, Figs. 1-5.-Holospira goldfussi (Mke.). Guadalupe river, about six miles above New Braunfels, Texas. Nos. $89,209,89,210$.

Fig. 6.-Holospira cockerelli Dall. Near Kingston, New Mexico. No. $89,211$.

Fig. 7.-Holospira regis Pils. and Ckll. Near Kingston, New Mexico. No. 89,208 .

Fig. 8. - Holospira crossei Dall. Hacheta Grande Mountain, Grant county, New Mexico, No. 65,738

Fig. 9.-Holospira chiricahuana Pils. Fort Bowie, Cochise county, Arizona. No. 87,118 .

Figs. 10-15.-Holospira roemeri (Pfr.). Hondo river, about two miles north of Hondo, Mredina county, Texas. No. 89,207.

Figs. 16-18. - H. rocmeri. High Bridge of the Pecos river, Valverde county, Texas. No. 89,206 .

Figs. 19-21.-Microceramus texanus (Pils.). Guadalupe river, above New Braunfels, Texas. No. 89,205.

Plate XXVII, Figs, 22-25.-Holospira ferrissi Pils. Manilla Mine, Huachuca Mountains. No. 87,115 .

Figs. 26-29.-Holospira chiricahuana Pils. Cave Creuk Carlynn, Chiricainua Mountains. No. 87,119.

Figs. 30-33.-Holospira cionella Pils. Fort Bume. N 87.117. 

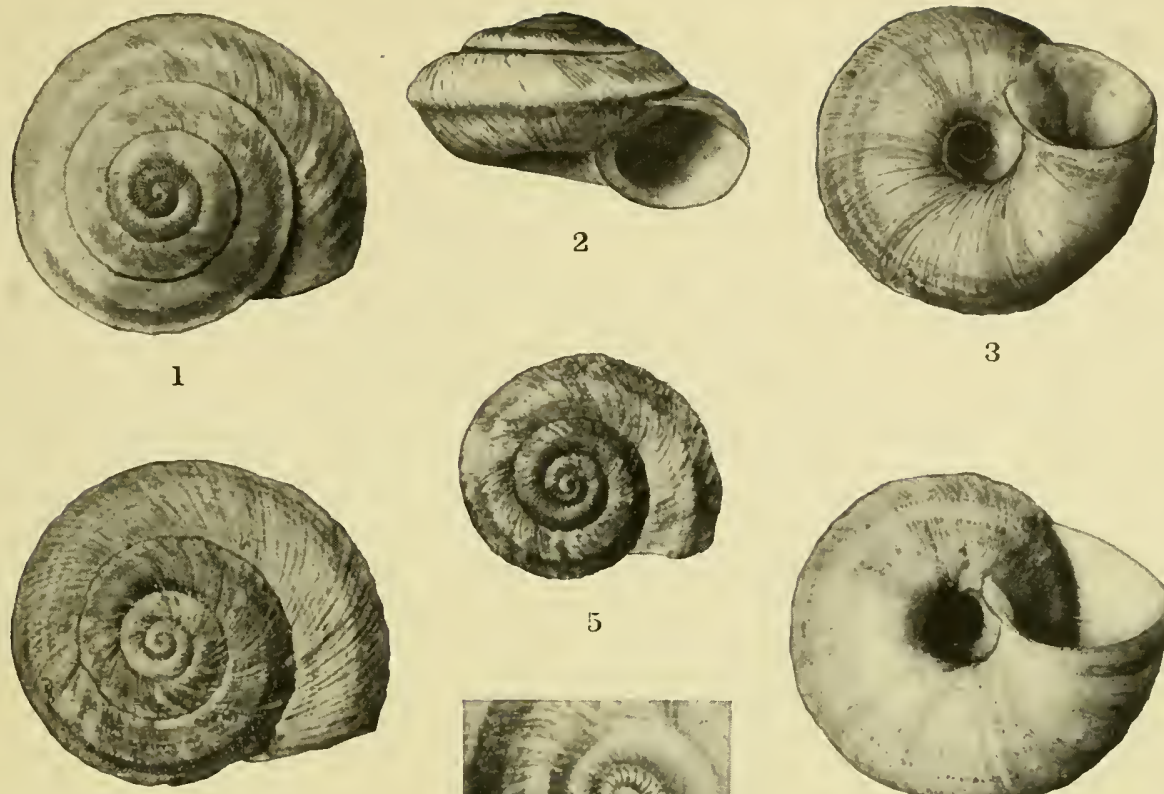

5
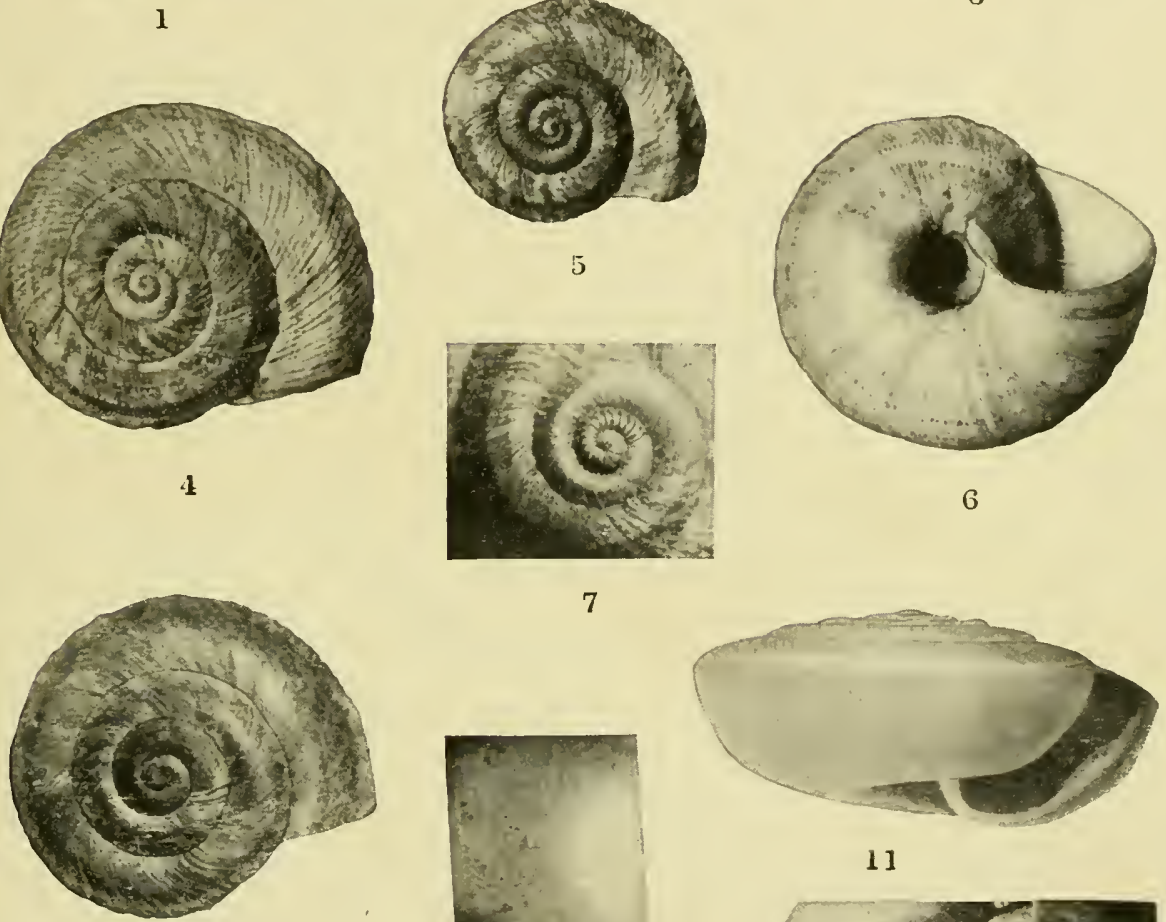

8
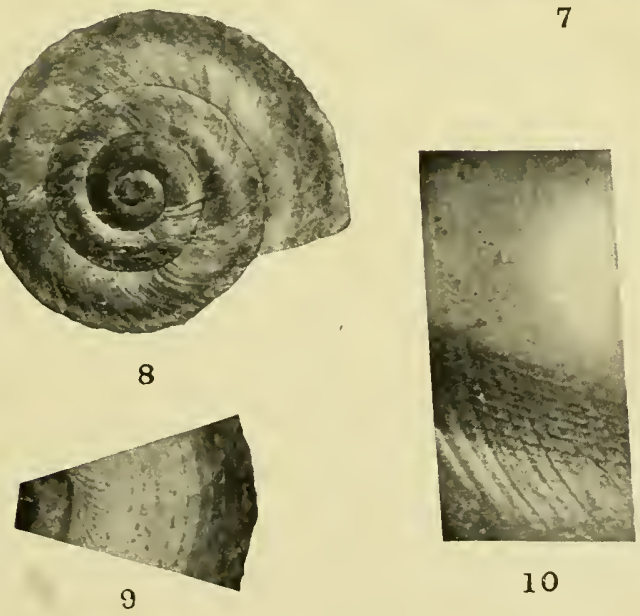

3

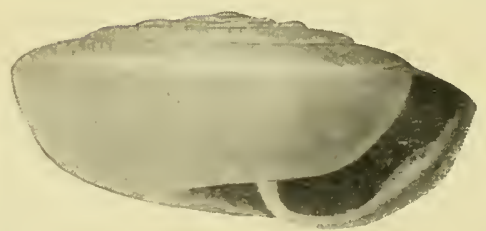

11

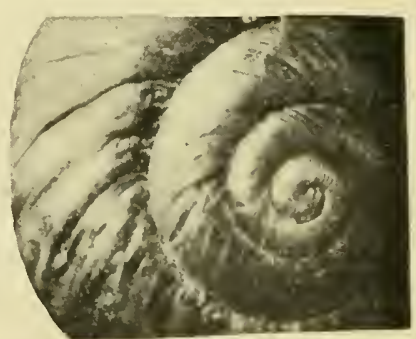

12
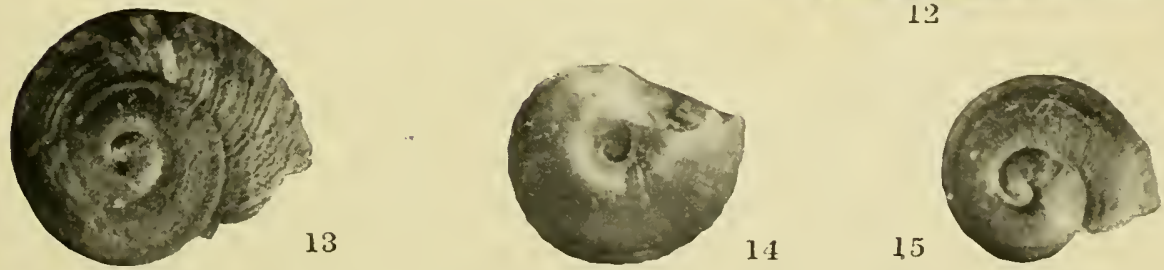

PILSBRY. MOLLUSCA OF THE SOUTHWESTERN STATES. 



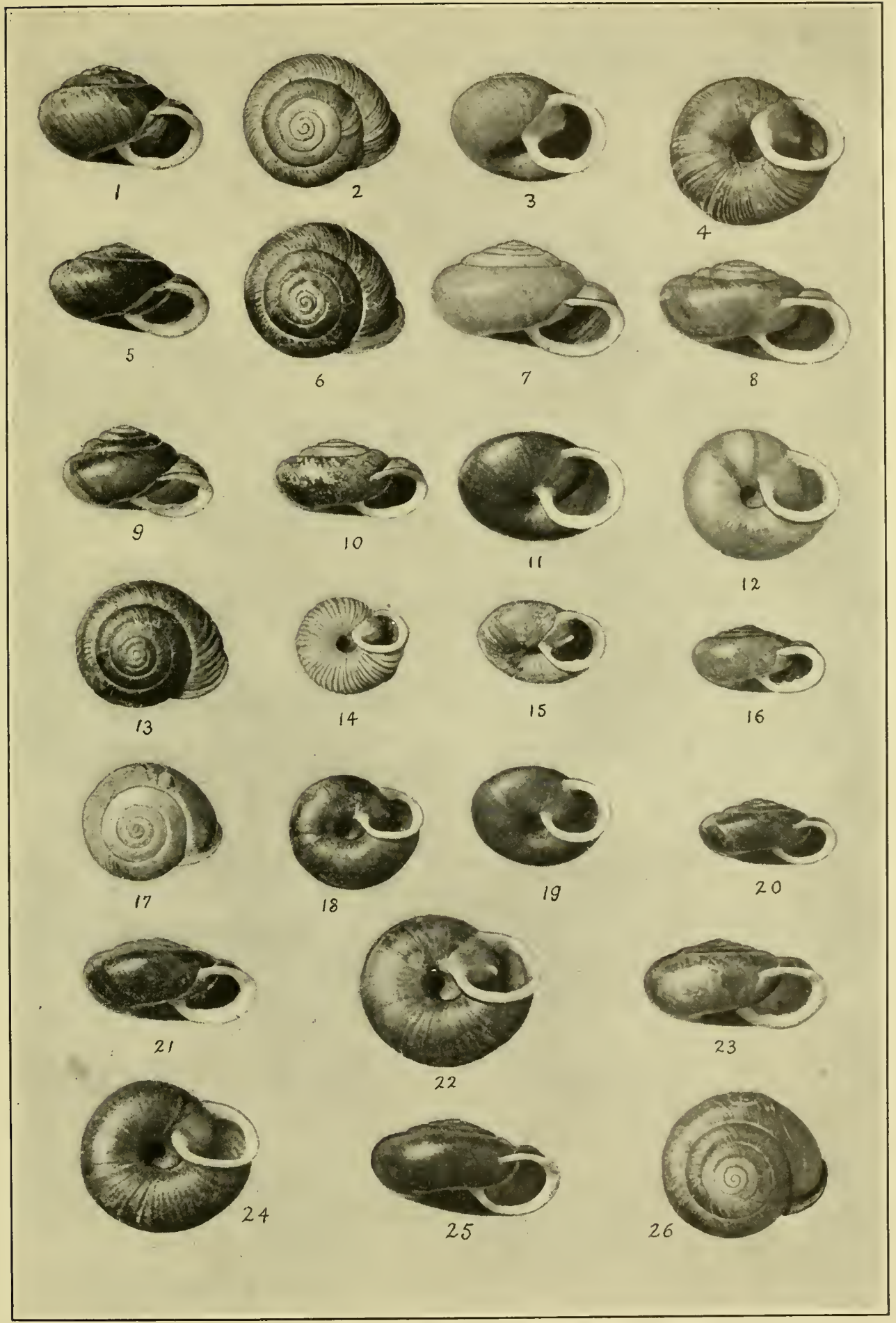

PILSBRY. MOLLUSCA OF THE SOUTHWESTERN STATES. 


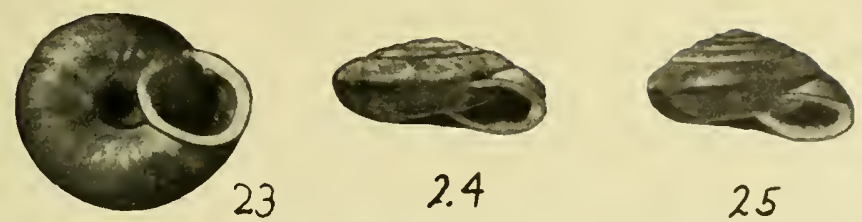

2.4

25

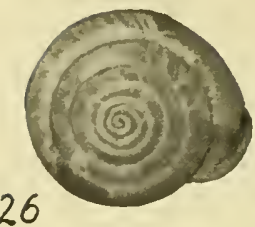

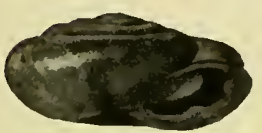

27
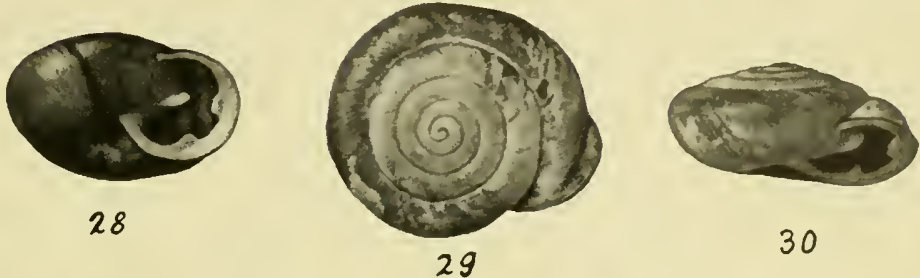

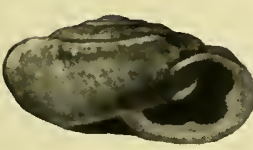

31
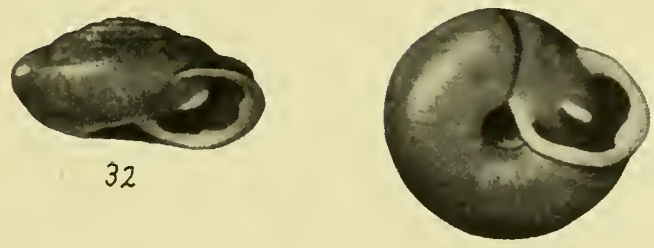

33

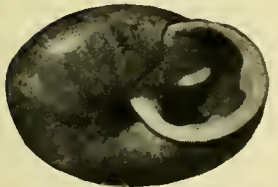

35
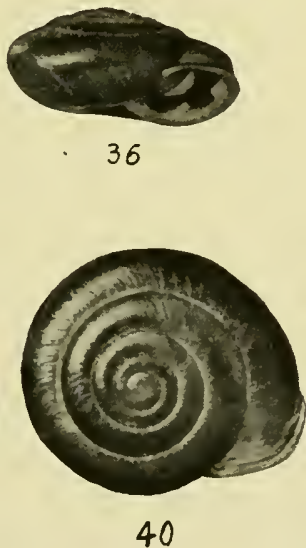

39

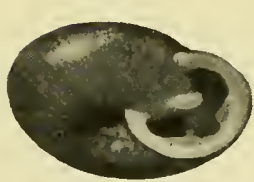

37
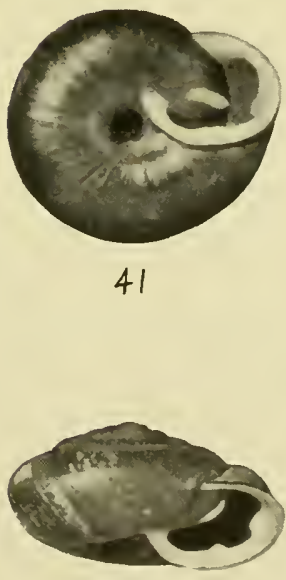

45

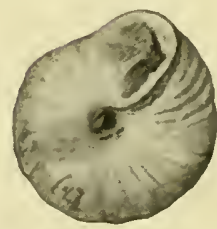

38
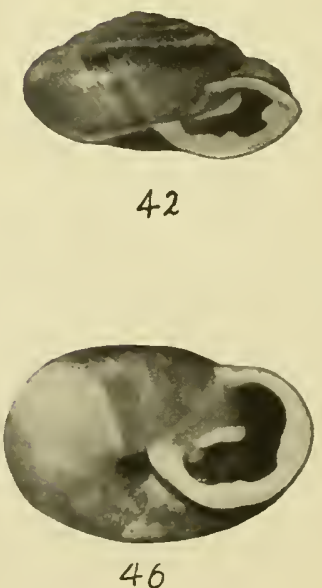

PILSBRY. MOLLUSCA OF THE SOUTHWESTERN STATES. 



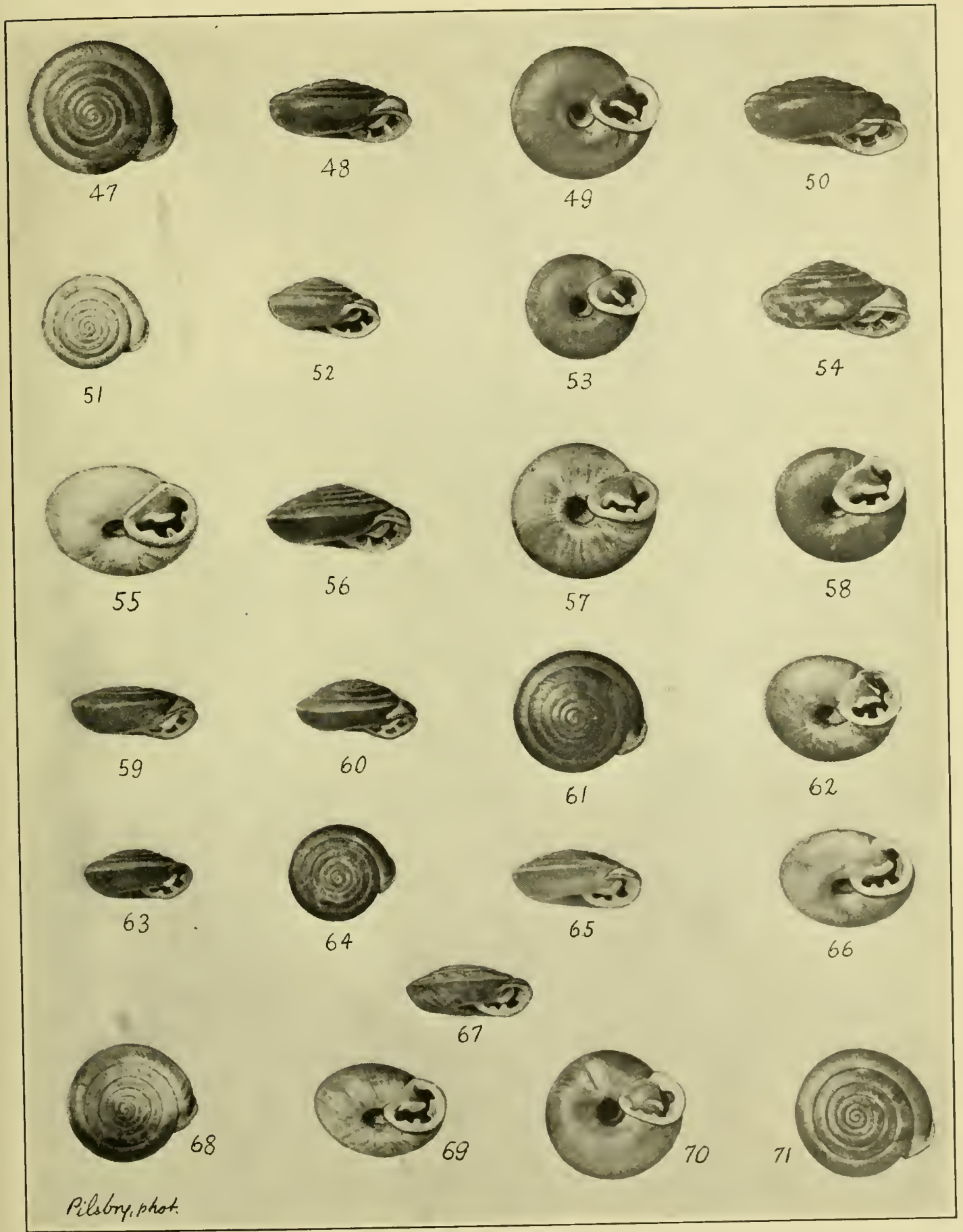

PILSBRY. MOLLUSCA OF THE SOUTHWESTERN STATES. 



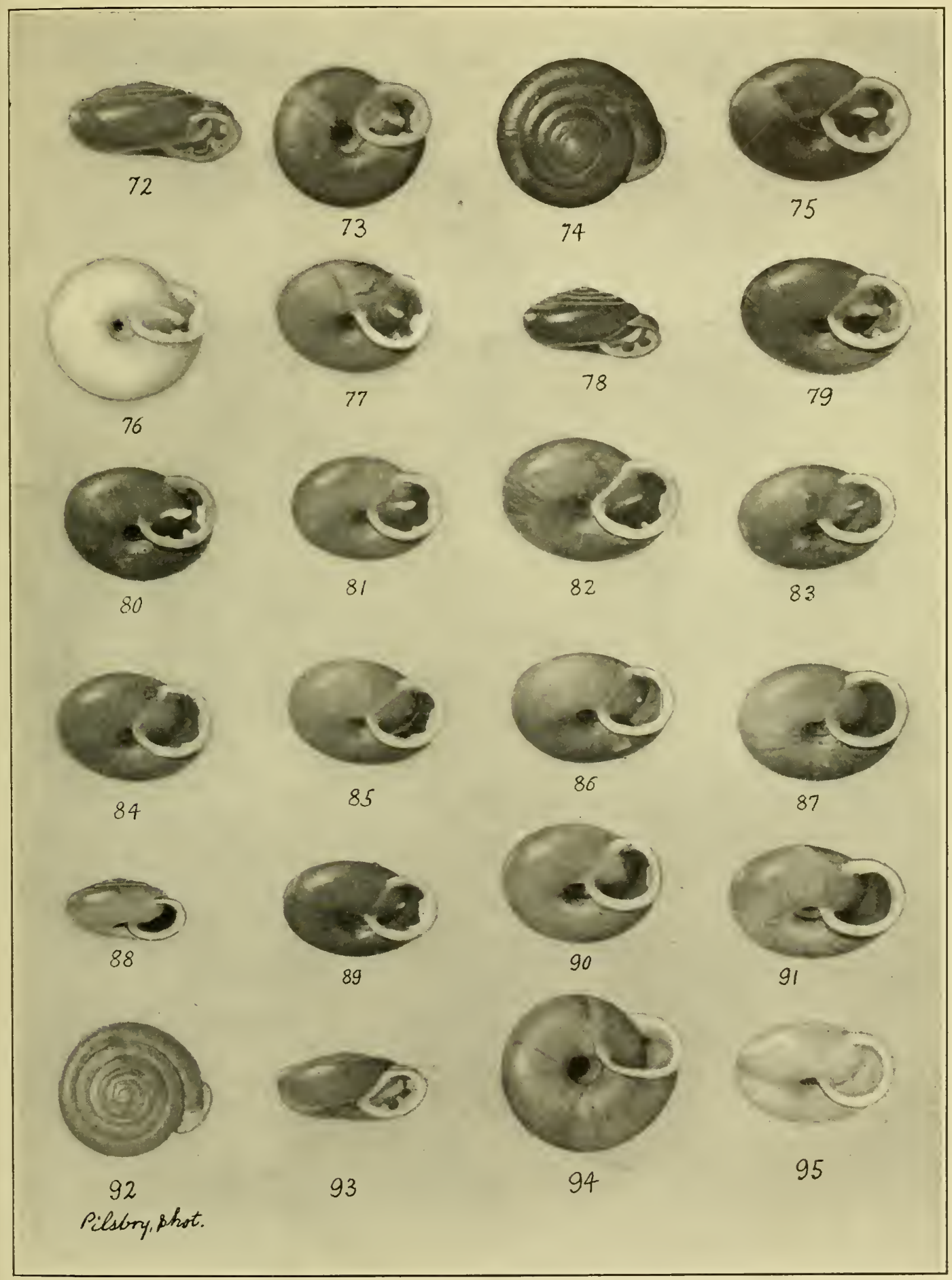

PILSBRY. MOLLUSCA OF THE SOUTHWESTERN STATES. 



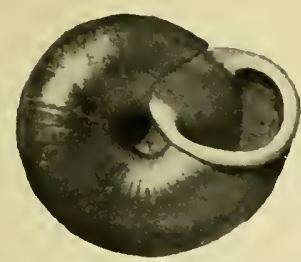

96

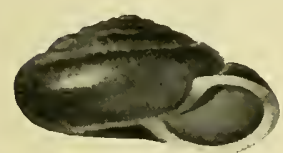

100

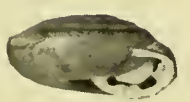

104

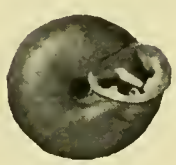

108

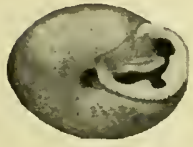

107
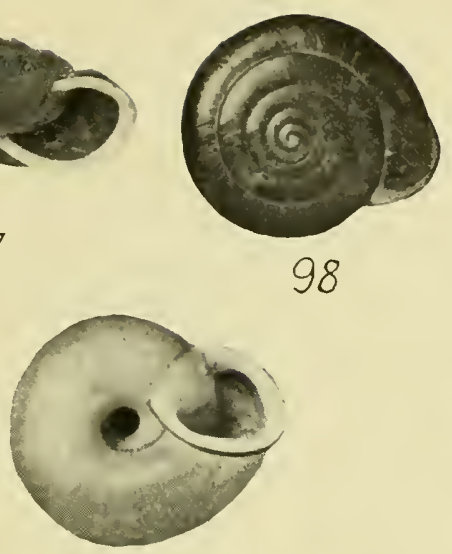

101

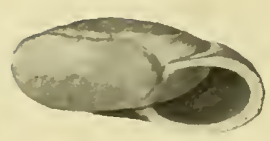

99

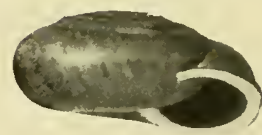

102

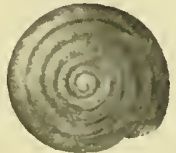

105

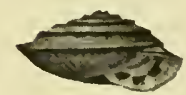

109

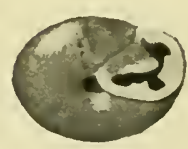

106

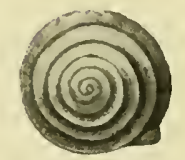

110

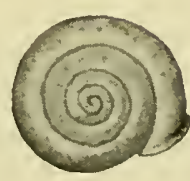

111

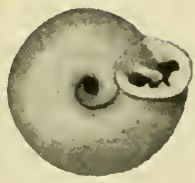

112

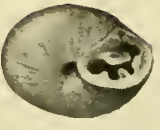

$1 / 3$

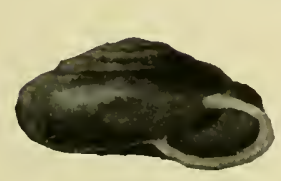

114

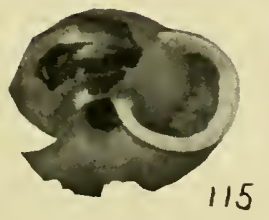

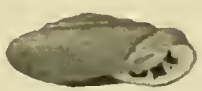

116

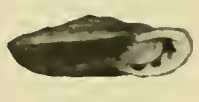

117

PILSBRY. MOLLUSCA OF THE SOUTHWESTERN STATES. 



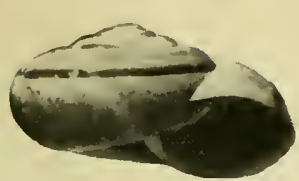

1

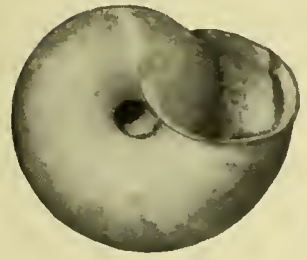

2

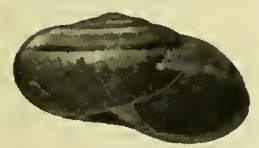

7

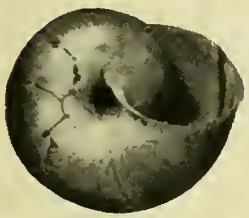

8

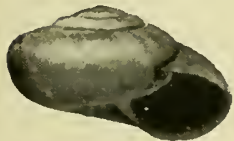

13

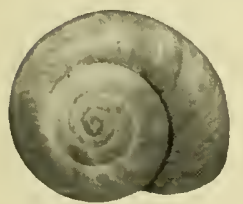

14

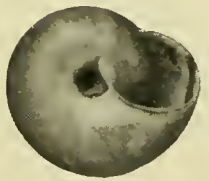

16
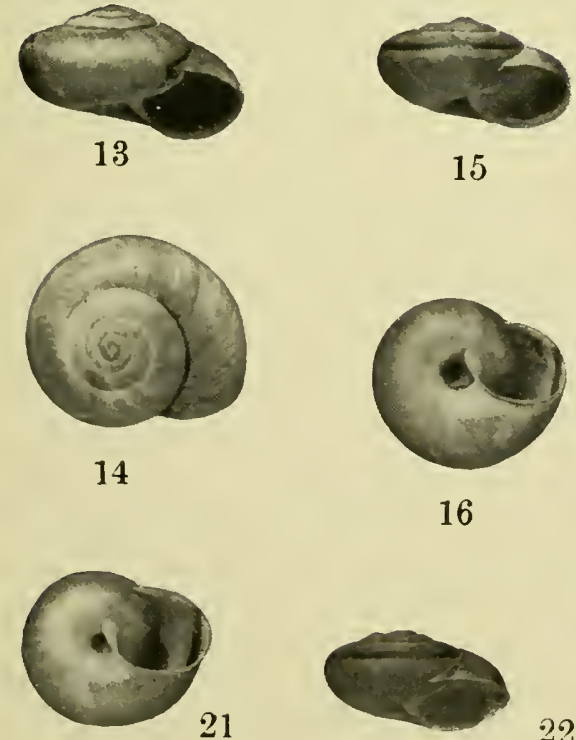

15

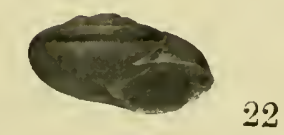

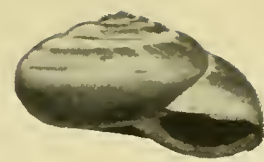

3

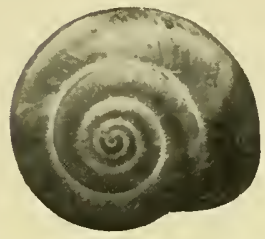

4

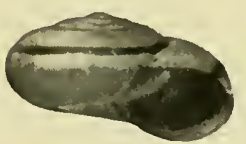

9

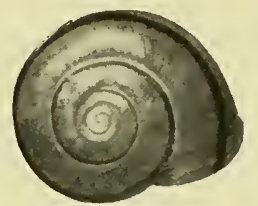

10
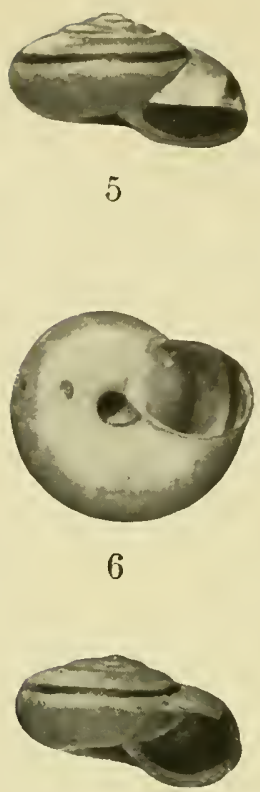

11

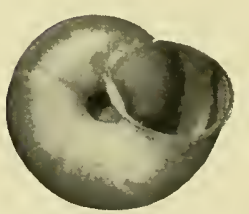

12

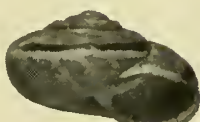

17

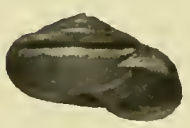

19

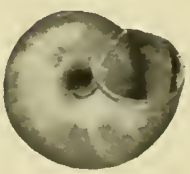

20

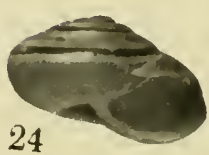

18
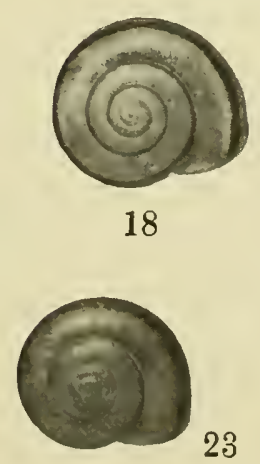

3

PILSBRY, MOLLUSCA OF THE SOUTHWESTERN STATES. 



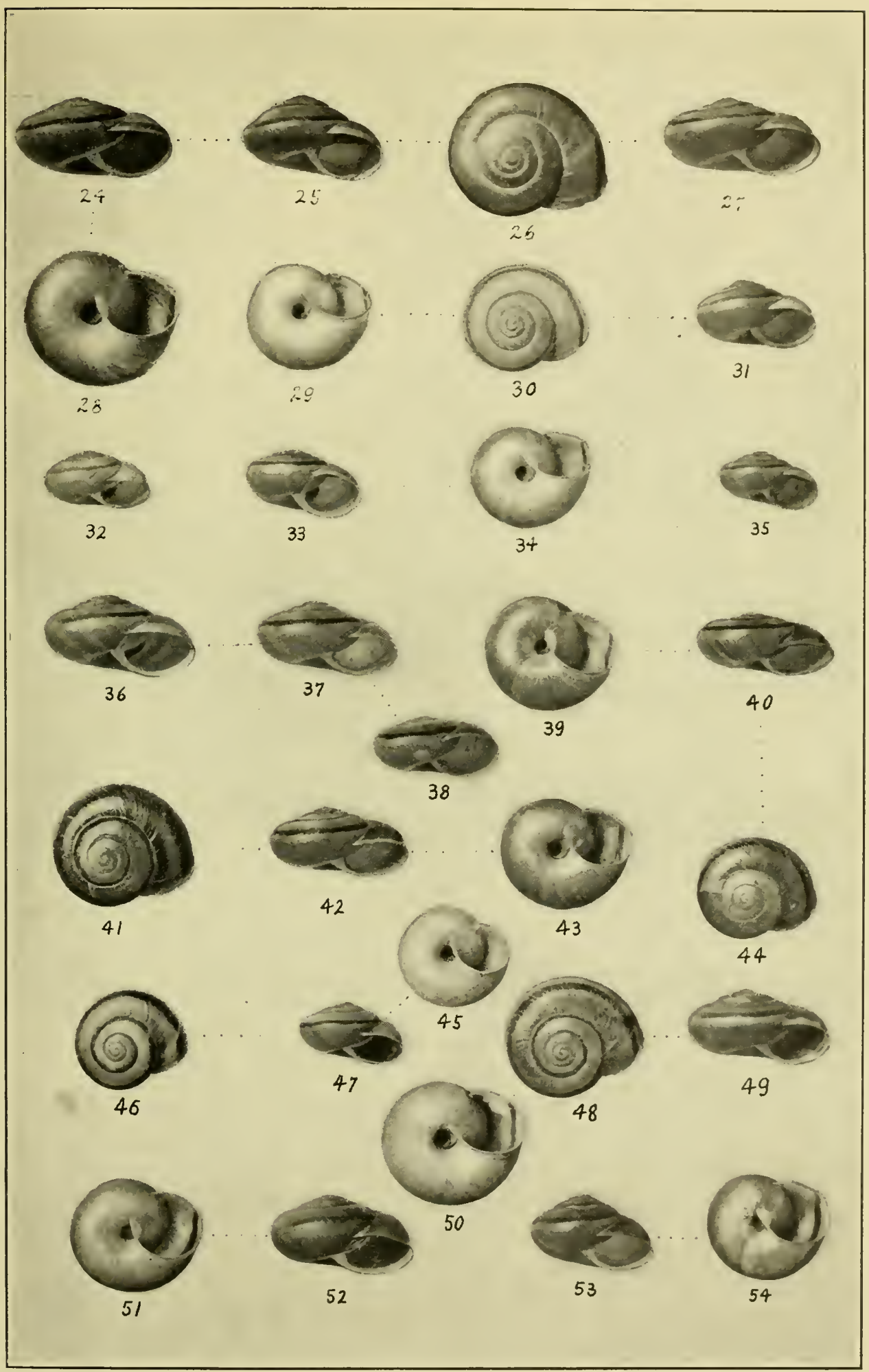

PILSBRY. MOLLUSCA OF THE SOUTHWESTERN STATES. 


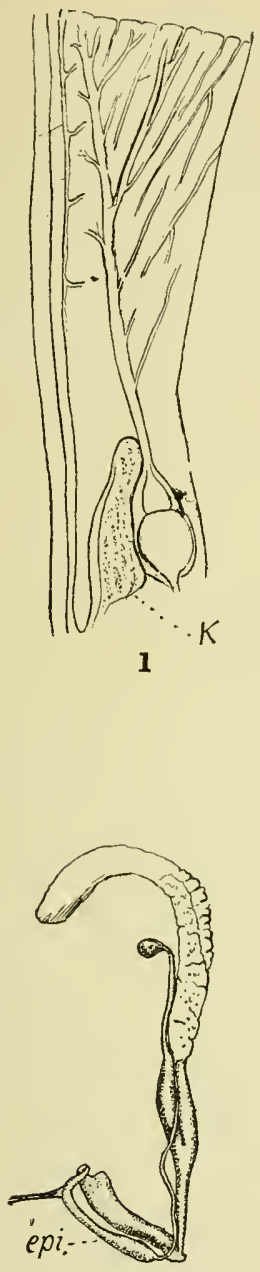

4

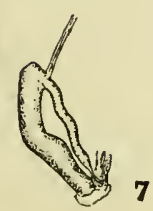

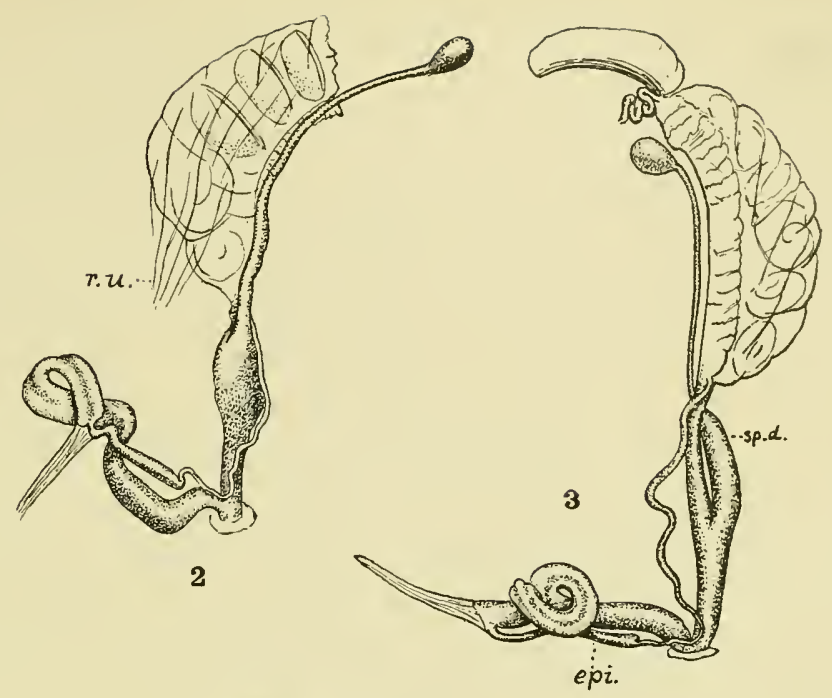
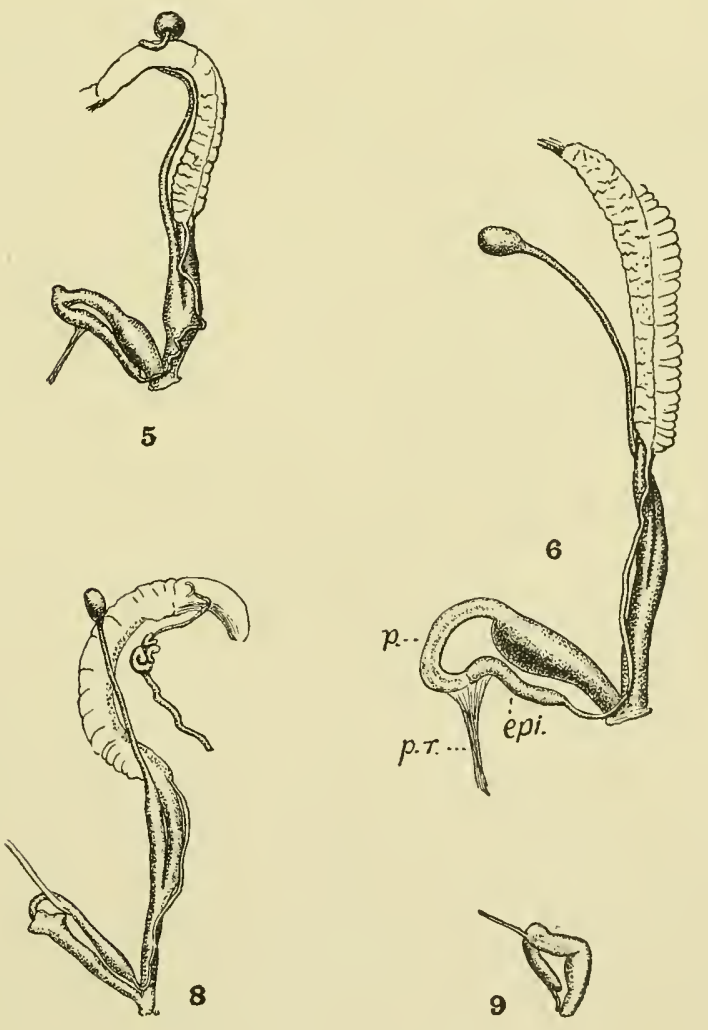

Pilabrodel.

PILSBRy. MOLLUSCA OF THE SOUTHWESTERN STATES. 



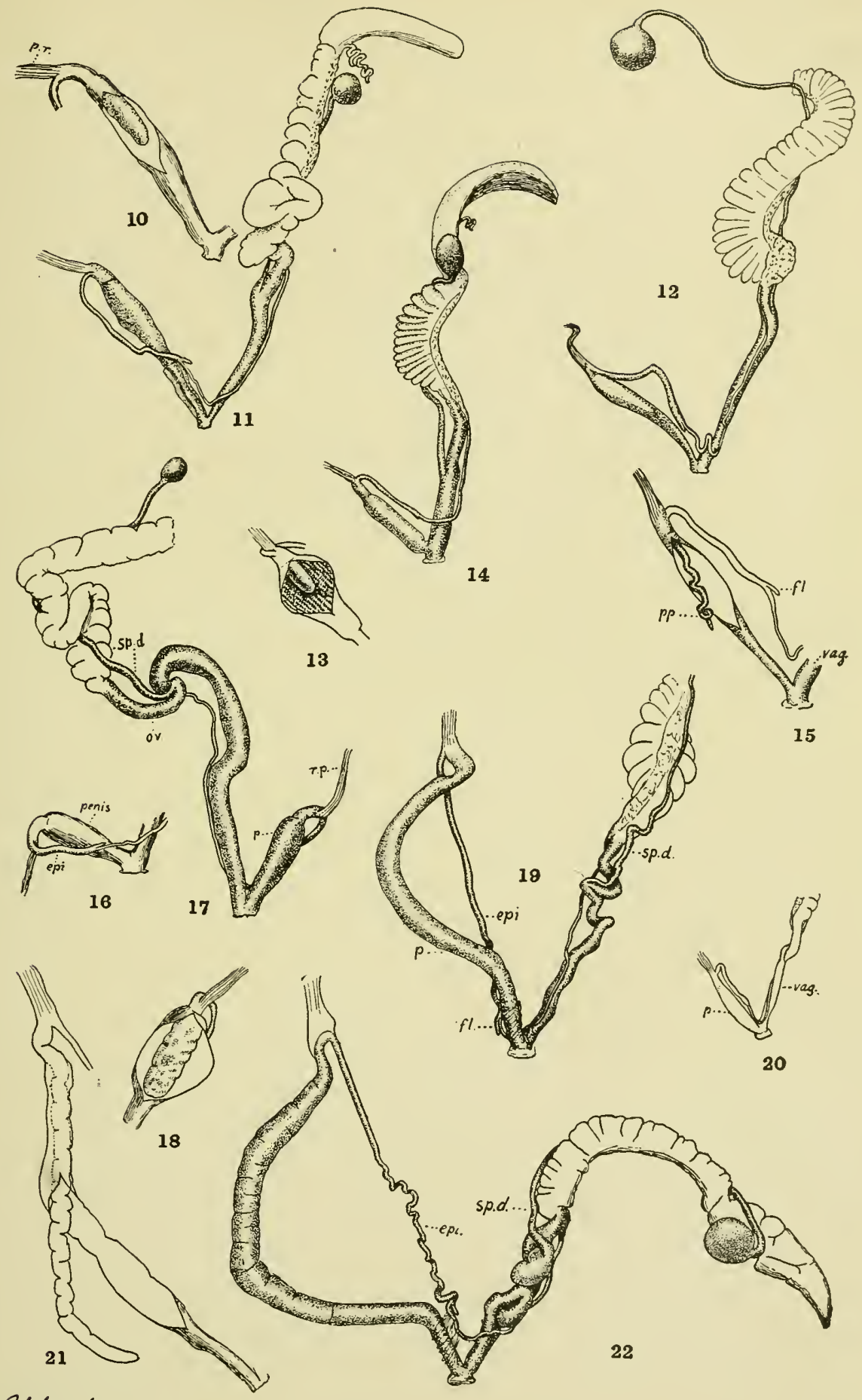

Pitslyy.del.

PILSBRY. MOLLUSCA OF THE SOUTHWESTERN STATES. 


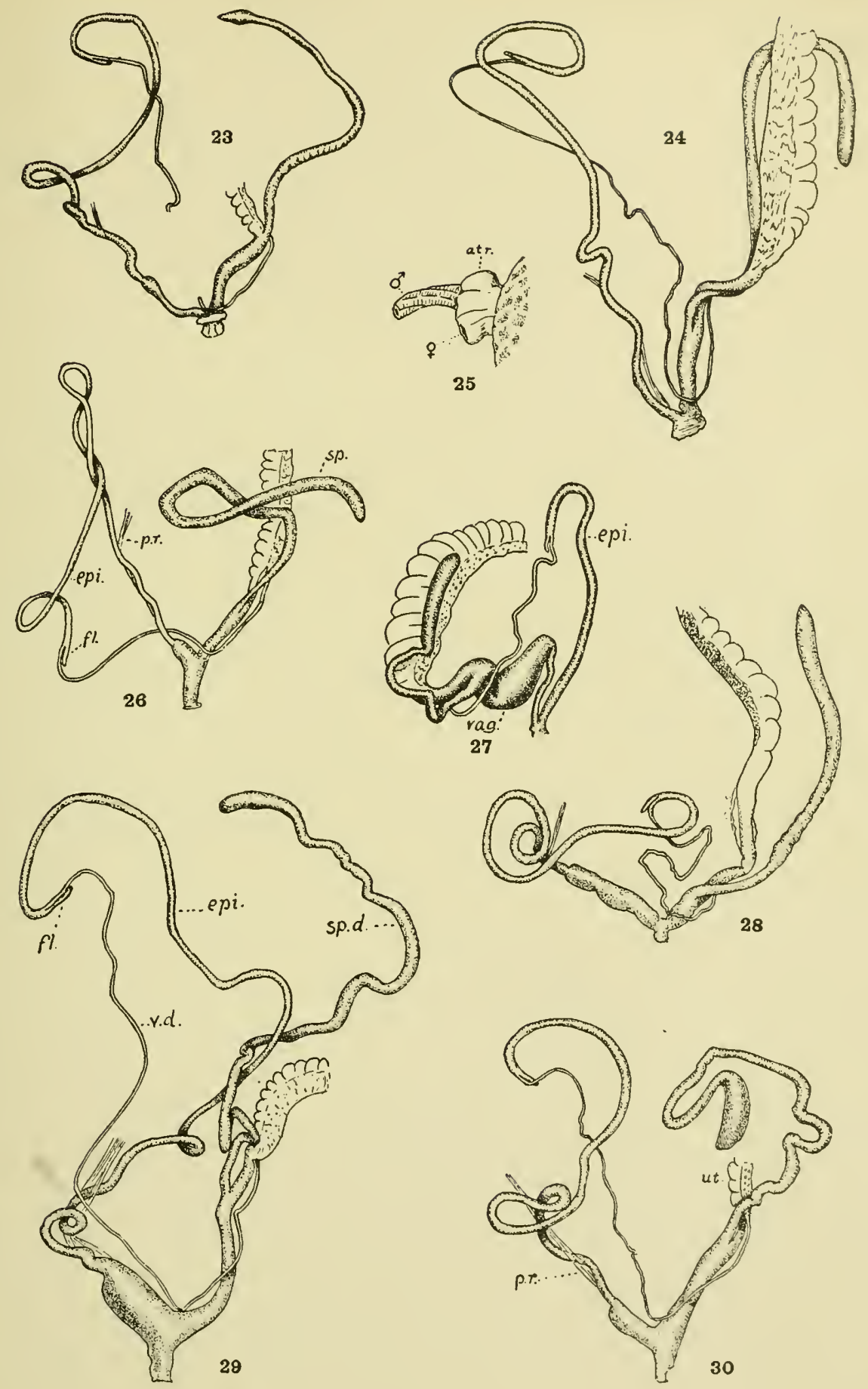

PILSBRY. MOLLUSCA OF THE SOUTHWESTERN STATES. 


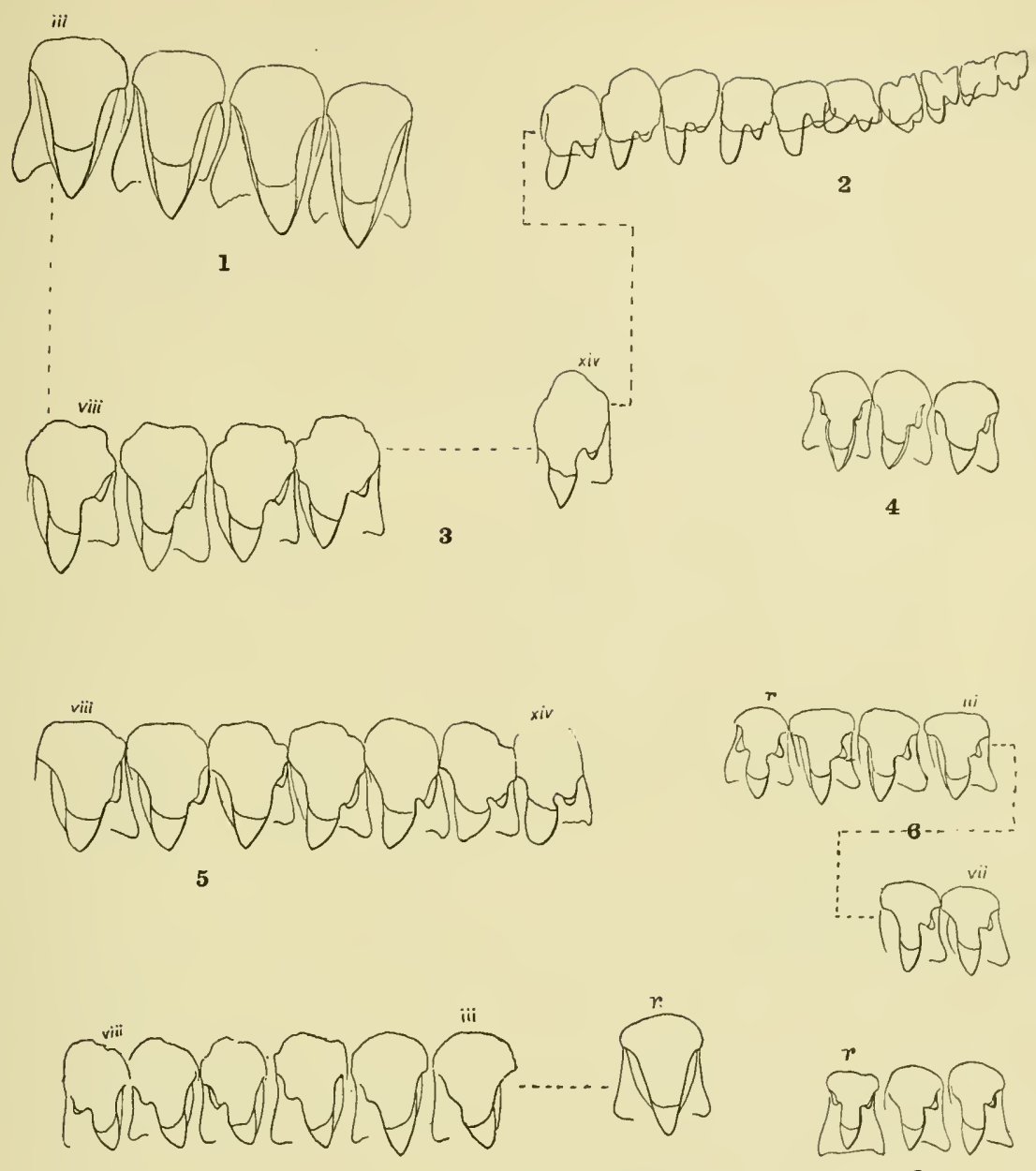

$$
7
$$$$
\text { m..... butury }
$$

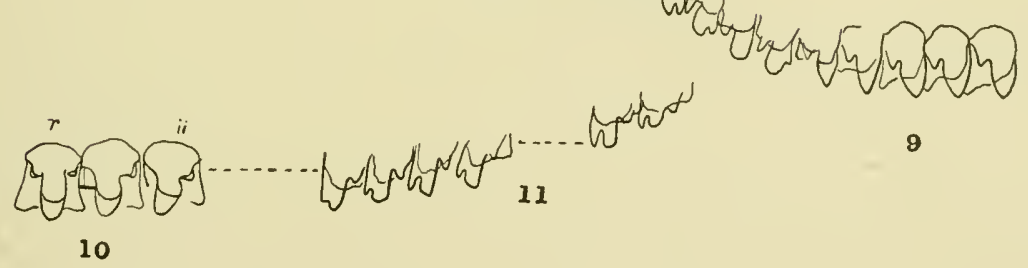

\section{ming}

PILSBRY. MOLLUSCA OF THE SOUTHWESTERN STATES. 


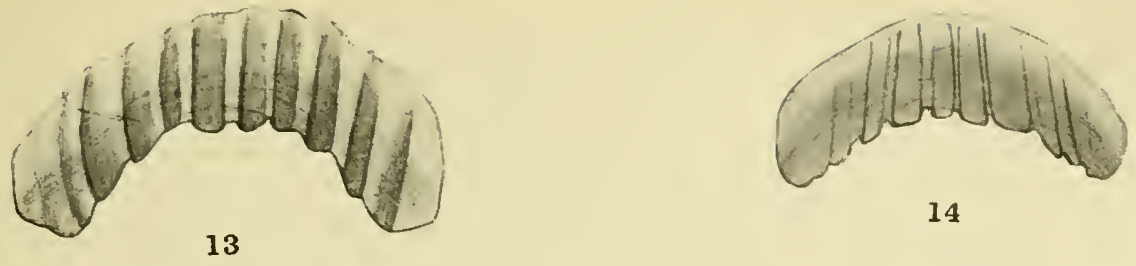

14
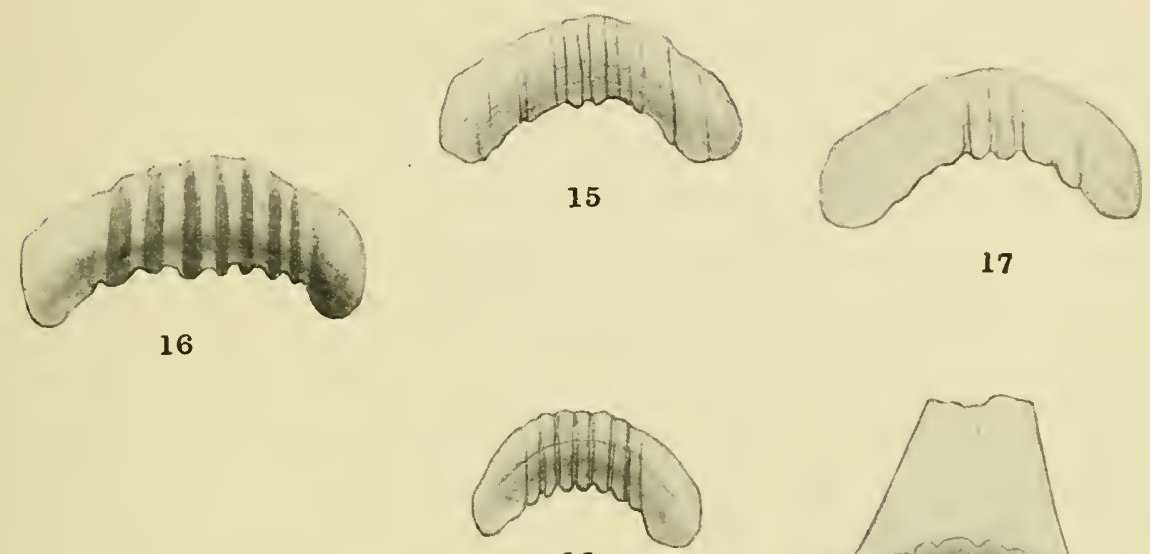

18
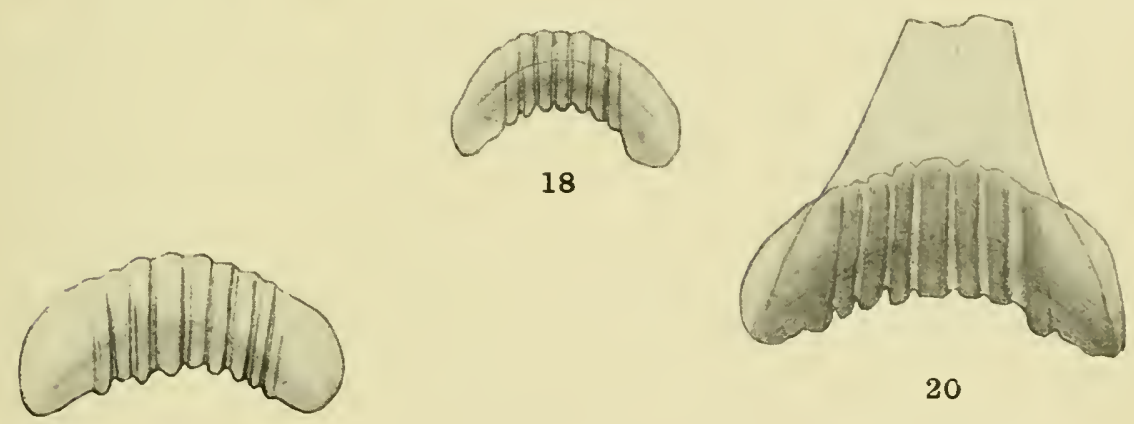

20

19

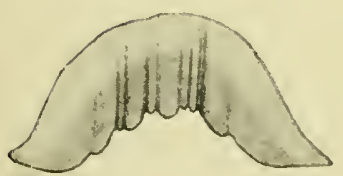

21

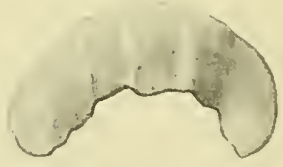

23

22

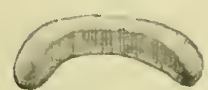

24

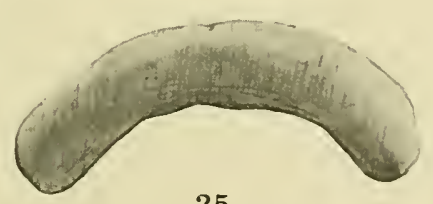

25

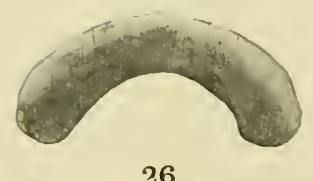

26

PILSBRY. MOLLUSCA OF THE SOUTHWESTERN STATES. 



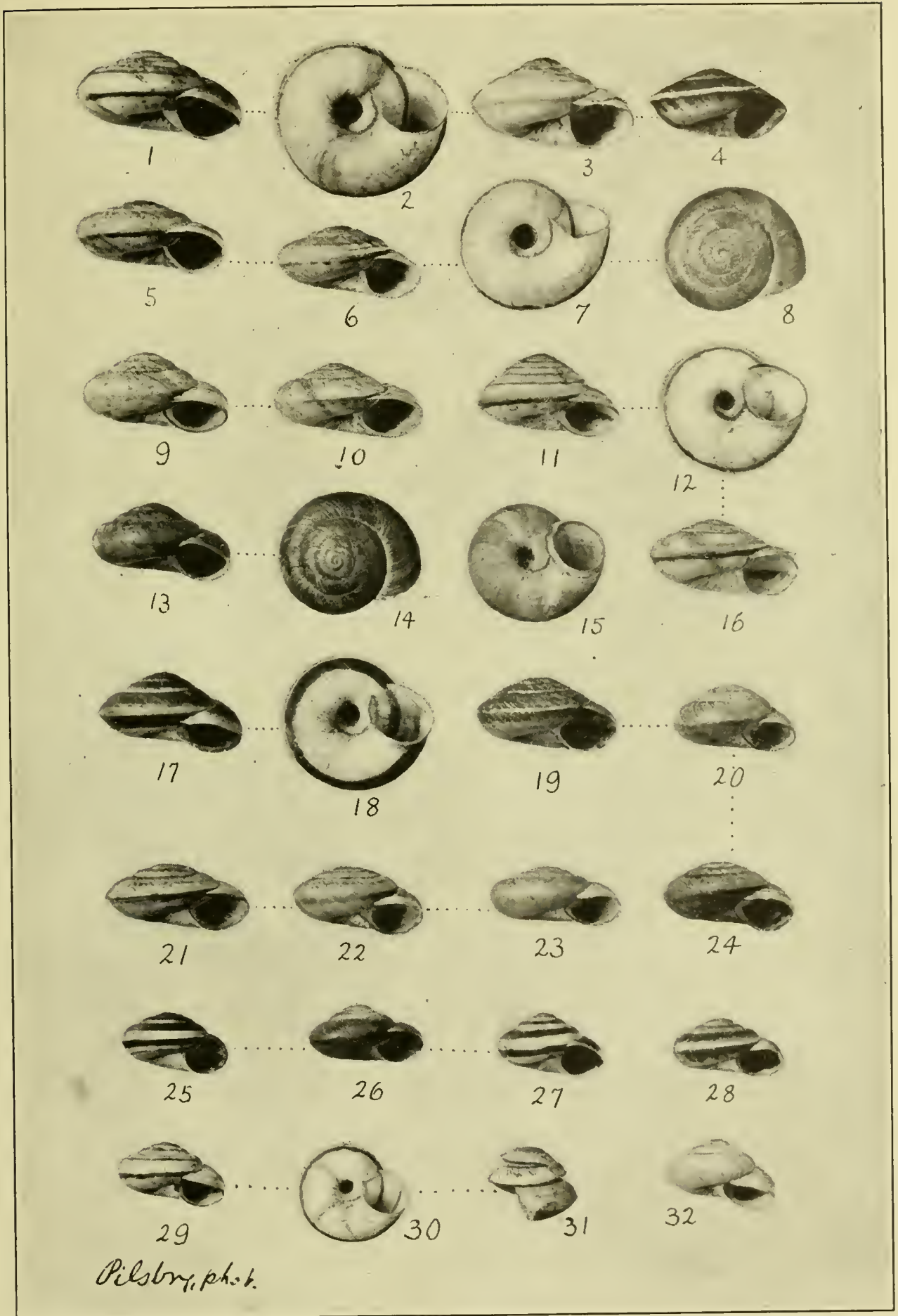

PILSBRY. MOLLUSCA OF THE SOUTHWESTERN STATES. 



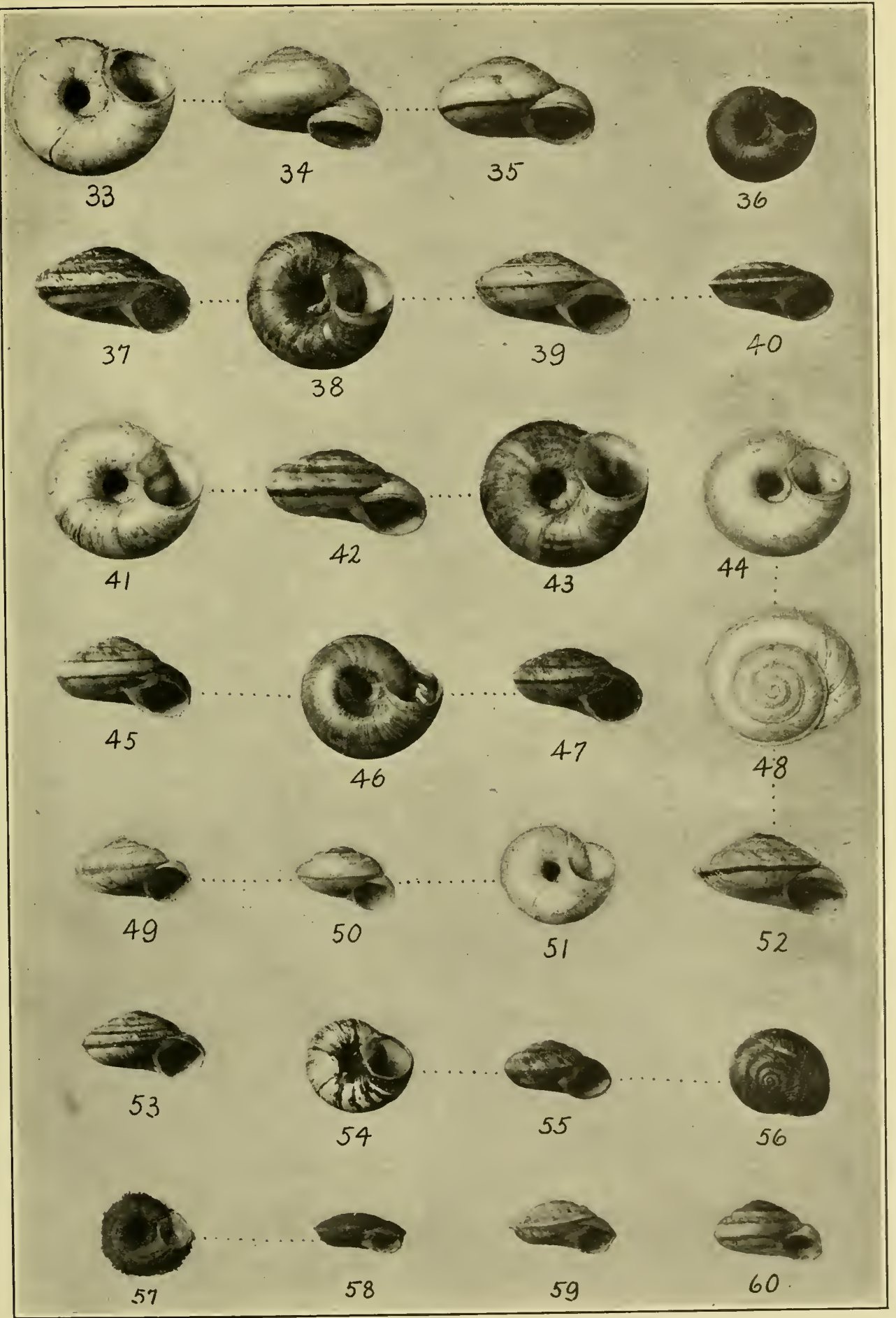

PILSBRY. MOLLUSCA OF THE SOUTHWESTERN STATES. 



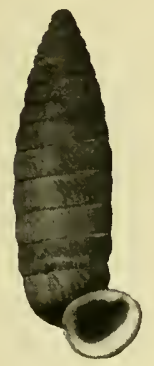

1

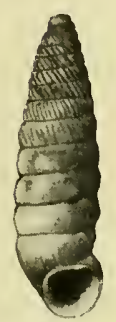

6

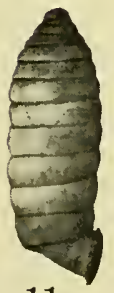

11

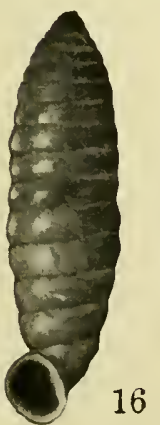

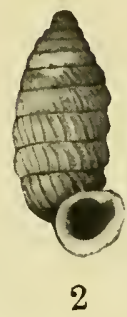

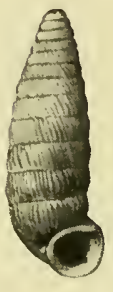

7

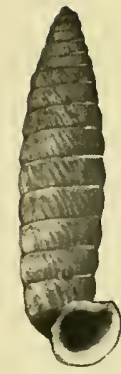

3

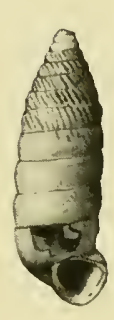

8

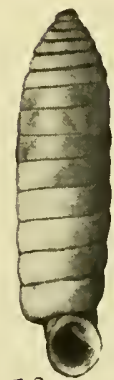

12
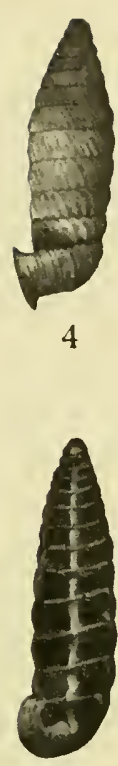

9
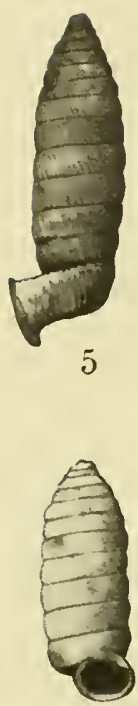

10
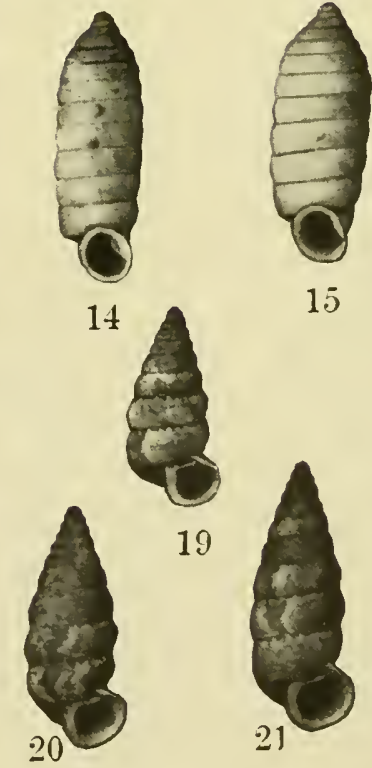

PILSBRY. MOLLUSCA OF THE SOUTHWESTERN STATES. 



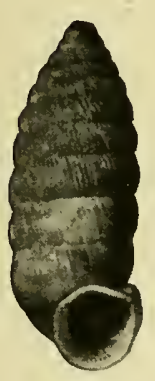

22

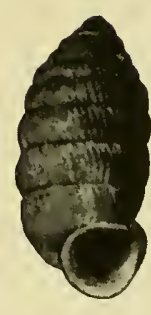

23
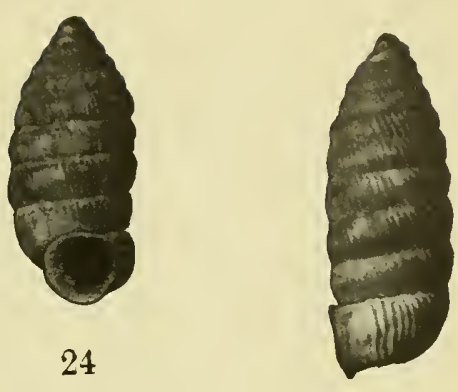

$\supseteq 5$
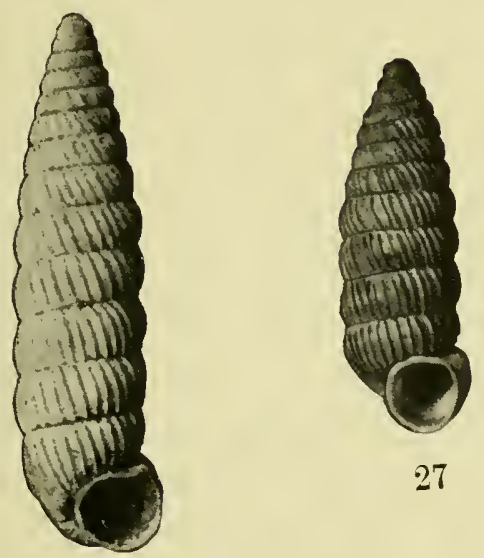

27
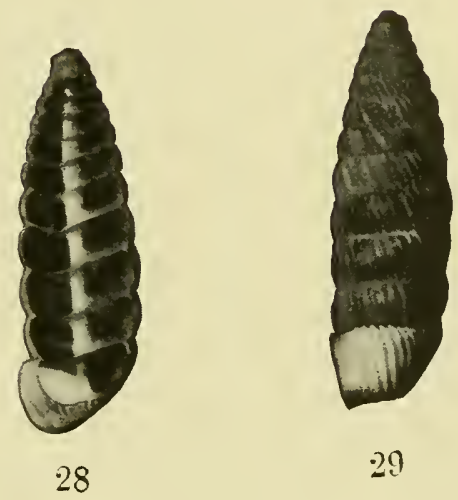

29

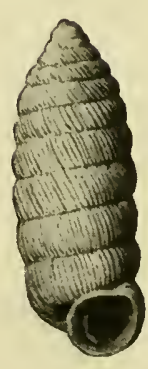

31

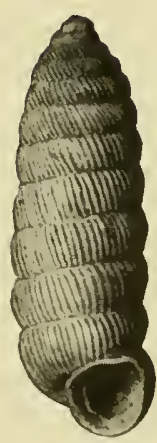

32

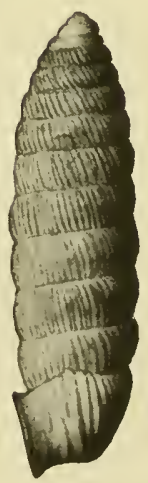

33

PILSBRY. MOLLUSCA OF THE SOUTHWESTERN STATES. 



\section{Mollusca of the Southwestern States. II.}

BY

H. A. Pilsbry and J. H. Ferriss. From the Proceedings of The Acudemy of Natural Sciences
of Philadelphia, March, 1906. 

MOLLUSCA OF THE SOUTHWESTERN STATES. II.

BI H. A. PILSBRY AND J. H. FERRISS.

The present paper deals with mollusks of Texas, New Mexico and Arizona, collected chiefly by the authors in 1903, and not included in the first paper of this series. ${ }^{1}$ No attempt has been made to present complete faunas; but in connection with the previous paper, about all the reliable data extant upon the snail faunas of the Chiricahua and Huachuca ranges in southeast Arizona and the eastern and southern borders of the Lower Sonoran area in Texas will be found herein. ${ }^{2}$ It has not been thought expedient to repeat data elsewhere accessible.

For the student of molluscan distribution, the life zones of the United States as mapped by Dr. Merriam ${ }^{3}$ emphasize the secondary and not the primary facts of distribution. The laws of temperature control, which he has developed with keen insight, do not define transcontinental zones of primary import zoologically. These zones are secondary divisions of vertical life areas of which the molluscan faunas were evolved in large part independently. The Sonoran fauna is probably intermingling more now with that of eastern North America than at any former time, at least so far as such sedentary forms as land mollusks are concerned.

Similar conclusions have been reached by Mr. A. E. Brown in dealing with Texan reptiles." The results of his study "establish three facts, hitherto not wholly free from uncertainty: first, that the boundary between the Austroriparian and Sonoran reptilian faunas lies approximately between the 96 th and 9Sth meridians of longitude in Texas; second, that the restricted Texan district of Cope is not Austroriparian but Sonoran; third, that transcontinental zones of distribution cannot be maintained in the Medicolumbian region for reptiles."

${ }^{1}$ Proc. A. N. S. Phila., 1905, p. 211.

${ }^{2}$ Some New Mexican records, chiefly from material collected by Prof. T. D. A. Cockerell in the upper Pecos valley, are added.

${ }^{3}$ Biological Survey, U. S. Dept. of Agriculture, Bulletin No. 11, Map. North American Fauna, No. 25, Plate I.

${ }^{4}$ Texas Reptiles and their Faunal Relations, Proc. A. N. S. Phila., 1903, pp. 543-558.

Post-Glacial Nearctic Centers of Dispersal for Reptiles, Proc. A. N. S. Phila, 1904, p. 464. 
"... . the community in reptiles between the sonoran and the Austroriparian is much less than that between the Sonoran and the Central; it is, in fact, limited to widely ranging genera .... the separate illentity of these two faunas [Sonoran and Austroriparian], as far back as they can be traced, confirms the conclusion already reached, from their present distribution, that the association of the Sonoran with the Austroriparian into one transcontinental zone is unnatural."

This terse statement only requires the substitution of "mollusks" for "reptiles" to serve as a summary of the results of our present investigation. In land mollusks, as in reptiles, the Sonoran types have pushed farther into the humid Austroriparian than the eastern types into the Sonoran area. Bulimulus and the texasiana group of Polygyra are cases in point; while Eastern subgenera of Polygyra, and practically all Austroriparian forms except the minute, widely ranging genera, stop short at the rise marking the approximate limit of the Cretaceous formation and the Sonoran area in Texas. The common boundary of the Austroriparian and Sonoran, while surprisingly sharp for continuous areas, is deeply accidented by the river valleys, which carry very narrow Austroriparian ramifications into Sonoran borders. Thus, along the San Marcos river in Hays county, the Guadalupe river in Comal county, and the San Antonio river in Bexar county, an Austroriparian fauna with such Eastern forms as Omphalina, Polygyra thyroides, $P$. monodon fraterna, $P$. auriformis, $P$. roemeri, Bulimulus $d$. liquabilis, etc., is found, while the fauna on the bluffs or away from the streams is frankly Sonoran. Farther southwest, the Austroriparian forms are wholly wanting, even where moist local conditions prevail, as in the immediate vicinity of the streams of Val Verde county.

A list of the forms characteristic of the eastern or lower portion of the Sonoran in Texas (Texan District of Cope) follows:

Praticolella berlandieriana

'Thysanophora hornii

Polygyra hippocrepis

Polygyra texasiana hyperolia

Polygyrat.texasensis

Polygyra mooreana

Bulimulus d. mooreanus

Bulimulus d, ragsdalei
Strobilops l. texasianus

Zonitoides nummus

Vitrea indentata umbilicata

Vitrea dalliana roemeri

Euconulus chersinus trochulus

Helicodiscus eigenmanni

Planorbis carus

Planorbula obstructa

${ }^{5}$ This species extends somewhat into the Austroriparian. 
Bulimulus d. pecosensis

Bulimulus alternatus mariøe

Holospira roemeri

Holospira goldfussi

Microceramus texanus

Euglandina singleyana

Bifidaria procera cristata
Goniobasis comalensis

Paludestrina seemani

Paludestrina diaboli

Ammicola comalensis

Cochliopa riograndensis

Potamopyrgus spinosus

Valvata micra

Nine genera of this list are not known to occur in the Austroriparian or humid region of Texas. For list of the latter fauna, the student is referred to the catalogue of Mr. J. A. Singley, cited below, from which a long list of Austroriparian forms of Eastern type may readily be compiled.

The first list of Texan mollusks of any extent was published by Römer in his excellent work on Texas, 1849. Numerous references to the terrestrial mollusks will of course be found in Binney's successive volumes. In $1878 \mathrm{Mr}$. A. G. Wetherby ${ }^{6}$ published some notes on the forms he found in eastern Texas (American Naturalist for 1878, pp. 184, 254). The principal source of information, however, is Mr. J. A. Singley's Contributions to the Natural History of Texas, part I, Texas Mollusca, published in the Fourth Annual Rep. Geol. Survey of Texas, 1893. In this list Mr. Singley has included with the records of his own extensive collecting, others from many sources, so that the records are of unequal value. The Texan list stands much in need of revision and a good many names thereon are doubtless to be rejected, either because the forms do not occur in Texas, as in the case of Ampullaria, or because of wrong identifications; yet the work cannot be done until resident naturalists take it up.

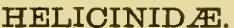

Helicina orbiculata tropica 'Jan' Ptr.

Texas: San Marcos, Hays county; Comal county, around New Braunfels; San Antonio, Bexar county; two miles north of Hondo, Medina county; Del Rio, Devil's river and High Bridge of the Pecos, Val Verde county.

Some colonies are all white; others are mingled with red or blue shells.

\section{HELICID $刃$.}

Praticolella berlandieriana (Moric.). Figs. 1, 2.

Texas: San Marcos, Hays county; Guadalupe river above New

'By error Mr. Wetherby's name was printed "W. G. Weatherby ", 
[March,

Braunfels, Comal county; San Antonio, Bexar county; Hondo river, two miles north of Hondo, Medina county; Del Rio, Val Verde county.

Mr. Ferriss took some thin, translucent specimens, $S \times 10 \mathrm{~mm}$., at Smithville. The shell varies from 9.8 to $11.7 \mathrm{~mm}$. diam. The pub-

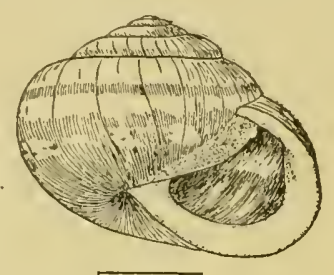

Fig. 1.

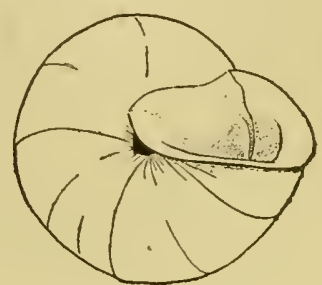

Fig. 2.

lished figures do not show that there is frequently a short lamellar tooth or callous on the parietal wall near the suture, a short distance within, as shown in the figured specimen from the Guadalupe river near New Braunfels.

Thysanophora hornii (Gabb).

Texas: Hondo river, near Hondo, Medina county; Rio San Filipe, near Del Rio; Devil's river, west of Del Rio, and Pecos river at the High Bridge, Val Verde county, all in river drift.

New Mexico: Florida mountains, near Deming, Grant county.

Arizona: Cochise county; Cave creek canyon in the Chiricahua mountains; Fort Bowie; drift of San Pedro river at Benson, and Manilla mine, at the west end of the Huachuca mountains.

This small species is a typical Thysanophora, closely related to the type of the genus. It varies but little throughout its extensive range, unless it be in the cuticular lines and hairs, which are worn off of the river-drift specimens. It has not before been reported in this country from east of Cook's, Grant county, N. M. Our collection of 1903 extended its known range in the United States more than 500 miles eastward, to the border of the Staked Plains in central-southern Texas. Further localities in Arizona are given in Nautilus, XII, p. 99.

In Mexico, T. hornii has been collected at Topo Chico, near Monterey, Nuevo Leon, and at Victoria, Tamaulipas (Proc. A. N. S. Phila., 1903 , p. 763). It is therefore one of the widely distributed species of the States both north and south of the international boundary in the Sonoran area.

Polygyra auriformis (Bld.).

Helix auriformis Bland, Ann. Lyc. Nat. Hist. of N. Y., VII, p. 37 (1858).

? Helix sayii Wood, Index Testaceologicus, Suppl., p. 22, pl.7, p. $34 n$ (1828).

Texas: Galveston (J. H. Ferriss); Calhoun county (Hubbard); 
Austin and San Antonio (Pilsbry, 1S85); along the Guadalupe river, three or four miles above New Braunfels (Ferriss and Pilsbry). Singley adds the localities Bastrop and Burleson counties. It is an Austroriparian species which reaches into the borders of the Lower Sonoran area along the river bottoms.

While the identity of Wood's $H$. sayi with auriformis is not establisherl with sufficient certainty to make a substitution advisable, in our opinion, yet there can be no doubt that Wood had either that species or one of its immediate allies. Helix sayi of Binney, 1840, being a homonym, may be changed to Polygyra sayana (Terrestrial Mollusks, III, pl. XXIII).

Polygyra hippocrepis (Pfr.). Figs. 3, 4.

The known range of this curious snail is exceedingly restricted. It has been found only near New Braunfels, in Comal county, Texas. We found it in abundance in April, 1903, on the west side of the Guadalupe river about four to six miles north of New Braunfels, under stones near and at the foot of the bluff, with Holospira goldfussi. Another place much nearer the town is on the rocky wooded hillside above the springs of Comal creek, where we found a few living ones. This place is just beyond the pleasure gardens.

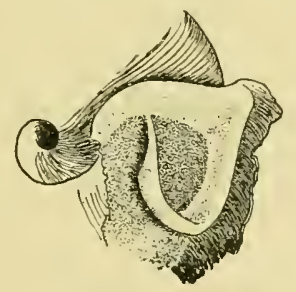

Fig. 3.

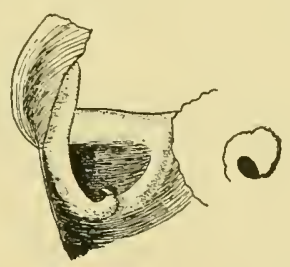

Fig. 4.

The structure of the aperture of $P$. hippocrepis has never been fully clescribed or figured. The parietal tooth is not $\mathrm{V}$-shaped as in other Polygyras, but U-shaped, hence the name hippocrepis-horseshoe. There is an internal tubercle on the columella, as in P. mooreana. 'The upper and lower lip-teeth enter and arch towards each other, forming a U-shaped curve, which stands close to but a little deeper than that formed by the parietal tooth. Where the two entering teeth join there is a natch and a delicate slender hook with the point curved towards the adjacent basal wall projecting forward. The immersion of the originally lower lip-tooth gives room for a secondary callous ridge along the basal lip, as shown in fig. 4 . 
These structures form in their way a more perfect barrier perhaps than that produced by other means in P. auriculata and uvulifera. The species stands isolated at present. It is perhaps an aberrant and highly evolved relative of the Tennessee-Arkansas group of $P$. jacksoni, etc.

Polygyra texasiana (Moricand). Pl. V, tigs. 16, 17, 20.

Specimens of typical $P$. texasiana were taken by us in Hays, Comal and Bexar counties, Texas. Ferriss took it at Galveston. The type locality is "Texas." In this widespread form the last two whorls are strongly rib-striate above, the riblets rapidly diminishing on preceding whorls; the embryonic whorl is smooth and glossy. The ribs are strongest just behind the lip, and here continue upon the periphery or to the base, which is elsewhere nearly smooth or merely rippled. Fresh shells show a reddish peripheral band on the pale brownishcorneous surface. Specimens figured are from the west side of the Guadalupe river above New Braunfels, Texas. Alt. 5, diam. $11 \mathrm{~mm}$.

Along the Rio Grande $P$. texasiana occurs with transition forms to $P$. $t$. hyperolia. See below.

Form with striate base. In some localities the ribs of the upper surface continue upon the base (pl. V, figs. 18, 19, Calhoun county, Texas), the other characters being unchanged. There are transitions to the normal sculpture of texasiana in some specimens, and we do not think it desirable to distinguish this form at present by a special name. Its distribution must be more fully worked out than we have been able to do. Calhoun county is on the Gulf coast near the southern angle of the State.

\section{P. texasiana hyperolia n. subsp. Pl. V, figs. 13 14, 15.}

Shell more depressed than texasiana, glossy, very finely striate, almost smooth, above and below, with several riblets behind the lip-constriction. Uniform brownish-corneous or paler beneath, without a peripheral band. Aperture smaller and slightly more oblique than in texasiana. Alt. 4 , diam. 9.3 to $10 \mathrm{~mm}$.

The type locality is the high land west of Devil's river. This is the common Polygyra along the Rio Grande in Val Verde county, extending north and northwest. The specimens from down the river, at Hidalgo, .... county, and Laredo, Webb county (collected by Singley), are either texasiana or transitional between texasiana and hyperolia in sculpture. At Del Rio, along the Rio San Filipe, Ferriss and I found still the texasiana and transition forms.

On the high land west of the Devil's river, Val Verde county, we found hyperolia in some numbers, under prostrate Yucea trunks and 
sometimes concealed in the shelter of the downward-drooping dead leaves on standing Yuccas. From this region they have been washed into the Devil's river, where bleached shells are abundantly found in the drift débris.

We also took specimens in the high land along the Pecos river, near the High Bridge (Viaduct, on some maps), east of the river, and in drift débris in the canyon.

In the interior counties of Texas we took specimens in the drift of the Hondo river, Medina county, about two miles north of Hondo.

Much farther northward Mr. Ferriss found hyperolia at Colorado City, Mitchell county, Texas.

In New Mexico Prof. J. D. Tinsley collected it on South Spring creek, near Roswell, in the Pecos valley, where it occurred fossil in a bed of white marl, three to four feet below the surface. It is not now found living in that locality. We are indebted to Prof. Cockerell for these specimens. ${ }^{7}$

$P . t$. hyperolia varies about as much as texasiana in size. Specimens from west of Devil's river measure from $3.8 \times 8 \mathrm{~mm}$., with $4 \frac{1}{2}$ whorls, to $4.2 \times 11 \mathrm{~mm}$., with 5 whorls.

This variety is not the Helix (Polygyra) tamaulipasensis of Lea, which is typical $P$. texasiana, as I have ascertained by a comparison of the type kindly made for me by Dr. W. H. Dall.

Polygyra texasiana texasensis (Pils.). Pl. V, figs. 11, 12.

Polygyra texasensis Pils., Nautilus, XVI, p. 31, July, 1902.

Similar to P.t. hyperolia in the depressed shape and smooth surface, without riblets above; but decidedly larger, with about $5 \frac{1}{3}$ whorls, the umbilicus broader than is usual in the other forms of the species.

Alt. 5.2, diam. $12.5 \mathrm{~mm}$.

Alt. 5.8, diam. $12.5 \mathrm{~mm}$.

Alt. 5.8, diam. $13.7 \mathrm{~mm}$.

Colorado City, Mitchell county, Texas; types collected by James $\mathrm{H}$. Ferriss in 1902, No. 83,258 , A. N. S. Phila.

This is a large edition of $P$. $t$. hyperolia, and further collections from the almost unknown northwestern half of Texas are needed to determine whether it is really distinct enough from that subspecies to call for recognition of the latter by name. In the large series of hyperolia collected there were, however, no forms as large as texasensis.

Polygyra mooreana (W. G. Binn). Pl. V, figs. 4-10.

This species stands close to $P$. texasiana, but the shell is smaller than

\footnotetext{
${ }^{7}$ Reported as $P$. triodontoides in The Nautilus, XIII, November, 1899, p. 84.
} 
any but the smallest texasiana, and with about the same number of whorls ( 5 to $5 \frac{1}{2}$ ) appears more closely coiled. It is constantly distinct by the elongated columellar tubercle within the last whorl (shown in fig. 9). This tubercle seems to be what Binney erroneously describes as "an internal transverse tubercle on the base of the shell" -an expression which would lead one to expect such a structure as that found in the Stenotremas. Binney states that the color is "white," but fresh shells are brownish-corneous, a little paler and somewhat transparent at the base. The diameter varies from 6.5 to $8 \mathrm{~mm}$. Variation in the degree of elevation is shown in the figures.

$P$. mooreana was originally described from Washington county, Texas. We took specimens at Smithville, Bastrop county, San Marcos, Hays county, around New Braunfels, Comal county (figs 4- $\mathbf{7}$ ), and on the Hondo river north of Hondo, Medina county (figs. $8,9,10$ ), everywhere in copious quantity. There are also specimens before us from Washington county, Belton, Fort Worth, Waco, Austin and Lee county. Further records are given by Mr. Singley in his valuable catalogue. It was taken at Galveston by Ferriss.

Polygyra mooreana tholus (W. G. Binn). Pl. V, figs. 1, 2, 3.

Larger than mooreana, with the last whorl far more openly coiled below, exposing more of the penultimate whorl in the much wider umbilicus. Specimens from Washington county measure:

Alt. 5.5, diam. 11, wiclth of umbilicus $4.2 \mathrm{~mm}$.; whorls 7 .

Alt. 4 , diam. 8.2 , width of umbilicus, $3 \mathrm{~mm}$.; whorls 6 .

This form holds such a relation to $P$. mooreana as $P$. $d$. sampsoni to $P$. dorfeuilliana, being very openly coiled beneath, with a deep and very long groove on the last whorl within the umbilicus. The internal ridge is like that of $P$. mooreana. It seems to be comparatively local in distribution and is certainly rare. We have never seen a fresh specimen. It was described from Washington county, Texas, the locality of the specimens figured. It is in the collection of the Academy also from Calhoun county. Ferriss took a few specimens at Galveston, and Singley found it in Fort Bend and Brazos counties. Von Martens reports a worn specimen found by Friedel at Vera Cruz, Mexico.

Polygyra roemeri (Pfr.).

Smithville, Bastrop county, Texas (Ferriss); San Antonio, Bexar county (Pilsbry and Ferriss); near New Braunfels, Comal county, one specimen (Pilsbry).

\section{BULIMULID平.}

The genus Bulimulus in Texas has caused much perplexity to students. Many and diverse have been the views held as to the rank 
and identity of the several forms. Several times since the first visit of one of us to Texas, in the winter of 1SS5-\$6, they have been carefully studied anew, with each time larger materials and better knowledge of the country. To the specimens already in the museum of the Academy about 1,000 were added by our expedition of 1903, from central and western Texas and Indian Territory.

The series is divisible into two species, $B$. dealbatus and $B$. alternatus maric; the first further split into numerous local races or subspecies. The typical forms of $B$. alternatus and $B$. schiedeanus do not, so far as we know, extend into Texan territory; both were described from Mexico where they range over a large area. B. patriarcha W. G. B., unquestionably a form of schiedeanus, was also described from Mexico (Buena Vista), and we have seen no specimen of it from within our borders. ${ }^{8}$

In the United States, Bulimulus has not been found west of the neighborhood of El Paso. We know nothing of what forms live in the State northwest of a line from Austin,to San Antonio, or north of the Southern Pacific Railroad from San Antonio westward to El Paso. Beyond some extension of the ranges of $B$. dealbatus mooreanus and $B$. alternatus mariœ, little is to be expected from the great unknown area.

The following forms are now recognized:

1. B. dealbatus mooreanus W. G. B., Pfr. Arid region of central and south Texas.

2. B. d. liquabilis Rve. Eastern and southeastern Texas.

3. B. dealbatus Say. Alabama to Kentucky, west to Kansas.

4. B. d. ozarkensis P. and F. Northern and western borders of the Ozark uplift.

5. B. $d$. ragsdalei Pilsbry. Bluffs of Red river and southwestern Texas.

6. B. d. pecosensis P. and F. Southwestern Texas.

7. B. d. pasonis Pilsbry. El Paso, western Texas.

8. B. alternatus marix (Albers). Southern Texas.

Of these forms, the anatomy of $B . d$. mooreanus, $B$. d. liquabilis, $B$. d. ragsdalei, $B$. $d$. pecosensis and the Val Verde county race of $B$. alternatus marice has been examined more or less fully. All agree in having a rather short, fusiform penis with a basal sheath which in-

\footnotetext{
${ }^{8}$ We do not mean to deny that the forms mentioned occur in Texas. The counties along the Rio Grande west of the mouth of the Pecos are still unexplored for shells, and $B$. schiedeanus especially may turn up in this region.
} 
[March,

cludes the vas deferens; a rather long and slender epiphallus, and a flagellum. An atrium can scarcely be said to be developed, but the vagina is rather long in all the forms. The globular spermatheca is borne on a long duct, which is lightly bound to the oviduct and is usually somewhat swollen near the mirldle. The right eye-retractor passes between the $\sigma^{\top}$ and $q$ branches, and there is an excessively weak and short penial retractor about $1 \mathrm{~mm}$. from the end of the flagellum, and inserted on the lung floor.

$B$. a. mario differs strongly from all forms of $B$. dealbatus by the great length of the penis with its appendages, and of the duct of the spermatheca. Moreover, the penial organs are longer than the spermathecal duct, while in mooreanus and pecosensis the spermathecal duct is the longer. These differences confirm the opinion, derived

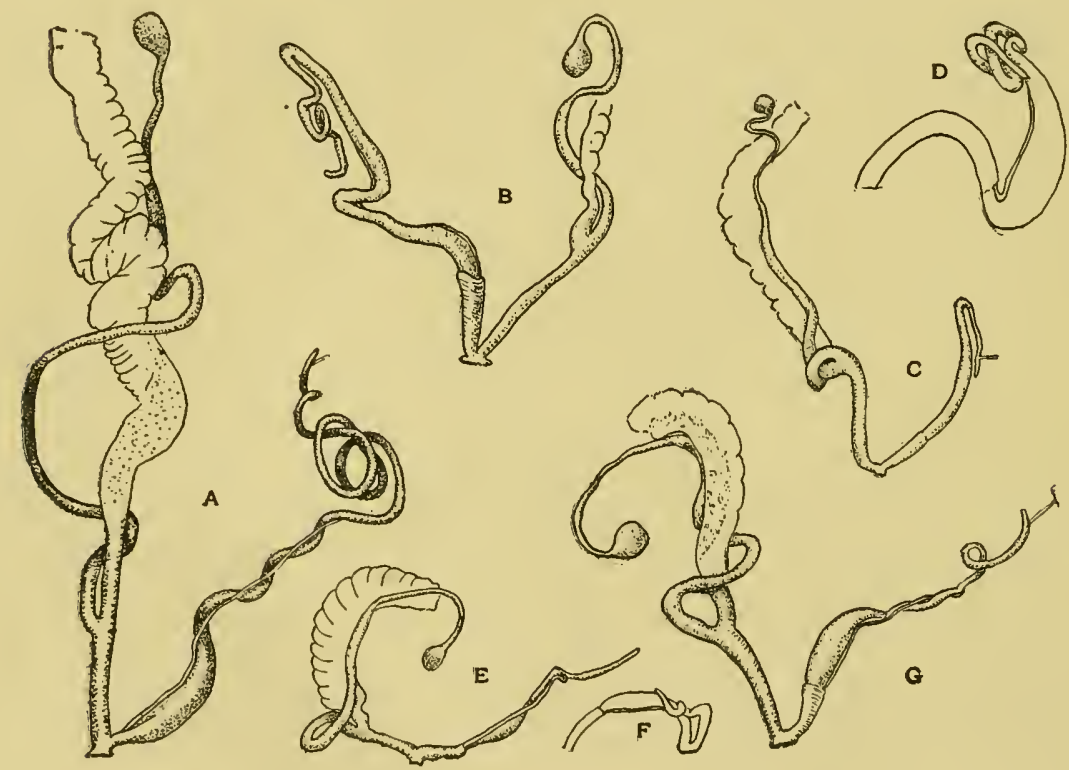

Fig. 5.-A, Bulimulus a. marix. B, B.d. liquabilis. C, B.d.pecosensis. D, penis of a fully mature individual of same E, $B . d$. ragsdalei. F, penis of another individual. G, B. d. mooreanus. Fig. D $\times 2 \frac{2}{3}$; the other figures $\times 2$.

from a study of the shells, that $B$. alternatus and dealbatus are well differentiated specifically.

The measurements of the genitalia in millimeters follows: 


\section{Proceedings of the Academy of Natural Seiences of Philudelphia, 1906.}

Page 133-Under heading Length of Spermatheca with duct, first line of table, change 5 to 50 . On last line of table change 1.5 to 15 . 



\begin{tabular}{|c|c|c|c|c|c|}
\hline & $\begin{array}{l}\text { Total length } \\
\text { of penis, } \\
\text { epiphallus } \\
\text { and } \\
\text { flagellum. }\end{array}$ & $\begin{array}{l}\text { Length } \\
\text { of penis } \\
\text { (to insertion } \\
\text { of vas } \\
\text { deferens). }\end{array}$ & $\begin{array}{l}\text { Length } \\
\text { of } \\
\text { vagina. }\end{array}$ & $\begin{array}{l}\text { Length } \\
\text { of sperma- } \\
\text { theca with } \\
\text { duet. }\end{array}$ & $\begin{array}{l}\text { Museum } \\
\text { number. }\end{array}$ \\
\hline $\begin{array}{l}B \text { a. mariø } \\
\text { Pecos river } \\
\text { Del Rio }\end{array}$ & $\begin{array}{l}58 \\
45\end{array}$ & $\begin{array}{l}34 \\
29\end{array}$ & 7 & 5 & $\begin{array}{l}84,627 \\
84,635\end{array}$ \\
\hline $\begin{array}{l}\text { B. d. liquabilis } \\
\text { San Marcos }\end{array}$ & 36 & 29 & 11 & 27 & 91,396 \\
\hline $\begin{array}{l}\text { B. d. mooreanus } \\
\text { Guadelupe river }\end{array}$ & 23 & 16 & 6 & 30 & $\$ 4,628$ \\
\hline $\begin{array}{l}\text { B. d. ragsdalei } \\
\text { Devil's river }\end{array}$ & 16 & 10.5 & 5 & $17^{\circ}$ & 84,638 \\
\hline B. d. pecosensis & $\begin{array}{l}19 \\
24\end{array}$ & $\begin{array}{r}11.5 \\
1.5\end{array}$ & 6 & 20 & 84,618 \\
\hline
\end{tabular}

B. dealbatus mooreanus ('W. G. B.,' Pfr.). Pl. VI, figs. 1-6.

Pfr., Monographia Hel. Viv., VI, p. 143 (1868).

Bulimus schiedeanus in part, W. G. Binney, Terr. Moll., IV, p. 129, pl.80, fig. 8.

Bulimulus schiedeanus var. mooreanus IT. G. Binney, Terr. Moll., V, p. 392, figs. 277, 278; Man. Amer. Land Shells, p. 400, figs. 438, 440.

The shell is thin, ovate-conic, opaque white above, coffee-with-cream colored below the periphery, or sometimes either white or coffee-tinted throughout; sometimes varied with a few gray streaks, or some scattered translucent-gray dots; surface smooth, with the spire more or less striate, apical whorls waxen or dark. Umbilicus narrow. Interior cream-white. Five specimens from New Braunfels measure:

$\begin{array}{llllll}\text { Alt. } & 26 & 22.5 & 25.5 & 23 & 22.5 \mathrm{~mm} \text {. } \\ \text { Diam. } & 16.5 & 13.5 & 14 & 12 & 13 \text { " } \\ \text { Aperture } & 15 & 12.8 & 12.6 & 11.8 & 12.8 \text { " }\end{array}$

Distribution, eastern division of the Lower Sonoran in Texas. Originally described from "Washington and DeWitt counties, Texas." Specimens from both of these are before us, and also from Hays, Comal, Guadalupe, Bexar, Medina, Frio, Uvalde and Victoria counties. Some shells from Fort Worth and Waco, in northern Texas, are also like mooreanus, while others resemble $B$. $d$. liquabilis.

$B$. d. mooreanus is smaller, thinner and smoother than the Mexican $B$. schiedeanus (Pfr.), but intergrades with B. d. liquabilis Rve. through certain specimens having ragged dark streaks, chiefly on the spire, such as fig. 5 of pl. VI. In the main, the subspecies is quite uniform 
in characters, and easily recognized. It is the only Bulimulus found in the greater part of the region it inhabits, and is one of the commonest forms in collections.

The specimens seen from Fort Worth are not unlike those referred to $B$. d. liquabilis from Waco, and it is not easy to decide upon which race they belong to. They are undifferentiated forms.

In Comal, Guadalupe, Bexar and Medina counties we found only typical mooreanus. In Frio county the shells are somewhat more solid and often whiter. In a series of 313 specimens from along the Guadalupe river above New Braunfels (pl. VI, figs. 2, 3, 4) I could find but one shell with any of the ragged stripes of $B$. d. liquabilis. In 165 taken along the river below San Antonio (pl. VI, fig. 1) there were 7 with some ragged stripes, at least on the upper whorls. A series of 55 mooreanus from Victoria had 4 striped shells (pl. VI, figs. $5,6)$. The percentage of intergrading specimens is therefore small.

B. dealbatus liquabilis (Reeve). Pl. VI, figs. 7-12.

Bulimus liquabilis Reeve, Conch. Icon., V, pl. 57, fig. 387 (Dec., 1848).

Bulimus confinis Reeve, Conch. Icon., V, pl. 86, fig. 643 (Feb., 1850).

Bulimulus schiedeanus Pfr., W. G. Binney, Terr. Moll., V, p. 391, fig. 276, but not the description.

The shell is thin, variable in shape but usually obese, the aperture half the total length or more. Translucent-corneous or brownishcorneous, more or less profusely marked with opaque whitish ragged streaks. Interior whitish or colored like the outside.

This is the form of the humid Austroriparian zone in Texas, as B.d. mooreanus is of the arid division. Specimens are before us from the following counties: Dallas, McLennan, Coryell, Bell, Travis, Lee, Hays, Jackson, Nueces. Also from Limestone Gap, Indian Territory.

Where the range of liquabilis adjoins that of mooreanus there is a belt of overlapping; but so far as we know the two do not actually occur together. At San Marcos, Hays county, for instance, B.d. liquabilis lives on the moist low alluvium along the San Mareos river, while $B$. d. mooreanus is found on the Cretaceous limestone hills above the town. It seems that the one form extends finger-like up some of the streams, while the other may occupy intervening upland or calcareous stations.

B. liquabilis and B. confinis were both described from "Texas."

$B$. d. liquabilis differs from mooreanus by the predominance of corneous-brown coloring. It is also usually more globose and less smooth. It is more globose than $B$. dealbatus, with less convex whorls, as a general rule, yet there seems to be practically complete intergradation between the races, and some Texas shells are not dis- 
tinguishable from those of Alabama, though most others could not be matched from east of the Mississippi. On the whole, the race has intimate relations to those east and west of it, yet seems in its own area to be sufficiently differentiated to be recognized.

Specimens from Jackson county (collected by J. D. Mitchell) are typical of liquabilis. They are small (pl. VI, figs. 9, 10, 11), well striped as usual, variable in the length of the spire, and generally have a strong, narrow lip-rib.

$\begin{array}{lcccccc}\text { Alt. } & 18.7 & 20.5 & 18.5 & 18 & 21 & \mathrm{~mm} . \\ \text { Diam. } & 12 & 12.5 & 11 & 10 & 12 & \text { “ } \\ \text { Aperture } & 11.5 & 11.5 & 10 & 9.5 & 11.5 & \text { " } \\ \text { Whorls } & 5 \frac{1}{2} & 5 \frac{3}{4} & 6 & 6 & 6 \frac{1}{3} & \end{array}$

Shells from Lee county (J. A. Singley), are larger, more globose, corresponding to Reeve's $B$. confinis. The corneous-brown tint largely predominates over the reduced whitish streaks. Lip-rib present in adults (pl. VI, fig. 12).

$\begin{array}{lccccc}\text { Alt. } & 19 & 22 & 25 & 17.6 \mathrm{~mm} . \\ \text { Diam. } & 14 & 14 & 15.2 & 11.5 \text { " } \\ \text { Aperture } & 12 & 13 & 14.8 & 10.3 \text { " } \\ \text { Whorls } & - & 6 & 6 \frac{1}{2} & 6 & \end{array}$

Waco specimens mostly have the spire longer, as do those from Belton, Austin and San Marcos. In the series from the latter locality (Ferriss and Pilsbry, 1903) there are about equal numbers of typical striped shells and nearly unicolored corneous-brown ones, with indistinct whitish streaks alternating with pale reddish on the spire (pl. VI, figs. 7, 8). They measure:

$\begin{array}{lllll}\text { Alt. } & 25.5 & 25.5 & 26 \text { mm. } \\ \text { Diam. } & 14 & 15 & 14.5 \text { “" } \\ \text { Aperture } & 14 & 14 & 14 \text { “ }\end{array}$

The genitalia of one of the unicolored shells are figured (fig. B). The individual supplying the preparation was that shown in fig. 7 of plate VI. Fig. 8 of the plate, a streaked shell, was found similar anatomically. Judging by these shells, the race liquabilis is quite appreciably different from mooreanus in the proportions of the genitalia.

Some specimens from Limestone Gap, Indian Territory, evidently belong to this race. 
The shells figured by Binney as B. schiedeanus (Manual of American Land Shells, p. 399, fig. 437) are apparently B.d.liquabilis. They are certainly not the true schiedeanus, of which figures may be found in the Manual of Conchology.

Bulimulus dealbatus (Say). Pl.VI, fig. 13.

Helix dealbata Say, Journ. Acad. Nat. Sci. Phila., II, p. 159, 1821.

Say gave the localities "Missouri and Alabama." His specimens in the Academy Museum are labelled Alabama. One of these three, agreeing with the dimensions given by him, is figured (pl. VI, fig. 13), as the type of the species. The Alabama form has a globose last whorl and rather large umbilicus. The aperture is a little more than half the total length of the shell, but much less than the diameter of the shell. The shell is profusely striped with ragged white stripes on a pale brownish ground. The type measures, alt. 19.4, diam. 12.2, length of aperture $10.6 \mathrm{~mm}$.

The same form occurs in Tennessee, Kentucky (Warren county), and west to Kansas (Shawnee county). Some specimens from the humid portion of Texas also seem to belong here.

B. d. ozarkensis n. subsp. Pl. VI, fig. 14, 15.

B. dealbatus Say, Pilsbry, Proc. A. N. S. Phila., 1903, p. 204 (Seligman, Mo.).

On the northern and western borders of the Ozark uplift this form has been differentiated. The whole shell, and especially the last whorl, is narrower, the aperture is smaller, ordinarily half the total length or less, and the umbilicus is narrower. The shape is about that of $B$. $d$. ragsdalei, but the last whorl is not rib-striate, though the spire is weakly so. Coloration as in dealbatus. Specimens measure:

$\begin{array}{lcccc}\text { Locality. } & \text { Seligman. } & \text { Rogers } & \text { Mam. Spring. } \\ \text { Alt. } & 26 & 21.6 & 21 & \text { mm. } \\ \text { Diam. } & 13.2 & 10.5 & 11 & \text { " } \\ \text { Aperture } & 12.8 & 10 & 10.8 \text { " } \\ \text { Whorls } & 7 & 7 & 6 \frac{1}{2} & \end{array}$

$\begin{array}{llccccc}\text { Alt. } & 22 & 21 & 20 & 20 & 17 \text { mm. } \\ \text { Diam. } & 11.3 & 11.2 & 9.7 & 10.8 & 9.4 \text { " } \\ \text { Aperture } & 11 & 10.2 & 9.5 & 10.8 & 9 & \text { " } \\ \text { Whorls } & 6 \frac{1}{2} & 6 \frac{1}{2} & 6 \frac{3}{4} & 6 \frac{1}{3} & 6\end{array}$

Distribution, northern and western outliers of the Ozark system: Mammoth Spring, Fulton county, Arkansas; Seligman, Barry county, southwestern Missouri (fig. 14); Rogers, Benton county, Arkansas (fig. 15); Limestone Gap, Choctaw Nation, Indian Territory. 
While only weakly characterized, this form seems to range over a considerable area, and apparently deserves recognition by name.

B. dealbatus ragsdalei (Pils.). Pl. VI, tigs. 16, 17.

Nautilus, III, p. 122; Man. of Conch., XI, p. 129.

The shell varies from the ovate shape of typical dealbatus to a more lengthened and slender form, and is conspicuously rib-striate, the striæ white on a tawny or white-blotched ground and weaker on the base of the shell. The lip-rib is strongly developed. Three adult specimens of the type lot measure:

$\begin{array}{lcccc}\text { Alt. } & 21.5 & 18.5 & 16.5 \mathrm{~mm} \text {. } \\ \text { Diam. } & 10.5 & 10.3 & \mathrm{~S} .3 \text { " } \\ \text { Aperture } & 10 & 9.3 & \mathrm{~S} & \text { " } \\ \text { Whorls } & 6 \frac{1}{2} & 6 \frac{1}{3} & 6 & \end{array}$

Only dead, more or less bleached shells have been taken from the top of the Red river bluff at the southern end of Warren's Bend, twenty-five miles northwest of Gainesville, Cooke county, and a mile north of St. Jo, Montague county, Texas.

Across the whole State of Texas nearly 400 miles distant, this form reappears on the Rio Grande river, in Val Verde county, in an area inhabited also by $B$. alternatus marice. We are quite unable to find any constant differences between these Southwestern shells and the Red river types, although the apparent absence of the form in the intervening territory suggests that the similar forms of the two areas are independent parallel modifications of dealbatus stocks, rather than actually connected genetically. Yet it is quite possible that the widely sundered colonies have been or still are connected through the great conchologically unknown area northwest of the oblique line across the State marking the limit of our explorations. Dead, bleached shells were found in abundance on the high land west of Devil's river, but the living ones for some time eluded us. Finally we found them hidden under the dead reversed leaves which thatch the trunks of Yuccas, and sometimes under prostrate dead Yuccas-retreats they share with the smooth race of Polygyra texasiana (pl. VI, figs. 18 to 22). The proportions vary a good deal, a series of adult shells measuring:

$\begin{array}{lccccccc}\text { Alt. } & 26.5 & 20 & 20 & 21.5 & 19 & 16.5 & 17 \mathrm{~mm} \text {. } \\ \text { Diam. } & 12.5 & 9.2 & 10.3 & 10 & 10.8 & 10 & 8 \text { " } \\ \text { Aperture } & 12.5 & 9 & 10 & 10.5 & 10.7 & 9.3 & 8 \text { " } \\ \text { Whorls } & 7 \frac{1}{3} & 7 & 6 \frac{3}{4} & 6 \frac{1}{2} & 6 & 5 \frac{1}{2} & 6 \frac{1}{2}\end{array}$


The average size of $7 S$ living shells is about $19 \times 9$ to $10 \mathrm{~mm}$. Fig. $1 S$ represents the largest shell taken, a dead one $26.5 \mathrm{~mm}$. long. There is but little variation in sculpture among shells from this place.

Along the Rio San Filipe, not far from the Rio Grande, in chapparal on the east side, we found numerous specimens differing from those of Devil's river by having the rib-striæ nearly obsolete on the last whorl except just below the suture. A large number of dead shells were found, but only very few living ones (pl. VI, figs. 23, 24). They have the dull reddish, white-streaked coloration and the shape of the Devil's river ragsdalei.

Bulimulus dealbatus pecosensis n. subsp. Pl. V1, figs. 26, 27.

B. d. schiedeanus var., Pilsbry, Man. of Conch., XI, p. 132, pl. 17, fig. 6.

The shell is conspicuously calcareous, whitish with some fleshy or sometines corneous or ochraceous streaks; upper whorls striate, the last somewhat roughened by irregular growth-wrinkles. Spire long, composed of numerous short convex whorls, the suture nearly horizontal; apex white or pale; aperture small, usually ochre-tinted in the throat, lip strengthened by a rib within.

$\begin{array}{llcccccc}\text { Alt. } & 31 & 29.7 & 26.5 & 24 & 22.8 & 21 & \mathrm{~mm} . \\ \text { Diam. } & 14.5 & 14 & 12.5 & 12 & 12.7 & 10.7 & \text { " } \\ \text { Aperture } & 15 & 14 & 12.7 & 10.3 & 11.5 & 10 & \text { " } \\ \text { Whorls } & 7 \frac{1}{4} & 7 \frac{1}{4} & 7 \frac{1}{3} & 7 \frac{1}{4} & 7 & 7 & \end{array}$

Type locality, on the mesa about $1 \frac{1}{2}$ miles southeast of the eastern end of the High Bridge of the Pecos (Southern Pacific Railroad), Val Terde county, Texas. We found one small colony of this form, in the midst of the large dark-mouthed $B$. alternatus marioe, and like that chiefly living on Agave. The extent of the colony was perhaps not more than 50 yards, but as the sun had already set, and we had just emerged from the labyrinthine side canyons of the Pecos, we had time to collect only about thirty-five specimens, each, most of them dead. Everywhere else in the region aromin the High Bridge we found only B. a. mario.

This form is clearly a stunted race of the larger and less slender B. schiedeanus of the Mexican fauna. B. schiedeanus has been considered specifically distinct from dealbatus by Binney and all the older authorities, as well as by von Martens, who gives a series of good figures in the Biologia Centrali Americana; but while the typical schiedeanus is distinct enough, there are not lacking specimens suggesting intergradation with some forms of dealbatus. If schiedeanus 
be retained as a distinet species, then the race pecosensis will be relegated to it as a variety.

Some specimens of pecosensis taken about thirty years ago by Dr. H. C. Wood, probably, as he informs me, from somewhere in the "Great Bend"' of the Rio Grande, were noticed in the Manual of Conchology, Vol. XI.

Bulimulus dealbatus pasonis Pils. Pl. VI, fig. 25.

Pilsbry, Nautilus, XVI, July 1902, p. 32.

The shell is smaller and more slender than any other form of dealbatus, the diameter about half, the aperture less than half the total length of the shell; nearly smooth, being sculptured with irregular growth-wrinkles only. The dead specimens are dull reddish-corneous with some streaks and mottling of opaque white. Whorls $5 \frac{3}{4}$ to 6 , quite, convex. Aperture small, ovate, the insertions of the lip and columella markedly approaching, without an internal lip-rib in the specimens seen. Unmbilicus comparatively large.

$\begin{array}{lrr}\text { Alt. } & 15.7 & 15.3 \mathrm{~mm} \text {. } \\ \text { Diam. } & 7.5 & 7.8 \text { “ } \\ \text { Aperture } & 6.8 & 6.7 \text { “ }\end{array}$

Franklin mountain, near El Paso, Texas. (J. H. Ferriss.)

This is the most distinct, as it is the most remote, of the races of $B$. dealbatus, and unless connecting forms come to light, it may well be given specific rank. The absence of regular striation on the spire, the converging ends of the lip and the diminutive size combine to give it individuality. As yet but few specimens have been found, and in a single place. Some individuals of the Val Verde county $B . d$. ragsdalei approach pasonis in size, but in a series of about 200 examined none approach the other characters of the present race.

Bulimulus alternatus mariæ (Albers). PI. VII.

Die Heliceen, p. 162 (1850).

Binney, Terr. Moll., V, p. 390, figs. 272, 273, pl. li $a$, upper and lower figs.; pl. li $b$, all figs.

This species is recognized by its dense, solid, calcareous texture, oblong shape and colored, usually dark brown or purplish interior, and by the great length of the penis and spermathecal duct. Its range extends in a wide belt along the Rio Grande, from the Gulf at least to the Pecos river. How much farther west we do not know.

B. mariœ was named by Albers for his daughter Mary, having been recognized as distinct on her birthday. The type, figured by Pfeiffer, is a ragged-striped shell with only a low prominence, hardly to be called 
a tooth, on the columella. Shells of this exact form and coloring at Laredo, Webb county, on the Rio Grande (pl. VII, fig. 28).

In a gcheral way, the eastern (typical) form of maric from Frio county and Laredo eastward differs from the western ( Val Verde county) form in several respects:

\section{Southeastern Form.}

Smaller, more oblong; lip more thickened; columella frequently toothed; often with ragged streaks, at least on the earlier whorls. Pl. VII, lower three lines of figures.

\section{Western Form.}

Larger, more conic; lip less thickened within; no columellar tooth; often streaked, but without ragged or mottled streaks. P1. VII, upper two lines of figures.

We do not think it advisable at present to make a subspecific separation, especially since none of the names proposed apply to the western race. The genitalia of this race are figured (fig. A).

While almost every colony of the eastern race has slight peculiarities in shape, relative abundance or absence of the several color-forms, ete., yet with large series the intergradation is seen to be so complete that we can find no ground for dividing them into several races, as Prof. Cockerell proposes. His plan (Journal de Conchyliologie, 1891, pp. 23, $24)$ is as follows:

1. With gray or brownish markings:

a. Without a columellar tooth, . . . . . alternatus Say.

b. Columellar tooth present, . . . . . . . . mariœ Alb.

2. Without color markings:

a. With no columellar tooth, . . . . . albidus Taylor.

b. A columellar tooth, . binneyanus Pfr. MS. W. G. B. $[=$ intermedius Singl., Ckll., Corpus Christi.]

The true B. alternatus (type in coll. A. N. S.) has not been found north of the Rio Grande, and in all probability does not reach our limits. The name binneyanus is preoccupied, so that were the race valid, we should use for that form the name intermedius Singley MS. Ckll., based on Corpus Christi shells. The type locality of albidus Taylor MS. Ckll. is Derby, Frio county, Texas.

Many perfectly adult Corpus Christi shells have no columellar tooth, and hence we should have to divide them between intermedius and albidus. Similarly, various specimens selected from the Derby, Frio county, series before me would be either alternatus, albidus or intermedius; while from the Hidalgo series, all four of the supposed varieties 
may be selected. The study of good series of shells taken at random and not selected shows that all lots of streaked shells are more or less mingled with white ones, and in colonies of toothed shells, fully adult and old individuals may be found without a tooth. On the other hand there seem, however, to be colonies without ragged-streaked individuals, and also communities in which no toothed shells are to be found.

Perhaps the colonies containing mottle-streaked or toothed individuals are mixed or hybrid communities. It is a case where experiments on Mendelian lines by some one on the ground might be productive of valuable results.

In illustration of the foregoing remarks, a few of the colonies represented in the collection of the Academy may be noticed in more detail. In studying these races it is absolutely essential that the snails be collected alive. The colors, particularly of the interior, are evanescent and fade quickly on exposure to the sun and weather, though they change very little if at all in the museum.

Corpus Christi, Nueces comnty (pl. VII, figs. 13, 14, 15, 16), collected by J. A. Singley. Of thick-set compact contour, strong, with a thick cream-tinted lip-rib, which is sometimes brown stained. Pinkish white, almost uniform with some very inconspicuous grayish or fleshy streaks. Not one in a lot of 43 is marked with brown streaks outside. Interior varying from pale yellow to reddish brown, the darker tint exceptional. Columella varying from strongly toothed to nearly straight. Whorls 6 , the earliest post-embryonic not distinctly striated. This form is the "binneyanus Pfr." of Binney, intermedius Singley MSS. of Cockerell.

$\begin{array}{lllllll}\text { Alt. } & 29 & 27.3 & 30 & 25 & 23 & \mathrm{~mm} . \\ \text { Diam. } & 16 & 14.5 & 15 & 14 & 12 & \text { " } \\ \text { Aperture } & 16.3 & 14 & 15.3 & 14 & 11.5 \text { " }\end{array}$

At Hidalgo, Hidalgo county (pl. VII, figs. 17, 18, 19), the shells are more slender, white, rarely streaked throughout (fig. 17), but almost all of a series of 41 are variegated on the earlier whorls (fig. 1S). Some are strongly toothed, but most shells have no columellar tooth. Interior brown.

$\begin{array}{llllll}\text { Alt. } & 30 & 29.5 & 29 & 28.5 \mathrm{~mm} . \\ \text { Diam. } & 13.5 & 13.5 & 13 & 14 \text { " } \\ \text { Aperture } & 14 & 14.5 & 13.5 & 14.5 \text { " }\end{array}$

A series from Brownsville consists of similar but less elongated shells. 
At Derby, Frio county (pl. VII, figs. 20, 21, 22, 23, 24), the shells are bluish white with bluish streaks, a few brown tinted with brown streaks. The columellar tooth is small or wanting. This form has been called albidus Taylor, Ckll.

At Laredo, Webb county (pl. VII, lower line of figs.), the shells are large and mostly long. The lot consists of pure white, and of coffeetinted, brown-streaked shells, with all intermediate forms. A columellar tooth is exceptionally developed.

At Del Rio, Val Verde county (pl. VII, figs. 9, 10, 11, 12), we found a more conic race. The shells are white, often with some very faint grayish streaks. Interior varying from ochre-yellow to dark brown. In the series of about sixty living shells before us, none has mottled markings, and while in a few there is a weak indication of the columellar tooth, it is as a rule absent. The larger ones measure 29 to 33 $\mathrm{mm}$. long, 16 wide. Some of the dead shells found in the same place are larger, $35 \times 18.5$ to $37 \times 17 \mathrm{~mm}$. A single albino was taken alive (fig. 12). These shells are from the plain along the San Filipe river, on the east side, not far from the Rio Grande. B. d. ragsdalei was found in the same place.

On the mesa west of Devil's river we found large dead shells like those from Del Rio but even larger, often with a low lump on the parietal wall, but no tooth on the columella. $39 \times 20.5$ to $35 \times 16 \mathrm{~mm}$.

At the Pecos High Bridge, on agaves, north of the railroad near the eastern end of the bridge, we found Bulimulus abundant and finely developed (pl. VII, figs. 1 to 7 ). The shape varies, but is always more conic than in the eastern localities. It is either nearly uniform white, or coffee-tinted varied with oblique brown or purplish streaks; these two color-forms in about equal numbers, found together on the same plants and connected by intermediate examples. Apex white. The interior is very dark purple-brown. The outer lip is usually but little thickened within, and the columella has no tooth, though often it is slightly salient in the middle. Whorls 7 to $7 \frac{1}{2}$.

$\begin{array}{lllllllll}\text { Alt. } & 36 & 37.5 & 33.3 & 34.5 & 36 & 33.3 & 37 & \mathrm{~mm} . \\ \text { Diam. } & 19 & 19 & 17 & 17 & 17 & 16 & 15 & \text { " } \\ \text { Aperture } & 17.8 & 17.8 & 16 & 16 & 16 & 16 & 14.3 & \text { " }\end{array}$

The last two measurements show the extremes of shape in a series of 150 living specimens (No. 84,627 A. N. S.).

Another set from east of the Pecos canyon about a mile from the Rio Grande is similar. The largest one measures, alt. 38, diam. 20.3, aperture $19 \mathrm{~mm}$. (pl. VII, fig. 8). 
OLEACINID丑.

Euglandina singleyana (W. G. Binn.).

Glandina singleyana W. G. B., Fourth Supplement Terr. Moll., V, p. 163 (1891).

Singley, Contrib. Nat. Hist. Texas, p. 302.

Sinking Spring, near San Marcos, Hays county, Texas, young specimens only; New Braunfels, Comal county, and its environs; San Antonio, Bexar county; Hondo river drift, near Hondo, Medina county, and in the canyon of the Pecos at High Bridge, Val Verde county. The last locality is the extreme southwestern point known for the species. Mr. Singley reports it also from Guadalupe, Goliad, Gonzales, Travis, Caldwell and Frio counties.

\section{PUPILLID丑.}

Pupilla muscorum (L.).

Benson, Arizona.

Pupilla blandi (Morse).

Texas: Flood débris of Guadalupe river, about four miles above New Braunfels, Comal county.

New Mexico: Pecos river drift at Pecos (Ckll.).

The occurrence of this species near New Braunfels is anomalous; that place lies far below its normal zone, and the shortness of the Guadalupe river precludes the idea that it could have drifted any great distance. Mr. Singley also found one specimen at or near the same place.

\section{Pupilla hebes (Anc.).}

Proc. A. N. S. Phila., 1900, p. 589, pl. 22, figs. 9, 10.

Huachuca mountains, Cochise county, Arizona. Two out of about a dozen specimens are sinistral. They are readily separable from the sinistral $P$. syngenes by the absence of a crest behind the outer lip.

Pupoides marginatus (Say).

In Texas we took this species at San Marcos, Hays county; New Braunfels, Comal county; Hondo river, Medina county, and near the Rio Grande at Del Rio, Devil's river four miles from mouth, and drift of Pecos river near High Bridge, Val Verde county.

Arizona: Drift of San Pedro river at Benson.

Bifidaria pellncida hordeacella (Pils.).

Texas: Drift of Sinking Spring, San Marcos, Hays county; Guadalupe river about four miles above New Braunfels, Comal county; Hondo river, two miles north of Hondo, Medina county; Rio San Filipe near Del Rio, Devil's river near its mouth, and Pecos river near 
the High Bridge, all in Val Verde county. Arizona: Benson. New Mexico: Drift of Pecos river at Pecos (Ckll.).

It varies somewhat widely in size, and is found in great quantity in drift débris along all the Texan rivers explorel.

Bifidaria pellucida parvidens (Sterki).

Drift débris of Pecos river at Pecos, New Mexico (Ckll.). This subspecies has not before been reported from so far east.

Bifidaria procera (Gld.).

Texas: Drift of Sinking Spring, San Marcos; Hondo river drift, two miles north of Hondo, Medina county.

The var. cristata Pils. and Van. was found copiously in the drift of Guadalupe river, Comal county; near Del Rio; Devil's river; and Pecos river near the High Bridge, Val Verde county. Also Benson, Arizona.

Bifidaria contracta (Say).

Texas: San Marcos; Guadalupe river drift, near New Braunfels; Hondo river, near Hondo; Rio San Filipe near Del Rio; Devil's river; Pecos river near High Bridge. Rather abundant in the river débris except on the Pecos, where but three shells were found. In 1885 Pilsbry took specimens at Galveston.

Bifidaria armifera (Say).

Texas: Drift of Guadalupe river four miles above New Braunfels, Comal county; Pecos river near High Bridge. New Mexico: Pecos, on the Pecos river, collected by T. D. A. Cockerell.

Bifidaria pentodon (Say).

Texas: Sinking Spring, San Marcos, Hays county; Hondo river, Medina county.

Vanatta has figured one of the specimens from Sall Marcos. Nautilus, XIX, pl. 6, fig. 11.

Bifidaria tappaniana (C. B. Ad.)

Pupa pentodon of authors, not of Sav.

Texas: Guadalupe river about four miles above New Braunfels, Comal county (figured by Vanatta, Nautilus, XIX, pl. 6, fig. 12); Hondo river, Medina county; Devil's river, Val Verde county.

Bifidaria perversa Sterki.

Drift débris of the San Pedro river at Benson, Arizona (Ferriss, 1904). Hitherto known from Nogales, Arizona. (E. H. Ashmun.)

Bifidaria ashmuni Sterki.

Huachuca mountains, Cochise county, Arizona (J. H. Ferriss.) Also from the following places, collected by E. H. Ashmun. Arizona: 
Near Jerome at Mescal Gulch, Walnut Gulch, Page's ranch, Kirwagen's ranch, and drift of Verde river; Navajo Springs; Santa Rita mountains; Oak Creek at Owensby's; drift of Little Colorado river at Holbrook; Nogales, both north and south of the international boundary. New Mexico: Mountain station, Oscura mountains, Socorro county; San Rafael, Valencia county; White Oaks, Lincoln county.

\section{Subgenus CH ENAXIS nov.}

The shell has a large hollow axis, open below, and about one-third the total diameter of the shell, the structure otherwise being like Bifidaria s. str.; peristome continuous and free. Type, B. tuba.

The Bolivian Infundibularia infundibuliformis (Orb.) ${ }^{9}$ resembles $B$. tuba in having a very large umbilicus, and we at first thought to associate the Arizonian species with it; but Infundibularia differs by the strictly conic shell, and in the aperture, which shows but one lamella, a very large angulo-parietal. Other lamellæ or plicæ, if they exist, must be very deeply immersed, as in the group Immersidens.

The type of d'Orbigny's species has been lost, and its internal structure is unknown. It was found with Bifidaria nodosaria (Orb.), a minute species, imperfectly described and figured, but probably not distinct from $B$. pellucida (Pfr.).

Bifidaria tuba n. sp. Fig. n.

Shell cylindric with a short apical cone, openly umbiticate, the umbilicus nearly one-third the diameter of the shell, penetrating welllike to the apex. Pale brown, smooth, with light growth-lines only. Whorls $5 \frac{1}{2}$, convex, the apex obtuse; last three whorls forming the cylindrical part of the shell. The last whorl is compressed around the umbilicus, and scarcely straightened in front. The aperture is shortoval, the peristome continuous, thin and well expanded. The angular and parietal lamellæ are combined into one long lamella, notched on the summit; where the two join, the inner end of the angular projects a little on the right side. The columellar lamella is massive, slightly bifid, deeply placed, and enters about as deeply as the parietal. There are small, short, upper and lower palatal and basal folds, in the typical positions, a short distance within the lip, usually with a minute denticle between them, and another at the base.

Length 3, diam. $1.5 \mathrm{~mm}$.

Drift débris of the San Pedro river, Benson, Cochise county, Arizona. Types No. 87,062 A. N. S. Phila.; cotypes in Ferriss collection. A

'Voyage dans l'A mérique Méridionale, Mollusques, p. 323, pl. 41 bis, fig. 7-10. 


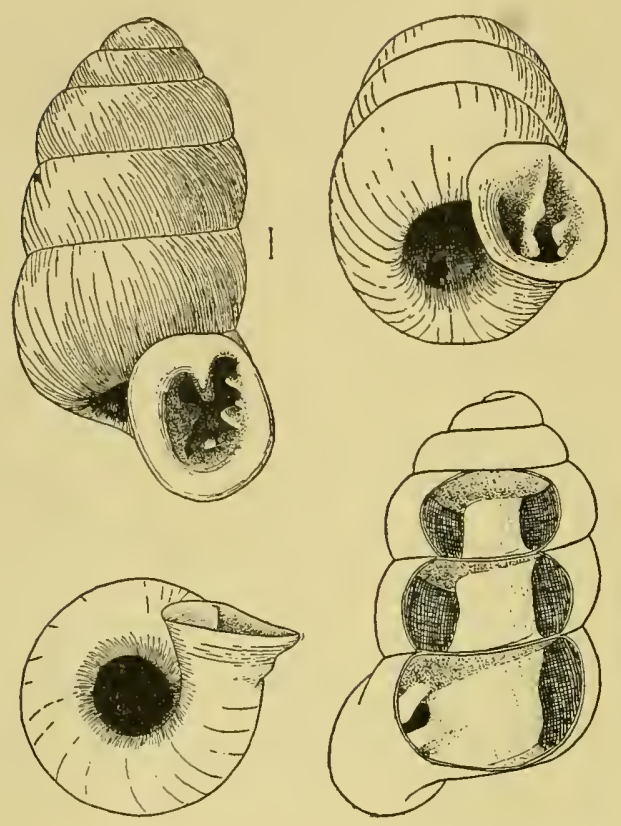

Fig. 6 .

single immature specimen was taken by Rev. E. H. Ashmun in drift of the Salt river, at Tempe, Arizona.

Remarkable for its ample umbilicus. The freshest specimens are about the color of Pupoides marginatus. None

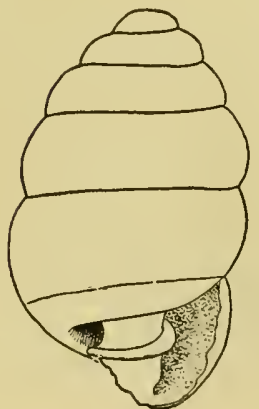

Fig. 7 were taken alive. In the adult shell opened (fig. 6) the parietal and columellar lamellæ do not enter deeply, though they go so far that the inner end cannot be seen in the mouth. One broken shell from Tempe, taken by Mr. Ashmun, and which has been in coll. A. N. S. P. for some years, lras a strong lamella on the columella, apparently at least a half-whorl long, but not penetrating much farther than fig. 7 shows. This lamella may perhaps be developed during the latter part of the neanic stage, to be resorbed in the fully adult condition. Further material is neederl to demonstrate this. It is possible that the Tempe shell represents a distinct species. It tapers slightly more than the types from Benson. 
Vertigo ovata Say.

Benson, Arizona: Drift of Devil's river, Val Verde county, Texas.

Vertigo binneyana sterki.

Benson, Arizona (Ferriss).

Vertigo oscariana Sterki.

Drift débris of the Guadalupe river, about four miles above New Braunfels, Texas, a single specimen, a little larger and stronger than Eastern (Austroriparian) examples.

Vertigo milium Gld.

San Marcos, Hays county; Guadalupe river above New Braunfels, Comal county, and on the Hondo river, Medina county, Texas, in flood débris. Only one specimen from each place, among thousands of other Pupillida, etc.

Strobilops labyrinthica texasiana n. subsp.

Shell moderately elevated with dome-shaped spire, brown, whorls $5 \frac{1}{2}$, the first $1 \frac{1}{2}$ smooth, pale-corneous, the rest regularly ribbed obliquely, the last whorl rounded peripherally or a trifle and obtusely subangular in front, the riblets passing over undiminished upon the base, which is as strongly sculptured as the upper surface (or sometimes smoothish just in front of the aperture). Aperture with expanded, thickened peristome and strong parietal callus, a single strong parietal lamella emerging to the edge of the callus, a second weak one visible within. About half a whorl inward there is a series of about six laminæ, the inner one upon the columella, the next short, strong and tongueshaped, bending outward; the third nearly twice as long, high and sinuous; the fourth very minute and low, often wanting, leaving a space; the fifth and sixth long and low; and just above the periphery on the outer wall a very weak, low, long seventh plica may usually be traced. Umbilicus rather large.

Alt. 1.5, cliam. $2.2 \mathrm{~mm}$.

Types No. 91,330 A. N. s. Phila., from drift of the Guadalupe river about four miles above New Braunfels, collected by Pilsbry and Ferriss, 1903. Other localities in Texas are Austin (Pilsbry), San Marcos (Pilsbry and Ferriss), New Braunfels (Ferriss, Pilsbry and Singley), Guadalupe river bottom, Victoria county, and Lavaca river, Jackson county (J. D. Mitchell), Lee county (Singley), Calhoun county (E. W. Hubbard), Gainesville (J. B. Quintard). A smaller form, diam. $2 \mathrm{~mm}$., was taken in drift clébris of the Hondo river about two miles north of Hondo, Medina county (Ferriss and Pilsbry). It also ranges northward into Indian Territory and to Kansas. 
This form, which for the present we subordinate to the old S. labyrinthica, is the only Strobilops except $S$. hubbardi which I have seen from Texas. It may be distinguished from $S$. virgo by the costulate base, wider umbilicus and far weaker inner parietal lamella. $S$. strebeli is a much more depressed cone.

The statement by Woodward, ${ }^{10}$ copied into American works, that $H$. labyrinthica occurs in pretertiary European strata, is misleading, since the American species is really not identical with any from European strata, though there are numerous allied forms in the European tertiaries. The genus became extinct in Europe, but survives in China, Helix diodontina Heude being a Strobilops. In America it has not been found in the Northwest or Pacific States, but extends south to Mexico, the West Indies and Venezuela, and a species apparently belonging to the genus has been described from the Galapagos.

\section{VALLONIID A世.}

Vallonia excentrica Sterki.

Galveston, under boards in a vacant lot. (Pilsbry, December, 1885.)

Vallonia perspectiva Sterki.

Texas: Drift débris of Devil's river, and of Pecos river near the High Bridge, Val Verde county. Arizona: Benson, in drift of San Pedro river.

Vallonia graoilioosta Reinh.

New Mexico: Drift of Pecos river, at Pecos (Cockerell!).

Vallonia cyolophorella Anc.

Arizona: Drift of San Pedro river, Benson, Cochise county, a single specimen.

\section{COCHLICOPID}

Shell oblong, cylindric-oblong or narrowly tapering, smooth and glossy, with imperforate axis ; a perture ovate or acuminate, the columella notcher below or continuous with the basal lip. Foot without pedal grooves. Kidney with direct ureter, of the Basommatophorous type. Genitalia with a long appendix on the penis, as in Achatinella and the Pupillido. Jaw and radula about as in Pupillido.

This group has usually been included in the Achatinidoe or Stenogyrido, but the direct ureter removes it to a group of primitive snails represented only by minute species in America, but by the beautiful Achatinellidoe and Partulidoe in Polynesia. Cocilianella (Cecilioides)

${ }^{10}$ Manual of the Mollusca, p. 286, edit. 2, 1868. 
belongs to the same family, and probably Glessula also, but the pallial organs of that Indian genus are unknown. The group is not related to the Achatinide.

Cochlicopa lubrica (Müll.).

Bear Park and Cave creek canyon, Chiricahua mountains, and Fort Bowie (Ferriss); Carr canyon, Huachuca mountains (Dr. H. Skinner); all in Cochise county, Arizona. Drift débris of Pecos river, Pecos, New Mexico (Ckll.).

\section{ZONITID再.}

Omphalina extends to the western border of the Austroriparian area in Texas. The form taken by us will be discussed in the concluding paper on Southwestern mollusks.

\section{Zonitoides minusoula (Binn.).}

Texas: San Marcos, New Braunfels, near Hondo, Del Rio, Devil's river and Pecos river. Everywhere common in drift débris. The specimens all show a tendency to be more widely umbilicate than typical Northern minuscula, a large part of them being typical Z. m. alachuana (Dall). Those from San Marcos and Comal county are of the size of Northern minuscula, but westward the shells reach a decidedly larger size, with the exception of the lot taken at Devil's river, which show but little tendency towards a wide umbilicus.

In Arizona, Ferriss took specimens of var. alachuana at Bear Park and Cave creek canyon, Chiricahua mountains, in the drift of San Pedro river at Benson, and in the Huachucas. Like other minutiæ, these shells are very rare in the Chiricahua and Huachuca mountains.

Helix mauriniana Orb., from Cuba, which has been put in the synonymy of minuscula, seems to be a Thysanophora close to or identical with $T$. saxicola (Pfr.), as Arango has already stated. $Z$. minuscula occurs also in Japan.

Zonitoides minusoula neomexioana Pils and Ckll.

This form is distinguished by the possession of minute and shallow spiral striation. It seems to be of somewhat common occurrence in New Mexico, and upon examining a set of seven specimens taken by me in Galveston in 1885 I find that they are similarly sculptured. They came from under boards in a lumber yard, and it may be that they were brought from New Mexico with lumber, though I do not know that any lumber was shipped from New Mexico twenty years ago. 
Zonitoides singleyana (Pils.).

Zonites singleyanus Pils., Proc. A. N. S. Phila., 1889, p. 84; 1888, pl. 17, fig. M. (New Braunfels).

Hyalinia lariuscula Sterki, Nautilus, VI, p. 53, Sept., 1892 (New Braunfels).

Texas: San Marcos, New Braunfels, Del Rio, Devil's river and Pecos river above the High Bridge; everywhere in river clébris.

Arizona: Drift of San Pedro river at Benson.

Zonitoides nummus Vanatta.

Proc. A. N. S. Phila., 1899, p. 524, figs. (New Braunfels).

This species seems to be confined to the Texan Lower Sonoran. We took it at San Marcos, Hays county; Guadalupe river above New Braunfels; Hondo river, Medina county; and in Val Verde county near Del Rio; along the Devil's river, and in the Pecos canyon above the High Bridge; everywhere in drift débris.

Zonitoides arborea (Say).

Texas: Galveston; Smithville, Bastrop county; Sinking Spring, near San Marcos, Hays county; near New Braunfels, Comal county.

New Mexico: Drift of Pecos river at Pecos (Cockerell).

Arizona: Cave creek canyon and Bear Park, Chiricahua mountains, Cochise county.

Vitrea indentata (Say).

Drift of Pecos river, Pecos, New Mexico (Ckill.). As usual, it is the Canadian and Carolinian form of the species which extends down the Rocky mountains into New Mexico, and not the Sonoran subspecies.

Vitrea indentata umbilicata ('Singl.,' Ckll.).

Ckll., Nautilus, XII, p. 120, Feb., 1899.

Texas: San Marcos, Hays county: around New Braunfels, Comal county; Hondo river two miles north of Hondo, Medina county; Del Rio, Devil's river and Pecos river at the High Bridge, Val Verde county; Alpine, Brewster county,

Arizona: Cave creek canyon and Bear Park, Chiricahua mountains; Fort Bowie. Also Florida mountains, Grant county, New Mexico. Large specimens of this race are probably what has been reported from Texas as sculptilis Bld.,- - a species which does not, we believe, occur in that State.

This Sonoran race differs from indentata by its distinctly perforate axis and larger average size, yet the perforation varies so much in size in specimens from the Carolinian zone that I would not myself have named the Southwestern form. The name is ill-chosen, since the shells are not "umbilicate," as that term is technically used, but" perforate." 
Vitrea hammonis (Ström).

Drift of the Pecos river at Pecos, New Mexico (Cockerell). The specimens scarely show a trace of spiral lines. The species is unknown in the Austroriparian and Lower Sonoran zones.

Vitrea dalliana roemeri n. subsp. Fig. 8 .

Shell openly umbilicate, the width of umbilicus contained about $4 \frac{3}{4}$ times in the diameter of the shell, pale whitish-corneous, in general shape resembling $V$. dalliana, $V$. wheatleyi and $V$. petrophila. Sculpture of very close and regular radial grooves, on the last whorl of large specimens becoming crowded and less regular, giving a striate appearance. The flat intervals between the grooves show no spiral striæ. The base is nearly smooth. Whorls $4 \frac{1}{2}$, but slightly convex, slowly widening, the last about double the width of the preceding. Suture scarcely impressed, translucent-margined below. Base convex. Aperture lunate, slightly oblique; the insertions of the peristome are distant.

Alt. 2, diam. $4 \mathrm{~mm}$. ; umbilicus $.85 \mathrm{~mm}$.; aperture $1.7 \times 1.65 \mathrm{~mm}$.
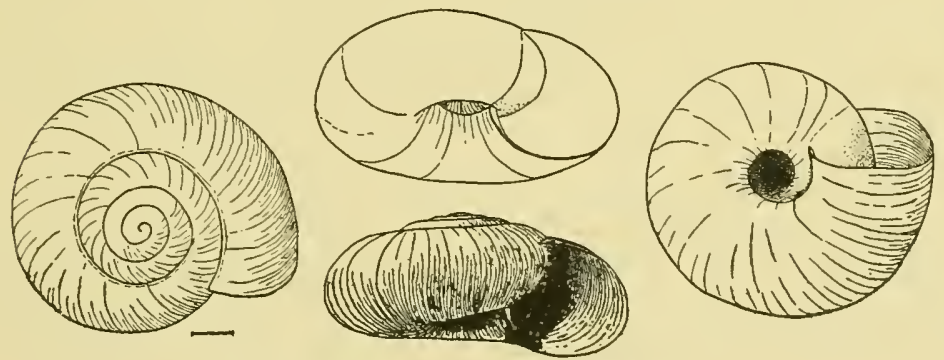

Fig. S.-Fitrea dalliana roemeri.

Sinking Spring creek, near San Marcos, Hays county, Texas. Types No. 91,318, A. N. S. Phila., collected by Pilsbry and Ferriss, 1903. Also taken in several places around New Braunfels, Comal county; in the drift débris of the Hondo river, two miles north of Hondo, Medina county; in drift of the Rio San Filipe near Del Rio, and of the Devil's river, Val Terde county. It has about the distribution of Holospira goldfussi and Helicodiscus eigenmanni.

This very pretty little species has a slightly more ample umbilicus than $V$. wheatleyi or petrophila, and the sculpture is closer and more regular than in either. The last whorl, in dorsal view, is wider than in $V$. wheatleyi. It is much smaller than $V$. hammonis.

$V$. dalliana roemeri attains a larger size than the Floridian $V$. dalliana and the shells have somewhat more regular and crowded grooves on 
the last whorl; it is less depressed, and the aperture is perceptibly less broad, more roundly lunate. The differences seem sufficient to call for subspecific separation. The Texan and Floridian areas of distribution
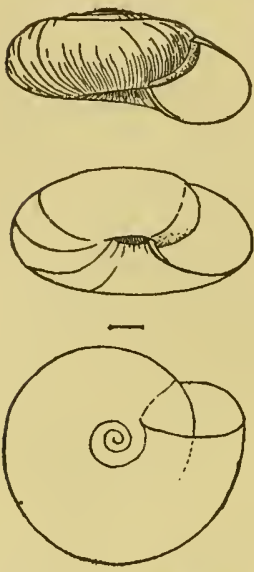

Fig. 9.-V. dalliana. seem to be separated, so far as our present data indicates. $\quad V$. dalliana should be looked for along the northern border of the Gulf. It is known now from peninsular Florida only.

Vitrea dalliana ${ }^{11}$ and roemeri are much smaller than $V$.hammonis, and seem to replace that in the Austroriparian and Lower Sonoran zones. When originally described it was compared with Zonitoides arborea (Say), but it is not really related to that but to the hammonis group. In fact $V$. hammonis, binneyana and dalliana form a group of very closely related species. In a large number of $V$.dalliana examined from several localities, the largest shell measures, alt. 1.6, diam. 3.2, width of umbilicus .75 , aperture $1.4 \mathrm{~mm}$. wide, $1.2 \mathrm{high}$. This shell, from Osprey, Manatee county, Fla., is here figured.

The figures do not represent the fine and beautiful sculpture of the surface.

Vitrea milinm meridionalis n. subsp.

Similar to $V$. milium but larger, diam. about $1.75 \mathrm{~mm}$., with nearly $3 \frac{1}{2}$ whorls, the first one finely, distinctly lirate spirally, the last whorl with oblique wrinkles much coarser than in milium, more or less anastomosing, and fine spiral striæ, the latter distinct on the base.

$V$. milium with the same number of whorls is smaller and more finely wrinkled, and in Maine and Ohio shells spirals on the first whorl are excessively weak or wanting, not deeply engraved to the tip, as in Texas shells.

Texas: San Marcos, in drift of Sinking creek, in the limestone hills; along the Guadalupe river above New Braunfels (type locality); Hondo river, Medina county ; drift of Pecos river. (Pilsbry and Ferriss.)

New Mexico: Cloudcroft, Sacramento mountains (Viereck); Santa Fé (Ashmun).

Arizona: Huachuca mountains (Ferriss); Walnut Gulch near Jerome (Ashmun).

Specimens from Baldwin and Clarke counties, Ala. (C. B. Moore),

11 Zonites dallianus Simpson, Pilsbry, Proc. A. N. S. Phila., 1889, p. 83, pl. 3, figs. 9-11. 
seem to be referable to this race. In the Northwest another form of the species, Z. milium pugetensis Dall, replaces the typical milium. Neither of the subspecies differs much from milium, but what differentiation there is seems to be correlated with geographic range.

This species was erroneously placed in Zonitoides in the Classified Catalogue of 1898 . We are now convinced that it belongs, as Morse demonstrated, to the subgenus Striatura of Vitrea.

\section{Vitrina alaskana Dall.}

V. pfeifferi Newc., Proc. Cal. Acad., II, p. 92, 1861 ; not of Deshayes, 1852.

Vitrina alaskana Dall, Land and Fresh-Water Mollusca of Alaska and Adjoining Regions, Harriman Alaska Exped., XIII, p. 37.

Arizona: Huachuca mountains (Ferriss), numerous rather small specimens, the only ones we have seen from Arizona. It seems to be a common species of the Canadian and Transition zones eastward, specimens being before us from the following places in New Mexico: Chicorico canyon near Raton (Cockerell); Las Huastus canyon, Sandia mountains, near Albuquerque (Miss Maud Ellis); near Las Vegas (Miss Mary Cooper); White Oaks and Gilmore's Ranch, Sierra Blanca (Ashmun); Fort Wingate (Dr. E. Palmer); James canyon, Clouderoft, Sacramento mountains (H. L. Viereck).

The type locality of $V$. alaskana is Carson valley, Nevada; but it has a wide range, from Alaska to the Mexican boundary and probably beyond, southward occurring only at high elevations.

Euconnlus fulvas (Müll.).

Drift of Pecos river, Pecos, New Mexico (Cockerell). Cave creek canyon, Cochise county, Arizona (Ferriss).

Enoonulus ohersinus trochulus (Reinh.).

Nautilus, XII, p. 116.

Texas: Sinking Spring, San Marcos, Hays county; New Braunfels and vicinity, Comal county; Hondo river, north of Hondo, Medina county; Rio San Filipe near Del Rio, and Devil's river, Val Verde county; everywhere in drift débris.

\section{ENDODONTID丑.}

Pyramidnla oronkhitei anthonyi Pilsbry. n. n.

Helix striatella Anthony, Boston Journ. of Nat. Hist., III, p. 278, pl. 3, fig. 2' 1840. Not Helix striatella Rang, 1831.

This shell, well known under the preoccupied name $H$. striatella Anth., has typically a rounded periphery and moderately developed oblique and sigmoid rib-striæ, 4 or 5 in the space of a $\mathrm{mm}$. on the front of the last whorl at the periphery. There are $3 \frac{1}{2}$ to $3 \frac{3}{4}$ whorls. 
Alt. 2.7, diam. $5.25 \mathrm{~mm}$. Type locality, Fairmount Park, Philadelphia, near "Strawberry Mansion," No. 68,89?, A. N. S. P., collected by E. G. Vanatta.

In my opinion the widespread Eastern race is not specifically distinct from Helix cronkhitei Newc., of northern California, etc., of which specimens from Dr. Newcomb are before me, but it evidently requires separation as a subspecies.

Arizona: Chiricahua mountains, Cochise county, at Fort Bowie, Bear Park and Cave creek canyon (Ferriss); Carr canyon, Huachuca mountains (H. Skinner).

New Mexico: Drift of Pecos river at Pecos (Ckll.).

Texas: In 1885 I dug a single specimen of this species from the bank of Comal creek, New Braunfels, where it occurred with several other land and fresh-water shells. Singley reports it from the Pleistocene of Swisher county. It is not known to occur living in Texas, or anywhere in the Austroriparian zone. Its occurrence in the Texan Pleistocene is anomalous, like the presence of Pupilla blandi at New Braunfels.

RADIODISCUS Pilsbry, n. gen.

Minute, cliscoidal, openly umbilicate Patuloid snails with the first $1 \frac{1}{2}$ whorls minutely engraved spirally, the rest of the shell densely radially costulate; aperture lunate, but slightly oblique and as high as wide. Type, R. millecostatus.

This genus is proposed for a group of tiny Pyramidula-like snails, various members of which have been found in Arizona, Mexico and South America as far south as Patagonia. In the spiral sculpture of the embryonic whorls these shells are like Helicodiscus; in shape and size they resemble Planogyra, but in that the embryonic shell is smooth. There are also some similar Polynesian forms, referred to Charopa, etc.

In the Endodontido, where small differences in the shell characterize extensive series of species, it seems desirable to recognize as of generic value such readily recognizable groups as Radiodiscus. The species are chiefly distinguished by their dimensions and the degree of fineness of the sculpture. There are several undescribed forms in the collection of the Academy.

Radiodiscus millecostatus n. sp. Fig. 10.

Shell very small, disk-shaped, chestnut-brown, the first whorl bluishwhite. Whorls $3 \frac{3}{4}$, slowly widening, separated by a very deep, channelled suture. The first whorl projects a little, and is microscopically striate spirally, the rest of the whorls are radially very densely costulate, the riblets nearly straight, delicate and much narrower than 
their intervals, and about 21 in number in a millimeter measured at the periphery, in the front of the last whorl. The last whorl is rounded throughout. The umbilicus is widely open, its width contained about three times in the diameter of the shell. The aperture is slightly oblique and deeply lunate. Alt. 1.1, diam. 2 mm.; diam. of umbilicus .6 to $.7 \mathrm{~mm}$.

Huachuca mountains, Cochise county, Arizona, (J. H. Ferriss) ; Carr canyon (Dr. Henry Skinner). Also in the State of Michoacan, Mexico, at Patzcuaro and Morelia ( . N. N. Rhoads, 1S99).

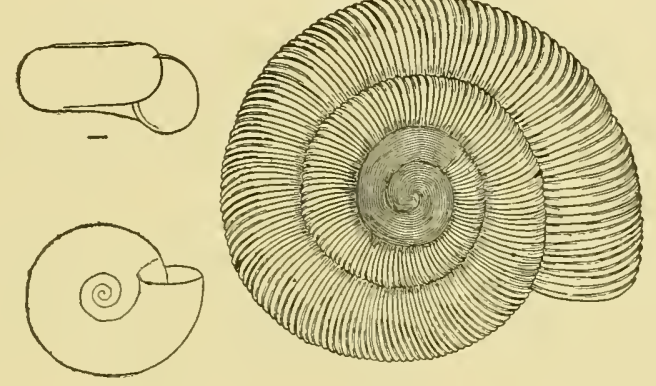

Fig. 10.

This tiny Patuloid, of a group new to our fauna, is one of the most interesting recent finds. It is related to $R$. hermanni (Helix hermanni Pfr.), of central and eastern Nexico, but that species is larger and more coarsely sculptured. The two species occur together at the Mexican localities mentioned above, but are readily separable. Dr. Henry Skimner found one broken specimen of $R$. millecostatus in Carr canyon, Huachncas.

\section{Genus HELICODISCUS Morse.}

This genus has hitherto been considered to include two species, lineatus (Say) and fimbriatus Wetherby. The accessions of Southwestern material show that several other forms must be recognized. The species are not very conspicuously differentiated, and young shells by themselves are not always readily placed; yet with adults we find no difficulty. The salient characters of the forms follow:

a.-Diam. of shell 3 to $3.5 \mathrm{~mm}$., whorls 4 to $4 \frac{1}{3}$; teeth almost always present. Eastern United States, . . . H. parallelus (Say). $a^{1}$.-Diam. of shell 4.5 to $5 \mathrm{~mm}$., whorls $4 \frac{1}{2}$ to $5 \frac{1}{2}$; often deficient in teeth.

b.-Spiral strix obsolete. Idaho. . . H. salmonensis (Hemph.). 
$b^{1}$.-Spiral striæ well developed, subequal; last whorl not deflexed at aperture.

c.-Umbilicus very wide; last whorl narrow, aperture very small. Arizona and New Mexico,

H. e. arizonensis n. subsp.

$c^{1}$.-Umbilicus smaller, more cup-shaped, last whorl wider. Texas, . . . . . . . H. eigenmanni Pils.

$b^{2}$. Spirals coarse, some of them more conspicuous, with a cuticular fringe; last whorl in fully adult shells abruptly deflexed in front. East Tennessee, North Georgia, H. fimbriatus Weth.

Helioodisous parallelus (Say). Pl. VIII, figs. 7, 8, 9, 10.

Helix lineata Say, Journ. Acad. Nat. Sci. Phila., I, p. 18 (1817); II, p. 373. Not Helix lineata Olivi, Zool. Adriatico, p. 177 (1792).

Planorbis arallellus Say, Journ. A. N. S. Phila., II, p. 164, (1821), corrected to parallellus in the Index, p. 407. (Upper Missouri.)

Helicodiscus lineatus Morse, Journ. Portland Soc., I, p. 25, figs. 61, 62, pl. 2, fig. 3; pl. 7, fig. 63 (1864). Binney, Man. Amer. Land Shells, p. 75.

This common species has been well described by Binney and others. It has ordinarily four whorls, but there may be as many as $4 \frac{1}{3}$ in exceptionally large shells. At least one pair of tubercular teeth may be seen in most specimens. Shells of maximum size measure:

Alt. 1.3, diam. $3.5 \mathrm{~mm}$. (Grand Rapids, Mich.)

Alt. 1.25, diam. $3 \mathrm{~mm}$. (Philadelphia.)

The typical form of $H$. parallelus is before me from localities in Ontario, Maine, Massachusetts, Connecticut, New York, New Jersey, Pennsylvania, Maryland, District of Columbia, Virginia, North Carolina, Ohio, Michigan, Minnesota, Indiana, Iowa, Kentucky, Tennessee, Alabama, Florida, Missouri, Kansas, Arkansas, Indian Territory.

I have not seen Texan specimens of typical lincatus, but it doubtless occurs in northern and eastern parts of the State.

In New Mexico, at Pecos, Las Vegas, Mesilla, Sandia mountains and other places, and in the Pecos river canyon near its mouth, Val Verde county, Texas, there is a form of $H$. parallelus with rather weak, sparse spirals, the intervals more distinctly striate radially than in typical parallelus. This seems to be a form of the southeastern Rocky mountains and southward to the Rio Grande, occupying territory between the ranges of $H$. eigenmanni and $H$. arizonensis, with some overlapping on the territory of the latter.

Say's first name, Helix lineata, was preoccupied, but his Planorbis parallelus applies to the same species. In the text of the Journal the first letter of the name did not print up, but the space in place of it shows that it had been there, and the $p$ is correctly supplied in the index. The type used in that volume of the Journal was old and full 
of "bad letters." All authorities agree that such obvious typographical errors should be corrected.

Helicodiscus eigenmanni Pils. Pl. VIII, figs 1, 2, 3.

Nautilus, XIV, p. 41. August, 1900 (Beaver cave, near San Marcos, Texas).

This fine species is easily recognized by its large size, the shell in all stages of growth being very much more robust than $H$. parallelus. It is sculptured with numerous spiral threads as in $H$. parallelus, and when fresh is pale yellow. Alt. 2 , diam. $5 \mathrm{~mm}$., with $5 \frac{1}{2}$ whorls.

We took specimens in the drift débris of Sinking creek at San Marcos. Hays county; on the Guadalupe river above New Braunfels, Comal county; on the Hondo river, Medina county, and in the drift of Devil's river, Val Verde county; Alpine, Brewster county. I have seen specimens also from Calhoun county (Hubbard), Lee county (Singley), and Navidad river bottom, Jackson county (J. D. Mitchell). It has not been reported from any place out of Texas, and seems to have about the same distribution as Holospira goldfussi.

Helicodisous eigenmanni arizonensis n. subsp. Pl. VIII, figs. 4, 5, 6 .

Shell larger than $H$. parallelus with $4 \frac{1}{2}$ to nearly $5 \frac{1}{2}$ whorls, the spire flat or convex, the umbilicus wider than in parallelus or eigenmanni. Surface closely and strongly lirulate spirally. Aperture oblique, lunate, very small.

Alt. 2, diam. $5 \mathrm{~mm}$., whorls $5 \frac{1}{2}$. (Fort Bowie.)

Alt. 1.5, diam. $4.6 \mathrm{~mm}$., whorls $4 \frac{1}{2}$. (Cave creek canyon.)

Arizona: Fort Bowie (type locality); Bear Park and Cave creek canyon, Chiricahua mountains; Huachuca mountains (Ferriss); Santa Rita mountains (Ashmun). New Mexico: Florida mountains, Grant county (Ferriss); Bland, Sandoval county (Ashmun); débris of Arroyo Pecos at Las Vegas (Ckll.).

Readily distinguished from $H$. parallelus when mature by the greater size, with wider umbilicus, more whorls and proportionately smaller mouth. Some specimens are two-toothed. H. eigenmanni has a smaller umbilicus, whorls of markedly greater calibre and a larger aperture.

Helicodiscus salmonensis (Hemphill).

Helicodiscus fimbriatus Wetherby (salmonacca Hemphill), W. G. Binney, Third Supplement to Terr. Moll., V, Bull. Mus. Comp. Zool., XIX, No. 4, p. 189 (May, 1890).

Helicodiscus fimbriatus var. salmonensis Hemphill, in Binney, t. c., p. 220 (May, 1890).

Helicodiscus fimbriatus Wetherby, var. salmonaceus Hemphill, Binney, Fourth Supplement, Bull. Mus.:Comp. Zool., XXII, No. 4, p. 177, pl. 3, fig. 8 .

Distinguished by the absence of spiral striæ, according to Hemphill. 
I have not seen specimens. Mr. Binney in his first note consiclers the Salmon river form identical with what Mr. Simpson reporter as $H$. fimbriatus from Inclian Territory, and gives no separate or definite description of it, though he mentions that Hemphill had given the (MSS.) name "salmonacea." The figure of one of the original specimens, given in Binney's Fourth Supplement, represents a shell with wide umbilicus and small aperture, like $H$. arizonensis, from which it differs, according to published information, by the smoother surface, arizonensis being constantly very well sculptured.

Punctum pygmæum (1)rap.).

San Marcos, Hays county; Comal county; Hondo river, Medina county; Devil's river, Val Verde county.

The form in this region is slightly larger than northeastern specimens, and is more strongly sculptured. There are barely four whorls, the first $1 \frac{1}{2}$ smooth, the next striate; the last two whorls have strice at regular intervals much larger, with about six fine strixe in each space, and the basal spirals are very distinct. This sculpture reminds one of the west coast forms, conspcctum, pasadeno and californicum, which however are decidedly larger and coarser shells of a dark brown color.

\section{SUCCINEID $¥$.}

Sucoinea lnteola Gld.

Gould, Proc. Bost. Soc. N. H., III, p. 37, June, 184S (Texas); Terr. Moll., II, p. 75, pl. 67e, fig. 1. (Florida; Texas, especially Galveston.) - Binney, Terr. Moll., V, p. 419; Man. Amer. Land Shells, p. 441.

Succinea texasiana Pfr., Monogr., II, 526; Roemer's Texas, p. 456, 1849 (Galveston).

Succinea lutescens Sowerby, Conchologia Iconica, XVIII, pl. 10, fig. $67 a, b$, 1872 (Texas).

We took specimens in Texas along the Guadalupe river above New Braunfels, Comal county; San Antonio, Bexar county; near Hondo river about two miles north of Hondo, Medina county, and in Val Verde county at Del Rio, high land west of Devil's river, and in the canyon of the Pecos near the High Briclge.

In Gould's original description the only locality given was Texas. In the Terrestrial Mollusks he states "found in Florida, and more abundantly in Texas, especially in the region of Galveston." Specimens collected at Galveston by the author in 1855 agree perfectly with Gould's figures, and that place may be taken to be the type locality. I have seen no Florida shells which I would refer with certainty to luteola, though $S$. floridana is closely related. 
Succinea concordialis Gld. Figs. 11, 12.

Gould, in Terr. Moll. U. S., II, p. S2 (Lake Concordia)._-Binney, Terr. Moll. U. S., V, p. 419; Man. Amer. Land Shells, p. 441.

Succinea forshcyi Lea, Proc. A. N. S. Phila., 1S64, p. 109; Obs. Gen. Unio XI, 134 (Rutersville, Texas).

Succinea haleana Lea, Proc. A. N. S. Phila., 1S64, p. 109 (Alexandria, La.).

Succinca halei Lea, Obs., XI, 136 (n. n. for S. haleana).

Distribution, Gulf States from Florida to the Rio Grande, on mud or herbage near the water's edge. Common from Louisiana westward, probably rare and local eastward.

The type locality, Lake Concordia, is not in Texas, as Gould and Binney supposed, but in Louisiana. The lake is an abandoned oxbow of the Mississippi river, opposite Naches, Mississippi. Some of Lea's original lot of $S$. halei (halcana) before me show that to be merely the young of concordialis. S. forsheyi Lea, of which two cotypes are in the Philadelphia collection, is surely identical with concordialis.

An adequate knowledge of the distribution of $S$. concordialis eastward awaits further exploration of the Gulf coastal peneplain, which in Mississippi, Alabama, Georgia and Florida has been very imperfectly examined for land mollusks. I have not seen $S$. wilsoni Lea, described from Darien, Ga., the figure of which looks a good deal like concordialis, though it seems to be less swollen basally. Specimens collected by Mr. A. A. Hinkley at Cypress creek, Ala., in 1895 are evidently concordialis; and a set of very pale shells, corneous instead of amber-colored, before me from Mayport, Florida, collected by M. A. Mitchell about twenty years ago, seems to agree with concordialis in everything but color. Northward it extends to Frierson (L. S. Frierson) and Bayou Pierre (George Williamson), in northwestern Louisiana, the specimens from these places being rather small. The species must also extend in a long lobe up the Mississippi and its tributaries, for typical specimens have lately been sent by Mr. A. A. Hinkley from Dubois, Illinois, and by Mr. T. Van Hyning from Des Moines, Iowa. Mrr. Van Hyning notes that "the animal is black with small yellow clots." These Northern shells may be distinguished from S.retusa by their pot-bellied figure and reddish apex.

In Texas, specimens were taken by us in April at San Nareos, Hays county; New Braunfels, Comal county; San Antonio, Bexar county; along the Rio Grande near and San Filipe river, at Del Rio, and along the Devil's river, Val Verde county. We have seen it also from Lee county (Singley) and spring creek, Victoria county (J. D. Mitchell).

It lives on the moist earth immediately adjacent to the water's edge, and where found is usually abundant. It is a thin shell, rather 
deeply amber-colored, with the apical whorls darker, reddish-orange. Whorls $3 \frac{1}{2}$, the last deeply descending, somewhat flattened above, very convex basally, having thus a more sack-like contour than $S$. retusa; this being its chief peculiarity. The sculpture consists of rather coarse wrinkles and often some indistinct spiral impressions on the last whorl. The aperture is symmetrically ovate, the columella concave throughout, with a delicate fold above. Large specimens from San Marcos measure:

Length 16.8, diam. 9, length of aperture 11.5 , width $6.7 \mathrm{~mm}$.

Length 16 , diam. 8, length of aperture 10.5 , width $6 \mathrm{~mm}$.

The mantle is intensely black, dappled throughout in the last whorl with rounded yellowish spots. Those above the kidney are brighter, more conspicuous and usually larger, of ten more or less confluent.

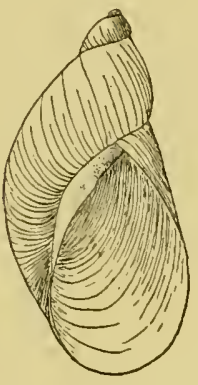

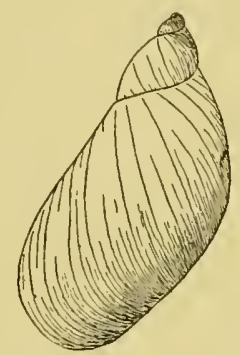

Fig. 11.

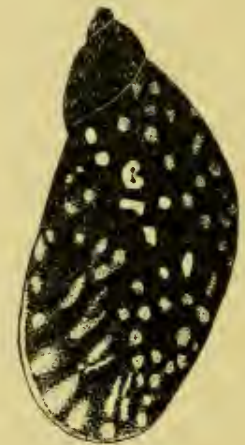

Fig. 12 .

Towards the edge of the mantle the spots are large and lengthened. The foot including head and eye-stalks is pale grayish-white, speckled with irregular grayish-black spots. The sole is pale yellow. Figs. 11 and 12 were drawn from specimens taken at San Marcos, Texas, near the river.

Specimens from the Rio Grande and Devil's river are of almost as large size; but in some situations it is much smaller, a set from along the San Filipe river at Del Rio measuring, length 12, diam. 6.7, length of aperture $8 \mathrm{~mm}$. Those taken at San Antonio and New Braunfels are also of small size. Such variation in size is apparently not racial, but dependent upon local conditions of the food supply, etc. The color and markings of the mantle are substantially the same in all colonies we found, though there is individual variation in the size of the light spots, figure 12 representing one of the darker individuals. 
Succinea grosvenori Lea.

Proc. A. N. S. Phila, 1S6t, p. 109 (Santa Rita Valley, Kansas?, and Alexandria, Louisiana); Obs. Gen. Inio, etc., XI, p. 135, pl. 24, fig. 10s.

S. mooresiana Lea, Proc. A. N. S. Phila., 1864, p. 109 (Court House Rock, Platte river, on the California route): Obs., XI, p. 136, pl. 24, fig. 109.

S. lineata W. G. Binner, Proc. A. N. S. Phila., 1857, p. 19 ; Man. Amer. Land Shells, p. 174.

This species is characterized by its very full, rounded whorls and irregular sculpture, often with traces of spiral lines, though as frequently without them. Having part of the original specimens of the above synonyms before us, we are convinced that the three supposed species cannot be separated, although one would hardly expect the same form to range from the lower Mississippi to and throughout the arid great plains and the mountain region of Colorado and New Mexico.

Succinca greerii Tryon, described from Vicksburg. Mississippi, is a little less swollen, with the suture not quite so deep, but it is doubtful whether the slight differences shown by the lot of eight specimens will prove constant.

The species belongs to the campestris group.

We took a few specimens of S.grosvenori at San Antonio, Texas, with $S$. concordialis and a large form of $S$. arara.

Succinea avara Say.

Texas: San Mareos, Hays county; Comal county; San Antonio, Bexar county; Deril's river, Val Verde county. Arizona: Benson, Cochise county.

\section{AURICULID丑.}

Caryohium exile 1I. C. Lea.

San Marcos, Hays county; New Braunfels, Comal county; Hondo river, Medina county, and Devil's river, Val Verde county, Texas. Common in clrift débris.

Carychium exiguum (Say).

Drift of Hondo river, Medina county; of Devil's river, Val Verde. county, and of Guadalupe river, Comal county, Texas.

\section{LYMNAID丑.}

Lymnæa columella Say.

New Braunfels, Comal county, Texas. A single slender specimen. Lymnæa desidiosa say.

Texas: San Marcos, Hays county; New Braunfels, Comal county; San Antonio, Bexar county; Rio san Filipe, Val Verde county.

Lymnæa humilis Say.

Guadalupe river, Comal county, Texas. 
Lymnæa bulimoides cockerelli n. subsp. Figs. 13-17.

shell subglobose, pale yellowish-corneous, composed of $4 \frac{1}{2}$ convex whorls which are finely striate but without spiral lines or malleation. spire very short, last whorl and aperture very large. Aperture shortovate, its length three-fifths to two-thirds that of the shell. Columella broadly expanded, not folded. Imbilicus large.

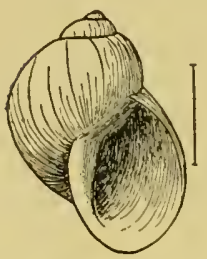

Fig. 13.

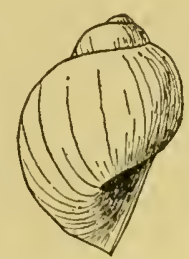

Fig. 14.

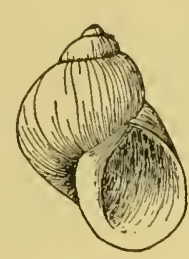

Fig. 15.

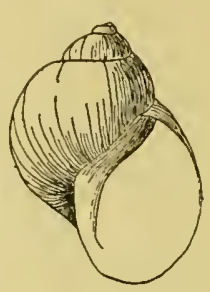

Fig. 16.

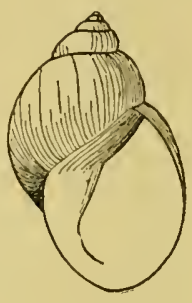

Fig. 17.

Las Vegas, N. M. Arroyo Pecos. Ogalalla, Neb.

$\begin{array}{lcllllllll}\text { Alt. } & 10 & 8.3 & \mathrm{~S} & \mathrm{~S} .7 & \mathrm{~S} .5 & 12 & \mathrm{~S} & 9 & \mathrm{~mm} . \\ \text { Diam. } & 7.2 & 6 & 6.2 & 6 & 6 & 7.8 & 6 & 6.6 & \text { “ } \\ \text { Aperture } & 6.7 & 5.3 & 6 & 5.7 & 5 & 7.5 & 5.8 & 6.1 & \text { “ }\end{array}$

New Mexico: Las Vegas (type locality, Miss Mary Cooper), and in the charcoal zone of the Pleistocene of Arroyo Pecos (T. D. A. Cockerell); near Farmington (George H. Pepper); Acama (Dr. E. Palmer). Colorado: Pool southeast of Denver (J. D. Putnam). Nebraska: Ogalalla (C. T. simpson). Dakota: Lake Hermann (P. C. Truman).

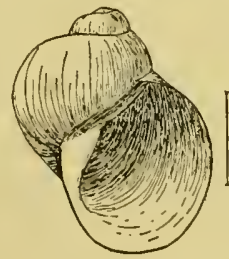

Fig. 18.

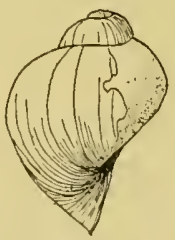

Fig. 19 .

This form differs from $L$. bulimoides and $L$. techella by its more globose shape and shorter spire, and so far as we have seen is readily separable from both. Figs. 13-15 represent the types from Las Vegas; 16, 17 are larger shells from Farmington, sent by Mr. George H. Clapp.

L. bulimoides sonomaensis Hemphill, from sonoma county, California, approaches cockerelli, but differs by the more rapidly expanding last 
whorl, narrower flat columella and narrower umbilicus, which is like that of typical bulimoides. A specimen measures, alt. 10, diam. 7.7, aperture $7.2 \mathrm{~mm}$. (figs. 18, 19).

Lymnæa bulimoides techella (Hald.). Figs. 20-23.

Limnoea techella Hald., Amer. Journ. of Conch., III, p. 194, pl. 6, fig. 4. (Texas.)

Shell obese, with acutely conic spire, of five or six convex whorls; pale yellowish or light brown, finely striate and usually malleated, the flattened facets obliquely lescending. Last whorl very ventricose, umbilicus large. Aperture short-ovate, about three-fifths the total length; basal lip expanded, columellar lip broadly dilated, without a fold. Umbilicus large.

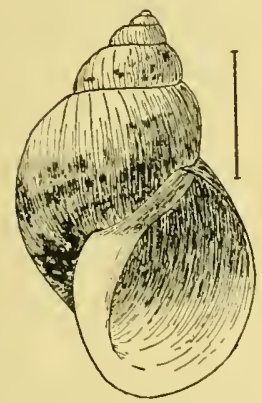

Fig. 20.

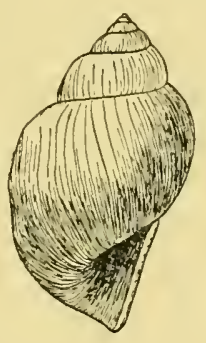

Fig. 21.

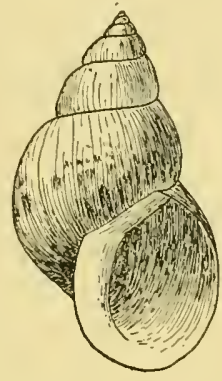

Fig. 22.

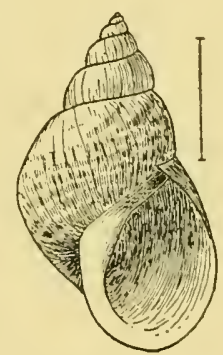

Fig. 23.

Cotype.

Length 8

Diam. 5.1

Aperture 4.9 San Marcos, Texas.

Tempe, Ariz.

In the area under consideration we have seen specimens from the following places:

Texas: Fort Worth (Sampson); Royse, Rockwall county (Ragsdale); Dallas (E. Hall); Houston (Pilsbry); San Marcos, Hays county (Pilsbry and Ferriss); mouth of Nueces river (Singley).

New Mexico: Albuquerque, and McCarty, Valencia county (Ashmun); Rio Grande at Mesilla (Cockerell).

Arizona: Salt river at Tempe (Ashmun).

Other records could probably be supplied from the literature, but it seems usually to have been referred to as L. bulimoides. Figs. 20-22 represent specimens from San Marcos, Hays county, Texas; fig. 23 is a more malleate shell from salt river, Tempe, Arizona. 
The young of one season have a comparatively shorter spire than old shells, the rate of descent of the suture progressively increasing somewhat. As usual, there are only traces of malleation at this stage. The erosion of the apices in all but one of the type lot (as mentioned by Haldeman) makes them shorter than they would otherwise be, giving much the appearance of $L . b$. cockerelli. Abundant series from Houston and San Marcos collected by Pilsbry, with others from various naturalists, demonstrate the identity of Haldeman's shells with the larger-spired adult form figured above. L. techella was formerly considered by one of us to be a synonym or race of $L$. cubensis Pfr., and $L$. bulimoides was treated as a variety of the same species. They are certainly very similar, but cubensis has a more triangular and less broadly developed columellar expansion; and in view of the way Lymnoa is being split up into species and races, it may be best to retain the several forms as distinct species or races until the subject can be taken up with ample material and time for the study of Antillean and Mexican forms together with our own.

\section{Planorbis trivolvis Say.}

Specimens referable to typical P.trivolvis were taken in Comal county, and at Del Rio, Devil's river and the Pecos river, Val Verde county, Texas.

\section{Planorbis bicarinatus Say.}

Guadalupe river, Comal county, Texas; abundant and typical.

Planorbis carus n. sp. Pl. IX, figs. 4, 5 .

Shell discoidal, biconcave, the spiral on the left side slightly more sunken and narrower than on the right. Trhorls $3 \frac{1}{2}$, convex, the last round peripherally and on both sides, curving more abruptly into the concavity on the left side. Sculpture of close, very regular obliquely radial rounded strice separated by slightly narrower deep grooves. Pale brown in color. Aperture but slightly oblique, heart-shaped, peristome thin, acute, a trifle dilated at its insertions. Diam. 3.3, alt. (thickness) $1 \mathrm{~mm}$.

"Sinking Spring" near San Marcos, Hays county, Texas; Guadalupe river about four miles above New Braunfels, Comal county. Rio San Filipe and Devil's river, and canyon of the Pecos river about a mile above the High Bridge, Val Verde county; everywhere in drift débris. Types from the last locality.

This little Planorbis is very distinct by its beautiful sculpture, constant in numerous specimens from five rivers in central and western Texas. It is much more abundant in the Rio Grande drainage than 
in Hays and Comal counties. It is about the size of $P$. parrus, but the aperture is less oblique and the sculpture differs. It was found with parvus in Comal county and in the Pecos canyon.

Planorbis filocinctus n. sp. PI. IX, figs. I, 2, 3.

Shell very small, biconcave, the spiral narrower and more deeply sunken on the left than on the right side. Whorls about $2 \frac{3}{4}$, the last broadly rounded peripherally, rounded also on both sides, but less convex on the right than on the left side. Sculpture of inconspicuous growth-lines and numerous thread-like spiral striœ. Color of bleached specimens white or faintly yellowish. Aperture oblique, heart-shaped, about as long as wide, excised moderately by the preceding whorl.

Greatest diam. of the disk 2.4, alt. (thickness) nearly $1 \mathrm{~mm}$.

San Pedro river, Benson, Arizona, in drift clébris. Types collected by J. H. Ferriss, 1904.

This little species may be at once recognized by its spiral striation, which is far stronger than in any other North American species. It is flattened less than $P$. parvus. Only five specimens were taken, but it is so unlike other known Mexican or United States Planorbes that there seems no doubt of its specific distinctness.

Planorbis parvus Say.

Guadalupe river about four miles above New Braunfels, Comal county; Devil's river, Val Verde county, Texas. San Pedro river, Benson, Arizona.

\section{Planorbis cultratus Orb.}

Pilsbry, Nautilus, III, p. 63, pl. 1, figs. 1, 2, 3.

This species is thin and delicate, very acutely carinate at the periphery which is close to the left side. In 1889 one of us reported it from Hidalgo, Texas, where it was taken by Mr. Singley. In 1903 we took a single young shell in the drift débris of Devil's river, Val Verde county. The young have a much less acute keel, in fact are angular rather than carinate, and they are less compressed in proportion. P. cultratus is found also in Florida (collected at Miami by S. N. Rhoads), Central America and the West Indies. Few of the specimens thus far known from Texas are fully mature or in good condition.

\section{Planorbis liebmanni Dkr.}

Canal at New Orleans, Louisiana (H. Hemphill!). In Texas at Waco (Hemphill), Austin (E. Hall), San Mareos, New Braunfels, Hondo river, Del Rio, Devil's river and Pecos river (Ferriss and Pilsbry); also in the southeastern part of the state in Victoria county (J. D. Mitchell) and near Brownsville, Cameron county (Clapp). Also in Mexico. 
Well-grown specimens have a diameter of 9 to $10 \mathrm{~mm}$., with about 5 whorls.

Segmentina obstructa (Morel.).

Except for the teeth, this species is not distinguishable from Planorbis licbmanni Dkr. It does not, however, attain quite so large a size, the largest we have seen measuring slightly less than $9 \mathrm{~mm}$. diameter. The teeth are found in very young shells also; but never more than one set is present at any stage of growth, so far as seen. Specimens are before us from the following places, all in Texas:

Austin (E. Hall); San Marcos, Hays county; New Braunfels, Comal. county; Hondo river north of Hondo, Medina county (Pilsbry and Ferriss); Brownsville, Cameron county (sent by G. H. Clapp); Hidalgo, Hidalgo county (Singley); Rio San Filipe, Devil's river and Pecos river, Val Vercle county (Ferriss and Pilsbry).

It has also a wide range in Mexico.

The genus Segmentina was based upon the European species $S$. nitida Müll. This is a very glossy, flattened shell with acutely angular periphery, simple thin lip, deeply embracing whorls, and barriers composed of three lamine (parietal, basal and upper) transverse to the whorl, leaving a narrow, three-branched space between them.

In eastern Asia a modification of this type is found in such species as S. largillierti (Phil.), forming the subgenus Polypylis Pils. The shell is less compressed and not carinate. but glossy with deeply clasping whorls. The parietal lamina is obliquely transverse, the others transverse, basal long, a shorter one in the outer wall, and one or two in the upper margin. There are several or many barriers.

The American forms, subgenus Planorbula Hald., have less smooth and much less compressed shells, the whorls only slightly clasping, of ten angular or subangular on the right side but rounded peripherally. There are six laminæ: a sigmoid, obliquely entering parietal with a small tubercular clenticle near its lower or left end; a transverse basal ; an obliquely entering outer lamina with a transverse one above it, and a small entering lamina in the upper margin.

In S. armigera the entering lamella in the outer margin curves upward slightly at its imer end. In S. wheatleyi all of the laminæ are much more strongly developed, and the entering outer one is much longer, running up in a long curve behind the transverse lamina above it. The structures are, however, fundamentally identical in the two species.

In the Antillean and Mexican group to which S. obstructa belongs 
the whorls are rounded, the paretal laminæ are as in Planorbula except that the larger one stards more obliquely, the basal lamina i transverse, but all the rest on the outer wall are entering plic $\infty$, the larger lower one curving downuard a little at its imner end, not upwart as in armigera and wheatleyi. As in all American forms of the genus only one set of lamina seems to be present in any individual, though the earliest set is formed at a rery early age. In the European and Asiatic species several sets are usually present.

\section{PLEUROCERATID 2 E.}

Goniobasis comalensis I'ilsbry. Figs. 24-23.

Mclaniu mufa Lea?, Römer, Texas, p. 457 ("In den Quellen des ComalSpring bei New Braunfels sehr häufig"').

Melanin pleuristriata Say, A. G. Weatherby [Wetherhy] Ameriean Naturalist, April, 1S78, p. 254, with rar. marmocki (springs if southwestern Texas).

Goniobasis comalensis Pils., Nautilus, IV, p. 49, Sept., 1890 (Comal creek, New Braunfels).

$G$. pleuristriata Say and $G$. comalensis Pils, Singic g, Contrib. Nat. Hist. Texas, Geol. Surv. Tex. Ann. Rep., 1892, pp. 311, 312.

Shell conic-turrite, thin but strong, covered with an olive-brown cuticle. Whorls of the spire with a distinct keel which projects a short distance above the suture, and is usually wanting on the last two

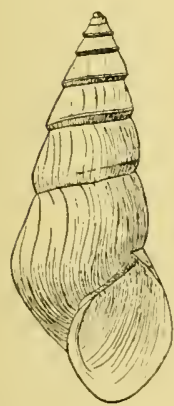

Fig. 24 .

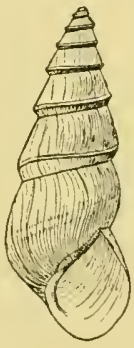

Fig. 25.

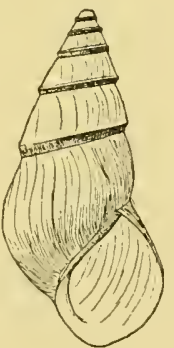

Fig. 26.

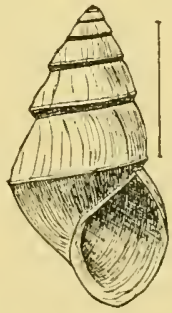

Fig. 27.

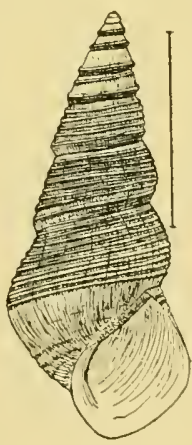

Fig. 28.

whorls; the whole surface showing fine sigmoid growth-strix, and in the best specimens very faint, minute, spiral striæ. Aperture orate, the outer lip thin, sigmoid, retracted below the upper insertion; basal lip rounded or subangular. Columella arcuate, somewhat thickenerl. Whorts about 7 in the most perfect shells, but usually fewer, the upper ones being croded.

I.ength 18 , diam. 7.3 , aperture $7.3 \mathrm{~mm}$.

Comal creek at New Bramfels, Comal county, Texas. Also in the 
Guadalupe river 6 to 4 miles to the north; San Marcos river at San Mareos, Hays county, on the dam above the fish hatchery (Pilsbry and Ferriss; singley); a variety from Bexar county (A. G. Wetherby).

This form differs from Melania pluristriata Say (M. rubida Lea) of central Nexico, by its far smaller size and less ample aperture. The type of pluristriata measured $1.25 \times .55$ inches; of mbida $1.30 \times .57$ inches; and the specimens from Lake Chapala examined by Dr. von Martens from $26 \times 12$ to $35 \times 13$ mm., while no Texan shell we have seen, in many hundreds examined, reaches 1 inch long. Von Martens refers the Mexican species to Pachycheilus. Dr. William H. Dall, to whom we submitted specimens of $G$. comalensis for comparison with the type of M. rubida Lea, writes that "though the general form is the same, the rubide is very much larger and perfectly distinct." The examples figured are from Comal creek, New Braunfels, near the mill.

The ascertained distribution of $G$. comalensis comprises only the short rivers of a single small system emptying into Espirito santo Bay, intercalated between the Colorado and Nueces basins, and comprising the Guadalupe and San Antonio rivers and their tributaries.

The Cioniobases are known from these streams only at the edge of the "Edwards Platean." As they live on rocks, ete., in swift water, it is not likely that they approach much nearer to the Gulf. In the

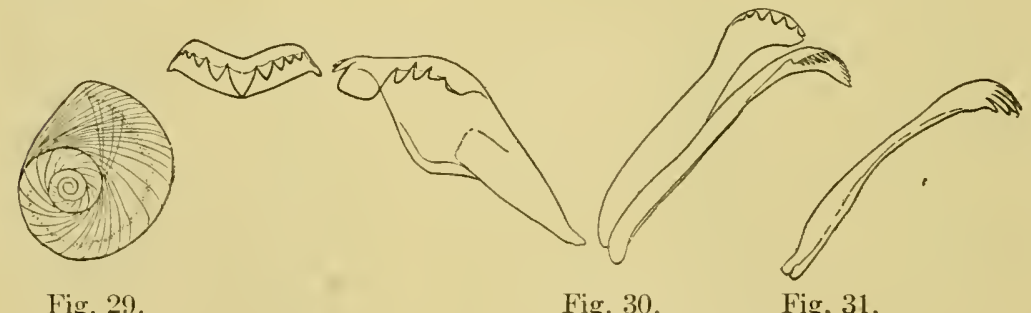

Fig. 29.

Fig. 30 .

Fig. 31 .

Colorado river, where I'ilsbry collected in 1855, nothing was seen of the species, nor has it been reported from the Nueces or its branches. WV saw no sign of Goniobasis in the tributaries of the Rio Grancle, where our collecting was extensive enough to have found it if it existed..$^{12}$

The operculum (fig. 29) consists of about four whorls, the nucleus being situated at about the lower third of its length. It is closely

$\left\lceil{ }^{12}\right.$ In the collection of the Academy there are several specimens labelled "Dallas county," received from Mr. J. A. Singley. This is in the Trinity river drainage, but singley in his eatalogue of 1893 , issued long after these specimens were placed in the collection, expressly states that he found the speeies nowhere but in Comal and Hays counties. There was probably some error in labelling the specimens. 
marked with growth-wrinkles, and shows some striæ at right angles to them.

The radula (fig. 30) is normal for Goniobasis. The central tooth has $4,1,4$ denticles, the inner lateral 2, 1, 4, inner uncinus 7 , outer about 20 denticles. An inner uncinus in profile is drawn on the extreme right side (fig. 31), to show the length of the denticles, which are foreshortened in fig. 30.

$G$. comalensis is dimorphic, like $G$. virginica and many other species. At New Braunfels the smooth form described as typical predominates, but there are also some individuals with numerous acute spiral ridges, about fifteen on the last whorl, but often fewer by suppression of those just below the periphery.

At San Marcos only the smooth phase was found, in several hundred specimens taken.

A series of 12 labelled "Bexar county," received from A. G. Wetherby, consists wholly of multistriate shells, which moreover, although collected alive, are of a whitish or livid whitish tint, in this respect approaching the Mexican pluristriatus. The largest of this lot is $23.5 \mathrm{~mm}$. long, 9.3 wide. exceeding in size any seen from Comal or Hays counties. These are part of the lot collected by Mr. G. W. Marmock, of Bexar county, and commented on by Wetherby in the American Naturalist for 1S7S. 'The "variety marmocki"' mentioned by him, but without a word of definition, may have been the smooth form of the species, but there is nothing to indicate this either in Wetherby's note or the set of shells he sent to Tryon. ${ }^{13}$ is Whi- Atuiato! Form fontinalis, nov. Figs. 22-35.

In a small spring in the pleasure garden near New Braunfels, one of the fountains of Comal creek, we found only very small shells, the largest 7 to $8.3 \mathrm{~mm}$. long, 4.3 to $4.7 \mathrm{~mm}$. wide, and of a markedly short, conic shape. The old ones are much eroded, and none are of the multistriate phase. This race inhabits only the springs and the rapid streams from them for a short distance down.

In another, much larger spring, and the stream from it for about fifty yards down, the shells are also dwarfs, though somewhat larger than those from the smaller spring.

These springs flow out of the limestone rock, the water being beantifully clear. It is not cold, being perceptibly warmer than the river at the time of our visit, about the middle of April. There is very little vegetation upon the rocks, and the small size of the snails may be due

${ }^{13} \mathrm{Mr}$. Wetherby also mentions that "Helix photus Pfr."' was collected by Mr. Marmock. This name may be an error for $I I$. tholus $\mathrm{IT}$. G. B. 


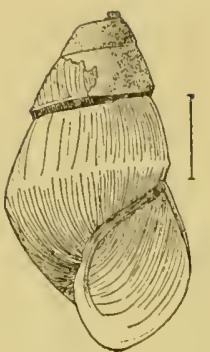

Fig. 32.

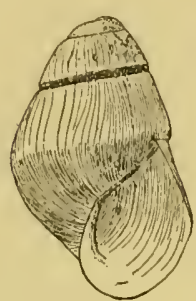

Fig 33 .

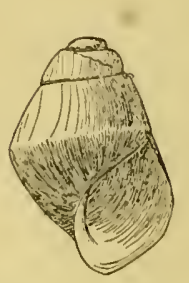

Fig. 34 .

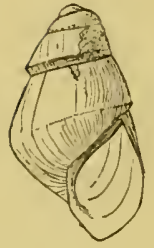

Fig. 3 .

to insufficient food supply. Indiviciuals are, however, very numerous. Associated with them are numerous Physas, also of pygmy proportions, though evidently adult. The snails of these springs evidently constitute physiologic rather than morphologic varieties.

\section{AMNICOLID平}

Paludestrina seemanni ( $\mathrm{F} A \mathrm{l}$.).

New Mexico: South Spring creek, near Roswell, in a Pleistocene deposit (Cockerell and Tinsley, 1899).

Texas: Drift débris of Pecos river, about a mile above the High Bridge, Val Verde county (Pilsbry and Ferriss, 1903).

Dr. R. E. C. Stearus has recorcled this species from Death ralley, Inyo county, California. The specimens, some of which are before me, are somewhat more robust than those from New Mexico and Texas. The above records largely increase the eastward range of the species.

Paludestrina diaboli n. sp. Fig. 3 fi.

Shell rery slender, turrite, shaped about like $P$. secmanni; composed of $4 \frac{1}{2}$ very convex whorls separated by a deep suture.

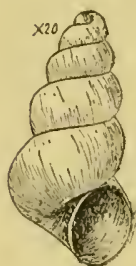

Fig. 36 . Surface smooth. Aperture vertical, oval, a trifle narrower above than below, but not angular there. Peristome continuous, barely in contact with the preceding whorl for a short distance near the upper end. Umbilicus small but distinct.

Length 1.3 , cliam. $.62 \mathrm{~mm}$.

Drift débris of the Devil's river, about four miles from its mouth, Val Verde county, Texas. A single shell was also found on the Rio San Filipe near Del Rio, in the same county.

The shells were all taken dead and bleached. It is readily separable from $P$. seemanni by its diminutive size. This is the smallest species of its family known from North America. 
Amnicola comalensis 11. sp. Fig. 37 .

Shell distinctly perforate, ovate, thin, corneous, faintly marked with growth-lines. Spire regularly conic, the apex obtuse. Whorls $4 \frac{1}{2}$, regularly convex, not shouldered, the suture well impressed. Aperture ovate, subangular above, the peristome adnate for a short distance above the perforation.

Length 3.9, diam. 2, length of aperture 1.3 $\mathrm{mm}$.

Comal creek, near New Braunfels, Comal county, Texas. Also from the Guadalupe river about four miles above New Braunfels.

This species is much smaller than A.limosa, decisa, or other forms resembling it in color

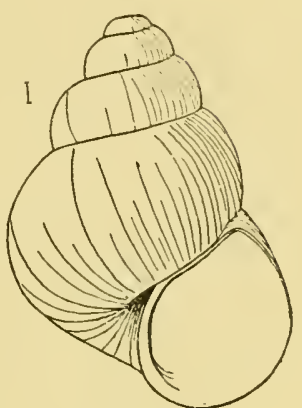

Fig. 37 . and shape. A. cincinnatiensis Anth. and the very closely related $A$. peracuta $\dot{\mathrm{P}}$. and $\mathrm{W}$. both have more shouldered whorls, and are much larger than $A$. comalensis.

Cochliopa riograndensis 11 . sp. Pl. IX, figs. 10, 11, 12, 13.

Shell of the usual depressed-turbinate shape, openly umbilicate, of a slightly olivaceous corneous tint. Surface faintly marked with growth-lines, and sculptured with unequal spiral threads, a few of the larger ones dark colored. One thread at the shoulder is usually the most prominent. In some shells the spirals are very weak, hardly perceptible. Whorls $3 \frac{1}{2}$, moderately convex, flattenerl and sloping below the suture, elsewhere rounded. Aperture quite oblique, rotundly ovate, the peristome thin, equably arched except near the outer and columellar insertions where it is noticeably straightened. The ends are connected across the parietal wall by a thin or thick callus. The columella is not noticeably thickened.

Alt. 2, diam. $2.8 \mathrm{~mm}$.

Alt. 1.65 , diam. $2.65 \mathrm{~mm}$.

Found in drift débris of Rio San Filipe near the Rio Grande, Val Verde county, Texas, thirty-six specimens. Pilsbry and Ferriss, 1903. Types, 91,324 , A. N. S. Phila. A single shell was also picked out of similar débris on the Devil's river, about four miles from the Rio Grande, in the same county.

This discovery of this form adds a new genus to the fama of the United States and greatly extends the distribution of the group, the 
other species being Central American. ${ }^{14}$ The shell has much the appearance of Valvatu, but is readily distinguished from that by its ovate, not circular aperture, which is more or less conspicuously angular above, and by having the whorls more compactly coiled. It should, however, be said that we could not verify the generic reference of $C$. riograndensis by examination of the operculum or radula, as unfortunately none of the shells we obtained were living, though some were fresh in appearance, and the operculum was not found. It consists of few whorls in Cochliopa, as in Amnicola, while that of Valrata is many-whorled with central nucleus.

C. riograndensis is not closely related to any of the known species, being of lighter texture, much more openly umbilicate, and with somewhat different sculpture.

\section{VALVATID无.}

Valvata micra n. sp. Pl. IX, figs. 7, 8, 9.

Shell excessively small, composed of $2 \frac{1}{2}$ tubular whorls; spire nearly flat; the last whorl is nearly round, barely or not quite in contact with the preceding at the aperture, near which it enlarges more rapidly. Suture deep. Surface finely, weakly striate. Aperture moderately oblique, subcircular, the peristome simple, continuous. Umbilicus ample but rapiclly narrowing within.

Alt. .4S, diam. 1.15 to $1.2 \mathrm{~mm}$.

Drift débris of Guadalupe river about four miles above New Braunfels, collected by Pilsbry and Ferriss, 1903.

This is one of the smallest mollusks known, yet the dilation of the

\footnotetext{
${ }^{14}$ Prof. von Martens defines four species of Cochliopa in the Biologia Centrali Americana-guatemalensis Morel., tryoniana Pils., trochulus and infundibulum Marts. (pp. 42S, 429). He omits $C$. rowelli Tryon, which was originally described from Clear Lake, California. Rev. J. Rowell, who found the original specimens, now states (in litt.) that "Cochlicopa Rowellii was named from shells collected by me near Baulinas Bay (not Clear Lake), Marin county, California." There are authentic specimens from Central America in the collection of the Academy, so that I still doubt whether the species really was actually collected in California.

Prof. von Martens surmises that $C$. guatemalensis (Morel.), which he had not seen, may not be different specifically from $C$. tryoniana; but it is in fact not even closely related to that species, being very much smaller, more depressed, and evenly seulptured with threadlike spirals. The suture descends shortly in front in fully mature shells. An additional locality is Polvon, in western Nicaragua (IcNiel in coll. A. N.S. Phila.). I have examined the radula of $C$. guatemalensis which proves to be Amnicoloid, and demonstrates the species to be a Cochliopa, not a laliata as Morelet supposed. The central tooth has the formula ${ }_{3-3}^{4.3}$, the inner lateral has 6 clenticles, the third from the inside being largest, and its body has the usual boss or projection below. The inner uncinus has 13, the outer very many excessively minute denticles.
} 
whorl at the aperture shows it to be adult. Five specimens were taken. The shells are all more or less bleached, the freshest being of a pale corneous tint. The round whorls, deep suture and general appearance are quite unlike any Planorbis or Vallonia, and indicate, we think, either that it is a Valvata or an Amnicoloid snail comparable to Horatic Bgt. or Daudebardiella Bttg. in the Palæarctic fauna. Until fresh specimens with the soft parts or operculum are found, the position of this molluscan aton will remain uncertain.

Valvata micra nugax (pl. IX, fig. 6), a slightly larger form, alt. .9 diam. $1.5 \mathrm{~mm}$., with three whorls and a projecting spire, may prove to be a distinct species; but for the present, until more specimens are found, it may be placed under V. micra as a variety or form.

\section{Pisidium singleyi Sterki.}

\section{CYRENID 平.}

Nautilus, XI, 1898, p. 112 (type loc. Guadalupe river, Comal county, Texas). Drift débris of Guadalupe river about four miles above New Braun$\mathrm{f} \in \mathrm{ls}$, and of Devil's river, Val Verde county, Texas. A closely related form was found near Del Rio.

\section{Pisidium compressum Prime.}

New Braunfels, Comal county, Texas. Mr. J. A. Singley found $P$. trapezoideum Sterki at the same place (coll. A. N. S. Phila. No.60,127).

Pisidium abditum huachucanum n. subsp.

The shell is quite inflated, dark brownish-olive, irregularly striate and marked with several conspicuous dark growth-arrest streaks; very inequilateral, the beaks low and near the anterior end. Anterior end abruptly truncate, posterior end produced and rounded. Hinge rather narrow, the lateral teeth in the right valve single, short and high, triangular; in the left double. Length 5.1, alt. 4.3, diam. $3.4 \mathrm{~mm}$.

Stream in Carr canyon, Reef, Cochise county, Arizona, collected by C. R. Biedermann, February S, 1904.

Specimens were submitted to Dr. V. Sterki, who could not identify the form with any known species. About half of the shells are more compressed than those described as typical, one measuring, length 4.1 , alt. 3.4, diam. $2 \mathrm{~mm}$. The very inequilateral, anteriorly truncate outline and low beaks are characteristic of both the obese and compressed forms.

\section{Eupera singleyi (Pils.).}

Sphorium (Limosina) singleyi Pils., Proc. A. N. S. Phila., 1S\$9, p. S8, pl. 3, figs. 14, 15 (May 14, 18s9).

? Cyclas maculata Morelet, 1859 , not of Anton, $1839=$ Spharinm yacatanense Fischer and Crosse, Miss. Sci. Mex., Moll., II, p. 653 (1S94).

This species is now known to us by specimens from the following 
places, all in Texas: White Oak bayou, Houston (Singley); Cedar creek, Hudson county (G. C. Heron, type locality); Lavaca river, Jackson county (J. D. Mitchell); New Bramfels, Comal county (Singley, Ferriss and Pilsbry); Guadalupe river about four miles above New Braunfels (Singley, Ferriss and Pilsbry); Devil's river, Val Verde county (Ferriss and Pilsbry).

It is a prettily maculate little clam, wiclely distributed in Texan waters. The largest shell I have seen measures $6 \mathrm{~mm}$. long. It may prove to be specifically iclentical with E. maculata Morelet of Yucatan, but that name is preoccupied by Anton for another species of the same group. Both were described as Cyclas and belong to Eupera. For this reason Crosse and Fischer proposed to substitute the name yucatanense; but five years previously I had described and figured S. singleyi. The latter name will therefore stand.

\section{UNIONIDÆ.}

A list of species taken by us in Arkansas, Indian Territory and Texas will be published elsewhere. As our work in these States was done in the early spring, we found most of the streams too high for effective collecting of bivalves.

\section{Explanation of Plates V-IX.}

Plate V.-Figs. 1, 2, 3.-Polygyra mooreana tholus (IV. G. B.). Washington county, Texas. No. 251, A. N. S. Phila.

Figs. 4, 5, 6, 7.-Polygyra mooreana (W. G. B.). Guadalupe river, Comal county, Texas. No. 91,36t. Figs. 8, 9, 10.-Hondo river near Hondo, Texas. No. $91,361$.

Figs. 11, 12.--Polygyra texasiana texensis Pils. Types. Colorado (ity, Texas. No. 83,258 .

Figs. 13, 14, 15.-Polygyra texasiana hyperolia Pils. and Ferr. West of Devil's river, Texas. No. 91,363.

Figs. 16, 17, 20.-Polygyra texasiana (Moric.). Typical. Guadalupe river Comal county, Texas, No. 91,362.

Figs. 18, 19.-Polygyra texasiana (Moric.). Race with striate base, Calhoun county, Texas. No. 229, A. N. S. Phila.

Plate VI.-Fig. 1.-Bulimulus dealbatus mooreanus (W. G. B.). San Antonio, Texas. No. 84,626 .

Figs. 2, 3, 4.-B. d. mooreanus. Guadalupe river above New Braunfels. No. 54,628 .

Figs. 5, 6.-B. d. mooreanus. Victoria, Texas. No. 76,210.

Figs. 7. 8.-B. d. liquabilis (Rre.). San Marcos, Texas. Nos. 91,396 and 91,397 .

Fig.s. 9, 10, 11.-B.d.liquabilis. Jackson county, Texas. No. 76,286.

Fig. 12,-B. d. liquabilis. Lee county, Texas. No. 58,379

Fig 13.-Bulimulus dealbatus (Say). Type. No. 58,381, A. N. S. Phila. Alabama. 
Fig. 14.-Bulimulus d. ozarkensis Pils. and Ferr. Seligman, Missouri. No. 83,132

Fig. 15.-B. d. ozarkensis Pils. and Ferr. Rogers, Arkansas. No. 91,35s.

Figs. 16, 17.-Bulimulus d. ragsdalci Pils. Types. Nontague county, Texas. No. 58,380.

Figs. 1S, 19, 20, 21, 22.-B. $d$. ragsdalei. Southwestern herd. West of Devil's river, Val Verde county, Texas. Nos. 91,356 and \$1,63s.

Figs. 23, 24. - B. d. ragsdalei Southwestern herd. Del Rio, Texas. Nos. 87,486 and 91,355 .

Fig. 25.-Bulimulus $d$. pasonis Pils. Type. Near El Paso, Texas. No.

Figs. 26, 27.-Bulimulus $d$. pecoscnsis Pils. and Ferr. Near the Pecos river. Nos. 91,359 and 84,618 .

Plate VII.-Varieties of Bulimulus alternatus maria (Alb.).

Figs. 1-7.-Near the High Bridge of the Pecos. No. 84,627, A. N. S. Phila. Fig. 4 and 5 represent young shells.

Fig. S.-Near the Rio Grande, east of the Pecos river. No. \$1,625.

Figs 9, 10 11. - Near Rio San Filipe below Del Rio. No. \$4,635.

Fig. 12.-Near Rio San Filipe below Del Rio. An albino, taken alive.

Figs. 13, 11, 15, 16.-Corpus Christi, Texas. No. 60,136.

Figs. 17, 18, 19.-Hidalgo, Texas. No. 60,094.

Figs, 20-24.-Derby, Frio county, Texas. No. 60,501.

Figs. 25-30.-Laredo, Webb county, Texas. No. 60,502.

Plate VIII.-Figs. 1, 2, 3.-Helicodiscus cigenmanni Pils. San Marcos, Texas. No. 91,320

Figs. 4, 6.-II. e. arizonensis Pils. and Ferr. Fort Bowie, Cochise county, Arizona. No. 87,077, A. N.S. Phila.

Fig. 5.-II. e. arizonensis. A more depressed specimen. Cave Creek Canyon, Chiricahua IIountains No. 87,076 . A. S. N. Phila.

Figs. 7, 8, 9, 10.-Helicodiscus parallelus (Nay). Philadelphia, Pa. No. 78,272, A. N. S. Phila.

Plate IX.-Figs. 1, 2, 3.-Planorbis filocinctus Pils. and Ferr. Type.

Figs. 4, 5.-Planorbis carus Pils. and Ferr. Type.

Fig. 6.-Taliata micra nugax Pils. and Ferr. Type.

Figs. 7, 8, 9.-Talvata micra Pils. and Ferr. Type.

Figs. 10, 11, 12, 13.-Cochliopa riograndensis Pils. and Ferr. Cotypes. 



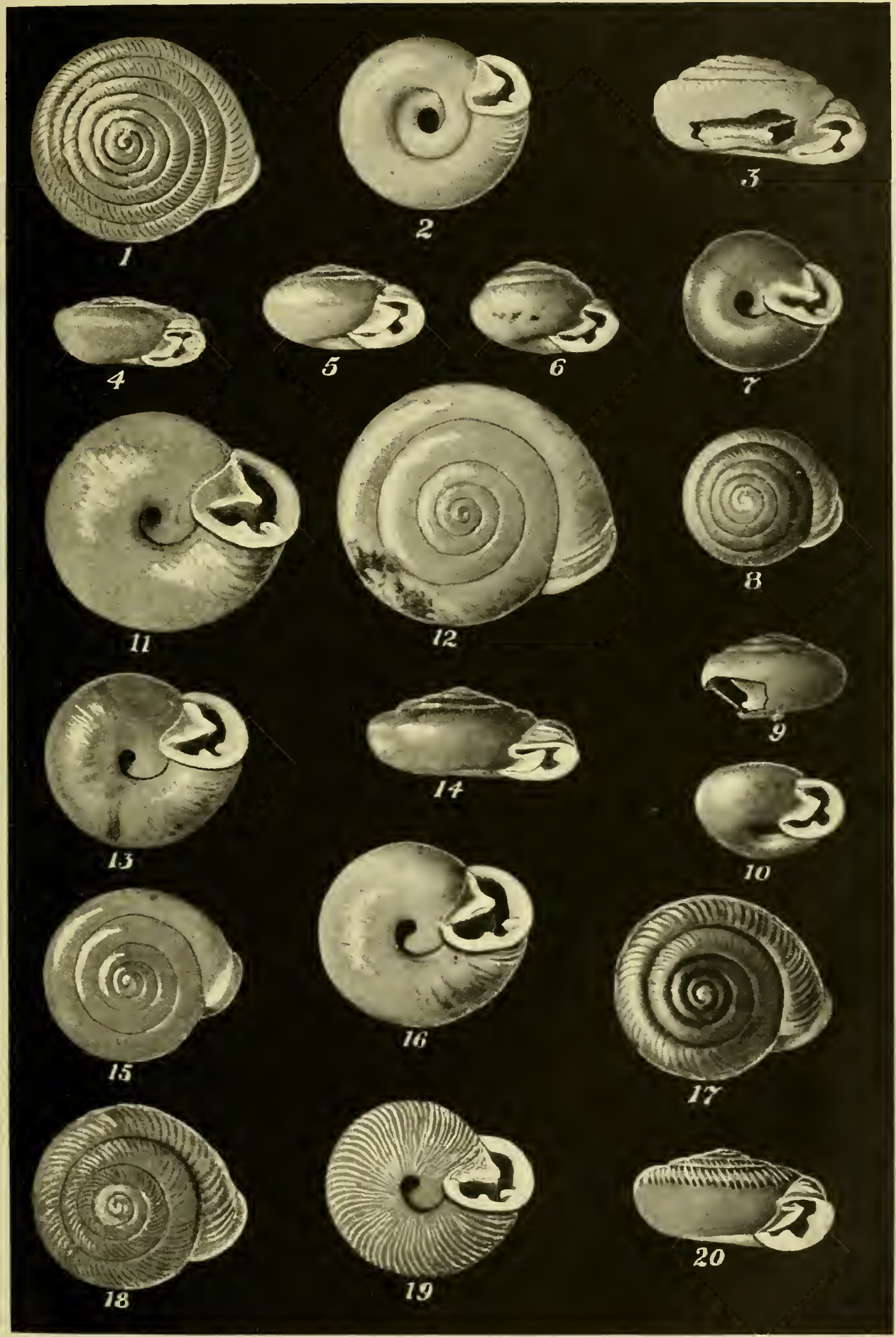

PILSBRY AND FERRISS. MOLLUSCA OF SOUTHWESTERN STATES. 


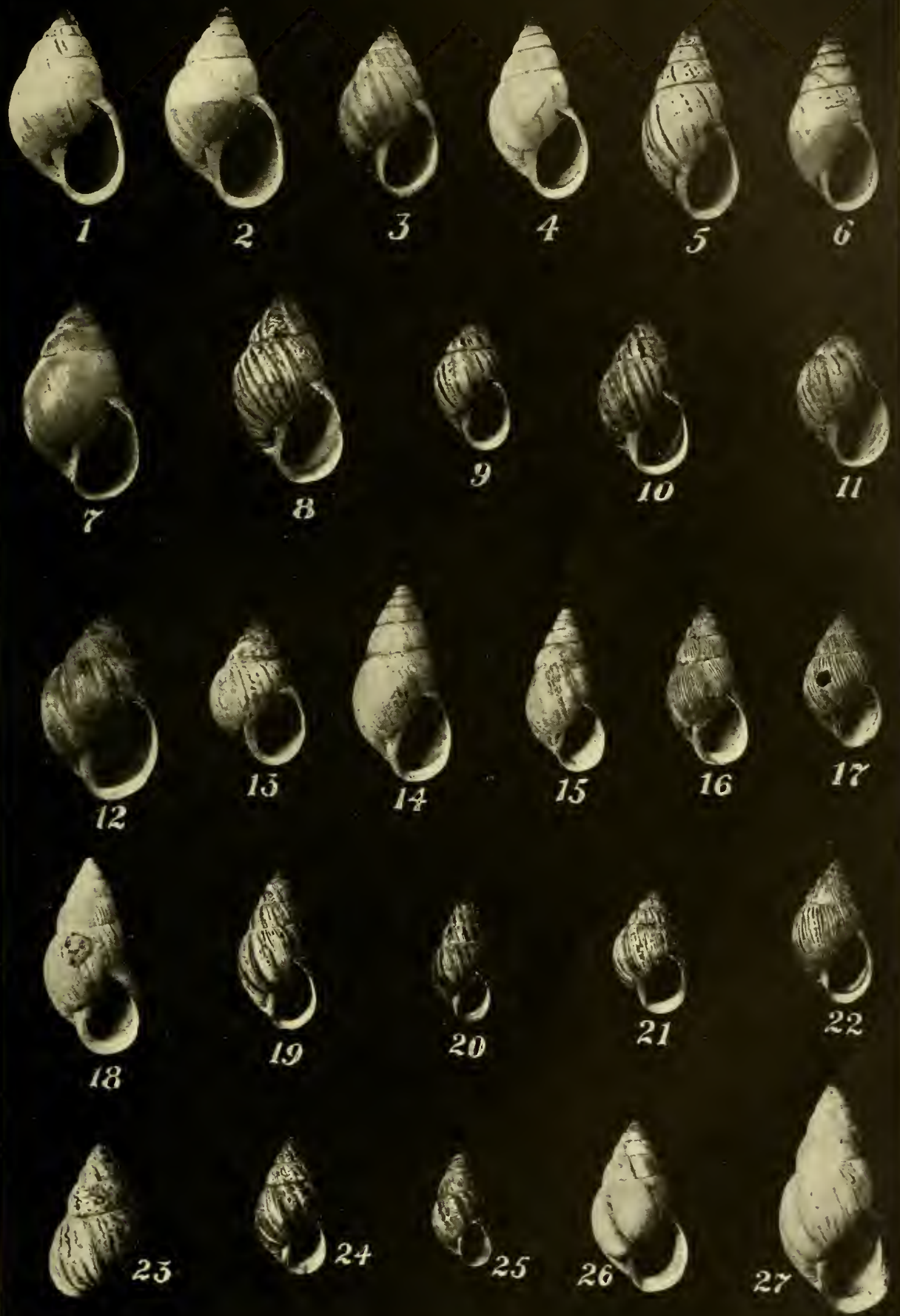

PILSBRY AND FERRISS. MOLLUSCA OF SOUTHWESTERN STATES. 


PROC. ACAD. NA'T. SCI. PHILA. 1906.
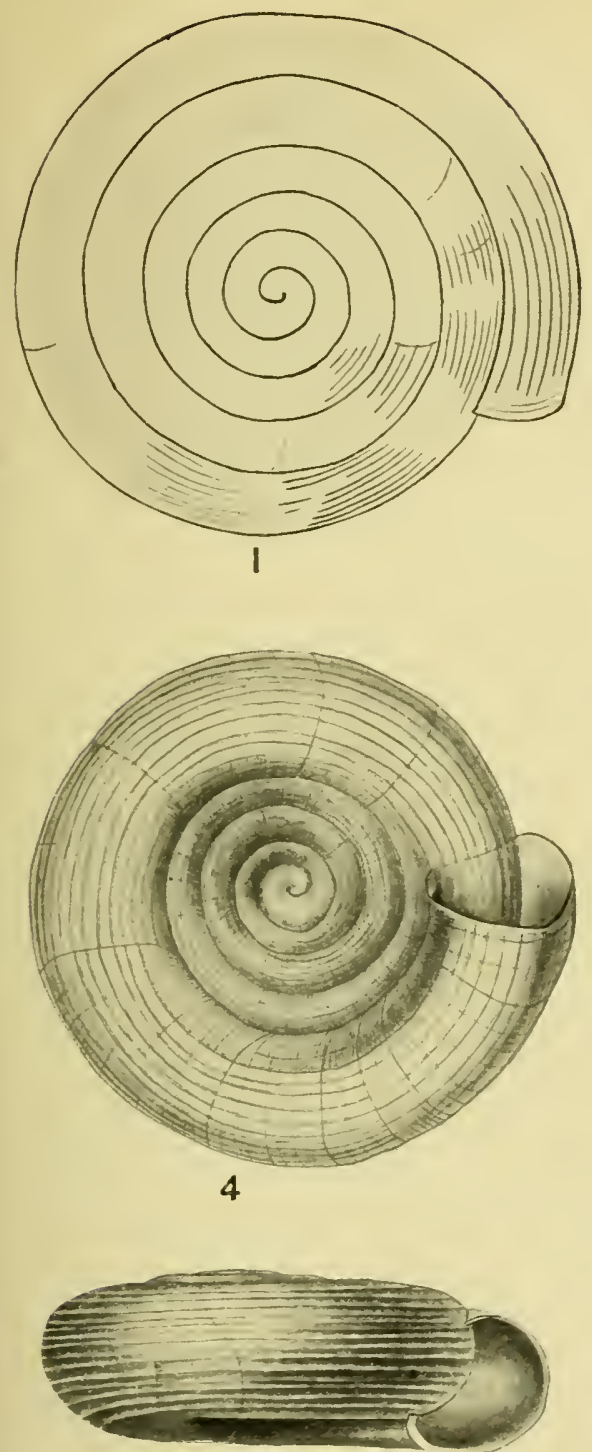

5
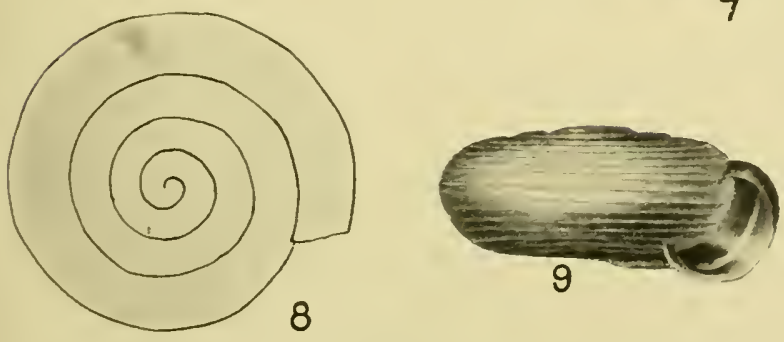

PLATE VIII
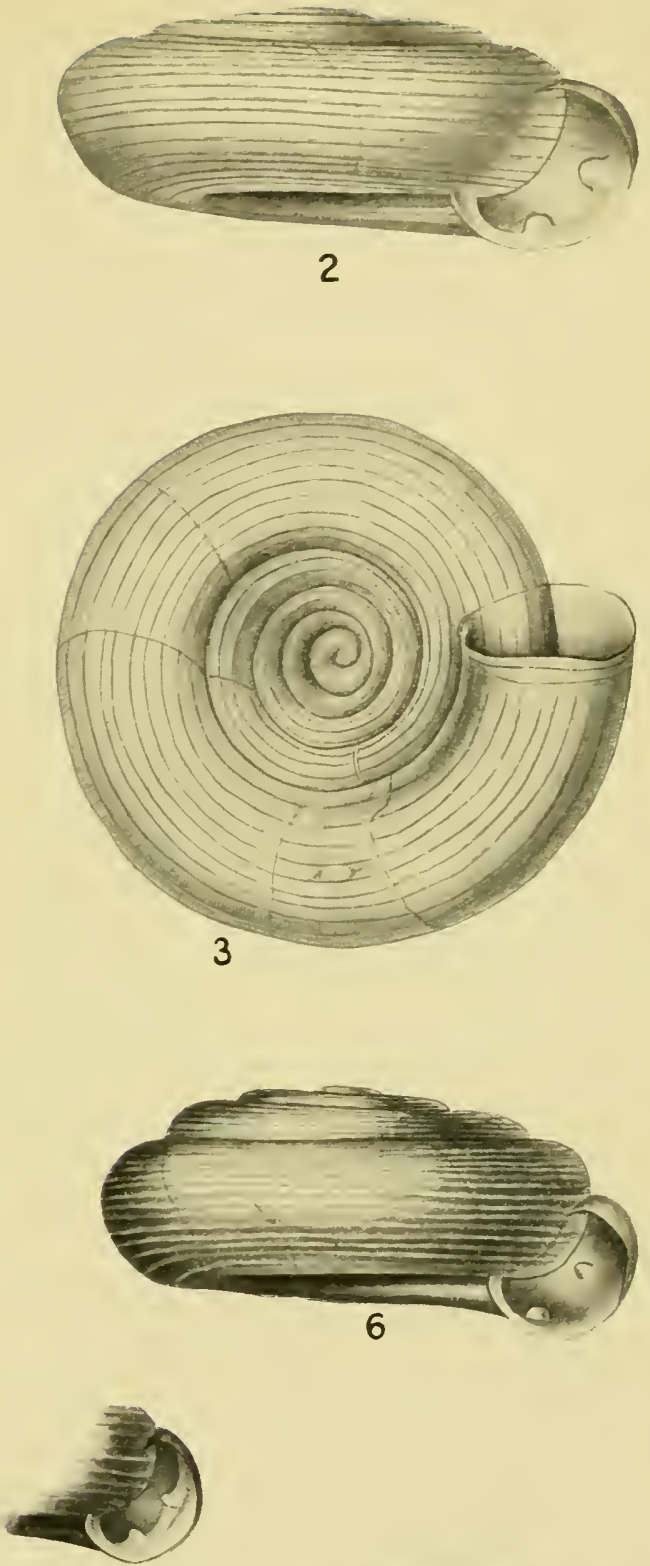

7

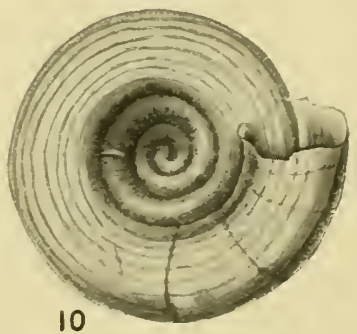

TOLISCA OF SOUTHVESTERN STATES. 


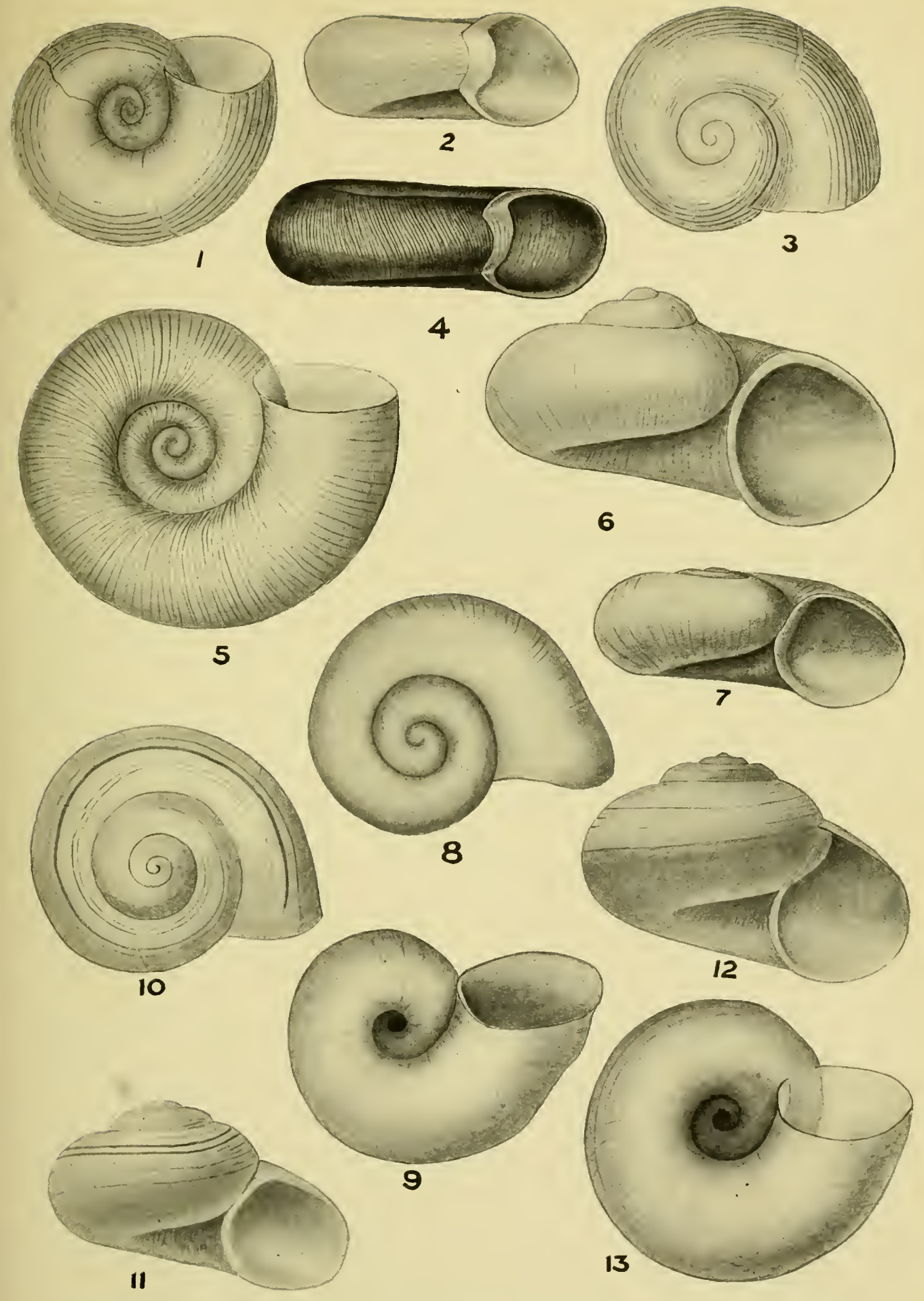

PILSBRY AND FERRISS. MOLLUSCA OF SOUTHVESTERN STATES. 



\section{Mollusca of the Southwestern States,}

III : The Huachuca Mountains, Arizona.

A New Sonorella from the Rincon Mountains. A rizona.

BY

H. A. Pilsbry and J. H. Ferriss.

From the Proceedings of The Acudemy of Natural Scionces

of Philadelphia, November, 1909. 



\section{MOLLUSCA OF THE SOUTHWESTERN STATES, III: THE HUACHUCA MOUNTAINS, ARIZONA.}

BY HENRY A. PILSBRY and JAMES H. FERRISS.

The Huachuca Mountains stand in the southwest angle of Cochise county, Arizona, their southern foothills reaching over the international boundary. The highest summits do not quite attain 10,000 feet. Northward the Whetstone range looms up, a fine if arid mountain mass, as yet unexplored for shells. On every side lies the desert, barren of molluscan life. Our purpose is to give an account, incomplete as it now may be, of the molluscan life of this range. ${ }^{1}$

The Huachucas have not yet been accurately mapped. The sketch

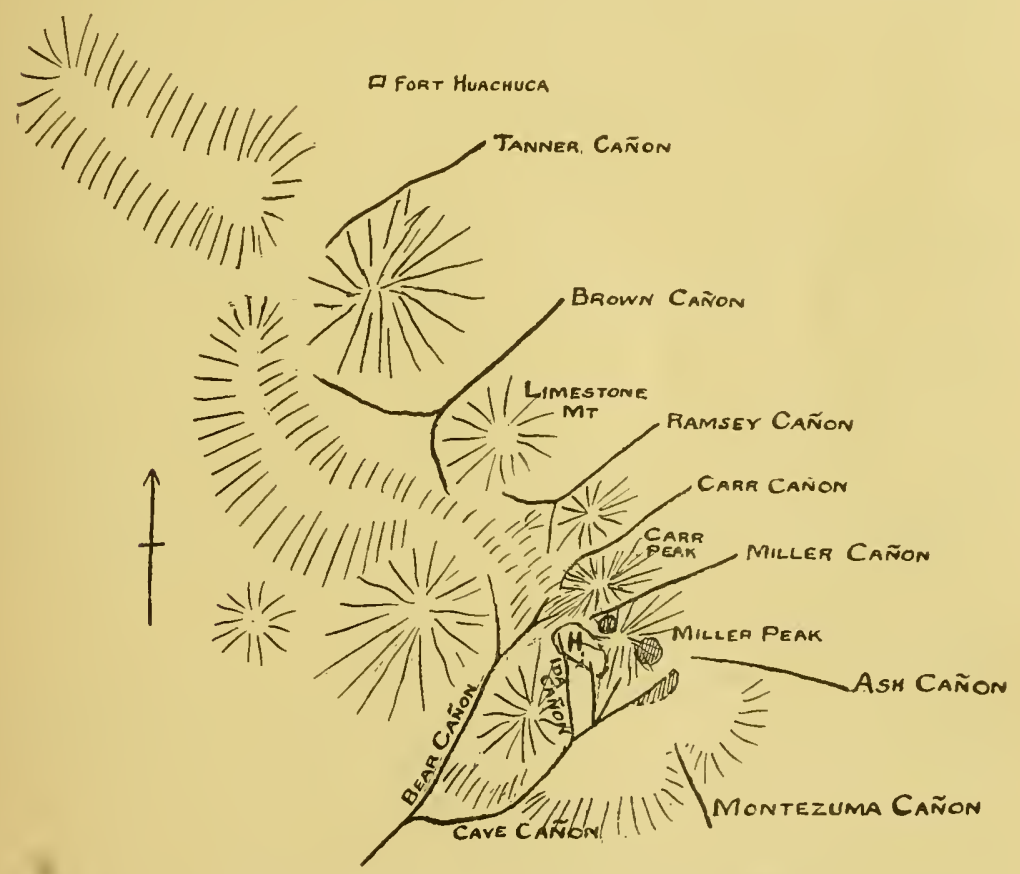

Fig. 1. Sketch-map of Huachuea Mountains.

${ }^{1} \mathrm{~A}$ few new records are added of species taken in river drift at Benson, Cochise county, some distance northward from the Huachuca range. These forms were derived from some other district. Other records from Benson may be found in our Mollusca of the Southwestern States, II, 1906, and in Dall, Proc. U.S. Nat. Mus., XIX, 1896. 
here given shows the general positions of localities mentioned in the text.

The first mollusks collected in the Huachucas were taken by a Mr. Cox, who sent some Helices to Dr. Isaac Lea many years ago, with the locality "Tucson." These shells are what we now call Ashmunella varicifera. Nothing is known of Cox beyond his name on the label. At the time these shells were collected Tucson was no doubt the nearest settlement or post to the Huachucas, and hence was put down as the locality. It is not unlikely that Cox picked up these shells in the course of a chase from the army post at Tucson after marauding Apaches. Be this as it may, Ashmunella varicifera is an indubitable Huachucan snail, and was collected at a time when hostile and dangerous Indians occupied that country. On the death of Dr. Lea the specimens came into the possession of the National Museum, where they are now preserved.

In $1880 \mathrm{Mr}$. Bland described a snail, Triodopsis levettei (now Ashmunella levettei), collected by Dr. G. M. Levette, and thought to be from near Santa Fé, New Mexico. Explorations in that region have shown that the Ashmunellas there are of a somewhat different type, and the true habitat of the species was not known until Mr. Ferriss rediscovered the species in the Huachucas, where it is restricted to the heads of certain canyons. It is certain, therefore, that Dr. Levette had forgotten where he procured the original specimens, which are now in the American Museum of Natural History, New York.

The first snails actually reported from the Huachucas were collected by Dr. Edgar A. Mearns, U. S. A., a member of the party surveying the Mexican boundary in 1892-1894. They were described by Dr. W. H. Dall in two papers, ${ }^{2}$ published in 1895 and 1896 . Six species were obtained in the Huachuca range ${ }^{3}$

Polygyra levettei [ = Ashmunella l. angigyra].

Polygyra mearnsi [ = Ashmunella mearnsi].

Epiphragmophora hachitana, depressed variety from Tanner Canyon [ = Sonorella dalli $]$.

Patula strigosa var. [ = Oreohelix s. huachucana].

${ }^{2}$ Diagnoses of new mollusks from the survey of the Mexican boundary, in Proc. U. S. Nat. Mus., XVIII, 1895, p. 1, and Report on the mollusks collected by the International Boundary Commission of the United States and Mexico, 1892-1894, same Proc., XIX, pp. 333-379.

${ }^{3}$ Dr. Dall's pioneer work on southern Arizona shells was published prior to the anatomical researches which led to the establishment of new genera for the Helices of that region. He had only dry shells to deal with, and hence followed the generic nomenclature current at that time. 
Patula s. concentrata $[$ = Orcohelix s. concentrata $]$.

Cionella lubrica $[=$ Cochlicopa lubrica $]$.

Several Huachucan species were figured by Mr. Paul Bartsch in his monograph of Sonorella, 1904, and S. dalli n. sp. was described.

The seven species of snails mentioned above sum up all that was known of Huachucan mollusks prior to the visit of Mr. Ferriss in 1902. In 1904 the range was again visited, ${ }^{4}$ and again in 1907 Messrs. Ferriss and L. E. Daniels made extensive collections. Dr. Henry Skinner, the well-known entomologist, made a useful collection of shells in Carr Canyon, in August, 1905, and Mr. C. R. Biederman has contributed a few species from the same place.

The present report is based upon practically all of the material ever collected in the Huachucas. Through the unfailing kindness of Dr. Dall, the series in the National Museum has been examined. Dr. Gratacap has permitted a re-examination of the types of Ashmunella levettei; and Dr. Bartsch has assisted with various helpful services.

\section{HELICID Æ⿸厂}

Genus SONORELLA Pils.

The Huachucan Sonorellas are all distinct specifically from those of other ranges. So far as known anatomically, they belong to groups special to this range; hence speak for a long isolation.

Omitting $S$. huachucana, which is unknown anatomically, the species of the Huachuca and Patagonia Mountains can be determined by this key:

a.-Penis long (about $40 \mathrm{~mm}$. in a shell $27 \mathrm{~mm}$. diam.), with a short hollow papilla containing a tube; epiphallus long, 49-60 $\mathrm{mm}$.; flagellum present, . . . . . . . . S. dalli. $a^{1}$.-Penis and epiphallus short, the former containing a fleshy, cylindric papilla over half the length of penis; flagellum vestigeal or wanting.

b.-Vagina about as long as penis; spermatheca and duct about four times as long, . . . . . . S. rowelli.

$b^{1}$.-Vagina much longer than the penis; spermatheca and duct not differing greatly from vagina in length.

c.--Penis 5 to 7.5 , papilla 3.3 to $5 \mathrm{~mm}$. long; upper part of vagina muscular, swollen, usually fusiform,

S. granulatissima.

$c^{1}$.--Penis 12 to 19 , papilla 9 to $13 \mathrm{~mm}$. long; vagina slender, with a small fleshy node midway, . . S. danielsi.

See Southwestern Shells, Nautilus, XVIII, Sept., 1904, pp. 49-52, and Mollusca of the Southwestern States, Proc. A. N. S. Phila., 1S95, pp. 211-290. 
Sonorella huachucana Pilsbry. Pl. XIX, figs. 16, 17.

S. virilis huachucana Pilsbry, Proc. A. N. S. Phila., 1905, p. 267, pl. 17, fig. 24

This is a non-granulose species with conspicuous pale borders along the brown band. We formerly thought it a subspecies of $A$. virilis of the Chiricahua range, but since all the other Helices of this range are specifically distinct, it is not likely that huachucana will prove an exception. It comes from Brown's and Bear Canyons, and must be rare or very local. None were taken in 1907.

The soft anatomy is unknown. We therefore know nothing of its relationships with other species. Fig. 16 represents a shell from Bear Canyon. Fig. 17 the type from Brown's Canyon.

\section{Group of S. dalli.}

Sonorella dalli Bartsch. Plate XIX, figs. 1, 2, 3.

Sonorella dalli Bartsch, Smiths. Miscell. Coll., Vol. 47, p. 193, pl. 31, fig. 1 (Oct. 10, 1904).

Epiphragmophora hachitana, depressed variety from Tanner Canyon, DALL, Proc. U.S. N. M., XIX, pp. 339, 340, pl. 31, figs. 7, 10 (1896).

Specimens were taken only in Tanner Canyon, the type locality. It is probably restricted to this place. It is a fine species, distinguished by the broad, flattened shape, very open umbilicus and much deflexed last whorl. The largest specimen taken measures $28 \mathrm{~mm}$., the smallest $23 \mathrm{~mm}$. diameter. Compared with $S$. granulatissima latior, which also occurs in Tanner Canyon, S. dalli is more openly umbilicate, the aperture is flattened above, the oblique sculpture is coarser. In some old specimens the front edge of the parietal callus is thickened, a narrow ridge connecting the ends of the lip.

The penis (pl. XXII, fig. 4) is extremely long, slightly enlarged distally, its walls thin, with most minute and close transverse rugæ. It contains a smooth papilla, tapering to an obtuse apex, and about one-fifth the length of the penis. The papilla is hollow with rather thin walls. Within it a slender tube runs from the epiphallus to the apex, where it opens by a lateral pore. This tube is lightly attached to the wall of the penis-papilla. It is indicated by dotted lines in fig. 4. The epiphallus is extremely long, terminating in a short flagellum. The penis retractor muscle, $7 \mathrm{~mm}$. long, is inserted upon it $4 \mathrm{~mm}$. from the end of the penis. The long vagina has a slender neck, enlarging moderately above.

The spermatheca is globular, on a duct much shorter than the penis. 
In one specimen dissected it bears a minute diverticulum about $1 \mathrm{~mm}$. long, $2 \mathrm{~mm}$. from the base of the duct. In another individual no diverticulum was found, so that it may possibly be abnormal or pathologic. The measurements of the organs in two individuals preserved in formalin follow:

Length of penis

No. 94,384. No. 94,358.

"penis

$39 \mathrm{~mm}$.

8 "

$41 \mathrm{~mm}$.

" epiphallus,

" flagellum,

"vagina,

49 "

9 "

$"$

4 "6

60 "

"

"spermatheca and duct,

34 "

3 "

25 “

27 “"

The jaw (pl. XXII, fig. 6) has five strong ribs grouped in the middle half of its length.

The radula has about $41,1,41$ teeth (pl. XXII, fig. S). The central and lateral teeth have mesocones only; on the 17 th an ectocone appears. On the outer marginal teeth the inner cusp or sometimes both cusps are bifid, but the ectocone is not split into several cusps as in some other species.

The excessive length of penis and epiphallus, and especially the hollow, thin-walled papilla containing a separate duct or tube (a structure unique in the genus), are characters which set $S$. dalli apart from all other known Sonorellas. It stands alone in its own line of differentiation.

\section{Group of S. granulatissima.}

These forms are elosely related to the group of $S$. hachitana, but differ by the thick, quite cylindric penis-papilla, solid except for the minute perforation, and very obtuse or truncate at its distal end, and by having no flagellum or only a minute vestigeal one. In the hachitana group the papilla tapers, at least at the distal end, and a minute but distinctly developed flagellum is present in known forms. The distinction is only a small matter, but serves to distinguish the Huachucan forms. S. rowelli (Newc.), from a little farther west, belongs to the same group.

The dimensions of the genitalia in several specimens of each form are given in the accompanying table. Most of the specimens were preserved in alcohol in the field, and some variation is doubtless traceable to various degrees of contraction. 


\begin{tabular}{|c|c|c|c|c|c|c|c|}
\hline $\begin{array}{l}\text { Species, Locality } \\
\text { and Musem No. }\end{array}$ & Penis. & $\begin{array}{c}\text { Pa- } \\
\text { pilla. }\end{array}$ & $\begin{array}{c}\text { Epi- } \\
\text { phallus }\end{array}$ & $\begin{array}{l}\text { Flagel- } \\
\text { lum. }\end{array}$ & $\begin{array}{l}\text { Ya- } \\
\text { gina. }\end{array}$ & $\begin{array}{l}\text { Sperm- } \\
\text { atheca } \\
\text { and } \\
\text { dict. }\end{array}$ & $\begin{array}{l}\text { Diam } \\
\text { of } \\
\text { shell. }\end{array}$ \\
\hline $\begin{array}{l}\text { S. granulatissima, } \\
\text { Ramsey, } \$ 3,257 \ldots \ldots \ldots . . \\
\text { Miller Cn., } 94,336 \ldots \ldots . \\
\text { Carr Cn., } 90,404 \ldots \ldots \ldots\end{array}$ & $\begin{array}{l}7.3 \\
6 \\
5.5\end{array}$ & $\begin{array}{l}4.8 \\
4 \\
4\end{array}$ & 6 & $\begin{array}{l}0.7 \\
0 \\
0\end{array}$ & $\begin{array}{l}21 \\
28 \\
10\end{array}$ & $\begin{array}{c}24-25 \\
22\end{array}$ & $\begin{array}{l}19 \\
21 \\
18\end{array}$ \\
\hline $\begin{array}{l}\text { S. g. latior. } \\
\text { Tanner Cn., 94,387...... } \\
\text { Brown Cn..94,356..... } \\
\text { Brown, w. Hork, 94,359.. } \\
\text { Salvation, } 94,395 \ldots \ldots \ldots \\
\text { Limestone Mt., } 94,393 \ldots\end{array}$ & $\begin{array}{l}6 \\
6 \\
5 \\
7 \\
7.5\end{array}$ & $\begin{array}{l}3.5 \\
4.5 \\
3.3 \\
5\end{array}$ & $\begin{array}{l}5 \\
6 \\
4\end{array}$ & $\begin{array}{l}0 \\
0 \\
0 \\
0 \\
0\end{array}$ & $\begin{array}{l}17 \\
21 \\
14 \\
27 \\
21\end{array}$ & 16 & $\begin{array}{l}21-22 \\
18.5 \\
18 \\
20 \\
23\end{array}$ \\
\hline $\begin{array}{l}\text { S. danielsi. } \\
\text { Head of Bear, } 94,318^{5} \\
\text { Ditto, } 94,317 \ldots \ldots \ldots \ldots \ldots \\
\text { E. fork Cave, } 94,352 \ldots \ldots \\
\text { Miller Pk., } 94,337 \ldots \ldots \ldots\end{array}$ & $\begin{array}{l}18.5 \\
15 \\
12 \\
13.5\end{array}$ & $\begin{array}{l}13 \\
10 \\
8.5 \\
9\end{array}$ & 10 & $\begin{array}{l}0 \\
0 \\
0 \\
0\end{array}$ & $\begin{array}{l}27.5 \\
17.5 \\
19\end{array}$ & 22 & $\begin{array}{l}19 \\
18.5 \\
19 \\
18-19\end{array}$ \\
\hline
\end{tabular}

Sonorella granulatissima Pilsbry. Pl. XIX, figs. 7, 8, 9; pl. XXI, figs, 1-4.

Proc. A. N. S. Phila., 1905, p. 262, pl. 17, figs. 21-23; pl. 1s, figs. 41-43, 51-54.

The typical form is found in Ramsey (figs. 7, 8), Carr and Miller (fig. 9) Canyons. Types were from Ramsey. The shell is distinguished by its very dense beautiful granulation and the faintness or absence of spiral lines, though on some specimens they are present, but very weak.

I have examined the genitalia in a number of individuals from each of the three canyons mentioned above. Figs. 1, 2, 3 represents one of the two cotypes. Fig. 4 is from an example from Miller Canyon. The chief feature is that the upper part of the vagina has thick muscular walls, the outer layer consisting of glossy circular muscular fibers. Usually this part is more or less swollen and fusiform. The lower part of the vagina is thin-walled. This feature was conspicuous in every one of about 20 individuals of 12 lots of $S$. granulatissima and $S . g$. latior which were examined. The penis is short, its lengtl contained 3 or 4 times in that of the vagina. It is abruptly truncate distally. The penis-papilla is quite short, 3.3 to $5 \mathrm{~mm}$. long, cylindric, truncate at the end, and coarsely wrinkled. It is fleshy, perforated by a minute pore, which opens at the end. The rather short epiphallus has no flagellum in any example opened with the exception of one of the cotypes, in which there is a minute, vestigeal flagellum about $0.7 \mathrm{~mm}$.

${ }^{5}$ Measured from a fresh, drowned example. 
long, and bound to the vas deferens by the outer muscular fascia. As a rule, with rare exceptions, therefore, the flagellum is absent.

Sonorella granulatissima latior Pils. Pl. XIX, figs. 4, 5, 6 .

Proc. A. N. S. P., 1905, p. 264, pl. 18, figs. 21-28.

Usually a larger shell than S. granulatissima, the last whorl more depressed, approaching $S$. dalli in shape. Originally described from Brown's Canyon, it is now known also from the south side of Limestone Mountain, east fork Salvation Ridge ${ }^{s}$ and from Tanner Canyon. Three cotypes are figured.

The genitalia have been examined in numerous examples from Tanner Canyon (pl. XXI, fig. 6), Brown's Canyon, east fork of Salvation Ridge and Limestone Mountain. The characters are identical with those of $S$. granulatissima. All of them have the upper part of the ragina swollen, and there is no flagellum. Measurements of sereral alcoholic specimens are given in the table.

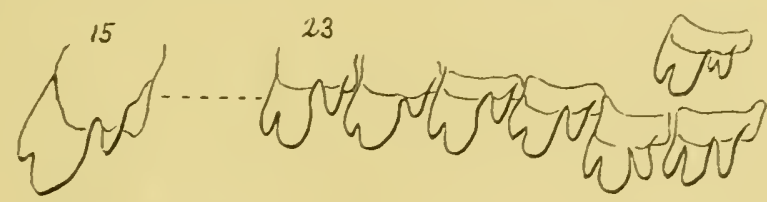

Fig. 2. Marginal teeth of S. g. latior, Tanner Canyon.

The radula has $38,1,38$ teeth, with 10 laterals. The outer marginal teeth have the inner cusp deeply bifid, the outer one sometimes split (fig. 2, No. 94,383, Tanner Canyon).

Sonorella granulatissima parva Pils. Pl. XIX, figs. 10, 11, 12.

To further information on this small race from the northwestern end of the range has been received. S. mearnsi Bartsch, from 4 miles south of the international boundary, a few miles east of the San Pedro river, is another form which will probably prove to be closely allied to granulatissima and rowelli when the anatomy can be examined.

Sonorella danielsi n. sp. Pl. XIX, figs. 13, 14, 15; pl. XXI, figs. 5, 7.

S. granulatissima (in part), Pilsbry, Proc. A. N. S. P., 1905, p. 263, pl. 18, figs. 39, 40, 41;pl. 11, fig. 10 (Miller Cn.); also pl. 18, figs. 36, 37, 39 (Ida Cn.).

The shell is more depressed than granulatissima, yellow with a conspicuous dark band without pale borders, the early whorls fleshcolored; surface glossy, the granulation of the last whorl very weak,

'Salvation Ridge forms the divide between Brown and Tanner Canyons on the northeast side and what we supposed to be Salvation Camp Canyon on the south. We collected only on the ridge, which is shown on the map at the heads of Brown and Tanner Canyons. 
nearly effaced, spiral incised lines well developed above the periphery. Umbilicus wider than in granulatissima.

Alt. 10, diam. $19 \mathrm{~mm}$; whorls $4 \frac{1}{2}$.

The animal is slaty-blackish, the back paler, brownish-gray, collar of mantle dark slate. The sole is slate colored at the sides, the middle gray, but the areas are not bounded by lines. The lung has faint venation; pulmonary vein breaking up into several large branches.

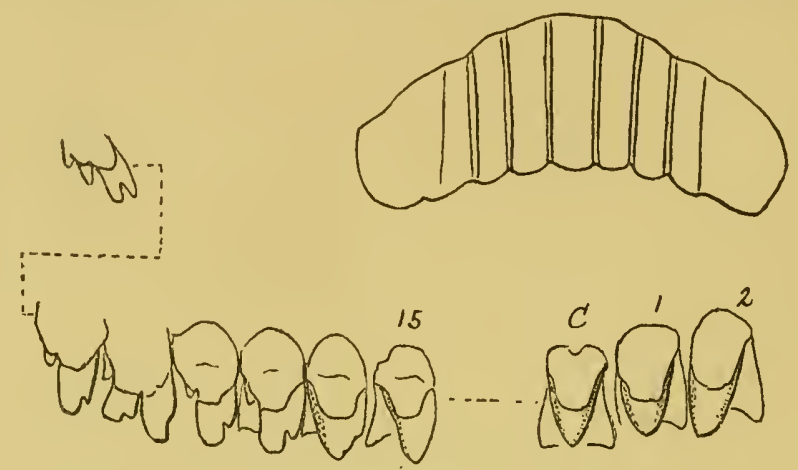

Fig. 3. Jaw and teeth of a cotype of Sonorella danielsi.

Genitalia.-The penis is very large, stout, subcylindric, half the length of the vagina or longer. It collapses at the base, where not filled by the papilla, and has several strong longitudinal folds inside. It contains a long cylindric papilla which is abruptly truncate at the end and wrinkled throughout. There is no flagellum. The long vagina is rather slender throughout, with an annular swelling or node about midway of its length. It is longitudinally rugose within, the rugæe coalescent at the node. Other organs as usual. Fig. 7 was drawn from a drowned specimen which had not been in alcohol (No. 94,318).

The jaw has six or seven very low, wide ribs, parted by narrow intervals. The radula has about $47,1,47$ tceth. In most rows the fifteenth tooth has an ectocone. No marginal teeth with the ectocone bifid were seen. The nineteenth tooth, in the radula figured, is abnormal. One of the outer marginals is shown above it.

Types No. 94,318 A. N. S. 1'., from head of Bear Canyon; also Miller Peak and east fork of Cave Creek.

Sinilar forms, but with the ground-color not yellow but pale brown (as in granulatissima), occur in Ida Canyon, Cave Creek and Ash Canyon (pl. XIX, fig. 18).

This species replaces granulatissima on the south side and east end 
of the Huachuca range. It differs from S. granulatissima chiefly in the genitalia, the larger penis and the shape of the vagina being constant features in the series of both species dissected. Specimens have been dissected from five lots, from the head of Bear Canyon (fig. 7), east fork of Cave, and from Miller Peak (fig. 5). One individual of several from the latter place seems to have the very minute bud-like vestige of a flagellum.

The shell will be recognized by its yellow, glossy surface and depressed shape. The brownish forms from Ida and Ash Canyons, mentioned above, require more study, with better fresh or alcoholic material than we can command at this time. One from Ash Canyon is figured, fig. 18.

Named in honor of Mr. L. E. Daniels, who accompanied Mr. Ferriss in the expedition of 1907.

\section{Genus ASHMUNELLA Pils. and Ckll.}

The Ashmunellas of the Huachuca range, while very diverse in appearance, belong to a single closely related group. Probably all descended from an ancestral stock not unlike $A$. levettei angigyra, the most widely distributed form, and the one showing most affinity to species of the Chiricahua and other ranges. The common ancestry of the whole series is demonstrated by the intermediate stages found among the shells, and by the soft anatomy, which is so much alike in all that it would probably be impossible to tell the species apart without the shells, yet differing characteristically from the soft parts of all Ashmunellas of the Chiricahuas or other ranges by the sacculated or varicose spermatheca and the shape of the penis.

The species and races form a beautiful chain of variations, pretty completely connecting those having most complicated apertures with those in which the aperture is toothless, thus: bifurca-levetteiursina-heterodonta-varicifera.

Evolution has proceeded from fully toothed apertures towards toothless apertures. In other words it has been retrogressive, marked by degeneration of complex structures.

Soft Anatomy of Ashmunella.-Time has not admitted a full examination of the anatomy, but the genitalia of many individuals have been studied. These organs are so similar in all of the forms that one description will suffice. The penis (P.) is rather large for an Ashmunella. Inside it has six unequal fleshy longitudinal ridges, interrupted in the middle (pl. XX, fig. 6). This point is marked externally by a slight constriction. The epiphallus (epi.) is very long. terminating in a minute flagellum $(f$.). The retractor muscle $(r p)$. 
is attached to the epiphallus, but sends down a band to the apex of the penis. The vas deferens $(v d$.$) is very long and free. The$ vagina is short. Spermatheca $(s p$. ) is not distinctly divided into head and duct. The distal two-thirds or more is of about equal caliber, and distinctly varicose or sacculated. The proximal portion is a little contracted. This form of spermatheca is special to the Huachucan species, and unlike those of other districts. The other organs show no peculiar features. The dimensions of the organs in millimeters are as follows:

\begin{tabular}{|c|c|c|c|c|c|c|c|}
\hline Species. & Penis. & $\begin{array}{l}\text { Epip- } \\
\text { hallus } \\
\text { and } \\
\text { flagel- } \\
\text { lum. }\end{array}$ & $\begin{array}{l}\text { Flagel- } \\
\text { lum. }\end{array}$ & $\begin{array}{l}\text { Va- } \\
\text { gina. }\end{array}$ & $\begin{array}{l}\text { Sperm. } \\
\text { atheca } \\
\text { and } \\
\text { duct. }\end{array}$ & $\begin{array}{l}\text { Diam. } \\
\text { of } \\
\text { shell. }\end{array}$ & $\begin{array}{l}\text { Mu- } \\
\text { seum } \\
\text { No. }\end{array}$ \\
\hline 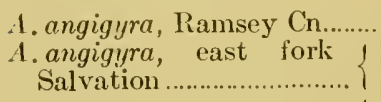 & 5 & $\begin{array}{l}24 \\
28 \\
28\end{array}$ & 1.3 & $\begin{array}{l}3 \\
4.5\end{array}$ & $\left.\begin{array}{l}22 \\
22.5 \\
21\end{array}\right\}$ & $13-14$ & $\begin{array}{l}83,269 \\
94,396\end{array}$ \\
\hline A. bifurca, Tanner Cn......... & $\begin{array}{l}5 \\
4.5 \\
7\end{array}$ & $\begin{array}{l}34 \\
31 \\
42\end{array}$ & 1.5 & $\begin{array}{l}4 \\
4\end{array}$ & $29\}$ & 15 & 94,388 \\
\hline A. ursina ....................... & $\begin{array}{l}7 \\
8\end{array}$ & $\begin{array}{l}42 \\
43\end{array}$ & & $\begin{array}{l}4 \\
3.5\end{array}$ & $\left.\begin{array}{l}28 \\
26\end{array}\right\}$ & $16-18$ & 94,351 \\
\hline $\begin{array}{l}\text { A. ursina, Bear Ch............ } \\
\text { A. heterodonta, Cave Creek..... } \\
\text { A. microdonta, Cave Creek..... } \\
\text { A. varicifera, Wickersham } \\
\text { Rock }\end{array}$ & $\begin{array}{l}5 \\
7 \\
8 \\
7.5 \\
6\end{array}$ & $\begin{array}{l}46 \\
34 \\
40 \\
35 \\
29\end{array}$ & $\begin{array}{l}1 \\
1.5 \\
1.8\end{array}$ & $\begin{array}{l}4 \\
5 \\
7.5 \\
5 \\
4\end{array}$ & $\begin{array}{l}32 \\
24 \\
26 \\
27 \\
25\end{array}$ & $\begin{array}{l}16 \\
16 \\
19 \\
18 \\
17\end{array}$ & $\begin{array}{l}94,349 \\
94,350 \\
94,347 \\
94,340 \\
94,341\end{array}$ \\
\hline
\end{tabular}

All the specimens were measured from alcoholic preparations except 1. levettei ursina, 94,349, which was dissected fresh.

The figures on plate XX represent the following species:

1. levettei ursina, No. 94,351, head of Bear Canyon (pl. XX, fig. 1).

1. levettei ursina, No. 94,349, head of Bear Canyon (pl. XX, fig. 4). Atrium protruding.

A. l. angigyra, No. 83,269, Ramsey Canyon; type lot (pl. XX, fig. 2).

A. . heterodonta, No. 94,350, head of Cave Creek.

A. microdonta, No. 94,347, head of Cave Creek; type lot (pl. XX, fig. 7).

A. varicifera, No. 94,340 and 94,341, Miller Peak, Ash Canyon side (pl. XX, fig. 3). Atrium protruding. Fig. 6, the penis opened. Fig. 5, spermatheca of another individual. 
Ashmunella varioifera Ancey. Fig. 4.

Polygyra chiricahuana, in part, Dall, Proc. U.S. Nat. Mus., XIX, pl. 32, figs. $9,10,12$.

A. chiricahuana var varicifera Ane., Journ. of Malacology, VIII, Sept. 30, 1901 , p. 77 (near Tucson, Cox). A. l. heterodonta or chiricahuana, Pilsbry, Proc. A. N. S. Phila., 1905, p. 242, pl. 15, figs. 94, 95.

The shell is depressed, the spire low, varying from convex to lowconoidal, the periphery of the last whorl situated above the middle, obtusely subangular in front. Color rather light-brown and opaque; or corneous-brown and somewhat transparent (sometimes pure white). Surface rather glossy, lightly marked with growth-lines and faint traces of incised spiral lines. Umbilicus rather narrow but open. Aperture oblique, at about $45^{\circ}$ with the axis. Peristome rather narrow,
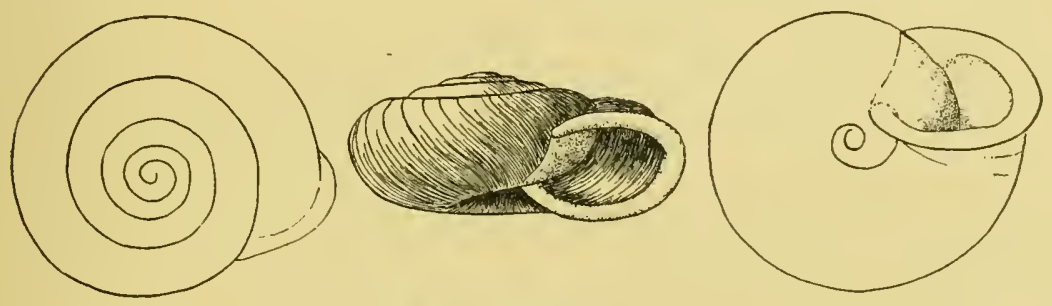

Fig. 4. Ashmunella varicifera Ancey.

reflexed, recurved at the edge, having a low, indistinct thickening of the inner rim of the outer lip, and sometimes the very slight indication of an outer basal tooth.

At resting stages young shells form a callous thickening within the lip, which shows through as a radial streak in some adult shells.

Alt. 8 , diam. $16 \frac{1}{2}$ to $17 \mathrm{~mm}$.; whorls $5 \frac{1}{2}$.

" $10 \frac{1}{2}$, " $18 \frac{1}{2}$ " " 6 .

South side of Miller Canyon near its head; Wickersham Rock, Miller Peak, and in the east fork of Cave Creek Canyon; also a mountain on the south side of the mouth of Ash Canyon. These localities, except the last, are indicated by three areas of vertical shading on the map. Miller Peak is about 9,800 feet high.

This species has not been fully described before. The "varices" to which the name is due are only occasionally present in adult shells. They are also seen in $A$. chiricahuana, which is so similar that until now the Chiricahuan and Huachucan snails were supposed to belong to one species. The soft anatomy shows at once that we have to do with two species. A. varicifera has genitalia exactly like A. lcrettei except that the epiphallus is somewhat shorter. The spermatheca is not differentiated from its duct, the whole form a long somewhat 
varicose cylindric body, while in chiricahuana the duct is extremely long, swollen at the end. The proportions vary widely in the two species, as follows:

A. varicifera. A. chiricahuana

Length of penis, epiphallus and flagellum, 37 to $44 \mathrm{~mm}$. $\quad 73 \mathrm{~mm}$.

Length of spermatheca and duct, . . . 25 to 27 " " 56 "

Length of vagina, . . . . . . . 4 to 5 " 9 "

The size of the shells is about equal. It appears from this that A. varicifera is a simplified member of the $A$. levettei stock, while $A$. chiricahuana belongs to another group of species.

The type locality of $A$. chiricahuana is Fly Park, Chiricahua Mountains.

Extract from Mr. Ferriss' Field Notes.-On the Cave Creek side we found A. varicifera larger than the lot from Wickersham's Rock on the peak, and generally albino. Out of one hole containing 29, only two were dark colored. On the other side of the east fork of Cave Creek they were larger but all dark. On the south side of the range there is a strong tendency to albinism in the Ashmunellas, Sonorellas and Oreohelix.

Ashmunella microdonta n. sp. Fig. 5 .

The shell resembles $A$. varicifera in general appearance, but differs by having fewer whorls, the last wider viewed from above; umbilicus much wider, exposing more of the penultimate whorl. The lip is toothless except for a very low vestige in the basal margin in some specimens; but there is a minute tubercular parietal tooth in over

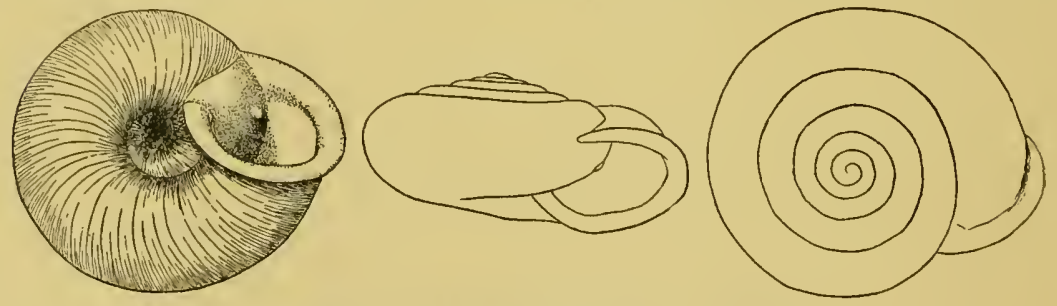

Fig. 5. Asmunella microdonta. Cotype.

half of those examined, while it is perceptible as a faint thickening in all. The shell is chestnut colored, usually with one or two varixstreaks on the base; lip white or with its upper half reddish-brown.

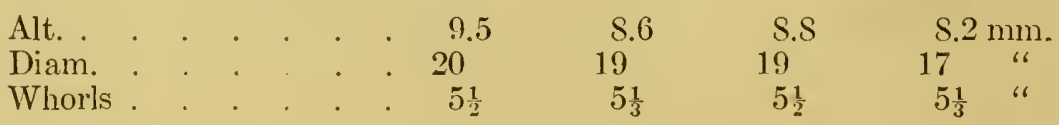


Cave Creek Canyon, for one-eighth of a mile at the head.

This is another modification of the levettei stock, differing from heterodonta and varicifera by its wider umbilicus and less closely coiled whorls, from the former by deficient lip teeth, and from the latter by the usual presence of a minute parietal tooth. In genitalia it does not differ from typical levettei. While not conspicuously differentiated, we have thought it well to give the form specific rank.

Ashmunella levettei heterodonta Pils. Fig. 6.

Proc. A. N. S. Phila., 1905, 241, pl. 15, figs. 81-91. Nautilus, XYIII, p. 51 .

This form has the shape of $A$. levettei, and typically has a low, straight-topped tooth within the outer lip, a small tubercular tooth at junction of outer and basal margins, and a faint prominence in the position of an inner basal tooth. The parietal tooth is minute or wanting. There are barely over 6 whorls, which therefore are a little wider than in A. levettei.

We have elsewhere noted the extreme variability of the teeth in heterodonta. They may be much more developed than described above, or so degenerate that only faint traces of teeth are discernible. A form-chain connecting levettei and varicifera exists. Whether hybridism plays a part here remains uncertain.

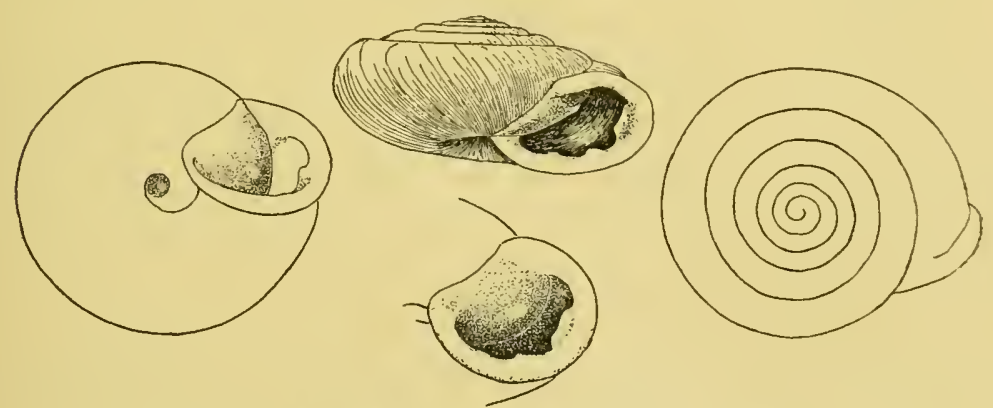

Fig. 6. Ashmunella levettei heterodonta. Cotype.

This form occurs in the heads of Ida and Cave Canyons. In one place heterodonta goes over the divide two or three hundred feet, but in no other case do these species cross to the other side of the range. A. levettei or heterodonta are not found in varicifera territory. There is no mingling of Ashmunellas except large and small forms of levettei. The peculiarities of habit, variation, etc., of the Ashmunellas, Oreohelices, etc., is worthy of a year's study in the Huachucas. The area 
of heterodontu is marked $H$ on the map. Cave Creek Canyon, like that of the same name in the Chiricahua range, has a large basin and many branches.

Ashmunella levettei ursina n, subsp. Fig. 7 .

A. levettei Pilshry, P'roc, A. N. S. Phila., 1905, p. 238, pl. 15, figs. 72-78.

The shell is like A. levettei, capacious and glossy. The aperture is less obstructed by the teeth. The parietal tooth is smaller, straight, not curving inward at the axial end, or almost imperceptibly so, and without an outer branch running towards the upper insertion of the lip.

Alt. 9, diam. 18, diam, aperture $\$ .5 \mathrm{~mm}$; whorls fully $6 \frac{1}{2}$.

“ $7.2 \quad$ " 16 n1m. ; whorls $6 \frac{1}{3}$.

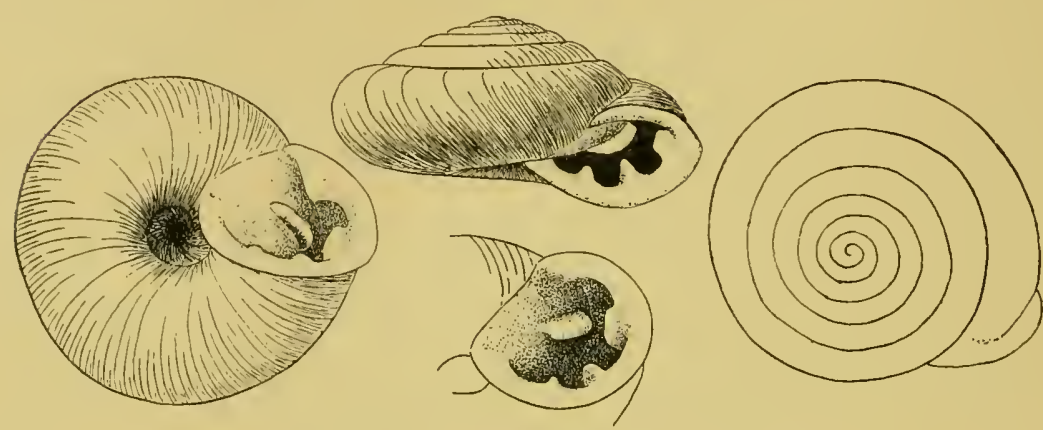

Fig. 7. Ashmunella levettei ursina. Type.

Heal of Benr Canyon, about 7,500 feet eleration. Types No. S7.089 A. N. S. P. It also occurs in the head of Miller Canyon. In Bear Canyon there are many beautiful albino specimens, ocer:rring with others of the normal chestnut color. 'The range of ursinc lies westward from that of heterodonta.

This is the race formerly referred by us to typical 4 . levettei.

Ashmunella levettei (Bland). Fig. 8 .

Triodopis lerettei Bland, Annals of the New Tork Academy of sciences, II, 1S52, p. 115, cuts. Bimney, Manual of American Land shells, p. 385 , fig. 419. Ciratacap, Bull. Amer. Mus. Nat. Hist., NIV, p. $3 \& 3$.

The type specimen of this species (fig. S) was supposed to come from Santa Fe Canyon, New Mexico, but it is distinctly of Huachucan type. The periphery is rounded. The glossy surface is marked with fine growth-wrinkles, and on the last whorl very fine and very faint spiral lines. The parietal callus is distinct, but thin at the edge. The parietal tooth is long, high, straight, but at the axial end it becomes low and curves strongly inward. From the distal end of the tooth a 
low but distinct branch runs towards the outer termination of the lip. This branch is brownish, like the callus it rests upon, hence might easily be overlooked. The outer lip-tooth is slightly emarginate at the top, and curves inward. The outer basal tooth is compressed and larger than the imner one, which is also somewhat compressed.

Alt. 8, diam. $16 \mathrm{~mm}$; diam, of aperture $7.9 \mathrm{~mm}$; ; whorls $6 \frac{1}{2}$.

Description and figure from the type specimen, No. 1,27t of the Binney and Bland Collection, American Musem of Natural History, Sew lork. We owe the opportunity of sturlying this specimen to the kindness of Dr. I. P. Gratacap.

Some specimens from Miller Canyon are identical in characters with the type of levettei. It probably was collected in that canyon.

In Carr Canyon there is a similar race having some differential characters. Dr. Henry Skinner collected a series of several hundred shells. They were taken about midway of the canyon as shown in the map. These shells vary in size:

Alt. 6, diam. 13 mm. ; whorts $6 \frac{1}{4}$.
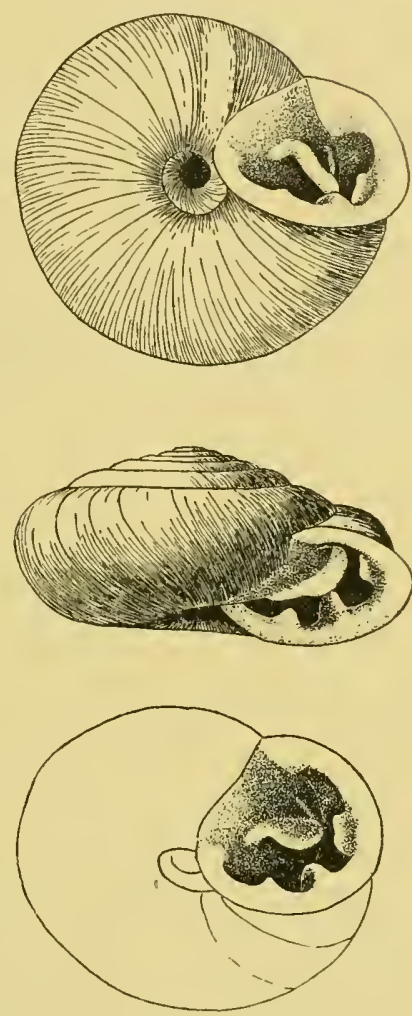

Fig. S. Ashmunella levettei (Bland). Type specimen.

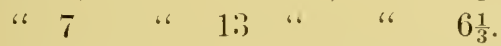

" 7.5 " $\quad 15$ " d diam. aperture $7 \mathrm{~mm}$; ; whorls $6 \frac{1}{2}$.

The last whorl is rather depressed and periphery is slightly angular in front, these being the main differences from typical A. lcvettei. In some specimens the shape of the aperture and of the parietal tooth is exactly as in levettei, but most examples have the aperture smaller, the lip-ends approaching somewhat more, and connected by the thickcned edge of the parietal callus. The parietal tooth almost always is recurved at the axial end, and bears a more or less distinct recurrent branch from the distal end, as in levettei. In some examples, however, the parietal tooth is straight and there is no perceptible outer branch; the upper margin of the lip descends more deeply on the parietal wall than in the type of levettei. The young snails form a very thick lipcallus at resting stage. 
This Carr Canyon race is intermediate between typical levettei and bifurca.

Ashmunella levettei bifurca n. subsp.

In Tamner Canyon the shells resemble those of Carr Canyon. They are glossy, dark chestnut colored, depressed, the last whorl angular in front. The aperture is small, the lip-ends connected by a distinct, uften heary parietal cord. The outer lip-tooth is pushed farther back into the month. The parietal tooth curves inward at its axial end, and usually gives off a distinct branch from the distal end, though this may be weak or wanting in some examples. The mbilicus is usually wider than in other forms of levettei. The whorls coil closely.

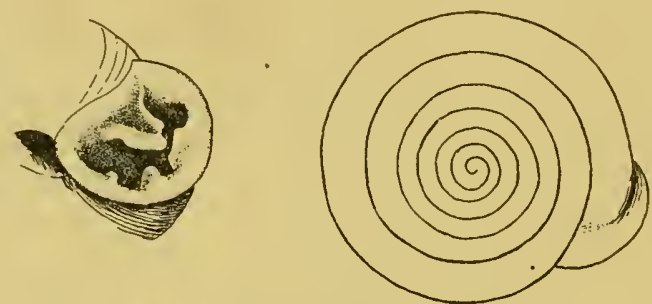

Fig. 9. Ashmunella levettei bifurca. Type.

Alt. 6.6, diam. 15, diam. of aperture $6.9 \mathrm{~mm}$., whorls fully $6 \frac{1}{2}$.

This race is intensified in the development of apertural teeth. 1. mcarnsi (Dall) is more depressed and has less numerous, less closely eoiled whorls.

The spermatheca is more slender, scarcely sacculate or less conspicuously so than in other Huachucan species; and is a little enlarged towards the end, the lower part of the duct slender.

Ashmunella levettei angigyra Pils.

Proc. A. N. S. Phila., 1905, p. 240, pl. 14, figs. 47-54 (shell); pl. 21, fig. $2 S$ (genitalia); pl: 22, fig. 12 (teeth); pl. 23, fig. 14 (jaw).

Smaller, more depressed than levettei, and more or less angular at the periphery, teeth contracting the aperture more.

The types, described and illustrated as above cited, were from Ramsey Canyon (called "Conservatory Canyon" in the original paper). Those from northwestward and along the warm dry slopes of the ridge are more typical of the race, being smaller and more angular. The parietal tooth is straight and rather small, without an outer branch. It occurs along the northeastern side of the range from northwest to southeast as follows: Babokomari Creek; Fort Huachuca; Tanner Canyon, over the range, west fork, and along cliffs south of 
the canyon; Brown's Canyon; Limestone Mountain, 9,000 feet; Ramsey Canyon; also over the range on the foothills of Bear Canyon at about 5,000 feet, where it is very widely separated from other known localities, and very small, diam. 9.5 to $11 \mathrm{~mm}$.

The race from Carr Canyon is intermediate between angigyra and levettei in size and shape of the last whorl. The examples from Lime-
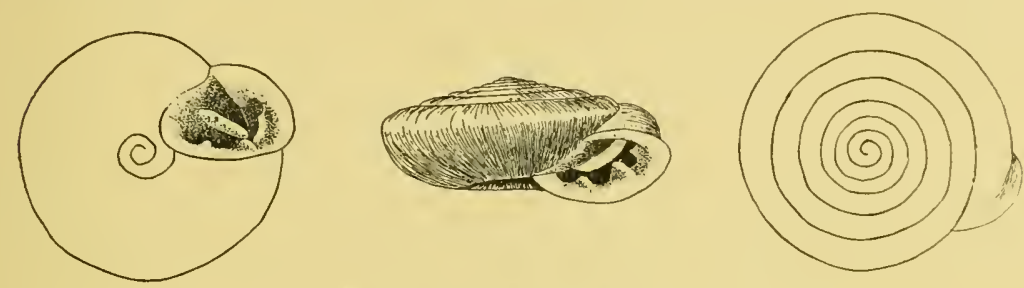

Fig. 10. Ashmunella levettei angigyra. Cotype.

stone Mountain and Salvation Ridge approach those of Carr Canyon in size and apertural teeth, and would probably be grouped with that race rather than with typical angigyra, if the two be separable.

A. l. angigyra is the common and widely distributed Ashmunella of the Huachucas. The other forms are very local.

The epiphallus is curiously flattened, dumbbell-shaped in section in several individuals (alcoholic) from east fork of Salvation Canyon, and the lower part of the spermatheca duct is slender.

Ashmunella mearnsi (Dall).

Polygyra mearnsi Dall, Proc. U. S. Nat. Mus., XVIII, 1895, p. 2 (Hachita Grande and Huachuca Mountains); XIX, 1896, p. 343, pl. 32, figs. 7, s, 11.

This species was described as from two widely separated localities. It differs from all other Huachucan species by having fewer, less closely coiled whorls. In these features it belongs to a small group of forms from southwestern New Mexico, composed of A. walkeri Ferriss and $A$. kochi Clapp. We have much to learn about the snails of these alluring desert mountains, but it seems likely that there was a mistake in the locality Huachuca Mountains, and that the species really came from the Hacheta Grande Mountains only.

\section{Genus OREOHELIX Pilsbry.}

The Huachucan Oreohelices have been described and illustrated as fully as possible to us in the first paper of this series.

Oreohelix strigosa concentrata (Dall).

Carr Canyon, 7,000 feet; Limestone Mountain, 8,000 feet; Miller Peak, Ash Canyon. The shells from Miller Peak are rather openly umbilicate 
and have a peculiar facies. Some greenish-white ones remind one of Circinaria concara.

Oreohelix strigosa huachucana ( 1 ils.).

Ramsey, Brown, Carr, Miller, Care Creek and Ida Canyons; north side of Miller Peak.

Genus THYSANOPHORA Strobel.

Thysanophora hornii (Gabb).

Manilla mine, near the northwest end of the range.

\section{UROCOPTID Æ.}

Holospira ferrissi Pils.

Manilla mine, near the northwest end of the range. The locality Fort Bowie, formerly cited by us, was an error.

\section{LIMACID Æ.}

Agriolimax hemphilli ashmuni Pilsbry and Vanatta.

Nautilus, XXII, p. 108.

Limaces are rare in Arizona, but Mr. Ashmun took specimens at Nogales, Pima county, 4,000 ft. elevation, and they were found by one of us in Miller, Brown and Tammer Canyons in the Huachucas.

These slugs belong to the very widely distributed group of Agriolimax lavis, but we have not been able to refer them directly to any described race. By the development of entocones on the lateral teeth they differ from A. campestris (including montanus Ing.), and agree with A. hemphilli (Binney), ${ }^{7} A$. stenurus (Strebel) ${ }^{8}$ and $A$. berendti (Strebel). ${ }^{9} \quad$ Whether these forms are specifically distinct or not remains to be determined. Their distinctive characters do not seem important.

The alcoholic specimens from Miller Canyon have the general aspect externally of A. campestris. The rounded back is black, flanks sooty brown. The mantle is large, and more than half of it is free, so that when lifted and turned back it more than covers the posterior adnate portion. Under it the surface is yellowish. 'The sole is very narrow, conspicuously tripartite. The central tooth is tricuspid. Iaterals have a small entocone elevated on the side of the mesocone; ectocone

${ }^{7}$ Limax hemphilli $\mathbb{W}$. G. Binney. Third Supplement to Terrestrial Mollustis, V, 1S90, p. 201, pl. 1, fig. 13; pl. 2, fig. 3; pl.8, fig. E (Julian City, Cal.). Fourth Supplement, p. 166, pl. 3, fig. 1 (var. pictus Ckll., San Tomas River, L. Cal.).

${ }^{8}$ Limax stenurus Strebel, Beitrag Mex. Land und Süsswasser Conchyl., IV, 1880, p. 21 (State of Vera Cruz, Mexico).

- Limax berendti Strebel, t. c., P. 22 (Coban, Guatemala). Cf. also L. jalapensis Strebel, $l$. $c$. 
well developed. There are 13 lateral teeth, the 13 th being transitional to the marginals, which are simple, thorn-shaped. Jaw as usual. The penis is large, much twisted, terminates in an obtuse "flagellum" or blind sack, and it has a fleshy sensory papilla in the anterior enlargement, shown by dotted lines in fig. $8 c$. In front of this enlargement it is very slender. It has an extremely slender retractor muscle (p.r.). Other organs as usual in the group.

Examples from Tanner Canyon have the same genitalia, but differ

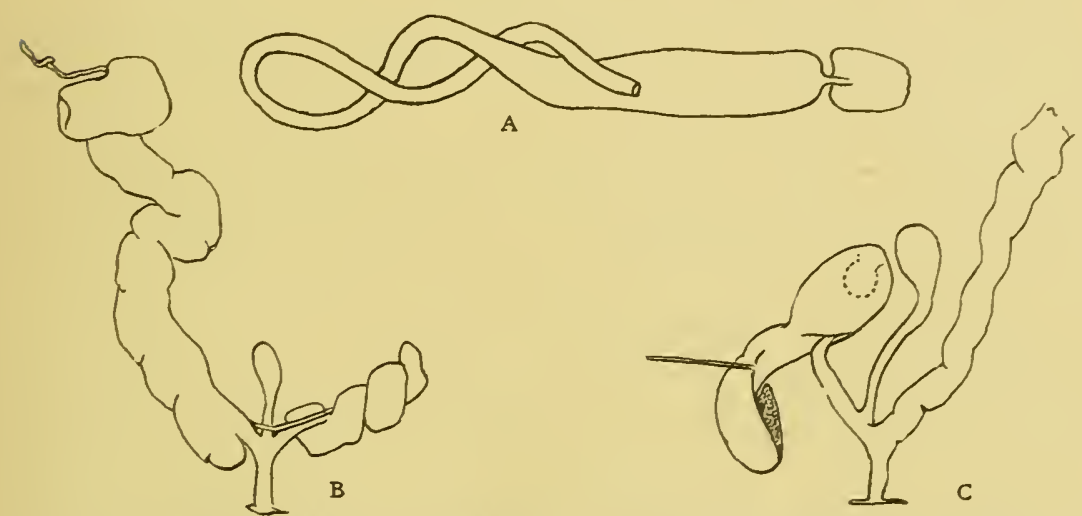

Fig. 11. Agriolimax hemphilli asimuni. $a, b$, alimentary canal and genitalia of a specimen from Togales. $c$, genitalia of the type from Miller Canyon.

in external color. They are pale soiled buff, with a slightly darker reticulation back of the inantle, which is closely flecked with gray. These slugs are therefore not unlike $A$. hemphilli pictus Ckll.

According to Mr. Binney, A. hemphilli has 50, 1, 50 teeth with 10 laterals. This is somewhat unlike our slug, which has more lateral teeth, though of the same shape; moreover, the penis of A. hemphilli seems to differ from the Arizona form, which occurs in a region otherwise wholly diverse in its mollusk population. A. stenurus and $A$. berendti of Strebel belong to the tropical fauna. Since the Arizona form differs materially in dentition from the described alpine slugs of Colorado, we have thought it safest to give a special name to the mountain slug of Arizona, until such time as the sereral forms can be actually compared by some observer, and their relations to one another elucidated.

The types of A. hemphilli ashmuni are No. 94,366 A. X. S. P., from Miller Canyon, Huachuca Mountains.

\section{ENDODONTID $Æ$ F.}

Pyramidula (Gonyodiscus) cronkhitei (Newc.).

Wickersham's, Miller Peak; Carr Canyon. 
Pyramidula (Gonyodisous) shimeki cookerelli Pils.

"Reef," Carr Canyon, at 5,000 feet (C. R. Biederman).

Radiodiscus millecostatus Pils. and Ferr.

Carr Canyon; Miller Peak, near the top and on the north side, and in Wickersham's Gulch; Wickersham's.

Helicodiscus eigenmanni arizonensis Pils. and Ferr.

Found in 1904, no special locality recorded.

\section{ZONITID丑.}

Zonitoides arborea (Say).

Wickersham's Rock, Miller Peak; Tanner Canyon; Ash Canyon.

Zonitoides minusoula (13inn.).

Wickersham's, Miller Peak; Tanner Canyon; Benson.

Zonitoides minuscula alachuana (Dall).

Ash Canyon; Wickersham's.

Zonitoides milium meridionalis Pils. and Ferr.

Wickersham's.

Vitrea indentata umbilicata (Ck11.).

Tanner Canyon; Wickersham Gulch; Miller Canyon, one very large example, diam $6.7 \mathrm{~mm}$; Ash Canyon.

Euconulus fulvus alaskensis Pils.

Wickersham's rock, Miller Peak.

Vitrina alaskana Dall.

Wickersham's, Miller Peak.

\section{SUCCINEID巫}

Sucoinea avara Say.

Tamner and Ash Canyons.

\section{VALLONIID \&.}

Vallonia perspeotiva Sterki.

Tanner, Pine and Ash Canyons; Wickersham's, Miller Peak.

Vallonia cyclophorella Ancey.

Wickersham's, Miller Peak.

\section{PUPILLID丑. ${ }^{10}$}

\section{Pupilla hebes (Ancey).}

Wickersham's, Miller Canyon.

${ }^{10}$ Pupoides hordacea (Gabb) and Pupilla syngenes (Pils.) were found in rive1 drift at Benson. Of the latter both dextral and sinistral shells, one of each. 
Bifidaria quadridentata Sterki.

Wickersham's, Miller Canyon. One specimen.

Bifidaria ashmuni Sterki.

Ash Canyon.

Bifidaria cochisensis Pils. and Ferr.

Tanner Canyon, abundant. This form and the following will be described in the next paper of this series, in connection with a general review of the group of $B$. ashmuni.

Bifidaria coohisensis oligobasodon Pils. and Ferr.

Ash Canyon.

Bifidaria pilsbryana Sterki.

Wickersham's, Miller Peak.

Bifidaria tappaniana (C. B. Ad.).

Tanner Canyon, 6,000 feet; also San Pedro drift at Benson. ${ }^{11}$

Vertigo ovata Say.

Ash Canyon; Tamner Canyon, 6,000 feet; also San Pedro drift at Benson.

Vertigo modesta parietalis Anc.

Wickersham's, Niller Peak.

Vertigo conoinnula Ckll.

Wickersham's, Miller Peak; one immature shell.

Vertigo milium Gla.

Tanner Canyon, 6,000 feet; drift of San Pedro river at Benson.

\section{FERUSSACID $Æ$.}

Cochlicopa lubrica (Müll.).

Tanner Canyon, 6,000 feet; Carr Canyon; Wickersham's, Miller Peak.

\section{LYMNÆID Æ.}

Lymnæa parva Lea.

Ash Canyon; a few very young specimens.

\section{PHYSID Æ.}

Physa virgata Gld.

Small, slender, long-spired examples, clearly of the virgata type, were taken in Tanner Canyon, in a spring at about $6000 \mathrm{ft}$.

${ }^{11}$ Bifidaria pentodon (Say) was taken in San Pedro drift at Benson, Cochise county, Arizona. 


\section{AMNICOLID平.}

Paludestrina stearnsiana Pils.

Ash Canyon, one bleached specimen; spring in Tanner Canyon, numerous living examples.

\section{PELECYPODA}

Pisidium abditum huachucanum Pils. and Ferr.

Stream in Carr Canyon (C. R. Biederman, type loc.); spring in Carr Canyon, 7,000 feet; springs in Tanner Canyon at 6,000 and 7,000 feet; spring at the mouth of Ash Canyon, 4,500 feet; artificial pond at the mouth of Huiter Canyon, 4,500 feet (L. E. Daniels, October, 1907).

This is, we believe, the only Pisidium recorded from Arizona.

\section{Explaxition of Plates MIX to NXI.}

Plate NIX.- Figs. 1, 2, 3-Sonorella dalli Bartsch. Tanner Canyon.

Figs. 4, 5, 6-Sonorella granulatissima latior Pils. Cotypes.

Figs. 7, 8-Sonorella gramulatissima Pils. Cotypes.

Fig. 9-Sonorella granulatissima Pils. Miller Canyon.

Figs. 10, 11, 12-Sonorella granulatissima paria Pils. Cotypes.

Figs. 13, 14, 15一Sonorella danielsi Pils. and Ferr. Cotypes.

Fig. 16-Sonorella huachucana Pils. Bear Canyon.

Fig. 17--Sonorella huachucana Pils. Type.

Fig. 18-Sonorella danielsi P. and F., brown variety. Ash Canyon, No. 94,385 .

PLAte XX.-Fig. 1-Ashmunella levettei ursina Pils. and Ferr. No. 94,351.

Fig. 2-Ashmunella l. angigyra Pils. No. 83,269.

Fig. 3-Ashmunella varicifera Anc. No. 94,341.

Fig. 4-1shmmella levettei ursina P. and F. No.94,349. Atrium and ends of penis and vagina protruding.

Fig. 5-A shmunella varicifera Anc. Spermatheca of another individual.

Fig. 6-Ashmunella varicifera Anc. Penis opened.

Fig. 7 -1 shmunella microdonta Pilsbry and Ferriss. No. 94,347. One of the cotypes.

Plate XXI.-Fig. 1-Sonorella granulatissima Pils. No. \$3,257. Cotype.

Fig. 2-Ditto. Penis opened to show papilla.

Fig. 3-Ditto. Penis, epiphallus and flagellum.

Fig. 4-Ditto. No. 94,336. Miller Canyon.

Fig. 5-Sonorella danielsi Pilsbry and Ferriss. No. 94,337.

Fig. 6-Sonorella danielsi Pilsbry and Ferriss. No. 94,31s. Type.

Fig. 7-Sonorella g. latior Pils. No. 94,387. Tanner Canyon.

Plate XXII.-Figs. 1, 2, 3-Sonorella rinconensis Pils, and Ferr. Central, lateral and marginal teeth.

Fig 4-Sonorella rinconensis. Type, genitalia. $\times 2$

Fig. 5-Sonorella dalli Bartsch. No. 94,384, genitalia. $\times 2$.

Fig. 6-Sonorelle dalli Bartsch. Jaw. 


\section{A NEW SONORELLA FROM THE RINCON MOUNTAINS ARIZONA.}

BY H. A. PILSBRY and J. H. FERRISS.

The Rincon Mountains lie near the western border of Cochise County, Arizona, north of the Whetstone Mountains, which are north of the Huachuca range.

In 1907 one of us (Mr. Ferriss) visited the range and procured specimens of a large Sonorella, the first molkusk known from these mountains.
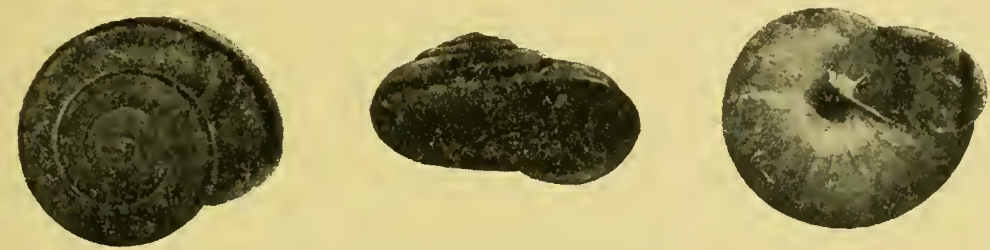

Fig. 1. Sonorella rinconensis. Cotypes, nat. size.

Where visited the range is rather dry. The rock is granitic, of pre-Cambrian age. ${ }^{1}$ Besides Sonorella rinconensis only a few shells were taken, minute forms common to the region. Sonorella rinconcnsis was found sticking to large rocks and boulders, a habit not hitherto noticed in the genus. They are rare, the biggest bag made being six in one day.

Sonorella rinconensis n. sp. Pl. XXII, figs. 1-4, 7 .

The shell resembles $S$. ashmuni Bartsch in shape. It is pale brown fading to white around the umbilicus, with a broad chocolate shoulderband, widely whitish-bordered above and below. The surface is smoothish, marked with delicate growth-lines, and under the lens some faint spiral lines may be traced on the last whorl near the suture. The embryonic whorls have sculpture of the $S$. hachitana type. The whork increase rather slowly to the last, which is much widened, and well rounded peripherally. It descends a litfle in front. The aperture is rotund-lunate; peristome slightly expanded, dilated at the columella as usual. Umbilicus about as in S. ashmuni.

Alt. 16, diam. 26.5, width of umbilicus $4 \mathrm{~mm}$.; whorls fully 5 .

The penis is extremely long and slender, and contains a very long papilla. Its lower end is enveloped in a sheath. The retractor

${ }^{1}$ Cf. W. P. Blake, Some Salient Features in the Geology of Arizona, with Evidences of Shallow Seas in Paleozoic Time, Imerican Geologist, Vol. 27, 1901, p. 160 . 
muscle is inserted distally on the lung-floor, as usual. The vagina is excessively long, longer than the penis, and of about equal diameter throughout (slightly over $1 \mathrm{~mm}$.). The spermatheca is globular, its duct much shorter than the vagina. The organs of an individual drowned and dissected fresh measure as follows:

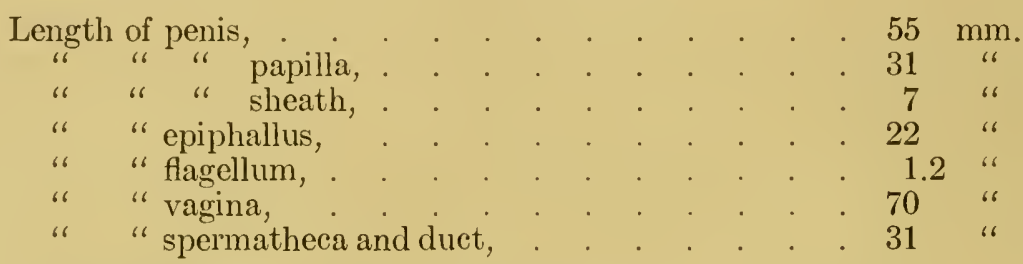

The liver is maroon colored when fresh.

Types No. 94,313 A. N. S. P., from Rincon Peak, Rincon Mountains, Cochise County, Arizona; cotypes in coll. Ferriss. Specimens were also taken on Mt. Mica and Wrong Mountain, Rincon range.

The jaw (pl. XXII, fig. 7) has six or seven strong ribs, projecting on both margins.

The radula has $26,15,1,15,26$ teeth (pl. XXII, figs. 1, 2, 3). The central and lateral teeth are unicuspid, the cusps stout and obtuse, longer than the basal plates. At about the sixteenth tooth an ectocone appears. Towards the outer edge of the radula the inner cusp becomes bifid; and in many but not all of the outermost six or eight marginals the ectocone is split into two or three denticles (fig. 3).

Conchologically this form stands very close to $S$. ashmuni Bartsch, from Richinbar, south of Prescott, Arizona; also found at Jerome, and at Purtyman's ranch on Oak Cleek, 40 miles from Jerome. It would probably be scarcely possible to separate the two species by the shells alone. The genitalia, however, are widely diverse. S. ashmuni (Oak Creek) has genitalia of the type found in hachitana-like Sonorellas of the Peloncillo, Florida and Dos Cabezas ranges, while S. rinconensis has the penis and vagina excessively lengthened While quite unlike any known form, it seems nearer to $S$. virilis than to other species which have been dissacted, but differs from that by its far shorter penis-papilla and by the vagina, which is much longer than the penis, while in $S$. virilis the penis is longer.

Plate XXII.-Figs. 1, 2, 3-Sonorella rinconensis Pils. and Ferr. Central lateral and marginal teeth.

Fig. 4-Sonorella rinconensis. Type, genitalia. $\times 2$.

Fig. 5-Sonorella dalli Bartsch. No.94,384, genitalia. $\times 2$

Fig. 6-Sonorella dalli Bartsch. Jaw.

Fig. 7-Sonorella rinconensis. Jaw.

Fig. 8-Sonorella dalli. Teeth. 


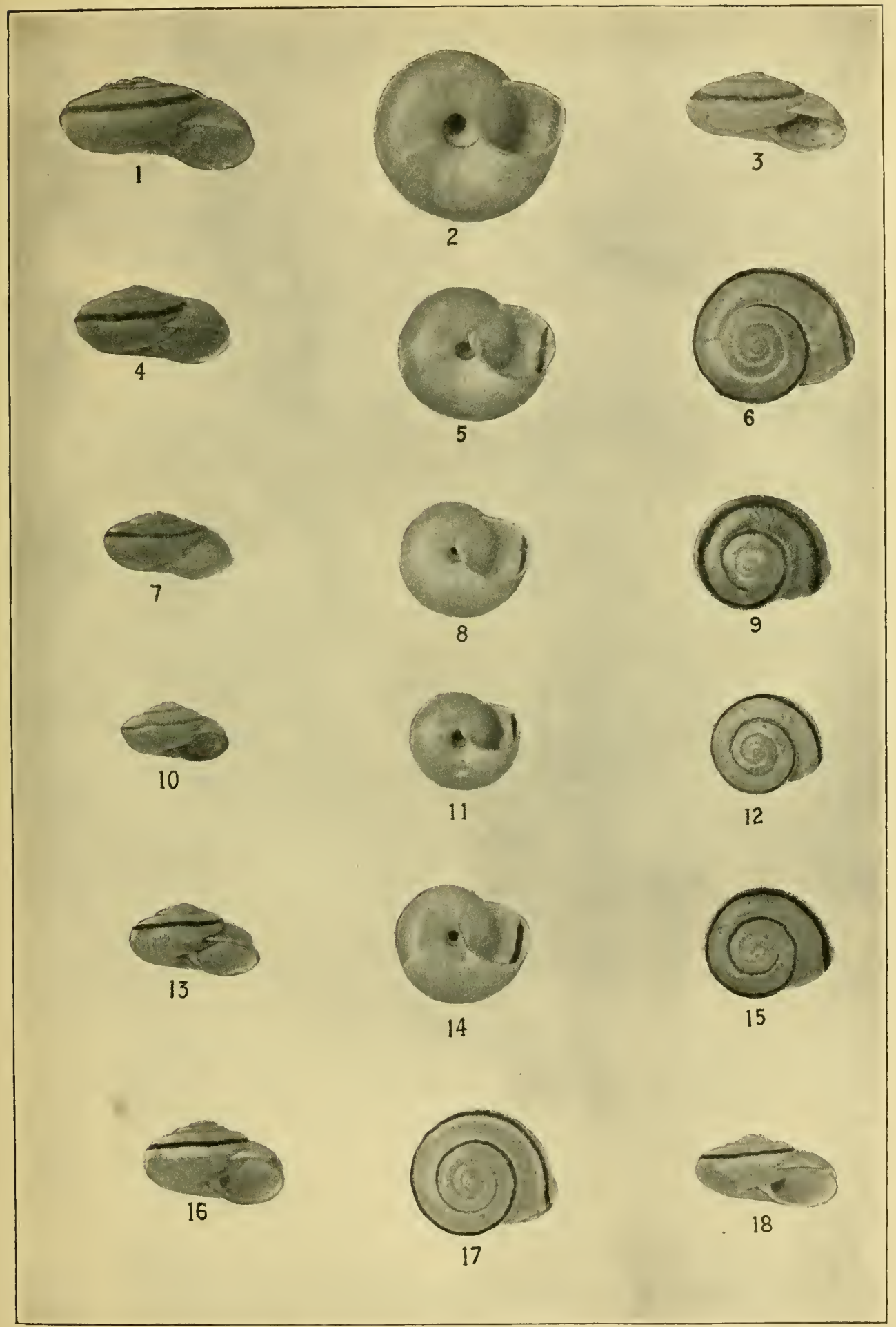

PILSBRY AND FERRISS: MOLLUSCA OF SOUTHWESTERN STATES. 


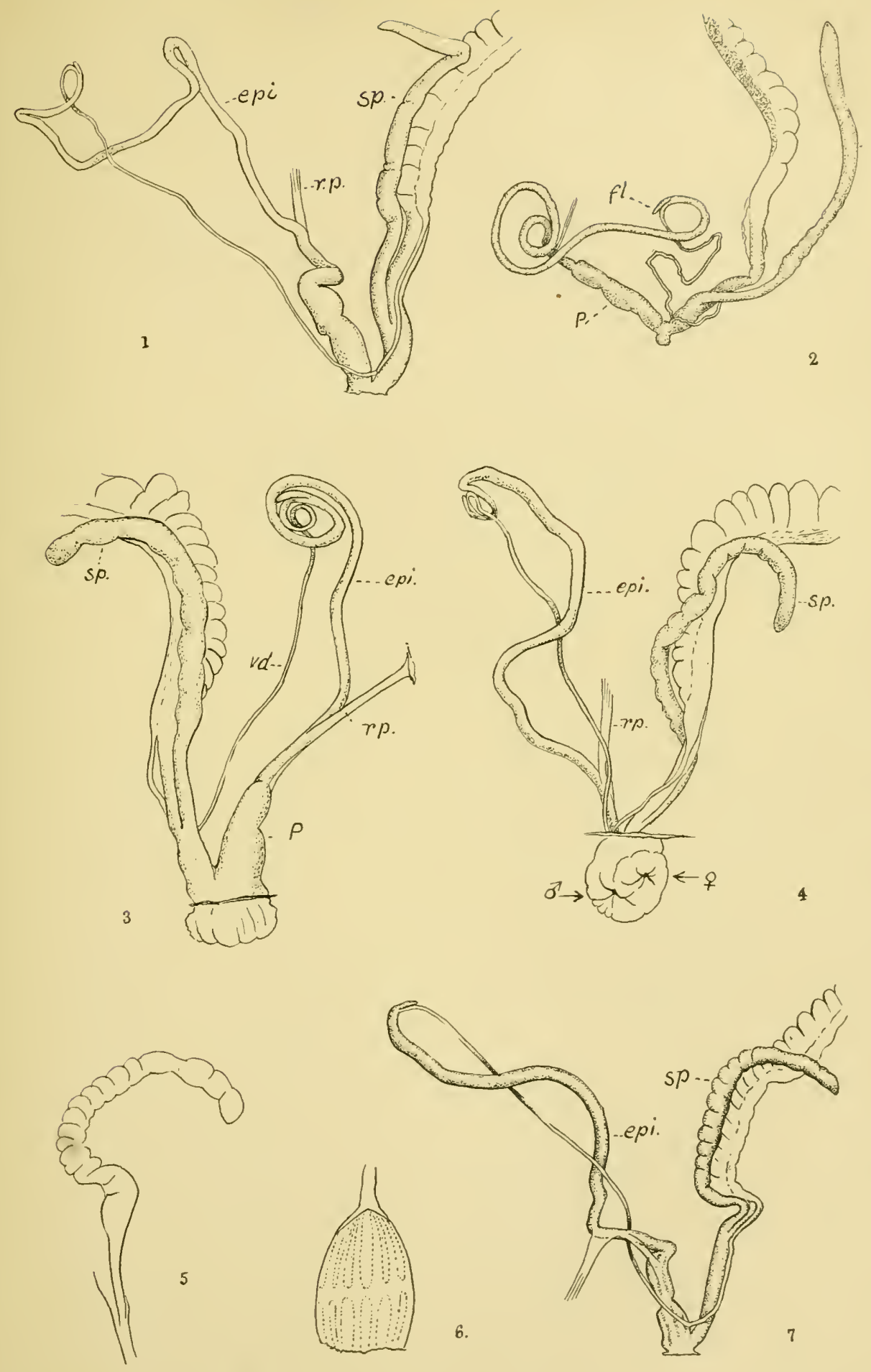

PILSBRY AND FERRISS: MOLLUSCA OF SOUTHWESTERN STATES. 



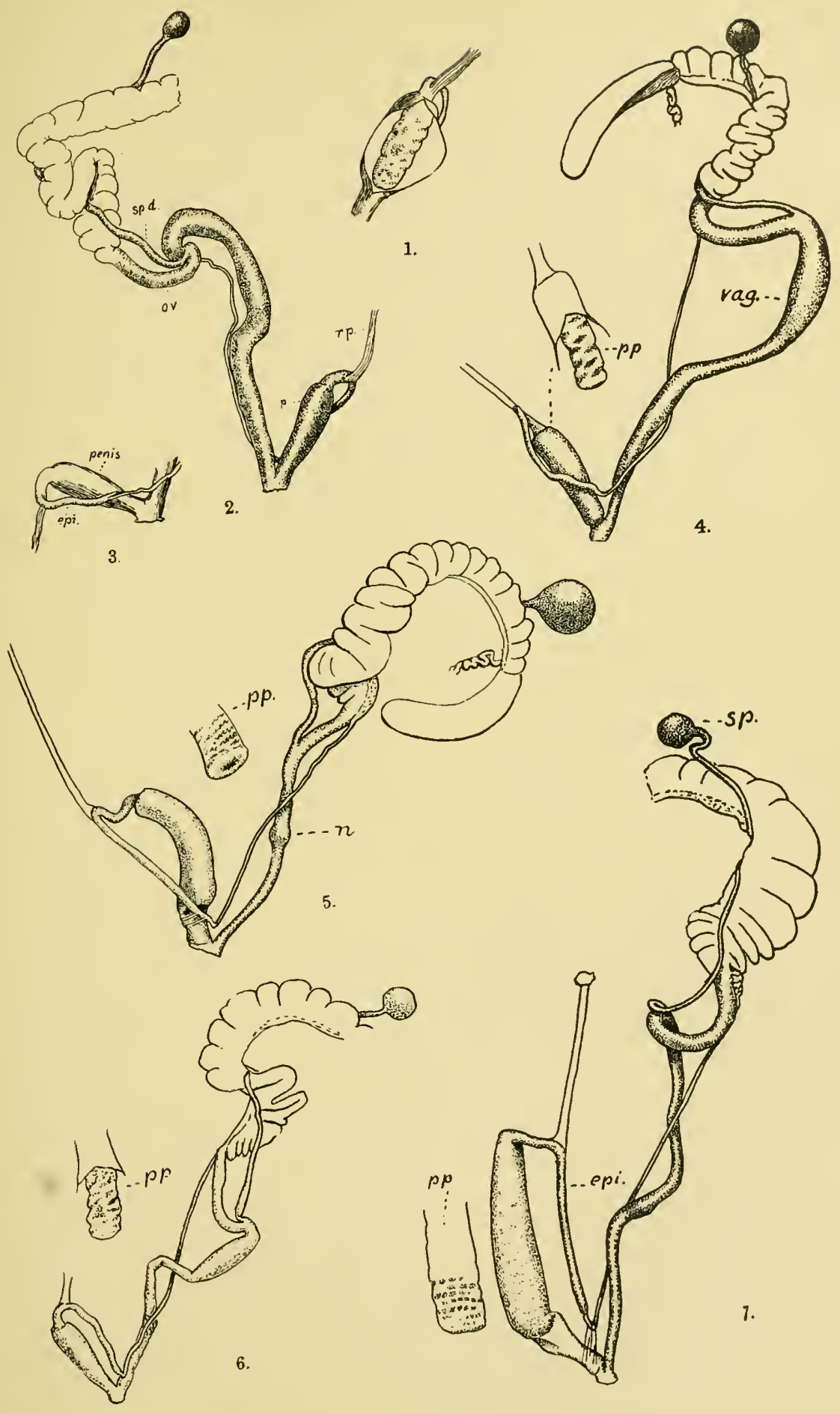

PILSBRY AND FERRISS: MOLLUSCA OF SOUTHWESTERN STATES. 



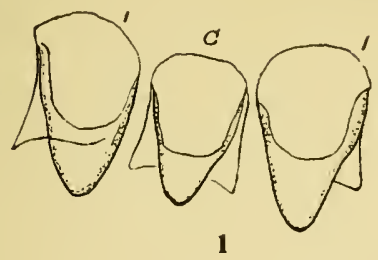

$4 j^{25} \cdots \overbrace{}^{16}$
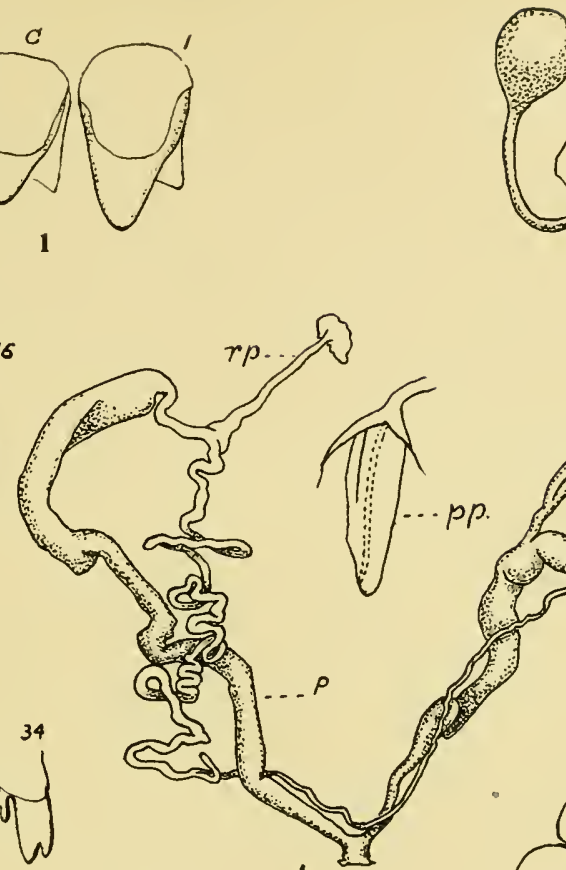

mant. ving
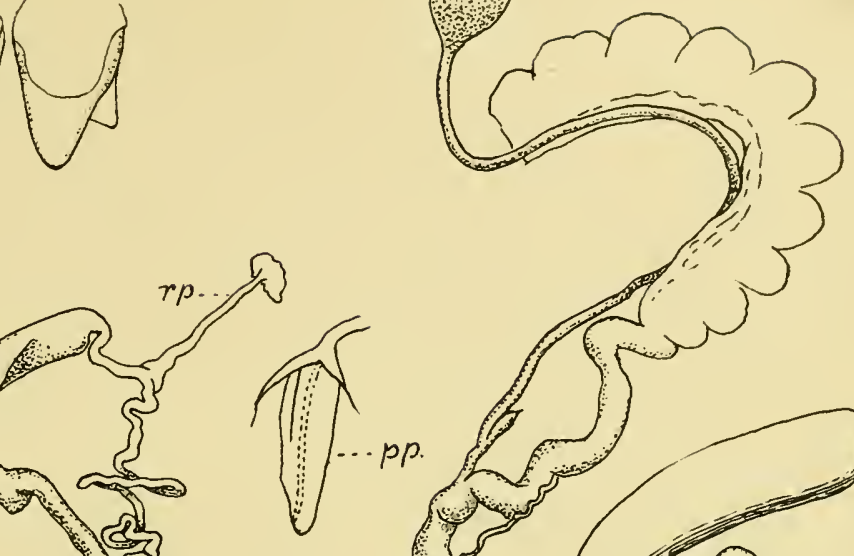



\section{Mollusca of the Southwestern States. \\ IV. 'The Chiricahua Moun- tains, Arizona.}

BY

H. A. Pilsbry and J. H. Ferriss.

From the Proceedings of The Acudemy of Natural Scionces of Philadelphia, February, 1910.

Issued April 25, 1910. 


MOUNTAINS, ARIZONA.

\author{
BI H. A. PILSBRI AND J. H. FERRISS.
}

\title{
Contents.
}

Introduction.

I. Conditions determining the isolation of snail colonies, p. 46.

III. Influence of environment on the shell, p. 47.

III. Factors in the formation of species and races, p. 49.

IV. Distribution of Chiricahuan mollusks, p. 50.

V. Systematic descriptions of species, p. 53 .

The Chiricahua Mountains stand near the southeastem angle of Arizona, extending for about fifty miles from northwest to southeast, being one of the numerous short roughly parallel ranges of that part of New Mexico and Arizona. The Peloncillo range, lower and very arid, sharply limits the horizon eastward, distant about twenty miles. The next range westward is the Dragoon Mountains, fully thirty miles away. These ranges are separated by mesa having an elevation of about 5,000 feet, but lower in the middle.

The northwestern end of the range is known as the Dos Cabezas Mountains, being separated from the main range by a depression to 5,500 feet near Fort Bowie. The mountains as far south as White Tail Canyon are rather arid, the trees stunted oaks and piñons, with small beech, walnut, willow, buttonwood, etc., in the canyons. The Cave Creek region is much more verdant and at elevations of $\$, 000$ feet and over there are fine pine and spruce forests.' The mountains are rugged, alnost everywhere cut into sharp ridges and peaks, the slopes steep and stony or rocky, often broken by cliffs. The accompanying map gives a general idea of the positions of the various valleys or canyons mentioned herein. Various maps of single canyons give the locations of collecting stations. ${ }^{2}$

${ }^{1}$ For an account of the flora of the Chiricahuas see J. C. Blumer, The Plant Geography of the Chiricahua Mountains, Science, XXX, p. 720, November 19, 1909 .

2 The general map of the range and that of Cave Creek Canyon were drawn from sketches made by both authors, with some few additions to the general map from a map of the Chiricahua Forest Reserve, published by the Forest Service, U. S. Department of Agriculture, 1906. This map is very inaccurate in many details, yet useful in the absence of anything better. The other maps of canyons are from the note-book of one of the authors. Elevations where given herein are in part from the Forest Reserve map, in part estimated; and all must be accepted as only approximate. 
The highest part of the range, and that florally and faunally richest, has been included since 1906 in a U. S. Forest Reserve; the rest of the range has no timber large enough to tempt the lumberman, and

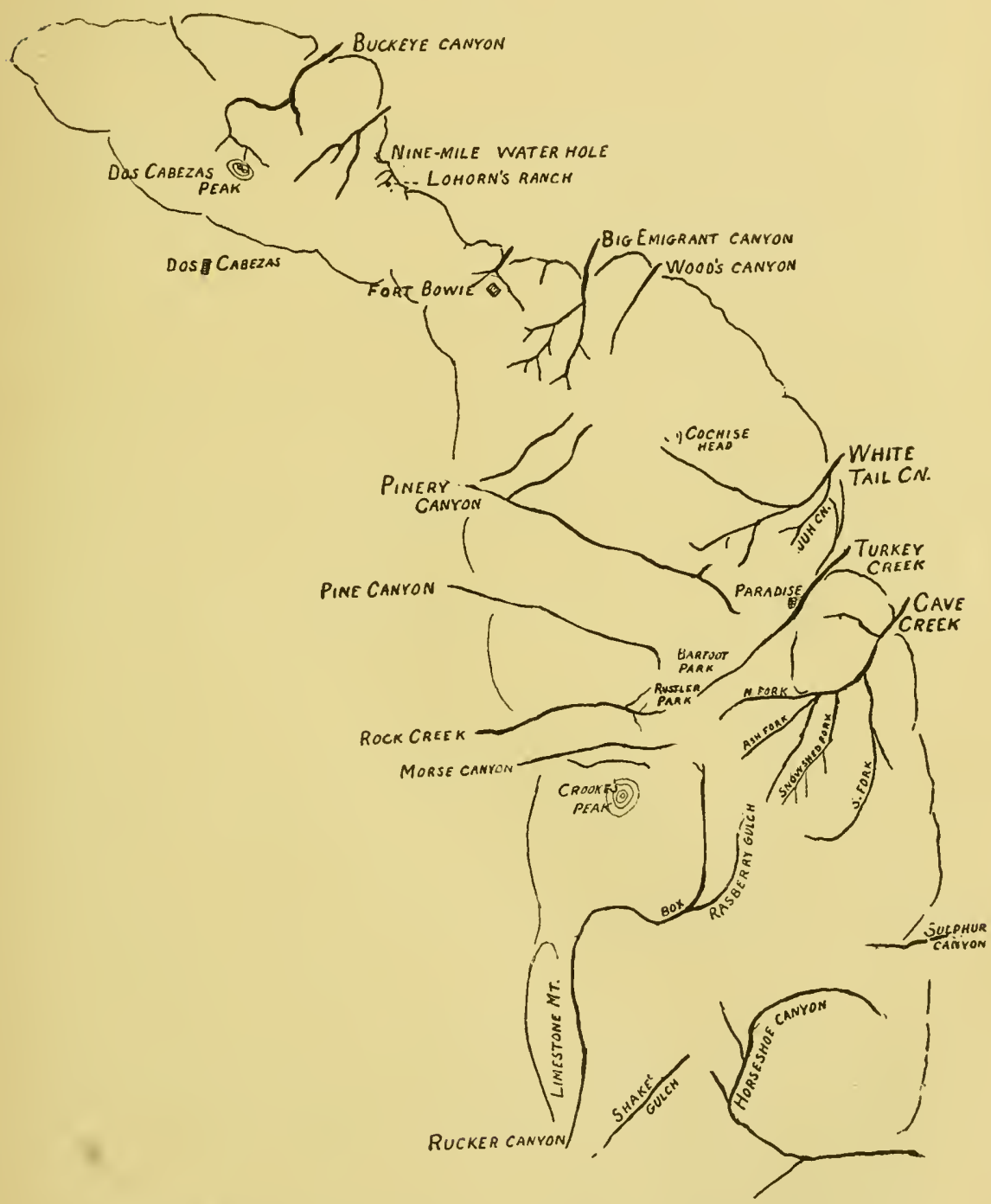

Fig. 1.-Map showing positions of the canyons in the Chiricahua range.

serves as cattle ranges. The conditions of molluscan life are likely to remain undisturbed for many years.

We have herein given an account of the present status of the mollus- 
can fauna as full as circumstances permitted. In many of the canyons we have endeavored to locate the individual snail colonies with sufficient detail to insure their recognition by subsequent observers, so that their further evolution may be followed. Large areas still remain to be explored, and neither author has had time to fully study the material collected.

The first record of mollusks from the Chiricahuas was made by Dr. R. E. C. Stearns, who in 1890 describes specimens of Holospira arizonensis. ${ }^{3}$ collected by Mr. Vernon Bailey for the U. S. Department of Agriculture at Dos Cabezas, in the western foothills of the Dos Cabezas Mountains. In 1895 Dr. W. H. Dall described Polygyra chiricahuana and subsequently (1S97) he reported Pyramidula striatella, Thysanophora ingersolli and Zonitoides arborea, ${ }^{4}$ all from Fly's Park in the central Chiricahuas, collected by Dr. Fisher. No other species were known from the range prior to the first visit by Mr. Ferriss in February, 1904. Numerous new species were found during this brief visit, notwithstanding the unfavorable season. In November, 1906, both of us collected in the range, exploring the principal canyons from Buckeye in the north to Cave Creek and the parks about its head. In November, 1907, Messrs. Ferriss and J. E. Daniels spent two weeks in the Chiricahuas, and in 1908, from September 20 to November 15, Ferriss continued the work of exploring the southern canyons.

\section{Conditions Deterinning the Isolation of Snail Colonil:s.}

The faunas of the several mountain l'anges of southern Arizona are separated one from another by the intervening nearly level mesa, where snails are absolutely wanting and camot exist. This is due not alone to their greater aridity, higher temperature and xerophytic flora, but chiefly we believe to the absence of rocks, in the interstices of which snails might burrow below the dry surface to depths where a certain amount of moisture is retained. The mesa forms a barrier as impassable to land snails as an equal expanse of sea; and can be surmounted only by minute forms light enough to be transported by the wind. During the existence of the present conditions. Which probably were initiated in the Pliocene, the larger snails of each range have been absolutely isolated.

Owing to the general north and south trend of the ranges, the main canyons run eastward or westward, thus exposing a very hot slope

${ }^{3}$ Proc. U. S. Nat. Museum, XIII, 1890.

4 Proc. U. S. Nat. Museum, XVIII, 1895, and XIX, 1897. 
with little vegetation northward and a more shaded slope on the south side, having more vegetation, but deeply interrupted by side canyons and ravines. These conditions may be illustrated by the map of White Tail Canyon (p. 75). It will be noticed thereon that on the southern side of the canyon the collecting stations are nearly all on northwestern slopes, none on northeastern. The latter are barren, and except near the top of the ridge form impassable barriers to mollusks. In the more arid portion of the range, snails are rarely found, often wholly wanting, on the slopes with mainly southern exposure. These conditions of exposure determine the limits of snail colonies, absolutely inhibiting migrations of much extent, though the anastomosing heads of adjacent canyons sometimes supply favorable slopes.

The isolation of snail colonies is further favored by the habits of most of the Helices, which live deep in rocky talus or slides. They probably crawl about in the open only on rare occasions, and are wholly incapable of crossing slopes where shelter is lacking. We have never found living Helices on the surface in the Chiricahua Mountains, and with the exception of Oreohclix chiricahuana, living individuals were always found well buried in the rocks. Of some species, not even dead shells have been found on the surface. Some of these races apparently live and die under the surface.

The progressive growth of the canyons by the deepening of lateral ravines and formation of new ones constantly accentuates the isolation of colonies by forming new slopes, of which one in each case is likely to be arid and therefore a barrier to the spread of snails. Moreover, the removal by erosion of stratified rocks, especially limestone, exposes ridges of granitic or eruptive rocks, in which snails are generally scarce, and some genera never present. Since the period of isolation of the several ranges, there has therefore been progressive isolation of colonies within each range.

\section{Influence of Environment ox the SHELl.}

Relation of Climate to Shell-texture.-Notwithstanding the aridity of the climate, the Chiricanuan suails show none of the characteristics which some recent authors have considered to be the direct reactions to the desert environment. With the exception of Oreohelix chiricahuana, none of the species are conspicuously earthy, and none differ markedly in sculpture from snails of more humid districts.

Rude, irregular sculpture and opaque chalky substance characterize land snails which live exposed to the sun. In such places their 
active life and periods of growth are certainly limited to dewy nights and times of rain, ${ }^{5}$ whether they live in a reasonably humid region, as Cerion on the coast of Cuba, or in an arid region, as some Oreohelices of the Rocky Mountains. Pulmonate land snails which pass their lives hidden from the sun or shaded by dense foliage, do not have notably chalky shells, even in Arizona where a great part of the year is dry. We regard the opacity and cretaceous texture of exposed suails as in no way due to the direct action of climatic factors, ${ }^{6}$ but as a protective adaptation to excessive sunlight, which would readily penetrate thin shells, or those composed largely of conchiolin. ${ }^{7}$

Oreohelix chiricahuana and in some cases Holospira are the only Chiricahuan snails which live on or close to the surface, uncovered or only partially protected; these are also the only suails which have the shell notably chalky and opaque. The snails of the dryest (Dos Cabezas) part of the range are not "desert snails" in appearance. They live where little light or none can penetrate.

Relation of Exposure to Size.-The size of individual snails (excepting the heliophilous group discussed above) is almost wholly a function of the exposure. Snails living on northern or northwestern exposures are invariably larger than those from southern or eastern exposures, regardless of elevation, ${ }^{8}$ unless other conditions are conspicuously unfavorable. This is apparently due to the more abundant cryptogamic or other plant food, the growth of which is favored by the more humid slopes, ${ }^{9}$ as well as the greater duration of humid growing periods. As would naturally be expected, the difference in size of the snails is more marked in rather dry or semi-arid regions than in those abundantly watered and shaded. Our measurements of Sonorella support the observations already published on other species.

In some cases the divergence has proceeded so far that diversity of size becomes an important specific character, as in the case of Sonorclla leucura and micra, living on opposite sides of White Tail

${ }^{5}$ Additions to the shell are made only when the animal is active, during humid periods, and thus exposed neither to arid winds or alkaline dust. Growth of the shell does not proceed when the snail is retracted and at rest, but only when it is in full activity, with the mantle fully produced.

${ }^{6}$ As claimed by Dr. IV. H. Dall, Proc. A. N. S. Phila., 1896, pp. 411, etc.

${ }^{7}$ A long list of conspicuously opaque, chalky snails which astivate in the full glare of the sun could be given. We may mention Leucochroa, Cerion incanum maritimum, etc., Bulimulus alternatus, Oreohelix strigosa huachucana. Allied species which live in more shaded places tend to lose their opacity; $c f$. Oreohelix barbata and $O$. clappi.

${ }^{8}$ At least within limits of $t w o$ or three thousand feet.

- We have already given data in support of this fact in Proc. A. N. S. Phila., 1906, pp. 552-555, and in other places. 
Canyon. Where snails are gathered from one limited region and those from various colonies are not kept separate, the measurements of such series when plotted may form conspicuously bimodal curves, due to the mixture of shells from different exposures. Such results are entirely worthless in the study of the relations of organism to environment.

We have made no exhaustive series of measurements to ascertain whether the height of the spire varies with elevation of the station, but such observations as we have made indicate that it does not. In the helices there is rather wide individual variation in height of spire at all levels indifferently. ${ }^{\mathbf{1 0}}$

Influence of the Character of the Rock.--Land suails are notoriously more abundant on limestone than where the country rock is igneous. They are also usually heavier, the shell-walls thicker, though this is not the case with all species. The individuals apparently reach at least as large a size where lime is scarce as where it is abundant, if other conditions (exposure and humidity) are about equal. In several cases the largest individuals occurred under granitic rock, as in the case of Sonorella bicipitis at Nine-mile water-hole.

Enemies.-Field mice are apparently the chief enemies of the larger snails of the Chiricahuas. We often found unmistakable evidences of their destructive activity. The crevices of rock-piles which harbor most of the snails are often accessible to mice; and no protective device seems to have arisen effective against the latter. Oreohelix barbata, which from the dirt on its hairy coat is rather hard to see, we noticed on several occasions had been cruelly preyed upon by mice. We can offer observations upon predacious insects.

\section{Factors in the Formation of Races and Species.}

The several modifications of the shells which we have noted above as correlated to some extent with external factors are only in minor part such features as serve to signalize species. ${ }^{11}$ Thus in Sonorella the species are based mainly upon characters of the genitalia. In Ashmunella upon the teeth of the aperture and the shape of the last whorl. In Holospira the shape of the spire and its sculpture are the chief differential features. Moreover, in many cases, allied but

${ }^{10}$ Bellini's recent claim that on Capri the snails from greater elevations have higher spires, due to diminished atmospheric pressure, seems to us fantastic in the extreme.

${ }^{11}$ In White Tail Canyon, however, Sonorella micra and Ashmunella lepiderma differ from their fellows on the more shaded side of the canyon by features mainly traceable to the different exposure and rock. 
distinct species live under conditions which so far as we can see are identical. The subterranean Sonorellas, such as bicipitis, optata, bowiensis and leucura inhabit slopes having similar exposure, vegetation, elevation, and rock cover, yet they differ characteristically in genitalia. At the same time, one style of genital organs seems to be as fit as another. Nearly all of the Holospiras live in very similar places. The local differences in the stations of the typical colonies of Oreohelix chiricahuana, obsoleta and percarinata are apparently less than the differences between the several stations of colonies of chiricahuana. If the conditions seem practically identical on parallel slopes of clifferent canyons, it seems hopeless to search for differential conditions among several rock-piles or taluses along one canyon side, having the same exposure, composed of the same rocks, separated perhaps only by arid gulleys or barren "earth slopes; yet such taluses often harbor perceptibly different colonies of the same species.

The facts developed in our Arizona work lead us to doubt the potency of environment as a direct agent in effecting specific differentiation, or at least to assign such factors a wholly subsidiary role. The facts seem explicable only on the hypothesis of variations existing or arising in the constitution of the egg, leading to modifications of the adult organism which for the greater part are indifferent as affecting the well-being of the race. Such adaptation as exists would apparently be due to selection. The isolation of small colonies in these mountains must favor the survival of what are currently called mutations occurring therein. The occasional mingling of neighboring colonies in which diverse variations have arisen seems to have led to such heterogeneous colonies as we have described in Holospira. ${ }^{12}$

We have no definite evidence to offer bearing upon the amplitude of individual variations or "mutations," yet we may again mention the fact that in many species nearly every colony has its minor peculiarities-peculiarities far below the grade usually called "specific," yet appreciable to the trained eye. ${ }^{13}$ It may be inferred from this fact that the amplitude of "mutations" is ordinarily not great.

\section{Distribution of Chiricahuan Mollusks.}

The snail fauna of the Chiricahuas consists of 51 species, falling into two main categories:

${ }^{12}$ We believe this to be the explanation of the diversity of colonies in the polychromatic arboreal snails such as Partula and Liguus, in which some colonies of a given species are homogeneous, while others are heterogeneous, snails of several definite color-patterns being the offspring of a single mother.

${ }^{13}$ Onty the application of careful biometric methods can fully or definitely bring out these minute differences. 
1. Species peculiar to the range: all forms of the genera Sonorella. Orcohelix, Ashmunella and Holospira, 21 species with 14 subspecies. These are the larger snails of the fauna, without exception larger and heavier than any of the snails ranging also outside of the Chiricahuas. The member's of this group of forms have probably been isolated in these mountains since the beginning of the present climatic cycle. They are too heavy to be transported across the mesa by wind, and the probability that they would be carried by birds or other accidental means is so remote as to be negligible. All of them were apparently derived from not more than six ancestral specific stocks; the species of Ashmunella and Holospira forming homogeneous groups probably of common ancestry, while in Sonorella and Oreohelix the species fall into two groups.

2. Species having a distribution outside of the range: all of them smaller than the preceding and many minute.

(a) Alpine forms, mainly living above 7,500 feet, and elsewhere found only in the Canadian zone of the Rocky Momintains northward. Those found also in the Huachuca range are indicated by the letter $\mathrm{H}$.

Thysanophora ingersolli meridionalis. Vertigo columbiana utahensis. Vitrina alaskana, $\mathrm{H}$.

Euconulus fulvus alaskensis, $\mathrm{H}$. " modesta parictalis, $\mathrm{H}$.

" coloradoensis basidens.

Pyramidula cronkhitei, $\mathrm{H}$.

(b) Transition zone forms chiefly having an almost continental distribution in that zone, also ranging into highel and lower zones.

Zonitoides arborea, about $\$, 000$ feet, $H$.

Cochlicopa lubrica, 6,000-8,000 feet, $\mathrm{H}$.

Pupilla hebes, 7,500-\$,000 feet, $\mathrm{H}$.

Vertigo mitium, 8,000 feet, $\mathrm{H}$.

Succinea avara, about 6,500 feet, $\mathrm{H}$.

The species of groups $(a)$ and $(b)$ are forms which from their wide distribution must be of considerable antiquity, all probably having existed practically unchanged since before the initiation of present climatic conditions in Arizona. The absence of any form of the Orcohelix strigosa group is remarkable, on account of the very wide di-tribution of this Transition zone type in the Rocky Mountains.

(c) Upper Sonoran species, most of them widely distributed in the Southwest, some ranging into the Lower Sonoran. Those found also in the Huachuca and Florida ranges marked with the letters $H$. and $\mathrm{F}$. 
Thysanophora hornii, ${ }^{14}$ H. F.

Agriolimax hemphilli ashmuni, ${ }^{15} \mathrm{H}$.

Zonitoides milium meridionalis, $\mathrm{H}$.

" minuscula alachuana, $\mathrm{H}$.

Vitrea indentata umbilicata, $\mathrm{H}$.

Helicodiscus eigenmanni arizonensis, $\mathrm{H}$.

Radiodiscus millecostatus, ${ }^{15} \mathrm{H}$.

Punctum californicum. ${ }^{15}$

Vallonia perspectiva, ${ }^{14} \mathrm{H} . \mathrm{F}$.
Bifudaria pellucida hordeacella .

" quadridentata, ${ }^{15} \mathrm{H}$.

" pilsbryana, H. F.

" perversa. ${ }^{14}$

" ashmuni, ${ }^{14}$ H. F.

" cochisensis, ${ }^{14} \mathrm{H}$.

" dalliana. ${ }^{14}$

" tuba. ${ }^{1 *}$

With the single exception of Agriolimax, all of these are very small or minute snails, certainly capable of being carried long distances by cyclonic winds, and it is likely that their wide distribution may be attributed in part to such means, though it is not improbable that a considerable number of the forms may have existed before the isolation of the Arizona ranges.

Twenty-two of the thirty species of groups $2(a, b, c)$ have been found in the Huachuca range. ${ }^{16}$ These are indicated in the list above by the letter $\mathrm{H}$. Four species, marked $\mathrm{F}$ in the list, occur in the far poorer fauna of the Florida Mountains.

FAUNAL ZONEs represented in the Chiricahuas are the Canadian, the Transition, and the Upper Sonoran. Zones dependent upon elevation are less distinctly marked in mollusks than in plants or vertebrates, local exposure and suitable conditions of moisture controlling the distribution of species to such an extent that the elevation zones are extremely irregular. It appears, however, that the Canadian zone forms are strictly confined to the high "parks" and peaks. The characteristic Transition zone species are also for the most part high on the range, as are also five species which, from their distribution elsewhere, are considered to be Upper Sonoran. Seven of the eighteen Upper Sonoran species have been found only below 7,000 feet, while six have a general range.

In the group of species peculiar to the Chiricahua range, and which must apparently be considered Upper Sonoran, many of the forms are very local in distribution and belong to the middle and lower zones of the range. Those having a wider distribution often have a great vertical range, as the following examples:

14 Found only low, below 7,000 feet.

${ }^{15}$ As yet found only at about 8,000 feet or above, but none of them known from much further north than the Chiricahua range.

${ }^{16}$ Proc. A. N. S. Phila. for 1909, pp. 49S-516. 
Sonorella virilis, 6,000 to 9,000 feet.

Oreohelix clappi, 6,000 to over $\$, 000$ feet.

Ashmunella chiricahuana, 6,000 to \$,500 feet.

" angulata, 6,000 to over $\$, 000$ feet.

Sonorella virilis leucura. S. micra, Ashmunella proxima. A. fissidcns and their subspecies, and Holospira, seem, in their several areas. to range from low to as high as suitable cover and slope-expo:mre are found. Ashmunella esuritor, metamorphosa and duplicidens belong to the higher levels (where the flora is rery different). while A. ferriesi has not been found over 6,500 feet, if so high as that.

In general, the specially Canadian and Transition species seem to be more sharply limited in their range downward than the Upper Sonoran forms are in their extension uprard. We attribute this as much to the difference in plant life as to any more direct climatic conditions.

The Lower Sonoran zone, in this area, has no land molluscan fauna, but Physa and Lymncea occur in the cienega east of the Chiricahuas.

\section{Srstematic Descriptions of SPECies.}

\section{Family HELICID丑.}

This family comprises four genera in Arizona: Sonorella Pils., Oreohelix Pils., Ashmunella Pils. and Ckll., and Thysanophor strebel. Ashmunella is confined to a comparatively small area in the southeastern corner of the territory; but the other genera extend to the northern border, but they are only locally distributed, and some or all may be absent over areas of hundreds of square miles. Ashmunella and Sonorella are Upper sonoran genera. Oreohelix belongs to the Transition zone, often extending into the Canadian (where it is usually dwarfed), and sometimes into the Upper sonoran zone, where it is mainly represented by special species.

The genera Ashmunclla and Sonorella are curionsly diverse in modes of racial differentiation. In Ashmunella the shell has been most modified. In series of allied forms from successive canyons of a single range the shells will show much greater divergence than the soft parts. This is well illustrated by the Huachucan series, which, with conspicuous differences among the shells, shows hardly any in the soft parts. In Sonorella, on the other hand, the shells from a series of successive canyons may show barely perceptible differences, but the genitalia have been so modified in detail that the species are instantly recognizable from these organs. The conditions in Sonorclle 
form a strong argument against modification by the action of environment. The differentiation affects internal organs concerned solely in the act of reproduction, and only in the most remote manner connected with parts directly acted upon by external factors.

Genus SONORELLA Pilsbry.

Sonorella is the most characteristic Helicid snail of the mountains of southern New Mexico and Arizona. It is more widely distributed than either Ashmunella or Oreohelix, inhabiting mountains too arid to support either of the other genera, such as the Peloncillo, Dos Cabezas and Rineon ranges. In the Grand Canyon of the Colorado we dug them from the cruelly sharp rock-slides of the pre-Cambrian zone, in deep, sunless canyons where no other snails penetrate; and they exist equally on the plateau at the rim, 5,000 feet above the sea.

This tolerance of untoward conditions is doubtless due in part to their deep digging habit. Sonorella is usually found well down in the rocky talus or slide, in the layer against the earth, where a certain degree of moisture remains. In some places Ashmunella accompanies Sonorella in the same slides. This is especially the case in the more verdant and humid canyons, such as Cave Creek in the Chiricahuas, where Sonorella. Ashmunella and Oreohelix clappi may be found together.

Oreohelix (except O.clappi and $O$. barbata) lives on the surface, on or under the top stones, or around dead mescal, bear grass or yuccas. While apparently fitted to live in exposed and extremely arid places, yet in southern Arizona Oreohelix certainly does not inhabit the more arid ranges where Sonorella exists.

Oreohelix and Ashmunella may sometimes be collected in copious quantity, but Sonorella is almost always rare. In the Dos Cabezas range a half dozen living adults would be a good day's bag for any collector, and in dry weather, at least, this would mean very hard work. In less arid localities the snails are less scarce; but as a general rule to collect living Sonorellas successfully is the most strenuous physical labor, nccasionally enlivened by danger of broken limbs from falling rocks or caring in of holes, in slides of heavy rock. Strong gloves are necessary in "quarrying" for Sonorella. In spite of strained muscles, bruises and bleeding fingers, the fascination of Sonorella hunting is irresistible. The game gains in value from the hardihood brought out in the chase, and it is only after one has forgotten the labor that he can part with a single specimen of the rarer species.

Chiricahuan Sonorellas belong to two very diverse groups distinguished as follows: 
Key to Chiricahuan Species of Sonorella.

a.-Penis comparatively short, very much less than the diameter of the shell, and about $\frac{1}{4}$ to $\frac{1}{2}$ the length of spermatheca and its duct (Group of S. hachitana).

b.-Penis-papilla anmulate, the free end more or less pointed; epiphallus less than half the diameter of shell; whorls $4_{4}^{3}$ to $5 \frac{1}{4}$.

c.-Flagellum wanting or vestigeal; diameter of shell 15.5 to $25 \mathrm{~mm}$. ......................................................... optata.

$c^{1}$.-Flagellum distinct but minute; diameter of shell is to

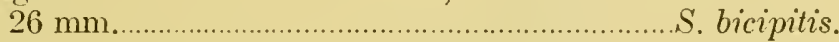

$b^{1}$.-Penis-papilla plain, cylindric with obtuse end; epiphallus about half the diam. of shell; penis larger; whorls about $4 \frac{1}{2}$. c.-Umbilicus contained about $5 \frac{1}{2}$ times in diameter of the shell, which is depressed, 15 to $18 \mathrm{~mm}$. in diameter.

S. bowiensis.

$c^{1}$.-Umbilicus contained about 10 times in diameter of shell, which is subglobose, 13.5 to $20 \mathrm{~mm}$. in diameter.

S. binneyi.

$a^{1}$.-Penis very large, its length exceeding the diameter of the shell, and not differing much from the length of spermatheca and duct; penis-papilla and vagina very long (Group of S. virilis).

b. - Shell moderately solid, larger.

c.-Diameter of shell 16 to $21 \mathrm{~mm}$.............................S. viritis.

$c^{1}$.-Diameter of shell 18 to $25 \mathrm{~mm}$.; more depressed. S. v. leucura.

$b^{1}$.- Shell thin, smaller, diameter 12 to $15 \mathrm{~mm}$................ $\mathrm{s}$. micra.

\section{Group of Sonorella hachitana.}

Sonorella bicipitis n. sp. Pl. I, figs. 1-5.

Shell of the group of $S$. hachitana, the umbilicus about one-serenth the total diameter, and one-third covered by the dilated columellar lip; brown, fading to white around the umbilicus, encircled above the periphery with a dark chestnut band bordered above and below with white bands of about the same width; the brown band visible on about two whorls of the spire, the upper white band visible also on the penultimate whorl. Whorls $4 \frac{3}{4}$ to 5 , rather slowly increasing at first, the penultimate and last whorls rapidly widening. Surface nearly smooth to the eye, glossy. Embryonic shell consisting of $1 \frac{1}{2}$ whorls. The first half whorl has distinct radial ripples; the next whorl has close, fine wrinkles in the direction of growth-lines, and interrupted by delicate, spirally descending threads. The third whorl shows some very sparse punctation. Later whorls are marked with fine growth-ripples, and usually show, under a strong lens, some excessively faint spiral lines above the periphery. The last whorl descends 
moderately in front, and is well rounded on periphery and base, as usual. The aperture is large, oblique, rounded, nearly as high as wide. Peristome thin, narrowly expanded outwardly, the basal margin a trifle reflexed, columellar margin dilated in a curved triangular plate over about one-third of the umbilicus. Alt. 14, diam. $23 \mathrm{~mm}$; aperture, alt. 12, diam. $13 \mathrm{~mm}$.

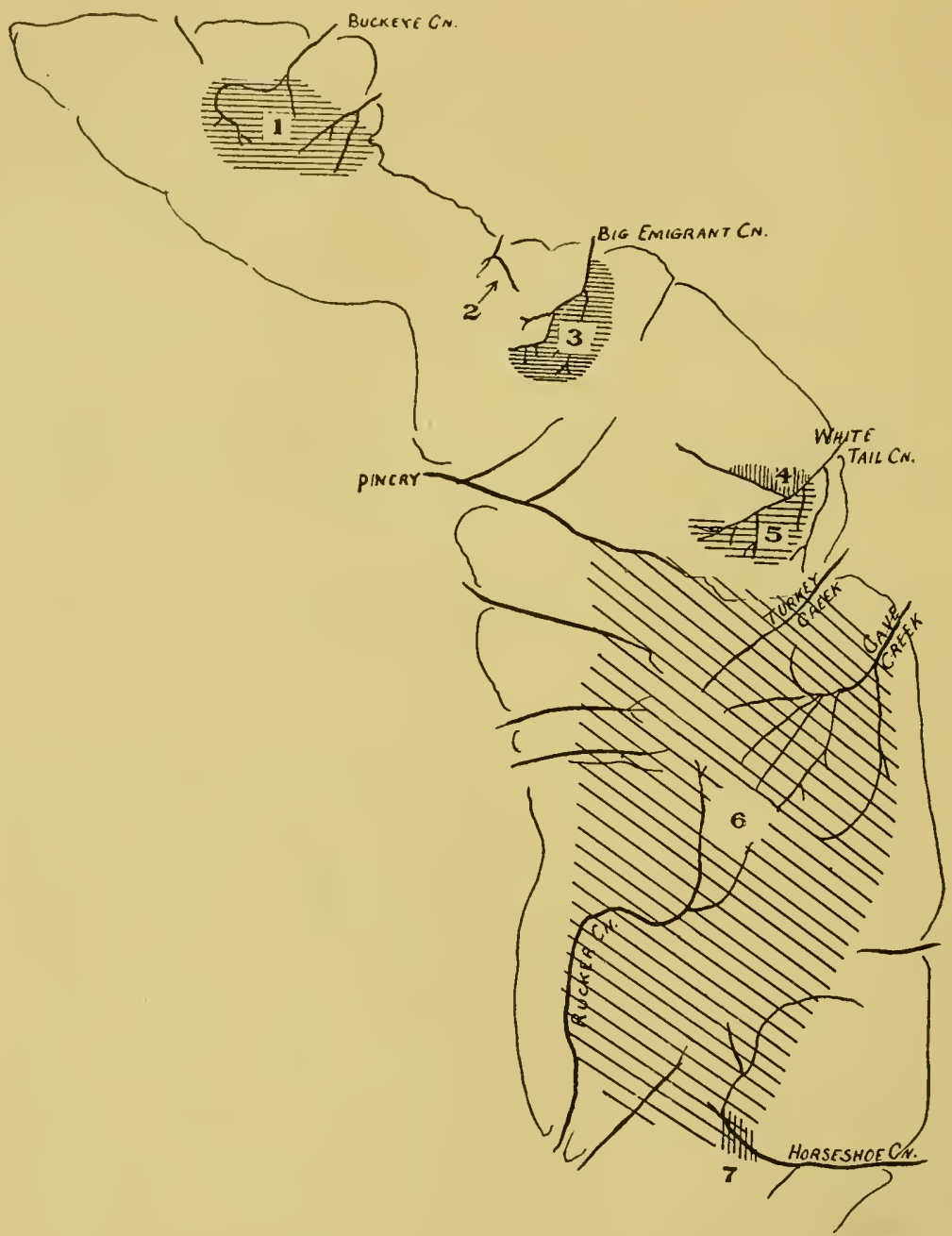

Fig. 2.-Distribution of Sonorella in the Chiricahua Mlountains: 1, S. bicipitis; 2, S. boviensis (at point of the arrow); $3, S$. optata; $4, S$. micra; 5, S. virilis leucura; 6, S. virilis: 7, S. binneyi. Large areas between 1 and 2 and between 3 and 4 are unexplored. 


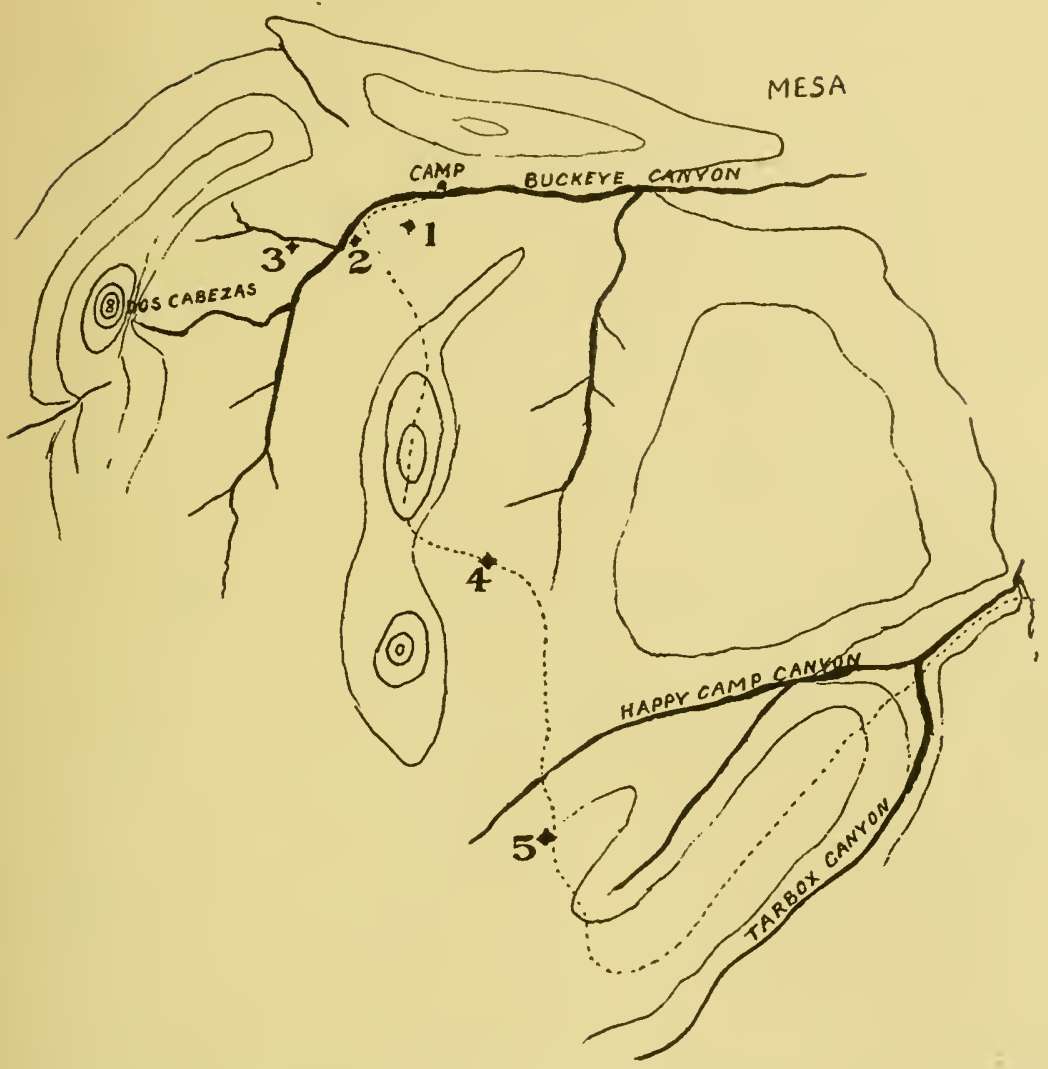

Fig. 3.-Principal collecting stations in the northem canyons of the Dos Cabezas range.

Genitalia, Pl. III, figs. 1, 2, 4, 7. Pen is of moderate length, somewhat less than one-third the length of spermatheca and dict, with a long retractor muscle; the penis-papilla $(p p$.) cylindric, amnulated distally, with conic tip. Epiphallus somewhat shorter than penis; flagellum 0.6 or $0.7 \mathrm{~mm}$. long. Vagina generally not much longer than the penis. Sole (in alcohol) ochre or dirty white, uniform or with slightly darker sides. Back gray, the flanks and tail very pale.

Jaw with 6 to 8 ribs, grouped in the median half. Radula with $26,12,1,12,26$ to $27,13,1,13,27$ teeth, centrals and laterals withont ectocones; some of the marginals with both cusps bifid.

Type No. 94,32S A. N. S. P., from Buckeye Canyon, Dos Cabezas range of the Chiricahua Mountains, at Station 1, fig. 3.

It ranges throughout Buckeye and Happy Camp Canyons, and at 
Nine-mile Water-hole, living deep under stones and rocks. Buckeye Canyon is the first from the northern end of the range. Its upper branches drain the eastern flanks of Dos Cabezas Peak. At the time of our visit in November there was water at intervals in the stony bed of the canyon as far down as our camp, near the reduction plant of the Buckeye gold mine. Tarbox and Happy Camp Canyons unite into a wide valley about a mile from the mesa. The mouth of this valley is half closed by a great reef of light gray granite rocks which forms a conspicuous landmark from the mesa. The country rock of these canyons is mainly metamorphic, but in part granitic.

This species has the same apical sculpture as $S$. bowiensis and S. optima. It differs from optima in the shape of the penis-papilla, the presence of a flagellum, the shorter inner cusp of the marginal teeth, the larger aperture and narrower umbilicus. S. hachitana from the Big Hachet Mountains has a decidedly smaller aperture. In shell characters $S$. bicipitis stands nearest $S$. huachucana, but the apical sculpture of the latter is much less distinct, without the oblique threads on the last embryonic whorl which are characteristic of $S$. bicipitis and related forms. This species is represented by 43 adult shells, of which 17 were taken alive, and many young ones. The colonies are wiclely separated ${ }^{17}$ and small; living shells are rare, and their collection involves the removal of much rock. The physical conditions are very similar in all the stations in Buckeye and Happy Camp Canyons. All the stations are on steep well-drained slopes facing northward, the earth very dry (in November), even under a couple of feet of rock, and scantily protected by low scrubby oak brush. At Nine-mile Water-hole the conditions are quite different as noted below.

In the type locality, Station 1 (pl. I, figs. 1, 2, 3, and pl. III, fig. 7), we took 7 living adult and 6 young specimens measuring as follows:

\begin{tabular}{|c|c|c|}
\hline .14. & 14.2 & 14 \\
\hline Diam & 23.3 & 23 \\
\hline
\end{tabular}

This station is high on the steep south side of the canyon.

In a lot of 23 from Station 3 (No. 94,326), 7 are adult living shells, measuring :

${ }^{2 i}$ This must be understood in a comparative sense, as indicating that many apparently suitable situations examined were found barren. Doubtless a longer search would show that a large number of small colonies exist. We worked two days in Buckeye and several hours in Nine-mile. 


$\begin{array}{llllllll}\text { Alt ........... } & \ldots 12.8 & 12.2 & 12.2 & 12.7 & 12 & 11.8 & 11.5 \mathrm{~mm} . \\ \text { Diam ....... } & \ldots \ldots .21 & 21 & 20.5 & 20 & 19.2 & 19 & 18.5 \mathrm{~mm} .\end{array}$

Ten adults from the slopes around the head of the southeastern branch of Buckeye Canyon, Station 4, vary from 18.7 to $22 \mathrm{~mm}$. diameter (No. 94,325).

Thirteen adults were taken at Station 5, near the head of Happy Camp Canyon, only one alive.

\begin{tabular}{|c|c|c|c|c|c|c|c|}
\hline Alt... &. .13 & 13 & 12.6 & 12.3 & 12.3 & 11 & 11.7 \\
\hline Diam.. & 22.3 & 21 & 20.7 & 20 & 20.2 & 20 & 19 \\
\hline Dian.... & $\begin{array}{l}11.7 \\
19.2\end{array}$ & $\begin{array}{l}11.8 \\
19.2\end{array}$ & $\begin{array}{l}12 \\
19\end{array}$ & $\begin{array}{l}11.2 \\
19.2\end{array}$ & $\begin{array}{l}11 \\
19\end{array}$ & $\begin{array}{l}10 . \\
18\end{array}$ & \\
\hline
\end{tabular}

At Nine-mile Water-hole we obtained a single living adult snail and 8 young (No. 99,324). These, with a specimen taken by Mr. Ferriss in 1905 , indicate a large race at this place, with a slightly larger umbilicus than the types, and more closely approaching lip-ends (pl. I figs. 4,5 ). The soft anatomy, sculpture and color are like typical $S$. bicipitis. Whorls barely 5 . Two adults measure:

\begin{tabular}{|c|c|c|}
\hline Alt. & .15 & $\mathrm{~mm}$. \\
\hline Diam.... & 26 & 25.5 \\
\hline Aperture alt. & 13 & 13 \\
\hline " diam. & 14 & 14.5 \\
\hline
\end{tabular}

The genitalia are figured pl. III, fig. 2 .

Nine-mile Water-hole is a shallow amphitheatre open eastward to the mesa, its slopes covered with great weathered boulders of coarsegrained light gray granite, among which ferms grow luxuriantly. A tiny stream trickles among the rocks, collecting into a stagnant pool at the base. A man can make his way in the interstices between and under the rocks, in some places, but as very few of them are movable, it is almost impossible to obtain the shells.

Specimens were dissected from Stations 1, 3, 4, 5 and from Nine-mile Water-hole. All have a distinct sheath at the base of the penis, attached also to the epiphallus and partially enveloping the latter throughout a part of its length. This sheath varies from about onethird the length of the penis in the type lot, to about a half in that from Nine-mile. The penis-papila in transverse section (fig. 7, pp.) shows a group of minute ducts, but there seems to be a single terminal orifice. The vagina is longer in the types than in other lots examined. 
Measurements of genitalia in millimeters.

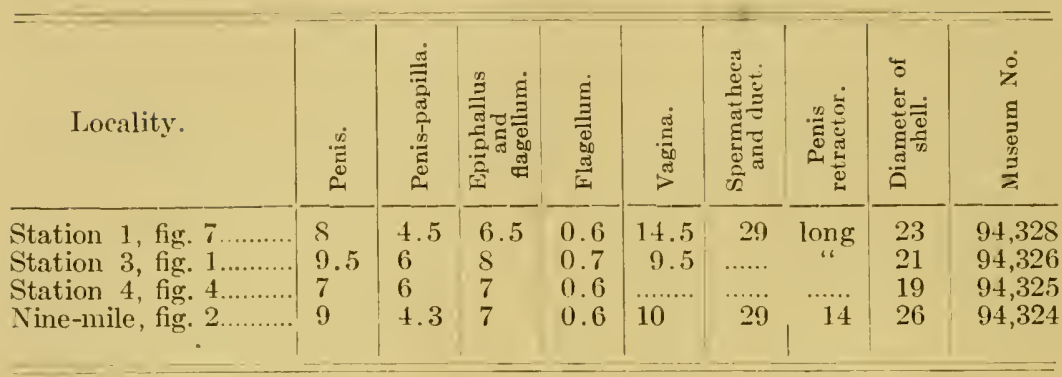

In the alcoholic specimen from Nine-nile, the sole is tripartite by faint longitudinal impressed lines, with a median groove due to partial folding of the foot. There are transverse lines as shown in pl. III, figs. 3 and 6 . The granulation above is fine and pebble-like as usual in Sonorella. 'The cesophagus is short, expanding into a large crop, on which the loose and open salivary glands lie. The liver is reddish purple. The buceal retractor and left ocular retractor are united in their posterior third, the tail and right ocular retractors being free to their common insertion. The lung is like that of Sonorella optata.

In the specimens from Stations 3, 4 and 5, no longitudinal impressed lines could be traced on the sole.

The jaw varies a good deal; a specimen from the type lot has six wide ribs. From Station 4 and Nine-mile the jaw has eight narrow ribs.

All of the radula examined agree in having decidedly fewer teeth in a transverse row than $S$. hachitana flora or $S$. optata.

Sonorella optata n. sp. Pl. I, figs. 6-12, 17-19.

The shell is umbilicate, umbilicus slightly less than one-seventh the diameter, similar to $S$. hachitana. Pale brown, fading to whitish around the umbilicus, encircled by a rather wide dark chestnut band above the periphery, bordered above and below with paler, whitish bands. The spire is low conic. Whorls $5 \frac{1}{4}$, slowly increasing to the last, which is much wider, and descends deeply in front. The embryonic shell consists of $1 \frac{1}{2}$ whorls. The first half whorl has radial wrinkles, and begins in a smooth tip; then a small areolate area follows, after which there are curved, forwardly descending delicate threads reaching the suture below, but weak or obsolete on the summit of the whorl, which is irregularly roughened; there are also some forwardly ascending threads in places. The first neanic whorl has sculpture of slight growth ripples and an indistinct roughening or punctation. Subse- 
quent whorls are lightly marked with growth-lines only. The aperture is very oblique, subcircular; peristome thin, a little expanded, narrowly reflexed below, the columellar margin dilated. Alt. 15, diam. 24 mm.; alt. aperture 11.7 , width $13 \mathrm{~mm}$.

Penis small, usually shorter than the vagina, and less than one-third as long as the spermatheca and duct. Epiphallus short, the flagellum apparently absent or reduced to a very minute adnate cœecum (pl. IV, figs. $1,2,3,4,5,7$ ). Radula with $35,1,35$ (summit of Cross J Mt.) to $3 \mathrm{~S}, 1,38$ teeth, about 14 laterals, an ectocone appearing on the 11 th to 13 th. The entocone is bifid on the outer 15 to 18 marginals, and the ectocone occasionally so on some teeth, though generally simple. Six radulæ from 5 stations examined. The jaw has 5 ribs in two, 6 and 7 in two other examples. The crops and osophagus as far as the stomach are conspicuously sulcate or corrugated longitudinally.

Type locality, head of Big Emigrant Canyon at Station 1, on a steep slope shaded by pinyons, under large stones (limestone). The species occurs in numerous colonies throughout Big Emigrant Canyon, except on slopes with southern exposure. See map on p. 121.

This handsome species, like others of the hachitana group, is illcharacterized as far as the shell is concerned, but the genitalia are characteristic by the small penis and absence of a free flagellum. In the Chiricahua Mountains it is related to S. bicipitis of the Dos Cabezas range, but in that the penis is well developed and the flagellum, though small, seems to be invariably present. In all of the numerous examples opened the crop and intestine to the stomach are deeply furrowed longitudinally, a condition observed in no other Sonorella. To what extent this corrugation may be due to the state of the specimens is uncertain. It happened that by some unaccountable oversight all of the Big Emigrant Sonorellas were cooked and pulled without drowning, and then were preserved in alcohol too strong to give the best results.

All of the following colonies but one are on limestone.

Type locality, Station 1. Thirty adult specimens were taken, ten of them alive. They measure as follows:

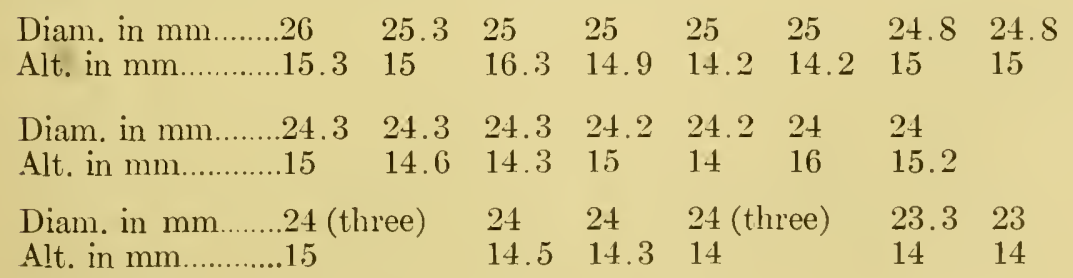


Diam. in $\mathrm{mm} \ldots \ldots .23 \quad 23 \quad 23 \quad 23 \quad 22.8$

Alt. in mm ..........14 $13.5 \quad 13.1 \quad 13 \quad 13.5$

The total variation in diameter in this colony is $3.2 \mathrm{~mm}$. The variation in altitude is comparatively greater, owing to the varying degree of elevation of the spire. 70 per cent. of the lot are from 24 to $25 \mathrm{~mm}$. in diameter. Figures 6-9 were drawn from specimens of the type lot from this Station.

Station 4. Cleft in the rocky summit of hill at fork of Big Emigrant Canyon, facing mouth of canyon (pl. I, fig. 10). Ten specimens, two alive, measure:

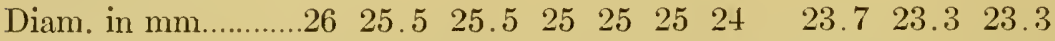

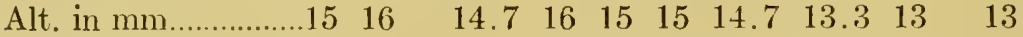

They differ from the type lot in having the aperture barely perceptibly larger, umbilicus smaller. In a specimen of the type lot $25 \mathrm{~mm}$. in diam. the aperture measures $11.4 \times 13.1 \mathrm{~mm}$. In one of the same diameter from Station 4 it is $12 \times 13.4 \mathrm{~mm}$.

Spirally striate forms. - The shells from Stations 2, 3, 5, 6-Big Emigrant Mountain and Cross J Mountain-usually show numerous spiral striæ on the upper surface of the last whorl, but this character is variable; in some shells of each lot no spiral striæ can be made out.

Station 2. Close to the creek in the middle branch of Big Emigrant Canyon, under stones. Three dead shells measuring 23.5, 22.3 and $21.8 \mathrm{~mm}$., and similar to those from Big Emigrant Mountain. This place is probably about 1,000 feet lower than the type locality.

Station 3. Big Emigrant Mountain. This name is given to a mountain about four miles above the fork of Big Emigrant Canyon on the left side of the east branch. November 11 and 12 it was visited. On the side toward the canyon, under a rocky bluff, under stones among scrub oaks (Quercus hypoleuca?), in a situation resembling that of Sonorella bowiensis, numerous specimens of a small form were taken, almost all dead shells. Sixty-five adults taken measure in diameter as follows:

\begin{tabular}{|c|c|c|c|c|c|c|c|c|}
\hline Diam. in $\mathrm{mm}$. & .20 . & 20 & 19.5 & 19.3 & 19 & 18.8 & 18.5 & 18.3 \\
\hline No. of shells. & 1 & 1 & 4 & 1 & 6 & 4 & 7 & 6 \\
\hline & 1 & 7. & 17. & 17.3 & 17 & 16.5 & 16 & \\
\hline of shells... & 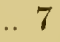 & 4 & 4 & 5 & 7 & 3 & 4 & \\
\hline
\end{tabular}

The shells are in the average more depressed than typical $S$. optata. The largest measures, alt. 10.5, diam. 20.5, aperture $9.2 \times 11.2 \mathrm{~mm}$. Another, alt. 10.5, diam. 18.5, aperture $8.3 \times 9.9 \mathrm{~mm}$. There are 
about $4 \frac{1}{2}$ whorls, the last with some spiral lines on the upper surface, sometimes very faint.

From the west side of Big Emigrant Mountain (pl. I, figs. 11, 12, $18,19)$ a lot of 32 living adults was taken, of almost equally small size (No. 94,320).

$\begin{array}{lrrrrrrr}\text { Diam. in mm ............21.4 } & 20.5 & 20 & 19.75 & 19.5 & 19 & 18.7 & 18.3 \\ \text { No. of shells............... } 2 & 2 & 4 & 6 & 7 & 9 & 1 & 1\end{array}$

The degree of elevation is somewhat variable. In one specimen (pl. I, fig. 19) the dark band is wanting. This is the only case of the kind among our Chiricahua Sonorellas.

Another lot of 35 living adult shells from another place on Big Emigrant Mountain average larger.

$\begin{array}{lrrrrrrrr}\text { Diam. in mm............23 } & 22.5 & 22 & 21.5 & 21 & 20.5 & 20 & 19.8 & 19 \\ \text { No. of shells................ 1 } & 1 & 1 & 7 & \mathrm{~S} & 7 & 8 & 1 & 1\end{array}$

Station 6, high in the valley worth of Cross J Mountain, 42 adult shells, most of them "dead," measure:

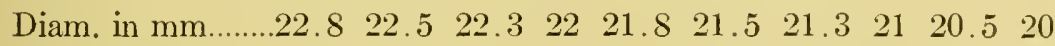

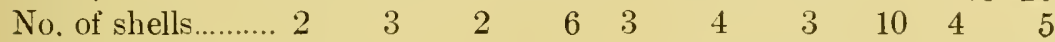

Most shells show spiral lines, as in those from Big Emigrant Mountain. The specimens were taken in the area indicated in the sketch on p. 87 , but similar dead shells were seen throughout the valley, on both sides of the ravine. The rock of this valley is limestone.

Eastward from this valley (Station 6) a rugged ridge of coarse crumbling granitic rock runs towards the mouth of the canyon (see map). Five dead shells found on the outer side of the crest of this ridge are like those from the valley, but smaller, diam. 18.5 to 20.5 $\mathrm{nm}$.

Station 5. Among rocks at and near the north side of the summit of Cross J Mountain. The rock here is angular, friable and cherty. The shells, 29 adults, mostly "dead," resemble the larger colony from Big Emigrant Mountain, most of them showing fine spiral lines. The elevation is estimated at 8,000 feet. See sketch on p. $\delta 7$.

\begin{tabular}{|c|c|c|c|c|c|c|}
\hline Diam. in $\mathrm{mm}$.. & .23 & 22.8 & 22.2 & 22 & 21.8 & 21.5 \\
\hline No. of shells.. & 2 & 1 & 1 & 5 & 4 & 1 \\
\hline & .21 .2 & 20.8 & 20 & 20.2 & 20 & 19. \\
\hline No. of shells. &. .5 & 1 & 4 & 1 & 1 & 3 \\
\hline
\end{tabular}

Small form of S. optata (pl.I, fig. 17). Some very small specimens were taken near the head of Big Emigrant Canyon south of Station 1, 
the exact spot not noted. Two living ones measure, alt. 9.8, diam. $16 \mathrm{~mm}$., and alt. 9.2 , diam. $16 \mathrm{~mm}$.

A bleached shell was found at Station 2; alt. 11, diam. $18 \mathrm{~mm}$.

Soft anatomy of $S$. optata. Specimens from four colonies have been dissected. In the type lot from Station 1, the sole is pale, unicolored. In some other lots the narrow side areas are a shade darker. The genitalia ( $p l$. IV, fig. $1-4,7$ ) are characterized by the very small penis and absence of a flagellum, verified in several examples opened. The lung (fig. 4, right fig.) has venation much as I have
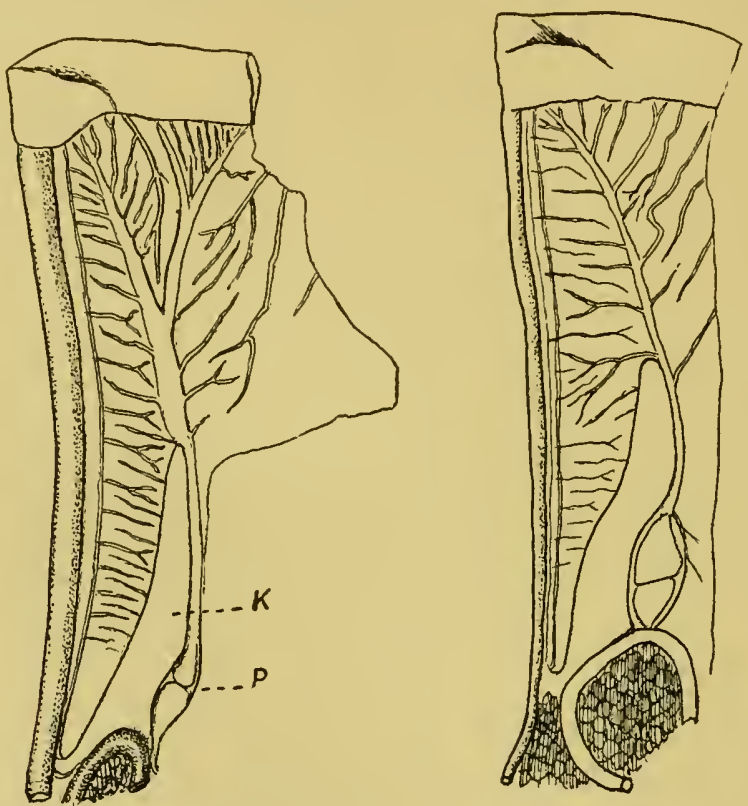

Fig. 4.-Pallial region of Sonorella optata, two individuals. $\mathrm{K}$, kidney; $\mathrm{P}$, pericardium.

described for S. ashmuni. The secondary ureter is open throughout, being defined by a thread-like ridge only. Length of lung 26, of kidney 14, of pericardium $5 \mathrm{~mm}$. The foregut and crop are deeply sulcate longitudinally.

In specimens from the cleft in Big Emigrant Canyon (No. 94,321), the penis is rather larger (pl. IV, fig. 4). It has a thin, rather short basal sheath and long retractor. The penis-papilla is slender, cylindric, weakly annulate, with obtusely conic end. There is an excessively short cocum representing the flagellum, not free from the integument and hardly visible except by transmitted light. The 
crop and foregut are longitudinally sulcate. Salivary glands long, united over the upper surface of the crop.

The form from north side of Big Emigrant Mountain (Station 3, No. 94,322) is similar. Genitalia (pl. IV, fig, 1) with long penispapilla, its end long-conic. Flagellum a barely perceptible bud bound in the integument. Lung with venation typical or (in one of several examined) the pulmonary vein has a large branch on the cardiac side, where the venation is otherwise very faint. Length of lung 27 , of kidney 14, of pericardium $4.5 \mathrm{~mm}$. (fig. 4, left fig.). The crop and foregut are deeply sulcate longitudinally. No. 94,320, from west side of Big Emigrant Mountain are similar. As usual in this species, the penis-papilla has a somewhat glans-like end (fig. 2).

No. 94,323, from summit of Cross $J$ Mountain, has the sole pale in the middle, shading into gray at the sides. No flagellum. Foregut corrugated. The penis-papilla is obtuse, but the specimen is not quite mature (pl. IV, fig. 7). A half-grown shell has very minute genitalia (pl. IV, fig. 5) with a very short papilla.

Measurements of genitalia of $S$. optata in $\mathrm{mm}$.

\begin{tabular}{|c|c|c|c|c|c|c|c|c|c|}
\hline Locality & 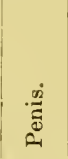 & 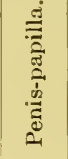 & 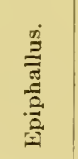 & 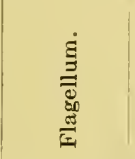 & 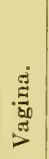 & 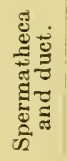 & 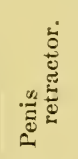 & 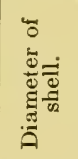 & 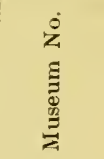 \\
\hline $\begin{array}{l}\text { Station 1, fig. } 3 \ldots \ldots \ldots \ldots \ldots \\
\text { Station 4, fig. } 4 \ldots \ldots \ldots \ldots \ldots \\
\text { Station 3, fig. 1............... } \\
\text { Near Station } 3 \text {, fig. } 2 \ldots \ldots . \\
\text { Station 5, fig. } 7 \ldots \ldots \ldots \ldots \ldots\end{array}$ & $\begin{array}{l}5 \\
7 \\
4.5 \\
5 \\
4.6\end{array}$ & $\begin{array}{l}3 \\
4 \\
4 \\
2.6 \\
2.6\end{array}$ & $\begin{array}{l}3.3 \\
3.5 \\
5 \\
5 \\
2.75\end{array}$ & $\begin{array}{c}0 \\
\text { vestigeal } \\
\text { " } \\
0\end{array}$ & $\begin{array}{l}8 \\
8 \\
6 \\
5 \\
7\end{array}$ & $\begin{array}{l}26 \\
24 \\
20 \\
\ldots\end{array}$ & $\begin{array}{r}10+ \\
7.5 \\
\ldots \ldots . \\
\ldots \ldots . . \\
\text { long }\end{array}$ & $\begin{array}{l}25 \\
25.5 \\
1 S .5 \\
19.5 \\
20\end{array}$ & $\begin{array}{l}94,319 \\
94,321 \\
94,322 \\
94,320 \\
94,323\end{array}$ \\
\hline
\end{tabular}

Sonorella bowiensis Pils. Pl. I, figs, 13-16.

Sonorella hachitana bowiensis Pils., Proc. A. N. S. Phila., 1905, p. 260, pl. XVIII, figs. 29-32 (shell); pl. XX, figs. 10, 11 (genitalia); pl. XXIII, fig. 22 (jaw).

Forty-one living and twenty-eight dead adult specimens were taken at the type locality in 1906 . It is a very pretty shell, quite constant in all its characters.

The shell is somewhat transparent, pale comeons-brown becoming lighter almost corneous-whitish near the umbilicus. There are ustually one or two obliquely radial whitish streaks on the last whorl. The chestnut band above the periphery is about one millimeter wide, is visible on $2 \frac{1}{2}$ to 3 whorls, and has a very faint paler border below, hardly visible; no noticeable pale border above the band. Whorls 
$4 \frac{1}{2}$, rather slowly widening to the last, which is nearly double the width of the preceding, and well rounded peripherally. The embryonic shell consists of $1 \frac{1}{2}$ whorls; the apex is smoothish; then a radially wrinkled area follows to the end of the first half whorl; the next whorl has forwardly descending delicate threads on its outer or peripheral half, the inner half being irregularly, shallowly pitted and roughened. The succeeding neanic whorls are lightly striate obliquely and very slightly, minutely roughened. The last whorl descends rather deeply in front. The umbilicus is contained about $5 \frac{1}{2}$ times in the diameter of the shell. ' The aperture is very oblique, peristome expanded, the ends strongly converging, the columellar end dilated, slightly impinging on the umbilicus.

Measurements of seven specimens were given in our former paper, with diameters of 15 to $17.8 \mathrm{~mm}$. Sixty-nine adults taken in 1906 have the following diameters:

\begin{tabular}{|c|c|c|c|c|c|}
\hline Diam. in $\mathrm{mm}$.. & 15.5 & 15.8 & 16 & 16.2 & 16.3 \\
\hline No. of shells................ & 3 & 2 & 22 & 2 & 7 \\
\hline iam. in & 167 & 16.8 & 17 & 17.8 & s \\
\hline No. of shells. & 4 & 6 & 12 & 1 & \\
\hline
\end{tabular}

About 84 per cent. are from 16 to $17 \mathrm{~mm}$. in diameter, and the total range in diameter is only $3 \mathrm{~mm} .{ }^{18}$ Otherwise variation is seen only to a very slight extent in the width and intensity of the band and in the degree of deflection at the aperture.

Type locality.-Quartzite Hill, back of Dixon's place, about a mile south of old Fort Bowie. It has been found nowhere else.

The locality was wrongly given as "Bowie" in our former paper. Bowie is a station on the S. P. Railway about 15 miles from Fort Bowie, and on the mesa where no snails live. Fort Bowie is now deserted, and only the roofless adobe buildings and the cemetery remain.

Sonorella bowiensis was found only in one colony very limited in extent but prolific in individuals. This colony - the only place where we have ever found Sonorella in abundance-is in a small thicket of long-leaved scrub-oaks with some underbrush of service berries (Amelanchier sp.) under a low eliff, somewhat more than half way to

18 The concentration around the diameters 16 and $17 \mathrm{~mm}$. is partly due to the fact that all shells more than 15.8 and less than 16.2 were counted as 16 , and similarly with 17 , giving a wider range than with any intermediate measurements. 
the summit of Quartzite Hill, back of Dixon's place, shown at (1) in the photographic reproduction below. The snails were under small stones and dead leaves. The abundant shelter and food and favorable northeastern slope apparently led to an unusual multiplication of individuals, but no environmental factor seems to account for their very small size. We searched the neighboring Bull Hill thoroughly for Sonorella, but without success. Probably a more extended exploration would result in finding other colonies in the Fort Bowie Valley. Bowie Mountain and Helen's I)oom should be examined.

The single locality of $S$. bowiensis lies between the ranges of $S$. bicipitis and S. optrata.

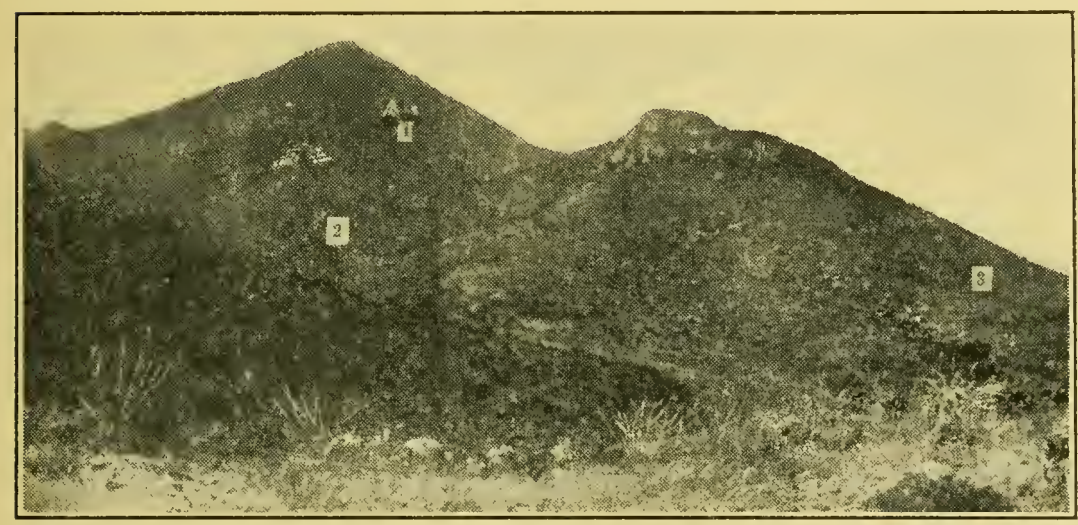

Fig. 5.-Quartzite Peak and Bull Hill, from the ridge on east side of the creek, looking across Dixon's place, showing type localities of Sonorella bowiensis (1) and Holospira cionella (2).

S. bowiensis differs from $S$. bicipitis by the rounded end of the penispapilla and the actually and comparatively longer penis, over half the length of spermatheca and duct, though the shell is smaller. The shell differs by its smaller size and the faintness or absence of white bands bordering the chestnut zone.

The living animal is slate color on head and back, sides of foot pale blue, borders of the foot orange; liver brown. In alcohol the back is slate, sides, tail and sole whitish. The sole has slightly darker lateral areas marked off with faint grooves. The crop is long and smooth.

I have figured the genitalia of a specimen (pl. IV, fig. 6) for comparison with that previously published. The well-developed penis has a long basal sheath, the lower part of the penis itself being quite 
slender. The papilla is cylindric, somewhat more than one-third the length of the pen is, with a blunt, rounded end. The penis retractor is long. The organs measure as follows: length of penis $12 \mathrm{~mm}$; of penis-papilla $4.4 \mathrm{~mm}$; epiphallus and flagellum 12 ; flagellum 0.6 ; vagina 10 ; spermatheea and duet $21.5 \mathrm{~mm}$. The atrium is extremely short.

In its genitalia this species resembles $S$. binneyi from the southern end of the range, and to a less extent $S$. rowelli. The embryonic seulpture is like that of $S$. bicipitis, but the spirally protractive threads are more numerous and closer.

S. binneyi differs from $S$. bowiensis by the very much smaller penis, nnly half the length of that of $S$. bowiensis in a larger shell; by the different shape of the papilla, and the absence or very minute size of the flagellum. The shell also is invariably larger than S. bowiensis, even in the most arid situations.

Sonorella binneyi n. sp. Pl. II, figs. 13-18.

The shell is depressed globose, narrowly umbilicate, quite thin but moderately strong; pale brown with some whitish oblique streaks, and fading to opaque white around the umbilicus, encircled with a narrow chestuut band at the shoulder, narrowly showing above the suture on the penultimate whorl. Surface slightly shining, marked with fine, rather sharp growth-striæ. Whorls $4 \frac{1}{2}$, convex, the first ninutely roughened but without distinct pattern of sculpture. The last whorl is very wide (viewed from above), inflated, rounded peripherally, very convex beneatn. It descends in front. The aperture is very large, strongly oblique, elliptical, the ends of the lip converging. Peristome thin, very slightly expanded throughout, dilated at the columellar insertion.

Alt. 13, diam. 20; width of aperture 12.8, oblique alt. $11 \mathrm{~mm}$.; width of umbilicus $1.7 \mathrm{~mm}$.

Alt. 11.5, diam. $18 \mathrm{~mm}$.

Alt. 10.5 , diam. $16 \mathrm{~mm}$.

Horseshoe (Mo) Canyon, the types from Station 1, two miles up the Canyon. Also found near the red box of Horseshoe Canyon.

The genitalia (pl. III, fig. 5). The penis is somewhat longer than the vagina. It contracts into a narrow neck at the base, and contains a cylindric papilla, obtuse at the free end, and from one-sixth to about 
one-third the length of the penis. Epiphallus not very unlike the penis in length. Flagellum as usual in the genus. The ragina ishort. Spermatheca oval, on a long duct. Two specimens of $\mathrm{N}$. 97,414 measure:

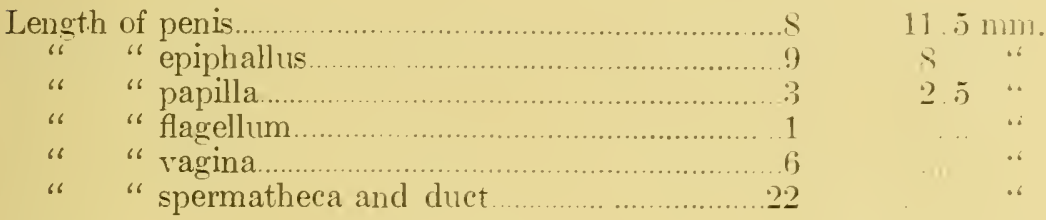

The jaw has five ribs. The pericardiun is about half as long as the kidney.

In its soft anatomy, this species resembles $S$. bouiensis Pils. and also $S$. rowelli (Newc.), but differs from the latter by having a clistinct flagellum. The shell is more like $S$. rowelli, but differs from both species by its more inflated contour and very large aperture. In conchological characters the species is, for a Sonorella, very distinct, and unlike other known Chiricahuan snails.

The smallest specimen seen measures, alt. 8. diam. 13.5 mm. This species is named in memory of ITilliam G. Binney.

\section{Group of Sonorella viritis.}

These forms are distinguished from all other Helices known to us by the enormous length of the penis and its papilla. Sonorclla rinconensis, which has an equally long penis, but a comparatively short papilla, is apparently the most nearly related species. All other known Sonorellas have the penis short or of moderate length. All known species of this group are Chiricahuan. The sculpture of the embryonic shell resembles that of the group of SS. hachituno. but usually the pattern is very indistinct.

Sonorella virilis Pils. PI. II, figs. 1-6.

S. virilis Pils., Proc. A. N. S. Phila., 1905, p. 266, with var. circumstriata, p. 267.

This species was described from a single shell which so far as we can learn was probably taken in Rucker Canyon. The variety circumstriata was described from the talus at the foot of Reed's. Mountain, about a half mile below Reed's place, Station 11 in Cave Creek. The series now available shows that this variety is scarcely di-tinct enour]. 
for recognition, or at least that it is difficult to decide upon some specimens. Figures 1, 2, 3 represent specimens from Station 11, at the foot of Reed's Momintain, Cave Creek Canyon. Figs. 4, 5 are from about two miles up the south fork of Cave Creek. All of these are of the form circumstriata.

Fig. 6 is from spring branch near Rucker Canp, head of Rucker Canyon. This shell, and others from the head of Rucker, has a broad conspicuous white border above the brown band, a narrower one helow it; the brown band is broader than in Cave Creek shells. The spire, viewed from above, is narrower, the last whorl therefore wider.

Specimens from further down Rucker have much less conspicuous white borders along the band, and are like the type of virilis.

This species also occurs in Morse Canyon, the foot of Bonito Canyon, and Shake Gulch, and in Horseshoe Canyon near the Red Box.

In the Cave Creek Canyon Valley it may be found almost anywhere suitable rock cover exists, though there are large areas without it, where the slope is slight or with southern exposure. Rock "slides" or northern exposures with abundant rock are its chief haunts. It was taken at stations $3,4,5,11,12,13,14$, also near the branch leading toward Paradise, in the ravines west of Reed's Mountain, and various places throughout the South Fork as far as explored-about two miles up. None were taken on the great ridge where Stations 6 and 7 are situated, or on the ridge marked 10 . The valley south of the stream from the falls has not been explored. The Sonorellas were also found in a great rock slide (trachyte?) on the south side of a peak near the sawmill, in Barfoot Park, Station 1, and in the head of the adjacent canyon rumning westward. See map on p. 107.

S. virilis (circumstriata) was found also in Paradise Canyon about two miles below l'aradise, and in Pine Canyon.

Tariation.-There is the usual variation in degree of elevation of the spire, and slight variation in ground color of the shell, in all of the lots examined, but various colonies differ in size, as may be seen by the table of measurements of specimens from four places. This size variation is not in the least correlated with elevation, but is invariably comnected with the exposure to the sum. Thus it will be noted that at Stations 1 and 12 the mode is at $18 \mathrm{~mm}$. diameter, the total range from 16 to $20 \mathrm{~mm}$. Both of these stations are on sunny southern slopes, Station 1 being Barfoot Park at an elevation of over 8,000 feet, while Station 12 is only about 100 feet above the bottom of Cave 
Creek, at an elevation of about 6,000 feet. These small specimens contrast with those from Stations 13, from shaded slopes, where the mode is at 20 to $20.5 \mathrm{~mm}$., and the range from 17.75 to $21 \mathrm{~mm}$. . Large shells occur at Station 11, at the shaded and humid base of Ried's Mountain, about 6,000 feet elevation, and at the head of Pine Canyon, at about 8,000 feet, also in a comparatively humid and well-shaded situation. The shells from other places, while too few to be worth tabulating, or to give reliable curves, support the above conclusions as far as they go.

Diameter in $\mathrm{mm}$.

16.

$16.25 \ldots$

16.5

$16.75 \ldots .$.

17.

$17.25 \ldots$

$17.5 \ldots \ldots$

$17.75 \ldots$.

18.

$18.25 \ldots . .$.

$18.5 \ldots \ldots . . .$.

$18.75 \ldots .$.

19.

$19.25 \ldots$

$19.5 \ldots \ldots$.

$19.75 \ldots .$.

20.

$20.25 \ldots$

20.5 .

$20.75 \ldots$

21.

22.

Total.....

Sta. 1. Sta.
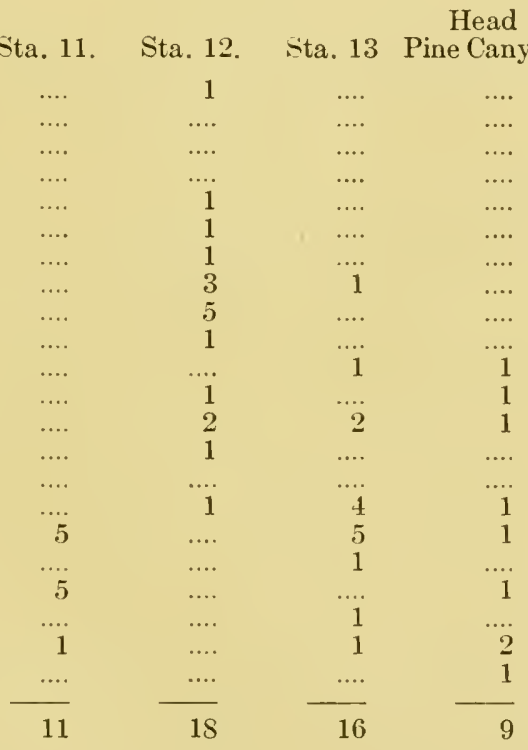

The sole, in alcoholic examples, is yellowish in the central field, the lateral areas grayish, grooves rather indistinct. The back is blackish, sides pale.

Specimens from numerous lots were dissected, genitalia of two being figured (pl. I. fig. 6, No. 94,335 from Station 13, South Fork of Cave Creek, and fig. 4, No. 94,332, from Station 11, Cave Creek). The penis is longer than in the original type specimen, but in about the same proportion to the length of the vagina, which varies considerably. This difference in length is perhaps due to the different modes of preservation. The basal sheath of the penis and its retractor are both quite short. The arcuate shape of the penis is due to its position near the periphery of the last whorl when the animal is retracted. 
Measurements of the genitalia in millimeters.

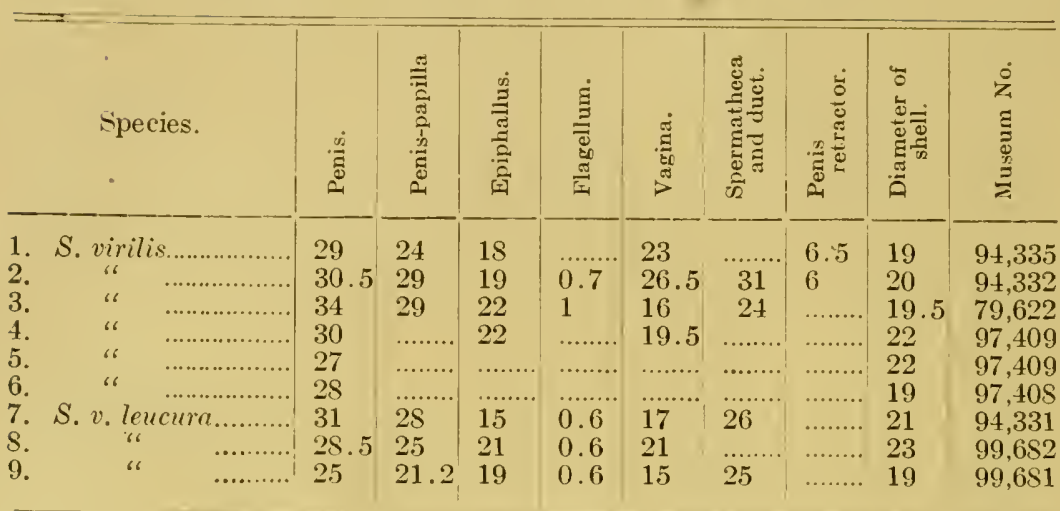

The specimens measured are from the following localities:

1. South Fork of Cave Creek.

2. Foot of Reed's Mountain, Cave Creek.

3. Rucker Canyon (?). Original type of S. viritis.

4, 5. Head of Rucker Canyon.

6. Rucker Canyon at mouth of Raspberry Gulch.

7. White Tail Canyon, Station 4.

8. White Tail Canyon, Station 14.

9. White Tail Canyon, Station 00.

Sonorella virilis leucura subsp. nov. Pl. II, figs. 7-9.

The shell is decidedly more depressed than S. virilis or S. v. "circumstriata," though the spire is about equally convex; the umbilicus is wider; the aperture is smaller, and the ground-color is paler, subopaque, whitish, tinted more or less with brown, nearly white on each side of the dark band, and pale around the umbilicus.

Embryonic and neanic stages.-There are $1 \frac{3}{4}$ embryonic whorls. The depressed tip is smoothish, followed by only a few radial wrinkles; following embryonic whorl is roughened with low granules lengthened in a radial direction, or short, irregularly waved or vermiculate radial wrinkles; over these there is a pattern of grains in regular squares at first, but soon forming protractive rows, the grains becoming indistinct. On the first post-nepionic whorl the fine striæ are more or less interrupted or minutely indented in places. The post-nepionic whorls as far as the fourth whorl are clothed with rery short deciduous hairs, so delicate that the slightest attempt to clean the shell removes them, 
and they probably never persist in the adult stage. All immature specimens taken by us in Norember, from diam. $10 \mathrm{~mm}$. on, hare a strong cullous rib within the lip-edge.

Adult stage.-There are $4 \frac{1}{2}$ whorls in small, $4 \frac{3}{4}$ in large individuals of the type lot, slowly increasing at first, the last whorl seen from above about twice as wide as the penultimate. The lip is blunt with rusty edge, but not thickened within. The outer margin is slightly expanded, the basal a trifle more so; parietal callus rather thick at the edge, straight. The umbilicus contained about 5.2 times in the total diameter. Alt. 11.8, diam. $23.5 \mathrm{~mm}$; aperture $10 \times 11.3 \mathrm{~mm}$.

Distribution: Southern side of White Tail Canyon, Chiricahua Mountains, Stations 1, 2, 3, 4, 5, 9, 12, 14. Type locality, Station No. 14. Also in Jhu Canyon. See map, fig. 6, p. 75 .

This is the only Sonorella on the southern side of White Tail Canyon, living on steep slopes varying from northeast to north or northrest. It occurs (in November) rather deep under rocks, and excepting on the more arid slopes and ridges, colonies may be found where suitable shelter occurs throughout the length of the canyon, generally rather high on the slopes, but in at least one case only about 20 feet above the bed of the canyon. The more favorable slopes, such as those Stations 5, 14, 15 are situated on, are wooded with pinyon below, oak and a few long-leaf pine above. The ridges and slopes with southern or eastern exposure are barren or nearly so. The rock is limestone, mostly with covering of earth and fine stone, and there are no rock slides. Stations 1, 2, 4, and 9 are decidedly more arid and barren than 5 and 14, Station 5 being near the bottom of a deep narrow ravine, densely wooded, while Station 14 is on a steep shady northern slope. The lots taken show that the shells respond to more favorable conditions by reaching a larger size, as seen in the table of measurements.

The shells from Station 5 have the spire somewhat more depressed than any other lot. Those from near Jim Artels' old camp, near head of White Tail not far from Station 1, are the smallest.

The table following shows the shells from high on the ridge (Stations 1 and 4) to be in the main smaller than those from the mid-slope; but this ridge becomes very dry above, with less shade, while the slope lower down is well shaded on northwest exposures (caused by the lateral washes and ravines, running northward), the northeast exposures being for the most part barren. The size of individuals in the colonies collected appear, therefore, to be related to the amount of shade and moisture. 
Measurements of 152 shells from six stations follow:

\begin{tabular}{|c|c|c|c|c|c|c|}
\hline $\begin{array}{c}\text { Diameter in } \\
\mathrm{mm} .\end{array}$ & $\begin{array}{l}\text { Near } \\
\text { sta. } 1 .\end{array}$ & Sta. 4. & Sta. 2. & Sta. 5. & Sta. 9. & Sta. 14. \\
\hline $18 \ldots \ldots \ldots \ldots$ & 1 & $\ldots$ & $\ldots$ & $\ldots$ & $\ldots$ & $\ldots$. \\
\hline $18.25 \ldots \ldots$ & 2 & .... & $\ldots$. & $\ldots$ & .... & $\ldots$ \\
\hline $18.5 \ldots \ldots \ldots$ & 2 & $\ldots$ & $\ldots$ & $\ldots$ & $\ldots$ & $\ldots$ \\
\hline $18.75 \ldots \ldots$ & 9 & $\ldots$. & $\ldots$. & ... & .... & $\ldots$. \\
\hline $19 \ldots \ldots \ldots$ & 4 & $\ldots$ & .... & $\ldots$ & $\ldots$. & $\ldots$. \\
\hline $19.25 \ldots \ldots$ & 2 & $\cdots$ & $\cdots$ & .... & $\ldots$. & $\ldots$. \\
\hline $19.5 \ldots \ldots \ldots$ & 1 & .... & $\ldots$ & .... & .... & $\ldots$ \\
\hline $19.75 \ldots \ldots$ & 3 & 1 & .... & $\ldots$ & 1 & $\ldots$ \\
\hline $20 \ldots \ldots \ldots \ldots$ & 1 & 1 & .... & $\ldots$ & 2 & \\
\hline $20.25 \ldots \ldots$ & .... & .... & $\cdots$ & $\cdots$ & .... & 1 \\
\hline $20.5 \ldots \ldots \ldots$ & $\ldots$ & & & $\cdots$ & & $\ldots$ \\
\hline $20.75 \ldots \ldots$ & $\cdots$ & 2 & 1 & .... & 3 & \\
\hline $21 \ldots \ldots \ldots$ & $\ldots$ & 2 & & $\cdots$ & 10 & 7 \\
\hline $21.25 \ldots \ldots$ & .... & $\cdots$ & 2 & $\cdots$ & 3 & 5 \\
\hline $21.5 \ldots \ldots \ldots$ & $\ldots$ & 1 & & 1 & 2 & 3 \\
\hline $21.75 \ldots \ldots$ & $\ldots$ & 4 & 2 & & & 9 \\
\hline $22 \ldots \ldots \ldots \ldots$ & $\ldots$ & 2 & .... & 2 & 1 & 11 \\
\hline $22.25 \ldots \ldots$ & $\ldots$ & .... & $\ldots$ & 2 & $\ldots$ & 4 \\
\hline $22.5 \ldots \ldots \ldots$ & $\ldots$ & & .... & 2 & $\ldots$ & 3 \\
\hline $22.75 \ldots \ldots$ & $\ldots$ & 1 & .... & & .... & 5 \\
\hline $23 \ldots \ldots \ldots \ldots$ & $\ldots$ & 1 & 1 & 4 & $\ldots$ & 6 \\
\hline $23.25 \ldots \ldots$ & $\cdots$ & $\cdots$ & $\cdots$ & 3 & $\cdots$ & \\
\hline $23.5 \ldots \ldots \ldots$ & $\ldots$. & .... & .... & & .... & 1 \\
\hline $23.75 \ldots \ldots$ & .... & ... & & 3 & $\ldots$ & \\
\hline $24 \ldots \ldots \ldots$ & $\ldots$ & $\ldots$ & 2 & 5 & $\ldots$ & 1 \\
\hline $24.25 \ldots \ldots$ & $\ldots$ & $\ldots$ & $\ldots$ & 2 & $\ldots$ & ... \\
\hline $24.5 \ldots \ldots$ & $\cdots$ & $\cdots$ & $\ldots$ & & $\cdots$ & $\cdots$ \\
\hline $24.75 \ldots \ldots$ & $\ldots$ & .... & $\ldots$ & 1 & .... & .... \\
\hline $25 \ldots \ldots \ldots$ & .... & $\cdots$ & .... & & $\cdots$ & $\cdots$ \\
\hline $25.25 \ldots \ldots$ & $\cdots$ & $\cdots$ & $\cdots$ & 1 & $\cdots$ & $\cdots$ \\
\hline No. of she & 25 & 15 & s & 26 & 22 & 56 \\
\hline
\end{tabular}

Soft anatomy.-Several specimens were dissected, from three stations, 14, 4 and from near Station 1. The genitalia do not differ from these organs in $S$. virilis circumstriata. Measurements may be found on p. 72. An example from Station 4 (No. 94,331) is illustrated (pl. $\mathrm{V}$, fig. 5). It shows the penis kinked in a way unusual in the species.

The sole is tripartite in color, the central area, half the total width, being pale isabelline, the side areas gray. The foot is gray above, darkest on the back; top of the tail of a dirty yellow tint.

Sonorella micra n. sp. Pl. II, figs. 10-12.

The shell is small, thin, the umbilicus contained about five times in the total diameter; pale brownish-corneous, a little paler around the umbilicus, and with scarcely perceptible pale borders above and below the dark chestnut band above the periphery; only slightly glossy. Spire very low. The embryonic shell consists of $1 \frac{1}{2}$ convex whorls; after the smooth apex, there are a few arcuate radial ripples; and the 


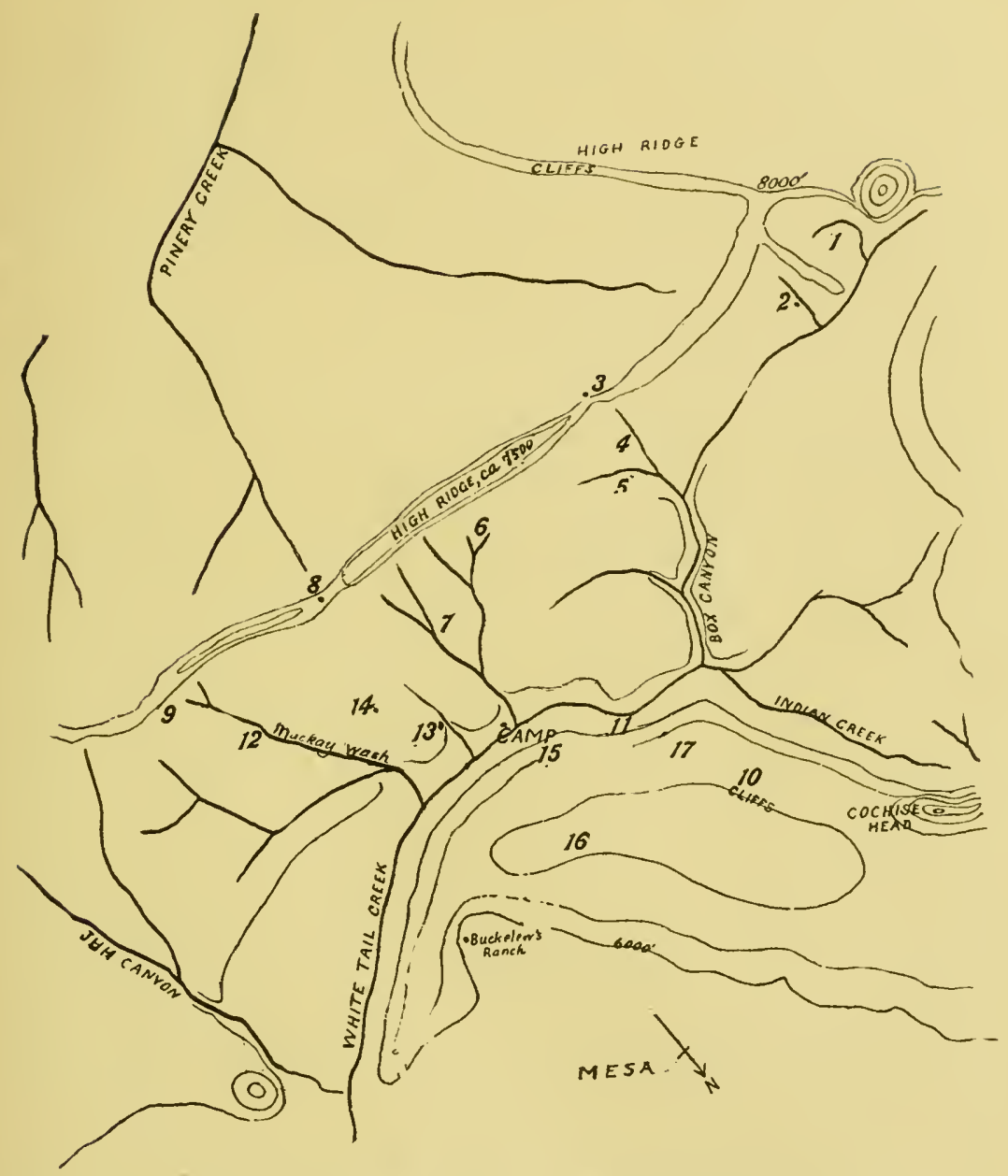

Fig. 6.-Collecting stations in White Tail C'anyon.

rest of the embryonic shell has irregular rugosities or asperities, short, but longest in a radial direction; over these there are granules arranged as in S. v. leucura. When absolutely unworn they bear delicate hairs in young shells. The following post-embryonic whorls are delicately striate, and as far as the beginning of the fourth whorl, fresh and uncleaned young shells have close, short and very delicate hairs. The last whorl has delicate growth-lines, but no trace of spiral strix; it is rounded at the periphery and descends a little in front. The aperture is oblique, rounded. The peristome is thin, outer margin scarcely 
noticeably expanded, basal margin somewhat more so; columellar margin rather broadly dilated and brought forward. The parietal callus is short, thin and transparent.

Alt. 7.2 , diam. $14.5 \mathrm{~mm}$; aperture $7.5 \mathrm{~mm}$. wide, 7 high. Whorls $4 \frac{1}{4}$.

Distribution: North side of White Tail Canyon, in slides of igneous rock (rhyolite), at Stations 10, 11, 15, 16, 17. Type locality, Station 10. See map on p. 75 .

This is the smallest Sonorella yet known from the Chiricahuas. It is allied to $S$. viritis by the genitalia and the indistinct sculpture pattern on the embryonic whorls, but differs by its diminutive size, thin shell, comparatively narrower umbilicus and the absence of distinct white borders along the brown band.

$S$. micra occupies the north side of White Tail Canyon to the exclusion of $S$. virilis leucura, which lives on the opposite or south side. It lives in "slides" of angular, dark purplish-gray rock (rhyolite), together with Ashmunella lepiderma, and can be found only deep in the rocks, where they rest on the earth below. The slopes are mainly toward the south and west, hence exposed to the direct sun, rarely shaded to any extent by the small trees. The snails are found from the bottom of the canyon (Station 11) to perhaps 6,800 feet (Station 16), where they occur over the crest of the ridge, in an extensive slide sloping northward. The type locality, Station 10, is below the great cliffs along Indian Creek. The lower stations are easily accessible, but the higher call for arduous climbing and, from the nature of their haunts, the work of quarrying the snails out is severe. IVe secured but few living specimens, but many dead shells, more or less fresh, show the species to be remarkably constant. Besides a slight variation in elevation of the spire, no variation in form is noticeable. Measurements of two lots follow :

$\begin{array}{lrccrrr}\text { Diam. in mm.......12.75 } & 13 & 13.25 & 13.5 & 13.75 & 14 & 14.25 \\ \text { Station } 10 \ldots \ldots \ldots \ldots .1 & 0 & 0 & 1 & 2 & 7 & 4 \\ \text { Station } 17 \ldots \ldots \ldots \ldots .0 & 1 & 0 & 4 & 4 & 10 & 4 \\ \text { Diam. in mm.......14.5 } & 14.75 & 15 & 15.25 & & & \\ \text { Station } 10 \ldots \ldots \ldots \ldots .4 & 7 & 7 & 1 & & & \\ \text { Station } 17 \ldots \ldots \ldots \ldots .1 & 3 & 2 & 0 & & & \end{array}$

On the southern side of the canyon we found a few dead specimens among limestone rocks about 20 feet above the bed of the canyon, below the junction of Indian Creek. They agree fully with those from the north side of the canyon. 
S. micra occurs associated with Ashmunella lepiderma in the same rock slides. Both are modified in the same manner, the shell differing from allied species in being smaller, thinner, dull, with a greater or less development of cuticular processes. The reduced size compared with the species on the opposite side of the canyon is without much doubt due to the sun-scorched exposure. We have not found that living on igneous rock has any tendency to dwarf Sonorellas, though the tenuity of the shell may fairly be attributed to that influence.

The animal in alcohol is pale grayish, darker on the back. Sole with the usual pale central area and slightly darker side areas, not defined by lines.

The genitalia of a drowned specimen in good condition from Station 10 is drawn in pl. V, figs. 1, 2. Unfortunately the penis was exserted in all of this lot. Except in being smaller and more slender, the organs resemble closely those of $S$. viritis. The penis in this figure is shown partially everted, the long papilla $(p p$.) projecting. In fig. 2 the epiphallus is shown partially uncoiled. The flagellum is well developed for a Sonorella. Pl. V, fig. 3, represents the organs of another specimen, from Station 17, with the penis normally retracted. The end of the penis-papilla is shown in outline

Measurements in millimeters of the genitalia of two specimens follow:

\begin{tabular}{|c|c|c|c|c|c|c|c|c|}
\hline Penis. & Papilla. & Epiphallus. & Flagellum. & Vagina. & $\begin{array}{l}\text { Sperma- } \\
\text { theca } \\
\text { and duct. }\end{array}$ & $\begin{array}{l}\text { Penis } \\
\text { retractor. }\end{array}$ & $\begin{array}{l}\text { Diameter } \\
\text { of shell. }\end{array}$ & $\begin{array}{l}\text { Museum No. } \\
\text { of shell. }\end{array}$ \\
\hline $\begin{array}{l}17 \\
14\end{array}$ & $\begin{array}{l}14 \\
11\end{array}$ & $\begin{array}{l}10.5 \\
13\end{array}$ & $\begin{array}{l}0.6 \\
0.5\end{array}$ & $\begin{array}{l}8 \\
9\end{array}$ & $\begin{array}{l}16 \\
17\end{array}$ & $\begin{array}{l}8+ \\
4.5\end{array}$ & $\begin{array}{l}14.8 \\
14\end{array}$ & $\begin{array}{l}94,334 \\
94,330\end{array}$ \\
\hline
\end{tabular}

\section{Genus OREOHELIX Pilsbry.}

The Chiricahua Mountains harbor two groups of Oreohelix with a well-developed nearly black, green or yellow cuticle, so far unknown elsewhere. In one of these, the barbata group, the shell is bi-convex, with whorls of small calibre, a wide umbilical cavity and numerous spiral wreaths of cuticular fringes. The other, the $O$. clappi group, has an orbicular shell usually banded, with large tubular whorls and a smaller, rapidly diminishing umbilicus. In one of the forms both the cuticle and the shell beneath possess well-defined spirals similar to the cuticular fringes of $O$. barbata; but here the likeness ends. In general appearance these Chiricahuan forms have little resemblance to groups of Oreohelix in the Huachucas or elsewhere. The clappi 
group further differs from the $O$. strigosa group in possessing radially costulate apical whorls.

Snails of both of these groups live immured in the shaded rocks of the mountain "slides," composed of broken rock or spawls tumbled down from the peaks above. O. clappi lives from 5,000 to 7,000 feet, and $O$. barbata from 7,000 to 10,000 feet above the sea. The dead shells are seldom found upon the surface. Oreohelix chiricahuana, in the same mountain range, requires but little covering, and is found in dry situations, often with but a single leaf or a small spawl for protection. It agrees with the Oreohelices of other regions in having a very thin cuticle, often wanting. Dead agavas and yuccas furnish a home for these, the Holospiras and Succinca avara; but O. barbata and $O$. clappi, the Ashmumellas and Sonorellas require an atmosphere with more moisture, and dwell from one to two feet below the surface. He who finds must dig.

All Chiricahuan Oreohelices are confined to that range, and none of them are closely related to species found elsewhere. All are conspicuously variable in each colony and in different colonies, nearly every one of which shows a degree of racial differentiation, so that one acquainted with these shells, even as imperfectly known at present, could locate himself if lost in the Chiricahuas by digging for Oreohelices!

No adequate discussion of these shells can be entered into without more and better illustrations than are possible to us at this time, and long series of measurements. We have merely indicated briefly the salient features of each colony.

\section{The Oreohelix clappi series.}

'The group of local races which for taxonomic purposes is considered to compose the species $O$. clappi comprises about a dozen colonies, scattered over the range for a distance of about 44 miles. The relationships of the snails of these colonies may be expressed diagramatically thus:

$$
\begin{array}{r}
\text { Emigrans-Onion Creek-Reed's Mt.-type-_-_-Cataracta } \\
\text { Horseshoe--Shake Gulch-Rucker Box }
\end{array}
$$

The forms toward the left in this diagram are successively more roughly sculptured, toward the right they are smoother. The type happened to be of intermediate character, and near the central point of the range of the species. The upper line forms a variation-series extending from Big Emigrant Canyon (emigrans) to the Falls of 
Cave Creek (cataracta). The lower line is a similar but independent chain from the southem canyons, a considerable distance from the nearest of the more northern group.

From Big Emigrant Canyon to Shake Gulch the Stations mentioned above run in a general direction from northwest to southeast. From the emigrans station to Onion Creek station is about 16 miles; thence to Cave Creek, 4; to Cave Creek Falls (var. cataracta), 2; to Rucker Box, 12; to Shake Gulch, 12. Total, 44 miles as the crow flies; but it is 55 by trail.

One peculiarity runs throughout the entrire clappi series: they are hard to catch. Except at Onion Creek they were grouped in small families and the families did not seem to be upon speaking terms. They were clannish and confined their travels to one particular rock slide. In only two instances was the same form foumd in two slides of rock, though the rocks were well explored for miles around. At Onion Creek they were plentiful; about 100 were collected there in an hour.

Oreohelix clappi emigrans n. subsp.

This shell is similar in outline to O. clappi, but more sharply angular at the periphery, or even carinate in front. Cuticle thicker, rough, usually persistent, dark olive brown in color, lusterless, not banded, coated and caked with a deposit of humus. The sculpture after the embryonic shell consists of oblique, umeven, rather sharp strix, and
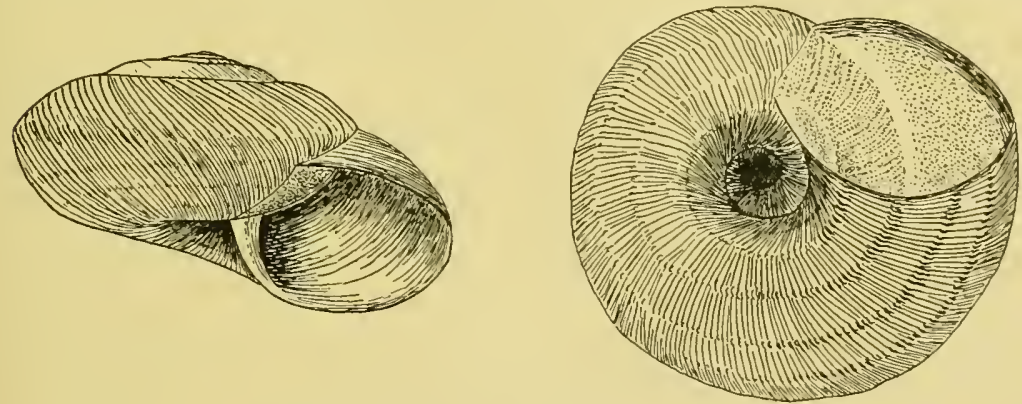

Fig. 7.-Oreohelix clappi emigrans.

on the last whorl some coarse wrinkles. The stria are sharper than in $O$. clappi and close together up to the last whorl; on the base they are thread-like, crimped and waved at the intersections of four or five circular rows of short cuticular appendages, which are usually retained only on the latter part of the base. In immature shells the threadlike striæe are surmounted by delicate cuticular laminæ, more or less felted together by the adhering dirt. The aperture is rounded- 
piriform, the lip margins converging, thickened at the ends and connected by a thin film across the parietal wall. Interior bluish white. Alt. 9, diam. $16 \mathrm{~mm}$., whorls 5 .

Big Emigrant Mountain, on the south side of Big Emigrant Canyon, at about 7,000 feet elevation, taken in some numbers in a shattered column of stone and also in a rock slide. This place is about 20 miles across the mountains northwest from the Cave Creek Station for O. clappi.

O. c. emigrans is the dirtiest of the gromp-in its natural state as black as the soil. It is well distinguished by the sculpture, and would be considered a separate species in a less variable group than Oreohelix.

\section{Oreohelix clappi Ferriss.}

Oreohelix clappi Ferriss, Nautilus, XVIII, p. 53 (Sept., 1904). Pilsbry, Proc. A. N. S. Phila., 1905, p. 285, pl. 25, figs. 54-56 (shell); pl. 19, fig. 8 (genitalia); pl. 22, fig. 4 (teeth); pl. 23, fig. 26 (jaw).

The shell is moderately depressed, with tubular whorls and deep suture, the altitude about two-thirds the diameter and about equally convex above and below the peripheral angle. The umbilicus at the opening is about one-sixth the diameter and contracts rapidly, only the penultimate whorl visible. Calcareous layer of the shell is brownish white under a thin greenish-yellow cuticle with some darker oblique streaks, which become in mature shells darker and crowded near the aperture. Many possess two indistinct transparent olive spiral bands, one above, the other just below the periphery. In old individuals the cuticle remains only in ragged shreds. The first $1 \frac{1}{2}$ embryonic whorls are strongly ribbed radially; these riblets are regular and narrower than their intervals. At the end of the embryonic shell the whorl slightly widens abruptly, with sculpture of rather coarse irregular obliquely radial wrinkles and traces of fine spiral striæ. The last whorl has unequal, irregularly spaced oblique wrinkles, weak and low at the base, which is densely covered with minute wavy spiral striæ, obsolete in old individuals. Where the wrinkles pass over the angular periphery they are sometimes somewhat more emphatic, a little pinched up. There are no spaced circular threads or cuticular fringes on the base. Whorls $4 \frac{3}{4}$, convex, the last double the width of the preceding. Base very convex. The aperture is very shortly ovate or nearly circular, very oblique, and about one-half the diameter of the shell. The ends of the lips converge. The short parietal callus is a thin transparent film, or in old shells the peristome is continuous, as a raised parietal ledge. Old age is expressed by a deeper descent of the last whorl and closer approach of the lip margins, as usual in the genus Oreohelix. 
Seven fully adult shells of the original lot measure:

$\begin{array}{ccccc}\text { Alt. } & 10, & \text { diam. } & 15 & \mathrm{~mm} \\ \text { " } & 9, & \text { " } & 14.3 & \text { " } \\ \text { " } & \mathrm{S} .7, & \text { " } & 14.5 & \text { " } \\ \text { " } & 9, & \text { " } & 14.3 & \text { " } \\ \text { " } & \mathrm{S} .5, & \text { " } & 14.3 & \text { " } \\ \text { " } & 9.5, & \text { " } & 14.9 & \text { " } \\ \text { " } & \mathrm{S.9} & \text { " } & 14 & \text { " }\end{array}$

This exact form has been found only at the type locality on the sonth side of Cave Creek below the place marked Camp on the map, p. 107 , where it was taken in 1904 , deeply imbedded in rotten shale near the water's edge. About 30 specimens.

In its native state $O$. clappi is covered with humus, perhaps attached by mucus. But few specimens were found except in the type Station. Its habit of burying deeply in the soil probably accounts for its rarity.

Elsewhere in Cave Creek Canyon a slightly different form (see below) was found in 1906 at Stations $9,11,12$, near 13, 14 and in the ravine west of Reed's Mountain. These stations are all near the bottom of the canyon. It was not found higher up. Here it occurs with Sonorella, Ashmunella chiricahuana, A. ferrissi and A. angulata.

2. Lower Cave Creek Form. - The shells taken in 1906 at Stations 9, 11, 12 and near 13, 14, Cave Creek, are slightly more angular at the periphery than the types, and the growth-wrinkles bear short cuticular lamellæ where they pass over the peripheral angle in fresh and unrubbed individuals not fully mature. Often, but not always, there are three circular rows of inconspicuous granules at wide, equal intervals on the base, a weak or vanishing development of the basal sculpture of O.c. emigrans. The two brown bands (one at the outer third of the upper surface of the last whorl, the other below and near to the peripheral angle) are usually more distinct than in the type lot of clappi. A small series of fully adult shells from Station 12 measure:

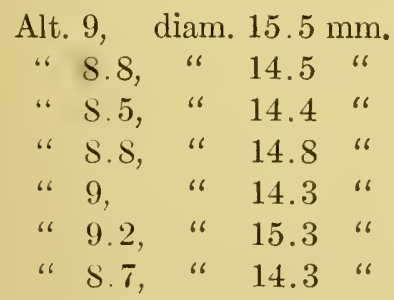


3. Onion Crele Fora. - This form resembles the second form from Cave Creek and $O$. c. emigrans in shape. Compared with O. clappi the whorls are flatter, less convex, sutures not so deep. The last whorl invariably falls to the aperture further below the angle of the preceding whorl, and the peripheral angle continues strong as far as the lip-edge.

Cuticle thin, persistent, not ragged or broken, light greenish olive, lustreless, with occasional dark oblique lines, which, near the aperture, become crowded. It is seldom banded spirally and then the bands are indistinct, obscure brown and transparent. The growth-striæ are sharper, more distinct than in Cave Creek clappi. It is very densely and distinctly striated, spirally. Oblique waved riblets and traces of spiral wreaths on the base, as in O.c. emigrans, are shown in young shells, and sometimes upon the penultimate whorl of the mature shell within the aperture, but seldom persistent upon the exterior. There are nearly 5 whorls. The aperture is pear-shaped, its upper margin nearly straight (consequent upon the flatness of the whorls);
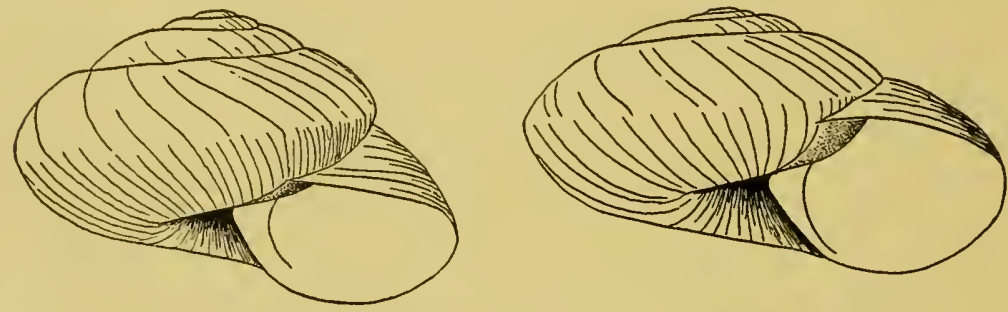

Fig. 8.-Oreohelix clappi, lower Cave Creek, station 12.

not arched, as in typical $O$. clappi. The smaller shells measure about $8.8 \times 15 \mathrm{~mm}$.; the largest in about one hundred specimens measure:

$\begin{array}{lllll}\text { Alt. } 10 \frac{1}{2} \text {, diam. } & 17 \frac{1}{2} & \mathrm{~mm} \text {. } \\ \text { " } 10 \frac{1}{2}, & \text { " } & 17 & \text { " } \\ \text { " } 10 \frac{1}{2}, & \text { “ } & 17 & \text { " } \\ \text { " } 10, & \text { " } & 17 & \text { " } \\ \text { " } 10 \frac{1}{2}, & \text { " } & 16 & \text { " }\end{array}$

Found at the head of the main fork of Onion Creek, a branch of Turkey Creek, on the north side of the range. It was found in a shattered column of quartzite in company with Ashmunella, Sonorella, Succinea avara and two rattle-snakes, Crotalus pricei and C. lepidus. Oreohelix chiricahuana dwelt in the limestone over the ridge, less than a half mile distant. The station is about 4 miles from the locality of $O$. clappi and $\mathbf{1 6}$ from that of $O$.c. cmigrans, and upon a direct 
line between the two. This is the greenest in color of the group, the texture of the cuticle is the most harsh and it is the largest in diameter.

4. Form from Rucker Canyon.-The sculpture in this form is weak, the oblique wrinkles smooth, in part effaced, and lower on the base; spiral striation weak or subobsolete, hardly noticeable above. Cuticle glossy, persistent, varying from rather bright green or greenishyellow to brownish-olive, the two brown bands distinct. There are sometimes two fainter bands, one above, the other on the base. The last whorl is only very obtusely angular, the angle, well rounded, usually falls less in front than in the Onion Creek lot. The aperture is conspicuously longer than in typical O. clappi; upper margin decidedly arched. In old shells the lip-ends approach closely, but are not commected as in the typical $O$. clappi, the callus between them remaining thin and transparent.

Up to $3 \frac{1}{2}$ whorls the young carry five strong cuticular fringes below, one at the periphery and one above. The cuticle in larger shells is smooth.

The largest in 45 measured:

$\begin{array}{ccccc}\text { Alt. } & 10, & \text { diam } & 16 \frac{1}{2} & \text { mmm. } \\ \text { " } & 10, & \text { " } & 16 \frac{1}{2} & \text { “ } \\ \text { “ } & 10, & \text { “ } & 16 \frac{1}{2} & \text { “. } \\ \text { " } & 9 \frac{1}{2}, & \text { “ } & 15 \frac{1}{2} & \text { “ } \\ \text { “ } & 9, & \text { ". } & 15 \frac{1}{2} & \text { “ }\end{array}$

This is the handsomest of the group in color and, with the exception of $O$. c. cataracta, the smoothest, the base being polished with somewhat of a varnish-like gloss. The last whorl is even more rounded peripherally than in typical O. clappi. In 1908 it was found in a deep gulch, the "box" of Rucker Canyon, at about $\$, 000$ feet elevation, on both sides of the stream in sliding rock, where the atmosphere was as moist as the stations on Care Creek, about 12 miles distant. It is a near neighbor with $O$. barbata, a small form of the latter being plentiful at the twin caverns in the box, while $O$. clappi was found half a mile farther down the stream.

5. SHake Gulch Fori.-The shell is sharply angular peripherally, the angle becoming obtuse near the lip; whorls flattened above; cuticle dull, lusterless, persistent, obscure olive at the base, the upper surface with a russet suffusion, peristome black-bordered. There are one or two faint bands. The surface is obliquely, rather obtusely, wrinkled, the base distinctly striate spirally, growth-lines low, nnt waved. The sculpture of the embryonic shell is rery weak, and 
seems closer than usual. Unfortunately, no young examples were taken.

This form is usually more depressed than that from Onion Creek, with less sharp oblique sculpture. It resembles the remote Onion Creek colony in the lusterless cuticle. Fourteen of about 20 shells taken measure:

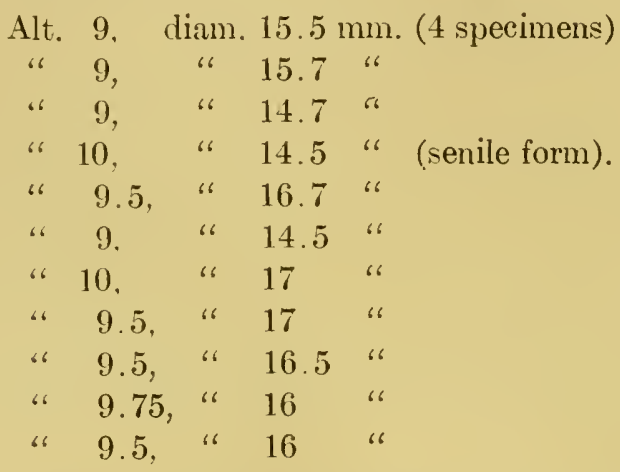

Shake Gulch, where these shells were found, is on the southwest side of the range at about 5,500 feet elevation about 12 miles from the Rucker "box."19 They live in a rock slide near the stream.

6. Horse-shoe Canyon Form. - Similar to the preceding except that the peripheral angle is less acute; between the Shake Gulch and Rucker lots in form. Fragments of a long cuticular fringe remain in places in the suture from the third whorl to near the aperture, but there are no spiral series of granules or cuticular prominences on the hase, thereby differing from $O$. c. emigrans, and like the forms geographically nearest. Only two collected, both adult, measuring alt. 9, dian. $16 \mathrm{~mm}$.

Found in Horse-shoe Canyon about ten miles from the mouth, in slide rock, on the opposite side of the main fork from the Red Box, at about 7,000 feet elevation. Both shells taken were freshly dead.

\section{Oreohelix clappi cataracta n. subsp.}

The shell is depressed, nearly lens-shaped; periphery strongly angular, bright olive green, thin, polished, translucent, occasionally marked with two transparent bands; $4 \frac{1}{2}$ whorls, the last wider than in clappi; with the periphery near the flattened top, base strongly convex. Aperture nearly all below the periphery. Parietal callus short,

19 Shake Gulch is so named from the circumstance that "shakes" (split shingles) are there made from the cypress. 
merely a thin film on the penultimate whorl. Cuticle smooth and without "fringes" in young or old, very delicately striated spirally; sculpture of the embryonic whorl delicate, usually wom off.

Probably only the first of those measured is mature:

Alt. 6.1, diam. $13.8 \mathrm{~mm}$.

$\begin{array}{lllll}\text { " } & 6 \frac{1}{2}, & \text { ، } & 12 & \text { “ } \\ \text { " } & 6, & \text { " } & 12 & \text { “ } \\ \text { " } & 6 \frac{1}{2}, & \text { " } & 11 & \text { “ } \\ & \text { ". } & 11 & \text { “ }\end{array}$

Found at the Cave Creek Falls in broken rock sprayed by the falls, and near the water's edge, in company with a very small form of
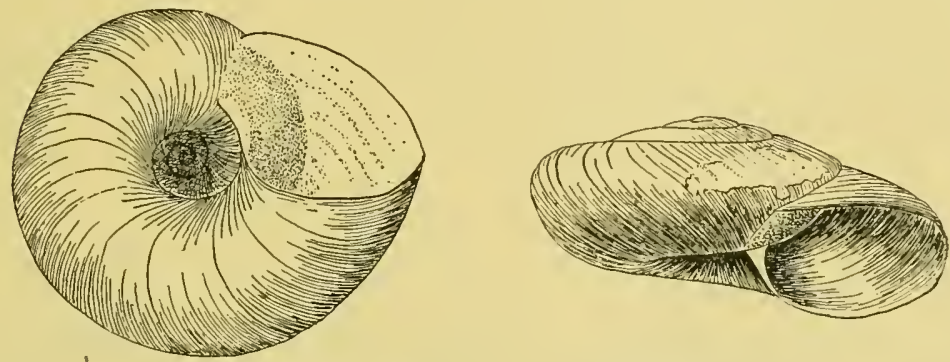

Fig. 9.-Oreohelix clippi cutaructa P. and F.

Ashmunella chiricahuana. It was also found occasionally among the rocks higher up the slide with $O$. barbate and Ashmunclla angulata. About 25 were found in two visits to the stations. None were alive, but some perfectly fresh. It is probably a deep burrower. This is the only station where $O$. barbata and $O$. clappi were found together.

$O$. c. cataracta is quite a distinct race. The green, polished base reminds one of Omphalina. It is the smoothest and most depressed form of $O$. clappi.

Oreohelix chiricahuana Pilsbry. Fig. 10.

Proc. A. N. S. Phila., 1905, p. 2\$3, pl. XI, figs. 1-3 (shell), pl. XIX, fig. 4 (genitalia), pl. XXIII, fig. 24 (jaw).

The range or this species extends from Emigrant Canyon to Limestone Mountain, a distance of about 50 miles. Its range is markedly discontinuous towards the north and south ends, but from White Tail to Cave Creek Canyons the colonies are not widely separated. It is always found on limestone, never where the country rock is metamorphic or igneous.

The several races differ as follows: 
a. - Siculpture of sharp fine strie along the lines of growth, conspicuous on the base, where there are also spiral strix and some widely spaced larger spirals.

b. - Shell smaller, diameter about $11 \mathrm{~mm}$., whorls $4 \frac{1}{2}$ to 5 ; peripheral keel well expressed O. chiricahuana

$b^{1}$. - Thell larger, diameter about $14 \mathrm{~mm}$., whorls $5 \frac{1}{4}$; peripheral keel strongly projecting, the whorl hollowed above and below it O. c. percarinata $a^{1}$ - - Ticulpture obsolete, the oblique strix comse and blunt, the base especially much smoother; spiral sculpture weak or wanting; diameter usually 12 to $15 \mathrm{~mm}$., whorls $5 \frac{1}{3}$ to $5 \frac{1}{2} \ldots \ldots . .$. . c. obsoleta.

The type locality is on the slope with southern exposure below the cave in Cave Creek Canyon, Station $S$ on map, p. 107. The dry ravine has steep sides of steeply dipping, more or less calcareous shale and earth formed by its decomposition. The dead shells are profusely scattered; living ones are under dead mescal (Agave), sotol (Dasyiirion) and bear-grass, with Thysanophora horni, Succinea avara, Titrea

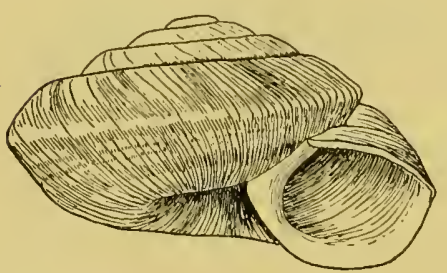

Fig. 10.--O). chiricahmana, Cave (reek, stations.

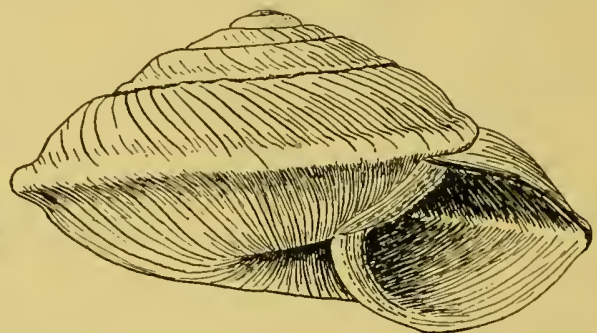

Fig. $11-0$. c. percarinata P. and F. Cross J Mountain

indentata and Holospira. The colony here is about 250 yards long and perhaps 100 wide in the widest place. The shells are very uniform in size:

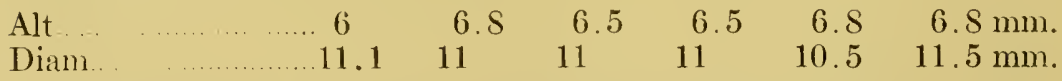

The shells are white, with the earlier whorls flesh-tinted, a faint fleshy-corneous band at the onter third of the top of the last whorl, which has two grayish or fleshy corneous bands on the outer half of the base or a general fleshy corneous suffusion there. A scalariform mutation rarely occurs.

From the cave we found large colonies at intervals westward nearly to the western rim of the valley, at Stations 5, 6 and 7 on map, p. 107. At Station 5, on a steep north slope along the creek, under rocks, about 3 miles west of the cave, the shells are similar but larger, 12 to $13 \mathrm{~mm}$. in diameter. 
At Station 6, about half way up the north side of the limestone ridge, the shells were like those from the cave in size, but somewhat whiter, more calcareous. Near and at the top of the ridge, along the southern side, east and west of station 7, O. chiricahuana is widely distributed. The shells here are like those from station 6 , but smaller, the largest $10 \mathrm{~mm}$. in diameter. This colony is probably 1,500 feet higher than the cave. The smaller size of the shells from Station 7 may probably be correlated with a dryer and hotter habitat. How far down the south slope it extends we did not learn. We found $O$. chiricahuana nowhere else in Cave Creek Canyon, nor has the typical form been encountered elsewhere.

Oreohelix chiricahuana percarinata n. subsp. Fig. 11.

The shell is larger than typical $O$. chiricahuana, whitish, clouded and suffused with flesh color, depressed, with a compressed, projecting peripheral keel, the last whorl excavated, concave above and below the keel, elsewhere strongly convex. Striation oblique, rather coarse and quite irregular above, sharper and strongly arcuate below. Spiral

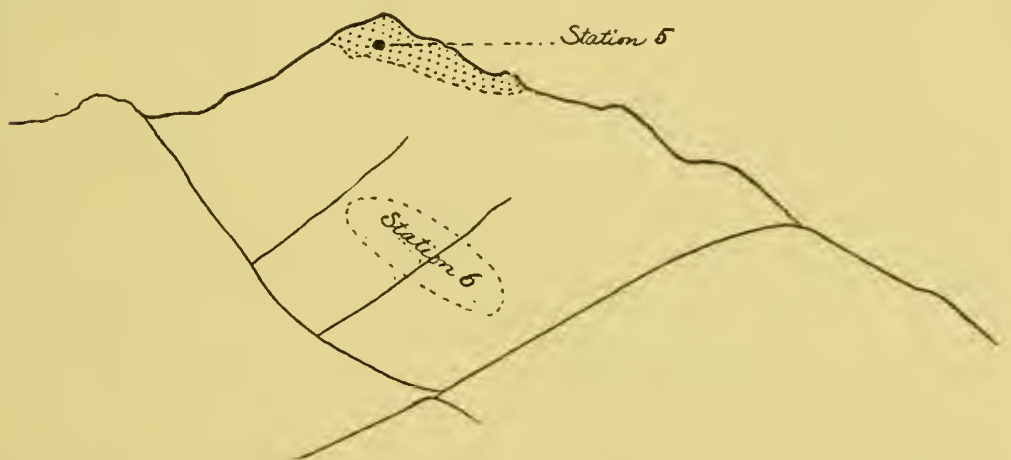

Fig. 12.-Summit Cross of J Mountain, seen from the mouth of Big Emigrant Canyon, at $\mathrm{X}$ on map, p. 121. Entire range of $O$. c. percarinata shaded. At Station 5 and over much of the slope around Station 6 , Sonorella optata was found. High granitic spur on left.

threads few and fine or wanting on the upper surface; on the base there are two to four major spirals at wide intervals, with fine spiral threads over the whole base. The last whorl rarely falls far below the carina at the aperture. Alt. 8 , diam. $14 \mathrm{~mm}$.; whorls $5 \frac{1}{4}$.

Simmit of Cross $J$ Mountain near the mouth of Big Emigrant Canyon, Station 5 on map, p. 121. November 12, 1906. This locality is farther north than any other known colony of Oreohelix in the Chiricahua range. The Oreohelices were found around the summit, which is probably about 7,500 feet elevation, and along the ridge northward, down about 500 feet, but not in the valley (Station 6 ), where Sonorella 
lives. This slope of the mountain is limestone, becoming cherty above, but the summit is angular, friable quartzite (?), among the fragments of which the Oreohelices live. None were found on the ridge rumning toward the mouth of the canyon, which is composed of a disintegrating, coarse-grained granitic rock. There is little vegetation of any kind on the upper part of Cross $J$ Mountain. The station is rocky, barren and exposed. The snails are moderately abumdant, though living ones are hard to get.

Paradise Canyon. On the south side, about two miles below the town of Paradise, Orcohelix was found in some abundance, but owing to the snow which covered the ground at the time we camped there (November 20) but few living examples were taken. The form is almost identical with that of Cross $J$ Mountain, the adult differing only in having the radial striation on the base a little more regular, and the major spirals, of which there are three or four, often somewhat stronger, though in some shells they are hardly noticeable. In young and half-grown shells a thin cuticular thread runs along the summit of each of the striæ, and at the intersections of the major spirals these threads rise in short triangular processes. This feature was not observed in the shells from Cross J Mountain.

Another similar lot was taken on the northern slope of the canyon. These places are probably not far from the 6,000 feet contour, being thus much lower than Cross J Mountain.

The separation of these colonies from the Cross J Mountain colony of 0 . c. percarinata probably indicates independent erolution of the same characteristics, since an area occupied by $O$. chiricahuana obsoleta lies between Big Emigrant and Paradise Canyons.

Oreohelix ohiricahuana obsoleta n. subsp. Fig. 13.

In White Tail Canyon, this form of $O$. chiricahuana was taken at Stations 1, 2, 3, 6, 7, 8, 12, 14-all on the southern side except 3, which is just over the crest of the ridge on the Pinery side. The sculpture is rather rude and blunt, the striation less sharp than in the Cave Creek form, being effaced or subobsolete especially on the base where spiral lines are wanting or rarely weakly indicated, while Cave Creek chiricahuana has sharp, subregular striation and distinct spirals. Two or three inner whorls are brown, the rest being white with some faint gray streaks and scattered dots. Whorls $5 \frac{1}{3}$ to $5 \frac{1}{2}$ ( $4 \frac{1}{2}$ in typical chiricahuana), the last carinated as in chiricahuana. The shape varies from typical to decidedly more elevated, and the size everywhere exceeds that of Cave Creek shells. A series from the typical Station 14, where it is abundant, measures: 


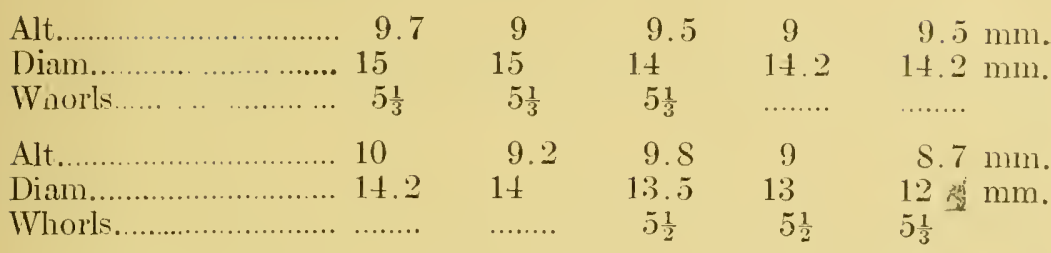

In these shells the peripheral angle is about as in Cave Creek types, but the base is smoother, the striation nearly effaced, and spiral strix are wanting or very rarely a few may be faintly seen under the keel. Shells from Stations $1,2,6,7,8,12$ agree with those from 14. These stations are on rather steep slopes with generally northern exposure, and from somewhat over 6,000 to about 7,000 feet elevation. The distribution over this area is nearly or quite continuous.

At Station 3, just over the crest of the ridge, on the Pinery Canyon side, probably a little over 7,000 feet elevation, the shells are smaller, 11.8 to $13 \mathrm{~mm}$. diameter; otherwise similar. This station is very high and exposed, on a sunny slope, hence extremely dry and arid; but the following record shows that mere elevation is not a factor of importance. On the south side of White Tail Creek, only
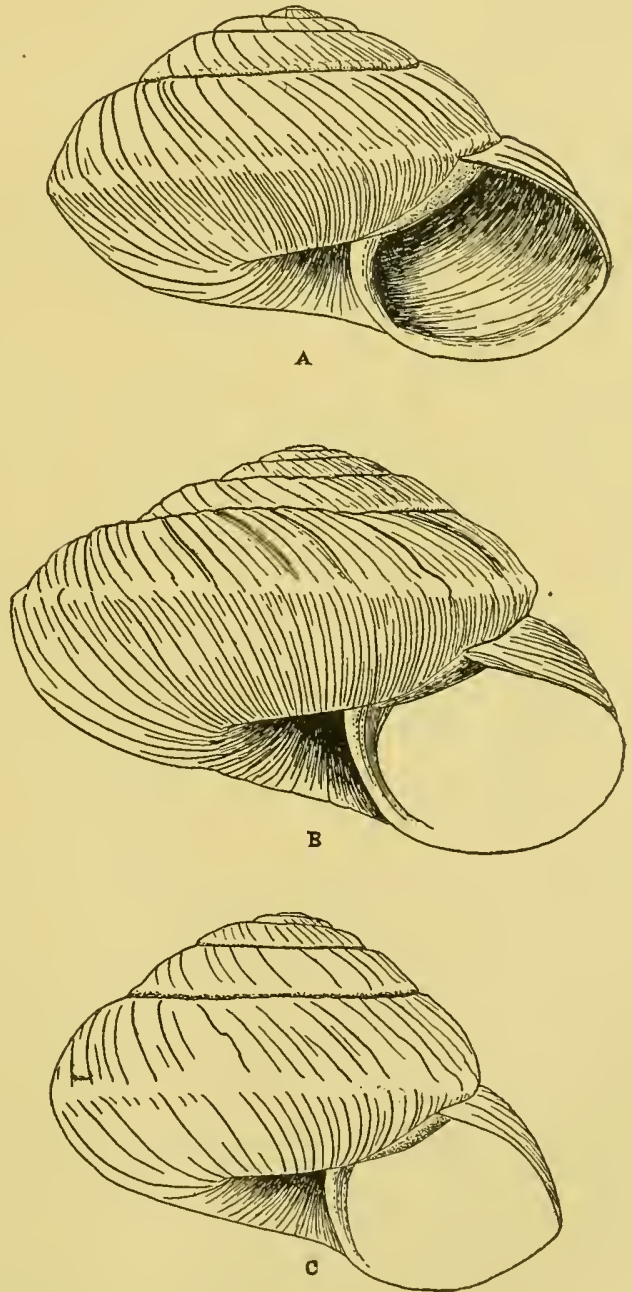

Fig. 13.-O. c. obsolett $\mathrm{P}$. and F. A, White Tail, Station 14; B, C, Iimestone Mountain. Drawn to same scale as figs. 10 and 11 . 
a few feet above the bed of the canyon, at and below the mouth of Indian Creek, the shells are equally small, 12 to $13 \mathrm{~mm}$. in diameter. The station is deficient in herbage, more barren than higher up the slopes.

In the Box Canyon of White Tail we found a colony which differed from all other lots of the White Tail region in sculpture, the striation being distinct and rather sharp on the base, as in typical chiricahuana, and with very weak traces of fine spiral lines. The peripheral keel projects more, approaching the shape of the race from Big Emigrant Canyon; otherwise the shape, size and number of whorls is as in O. c. obsoleta. The conditions at this station were infortunately not noted particularly.

No specimens of this shell were taken by Ferriss and Daniels in 1907, as they did not explore the limestone ridges. In 1908 Ferriss and Pomeroy found it again in Hand's Pass, over the range from White Tail, in the head of Pinery Canyon.

The embryonic shell is strongly, regularly ribbed. The shell has $5 \frac{1}{4}$ whorls, rounded, arcuate, keel nearly obsolete near the aperture in mature shells; aperture nearly round, the angle formed by the peripheral keel hardly perceptible.

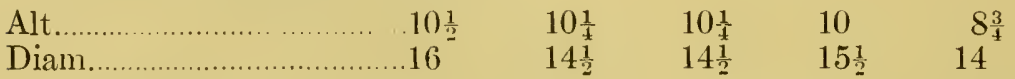

They were found for several miles upon both sides of the trail in the scattered stone upon the hillsides and around the cliffs.

In the head of Mackey's Wash, sloping to the north, a few were found, but no aged shells. The major spirals upon the under surface are represented by very low, obtuse ridges. The keel becomes very obtuse on the last whorl near the aperture. O.c. obsoleta was also found in the head of Onion Creek (between Paradise and Jhu Canyons).

In $1907 \mathrm{Mr}$. Ferriss passed over the wide part of the range from Paradise to the mouth of Rucker Canyon and Shake Gulch, some 25 miles from the Cave Creek Station, and here again O. c. obsoleta (fig. $13 b, c$ ) was found in a foothill known as Limestone Mountain, about ten miles in length and some 7,000 or 7,500 feet above the sea. These are the largest specimens so far found, thick and rounded, opaque white or pink-white and very little clouded. The wrinkles were coarse but obtuse upon the upper surface, the base smooth, without a trace of spiral lines.

\begin{tabular}{|c|c|c|c|c|}
\hline Alt.. & .11 & $10 \frac{1}{4}$ & 11 & 12 \\
\hline Diam.. & $.16 \frac{1}{4}$ & 16 & $15 \frac{1}{2}$ & $15 \frac{1}{2}$ \\
\hline
\end{tabular}


In "Canyon No. 3" (not knowing a better name) the shells were sometimes specked with transparent dots.

\begin{tabular}{|c|c|}
\hline $.11 \frac{1}{4}$ & $11 \frac{3}{4}$ \\
\hline Diam... & $16 \frac{1}{4}$ \\
\hline
\end{tabular}

Limestone Mountain is thickly covered with juniper, nountain mahogany and other trees and shrubbery, for it is in a U.S. Forestry Preserve. The shells were found in the upper part of the mesa before the rough ground was reached, in company with Holospira, but small in size. As the hill became higher the shells were larger and more numerous. Here also was found a toothed form of Ashmunella and also Pupæ and other of the smaller species. The mountain is composed entirely of limestone, upon the northern slope at least. Rocky cliffs and talus gave the smails ample shelter. Between this station and the Cave Creek Station, about 25 miles distant, there are no limestone exposures and no Oreohelix chiricahuana.

Oreohelix barbata Pils. Pl. V1, Figs. 1-3.

Oreohelix barbata Pils., Proc. A. N. S. Phila., 1905, p. 2S0, pl. 25, figs. 57, 58 (shells); pl. 19, figs. 5 (genitalia); pl. 22 , fig. 6 (teeth).

Twenty colonies of this species have been found, all between the head of the southeast fork of Pinery Canyon and the Rucker "box," at elevations of not less than 7,000 feet, and within a distance of twelve miles in length and two to three miles in width. They dwell upon all sides of these high peaks in the rock slides or talus, and among the rocks upon the

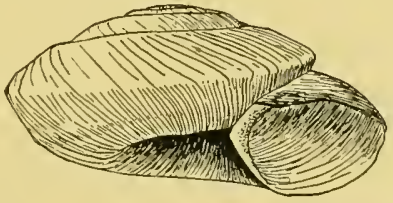

Fig. 14.-O. barbata, denuded shell from Cave Creek, Station 4. slopes of the gulches and ravines. Ferriss and Daniels found the most robust specimens living under fron two to three feet of rock well covered over with sod, with the most perfect specimens of Ashmunella chiricahuana, a toothed Ashmunella, Sonorella virilis and the little mountain rattle-snake, Crotalus pricei. In Cave Creek Canyon they often occur under one or two feet of rock.

In their own territory Ashmunella, Sonorella and the other forms of Oreohelix are usually to be found wherever the conditions are favorable; but it is not so with $O$. clappi and $O$. barbata. These snails are found only by chance, in isolated colonies. and these colonies are usually divided into families, the old pair and their spring crop of all sizes when not fully matured live together.

Every colony as a rule has some peculiarity. $O$. barbata ranges 
in color from pale greenish to dark reddish brown, some with wide indistinct red bands. Many lose their fringes and part of the cuticle before maturity. In one colony the shells were entirely naked. 'The rows of cuticular fringes vary in number from five to ten. In size, the shells are from $14 \frac{1}{2} \mathrm{~mm}$. diameter down to $10 \mathrm{~mm}$. in the race minima. Elevation above the sea apparently does not control size. The smaller forms usually dwell at 10,000 feet, and the largest at 7,000 , but a pigmy form was found at the lowest altitude, and the most robust at about $\$, 500$ feet.

The deflection or dropping of the last whorl at the aperture is not uniform or consistent in any colony, but it has significance in connection with the proportion of individuals so modified. In some colonies, as that in Cave Creek, the last whorl as a general rule drops very little, while in Barfoot Park it usually descends deeply.

In Cave Creek Canyon this species is confined to the border and slope of the westem escarpment. Ferriss (1904) took the types in the talus half a mile below the falls of Cave Creek. These have $4 \frac{1}{3}$ whorls, and are pale greenish ; the cuticular lamine light russet. There are four to six, usually five, circular wreaths of triangular cuticular scales, one small one being midway between periphery and suture, but often wanting, one at periphery, and three or four on the base.

The last whorl is strongly angular throughout, and risually does not descend very deeply in front. Parietal callus thin and moderately long.

Alt. 7 , diam. $13.5 \mathrm{~mm}$., not including cuticular processes.

" 5 , " $12 \mathrm{~mm}$.

In 1906 we found almost similar specimens at Station 4 (marked by two dots on the map, p. 107), darker in color, with sometines as many as eight cuticular wreaths, sharply carinated or angular at the periphery. These were on a well-shaded northern slope, under rocks in a coarse talus. This place is two or three hundred feet above the bed of the "wash" and about one hundred below the cliffs, just opposite a little grove of aspens among the oak scrub, which form a conspicuous landmark near the head of the "wash," from their rarity in this canyon. The snails here had been preyed upon by the mice.

In Turkey Creek near the head of one of the eastern branches at an elevation of about $\$, 500$ feet, Ferriss and Daniels took fully developed examples in 1907 (pl. VI, figs. 1, 2, 3). The shells are strongly angular to the aperture, and measure 13 to $14 \frac{1}{2} \mathrm{~mm}$. diameter, with $4 \frac{1}{2}$ to $4 \frac{3}{4}$ whorls. They have 7 beautifully developed wreaths in the best preserved individuals. The last whorl drops fully $2 \mathrm{~mm}$. at the 
aperture. They were found in a talus upon an eastern slope of a steep mountain side, and possessed the best developed, longest and most persistent cuticular wreaths.

A second colony in the head of one of the eastern forks of Turkey Creek, found in 1908, approaches more closely the Barfoot Park series. The shell is greenish under a pale brownish cuticle with a red band; five short cuticular wreaths; last whorl drops $1 \mathrm{~mm}$.; margins of aperture connected by thick callus. Diam. 12, alt. $7 \mathrm{~mm}$.

These snails live in numerous colonies around the region of the Falls of Cave Creek and the heads of the branches northward as far as Turkey Creek. As the original photographic figures do not show the shape clearly, a new figure has been drawn (fig. 14) of a shell denuded of cuticular fringes, from Cave Creek, Station 4.

Blunt-edged Variety.-In Barfoot Park, Rustler's Park, at about 9,000 feet, a slide at the head of Turkey Creek, Ash fork of Cave Creek, Snow-shed Mountain at the head of Cave Creek, and the head of Rock Creek, a form occurs in which the shell is smaller than typical $O$. barbata and in fully adult shells the last whorl often descends the full width of the former whorl: the periphery also is somewhat less sharply angular, and becomes almost rounded near the aperture.

Alt. 5.5, diam. 11.3 mm., Station, Barfoot Park.

This is distinctly a decadent form, as denoted by the tendency of adult shells to assume the old-age feature of a very deeply descending last whorl. In Barfoot Park it lives in a deep slide of igneous rock having a southern exposure. In Rustler's Park in a few stones on the hillside.

On the Ash fork of Care Creek a colony has $4 \frac{1}{2}$ whorls, the shell is white under the cuticle, which is dark reddish brown above, lighter brown below; occasionally with five cuticular fringes; last whorl drops $1 \mathrm{~mm}$. Diam. 12, alt. $6 \frac{1}{2} \mathrm{~mm}$., aperture $4 \frac{1}{4} \mathrm{~mm}$.

A colony at the spring branch of Rucker Canyon, north side and near the head, Station $10 a$, resembles the above closely (pl. VI, figs. 4, 5). The umbilicus is a little more open, cuticle dark reddish brown, banded with red above; six cuticular fringes. Diam. $12 \frac{1}{2}$, alt. $6 \mathrm{~mm}$. It is strongly angular to the aperture, and the last whorl falls much more in front than is usual in Cave Creek shells.

In a slide of rock on the north side at the head of Raspberry Gulch (a tributary of Rucker Creek, which it enters at the Box Canyon) a colony had only 4 whorls. The umbilicus measured $3 \frac{1}{2} \mathrm{~mm}$. wide. Cuticle dark reddish brown, with a short fringe on the periphery; last whorl drops $1 \frac{1}{2} \mathrm{~mm}$. Diam. 12 , alt. $6 \frac{1}{2}$. 
On the west slope of Snow-shed Momtain, at the head of Cave Creek, almost one continuous talus, was a colony similar to the preceding. Shell transparent when young, oceasionally with 5 short fringes. Diam. only $10 \frac{1}{2}$, alt. $5 \frac{3}{4} \mathrm{~mm}$.

In a dry talus fully exposed to the sum and sloping to the south on the head of Rock Creek was a colony heavily covered at maturity with 9 or 10 black fringes, periphery rounded as in the Rustler Park and Barfoot Park specimens; aperture $4 \frac{1}{2} \mathrm{~mm}$. Margins connected by a thick callus; umbilicus varies from 3 to $3 \frac{1}{2}$. Diam. 11, alt. $6 \frac{1}{4}$.

The five colonies above were found by Ferriss in 1908 .

In 1907 Ferriss and Daniels found a small heavily fringed form in the talus of a gulch in the head of the southeast fork of Pinery Canyon, that in fringes resembles the type of barbata.

Like the above it had from 9 to 10 long fringes. The last whorl dropped but one $\mathrm{mm}$. Diam. 11, alt. 6 , aperture $4 \mathrm{~mm}$.

Oreohelix barbata minima n. subsp. Pl. V1, figs. 6,7 .

At the head of Rucker Canyon (Station 11 $\frac{1}{2} \mathrm{~A}$ ) and in the Rucker Box, Ferriss and Daniels found colonies in 1907 that were still further depauperate than the above. Ferriss relocated the latter colony in 1908. These shells possess $4 \frac{1}{4}$ to $4 \frac{1}{2}$ whorls, the last whorl regularly angular, the angle weakening near the aperture in old shells. Toward the end the whorl falls deeply at maturity. There are from 6 to 7 spiral fringes in the best preserved examples, but adults generally are denuded or show only traces of the spiral wreaths. The margins of the lip converge and form a perfect union in maturity, being joined by a very short parietal callus, and the aperture is sometimes raised above and free from the penultimate whorl.

The shells from the head of Rucker are uniform brown in color and measure:

Alt. 5, diam. 10.3, umbilicus 3, diam. aperture 3.5 mm.; whorls $4 \frac{1}{2}$ " 5 , " 10 , " 3.1 " " 3.25 " " $4 \frac{1}{3}$

Those from Rucker Box are light brown, sometimes albinistic, light green.

Six specimens from the Box of Rucker Canyon, type locality, measure:

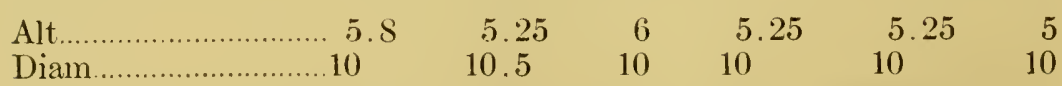

This is the most decadent race, being reduced in size in addition to the deeply descending last whorl and in old shells the nearly or quite free peristome. Colonies of larger forms of $O$. barbata occur at greater 
elevations than the Rucker Box (about 7,000 feet), so that the degeneration is probably due to other local causes.
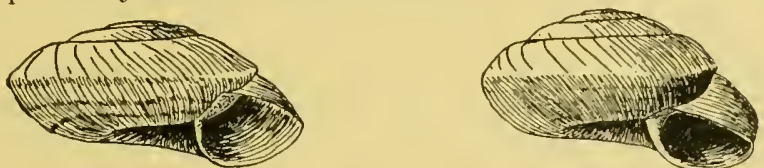

Fig. 15.-O. b. minima P. and F., Rucker Canyon, Station $11 \frac{1}{2} a$.

Genus ASHMUNELLA Pils. and Ckll.

A study of the genitalia of Chiricahuan Ashmunellas leads to the conclusion that all the species of that range are of common ancestry, and more closely related inter se than any are to New Mexican or Huachucan species. In other words, the specific differentiation has been mainly subsequent to the isolation of this fauna.

In both Chiricahuan and Huachucan species the penis is bipartite, consisting of an upper and a lower portion separated by a submedian constriction. In the Huachucan series the upper segment is enlarged like the lower (see plate $\mathrm{XX}$, Proc. A. N. S. Phila., 1909). In Chiricahuan forms the upper segment of the penis is very narrow, hardly larger than the epiphallus, but its distal end is invariably a little swollen, and contracts abruptly where it passes into the epiphallus ${ }^{20}$. The penis retractor is extremely short in Chiricahuan species, longer in Huachucan. The spermatheca is more or less

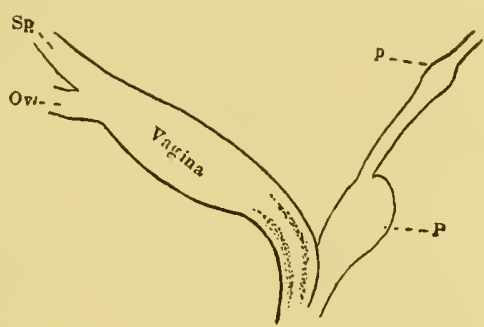

Fig. 16.-Terminal ducts of genitalia of Ashmunella p.albicauda, Station 4 , White Tail Canyon. Sp, base of spermathecal duct; $O v i$, base of oviduct; $P$, lower, swollen portion of penis; $p$, upper end of penis. varicose in Huachucan species, but this is hardly apparent in Chiricahuan forms. The vagina in the Chiricahuan series is swollen and muscular in its upper part, smaller with thinner walls below. In other respects the organs are alike in the two series. These considerations lead to the conclusion that the whole Chiricahuan series of Ashmunella constitutes one phylum, the Huachucan series another. Doubtless the two phyla were of common ancestry; but their evolution on the two parallel mountain ranges has been independent. The extraordinary resemblances between some Chiricahuan and Huachucan species, which led us in 1905 to

20 The slender upper continuation of the penis was not always recognized in our former (1905) work on Chiricahuan snails, although once understood it is clear enough. 
unite some of them specifically, ${ }^{21}$ are wholly due to evolution along parallel lines in the two stocks. This orthogenetic evolution has resulted in the most extraordinary parallelism. By degeneration of the teeth of the aperture, wholly toothless forms have arisen as terminal evolution products in both phyla; and these are so similar in shell-characters that they are indistinguishable. Other forms in both phyla have evolved a V-shaped parietal tooth, like that of Polygyra.

While the shell is extremely conservative in Sonorella, in the related genus Ashmunella it appears to be the most plastic part of the organism. As in Polygyra and many other molluscan groups in which complex hard parts have been evolved, many races and species are characterized by varying degrees of degeneration of the teeth of the aperture. In the current phraseology, this may be due to the action of an inhibiting factor, earlier or later checking the development of teeth. This seems to have taken place independently in most of the centres of Ashmunella evolution. Toothless apertures are no doubt primitive in the Belogenous Helices, so that secondarily simplified forms, such as A. varicifera and A. chiricahuana, have completed an evolution cycle, returning to the primitive simplicity of aperture. Whether such forms can give rise to new series having dentate apertures remains uncertain.

\section{Key to Chiricahuan Ashmunellas.}

I.-Aperture toothless or with very small vestiges of teeth only.

a.- Shell chestuut brown, glossy, the lip narrow, without traces of teeth A. chiricahuana.

$a^{1}$.-Shell light brown without much luster; usually with a callous ledge within the outer lip, or other weak restiges of teeth.

A. esuritor.

b.-Penis normal.

$b^{1}$.-No penis; vagina long, much swollen above..A. metamorphosa.

II.-Aperture obstructed by three or four large teeth.

a.-Very acutely carinate, the carina projecting above the suture; whorls of the spire flat.

A. ferrissi.

$a^{1}$-Carina not projecting at sutures or wanting.

b.-Surface papillose or scaly; shell thin, strongly carinate.

$b^{1}$.- Surface not scaly or conspicuously papillose.

A. lepiderma.

c. - Basal tooth single, bifid, or with two basal teeth nearer together than the outer one is to the outer lip tooth.

d.-Periphery obtusely angular in front, becoming rounded; young with a slight lip-rib only....

$d^{1}$.-Periphery strongly angular or carinate. A. duplicidens.

${ }^{21}$ In 1905 we considered the Chiricahuan Ashmunella proxima to be a subspecies of the Huachucan A. levettei. The Huachucan A.varicifera we thought identical with the Chiricahuau $A$. chiricahuana. 
e.-Whorls fully 6 ; lip narrow, convex, not forming a projecting angle above....................... p. fissidens.

$e^{1}$.-Whorls $5 \frac{1}{2}$; lip wide, angulated above; young forming a very heavy lip-rib........................... p. albicauda.

$c^{1}$. - Three lip teeth separated by nearly equal spaces.

d.-Corneous or light brown; whorls of the spire convex; outer basal tooth not greatly compressed.

e.-Corneous; basal teeth subequal and well separated.

A. proxima.

$c^{1}$.-Basal teeth somewhat united, the imner often reduced. young shells having a very heavy lip-rib.

A. p. emigrans.

$d^{1}$.- Shell dark brown; whorls of the spire flattened; outer basal tooth strongly compressed, entering. A.angulata.

The genitalia are very similar in all Chiricahuan species examinedso similar that we omit detailed descriptions and merely add here a table of measurements in $\mathrm{mm}$. of the organs in examples of the several species.

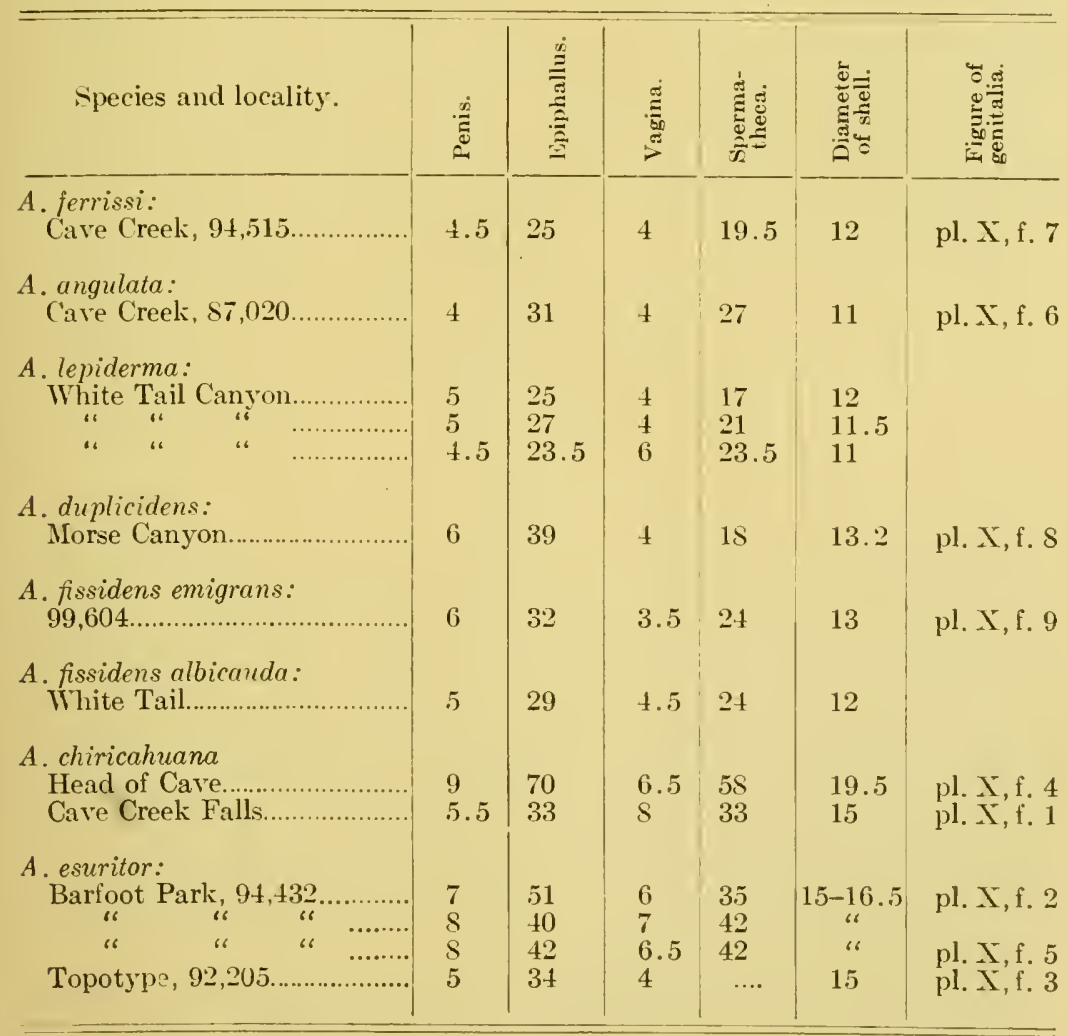




\section{Group of Ashmunella proxima.}

From Old Fort Bowie these forms extend southeastward to the end of the Chiricalua range. Northward beyond the depression at the Fort, in the Dos Cabezas end of the range, no Ashmunella has been found. The mountains here are apparently too barren and dry for Ashmunella, though they support the more hardy Sonorellas.

The colonies seem to be small and widely separated in the area northwestward of White Tail Canyon, but much of that country remains to be explored, especially between Big Emigrant and White Tail Canyons, as well as the entire region of the southwestern watershed.

$A$. ferrissi and A. angulata are distinct from the others by their flattened whorls and conspicuously compressed outer basal tooth. The other species are intimately related, and their variations make a complexly branching form-chain. An adequate study of the material in hand, some thousands of shells, would require more ample time than we can give. Since not half of the territory is adequately covered by our series, we must leave full consideration of the subject for another occasion.

Our knowledge of the forms from Rucker and Horseshoe Canyons and the region around them is still very defective. The forms seem to be related somewhat, as shown in the following diagram:

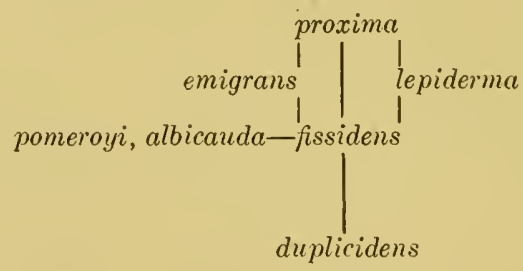

If a single basal tooth is primitive, then $A$. duplicidens is the least evolved member of the series and of the whole Chiricahuan group of Ashmunellas. Then A. proxima and lepiderma would be the most evolved. All of the forms with more or less concrescent basal teeth are extremely variable in the degree of union of these teeth. Every colony of fissidens, emigrans, albicauda, pomeroyi and duplicidens shows great individual variation in this respect. There seems to be complete intergradation between the separated basal teeth of proxima and the united teeth or single tooth of fissidens and duplicidens.

Ashmunella lepiderma n. sp. Pl. VII, figs. 1-7.

Shell umbilicate, the umbilicus about one-fifth the total diameter of the shell, much depressed, biconvex, acutely carinated peripherally, 
thin, corneous-brown. The surface is lusterless, sculptured with fine, unequal wrinkle-strix, and covered with a network of cuticular scales or processes (readily removed by cleaning). There are $5 \frac{1}{2}$ whorls, the first one corneous and glossy, the first three convex; subsequent whorls convex above, impressed above the lower suture; last whorl is distinctly impressed above the projecting peripheral keel, the base convex; in front it descends slightly or not at all to the aperture, and is narrowly, rather deeply, guttered close behind the lip on the base. The aperture is lumate, contracted by four teeth: a wide one within the outer lip, two contiguous tubercles in the basal lip, and an oblique straight parietal tooth. Parietal callus thin and transparent.

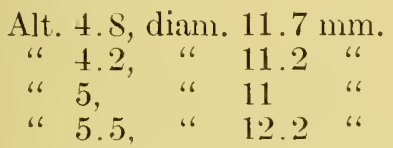

White Tail Canyon, on the northern side only, at stations 10, 11, 16, 17, etc., in "slides" of igenous rock (rhyolite); type locality, Station 11 , in a slide of angular rhyolite, coming down to the trail in the bed of the canyon, with Sonorella micra. See map on p. 75.

Genitalia are of the type usual in the fissidens group. The epiphallus and spermatheea are a little shorter, proportionately, than in A. p. albicauda or emigrans. Neasurements of the organs of three individuals may be found in the table on p. 97. The mantle within the last whorl is cream-white with a few inconspicuous gray dots; collar pale slate-tinted.

This species, of which sereral hundred specimens were taken, inhabits suitable rock-slides over the whole northern side of White Tail Canyon. At Station 11 it occurs close to the bottom of the canyon, and only a short distance from where $A$. fissidens is found on the opposite side. The slopes of this side of the canyon are steep, interrupted by cliffs, and the heights are difficult of access. At Station 16 there are extensive rock slides sloping northward towards the mesa, and perhaps 1,500 feet higher than station 11. Here it passes over the ridge and inhabits the opposite slope. While belonging to the fissidens group, this species is very distinct by its sculpture of cuticular scales, the strong carination, thin texture, etc. The young shells form only a weak callous rib within the lip at resting periods.

At all the stations there is considerable variation in size and, as in all Chiricahua Ashmunellas, the height of the spire varies a good deal among individuals of any colony. At Station 17 the shells average 
smaller than in other places, about $4 \times 10.3 \mathrm{~mm}$; but a few are as large as $11.5 \mathrm{~mm}$. diameter and many as small as $9.5 \mathrm{~mm}$. The scale-like sculpture is especially well developed in shells from this station. In some colonies the cuticular scales are minute, sparse or even wanting in adult shells.

At Hand's Pass, at the head of Jhu Canyon, this species reappears. The surface is regularly very minutely pustulate, some perfectly fresh shells having minute cuticular appendages on the pustules in places. There are also some cuticular spiral hair-lines on the base. Alt. 5, diam. $12 \mathrm{~mm}$., whorls 6 . This colony is separated from the type locality by the whole southern slope of White Tail Canyon, where lepiderma certainly does not occur. We have considered the possibility that the Hand's Pass form may be an independent convergent modification of the proxima stock; but in the absence of alcoholic material permitting a full comparison this hypothesis must remain in abeyance.

Ashmunella proxima Pils. Fig. 17.

Ashmunella levettei proxima Pils., Proc. A. N. S. Phila., 1905, p. 242.

This species was described from "Sawmill Canyon," otherwise known as Rigg's or Pine Canyon, where the senior author collected it in 1904 . We did not find it there in 1906, but our search wà impeded by snow. We found it near Fort Bowie in company with Sonorella bowiensis. The exact locality is a little thicket of long-leaved scrub oaks, just below a low rock-wall, somewhat more than half-way up "Quartzite Hill," on the side facing Dixon's house, shown at (1) in the sketch on p. 67. This is about a mile from Old Fort Bowie.

Similar shells were also taken at Crook's Peak (Ferriss and Daniels) in 1907; only two specimens.

In ranking $A$. proxima as a subspecies of $A$. levettei, a wrong estimate was made of its affinities. It is related to $A$. fissidens and duplicidens, but differs from both by having two distinctly separated teeth on the basal lip. A. levettei angigyra stands very near proxima in shell-characters, but the lower end of the tooth within the outer lip runs inward in angigyra, while in proxima the free edge of th is tooth runs parallel with the peristome. In angigyra the outer-basal and outer lip tooth are usually closer together than are the two basal teeth. This is not the case in proxima, in which the three teeth are about equally spaced. In soft anatomy the two are quite distinct. A. l. angigyra has a far longer penis of different shape and a shorter epiphallus and vagina than A. proxima; moreover, angigyra has a radula with more teeth, and 
there are more ribs on the jaw. The shell is corneous-brown, subacutely angular at the periphery, the angle weakening on the last part of the whorl, behind the lip, where the surface is more strongly striate. Spire convex. There are $6 \frac{1}{4}$ to $6 \frac{1}{2}$ very slowly widening, slightly convex whorls, the last descending somewhat in front. The aperture has a rather long, concave-topped tooth within the outer lip, its face concave. The basal lip has two tubercular teeth, a little comprer.ed laterally, the inner one smaller. These teeth divide the lower burder' of the aperture into three nearly equal bays. The parietal tooth is straight or slightly bent inward at the axial end; never V-shaped, as it frequently is in A. fissidens. Parietal callus thin. The umbilicus is rather wide, contained $4 \frac{3}{4}$ times in the dianeter of the shell. The surface is rather dull, finely striate, the strix appearing more or lesis
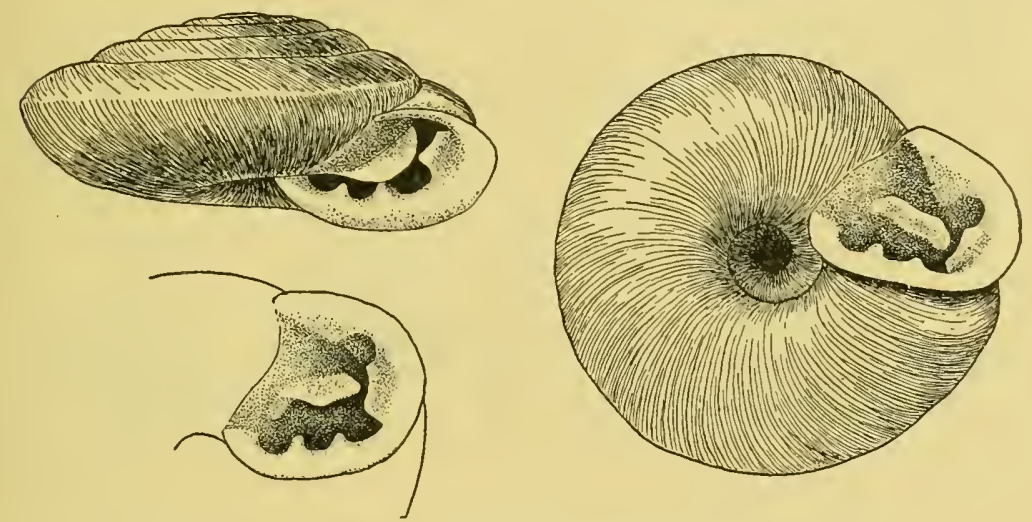

Fig. 17.-Ashmenelle proxima, Quartzite Peak, Station 1.

irregular or interrupted under a strong lens. The size varies little from $12 \mathrm{~mm}$. diameter.

In perfectly fresh young shells a delicate pattern of minute low granules on the upper surface may be seen with some difficulty. Some very weak traces of spiral strice may sometimes be made out on the base. The young shells have a callous rib within the lip, at resting stages, but it is apparently not formed as frequently as in A. fissidens.

The genitalia were figured in 1905, pl. 21, fig. 24. Having again examined the individual dissected, we note that the penis was incorrectly drawn. The swollen basal half is everted (as in pl. 21, fig. 23), hence does not show in the figure. The slender upper portion of the penis is shown, its distal end indicated by a slight node, only indistinctly drawn in my figure. With these corrections, it will be seen that the organs are like those of emigrans, fissidens and albicauda. 
The mantle within the last whorl is white, with the anterior vessels of the lung faintly traced in gray and having gray pigment along the periphery.

Southern forms resembling A. proxima.-Raspberry Gulch. A few specimens in poor condition are intermediate between proxima and fissidens as to the basal teeth, but the umbilicus is much narrower than in either, and the peripheral angulation is less pronounced, thus approaching $A$. duplicidens. There are over 6 whorls. Other southern localities for forms of A. proxima are Rucker Canyon and "Turtle Head," a station between Crook's Peak and the mouth of Rucker.

A. fissidens should by rights be subordinated to proxima as a subspecies, on account of the various intermediate forms; yet the status of the races can be more clearly expressed by the artificial device of making it a "species."

Ashmunella proxima emigrans n. subsp. Fig. Is.

On Big Emigrant Mountain, Big Emigrant Canyon, a race was found having some characters of $A$. fissidens. The shell is somewhat larger

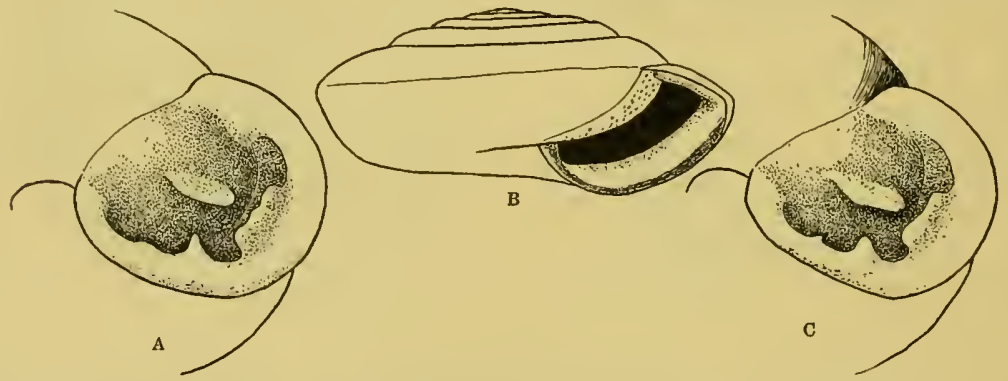

Fig. 1S.-A. p. emigrans. A, C, apertures of adult sliells. B, young shell $11 \mathrm{~mm}$. diam. Big Emigrant Canyon.

than proxima, more robust, with slightly less than 6 whorls. The two basal teeth are less separated, somewhat united by a callus at their bases, and the inner one is generally smaller, frequently very small. There is often the weak trace of an upper branch, making the parietal tooth $V$-shaped. Fine spirals may be seen on the base of the shell. The young shell forms a very strong callous rib within the lip, as in A. fissidens. The umbilicus is narrow, contained five times in the diameter of the shell. Alt. 5.S, diam. $13.2 \mathrm{~mm}$.

This shell is like $A$. fissidens except in the single character of having the basal teeth more widely separated. As in that species, the inner of the two basal teeth is quite variable in size. It is a race intermediate in character between fissidens and proxima. 
Genitalia (pl. X, fig. 9) not materially differing from A. p. albicauda. The swollen basal portion of the penis is less than half the total length. The penial retractor is less than one millimeter long.

\section{Ashmunella fissidens Pils.}

Proc. A. N. S. Phila., 1905, p. 243.

This species was described from "dead" and discolored specimens, thought to be from Cave Creek Canyon, collected by one of us (Mr. Ferriss) in the course of a flying trip through the mountains in the winter of 1904. In 1906 we collected extensively in Cave Creek; a year later Messrs. Ferriss and Daniels did additional work there, but nothing was seen of $A$. fissidens. The location of the type colony, therefore, remains uncertain. It is likely that the shells were picked up in White Tail Canyon, also hurriedly traversed in 1904. While the prevalent form in White Tail differs from fissidens in several respects, yet near the head of the canyon some exactly similar shells were found by us in 1906. A lot from near the head of the left branch (going up) (near Jim Artel's old camp) is typical fissidens; and we suggest that this be regarded as the type locality in case true fissidens is not hereafter found in Cave Creek.

In these shells the lip is not produced forward in an angle near the upper insertion, and the upper angle is not filled with a callus ; the lip is narrow with rounded face; there is no upper branch developed on the parietal wall, unless very weakly in some old shells; there are fully 6 whorls; the young develop only a weak lip-rib at resting stages.

Certain forms from much further south, in Shake Gulch, the foot of Bonito Canyon and Limestone Mountain, seem to be referable to A. fissidens; but they are less angular, becoming rounded behind the lip, and the umbilicus is decidedly smaller. More material is needed to fix their status.

Ashmunella fissidens albicauda n. subsp. Fig. 19.

The upper end of the parietal wall stands more or less free and the lip, near its upper insertion, runs forward in an angle; the posterior angle of the aperture is heavily calloused, and the parietal tooth is usually V-shaped by development of a weak upper branch. The young shells form a very thick and heavy callus within the lip at resting stages (fig. 19D).

Adult shells are invariably acutely angular in front, the angle weakening and almost disappearing on the latter part of the whorl. Behind the aperture the striation is stronger and sometimes amounts 
to an irregular costulation. There is an angular gutter behind the basal lip, and the reddish-brown color gives place there to a wide buff stripe which borders the lip. The whole base has a sculpture of extremely minute spiral lines in fresh examples; and under the microscope a very minute spiral lineolation is seen between these spiral lines, which are readily visible with a hand lens. The upper surface also shows very faint spiral lines in places, and there is often some

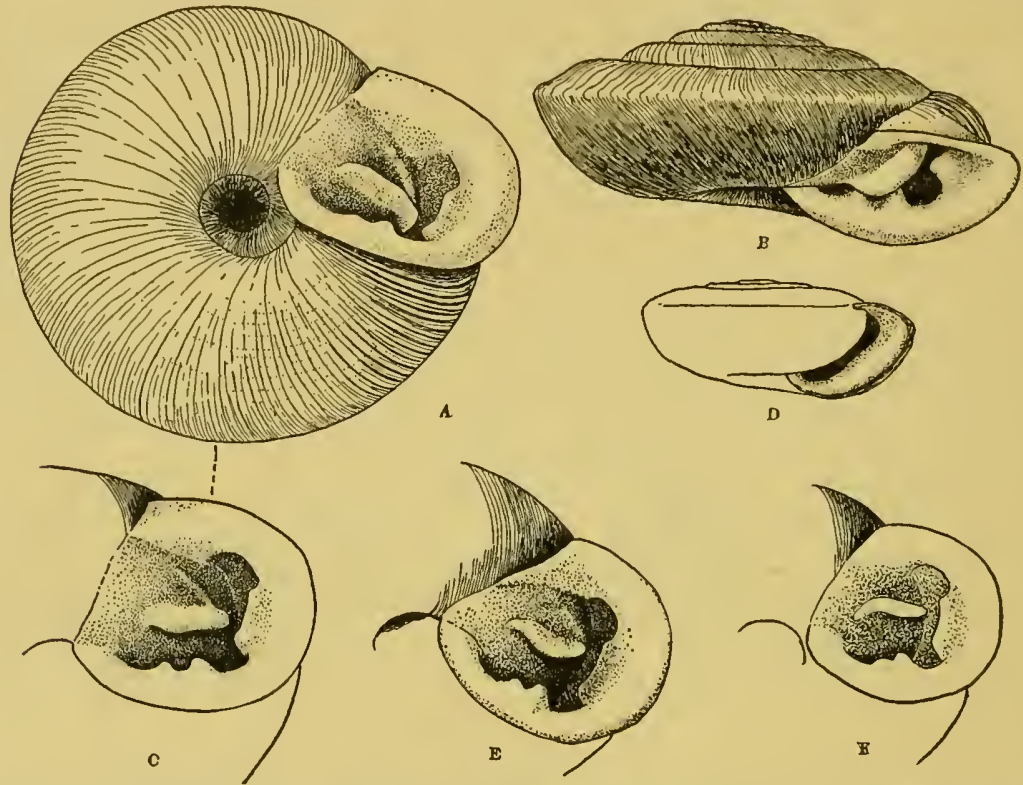

Fig. 19.-Ashmunelle $f$. albicauda P. and F. A-C, from Box of White Tail (diam. $13.3 \mathrm{~mm}$. ) ; D, Station 14 (diam. $7 \mathrm{~mm}$.); E, Station 2 (diam. $12 \mathrm{~mm}$.); F, Station 14 .

interruption of the growth strix, giving a slight appearance of punctation. Seven specimens from Station 14 measure:

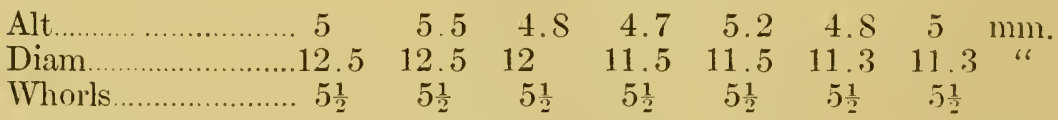

While variable in size and elevation of the spire, which may be nearly flat or low-conic, and in the shape of the basal teeth, the variations do not seem to differ in the several colonies.

Terminal ducts of the genitalia are figured on p. 95, fig. 16, and the measurements are given in the table, p. 97. The epiphallus in the individual measured (No. 97,939, Station 4, in White Tail Canyon) is 
shorter than in A. p. emigrans or A. duplicidens, but this may be an individual character.

A. $f$. albicauda is found in White Tail Canyon almost everywhere on the southern side, but not on the opposite slope of the canyon. Specimens were taken at Stations 1 to $5,9,12,14$, on the south side of the Box Canyon and on the south side below Indian Creek, ranging from about 20 feet above the creek bed (at the last place) to about $\bar{\tau}, 500$ feet elevation on the rim southward, where indeed it was taken at Station 3, which lies across the acute divide and on the Pinery side. Not one single specimen was found on the north side of the canyon, where $A$. lepiderma replaces it, coming down to the bottom of the canyon.

The range of A. fissidens in the Pinery and Pinery Canyon is unknown. The great Pinery Talley lay before us in splendid panorama from the ridge south of White Tail Canyon and again from the ridge north of Barfoot Park. Probably its ravines are inhabited by fissidens and perhaps forms connecting that with $A$. proxima. It may be noted that the large Sonorella of White Tail Canyon is a race of S. viritis, of Barfoot Park, etc.

At all stations in White Tail Canyon where many shells were taken, the same variations in height of spire noted under $A$. duplicidens were noticed. Otherwise there is variation in the size of the outer lip-tooth and especially in that of the inner tubercle of the basal tooth. The parietal tooth may be either straight at its axial end or abruptly curved inward, and, when turned inward, a low ridge usually rums to the outer end of the lip, making the parietal tooth $V$-shaped.

Ashmunella fissidens pomeroyi n. subsp. Fig. 20.

In Hand's Pass, head of Jhu Canyon, Ferriss and Pomeroy collected
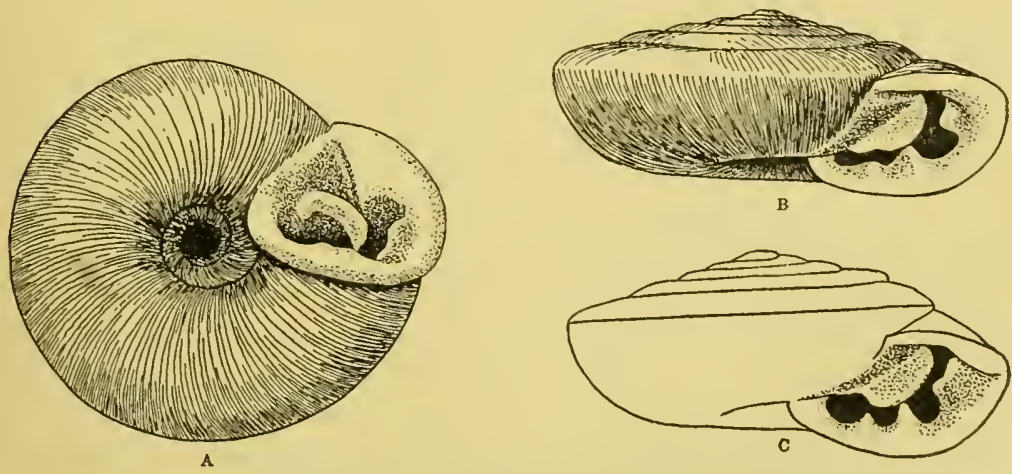

Fig. 20.-Ashmenelle $f$. pomeroyi $\mathrm{P}$. and $\mathrm{F}$., Hand's Pass. 
in 1908. The shells are similar to those of White Tail Canyon in general appearance, but differ in certain particulars, constituting a minor race. They are in the average smaller, diam. $8 \frac{1}{2}$ to $11 \frac{1}{2} \mathrm{~mm}$., rarely $13 \mathrm{~mm}$., with $5 \frac{1}{2}$ whorls; the umbilicus is noticeably wider; the lip is heary and wide. The basal teeth vary from completely united to distinctly bifid, as in White Tail fissidens, or rarely they are almost separated. In most examples these teeth are more united than in White Tail specimens. The shape of the parietal tooth also varies from V-shaped to simple. All of the shells_are more angular and more depressed than $A$. duplicidens.

Ashmunella duplicidens Pils. Pl. VIII, figs. 1-8.

Proc. A. N. S. Phila. 1905, p. 244.

After the first $1 \frac{1}{2}$ whorls the next four whorls more or less appear minutely punctate in the best preserved examples, though in most only an indistinctly interrupted condition of the striæ can be made out. Under the compound microscope some very fine close spiral striation is seen on the base. The basal tooth is ordinarily doubled as in figs 5 and $S$; but sometimes is simple, the inner tubercle being represented only by a sloping callus, as in figs. 1-3, 6, 17 .

Immature shells form only a thin narrow rib within the lip at resting stages, and have a wicler, somewhat less angular, aperture than $A$. fissidens. This thin lip-rib is subsequently wholly, or almost wholly, absorbed, so that adult shells do not show whitish varix-streaks.

Figs. 3 and 7 show the extremes of elevation and depression of the spire. All of these figures are from topotypes, from Station 1 in Barfoot Park - an extensive slide of coarse rock on a southern exposure. It is an abundant species in this place.

In $1907 \mathrm{Mr}$. Ferriss found A. duplicidens in the head of Morse Canyon, large shells, 13 to $14 \mathrm{~mm}$. diam., with over 6 whorls; in Rucker Canyon, 7,000 to 8,000 feet; and on Rucker Peak, where they are also rather large. Small shells, 10.5 to $11.5 \mathrm{~mm}$. diam., were taken at the Box of Rucker. A specimen from Crook's Peak measures $14 \mathrm{~mm}$. diam.

Large and well-developed duplicidens was found in Care Creek Canyon on the first branch west of the Falls fork of Cave Creek, diam. 14 to $15 \mathrm{~mm}$., and at the Falls.

The genitalia of a specimen from the head of Morse Canyon are figured, pl. X, fig. S. The penis tapers more gradually than in allied forms, the distinction between its swollen basal half and the slender distal portion being obscure. This was also the case in the individual figured in 1905 from the type lot, but in that preparation the enlarged basal portion of the penis was everted, hence does not show at all in 
the figure. The lung is $18 \mathrm{~mm}$. long, kidney $7.5 \mathrm{~mm}$., pericardium $3.5 \mathrm{~mm}$. The mantle withm the last whorl is cream-colored with sparse black maculation. Earlier whorls have eopious black pigmentation along the top of the whorls.

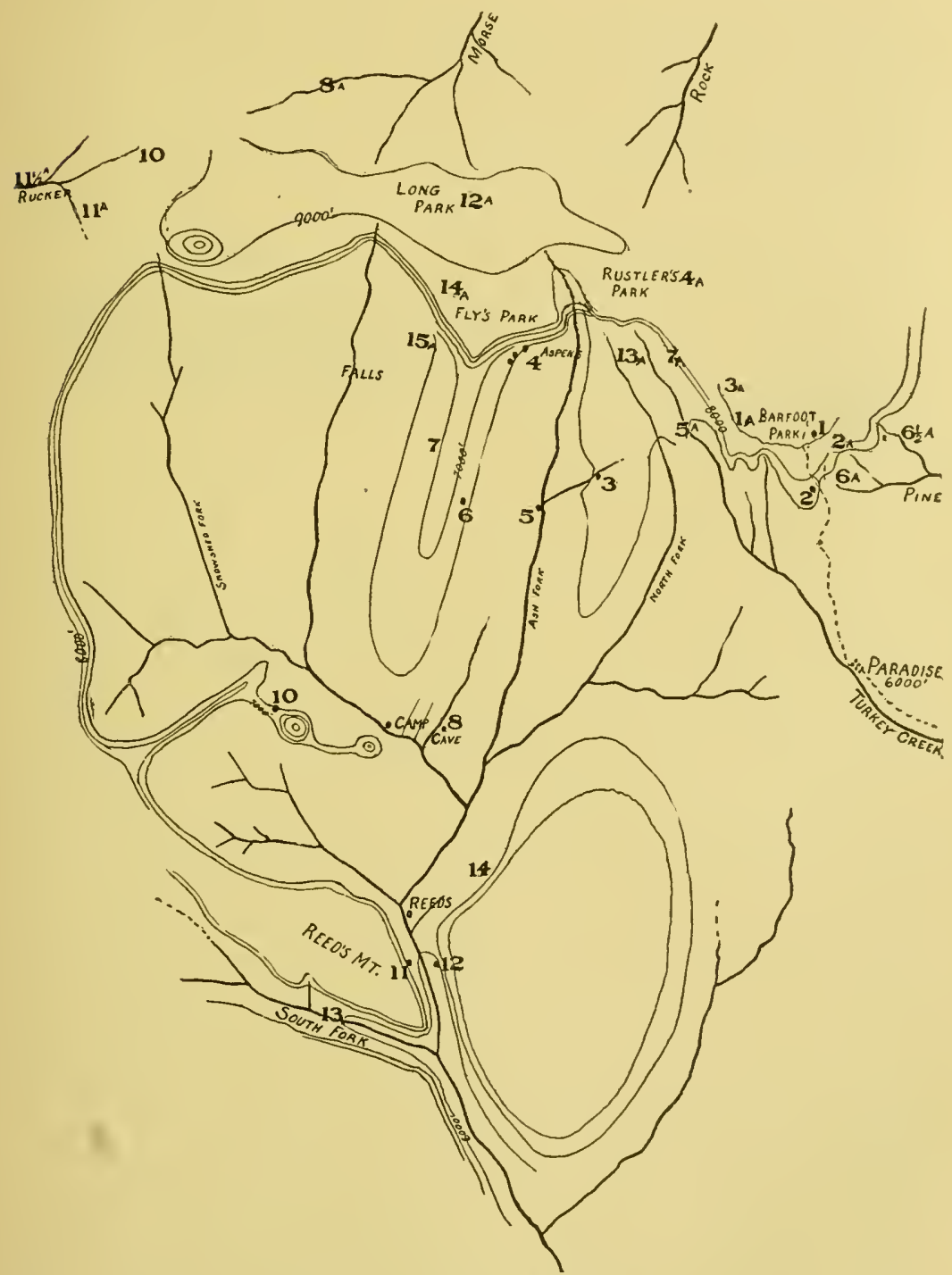

Fig. 21.--Principal collecting stations in Care Creek and the Parks at its head. Stations marked $A$ were explored in $1907-8$ by Ferriss, the others in 1906 by Ferriss and Pilsbry 
The specimens figured (topotypes) measure: Alt. 6, diam. $13 \mathrm{~mm}$., whorls $6 \frac{3}{4}$; alt. 6 , diam. $12.2 \mathrm{~mm}$., whorls $6 \frac{1}{2}$. The smallest specimen seen is from Rucker Canyon, 7,000 feet, measuring alt. 4.9, diam. $10.5 \mathrm{~mm}$., whorls $5 \frac{1}{2}$.

A. duplicidens stands very close to $A$. fissidens, but it differs by the more obtuse, though bluntly angular, last whorl, and by the young shells, which form only a very thin, narrow rib within the lip in resting stages, while in fissidcns a very strong and heavy callus is deposited. The basal teeth are more united than in typical fissidens.

A. duplicidens, fissidens and proxima are terms of one series of forms differing chiefly, so far as the adult shells are concerned, in the degree of separation of the basal tooth, which in duplicidens is a single more or less bifid prominence, while in proxima there are two distinct teeth. When the canyons opening westward, between Rucker and Ft. Bowie, have supplied series of shells as copious as those we have obtained in the eastward canyons, another chapter may be added to the history of this group.

Ashmunella angulata Pils.

Proc. A. N. S. Phila., 1905, p. 244.

In the south fork of Care Creek we found this species abundantly. This is the type locality and here it attains the largest size. A few dead ones were picked up on a mountain-side southeast of Paradise, towards Cave Creek, and at Station 12, in Cave Creek. It reappears at the head of the canyon at the Falls, and at Stations 3 and 4 and in the head of Turkey Creek. At these places the shells are smaller.

In 1907 Ferriss and Daniels took some specimens in Barfoot Park, Station 1a. They are much less angular at the periphery than the Cave Creek form. In $190 \mathrm{~S}$ it was taken in Horseshoe Canyon at the "Red Box" (10 miles up the canyon) and at "5-mile camp"; also in Rock Creek, at the head of Raspberry Gulch and in the Spring Branch of Rucker Canyon. These localities greatly extend the range of the species. The compressed outer basal tooth and less convex whorls readily separate $A$. angulata from A. proxima. Young shells deposit a lip-callus at resting periods. It is thick in the middle, tapering at the ends, as figured in our former paper, pl. XI, fig. 11.

Our former figure of the genitalia of A. angulata (1905, pl. 21, fig. 26) is not satisfactory in one point, the slight enlargement marking the upper end of the penis being omitted. This enlargement is rather small yet distinct in the individual figured, which has been re-examined, and is present in all the specimens opened (seven) from several stations. 
A new figure is given, $\mathrm{pl}$. $\mathrm{X}$, fig. 6, representing a specimen from Cave Creek near Reed's Mountain, No. 87,020. The penial retractor muscle is longer than in $A$. proxima and its allies.

Ashmunella ferrissi Pils. Fig. 22.

A. ferrissi Pils. Proc. A. N. S. Phila., 1905, p. 247, pl. 16, figs. 108-110, 113.

The type locality is in the talus at the foot of Reed's Mountain, at Station 11, about a half mile below Reed's house, where it is found with A. chiricahuana, Sonorella virilis, etc. Additional specimens were taken here in 1906. The figures represent an elevated and a depressed specimen.
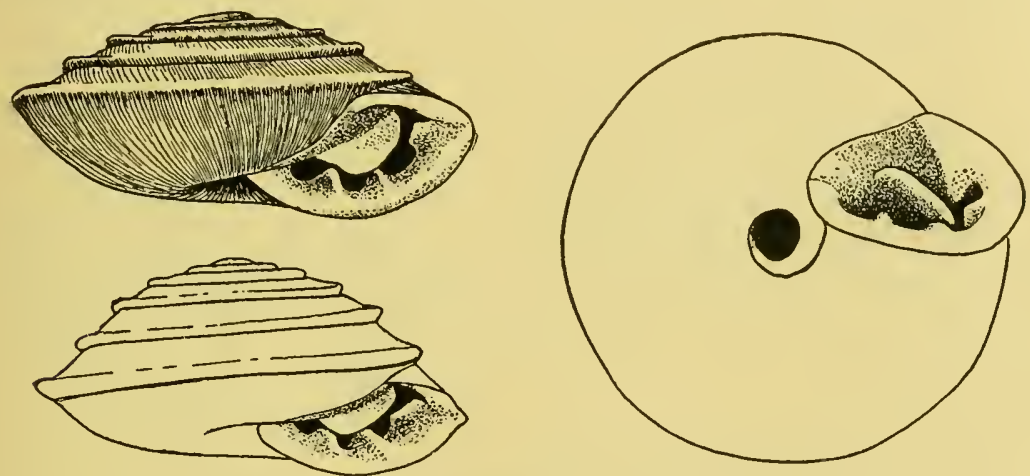

Fig. 22.-Ashmunella ferrissi, Cave Creek, Station 11 (topotypes).

The embryonic shell seems to comprise the first $1 \frac{3}{4}$ whorls. The initial half whorl is smooth and glossy; then growth-striæ begin below the suture, gradually extending over the whole width of the whorl. The third and fourth whorls are very minutely indistinctly marked with subregularly arranged points, as though . hairy in the immature stage, though none taken retain any hairs. The rest of the whorls are finely striate. The base also is marked with very fine, unequal growthstriæ, and under a strong lens shows faint, extremely fine and close spiral striæ. These are also faintly visible in places on the upper surface. The carina first appears above the suture at the end of the second whorl in some examples, in others at the end of the third.

There is considerable variation in size and degree of elevation. Three of the specimens taken in 1906 at the type locality measure:

Alt. 6.2, diam. $12.5 \mathrm{~mm}$.

" 5.2 , " 511.8 “

" 5.6 , " 10.6 "

The punctation of the early neanic whorls, not noticed when the 
species was first described, shows that $A$. ferrissi is related to $A$. angulata, a much more widely spread species.

Genitalia as usual in the group. Basal half of the penis is swollen. As in $A$. angulata, the retractor muscle of the penis is longer than in A. duplicidens, proxima, etc. The mantle within the last whorl is white (pl. X, fig. 7).

\section{Group of Ashmunella chiricahuana.}

This group is distinguished by the very long spermatheca and epiphallus and the open aperture, which is either toothless or provided with minute vestigeal teeth which do not sensibly obstruct the opening.

A. chiricahuana has never been found to have any trace of teeth. It varies in size and degree of elevation of the aperture. A. esuritor frequently retains minute vestiges of teeth, but they are variable and often hardly noticeable. It is less evolved than A. chiricahuana in retaining this functionless reminiscence of the toothed ancestral form. The series is exactly parallel to the $A$. levettei-varicifera series in the Huachucas, but there the degeneration of teeth has been more recent and all stages of the process still exist.

Ashmunella chiricahuana (Dall). Fig. 23.

Proc. A. N. S. Phila., 1905, p. 250.

This fine Ashmunella is widely distributed in Cave Creek Canyon, living on reasonably moist north slopes where there is good rock shelter, with Sonorella. In 1906 we took specimens at Stations 3, 4, 5,11 , and in the ravines west of Reed's Mountain between that and Station 10. In 1907 and 1908 the following localities were added by Mr. Ferriss: Cave Creek Falls, head of Cave Creek near Long Park, Long Park at 8,000 feet. 'The types were from the adjacent Fly's Park (No. 124,481 U.S. N. M.). The figures published by Dr. Dall reprecent $A$. varicifera, a Huachucan species, and we have therefore given new illustrations.

The color varies from light brownish-corneous to light chestnut, and occasionally albinos are found. The surface is very glossy. Young specimens form a strong wide white rib within the lip when a resting stage occurs. This persists as a yellow blotch or stripe in the adult stage.

Some specimens, as those from Cave Creek, Station 5, and the head of Cave Creek, show traces of punctation on the intermediate whorls not visible in most others.

The chief variation, aside from tint, is in the elevation of the spire. 
Two examples, extremes of a continuous series, are figured to illustrate this (fig. $23 c, d$ ), from about the middle of the amphitheatre west of Reed's Mountain. This variation is not peculiar to any special colonies, though greater in some lots than others.

At the Cave Creek Falls there is a small form. Three specimens measure as follows:

\begin{tabular}{|c|c|c|c|}
\hline Alt. & S & 7 & $6.7 \mathrm{~mm}$. \\
\hline Diam... & .16 & 16 & 13.5 " \\
\hline Whorls. & $5 \frac{1}{2}$ & $5 \frac{2}{3}$ & $5 \frac{1}{3}$ \\
\hline
\end{tabular}

The genitalia of two individuals are figured. Pl. X, fig. 4, is from one of the very large shells of the head of Cave Creek at about $\$, 000$

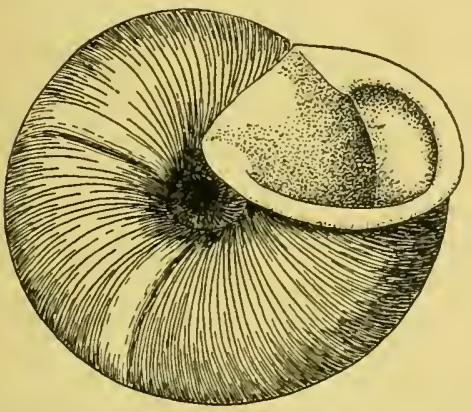

A

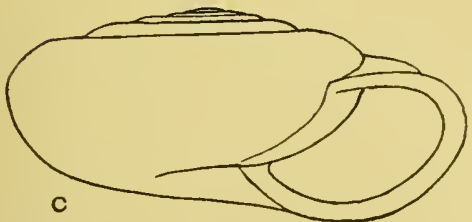

Fig. 23.-A. chiricahuana (Dall). A, B, Cave Creek Canyon; C, D, amphitheatre of Cave Creek.

feet elevation, near Long Park, diam. $19.5 \mathrm{~mm}$. The ducts are very long in these large snails. Both penis and spermatheca adhere to the uterus throughout part of their length, the penis looping under the spermatheca. The vagina is stout down to its base. Pl. X, fig. 1, was drawn from one of the very small shells of the Cave Creek Falls, diam. 13.5 to $16 \mathrm{~mm}$. The ducts are shorter and the base of the vagina is thin-walled. The penial retractor is longer in this species than in the toothed species, but not so long as in the Huachucan Ashmunellas.

The collar and foot are slate-colored; mantle-lining of the last whorl cream-white, not maculate. 
In a former paper ${ }^{21}$ we mentioned a form of Ashmunella from Miller Canyon, Huachueas, which, so far as the shell is concerned, agrees exactly with $A$. chiricahuana.

Specimens collected in 1907 have now been dissected. The Huachucan form proves to be practically identical with $A$. levettei in the soft anatomy, and abundantly distinct from $A$. chiricahuena in the proportions of the organs, especially of the spermatheca and its duct, as will be seen by the following table:

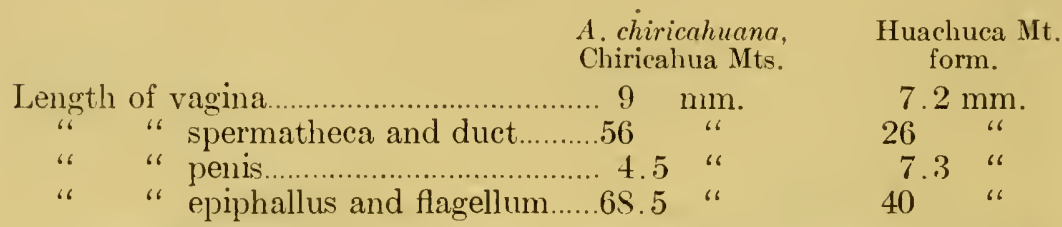

The spermatheca in the Huachucan form has the long, cylindric, weakly sacculate shape of that of $A$. levettei, wholly unlike that of A. chiricahuana. This form has been fully described and figured in a former paper. It is undoubtedly the shell indicated as A. chiricahuana var. varicifera Ancey, and will now be called Ashmunella varicifera.

Ashmunella esuritor Pils. Pl. IX, figs. 1-8.

Proc. A. N. S. Phila., 1905, p. 249, pl. 13, figs. 23-26 (shell); pl. 21, figs. 30, 25 (genitalia).

The type locaiity is not in Barfoot Park proper, but in a small park of yellow pine on the road from Paradise, about a mile before it crosses the ridge or divide going to Barfoot. This is the first grove of yellow pine on the road up. The type locality is a small conical pile of earth and rocks about ten feet to the left of the road. ${ }^{23}$ It was covered with snow at the time of our visit, but a small series of living specimens was taken, No. 92,205 A. N. S. P. About a mile below this place, toward Paradise, where a few yellow pines first appear among the oak scrub, we found a few examples. It will probably be found in many other suitable places in this immediate vicinity, reached by the road from Paradise to Barfoot Park. Our work in this place was impeded by a heavy snowfall, which lay knee-deep among the pines.

In the topotypes (No. 92,205) the diameter varies from 14.5 to 16 mm., whorls 6 to $6 \frac{1}{2}$. The degree of elevation of the spire is quite

${ }^{21}$ Mollusca of the Southwestern States I, Proc. A. N. S. Phila., 1905, pp. 242, 251, pl. XV, figs. 94, 95.

${ }_{22}$ We would ask future collectors to preserve this small type colony by taking only a moderate number of specimens there. 
variable, as in all the related species. Two of this lot are figured, pl. II, figs. $1,2,4,5$. In one or two shells there is the minute vestige of a parietal tooth (figs. 4, 5). The soft parts were partially spoiled when studied, but I have figured the terminal ducts of the genitalia, pl. X, fig. 3. The spermatheca was broken. Other organs agree with the type figured in 1905 .

The genitalia of two specimens are figured, pl. $\mathrm{X}$, figs. 2, 5. The penis and vagina conform in shape to the usual Chiricahuan type. The retractor muscle of the penis is well-developed, but short, about $2 \mathrm{~mm}$. long. The epiphallus is very long. Measurements of the organs may be found on p. 97. The penis and epiphallus are decidedly longer in three specimens of this lot dissected than in the type or topotype of esuritor. The spermatheca of the types of esuritor is unusually swollen distally, as correctly represented in the figure published in 1905.

Additional specimens (pl. IX, figs. 6, 7, 8) from the east side of Barfoot Park, Station 1a, were taken by Mr. Ferriss in 1907. The penultimate and two preceding whorls have the fine striæ interrupted irregularly, in places forming minute granules, and there is besides some indistinct appearance of punctation on the spire. There are very fine spiral lines on the base. There is a wide prominence, hardly to be called a tonth, within the outer lip in most examples, but in some this is very low or wanting, and in none quite so prominent as in the type of $A$. metamorphosa. Edentulous specimens resemble $A$. chiricahuana closely, but they differ from that species by the slightly more depressed shape, by having a rather deep, narrow gutter behind the lip (almost wanting in $A$. chiricahuana), by the smaller aperture in shells of the same diameter, and by having the umbilicus wider within, though not at its mouth. Three adults, No. 94,432, measure:

\begin{tabular}{|c|c|c|c|}
\hline Alt. & S & 7.3 & $6.7 \mathrm{~mm}$ \\
\hline Diam. &. .17 & 16.3 & 15 \\
\hline Whorls & $6 \frac{1}{2}$ & $5 \frac{3}{4}$ & 6 \\
\hline
\end{tabular}

In 1906 we dug out a small series of dead shells (No. 97,930) from under the snow and rocks in the head of Pine Canyon, ${ }^{23}$ perhaps fifteen minutes walk down from Barfoot Park. The callous "tooth" within the outer lip is either weak or wanting in these examples, and four out of ten adults taken show the weak trace of a parietal tooth. The most

${ }^{23}$ This canyon, which runs westward from Barfoot Park, is sometimes called Riggs' Canyon, or Saw-mill Canyon. At its head a saw-mill stood, but it was removed in the spring of 1907. 
elevated shell of this lot is drawn in pl. IX, fig. 3, Alt. 9, diam. $17 \mathrm{~mm}$., with $6 \frac{1}{2}$ whorls.

The specimens measure:

\begin{tabular}{|c|c|c|c|c|c|}
\hline Alt & 7 & 8 & 9 & 7.5 & $\mathrm{~mm}$. \\
\hline 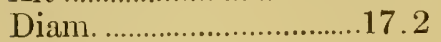 & 17 & 16.5 & 17 & 16 & \\
\hline Whorls...... & $6 \frac{1}{4}$ & $6 \frac{1}{1}$ & $6 \frac{1}{2}$ & $\ldots$ & \\
\hline Alt. & 7.5 & S & 7.5 & 7 & $\mathrm{~nm}$ \\
\hline …........16.4 & 16.5 & 16 & 15.5 & 15 & \\
\hline Whorls............................ 6 & $6 \frac{1}{3}$ & $6 \frac{1}{2}$ & 6 & $5 \frac{3}{4}$ & \\
\hline
\end{tabular}

A single shell from Onion Creek has a distinct callous prominence within the outer lip and a low tooth in the basal lip. Anatomically it resembles the topotypes of $A$. esuritor so far as can be made out, the soft parts being mutilated in pulling. The mantle is white within the last whorl.

\section{Group of A. metamorphosa.}

Ashmunella metamorphosa Pils. PI. IX, fig. 9.

Proc. A. N. S. Phila., 1905, p. 252, pl. 16, fig. 115 (shell); pl. 22, fig. 8 (radula); pl. 23, fig. 16 (jaw); pl. 21, fig. 27 (genitalia).

With one exception the original figures of this species, cited above, were taken from one specimen. Fig. 114 of plate XVI (1905) represents another shell, probably not conspecific. It is now proposed to restrict the type of $A$. metamorphosa to the broken shell represented on pl. XVI, fig. 115, the anatomy of which was figured. This is No. 88885 A. N. S. P.

This shell (pl. IX, fig. 9) resembles A. esuritor in contour. There is a deep furrow behind the narrowly reflexed basal and outer lips. The outer lip bears a long low callus on its inner edge. Above this callus it is brown, elsewhere white. Whorls 6 . The surface is not well preserved and shows no minute sculpture, being somewhat worn. Alt. 8.8, diam. probably about $17 \mathrm{~mm}$. It is a fully adult, but not old, individual. In p!. IX, fig. 9, the aperture of the type specimen of $A$. metamorphosa is drawn, the former photographic figure being unsatisfactory.

Barfoot Park, collected by James H. Ferriss, February, 1904.

We have nothing to add to the description and figures of genitalia jaw and teeth given in 1905. Having again examined the genitalia of the type, we see nothing to indicate that it is abnormal. The possibility that it is the $q$ phase of a proterandrous form has been considered, but the absence of such a condition in the other species of the genus makes against such hypothesis. If normal, the genitalia 
of this snail indicate one of the most distinct Chiricahuan species, a penis and its retractor being absent, as in some slugs.

The lot originally referred to this species consisted of three specimens, two being included in Mus. No. \$8,886. The soft parts of one of these were mutilated and not preserved. The other one has been dissected and proves to be $A$. esuritor. When we were in Barfoot Park near the end of November, 1906, snow lay almost knee-deep among the big pine trees and living snails were hard to find. Some dead shells (No. 97,930), taken in the head of Pine Canyon, may be metamorphosa, but we refer them for the present to A. esuritor. No shells known to have the anatomical peculiarities of $A$. metamorphosa have been taken since 1904.

We have found no character in the shell to certainly distinguish A. metamorphosa from $A$. esuritor. The latter varies from forms with a nearly simple lip, like $A$. chiricahuana, to those with various callous vestiges of teeth, as shown on the plate, figures 1 to $S$. Further collections of specimens in the flesh are needed.

Thysanophora hornii (Gabb).

Helix hornii Gahb, Amer. jour. of Conch., II, 1866, p. 330, pl. 21, fig. 5 (bad).

Thysanophora hornii Gabb, Pilsbry, Nautilus XI, 189S, p. 105; XIII, Jan., 1900, p. 98; Proc. A. N. S. Phila., 1903, p. 763; 1896, p. 126; Hinkley, Nautilus XXI, 1907, p. 172 (Tampico); Dall, Proc. U. s. Nat. Mus., XIX 1896, p. 336.

Not Patula horni Gabb, IV. G. Binney, Man. Amer. Land shells, Bull, 28 , U. S. N. M., 1885, p. 169

Chiricahua Mountains: near Dos Cabezas cave; near Lawhorn's ranch, mouth of Big Emigrant Canyon; White Tail Canyon above Stations 4 and 11, rare; Cave Creek Canyon on the slope below the cave, at Station 6, and about a half mile up the routh Fork.

Thysanophora ingersolli (Bland). Fig. 24, A, B, C.

Helix ingersolli Bland, Anu. Lyc. Nat. Hist. of New York, XI, 1874. p. 151 , figs.

Microphysa ingersolli Bld., IT. G. Binney, Terr. Moll., V, p. 173, fig. $\$ 2$ (shell); pl. III, fig. V (teeth); Man. Amer. Land shells, 1SS5, p. 170, fig. 160.

Thysanophora ingersolli Bld., Dall, Proc. U. S. N. Mus., XIX, p. 366 (Fly Park); Pilsbry, Nautilus XI, p. 105; J. Henderson, The Mollusea of Colorado, Univ, of Colo. Studies IV, No. 3, p. 169.

This species differs from the typical forms of Thysunophora by the absence of cuticular laminx or hairs, the surface being clean and bright, with the appearance of a Vitrea. Under very high magnification some spiral striæ are visible on the intermediate whorls, but not on the first. In the typical form, the aperture is narrowly lumate, the spire almost flat, umbilicus nearly one-fourth of the diameter, "Height 2.5, diam. $4 \mathrm{~mm}$." In many Colorado examples the umbilicus is narrower, about one-fifth the diameter of the shell. 
The localities for $T$. ingersolli in Colorado have been given by Henderson (l.c.). specimens are in coll. A. N. S. from Field, British Columbia (Stew. Brown). In New Mexico we have seen it from Sapello Canyon at Benlah (Cockerell); Sandia Mountains near Albuquerque (Miss Maud Fllis); Bland (Ashmum); James Canyon, Clouderoft, Sacramento Mountains (Rehn and Viereck). In Arizona we have it from Bill Williams Mountain near Williams (Ferriss and Pilsbry) and the top of Mt. Mingus, near Jerome (Ashmun). A specimen from this place is drawn in figs. 23, $a, b, c$, alt. 2, diam. 4.4, width of umbilicus $1.15 \mathrm{~mm}$., whorls $5 \frac{1}{4}$. It does not occur in the Chiricahua Mountains.

Thysanophora ingersolli meridionalis n. subsp. Fig. 24, D, E, F.

Shell with a wider aperture than $T$. ingersolli; whorls not quite as closely coiled, scarcely 5 in a shell of over $5 \mathrm{~mm}$. diam.; umbilicus about one-fourth the total diameter; spire nearly flat. Alt. 2.3, diam. 5.2 , width of umbilicts $1.3 \mathrm{~mm}$., whorls $4 \frac{3}{4}$.

Chiricahua Mountains in Bear Park, Long Park, head of Cave Creek,
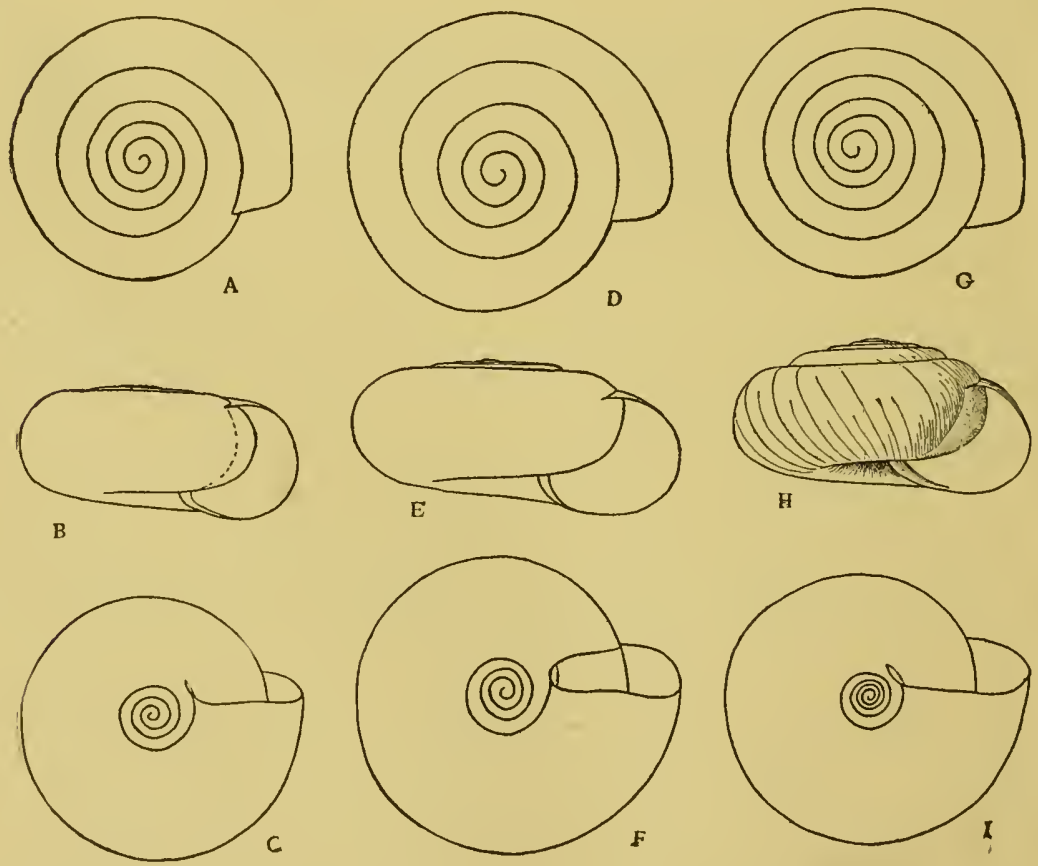

Fig. 24.-A, B, C, Thysanophora ingersolli (Bld.), Mt. Mingus, near Jerome, Arizona; D, E, F, T. i. meridionalis P. and F., Long Park, Chiricahua Mountains, Arizona; G, H, I, T. i. contexior (Anc.), Weston, Oregon. 
8,000 feet, Pine Canyon, 7,500 feet, and "Box" of Rucker Canyon. It has been listed by Dall from Fly's Park.

While not strongly differentiated, adult shells of this race are readily distinguishable. The aperture clasps the preceding whorl less deeply than in ingersolli. The microscopic spiral striation also is somewhat better developed in the examples compared.

Thysanophora ingersolli convexior (Ancey). Fig. 24, G, H, I.

Microphysa ingersolli var. convexior Ancey, Conchol. Exch. II, p. 64, Nov., $1 S 57$ (Logan Canyon, Utah).

"Shell a little smaller; spire scarcely planulate, the apex not subimmersed, distinctly convex; whorls 5 , not $5 \frac{1}{2}$, regularly but less slowly increasing, umbilicus smaller" (Ancey).

This form has not been figured. IVe have seen no topotypes, but examples from Weston, in eastern Oregon, collected by Henry Hemphill, evidently belong to the same race. One of these is figured (fig. $24, g, h, i)$. The specimen figured measures, alt. 2.5, diam 4.8, width of umbilicus $1 \mathrm{~mm}$., whorls $5 \frac{3}{4}$. The aperture is a little wider than in typical ingersolli.

\section{Family UROCOPTID正 Pils.}

\section{Genus HOLOSPIRA von IIartens.}

All of the Holospiras now known from Arizona belong to a single group of elosely related species, characterized by the light brown shell, having a stout lamella on the axis in the penultimate and first part of the last whorl, often in addition a superior or parietal lamella, and sometimes a basal lamella also. In several of the forms the lamellæ vary from one to three, as we have demonstrated by cutting from twenty to fifty individuals of a single colony. In colonies so varying, the number of internal lamellæ is not correllated with age, size or any other external feature of the shells, so far as we can discover, after collecting and examining hundreds of shells from a great number of colonies. The subgeneric divisions (Eudistemma, Tristemma) based upon the number of internal lamellæ in shells of this type have, therefore, no basis in nature. While the Arizona species differ somewhat from the Mexican type of the subgenus Bostrichocentrum in texture and sculpture, it does not seem that the differences are of subgeneric importance, and for the present we will place them in that group.

The variations in the internal lamellx recorded below are really less discontinuous than might be supposed by the tables. The axial lamella is invariably present, but it varies in strength and length. The superior lamella may be very strong and over a half whorl long, 
but in other individuals of the same colony it may be small or barely observable, so that the series from a strong lamella to none is practically a continuous one in some colonies, though usually this lamella is either distinctly developed or wholly wanting. The same statement applies to the basal lamella, except that it is never very large and usually quite small and short when present.

The study of these races is extremely complex, and we have been unable to find time to enter upon it seriously. Any full record of a form should take into account the number of ribs on a whorl or their distance apart, as well as the proportions of the shell, number of whorls, length of cone, and the lamellæ.

(a) In many colonies a longer and a shorter form may be selected, with only few intergrading specimens; and there may also be a noticeable difference in sculpture. Such colonies may perhaps be hybrid, composed of two incipient races. (b) Different colonies in the same district, often living under apparently identical conditions, and frequently in close proximity, may show differences in size, ribbing or comparative frequency of certain combinations of lamellæ, in fact, incipient racial divergence. The mingling of two or more such colonies by their spread, aided by changing conditions of surface, may have given rise to colonies of the $(a)$ type.

In some cases, where the colonies are widely separated, they have apparently erolved into reasonably distinct subspecies, probably in the absence of intermigration. The Cave Creek colonies of $H$. chiricahuana illustrate this.

Holospira arizonensis Stearns. Pl. XI, figs. 1-4.

H. arizonensis Stearns, Proc. U. S. Nat. Mus., XIII, 1890, p. 208, pl. 15, figs. 2, 3 (Cave at Dos Cabezas). Bartsch, Proc. U. S. Nat. Mus., Vol. 31,1906, p. 134.

This species has hitherto been known by fourteen fragments and one perfect specimen, the type No. 104,392 U. S. N. M. It measures, length 12.8, diam. at 10th whorl $4.2 \mathrm{~mm}$., whorls 12 . We did not visit Dos Cabezas Care, but our guide and driver, Mort Wien, passed there and collected a series of shells from close to, almost in, the mouth of the care. ${ }^{24}$ Fresh shells are pale comeous brown, glossy, bluish and subtransparent in places on the intermediate whorls. First $2 \frac{1}{2}$ whorls smooth; following 6 whorls sharply striate, the striation gradually disappearing, so that two or three whorls preceding the last are smoothish. The last whorl is dull, coarsely striate, its outer wall

${ }^{24}$ It is stated that Mr. Vernon Bailey collected the types in the cave. They had doubtless been carried there by wind or mice. This accounts for the broken condition of all but one specimen of the type lot. No Arizonian IIolospira lives in caves or shaded or damp places. They live in dry and sumny situations. 
flattened and tapering to the base, which is a little gibbous and rounded. Its latter part is straightened and runs forward shortly beyond the preceding whorl, the upper wall descending slightly. Otherwise it is not noticeably contracted behind the aperture. The outer lip is narrowly expanded and revolute, and is lined within with a rather thin white callus.

One living specimen in the lot is an albino, pure white with some bluish spots.

The axial lamella is strongly developed; superior lamella variable, but usually strong and extending through the last half of the penultimate whorl. Basal lamella variable, usually wanting, but sometimes strong. Twenty specimens opened give the following data:

Three lamellæ: superior, axial and basal (15\%)-

Length 14 , diam. 4 mm.; whorls $12 \frac{1}{2}$.

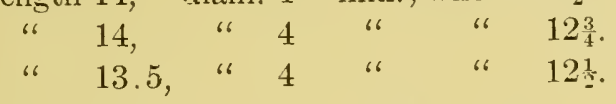

Two lamellæ: superior and $\operatorname{axial}^{\top}(65 \%)-$

Length 14.8 , diam. 4 mm.; whorls $13 \frac{1}{4}$.

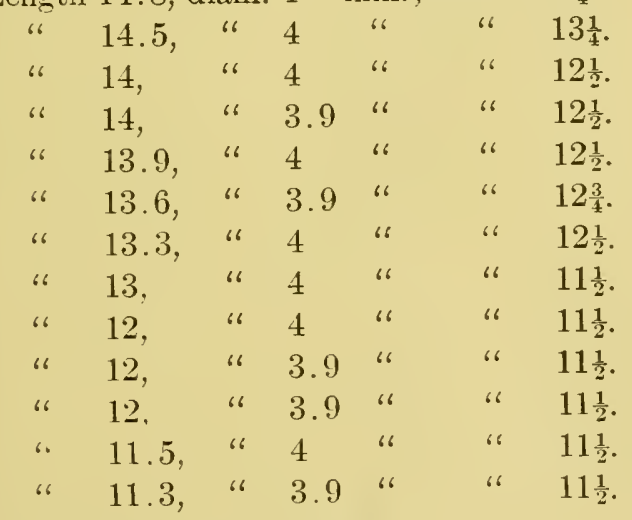

One lamella: axial $(20 \%)-$

Length 12 , diam. $3.8 \mathrm{~mm}$; ; whorls $11 \frac{1}{2}$.

$$
\begin{array}{lllllll}
\text { " } & 11.8, & \text { " } & 3.8 & \text { " } & \text { " } & 11 \frac{1}{2} . \\
\text { " } & 11.3, & \text { " } & 3.8 & \text { " } & \text { " } & 11 \frac{1}{2} . \\
& \ldots . . . & \text { " } & 4 & \text { " } & \text { " } & \ldots \ldots . . \text { (spire broken). }
\end{array}
$$

The above specimens were taken at random.

Holospira arizonensis emigrans n. subsp. Pl. XI, figs. 5-8.

The shell is in the average more slender than arizonensis, with more numerous whorls; striation slightly finer, and often extending weakly upon the smoother lower whorls; the last whorl has a broad contraction 
behind the lip, preceded by an opaque white, very coarsely striate, inflation; base opaque white, projecting more than in the type; callus within the outer lip is very heavy. Color dull corneous brown, like the type.

Head of Big Emigrant Canyon, in the region of piñon pine groves. Type No. 99,701 A. N. S. P. from Station 1; also taken at several stations eastward in the same neighborhood.

The head of Big Emigrant Canyon is cut into numerous small ravines, the northern slopes of which are wooded with piñons. The rock is limestone. Here Holospira was found in large numbers. In the type lot 25 specimens, taken wholly at random from a series of some hundreds, were opened and measured.

Three lamellæ: superior, axial and basal (16\%7)--

Length 13.5 , diam. $4 \mathrm{~mm}$.; whorls $13 \frac{1}{3}$.

$\begin{array}{lllllll}\text { " } & 13, & \text { " } & 3.9 & \text { " } & \text { " } & 13 \frac{1}{2} \text {. } \\ \text { " } & 12.3, & \text { " } & 3.9 & \text { " } & \text { " } & 12 \frac{1}{2} \text {. } \\ & 12, & 4 & \text { " } & \text { " } & \mathbf{1 2} \frac{1}{3} \text {. }\end{array}$

Two lamellæ: superior and axial (24\%)-

Length 13.4, diam. $3.9 \mathrm{~mm}$.; whorls $13 \frac{1}{2}$.

\begin{tabular}{|c|c|c|c|c|}
\hline 13, & " & 3.9 & “ & " \\
\hline 13, & " & 3.9 & “" & "6 \\
\hline 13, & $"$ " & 3.9 & " & " \\
\hline 12.9 & " & 3.5 & " & " \\
\hline 12.2 & " & 4 & " & " \\
\hline
\end{tabular}

One lamella: axial $(60 \%)-$

Length 15.1, diam. $3.9 \mathrm{~mm}$.; whorls 16.

\begin{tabular}{|c|c|c|c|c|c|}
\hline & 3.9 & 6 & 3.9 & "6 & 66 \\
\hline 66 & 13.9 , & " & $3 . S$ & " & "6 \\
\hline 16 & 13.8 & $" 6$ & $3 . S$ & $"$ & "6 \\
\hline "6 & 13.5 & " & 3.9 & " & " \\
\hline " & 13.1, & $"$ & 3.9 & " & " \\
\hline "6 & 13 & $"$ & 3.9 & " & $"$ \\
\hline " & 13 & 16 & 4 & " & " \\
\hline " & 13 & 66 & $3 . S$ & " & " \\
\hline " & 12.5 & 6 & $3 . S$ & " & " \\
\hline " & 12.4, & " & 4 & " & "6 \\
\hline " & 12.3 , & $" 6$ & 3.6 & " & $"$ \\
\hline " & 12, & $"$ & 3.9 & " & " \\
\hline " & 11.9 & " & 3.3 & " & " \\
\hline 6 & & " & 3.9 & " & " \\
\hline
\end{tabular}


The smallest individual in the lot measures, length 11, diam. 3.4, whorls $12 \frac{1}{3}$. It has superior and axial lamellæ.

In another lot from a colony not far from Station 1, in 20 shells opened the proportions are:

Three lamellæ, superior, axial and basal.

Two lamellæe, superior and axial One lamella, the axial

4 specimens,
10
6

Two other small lots were taken a mile or two southeast from Station 1, the shells resembling the type lot, though perhaps there may be a greater proportion of slender specimens among them.

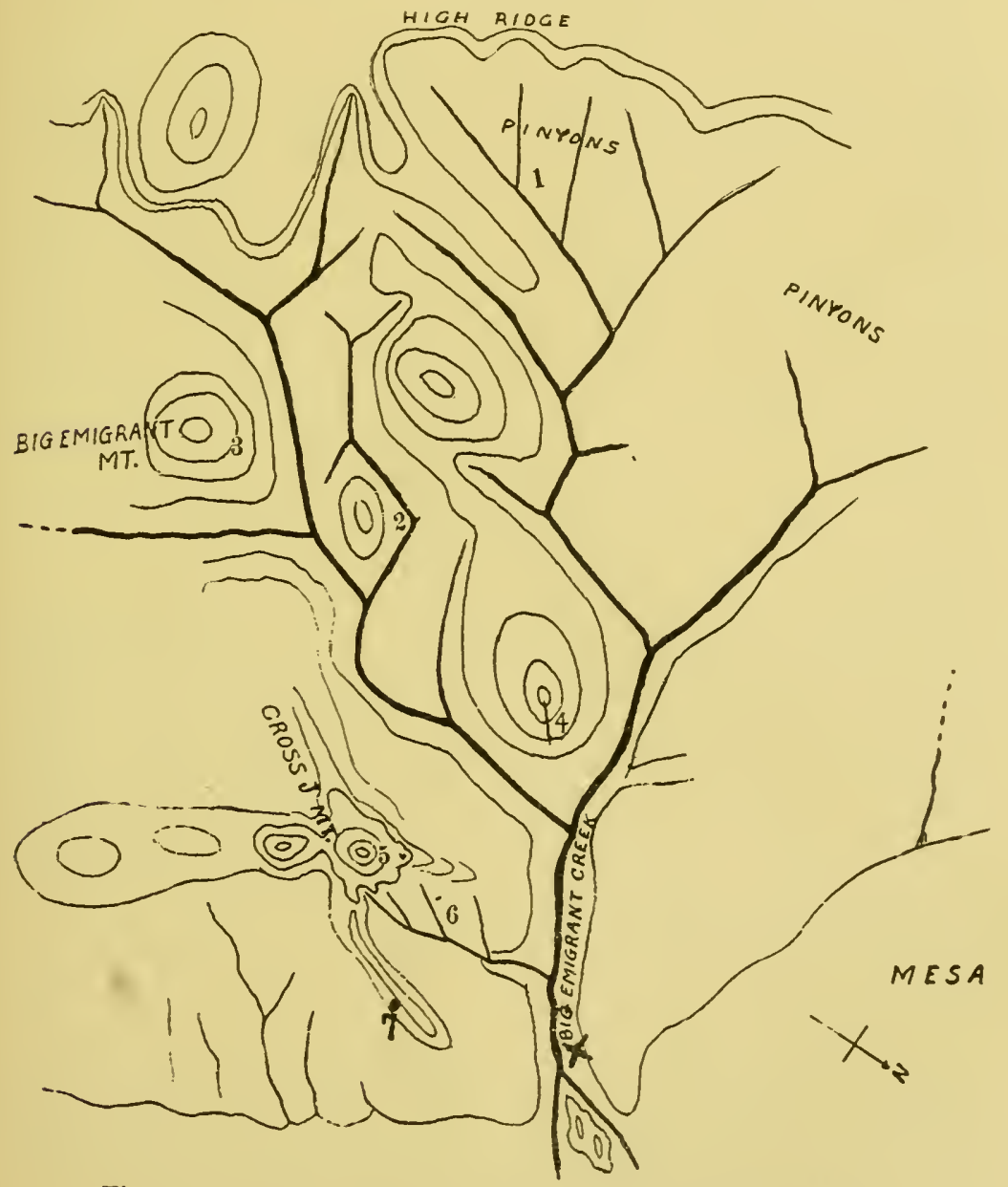

Fig. 25.-Principal collecting stations in Big Emigrant Canyon. 
At Station 2, at the bottom of the canyon (middle branch), a few dead specimens sharply, but very finely, striate throughout were found (pl. XI, figs. 9, 10, 11, 12). On the tapering cone and basal whorl the strix are coarser. At the head of this branch a small series (about 25) of similar shells was found. They are hardly distinguishable from $H$. cionella. Holospira colonies are scattered profusely all over the head slopes of Big Emigrant Canyon. We doubt whether more than one specific stock is represented there, though when thoroughly worked several minor races might be mapped out.

Holospira cionella Pils. Pl. XII, figs. 1, 2.

Proc. A. N. S. Phila., 1908, p. 217.

The types of this species came from near Old Fort Bowie. The fort stands on the narrow and low neck which unites the Dos Cabezas range with the Chiricahuas proper. Only the adobe walls now stand; only the cemetery remains to be guarded! The ridge has here a minimum elevation of 5,500 feet. About a mile south Mr. Dixon's place lies in the valley east of two conical peaks, known as Bull Hill and Quartzite Peak, the former of cherty limestone formation. Holospira cionella is found on the slope of Bull Hill facing the fort, the exact spot being along a tiny gully which crosses the trail to the fort. This place is indicated on the right at (3) in the photograph reproduced on page 67. It probably has an elevation of 6,000 to 6,200 feet. Another colony is on the lower slope of Quartzite Peak, toward Dixon's house, also indicated in the photograph at (2). Specinens from this place agree most closely with the original types of cionella.

The figured types (pl. XII, figs. 1, 2) are cylindric shells, evenly and rather finely but strongly rib striate, the striæ not weaker on the latter whorls; they are coarser on the swelling behind the contraction preceding the lip. Out of 11 shells of the type lot opened, 9 have an axial lamella only; 2 have axial and superior or parietal lamellæ. When originally describing this species only a few specimens were opened, and all happened to have one lamella only. The four specimens figured in 1905 measure as follows (the first three may be considered cotypes):

Length 12, diam. $3.1 \mathrm{~mm}$.; whorls $12 \frac{1}{2}$.

$\begin{array}{lllllll}\text { " } & 11.3, & \text { " } & 3.25 & \text { " } & \text { " } & 12 . \\ \text { " } & 11, & \text { " } & 3.25 & \text { " } & \text { " } & 12 . \\ & 8.7, & \text { " } & 3 & \text { " } & \text { " } & 11 .\end{array}$

Bull Hill (pl. XII, figs. 4-8). Specimens from the locality facing the Fort are all smaller than the types, though a few individuals of the original lot, such as pl. 27 , fig. 31 , of our former paper, are entirely similar. 
Twenty taken at random measure:

Two lamellæ: axial and parietal-

Length 10, diam. 3 mm.; whorls 12.

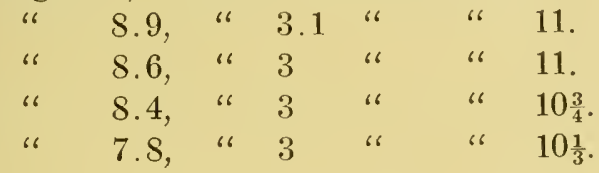

One lamella, the axial-

Length 9.8, diam. 3 mm.; whorls $11 \frac{1}{2}$.

\begin{tabular}{|c|c|c|c|c|c|}
\hline 6 & 95 & "6 & 3.1 & " & "6 \\
\hline " & 9.4 & " & 3 & " & " \\
\hline " & 9 & " & 3.1 & " & "6 \\
\hline " & 9 & 16 & 3 & " & " \\
\hline “" & 8.9, & 6 & 3 & "6 & " \\
\hline "، & 8.8, & " & 3 & " & 6 \\
\hline “6 & 8.8, & "6 & 3 & " & " \\
\hline 16 & 8.5, & 6 & 3 & " & " \\
\hline “6 & S. 4 , & $"$ & 3 & “" & " \\
\hline "6 & 8.4, & "6 & 3 & " & $"$ \\
\hline “" & 8 & $" 6$ & 3 & " & " \\
\hline "6 & S, & $" 6$ & 3 & " & "6 \\
\hline " & 7.7 & "6 & 3 & " & $"$ \\
\hline "6 & 7.2 & " & 3 & 6 & "6 \\
\hline
\end{tabular}

Goodwin's Canyon, near Lawhorn's ranch, not far south of Nine-mile Water Hole, is the locality of a small series taken by Mort Wien (pl. XII, fig. 3). They are decidedly wider than Fort Bowie cionella, and have either two or three lamellæ in the few examples opened. It is apparently a subordinate race of cionella. The largest and smallest measure:

Length 11, diam. $3.5 \mathrm{~mm}$.; whorls $12 \frac{1}{3}$. " 10 , " 3.5 " " $11 \frac{1}{2}$.

Some specimens of similarly wide shape, but with only the axial lamella, in a few opened, were taken by Mort Wien "a half mile from Dos Cabezas Cave."

Holospira cionella intermedia n. subsp. Pl. XIII, figs. 1-14.

The head and southern slope of White Tail Canyon are inhabited by a race closely related to C. cionella, but remarkably polyınorphic. The internal lamellæ vary from one to three, but in most colonies there are one or two, the former number predominating. The sculpture 
is always coarse on the cone, but on the cylindric part it may be coarse, partially effaced, or fine, in specimens of the same colony, while in some other colonies one or other of these conditions may be developed separately. The White Tail series deserves far more study than we have been able to find time for.

The shell differs from $H$. cionella by the perceptibly longer taper and coarser striation of the terminal cone, and slightly greater development of the basal erest. In the form selected as type (pl. XIII, fig. 3) the ribs continue throughout, but in many examples of the same lot they weaken more or less on the penultimate and next earlier whorls. The callus within the aperture is very heavy.

Type locality on the south side of the "box" of White Tail Canyon. Types (pl. XIII, fig. 3,) No. 99,684 A. N. S. P. It also was taken at Stations 1, 2, 3, 4, 5, S, 14; most or all of these colonies being of considerable extent, although the gathering in each case was made in a small area. The highest points are at Stations 1, 3 and 8 ; the lowest in the Box Canyon and between Stations 14 and 13. See map on p. 75. It was taken also in Jhu Canyon, Turkey Creek and Limestone Mountain. All of these stations are on limestone.

There is variation in sculpture in the type colony, some examples being strongly striate throughout, but in most the strix are weaker on the penult whorl. Pl. XIII, figs. 3, 4 and 5, represent shells from the type colony. Thirty-seven specimens of this lot opened measure:

(Shells with the ribs weak on penultimate whorl.)

One lamella: axial-

Length 13, diam. $3.9 \mathrm{~mm}$.

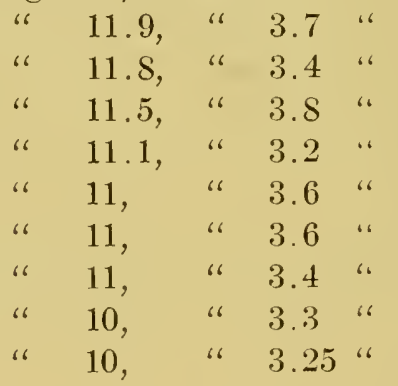

Two lamellæ: axial and superior-

Length 12.1, diam. $3.4 \mathrm{~mm}$.

" $11, \quad$ " $10,3.4$ " 30


Three lamellæ: axial, superior and basal-

Length 10 , diam. $3.4 \mathrm{~mm}$.

(Shells with strong ribs throughout.)

One lamella: axial-

Length 12, diam. $3.3 \mathrm{~mm}$. (Type specimen, pl. XIII, fig. 3).

\begin{tabular}{|c|c|c|c|}
\hline & 11.2, & 66 & 3.1 \\
\hline ، & 11 & "6 & 3.4 \\
\hline ، & 11 , & 6 & 3.4 \\
\hline ، & 11 , & 66 & 3.4 \\
\hline 6 & 10.6 & " & 3.3 \\
\hline “ & 10.6, & 66 & 3.3 \\
\hline " & 10.5, & 16 & 3.5 \\
\hline " & 10.5, & 66 & 3.2 \\
\hline “" & 10.5, & 16 & 3.7 \\
\hline 66 & 10.4 & 16 & 3.2 \\
\hline " & 10.3, & 66 & 3.5 \\
\hline “ & 10.3, & 16 & 3 \\
\hline “ & 10 & "6 & 3.3 \\
\hline " & 10 & 16 & 3.25 \\
\hline 6, & 10 & " & 3.2 \\
\hline & 10 & " & 3.3 \\
\hline & 9.3, & $" 6$ & 3.5 \\
\hline
\end{tabular}

Two lamellæ: axial and superior-

Length 11.7 , diam. $3.4 \mathrm{~mm}$.

$$
\begin{aligned}
& \text { " } 11 \text {, " } 3.4 \text { " } \\
& \text { " } 10.7, \text { " } 3.2 \text { " } \\
& \text { " } 10 \text {, " } 3.5 \text { " } \\
& \text { " } 9, \quad \text { " } 3 \text { " } 3 \text { Specimen figured, pl. XIII, fig. } 5 .
\end{aligned}
$$

Station 2.-Similar specimens occurred at higher levels at Station 2. A large proportion of these specimens are ribbed throughout. The lamellæ in 15 shells opened are as follows:

10 shells have 1 lamella, the axial.

5 shells have 2 lamellæ, axial and superior.

Station 3.-Shells were taken under stones on the sumny side of the ridge, and another lot on the summit of the ridge. The majority of the shells are ribbed throughout, but some have the penultimate whorl nearly smooth. Most specimens are 10 to $11 \mathrm{~mm}$. long. In 13 opened: 
$S$ shells have 1 lamella, the axial.

5 shells have 2 lamellæ, axial and superior.

Pl. XIII, figs. 1, 2, Station 4, northwest branch of ravine back of Gardner's Mine, about three-quarters of the distance to summit. Some of the shells have the terminal cone slightly shorter than in the types. Sculpture variable, as shown in the figures. Internal lamellæ 1, 2 or 3 . In 20 specimens opened:

10 have 1 lamella, the axial.

8 have 2 lamellæ, axial and superior.

2 have 3 lamellæ, axial, superior and basal.

Below Station 5, pl. XIII, figs. 13, 14. The shells are small and ribbed throughout, rarely over $9 \mathrm{~mm}$. long.

Box Canyon.-In the Box Canyon, at two stations, one some distance below Station 5 (pl. XIII, figs. $6,7,8$ ), the other at the mouth of Indian Creek, the shells are long and slender, strongly ribbed throughout. Axial and superior lamellæ are present in a few opened.

Length 13, diam. $3.2 \mathrm{~mm}$.; whorls 14 .

$$
\text { " } 10 \text {, " } 3.2 \text { " " } 11 \frac{1}{2} \text {. }
$$

Station 8.-A small series agrees, at least superficially, with those from Station 14, which lies about 800 feet lower.

Station 14.- The shells do not differ much from the type lot. There is a longer and coarsely ribbed and a shorter, more closely ribbed, form. Of the longer form we opened 10 shells, 1 having three, 4 two, and 5 one lamellæ. In seven of the shorter form opened 1 has two lamellæ, 6 have one lamella.

Forms from head of Onion Creek.-Two forms are represented in the small lot examined. Pl. XIII, fig. 9, shows a slender shell with coarse, very widely spaced ribs: length 12 , diam $3.3 \mathrm{~mm}$., whorls $12 \frac{1}{2}$. It has one lamella, the axial. PI. XIII, figs. 10, 11, 12, represents the prevalent form, shorter than the preceding, very finely and closely ribbed throughout, or the ribs may be weak or subobsolete on the penultimate next preceding whorls. In five opened, only the axial lamella is present.

Length 10.5 , diam. $3.5 \mathrm{~mm}$; whorls $11 \frac{1}{2}$.

$$
\text { " } 9.5 \text {, " } 3.3 \text { " " } 10 \frac{1}{3} \text {. }
$$

Jhu Canyon.-At the head of Jhu Canyon a gathering consists of two forms, similar to pl. XIII, figs. 9-12, from Onion Creek. The larger form is near typical intermedia, but the smaller may represent 
another race of the White Tail type. The material is not sufficient for a definite decision.

Turkey Creek.-On the right (north) side, about two miles below Paradise (pl. XII, figs. 13, 14, 15, 16), Holospira apparently referable to intermedia was found in two colonies, very variable in size and sculpture. Internal lamellæ one, two or three.

Limestone Mountain.-Although very widely separated from the range of intermedia, the shells do not seem separable from that race. Four are figured, pl. XII, figs. 9, 10, 11, 12.

Holospira cionella capillacea n. subsp. Pl. XIII, figs. 15, 16.

Similar to intermedia except that the intermediate whorls are very finely, closely striated; only the axial lamella developed, in a few opened. Length 11.7 to 12 , diam. $3.5 \mathrm{~mm}$. White Tail Canyon, Station 10 , about half way to the summit of the ridge, below cliffs. This colony is the only one found in igneous rock (rhyolite). Sonorella micra and Ashmunella lepiderma occur in the same vicinity. Holospira was very scarce.

Holospira chiricahuana Pilsbry. Pl. XIV, figs. 5-S.

Proc. A. N. S. Phila., 1905, p. 219, pl. 26, fig. 9; pl. 27, figs. 26-29; p. 215, fig. 4.

The type locality of $H$. chiricahuana is on the steep slopes of a small dry ravine or wash tributary to Cave Creek, below and near the entrance of the cave. The slope faces the south and is composed of very steeply dipping friable calcareous shale and earth formed by its decomposition, with sparse vegetation, agave, sotol and bear grass. Dead shells are scattered in profusion, and the living ones lurk under bunches of dead bear grass, etc. The colony is about one-eighth of a mile long and perhaps 100 yards wide. This is also the type locality of Orcohelix chiricahuana. Map on p. 107, Station 8.

A majority of the specimens ( $\$ 2$ per cent.) have a superior or parietal lamella from $\frac{1}{4}$ to $\frac{1}{2}$ of a whorl long, on the roof of the penultimate whorl near its end, above the aperture or on the front side, but in some (1S per cent.) this is wanting. In those of the type lot formerly opened it was absent or very weak, but in others of the type lot, as well as in many topotypes opened, this lamella is more or less strongly developed. The interior of the outer lip is very heavily thickened with a white callus within.

All forms of $H$. chiricahuana thus far found have the shell strongly ribbed throughout, with no tendency to become smoother on the cylindrical portion.

While in the type form of $H$. chiricahuana the internal lamellæ are inconstant, yet in several other colonies localized in various parts of 
the Cave Creek Valley the lamellæ seem to be constant, so far as we can judge from the limited material taken. It must be remembered that many other colonies doubtless exist.

The additional locality, "Fort Bowie," given in our original account, was evidently due to some mixture of labels or specimens. Thorough search in 1906 showed that it does not occur there. The large specimen represented in pl. XXVII, fig. 26, of our paper of 1905, was probably not from the type locality, but picked up somewhere else in Cave Creek Valley.

Fifty specimens opened, taken at random from a lot of several hundred topotypes, measure as follows:

Two lamellæ: parietal and axial-

$\begin{array}{cccccc}\text { Length. } & \text { Diam. } & \text { Whorls. } & \text { Length. } & \text { Diam. } & \text { Whorls. } \\ 10.8 & 3.1 & 12 \frac{1}{3} & 9.2 & 3 & 11 \frac{3}{4} \\ 10.8 & 3 & 12 \frac{1}{3} & 9.2 & 2.9 & 11 \frac{1}{2} \\ 10.4 & 3.1 & 12 \frac{1}{3} & 9.1 & 3 & 11 \frac{3}{4} \\ 10.3 & 3 & 12 & 9.1 & 3 & 11 \frac{1}{3} \\ 10.1 & 3 & 12 & 9.1 & 3 & 11 \frac{1}{2} \\ 10 & 3 & 12 \frac{1}{3} & 9 & 3 & 11 \frac{1}{2} \\ 10 & 3 & 12 & 9 & 3 & 11 \frac{1}{2} \\ 10 & 3 & 12 & 9 & 3 & 11 \frac{1}{2} \\ 10 & 3 & 11 \frac{3}{4} & 9 & 3 & 11 \frac{1}{2} \\ 9.9 & 3.1 & 12 & 9 & 3 & 11 \frac{1}{2} \\ 9.9 & 3 & 11 \frac{1}{2} & 9 & 3 & 11 \frac{1}{2} \\ 9.8 & 3 & 12 & 9 & 3 & 11 \frac{1}{3} \\ 9.8 & 3 & 12 & 9 & 3 & 11 \\ 9.7 & 3.1 & 11 \frac{1}{2} & 9 & 3 & 11 \\ 9.6 & 3 & 12 & 9 & 3 & 11 \\ 9.5 & 3.1 & 11 \frac{1}{3} & 8.9 & 3 & 11 \\ 9.5 & 3 & 11 \frac{3}{4} & 8.9 & 3 & 11 \\ 9.5 & 3 & 11 \frac{1}{2} & 8.7 & 3 & 10 \frac{1}{2} \\ 9.5 & 3 & 11 \frac{1}{2} & 8.6 & 2.9 & \\ 9.5 & 3 & 11 \frac{1}{2} & 8 & 2.9 & \end{array}$

One lamella: the axial-

$\begin{array}{lccccc}\text { Length. } & \text { Diam. } & \text { Whorls. } & \text { Length. } & \text { Diam. } & \text { Whorls. } \\ 10.6 & 3.1 & 12 \frac{1}{2} & 9 & 3 & 11 \\ 10 & 3.1 & 11^{\frac{3}{4}} & 9 & 3 & 10 \frac{3}{4} \\ 10 & 3 & 12 & 8.9 & 3 & 11 \frac{1}{3} \\ 9.9 & 3.1 & 11 \frac{1}{2} & 8.9 & 2.9 & 11 \\ 9.5 & 3 & 12 & & & \end{array}$

Holospira ohiricahuana ternaria n. subsp. PI. XIV. figs. 1-4.

At the end of the penultimate whorl there are usually three internal lamellæ: parietal, axial and basal. Shell usually larger with more whorls, but otherwise as in the type. 
I.ength 12.2 , diam. $3.4 \mathrm{~mm}$.; whorls $13 \frac{1}{3}$.

\begin{tabular}{|c|c|c|c|c|}
\hline 11, & 6 & 3.2 & "6 & " \\
\hline 11.1, & "6 & 3.3 & " & " \\
\hline 10.3, & " & 3.1 & " & " \\
\hline 10.8, & " & 3.1 & " & "6 \\
\hline 9.4, & " & 3.1 & "6 & " \\
\hline
\end{tabular}

Station 6, about half way up the northern slope of a long ridge which projects into Cave Creek Valley from the western border.

Fifty-three specimens were taken from a single small colony. The frozen ground did not encourage a thorough investigation. Out of 20 opened, 17 have three internal lamellæ and three have only one, the axial.

Holospira ohiricahuana optima n. subsp. Pl. XIV, figs. 13-15.

The shell is larger and perceptibly more slowly tapering than $H$. chiricahuana, with more whorls, and only one internal lamella, the axial, in 20 specimens opened.

Station 5, at the base of the north slope of the ridge mentioned above, close to the stream, under stones. The larger size of the shells might be thought due to the more humid and shaded situation than that inhabited by the typical form, were it not that Holospira prefers hot and arid places and does not exist at all in damp situations. A single colony found. About 75 shells were taken. Thirty-five of them, unselected, measure as follows:

$\begin{array}{lccccr}\text { Length. } & \text { Diam. } & \text { Whorls. } & \text { Length. } & \text { Diam. } & \text { Whorls. } \\ 14.3 & 3.7 & 14 \frac{3}{4} & 13 & 3.5 & 13 \frac{1}{2} \\ 14 & 4 & 13 \frac{3}{4} & 13 & 3.5 & 12 \frac{3}{4} \\ 14 & 3.9 & 13 \frac{3}{4} & 13 & 3.3 & 13 \frac{1}{2} \\ 14 & 3.7 & 14 \frac{1}{2} & 13 & 3.3 & 13 \frac{1}{2} \\ 13.9 & 3.7 & 13 \frac{1}{2} & 13 & 3.4 & 13 \frac{1}{2} \\ 13.9 & 3.5 & 13 \frac{3}{4} & 13 & 3.2 & 13 \frac{1}{3} \\ 13.9 & 3.3 & 13 \frac{3}{4} & 12.9 & 3.6 & 12 \frac{3}{4} \\ 13.8 & 3.6 & 14 & 12.8 & 3.5 & 13 \frac{1}{2} \\ 13.8 & 3.3 & 14 \frac{1}{2} & 12.7 & 3.3 & 13 \frac{1}{2} \\ 13.6 & 3.3 & 14 \frac{1}{2} & 12.7 & 3.3 & 13 \\ 13.5 & 3.5 & 14 & 12.6 & 3.4 & 13 \frac{1}{3} \\ 13.5 & 3.5 & 14 & 12.5 & 3.5 & 13 \frac{1}{3} \\ 13.3 & 3.5 & 14 & 12.1 & 3.25 & 13 \\ 13.3 & 3.4 & 14 \frac{1}{2} & 12 & 3.7 & 12 \frac{1}{2} \\ 13 & 3.8 & 13 \frac{1}{4} & 12 & 3.3 & 13 \frac{1}{2} \\ 13 & 3.8 & 13 \frac{1}{4} & 11.3 & 3.5 & 12 \frac{1}{2} \\ 13 & 3.6 & 13 \frac{3}{4} & 11.2 & 3.3 & 13 \frac{1}{4} \\ 13 & 3.5 & 13 & & & \end{array}$


Holospira chiricahuana gracilis n. subsp. Pl. XIV, figs. 9-12.

The shell is more slender and tapers more slowly than the type, and has more whorls. It is more slender than H. c. optima. Only the axial lamella developed in 19 out of 20 specimens opened, the other one having a strong parietal lamella also.

Found at Station 10, on the crest of a narrow ridge, a spur from the south wall of Cave Creek Valley, which terminates in a high conical hill standing not far from the creek. This is the only colony of the species found south of Cave Creek, the others being north of the creek. One colony of small extent.

Thirty specimens measure:

$\begin{array}{lccccc}\text { Length. } & \text { Diam. } & \text { Whorls. } & \text { Length. } & \text { Diam. } & \text { Whorls. } \\ 11.7 & 3.1 & 14 & 10.9 & 3 & 12 \frac{3}{4} \\ 11.7 & 3 & 14 & 10.9 & 3 & 13 \\ 11.5 & 3 & 14 & 10.8 & 3 & 13 \\ 11.5 & 3 & 13 \frac{1}{2} & 10.7 & 3 & 12 \frac{1}{2} \\ 11.5 & 3 & 13 \frac{1}{2} & 10.5 & 3 & 13 \frac{1}{4} \\ 11.3 & 3 & 13 \frac{1}{2} & 10.4 & 3 & 13 \\ 11.2 & 3 & 13 \frac{1}{2} & 10.3 & 3 & 12 \frac{1}{2} \\ 11.1 & 3.1 & 13 \frac{1}{3} & 10.3 & 2.9 & 12 \frac{1}{2} \\ 11.1 & 3 & 13 \frac{1}{3} & 10.2 & 3 & 12 \frac{1}{3} \\ 11 & 3 & 13 \frac{1}{3} & 10.1 & 3 & 12 \frac{1}{2} \\ 11 & 3 & 13 \frac{1}{2} & 10.1 & 3 & 12 \frac{1}{3} \\ 11 & 3 & 12 \frac{1}{2} & 10 & 3 & 12 \frac{1}{3} \\ 11 & 3 & 13 & 10 & 3 & 12 \\ 11 & 2.9 & 13 \frac{1}{2} & 9.9 & 3 & 12 \\ 10.9 & 3 & 13 & 9.9 & 2.9 & 12 \frac{1}{2}\end{array}$

\section{LIMACID丑.}

Agriolimax hemphilli ashmuni Pils. and Van.

Barfoot and Long Parks. The specimens vary from a pale yellowishgray to the blackish color of the types.

\section{ZONITID $\nexists$ 巴.}

Vitrina alaskana Dall.

Long Park, 8,000 feet; Head of Cave Creek, at about the same elevation; Barfoot Park.

Zonitoides arborea (Say).

Head of Cave Creek, 8,000 feet; Long Park, Station 12 A; Rustler Park; Rucker Canyon. It is not commonly diffused, and seems to be absent in the dryer part of the range.

Zonitoides milium meridioualis $P$. and $F$.

Quartzite Peak, near Fort Bowie; head of Cave Creek, 8,000 feet; 
Rustler and Long Parks; head of Pine Canyon; Rucker Canyon, 7,000 feet.

Zonitoides minuscula alachuana (Dall).

Barfoot Park; Pine Canyon; Spring in lower Rucker Canyon.

Vitrea indentata nmbilicata (Ckll.).

Chiricahua Mountains; Buckeye Canyon, in the Dos Cabezas range; Bull Hill and Quartzite Peak, near Fort Bowie; Big Emigrant Canyon at Stations 1, 2, 3, 5, 6; White Tail Canyon at about all the stations east of Stations 4 and 5 , at all elevations; Jhu Canyon; Paradise Canyon, on the right side, below the town; Cave Creek Canyon, Stations 4, 6, S, 11, 12, 13, 14; Barfoot Park; Long Park; Rustler Park; Rucker Canyon; Horseshoe Canyon. Probably occurs wherever snails live in the Chiricahuas.

\section{Genus EUCONULUS Reinhardt.}

The term Euconulus was proposed by Reinhardt in 1883 for the typical group of Conulus, in which he included Kaliella. Conulus being preoccupied, Pilsbry in $1900^{27}$ substituted Euconulus for the generic group, with fulvus as type. Dall, $1905 .^{28}$ has given the generic synonymy and references in full. Mr. J. W. Taylor in his monograph of British land shells (1908) has discussed the varieties of E. fulvus. His treatment of $E$. chersinus as a variety of fulvus was evidently due to the lack of specimens, for the two forms are much less alike than the several small British species of Hyalinia which he distinguishes, and in fact are unusually distinct as species go annong the small Zonitidæ. One of the European forms is apparently close to chersinus; but an intelligible exposition and revision of the Euconulus of Europe remains a desideratum. There is no trustworthy record of Euconulus fulvus from Japan, though $E$. fulvus alaskensis may naturally be expected to occur in the Kuril Islands, Yesso and Saghalin.

Euconulus fulvus alaskensis (Pils.).

Conulus fulvus alaskensis Pils., Nautilus, XII, February, 1S99, p. 116. Cf. Dall, Land and Fresh Water Mollusks, Harriman Alaska Exped., 1905, p. 40, and Pilsbry, Nautilus, XIII, 1908, p. 25.

Chiricahua Mountains: White Tail Canyon, high on the northeastern side below the confluence of Indian Creek; Cave Creek Canyon at Stations 3 and 4 near the northeastern rim; Barfoot, Long and Rustler Parks; head of Pine Canyon, 7,500 feet; Box of Rucker Canyon.

27 Nautilus, IIV, Nov., 1900, p. 81.

${ }^{28}$ Harriman Alaska Exped., Mollusks, p. 39. 
Chiefly or wholly found at high elevations, and very rare in the region north of Cave Creek.

$E$. fulvus alaskensis differs chiefly from fulvus by having about one whorl less in shells of similar size. On the first whorl the radial strix begin at the first fourth, and are about as close as on the rest of the shell. There are no spiral striæ on the first or later whorls. The last whorl has 90 to 105 striæ in $1 \mathrm{~mm}$. E. f. alaskensis was described from Dyea Valley, Alaska. It is also before us from Petropavlovsk, Kamchatka, collected by Dr. William H. Dall. It extends southward in the Rocky Mountains to the Chiricahua and Huachuca ranges, in southern Arizona, chiefly at high elevations.
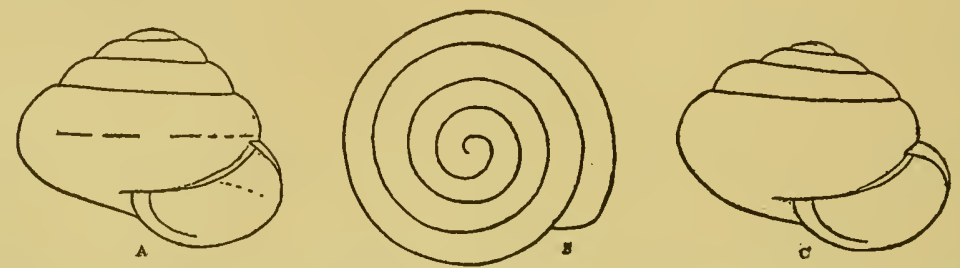

Fig. 26.-Euconulus fulvus alaskensis Pils. A, B, cotype, Dyea Valley, Alaska: C, Head of Cave Creek, Chiricahua Mountains.

Mr. E. G. Vanatta has made a careful study of the American forms of Euconulus fulvus in order to determine the status of the Chiricahuan form, using high magnification to bring out the minute sculpture. It appears that all the forms examined have a minute sculpture of excessively close, regular vertical striæ, though in some examples it is less distinct than in others. This sculpture, when strongly developed, lends a silk-like luster to the surface in quite fresh examples.

In $E$. fulvus from the northeastern United States the first whorl has fine spiral striæ and very indistinct traces of vertical (radial) striæ, not seen in some but legible, though weak, in other examples. The upper surface of the last whorl has about 126 vertical striæ in $1 \mathrm{~mm}$., crossed by spiral striæ. There are about 6 whorls (figs. 27, B, c, Herkimer Co., N. Y., No. 59,521 A. N. S. P., alt. 2.4, diam. $3.1 \mathrm{~mm}$. Fig. D, Buckfield, Oxford Co., Maine, No. 87,302 A. N. S. P., alt. 3.5, diam. $3.4 \mathrm{~mm}$.). The largest examples seen are from Buckfield, Me., collected by Mr. J. A. Allen.

An English example (fig. 27A, Burnley, England, R. Walton coll., 75,912 A. N. S. P.) has distinct vertical striæ on the first whorl as well as spirals, and on the last whorl there are 140 vertical striæ in $1 \mathrm{~mm}$., with no noticeable spirals. Alt. 2.4, diam. $2.8 \mathrm{~mm}$. 
It seems that there is considerable variation in the minute sculpture of $E$. fulvus, though it appears to be always somewhat coarser than in $E$. chersinus and, in the average at least, finer than in E. fulvus alaskensis.

Euconulus chersinus (Say) is, of course, a very distinct species from all of the preceding. No conchologist who actually exammes fulvus and chersinus with an ordinary hand lens could lump them. Mr. Vanatta's study of the microscopic sculpture has shown that there is little real difference between chersinus and polygyratus, and we are
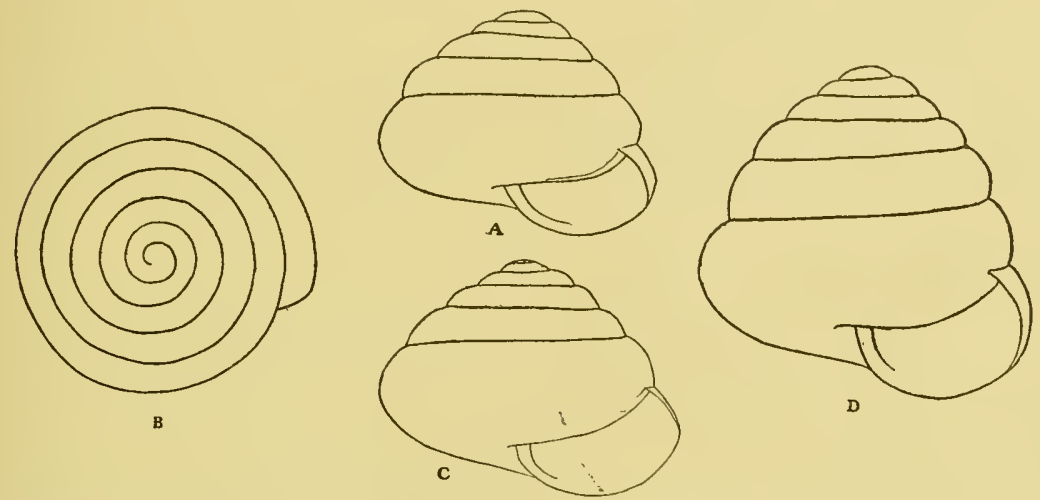

Fig. 27.-Euconulus fulvus (Müll.). A, Burnley, England; B, C, Herkimer County, N. Y.; D, Buckfield, Maine.

now disposed to drop the latter as a synonym. E. chersinus (polygyratus) occurs associated with fulvus in some Maine localities. $E$. chersinus has not been found in New Mexico or Arizona.

\section{ENDODONTID $\nexists$ F.}

Pyramidula (Gonyodiscus) cronkhitei (Newc.).

Foot of talus about half a mile below Reed's place, in Cave Creek Canyon, Station 11; head of cave, 8,000 feet; Barfoot Park; head of Pine Canyon; Long Park, 8,000 feet; "Box" of Rucker Canyon.

Helicodiscus eigenmanni arizonensis Pils. and Ferr.

Quartzite Peak near Fort Bowie; head of west branch of Big Emigrant Canyon and at Station 2; White Tail Canyon at Stations 4, 10, in the Box Canyon, and on both sides below the junction of Indian Creek; Cave Creek Canyon at Stations 4 and 14, 8,000 feet; Rustler's Park; head of Pine Canyon; Shake Gulch, Limestone Mountain.

Radiodiscus millecostatus Pils. and Ferr.

Head of Cave Creek, \&,000 feet, Station 14; Barfoot Park, Station 3; 
Pine Canyon, 7,500 feet; Rustler Park; Long Park, \$,000 feet; "Box" in Rucker Canyon.

This species is new to the Chiricahuas. It was originally described from the Huachuca range. It was found in some profusion in Long Park, many specimens exceeding the type in size, the largest $2.3 \mathrm{~mm}$. in diameter.

It is somewhat remarkable that this form, belonging to a southern genus and here at the northern edge of its known range, should be found only at high levels.

Punctum californicum Pils.

P. californicum Pils., Nautilus, XI, April, 189S, p. 134 (Fish Camp, Fresno County, California).

Head of Cave Creek, Station 14, S,000 feet; Rustler Park; Long Park. Found with Radiodiscus.
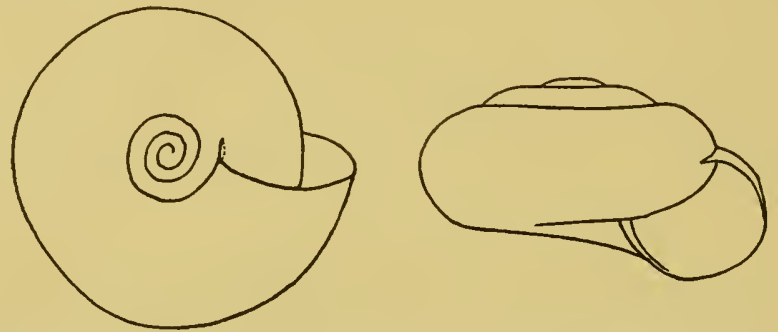

Fig. 2S.-Punctum californicum Pils., Rustler Park, Chiricahuas.

Only seven examples of this atom of life were found, none of them as large as the Califomia types, and probably not fully mature. The figured example measures alt. .S2, diam. 1.35, width of umbilicus .35 mm., whorls $3 \frac{1}{4}$. The first $1 \frac{1}{4}$ whorls are smooth; then very fine obliquely radial striæ appear. On the last whorl the striation is dense and fine, with thin delicate cuticular laminæ on the striæ, which give fresh shells a satin sheen where the light strikes, the color of the shell being light chestnut. Striæ at nearly regular intervals are slightly more prominent. At the periphery there are about 40 of the more prominent striæ in $1 \mathrm{~mm}$. The umbilicus is one-fourth the total diameter.

An adult shell of the type lot of $P$. californicum measures $1.8 \mathrm{~mm}$. diam., umbilicus $.42 \mathrm{~mm}$., therefore, slightly less than one-fourth the diameter. The sculpture is similar to that of Chiricahua $P$. californicum.

This snail is new to Arizona, having been known hitherto only from 
Fresno County, California. It is one of the very few forms common to Arizona and the West Coast.

VALLONIID Æ Pilsbry.

Vallonia perspectiva Sterki.

Summit of Cross J Mountain, Big Emigrant Canyon; Paradise Canyon below Paradise; White Tail Canyon; Spring in lower Rucker Canyon; Limestone Mountain.

FERUSSACID $\notin$ Bourguignat.

Cochlicopa lubrica (Müll.).

Chiricahua Mountains: Ridge between White Tail Canyon and the Pinery, Station 3; Jhu Canyon; Paradise Canyon; Cave Creek Canyon at Stations 4, 5 and 11 and $14 \mathrm{~F}$, very scarce; Barfoot Park; head of Pine, 7,500 feet; Long Park, 8,000 feet; Box of Rucker Canyon.

\section{PUPILLID㭌 Turton.}

Pupilladce Turton, Manual of the Land and Fresh-water Shells of the British Islands, p. 97 (1831).

Pupillidec, Pilsbry, Nautilus, XVIII, p. 107 (Jan., 1905).

Pupidre of authors.

The northern (Canadian) forms of this group approach their southern limit in the ranges of Southern Arizona. Vertigo is represented only by a few puny forms at high elevations. The Upper Sonoran Bifidariæ predominate, especially those of the section Immersidens.

The family name Pupillidce replaces Pupidce because the generic term Pupa was not based upon a member of this family.

Genus PUPILLA 'Leach' Turton.

Pupilla hebes (Ancey).

Box in Rucker Canyon; Spring branch of Rucker. The sinistral form of $P$. hebes (which we will call form nefas) was taken in Pine Canyon, 7,500 feet (type loc.), and at the head of Cave Creek, Station 14 , at $\$, 000$ feet. No dextral examples were taken at either of these stations.

Genus BIFIDARIA Sterki.

Bifidaria pellucida hordeacella (Pils.).

Summit of Cross J Mountain, Big Emigrant Canyon; Paradise Canyon below Paradise; White Tail Canyon; Cave Creek Canyon on slope below the cave; Shake Gulch, Limestone Mountain.

Bifidaria quadridentata Sterki.

Barfoot Park, one specimen. 
Section ALBINULA 'Ckll' Sterki.

Bifidaria pilsbryana Sterki.

Rustler's Park; White Tail Canyon; Pine Canyon, 7,500 feet; Box in Rucker Canyon; Limestone Mountain, in Shake Gulch.

\section{Section IMMERSIDENS Pils, and Van.}

In the central sierras, from the Grand Canyon of the Colorado to the Mexican State of Nichoacan, a distance of over 1200 miles, the typical (or procera) group of Bifidaria gives place to a great extent to a group in which the angular and parietal lamellæ are less united, joined only at the inner end of the angular lamella. The basal fold, when present, is radial, or transverse to the cavity. This group is morphologically in a more primitive stage than the eastern Bifidariæ, in which the angular and parietal lamellæ are more completely concrescent. Some of the species, however, have evolved very complicated apertures. Such forms as B. perversa and B. ashmuni are to be viewed as highly evolved members of a low group. Immersidens stands intermediate between Bifideria s. str. and Sterkia. In the latter group the angular and parietal lamellæ are not united.

The following forms from Arizona and New Mexico belong here:

Bifidaria perversa Sterki.

" ashmuni Sterki.

" ashmuni minor Sterki.

" cochisensis Pils. and Ferr.

" cochisensis oligobasodon Pils. and Ferr.

" dalliana Sterki.

" bilamellata Sterki and Clapp.

Bifidaria prototypus Pils., from Michoacan, Mexico, also belongs to the group, as a terminal member of a form-chain composed of ashmuni, cochisensis, oligobasodon, prototypus, which constitute successively simpler links in the chain. Probably the great unknown mountain region of Northern Mexico will supply other members of the group.

In order to complete the account of $B$. ashmuni and its allies, forms from the Huachuca Mountains and elsewhere have been described and illustrated below.

Key to Spccies of Immersidens.

a.-Shell sinistral, last whorl straightened and produced forward (fig. 29) B. perversa Sterki. $a^{1}$.-Shell dextral. 
b.-Columellar lamella ruming forward on the parietal wall in the position of an infraparietal lamella; inner end of the parietal lamella curving strongly toward the outer wall.

c.-Length about $2 \mathrm{~mm}$.

B. ashmuni Sterki. $c^{1}$.-Length 1.6 to $1.8 \mathrm{~mm}$ B. a. minor Sterki.

$b^{1}$.-Columellar lamella normal in position, horizontal and conspicuous in a front view.

c.-Parietal barrier $\lambda$-shaped, the inner end curving more or less towards the outer wall.

d.-Basal fold well-developed, radial.

B. cochisensis $\mathrm{P}$. and $\mathrm{F}$.

$d^{1}$.-Basal fold minute; angular lamella reduced.

B. c. oligobasodon P. and F.

$d^{2}$.-Basal fold wanting; angular lamella reduced.

B. prototypus Pils.

$c^{1}$.-Parietal lamella straight or bending slightly toward the columella at its inner end; shell small, rather slender.

d.-Length 2, diam. $0.85 \mathrm{~mm}$, or smaller; nearly cylindric.

$B$. dalliana Sterki.

$d^{1}$--Length 2 to 2.4 , diam. 0.9 ; spire tapering more.

B. bilamellata S. and $\mathrm{C}^{29}$

Bifidaria perversa Sterki. Fig. 29.

Bifidaria periersa Sterki, Nautilus, XII, December, 189S, p. 90 (Nogales).

Found in the Chiricahuas in the Valley of Turkey Creek below Paradise and in White Tail Canyon. Heretofore known only from Nogales and the drift débris of the San Pedro River at Benson, Arizona.

Bifidaria ashmuni Sterki. Fig. 30, $a, b, c$.

Bifidaria ashmuni Sterki, Nautilus, XII, Sept., 1898, p. 49 (Santa Rita Mountains, Arizona; Cook's Peak and Dripping Springs, Organ Mountains, New Mexico).

Bifidaria ashmuni form minor Sterki, t.c., Dec., 1898, p. 92 (Nogales, Arizona).

The typical form of $B$. ashmuni is nearly cylindric, tapering but slightly, composed of five strongly convex whorls. The last whorl becomes straightened and slightly sinuous in basal view, and has a more or less conspicuous oblique swelling or erest some distance behind

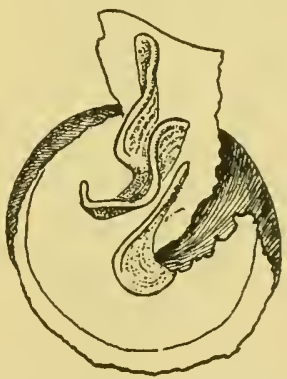

Fig. 29.-B. periersa, basal view, most of the basal wall removed to show the angular, parittal and and columellar lamellæ.

the aperture. This crest is not always so strong, as shown in fig. $30 \mathrm{c}$ (a specimen from Page's Ranch, Oak Creek, in central Arizona). The

${ }^{29}$ Bifidaria bilamellata Sterki and Clapp, Nautilus, XXII, pl. S, fig. 7 (March, 1909). Sterki, Nautilus, XXII, p. 126 (April, 1909). Yuma County, Arizona. 
peristome is well expanded, continuous, and usually stands shortly free from the whorl in front. The parietal lamella is sigmoid, bending far to the right at its inner end. The angular lamella, also sigmoid, runs from the peristome to the parietal lamella, the two lamellæ together forming a figure like the letter $\lambda$. The columellar lamella is broad and horizontal far within, but near the aperture it runs out upon the parietal wall, where it appears as a more or less elevated cord between the parietal lamella and the columella, occupying, therefore, the place of an infraparietal lamella. These lamellæ are well shown in fig. $30 \mathrm{~b}$, a basal view in which the base of the shell has been removed. The upper palatal fold is short, situated some distance within the mouth, but visible from in front. The lower palatal is long, entering, and so deeply immersed that it is not visible in a front view, being concealed behind the massive parietal barrier. There is a radially placed basal fold, scarcely or not visible in a front view. Length about 2, diam. $1 \mathrm{~mm}$.

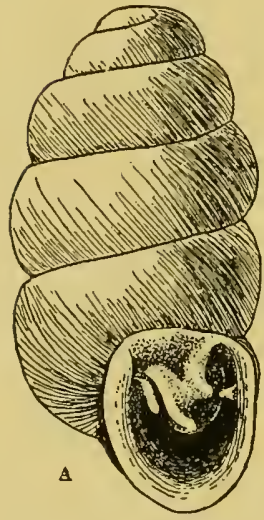

Fig. 30.-Bifidaria ashmuni Sterki. A, B, Florida Mountains, New Mexico;
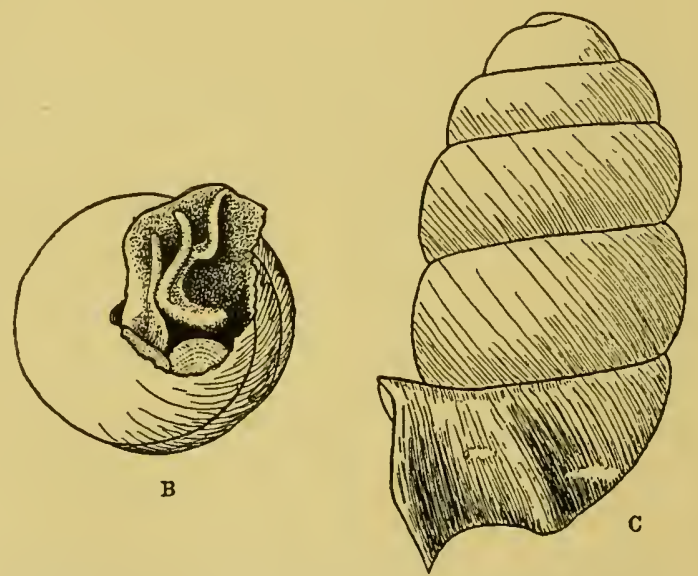

C, Page's Ranch, Oak Creek, Central Arizona.

Arizona: Coconino Co., Grand Canyon, on the Bright Angel trail about 100 feet below the rim (Ferriss and Pilsbry); Yavapai Co., Verde River, Walnut Gulch, Mescal Gulch and Kirwagen's ranch, all near Jerome, and along Oak Creek at Owensby's and Page's ranch; along the Santa Fe R. R. at Holbrook, Navajo Co., and Navajo Springs, Apache Co. (Ashmun); Cochise Co., in the Chiricahua range in White Tail Canyon below the mouth of Indian Creek and on Limestone Mountain (Ferriss and Pilsbry); Ash Canon, Huachuca range (Fer- 
riss and Daniels); Nogales, S. Cruz Co. (Ashmun). New Mexico: Valencia Co., along the Santa Fe R. R., at Grants (Ferriss and Pilsbry) and San Rafael (Ashmun); Mountain Station, Oscura Mountains, Socorro Co., and White Oaks, Lincoln Co., in Central New Mexico (Ashmun); Cook's Peak (U.S. N. M.); Dripping Spring, Organ Mountains (Cockerell); Florida Mountains, Luna Co. (Ferriss and Pilsbry).

$B$. ashmuni is distinguished by the strong development of the angulo-parietal lamella, which bends far to the right at its inner end, the very deep immersion of the lower palatal and basal folds, the continuation of the columellar lamella upon the parietal wall, alongside the parietal lamella, and the longer, usually more gibbous, "neck" of the last whorl.
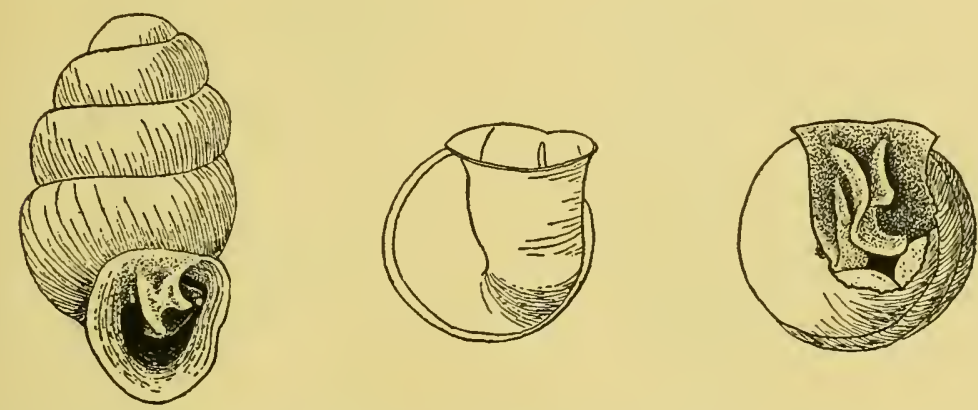

Fig. 31.-Bifidaria ashmuni minor Sterki, Nogales, Arizona.

B. ashmuni minor Sterki (fig. 31) is a small race, length about 1.6 mm., with 4 to $4 \frac{1}{2}$ whorls, found at Nogales, Arizona, and also on the Mexican side of the international boundary. The aperture is substantially like that of ashmuni.

Bifidaria cochisensis n. sp. Figs. 32,33 .

The shell is slightly tapering cylindric, like $B$. ashmuni, but the last whorl is less protracted and the crest or wave behind the aperture is very low, often not noticeable. The peristome is continuous as a slightly raised thread across the parietal wall (or in a less developed form it is rather widely interrupted above). Lamellæ weaker than in typical B. ashmuni, especially the angular lamella, which is straighter; parietal lamella less curved at its inner end. Columellar lamella wide and horizontal, not continued upon the parietal wall. Basal and lower palatal folds less deeply immersed than in B. ashmuni, readily visible in the mouth, the basal fold small. 
Length 2.5, diam. 1.1 mm. ?
“
2.2 ,
2.15
1.1
" $\}$
Cotypes, Tanner Canyon, fig. 32.
“
1.1
Santa Rita Mountains, fig. 33.

Southeastern Arizona: Chiricahua Mountains, White Tail Canyon; Summit of Cross J Mountain, Big Emigrant Canyon (Ferriss and Pilsbry). Huachuca Mountains, Tanner Canyon, 6,000 feet (Ferriss, type loc.). Santa Rita Mountains (Ashmun).
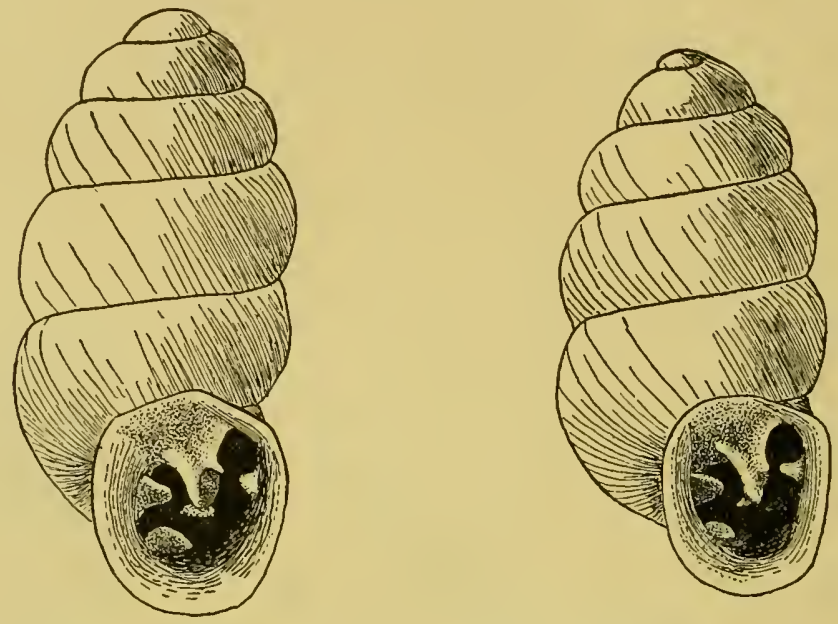

Fig. 32.-Bifidaria cochisensis P. and F. Types from Tanner Canyon, Huachuca Mountains.

The absence of a forward continuation of the columellar lamella on the parietal wall, between the parietal lamella and the columellar wall, is the most prominent feature of this species, though it has several other constant, if less conspicuous, differential characters. It is decidedly less aberrant than $B$. ashmuni, the lamellæ and folds, as well as the less protracted last whorl, approaching the normal Bifidaria type.

A modification of $B$. cochisensis also occurs in the Huachucas at Tanner Canyon and in the Chiricahua range on Limestone Mountain. The shell is smaller than usual in cochisensis, about 1.9 or $2 \mathrm{~mm}$. long. The teeth are much weaker, especially the angular lamella. The inner end of the parietal lamella is not much curved and is reaclily visible in an obliquely basal view in the aperture. The basal and palatal folds are less deeply placed, the lower palatal being visible below the apex of the parietal barrier in a front view. The basal 
fold is very small. The upper margin of the peristome is adnate for some distance. In this form, or race, if such it proves to be, $B$. ashmuni cochisensis makes its nearest approach to $B$. dalliana and to the following race.

Possibly Dr. Sterki at the time of his original description had cochisensis before him, together with typical ashmuni, since he mentions specimens from the Santa Rita Mountains. We have examined a lot collected by Mr. Ashmun at that place and find them all to be cochisensis. The terms of Sterki's original description apply only to the form herein defined as ashmuni, for he mentions the crest

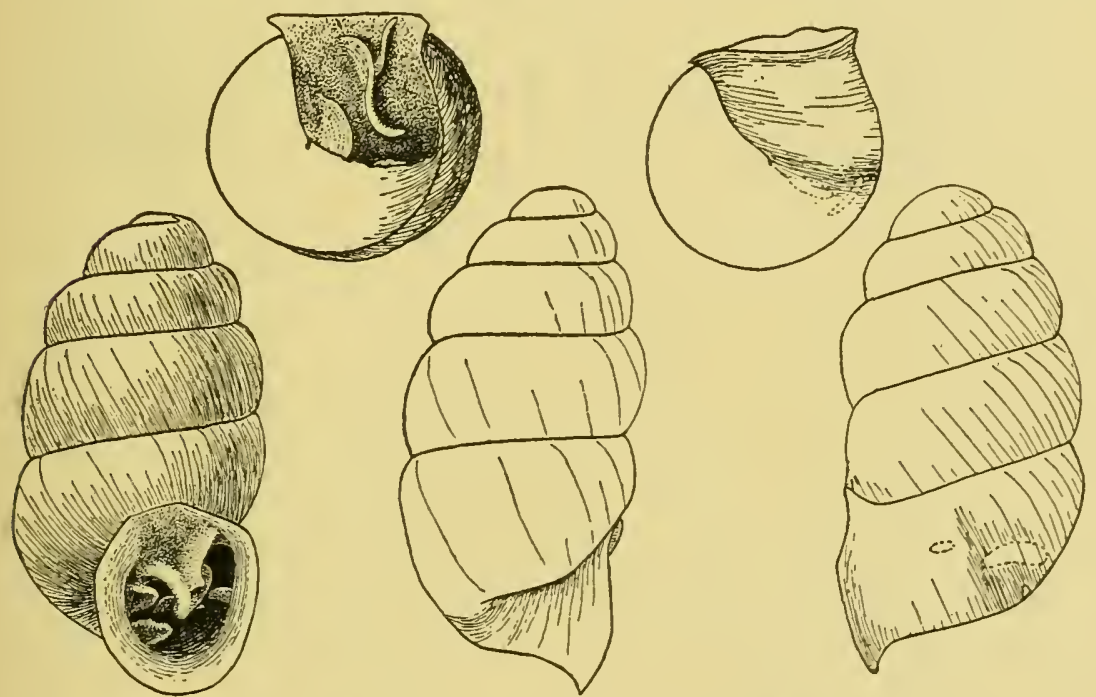

Fig. 33.-Bifidaria cochisensis P. and F. Santa Rita Mountains, Arizona.

"forming a projecting angle at the base" and the columellar lamella "ascending to the body-whorl between the parietal and columella." Careful examination of a series of several thousand examples, supplying data for the present account, has shown no intergrading forms between ashmuni and cochisensis, yet careful cleaning of the aperture is necessary for their discrimination.

Bifidaria cochisensis oligobasodon n. subsp. Fig. 34, $a, b, c$.

The shell is externally similar to $B$. cochisensis, but differs by the reduction of all the teeth. The parietal barrier is simplified (fig. $34 \mathrm{~b}$ ), and the basal fold is reduced to a minute tubercle or a mere vestige, or in a few apparently mature shells it seems to be wholly lost. Parietal margin adnate. 

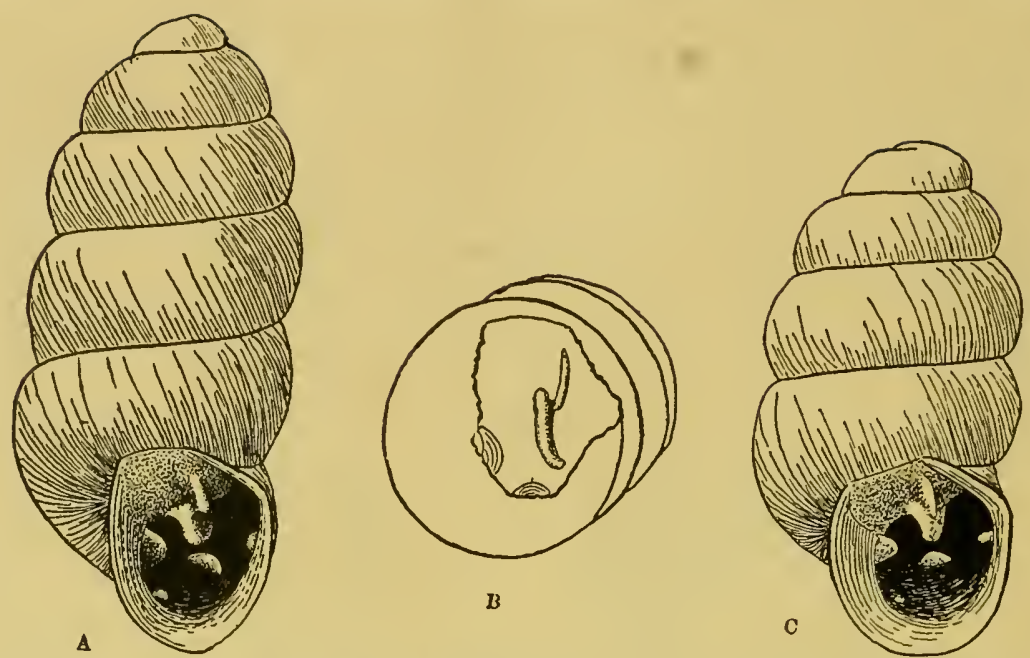

Fig. 34.-Bifidaria cochisensis oligobasodon P. and F. Ash Canyon, Huachuca Mountains.

Length 2.6, diam. $1.1 \mathrm{~mm}$.

" 2.1 , " 1 "

Ash Canyon, Huachuca range. Types No. 97,444 A. N. S. P., cotypes in Ferriss coll.

This form would be considered specifically distinct from cochisensis were it not approached by a small form of that species from Tanner Canyon, which has weaker teeth than the larger typical cochisensis. $B$. c. oligobasodon stands very near B. prototypus Pils. ${ }^{30}$ (fig. 35),
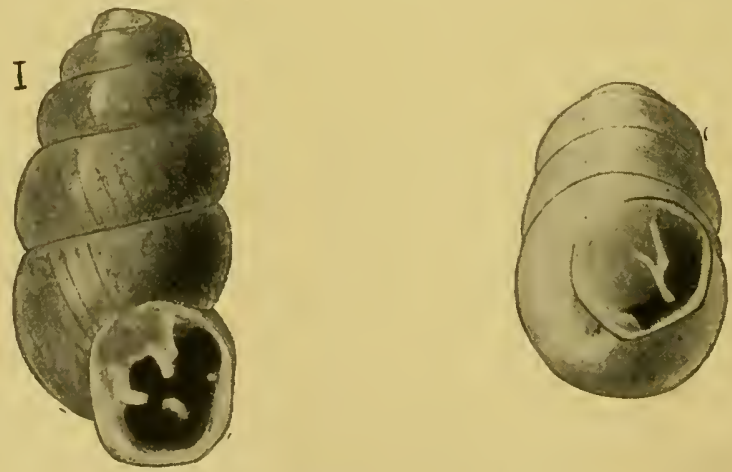

Fig. 35.-Bifidaria prototypus Pils.

${ }^{30}$ Proc, A. N.S. Phila., 1899, p. 400. 
described from the State of Michoacan, Mexico, figured here for comparison. In a long series of prototypus no specimen with even a vestigeal basal tooth was found. In view, therefore, of the very wide separation of the two forms geographically, it may be best to treat them as specifically diverse.

Bifidaria dalliana Sterki. Fig. 36 .

Bifidaria dalliana Sterki, Nautilus, XII, p. 91, Dec., 1898. Pilsbry and Vanatta, Proc. A. N. S. Phila., 1900, p. 593, pl. 22, fig. S.

Chiricahua Mountains: Quartzite Peak near Fort Bowie; White Tail Canyon in several places (Ferriss and Pilsbry); Limestone Mountain and Shake Gulch (Ferriss).

Other Arizona localities in collection A. N. S. P. are Nogales (type loc.), Santa Rita Mountains, Montezuma's Well, Salt River near Tempe, Kirwagen's ranch near Jerome; all collected by Mr. Ashmun.

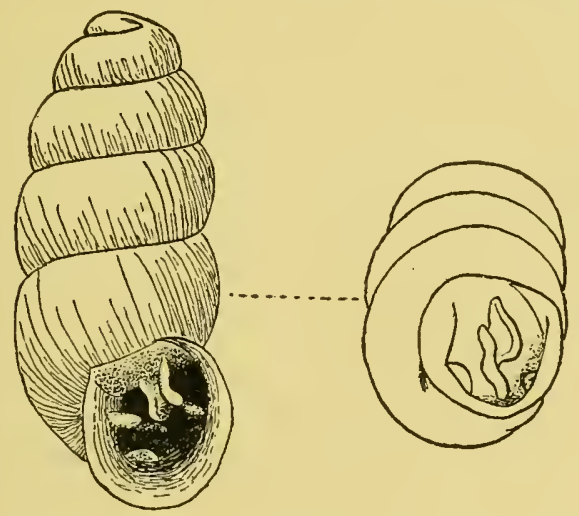

A

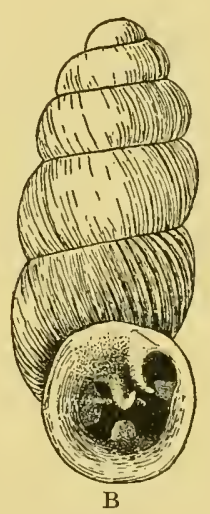

Fig. 36.-A. Bifidaria dalliana Sterki, front and obliquely basal views of a specimen from White Tail Canyon below the junction of Indian Creek, Chiricahua Mountains. B, B. bilamellata $\mathrm{S}$. and C, type.

$B$. dalliana is related to $B$. cochisensis, but differs by being conspicuously more slender, resembling B. p. hordeacella in shape, but it diverges more fundamentally by the parietal lamella, the inner end of which turns slightly toward the columella, while in B. ashmuni, cochisensis and perversa the inner end bends towards the outer wall.

In the Chiricahuas the specimens are often longer than the types, one figured here measuring $2 \mathrm{~mm}$. long, .85 wide.

Bifidaria bilamellata Sterki and Clapp stands very close to B. dalliana, but it differs by having a perceptibly more tapering spire, which is somewhat longer, and the columellar lamella has a vertical 
callus at its inner end (weaker or wanting in dalliana). The parietal lamellæ are substantially alike in the two species. For comparison we reproduce here the type figure of $B$. bilamellata (fig. $36 \mathrm{~B}$ ).

\section{Subgenus CHæNAXIS Pils. and Ferr.}

Bifidaria tuba Pilsbry and Ferriss.

A few examples were taken by Mort Wien about half a mile from Dos Cabezas Care, where it occurred with Holospira. This extends the known range of the species eastward.

Genus VERTIGO Müller.

Vertigo is a distinctly boreal element, confined in the Chiricahuas, so far as our observations show, to high levels. The species are identical with alpine forms of Colorado and Utah.

Vertigo columbiana utahensis Sterki.

Head of Cave Creek, 8,000 feet, one example.

Vertigo milium Gld.

Head of Pine Canyon, one specimen.

Vertigo modesta parietalis Anc.

Head of Cave Creek, 8,000 feet; Long Park.

Vertigo coloradoensis basidens Pils. and Van.

Rustler's Park.

\section{SUCCINEID Æ.}

Sucoinea avara Say.

Chiricahua Mountains: Cave Creek Canyon on the slope below the cave and at Station 6.

\section{BASOMMATOPHORA.}

No fresh-water snails were taken in the streams of the Chiricahuas, but Pilsbry found two species in the cienega about midway between the Chiricahua and the Peloncillo or Stein's Peak ranges: Lymnoa cockerelli Pils. and Ferr. and Physa virgata Gld. Both are widely if sparsely distributed in Arizona and New Mexico.

It is said that sometimes blind fish are washed out of the swollen springs in the ciénega when the snow melts on the mountains.

\section{PELECYPODA.}

Pisidium abditum huachucanum Pils.

Spring branch, head of Rucker Canyon, many young specimens only; Box in Rucker Canyon. 


\section{Explanation of Plates I-XiV.}

Figures 35 and $36 \mathrm{~B}$ were drawn by Helen Winchester; the other figures were drawn or photographed by H. A. Pilsbry.

Plate I-Figs. 1, 2,3-Sonorella bicipitis n. sp. Types from Station 1, Buckeye Canyon, No. 94,328 A. N. S. P.

Figs. 4, 5-S. bicipitis, Nine-mile Water Hole. Nos. 94,324 and 89,908 A. N. S. P.

Figs. 6, 7, 8, 9-Sonorella optata n. sp. Types from head of Big Emigrant Canyon. No. 94,319 A. N. S. P.

Fig. 10-S. optata-Cleft in summit between forks of Big Emigrant Canyon. No. 94,321 A. N. S. P.

Figs. 11, 12, 18, 19-S. optata. West side of Big Emigrant Mountain. No. 94,320 A. N. S. P.

Figs. 13, 14, 15, 16-Sonorella bowiensis Pils. Topotypes, from Quartzite Peak, near Fort Bowie. No. 94,327 A. N. S. P.

Fig. 17-S. optata, small form. Head of Big Emigrant Canyon. No. 99,7\$9 A. N. S. P.

Plate II-Figs. 1, 2, 3-Sonorella virilis Pils. Cave Creek, Station 11 (topotypes of var. circumstriata). No. 94,332 A. N. S. P.

Figs. 4, 5-S. virilis. Two miles up the south fork of Cave Creek. No. 94,335 A. N. S. P.

Fig. 6-S. virilis. Spring Branch near Rucker Camp, head of Rucker Canyon. No. 97,563 A. N. S. P.

Figs. 7, 8, 9-Sonorella virilis leucura $\mathrm{n}$. subsp. White Tail Canyon, Station 14. No. 99,682 A. N. S. P.

Figs. 10, 11-Sonorella micra n. sp. Station 10, White Tail Canyon. No. 94,334 A. N. S. P.

Fig. 12-S. micra. Station 17, White Tail Canyon. No. 94,330 A. N. S. P.

Figs. 13-18-Sonorella binneyi n. sp. Horseshoe Canyon.

Plate III-Fig. 1-Sonorella bicipitis Pils and Ferr. Genitalia of specimen from Buckeye Canyon. Station 3. $\times 3$. No. 94,326.

Fig. $2 \longrightarrow S$ : bicipitis. Genitalia of specimen from Nine-mile Water Hole. No. $94,324 . \times 3$.

Fig. 3-Side of the head of same specimen.

Fig. 4-S. bicipitis. Penis opened to show the papilla. Buckeye Canyon. Station 4. No. 94,325 .

Fig. 5-Sonorella binneyi Pils and Ferr. Genitalia of No. 97,414. Horseshoe Canyon.

Fig. $6-S$. bicipitis. Sole of specimen from Nine-mile Water Hole. No. 94,324

Fig. $7-S$. bicipitis. Genitalia of specimen from Buckeye Canyon, Station 1. $\times 3$. No. 94,328 (type lot).

Plate IV-Fig. 1-Sonorella optata Pils and Ferr. Genitalia of No. 94,322. Big Emigrant Mountain, $\times 3$, with details of penis, papilla and the vestigeal flagellum $(f$.).

Fig. 2-S. optata. West Side of Big Emigrant Canyon. No. 94,320. $\times 4$.

Fig. 3-S. optata. Big Emigrant Canyon, Station 1. No. 94,319. $\times 4$.

Fig. 4-S. optata. Cleft in Big Emigrant Canyon. No. 94,321. $\times 4$.

Fig. 5-S. optata. Genitilia of young snail. No.94,323. $\times 14$. Outline of penis papilla shown by broken line.

Fig. 6-Sonorella bowiensis Pils. Genitalia of a topotype. $\times 3$. No. 94,327 .

Fig. 7-S. optata. Genitalia of a nearly mature snail. No. $94,323 . \quad \times 4$. Cross J. Mountain.

Plate V-Fig. 1-Sonorella micra Pils and Ferr. Genitalia. $\times 4$. No. 94,334. From Station 10, White Tail Canyon. The penis is extended, its papilla projecting. 
Fig. 2-S. micra. Detail of same specimen showing the epiphallus extended.

Fig. 3-S. micra. No 94,330 . $\times 4$. Penis normally retracted, with detail of end of the papilla.

Fig. $4-S$. virilis Pils. Specimen from Station 11, Cave Creek Canyon. $\times 2$. No. 94,332 .

Fig. 5-Sonorella virilis lencura Pils. and Ferr. $\times 2$. White Tail Canyon, Station 4. No. 94,331. The twisted condition of the penis is an accidental or individual peculiarity of this specimen.

Fig. 6-S. virilis, $\times 2$. Cave Creek, Station 13. No. 94,335. With detail of opposite side of the ragina

Plate VI-Figs. 1, 2, 3-Orcohelix barbata Pils. An adult and two immature individuals from the head of Turkey Creek.

Fig. 4-O. barbata. Less fully scaled form with blunt periphery. Head of Rucker Canyon, Station 10A.

Figs. 5, 6, 7-O. barbata minima Pils. and Ferr. Rucker Canyon, Station $11 \frac{1}{2} \mathrm{~A}$.

Plate VII-Figs. 1, 2, 3, 4-Ashmunella lepiderma n. sp. White Tail Canyon, Station 11.

Figs. 5, 6, 7-4. lepiderma. Station 17.

Plate VIII-Figs. 1-S-Ashmunella duplicidens Pils.

Plate IX-Figs, 1, 2-Ashmunella esuritor Pils. Near Barfoot Park, Station 2. No. 92,205. Elevated specimen.

Figs. 3-Pine Canyon, No. 97,930. Elevated specimen.

Figs. 4, 5-Near Barfoot Park. No. 92,205. Depressed specimen.

Figs, 6, 7, 8-East side of Barfoot Park. No. 94,432. Diameter $16 \frac{1}{3} \mathrm{~mm}$.

Fig. 9-Ashmunella metarorphosa Pils. Aperture of type specimen. No. 88,885 .

Plate X-Fig. 1-Ashmunella chiricahuana (Dall). Falls of Cave Creek. No. 97,427 A. N. S. P.

Fig. 2-Ashmunella esuritor Pils. E. side Barfoot Park. No. 94,432.

Fig. 3-A shmunella esuritor. Topotype. No. 92,205.

Fig. 4-Ashmunella chiricahuana (Dall). Head of Cave Creek, near Long Park. No. 94,430.

Fig. 5-Ashmunella esuritor Pils. E. side Barfoot Park. No. 94,432.

Fig. 6-Ashmunella angulata Pils. Cave Creek Canyon. No. 87,020.

Fig. 7-Ashmunella ferrissi Pils. Topotype. No. 97,925.

Fig. 8-Ashmunella duplicidens Pils. Head of Morse Canyon.

Fig. 9-Ashmunella proxima emigrans Pils. Cotype. No. 99,604.

Plate XI-Figs. 1, 2, 3, 4-Holospira arizonensis Stearns. Topotypes from Dos Cabezas Cave. No. 99,700 A. N. S. P.

Figs. 5, 6, 7, 8-H. arizonensis emigrans n. subsp. Head of West branch of Big Emigrant Canyon. No. 99,701 A. N. S. P.

Figs. 9, 10, 11, 12-H. arizonensis. Form from Station 2, Big Emigrant Canyon. No. 99,702 A. N. S. P.

Plate XII-Figs. 1, 2-Holospira cionella Pils. Two cotypes. No. 87,117. A. N. S. P.

Fig. 3- H. cionella. Form from Goodwin Canyon. No. 99,710 A. N. S. P.

Figs. 4-8-H. cionella. Forms from Bull Hill, near Fort Bowie. No. 99,709 A. N. S. P.

Figs. $9,10,11,12-H$. cionella. Forms from Limestone Mountain. No. 97,424, A. N. S. P.

Figs. 13, 14, 15, 16-H. cionelln. Forms from below Paradise. No. 99, ‘26 A. N. S. P.

Plate XIII-Figs. 1, 2-Holospira cionella intermedia P. and F. White Tail Canyon, Station 4. No. 99,717. 
Figs. 3, 4,5-Holospira cionella intermedia P. and F. Types. Box Canyon of White Tail. No. 99,684

Figs. 6, 7. 8-Holospira cionella intermedia P. and F. Types. Box Canyon of White Tail, another colony.

Figss. 9, 10, 11, 12-Holospira cionella intermedia P. and F. Two forms from head of Onion Creek. No. 99,724.

Figs. 13, 14-Do. Below Station 5, White Tail Canyon. No. 99,718.

Figs. 15, 16-H. c. capillacea $\mathrm{P}$. and F. Southeast side of White Tail, below cliffs half way to summit. No. 99,727 .

Plate XIV-Figs. 1, 2, 3,4-Holospira chiricahuana ternaria n. subsp. Cave Creek, station 6 . No. 99,699 A. N. S. P.

Figs. 5, 6, 7, 8-Holospira chiricahuana Pils. Topotypes, cave in Cave Creek. No. 99,696 A. N. S. P.

Figs. 9, 10, 11, 12- $H$. chiricahuana gracilis n. subsp. Cave Creek, Station 10. No. 99,698 A. N. S. P.

Figs. 13, 14, 15-H. chiricahuana optima n. subsp. Cave Creek Station 5. No. 99,697 A. N. S. P. 


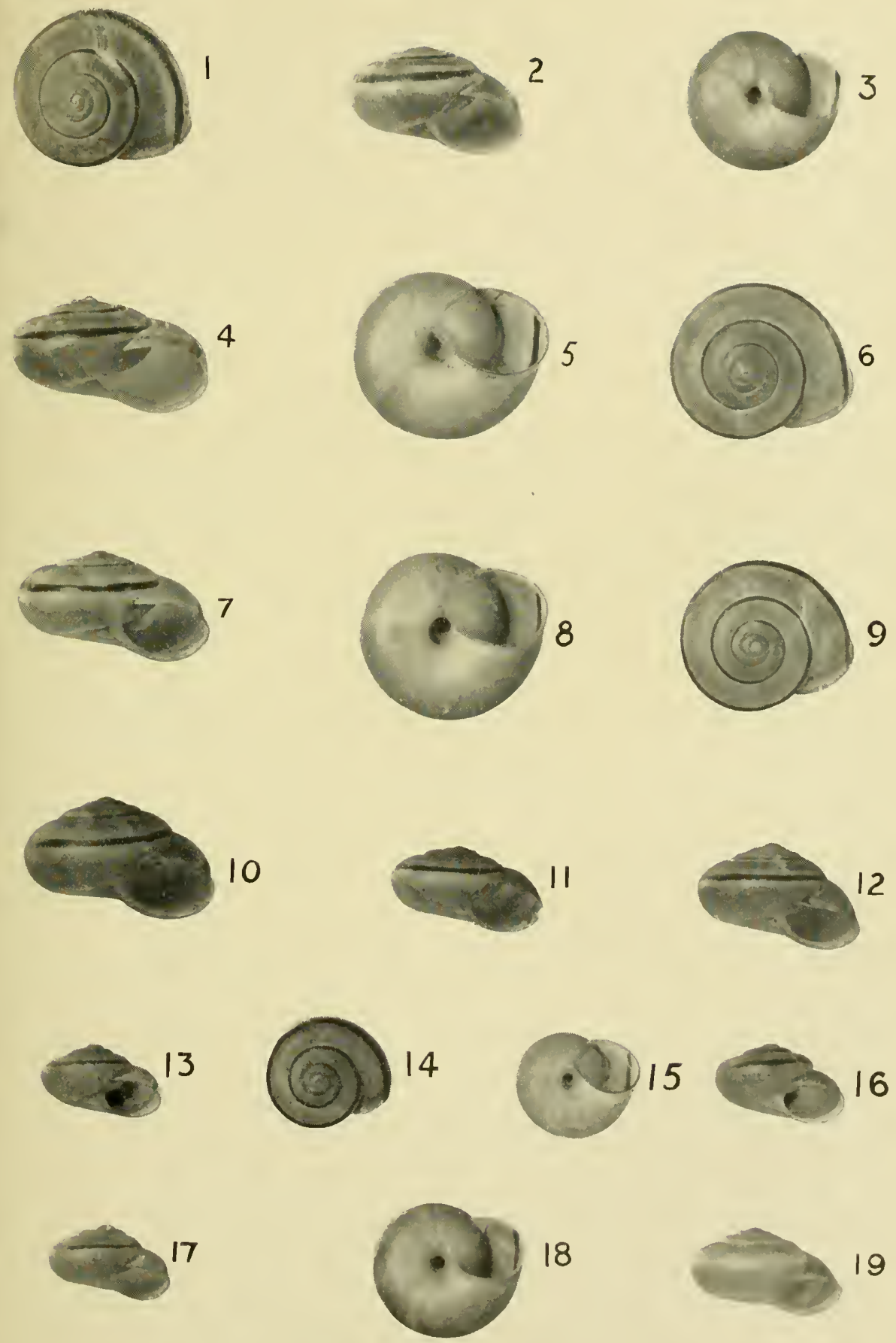

PILSBRY AND FERRISS: MOLLUSCA OF SOUTHWESTEKN STATES. 


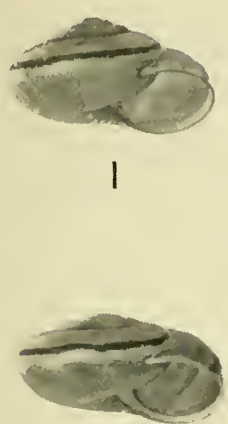

4

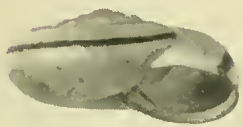

7

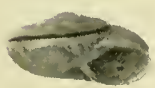

10

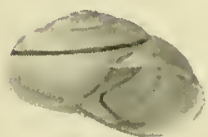

13

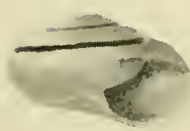

16
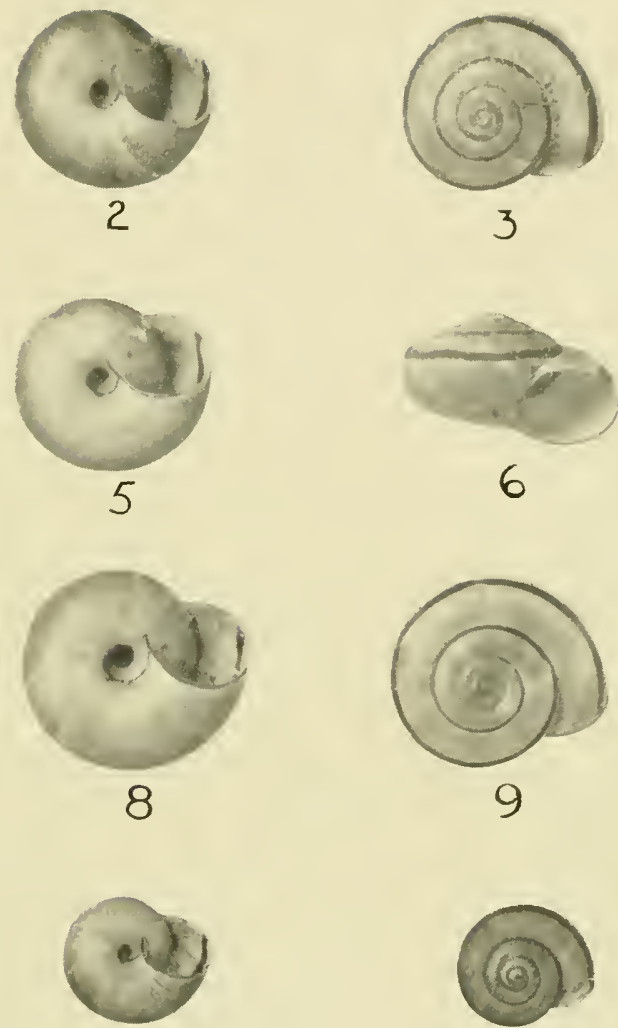

II
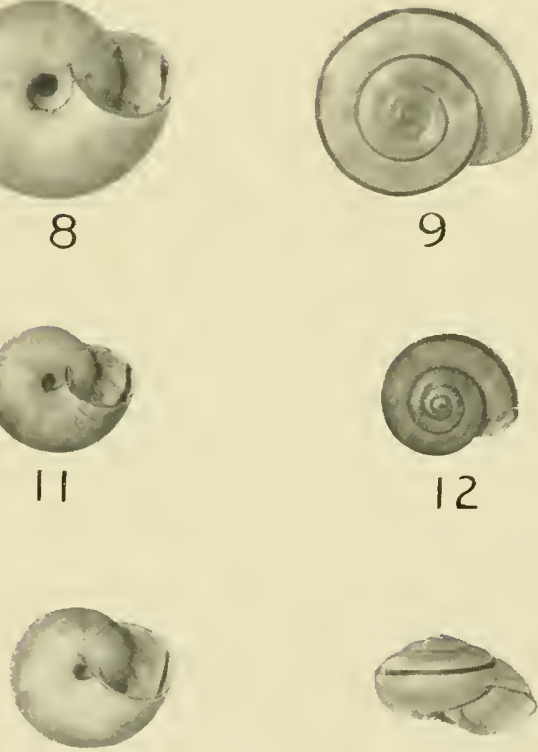

14

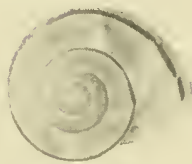

17
15
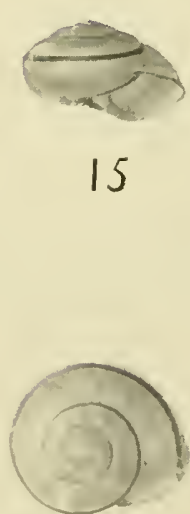

18 



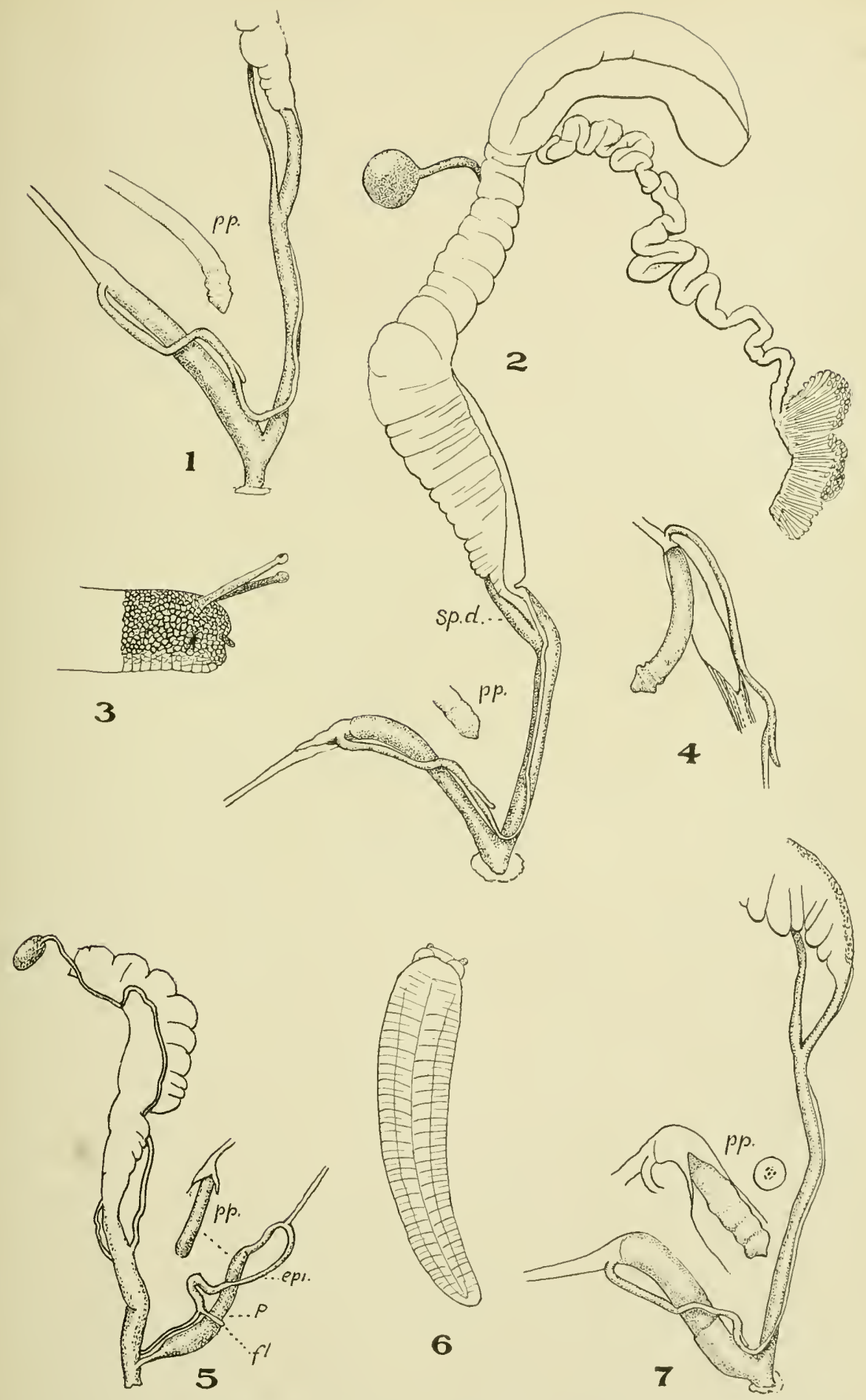

PILSBRY AND FERRISS: MOLLUSCA OF SOUTHWESTERN STATES. 



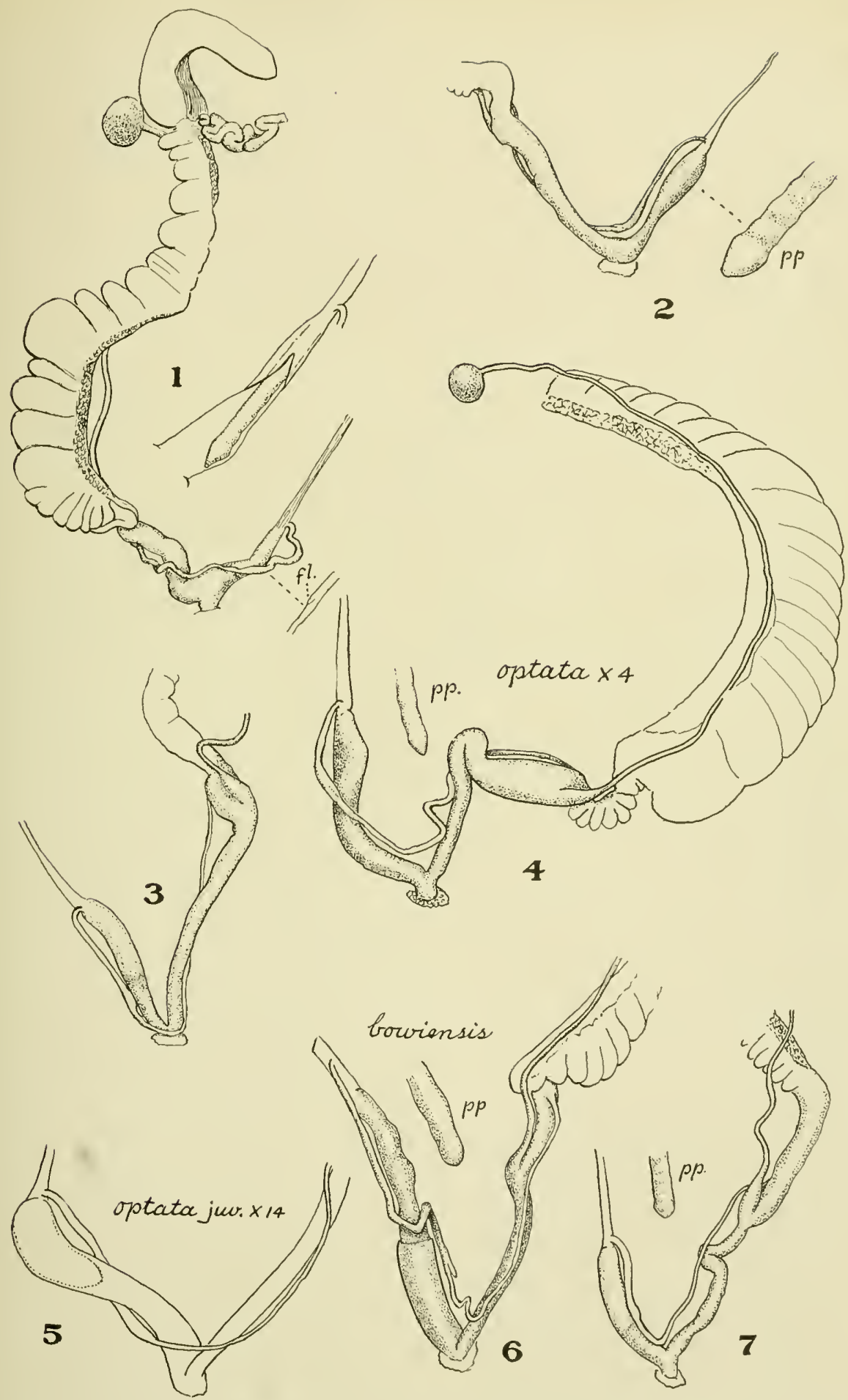

PILSBRY AND FERRISS: MOLLUSCA OF SOUTHWESTERN STATES. 


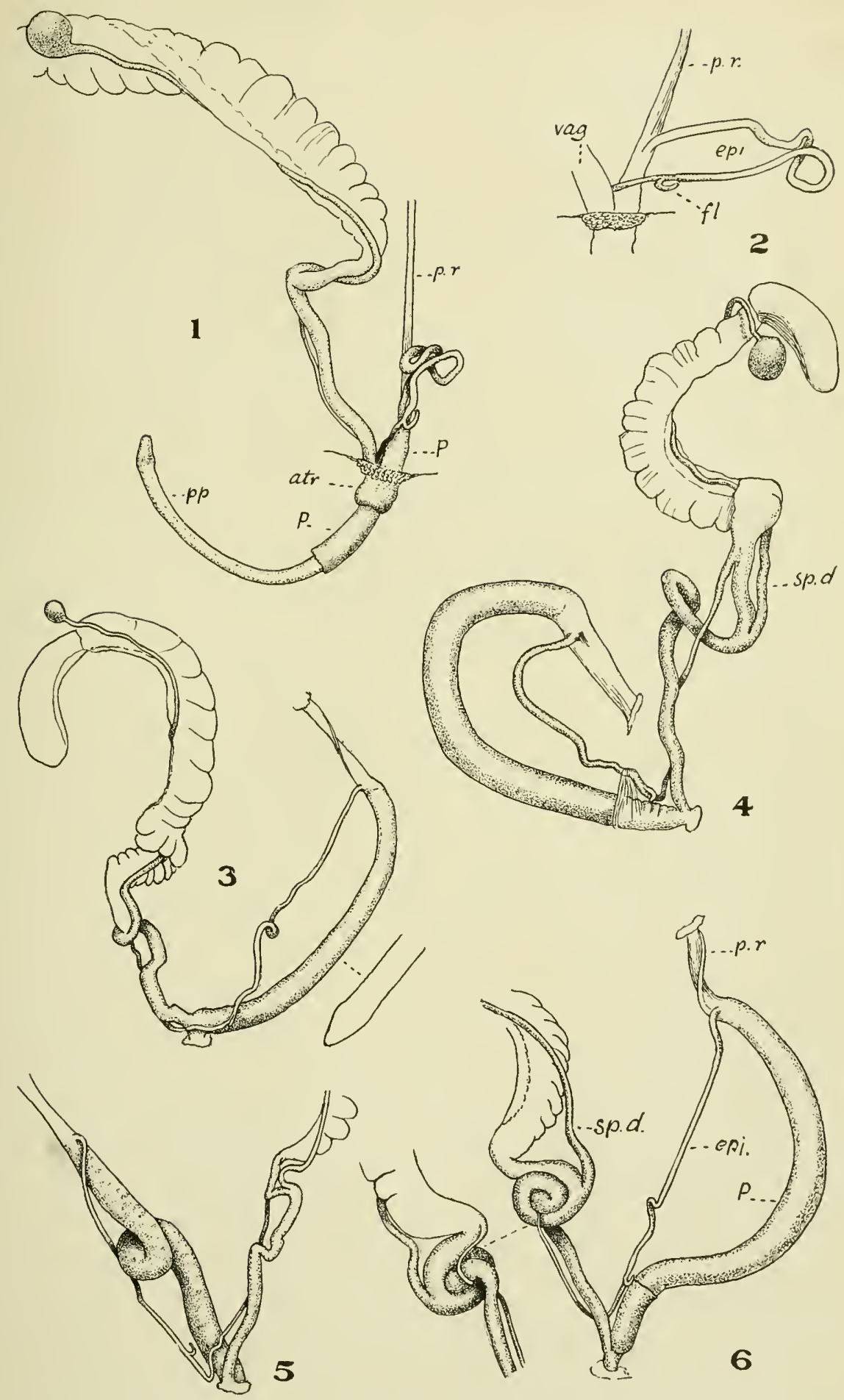

PILSBRY AND FERRISS: MOLLUSCA OF SOUTHWESTERN STATES. 


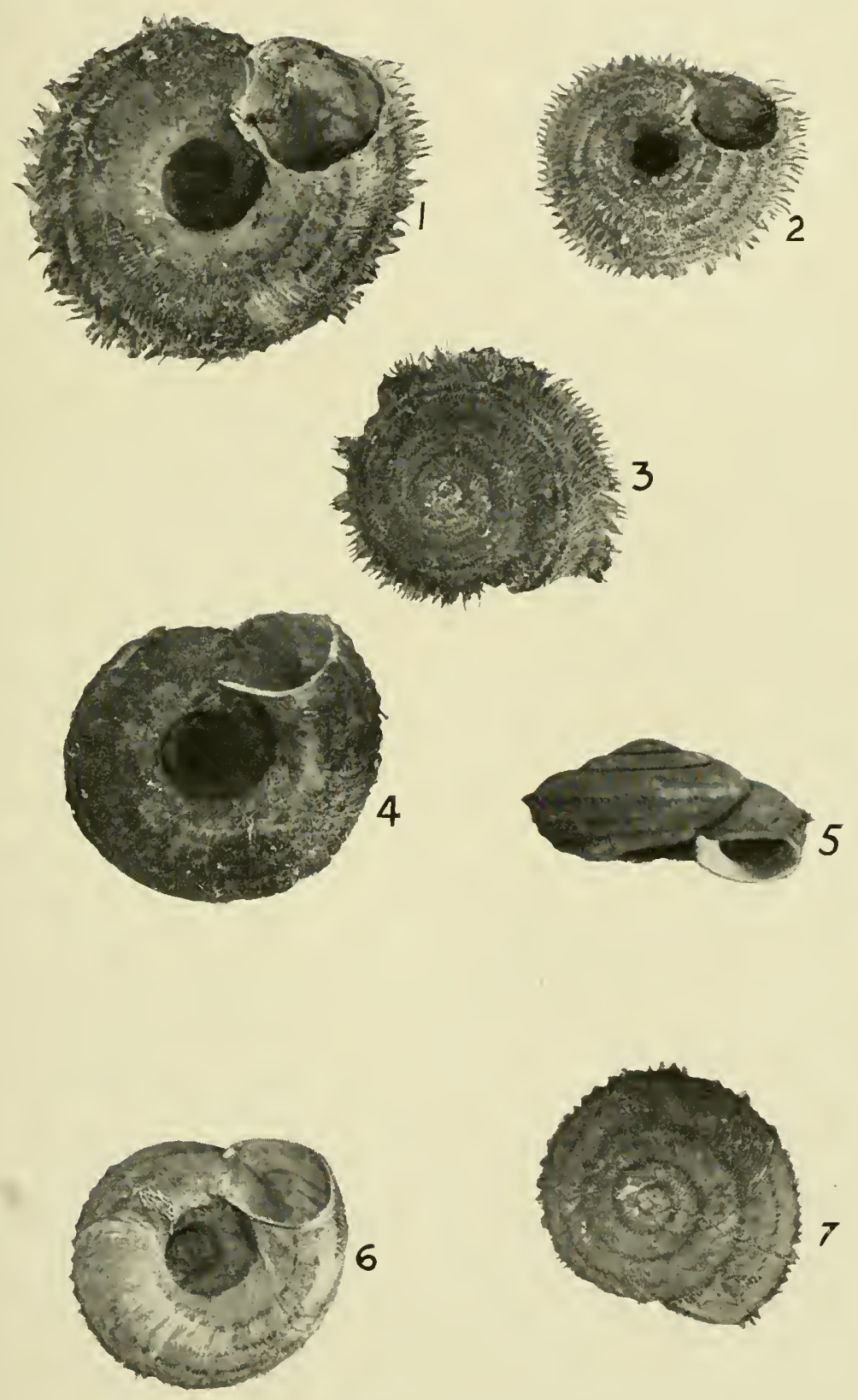

PILSBRY AND FERRISS: MOLLUSCA OF SOUTHWESTERN STATES. 


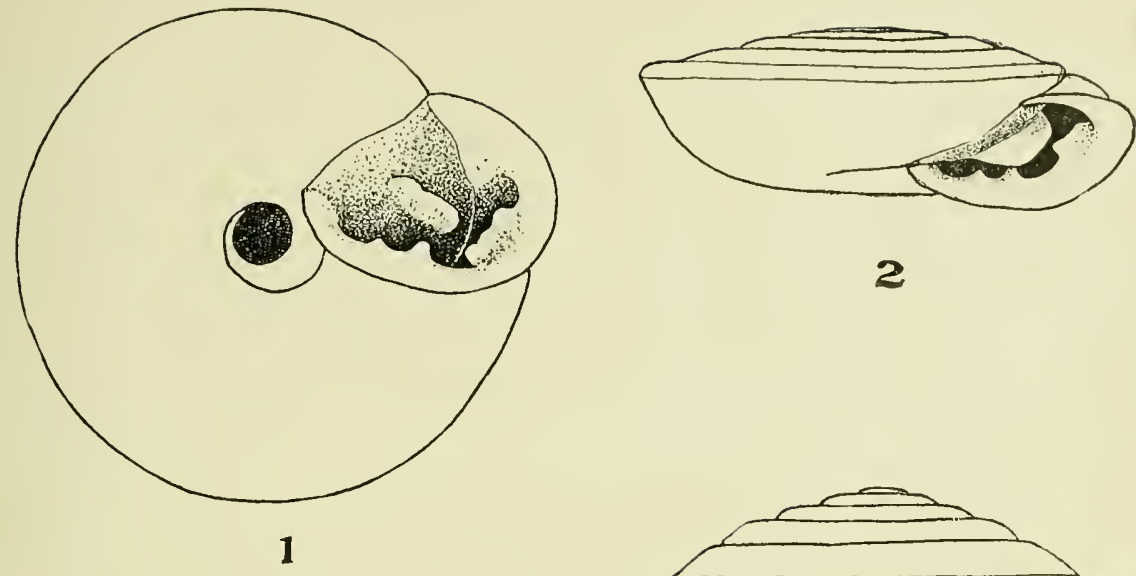

2
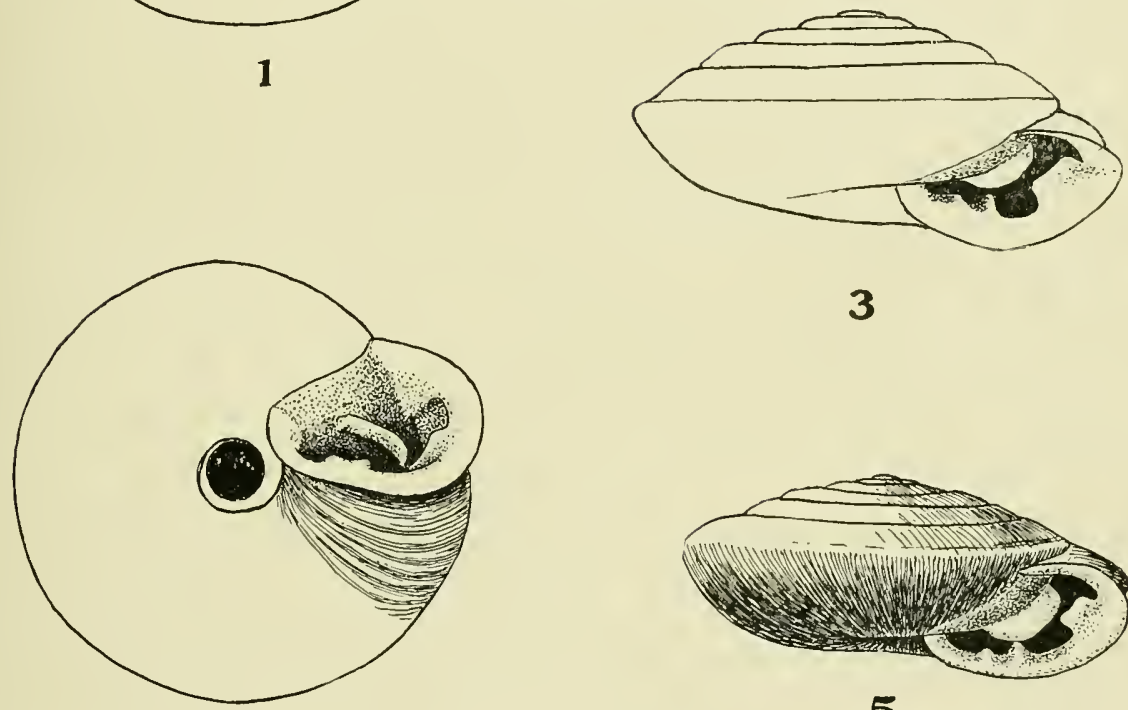

3

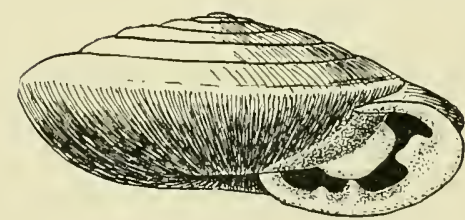

5

4
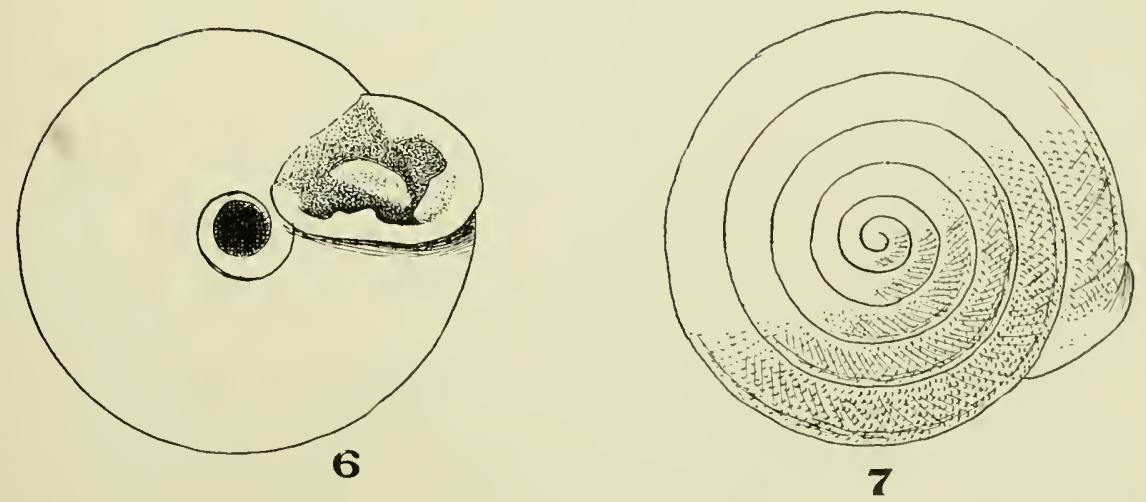

PILSBRY AND FERRISS. MOLLUSCA OF SOUTHWESTERN STATES. 


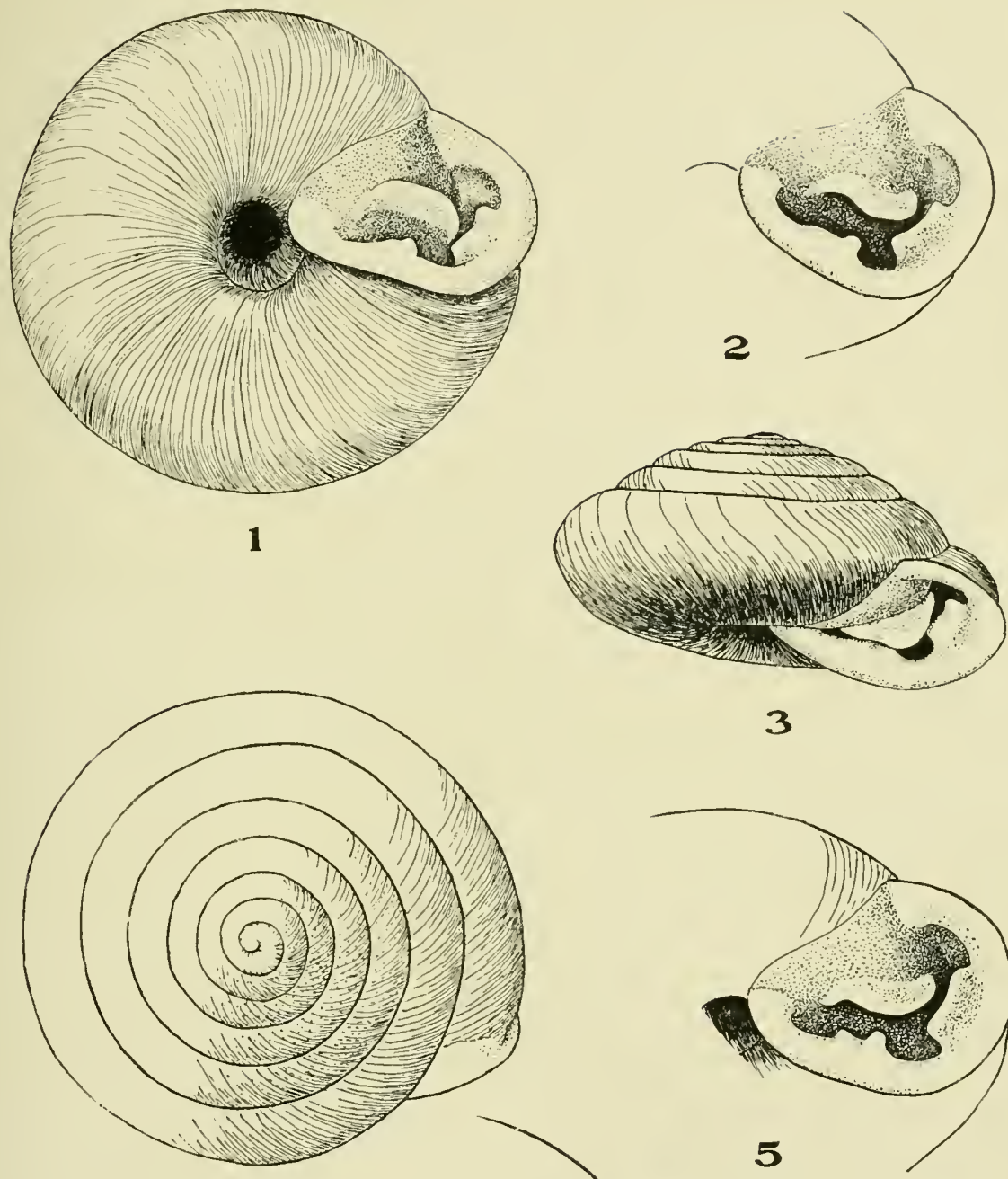

3
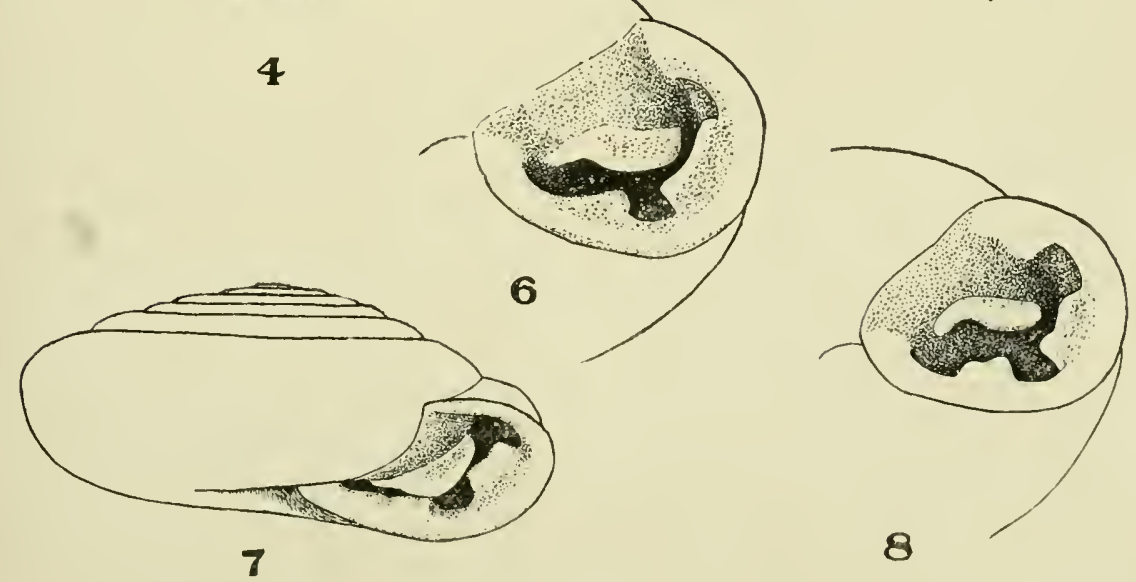

PILSBRY AND FERRISS: MOLLUSCA OF SOUTHWESTERN STATES. 


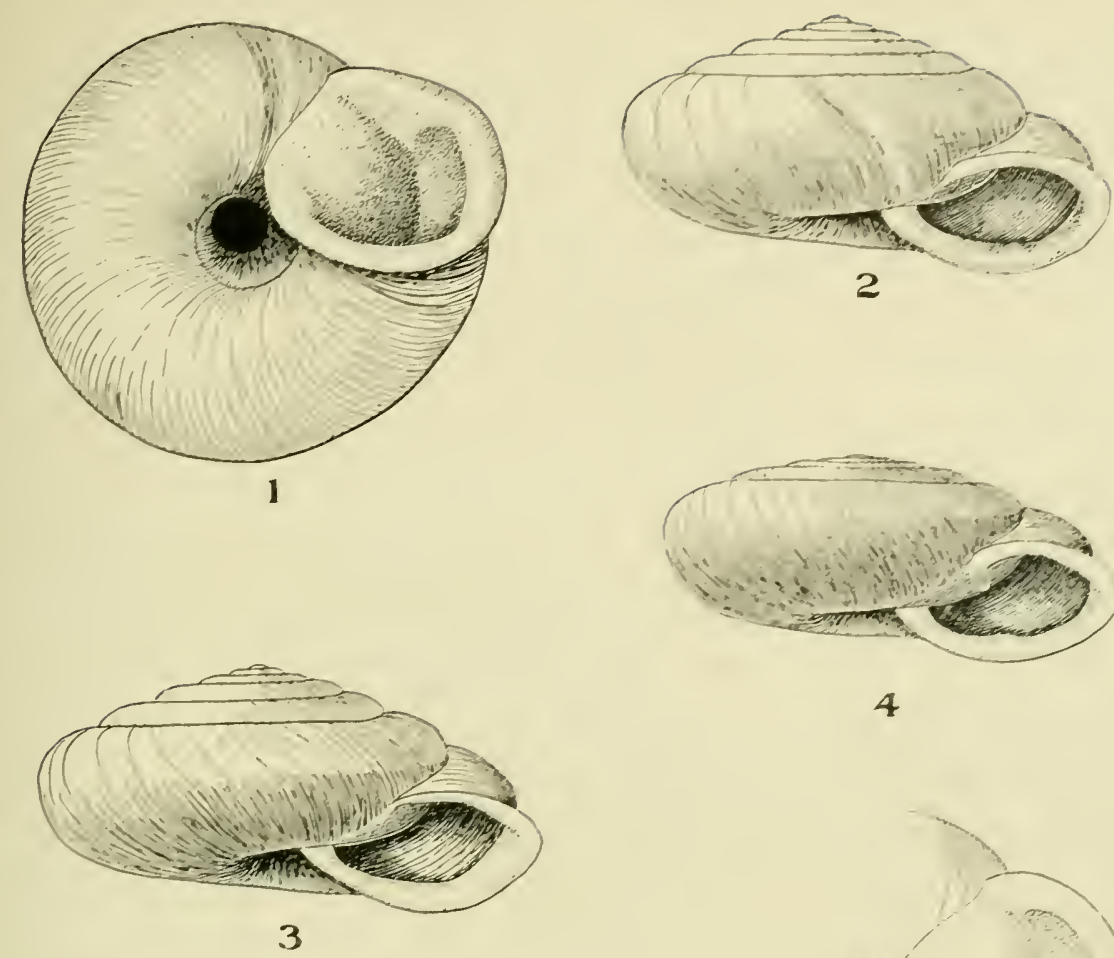

4
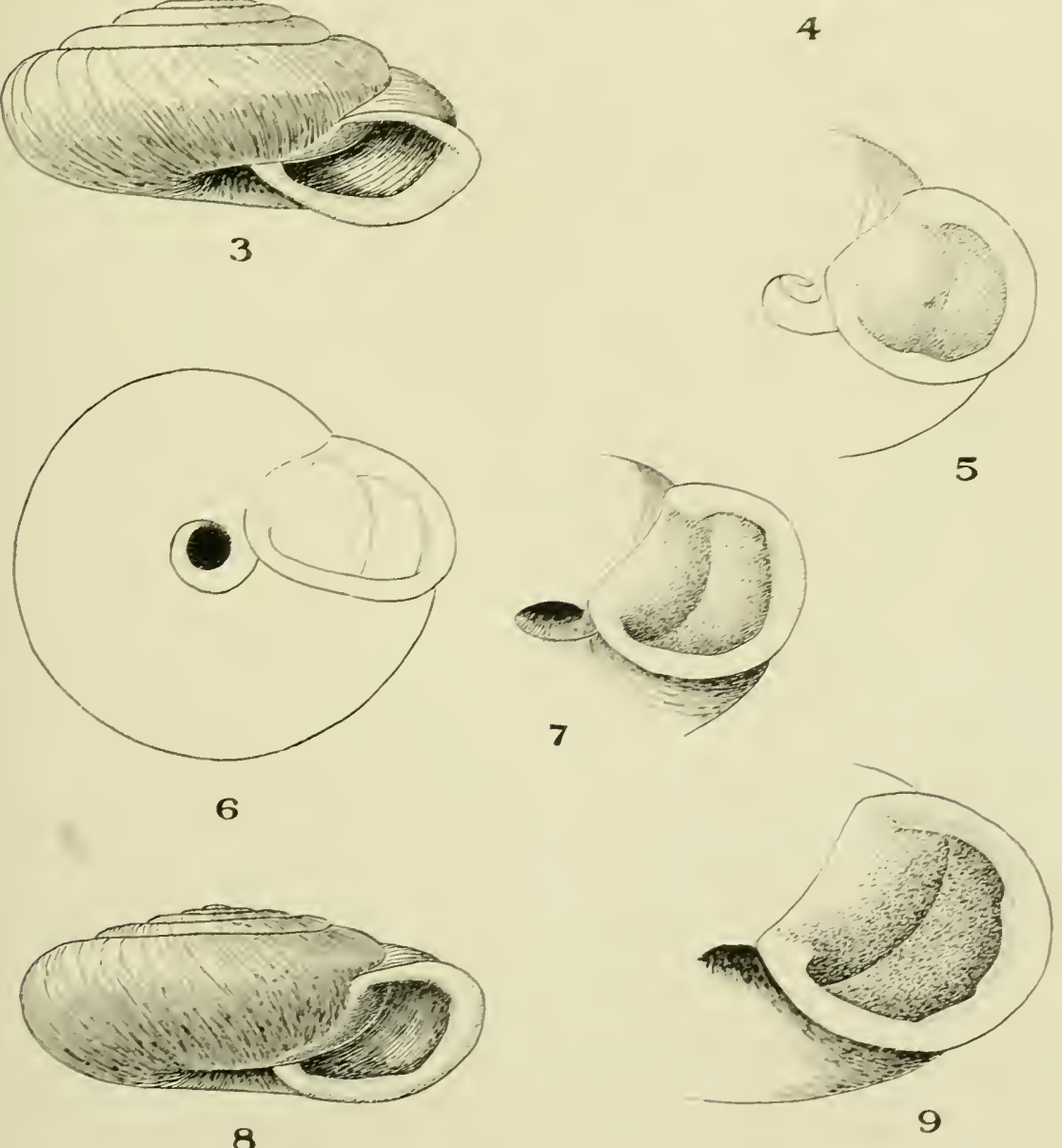

8

PILSBRY AND FERRISS. MOLLUSCA OF SOUTHUJESTERI: STATES. 



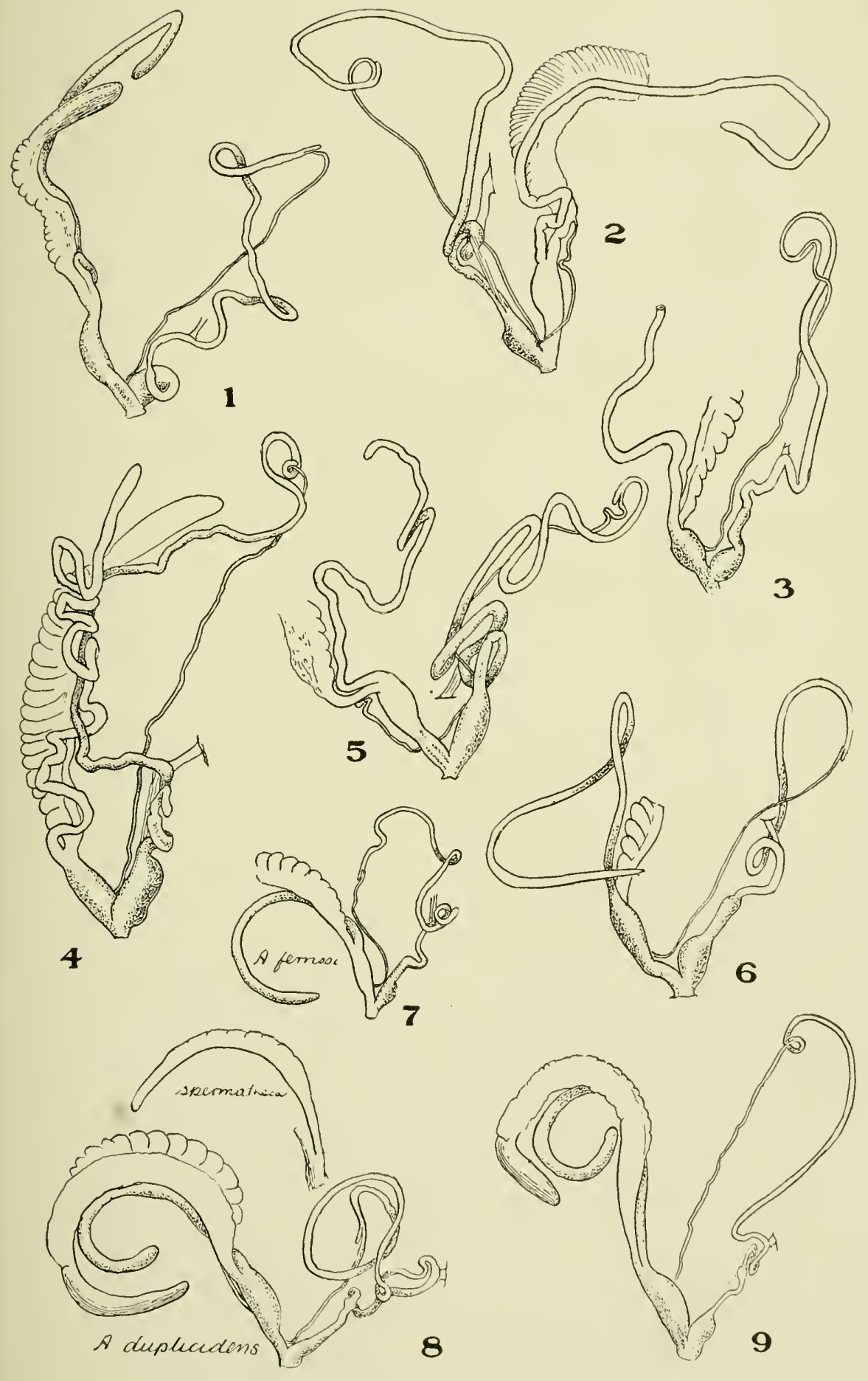

PILSBRY AND FERRISS: MOLLUSCA OF SOUTHWESTERN STA'TES. 


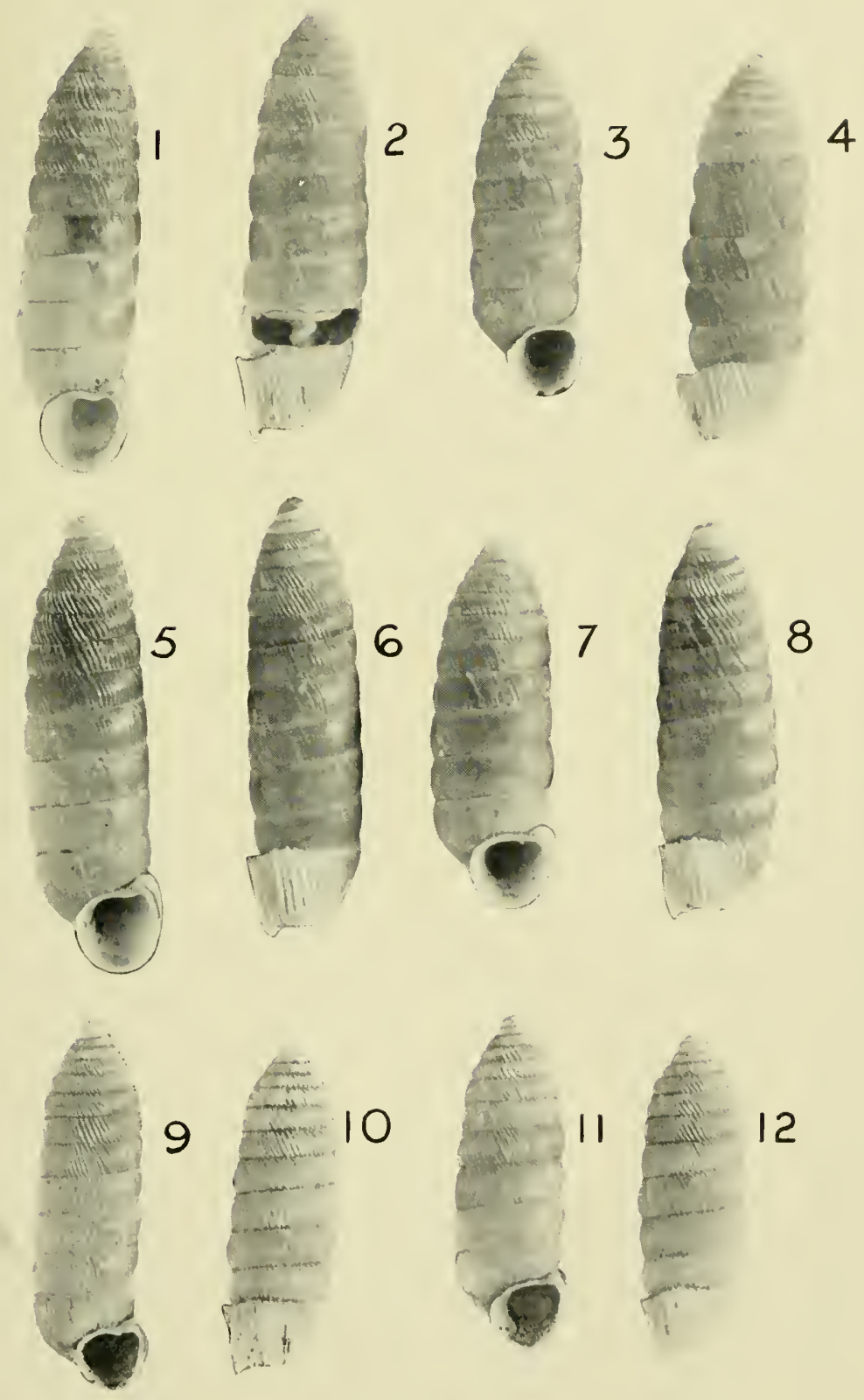

PILSBRY AND FERRISS: MOLLUSCA OF SOUTHWESTERN STATES. 


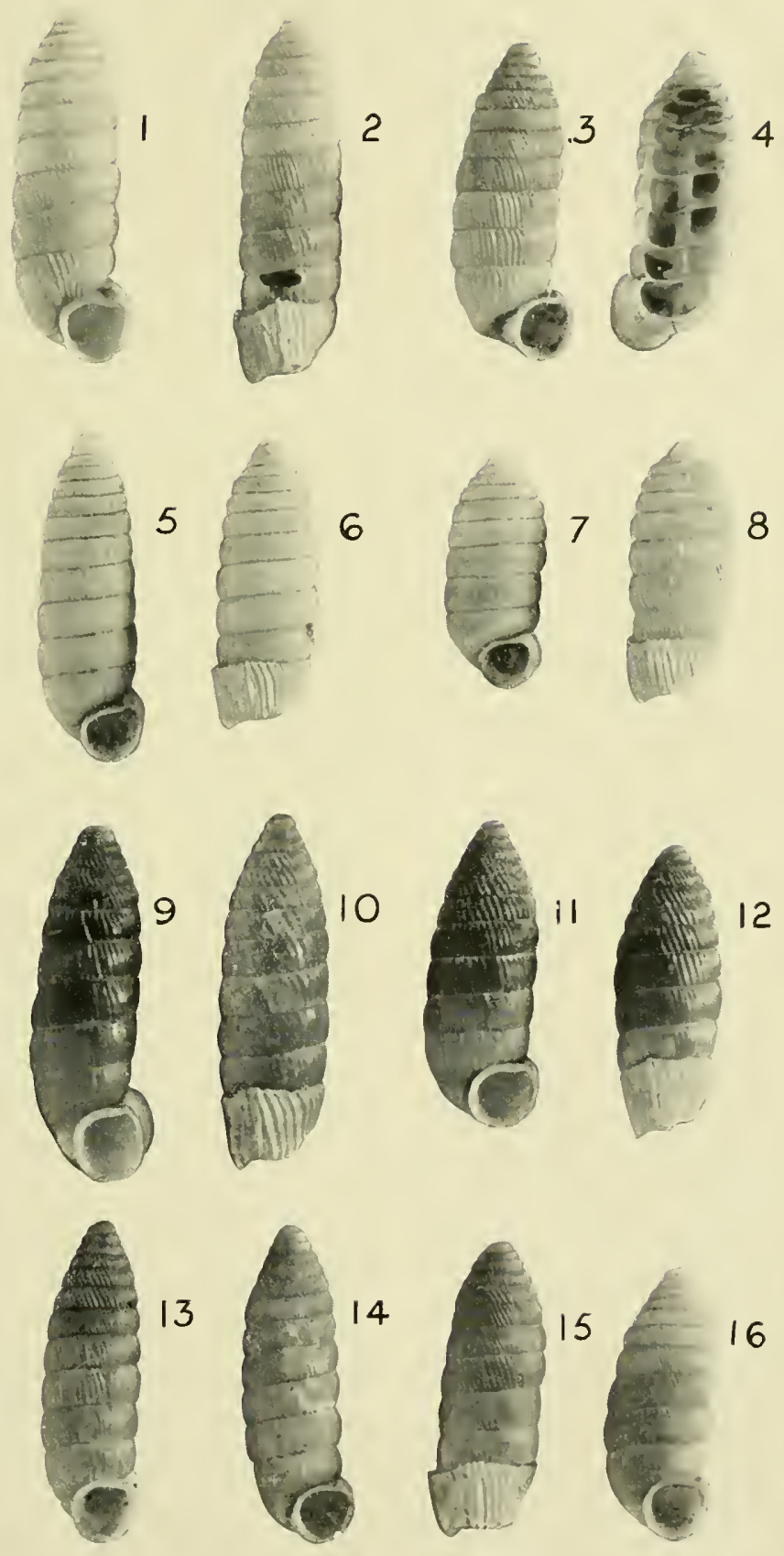

PILSBRY AND FERRISS: MOLLUSCA OF SOUTHWESTERN STATES. 


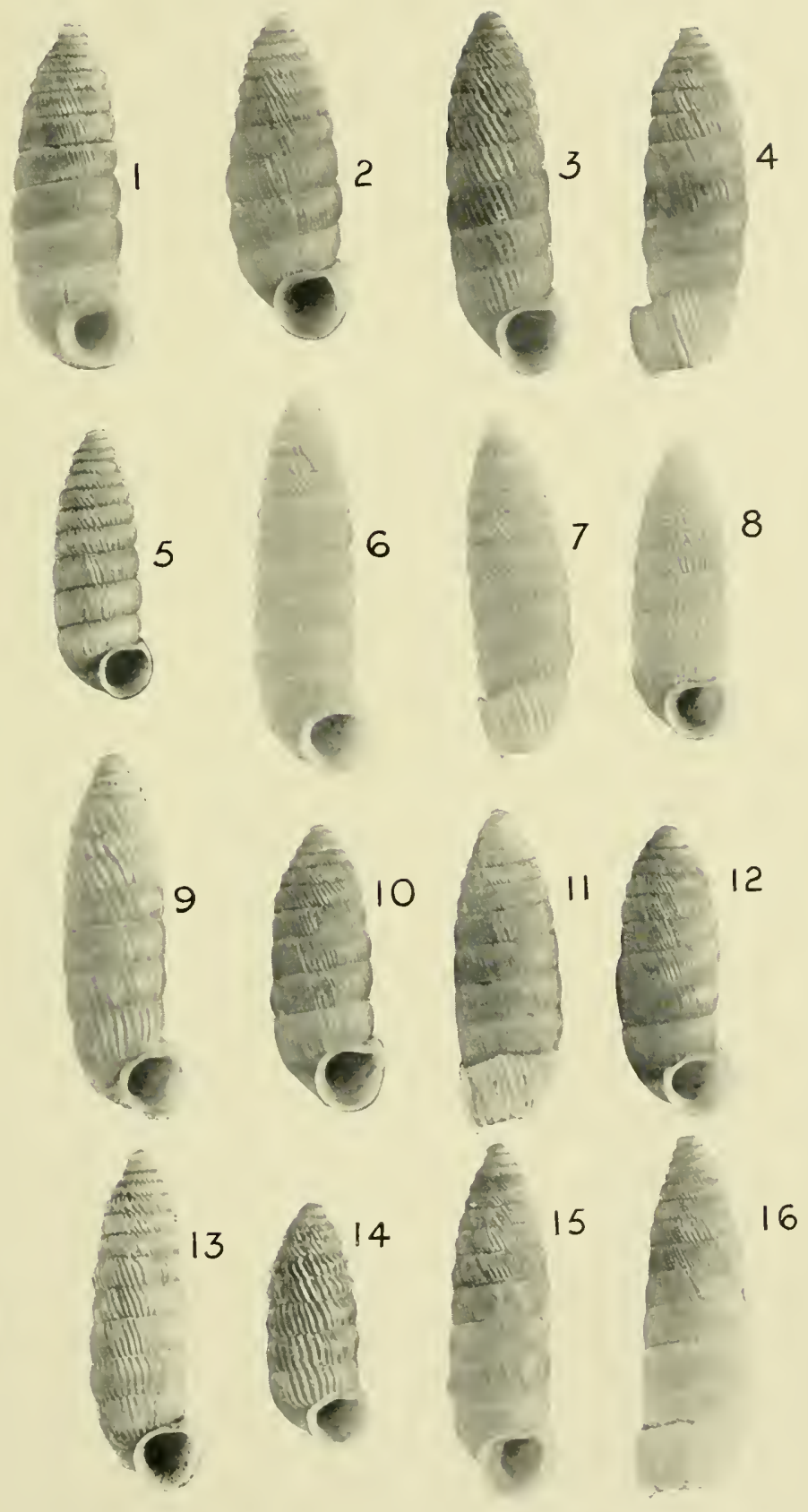

PILSBRY AND FERRISS: MOLLUSCA OF SOUTHWESTERN STATES. 


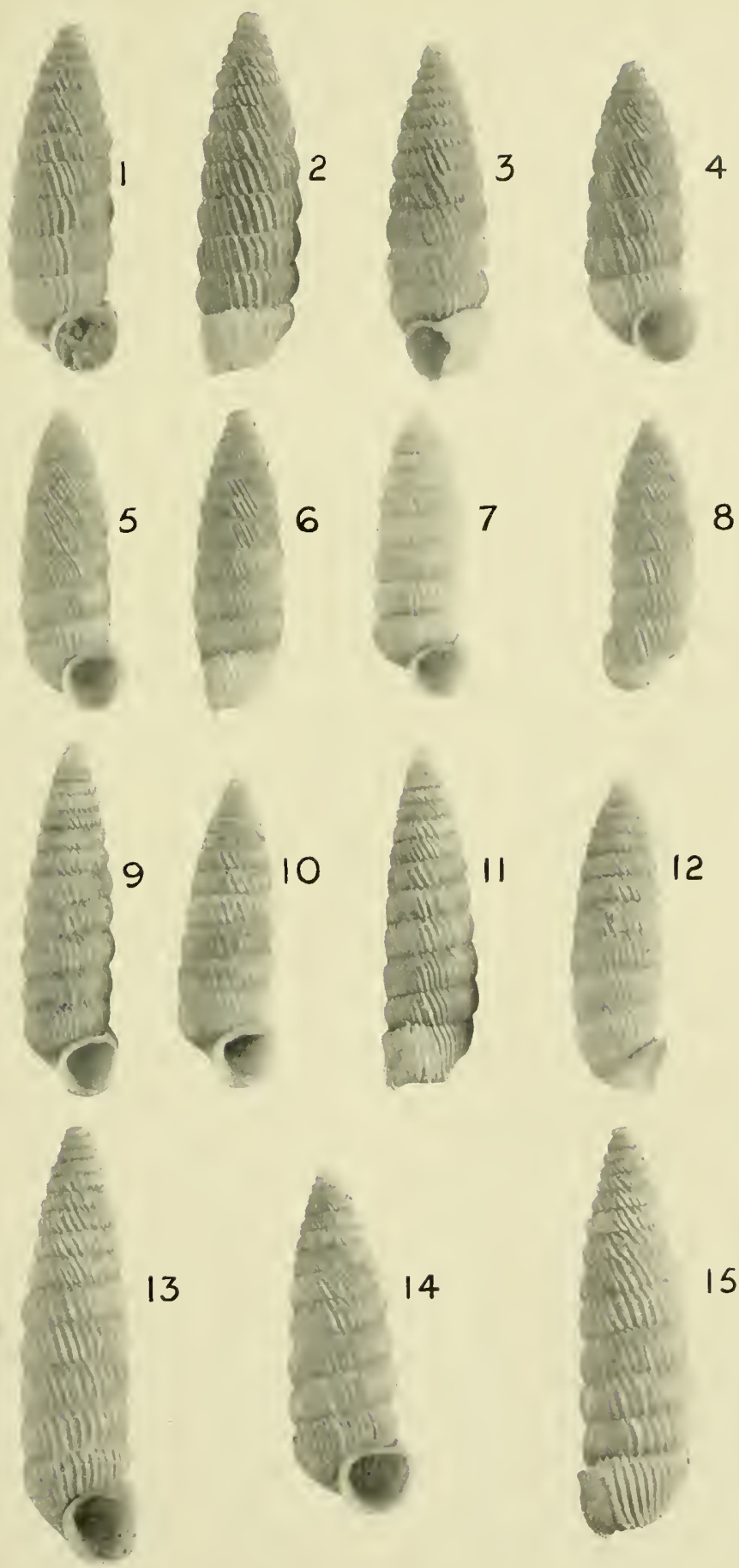

PILSBRY AND FERRISS: MOLLUSCA OF SOUTHWESTERN STATES. 



\section{Mollusca of the Southwestern States, $\mathrm{V}$ : The Grand Canyon and Northern A rizona.}

BY

Henry A. Pilsbry and James H. Ferriss.

From the Proceedings of The Acudemy of Natural Scionces of Philadelphia, March, 1911.

Issued May 24, 1911. 


MOLLUSCA OF THE SOUTHWESTERN STATES, V: THE GRAND CANYON AND NORTHERN ARIZONA.

BY HENRY A. PILSBRY AND JAMES H. FERRISS.

Prior to 1906 the work on southwestern mollusks of the mountain region had been confined to southern and central New Mexico and

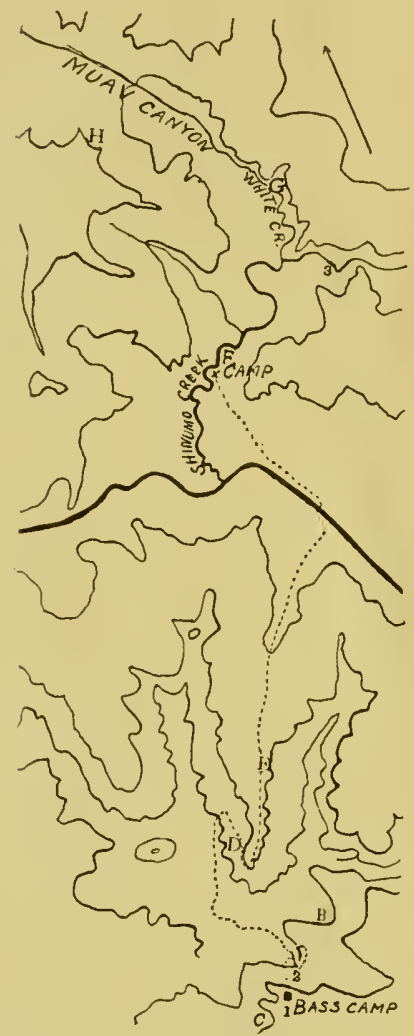

Fig. 1.-Grand Canyon in the vicinity of Bass Trail and Shinumo Creek, showing collecting stations, expedition of 1906 . Reduced and simplified from U. S. Geol. Surv. Topographic map, Shinumo quadrangle, edit. of August, 1908 .
Arizona. Between this region and the districts in Colorado and northern Utah which have been explored for snails, a great area, including the Grand Canyon of the Colorado, remained unworked. To obtain some knowledge of this region, the authors spent the month of October, 1906, in the Grand Canyon; also collecting on Bill Williams Mountain (elevation, 9,000 feet), on the plateau of northern Arizona, $6 \pm$ miles south of the Grand Canyon. In the canyon we collected at the terminus of the Grand Canyon Railroad, a branch of the Santa Fé, at El Tovar, the Bright Angel Trail, ${ }^{1}$ and at many localities reached from Bass Trail (also known as the Mystic Spring Trail), 24 miles west of the railroad, and on both sides of the river. Most of our stations here are shown on the accompanying map (fig. 1).

We did not visit John Hance's trail, the Red Canyon Trail so-called, which lies east of Grand Canyon, the railroad terminus. One species, Sonorella coloradoensis, was taken here by Dr. C. Hart Nerriam in 1589 , but otherwise the snail fauna is unknown. The Grand View Trail is also unvisited by collectors of shells. The Oreohelices and Pupillidie of the upper and intermediate slopes will doubtless prove interesting

1 We a re indebted to Dr. C. Montague Cooke, of Honolulu, for several species taken by lim at the "Indian Gardens," Bright Angel Trail. 
and well worth investigation on these two trails, both of which are easily accessible.

In 1909 (August 19 to October 25) Messrs. Ferriss and L. E. Daniels extended the work to the region north of the Grand Canyon, exploring the Powell Plateau and the western side of the Kaibab Plateau, going as far north as Kanab, Utah. A long and hard trip was also made westward to Mt. Trumbull. The route and stations are partly shown in fig. 2 . The northward extension of the route, to Fredonia, Ariz. (Station 3S), and Kanab, Utah, is not shown on the map. From Fredonia the route led southwest to Pipe Spring, Vermillion Cliff (Station 39), to Yellowstone Spring, southward across Antelope Valley (Station 40), to Mt. Trumbull, where the following stations were occupied:

43 , Base of northwestern part of mountain, 6,700 feet.

44 , Spring at northwestern part of mountain, 7,000 feet.

45, Northwestern part of mountain, 6,700 feet.

46, Hurricane Fault, 8 miles from Mt. Trumbull, 6,000 feet.

Station 41 is close to the figure 6 , on the Kaibab sheet

Fig. 2.-Part of route and collecting stations, expedition of 1909 , north of the Grand Canyon. $1000 \mathrm{ft}$. contours traced from U.S. Geol. Surv. topographic map, Kaibab sheet, edition of March, 1S\$6, reprinted January, 1900.

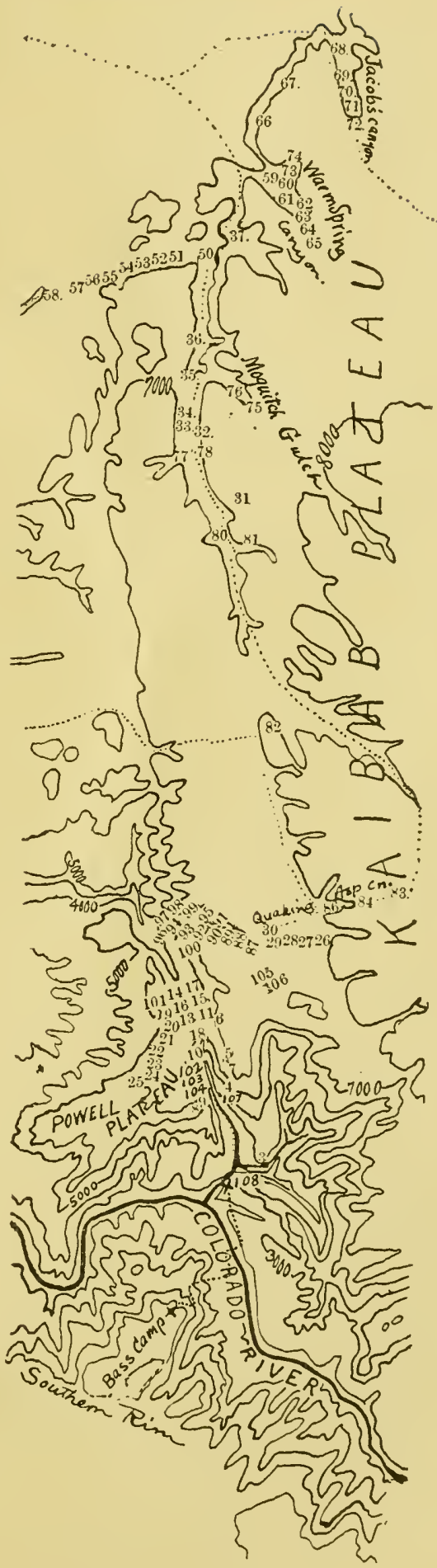


Powell Surver, long. $113^{\circ}$, lat. $36^{\circ} 2 \bar{\tau}^{\prime}$, on a limestone ridge between Finley's reservoir and Mt. Trumbull. Station 42, ant-hills on same road westward.

North of the northern rim of the Grand Canyon only one species of large size was found,-Oreohelix strigosa depressa (Ckll.); but this occurs in a multitude of colonies and in great variety of size and color. So far as we know, this form does not occur in Arizona south of the Colorado River in the Grand Canyon. The small shells are for the most part generally distributed on both sides of and in the Grand Canyon. Special to the. Grand Canyon, so far as we know, are the following forms:

Sonorella coloradoensis (Stearns).

Oreohelix yarapai, subspecies extremitatis, angelica and profundorum $\mathrm{P}$. and F.

Pupilla syngenes av'us $\mathrm{P}$. and F.

Only the first of these is generally distributed, being found on both sides of the river, and for at least 30 miles along its course; also on the plateau south of the canyon at Bass Station.

The work of collecting in the Grand Canyon is severe. The trails, except the Bright Angel or tourists' trail, are narrow and very steep. You will dig snails on taluses ending in cliffs dropping hundreds of feet; no sound comes back from the rocks your work dislodges. Also, the sandstone and metamorphic rock is hard on the hands. Oreohelix, in restricted localities, is sometimes very abundant, but Sonorella is always rare, and living ones can be obtained only by hard work. Satisfactory work along the south side can de done from the camps or hotels at the several trails. For work in the lower levels and on the north side of the river a camp outfit and pack animals are requred. These may be obtained at the Bright Angel, Bass, Grand View or Hance Trails.

The most productive horizons in the Grand Canyon are the Kaibab Limestone, which forms the slope immediately below the rim, and the talus at the foot of the Cross-bed or Coconino Sandstone, in sheltered recesses where a talus from the orerlying limestone terrain has accumulated. The deeper levels are comparatively umproductive, though Sonorella penetrates in suitable places nearly to the river.

The molluscan fauna of the Grand Canyon, with the sole exception of Sonorella, consists of species inhabiting northern Arizona on one or both sides of the canyon or of forms evidently derived from such species. It must, therefore, so far as mollusks are concerned, be considered a part of the Transition zone. Sonorella is the sole Lpper Austral genus. It inhabits both sides of the river, up to and even upon the rim. 
The canyon forms a barrier to the distribution of Oreohelix, the widely spread Arizonian species $O$. yuerepai not extending north of it, though very abundant in several subspecies on the southern side, while $O$. strigose depressa, very abundant north of the canyon, does not to our knowledge ocenr in the canyon or in Arizona south of it. Some of the smaller species may prove to be similarly restricted, but more copious data are required to prove that this is the case. The minute species, here as elsewhere, are widely distributed, probably owing to the facility with which they may be carried by cyclonic storms.

In a former paper of this series ${ }^{2}$ we cliscussed briefly the relation of descrt snails to their environments, concluding that the direct influence of desert climate had been overestimated basing this opinion upon the fact that these animals are quiescent except during the brief periods of damp or rainy weather; and accounting for the oparque and chalky textme of exposed snails as a protection against sumlight, probably bronght about by selection. A recent letter from Dr. Wm. H. Dall, giving his somewhat diverse views upon the same topic, is here printed, by permission, so that those interested in these questions from the standpoint of molluscan study may have both views before them. ${ }^{3}$

${ }^{2}$ Mollusea of the Southwestern States, IV: The Chiricahua Mountains, Proc. Acad. Not. Sci. Phila., 1910, pp. 47-50.

3 "In regard to direct action of sunlight and other factors of elimate on desert snails (among which I reckon only those really exposed to it, and not those like Astimunelle, which by descending into the rork piles reach a moderately humid clinate), my reasoning would be something like this: We know irritation of the surlace in snails causes exudation of mucous matter (mixed with lime in the case of shell bearers), which tends to thicken and incidentally to contract or corrugate new growth, this irritation may be alkali in lresh waters, sand or infusoria in pearl oysters, alkali dust on arid windy volcanie islands, like the Galapagos or st. Helena, and seorching sunlight in desert places. Now the first result would be to thicken the shell and exclude the irritant, otherwise the animal will die. Assuming that before reaching the point of absolute exhaustion the amount of mucus has a limit, this means a retardation of growth in the spiral direction, and if (assuming that the color glands ha ve also a linited amount of color to give the general serretion) it would be, in the case cited, abnormally diluted; with the result that the shell would tend to be whiter than the normal, not as a protection, but because of the dilution. This explains the white Bulimini, Clausilias and Pupas, so conspicuous on hot rocks in south Europe. Then comes in Natural Selection by killing off those which dicl not or could not sufficiently thicken themselves to ward off the light, and you have by the most simple direct action, without any heredity being ealled into play (unless through some transmission of acquired characters, wlich I regard in this case as very doubtful) all the characteristics of desert snails over the whole world developed in the individual by direct action.

"In the Galapagos snails the young nepionic whorls a re normal, and I believe would continue so except for the direct action of the environment. This affects those on the ground, grass and low shrubs. Those living on the higher trees escape (by my hypothesis) the dust and eontinue or remain nonnal in their growth." 


\section{List of Species.}

\section{HELICID $\approx$.}

Sonorella coloradoensis (Stearns). Pl. XII, figs. 26-30.

Helix (Arionta) coloradoensis Stearns, Proc. U. S. Nat. Mus., vol. XIII, p. 226 , pl. 15 , figs. 6, S, 12,1890 .

Sonorella coloradoensis Stearns, Pilsbry, Proc. Acad. Nat. Sci. Phila., 1900, p. 560. 1901. Bartsch, Smithsonian Misc. Coll., vol. XLVII, p. 1S9, pl. 32 , fig. 3 (shell of type), 1904 .

The type specimen of this species measures: alt. 10, diam. $16.4 \mathrm{~mm}$, umbilicus about $1.8 \mathrm{~mm}$. The locality given by Stearns and repeated by Bartsch, ${ }^{4}$ Grand Canyon of the Colorado opposite the Kaibab Plateau, alt. 3,500 feet, is somewhat indefinite, on account of the considerable extent of the Kaibab Plateau. Dr. C. Hart Nerriam, to whom we applied for further details, writes: "I collected the type of Helix coloradoensis Stearns in September, 18s9, in the Grand Canyon below the tank then known as Canyon Spring, not far from where John Hance afterward built what is known as the Hance Trail. At that time neither the Bright Angel nor Bass's Trail had been heard of."

This locality is, properly speaking, opposite what is now known as the Walhalla Plateau, not the Kaibab Plateau. ${ }^{5}$ As the river flows, it is about 13 miles east of the Bright Angel Trail, and 30 miles east of Bass's Trail. Owing to the sinuosity of the sides of the canyon, the actual distance along any level above the river gorge and below the rim would be at least three or four times as great.

The specimens,from the Bright Angel and Bass's Trails and from the north side differ from the type by having the umbilicus slightly larger.

The soft anatomy of the type was not described. One of us has dissected specimens from both sides of the river at Bass's Trail. The genitalia of a shell from "Spectacle Cove" (Station A) figured (fig. $3 \mathrm{~A})$ show the species to be a true Sonorella, related about as nearly to the forms found in the region immediately south of Tucson, as to any southern species. The penis $(p$. $)$ is swollen distally, narrow in its basal half, where it is enveloped in a rather long muscular sheath. It contains a tapering papilla (p.p.), not quite half as long as the penis. The epiphallus (epi.) is about equal to the penis in length, slightly larger than the vas deferens. There is no flagellum. The penis

- The localities for S. coloradoensis in Inyo and San Diego Counties, California, which Dr. Bartsch eredits to Pilsbry and Johnson, were taken by them from a paper by Dr. Stearns, Nautilus, VIII, p. 29. This paper was not noticed by Dr. Bartsch, who has shown that the shells in question are not $S$. coloradoensis.

'See U. S. Geol. Survey Topographic Map, Vishnu Quadrangle. 
retractor muscle inserts on the epiphallus. The vagina is rather short and slender. Atrium longer than usual in Sonorella. Length of the penis, $4.5 \mathrm{~mm}$; penis-papilla, $2 \mathrm{~mm}$.; vagina, $3 \mathrm{~mm}$.; spermatheca and duct, $21.5 \mathrm{~mm}$.
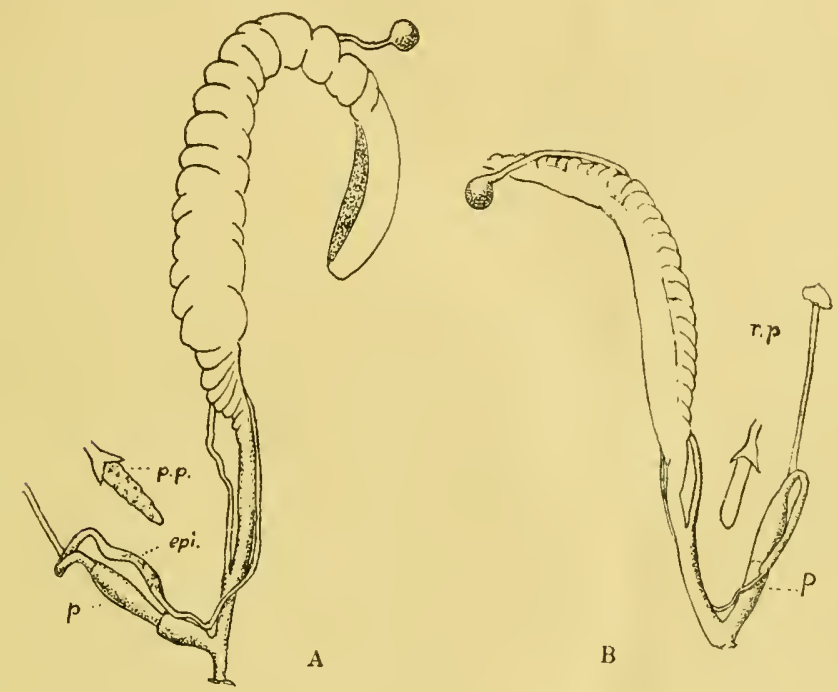

Fig. 3.-Genitalia of Sonorella coloradoensis. A, Spectacle Cove. B, bandless form from White Creek, Station G.

A specimen of the bandless form from White Creek, a branch of Shinumo Creek, shows only slight differences in the genitalia from the "Spectacle Cove" form. The atrium is shorter; penis-papilla more cylindric and blunter. Length of penis, $5 \mathrm{~mm}$; epiphallus, $4.7 \mathrm{~mm}$; penis-papilla, $2 \mathrm{~mm}$.; vagina, $3.5 \mathrm{~mm}$.

While $S$. coloradoensis seems to be generally distributed in the Grand Canyon, the colonies, except near the rim, are isolated and mostly small. Except during wet weather, the snails adhere to eruptive or metamorphic rocks, making white circles thereon like other Sonorellas. Specimens were taken by us at the following places:

(South side of the Colorado River.)

(1) Bass's Station, on the Grand Canyon R. R., about four miles south of the Grand Canyon. The shells vary from alt. 10.5, diam. 16 mm., to alt. 9.8 , diam. $15 \mathrm{~mm}$.

(2) Upper talus along the Bright Angel Trail from 100 to 400 feet below the rim. The specimens are like those from spectacle Cove, noticed below. 
[March,

(3) Station C: Upper talus-slope in the bay about $\frac{1}{2}$ mile west of Bass Camp, a few hundred feet below the rim. The shells here are small, alt. 8, diam. 13, width of umbilicus $2 \mathrm{~mm}$. None found alive. In some examples the shoulder-band is extremely faint, but in most of them it is distinct.

(4) Station A: "Spectacle Cove," an embayment at the foot of the cross-bed or Coconino sandstone, in a talus resting upon the Aubrey red sandstone, with Oreohelix yavapai profundorum.

Specimens measure:

Alt. 10, diam. 16.0, umbilicus $2.1 \mathrm{~mm}$.

" 9 , " 14.8 , " 2.0 "

All have a band at the shoulder. V'ery few living adults were taken, but, unlike the Oreohelices, the shells are entirely normal.

(5) Seep Spring, 2 miles west of Bass Trail, at base of the cross-bed sandstone. Shells like the preceding lot from the same level.

(6) Station B: Head of Starvation Tank Wash, around the point to the right from Bass Trail, at about 5,800 feet elevation (Pl. XII, figs. 29, 30).

(7) Station D: Bass Trail, on the Red Wall, 5.000 feet.

Alt. 10.1, diam. 16, umbilicus $2.1 \mathrm{~mm}$.

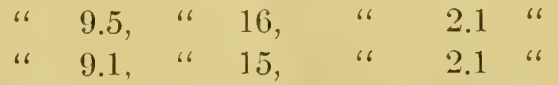

The shoulder-band is wanting in about half of the shells taken.

(S) Station E: Foot of Red Wall, on Bass Trail, elevation about 3,850 feet. Like the preceding, diam. 15 to $16.3 \mathrm{~mm}$. A few "bones" were taken still lower, at abont 3,000 feet, in a talus of the Red Wall limestone.

Alt. 8.9 , diam. 15.0, umbilicus $2.0 \mathrm{~mm}$.

Fig. 29. " 9.0, " 14.3 , “ 2.0 " ; whorls $4 \frac{1}{2}$.

" 8.5, " " $13.6, \quad$ " 1.9 "

" 8.2 , " $13.5 \mathrm{~mm}$.

The corneous, brown shell is more or less streaked with white and invariably has a narrow band at the shoulder.

(North Side of the Colorado River.)

(9) Station F: Shinumo Creek, near tamp, elevation about 2,500 feet.

Alt. 10.S, diam. 16.9, umbilicus $2.1 \mathrm{~mm}$; whorls $4 \frac{1}{2}$.

$\begin{array}{rrrrrr}\text { " } 10.8, & \text { " } & 16.5, & \text { " } & 2.1 & \text { " } \\ \text { " } 9.3, & \text { " } & 15.1, & \text { " } & 2.0 & \text { " }\end{array}$

Similar shells occurred at Station 3, Shinumo Box, 2,750 feet, 
the largest, alt. 12, diam. 17.2, umbilicus $2.5 \mathrm{~mm}$. (F. and D. 1909). Some of these shells are the largest taken up to this time, exceeding the types. The shoulder-band is faint or wanting on some shells.

(10) Station G: White Creek, about 1 mile above its confluence with Shinumo Creek (Pl. XIl, figs. 26-2s). Seven per cent. of the shells taken show a chestnut band. In the rest there is an ill-defined whitish band in its place. Bandless shells are rare in all other localities. The aperture is also more ample in this lot, someuhat trumpet-shaped, the lip is rather more thickened and rusty. and the parietal callus is generally thick at the edge.

Alt. 10, diam. 17.0, umbilicus $2.6 \mathrm{~mm}$.; aperture $8.8 \times 10.0 \mathrm{~mm}$.

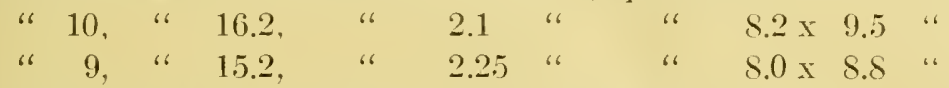

The genitalia of a specimen of this lot are figured, fig. $3 B$.

(11) Muav Box, Station 9, elevation 4,000 feet (F. and D., 1909). Diam. 15-16 mm. All taken have the shoulder-band.

(12) Station H: Mojave Amphitheatre below the red-wall sandstone (west side of Muar Canyon, near Dutton's Point). The shells are all banded, measure 14 to $16 \mathrm{~mm}$. diameter, and do not seem to differ from those taken on the shinumo at a much lower elevation. At this point the authors made a dry camp in 1906, being unaware that there was water a few miles beyond. In 1909 Ferriss and Daniels took a fine lot of unusually large and dark colored Sonorellas at Station 107, about two miles farther up Muav Canyon, but they were lost before reaching home.

(13) Station 104, 6,700 feet, and Station 9, 7,500 feet, east side of Powell Plateau (west of Muav Wash). Small, 13.5 to $14 \mathrm{~mm}$. diam.; banded; aperture dilated, as in the shells described under (10). This colony and those following were taken by Ferriss and Daniels, 1909.

(14) Station 5, east of Muar Canyon, near the Kaibab Saddle, 6,717 feet. Small shells, diam. about 13.5 to $15 \mathrm{~mm}$., with the mouth less dilated than in the preceding lot, nearly normal. All are banded.

(15) Station 25, west side of Powell Plateau, 6,700 feet. The shells are small, diam. about $14 \mathrm{~mm}$., with thickened lip and somewhat dilated mouth, as in Nos. (13) and (19).

(16) At Station 23, Horse Tank Canyon, on the west side of Powell Plateau, 7,000 feet, the shells are like those from No. (12). Some bandless individuals were also taken.

(17) Station 101, north end of P'orell Plateau, 6,700 feet. Only dead and bleached shells, normal in shape.

(18) Station 100, third amphitheatre north of the Kaibab Saddle, 
6,700 feet. Shells 14 to $15 \mathrm{~mm}$. diameter, nomal in shape and color, similar to lot No. (10). This is farthest north for the species.

Oreohelix yavapai profundorum n. subep. Pl. XII, figs. 1-14.

The shell is opaque-white with some brownish, corneous streaks and often two fleshy, brown bands, the inner whorls more or less fleshtinted; solid; with sculpture of rather wide, irregular, subobsolete growth-wrinkles, but no spiral strice. Whorls $4 \frac{1}{2}$ to 5 , the last angular or subangular in front, descending moderately or deeply to the aper ture, often becoming shortly free. Aperture very oblique or subhorizontal, the peristome slightly thickened and brownish, continuous and free or in contact with the preceding whorl for a short distance.

Fig. 1. Alt. 12.0, diam. 14.5 mm.

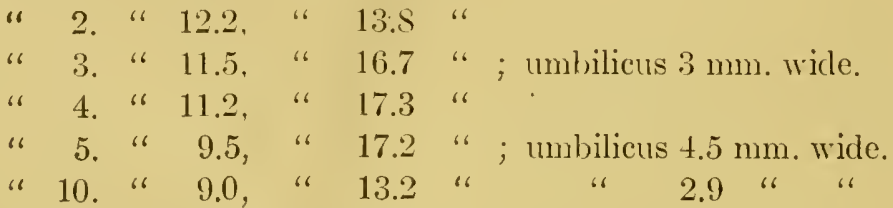

Adult shells measure from 13 to $17 \frac{1}{2} \mathrm{~mm}$. diameter.

The genitalia are figured (fig. 4). The lower half of the penis is

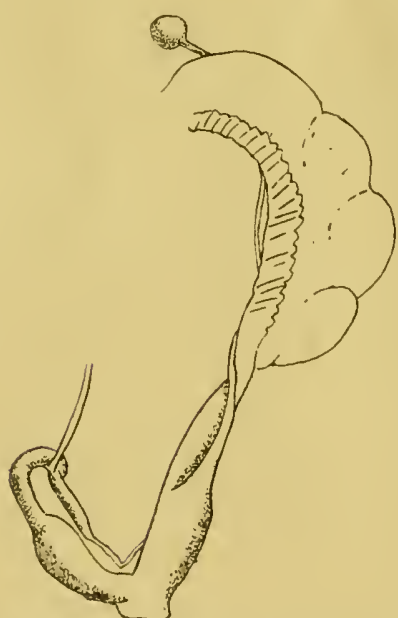

Fig. 4.-Oreohelix yarapai pro fundorum. much swollen, the upper half slender and cylindric, the retractor muscle inserted at its apex. The short epiphallus is rather stout. Vagina short and very large. The uterus in the individual figured contained four embryos; the shells $4.7 \mathrm{~mm}$. in diameter, with $2 \frac{3}{4}$ whor ls and acutely carinate periphery. The podocyst is larger on the upper embryos, but present in all.

Length of penis, $6.7 \mathrm{~mm}$; epiphallus, $3 \mathrm{~mm}$; vagina, $4 \mathrm{~mm}$.; spermatheca and duct, $17 \mathrm{~mm}$.

Out of 100 shells from the type locality, taken at random, 56 per cent. resemble figs. $1-3,44$ per cent. being like figs. 4,5 . The race is therefore markedly senile.

Grand Canyon, in "Spectacle Cove," Station A, the head of a recess in the cross-bed sandstone south of where the Mystic Spring or Bass Trail zigzags down, in a talus resting on the red sandstone forming the Le Conte Plateau. Elevation about 
5,700 feet. Cotypes, No. 103,234 A. N. S. P., collected by Ferriss and Pilsbry, October, 1906.

The embryonic shell, of $2 \frac{1}{4}$ whorls, shows fine subregular ripples along the lines of growth, and in places some fine, very faint spiral striæ may be traced; on the base these spirals are more distinct. They continue there during the first part of the neanic stage, but disappear after a diameter of 8 or $9 \mathrm{~mm}$. has been attained. The main spirals are widely spaced, as in 0 . yarapai, but at all stages of growth they are very weak. The embryonic shell is light brown. Some maculæ and streaks of opaque cream-white appear after the third whorl. In the adult stage the surface becomes dull white and somewhat chalky from loss of the very thin cuticle, which is present in the embryonic and early neanic stages.

O. y. profundorum and the allied races, extremitatis and angelica, differ from 0 . yarapai by the very weak spiral striation of the embry-

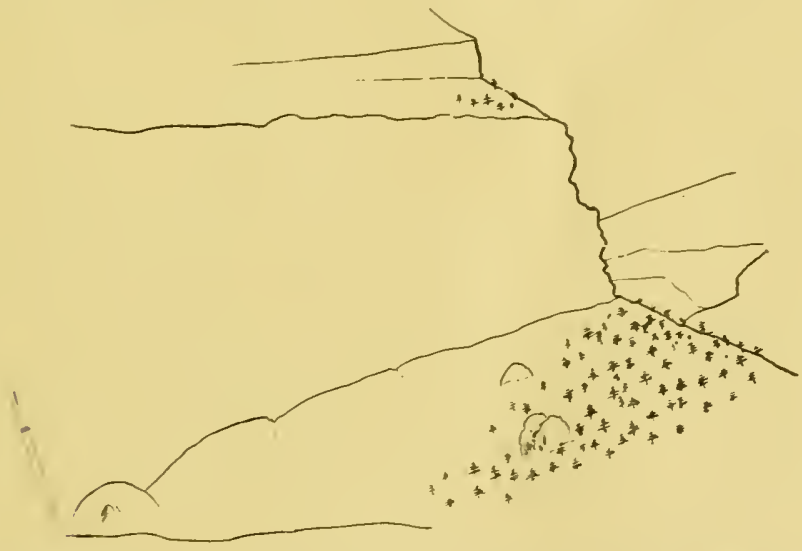

Fig. 5.-Spectacle Cove (Station A), from opposite side below Bass Trail. Type locality of Oreohelix yarapai profundorum on the mound at left end of talus slope.

onic shell. O. profundorum resembles 0 . yarapai, O. y. neomexicana and 0. borbata in having a very short penis, its length about half the diameter of the shell or less. In the strigosa group, so far as known, the penis is long. tro-thirds the diameter of the shell or more, in alcoholic examples. O. yarapai, neomexicana and profundorum are alike in genitalia. but $O$. borbate differs by having the retractor muscle inserted on the epiphallus. whilst in the others it is inserted at the apex of the penis.

The type locality of 0 . y. profundorum is in all embayment of the cross-bed sandstone. where a talus at its foot rests upon the red sand- 
stone. Living specimens were taken only on the last mound of the talus at the head of the wash, shown on the left in fig. 5. This mound is about 30 or 40 feet high, about 100 feet long, and has a great rock in the middle. Dead shells were scattered over the talus for about 200 yards westward, nearly as far as the large rocks shown in the edge of the piñons. Except where piñons are shown, the slope is covered with shrubs. The Oreohelices live among moss and grass, around and under stones in great profusion. With them live Cochlicopa, Pupilla, etc., and Sonorella coloradoensis, the latter found over the whole talus shown in fig. 5, but everywhere very scarce. Numerous other taluses at and below the same level were searched, but no other colony of Oreohelix was found. All other colonies of Oreohelix seen are on the upper slopes only a short distance below the rim of the canyon.

In the absence of any source on the lower levels, O. $y$. profundorum must have been derived from $O . y$. extremitatis, which inhabits the slope above the cross-bed sandstone, whence individuals have fallen into the abyss. The considerable divergence of the race on the lower level, and the fact that only one colony was found at that level, seem to indicate that most snails which are carried or fall over the cliff do not survive the terrific drop of several hundred feet.

In the series of several thousand shells taken there was one sinistral example.

That the colony of $O . y$. profundorum is decadent seems to be indicated by the fact that dead shells were found over an area many times greater than that now inhabited by living snails. The markedly senile character of the shells also foretells approaching extinction. Yet the local conditions appear altogether farorable and living individuals are very abundant in a limited area.

Oreohelix yavapai extremitatis n. subsp. Pl. XIl, figs. 15-21

At Station 2, near Bass's Trail, about 200 feet below the lim of the Grand Canyon, the Oreohelices (pl. XII, figs. 18-21) are more depressed than $O . y$. profundorum, less solid and less calcareous, invariably twobanded. The surface is more or less suffused with light brown, especially on the spire, and the very thin pellucid cuticle is retained, so that the shell has a slight luster. The embryonic whorls are like profundorum; the first third or half of the last whorl is acutely carinate in front, and the latter part descends very little (as in fig. 1S, 67 per cent. of the shells examined) or somewhat deeply (fig. 19, 33 per cent.). Widely spaced granose spirals (such as are characteristic of $O$. yavapai) 
are visible on the base in front of the aperture in most of the shells. The aperture is contracted less than in O. $y$. profundorum and the peristome is not thickened. The largest examples measure, alt. 8.2, diam. $16 \mathrm{~mm}$., the smallest alt. 8.3 , diam. $14 \mathrm{~mm}$. About 60 adults examined.

Fig. 1S. Alt. 8.0, diam. $15.8 \mathrm{~mm}$. ; width of umbilicus $4.7 \mathrm{~mm}$.

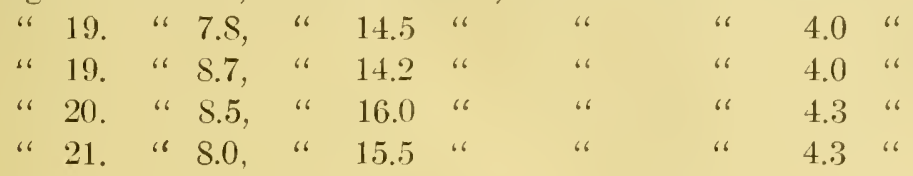

Cotypes are No. 103,236 A. N. S. P., collected by Ferriss and Pilsbry, 1906.

Similar shells occur on the upper slope at the same level, in a bay of the rim, about a half-mile west of Bass's Camp, on the southern rim of the canyon (pl. XII, figs. 15, 16, 17).

Fig. 15. Alt. 9.2, diam. $15.5 \mathrm{~mm}$; umbilicus $4.0 \mathrm{~mm}$. wide.

$\begin{array}{lllllllllll} & 16 . & \text { " } & 8.1, & \text { " } & 15.1 & \text { “ } & \text { " } & 4.1 & \text { " } & \text { " } \\ \text { " } & 17 . & \text { " } & 9.0, & \text { " } & 16.9 & \text { " } & \text { " } & 4.9 & \text { " } & \text { " }\end{array}$

Oreohelix yavapai angelica. PI. XII, figs. 22-25.

On the Bright Angel Trail, at Grand Canyon, from 100 to 400 feet below the rim, which has here an elevation of $6, \$ 66$ feet, the shells resenible $0 . y$. extremitatis in contour, except that the last whorl is somewhat more inflated. The color is light brown, usually with a brown band below the periphery, sometimes with another above, but this is often wanting. It is thimmer and larger than extremitatis, and spaced spirals are more distinct, being well-developed on both the base and upper surface. The embryonic whorls have faint spiral lines. The first part of the neanic stage (up to at least $11 \mathrm{~mm}$. diam., with nearly 4 whorls in some individuals) bears spiral rows of cuticular scales readily visible to the naked eye. There are about 8 spirals above, 10 below the periphery on the last whorl. The last whorl is but slightly deflexed in most examples, rarely (s per cent.) more or less deeply so, approaching fig. 25, which is an extreme individnal.

Fig. 22. Alt. 9.0, diam. 17.0 $\mathrm{mm}$. ; width of umbilicus $4.5 \mathrm{~mm}$.

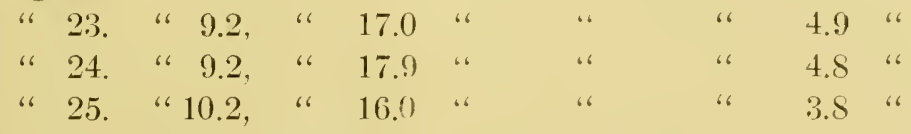

Individuals with deeply descending last whorl occurred chiefly at the lower level. 
Alt. 9.5, diam. $18.3 \mathrm{~mm}$.

$\begin{array}{rrrrr}\text { " } & 10.2, & \text { " } & 17.0 & \text { " } \\ \text { " } & 8.0, & \text { " } & 16.0 & \text { " } \\ & 9.5, & \text { " } & 16.0 & \text { " }\end{array}$

This race occupies the same zone as $0 . \%$ extremitatis, in the Kaibab limestone. The stations are about 20 miles apart, but including the windings of the canyon, as the snail travels, the distance would be far greater. The embryonic stage is very much alike in $O . y$. profundorum, extremitatis and angelica, but the neanic and adult stages differ.

Cotypes No. 103,239 A. N. S. P., collected by Pilsbry and Ferriss, 1906.

Oreohelix strigosa depressa (Ckll.). Pls. XIII, XIV.

[Patula strigosa] var. Cooperi Binney, Manual Amer. L. Shells, p. 166, fig. 153 (teste Ckll.).

Patula strigosa cooperi var. depressa (kll., Nautilus, III, p. 102, January, 1890 , canyon near Durango, Colo.

Oreohelix strigosa Gld., Pilshry, Proc. A. N. S. Phila., 1905, p. 272, pl. XXV. figs, $45-47$ (shell); pl. XI, figs. 14,15 (embryonic shell); pl. XIX, fig. 3 (genitalia); pl. XXII, figs. 1-3 (teeth); pl. XXIII, fig. 25 (jaw).

New Mexican examples of $O . s$. depressa have been fully described and figured in a former paper of this series. In the country north of the Grand Canyon it is an abundant snail, varying widely in size, form, color, and to a less degree in sculpture not only in different colonies, but frequently among individuals of one colony.

In some districts, as along the western escarpment of Powell Plateau, there is a marked tendency to lose the dark bands. In some other places beautiful albino shells occur in colonies composed chiefly of well-colored shells. There is a tendency in many places to produce more compactly coiled shells than typical depressa, the spire being higher and the total diameter and the umbilicus smaller in some of the shells. This culminates in a form of shell which is not distinguishable from $O$. cooperi, found in a few stations.

In some arid situations, especially the head of Quaking Asp Canyon, the shells are conspicuously drarfed, their development arrested. No colonies are markedly gerontic, though in a few there is a tendency towards senile characteristics in occasional individuals.

The spiral scilpture is generally distinctly developed, and sometimes some larger, widely spaced spirals can be seen on the base of the shell.

Specimens are illustrated on Plates XII and XIV. Some 
comment on the several lots follows, beginning at the northern stations, $^{6}$

(1) Jacob's Canyon (Pl. XIII, figs. 1-5), Oreohelices were taken at Stations 6S, 69, 70, 71. The typical form and coloring (fig. 1) prevail, but there is also one color-form not elsewhere encountered, in which the bands are purple-brown and very wide, the upper one spreading to the suture or learing a white belt below the latter (figs. 2-4). There are also some pearl-white and dirty white shells (fig. 5). The same color-forms occurred at Station 67 , below the mouth of ${ }^{B}$ Only one of us (Ferriss) collected $P$. S. depressa north of the Grand Canyon,
being accompanied there by Ir. L. E. Daniels. His impressions concerning the
relations of shell-chararters to the envirommental factors of elevation, humidity
and direction of slope are given below. It must be remembered that the con-
ditions in the Kaibab region are less accentuated than in the more arid mountains of the soutl.

"At the time our observations in "Mollusca of the Southwestern States, No. IV,' were written, environment seemed the controlling factor in the determination of size of the shell, northern exposures, with an abundance of shade and plant life and a longer growing season, would produce the larger shells. In the region north of the Grand Canyon many apparent exceptions to this rule were noted. Often colonies of the same species but 100 feet apart varied 100 per cent. in size. In a gulch facing north in the Powell-Kaibab saddle, in a box canyon with perfect snail enditions, the Oreohelix average $20 \mathrm{~mm}$. in diameter. Above the box, in a more open country, they average $24 \mathrm{~mm}$. and were more plentiful.

"In the canyons and amphitheaters of these plateaux, with the same exposure, moisture, shade, eleration-mineral, plant and all other conditions equal so far as we could understand--each colony stood out by itself in color, size and shape of the spire. These qualities seemed subject to mutation rather than controlled by environment.

"Thus, in Two-spring Canyon, the sheils in a colony on one side of a rock were 25 per cent. larger than those of the colony upon the other side, less than 100 feet distant; and a colony on the west side of the stream, no farther away, was larger than either. In the center of a colony on Powell Platean, a 'fanily' of larger shells was found.

"Until we crossed the Fiaibab Plateau, the collections of 1909 were at about the same eievation, in the limestone section. In Two-spring and Qualing Asp Canyons, both heavily wooded, the Ureohelices at the top, among the quaking asp, were $14 \mathrm{~mm}$. in diameter, gradually increasing in size, as we descended, to $25 \mathrm{~mm}$., as would naturally be expected.

"In snake Gulch, however, the largest shells were at the top, on slopes facing either north, west or south, the liameters rumning 25 and $26 \mathrm{~mm}$. at Castle Springs and vicinity. At Big springs, with abundance of shade and humidity the year around, and a warm southern exposure, the largest measurements were 21 , and at the lowest colony in the gulch less than $15 \mathrm{~mm}$.

"In Warm Springs Canyon, ruming from east to west parallel with snake Gulch, the smaller colonies were midway in the canyon, those at both the top and bottom of the canyon being unusually large and robust, and it was the same in Jacob's Canyon, another parallel canyon of this group running to the west.

"We collected Oreohelix at 22 stations, elevation about 6,700 feet, in the sarldle region of the Powell and Kaibab Plateaux; at 19 stations in Tro-spring and Quaking Asp Canyons in the Kaibab Plateau, at elevations between 6,500 and 8,250 ; at 20 stations in Snake Gulch, Kaibab P'latean, from 5,000 to 7,000 feet elevation; at 16 stations in Warm Spring and Jacob's Canyons, Kaibab Plateau, from 6,000 to 6,750 feet eleration." 
Jacob's Canyon, in the second gulch north of Warm Spring Canyon. It was not noticed at station $6 \mathrm{~S}$.

Fig. 1. Alt. 12.s, diam. 23.0, umbilicus $5.9 \mathrm{~mm}$.

$\begin{array}{lllllllll} & 2 . & \text { " } & 11.8, & \text { " } & 22.3, & \text { " } & 6.1 & \text { " } \\ \text { " } & 3 . & \text { " } & 11.3, & \text { " } & 22.7, & \text { " } & 6.0 & \text { " } \\ \text { " } & 4 . & \text { " } & 12.5, & \text { “ } & 21.8, & \text { " } & 6.0 & \text { " } \\ \text { " } & 5 . & \text { " } & 11.5, & \text { " } & 24.0, & \text { " } & 6.1 & \text { " }\end{array}$

(2) At Ntation 66 (1'l. NIII, figs. 6, 7), in the first gulch facing west, north of Warm Spring Canyon, the shells are smaller and usually more elevated, the last whorl at the aperture generally falling well below the lower band. Color and sculpture are normal.

Fig. 6. Alt. 12.0, diam. 19, umbilicus $5.0 \mathrm{~mm}$.

" 7. " 10.5 , " 17, " 4.6 "

(3) In the head of Shinumo Canyon (Pl. XIII, figs. 10, 11, 12), Stations 50,51,52, the shells are typical in form, but a majority of them have the bands weak, or one or both may be absent (figs. 10-12, Station 50, 5,500 feet elevation). Farther west, at Station 53, the bands are somewhat stronger. Beyond this, going west, the shells are smaller (Stations $54,55,56,57$ ), the last whorl falls more, and the ends of the lip approach-senile characters, doubtless indicative of unfavorable conditions leading to decadence of the race (Pl. XIII, figs. 13,14 , Station 55 , at 5,500 feet).

Fig. 10, diam. $20 \mathrm{~mm}$. Fig. 11, diam. $19 \mathrm{~mm}$. Fig. 12, diam. $17.7 \mathrm{~mm}$. (Station 50).

Fig. 13. Alt. 9.2, diam. $15.7 \mathrm{~mm}$. (Station 55).

" 14. " 7.8, " 14.5 " umbilieus $4 \mathrm{~mm}$.

" 15 . " 9.2 , " 15.7 "

(4) Moquitch Gulch, Stations 75, 76 (Pl. XIII, figs. 16-18). The shells are of medium size, more or less brown, with typical bands. An albino form, white with greenish, translucent bands, appears here.

Fig. 16. Alt. 11.7, diam. 1s, umbilicus $3.9 \mathrm{~mm}$. (Station 76). Fig. 17. Diam. $17.3 \mathrm{~mm}$. Fig. 1S. Diam. $1 \mathrm{~S} . \mathrm{S} \mathrm{mm}$. (Station 75).

(5) Continuing southward on Snake Gulch, we encounter snails essentially like those from Stations 49,50 and 37 in Stations 35, 34, 33. At Station 7S, boldly marked two-banded shells and beautiful albinos occur, as already figured from Moquitch Gulch. At Stations 32 and 77 most of the shells are large and dark, but a few are small.

(6) Warm spring Canyon (Pl. XIII, figs. S, 9). Finely dereloped shells occur at Stations $59,60,61,62,64,65$ and 73 or 74 , mostly with the normal color-pattern, but sometimes the bands are weak or almost absent, chiefly in shells from station 61 . 
At Station 60 only fossil examples were taken.

Fig. 8. Alt. 9.8, diam. 21.0, umbilicus $6.5 \mathrm{~mm}$. (Station 62).

"9. "11.0, " 22.7, " 6.3 " ( 61 ( 61 ).

(7) At Snake Gulch, below the Coconino Smelter, Station 49, the shells resemble those from station 66. having a low conoidal spire and depressed last whorl which falls decidedly at the aperture. Bands narrow, rather pale.

(8) At Station 37, Snake Gulch, at the north sicle of the mouth of Smelter Gulch, elevation 5,750 feet, the shells resemble those from Station 50 (see fig. 11).

(9) At Castle Springs, Station 79, the shells are large and dark, two-banded or more or less clouded (PI. figs. 19-21, 6,750 feet eleration). Similar examples are found at Riggs Spring, Station 81

Fig. 19. Alt. 11.S. diam, 27.ก mm. (Station 79).

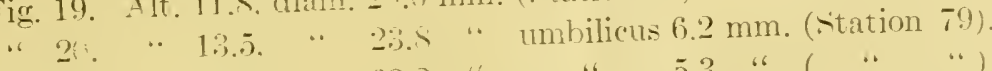

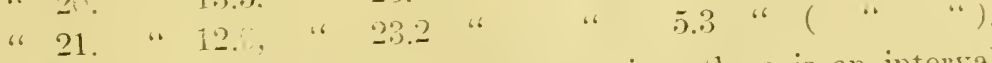

Between the preceding and following stations there is an interval of about 13 miles over the watershed in which no Oreohelices were found.

(10) Quaking Asp Canyon penetrates the Kaibab Plateau from the west, where it drains into Tapeats Creek. Two-springs Canyon is a branch of the head of Quaking Asp. From the lower end of Quaking Asp Canyon. Station 98, 6,500 feet elevation, to the head, Station $83,8,250$ feet. there is a gradual diminution in size of the shells, At Station 98 the shells are very large, diam 29 to 26 mint typical in form and color (Pl. NIII, figs. 24-26). At Station 97 the size averages smaller, and there are some albino shells, white with translucent, greenish bands. At Stations 99. 96, 94. 93, 92, 91, 90, 89,87, ss there are similar shells, the size diminished a little (Pl. XIII, figs. 22, 23. Station 91, 7,000 feet).

Stations $86,85.8+$ and $\$ 3$ show shells still further diminished, adults measuring, alt. 9 diam. $1+$ to alt. $\bar{\tau}$, diam. $11.5 \mathrm{~mm}$., with $4 \frac{1}{2}$ whorls (Pl. XIII. figs. 27, 2S. Station S4). The color is typical; the periphery angular in front and the last whorl descends only very little to the aperture. These colonies show no senile features. Their development has been arrested, the small number of whorls and the angular periphery being characters of youth.

At Two springs, station 27 , the shells resemble those from station 91. Farther up the canyon. Station 26, the shells became smaller, 
adults measuring 12 to $15 \mathrm{~mm}$. diam., as in the head of Quaking Asp Canyon.

Fig. 22. Alt. 12.0, diam. 19.3, umbilicus $4.5 \mathrm{~mm}$. (Station 91).

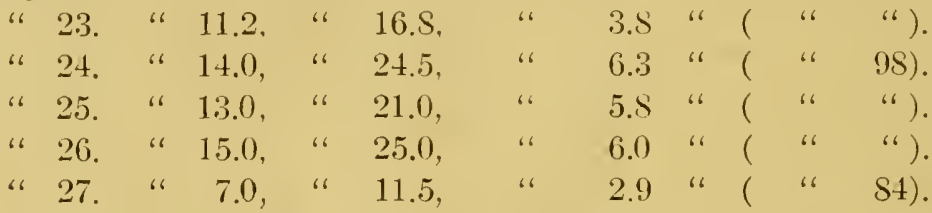

(11) At Station 100, Kaibab-Powell Saddle, 6,700 feet, the shells resemble those figured from Station 98 , but are smaller, diam. 17.5 to $21 \mathrm{~mm}$.

(12) Uff the north end of Porell Plateau, at Station 17 (Pl. XIV, figs. 1-4), there is wide color-variation in the colony, the following forms occurring:

Figs. 1, 3. Typical two-banded form, diam. 18 to $21 \mathrm{~mm}$.

Fig. 2. Upper band obsolete, the lower are reak same sizes.

Fig. 4. White, with greenish, translucent bands, diam $19 \mathrm{~mm}$.

(13) In other stations at the northern end of Powell Plateau, 13, 14, 15 (but not Station 16), and Station 105, near Oak Springs, the prevalent form (Pl. XIV, figs. 6, 7, S) Station 15, 6,500 feet) is rather less depressed than typical depressa, though the depressed form also occurs (Pl. XIV, fig. 5. same station). At Stations 13, 15 and 105 some examples are not distinguishable from 0 . cooperi (Pl. XIV, fig. 9, Station 15; fig. 23, Station 105); yet some examples seem to connect with normal depressa. At Station 1S, at 6,700 feet, two adult shells (Pl. XIV, figs. 10, 11) are of the cooperi form.

Fig. 10. Alt. 12.0, diam. 18.7, width of umbilicus $4.5 \mathrm{~mm}$.

" 11 . " 11.9, " " 18.0 , " 404.0 "

The material from these stations $(13,15,18)$ is too scanty to decide with certainty whether the series is divisible into cooperi and depressa or whether the globose specimens are inextricably connected with the depressa stock of the region. Except at Station 18, the cooperi form occurs with undoubted depressa, as at Station 105, where figs. 22 and 23 of Pl. XIV occurred together.

(14). The west side of Powell Plateau, Stations 25, 24, 22, 21, 20, 19 , and Station 16 at the north end, have a somewhat different race. There are typical two-banded depressa (Pl. XIV, figs. 13, Station 16) and also specimens lacking one or both bands (Pl. IIV, figs. 14, 15, Station 16, 6,700 feet; fig. 16, Station 19).

The specimens vary from quite large, diam. 25, to medium size, 
diam. about $19 \mathrm{~mm}$. At Station 16, s0 per cent. of the shells are bandless.

(15) On the east side of the Powell Plateau, Stations 10, 103, 8, 12, the shells are typical two-banded depressa (Pl. XIV, figs. 17, 18, 19, Station 103, 6,700 feet) varying to forms with the spire higher (figs. 20, 21, same station). Fig. 21, alt. 12.3, diam. 1s, umbilicus $4 \mathrm{~mm}$.

Thysanophora ingersolli (Bld.).

Bill Williams Mountain; Two-Spring Gulch, Kaibab Saddle.

Thysanophora hornii (Gabb).

Shinumo Creek, on the north side of the Grand Canyon. Farther north than this species has been reporterl hitherto.

\section{ENDODONTID死.}

\section{Pyramdula (Gonyodiscus) cronkhitei (Newc.).}

Bill Williams Mountain. It was not found in the Grand Canyon, but north of it was taken at Castle Springs and Rigg's Spring, Snake Gulch, Kaibab Plateau; Mt. Trumbull; also Deception Lake and Crocodile Lake near Kanab, Utah, 5,500 feet elevation.

\section{ZONITID丑.}

\section{Vitriua alaskana Dall.}

V. Pfeifferi Newc. not of Desh.

Living specimens were taken on Bill Williams Mountain. Numerous dead shells were found near a small spring in the Grand Canyon below the cross-bed sandstone, 2 miles west of Mystic Spring Trail. This spring is called Seep Spring on the topographic map, Shinumo quadrangle. The average size of adults here seems to be about $6 \mathrm{~mm}$. diam., but one shell measures $7.4 \mathrm{~mm}$. We did not find Titrina elsewhere in the Grand Canyon, but northward it occurred at Warm Spring Canyon and Rigg's Spring, Kaibab Plateau, and at Mt. Trumbull.

The living animal observed October 15, at Bill Williams Mountain, is far less voluminous than $V$. limpida. There is one small shell-lobe, covering the termination of the suture. In progression the tail does not project behind the shell.

Vitrea indentata umbilioatac 'Singl.' Ckll.

Bill Williams Mountain. Grand Canyon along the Bright Angel Trail from just below the rim to the base of cross-bed sandstone and at the Indian Gardens; Bass Station, Grand Canyon R. R.; Station $\mathrm{H}$, on the north side of the canyon. Also taken on the north side of 
the Grand Canyon on Powell Plateau; Kaibab-Powell Saddle; Castle Springs, Snake Gulch; Two Springs, Kaibab Plateau.

Euoonulus fulvus alaskensis (Pils.).

Bill Williams MIountain. Grand Canyon, Bright Angel Trail, from just below rim to base of eross-bed sandstone. Mystic Spring Trail about 200 feet below rim, and Station C, about a half-mile west of Bass's Camp; "Spectacle Core." Station A. North of the Grand Canyon; Powell Plateau, Station 1S; Kaibab Saddle and plateau at Stations 5, 7, 12, 66, 100; Riggs Spring, Snake Gulch; Castle Springs; Warm Spring Canyon; spring on the northwest side of Mt. Trumbull.

Zonitoides milium meridionalis Pils.

Bill Williams Mountain.

Zonitoides minuscula (Binn.).

Bill Williams Mountain. Base of Mt. Trumbull.

Zonitoides arborea (Say).

Bill Williams Mountain. Snake Gulch, Station $11 \frac{1}{2}$.

\section{LIMACID $\approx$.}

Agriolimax hemphilli ashmuni $\mathrm{P}$. and $\mathrm{V}$.

North of the Grand Canyon in Snake Gulch at Big Spring and Station 49, below the Coconino Smelter; also station $4 S$.

Snocinea avara Say.

\section{SUCCINEID $巴$.}

Bass Station, Grand Canyon R. R.; Grand Canyon on the Mystic spring Trail along the slope a few hundred feet below the rim, and in the amphitheatre $\frac{1}{2}$ to $\frac{3}{4}$ mile west of Bass's Camp, on the upper slope; "Spectacle Cove" and Seep Spring, 2 niles west of trail, below cross-bed sandstone; red wall sandstone at 5,000 feet. On the north side of the river we found it along Shinumo Creek, in the box of White Creek, and Ferriss and Daniels took it on the Kaibab Saddle, at Oak Springs,

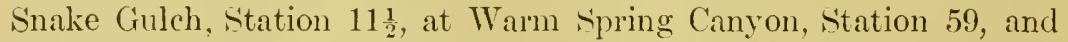
the Hurricane Fault, Station 46, 6,060 feet, near MIt. Trumbull.

It lives in a great variety of stations, a large form occurring in humid places, smaller shells in arid situations.

Succinea retusa Lea.

The Greens, 6 miles west of Kinab, Utah; Deception Lake, northwest of Kianab.

Succinea hawkinsi Baird.

The Greens, 6 miles west of Kianab. Utah. The specimens seem to be typical of this very rar? and distinct species, here first reported from so far south. 
Succinea grosvenori Lea.

North of the Grand Canyon at Big Spring, Snake Gulch, Station 78; Antelope Valley, Station 40, on ant hills; Finley Reservoir near Mt. Trumbull, and at the northwest base of the same mountain.

FERUSSACID 死.

Cochlicopa lubrica (Müll.).

Grand Canyon: Bright Angel Trail, from a short distance below the rim to the foot of the cross-bed sandstone and at the Indian Gardens. Mystic Spring Trail on the Spectacle Cove talus, Station A, and near Seep Spring, about 2 miles west of the trail, both places at the base of the cross-bed sandstone.

\section{PUPILLID $Æ$}

Pupoides marginata (Say).

Finley's reservoir near Mt. Trumbull.

Pupoides hordacea (Gabb).

Spring on the northwestern side of Mt. Trumbull and at Finley's reservoir; Antelope Valley.

Pupilla syngenes (Pilsbry).

Pupa syngenes Pils., Nautilus, IV, p. 3, May, 1890; V, p. 39, pl. 2, figs. 1, 2. Proc. Acad. Nat. Sci. Phila., 1S90, p. 296, pl. 5, figs. 1, 2 (Arizona); 1900, p. 606, with form dextroversa P. and V. (San Rafael, N. M.).

Pupa syngenes Dall, Nautilus, VIII, p. 35 (Beaver Creek, Montana).

This sinistral species was based on specimens from Arizona, the exact locality unknown, fully described and figured in these ProceEdicgs for 1890. Ten years later a dextral form was noted. Specimens of P. syngenes are before us from San Rafael and Grants, N. M., and Holbrook, Jerome, Purtyman's ranch on Oak Creek, and the Grand Canyon, Arizona. Dall has reported it from Beaver Creek, Mont., but none are known from Wyoming, Colorado or Utah.
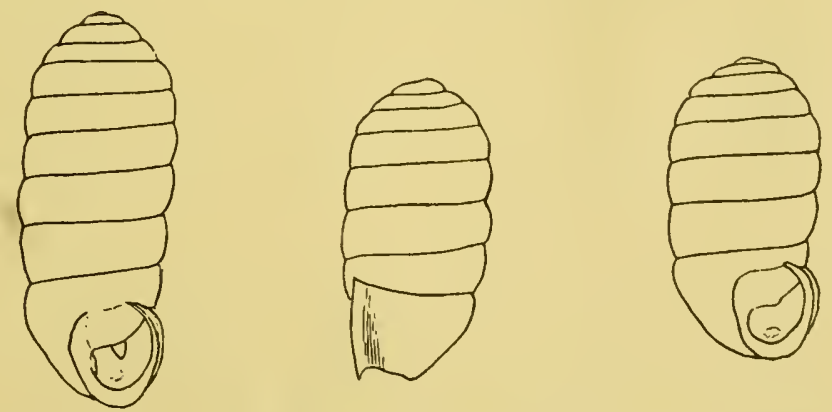

Fig. 6.-Pupilla syngenes dextroversa. San Rafael, N. MI. 
In Pupilla it is obvious that dextral forms are the more primitive, the sinistral forms derived from them. $P$. syngenes dextroversa, therefore, perpetuates the original stock of the species, of which $P$. syngenes is a divergent branch.

$P . s$. dextroversa (fig. 6) is subcylindric, a little wider near the upper end. The last whorl is flattened laterally, with a strong rounded crest and a deep constriction behind the lip, which is thin and very narrowly expanded. The parietal lamella is slightly over one-fourth of a whorl long; the columellar lamella small and deeply immersed and the lower palatal nodule well-developed or weak, but invariably present in adult shells. The size varies.

Length 4, diam. 1.7 mm., whorls 9 .

" 3 , " 1.6 " " $7 \frac{1}{2}$.

$P$. s. dextroversa differs from $P$. blandi by its larger, comparatively narrower and more cylindric shape, and the greater number of whorls. The two forms were doubtless of common ancestry.

Types of $P$. s. dextroversa are No. 79,460 A. N. S. P., from San Rafael, N. MI., collected by E. H. Ashmun. Also taken at Holbrook, Ariz. (Ashmun), at Grants, N. M. (Joshua Baily, Jr., and Albert Baily), and in the Grand Canyon of the Colorado, see below.

The specimens from San Rafael and Holbrook are mirror images of the sinistral $P$. syngenes found with them. At Grants very few were found, no sinistral ones with them.

It appears, therefore, that some colonies of the older dextral form occur unmixed with sinistral, and sometimes the sinistral form is found unaccompanied by dextral.

Our records of $P$. syngenes in the Grand Canyon follow.

North of the Grand Canyon Ferriss and Daniels took $P$. syngenes at Station 25, Powell Plateau; Stations 100, 5 and 7 on the KaibabPowell saddle; and at Station 66, Kaibab Plateau. It was associated with form dextroversa at Stations 5 and 7, near the "Stone House."

Grand Canyon at the Bright Angel Trail, about 100 feet below the rim. $P$. syngenes and $P$. s. dextroversa, 19 of the former, 12 of the latter, normal in shape, most adults having a palatal tubercle. $P$. syngenes was also taken near the base of the cross-bed sandstone, one specimen.

Mystic Spring or Bass Trail. At Spectacle Cove (Station A), on the Oreohelix talus, below the cross-bed sandstone, 103 examples of $P$. syngenes from half-grown to adult were taken, all of them sinistral. Adults vary from $3 \mathrm{~mm}$. long with 7 whorls to $3.7 \mathrm{~mm}$. with $\mathrm{S}$ whorls. Most of them are triplicate, the columellar lamella and lower 
palatal fold distinct. The larger ones from this place are typical in shape; the smaller are shorter than syngenes from any other locality in our series.
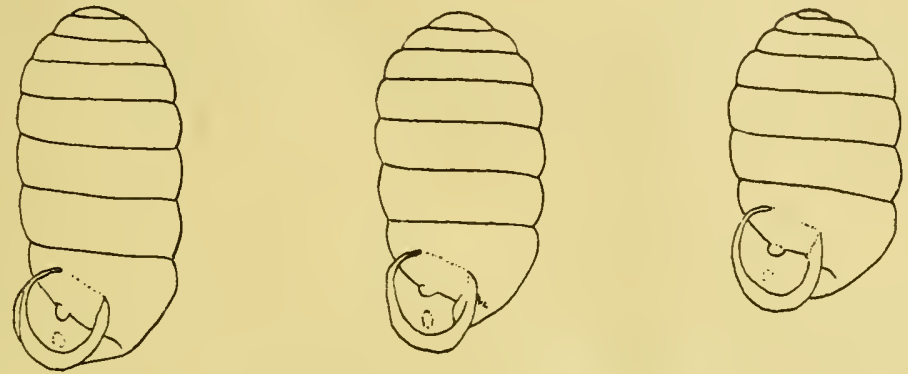

Fig. 7.-Pupilla syngenes Pils. Spectacle Cove, near Bass Trail. Lengths 3.8, 3.5 and $3.2 \mathrm{~mm}$.

Along the upper slope of the Bass or Mystic Spring Trail, Station 2, there is an extensive colony of syngenid forms. We found them most abundant in the humus, among low brushwood, about 200 feet below the rim. Two forms occur here together, a dextral form, P. s. dextroversa, and a sinistral, $P . s$. avus, described below, in about equal numbers, 272 of the former and 256 of the latter in the lot collected.

The $P$. s. dextroversa are typical in shape, but larger than the types; the crest is wide and rather far from the lip-edge; a lower palatal tooth is developed. Specimens measure:

Length 4.5, diam. $1.8 \mathrm{~mm}$., whorls 10 .

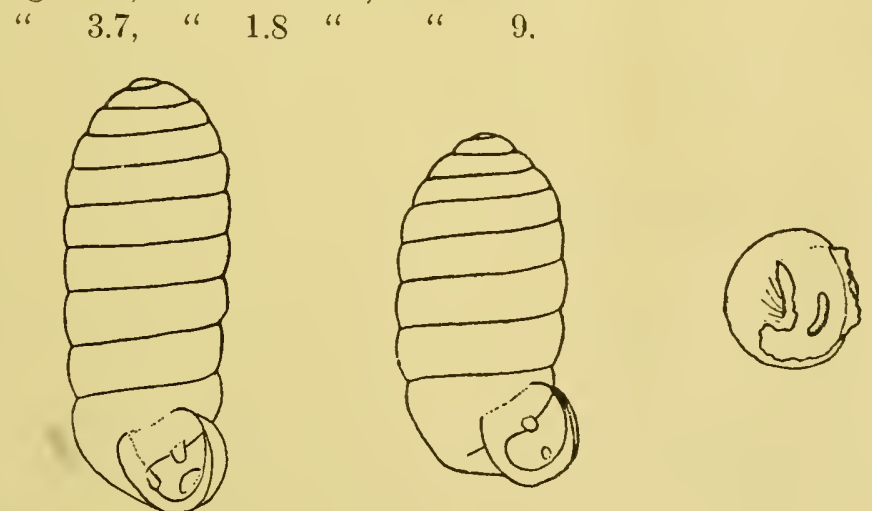

Fig. 8.-Pupilla syngenes form dextroversa P. and V. Bass Trail, about 200 feet below the rim. Lengths 4.5 and $3.75 \mathrm{~mm}$.

The last is the smallest adult seen from this place; most examples are over $4 \mathrm{~mm}$. long. Specimens of this lot are figured, fig. $S$. 
At about the same elevation about $\frac{1}{2}$ or $\frac{3}{4}$ mile west of Bass's Camp a similar specimen of dextroversa was taken.

Pupilla syngenes avas n. subsp. Fig. 9.

Shell sinistral, the last whorl deviating tangentially and ascending; teeth deeply immersed; parietal lamella much longer than in $P$. syngenes or dextroversa, about a half-whorl long.

Length 5.2, diam. $1.8 \mathrm{~mm}$., whorls $10 \frac{1}{2}$.

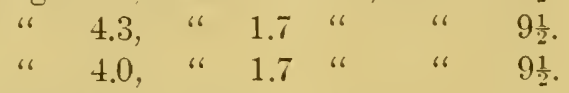

Types No. 94,220 A. I. S. P., from upper slope of the Grand Canyon along the Mystic Spring or Bass Trail, about 200 feet below the rim, Station 2; abundant with $P$. s. dextroversa.
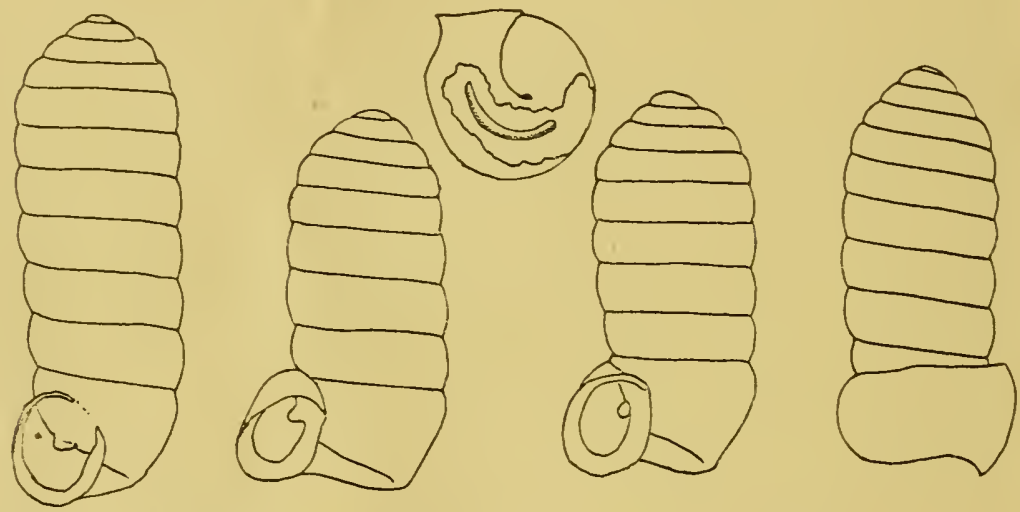

Fig. 9.-Pupilla syngenes arus, Cotypes. Lengths 5.2, 4, 4 and $4.2 \mathrm{~mm}$.

The special characters of this race, being those of senility, are unequally dereloped in different individuals. The figures give a fair idea of the variations. Finding these shells associated with about an equal number of $P$. s. dextroversa of about the same size, we at first were disposed to think them all one race in which the shell was indifferently dextral or sinistral; but on closer study it appears that the dextral forms never have the last whorl and aperture abnormal nor are the teeth so deeply immersed, or the parietal lamella so long. while almost every sinistral shell collected in this colony is markedly distorted. It seems, therefore, that although the two forms are of common origin and live together, the different direction of the coil probably prevents interbreeding, thus segregating the sinistral stock. which in this colony is now in a late stage of senile degeneration. 
Pupilla hebes (Anc.).

Pupa hebes Anc., Pils. and Van., Proc. Acad. Nat. Sci. Phila., 1900, p. 589, pl. 22, figs. 9, 10 .

Bill WVilliams Mountain.

Pupilla hebes kaibabensis n. subsp.

The shell is constantly much shorter than the typical form, length

2.7 to 2.8 , diam $1.5 \mathrm{~mm}$., whorls $5 \frac{1}{2}$. Kaibab Saddle, Station 100. types No. 103,2S3 A. N. S. P., collected by Ferriss and Daniels, 1909. Also Station 105 in the same region.

Bifidaria quadridentata Sterki.

Bill Williams Mountain.

Bifidaria pellucida hordeacella (Pils.).

Near the Mystic Spring Trail at Station A, on the Oreohelix talus, Spectacle Cove.

Bifidaria pilsbryana Sterki.

Bill Williams Mountain. Grand Canyon at the Bright Angel Trail about 100 feet below the rim; Mystic Spring Trail, Station A. Also north of the Grand Canyon at Stations 7, 12, 100 in the region of the Powell-Kaibab Saddle; Station 66, north of Warm Spring Canyon; and at a spring on the northwestern side of It. Trumbull.

Bifidaria ashmuni Sterki.

Bright Angel Trail, about 100 feet below rim. North of the Grand Canyon at Stations 7 and 12, Kaibab-Powell Saddle; Station 100, near Oak Springs; and at Mt. Trumbull. These places are all far north of its previously known range.

Vertigo concinnula Ckll.

Bill Williams Mountain.

Vertigo coloradoensis arizonensis Pils, and Van.

Bill Williams Mountain.

VALLONIID Æ.

Vallonia cyclophorella Anc.

Bill Williams Mountain. Grand Canyon about 200 feet below the rim and at the Indian Gardens, Bright Angel Trail. North of the Grand Canyon at Stations 1, 12, 106 and Oak Springs on the KaibabPowell Saddle; Quaking Asp Canyon; Rigg's Springs, Snake Gulch; Warm Spring Canyon; spring on the northwest side of MIt. Trumbull. A common shell in Arizona north of the Grand Canyon.

Vallonia perspectiva Sterki.

Grand Canyon at Seep Spring two miles west of the Mystic Spring 
Trail, below the cross-bed sandstone, and in "Spectacle Cove," Station A, at about the same level. It was not taken north of the Grand Canyon.

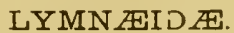

Lymnæa parva Lea.

Pipe Spring, Ariz.

Lymnæa obrussa Say.

Deception Lake near Kanab, Utah, small, slender specimens.

Planorbis tenuis Phil.

Reservoir back of Wrilliams, Ariz.

Planorbis deflectus Say.

Fredonia, Ariz., Station 3s, near the Utah boundary.

\section{PHYSID丑.}

Physa virgata Gld.

Reservoir back of Williams; Pipe Springs, Vermilion Cliffs, Station 39. Physa traskii I.ea and Ph. orbignyana Lea are synonymous with virgata.

Physa humerosa Gld.

Indian Gardens on the Bright Angel Trail in the Grand Canyon (C. M. Cooke). A small form, evidently referable to this species.

Physa gyrina Say.

The Greens, near Kanab, Utah. Another small Physa of uncertain identity was taken in Deception Lake, Utah.

\section{SPH ÆRIID $Æ$.}

Pisidinm sp. undet.

The Greens, Kanab Creek, near Kanab, Utah.

\section{Explanation of Plates XII, XIII, XIV.}

Plate XII.-Figs. 1-14.-Oreohelix yavapai profundorum P. and F. Cotypes. Spectacle Cove. No. 103,234 Acad. Nat. Sci. Phila.

Figs. 15-17.-Oreohelix yarapai extremitatis P. and F. Station C, Upper talus, west of Bass Camp. No. 103,237.

Figs. 1S-21.- O.y. extremitatis $\mathrm{P}$. and F. Cotypes. $100-400$ feet below the rim along the trail near Bass Camp. No. 103,236.

Figs. 22-24.-Oreohelix yarapai angelica P. and F. Cotypes. 100-400 feet below the rim. Bright Angel Trail. No. 103,239.

Fig. 25.-O. y. angelica. Same locality. No. 103,241.

Figs. 26-2S. - Sonorella coloradoensis (Stearns). Whitish, bandless form from White Creek, 1 mile above its junction with Shinumo Creek, Grand Canyon, north side. No. 103,255.

Figs. 29, 30.-Sonorella coloradoensis (Stearns). Head of Starvation Tank Wash, Grand Canvon, south side. 
Plate XIII.-Oreohelix strigosa depressa Ckll.-Figs. 1, 3, 5.-Jitrobs Canyon, Station 69. No. 103,208 Acad. Nat. Sci. Phila.

Figs. 2, 4.-Jacobs Canyon, Station 70. No. 103,143.

Figs. 6, 7.-First gulch opening west above Warm spring Canyon, Station 66. No. 103,141

Fig. S.-Warm Spring Canyon, Station 62. No. 103,138.

Fig. 9.-Warm Spring Canyon, Station 61. No. 103,116.

Figs. 10-12.- Shinumo Canyon, Station 50. No. 103,148.

Figs. 13-15.-Shinumo Canyon, Station 55. No. 103,197.

Fig. 16.-Moquitch Gulch, station 76. No. 103,205.

Figs. 17, 18.-Moquitch Gulch, Station 75. No. 103,204.

Figs. 19-21.-Custle Spring, Snake Gulch, Station 79. No. 103,172.

Figs, 22, 23.-Quaking Asp Canyon, Station 91. No. 103,226.

Figs. 24-26.-Quaking Asp Canyon, Station 98. No. 103,157.

Figs. 27, 28.- - Head of Quaking Asp Canyon, Station 84. No. 103,161.

Plate XIV.-Oreohelix strigosa depressa Ckll.-Figs. 1-4.-North end of Powell Plateau, Station 17. No. 103,1S6.

Figs. 5-9.- North end of Powell Plateau, Station 15. No. 103,179.

Figs. 10, 11.-North end of Powell Plateau, Station 18. No. 99,158.

Figs. 12-15.-West side of Powell Plateau, Station 16. Nos. 94,159 and 103,188 .

Fig. 16.-West side of Powell Plateau, Station 19. No. 103,180.

Figs. 17-21.-East side of Powell Plateau, Station 103. No. 103,18s,

Figs. 22, 23.-North end of Powell Plateau, Station 105. No. 103,177. 



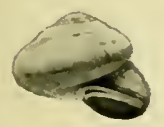

1

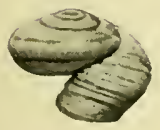

ii

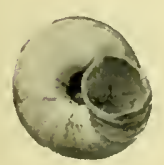

11

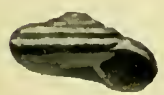

18
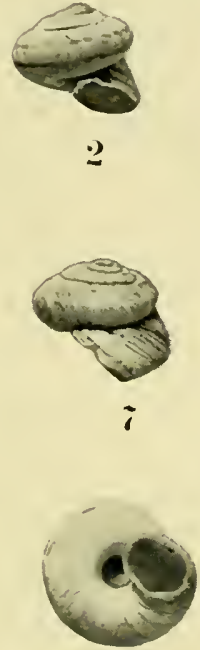

12

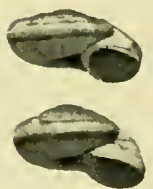

19

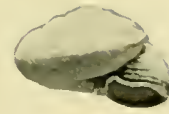

;
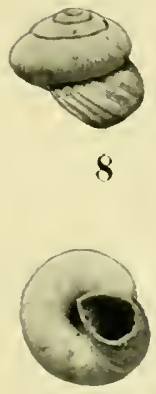

13
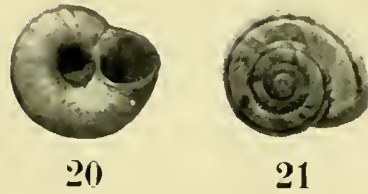

21

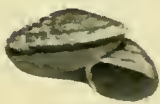

25
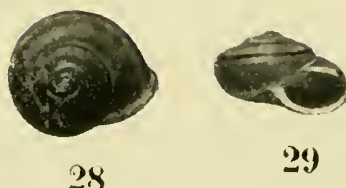

24

29
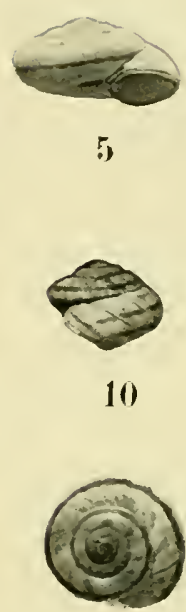

15)

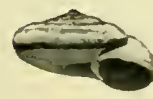

16

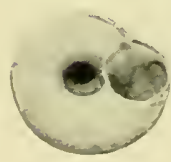

$1 \%$

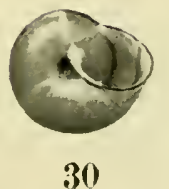

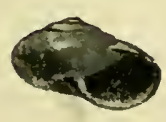

26

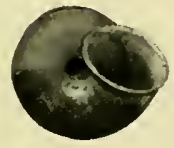

27

PILSBRY AND FERRISS: MOLLUSCA OF GRAND CANYON AND NORTHERN ARIZONA. 



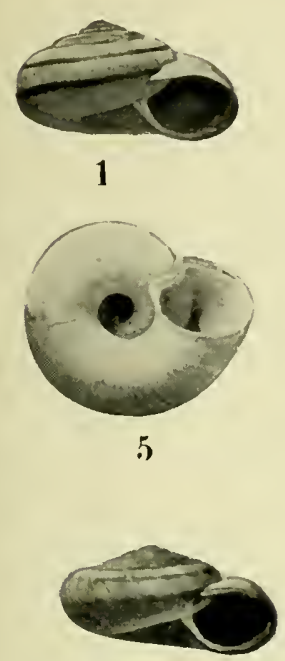

9

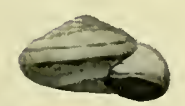

13

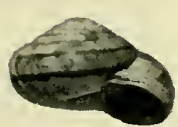

17

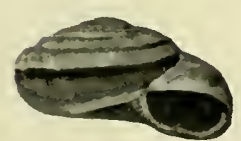

21

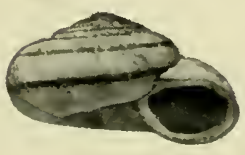

24
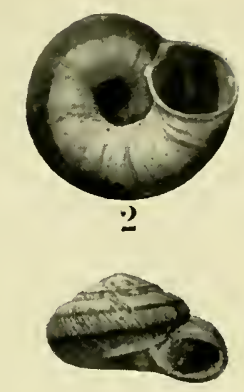

ii

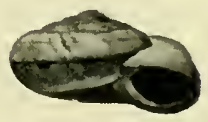

10

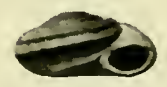

14

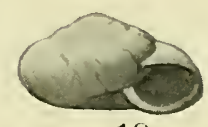

18

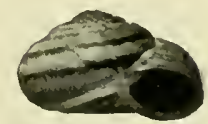

22

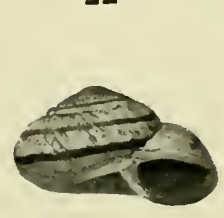

25
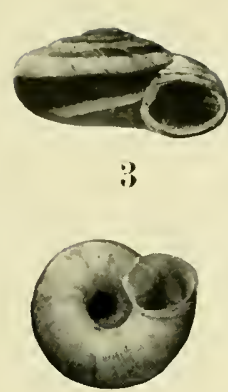

7

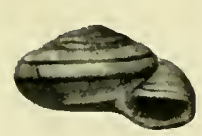

11

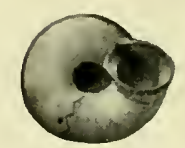

15)

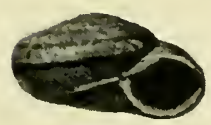

19
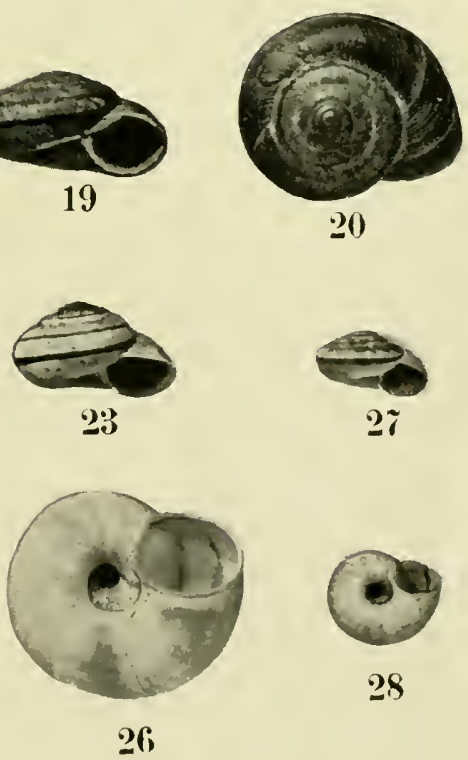

PILSBRY AND FERRISS: NOLLUSCA OF GFAND CANYON AND NORTHERN ARIZONA. 



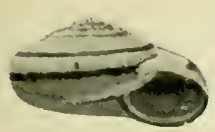

1

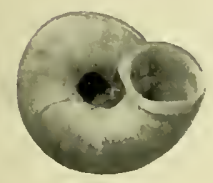

5

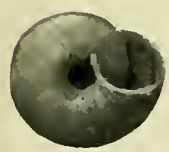

9

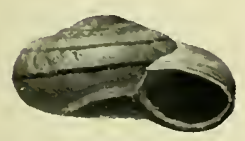

13

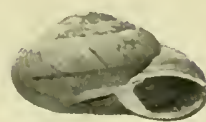

2

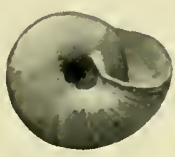

ii

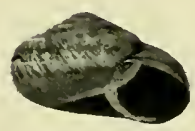

10)

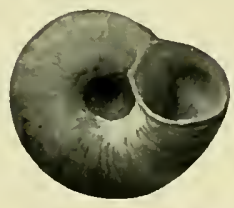

14

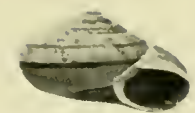

:;
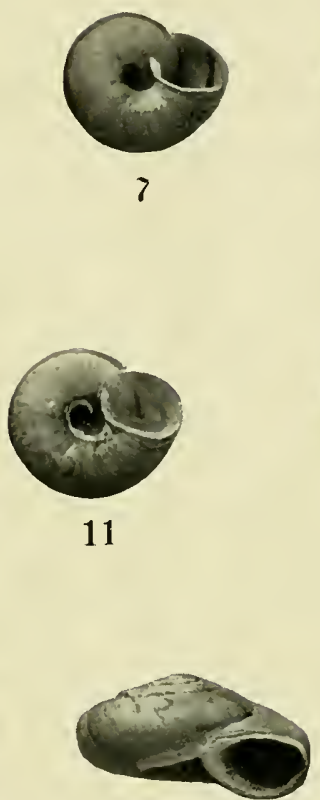

15)
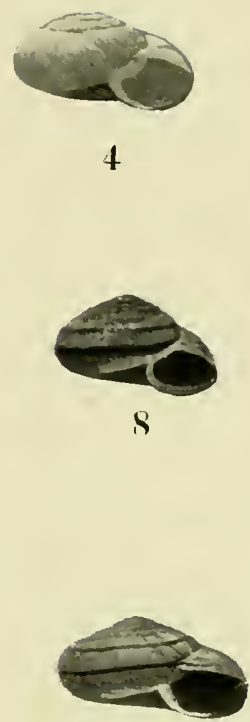

1 는

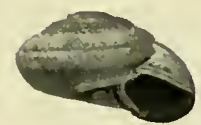

16

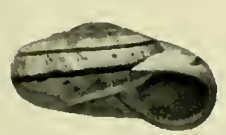

17

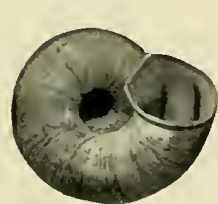

18

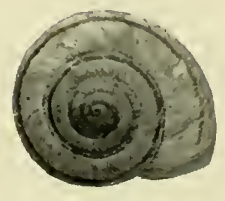

19

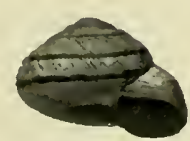

21

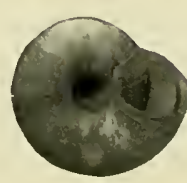

22

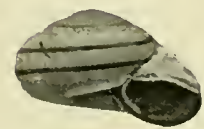

20

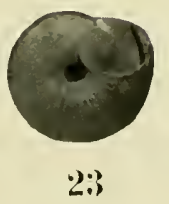

PILSBRY AND FERRISS: MOLLUSCA OF GRAND CANYON AND NORTHERN ARIZONA. 



\section{Mollusca of the Southwestern States, VI: \\ The Hacheta Grande, Florida, and \\ Peloncillo Mountains, \\ New Mexico.}

BY

HenRy A. Pilsbry.

From the Proceedings of The Academy of Natural Sciences

of Philadelphia, May, 1915.

Lssued July SO, 1915. 

MOLLUSCA OF THE SOUTHWESTERN STATES, VI: THE HACHETA GRANDE, FLORIDA, AND PELONCILLO MOUNTAINS, NEW MEXICO.

BY HENRY A. PILSBRY.

\section{The Big Hachet Mountains.}

The Big Hachet (or Hacheta Grancle) Mountains are a short range in southern New Mexico in sight of the Mexican boundary.

They may be reached from the station of Hachita, on the El Paso and Southwestern R. R., where provisions can be obtained. Water must be hauled in, unless the prospecting in progress at the time of our visit resulted in a successful well. There are no trails in the mountains. The extreme northern end of the range remains to be worked conchologically, as we could not reach it from our canp. A visit should be planned much earlier or later than ours (August), in order to have the advantage of what rain there is and also to avoid the excessive heat.

The highest peak, Hacheta Grande, has an elevation of about $8,500 \mathrm{ft}$., and is considerably higher than any other in the group. Several large canyons dissect the range, two of them forming broad basins.

There are no springs in the range, but sometimes after the infrequent rains a little water remains for a time in rocky basins in narrow canyons. We found one such hole containing about half a barrel. It was foul with drowned insects, yet most welcome, as our canteens were dry, towards the end of a two-day trip to Big Hachet Mountain.

The colonies of snails here as in other desert mountains are usually of small area. As the mountains are uninhabited and too dry for cattle ranges, there are few local place names and no roads or ranches to aid in locating collecting points. In the absence of any topographic map, we reproduce a rough map made from our field notes, which should enable anyone to exactly locate nearly every colony of snails found. For convenient reference we have named several prominent landmarks, such as Daniels Mountain, ${ }^{1}$ the highest peak northward as seen from Sheridan Canyon, and Teocalli Butte, west of our camp, both being inhabited by special races of snails.

1 Named for the writer's companion on this somewhat arduous trip. 
The Big Hachets are without timber. Only the higher peaks are in the pinyon zone. There are some scrubby cedars and old gnarled pinyon pines, nowhere numerous. On some of the higher slopes of Hacheta Grande Mt. there is a growth of very small scrub oak, sometimes so close as to impede travel, as it is mingled with a broad-leaved, black-spined agave. Elsewhere a small agave with white filaments is very abundant. There is also an agave zone surrounding the mountains, bounded outwardly by the zone of giant yuccas, both usual on the slopes leading to the mountains in this part of New Mexico. South of Daniels Peak the higher hills and buttes usually have Fouquieria and its characteristic society. The rock is hard limestone worn into holes and points, and containing few ill-preserved fossils, among which a Zaphrentis-like coral, crinoid stems and a spiral univalve are most abundant. Rattlesnakes, large centipedes, tarantulas and small brown scorpions are reasonably abundant. Birds and mammals are scarce, and owing to the absence of springs, the mountains are not available for cattle range. During the time we were there (August 20 to 26, 1910) the heat was intense from sunrise until after 9 P.M. Sky cloudless until midday, when small clouds gather, possibly covering $10 \mathrm{p}$. c. of the sky. There was very little wind. The annual rainfall is not known, but must be less than 9 or 10 inches, recorded from the region immediately northward.

Previous to the visit of Mr. L. E. Daniels and the writer, in August, 1910, the mollusks of these mountains had been collected by Dr. Edgar A. Mearns, U. S. A., while serving on the survey of the Mexican boundary.

Dr. Mearns started from Mesquite or Mosquito Springs, Chihuahua, 6 or 8 miles east of the mouth of Sheridan Canyon. Entering Thomson Canyon, he turned southward to get a practicable grade for mules up the steep ridge terminating in Daniels Peak. Passing near or over the summit he camped at its north end. From here his route lay along the ridge to the summit of Big Hachet Mt.; thence eastward to near our Station 9, south past our Station 8 , and back to camp, as plotted on the map, where his route is approximately indicated by small crosses. ${ }^{2}$ On this trip collections were made between camp and the first rise indicated on the map, on the out-journey to the peak, and somewhere between our Stations 9 and 8 on the return.

2 We would here acknowledge Dr. Mearns' kindness in plotting his route on our map and giving the above details of his visit. From the data it is now easy to determine the type localities of the species he found. 


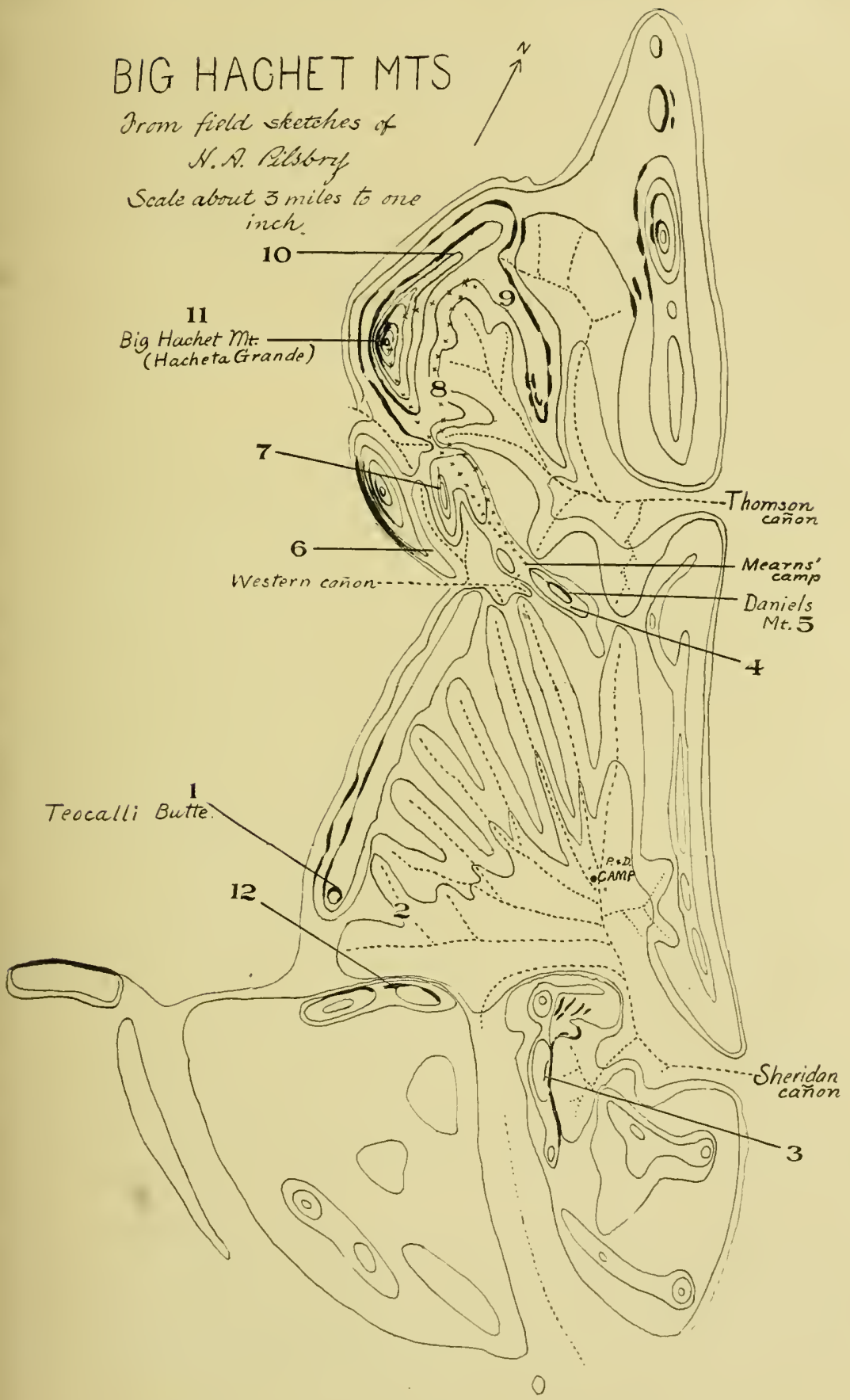

Fig. 1.-Sketch of the Big Hachet Range, showing collecting station: 
Dr. Mearns returned to Mesquite Springs along the ridge running from Daniels Mt. towards our camp in Sheridan Canyon, and along the wash ruming out of this canyon.

Dr. Mearus found the following seven species, which were determined by Dr. Wm. H. Dall: ${ }^{3}$

Patula strigosa Gould, var. concentrata Dall. [Specimens reported from summit of Hacheta Grande=Oreohelix hachetana.]

Epiphragmophora hachitana Dall [= Sonorella hachitana].

Polygyra mearnsii Dall [=Askmunella mearnsi].

Thysanophora hornii Gabb.

Holospira crossei Dall.

Holospira bilamellata Dall.

Holospira mearnsi Dall.

The relationships of the Big Hachet fauna are closest with the Florida and Organ ranges. Near related species of Sonorella and Ashmunella inhabit these three ranges, and Sonorellas very close to hachitana have been found in the Carrazolillo and Peloncillo Mountains. The Oreohelices ștand nearest to Chiricahua species. The Holospiras and Vallonia are special to the range, but the other small shells are common to most mountains of southern Arizona.

Holospira is the most generally distributed snail in these mountains. Its abstemious nature is evidently satisfied with the scanty moisture supplied by the rare rains and light snow, which is said to whiten the mountains for brief periods in the winter. No doubt a great many colonies and other local races of Holospira remain to be found.

Holospira lives only where there is limestone. We never found but one colony on igneous rock, and this was on a dyke in a limestone region. They are usually found on the hot slopes, east and south, where other snails are totally absent or very rare.

The subgenus Radiocentrum of Oreohelix is represented by two new species, making five now known. The new forms agree in genitalia and sculpture of the embryonic shell with those already known. In the large number examined ${ }^{4}$ no embryos were found, so that there can be very little doubt that the species of this group

${ }^{3}$ Diagnoses of new mollusks from the surver of the Mexican boundary, Proc. U. S. Nat. Mus., XVIII, 1S95; Report on the mollusks collected by the International Boundary Commission of the United States and Mexico, Proc. U. S. Nat. Mus., XIX, 1596.

${ }_{4}$ Besides dissecting several individuals cach of four of the species, we have pulled hundreds in cleaning the shells, without finding any embryos. Among ordinary Oreohelices it is rather exceptional to find an individual not gravid. 
are oviparous-a further character distinguishing them from Oreohelix, which is viviparous. It is also a more primitive feature.

Sonorella hachitana (Dall). Plate V, figs, $4,4 a, 4 b$.

Epiphragmophora hachitana Dall, Proc. U. S. Nat. Mus., XVIII, p. 2, 1895; IIX, p. 335, 1896.

Sonorella hachitana (Dall), Pilsbry, Proc. A. N. S. Phila. for 1900, p. 556, 1901; 1905, p. 257 (in part).

Sonorella hachitana (Dall), Bartsch, Smithsonian Misc. Coll., vol. 47, p. 190, Pl. 31, fig. 2 (shell of type); Pl. 29 (apex), 1904.

As this species is type of the genus Sonorella, ${ }^{5}$ the investigation of its soft anatomy had become a matter of importance, and to obtain living material was one of the chief objects of our quest in the Hachetas.

We found it at Stations 7, 8, 10 and 11. All of these stations are near or on Dr. Mearns's route to the summit of Hacheta Grande. Station 7 , on the western slope of a hill at the head of the northern branch of Western Canyon, was the most prolific locality. Here the Sonorellas may be found in some numbers under large stones on the steep slope near the hill-top, where there is some shade from the piñon pines.

Twenty-one adult shells from this station measure as follows:

$\begin{array}{lcccccc}\text { Diam. in mm } \ldots \ldots \ldots \ldots \ldots \ldots \ldots \ldots \ldots \ldots \ldots & 21.5 & 22 & 22.5 & 23 & 23.5 & 24 \\ \text { Number of shells } \ldots \ldots \ldots \ldots \ldots \ldots \ldots \ldots \ldots \ldots & 2 & 8 & 2 & 7 & 1 & 1\end{array}$

The shells vary somewhat in the degree of deflection of the last whorl, but very little in other respects. The last whorl descends more than in most related species. The color is pale fawn, fading to whitish in the middle of the base, and having a cinnamon-brown, shading into chestnut-brown, band above the periphery; this band is bordered with white on both sides. The aperture is rather small, its greatest diameter (including peristome) being 50 to 54 per cent. of the diameter of the shell.

At Station 8 only dead shells were found, but these are more variable in size, the extremes in a lot of 8 measuring:

Alt. 13.5, diam. $25.5 \mathrm{~mm}$; aperture diam. $13.6 \mathrm{~mm}$.

" 11 " 21.3 " " " 10.8 "

${ }^{5}$ Epiphragmophora hachitana Dall was originally designated as the type of Sonorella, but the soft anatomy of the genus was described from New Mexican specimens of what was subsequently determined as a small form of S. ashumni Bartsch, a species which at that time had not been discriminated from $S$. hachitana. The dissection of topotypes of hachitana shows that the New Mexican form is specifically distinct, though closely allied. 


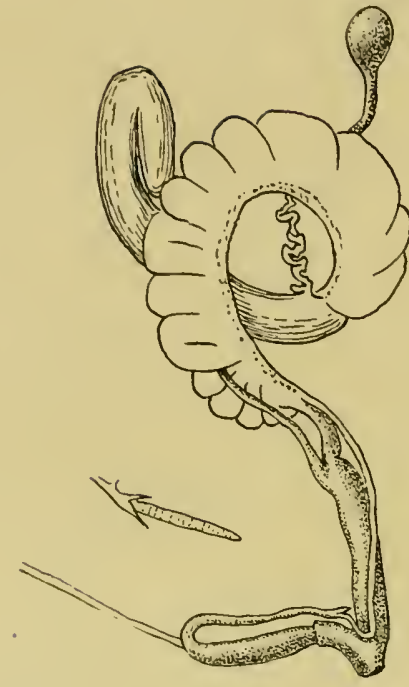

Fig. 2.-Crenitalia of S.hachitana, with detail of penispapilla.

At Station 5 two broken examples, much weathered, were dug out of the soil. Though practically adult, the largest measures only $18.2 \mathrm{~mm}$. diameter, the shell being quite as solid as in large individuals. It was probably dwarfed by the arid conditions before it became extinct in this place.

The genitalia are remarkable for the small size of the male organs. The penis is very slender, diameter $1 \mathrm{~mm}$., tapering downward, and encircled at the base by a short sheath. The penis-papilla is very slencler, gradually tapering, and annulate. The retractor muscle is terminal, long and slender. Epiphallus a little shorter than the penis. The vagina is slightly longer than the penis. Other organs as usual. Measurements of the organs of two individuals are given in the following table, with those of allied forms for comparison.

\begin{tabular}{|c|c|c|c|c|c|c|c|c|}
\hline & $\stackrel{2}{3}$ & 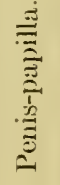 & $\frac{\stackrel{n}{\Xi}}{\stackrel{3}{\overline{3}}}$ & 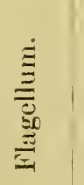 & 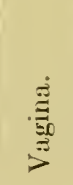 & 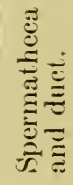 & 竞 & $\begin{array}{l}\dot{\bar{z}} \\
\vdots \\
\vdots \\
\underline{\underline{z}}\end{array}$ \\
\hline S. hachitana & 6.25 & +6 & 4.2 & 1.25 & 7.5 & 19 & & 103,095 \\
\hline S. h. flora. & 10 & $\begin{array}{l}4.3 \\
5.5\end{array}$ & 6.2 & $\begin{array}{l}1.0 \\
1.0\end{array}$ & 123 & 36 & & $\begin{array}{r}94,329 \\
9+329\end{array}$ \\
\hline “ & 9 & 4 & 6.5 & 0.5 & 10.5 & 29 & & 56,496 \\
\hline S. h. peloncillensis.... & $\begin{array}{l}11 \\
10\end{array}$ & $\begin{array}{l}6 \\
6.2\end{array}$ & $\frac{62}{7}$ & $\begin{array}{l}1.3 \\
1.25\end{array}$ & $\begin{array}{c}10.3 \\
9\end{array}$ & 29 & $9 . \overline{5}$ & $\begin{array}{l}94,513 \\
94,513\end{array}$ \\
\hline
\end{tabular}

The well-arched jaw has 7 or 8 ribs. The radula has about 22, 16 , $1,16,22$ teeth, both cusps becoming split on the marginal teeth.

In my former work on S. hachitana (1905) I referred shells from the Organ and Florida Mountains and from central Arizona to S. hachitana, which at that time was not known anatomically. While it must be admitted that the shells are very similar, I find differential 
anatomical characters, which, though not great, seem to be constant in a considerable number examined, and which favor the more analytical treatment of the hachitana group effected by Dr. Bartsch, - a view I formerly opposed. After examining many fresh specimens from both ranges, I separate the Florida and Hacheta Sonorellas subspecifically.

Whether the typical form of $S$. hachitana occurs outside of the Big Hachet range is doubtful. The Peloncillo range Sonorella (S. h. peloncillensis) is not easily distinguishable by the shell alone, but the proportions of the genitalia differ.

On the Carrizolillo Mts., top of two peaks near the boundary line, numerous "bones" were collected by Dr. Mearns (No. 126,596, U. S. N. M.). They agree with S. hachitana in the rather wide umbilicus, small aperture and deeply descending last whorl, but differ by the average smaller size, from alt. 10.8, diam. $19.3 \mathrm{~mm}$., to alt. 12.4 , diam. $21.4 \mathrm{~mm}$. It is apparently a small race of hachitana. The locality is about 30 miles east of Big Hachet Mountain.

Specimens reported as $S$. hachitana from the Chiricahua Mountains will doubtless turn out to be one of the species already described from there. Several resemble hachitana more or less in the shell, but all differ in genitalia.

The specimen reported from the Santa Rita Mountains (No. 105,385, U. S. N. MI.) is dead and broken. It is not hachitana, but probably an undescribed species near S. clappi P. \& F.

Ashmunella mearnsii (Dall). Plate V, figs. 1 to $1 b$.

Polygyra mearnsii Dall, Proc. U. S. Nat. Mus., Xvili, p. 2, 1895; XIX, p. 343, Pl. 32, figs. 7, 8, 11, 1896.

Up to this time A. mearnsii has been known from the original lot collected by Dr. Mearns about twenty years ago. ${ }^{6}$ We found it

${ }^{6}$ The figured type of A. mearnsii and nine specimens in various conditions of perfection are Cat. No. 130,012, C.S. N. M., said to be from the Huachuca IIts. In the adult shells of this lot the parietal wall of the aperture is built up and disjoined from the preceding whorl. In another lot, No. 130,013, L.S. N. M., three specimens, Hacheta Grande $\mathrm{Mt}$., the parietal callus is appressed. This difference in the parietal callus is exactly what we have noticed between the specimens from our Station 5 (near Dr. Mearns's camp site) and those from our Stations 10 and 11 , near and at the top of Hacheta Grande MIt., a place also visited by Dr. Mearns. We conclude, therefore, that there was a mistake of "Huachuca" for "Hacheta" in the label of No. 130,012; and that A. mernsii does not really live in the Huachucas. This secms the more likely because in several camping trips to the Huachucas this species was not found.

A record of A. mearnsi from the Organ Mountains, $\mathrm{N}$. M., has been published, on the authority of Professor Cockerell. We have not seen the specimen, but suspect that they are $A$. kochi Clapp.

We suggest that our Station 5 in the Hacheta Mountains be acepted as type locality for $A$. mearnsi. 
in great profusion at Station 5 on the east side- of Daniels Mountain, near the summit, with Holospira bilamellata. Also at Stations 7, 10 and 11 , the latter at the summit of Hacheta Grande.

The specimens from Station 5 (not far from the site of Dr. Mearms's camp) agree well with the original specimens, description and figure. Usually the parietal callus is raised from the surface as a thin, straight lamina, and in almost all of them the edge is more definite than in shells from other stations. The axial end of the parietal lamella is abruptly bent towards the columella and is more or less tubercular; Rarely the tubercle is almost free from the lamella. The spire is occasionally ahmost flat. The color in shells taken alive is translucent sayal brown. The diameter varies from 11.5 to $14.5 \mathrm{~mm}$.

In specimens from the summit of Hacheta Grande the parietal lamella are a little shorter; the axial end of the longer branch is

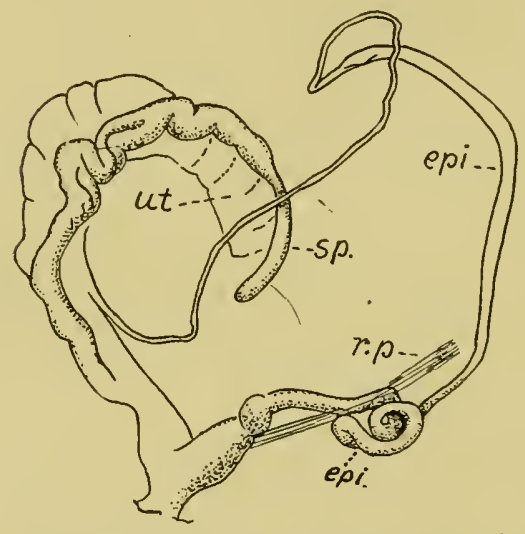

Fig. 3.-Genitalia of A. mearnsi. epi., epiphallus; $p$. , penis; $r . p$. , retractor of the penis; $s p_{\text {. }}$, spermatheca; ut., uterus. often straight, but more frequently is bent, or the bend is represented by a tubercle connected with, or almost free from the lamella. The edge of the parietal callus is appressed to the surface, and is often arcuate. The aperture varies in obliquity, as the figures show.

The penis is stout, bipartite. The epiphallus is strongly convoluted just beyond the insertion of the retractor musele. It is very long. No flagellum seen. The spermatheca is largest in the micldle, thin-walled. Length of penis $4.5 \mathrm{~mm}$; epiphallus 30 mm.; vagina $4 \mathrm{~mm}$.; spermatheca and duet $19 \mathrm{~mm}$.

A. mearnsi lives in the earth under stones, like $A$. walkeri in the Floridas, both being burrowing species. It is closely related to A. kochi Clapp and A. walkeri Ferriss, but quite distinct from both. A. levettei bifurca in the Huachucas is a less depressed shell with more whorls.

Oreohelix (Radiocentrum) hachetana n. sp. Plate VI, fgs. I to I $d, 6$.

The shell is depressed, umbilicate, the umbilicus about one-fourth the diameter of the shell; moderately solid, but thin, opaque whitish, obliquely streaked or smeared with various shades from light cimna- 
mon-drab to pale ecru-drab, often having a band of the same below the periphery; embryonic whorls fawn color. Spire convex or very low conic, $1 \frac{3}{4}$ embryonic whorls convex, sculptured with delicate, retractive radial rib-striæ, a few very fine spiral lines in the intervals (fig. 6); following whorls irregulary marked with weak growthlines, less convex, a little flattened or impressed above the suture, the last whorl convex, very indistinctly angular at the periphery, slowly descending to the aperture, convex beneath. The aperture is very oblique, about as high as wide. Peristome thin, the upper and basal margins somewhat prolonged and a little straightened, converging, joined by a thin, adnate parietal callus.

Alt. 9, diam. $15 \mathrm{~mm}$.; $5 \frac{1}{3}$ whorls.

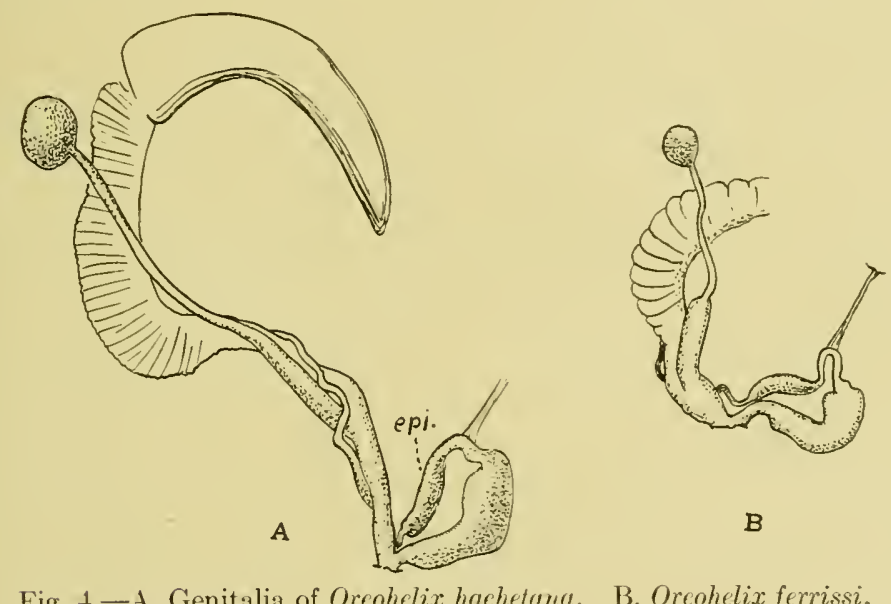

Fig. 4.-A. Genitalia of Oreohelix hachetana. B, Orcohelix ferrissi.

Genitalia (fig. 4,A). The penis is very short, its distal half enlarged. The walls of the rather large cavity are densely papillose, the papillæ long, arranged in oblique rows in some parts. Epiphallus about equal in length to the penis, its distal half enlarged. Vagina equal to the penis in length. Length of the penis, epiphallus and vagina $5 \mathrm{~mm}$; length of spermatheca and duct $15 \mathrm{~mm}$.

Summit of Hacheta Grande Mountain, at Station 11, collected August 25th, 1910, by H. A. Pilsbry. Also Station 10, Pilsbry and Daniels.

This species was collected in considerable quantity-sereral hundred living specimens. The "bones" are seen all over the upper four or five hundred feet of the peak, between Stations 10 and 11 of the map. Living snails were all taken on the west side and were most 
abundant at the summit near and north of the small stone "monument" or cairn which marks the summit, on and under stones. Also on the precipitous western slope at Station 10.

The species is very uniform in all its characters. The size varies. from 14 to $16 \mathrm{~mm}$. diameter, and in some shells the last whorl descends more than in others. Very few have the parietal callus thickened and a little raised. It differs from all forms of $O$. strigosa by its convex, radially costellate embryonic whorls, but in many adult shells this sculpture is effaced. O. ferrissi is probably the most nearly related species, though very different.

Oreohelix hachetana cadaver n. subsp. Plate VI, fig. 2.

The shell is larger than hachetana, the periphery rounded in adults except near the aperture in front, where it is distinctly angular. Umbilicus smaller, one-sixth the diameter of the shell.

Alt. 11.5, diam. $18.5 \mathrm{~mm}$.; barely 5 whorls.

Station 5, below the cliffs on the north side of the summit of Daniels Mountain, Daniels and Pilsbry, August 22d, 1910.

Only a few long-dead shells were found in this thirsty place, where, at the base of the cliffs there are a few small pinyon pines, mostly dead or moribund. Holospira and Ashmunella mearnsi live here in abundance.

A young shell, long dead, found at Station 6, may belong to the same variety.

Oreohelix (Radiocentrum) ferrissi n. sp. Plate VI, figs. 4 to $5 d$.

The shell is openly umbilicate, umbilicus conic, over one-fourth the total diameter; slightly convex above, base strongly convex; thin, light dull brown. The embryonic shell of $1 \frac{1}{2}$ convex whorls is finely lamellose striate radially (fig. $5 d$ ). Post-embryonic whorls have the surface densely lamellose along growth-lines, the lamellæ rising in triangular cuticular processes where they cross the spiral ridges of the shell. When denuded, the shell has a blunt, projecting peripheral carina; the upper surface has a wide, somewhat angular spiral ridge upon all the post-embryonic whorls, sometimes with one or two minor ridges; the lower surface has three to five low spiral ridges and some minute, weak spiral striæ; the whole shell being closely thread-striate along growth-lines. The last whorl usually does not descend in front. Aperture oblique, irregularly rounded, lip simple, the margins rather widely separated, parietal callus thin. Shells denuded of the cuticular processes measure:

Alt. 6.5 , diam. $14.5 \mathrm{~mm}$; $4 \frac{1}{2}$ whorls.

"6, " 615 " $4 \frac{1}{2}$ " 
Genitalia similar to $O$. hachetana, except that the lower third of the duct of the spermatheca is more enlarged. Length of penis $5 \mathrm{~mm}$.; epiphallus $5.5 \mathrm{~mm}$; spermatheca and duct $9 \mathrm{~mm}$. (fig. $4 \mathrm{~B}$ ).

Hacheta Grande Mts. at Station 3, on ledges of high cliffs opposite the mouth of Sheridan Canyon, under stones, Pilsbry and Daniels, August 21, 1910. Cotypes. No. 112,276, A. N. S. P. Also at Station 1, Teocalli Butte.

$O$. ferrissi has much the appearance of the Chiricahuan O. barbata Pils., but this resemblance is superficial. When denuded of the cuticular fringes, the two are quite different, the Chiricahuan species being much smoother, without the strong spiral ridges of $O$. ferrissi. Moreover, the sculpture of the embryonic shell is different. The shape of penis and epiphallus in $O$. ferrissi is like $O$. chiricahuana and $O$. clappi, both organs being enlarged distally, while in $O$. barbata the lower half of the penis is enlarged, the distal portion slender.

In well-developed shells the last whorl scarcely descends anteriorly, the upper margin of the lip being inserted on the peripheral carina. In some of the smaller adults, diam. $13 \mathrm{~mm}$., the last whorl is bent downwards; the upper and columellar margins of the lip converge and are connected by a raised parietal lamina, the mouth having a somewhat triangular contour. These are to be regarded as decadent (gerontic) individuals.

At Station 1, Teocalli Butte, the shells are all convex above, with a noticeably smaller umbilicus. The largest measures, alt. 7.8, diam. $15 \mathrm{~mm}$., with 5 whorls (Pl. VI, fig. 4b). This small colony is probably extinct or nearly so, as no living shells were found.

Our Station 3 is on ledges of high cliffs facing the mouth of Sheridan Canyon, and especially on a bench about half-way up. Here Ferriss's Oreohelix lives on an almost inaccessible cliff looking out over the mesa into Mexico. There is little vegetation on the ledges. On the talus slope below the cliff there is a growth of dwarf oak about knee-high, charming big wild roses of a species which we saw nowhere else, Cylindropuntia, Opuntia, bisnagas, etc. On top, above the cliffs, the Fouquieria, sotol, mescal society is found. The Oreohelix colony is of small extent; the ledges where they were observed living are probably not over a couple of square rods in area, with perhaps an equal area on the talus below the cliffs, where dead shells were found. These estimates are from memory, as I neglected to note the figures at the time.

The locality on the east side of Teocalli Butte is more restricted, and if posible more arid. 
Oreohelix ferrissi morticina n. subsp Plate V1, fig. 3.

Differs from $O$. ferrissi by the more convex spire and by the weakness of the spiral sculpture, there being no such pronounced spiral ridge on the upper surface of the whorls, and only very weakly sketched spirals on the base, whilst in $O$. ferrissi these ridges are very emphatic.

Alt. 7.2 , diam. $14.2 \mathrm{~mm}$; $4_{1}^{3}$ whorls.

Station 5, below the cliffs on the north side of Daniels Mountain, near the summit, with Holospira, ete.

Only a few long-dead shells were taken, but these surely indicate a local race which has finally succumbed to the increasing aridity of their station. Of large shells only Holospira and Ashmunella survive on this mountain, both of them being burrowing animals.

Thysanophora hornii (Gabb).

Found at Stations 3 and $\check{5}$. It is an almost ubiquitous Lower Śonoran snail.

\section{UROCOPTID $\approx$ 世.}

The study of a very large series of Hachita Holospiras has fully confirmed the results reached in our study of Chiricahuan species, that the number of internal lameldæ is variable in each species and colony, among perfectly mature or even aged individuals. They vary in a way it was impossible to foresee at the time when Holospiras were so rare that only one or two of a lot could be opened. Very naturally, the number of internal lamellæ was thought at that time to be of specific and even subgeneric value.

In some colonies it appears that the largest shells have in the average the greatest development of lamellæ, so that it might be thought that only the most vigorous individuals attain the full number; yet other races or colonies give a contrary result. No external character is correllated with the number of lamelli. Usually most of the shells of any one colony resemble each other in size, shape and sculpture, so that each lot has a certain individuality, though all of the characters vary more than is usual among the land snails. We have never found two species of Holospira living in one colony, either in the Hachitas or in any other district, in the course of several years, collecting, in many places in Texas, New Mexico and Arizona.

A comparison of the Holospiras of the Hachita Grande range with those of the Chiricahua range shows some interesting resemblances and differences. In both localities the internal lamellæ present (in 
almost every form known by large lots) may be (1) Superior, axial and basal, or (2) axial only. In Hachita forms we have also the combination (3) axial and basal, which is never found in the Chirieahuan series, where it is replaced by the combination (1) superior and axial. Every Hachita species has, therefore, in different specimens of the same eolony, the characters of the supposed subgenera or sections Bostrichocentrum, Haplostemma, Distomospira, and Tristemma, while a Chiricahuan species will belong to Bostrichocentrum, Eudistemma, and Tristemma. In external form and seulpture there are no differences greater than specific between the Hachita and Chiricahua species.

The Hachita Holospiras belong, if we accept the criterion of intergradation, to only one species, for which the prior name is $H$. crossei. Between this species and $H$. bilamellata there is a perfect series of intergrades in size, sculpture and number of whorls. IVe mean by this that some individuals of an $H$. crossei colony could not be distinguished from mearnsi; some mearnsi can be exactly matched in a colony of bilamellata, or of media; and certain slender shells of bilamellata would pass as longa. The other named forms are more distinct, probably because we did not happen to collect where the intergrading colonies live. The races are therefore based upon the forms dominant in each colony. One might easily define a half dozen species, if only a few shells from each place were in hand; or if the internal lamełlæ were taken to be of specific weight, it might be thought that there are between two and three times that number.

There are many colonies, most of which have some special characters. A thorough exploration of the northern end of the range will undoubtedly bring to light very many more forms, so that any treatment of the group must now be tentative. For our present purpose we consider the smallest form (crossei) and the largest (bilamellata) as species, ranking the others as subspecies, though in some cases they are more distinct than these two are from one another. Several thousand shells were collected.

The colonies at Stations 1, 2, 3, 12, are of very limited extent, physical features restricting them. Station 5 is much larger. The other Stations, $4,6,8,9,10,11$, merely represent collecting points in large areas where Holospira may be picked up almost anywhere over considerable tracts, while at the same time there are large areas in the region over which these stations are scattered where no shells can be found. 
Holospira bilamellata Dall. Plate VII, figs. 1 to $1 d$.

Holospira (Distomospira) bilamellata Dall., Proc. U. S. Nat. Mus., XVIII, 1895, p. 4; XIX, p. 896, p. 349, Pl. 31, fig. 3. Pilsbry, Man. of Conch., XY, 1902, p. 82, Pl. 16, figs. 5, 10, 11 . Bartsch, Proc. U. S. Nat. Mus. XXXI, 1906, p. 134. Daniels, Nautilus, XXVI, p. 41, Pl.5, fig. 9 (normal) and fig. $S$ (abnormal) shells.

The first four references cited above pertain to specimens of the original lot, of which there are 8 perfect shells in Coll. U. S. Nat. Mus. and 2 in Coll. A. N. S. Phila.

The species is distinguished from $H$. crossei chiefly by its greater size. It was found by Mr. Daniels and the writer in great abundance at Station 5, on the east side of Daniels Mountain under the cliff,s close to the summit, with Ashmunella mearnsi and Oreohelix, in the piñon zone. In most of the shells the external ribs weaken or disappear on the penultimate and one or two earlier whorls, but in some they continue to the last, as in the type lot of bilamellata.

Sixty examples from Station 5 opened, most of them measured give the following data:

(1) One lamella, the axial. 13 specimens $=21 \frac{2}{3} \%$.

Length 23, diam. $5 \mathrm{~mm}$; whorls 19

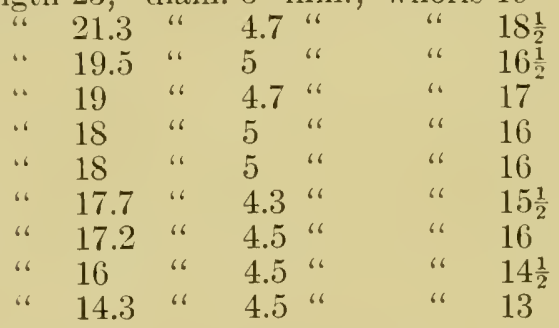

(2) Two lamellæ, axial and basal. 41 specimens $=68 \frac{1}{3} \%$.

Length 2.2, diam. $4.9 \mathrm{~mm}$.; whorls $18^{\frac{1}{2}}$

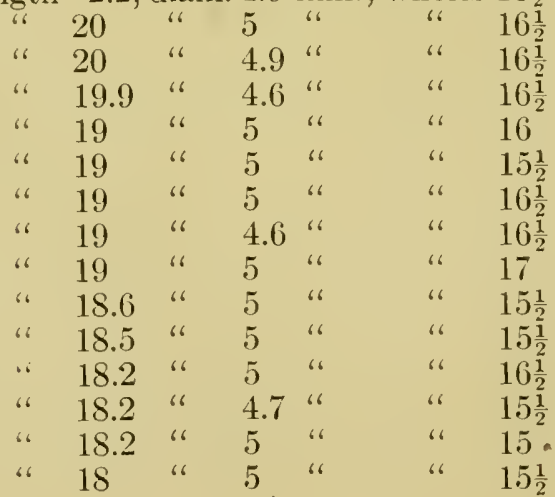


Length 18, diam. $5 \mathrm{~mm}$; ; whorls 16

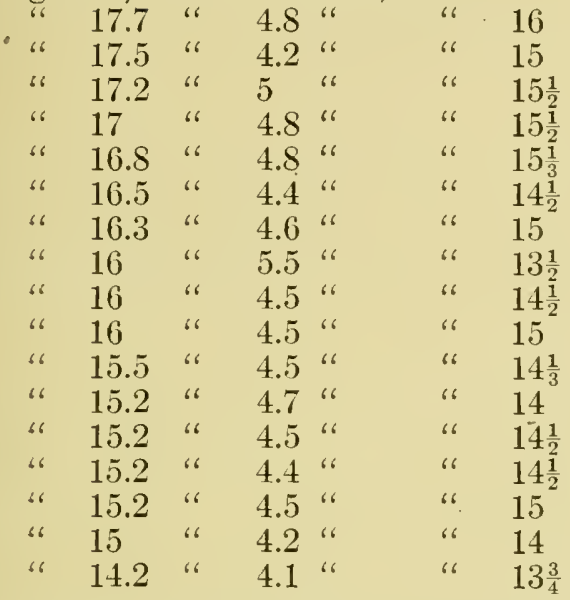

(3) Three lamellæ, superior, axial and basal. Six individuals $=10 \%$.

Length 20.5, diam. $4.9 \mathrm{~mm}$; ; whorls 17

\begin{tabular}{|c|c|c|c|c|}
\hline 20 & "6 & 5 & 6 & " \\
\hline 20 & $"$ & 4.9 & " & "6 \\
\hline 19.5 & $" 6$ & 4.9 & " & " \\
\hline 19 & " & 5 & " & " \\
\hline
\end{tabular}

In size, sculpture and shape, we can find no external character correllated with the differences in internal structure. The specimens from Station 5 are from one colony.

It will be seen that the typical bilamellata axial structure predominates, nearly $70 \%$ having that arrangement of lamellæ. The dimensions of this lot agree well with those given by Bartsch for 8 specimens in the U. S. Nat. Mus., but our lot, being larger, includes shells both larger and smaller than any in the original lot.

Holospira bilamellata longa n. form. Plate VII, figs. 2 to $2 b$.

Slender and pillar-like, the diameter contained four times or more in the length; whorls of the cone and last whorl costulate, 3 to 5 intermediate whorls usually smooth or nearly so. Aperture projecting laterally and forward; usually 3 internal lamellæ, in the beginning of the penultimate whorl, therefore ventral in position, the superior lamella generally very strong, and larger and longer than the basal.

Length 19.6, diam. 4 mm.; whorls 17

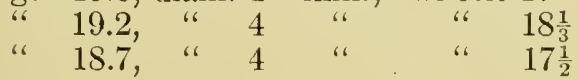


Length 17.9 , diam. $3.9 \mathrm{~mm}$; whorls 17

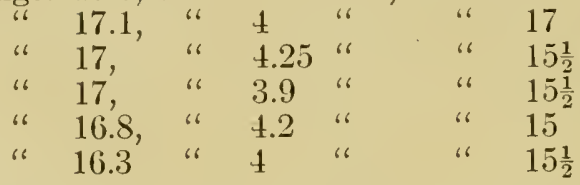

Station 4, on the south slope of Daniels Mt. near the summit. Types Nos. 112,269, A. N. S. P., collected by Pilsbry and Daniels, August 22, 1910.

Out of 20 shells opened, 16 have three lamellæ and 4 have two, the axial and basal. The pillar-like shape, numerous whorls, and prevalence of a superior lamella, as well as the deeper position of the lamellæ, are individually variable characters, yet in the aggregate they may suffice to define a race in this group.

These Holospiras live among rocks where there is very little xerophytic vegetation and the heat is terrific. The type lot was picked up at about the same elevation as Station 5, but there the exposure is less calorific, the sparse piñons and the cliffs afford shade, so that the soil retains some moisture.

Holospiras were seen scattered over a large area below and around Station 4.

Holospira bilamellata heliophila n. subsp. Plate VII, figs, 3 to $3 c$.

The shell is small, rather slender, with a long cone; strongly costate throughout; usually having axial and basal lamellæ within the middle part of the penultimate whorl. Peristome well expanded in the basal and columellar margins, but scarcely so near the upper angle.

(1) One lamella, the axial. 3 specimens $=15 \%$.

Length 14.2 , diam. $3.8 \mathrm{~mm}$; whorls 16

$\begin{array}{lllllll}\text { " } 13.3, & \text { " } & 3.7 & \text { " } & \text { " } & 15 \frac{1}{3} \\ & 13 & & 3.9 & \text { " } & & 14 \frac{1}{2}\end{array}$

(2) Two lamellæ, axial and basal. 13 specimens $=65 \%$.

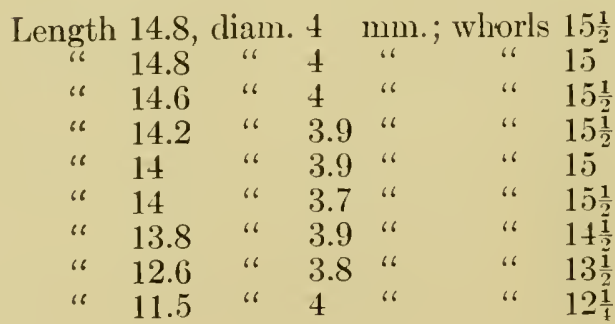


(3) Three lamellæ, superior, axial and basal. 4 specimens $=20 \%$.

Length 13.9, diam. $3.7 \mathrm{~mm}$; whorls $15 \frac{1}{2}$

" 13, " 4 " " 14

Station 1, northern and eastern sides of Teocalli Butte, at the base of the cliff. Types Nos. 112,265, A. N. S. P.

Twenty shells opened out of a series of over 250 show that the bilamellate form predominates. The largest shell noticed is 14.9 $\mathrm{mm}$. long, the smallest $11.5 \mathrm{~mm}$. There is rather wide variation in sculpture, but a large majority of the shells conform to fig. $3 a$ in this respect.

Holospira bilamellata insolata n. subsp. Plate VII, figs. 4 to $4 a$.

The shell is slender, with a rather long terminal cone; very strongly

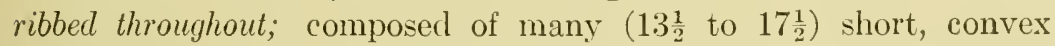
whorls, the last very shortly free in front. Peristome narrow, only very slightly expanded. Only the axial lamella developed in 14 out of 16 individuals opened, the other two having axial and basal lamellæ.

Length 15.5, diam. $3.6 \mathrm{~mm}$; whorls $17 \frac{1}{2}$

\begin{tabular}{|c|c|c|c|c|c|c|}
\hline & & & & & & \\
\hline & 15 & “ & 3.8 & " & “ & $16 \frac{1}{2}$ \\
\hline & 14.9 & $"$ & 3.5 & $"$ & $"$ & $16 \frac{1}{2}$ \\
\hline 8 & 14.8, & “ & 3.8 & " & “ & $16 \frac{1}{2}$ \\
\hline 66 & 14.5े, & $" 6$ & 3.6 & $"$ & “ & $15 \frac{1}{2}$ \\
\hline 86 & 14 & $"$ & 3.8 & $" 6$ & $"$ & $15 \frac{1}{2}$ \\
\hline & 13.5 & $\because$ & 3.8 & $" 6$ & $" 6$ & 15 \\
\hline & 13 & "، & $\begin{array}{l}3.7 \\
2.2\end{array}$ & "6 & " & $1+\frac{1}{2}$ \\
\hline & 13 & 6 & 3.3 & 6 & " & $15 \frac{1}{2}$ \\
\hline & & “ & $\begin{array}{l}3.20 \\
3.9\end{array}$ & " & “ & \\
\hline & 11.8, & "6 & 3.9 & "6 & " & $13 \frac{1}{2}$ (axial and basal lamellæ). \\
\hline
\end{tabular}

Station 6, on the southeastern slope of the mountain south of Big Hachet Mt.

This form differs from crossei and mearnsi by the more slender shape, long terminal cone, more numerous whorls and strong sculpture. It agrees with bilamellata in having many whorls, but differs by its slender form, longer cone, the prevalence of unilamellate shells, etc. $H . b$. heliophila stands nearest to insolata, but in that race the bilamellate form predominates. It is more conspicuously ribbed than any of the other Hacheta races.

Holospira bilamellata media n. subsp. Plate VII, figs. 5 to $5 c$.

The shell is cylindric with a long terminal cone; composed of many closely coilerl, convex whorls, all after the embryo rather strongly, 
sharply costulate; buff-whitish except where darkened by the presence of the soft parts, the last whorl shortly projecting; peristome narrowly expanded. Internal lamellæ one to three, but axial and basal most frequent. 75 individuals opened from the type locality.

Southern and western portions of Sheridan Canyon, at Stations 2, 12 and 3. Types Nos. 112,268 A. N. S. P., from Station 3, at the base of a cliff near the mountain top, facing the mouth of Sheridan Canyon, in company with Oreohelix ferrissi.

Specimens from the type locality measure as follows:

(1) An axial lamella only. 22 individuals $=29 \frac{1}{3} \%$.

Length 16.9, diam. 4 mm.; whorls 16

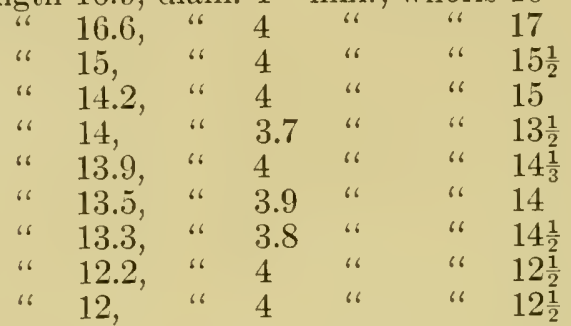

(2) Axial and basal lamellæ. 48 shells $=64 \%$.

Length 18.5 , diam. $4.25 \mathrm{~mm}$.; whorls $17 \frac{1}{2}$

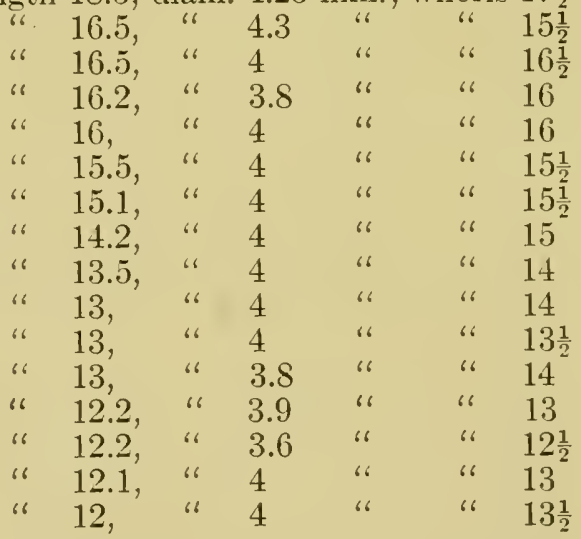

(3) Three lamellæ, superior, axial and basal. 5 shells $=6 \frac{2}{3} \%$.

Length 18, diam. $4 \mathrm{~mm}$.; whorls $17 \frac{1}{2}$

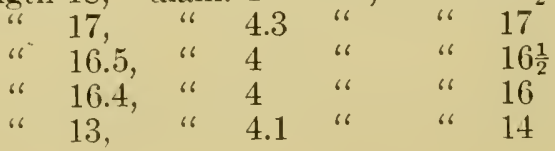


Also one shell which has two basal lamellæ. The upper partition was broken away in opening, so that the presence of a superior lamella is uncertain.

This form stands nearest to $H . b$. mearnsi, but the striation is sharper, not partially effaced on the later whorls and the cone is in the average longer. The habitats of mearnsi and media are rather remote from one another, and several other forms inhabit territory between them.

The specimens from Station 12 are more like mearnsi, the sculpture being weak on the penultimate and next earlier whorls. Out of 11 opened-

2 have one lamella, axial.

9 have two lamellæ, axial and basal.

1 has three lamellæ, axial, basal and superior.

Station 2 is on the northern slope of one of the ravines east of and running from Teocalli Butte, at the foot of an irregular projecting bench of limestone. It is much the lowest station where shells were found in the Hachetas. The shells are partly as rough as those from Station 3, but some approach those of Station 12. Out of 21 shells opened-

15 have two lamellæ, axial and basal.

6 have three lamellæ, axial, basal and superior.

In size the shells from Stations 12 and 2 are about equal to those from Station 3.

Holospira bilamellata mearnsi Dall. Plate VII, figs. 6, $6 a$

Holospira (Haplostemma) mearnsi Dall, Proc. U. S. Nat. Mus., XVIII, 1895, p. 4; XIX, 1896, p. 350, Pl. 31, fig. 1.

Holospira (Distomospira) mearnsi Dall, Bartsch, Proc. U. S. Nat. Mus. IXXI, 1906, p. 134.

Six shells of the type lot, the measurements of which are given by Dr. Bartsch, measure 14 to $15.8 \mathrm{~mm}$. long, 4.2 to 4.5 wide, with 14 whorls. Twenty shells were taken at our Station 8 , on the eastern slope of Hacheta Grande MI. (see map, p. 325). Ten were opened, 3 having only the axial lamella, which is very weak in two of them; 7 have axial and basal lamellæ. Measurements follow.

Length 17, diam. $4.5 \mathrm{~mm}$; whorls 15 ; an axial lamella.

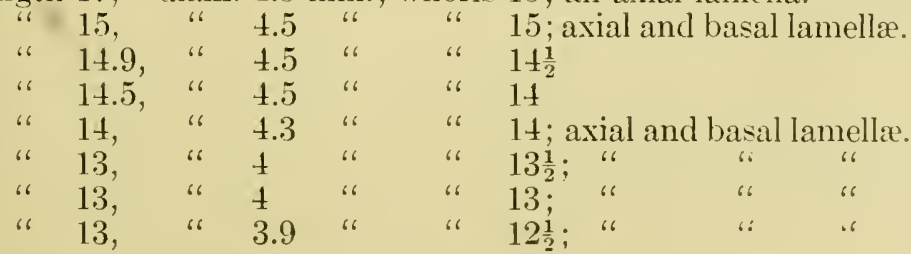


Length 12.6 , diam. 4 mm.; whorls $13 \frac{1}{2}$

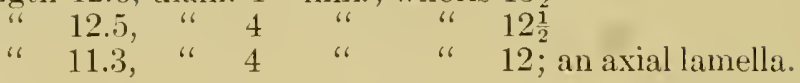

These shells connect $H$. crossei and $H$. bilamellata. specimens of intermediate size agree exactly with one of the type lot of mearnsi, kindly lent from the National Museum. The smallest shells are indistinguishable from crosse $i$, while the largest could not be separated from small bilamellata. Yet the colony as a whole has a certain inclividuality by its intermediate size, and as the form has been named, we let it stand as a convenient place for crossei-bilamellata intergracles. It is attached to $H$. bilamellata rather than to $H$. crossei, because the prevalent form, in the small lot opened, is bilamellate. All of the shells were collected in one spot where the writer sat resting. A large quantity could have been gathered had time and strength permitted. A few specimens are quite finely striate, while others are rather coarsely ribbed, like the type of mearnsi; still others being intermediate in sculpture. The sculpture in some shells becomes very much weaker on the penultimate and next earlier whorls.

H. mearnsi served as monotype of the subgenus Haplostemma Dall, characterized by the possession of an axial lamella only. Bartsch, opening another specimen, found a basal lamella also, and concluded that that lamella had been broken away in opening the original specimen. Since some fully adult examples are known to have an axial lamella only, it is likely that Dall's original diagnosis was correct for the specimen he opened, while Bartsch was also right as to the shell he examined and which we have seen.

Holospira crossei Dall. Plate VII, figs. 7 to $7 c$.

Holospira crossei Dall, Proc. U. S. Nat. Mus., XVIII, 1S95, p. 3 ; IIX, 1897 , p. 348, Pl. 31, fig. 2. Pilsbry, Man. of Conch., XT, p. 92, Pl. 23, fig. 75; Moll. S. W. States, ii, Proc. A. N. S. Phila., 1905, p. 217, Pl. 26, fig. S. Bartsch, Proc. U. S. Nat. Mus., XXXI, 1906, p. 137.

All of the above references were based upon the original lot, of which there are 11 perfect specimens in Coll. U. S. Nat. Mus. and 2 in Coll. A. N.S. P. One of these two has a very weak, hardly noticeable fold on the axis, the other has a very strong but short fold there.

The writer collected $H$. crossei at the type locality, the summit of Hacheta Grande. The exact spot, Station 11, is just off the western edge of the small level tract at the summit, which is marked by a small stone monument. Being much higher, this station is less dry than Station 5, where the large $H$. bilamellata abounds, and 
there is decidedly more vegetation. A few were picked up on the slope towards Station 10, dead shells being scattered all over the upper $500 \mathrm{ft}$. or more of this ascent.

Sixty specimens were opened, measurements of 31 being given below.

(1) No axial lamella, merely a callous or very inconspicuous node on the axis in the penultimate whorl. 15 individuals $=25 \%$.

Length 14, diam. 4 mm.; whorls 13 ; penult. whorl smooth.

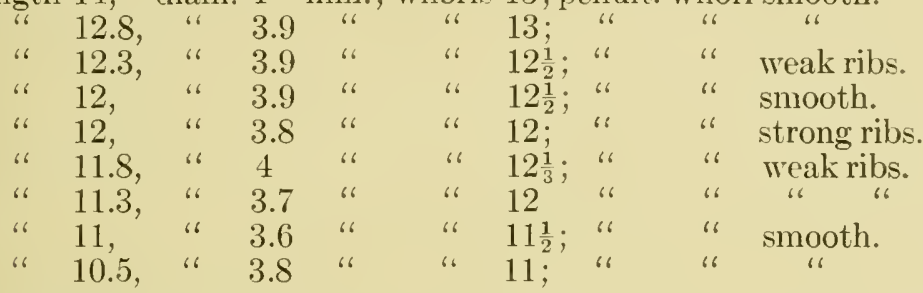

(2) Axial lamella in penultimace whorl short and strong; no other lamellæ. 30 inclivicluals $=50 \%$.

Length 13 , diam. 4 mm.; whorls $12 \frac{3}{4}$; penult. whorl weak ribs.

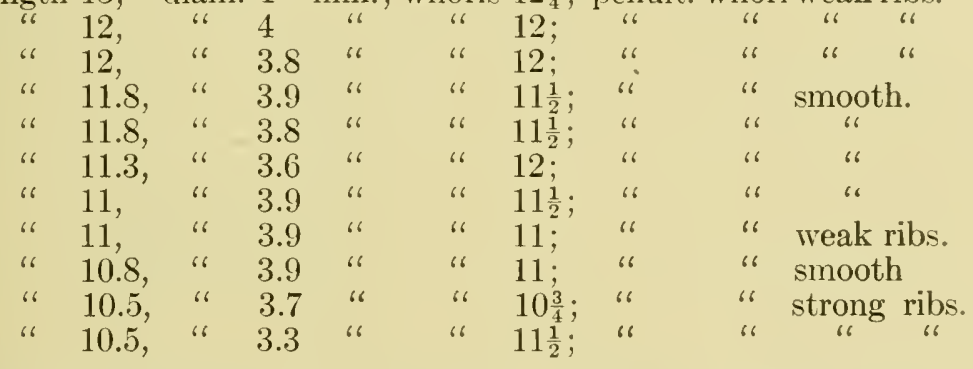

(3) Axial lamella short and strong or rarely weak; a basal lamella within last half of penultimate whorl. 12 specimens $=20 \%$.

Length 13, diam. 4 mm.; whorls $13 \frac{3}{4}$; penult. whorl smooth.

\begin{tabular}{|c|c|c|c|c|c|c|}
\hline 13 , & 6 & $" 6$ & $12 \frac{1}{2}$ & "“ & $"$ " & eak ribs. \\
\hline 13 , & 3.8 & $" 6$ & $13 \frac{1}{2}$ & 6 & 66 & 6616 \\
\hline 12.7, & 3.9 & 6 & $12 \frac{1}{2}$ & " & “ & smooth. \\
\hline 12.5 , & 3.8 & $" 6$ & 12 & "6 & $" 6$ & "6 \\
\hline 12.3, & 3.5 & " & $12 \frac{1}{2}$ & 6 & $" 6$ & strong ribs. \\
\hline 11.1, & 3.8 & $" 6$ & 12 & $" 6$ & 66 & " " " \\
\hline 11, & 3.9 & $" 6$ & $11 \frac{1}{4}$ & $" 6$ & 6 & weak ribs. \\
\hline
\end{tabular}

(4) Axial, basal and superior lamellæ in the last half of penultimate whorl. 3 indivicluals $=5 \%$.

Length 14, diam. 4 mm.; whorls 13 ; penult. whorl weak ribs.
" 12.7 , "
4.1
" " $12 \frac{1}{2} ;$ " "
$12 \frac{1}{2}$
" strong ribs,
"s smooth. 
The embryonic shell, of slightly over 2 whorls, is smooth and projects nipple-like. The following whorls of the cone are strongly ribbed, but the ribs weaken more or less on the cylindrical part, so that on the penultimate whorl they are often inconspicuous or almost wanting (for brevity called "smooth" in the above tables). There is of course complete intergradation in this character, so that the classification in the table is more or less arbitrary. The size averages larger in shells with 2 or 3 lamellæ, but there are exceptions. It will be understood that the measurements were based upon shells which to all external appearance are adult or old. After a careful study of the aperture and lip, I think that it may be accepted as certain that the variations in lamellæ recorded above are not dependent upon age of the individual.

At Station 10, on the northern slope of Hacheta Grande MIt, a small series was taken. All of them have the whorls of the cylindric portion smooth or nearly so, glossy, the cone and the last whorl, or its last half, being ribbed as usual. Ten specimens opened measure as follows:

Length 14.2, diam. 4 mm.; whorls 14 ; axial and basal lamellæ.

\begin{tabular}{|c|c|c|c|c|c|c|c|c|c|c|}
\hline & 66 & & "6 & 6 & & & 16 & 6 & & \\
\hline 13. & ، & +4 & "6 & "، & 12 & & "6 & " & & \\
\hline 13 & "، & 4.2 & " & " & 12 & & "6 & " & & \\
\hline 12.9 & "6 & 4 & "6 & " & 12 & & " & " & & \\
\hline 12.1, & " & 4.1 & "6 & " & 12 & & xia & & ell & only \\
\hline 11.5 & $"$ & 4 & " & "، & 12 & & " & & 6 & " \\
\hline 11.5 & " & 4 & "6 & " & 12 & & $" 6$ & & 6 & " \\
\hline 11.3, & " & 3.9 & “" & " & 11 & & “" & & 6 & " \\
\hline 10.3 & “" & 3.3 & "6 & " & 11 & & " & & " & " \\
\hline
\end{tabular}

This lot, by the size of some individuals and the large number $(50 \%)$ of bilamellate example, is intermediate between crossei and mearnsi, as it also is in the elcvation of the station. It has a feature of its own in the smooth median whorls, parallelled, however, by some individuals of crossei from the mountain top. None of the mearnsi seen are so smooth.

ZONITID Æ.

Vitrea indentata umbilicata (Ckll.).

Stations 3, 5 and 8.

Zonitoides minuscula alachuana (Dall).

Stations 8 and 11.

Cochlicopa lubrica (Müll.).

FERUSSACID里。

Station 8. Scarce. 


\section{PUPILLID Æ.}

Pupilla sonorana (Sterki).

Station 11. Abundant on the summit of Big Hachet Mt.

Bifidaria pellucidąh hordeacella (Pils.).

Stations $3,5,8$ and 11.

A peculiar short cylindric form, having less convex whorls, less tapering spire and blunter summit, was taken at Stations 3 and 5 .

Bifidaria pilsbryana Sterki.

Stations 8 and 11.

Bifidaria ashmuni Sterki.

Stations 3, 5, 8 and 11 .

\section{VALLONIID Æ.}

Vallonia sonorana n. sp. Fig. 5

The shell is very broadly, openly umbilicate, width of umbilicus contained about three times in the diameter of shell; whitish corneous. First $1 \frac{1}{2}$ whorls smooth, corneous, glossy; following whorls with sculpture of rather delicate riblets about $38-40$ on the last whorl, in fresh specimens bearing irregular cuticular extensions; the spaces between ribs delicately striate, the striæ irregularly anastomosing. Whorls $3 \frac{3}{4}$, strongly convex, rather slowly widening, separated by a

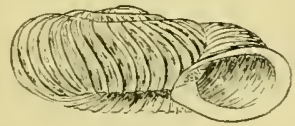

A

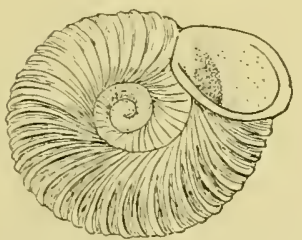

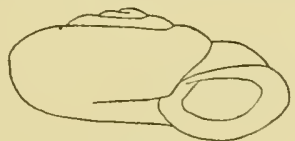

B

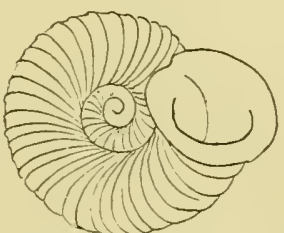

Fig. 5.-Vallonia sonorana. A, type; B, thick-lipped form.

deep suture; the last whorl deeply clescending close to the aperture. Aperture small, nearly circular, very oblique. The peristome is expanded and reflexed, slightly thickened within (in old specimens strongly thickened); the margins converge strongly and are connected by a very short parietal callus or are continuous, joined by a thin, slightly raised callus. The ample umbilicus is somewhat oblong. 
Alt. 1.1, diam. $2.7 \mathrm{~mm}$. (type, fig. 5A).

" 1.2 , " 2.6 " (fig. 5B).

Summit of Big Hachet Mountain, Station 11. Type No. 112,012, A. N. S. P., collected by Pilsbry, August 25, 1910.

This species is abundant at Station 11, in the dirt under stones. It is more closely related to $r$. perspectiva Sterki than to any other, but it is a very much larger shell. $T$. cyclopherella has far finer striation. $r$. gracilicosta has closer riblets and a much smaller umbilicus. r. albula has a smaller umbilicus.

Haring collected and identified some thousands of the Vallonias of Arizona and New Mexico in the last ten years, it was a surprise to find a species which differs conspicuously from the three mountain species mentioned above. As we have not found $T$. sonorana elsewhere in our work in southern New Mexico and Arizona, it seems likely that it is a southern species which barely crosses the international boundary. As a rule, Vallonias are rather widely. distributed snails.

The Holarctic genus Vallonia now comprises about 25 recent and pleistocene and a half dozen tertiary species, besides about a dozen named varieties. It is likely that some of these are mere synonyms. We have nine recent species in the United States, all of them readily recognizable, except $r^{r}$. excentrica, which is often hard to tell from pulchella.

Vallonia perspectiva Sterki.

Station 11, a few specimens taken with the preceding species.

\section{The Florida Mountains.}

The Florida range (accent on the $i$ ) is about twelve miles long, with a maximum elevation slightly exceeding $7,000 \mathrm{ft}$. It runs from north to south. A partially detached but adjacent continuation northward is known as the "Little Floridas." As in neighboring ranges, there is a long ascent or mesa before reaching the base of the mountains proper $(5,000 \mathrm{ft}$.), characterized by a zone of tree yuccas. The mountains are arid and rather barren, of limestone in the middle towards the top, granitic southward and porphyritic northward. Vegetation scrubby. We noted as common two small species of oak, hackberry, sotol, cylindropuntia, a broad-leared agave, etc. Barrel cactus (bisnaga) was seen at the foot.

In November, 1906, Mr. Ferris and the author clrove out from Deming 18 miles to Mr. Priser's cabin, where there is a small spring, in 
Spring Canyon. ${ }^{7}$ This is above the middle of the west side of the range. The summit here projects as a limestone butte, bounded by cliffs on the east, north and west sides. Access was gained to the top on the south side. The flat summit is covered with grass, Fouquieria, Cylindropuntia and other cacti, Agace, etc. No shells. There is a fine outlook, the jagged Organ Mountains silhouetted eastward. Around the base of this central summit we found Ashmunella walkeri and Sonorella by digging in the soil among the rocks, where there was shade. We found only seven species of snails in all.

Sonorella hachitana flora n. subsp. Plate $V$, figs. 3 to $3 c$.

Sonorella hachitana. .. Florida Mountains, Pilsbry, Proc. A. N. S. Phila., 1905, p. 257, Pl. 17, figs. 1-6 (shell), Pl. 20, fig. 12 (genitalia), Pl. 23, fig. 20 (jaw).

The shell is in the average larger than S. hachitana, with less distinct white borders along the shoulder band. Penis decidedly

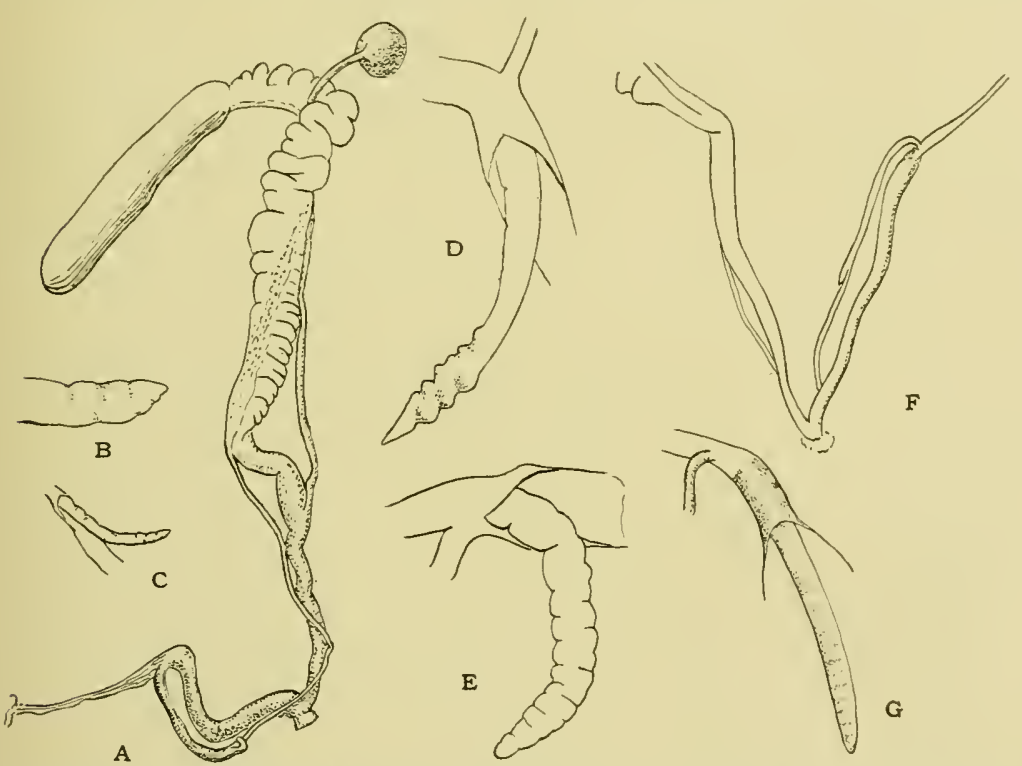

Fig. 6.-A-E, Sonorella hachitana peloncillensis. A, genitalia; B, C, penispapilla and end of same, enlarged; D, E, penis-papilla, two other individuals. F, G, S. h. flora, terminal ducts and penis-papilla.

7 This spring is not indicated on the U. S. G. S. Topographic sheet (Deming Quadrangle, edit. of Feb., 1899), and as our visit to these mountaius was unforeseen, we did not have the map. From memory we would say this spring is opposite Arco del Diablo of the map. Nr. Ferriss had made a flying visit to the range a year earlier, collecting ferus and a few snails on the slope facing the Little Floridas. 
longer, but the papilla and epiphallus only slightly or not longer than in hachitana.

Alt. 16, diam. 27, umbilicus $4 \mathrm{~mm}$.

120 specimens measure as follows, the upper line being diameters in $m m .{ }^{8}$ the lower line the numbers of specimens of each size:

$$
\begin{array}{cccccccccccccc}
22.7 & 23.7 & 24 & 24.5 & 2.5 & 25.5 & 26 & 26.5 & 27 & 27.5 & 28 & 28.5 & 29 & 29.7 \\
1 & 1 & 10 & 11 & 18 & 12 & 17 & 16 & 13 & 7 & 3 & 7 & 3 & 1
\end{array}
$$

The genitalia of $S$. h. flora (fig. 6, F, G) resemble the same organs in $S$. hachitana, except that the penis is decidedly and constantly longer, as are also the vagina and spermathecal duct. The penispapilla is indistinctly annulate and tapers slowly to the apex. The penis-retractor is long and slender, attached to the apex of the penis, and enveloping the base of the epiphallus. Measurements of the organs have been given on page 328 .

The pallial organs are much as in Sonorella optata, but there is no white thread defining the secondary ureter.

The sole, in alcoholic examples, resembles that of Sonorella bicipitis. It is ochraceous in the middle, pale gray at the sides. Back and flanks dark slate-gray, the tail fleshy-gray above, having an indistinct median line.

Jaw and teeth were described in a former paper of this series.

Ashmunella walkeri Ferriss. Plate V, figs. 2 to $2 e$.

This species was originally described from a few dead shells. We

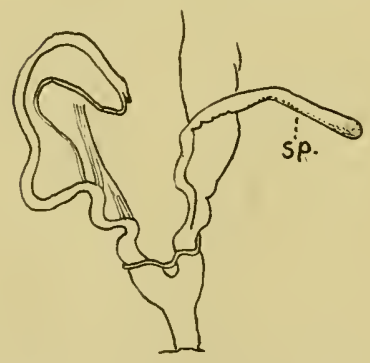

Fig. 7.-sp., spermatheca. found it living in abundance by digging in the soil among the rocks where there was shade. It lives in families or "pockets." The snails are very hard to pull, scarcely any coming out entire. When they do, the shell is very light colored, pale ocliraceous salmon or pale brown or entirely white. Old ones are dull, but the best-preserved adults have a little lustre.

The genitalia (fig. 7) have no peculiar features. The ducts are rather short. Length of penis $3 \mathrm{~mm}$.; epiphallus $14 \mathrm{~mm}$; vagina $2.5 \mathrm{~mm}$; spermatheca $10 \mathrm{~mm}$. The atrium is well developed and the flagellum distinct, though short as usual in the genus.

\footnotetext{
${ }^{3}$ Except the largest and smallest, the measurements disregard fractions less than half a millimeter, being designed only to show the general size.
} 
Oreohelix strigosa var.

Two broken and very old "bones" were found near the central peak above the spring, where we found Ashmunella and Sonorella. The largest one, evidently adult, has the periphery bluntly angular in front, becoming rounded on the last half whorl. There are faint traces of bands above and below it. Spire rather elevated. Height 10.6, diam. 17.5, umbilicus $4 \mathrm{~mm}$. It differs from $O$. $s$. depressa by the angulation of the periphery. Possibly an exploration of the southern end of the range, which from a distance looks rather good, would reveal living Oreohelices, but we looked for them in vain in the central and northern parts.

Thysanophora hornii (Gabb).

Vallonia perspectiva Sterki.

Bifidaria pilsbryana Sterki.

Bifidaria ashmuni Sterki.

\section{Peloncillo Mountains.}

Sonorella hachitana peloncillensis n. subsp.

The shell is a little less depressed than hachitana, with the last whorl not so deeply descending, the aperture not so oblique and a trifle larger.

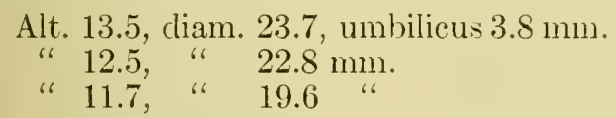

Peloncillo Mountains: Skull Canyon, Grant Co., New Mexico. Types, No. 94,513, A. N. S. P., collected by J. H. Ferriss, 1907.

The genitalia (figs. $6 \mathrm{~A}$ to $6 \mathrm{C}$, and figs. $6 \mathrm{D}, \mathrm{E}$, penis-papillæ of other individuals) resemble the same organs in S. flora. The penis is encircled by a sheath which reaches nearly to the middle. The penispapilla is slender, tapering, and subannulate or rather strongly annulate. Epiphallus and flagellum as usual in the group of hachitana. It differs from $S$. hachitana by the decidedly longer penis, which has a much longer basal sheath. The vagina is slightly shorter than the penis, while in S. hachitana and flora it is slightly longer. Measurements are given on page 328 .

The sole is fleshy-buff, of nearly uniform tint, the side areas not distinct. Back ashy; sides and tail flesh-tinted.

\section{Explanation of Plates V, VI, VII.}

Plate V-Figs. 1, $1 a, 1 b, 1 f$.-Ashmunella mearnsi (Dall). Station 5, Big Hachet Mits.

Figs. 1c, 1d, le.-Ashmunella mearnsi (Dall). Station 11. 
Figs. 2-2e.-Ashmunella walkeri Ferriss. Florida Mts.

Figs. 3-3c.--Sonorella hachitana flora n. subsp. Florida Mts.

Figs. 4-1b.-Sonorella hachitana (Dall). Station 7.

Plate VI-Figs. 1-1d.-Oreohelix hachetana n. sp. Cotypes. Station 11.

Fig. 2.-O. h. cadaver n. subp. Type. Station 5.

Fig. 3.-Orcohelix ferrissi morticina. Type. Station 5.

Figs. 4, 4a, 4c.-Oreohelix ferrissi Pils. Shells denuded of the cuticle and cuticular processes. Station 3.

Figs. 5-5c--O. ferrissi Pils. Cotypes. Station 3.

Fig. 5d.-O. ferrissi Pils. Young specimen, showing the embryonic and $1 \frac{1}{3}$ neanic whorls. Station 3 .

Fig. 6.-Oreohelix hachetana. Embryonic and part of the first neanic whorls of a paratype. Station 11 .

Plate VII-Figs. 1-1d.-Holospira bilamellata Dall. Station 5. Topotypes. Figs. 2-2b.-H. b. longa n. subsp. Cotype. Station 4.

Figs. 3-3c.-H. b. heliophila n. subsp. Cotypes. Station 1.

Figs. 4, 4a.-H. b. insolata n. subsp. Cotypes. Station 6.

Figs. 5-5c.-H. b. media n. subsp. Cotypes. Station 3.

Figs. 6, 6a.-H. b. mearnsi Dall. Station S.

Figs. 7-7e.-H. crossei Dall. Station 11. Topotypes. 


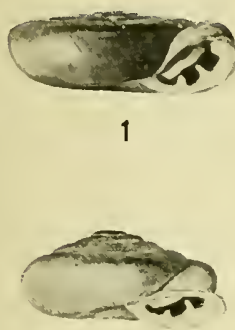

$1 c$

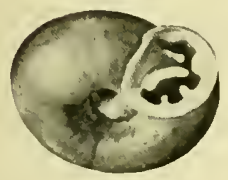

$1 f$

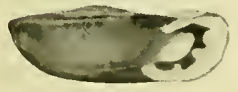

2

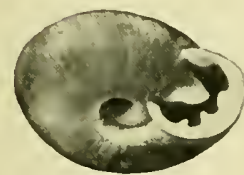

$2 c$

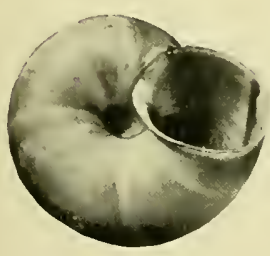

$3 a$

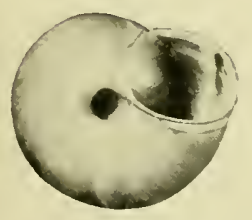

4

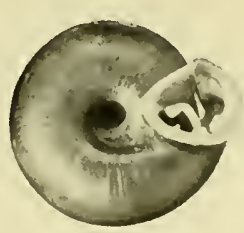

$1 a$

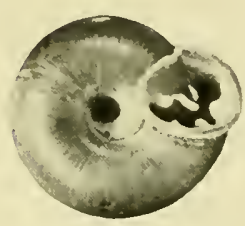

1d
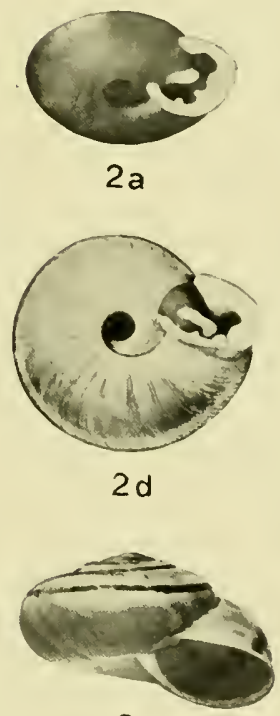

3
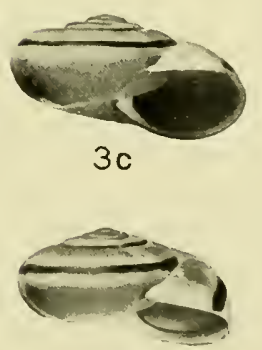

$4 a$

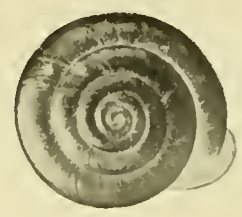

Ib

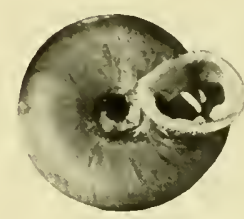

1e

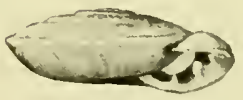

$2 b$

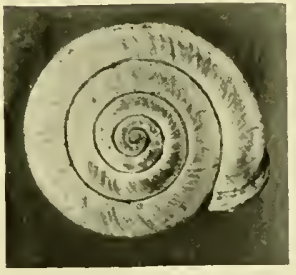

$2 \mathrm{e}$

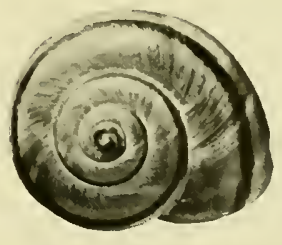

$3 b$

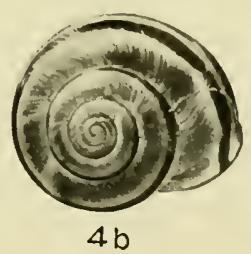





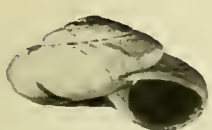

1

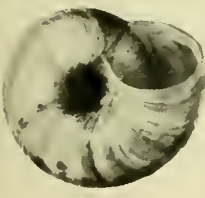

1d

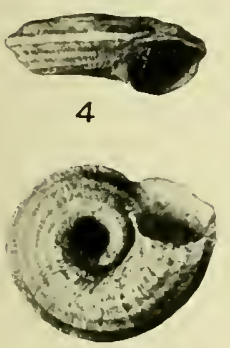

$4 a$

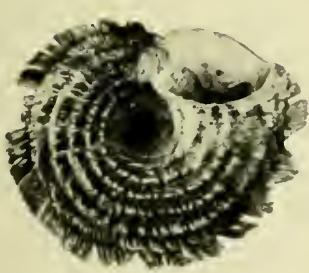

$5 a$

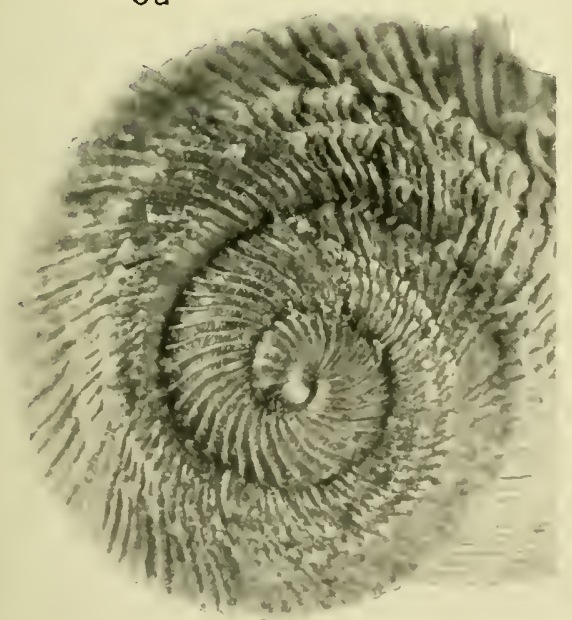

$5 d$

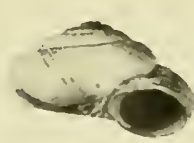

1b

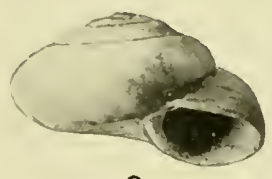

2

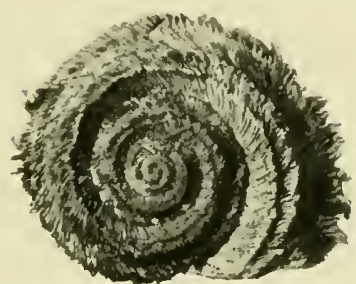

5

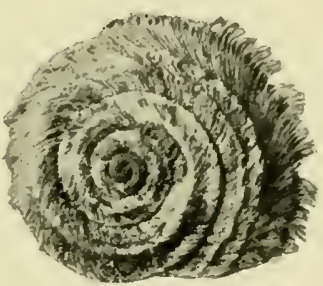

$5 b$

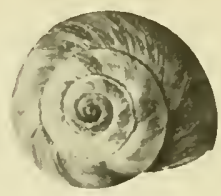

$1 \mathrm{c}$

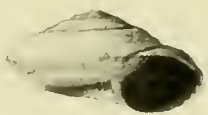

3

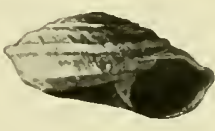

$4 \mathrm{~b}$

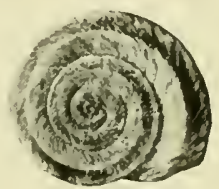

$4 c$

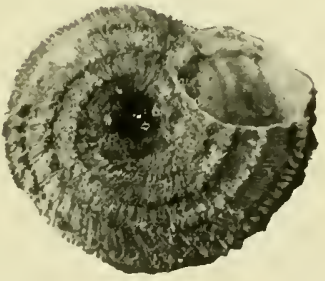

$5 c$

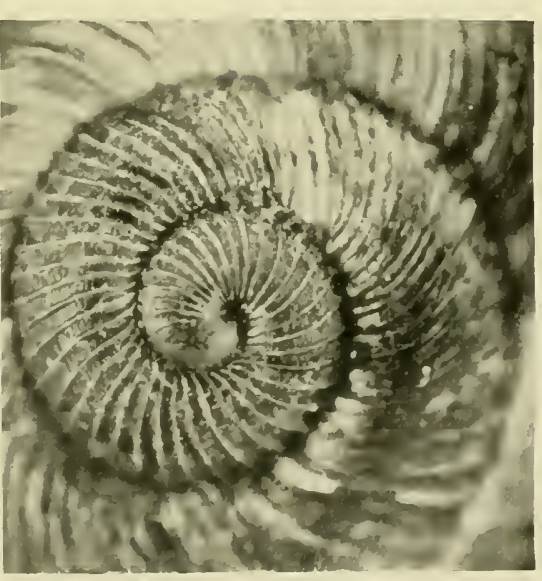

6

PILSBRY: MOLLUSCA OF THE SOUTHWESTERN STATES. 



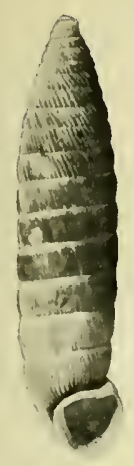

1

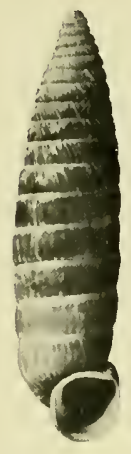

$1 a$

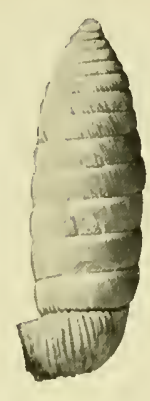

1b

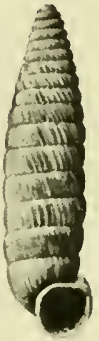

3

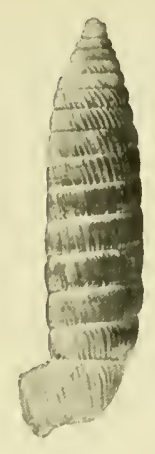

$1 \mathrm{c}$

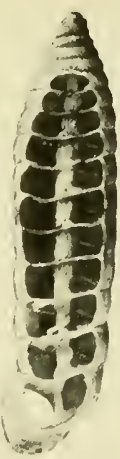

1d

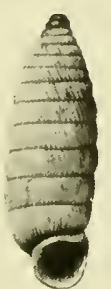

$3 b$

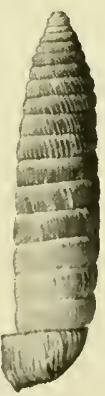

$5 b$

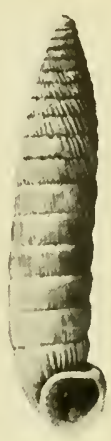

2

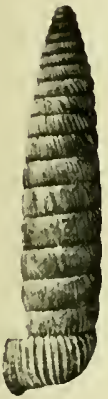

$2 a$

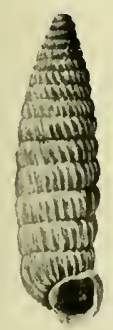

4

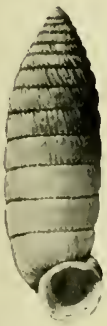

6

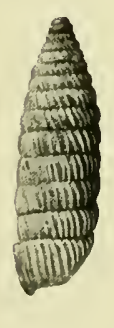

$4 a$

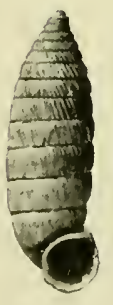

$6 a$

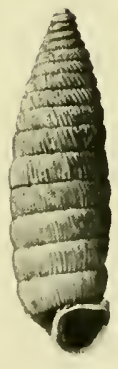

5
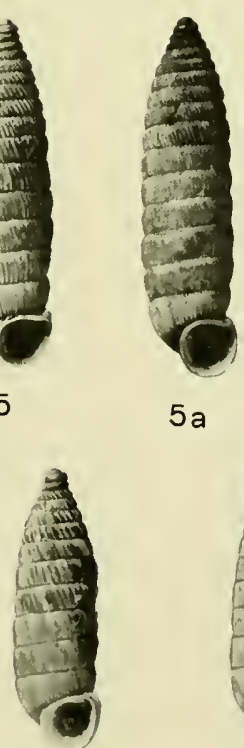

7

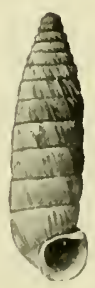

$7 a$
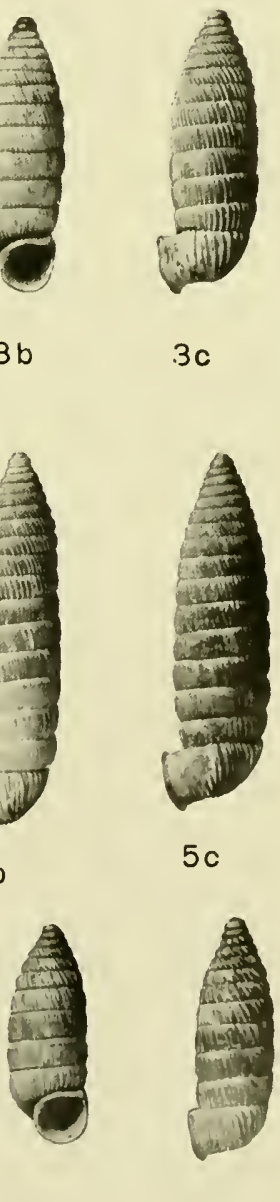

$7 b$

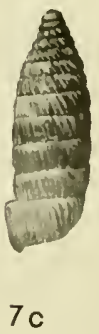

PILSBRY: MOLLUSCA OF THE SOUTHWESTERN STATES. 



\title{
Mollusca of the Southwestern States.
}

\author{
VII. \\ The Dragoon, Mule, Santa Rita, \\ Baboquivari, and Tucson \\ Ranges, Arizona.
}

\author{
BY \\ Henry A. Pilsbry and James H. Férriss.
}

From the Proceedings of The Academy of Natural Sciences of Philadelphia, June, 1915. 

MOLLUSCA OF THE SOUTHWESTERN STATES, VII: THE DRAGOON, MULE,
SANTA RITA, BABOQUIVARI, AND TUCSON RANGES, ARIZONA.

BY HENRY A. PILSBRY AND JAMES H. FERRISS.

This paper and the preceding one (VI) contain the account of mollusks collected in course of our explorations in 1910, from the middle of August to the middle of October. The forms obtained in the Santa Catalina Mountains will be described in connection with the collections made there by one of us (Ferriss) in 1913. We were ably assisted in the field by Mr. L. E. Daniels. ${ }^{1}$ Besides the ranges enumerated in the title, some account is given of several minor hill groups, all in the region south of the Southern Pacific Railroad. While this paper, with those already published on the Chiricahua and Huachuca Ranges, is monographic for the mollusks of Arizona south of the Southern Pacific, yet the field is far from exhausted. Our work is a reconnaissance rather than a complete malacological survey. Further species will reward search in the southwestern end and outliers of the Chiricahuas, the southern Dragoons, the Whetstone Range, and the mountains around and south of Tombstone. Further west we have explored only small middle sections of the Santa Rita and Baboquivari Ranges. Many hill and mountain groups between Tucson and Nogales remain untouched, most of them doubtless inhabited by endemic species of Sonorella. In the nearly waterless region westward between the Baboquivari Range and the Colorado River, almost nothing has been done aside from some account of the snails of the Comobabi Mountains, which we are now giving.

Going westward in southern Arizona from the eastern limit of the State, the general level falls and the mountains become lower and smaller. There is a gradual elimination of snails requiring a reasonable degree of humidity. Ashmunella and Oreohelix extend west to the Huachucas. Beyond that range they disappear. The small shells also abruptly diminish in number of genera and species, by

${ }^{1}$ We are indebted to Mr. J. C. Blumer, of Tucson, for several species from the Comobabi and Cababi Mountains, which we did not visit. 
elimination of the Transition Zone forms. Holospira, too, becomes rare. In the Santa Cruz River Valley it is known by one speciesat the present time, one specimen; and none are known from further west. The spread of this genus is not controlled by humidity. It lives in the driest and hottest situations, often at low elevations, but it is confined to limestone tracts, and limited by volcanic or metamorphic rock. The mountains westward, in the region under consicleration, are mainly volcanic, and the stony tracts are therefore unsuitable for Holospira.

The progressive impover:shment of the fauna leaves, in the Santa Cruz Valley and westward, a few Lower Sonoran Pupillidce, Zonitid $\propto$, Thysanophora (hornii), and the true desert snail, Sonorella. Sonorella will live in the most arid places, where the rainfall does not exceed 5 or 6 inches, so long as there is abundant rock shelter and a certain amount of shade, such as the shadow of a cliff or a small bush. Northern slopes are preferred. In exploring a new mountain or hill in the really arid country one aims for the northern or northwestern slope under the highest crags. If coarse talus or rock "slides" are found, persistent quarrying should produce Sonorella. In less arid mountains, such as the Santa Ritas, the most productive collecting stations are in the deep, verdant canyons.

The exact location of collecting stations, and especially of type localities, which we attempt in these papers, may seem meticulous to many zoologists. In humid areas, or in dealing with less sedentary animals, such exactness would hardly be worth while; if a type locality is fixed within a few miles, it is near enough. But here we deal with a region of intense local differentiation and with creatures which are often confined within narrow bounds by physical conditions. The hunt is difficult and laborious. The colonies are often so small, the country so vast, that, without careful clirections, one might make a season's campaign in the more complex ranges without relocating some former find which it might be important to investigate further. It is, moreover, important to show exactly what ground has been covered, in order that further exploration can be made to the best advantage, that the unexplored parts of the ranges may be gone over. In future it will be of interest to be able to trace the changes and fate of the smaller and more isolated colonies, such as that of Sonorella eremita, which covers an area of only a few square rods, many miles from any other snail colony. We suggest that future collectors continue our serial station numbers in each range, instead of beginning again at No. 1 . 


\section{The Dragoon Mountains.}

This range stands 25 or 30 miles west of the Chiricahua Mountains in Cochise County, Arizona. The well-known double-headed peak of Dos Cabezas is seen northeastward and the Whetstone Mountains westward, but the Dragoons are entirely isolated from other ranges. The Pearce mining district lies on the east side. To its proximity and the demand for mine timber the deforestation of the mountains is due. All of the timber was cut about 25 years ago, but the range, now forming the Dragoon Forest Reserve, shows good reproduction in places. At present the mountains are almost as bare as the Dos Cabezas.

The range is reached from Dragoon Summit, a station on the Southern Pacific R. R. at the northwestern foot of the mountains. North of the railroad the "Little Dragoons" form a low continuation of the range. There is a depression at Middle Pass (Middlemarch Canyon), where a road from Tombstone to Pearce crosses the range. We did not explore the southern half of the range, below Middlemarch, nor the Little Dragoons north of the railroad.

The mountains are formed of a complex of limestones and igneous rock, the granites forming wild labyrinths of narrow gorges abounding in cliffs and falls, separated by inaccessible crags and spires, which gave a refuge to the Apaches thirty or forty years ago. The limestones, forming a large part of the range, are accessible enough, though rather abrupt, and as usual they proved much more prolific of snails than the granitic and andesitic rocks.

The range was visited by us (Ferriss, Daniels and Pilsbry) in October, 1910. A week was spent in Tweed Canyon, where there is a small stream. The map (p. 366) showing collecting stations from Stations 7 and 8 northward was sketched from high points around Tweed Canyon and its northern amphitheatre. After Pilsbry had left, Ferriss and Daniels moved south to Middlemarch Canyon, and the stations (28-36) south of Station 8 are located by notes and a sketch made by them. ${ }^{2}$

\footnotetext{
2 The map is intended solely to show the positions of our collecting stations, many of which can probably be located exactly, and the others approximately, by the landmarks given. The contour lines merely show local relative elevation, not absolute altitude, and are not consistent on different parts of the map. The summit midway between Stations 5 and 12 on the northern ridge of the amphitheatre above Tweed Canyon is visible from the railroad at Dragoon Summit.
} 


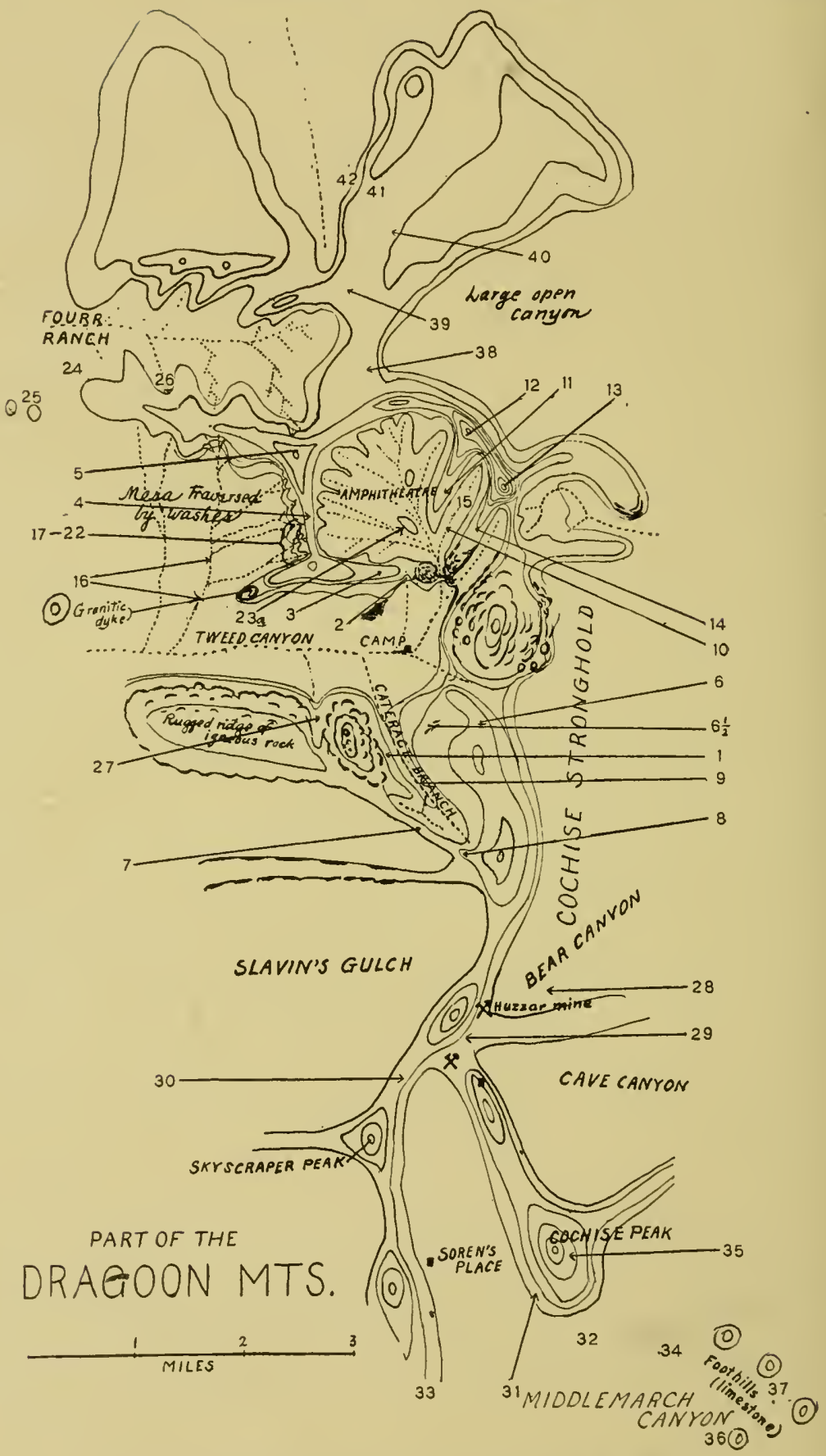

Fig. 1.-Collecting stations in the Dragoon Mountains. 
The fauna of this small range is strongly individualized, since all of the Holospiras and larger Helices are very distinct from species of other ranges, even the Sonorellas having well-defined conchological features. Like the Huachucas, there is (or was) an Oreohelix of the strigosa group, but hairy forms and the Radiocentrum group are wanting. The minute shells are all species common to the Chiricahua, Huachuca and other larger ranges, but the Transition and Canadian Zone species are very sparsely represented by Pyramidula cronkihitei, Cochlicopa lubrica and Vertigo coloradensis arizonensis only. Otherwise the fauna is purely Lower Sonoran.

The collecting stations are as follows:

Station 1. Slide of heavy, angular rock on west side of cataract branch of 'Tweed Canyon, below the crags of this side.

Station 2. Near the foot of small ravine next west of the granite defile forming the outlet of the Tweed amphitheatre.

Station 3. Near and at top of ridge above Station 2.

Station 4. Rim of amphitheatre, western side.

Station 5. Immediately north of small peak at N. W. of amphitheatre.

Station 6. Crag about half way up mountain on east side of cataract branch, overlooking part of Cochise Stronghold.

Station $6 \frac{1}{2}$. West of Station 6.

Station 7. Limestone ridge at the head of Cataract Branch.

Station 8. Higher up on the same ridge eastward.

Station 9. East side of the rocky bed of Cataract Branch, near the foot of the (dry) "falls."

Station 10. Bottom of eastward ravine in Tweed amphitheatre.

Station 11. Part way up ridge northwest of 10 .

Station 12. High peak at summit of preceding ridge.

Station 13. High peak southeast of 12 .

Station 14. Middle of ridge running from 13 to mouth of amphitheatre. 10.

Station 15. Near bottom of ravine north of 14, and further up than

Station 16. Arroyo in mesa in the mouth of Tweed Canyon.

Station 17. Third small ravine west of the large granitic spur in Tweed Canyon.

Station 18. Above Station 17, and separated from it by granitic dyke about 50 yards wide.

Station 19. Below Station 17.

Stations 20-22. Second ravine from large granitic spur in Tweed Canyon.

Station 22a. Second ravine west from Station 2, lower part of mountain.

Station 23. Second ravine west from Station 2, near summit of ridge. This station and the preceding one were not visited by 
Pilsbry and are not plotted on the map. They are believed to be east of the granitic spur (dyke) on the north side of Tweed Canyon.

Station 23a. Small hill in bottom of Tweed amphitheatre near an abandoned arrastra.

Station 24. Gully on mesa, running westward out of Fourr ranch.

Station 25. Foothill west of Fourr ranch.

Station 26. Gully at south fence of Fourr ranch.

Station 27. First ravine west of Cataract Branch in the igneous southern side of Tweed Canyon.

Station 28. Bear Gulch, half way down.

Station 29. Bear Gulch, near its head.

Station 30. Ridge west of Bear Gulch.

Stations 31, 32. East side of Soren Gulch.

Station 33. West side of Soren Gulch.

Station 34. Small limestone hill in Middlemarch Canyon.

Station 35. Cochise Peak.

Stations 36,37 . Small limestone hills eastward on mesa at mouth of Middlemarch Canyon.

Station 38. North side of north ridge of Tweed amphitheatre, $\frac{1}{4}$ mile west of Signal Peak.

Stations 39-42. Successive stations between the northern crest of Tweed amphitheatre and the northern foothills of the range.

\section{HFLICID $\AA$.}

Sonorella ferrissi Pilsbry, n. sp. Pl. VIII, figs. $3,3 a, 3 b$.

The shell is strongly depressed, umbilicate (the width of umbilicus contained six times in the diameter of the shell), rather solicl; of a pale brown tint, between cinnamon and wood-brown, fading around the umbilicus, having broad white bands above and below the narrow chestnut-brown shoulder band and crossed by one or several whitish streaks, reminiscent of former peristomes. The surface is semimat. The initial one-fourth whorl is smooth; a brief stage of coarse radial wrinkles ensues, followed by fine, short, interrupted radial wrinkles, so short as to be papillæ near the upper suture, and sparse, short elevations, arranged in spiral, forwardly descending series. On the second whorl these elevations become distinct, rather regular papillæ, which persist, in some examples, upon the third whorl. The last whorl has fine strix and microscopic wrinkling. The spire is but slightly convex. The whorls increase slowly, the last descends a little in front and is rounded at the periphery and base. The peristome expands very slightly in its lower half, and its edge has a rusty tint. It is thickened within by a rather wide but thin white callus, which shows as an opaque buff border behind the lip. The columellar termination is slightly dilated, and the parietal callus moderately thick in fully mature or old individuals. 
Height 7, diam. $14.2 \mathrm{~mm}$; $4 \frac{1}{2}$ whorls.

Genitalia (Plate XI, figs. 3, 3a).-The penis is somewhat slender, slightly shorter than the vagina, and a trifle longer than the epiphallus. It contains a cylindric papilla nearly as long as itself, transversely wrinkled in the distal third and rounded at the end (fig. $3 a$ ). The retractor muscle is inserted on the epiphallus near its base. There is no flagellum. Length of penis $4 \mathrm{~mm}$.; penis-papilla $3+$ $\mathrm{mm}$.; penial retractor $6 \mathrm{~mm}$.; epiphallus $3+\mathrm{mm}$.; vagina $5 \frac{1}{2} \mathrm{~mm}$.

Dragoon Mountains, from the northern ridge of Tweed Canyon to the ridges facing the northern slope of the mountains; types No. 103,097, A. N. S. P., from Station 38. Also taken at Stations $3,4,5,10,12,13,14,15,21,22,38-41$.

The shell in this extremely distinct species reminds one a little of Trichodiscina. There is no other Sonorella like it. The embryonic sculpture is a modification of the hachitana pattern. In the genitalia it resembles $S$. bicipitis of the Dos Cabezas range as much as anything. It is abundant in the northern part of the Dragoon Range, but Tweed Canyon apparently forms an impassable barrier to its spread southward.

We rarely found Sonorella ferrissi sealed to stones, forming small rings. Most living ones were seen loose under stones or in the earth, lying with the aperture up, like Eastern Helices, and sealed with a somewhat convex white epiphragm. It belongs exclusively to the limestone terrain.

Sonorella dragoonensis n. sp. Pl. VIII, figs. $1,1 a, 1 b$.

The shell is rather depressed, umbilicate (the umbilicus contained $6 \frac{1}{2}$ times in diameter of the shell), thin, somewhat translucent, pale buffy brown, with whitish bands on both sides of a chestnut-brown band at the shoulder. The spire is low, conic, whorls $4 \frac{2}{3}$, moderately convex. First one-third whorl smooth, followed by a brief stage of coarse radial wrinkles, continuing longest near the lower suture, and succeeded by papillæ and short, vermiculate radial wrinkles, interrupted by short wrinkles in a spiral direction, which on the lower part of the whorl bear epidermal bristles, beginning on the latter half of the first whorl, and continuing throughout the embryonic and neanic stages as far as the end of the third whorl. It is succeeded by an excessively minute vermiculate sculpture, which rapidly becomes fainter and disappears on the last two whorls, which are glossy and nearly smooth except for faint growth lines. Last whorl wide, descending in front. Aperture very oblique, round-oval. Peristome thin, very narrowly expanded throughout, 
a little recurved below; the margins approaching, parietal callus short, thin except in old shells.

Alt. 11.25 , diam. 19.5, alt. aperture 10.5, diam. $9.25 \mathrm{~mm}$.

" 12

20.5

11 ,

Back dusky, tentacles dark, sole pale yellowish, with faint longitudinal lines, demarking the areas, near the tail.

Genitalia (Pl. XI, figs. 4, 4a, No. 103,093, from Station 29).The penis is large, cylindric, encircled by a small muscular sheath at the contracted base, its retractor muscle inserted upon the apex of the penis and the base of the epiphallus. The walls of the penis are thin. Papilla (fig. 4a) nearly as long as the penis, stout, cylindric, having obliquely longitudinal corrugation near the end, the apex being obtusely conic with terminal pore. The flagellum is longer than usual. Epiphallus is about equal to the penis in length. The vagina is decidedly shorter than the penis. The duct of the spermatheca is very long.

Length of organs in $\mathrm{mm}$.:

No. 103,093.-Penis, 10; epiphallus, 10; flagellum, 1.3; papilla, 8; vagina, 6 ; spermatheca and duct, 39 .

No. 103,094.-Penis, 11; epiphallus, 9; flagellum, 1.3; papilla, 7.5; vagina, 7 .

The jaw is highly arched, with five broad, unequal ribs.

Dragoon Mountains. Types from Station 28, Bear Canyon, No. 103,094, A. N. S. P., collected by Ferriss and Daniels, November, 1910. Also at Station 29, south of the Huzzar Mine, in the same vicinity.

This species is related to Dos Cabezas species by the position of the insertion of the penis-retractor, the cylindric penis-papilla and the short vagina. It differs from all of these in its very large and differently sculptured penis-papilla, and the thin shell, with rounded aperture and minute granulation and hairs on the neanic whorls, and a different pattern on the embryonic whorls. It is not closely related to any species of the ranges further west.

Other specimens, topotypes, from Station 28 measure:

Ait. 11, diam. $21 \mathrm{~mm}$.

$\begin{array}{lllll}\text { " } & 11.3, & \text { " } & 20.5 & \text { " } \\ \text { " } 10.8, & 10.2, & \text { " } & 19 & 18.5\end{array}$

Specimens from Station 29 measure:

$\begin{array}{ccccc}\text { Alt. } 10.9 \text {, diam. } & 20 & \mathrm{~mm} \\ \text { " } 10.3, & \text { " } & 18 & \text { " } \\ \text { " } 10, & 20 & \text { " } \\ \text { " } 9, & \text { " } & 17.3 & \text { " }\end{array}$ 
Sonorella apache n. sp. Pi. V1lI, figs. $2,2 a, 2 b$.

The shell is depressed, with low, conoidal spire, umbilicate (the width of umbilicus contained nearly 9 times in the diameter of the shell), extremely thin; mat isabella color above, paler below, glossy and diaphanous in the central half of the base, encircled by a narrow chestnut-brown band above the periphery. Whorls $4 \frac{1}{2}$, the embryonic shell comprising $1 \frac{1}{2}$; sculptured like that of $S$. dragoonensis. The neanic whorls are very minutely crinkled and closely set with short bristles in irregular oblique lines. About 110 of these bristles stand on one square millimeter, on the upper surface of the last whorl in front of the aperture. The bristles are rather delicate on the last whorl, and in cleaning the shell they are likely to be removed in large part. The last whorl is wide and descends rather deeply in front. The aperture is very oblique, subcircular. Peristome thin, the upper and outer margins very narrowly expandling, basal margin slightly recurved, columellar margin dilated, running forward. The ends of the peristome converge strongly, and are connected by a very thin, short, parietal film.

Alt. 10.25 , diam. 16.8 , width of umbilicus 1.9 , aperture $8.5 \times 9.7 \mathrm{~mm}$. " 10 " $17 \mathrm{~mm}$.

Genitalia (Pl. XI, figs. 5 to $5 c$ ).-The penis is short and very thick, cylindric, obtuse at the ends, much shorter than the vagina. It has very thin walls, and is filled by a thick, fleshy papilla (fig. 5a). This is thick-walled with a rather large cavity having plicate walls so that it is star-shaped in section (fig. 5b). At the upper end of its cavity there is a short, conic nipple (fig. $5 c$ ); at the distal end of the papilla the cavity opens by a transverse slit. The retractor muscle of the penis is inserted on the epiphallus near the penis. The epiphallus passes imperceptibly into the vas deferens. There is no flagellum. The lower end of the vagina is swollen, having thick, fleshy walls. The organs measure as follows: Penis 7, penis-papilla 5 , retractor muscle 8 , vagina $11 \mathrm{~mm}$.

Dragoon Mountains, the types from the southern or Cataract branch of Tweed Canyon, at Station 9, on the east side of the rocky bed near the foot of the "falls," No. 111,529. Also found at Station 1, a large slide of heavy, angular stone further north on the same branch, rather high on the west side of the ravine, under the great crag. A few dead shells were found at Station 27, in a gulch of the rugged south wall of Tweed Canyon, and at Station 10, on the eastern ridge of the amphitheatre of upper Tweed Canyon. 
This species is somewhat related to $S$. dragoonensis, but differs by its smaller size, thinner shell, decidedly smaller umbilicus, and by having the last whorl densely hairy, the hairs extremely short and close. S. apache differs from $S$. dragoonensis rather conspicuously in soft anatomy. The penis is shorter with a differently constructed papilla; there is no flagellum; the vagina is much longer and is strongly swollen at the base. The anatomical characters of both have been examined in several specimens from different stations.

The delicately hairy periostracum will serve to separate $S$. apache from other species of the genus. It is an extremely distinct species.

Its home is among the great crags around Cochise Stronghold, a favorite resort of the Apaches. Station 10 is some miles northward of the other stations and at a somewhat greater elevation.

S. apache was found only in igneous or metamorphic rock, never in the limestone. It was not found sealed to the rock, nor were any white circles seen on the rocks it inhabits, thus differing from nearly all other Sonorellas collected by the authors.

Other specimens, from Station 1, measure:

Alt. 10.5, diam. $17.5 \mathrm{~mm}$.

$\begin{array}{ccccc}\text { " } & 11, & \text { " } & 17 & \text { " } \\ \text { " } & 9.2, & \text { " } & 15 & \text { " } \\ & 8.8, & 14 & \text { " }\end{array}$

Station 1 is conspicuous from the hillside on the east side of the mouth of Cataract Branch, as a long, bare streak in the dense brush which clothes the slope below the crag at the west side, some distance up the ravine, and rather high on the side. One living shell and numerous "bones" were found by quarrying in the heavy rock of the slide. More living shells were taken at Station 9, the type colony.

The largest shell seen is a dead individual from Station 27, measuring $18.5 \mathrm{~mm}$. in diameter.

Oreohelix strigosa var.

A young dead specimen was found at Station 2, under a stone, and two fragments of the last whorl at Station 13; both in the limestone region, but at very different elevations, Station 2 being only a hundred feet or so above the bed of Tweed Canyon, 13 on the highest peak of its rim. The largest fragment, half of the last whorl of an adult shell, has a diameter of $18.5 \mathrm{~mm}$. It shows a slight peripheral angle, otherwise resembling $O$. s. depressa Ckll.

This Dragoon species seems from the fragments to be a more depressed shell than the extinct Oreohelix of the Florida Mountains, but it may be the same as the Huachucan race. 
As we searched the range carefully for Oreohelix after finding one on the first day, it is probably extinct, not surviving the destruction of the woods. There remains a possibility that it may survive in some part of the mountains not covered by our collecting stations.

Thysanophora hornii (Gabb).

Stations $2,3,6,6 \frac{1}{2}, 10,11,18$, all in the limestone region north of Tweed Canyon.

\section{UROCOPTID E.}

Holospira is rarely if ever found on igneous or metamorphic rock; and as the Dragoons are traversed by many dykes, the limestone areas where Holospiras live are divided by tracts barren of these snails. This has resulted in the differentiation of several species which though variable do not intergrade, so far as we know. In the Hacheta Range the limestone is continuous, and while there has been a good deal of differentiation, the several extreme forms are connected by those intermediate in structure and location.

It must be admitted that our knowledge of the Dragoon Holospiras is fragmentary. The whole foothill region, where they abound, needs attention. They are easily found, and in large numbers.

Holospira danielsi n. sp. Pl. XIV, figs. 1 to $3 a$.

The shell is cylindric, the upper fourth (or third) tapering to the slightly mamillar, obtuse summit. Tilleul-buff, becoming darker towards the summit. Nearly $2 \frac{1}{2}$ embryonic whorls are smooth; then slightly retractive axial ribs appear, rather low and delicate on the first neanic whorl, after which they become strong, widely separated, oblique (retractive) on the conical portion, still more wiclely spaced and vertical on the cylindric portion of the shell, where the summits of the ribs are more or less irregular from breakage due to being in part hollow there. On the penultimate whorl there are 13 ribs (more or less). On the last half of the last whorl the ribs become closer (or many may be interposed). The whorls are rather strongly convex, the last one tapering downwards, being compressed below the periphery; base rimate but not perforated. The last fourth of the last whorl is somewhat straightened but not built forward beyond the level of the ventral face of the shell. Aperture rounded-ovate. Peristome narrowly expanded except at the upper outer angle, where it is simple and obtuse. The axis is rather slender, subequal except at the ends. In the last part of the penult and first part of the last whorl there is a strong, short, obtuse columellar lamella close to the base; a parietal lamella, much longer and usually strong (and frequently a smaller basal lamella). 
Length 11.5 , diam. $3.5 \mathrm{~mm}$; $12 \frac{1}{2}$ whorls.

Dragoon Mountains, Cochise County, Arizona, from Tweed Canyon to the northern end of the range, on limestone, under stones, dead agaves, sotols, etc. Type locality Station No. 2, Tweed Canyon, No. 112,199, A. N. S. P.

They live on the most exposed, hottest slopes, often in great profusion, but are not found on the mesa, where $H$. campestris occurs.

This beautiful snail is very distinct from all of our species by its strong, rude, widely spaced ribs. One of the northwest Mexican Holospiras, H. minima, has the same type of sculpture, though less coarse than in the typical $H$. danielsi, which is the most strongly costate species known.

Like other Arizonian Holospiras, the internal lamellæ are variable, two or three (parietal and axial, or parietal, axial and basal) being developed. Otherwise the chief variation is in the number of ribs, and also in size.

Twenty specimens of the type lot, opened, taken at random, measure as follows:

Length 12, diam. 3.6 mm.; whorls 13 ; lamellæ 2 .

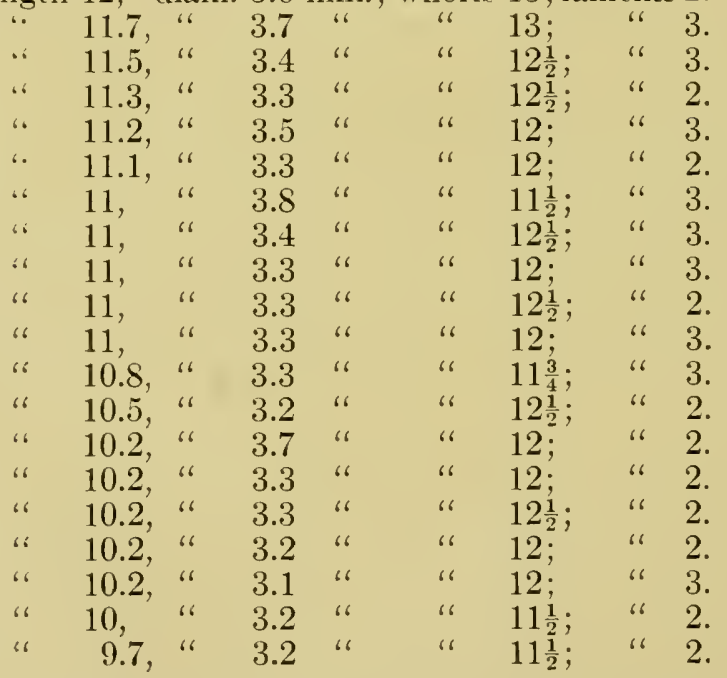

The smallest shell noticed in the type lot measures $8.2 \times 3.2 \mathrm{~mm}$, with 10 whorls. The trilamellate shells are slightly outnumbered by those with two lamellæ, forming 45 per cent. in the lot measured; but this may be accidental. Three lamellæ predominate in the larger shells, two in the smaller. 
The sculpture is less variable in this lot than in some others. Ten specimens, taken at random, have $10,12,12,13,13,13,15,17$, 17,17 ribs on the penultimate whorl. These fairly represent the lot, so far as can be told without extensive counting. None counted have more than 17 rilss (see Pl. XIV, figs. 1, 1a, 1b).

Station 3 (summit of ridge above Station 2), but west of where the trail crosses ridge). Shells exactly like those of Station 2, but perhaps a little more variable in size, length 9 to $12 \frac{1}{2} \mathrm{~mm}$. in extreme specimens.

Station 4 (summit of ridge further northwest, several hundred feet higher than Station 3). These shells are conspicuously larger than at Stations 2 and 3. Part of the shells are typical in sculpture, but in most of them the ribs are much more numerous, closer, smooth, and more regularly spaced. These close-ribbed shells agree with those from Station 5 and from Station 12, a peak on the opposite (east) side of the rim of the amphitheatre of Tweed Canyon. Probably the close-ribbed type of shell extends around the whole rim from Station 4 to Station 12 .

Two out of fifteen opened have 3 lamellæ (both having many ribs), and three have only the columellar lamella (ribs few). The rest, including both many- and few-ribbed shells, have 2 lamellæ. This lot was picked up in several places along the summit of the narrow ridge, perhaps in an area of $20 \times 100$ yards. It therefore may comprise several colonies, and we cannot now tell whether fine- and coarse-ribbed shells occur actually together or not. There may be 12-15 ribbed colonies and 20-30 ribbed colonies, or possibly both sorts may live together. The measurements give extremes of size and are from "selected" shells.

Length 12.5, diam. $4.1 \mathrm{~mm}$.; whorls $12 \frac{3}{4}$; lamellæ 3 ; ribs 21.

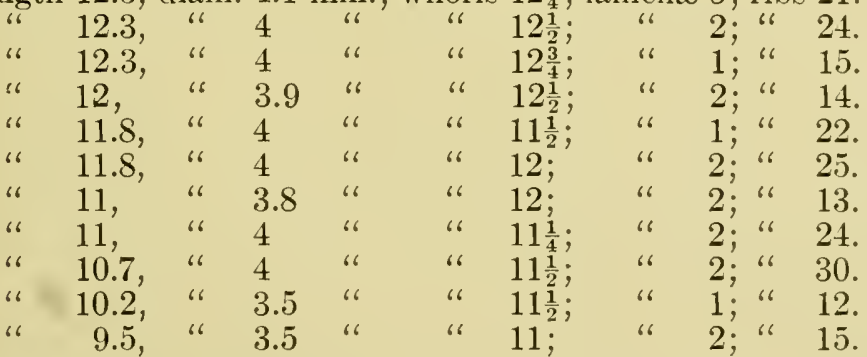

Station 5 (north of summit of peak north of Station 4). Shells are like the fine-ribbed ones from Station 4. No really coarse-ribbed forms were taken. Extreme and average shells measure as follows: 
Length 12.3, diam. 4 mm.; whorls $12 \frac{3}{4}$; lamellæ 1 ; ribs 27.

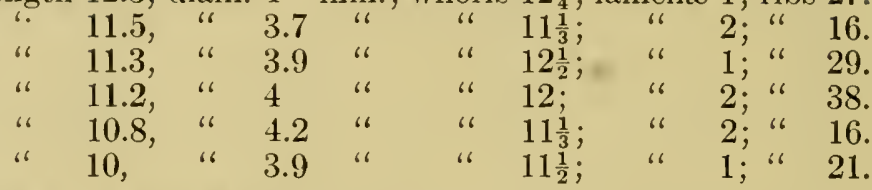

Station 18 (PI. XIV, figs. 3, 3a). In the third ravine west of the granitic spur on north side of Tweed Canyon, above a dyke of igneous rock about 50 yards wide. Below this dyke, at Station 17, Holospira campestris cochisei is found. A deep gulley or "wash" extends from the ravine upon the mesa. The shells at Station 18 are a little more finely ribbed than typical $H$. danielsi and to that extent approach $H$. campestris cochisei. Out of 16 opened, 9 shells have 3 , and 7 shells have two internal lamellæ. Measurements follow.

Length 11.3, diam. 4 mm.; whorls $12 \frac{1}{3}$; lamellæ 2 ; ribs 22.

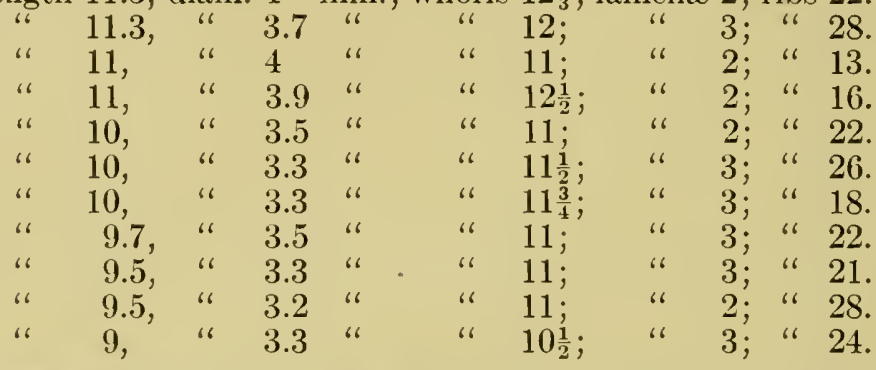

Station 20 (mouth of the second ravine west of granitic spur, Tweed Canyon). Shells similar to the preceding lot.

Station 22 (bed of the same ravine several hundred yards above the mouth). Shells similar, but averaging larger, though some are equally small; lamellæ one or two.

Length 12.5, diam. $4 \mathrm{~mm}$.; whorls $12 \frac{3}{4}$; ribs 16 .

\begin{tabular}{|c|c|c|c|c|c|}
\hline & \multicolumn{3}{|c|}{ " 3.9} & \\
\hline & & 3.5 & " & & \\
\hline
\end{tabular}

Specimens from the southeastern part of the upper amphitheatre of Tweed Canyon have only one or two lamellee (parietal and axial), those with one slightly predominating. The parietal lamella is moderate or small when developed. They are also perceptibly stouter in figure than the types, and the number of ribs is, in the main, greater.

Station 10 (floor of the upper amphitheatre of Tweed Canyon, southeastern branch). Not a favorable station for Holospira, being shaded by a dense growth of shrubs and trees. A few specimens taken have one or two lamellæ, and the aperture is built forward further than in the types. Ribs as in the following. 
Station 15 (further east on the same branch, a little higher). Rather stout shells, with the mouth built out shortly (nearly $1 \mathrm{~mm}$.); about 15 ribs; lamellæ one or two. $12 \times 4 \mathrm{~mm}$.

Station 13 (eastern peak of the rim of Tweed Canyon). Fineribbed, like Pl. XIV, figs. 5, $5 a$.

Station 11 (steep, stony, arid, southern slope of ridge projecting into amphitheatre, vegetation xerophytic). The shells are greater in diameter than the types, very uniform in sculpture, having 16 or 17 ribs on the penultimate whorl, the peristome built forward further than usual in the type lot. $10.5 \times 3.7 \mathrm{~mm}$. axial or axial and superior lamellæ.

Another lot, taken a couple of hundred feet higher, are similar in form, sculpture and lamellæ; ribs 15 to 19 .

Station 12 (peak on eastern rim of amphitheatre). The shells are larger than at the preceding stations, with more ribs, 26 to 28 on the penultimate whorl. Half of those opened have one, half two lamellæ, the superior lamella not very strong. These shells are like those from Station 4 and 5. See Pl. XIV, figs. 4 to $4 b$.

Length 13.7 , diam. 4.2 mm.; whorls 13 .

$$
12, \text { " } 4 \text { " " } 11 \frac{3}{4} \text {. }
$$

Station 40 (between crest and foothills, north end of the range). Stout, rather large shells, with a strongly developed columellar lamella only in several opened. 37 to 43 ribs, nearly or quite as wide as their intervals. (Pl. XIV, figs. 5, 5a).

Length 12.3, diam. $4 \mathrm{~mm}$. $10.5, " 4.1$ " "

These shells have more ribs than any other colony of $H$. danielsi, and they may be referable to $H$. campestris cochisei. The shells are, however, larger than the latter, some of the ribs are broken down, as in danielsi, and the locality is distant from other known colonies of H.c. cochisei. Only a very small lot was taken, and, pending further collections, its identity may be left undecided.

Station 39 (between crest and foothills at north end of the range). Much larger than the typical form, stouter, with few, strong and widely separated ribs. Only the axial lamella developed. (Pl. XIV, figs. 2 to $2 c$ ).

Length 13.3, diam. $4.8 \mathrm{~mm}$.; whorls 13 ; ribs 15 .

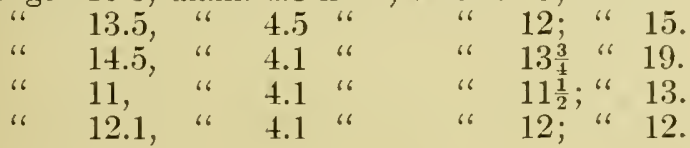


Station 42 (further north than Station 39). Similar to the above, having the same rude sculpture, but a little smaller in the average, length 11 to $13 \mathrm{~mm}$.

Station 41. Shells like Pl. XIV, figs. 4-4b.

Holospira campestris n. sp. Pl. XV, figs. 1, 2.

The shell is shortly rimate, cylindric, with very short terminal cone and mamillar apex. $2 \frac{1}{2}$ embryonic whorls smooth (the last half whorl very narrow), following whorls closely and finely striate, the strix of the conical portion narrower, hence appearing more widely spaced than those of the cylindric portion, on which they are as wide as the intervals. On the penultimate whorl there are about 70 striæ. The last whorl is decidedly compressed below the periphery, tapering downwards, somewhat more coarsely sculptured on the latter part. It is shortly rimate and built forward shortly from the preceding whorl. All of the whorls are very strongly convex. The aperture is angular at the upper outer part, elsewhere rounded. Peristome narrowly expanded. Axis cylindric, in the latter part of the penultimate and first part of the last bearing a stout axial lamella. There is also a long and strong parietal or superior lamella, and sometimes a basal lamella. Length 11.5, diam. $3.7 \mathrm{~mm}$; whorls 12 .

Mesa at western foot of the Dragoon Mountains at Station 26, along a "wash" or gulley at the south fence of the Fourr ranch, No. 112,214 , A. N. S. P. Also Stations 24, 25, in the same vicinity, etc.

Other specimens of the type lot (Pl. XV, figs. 1 to $1 d$ ) measure as follows. All but one of the specimens opened have two lamellæ, one having three.

Length 12, diam. $3.9 \mathrm{~mm}$.; whorls 12.

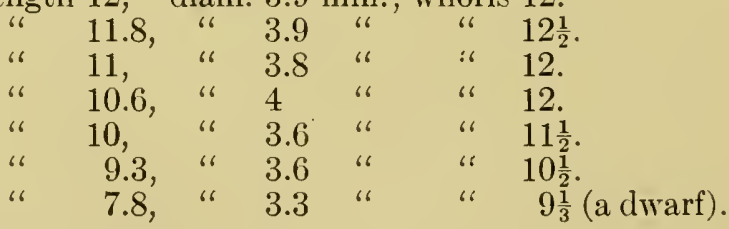

At Station 24, a gulley running out of the Fourr ranch, the shells are 9 to $10 \mathrm{~mm}$. long, otherwise similar.

At Station 25, foothills west of the Fourr ranch (Pl. XV, fig. 2) the shells are smaller, with sculpture like the type. The peristome adheres for a short distance to the preceding whorl, or is very shortly free. The columellar lamella is within the front of the last whorl; 
parietal lamella when present is very small, and most specimens lack it. They are very uniform in size and sculpture, in a long series taken.

Length 8.7, diam. 3.2 mm.; whorls 10 ; lamellæ 1 .

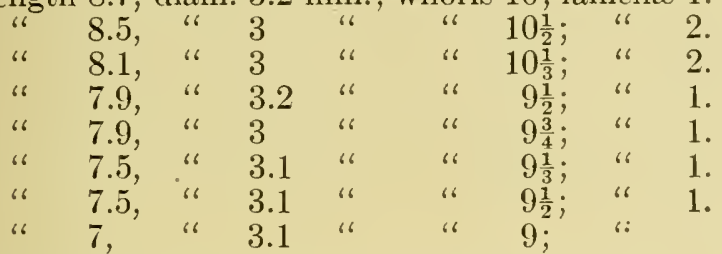

Holospira campestris cochisei n. subsp. Pl. XlY, figs. 6 to $8 b$.

Similar to campestris, but more slender, with fewer ribs (28 to 40 on the penultimate whorl, in the type lot), the intervals wider. Internal lamellæ three, the parietal very long and strong.

Length 10.5, diam. 3.3 mm.; whorls 12 ; lamellæ 3 .

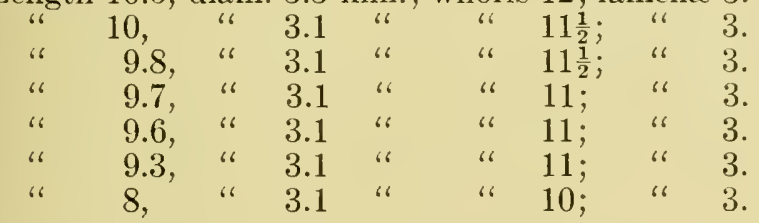

Dragoon Mountains: along the sides of an arroyo or gulley on the mesa within the wide mouth of Tweed Canyon, Station 16; Types No. 112,219, A. N. S. P. Also Stations 17, 19-23, and 27, all in Tweed Canyon.

The type locality, Station 16 (Pl. XIV, figs. 7-7f), is on the sloping sides of the arroyo, which is about 15 feet deep, and meanders across the mesa. Near the mountain the gully deepens to $30-40$ feet, the sides become subvertical, and Holospira disappears. The mesa is grassy with some bunches of bear grass. There are some small oaks, juniper, catclaw, etc., in the arroyo. The shells are found under dead sotol and sometimes stones, etc. They reappear just below the igneous dyke near the base of the mountain, Station 17, but do not cross the dyke. Several other arroyos in the same plain were not examined, and there are doubtless many Holospira colonies in the neighborhood.

Station 19, on the slope near foot of mountain, below the igneous dyke. The shells resemble types of H.c. cochisei except that they are more finely, closely ribbed, ribs 45 to 50 on the penultimate whorl. Ten specimens opened are trilamellate.

Station 20. Mouth of second ravine west from granitic spur. 
Station 21, hillside, eastern slope of second ravine from granitic spur, up to about 600 feet above bed of ravine. The shells are variable, as would be expected in a lot gathered over a considerable area, having 35 to 50 ribs on the penultimate whorl. Out of 11 opened, one has 3 lamellæ, ten have two, superior and axial. (Pl. XIV, fig. 6.)

Station 22, in the bed of the same ravine. Shells having about 56 ribs on penultimate whorl. Eight opened have 3 very strong lamellæ.

Station 23. Between Stations 21 and 2, near top. Like the preceding, lamellæ 2 or 3 .

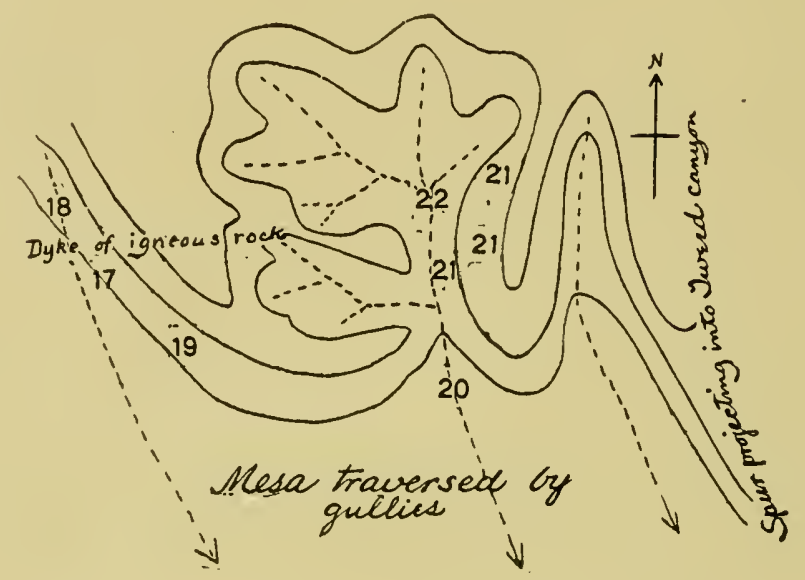

Fig. 2.-Sketch to show positions of collecting stations west of the spur in Tweed Canyon. Contour interval about $400 \mathrm{ft}$. The granitic dyke about 50 yards wide between Stations 17 and 18 separates colonies of H.c. cochisei (below) from those of $H$. danielsi (above).

Station 2\%. Rather large, length $11 \mathrm{~mm}$. with 12 whorls and 36 ribs on the penultimate whorl to $13 \mathrm{~mm}$. long, with $13 \frac{1}{2}$ whorls and 28 ribs. (Pl. XIV, figs. 8 to $8 b$.) This station is in a gulch on the south side of Tweed Canyon, the nearest approach to the area of $H$. millestriata. It shows no approach to that species in sculpture, which is coarser than in most cochisei. Some of the ribs were hollow and are broken down, as in $H$. danielsi. This condition is also seen to a less degree in some specimens of cochisei from the type locality.

Holospira millestriata n. sp. Pl. XV, figs. 3 to $5 c$.

The shell is shortly rimate, tilleul-buff, composed of about $11 \frac{1}{2}$ convex whorls, of which the last 5 form the cylindrical, those preceding the conical portion. Embryonic 2 whorls smooth, somewhat nipple-like, the second whorl becoming very narrow. Succeeding 
whorls of the cone somewhat more sharply striate than the cylindric portion, upon which the striæ are very fine and close; typically about 90 fine, close strix on the penultimate whorl. The latter part of the last whorl is slightly compressed and has slightly coarser, sharper striæ. The aperture is carried very shortly free, is not calloused within, and has a narrowly reflexed lip. Within the latter part of the penultimate and first part of the last whorl there is a rather stout, obtuse lamella on the axis. No lamellæ on the upper or basal walls of the cavity.

Length 12, diam. $4 \mathrm{~mm}$; 12 whorls.

Dragoon Mountains, south of Tweed Canyon, the types from Station 7 , the summit of a limestone ridge separating the head of Cataract Gulch from the next canyon opening westward, south of Tweed Canyon, No. 112,225, A. N. S. P., collected by Ferriss, Pilsbry and Daniels, October, 1910. Also taken at Station 7, and Stations 29 to 37 southward from Stations 7 and 8 .

$H$. millestriata is related to $H$. campestris, from which it differs by having more numerous, finer striæ, and by the absence of internal lamellæ on the parietal and basal walls of the cavity, in a long series of shells opened. Its range is separated from that of $H$. campestris by the ridge of eruptive rock which runs from Cochise stronghold along the south side of Tweed Canyon westward to the mesa; no Holospiras being found on this ridge, so far as we know. The isolation of the two species seems, therefore, to be complete. The species is quite constant in hundreds of shells collected from many colonies, as noted below; but in two stations in small hills on the mesa eastward of Middlemarch Canyon there is notable variation. Further study should be given to these small forms of the border between mountain and plain. In over a hundred shells opened from all the colonies, only one has a very weak trace of a superior lamella, all others having only a stout axial lamella.

The type locality, Station 7, is on the divide, a ridge above an abandoned mine and cabin. It may be reached by ascending Cataract Gulch from Tweed Canyon, but much more easily along the mountains eastward, as the gulch is rather a neckbreaker. The specimens are quite uniform in sculpture. Length up to $12.2 \mathrm{~mm}$., and very rarely as short as $9.3 \mathrm{~mm}$., with 10 whorls. (Pl. XV, figs. $3,3 a, 3 b)$. Out of twenty opened, one has a weak, hardly perceptible trace of the superior lamella, the others having the axial lamella only. A series of $\mathbf{1 0 0 0}$ or more was taken. It occurs under stones, etc., in places where there is no shade. 
At the adjacent Station 8, eastward and slightly higher, the shells average smaller-about $10.5 \mathrm{~mm}$. long-but are otherwise similar.

Station 29. Bear Gulch, near top, and Station 30, ridge west of Bear Gulch, typical shells.

Stations 31, 32, on the east side, and Station 33 on the west side of Soren Gulch, typical shells.

Station 34. A small limestone hill in Middlemarch Canyon. The shells have perceptibly coarser sculptures than in the types, about 70 riblets on the penultimate whorl. One internal lamella, the axial.

Station 35. Cochise Peak. Similar to the shells from Station 34.

Station 36 . Small limestone hills eastward on the mesa of Middlemarch Canyon. The shells here are smaller than typical millestriata, and vary from the typical fine ribbing to somewhat coarser (Pl. XV, figs. $4,4 a$, the prevalent form), and a few are as coarsely sculptured as $H$. campestris cochisei, the coarsest having 48 ribs on the penultimate whorl. The proportions of diameter to length also vary a good deal, as shown in the figures and measurements. All the specimens opened have a single lamella, the axial.

Length 9.5, diam. $3.6 \mathrm{~mm}$.; whorls 11 .

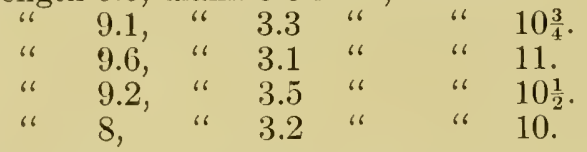

Station 3\%. Another colony near the preceding, consists of very small shells. (PI. XV, figs. 5 to $5 c$.)

Length 9, diam. $3.2 \mathrm{~mm}$; whorls $10 \frac{1}{2}$. 7.2 , " 3.2 " " $9 \frac{1}{2}$.

It is evident that $H$. millestriata, which is very constant in the mountains, varies in size, proportions and sculpture in the different ecologic conditions of the lower, more arid mesa.

\section{ZONITID Æ.}

Vitrea indentata umbilicata Ckll.

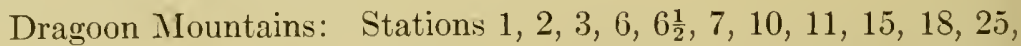
$26,28,29,35$; therefore generally distributed, probably wherever snails live, as some of the stations were only hastily examined for the larger shells.

Zonitoides arborea (Say).

Dragoon Mountains: Station 28. 
Zonitoides minuscula alachuana (Dall).

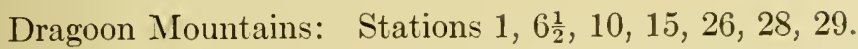

Striatura milium meridionalis $\mathrm{P}$. and $\mathrm{F}$.

Dragoon Mountains: Stations 1, 6, 10, 29.

Euconulus fulvus (Mlüll.).

Dragoon Mountains: Stations 1, 10, 15, 28 and E. f. alaskensis, Station 29.

\section{ENDODONTID平.}

Pyramidula cronkhitei (Newc.).

Dragoon Mountains: Stations 28, 29.

Radiodiscus millecostatus Pils. and Ferr.

Dragoon Mountains: Stations 1 and 10; rare.

Helicodiscus arizonensis Pils. and Ferr.

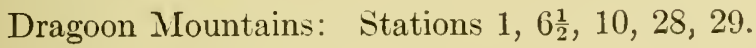

Punctum californicum Pils.

Dragoon Mountains: Station 10, in the amphitheatre or upper basin of Tweed Canyon. The specimens are a little more openly umbilicate than the type, but the riblets are more unequal than in $P$. pygmoum, and spiral lines are scarcely discernible.

\section{SUCCINEID $Æ$.}

Succinea avara Say.

Dragoon Mountains: Stations 2, 3; single dead specimens.

\section{FERUSSACID $Æ$.}

Cochlicopa lubrica (Müll.).

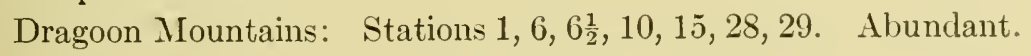

\section{PUPILLID平.}

Bifidaria ashmuni Sterki.

Dragoon Mountains: Stations 1, 3, 6, 10, 11, 15, 25, 26, 29.

Bifidaria perversa Sterki.

Dragoon Mountains: Stations 2, 3, 22.

Bifidaria dalliana Sterki.

Dragoon Mountains: Stations 3, 6, 26.

Bifidaria pilsbryana Sterki.

Dragoon Mountains: Stations 1, 2, 10, 11, 15, 18, 25, 28, 29.

Vertigo coloradensis arizonensis $\mathrm{P}$. and $\mathrm{V}$.

Dragoon Mountains: Station 25. 


\section{VALLONIID A世.}

Vallonia perspectiva Sterki.

Dragoon Mountains: Stations $1,6,10,15,25,26,28,29 . \quad$ In copious numbers.

\section{The Mule Mountains.}

This group is between the southwestern outliers of the Chiricahua Range and the Huachucas, and is much lower than either, the highest summits about 7,000 feet. The greater part of the group is igneous rock, but the Escabrosa Ridge, running along the western and southern borders, is limestone. Collecting was done in the vicinity of Bisbee and Warren, August 29 and 30, 1910, by Daniels and Pilsbry. We found nothing in the igneous area, but Sonorella probably lives on the higher peaks.

The Geological Survey has published a topographic sheet of this region.

Sonorella bartschi n. sp. Pl. VIII, figs. $4,4 a, 4 b$.

The shell is strongly depressed, rather openly umbilicate (width of umbilicus contained nearly six times in the diameter of shell), moderately strong, though thin; color between cinnamon and wood brown, fading to white around the umbilicus, and encircled above the periphery with a dark chestnut band, bordered above and below with white bands, as wide as the dark band or wider. Surface glossy; initial $\frac{1}{3}$ whorl of the embryonic shell smooth; a few radial wrinkles follow, after which it has radial striæ which become more or less interrupted, forming irregular, long granules; beginning with the second whorl, there are short hairs, subregularly placed in forwardly descending rows; these continue to the penultimate whorl, where they weaken and disappear. The last whorl has a weak sculpture of growth wrinkles only.

Whorls about $4 \frac{1}{2}$, rather slowly increasing, convex, the last descending well below the periphery in front. Aperture strongly oblique, subcircular. Peristome thin, expanded rather slightly above, strongly below, the ends approaching and joined by a very short but distinct parietal callus.

Alt. 11.2 , diam. $20 \mathrm{~mm}$; aperture $9.7 \times 10.5 \mathrm{~mm}$.; umbilicus 3.5 mm. wide; whorls $4 \frac{3}{4}$.

Alt. 10.2 , diam. $18 \mathrm{~mm}$; a aperture $8 \times 9 \mathrm{~mm}$.; umbilicus $3.3 \mathrm{~mm}$. wide; whorls $4 \frac{1}{2}$.

The back and tentacles are slate colored, sides gray. The sole shows no longitudinal divisions or areas. 
The penis is long, its lower half very slender, enveloped in a long sheath composed of glossy circular muscular tissue. The upper half is somewhat swollen. The penis-papilla (fig. 1a) is rather short, cylindric, very faintly wrinkled transversely, the distal end obtuse, rounded. The flagellum is about $0.8 \mathrm{~mm}$. long. The vagina is about half as long as the penis. Other $q$ organs as usual in the genus (Pl. XI, fig. 1, from Station 1, near Bisbee, No. 103,095). Length of penis $14 \mathrm{~mm}$; epiphallus $11 \mathrm{~mm}$; penis-papilla about $5 \mathrm{~mm}$; vagina $7 \mathrm{~mm}$; spermatheca and duct $22 \mathrm{~mm}$.

Mule Mountains: Mt. Ballard, in the Escabrosa Ridge; about 2 miles west of Bisbee, Arizona, on a ledge of the north side near the summit. Type No. 103,095, A. N. S. P., collected by Pilsbry, August 31, 1910. It was also taken on the northern slope of a limestone hill about two miles east of Warren, Arizona.

Other specimens from the type locality measure as follows:

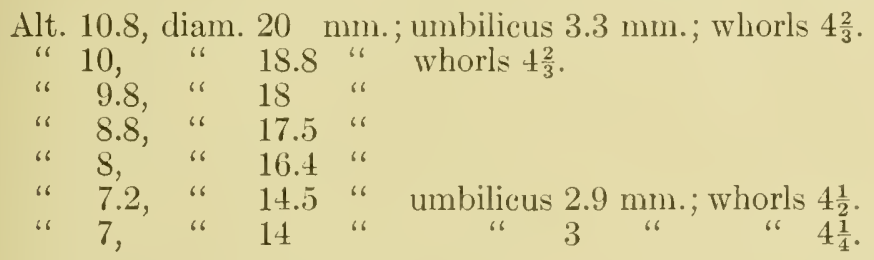

The shell is quite characteristic by its conspicuous white bands bordering the dark band at the shoulder, the rather open umbilicus, and the nearly circular, strongly oblique aperture. It is a handsome snail when fresh, not closely resembling any other species we have seen. Its nearest neighbor is S. mearnsi Bartsch, from San José Mountain, which lies just south of the international boundary near Naco, a railroad station on the El P,aso and Southwestern R. R. S. mearnsi has a narrower umbilicus, less conspicuous white bands, only 4 whorls, the periphery of the last somewhat subangular, and the surface is very minutely granular.

The hairs of the neanic whorls are very delicate and fugacious; but when they are gone the spire still remains rougher than the last whorl, having an indistinct pattern of radial wrinkles or irregular, long granules. This disappears entirely on the last whorl. The embryonic whorl (bcyond the initial half-whorl, which is alike in nearly all Sonorellas) is not marked with the protractive raised lines or series of granules of S. hachitana and its numerous group.

By its genitalia $S$. bartschi resembles the Chiricahuan S. bowiensis, but that differs by having close, finely developed sculpture of threads 
forming tangents and $V$-shaped figures on the last embryonic whorl, as well as in various features of the adult shell.

We do not find in the shells of the Warren form any constant difference from those of the type locality; but the genitalia (Pl. XI, fig. 2) and jaw (Pl. XI, fig. 2b) differ somewhat in the only living adult taken. The penis has scarcely any sheath; only a few fibres bind the epiphallus. Flagellum more minute. Penis-papilla (fig. $2 a$ ) nearly half the length of the penis, tapering and nrinkled. The penial retractor is inserted on the epiphallus near its base. The vagina is nearly as long as the penis. Length of penis $10 \frac{1}{2} \mathrm{~mm}$.; epiphallus $10 \mathrm{~mm}$; penis-papilla $5 \mathrm{~mm}$.; vagina $9 \mathrm{~mm}$.

The jaw (Pl. XI, fig. 2b) has about 5 weakly developed ribs.

Thysanophora hornii (Gabb).

Limestone hill 2 miles east of Warren.

Holospira arizonensis mularis n. subsp. $\mathrm{Pl}$. $\mathrm{XV}$, fos. s to Se.

The shell is very shortly rimate, cylindric, with short terminal cone, wood brown or avellaneous, the last half of the last whorl opaque white; composed of $10 \frac{1}{2}$ to $13 \frac{1}{2}$ whorls, the first two smooth. The last half of the second and first half of the third whorl are narrower than the preceding and following whorls, as usual, and the apex projects somewhat nipple-like. Following whorls of the cone are quite convex, and are sharply, closely and obliquely striate. On the eylindrical portion the whorls are only weakly convex, and gradually lose the striæ, so that the penultimate and often one or two earlier whorls are smooth or nearly so, the last half-whorl becoming strongly, sharp!y striate again. The last whorl is compressed latera!ly on the back but becomes rounded near the aperture, preceding which it is somewhat contracted. The aperture is rotundovate, peristome shortly free of the preceding whorl, and quite narrowly expanded. Internal axis rather small, in the last part of the penultimate and the beginning of the last whorl becoming a moderate, obtuse lamella. Typically there are no other lamellæ, but in a small number of specimens a superior lamella, or superior and basal lamellæ are developed, both very weak.

Length 13.1, diam. 4.2 mm.; whorls 12.

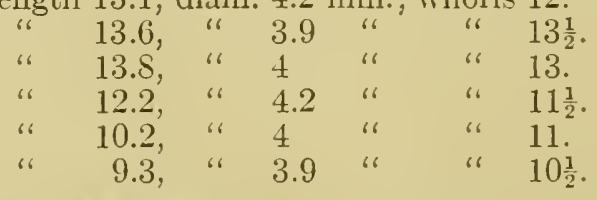

Mule Mountains, on the northern slope of the Escabrosa Ridge, west of Bisbee. Arizona, at about 6,000 to 6,500 feet elevation. 
Type No. 112,236, A. N. S. P., collected by Pilsbry and Daniels, August 29, 1910.

The Escabrosa Ridge, or mountain side on the left, ascending the first left-hand ravine above Bisbee on the Tombstone Road, is the home of this Holospira. Extensive burning of the brush has narrowed their range and decreased their numbers, at least for the time, so that the series collected was not large. ${ }^{3}$ Some very small scrub oaks remain in places; there are three species of agave, some sotol and bear-grass, a few cylindropuntias, and many herbaceous plants, now after the summer rains gay with flowers; over everything a little scarlet morning-glory, which we afterward found common in the ranges westward.

Out of 20 shells opened, 18 have the axial lamella only; one has also a small superior or parietal, and one has superior and basal lamellæ, both very low and small.

This is a larger and longer species than $H$. ferrissi, and further distinguished by the smooth later whorls and deficient internal lamellæ. The Chiricahuan $H$. arizonensis Stearns differs chiefly by having the internal lamellæ larger.

Holospira ferrissi fossor n. subsp. Pl. Xr, figs. 6 to $6 b$.

The short, cylindric shell is ribbed throughout, with about 47 ribs on the penultimate whorl. The last whorl is conspicuously flattened on the back, then gibbous (the gibbosity internally filled with white shelly material) and contracting to the aperture, the basal crest rather conspicuous. These features are more conspicuous than in H. ferrissi. There is an obtuse axial lamella in the front of the last whorl, and typica!ly no other lamellæ; but three specimens out of 20 opened show a weak parictal lamella also. The color is wood brown or avellaneous, with the usual white patch on the last whorl.

Length 8.7 , diam. $3.3 \mathrm{~mm}$.; $10 \frac{1}{3}$ whorls (type).

$\begin{array}{llllllll} & 6.4, & \text { " } & 3.3 & \text { " } & 8 \frac{1}{3} & \text { " } & \text { (shortest shell). } \\ \text { " } & 9.8, & \text { " } & 3.6 & \text { " } & 10 \frac{1}{2} & \text { " } & \text { (largest shell). } \\ & 9.3, & & 3.3 & & 10 \frac{3}{4} & & \text { (slender shell). }\end{array}$

Mule Mountains: on slopes of a limestone peak about 2 miles east of Warren, Arizona. Type No. 112,238, A. N. S. P., collected by Pilsbry and Daniels, August 31, 1910.

The town of Warren may be reached by a trolley line from Bisbee. It lies lower than Bisbee and is separated from the plain by a range

'180 specimens in the lot taken by Pilsbry, probably as many or more taken hy Daniels; most of them dead shells. 
of hills which reach about 5,500 feet elevation. On the northern and northwestern slopes of one of these, about two miles east of the town, we colleeted Sonorella, Holospira and some smaller shells. Holospira is very abundant (over 1,500 eolleeted by H. A. P.), living in mellow earth under stones, in "nests" of from six to twenty or more, usually standing vertically, apex up, and buried in earth up to the summit. While the seulpture of this speeies is coarser than that of typical $H$. cionella, yet there are some equally coarse individuals of the latter. It is quite possible that $H$. cionella may eventually be ranked as a subspeeies of $H$ ferrissi.

In the débris of the San Pedro River above the S. P. R. R. briclge, near Benson, Arizona, we found three specimens representing as many races of Holospira. One is the upper half of a slowly tapering speeies, evidently new. The others are probably races of $H$. ferrissi. One specimen has the appearance of a small $H . f$. fossor. It has the same sculpture, a low axial lamella, and measures, length 7.6, diam. $3.1 \mathrm{~mm}$., $9 \frac{3}{4}$ whorls.

The other shell resembles $H$. ferrissi in having three internal lamellæ, the superior and axial lamellæ being strongly developed. The ribbing is as fine as in the most finely ribbed ferrissi-decidedly finer than in fossor. The form is more slender than in ferrissi. This shell apparently represents another subspeeies or loeal race of $H$. ferrissi. As it may have drifted a long distance, it had better be left nameless until found in its natural habitat.

Holospira ferrissi sanctæcrucis n. subsp. Pl. XV, fig. 7.

The shell is similar to the most slender and fine-ribbed examples of $H$. ferrissi in form and sculpture, except that the apical whorls are more mucronate. The three internal lamellæ are lateral in position, strongly developed, especially the superior one, whieh is a halfwhorl long.

Length 8.5, diam. $3.2 \mathrm{~mm}$.; whorls $11 \frac{3}{4}$.

Valley of the Santa Cruz River, above Tueson, Arizona. Type No. 112,239, A. N. S. P., found in flood débris of the river a short distance above the Congress St. bridge, Tueson.

This is some distance west of any other record of Holospira in the United States. In Mexico the genus extends to the Gulf of California. The lamella are much stronger than in any of the lot of H. ferrissi which we have opened.

Although there eannot be much doubt that this species inhabit: some limestone hill not far from the river, we failed to find it in the quite limited time we spent in the neighborhood. It may have 
Hoated many miles, as the river merits that name in time of flood, though usually reduced to a chain of infrequent pools or an insignificant rivulet. The term river, in the arid belt, refers to the bed and banks rather than to the water, which is often conspicuous for its absence during a great part of the year.

\section{ZONITID $巴$.}

Vitrea indentata umbilicata (Ckll.).

Two miles west of Bisbee, and about the same distance east of Warren, on limestone hills, with Holospira.

\section{PUPILLID ÆE.}

Bitidaria pellucida hordeacella (Pils.).

Limestone hill about 2 miles east of Warren, Arizona.

\section{Benson, Arizona.}

Benson, Cochise Co., at the junction of the Southern Pacific and El Paso and Southwestern Railroads, is in a flat region, with no mollusk fauna in its immediate environs. The San Pedro River, flowing northward about a mile east of the town, brings down considerable flood débris containing shells. The source of these is probably in the foothills of the Whetstone Mountains, not far away; possibly also the hill country about Tombstone, or even further south.

The San Peclro carries more water than any other stream in the lower tier of counties between the Rio Grande and the Colorado, and so far as we know it is the only one maintaining a constant flow. At Benson it is a turbid stream 20 to 30 feet wide, with vertical, dirt banks about 8 feet high (September 1st), meandering in a flood plain covered with mesquite.

Mr. Ferriss collected a few shells from the river drift in 1904; and in 1910 Pilsbry and Daniels, having an hour or two between trains, collected a small bag of shell-bearing débris near the S. P. R. R. bridge. In this sample the most abundant mollusk is Bifidaria procera cristata. The small Zonitoides, Bifidaria p. hordeacella, Pupoides marginata and Tertigo ovata are next in abundance. All the species except Vallonia gracilicosta are Lower Sonoran forms.

THYSANOPHORA HORNII (Gabb).

Holospira ferrissi Pils. (variety). See p. 388.

" F. Fossor P. and F. See p. 387.

" n. sp. (spire only).

Vitrea indentata umbilicata (Ckll.).

ZoNitoides MiNusCUla ALACHUANA (Dall).

" Singleyana (Pils). 


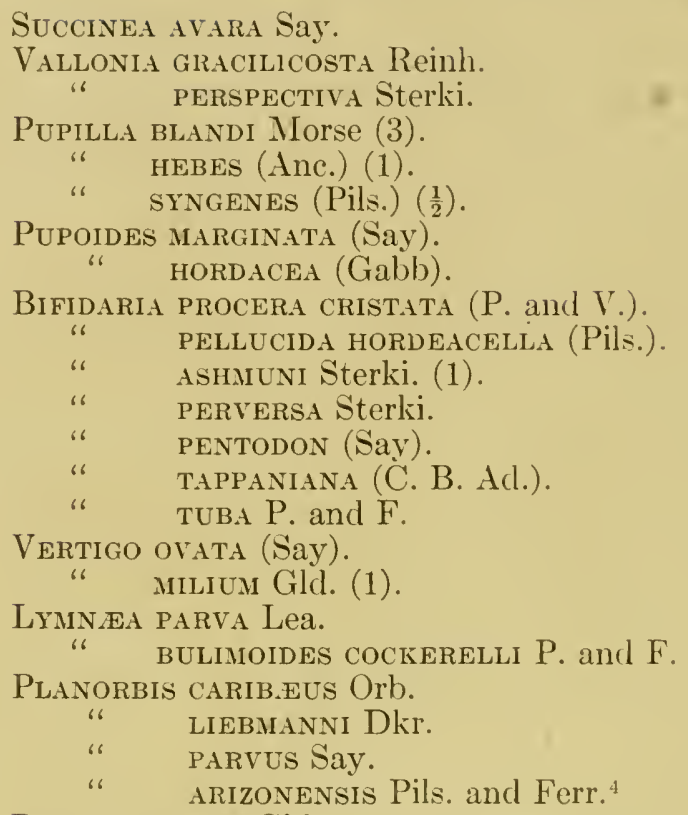

Physa virgata Gld.

Aminicola sp. (two dead specimens).

Sph.ærium triangulare (Say).

Pisidiuar compressum Prime.

Vertigo milium, Bif. tappaniana and Sphorium triangulare (one valve) were obtained in 1904, not in 1910. The latter is new to the fauna of the United States, but having compared with the type specimens, we are satisfied of its identity.

Part of the specimens we refer to Lymnoa parva agree with cotypes of $L$. dalli; but we have been unable to make a satisfactory division of the material.

Columella edentula (Drap.) in the Huachucas.- We may add here a species accidentally omitted from the Huachuca list published in part III, of this series (1910). It was found at Wickersham's, Miller Peak.

\section{The Santa Rita Mountains.}

This fine and well-wooded range forms the eastern boundary of the Santa Cruz River Valley. IVe drove in from Siding No. 4 on the Sonora Railroad, camping at Agua Caliente, a large tepid spring flowing into an artificial pool at the mouth of the canyon of the same name, the elevation about 3,800 feet. Several Sonorella

- Planorbis arizonensis, new name for P. filocinctus Pilsbry and Ferriss, Proc. A. N. S. Phila., 1906, p. 165, not of Sandberger. 
colonies were found near by. Our second camp was at the cabin in the saddle at the head of Agua Caliente Canyon, somewhat above 7,000 feet and close to collecting Station 6 of map. There is a good spring. The best collecting is in Walnut Canyon, Station 5, where three species of Sonorella live. From above this camp there is fine timber, but no land shells worth mentioning up to the summit of Mt. Hopkins. Good collecting stations were found in Madera Canyon which would be an excellent place to camp. "We also reachect the head of Josephine Canyon from this camp. A two-day excursion was made, via Brandt's mining camp, over the 8,500 -foot saddle north of Old Baldy, and down Camperel Canyon ${ }^{5}$ to perhaps 7,000

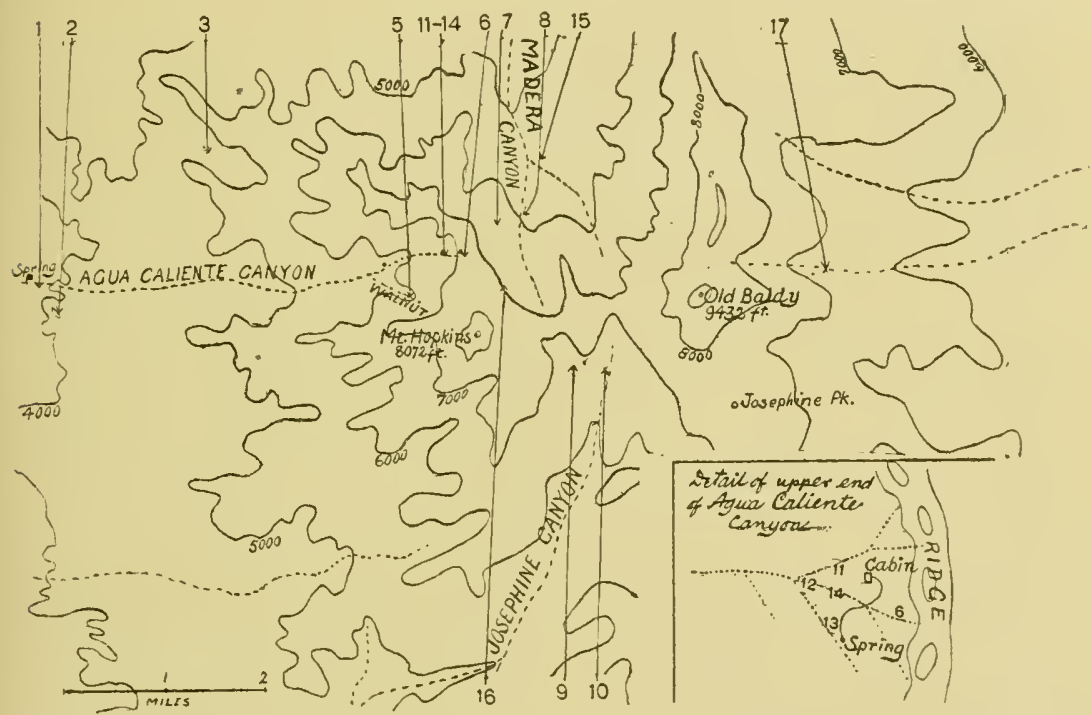

Fig. 3.-Collecting stations in the Santa Rita licurtains. Contour interal, 1000 feet.

feet. There is fine pine on the top and extending some distance down. Also some huge spruce and hemlock trees. We passed through aspens, then small-leaved maples, to walnuts, in the bed of the canyon. Sonorella clappi occurs here, and a few specimens of a Sonorella (occidentalis), which we provisionally rank as a subspecies of the Huachucan S. granulatissima. It will be seen that our work extended nearly across the middle of the highest part of the range in a rather narrow band, the collecting stations being marked on the accompanying tracing simplified from the U.S. G. S. topographic map.

${ }^{5}$ This canyon is not named on the topographic map. On it Stetson's dam is situated, lower down. 
The absence of the common western Sonorellas (santaritana and walkeri) on the eastern slope, and the occurrence there of another species (S. g. occidentalis) indicates a certain amount of local faunal differentiation, and it seems likely that work in the northern, southern or eastern parts of the range would result in a number of additional species of Sonorella. By the ahsence of Oreohelix and Ashmunella (in the parts we explored), the Santa Ritas differ remarkably from the Huachueas, the next range eastward.

We obtained very few small shells.

Titrea indentata umbilicata (Ck1l.), Stations 7, 12, 17.

Euconulus fulvus (Müll.), Station 7.

The loeations of collecting stations follow.

Station 1. In rock along banks of stream flowing from Agua Caliente Canyon, immediately south of the spring.

Station 2. Northern base of bluff southeast of Station 1.

Station 3. About half way up "Soldier Canyon," a short canyon immediately north of the mouth of Agua Caliente.

Station 4. Pool of Agua Caliente Spring (Physa humerosa (?), frogs, etc. collected).

Station 5. Walnut Canyon or branch of Agua Caliente, which opens about 200 yards below the miners' cabin midway of $\mathrm{A}$. C. Canyon. Shells abundant above and below the mine, in piles of heary granite rock. None found in "Walnut basin" higher up.

Station 6 . On the ravine south of cabin in the saddle, at head of Agua Caliente.

Station 7. Madera Canyon, about half way down the steep slope from camp.

Station 8. Madera Canyon, about 100 yards above "Old Johns Camp" in an extensive rock pile in the bed of the canyon, about 10 feet above the stream. This is opposite the saddle at head of Agua Caliente.

Station 9. Head of Josephine Canyon, on the flank of Mt. Hopkins, in friable, angular, rocky banks of canyon.

Station 10. Head of Josephine Canyon, a few hundred feet up the branch leading to the saddle next to Old Baldy.

Station 11. About 100 yards west of camp in saddle.

Station 12. Half a mile down (west) from camp.

Station 13. About 10 rods above Station 12, on the branch leading to the spring near camp.

Station 14. A short distance above Station 12 on the branch rumning near camp.

Station 15. Bed of Madera Canyon near the fork.

Station 16. Eastern (Madera) flank of Mt. Hopkins, about a mile south of Station 7 .

Stations 17, 17 $\frac{1}{2}$. Camperel Canyon, on the eastern slope of the range. 
Sonorella santaritana n. sp. PI. IX, figs. 1 to 3.

The shell is depressed, umbilicate (the width of umbilicus contained between 6 and 7 times in diam. of shell), solid, between cinnamon-buff and pinkish-buff, becoming whitish on the base, and having a chestnut-brown shoulder band bordered with white.

The surface is rather glossy. Embryonic shell of $1 \frac{1}{2}$ whorls; after a very short initial smooth stage, the surface becomes radially rippled, then densely granular, the granules lengthened in an obliquely spiral direction, becoming longer with the growth of the embryo, the last $\frac{2}{3}$ whorl of the embryo marked with threads forming $V$-shaped figures, their intervals densely, subregularly wrinkled radially.

The post-embryonic whorls have very fine, inconspicuous growth lines and excessively faint spiral lines on the last whorl, above and at the periphery. The spire is very low conic. Whorls $4 \frac{1}{2}$, convex; the last descends deeply in front. The aperture is very oblique, small; peristome narrowly expanding, pale brow'n at the edge, the margins conrerging, so that the thin, transparent parietal callus is short. In the last whorl the umbilicus enlarges to about double its previous width.

Alt. 13, diam. 23, width of umbilicus $3.6 \mathrm{~mm}$; aperture $10.5 \times 12 \mathrm{~mm}$.

Santa Rita Mountains, Arizona, in Walnut Canyon (a branch of Agua Caliente Canyon) at about 6,000 feet elevation, Station 5, Ferriss, Daniels and Pilsbry, 13-IX-1910. Type No. 112,105, A. N. S. P. Also taken at Stations 11,12 , 13,14 , between 6,000 and 7,000 feet, near the head of Agua Caliente Canyon; Stations 7, 8, 16, in Madera Canyon, from about 5,700 to nearly 7,000 feet, and at Stations 9 and 10, in the head of Josephine Canyon, near the ridge connecting $\mathrm{M}$ t. Hopkins and Old Baldy, at about 6,500 feet.

Genitalia (fig. 4).-The penis and vagina are extremely long. Penis is rather slender, and lies in three folds in the

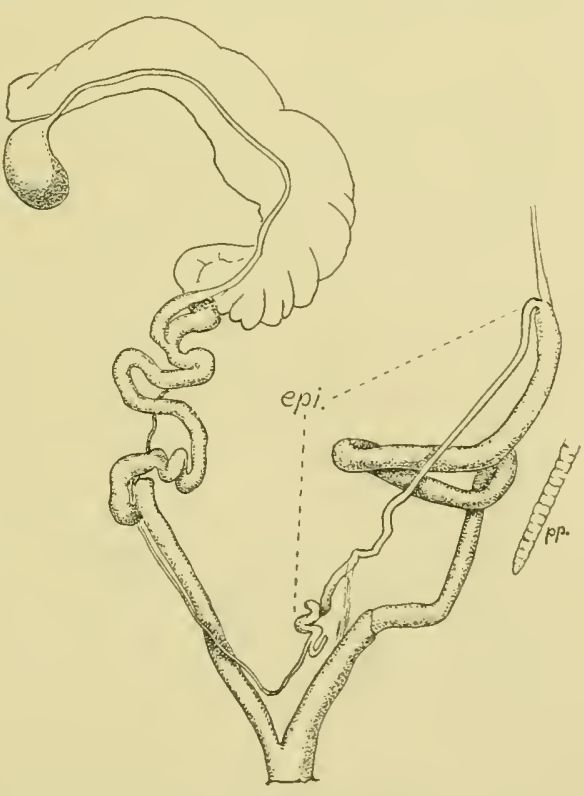

Fig. 4.-Genitalia of S. santaritana. epi., epiphallus: $p p$., end of the penis-papilla. 
body. It has a basal sheath, and a slender, conspicuously annulated papilla, one-third the length of the penis or longer. The flagellum is well developed for Sonorella. The penial retractor is inserted at the apex of penis and base of epiphallus. The vas deferens is slender throughout. Measurements of the organs in mm. follow.

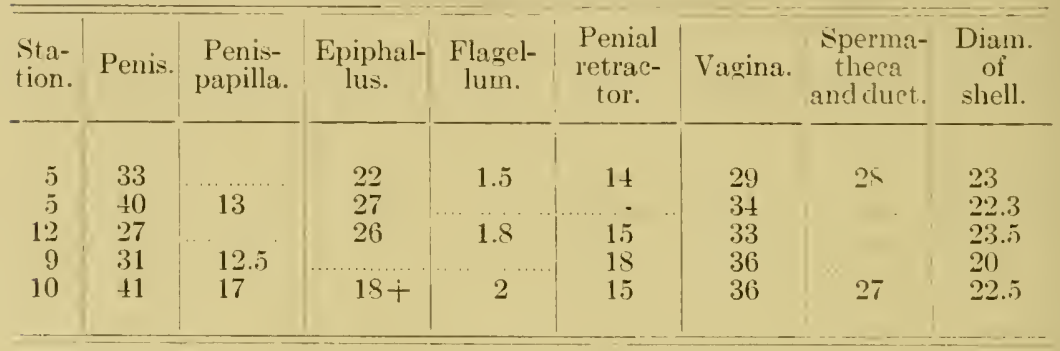

Specimens from Station 11, and numerous others from Station 5, opened but not measured, were sufficiently examined to show that the specific characters-great length of penis and vagina-are constant.

S. santaritana differs from other species of the same range by its wider umbilicus, the more approaching ends of the lip, and especially by the great length of penis and vagina. In the characters of the genitalia it is nearest to $\mathrm{S}$. rinconensis $\mathrm{P}$. and $\mathrm{F}$. (these Proceedings for 1909, Pl. XXII, fig. 5). That species differs by having a still longer vagina, and a more capacious shell with larger aperture and relatively smaller umbilicus. S. dalli and S. virilis are somewhat related, but differ in characters of both genitalia and shell.

This is the most abundant and widely distributed Sonorella of the part of the Santa Rita Range which we explored.

In size, specimens from Walnut Canyon (Pl. IX, figs. 1-2b) measured from 19 to $25.8 \mathrm{~mm}$. diameter, but only in one colony were such small ones found, the minimum size in other colonies is about 21.5 $\mathrm{mm}$.

In Stations 10, 11 and 14 they run from 20.4 to $22.5 \mathrm{~mm}$. In other stations the size is about typical.

A beautiful albino (Pl. IX, fig. 3) was taken at Station 5. It shows very faint traces of the shoulder band and the embryonic shell is faintly buff, but otherwise it is pure white. Genitalia as in the colored form.

Sonorella walkeri n. sp. PI. 1X, figs $4,4 a, 4 b$.

The shell is umbilicate (the width of umbilicus contained about 9 times in the diameter of the shell), rather solid, pale cinmamon, 
fading to white around the umbilicus and on both sides of the chestnutbrown shoulder band.

The surface is glossy, lightly marked with growth lines, and under a strong lens showing impressed spiral lines on the upper surface of the last whorl (lacking, however, in many individuals). Initial $\frac{1}{3}$ whorl radially rippled, granulation then beginning, the last $\frac{2}{3}$ whorl having close protractively spiral threads, the intervals densely wrinkled radially. Spire very low conic. Whorls $4 \frac{2}{3}$, the last descending in front. The aperture is rounded oval; peristome narrowly expanding, inconspicuously brown-edged, slightly thickened within, the margins converging, joined by a thin, brownish-edged parietal callus.

Alt. 14, diam. $23 \mathrm{~mm}$; umbilicus $2.6 \mathrm{~mm}$; aperture $12 \mathrm{x} 13 \mathrm{~mm}$.

Genitalia (Pl. XII, figs. $1-3,5,5 a$ ).-The penis is small and slender, at the base enclosed in a short but thick sheath. Penis-papilla cylindric, more than half the length of penis, tapering distally to a blunt or a somewhat pointed end. Retractor muscle inserted on the epiphallus near its base. Epiphallus as long as the penis or somewhat longer, terminating in a minute, bud-like flagellum. Lower part of the vas deferens large, its diameter equal to or exceeding that of the epiphallus. Vagina usually about twice the length of the penis.

Santa Rita Mountains, the type from Station 5, Walnut Branch of Agua Caliente Canyon, at about 6,000 feet, with S. santaritana and S. clappi, type No. 112,164, A. N. S. P., collected by Ferriss, Daniels and Pilsbry, 1910. Also taken at Station 3, "Soldier Canyon," at about 4,500 feet, and in Madera Canyon at Stations 7, 8 and 15 .

This fine species, named for Dr. Bryant Walker, is not uncommon, though less generally distributed than $S$. santaritana. In the type locality it lives with $S$. santaritana and $S$. clappi, sometimes all under the same rock, sometimes in separate rock piles. The smallest specimens, Station 5, measure $20 \mathrm{~mm}$. in diameter; the largest, Station 15, $24.3 \mathrm{~mm}$.

Station 3 is in a small canyon running in north of the mouth of Agua Caliente, opening to the mesa between two high granite crags. The rock is a coarse granite, and shells are not numerous. A single giant cactus growing here is further east than we have seen the species elsewhere.

Many specimens have been dissected. The slencler, short penis, with a short, thick basal sheath, and the enlarged free vas deferens 
are conspicuous characters. The smaller umbilicus and less depressed contour separate it from $S$. santaritana, which also differs more fundamentally by its genitalia. S. walkeri is very much like S. clappi in soft anatomy. Its relation to S. huachucana Pils. remains to be defined when that species shall have been dissected. Measurcments of the organs in $\mathrm{mm}$. follow.

\begin{tabular}{|c|c|c|c|c|c|c|}
\hline $\begin{array}{l}\text { Sta- } \\
\text { tion. }\end{array}$ & Penis. & $\begin{array}{l}\text { Penis- } \\
\text { papilla. }\end{array}$ & $\begin{array}{l}\text { Epiphal- } \\
\text { lus. }\end{array}$ & $\begin{array}{l}\text { Flagel- } \\
\text { lum. }\end{array}$ & Vagina. & $\begin{array}{l}\text { Sperma- } \\
\text { theca } \\
\text { and duet. }\end{array}$ \\
\hline $\begin{array}{r}5 \\
5 \\
\text { j } \\
15 \\
3\end{array}$ & $\begin{array}{l}4.7 \\
5 \\
4 \\
4.3 \\
4 \\
7\end{array}$ & $\begin{array}{l}2.3 \\
3 \\
2.3 \\
2.5 \\
3 \\
5\end{array}$ & $\begin{array}{l}5 \\
5 \\
6 \\
7.3 \\
6.5 \\
6.7\end{array}$ & $\begin{array}{c}1 \\
\text { Minute } \\
، \\
0.7 \\
\text { Minute }\end{array}$ & $\begin{array}{c}8 \\
7 \\
10 \\
10 \\
7.5 \\
7\end{array}$ & 26 \\
\hline
\end{tabular}

Sonorella walkeri aguacalientensis n. subsp. Pl. IX, figs. 5, 5a, 5b, 6, 6a, $6 b$.

A form with the shell not constantly distinguishable from $S$. walkeri was found in some abundance at Stations 1 and 2, in the

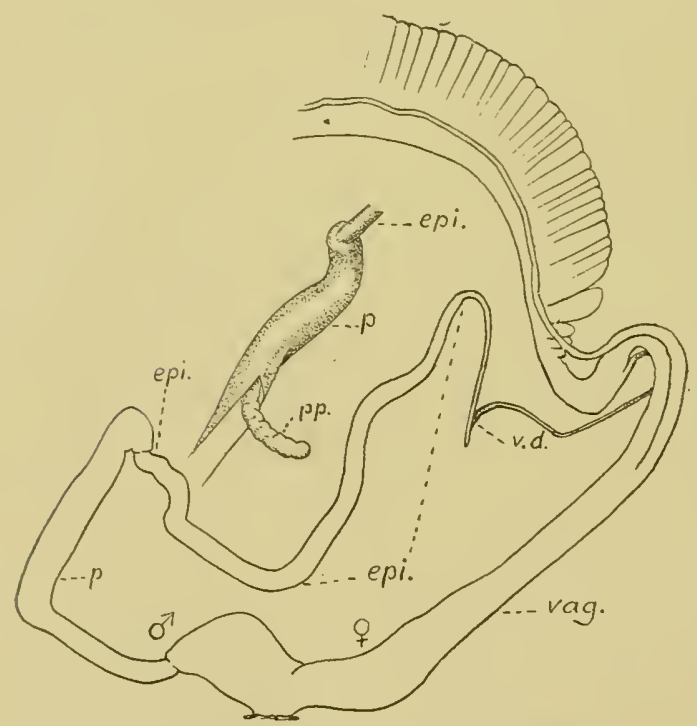

Fig. 5.-Genitalia of S. w. aguacalientersis, Station 2, with detail of penis-papilla $(p p$.). epi., epiphallus; p., penis; rag., vagina; v.d., vas deferens. mouth of Agua Caliente Canyon. Station 1 is in rocks on the bank of the wash rumning out of the canyon, immediately southeast of the fine spring of tepid water which gives this canyon its name. This is the lowest Station for any snail found in these mountains, the elevation being about 3,800 feet. All of the alcoholic specimens of this lot were lost after leaving the mountains, so that the anatomical characters are unknown. The shells measure 19 to $24 \mathrm{~mm}$. in diameter and live in crevices or under fragments of a friable, shale-like rhyolite, of a dark vinaceous-drab color. See Pl. IX, figs. $6,6 a, 6 b$. 
Station 2, at the base of bluffs southeast of Station 1 and somerhat higher, afforcled a few similar shells (Pl. IX, figs. 5, 5a, 5b). One preserved in spirit differs from $S$. walkeri by having a decidedly longer penis, penis-papilla and epiphallus. There is no flagellum, and no penial retractor muscle was found. (Fig. 5.) These differences, if confirmed by further dissections, in our opinion, indicate a distinct species; but to direct attention to it we now rank the race as a subspecies of $S$. walkeri. The diameter at Station 2 runs from 22.3 to $24 \mathrm{~mm}$. The elevation of this Station is between 4,100 and 4,200 feet, according to the topographic map.

Sonorella clappi n. sp. PI. IX, figs. $s, S a, s b$.

The shell is umbilicate (umbilicus contained about 8 times in the diameter), thin, depressed, semimatt, cinnamon, the base paler, fading to olive-buff in the middle, and with a chestnut-brown shoulder band having paler borders. Embryonic shell of $1 \frac{2}{3}$ whorls, the initial $\frac{1}{4}$ whorl smooth, the rest densely and evenly reticulate-granulous, having an indistinct zigzag pattern in some places, but without the spirally descending threads of the hachitana type. Subsequent whorls are lightly striate and microscopicalty wrinkle-granose, this sculpture becoming weaker on the base. Whorls $4 \frac{1}{3}$, the last descending in front, rounded peripherally. Aperture rounded-oval, the peristome thin, narrowly expanded.

Alt. 10.3, diam. $19 \mathrm{~mm}$; umbilicus $2.4 \mathrm{~mm}$. (type).

"10.3, " 18 " (globose topotype).

" 9 , " 17.7 " (depressed topotype).

Genitalia (Pl. XII, figs. 6, 7).---Penis slender throughout, with a thick, short basal sheath and a long papilla. Epiphallus and vas deferens slender, the former terminating in a minute flagellum, the retractor muscle inserted close to its base. Vagina shorter than the penis. Measurements in $\mathrm{mm}$. follow.

\begin{tabular}{|c|c|c|c|c|c|c|}
\hline $\begin{array}{l}\text { Sta- } \\
\text { tion. }\end{array}$ & Penis. & $\begin{array}{l}\text { Penis- } \\
\text { papilla. }\end{array}$ & $\begin{array}{l}\text { Epiphal- } \\
\text { lus. }\end{array}$ & $\begin{array}{l}\text { Flagel- } \\
\text { lum. }\end{array}$ & Vagina. & $\begin{array}{l}\text { Sperma- } \\
\text { theca } \\
\text { and duct. }\end{array}$ \\
\hline $\begin{array}{r}8 \\
12\end{array}$ & $\begin{array}{l}8.5 \\
6.5\end{array}$ & 6 & 8.5 & $\begin{array}{l}\text { Minute } \\
\text { Minute }\end{array}$ & $\begin{array}{l}5 \\
3\end{array}$ & 25 \\
\hline
\end{tabular}

Santa Rita Mountains: Station S, Madera Canyon, type No. 112,163. Also taken at Station 16, Madera Canyon; 6, 12, 13, 11 near the head of Agua Caliente Canyon; abundantly at Station j, 
Walnut branch of Agua Caliente; and Stations 17 and 17 $\frac{1}{2}$, Camperel Canyon, on the eastern slope of the mountains, at about 6,500 feet.

This is a smaller, thinner shell than other Santa Rita Sonorellas, and readily distinguished by its microscopic granulation and the beautiful sculpture of the embryo. It is variable in degree of elevation of the spire, size of umbilicus and color. In Madera Canyon the shell has a russet hue.

In Walnut Branch of Agua Caliente the color ranges from almost chamois in the thicker old individuals to nearly water green in those barely grown to full size. The mieroseopic granulation is sometimes typically developed on the last whorl, but more often more or less obsolete, sometimes only visible in a few places; and most specimens show incised spiral lines on the last whorl, occasionally quite distinct and numerous. Around the head of Agua Caliente Canyon the color is similar to the Walnut Branch lot.

S. clappi resembles the Huachucan $S$. granulatissima and $S$. danielsi in the embryonic sculpture and the general appearance, but in those species the aperture is more oblique than usual in S. clappi and the genitalia are conspicuously different. Haring dissected a good many individuals of all of these species, I feel confident that the genitalia afford the most reliable specific characters. S. clappi is very much like $S$. walkeri in genitalia.

A couple of shells from Station $17 \frac{1}{2}$, Camperel Canyon, on the eastern slope of the range, resemble the Agua Caliente form in being light colored. One from Station 17, in the same canyon, is the (larkest of all, being nearly a sorghum-brown color, more vinaceous where the cuticle is worn off. The genitalia (Pl. III, figs. 4, 4a) differ from typical $S$ : clappi by the longer penis and penis sheath, and the shorter vagina. Length of penis 13 , penis-papilla 10 , epiphallus 10 , fiagellum 1 , vagina $4 \frac{1}{2} \mathrm{~mm}$.

A bleached Sonorella, No. 105,385, U. S. N. M., collected, or at least sent to Dr. I. Lca in 1860 , by H. C. Grovenor, is labelled "Santa Rita Mountains, 6,000 feet above the sea." It is rery thin and appears under the lens to have been granular. The lip-ends converge, as in $S$. clappi, from which this shell differs by its larger size and less depressed shape; diam. $20.5 \mathrm{~mm}$. It is probably a distinct speeies related to $S$. clappi, but it is not in condition for description. The spire is broken.

Sonorella granulatissima occidentalis n. subsp. Pl. IX, figs. 7, $7 a, 7 b$.

Similar in sculpture to $S$. granulatissima, but differing by the narrower last whorl, which is less convex above; the light borders of the chestnut-brown band, and the less depressed spire. 
Alt. 12, diam. $19.6 \mathrm{~mm}$; umbilicus $2.8 \mathrm{~mm}$; $4 \frac{2}{3}$ whorls.

Santa Rita Mountains at Station 17 (Camperel Canyon), on the northeastern flank of Old Baldy. Type No. 112,165, A. N. S. P.

We regret that the jar containing the soft parts of this species proved leaky, and its contents were lost. It scems to be related to S. gramulatissima, as the sculpture is very similar.

\section{Suall Ranges and Hills of the Santa C'ruz River Valley.}

Between Tucson and Nogales and the Santa Rita and Baboquivari Mountains there are many buttes and ranges of hills or small mountains, a few of which we visited, finding in cach a special species of Sonorella and sometimes a few small shells.

Among the more important ranges which should be investigated we may mention the Tumacacori (or Atascoso) range, an extensive mass of arid looking mountains, extending south to the Mexican line, and probably supporting little but Sonorella. They are easily accessible from the Sonora R. R., being about 6 miles from "Siding No. 4." These mountains on the south pass into the Sierra de los Pajaritos, which lie west of Nogales-" "a confused mass of rocky crags, peaks, flat-topped mountains with vertical sicles, enormous trachyte dykes, steep narrow ridges and deep canyons." They are covered with "a fine growth of oak, juniper and manzanita, while magnificent walnut, sycamore and ash trees line the canyons." Water supply precarious except in the wet seasons. These fine mountains are unknown to the conchologist.

Various species reported from Tucson were certainly brought there from more or less distant localities. Sonorella granulatissima, reported by Bartsch, Smiths. Misc. Coll., Vol. 47, p. 193, and Ashmunella varicifera Ancey are Huachucan species. The following species were taken in the drift débris of the Santa Cruz River, near Tucson, chiefly above the bridge. The fresh-water shells are mainly fossils, washed out of, or exposed upon the low dirt banks, where the stream has cut down through a former cicnega. Part of the land shells probably washed in from the Tumamoc and other eastern foothills of the Tueson Range. We found Bifidaria tuba and Thysanophora hornii on the Tumamoc Hills, and with other minutiæ, in débris washed down from the hills at the hill terminus of Congress St.

ThISANOPHORA HORNII (Gabb.).

Holospira FERRISSI SANCTACRUCIS P. and F. (see p. 388).

Zonitoides singleiana (Pils.).

SuCCINed aVara Say. 
Pupoides marginata (Say).

Bifidaria procera cristata P. and V.

" PELLUCIDA HORDEACELLA (Pils.).

" TUBA P. and F.

Vertigo ovata Say.

LYMNAEA PARVA Lea.

" obrussa Say.

" Bulimoides COCKERELli $P$. and F.

Planorbis tenuis Phil.

" CARIBAUS Orb.

" PARVUS Say.

" ARIZONENSIS P. and F.

Physa virgata Gld.

Paludestrina protea (Gld.).

Pisidium pauperculum (Sterki). ${ }^{6}$

" Compressum Prime (KIrklandi Sterki).

ANODOnTA DEJECTA Lewis, fossil and recent, fragmentary.

In the drift débris of the Santa Cruz River at Amado's Ranch (not far from the mouth of Sopori Creek) we took the following:

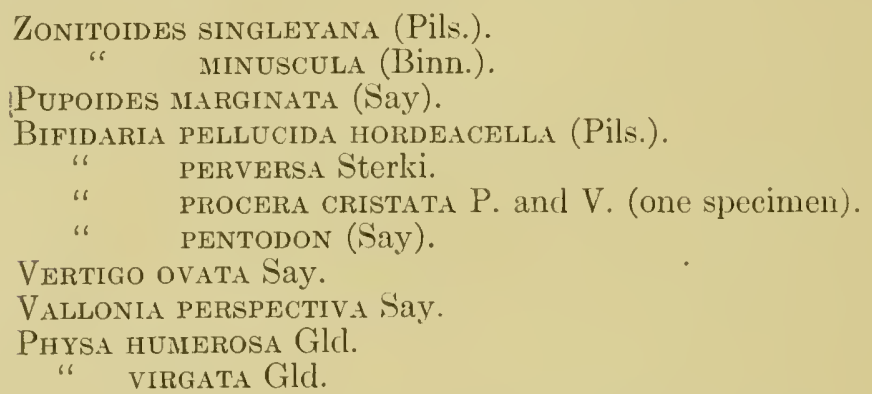

On Sopori Creek, five miles west of Amado's Ranch.

Thysanophora hornil (Gabb).

Pupoldes marginata (Say).

Physa sp. undet.

Sonorella arizonensis (Dall).

Epiphragmophora arizonensis Dall, Proc. U. S. Nat. Mus., XVIII, p. 1, 1895. Sonorella arizonensis (Dall), Bartsch, Smiths. Misc. Coll., XLVII, p. 198, Pl. 33, fig. 6.

This is a rather globose species with narrow umbilicus, quite unlike anything we found. The type is a bleached specimen found in the Santa Cruz River at Tucson, which no doubt drifted down from above. As no Sonorella lives at or near the river level, it must have been washed down from some mountain or rocky hill in the

${ }^{6}$ The species of Pisidium in these lists were determined by Mr. E. G. Vanatta. 
river valley, and will eventually be found again. Great quantities of the drift débris of the Santa Cruz which we looked over did not produce a second specimen, though minute shells were abundant. Only by a rare chance would so turbulent a stream as the Santa Cruz in flood carry Sonorella very far. In its ordinary condition there is a succession of small pools connected, in places, by a slender rivulet; but after heavy rain we have seen turbid water from bank to bank for a brief time.

Sonorella tumamocensis n. sp. Pl. X, figs. $4,4 a, 4 b$.

The shell is depressed, umbilicate (umbilicus contained about 6 times in the diameter of the shell), thin, light pinkish cinnamon, fading to whitish on the base, and having indistinct whitish borders above and below the rather narrow chestnut-brown shoulder band. Apical sculpture is of the hachitana type, but usually very weak, the initial half-whorl smooth, without the usual radial ripples; the rest of the embryonic shell is marked with a few delicate, interrupted tangential (protractive) threads, on a nearly smooth ground, having weak growth ripples only. The subsequent neanic and last whorls have weak growth lines. Whorls $4 \frac{1}{2}$, convex, the last slowly descending in front. Aperture rounded, nearly as high as wide. Peristome thin, the outer and basal margins very narrowly expanded. The columellar lip, in basal view, shows very little ditation.

Alt. 10.5, cliam. $17.5 \mathrm{~mm}$; aperture $8.7 \times 9.5 \mathrm{~mm}$.; umbilicus $2.8 \mathrm{~mm}$. wide.

Other specimens measure:

$\begin{array}{ccccc}\text { Alt. } & 10.5 \text {, diam. } & 18 & \text { mm } \\ \text { "6 } & 9, & 17 & \text { " } \\ \text { " } & 9, & \text { " } & 16 & \text { " }\end{array}$

Genitalia (Pl. XIII, fig. 5).-The penis is about as long as the vagina, slender in its lower part, somewhat swollen above. Around the base there is a very short sheath of very loose open texture. It contains a slender, slowly tapering papilla about one-third as long as the penis, its surface closely grooved spirally, the apex obtuse but small. The epiphallus is slender, terminating in a vestigeal, budlike flagellum. The retractor muscle is inserted on the epiphallus. Other organs as usual.

Top of the head and back are slate-colored, shading into gray on the sides, whitish towards the edges of the foot. Tail and sole white. Faint lines define the three areas of the sole. Jaw (Pl. XIII, fig. 8) has 3 or 4 very weak ribs. 
Tumamoc Hill, near Tucson, Pima Co., Arizona. Types No. 112,245 , A. N. S. P., collected by Ferriss, Pilsbry and Daniels, October 1, 1910; topotypes in collections of Ferriss and Daniels. Specimens were taken by Mr. J. C. Blumer under volcanic eliffs on the northeast side of Cat Mountain, in the Tucson Range.

The shell closely resembles S. eremita of the Mineral Hill group, but it is much thinner with the peristome decidedly less expanded and the embryonic whorls smoother. The penis is very much longer than in eremita. A comparison with the unique type of S. arizonensis Dall, kindly made by Dr. Paul Bartsch, shows that that species is quite distinct.

We would be disposed to consider tumamocensis a subspecies of $S$. rowelli were it not that in individuals having the shell about the same size as rowelli the penis, penis-papilla, epiphallus and vagina are about twice as long; the spermathecal duct remaining about equal in the two species. The shape of the penis-papilla is different, that of tumamocensis being longer, slender and tapering. For comparison we have added measurements of the organs of $S$. rowelli to the table on p. 408. The columellar lip dilates much less than in S. comobabiensis or S. sitiens.

The penis is very much longer, its papilla both absolutely and relatively much shorter than in $S$. papagorum.

The Tumamoc Hills are an outlying spur of the Tucson Range, about a mile from Tucson west of the Santa Cruz River. There are three hills: Tumamoc, 3,092 feet, on the northern slope of which the Desert Botanical Laboratory of the Carnegie Institution of Washington stands; Sentinel, 2,885 feet, and a lower nameless hill of 2,672 feet elevation. The hills are volcanic, formed of an old andesite flow, largely covered by rhyolite (which is the characteristic rock of the Tucson Range) and later flows of basalt. ${ }^{7}$ Sonorella occurred in great piles of black basalt, on the north slope of Tumamoc Hill, from just below the flat summit down half way to the Desert Laboratory. Most of them were taken not far from the 2,750-foot contour (our Station 35). Living snails are very scarce and hard to get. None were found on the other slopes of Tumamoc Hill, nor could we find them on Sentinel Hill. On the 2,672-foot hill, at the end of Congress St., we took only Bifidaria tuba.

7 Topographic and geological maps of these hills, with accounts of their physical features and vegetation, may be found in the following publicatious of the Carnegie Institution of Washington: D. T. Macdougal: Botanical features of North American deserts, 1908. Volney M. Spalding: Distribution and movements of desert plants, 1909. 
Except for the specimens of S.tumamocensis, taken by Mr. Blumer at Cat Mountain, the Tucson Range, about 25 miles long, is not explored for shells.

Sonorella papagorum n. sp. PI. VIIl, figs. $8,8 a, 8 b$.

The shell is depressed, umbilicate (the umbilicus contained about 9 times in the diameter of the shell), rather thin, somewhat glossy, light pinkish cinnamon, fading to whitish around the umbilicus, and a trifle pale at the edges of a dark chestnut-brown band at the shoulder. Apical sculpture is of the hachitana type, but very weakly developed, the initial half-whorl smooth, the rest of the embryonic shell similar to that of S. tumamocensis. Subsequent whorls are lightly marked with growth lines. Whorls $4 \frac{3}{4}$, convex, the last descending slowly in front. Aperture oblique, rotund-oval. Peristome slightly expanded above, the outer and basal margins rell expanded, thin; columellar margin broadly dilated, partly covering the umbilicus.

Alt. 14, diam. $23 \mathrm{~mm}$; a aperture, alt. 11.8, diam. $13.6 \mathrm{~mm}$; width of umbilicus $2.7 \mathrm{~mm}$.

Genitalia (Pl. XIII, fig. 4).--Penis small and slender, about equal in length to the vagina and of equal calibre throughout. A short, loose sheath envelops its base. The penis-papilla is nearly as long as the penis, very slender, slowly tapering, indistinctly annulate. The slender epiphallus bears the retractor muscle and terminates in a very minute flagellum. Female organs as usual. Jaw (fig. 6) has five or six strong, unequal ribs, or in one specimen four unequal weaker ribs. It is quite variable.

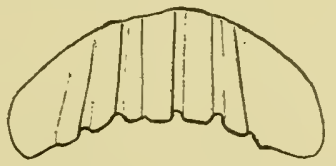

Fig. 6.-Jaw of Sonorella papagorum.

The shells show but little variation, excepting size.

Alt. 13.8, diam. $23.5 \mathrm{~mm}$; aperture $12 \times 13.3 \mathrm{~mm}$.

" 12 , " 20.5 " " $10 \times 11.7$ "

Black Mountain, near the mission of San Xavier del Bac, in the Papago Indian Reservation, Pima Co., about 9 miles south of Tucson. Types No. 112,161, A. N. S. P., collected by Pilsbry and Daniels, October 5, 1910.

This shell is less solid than $S$. eremita, with a narrower umbilicus and far weaker apical sculpture. 
Black Mountain is a rather remote and isolated outlier of the Tucson Range, which has here its southeastern terminus. It is a long, straight, level-topped ridge, divided by a deep gap into a longer and a shorter mountain. The slopes are everywhere very steep, covered with black basalt, like Tumamoc Hill at Tucson. Slicles of this rock oceupy a large part of the slopes. Between the slides, which are, of course, barren of vegetation, there is some desert verdure. Ocotillo, mesquite, cat-claw, palo verde, ete., are typical plants, and giant eacti grow on the south side. No agave or sotol were seen. The Sonorellas are found rather deep in the slides. They probably inhabit the whole northern slope, but we worked only a couple of hours, on the north side of the east end, close under the summit. Some hazard attends the hunt in these slides, which are sø stcep that the heavy rock starts to move on small provocation. Black Mountain, like the rest of the Tucson Range, is very dry. It stands on a plain much lower than the Mineral Hill group and higher than Tucson. The station where Sonorella was collected we would roughly estimate as 3,200 or 3,300 feet above the sea.

Sonorella eremita n. sp. Pl. Vill, figs, 7 to $7 e$.

The shell is globose-depressed, umbilicate (the width of umbilicus contained about $6 \frac{1}{2}$ times in the diameter of shell), more solid than other species of the same region, glossy, pinkish buff, fading to nearly white around the umbilicus, and having a chestnut-brown shoulder band, without noticeable light borders. The embryonic shell, of about $1 \frac{1}{3}$ whorls, has strongly developed sculpture of the hachitana type. The initial half-whorl has some radial ripples or wrinkles; then there appears a series of long, protractive threads on the outer two-thirds, meeting shorter forwardly ascending threads on the inner third; the intervals occupied by short radial impressions. The threads are subject to more or less interruption, particularly on the greatest convexity of the whorl. The later whorls are marked with very fine, unequal growth-lines.

The spire is very low, conoidal. Whorls $4 \frac{1}{2}$, moderately convex, the last slowly descending in front. The oblique aperture is rounded, but slightly wider than high. Peristome slightly expanded above, the outer and basal margins expanding more, slightly thickened. the margins converging, connected by a very thin parietal film.

Alt. 11.9, dian. $19.3 \mathrm{~mm}$.; umbilicus $3 \mathrm{~mm}$.

IVest end of San Xavier Hill, Mineral Hill group, about 20 miles S. S. IV. of Tueson, Pima Co., Arizona. Types No. 112,161, A. N. S. P., collected by Pilsbry and Daniels, 1910. Topotypes in collections of Ferriss and Daniels. 
The top of the head is gray, integument elsewhere cream-tinted. The median area of the sole is whitish, twice as wide as cither side area, the latter flesh-tinted.

The genitalia (Pl. XIII, figs. 2, 10).--Penis very small and slender, having a very short, weak basal sheath of a few loose fibres. The papilla is coarsely annulated, very slender and long. The penisretractor muscle is inserted on the epiphallus, which is extremely slender, not so wide as the vas deferens, but enlarged a trifle where it joins the latter. There is no flagellum. Female organs as usual.

Jaw having four or five unequal ribs, sometimes rather weak (Pl. XIII, figs. 6, 6a).

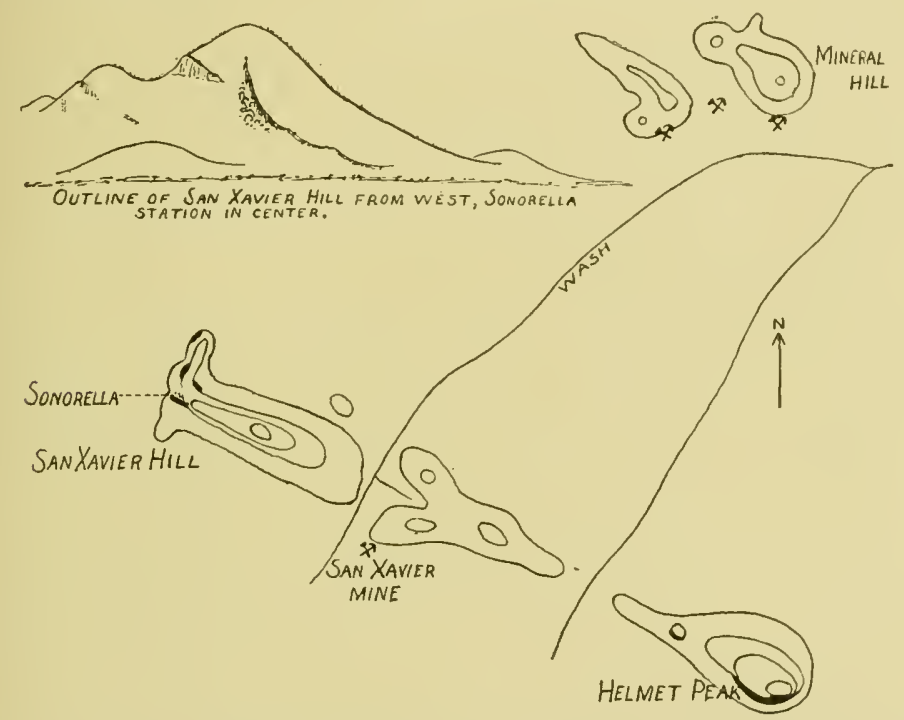

Fig. 7.-Plan of the Mineral Hills, scale 2 inches to a mile, with sketch of the type locality of Sonorella eremita.

In the genitalia, as well as the shell, this species resembles $S$. papagorum, but it differs by having a smaller penis and by the very slender epiphallus, which is actually smaller than the vas deferens in several specimens dissected. In $S$. tumamocensis the penis is very much longer. The shell is smaller than $S$. papagorum, with far more strongly developed apical sculpture than in any other species of this district. It is also more solid, and, having an aspect of its own, is not likely to be confused with any other Sonorella known to us.

The size is quite variable: 
Alt. 12.7, diam. $21.3 \mathrm{~mm}$.; whorls $4 \frac{1}{2}$.

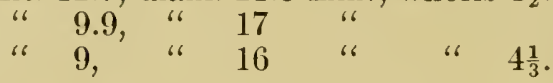

There was a scalariform specimen among the bones. It measures $13.3 \mathrm{~mm}$. high, 16.6 wide. The normal height for a shell of this diameter should be about $9.5 \mathrm{~mm}$.

The Mineral Hill group, Twin Buttes and Tinaja Hills are much degraded outliers of the Sierrita Mountains. Only the Mineral Hill group has been worked for land snails, though all doubtless have Sonorellas-and very little else.

The Mineral Hills are about 20 miles west of south from Tucson and about 7 miles north of the Sierritas. ${ }^{8}$ They stand at the summit of a long slope, rising about 1,000 feet in ten miles from San Xavier del Bac, on a mesa of perhaps 3,600 feet elevation. The xerophytic vegetation extends over the hills, mesquite, cat-claw, palo verde, ocotillo and sotol being the more conspicuous plants, to which may be added tree cacti on southern slopes, and on the mesa many opuntias, cylindropuntias and a few barrel cacti and yuccas. The absence of Agave is peculiar. These hills are a favorite resort of rattlesnakes. I got also a coral snake. No mollusks whatever were found on Mineral Hill or Helmet Peak. San Navier Hill is composed of white subcarboniferous limestone, like the hills southeastward, except at the western end, which is whitish quartz, with a spur to the north of coarse pinkish-gray granite. There is a depression in this end of the hill, between short, low cliffs of white quartz. The cliff towards the south has partly fallen in a tumble of huge blocks with some smaller stone between them. This talus is perhaps 200 feet long to the last scattered blocks, and at the widest 40 feet wide; its lower end about 200 feet above the mesa. In it we found the Sonorella described above. "Bones" were abundant, but living snails extremely scarce, and confined to the deeper portions of the talus, between the piled-up quartz blocks. The entire range of this species is not much greater than the area occupied by a moderatesized house. In this insignificant fastness it is making a last stand against extermination.

We found no snails in a hill covered with granite boulders about 3 miles north of west from San Xavier Hill. It is possible, though unlikely, that some insignificant colony may exist there.

${ }^{8}$ While there we occupied a comfortable camp at the copper mine of Mr. L. D. Chilson, of Tucson, whose courtesy we would here acknowledge. 
Sonorella sitiens n. sp. Pl. VlII, figs. 5 to $5 c$.

The shell is depressed, umbilicate (the width of umbilicus contained nine to ten times in the diameter of the shell), rather thin, cinnamon colored (varying in tone), paler around the umbilicus, encircled by a chestnut-brown band at the shoulder, bordered with a white band above and below. Surface somewhat glossy. The initial fourth of a whorl is smooth; the rest of the embryonic shell has very fine, anastomosing and interrupted radial wrinkles, and on some specimens there are the faintest traces of spiral threads. The neanic and last whorls are marked with delicate growth lines. Spire low; whorls $4 \frac{1}{2}$, convex, the last slowly descending in front. Aperture oblique, rounded oval. Peristome thin, the upper margin hardly expanded, outer and basal margin, a little expanding.

Alt. 11, diam. $20 \mathrm{~mm}$.; aperture, alt. 10, diam. $12 \mathrm{~mm}$.

The back, top and sides of head are slate colored, the tail and a wide band above the foot edges whitish.

Genitalia (Pl. XIII, fig. 3).- - The penis is swollen distally, becoming narrow, in its basal half, which is enveloped in a muscular sheath, the outer edge of which is attached to the end of the epiphallus. The penis-papilla is extremely short and wide, cylindric, with a few annular corrugations and a shortly conic end. The epiphallus is slender, swollen at its distal end, without trace of a flagellum. The lower part of the vagina is very stout. Other organs as usual.

Jaw (Pl. XIII, fig. 7) has 8 strong, narrow ribs.

Northwestern end of Las Gijas above Las Gijas Mine, Pima Co., Arizona. Types No. 112,158, A. N. S. P., taken by Ferriss and Pilsbry, September 27, 1910.

The shell is less solid than $S$. eremita, the aperture decidedly larger, the umbilicus smaller. The color also is darker. It differs from eremita conspicuously in the genitalia, the penis of $S$. sitiens being provided with a sheath of half its length, and the papilla being extremely short and stout, while in S. eremita the sheath is represented only by a few loose muscular fibres at the base, and the papilla is very slender and comparatively long. No other Sonorella known has a penis-papilla like that of $S$. sitiens. Several specimens dissected are entirely similar in genitalia.

The spire is very low in most of the specimens, but in one (Pl. VIII, fig. $5 c$ ) it is more conic. In this shell the white borders of the shoulder band are very narrow. It measures, alt. 12, diam. 18.5 mm., aperture $9.5 \mathrm{~mm}$. high, 10.8 wide.

Five other adult shells measure: 
Alt. 11, diam. $19 \mathrm{~mm}$; aperture $9.9 \times 11.25 \mathrm{~mm}$.

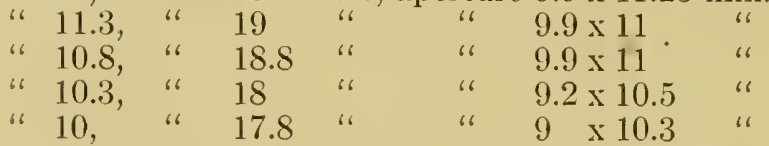

The most closely related species seems to be $S$. rowelli. This, however, has a larger penis-papilla and a slightly wider umbilicus.

The low and inconspicuous range Las Gijas (the Quartz Hills) lies south of the well-known landmark Cerro Colorado, and west of the northern end of the Tumacacori Range. At the northrest end there is a mine, and a ranch building stands on the bank of a small stream, the Gija Wash. The hill above the mine is strewn with rounded boulders of coarse-grained granite, weathering to angular gravel. Most of the loose rock is too massive to move, so that suitable situations for snails are scarce. We found the first Sonorellas on the slope above the mine. Working up over the rounded top of the hill and along the ridge a half mile south we crossed a low rock dyke, where a few more shells and a large colubrine snake were taken. None were found among the rocks at the head of the canyon east of this ridge. The other hills at this end of the range are rounded, grassy, with little rock. On top there is much sotol, ocotillo, a few cacti, etc. We found the pygmy Agave parviflora here. It was not seen elsewhere.

In the débris of the Gija Wash we found Thysanophora hornii (Gabb), Zonitoides minuscula (Binn.) and Bifidaria pelleucida hordeacella (Pils.).

Measurements of the genitalia of the preceding species are here given together. The species identified as $S$. rowelli (Nc.) in these Procendings for 1905 being added for comparison.

\begin{tabular}{|c|c|c|c|c|c|c|c|c|}
\hline & 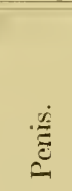 & 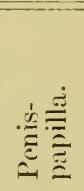 & 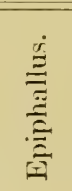 & 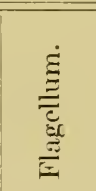 & 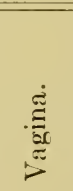 & 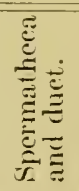 & 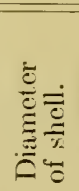 & 总 \\
\hline 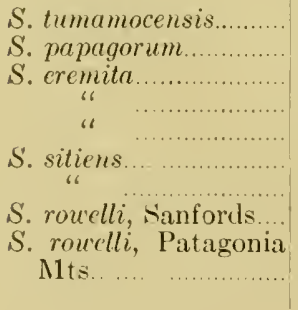 & $\begin{array}{l}10 \\
6 \\
4.2 \\
3.5 \\
4.4 \\
6 \\
7 \\
5 \\
4\end{array}$ & $\begin{array}{l}3.7 \\
5 \\
2.9 \\
2.7 \\
\cdots 1 \\
1 \\
2\end{array}$ & $\begin{array}{c}10 \\
7 \\
\cdots \ldots \\
4 \\
4.5 \\
5 \\
5\end{array}$ & $\begin{array}{c}\text { Trace } \\
0.5 \\
0 \\
0 \\
0 \\
0 \\
0 \\
\text { Trace } \\
0\end{array}$ & $\begin{array}{l}10.7 \\
7 \\
5.5 \\
6 \\
3.5 \\
5 \\
5 \\
5.3 \\
\\
4.5\end{array}$ & $\begin{array}{l}23.5 \\
28.5 \\
2.5 \\
25 \\
28 \\
25 \\
20\end{array}$ & $\begin{array}{l}17.5 \\
23 \\
19 \\
20 \\
20 \\
17 \\
15.4\end{array}$ & $\begin{array}{c}103101 \\
103099 \\
103100 \\
، \\
“ \\
103102 \\
6 \\
83273 \\
83268\end{array}$ \\
\hline
\end{tabular}


Sonorella sitiens arida n. subsp. Pl. VIII, figs. $6,6 a, 6 b$.

The shell resembles $S$. sitiens, but differs in these features: the umbilicus is decidedly wider, its diameter contained 6 to nearly 7 times in that of the shell; the color is paler; the aperture is noticeably smaller. The embryonic $1 \frac{1}{2}$ whorls show distinct spirally protractive threads in young individuals.

Alt. 10.8, diam. $19 \mathrm{~mm}$.; aperture, alt. 9, diam. $10.2 \mathrm{~mm}$; umbilicus $3 \mathrm{~mm}$.

Alt. 10, diam. $18.5 \mathrm{mmm}$; aperture, alt. 9, diam. $10 \mathrm{~mm}$.; umbilicus $3 \mathrm{~mm}$.

Alt. 10.25, diam. $19.9 \mathrm{~mm}$; aperture, alt. 9.9, diam. $11 \mathrm{~mm}$; umbilicus $2.9 \mathrm{~mm}$.

Cerro Colorado, around the base of a conspicuous erag at the southeastern end of the range. Types No. 112,160, A. N. S. P., collected by Pilsbry and Ferriss, September 28, 1910.

The first two measurements are of cotypes from the south side of the crag. The third specimen measured is the only arlult shell taken on the north side of the crag, perhaps a hundred feet higher.

This form stands very close to $S$. sitiens, yet the difference in the size of umbilicus is constant in the small series examined; no communication between the colonies of Cerro Colorado and Las Gijas can have taken place for a very long period, so that in the present state of our knowledge it seems proper to keep the forms of the two hill-groups subspecifically separate.

Unfortunately, no living examples were found, so that the anatomical characterization of the subspecies remains to be worked out.

The Cerro Colorado ("Red Hill") lies a few hours' travel north of Las Gijas. The northern slopes are grassy and rounded, but west and south it is carved into bold, fantastic crags and pinnacles of dull red rhyolite-a landmark which catches the eye for a long distance.

Our work here was brief. Scarcely an hour was spent around a crag which stands at the southeastem extremity, about two miles from the Cerro Colorado Mine on the Aravaca Road. Here the Sonorella described above was taken, only a few dead specimens. No doubt, the cliffs westward, higher up, would yield better results, though little can be expected in such a dry situation. Neighboring low crags of milk-white quartz, at a lower level southward, were found bạrren.

\section{Sonorella sitiens comobabiensis n. subsp.}

The shell is similar to $S$. sitiens in general shape, its width contained about 9 times in the greatest diameter of the shell. It is smaller within, and enlarges more in the last whorl than that of S. tuma- 
mocensis, but the enlargement is largely concealed by the overhanging and dilated columellar lip. It is light pinkish cinnamon, fading to white around the umbilicus, usually with a white streak on the last whorl, left by a former resting stage, and with white bands above and below the rather wide chestnut-brown shoulder band. The apical sculpture is of the sitiens type, but some interrupted, descending spiral threads are visible on the best examples; subsequent whorls are lightly marked with growth lines. The aperture is larger than in S. tumamocensis, but less ample than that of S. vesperus. The peristome expands distinctly, though narrowly.

Alt. 10.1, diam. 18, longest axis of aperture $10.1 \mathrm{~mm}$; $4 \frac{3}{4}$ whorls.

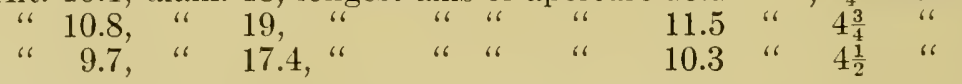

Comobabi Mountains, at the base of a cliff on the north side of the highest part of the range, elevation about 4,000 feet. Type and paratypes No. 112,252, A. N. S. P., other paratypes in Ferriss collection. Also taken in the Cababi Hills, about 10 miles restward, in a slicle of volcanic rock on the north side of the highest peak, about 3,000 feet elevation. All were collected by Mr. J. C. Blumer, of Tueson, in the course of botanical exploration.

About 120 specimens were collected, some of them showing the surface and color unimpaired, though all were dead shells. We are therefore unable to give any information on the soft parts. The shell is very much like S. sitiens of Las Gijas, further south, and east of the Baboquivari Range; but on account of the wide separation of the localities, it is likely to be subspecifically or even specifically distinct.

The Comobabi Mountains form a short range, about 75 miles west of Tucson. The Cababi Hills, immediately west, and the Qui-i-tomoc Hills, a short distance south, are parts of the same group. It is evidently rich in shells, as Mr. Biumer found $S$. $s$. comobabiensis on the highest peaks (near the south end) of both Comobabi and Cababi, and a form which we cannot distinguish from S. vespertina on the north side of the largest peak of the Qui-itomoc Hills. Somewhere in the Cababi Mountains, the exact location not given, Mr. Frank Cole collected two forms, which we provisionally refer to $S$. ashmuni as varieties; one of them is the largest Sonorella known.

Sonorella ashmuni capax n. subsp. Pl. X, figs. $7,7 a, 7 b$.

The shell is umbilicate, the umbilicus very narrow within, but in the last half-whorl widening to about three times its former width, 
oblong, contained between seven and eight times in the diameter of the shell. Avellaneous in color, paler around the umbilicus and slightly so on both sides of the chestnut-brown shoulder band. Surface glossy, lightly striate, the embryonic shell of $1 \frac{2}{3}$ whorls with S. hachitana sculpture.

Whorls 5, slowly widening, the last whoil very broad and capacious, rather strongly descending to the aperture. The aperture is very large, oblique, the peristome well expanded except near the upper termination; margins converging, joined by a thin callus.

Alt. 15.7 , diam. $28.4 \mathrm{~mm}$.; umbilicus $3.7 \mathrm{~mm}$; aperture $16.4 \mathrm{~mm}$. wide, 13.7 high.

Cababi Mountains (about 75 miles west of Tucson), collected by Frank Cole, March, 1915. Type No. 112,253, A. N. S. P., cotypes in Ferriss collection.

This is one of the largest species, very much resembling $S$. ashmuni Bartsch, from Richinbar, Yavapai Co., which has a slightly smaller aperture. As the localities are several hundred miles apart and separated by the depression of the Gila.River, they will probably turn out to be distinct when the genitalia of both are examined; but as no differences which could reasonably be called specific appear in a close comparison of the types, we rank the southern form as a Eubspecies.

The nine specimens collected measure 28.4, 27.9, 27.8, 25.5, 24.8, $24.6,24.5,24,23.9 \mathrm{~mm}$. cliameter, being therefore variable in size.

Sonorella ashmuni ambigua n. subsp. Pl. X, figs. $6,6 a, 6 b$.

The shell is smaller than S. a. capax (diameter 20.9 to $23.4 \mathrm{~mm}$.) with the last whorl widening somewhat less, the aperture more rounded.

Alt. 13.5 , diam. $22.5 \mathrm{~mm}$; umbilicus $3 \mathrm{~mm}$; aperture $12.2 \mathrm{~mm}$. wicle, 11 high. Whorls $4 \frac{1}{2}$.

Cababi Mountains; No. 112,254 sent with the preceding, but whether collected in the same place is not known. They were taken in March, 1914, by Mr. Frank Cole, Mr. Ferriss' guide in 1913.

Thirty-two specimens measure as follows in diameter: 20.9, 21 (2), 21.1, $21.3(2), 21.4(2), 21.5,21.6(2), 21.7(2), 21.8,22$ (5), $22.2(2), 22.3,22.4,22.5$ (3), 22.6, 22.7, 23, 23.2, 23.3, 23.4.

We are in some doubt about the status of this form, but it is readily separable from $S$. a. capax in the series seen. The genitalia when examined will no doubt clear up the uncertainty. 


\section{The Baboquivari Mountains.}

We had not intended at first to visit the Baboquivaris. From our camp, above 7,000 feet in the Santa Ritas, the long ridge, sixty miles distant, bounded the western horizon. We could see the wonderful obelisk of Baboquivari Peak catch the morning sun while the great valley between slept in dusk. At evening it stood silhouetted, velvet black, between the purple valley and flaming sky. To visit this range, beyond which there is no water, became an obsession, and finally we made the two-day journey by wagon, camping midway on Sopori Creek, where there was a little stagnant water for the horses.

The Baboquivari Range is a single, long, north and south ridge with numerous short lateral spurs. Its chief landmark, Baboquivari Peak, is a huge obelisk of dull red rhyolite, standing on the main axis of the range, flat topped, its sides practically vertical. The foothills and lower slopes of the range have many barrel cacti, opuntias, agaves, very few giant cacti. The lower courses of the canyons are green with mesquite and cat-claw. "The higher mountains are grassy and lack large cacti; only a flat Mamillaria and the little rainbow cactus were noticed. There is some scattering oak, size of a peach tree, on western and northern slopes, and very few stunted pinyons around the high crags. The herbaceous plants are chiefly the same as in the Santa Ritas. Sycamore Canyon has a richer sylva-buttonwood, walnut, hackberry, a fine dark-leaved species of oak, etc. There is water in Oro Fino and Sycamore Canyons, and we found some also near the head of Thomas Canyon, about half a mile below the peak. Near the mouth of Sycamore there was in 1910 a foresters' house (which we occupied), a corral and a pump. Much further up there is running water. Our collecting stations, enumerated below, are shown on the accompanying sketch map. ${ }^{9}$

The following collecting stations were found:

Station 21. Mt. Mildred, north side of the butte at summit of the talus slope.

\footnotetext{
' We are indebted to Professor R. H. Forbes, of the University of Arizona, for information correcting the names we had heard of the canyons. Sycamore Canyon is also known as Brown's or Wasson and Brown's Canyon. Sabino Otero has for many years ranged cattle in this canyon, and from this some persons have ealled it Otero Canyon. We were also given the name Baboquivari Canyon for Oro Fino Canyon. No topographic map has been published, so that hasty note-book sketches made by one of us in course of a long day's tramp from Oro Fino Canyon to the Peak and down to camp in Sycamore Canyon, have been utilized to locate our type localities.
} 


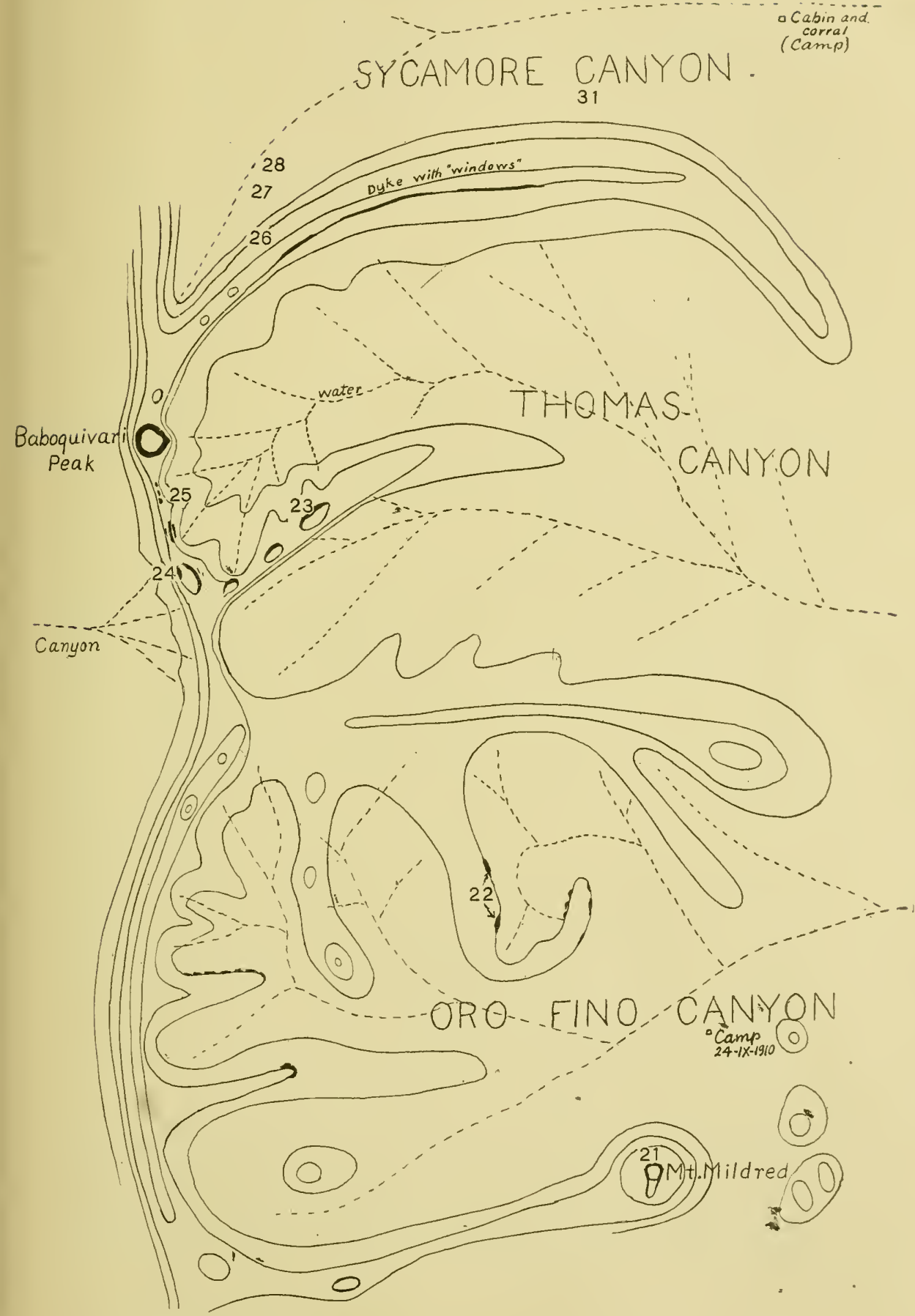

Fig. 8.-Map of a section of the Baboquivari Range, to show type localities and other collecting stations. 
Station 22. Low crags in the northern part of Oro Fino Canyon. Station 23. Crags on the southern rim of the northern branch of Thomas Canyon.

Station 24. West side of the main ridge near summit, south of Baboquivari Peak. Vitrea indentata umbilicata and Sonorella vespertina.

Station 25. East side of ridge, about half a mile from the peak.

Station 26. Near the southwestern head of Sycamore Canyon, between one and two hundred yards below the summit of the ThomasSycamore ridge, in a rock "slide."

Station 27. About 1,000 feet below Station 26, near the bottom of the canyon.

Station 28. Not far below Station 27.

Station 29. Bed of upper Sycamore Canyon, about a mile above the foresters' cabin, and not far above the dam.

Station 30. Creek in Sycamore Canyon (a small Physa, not determined with certainty, was the only fresh-water shell found at this station).

Station 31. Sycamore Canyon, about 3 miles up its bed, and $\frac{3}{4}$ mile up a southwestern branch ravine. Succinea avara Say and Sonorella baboquivariensis only.

Sonorella vespertina n. sp. Pl. X, figs. $5,5 a, 5 b$.

The shell is umbilicate (width of umbilicus contained 9 or 10 times in diameter of the shell); cinmamon, fading to whitish around the umbilicus, and with white bands above and below the chestnutbrown shoulder band. Surface glossy, the initial half-whorl having some radial wrinkles, the rest of the embryonic shell without any distinct sculpture, though there is some extremely indistinct radial roughness, stronger near the suture. In fresh young shells of $2 \frac{1}{2}$ whorls the surface of the last embryonic and first neanic whorls is densely set with very short hairs, extending also over the base. These are fugacious, lost with further growth. The later whorls are marked with the usual growth lines. Whorls $4 \frac{1}{2}$, the last rapidly widening, rather steeply descending close to the aperture. Peristome narrowly expanded on the outer and basal margins, dilated and reflexed at the columellar insertion.

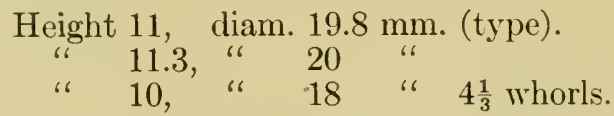

Genitalia (Pl. XIII, fig. 9).-The penis is very small and tapers distally to the epiphallus, the long penial retractor being inserted on the latter. The flagellum $(f$. $)$ is represented by a minute bud or a slight swelling. The penis-papilla (fig. $9, p p$.) is slender, tapering, 
and weakly annular. The vagina is slender and long. Free vas deferens very long. The organs of two individuals measure:

$\begin{array}{cccc}\text { Penis. } & \text { Papilla. } & \text { Epiphallus. } & \text { Vagina. } \\ 3.2 & 2.5 & 5.5 & 5.5 \mathrm{~mm} . \\ 3 & 2.5 & 7 & 5.5 \mathrm{~mm} .\end{array}$

Baboquivari Mountains, at Station 24, on the west side of the ridge, close to the summit, a half-mile south of Baboquivari Peak. Type No. 111,554, A. N. S. P., topotypes in collections of Ferriss and Daniels. Also on the north side of the highest peak of the Qui-i-tomoc Hills, J. C. Blumer.

This species is readily distinguished from $S$. baboquivariensis by the wider umbilicus, smaller aperture, the shorter, steeper descent of the last whorl to the aperture, and the absence of distinct sculpture on the embryonic whorl; also by the very different genitalia.

By the small penis and slender, tapering penis-papilla, S. vespertina is closely related to $S$. tumamocensis and S. eremita. In shell characters it comes very close to $S$. sitiens, which differs by the form of its penis-papilla.

$S$. vespertina was found at our only collecting station west of the summit of the range, but it occurred there in considerable abundance. Over 100 living individuals and numerous "bones" were taken by two of us in about three-quarters of an hour, in the course of our tramp from camp in Oro Fino Canyon to the peak and down to camp in Sycamore Canyon.

The specimens taken in the Qui-i-tomoc Hills have not been dissected, but we camnot distinguish the shells from the Baboquivari vespertina.

Sonorella baboquivariensis n. sp. PI. X, figs. 1 to $2 b$.

The shell is very narrowly umbilicate, globose-depressed, thin, glossy, cinmamon or sayal brown, fading or whitish around the umbilicus and on both sides of the broad chestnut-brown shoulder band. First third of a whorl smooth, the following whorl with sculpture of irregular radial wrinkles, over which run spiral, slowly descending, irregular threads; later whorls marked with fine growth lines as usual. Whorls $4 \frac{1}{2}$, the last very wide, its last fourth slowly and rather deeply descending. The aperture is very large, strongly oblique. Peristome narrowly expanding throughout, the columellar margin brown-edged, broadly dilated and reflexed half over the umbilicus. The parietal callus has an opaque, pale brown edge.

Height 13.2, diam. $21 \mathrm{~mm}$.

Genitalia (PI. XIII, fig. 1).- The penis is long, the distal fourth 
enlarged, the rest slender. The basal third or less is sheathed, the sheath composed of firm, circular muscles. The papilla (fig. 1, pp.) is cylindric, with a conic, glandiform end. The retractor muscle is inserted on the epiphallus, which is nearly as long as the penis, and bears a short flagellum. The vagina is about three-fourths as long as the penis. In two individuals the organs measure, in mm.:

\begin{tabular}{c|c|cc|c|c|c}
\hline $\begin{array}{c}\text { Sta- } \\
\text { tion. }\end{array}$ & Penis. & Papilla. & $\begin{array}{c}\text { Epiphal- } \\
\text { lus. }\end{array}$ & $\begin{array}{c}\text { Flagel- } \\
\text { lum. }\end{array}$ & Vagina. & $\begin{array}{c}\text { Diam. } \\
\text { shell. }\end{array}$ \\
\cline { 1 - 2 } 25 & 12 & 3 & 11 & 0.75 & 9 & 21 \\
2.5 & 10 & 2.7 & 8.5 & 0.75 & 8.2 & 19 \\
\hline
\end{tabular}

Baboquivari Mountains, the types No. 111,549, A. N. S. P., from Station 25, in the head of Thomas Canyon about half a mile from Baboquivari Peak. Also at Station 23, at the northern bases of crags at summit of the spur which divides Thomas Canyon. In Sycamore Canyon, at Station 26, in a slide on the ridge of the head branch, about 300 feet or more below the summit; Station 27, about 1,000 feet lower, near bed of canyon; Station 28, still lower, and Station 31, further down the canyon, low on the south side.

In Oro Fino Canyon it was taken at Station 21, at the foot of the cliffs on north side of Mount Mildred, a conspicuous butte at the southern side of the mouth of the canyon; also Station 22, among low crags near the north side of the canyon.

This is the common species of the Baboquivaris throughout the short section of the range which we explored. It is distinguished by having a larger aperture than any other Sonorella known. The rather long penis with a strong basal sheath and a papilla of very peculiar and characteristic shape are diagnostic of the soft anatomy, and confirmed in a number of individuals from several stations.

All of the stations are on the eastern watershed of the range. The only collecting station on the western slope (24) had a quite different Sonorella, S. vespertina.

The size is smaller in Oro Fino Canyon. At Station 22 the shells are decidedly more solid and more opaque than the types. Height 12, diam. $18 \mathrm{~mm}$. to height 13, diam. $19.5 \mathrm{~mm}$.; $4 \frac{1}{2}$ whorls. Soft anatomy is typical.

Specimens from high on the ridge near the head of Sycamore Canyon, Station 26, are also rather small, diam. 18 to $19.3 \mathrm{~mm}$. Near the bottom of the canyon, at Station 27, the shells measure 19 to 
$21 \mathrm{~mm}$. At Station 28, still lower, the range in diameter is from 17 to $20 \mathrm{~mm}$. At Station 31, much nearer the mouth of the canyon, the shells are about typical.

Sonorella baboquivariensis depressa n. subsp. Pl. X, figs. $3,3 a, 3 b$.

The shell is more depressed than typical baboquivariensis with the umbilicus decidedly more widely open; aperture smaller. Alt. 9.8, diam. $17.7 \mathrm{~mm}$.

Baboquivari Mountains, low in upper Sycamore Canyon, Station 29. Type No. 111,559, A. N. S. P.

\section{Explanation of Plates VIII to XV.}

Plate VIII.-Figs. 1-1b.- Sonorella dragoonensis. Type. Station 28, Dragoon Mountains. No. 103,094.

Figs. 2-2b.-Sonorella apache. Type. Station 9. No. 111,529.

Figs. 3-3b.-Sonorclla ferrissi. Type. Station 38. No. 103,097.

Figs. 4-1b.-Sonorella bartschi. Type. Station 1, Mule Mountains. No. 103,095 .

Figs. 5-5c.-Sonorella sitiens. Type. Las Gijas. No. 112,158.

Figs. 6-6b. Sonorella sitiens arida. Type. Cerro Colorado. No. 112,160.

Figs. 7-7e.-Sonorella eremita. Type. Mineral Hills. No. 112,159.

Figs. S-8b.-Sonorella papagorum. Type. Black Mountain. No. 112,161.

Plate IX.-Figs. 1-1b.-Sonorella santaritana. Type. Station 5. Santa Rita Mountains. No. 112,105.

Figs. 2-2b.-Sonorella santaritana. Station 5. No. 112,107.

Fig. 3.-Sonorella santaritana. Albino. Station 5. No. 112,106.

Figs. 4-4b.-Sonorella walkeri. Type. Station 5. No. 112,164.

Figs. 5-5b.-Sonorella walkeri aguacalientensis. Type. Station 2. No. 112,162 .

Figs. 6-6b.-Sonorella walkeri aguacalientensis. Station 1. No. 112,166.

Figs. 7-7b.-Sonorella granulatissima occidentalis. Type. Station 17. No. 112,165 .

Figs. 8-8b.-Sonorella clappi. Type. Station 8. No. 112,163.

Plate X.-Figs. 1-1e.-Sonorella baboquivariensis. Types. Station 25, Baboquivari Mountains. No. 111,549 .

Figs. 2-2b.-Sonorella baboquivariensis. Station 22. No. 111,560.

Figs. 3-3b.-Sonorella baboquivariensis depressa. Types. Station 29 . No. 111,559 .

Figs. 4-4b.-Sonorella tumamocensis. Type. No. 112,245.

Figs. 5-5b.-Sonorella vespertina. Type. Station 24 . No. 111,554.

Figs. 6-6b.-Sonorella ashmuni ambigua. Type. No. 112,254.

Figs. 7-7b.-Sonorella ashmuni capax. Type. No. 112,253.

Plate XI.-Fig. 1.-Sonorella bartschi n. sp. Genitalia. No. 103,095, A. N.S. P.

Fig. 1a.-Penis-papilla of same.

Figs. 1b, 1c.-Jaws of two topotypes. No. 103,095.

Fig. 2.-Sonorella bartschi, variety. Genitalia. Near Warren, Arizoni.

Fig. 2a.-Penis-papilla of same.

Fig. 2b.-Jaw of same.

Fig. 3.-Sonorella ferrissi n. sp. Genitalia.

Fig. 3a.-Penis-papilla of the same.

Fig. 4.-Sonorella dragoonensis, n. sp. Genitalia. No. 103,093.

Fig. 4a.-Penis slit open showing the penis-papilla of same.

Fig. 5.-Sonorella apache n. sp. Genitalia. 
Fig. 5a.-Penis-papilla of the same.

Fig. 5b.-Median transverse section of the penis-papilla.

Fig. 5c.-Upper end of the penis-papilla opened to show the conic nipple in the apex of the cavity.

Plate XII.-Figs. 1, 1a.-Sonorella walkeri. Genitalia and detail of penis-papilla, epiphallus and flagellum. Station S, Santa Rita Mountains.

Fig. 2.-Sonorella walkeri. Genitalia. Station 5, Walnut Canyon, Santa Rita Mountains.

Fig. 3.-Sonorella walkeri. Genitalia. Station 5.

Figs. 4, 4a.-Sonorella clappi var. Genitalia and detail of penis-papilla, epiphallus and flagellum. Station 17, Santa Rita Mountains.

Figs. 5, 5a.-Sonorella tralkeri. Genitalia and detail of penis-papilla, epiphallus and flagellum. Station 15.

Fig. 6.-Sonorella clappi. Genitalia. Station 8 .

Fig. 7.-Sonorella clappi. Genitalia. Station 12.

Plate XIII.-Fig. 1.-Sonorella baboquivariensis. Genitalia and detail of penis-papilla. Station 25, Baboquivari Mountains.

Figs. 2, 10.- Sonorella eremita. Genitalia of two individuals of the type lot, No. 103,100.

Fig. 3.-Sonorella sitiens. Genitalia and detail of penis-papilla, and epiphallus of a topotype. No. 103,102.

Fig. 4.-Soronella papagorum. Genitalia and detail of penis-papilla. No. 103,099 .

Fig. 5.-Sonorella tumamocensis. Genitalia and detail of penis-papitlit.

Figs. 6, 6a.-Sonorella eremita. Jaws of two individuals.

Fig. 7.-Sonorella sitiens. Jaw of type. No. 103,102.

Fig. 8.-Sonorella tumamocensis. Jaw of types. No. 103,101.

Fig. 9.- Sonorella vespertina. Terminal ducts of genitalia with detail of end of the penis-papilla. Cotype.

Fig. 10.-Sonorella eremita. Terminal ducts of genitalia. No. 103,100.

Plate XIV.-Figs. 1-1b.-Holospira danielsi. Type and paratypes. Tweed Canyon, Station 2. No. 112,199.

Figs. 2-2c.-H. danielsi. Station 39. No. 112,198.

Figs. 3, 3a.-H. danielsi. Station 1S. No. 112,195.

Figs. 4-4b.-H. daniclsi, variety. Station 12 . No. 112,196.

Figs. 5, 5a.-H. danielsi, variety (?) Station 40. No. 103,092.

Fig. 6.-Holospira campestris cochisei. Station 21. No. 112,218

Figs. 7-7f.-Holospira compestris cochisei. Cotypes. Station 16. Figs. $7 d, 7 e$ opened to show the internal lamellæ. No. 112,219.

Figs. 8-8b.-Holospira campestris cochisei. Station 27. No. 112,220.

Plate XV.-Figs. 1-1d.-Holospira campestris. Type and paratypes. Station 26, Dragoon Mountains. No. 112,214.

Fig. 2.-H. campestris. Station 25, Dragoon Mountains. No. 112,215.

Figs. 3-3b.-Holospira millestriata. Type and paratypes. Station 7, Dragoon Mountains. No. 112,225.

Figs. 4, 4a.-Holospira millestriata. Station 36, Dragoon Mountains. No. 112,227 .

Figs. 5-5e.-Holospira millestriata. Station 37, Dragoon Mountains. To. 122,235 .

Figs. 6-6b.-Holospira ferrissi fossor. Type (fig. 6b) and paratypes, near Warren, Arizona. No. 112,238.

Fig. 7.-Holospira ferrissi sanctacrucis. Type. Santa Cruz R., Tueson, Arizona. No. 112,239.

Figs. 8-8e.-Holospira arizonensis mularis. Type and paratypes. Near Bisbee, Arizona. No. 112,236. 


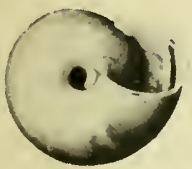

1

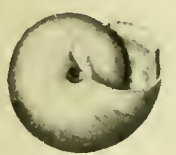

2

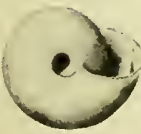

3

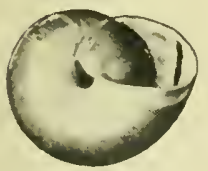

5

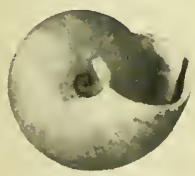

6

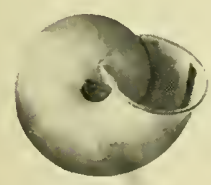

7

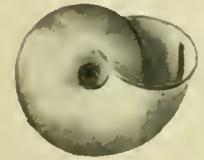

$7 c$

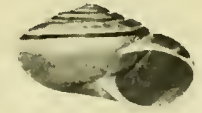

$1 a$

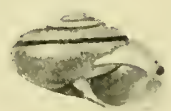

$2 a$

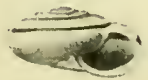

$3 a$

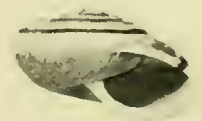

$5 a$

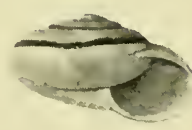

$6 a$

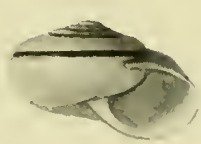

$7 a$

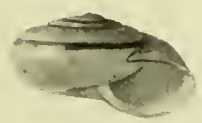

$7 d$

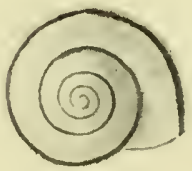

$6 b$

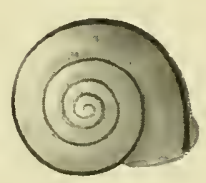

$7 b$

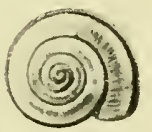

$3 b$

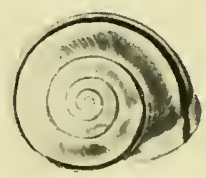

$5 b$

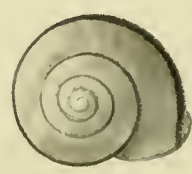

$7 \mathrm{e}$

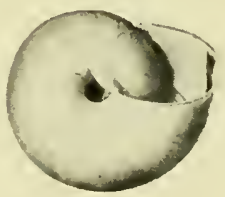

8
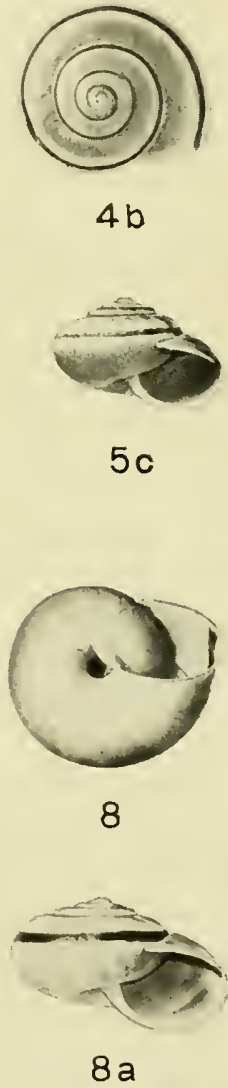

$4 b$

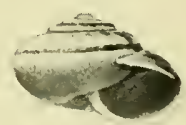

$5 c$

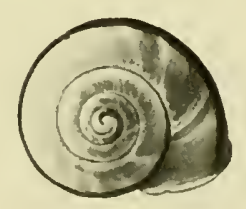

$8 b$

PILSBRY AND FERRISS: MOLLUSCA OF THE SOUTHWESTERN STATES. 



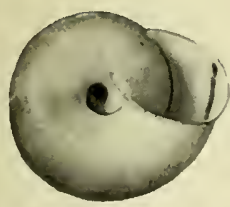

1

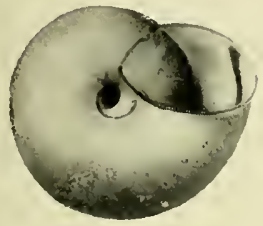

2

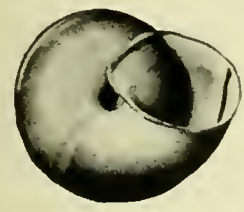

4

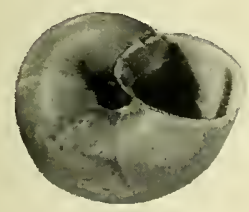

5

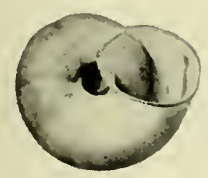

6

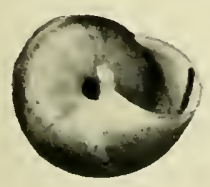

$7 a$
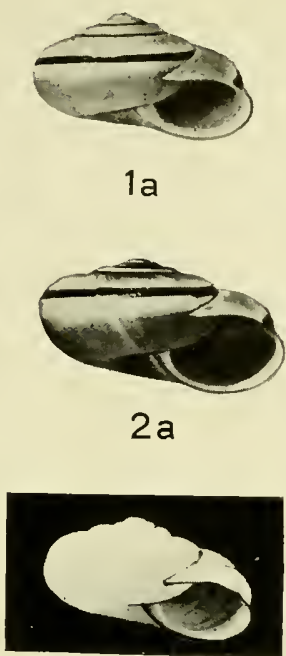

3

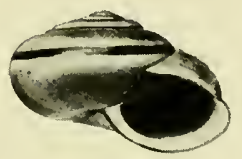

$4 a$

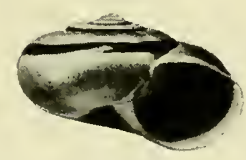

$5 a$

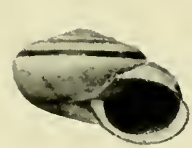

$6 a$

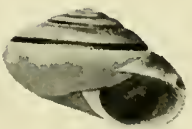

7

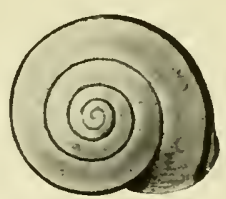

1b

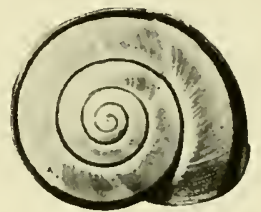

$2 b$

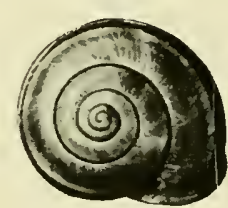

$4 b$

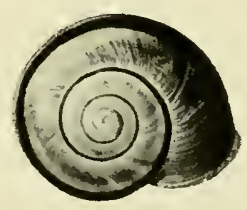

$5 b$

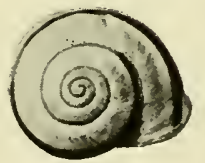

$6 \mathrm{~b}$

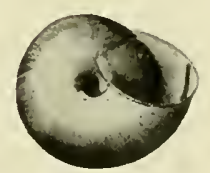

$8 a$

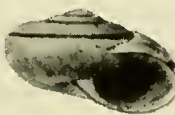

8

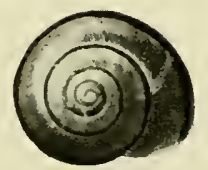

$7 b$

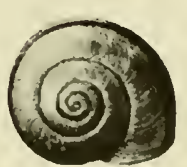

$8 b$

PILSBRY AND FERRISS: MOLLUSCA OF THE SOUTHWESTERN STATES. 



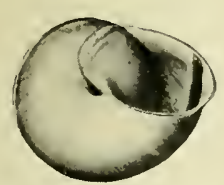

1

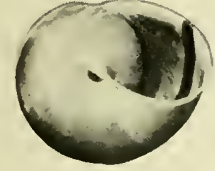

$1 \mathrm{c}$

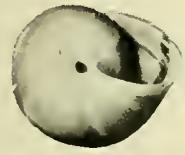

2

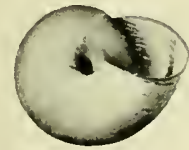

3

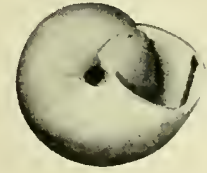

5

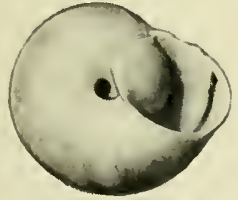

6

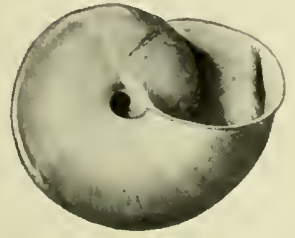

7

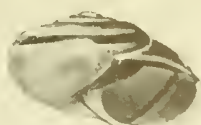

$1 a$

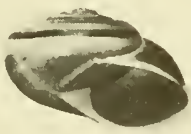

$1 d$

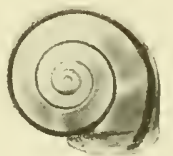

$2 b$

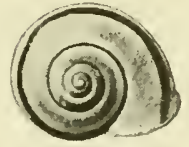

$3 b$

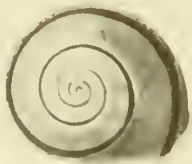

$1 \mathrm{e}$

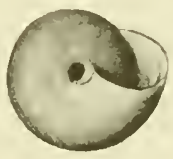

4

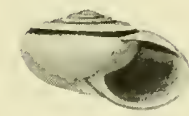

$3 a$

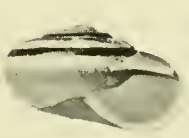

$5 a$

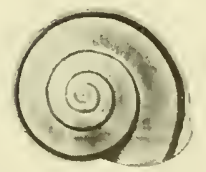

$5 b$

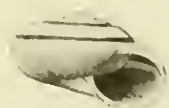

$4 a$

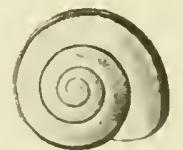

$4 b$

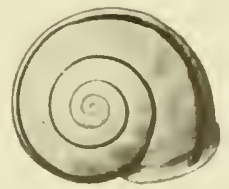

$6 b$

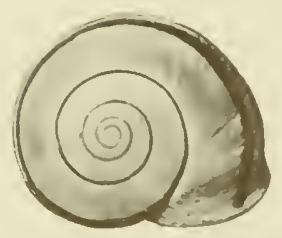

$7 \mathrm{~b}$

PILSBRY AND FERRISS: MOLLUSCA OF THE SOUTHWWETERN STATES. 



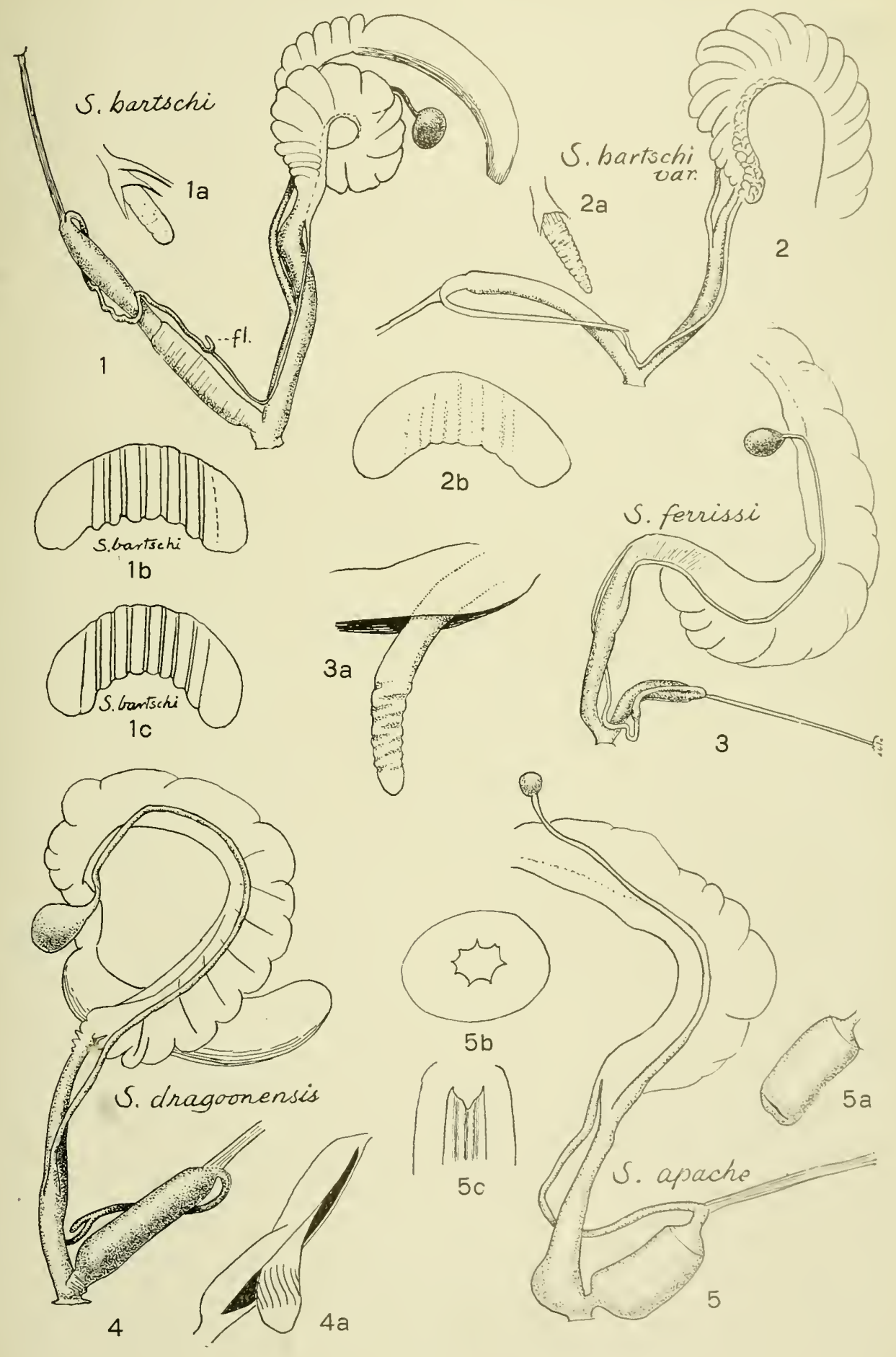

PILSBRY AND FERRISS: MOLLUSCA OF THE SOUTHWESTERN STATES. 



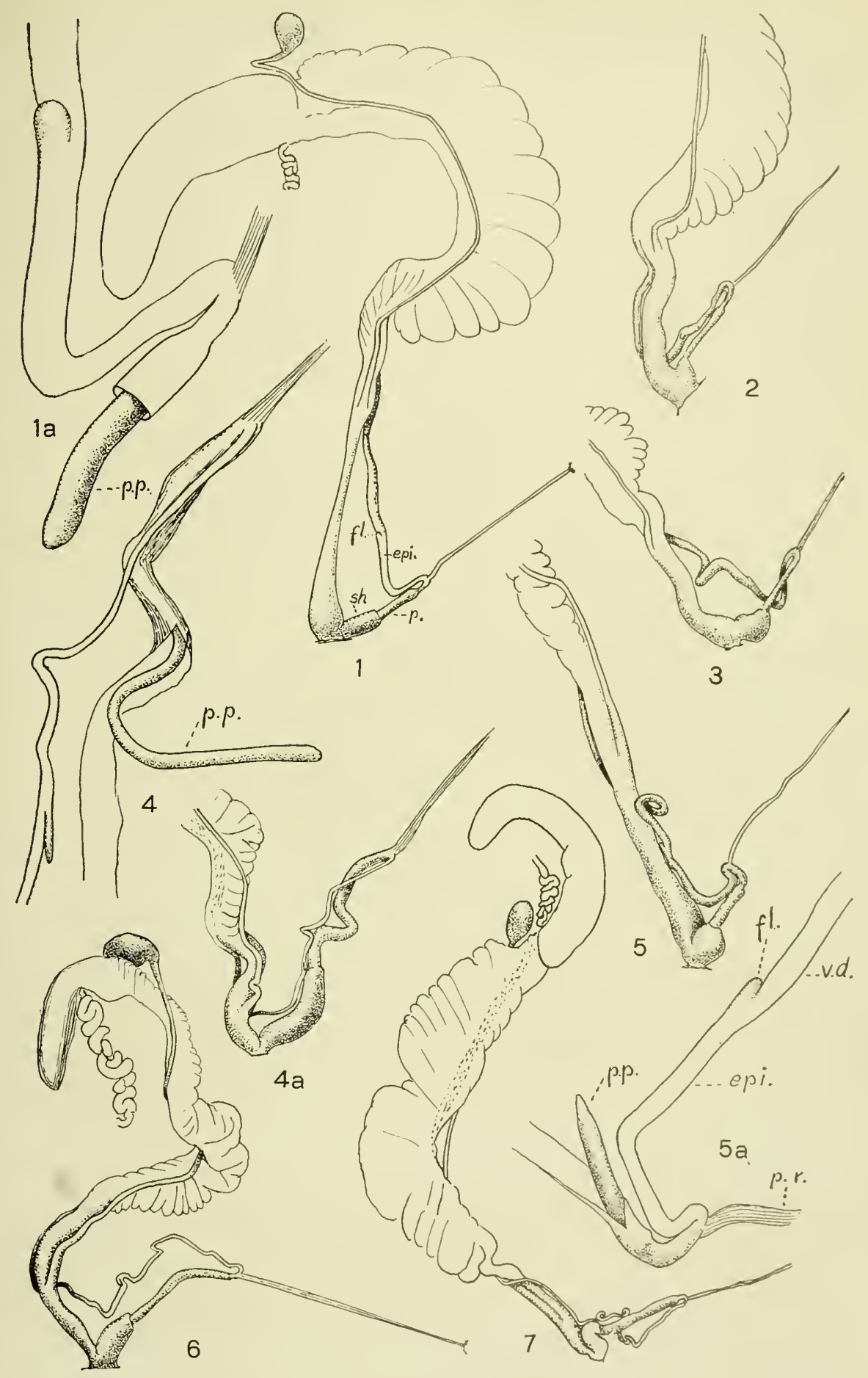

PILSBRY AND FERRISS: MOLLUSCA OF THE SOUTHWESTERN STATES. 



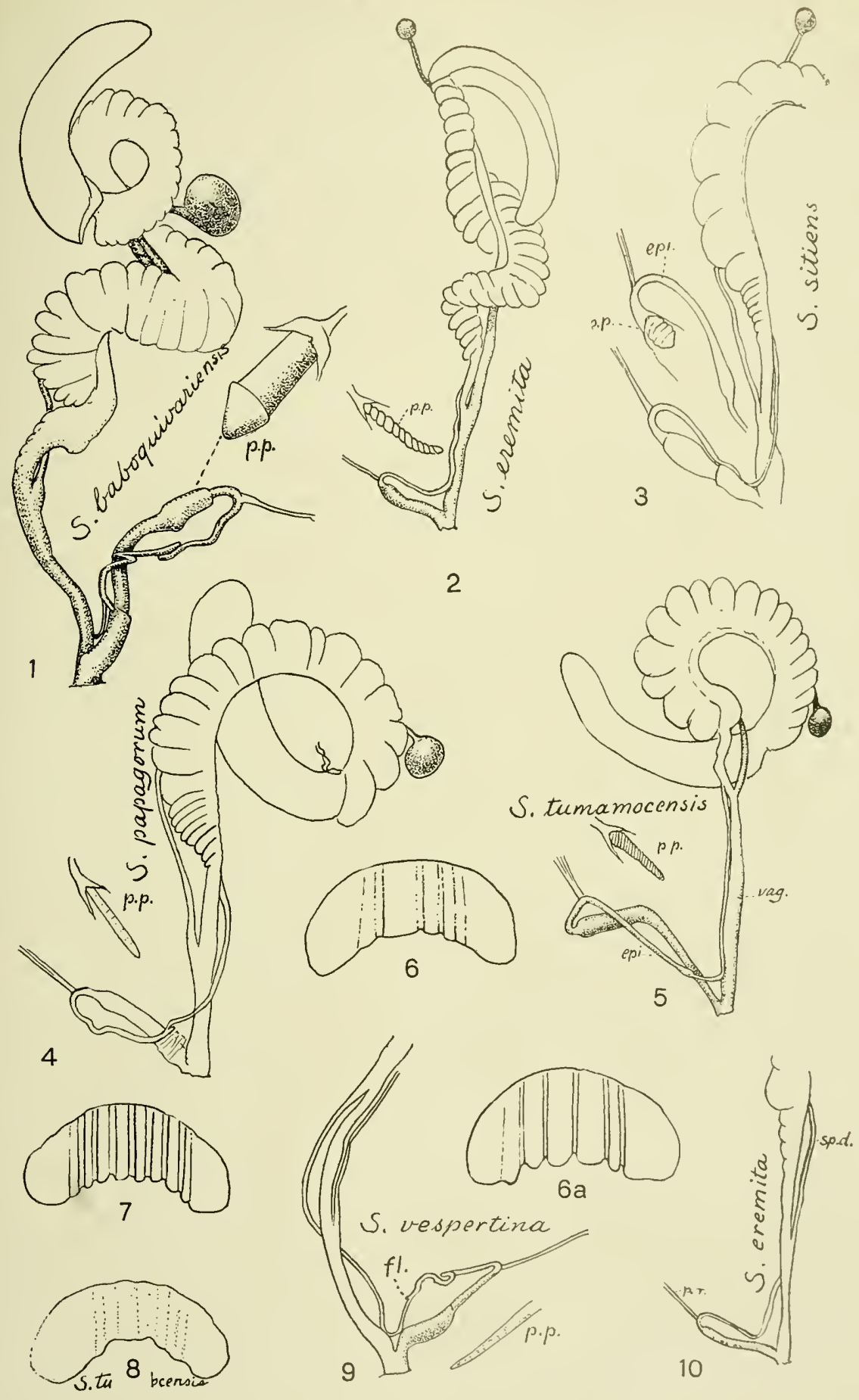

PILSBRY AND FERRISS: MOLLUSCA OF THE SOUTHWESTERN STATES. 


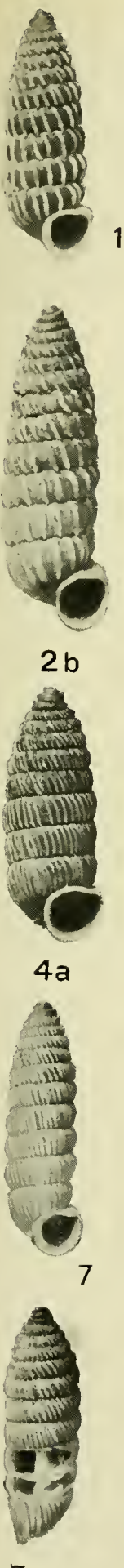

7 e

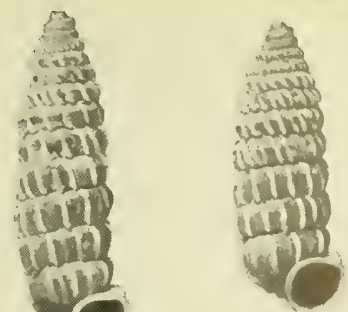

$1 a$
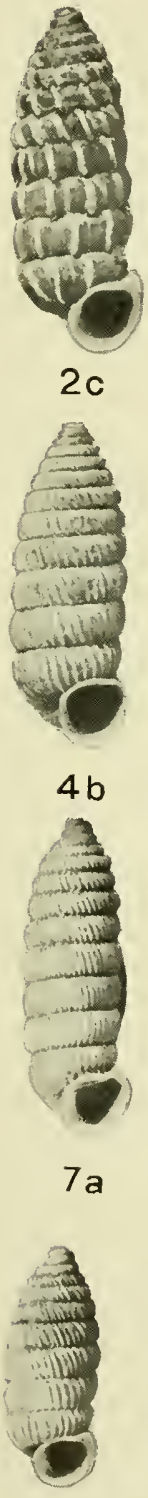

$7 f$ 1b
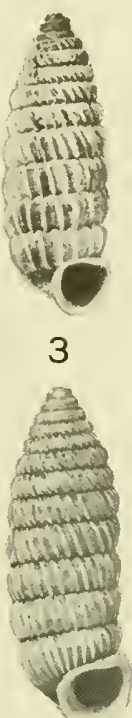

5
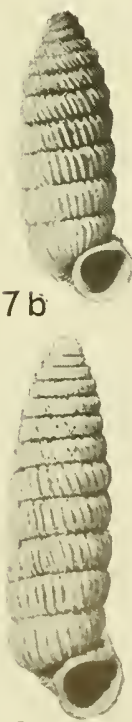

8

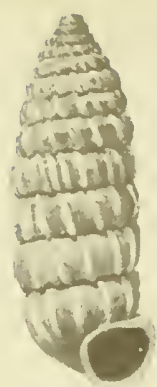

2

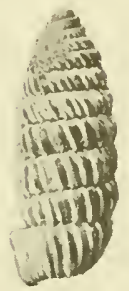

$3 a$

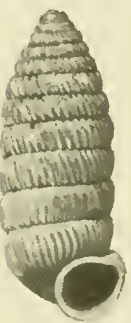

$5 a$

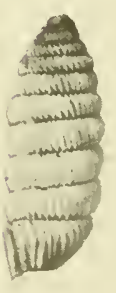

$7 c$

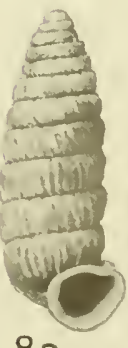

$8 a$
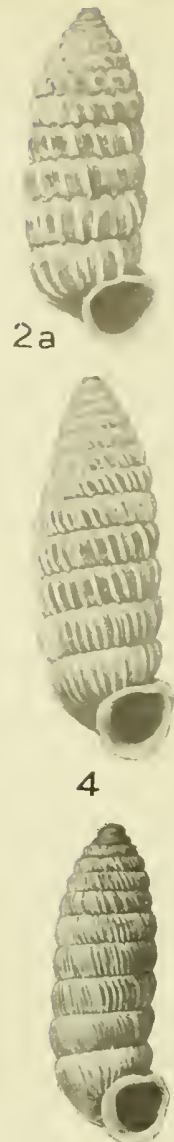

6

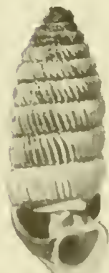

$7 d$

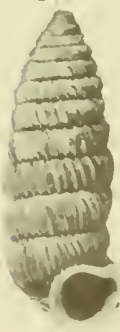

$8 b$

PILSBRY AND FERRISS: MOLLUSCA OF THE SOUTHWESTERN STATES. 



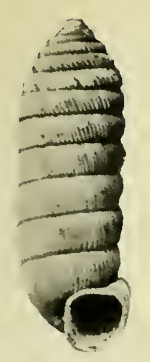

1

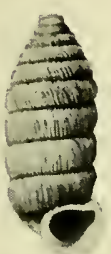

2

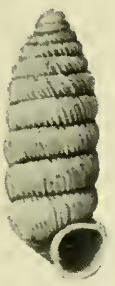

$4 a$

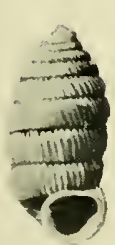

6

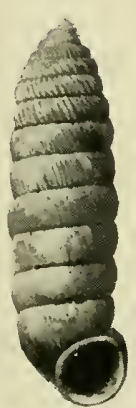

$8 a$

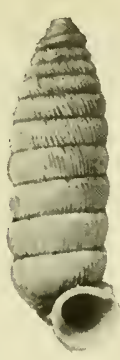

$1 \mathrm{a}$
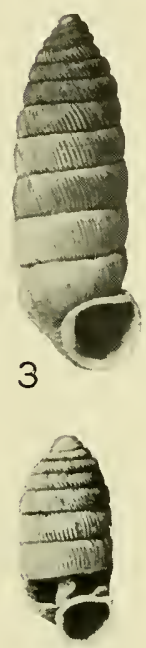

5

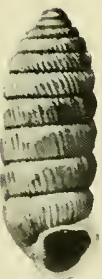

$6 a$

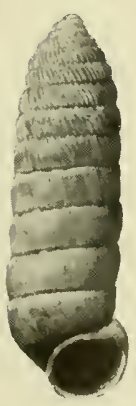

$8 b$

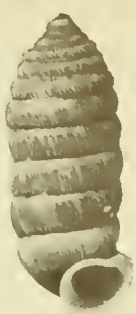

$1 \mathrm{~b}$

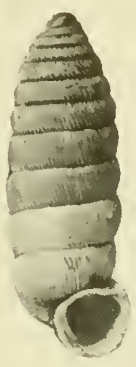

$3 a$

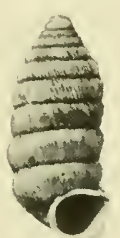

$5 a$

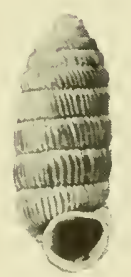

$6 b$

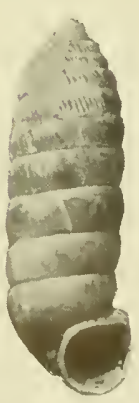

$8 \mathrm{c}$
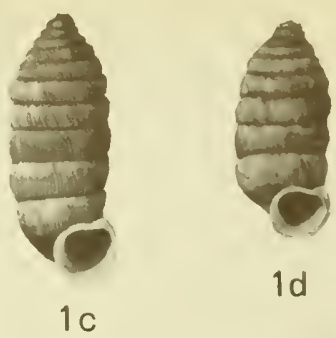

$1 d$
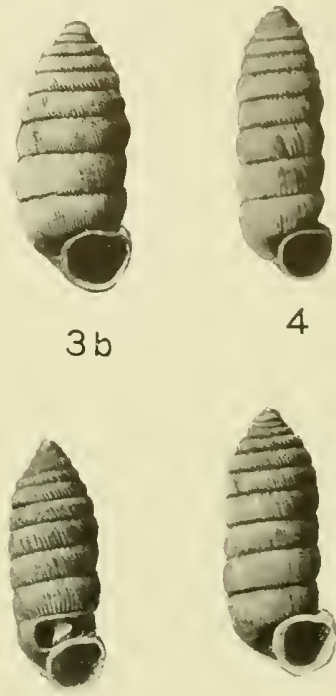

$5 b$

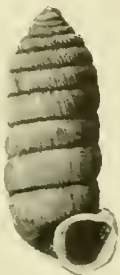

$5 c$

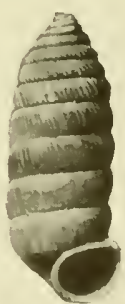

8

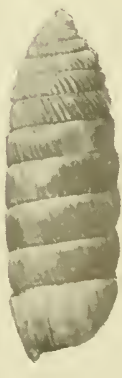

$8 d$

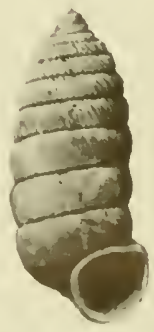

$8 \mathrm{e}$

PILSBRY AND FERRISS: MOLLUSCA OF THE SOUTHWESTERN STATES. 



\title{
Mollusca of the Southwestern States, VIII: The Black Range, New Mexico.
}

\author{
BP \\ H. A. Pilsbry and J. H. Ferriss.
}

From the Proceedings of The Academy of Natural Sriences of Philadelphia, March, 1917. 



\section{MOLLUSCA OF THE SOUTHWESTERN STATES, VIII: THE BLACK RANGE, NEW MEXICO.}

BY H, A. PILSIBRY AND J. H. FERRISS.

In the summer of 1915, beginning in the second weok of August, we collected in the Black Range of New Mexico. Approaching from the west, by way of the Mimbres Valley and up (iallina Canyon, we reached the erest above the hearl of Silver Creek. Subserjuent camps were made at intervals from Sawyer Peak, the southern end of the range, to Reed's ranch on Black Canyon, our route being along the crest trail, with numerous short trips down the slopes, and a twoday trip to Kingston, in the eastern foothills. After September 12 th Ferriss eontinued the exploration alone, in Morgan and Diamond Creeks on the main range, then eastward to Chloride, the Cuchillo Mountains and the San Mateo Mountains, west of San Marcial, in the southern edge of Socorro County. Travel was by pack train. Throughout the trip we had the services of an excellent packer, Teodoro solis, a native of Chihuahua.

The Black Range is on the boundary between Grant and Sierra Counties, about 40 miles north of Deming, New Mexico. In the north it forms part of the eontinental divide. The Mimbres River Valley on the west isolates the Black from the Mogollon Range and its outliers. The range is narrow and sharp, its flanks deeply furrowed, but without long spurs. Hillsboro Peak is $10,000 \mathrm{ft}$. high. Much of the erest trail is from 8,500 to slightly over $9,000 \mathrm{ft}$. elevation.

Fine forest extends down nearly to the 7,000-foot contour. It has been well proteeted against fire and its remoteness has doterred the lumberman. The yellow pine, spruce and quaking asp are large and the ground well covered with forest mold.

There seem to be limestone outcrops on all sides of Sawyer l'eak. The scattered exposures of these ledges were traced from the south end of the range up the west side at between $\overline{\tau, 000}$ and 8,000 fert, as far as Iron Creek at our Station 16. Limestone wals not seen on that side of the range further north, on Black ('anyon or Diamond Creek, where it was looked for down to about 6,000 feet. On the east side limestone appears in the foothills at intervals, as around Kingston and Hillsboro, at Hermosa, Chloride, and some distance further north. Otherwise the Black Range is of igneous or meta- 


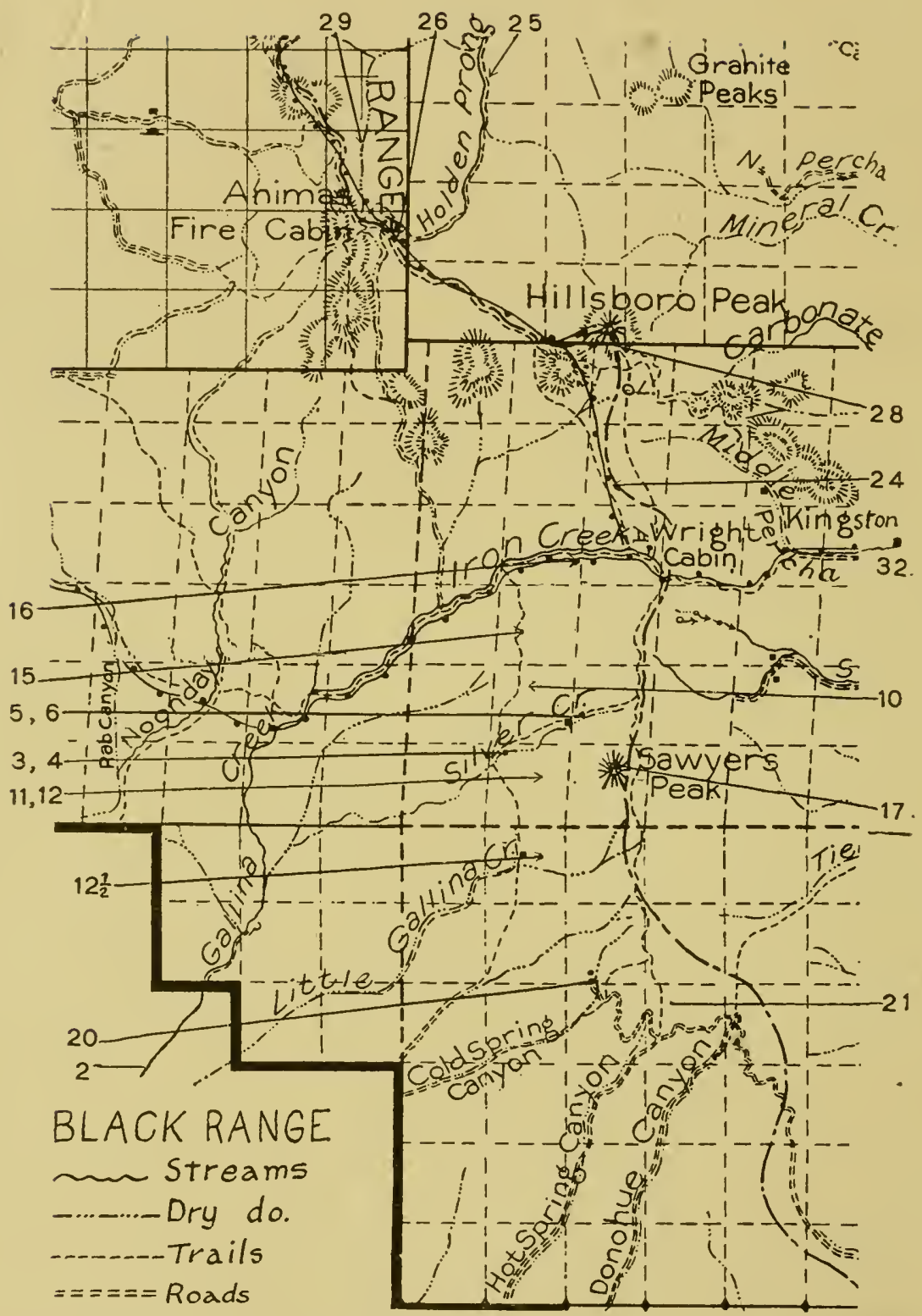

Fig. 1.-Collecting stations in the Black Range, southern section. The map is ruled into square miles. 


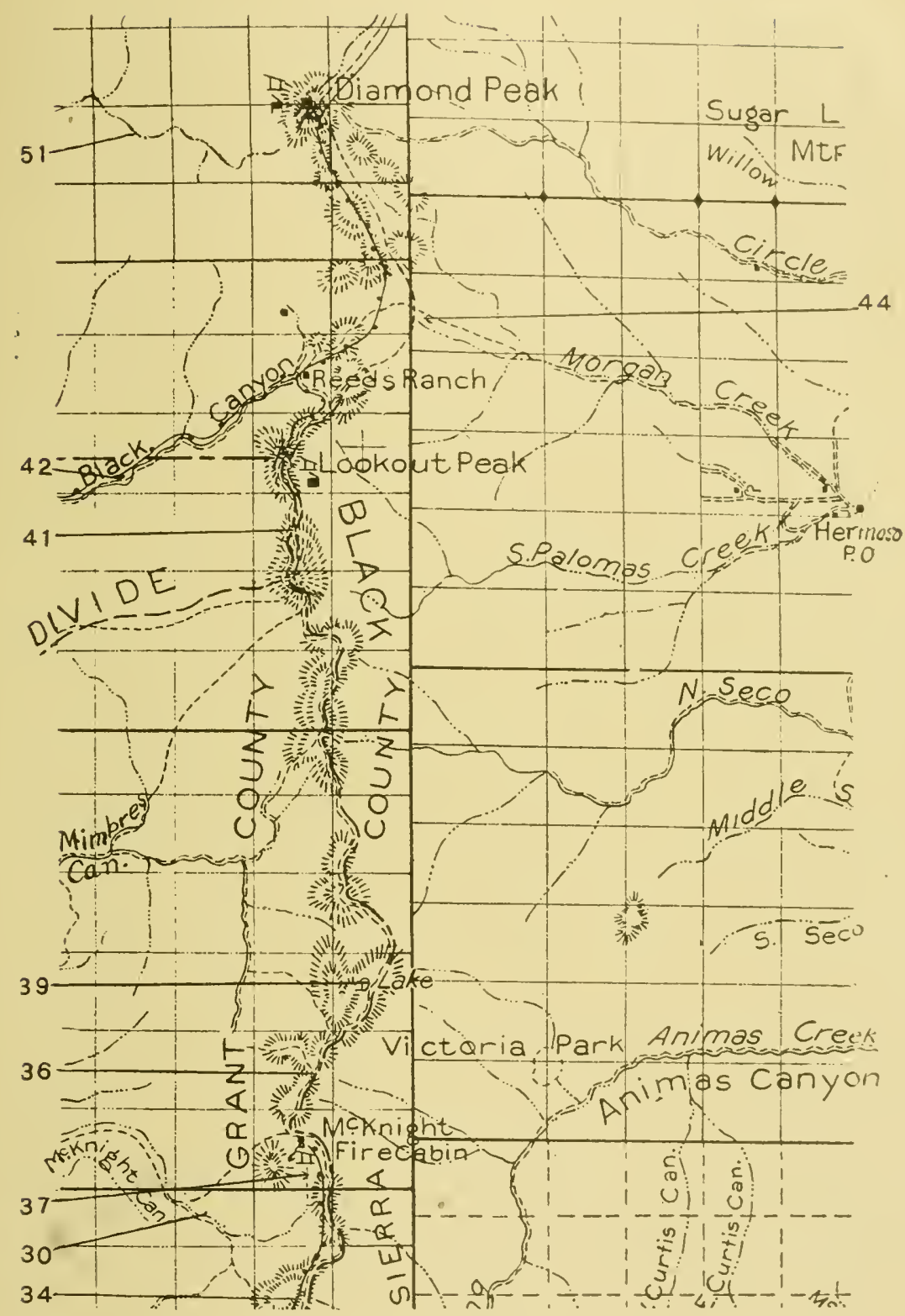

Fig, 2.-Collecting stations in the Black Range, northern section. The map is ruled into square miles. 
morphic rock. Except at the southern end, there is no mining in the range at present.

A good crest trail is maintained by the Forestry Service, and several cabins along it are occupied by forest rangers during the dry season. At the time we were there, the range was uninhabited except for two men caring for mines in Silver Creek, and several at Reed's ranch on Black Canyon. Deer, bear and wild turkeys are abundant. There are no rattlesnakes in the forest zone, though occasionally seen up to about 6,000 fect.

Eastern Foothills of the Black Range.-Returning to Deming from Chloride, the limestone ridges about Chloride were found barren of shells, although they had been seen there by miners at an earlier day. At the Oliver Mine, on Mineral Creek, 4 miles above Chloride, Oreohelix pilsbryi was found. A few miles southward, on the north side of a limestone mountain at Sam's Canyon, Holospira cockerelli was abundant, and a few very old "bones" of Oreohelix metcalfei and cooperi were found. Again in a like situation on the Little Palomas Creek, Holospira was plentiful, and again at Hermosa. This is a small village on the Big Palomas Creek, all that remains of a settlement of over 2,000 nimers in flush times. Teodoro had seen shells here years ago, when employed as superintendent at the Ocean Wave Mine, but not even "bones" remain. Across the stream, however, and down stream for a mile or more, Oreohelix and Holospira were abundant. Hard digging was required to get living shells, as the hillside of fine soil and limestone spawls had been eompletely plowed up by herds of goats. The snails found shelter under the roots of dead oaks and in undisturbed rock.

In the foothill region there was extensive mining years ago, with consequent destruction of the small wood which grew in favorable places.

Although a sharp lookout was kept, nothing further was found on the return trip except a colony of Ashmunella in a slicle of igneous rock along the wagon road near the mouth of a small creek tributary to Las Animas River. All were dead except a few very young ones.

No topographic map has been published. Our collecting stations are therefore plotted (pp. 84 and 85) on the Forest Service Temporary Base Map of the Gila National Forest. ${ }^{1}$ A list of the stations is given at the end of this article.

\footnotetext{
1 Second edition, corrected to January 1, 1916.
} 
The Cuchillo Range.

This range is about six miles east of Chloride, the post office of Fairview at the foot of the mountains. The peaks probably reach up to 7,500 feet.

On a brushy northern slope on the Thomas sicale trail, in the southern end of the range, Oreohelix metcrlfei cuchillensis and Holnspira cockerelli were found in abundaner. The cover was scant, and cattle plentiful. Both species were found again a couple of miles further on, in Frank Calhoun's pasture. In both places they liver in groves of oak, under limestone spawlis and dead timber.

At the north end of the range the peaks are higher. some having large outcrops of fossiliferous limestone, but the only eviclences of living shells obtained were a few "bones" of Helicodiscus. In rlrift debris, however, were many small shells which apparently graze on the grassy slopes and meadows.

\section{The sax Mateo Raxge.}

The san Mateo Range probably reaches a height of 8,000 feet. The southern end is about 15 miles north of Monticello Post Office, a village on the Cañada Alamosa. The rock in this part of the range is a friable, crumbling granite. Nearly the entire southern end is a continuous slope of granitic fragments. many feet in depth. The mesa continues nearly to Monticello. Pinyon, juniper and lowgrowing shrubs cover the hillsides. Along Chippy Creek, walnut, quaking asp and yellow pine prevail.

Around the edges of the rocky slides. Oreohelix cooperi and Ashmunella were fairly abundant, but the smaller shells were scarce. A day given to the peaks overlooking san Marcial, a couple of mile: farther, added only a few $O$. cooperi to the collection.

\section{Characteristics of the Black Range Mollusk Falya.}

The snail fauna of the Black Range is like that of the Mogollon Range in the rich development of Asmmella, the species being also related. Coarsely gramulate species are a unique feature. It differ: from the ranges southward and westward by the absence of sonorelle. A special feature of the range is the Oreohelix metcalfei group, wonder- fully varied in shape and sculpture. No doubt further members of this group will be found in sierrat and socorro Counties. Orcoheli.r swopei also is special to the northern end of the Black Range, so far as we know.

The crest of the range everywhere las an abundant Camadian 
zone fauna of small shells, Tertigo, Pupilla, Vitrina, Thysanophora ingersolli, etc., in common with similar elevations as far west as the Santa Catalinas in Arizona. Also the Canadian Oreohelix cooperi.

\section{List of SPECiES.}

The specimens have been studied by both authors. Types are in coll. A. X. .. Phila.; paratypes in coll. Ferriss.

\section{HELICID丑.}

ASHMUNELLA.

The Black Range Ashmunellas resemble those of the Mogollon and Chiricahua Ranges in the genitalia. The penis is more or less distinctly bipartite by a submedian constriction.

In A. binneyi, A. tetrodon, and in A. mogollonensis of the Mogollon Range, a retractor muscle of a few slender strands attaches to both segments of the penis and to the epiphallus further up, but there is no continuation attaching to the diaphragm.

In $A$. mendax and A. cockerelli with its subspecies there is, in addition to the incoherent penial retractor just described, a broad, very thin and extremely short band comnecting the epiphallus with the diaphragm. This is similar to the condition in most other Ashmunellas except that the connection with the diaphragm is here very short.

All of the species have the usual short flagellum, about $1.5 \mathrm{~mm}$. long. The constancy in Ashmunella of this minute, seemingly vestigeal organ is remarkable.

Aside from the particulars noted above, the organs are much alike in the several species. For convenient comparison the measurements. in millimeters, are given in one table, A. mogollonensis being added for comparison.

\section{Ashmunella tetrodon Pils. and Ferr.}

Ashmunella tetrodon P. \& F., Nautilus, XXIX, June, 1915, p. 15, Pl. 1, figs. 1-3a.

Southern slope of the San Mateo Mountains, Socorro County, New Mexico.

This species was described from the western slope of the Mogollon Mountains, and its occurrence in the san Mateo Range appears anomalous. The numerous specimens obtained are quite constant, showing none of the variations noted in the Mogollons.

The genitalia of one of these specimens are figured, Pl. I, fig. 6. 


\begin{tabular}{|c|c|c|c|c|c|c|c|}
\hline - & 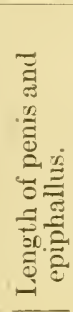 & 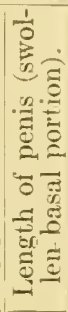 & 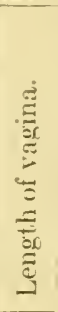 & 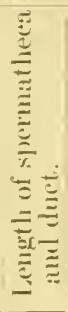 & 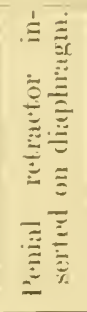 & $\begin{array}{l}\bar{\Xi} \\
\frac{\Xi}{*} \\
\vdots \\
\vdots\end{array}$ & 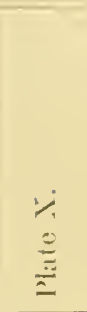 \\
\hline A. mogollonensis...... & 53 & 3 & 7.5 & 42 & None & & Fig. 3 \\
\hline A. mendax, Sta. 2 & 56 & 5 & 9 & 40 & Short & 16.5 & Fig. 1 \\
\hline "Sta. 32 & 54 & 4.5 & 6.5 & 63 & Short & 19 & \\
\hline$" \quad$ Sta. $16 \ldots$ & 61 & 6.5 & 8.5 & +2 & Short & 20 & \\
\hline " Sta. 26............... & 3.5 & 3.5 & & & short & 17 & \\
\hline A. binneyi, Sta. $15 \ldots$ & 42 & & & 2.5 & None & & \\
\hline Sta. 13 & 35 & 4.5 & $6 . \overline{5}$ & $2 \cdot 2$ & None & 15.5 & \\
\hline "Sta. T... & 42 & 4.5 & & 34.5 & None & $15-16$ & Fig. 5 \\
\hline A. cockerelli, Sta. 20 .. & 45 & 5.5 & 5 & 35 & short & 17 & Fig. 2 \\
\hline A. $c$, perobtusa, Sta. 21 & 40 & 5.5 & 5 & 23 & short & 16.7 & Fig. 4 \\
\hline A. tetrodon, S. Mateo........ & 28 & 4 & $\tilde{j}$ & 23 & None & 13.5 & Fig. 6 \\
\hline A. t. animorum, Sta. $26 \ldots .$. & 37 & 4 & 6 & 31 & None & 14 & \\
\hline
\end{tabular}

Ashmunella tetrodon fragilis n. subsp. Pl. VII, figs, 1-1 $b$.

The shell is markedly thimner than A. tetrodon, and subangular peripherally, the periphery situated high. Basal teeth small and well separated. Parictal tooth smaller than in A. te'rodon. There is no denticle between its inner end and the upper termination of the lip.

Alt. 6.5, diam. $14 \mathrm{~mm}$. $5 \frac{1}{3}$ whorls. No. 115,753, A. X. . . P.

One colony was found, Station 58 , in slides on south side of Cave Creek, near its mouth, and an equal distance from where the wagon road starts up a long-grade hillside on the trail from Chloricle to Hillsboro, in the eastern foothills of the Black Range.

Ashmunella tetrodon animorum n. subsp. Pl. V1I, figs. 2-2b.

The shell resembles $A$. tetrodon, but differs by having the basal teeth much closer together and united by a callus. The parietal tooth is simple; the outer lip-tooth is long. Color light buff, with a slightly brownish tinge above. Under a strong lens some imperfect granulation is produced by the interruptign and irregularity of the growth strix on the penult whorl. There is also an extremely minute spiral striation on the later whorls.

Alt. 7, diam. $15 \mathrm{~mm}$; $5 \frac{1}{4}$ whorls (type, No. 115,747).

" 5.4, " 12 " (Station 36).

Black Range, from Station 26. Holden's spring (type loc.), north- 
ward to Black ('anyon (Reed's) and Morgan Creek. Taken at 15 stations.

This is a common shell at high elevations, in the mountains north of Hillshoro Peak. Especially in the labyrintl of canyons forming the heads of Las Animas Canyon, but also on the western slope of the range. Most of the stations are between 8,000 and 9,000 feet. It was found mainly under dead wood on shady and rather humid slopes.

Very often the inner of the two basal teeth is wanting, being reduced to a sloping callus against the other tooth.

Ashmunella cockerelli n. sp. Pl. V1I, figs. 3, 4, 9 .

The shell is umbilicate (umbilicus between one-fifth and onc-sixth the total diameter, enlarging in the last half whorl, rather tubular further in); depressed; carinate at the periphery; the shape recalling: Polygyra carolinensis and obstricta; wood-brown above, usually somewhat paler at the base, having a huff streak inclieating a former resting stage about the middle of the last whorl. Surface lusterless except the earliest whorls. Sculpture of close-set, irregular pebble-like granules on the last whorl, finer on the whorl preceding, before which it is finely striate and slightly punctate, the first $1 \frac{1}{2}$ whorls smooth and glossy. The inner whork are convex, the penult whorl flattened, the last somewhat convex above, but exeavated on both sides of the strong peripheral keel. It is rather swollen below the keel, particularly in the last half. It descends shortly in front, and is guttered behind the outer and basal margins of the lip. The aperture is very oblique, subeircular and toothless. Lip is reflected and somewhat thickened within.

Alt. 8.2 , diam. 16.4 mm.; $5 \frac{1}{3}$ whorls (type, figs. 3,9 ).

" 7.2 , " 17.8 "

South of Sawyer's Peak, on slopes of the ravine at Grand Central Mine (Station 20), and in the next two ravines on the trail to the

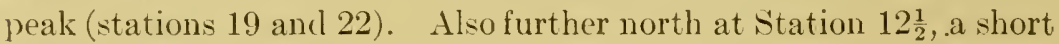
distance above Spade's cabin.

This species, which it gives us pleasure to name for Professor T. D. A. Cockerell, is remarkable for its strong carina and roughly pebbly sculpture, which is coarsest on the latter part of the whorl. The upper surface is usually convex, but often nearly flat. The periphery of the penult whorl frequently projects a little above the suture in the individuals with flattened spire. 
Ashmunella cockerelli perobtusa n. subsp. Pl. VIl, figs. 7 , in

The shell is sharply angular in the young, and on the front of the last whorl, but becomes rounded and rather swollen in the last third. The granulation is minute, as in the following race, and in places. the granules are linked into spiral lines.

Alt. 7.8 , diam. $16 \mathrm{~mm}$; $5 \frac{1}{3}$ whorls.

Locality, station 21, a ravine about two miles to the left of the trail (going down) from the camp site on Sawyer Peak to the Grand Central Mine, and at a somewhat higher level than the mine.

Type No. 115,750, A. N. S. P.; paratypes in Ferriss coll.

As one of the authors was lost when he found this colony, its exact location cannot be male perfectly clear; yet by turning along a trail which branches to the left before the steep descent into the second ravine from the Grand ('entral Mine, the snail hunter must get into the vicinity of the perobtusa colony. It is in a ravine on the left side of said trail.

Ashmunella cockerelli argenticola n. subep. Pl. Yil, fig. . .

This form differs from $A$. coclierelli by the far smoother surface; the granulation being very fine, and on the base the granules are connected into spiral threads, closely placed, and not visible over the whole base. The keel is strong, and continues to the lip, ther(by differing from A. c. perobtusa.

Alt. 7.4 , diam. $16 \mathrm{~mm}$. (type).

Upper Silver Creek and its branches, above 7,500 feet, to the northern flank of sawyer Peak, about 500 feet below the summit. It was taken at stations $3,4 \frac{1}{2}, 6$ and 9 on Silver Creek, 10 and $10 \frac{1}{2}$ on a tributary from the north which enters at Mitchell Cray's cabin, 11, gulch south of Cray's cabin, and $17 \frac{1}{2}$ near the summit of sawyer Peak. The type locality is silver Creek just below the box, where the trail makes a detour on the steep northern slope. This is probably between 8,000 and 8,500 feet, Gray's cabin being at 7,500 feet.

In the type locality, Station $4 \frac{1}{2}$, the diameter is 15 to $16 \mathrm{~mm}$., and the keel projects but little or not at all above the suture. Some lots vary more. At Station 11 the diameter is from 13.7 to $16 \mathrm{~mm}$., and the keel of the penult whorl often projects. In some lots there are coarse, conspicuous wrinkles of growth, as at Station 10. The spire varies in convexity in all lots, and is often almost flat.

Ashmunella binneyi n. sp. Pl. vil, fig. s.

The shell is depressed, with low but convex spire and angular periphery; isabella color above, paler bolow. S'culpture of rery minute, interrupted, somewhat anastomosing strie along growthlines; some weak traces of spiral lines on the bate. Whorls slowly 
widening, convex, the last angular or subangular in front, descending a little to the aperture. Umbilicus widening rapidly in the last whorl, one-fifth the total diameter. Aperture toothless, rounded, lunate, the peristome white, evenly and rather narrowly reflected throughout.

Alt. 7, diam. 15.5 mm.; 5 whorls. (Type, Station $8_{2}^{1}$.)

Diam. 13.5 to $16.7 \mathrm{~mm}$. (Station 15 ).

Black Range at stations 7 and $8 \frac{1}{2}$, on Silver Creek above the "box"; 13, head of Bull Top Creek, and 15, Spring Creek, a tributary of Iron Creek. The type locality, Station $8 \frac{1}{2}$, is near the deserted cabin just above the box of Silver Creek, at an elevation of about 8,500 feet.

This species differs from A. mendax by the angularity and the microscopic seulpture of the last whorl. Also by the absence of any penial retractor muscle attached to the diaphragm. It is far smoother than any form of $A$. cockerel' $i$, and not carinate.

It is certainly far less widely spread than $A$. mendax. We found it only in an area of a couple of miles along the western flank of the range, from Upper Silver Creek to Upper Spring Creek, well within the heavily forested zone. No doubt it will be found over a somewhat wider area; yet its absence in our many stations both north and south inclicate that it is a relatively local species.

Ashmunella menajax n. sp. Pl. VII, figs. $6,6 a, 6 b$.

The shell resembles $A$. mogollonensis, but is less robust, with different microscopic seulpture, lighter colored, being between tawny-olive and saccardo umber, often with a lighter streak from a former resting period. The third and fourth whorls have minute growth-wrinkles interrupted to form oblong granules in places, and an excessively minute spiral striation. On the last whorl the growthwrinkles are low, unequal and continuous, and there are many weakly impressed spiral lines. Last whorl descends slightly in front. The aperture is small, toothless; lip white, narrowly reflected. The umbilicus is cylindric within, but in the last whorl opens out to more than twice its former diameter.

Alt. 9.3, dian. 20, width of umbilicus $5.2 \mathrm{~mm}$, ; $5 \frac{1}{2}$ whorls.

Black Range, at the following stations: 2, Gallina Canyon, 4 miles above Pryor's upper cabin. Sawyer Peak at stations 1S, northeast, and 23, east of camp on the saddle, about 20 minutes' walk down the mountain. Stations 16 , Iron Creek above confluence of Spring Creek, and $16 \frac{1}{2}$, around Wright's cabin, near the head of the creek. Station 26, Holden's Spring, at one of the heads of Holden's Prong of Animas Canyon. Station 2S, southwest side of Hillsboro 
Peak. Station 27, west of Animas ranger cabin, and Station 30, about $3 \frac{1}{2}$ miles west, down the mountain. Station 49, Black Canyon, above Diamond Bar ranch house, on the western slope of the range. Station 32, garden of Stephen Reay, west end of Kingston. Type locality, Station 16.

The shell, while superficially very like A. mogollonensis, is easily distinguished by the somewhat granose intermediate whorls and far less deeply engraved last whorl. In A. mogollonensis there is no granulation, and the last whorl is very deeply and closely engraved spirally (Pl. VII, fig. 10). In the genitalia, the presence of a very short, broad penial retractor attached to the diaphragm distinguishes mendax (Pl. X, fig. 1) from mogollonensis (Pl. X, fig. 3), in which there is none.

This snail has a remarkable range. The lowest colonies on both sictes are far below the forest, especially on the west side, where it was found in great numbers in the arid Gallina Canyon. The examples here are rather small, diam. 16 to $17.3 \mathrm{~mm}$. On the east side we took it under wood and rubbish in a garden of Kingston, where it was common. Most of the other localities are along the crest of the range, in the humid forest zone. The type locality is on the south side of Iron Creek some distance above the mouth of spring Creek, at the entrance of a ravine from the south, where there has been rather extensive mine prospecting.

A figure of the genitalia of $A$. mogollonensis P. \& F. is given for comparison, Pl. X, fig. 3.

\section{OREOHELIX.}

Three of the four species belong to the southern group of species having swollen penes. The fourth, $O$. cooperi, is here at the southern border of its vast range.

Most of the specimens taken between the middle of August and the middle of October contained embryos. A few collected in the latter part of October contained none.

Oreohelix swopei n. sp. Pl. IX, figs. 2, 3-3b.

The shell resembles $O$. strigosa depressa. It has an ample umbilicus, a low, conic spire, obtuse and rounded at the summit, and a slightly angular periphery. Color fawn or vinaceous fawn, with two chocolate or lighter bands in the usual positions, and finely, irregularly speckled and streaked with creamy markings, partly the result of wear. The surface is glossy where unworn, marked with irregular growth-lines and fine wrinkles, which form sharp little folds just above the suture on some of the intermediate whorls. No spiral striation. The embryonic shell, of $2 \frac{1}{3}$ flat whorls, shows growth- 
lines and faint traces of mieroscopic spirals, and on its last third there are usually several small spiral threads. The young stages have an acutely angular periphery, which becomes bluntly angular on the last whorl, which deseends very little in front. The aperture is strongly oblique.

Alt. 12, diam. $21 \mathrm{~mm}$. (type).

$$
\begin{array}{lllll} 
& 12, & \text { " } & 22 & \text { " } \\
& 13.2, & \text { " } & 20 & \text { " }
\end{array}
$$

Black Range, at stations 44, 45 and 48, head of Morgan Creek; 42, Black Canyon, 4 miles below Reed's ranch; 50 and 51, on Diamond Creek, about 3 miles below the summit, and again about half way down.

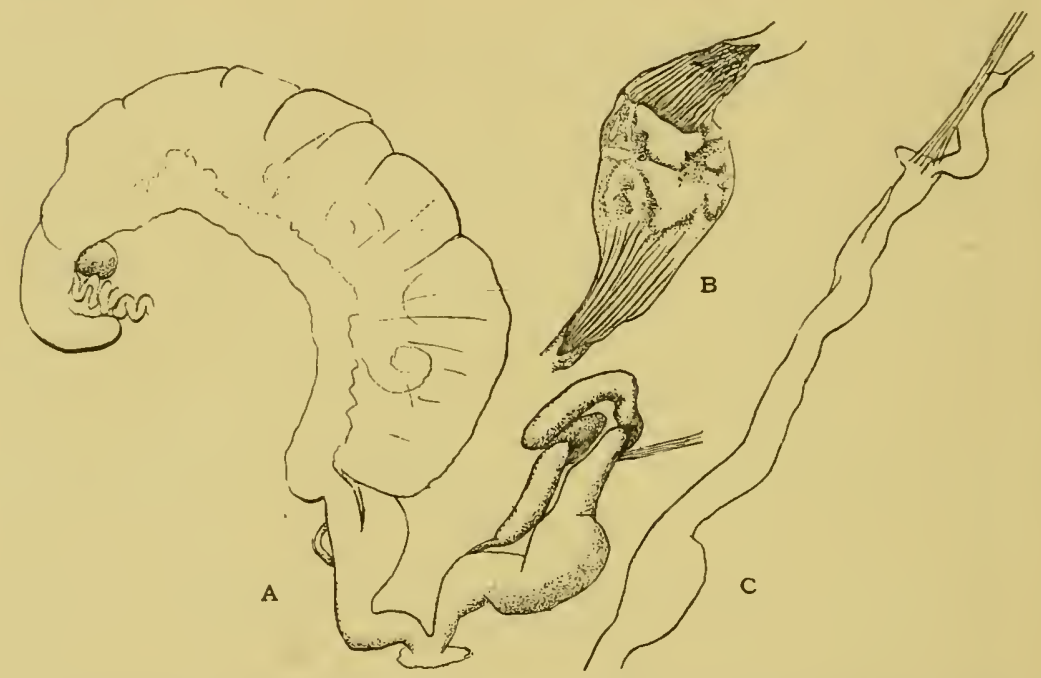

Fig. 3.-Reproductive organs of Oreohelix swopei. $\quad b$, the penis opened, showing fleshy organs in the swollen portion. $c$, the penis and epiphallus stretched straight.

This snail is named in honor of Dr. S. D. Swope, of Deming, New Mexico, in acknowledgment of his interest in scientific matters and his kindly help in furthering our investigation. That we risited the Black Range at all was clue to his alluring pieture of its beauties.

In the field this shell was taken for $O . s$. depressa. It was found among rocks on the well-shaded slopes of ravines, usually with O. cooperi and Ashmunella. The absence of spiral striation on the last whorl aroused suspicion of the reference to $O$. s. depressa, and on closer study it was found to differ by the far smoother embryonic shell, and espeeially by the soft anatomy, the male organs being quite different in the two speeies. In $O$. s. depressa the lower part 
of the penis is not swollen, and its cavity contains four or five subequal longitudinal ridges. These structures have been found constant in a great many specimens dissected, from L'tah, Colorado, Arizona and New Mexico. ${ }^{2}$ In $O$. swopei the lower part of the penis is conspicuously swollen, its eavity containing several large, irregular, fleshy processes (fig. $3 b$ ), below which there are many small longitudinal eords (fig. 3).

The organs measure:

Length of penis

" swollen portion of penis.
$"$ of epiphallus
$"$ of penial retractor
". of spermathera and duct

Diameter of shell.

$\begin{array}{ll}22 & \mathrm{~mm} . \\ 8.5 & 6 \\ 4.5 & \text { " } \\ 7 & \text { " } \\ 6.5 & \text { " } \\ 21 & \text { " } \\ 21 & \end{array}$

$O$. concentrata differs by its far shorter penis.

In the specimen dissected, taken about September 15, there were eight embryos (Pl. IX, fig. 13), the largest $4.2 \mathrm{~mm}$. diameter. The base shows many smooth spiral lines and bands cutting through densely erowded, erinkled radial striæ. When these are worn off it appears almost smooth, the apparently strong spiral sculpture shown in the figures being euticular.

A few beautiful albino shellswere found in one rock pile in Station 45 . Oreohelix metcalfei Ckll. Pl. IIII, fig. 5.

Oreohelix strigosa metcalfei CkII., Nautilus, XVIII, 1905, p. 113. Pilsbry, Proc. A. N. S. Phila., 1905, p. 27S, Pl. 25, figs. 4t, 48, 52.

This speeies was described from shells collected by Mr. O. B. Metealfe "near Kingston," the exact spot not designated. We hunted one day around Kingston, but did not find it. The country near the town is rather discouraging-steep stony hills with practically no shade, though there is abundant limestone. Probably we did not go far enough afield. We suspect that the colony was either nearer the mountains or northward, probably not in the immediate vicinity of the town.

Three very old "bones" were found by one of us in Sam's Canyon, Station 53, some miles south of Chloride. These oecurred with Holospira, like the original lot.

It appears that the O. metcalfei group, in Grant, Fierra and socorro Counties, comprises a series of forms largely parallel to the O. huydeni series in Utah and Colorarlo, but eren more remarkable in its extremes of form and sculpture.

'See these Procendings for 1905 , p. 272, Pl. 19, fig. 3; 1916, p. 345, P1. 19, figs. 1-4, 6, 7; Pl. 20, fig. S. 
On the west slope of the Black Range there are two forms: (1) in the south. O. $m$. concentrica, broadly umbilicate, with low, wide spiral cords on the base, and (2) further north. $O$. $m$. radiata. with strong raclial sculpture, remarkably like O. elrodi. On the eastern slope we have (3), southward. 0 . m. acutidiscus. broadly umbilicate, with fine spiral and coarser radial sculpture, and (4) further north. O. hermoscnsis. nearly smooth, angular only in front. Still further north a few "bones" of typical metcalfei were found, acutely keeled throughout and nearly smooth. Northeast of here was found O. m. cuchillensis, which is so weakly angular that we at first thought it a form of $O$. strigosa depressa. Further west $O$. pilsbryi was found. Further north, in socorra County, there is $O$. sucorroensis, an angular, roughly seulptured shell, as yet known only by perfectly bleached "bones."

The mctcalfei group therefore comprises, besides the original trpe, forms resembling $O$. haydeni. $O$. clrodi and $O$. strigosa depressa: each being alone in its district. The distribution may be represented diagrammatically thus:

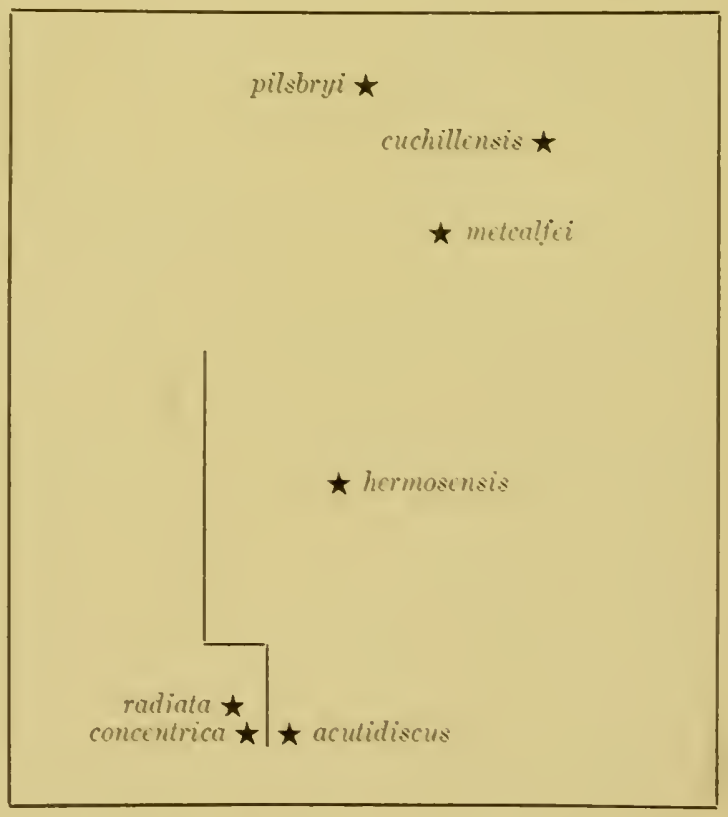

Diagram to show localities of the races of Orcokelix metcalfei relative to one another and to the crest of the Black Range from sawyer to Diamoud Peak. seale about 16 miles to an inch. 
Oreohelix metcalfei concentrica n. subsp. l'l. v'll, figs. 1-1d.

The shell is much more broadly and openly umbilicate than O. metcalfei; cartridge buff, inconspicuously mottled with gray or light (lral, the embryonic whorls pinkish cinnamon, and the peripheral keel bordered below with a brown band. Seulpture of about five extremely low spiral cords on the hase, and usually traces of two or three above, their intervals fincly and sharply striate spirally, and there are very fine, irregular stria along growth-lines, sharp where they pass over the keel and spiral cords, elsewhere wrak. The last whorl does not descend in front.

Alt. 9.3, cliam. $21.5 \mathrm{~mm}$; $4_{4}^{3}$ whorls.

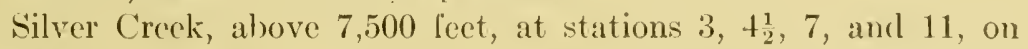
limestone outerolss. Type No. 115,755 , A. N. S. P. from Station 7, above the box of Silver Creek, on the north side.

In most specimens the intervals between the cords on the base are dull brown, or when concolored the spiral strixe make them appear darker, giving an appearance of relief to the cords. A few inclividuals from Station 11 (a branch ravine of Silver Creck south of Gray's cabin) have the base blackish chocolate.

specimens with the spiral cords on the base less conspicuous and the color usually darker-clouded and banded with dull walnut brown in varying degree-were found at Station 20, at the Cirand Central Nine; Station 19, the next gulch north of that where the mine is; also Station 22, the succeeding gulch north (Pl. VIII, fig. 1d). At Station $17 \frac{1}{2}$, on the west side of Sawyer Peak about 500 feet below the summit, similar shells were found, varying from nearly typical color to broadly banded below with chocolate, the spiral cords therefore incouspicuous.

Genitalia as in $O . m$. radiata.

The embryonic shell (Pl. IX, fig. 10) is very beautiful. 'The first whorl is smooth, cuticular lamine along growth-lines then appearing gradually. From these triangular processes risc, forming 3 or 4 spiral series above, usually 4 below a peripheral series of larger processes.

The embryos of radiata, acutidiscus and hermosensis are identical with those of concentrica.

Oreohelix metcalfei radiata $\mathrm{n}$. subsp. PI. VIII, figs. $2,2 a, 3-3 c, 6,6 a$.

The shell is more openly umbilicate than $O$. metcalfei, with irregular sculpture of strong wrinkles in the direction of growth-lines, the leus showing fine spiral strix between the wrinkles of the lower surface, very few on the upper surface. Faint traces of a few coarse spirals 
on the base may be discerned in most examples. The last whorl usually does not descend in front (but in some exceptional specimens it descends). The typical color is cartridge-buff, with some creambuff clouding above, the early whorls being light pinkish cinnamon; but it raries, some shells having a bister band below the periphery, or this may be widened, suffusing much of the base (figs. 6, 6a), with also a cinnamon line on the upper surface. In a few examples, all of the base except within the umbilicus is between chocolate and black, the upper surface being brownish.

Alt. 9, d am. $19.4 \mathrm{~mm}$.

Limestone outcrops on Iron Creek, Station 16, some distance above the confluence of Spring Creek and on Spring Creek, Station 15 (type loc.).

The Iron Creek specimens are nearly all of the pale typical color.

The genitalia of a specimen from Station 15, the type locality, were figured, sub nom. O. metcalfei, in Proc. A. N. S. Phila., 1916, p. 352, Pl. XXII, fig. 10. Embryonic shell (Pl. IX, fig. 11) as in O. m. concentrica.

Oreohelix metcalfei aoutidiscus n. subsp. Pl. VIII, figs. 4, $4 a$.

Broadly umbilicate, like $O$. $m$. concentrica, from which this race differs by having stronger growth-wrinkles (though much less coarse than in $0 . m$. radiata), and in place of the spiral cords of concentrica there are slightly enlarged striæ, the whole base being finely striate spirally between the riblets. It is mottled and clouded profusely, above and below, with walnut brown. The keel is very acute.

Alt. 10.4, diam. $22.4 \mathrm{~mm}$.; $5 \frac{1}{3}$ whorls.

Station 23, about 1,000 feet below the summit of Sawyer Peak, east of and below the camp site on the saddle, on a small outcrop of limestone.

In another place down the mountain southeast from camp, Station 18 , we found a colony differing by being cartridge buff, a few with a band below the periphery. Both of the localities are on the opposite side of the mountain from the known localities of $O . \mathrm{m}$. radiata. The embryonic shells are like those of radiata and concentrica.

Oreohelix metcalfei hermosensis n. subsp. Pl. IX, figs. 4, $4 a, 4 b$.

The shell is solid, cartridge buff with a narrow chocolate band below the periphery, and some indistinct pinkish cinnamon mottling, especially above. The surface is nearly smooth, having light irregular growth-lines and no spiral striæ. The last whorl descends in front. It is strongly angular in front of the aperture, the angle becoming weak on the last half. The umbilicus about as in metcalfei. 
Alt. 12.3, diam. $21.4 \mathrm{~mm}$; $5 \frac{1}{3}$ whorls.

Stations 55 and 56, near Hermosa, Sierra County, New Mexico.

This subspecies resembles $O$. metcalfei in color and the smooth surface, but differs by wanting the strong keel of the last whorl.

Genitalia are substantially as in $0 . m$. radiata. The penis is figured, fig. $4 a$, and opened, fig. $4 b$. The lower portion has several very irregular and unequal fleshy ridges within, upper portion papillose. Length of penis $13 \mathrm{~mm}$., of its thickened lower part $5 \mathrm{~mm}$.; length of epiphallus $3.5 \mathrm{~mm}$.; of penial retractor $6 \mathrm{~mm}$. Diameter of the shell $20.5 \mathrm{~mm}$.

The embryonic shells (Pl. IX, fig. 12) are exactly as in the forms of metcalfe $i$ from the Black Range. In the adult shell the embryo photographs abnormally dark on account of its yellow hue.
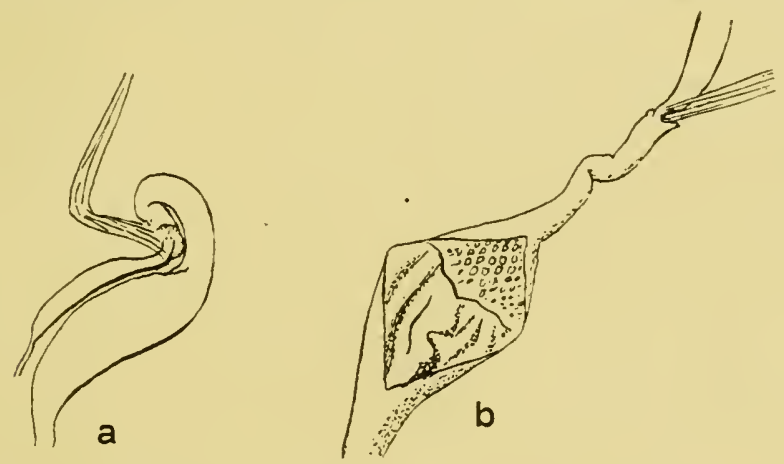

Fig. 4.-Penis of Oreohelix metcalfei hermosensis. $a$, exterior; $b$, the same opened.

Oreohelix metcalfei cuchillensis n, subsp. PI. IX, figs. 1, 1a, $1 b$.

This form is smaller than hermosensis, and the peripheral angle in front of the aperture is weaker, scarcely noticeable. Typically there are very minute and superficial spiral striæ, but on many specimens these cannot be made out. The last whorl descends little or not at all in front. There is about a half whorl less.

Alt. 9, diam. $18.2 \mathrm{~mm}$.; $4 \frac{3}{4}$ whorls.

Cuchillo Mountains, Sierra County, at two stations about two miles apart, at the southern end of the range.

We have hesitated between uniting this with $0 . m$. hermosensis and giving it separate standing. The sizes intergrade in a small number of specimens, cuchillensis varying from 15.4 to $20 \mathrm{~mm}$. diameter; yet where this is the case, the specimens are readily separable by other charaeters. Except for one specimen of $20 \mathrm{~mm}$. diam., none of the lot of over 200 specimens exceeds $19 \mathrm{~mm}$. diameter. 
The genitalia are substantially similar to $0 . m$. hermosensis except for the smaller size. Length of penis 7, of its internally thickened lower portion $4 \mathrm{~mm}$.; of epiphallus $3 \mathrm{~mm}$.; of penial retractor $6.5 \mathrm{~mm}$.; diam. shell about $17.5 \mathrm{~mm}$. (No. 112,917, A. N. S. P.)

No embryos were found in a few specimens preserved in spirit, taken in October.

Oreohelix pilsbryi Ferriss. Pl. VIII, figs. 7-7c.

Oreohelix pilsbryi Ferriss, Nautilus, XXX, January, 1917, p. 102.

While closely related to $O$. metcalfei, this form appears to be sufficiently distinct for specific rank. It is most like $O . m$. concentrica, but differs by the narrow, strongly raised spiral liræ and the smaller umbilicus. It is also relatively higher, resembling some forms of $O$. haydeni from the Oquirrh Range, in Utah. There are usually four spirals on the base, two on the upper surface. The embryonic whorls of adults and the genitalia (figured in Proc. A. N. S. Phila., 1916, Pl. XXII, fig. 8) are substantially as in $O$. metcalfei radiata and the other forms of that species. Embryos were not found in the uterus in the few specimens preserved in spirit.

It was found only near the Oliver Mine, on Mineral Creek, about 6 miles from Chloride, Sierra County. Several hundred living examples were obtained. See Nautilus, XXX, p. 102.

Oreohelix cooperi (W. G. B.) PI. IX, figs. 5-9.

This region, which forms the southern border of the vast area of cooperi, has a capacious form of the species. Many examples are typical in coloring (figs. 7, 9), but pale shells with faint bands or none are abundant, especially on Silver Creek (figs. 6, 8, 8a). Occasionally throughout the range, specimens were found with very broad, almost black bands (figs. 5, 5a). These color forms are to be found together, throughout the forest zone of the range. Thus, figs. 5-7 (Station 9)

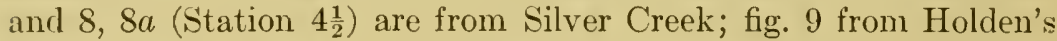
spring (Station 26). The extremes of elevation of the spire may also be found in single colonies. The shape and color mutations or forms are spread throughout the range, though particular color-forms are often prevalent at one or another station.

The specimens figured measure as follows:

Figs. 5, 5a, alt. 14, diam. $20 \mathrm{~mm}$.

$\begin{array}{lllll}\text { Fig. } 6, & \text { " } & 13, & \text { " } & 20 \text { " } \\ \text { Fig. } 7, & \text { " } & 15.6, & \text { " } & 20.6 \text { " } \\ \text { Figs. } 8,8 a, & \text { " } & 16.7, & \text { " } & 22 \\ \text { Fig. } 9, & \text { " } & 14.3, & \text { " } & 20.5 \text { " }\end{array}$


Localities in the Black Range and environs are given below. It is not confined to limestone exposures, but is quite sparsely seattered on shaded hillsides throughout the forested zone of the range from Sawyer Peak northward.

Sawyer Peak, Station $17 \frac{1}{2}$, west side of the north peak, near the summit.

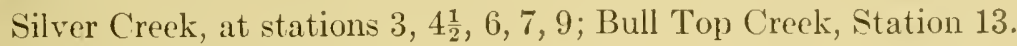

Spring Creek, Station 15; Iron Creek, stations 16 and $16_{2}^{1}$ (Wright's eabin). Between Iron Creek and Hillsboro Peak.

Heads of Animas Canyon at Holden's Spring, Station 26, and at stations 29, 30, 32, 33, northward.

Near Mcínight's cabin, Station 36 ; stations $38,39 \frac{1}{2}, 40$, the last 8 miles north.

Black Canyon region at stations $41,42$.

Morgan Canyon, stations 44 , $45,48$.

Diamond Creek, Station 50, about halfway down the mountain on the west side.

East of the Black Range it was taken at-

Sam's Canyon, about 6 miles south of Chloride, dead only.

San Mateo Mountains, everywhere on the south side, abun-

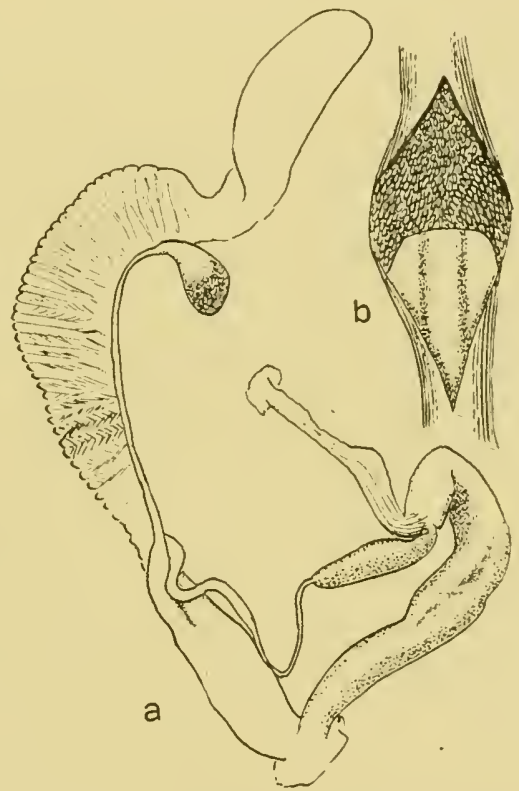

Fig. 5.-Reproductive organs of Oreohelix cooperi from Holden's Spring, Black Range, with detail of the penis, opened at upper end of the internally ribbed portion. dant.

Specimens from Holden's Spring (Station 26) were dissected last year. See Proc. A. N. S. Phila., 1916, p. 351. Two more have been opened, giving the following measurements of the genitalia:

No. 115,156 .

Silver Creek. Station $4 \frac{1}{2}$.

Length of penis $21 \mathrm{~mm}$.

" epiphallus

" penial retractor muscle.

Diameter of the shell.
$11 \quad \cdots$

4.5

No. 112,920.

San Mateo

Mountains.

$13.5 \mathrm{~mm}$.

$\begin{array}{ll}8 & 6 \\ 5 & 6\end{array}$


The lower part of the penis contains two or three fleshy ridges, the upper ends of which project a little into the cavity of the thinwalled portion.

Thysanophora ingersolli (Bld.).

Common throughout the humid forested zone, especially among aspens. Taken at 16 stations, from Sawyer Peak to Black Canyon.

Thysanophora hornii (Gabb).

Not found in the Black Range. A few were taken in the Cuchillo Mountains.

Holospira cockerelli Dall.

\section{UROCOPTID $Æ$.}

Holospira cockerelli Dall, Nautilus, XI, October, 1897 , p. 62. Pilsbry, Proc. A. N. S. P., 1905, p. 218, Pl. 26, fig. 6.

Sam's Canyon, about 4 miles south of Chloride. Cuchillo Mountains. Big Palomas Creek, near Hermosa, in a mountain across stream, above the fork, at Ocean Wave Mine; also in the next peak below. Little Palomas Creek, in a limestone mountain 2 miles north of Black Bob's ranch.

The specimens from the Little Palomas are about typical in size: Length $12.5 \mathrm{~mm}$., $13 \frac{1}{2}$ whorls.

$$
\text { " } 10.5 \text { " } 12 \text { " }
$$

The largest are from the Cuchillo Mountains on the south side of the peak, where some are $16.8 \mathrm{~mm}$. long, with $16 \frac{1}{2}$ whorls. Specimens from the other localities are intermediate in size. All we have opened have a single short lamella low on the axis in the penult whorl.

The type was found in drift clebris of the Rio Grande. Subsequently Mr. Metcalfe found one "near Kingston"-probably northward near the southern localities given above.

We did not find Holospira regis Pils. and Ckll., which was collected by Mr. Metcalfe somewhere in the Kingston district.

\section{ENDODONTID}

Pyramidula cronkhitei (Newe.).

Found everywhere (18 stations) throughout the wooded zone. Also in the Middle Percha drift below Kingston, Mineral Creek near Chloride, and Little Palomas Creek; probably washed down from above.

Helicodiscus arizonensis $\mathrm{P}$. and $\mathrm{F}$.

Rather sparingly found at many stations throughout the Black Range, from the summit to the level of Kingston. Also San Mateo and Cuchillo Mountains. 


\section{VITRINID里.}

Vitrina alaskana Dall.

From the summit of the ascent north of Wright's cabin northward to Black Canyon; abundant, especially near McKnight's cabin, on bits of wood, etc. Not seen south of Iron Creek.

\section{ZONITID平.}

Polita indentata umbilicata (Ckll.).

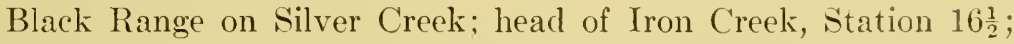
Animas Creek above the box, Station 25; Bear Wallow, Reed's ranch, Station 43. It is rare at the higher levels. In dryer, lower country it was taken at Station 1, Gallina Creek, on Little and Big Palomas Creeks, near Chloricle, and in the Cuchillo and San Mateo Mountains.

Zonitoides arborea (Say).

Found throughout the Black Range; taken at 17 stations.

Zonitoides minuscula alachuana (Dall).

Iron Creek, stations 16, 16 $\frac{1}{2}$; Holden's Spring; drift of Percha below Kingston; Oliver Mine, near Chloride.

Striatura milium meridionalis $\mathrm{P}$. and $\mathrm{F}$.

Station 28, south side of Hillsboro Peak; Station 26, Holden's spring.

Euconulus fulvus (Drap.).

Everywhere along the crest, from Sawyer Peak to Black Canyon. Also in drift at Station 1, Gallina Creek, and below Kingston; Oliver Mine near Chloride; San Mateo Mountains.

\section{LIMACID 里.}

Agriolimax campestris (Binn.).

Taken at 6 stations in the wooded zone of the Black Range.

\section{PUPILLID Æ®.}

Pupilla blandi pithodes n. subsp.

The shell is short, cylindric with rounded ends, chestnut brown, slightly shining. Whorls somewhat convex, the last slowly ascending a little in front, somewhat flattened and tapering to the rather narrow base, noticeably contracted behind the lip, having a quite. low (or sometimes rather strong) crest, of the same color as the rest of the shell, behind the contraction. Parietal lamella deeply placed, about one-third of a whorl long. Lower palatal plica rather long. Columellar lamella well developed, short.

Length 3.2 , diam. $1.8 \mathrm{~mm}$. 
Black Range, abundant in the forested zone, chiefly among aspens. Type locality, Station 39, around the cattle-trap and lake between MeKinight's and Mimbres forester stations.

It was taken at stations $5,9,16 \frac{1}{2}, 17,26,28,30,31,33,34,37$, 39, 42 and 47, well scattered over the ridge and upper slopes from Sawyer Peak to Black Canyon. Single bleached shells were taken in the drift debris of Gallina Creek at Station 1, and in the debris of Middle Percha Creek below Kingston. These were doubtless carried down from the forest zone by freshets.

This is relatively wider and shorter than P. blandi, with a far less developed crest behind the lip. Typical $P$. blandi is a decidedly smaller shell.

Pupoides marginatus (Say).

A bleached shell was found in drift of the Middle Percha Creek below Kingston, therefore in the foothills rather than the Black Range itself.

Gastrocopta pellucida hordeacella (Pils.).

Middle Percha Creek, below Kingston. Not found in the mountains.

Gastrocopta pilsbryana (Sterki).

Not uncommon on top. It was taken at 8 stations between Silver Creek and MeKnight's ranger cabin. Also on Mineral Creek, near the Oliver Mine, Station 52, and in the Cuchillo Mountains.

Gastrocopta ashmuni (Sterki).

Stations 16, Iron Creek, and 54, Little Palomas Creek, a single shell at each. The former station, probably above 7,500 feet, is unexpected, and above its usual zone in this part of New Mexico.

Gastrocopta quadridens Pils.

Stations $16 \frac{1}{2}$, Iron Creek near ITright's cabin, and 28, south side of Hillsboro Peak.

Vertigo coloradensis arizonensis $P$. and $V$.

Taken at 10 stations along the range, above 7,500 feet, and doubtless to be found in the forest zone wherever minutiæ are looked for, especially among aspens.

Vertigo modesta n. subsp.

This new subspecies will be described in the next paper of this series. It was taken in the Black Range at stations $1,9,16 \frac{1}{2}, 24$. $26,28,30,34,39,47$. 
VALLONIID $\nexists$.

Vallonia perspectiva Sterki.

Silver Creek, Station 9, elevation 8,000 feet, in the forest zone, and above its usual range. Much lower down it was taken at Station 42, Black Canyon, about 4 miles below the crest; in drift of the Middle Percha below Kingston; Station 54, on Little Palomas Creek, and in the Cuchillo Mountains.

Vallonia eyclophorella Ckll.

On the crest at stations $16 \frac{1}{2}, 39$, and 47 .

\section{FERUSSACID $\nexists$ E.}

Cochlicopa lubrica (Müll.).

Found sparingly but generally spread throughout the Black Range, from Silver Creek to Black Canyon; also on lower levels at Station 1, Kingston, Little Palomas Creek, Cuchillo and San Mateo Mountains.

\section{SUCCINEID $Æ$.}

Succinea avara Say.

Station 1, Gallina Canyon; Middle Percha below Kingston. Not in the forest zone.

Physa sp. undet.

\section{PHYSID 王.}

Middle Percha Creck. Kingston; Animas River near junction of Cherry Creek; both in the eastern foothills of the Black Range.

\section{Collecting Stations in the Black Range.}

Many of the stations are plotted on the maps, pp. 84 and 85 ; most of the others may be loeated by their relation to those plotted.

1. Middle branch of Gallina Creek about 2 miles above Pryor's upper eabin.

2. Same, 4 miles above eabin, at' the fork.

3, 4. Limestone ledges on north and south sides of Silver Creek, a few hundred yards above Mitchell (rray's cabin $(7,500$ feet).

$4 \frac{1}{2}$. Silver Creek just below the "box," where the trail makes a detour.

5 . Silver Creek above the box, on north side, near a deserled eabin.

6 . Silver Creek, north side, a short distance above station 5 .

7. Silver Creek, north side, above the preceding.

S. Saddle above the head of Silver Creek.

9. South side of the "box" of Silver Creek.

10. Gulch tributary to Silver Creek on north side, near Strohm's "mine."

11, 12. Guleh tributary to Silver Creek, about a mile south of Gray's cubin, and not far from the same elevation.

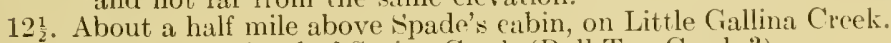

13. Branch of the head of Spring Creek (Bull Top Creek ?).

15. Outcrop of limestone on east side of Spring Creek, where a small ravine enters from the east.

16. Iron Creek, where a ravine with numerous prospect holes enters from the south, between confluence of Fpring Creek and Wright's eabin.

16 $\frac{1}{2}$. Wright's rabin, near the head of Iron Creek. 
17. Western side of the north summit of Sawyer Peak about 500 feet below the stummit.

$17 \frac{1}{2}$. Samc vicinity, $3-500$ fect below summit.

18. Northeastern flank of Sawyer Peak, a half mile below camp on saddle.

19. Ravine next up the trail to Sawyer Peak from Grand Central Mine.

20. Grand Central Mine, on the mine side of the ravine.

21. About 2 miles east of the trail from Sawyer Peak to Grand Central Mine, and not much higher than the mine.

22. Ravine north of Station 19.

23. A limestone ledge, 20 minutes' walk down the mountain east from the camp on the saddle of Sawyel Peak.

$23 \frac{1}{2}$. Hillside south of Wright's cabin near head of Iron Creek.

24 . Top of the steep trail north of Wright's cabin.

25. Just above the box of Holden Prong of Animas Canyon, several miles betow Holden's Spring.

26. Hillside southward above Holden's Spring.

27. A branch of Noonday Canyon, heading opposite Holden Spring, perhaps 2 miles down.

28. South side of Hillsboro Peak, among aspens.

29. Branch of Animas Cauyon 1 mile west of Animas ranger cabin.

30. Branch of McKinight Canyon, running westward, about $3 \frac{1}{2}$ miles west of Animas cabin and 2 miles from the summit trail.

31. Drift debris of Middle Percha Creek, near Kingston.

32. Garden of Mr. Stephen Reay, west end of Kingston.

33. Along summit trail, 2 or 3 miles north of Animas ranger cabin.

34. About half way between Animas and MeKnight's ranger eabins, in aspens along the summit trail.

35. Rocky hillside about 2 miles north of Mefinight's cabin, along the trail.

36. Roeky slide facing south about a mile north of IIcKinight's cabin.

37. Head of Mclinight's Canyou.

3S. Mclinight's Canyon below the "box."

39. Around lake and eattle-trap, on the shoulder of Mimbres Peak.

40. Eight miles north of MeKinight's cabin, on trail.

41. About $1 \frac{1}{2}$ miles south of Black Canyon ranger station.

42. Black Canyon about 3 to 4 miles below Reed's ranch.

43. Bear Wallow, Reed's ranch, among aspens.

44. Head of Morgan Creck, near the Hermoso trail. Stations 45, 47 and 48 are in the same vicinity.

45. North and west sides of the head of Morgan Creek.

46. Rock slides south of Reed's ranch.

47. Trail half a mile south of Reed's ranch.

48. Norgan Creek, 1 mile below station 44 .

49. Black Canyon, 1 mile above Diamond Bar Ranch.

50. Diamond Creek, about 4 miles below crest of range.

51. Diamond Creek, about 3 miles below erest of range.

52. Mineral Creek at Oliver Mine, 4 miles above Chloride.

53. Sam's Canyon, 4 miles south of Chloride.

54. Limestone MIountain on Little Palomas Creek, 2 miles north of Bob's ranch.

55. First mountain across creek above forks at Ocean Wave Mine, Big Palomas Creek near Hermosa.

56. Next peak below 55 .

57. Reservoir on the Animas near mouth of Cave Creek, ranch of Rue Panka.

58. Rock slicles on south side of Cave Creek between its mouth and the trail to Hillsboro.

Cuchillo Range. Three stations at the south end of this small range, 6 mile; east of Chloride.

San Mateo Range, in the south end, 6 miles from Monticello. Several rock slides, in the vicinity of Chippy Creek and on the southern slope, were investigaterl. 


\section{Explanation of Plates VII, VIII, IX, X.}

Plate VII.-Figs. 1, $1 a, 1 b$.-Ashmunella tetrodon fragilis n. subsp. Type. Station 58. No. 115,753.

Figs. 2, 2a, 2b.-Ashmunella tetrodon animorum n. subsp. Type. Station 26. No. 115,747 .

Figs. 3, 3a, 3b. -Ashnunclla cockerelli n. sp. Type. Station 19. No. 115,748 .

Fig. 4.-Depressed specimen of the same lot.

Fig. 5.-Ashmunella cockerclli argenticola n. subsp. Type. Station $4 \frac{1}{2}$. No. 115,749 .

Figs. 6, 6a, 6b.-Ashmunella mendax n. sp. Type. Station 16. No.

115,754 .
Figs. $7,7 a .-A$ shmunella cockerelli perobtusa n. subsp. . Type. Station 21. No. 115,750 .

Fig. S.-Ashmunella binneyi n. sp. Type. Station $S_{2}^{\frac{1}{2}}$. No. 115,751 .

Fig. 9.-Ashmunella cockerelli n. sp. Enlarged view of type.

Fig. 10.-Ashmunella mogollonensis Pils. Enlarged view of specimen from the Mlogollon Range.

PLATE VI1I.-Figs. 1-1c.-Oreohelix metcalfei concentrica n. subsp. Type. Station 7 . No. 115,755. 1d, dark specimen of same from Station 2.2.

Figs. 2, 20.-Oreohelix metcalfei radiata n. subsp. Station 15.

Figs. 3-3c.-Oreohelix metcalfei radiata n. subsp. Type. Station 15. No. 112,899 .

Figs. 4, 4a.-Oreohelix metcalfei acutidiscus n. subsp. Type. Station 23. No. 115,757 .

Fig. 5.-Oreohelix metcalfei Ckll. Type. No. 10,941.

Figs. 6, 6a.-Oreohelix metcalfei radiata n. subsp. Station 16.

Figs. 7-7c.-Oreohelix pilsbryi Ferriss. Type. Station 52. No. 112,918n.

Plate IX.-Figs. 1-1b.-Oreohelix metcalfei cuchillensis n. subsp. 'Type. No. 115,760

Fig. 2.-Oreohelix swopei n. sp. Elevated example from Station 45.

Figs. 3-3b.-Oreohelix swopei n. sp. Type. Station 45. No. 112,896.

Figs. 4-4b.-Oreohelix metcalfei hermosensis n. subsp. Type. No. 115, 759.

Figs. 5, 5a, 6, 7.-Oreohelix cooperi (IV. G. B.). Station 9. No. 115,280.

Figs. S, Sa.-Oreohelix cooperi (W. G. B.). Station 4: No. 115,156.

Fig. 9.-Oreohelix cooperi (IV. G. B.). Station 26. No. 115,306.

Fig. 10.-Oreohelix metcalfei concentrica. Embryos. No. 115,315.

Fig. 11.-Oreohelix metcalfei radiata. Embryos. No. 115,319.

Fig. 12.-Oreohelix metcalfei hermosensis. Embryos. No. 112,922.

Fig. 13.-Oreohelix swopei. Embryos. Station 41.

Plate X.-Fig. 1.-Ashmunella mendax n. sp. Station 16.

Fig. 2.- Ashmunella cockerelli n. sp. Station 20.

Fig. 3.-A shmunella mogollonensis P. and $\mathrm{F}$.

Fig. 4.-Ashmunella cockerelli perobtusa $\mathrm{n}$. subsp. Station 21.

Fig. 5.-Ashmunclla binneyi n. sp. Station 7.

Fig. 6.-A shmunclla tetrodon P. and F. San Mateo Mountains. No. 112,921. 



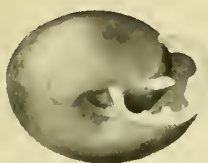

1

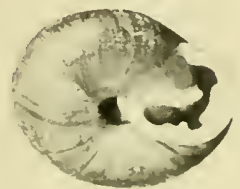

$2 a$

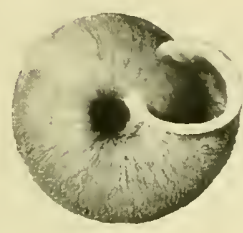

$3 b$

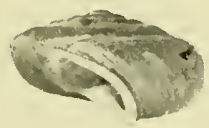

7
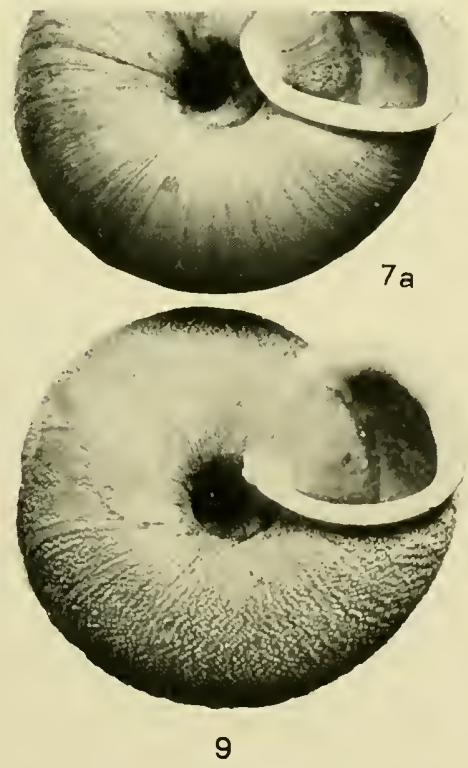

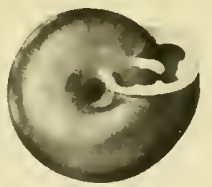

$1 \mathrm{~b}$
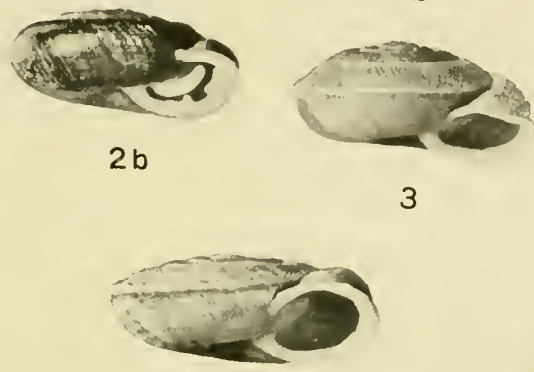

4

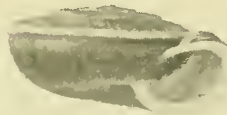

5

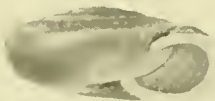

8

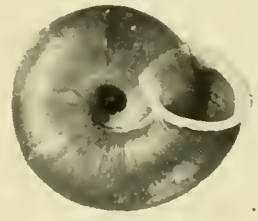

$6 a$

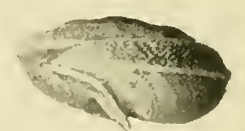

$3 a$

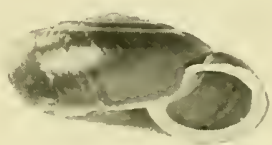

6

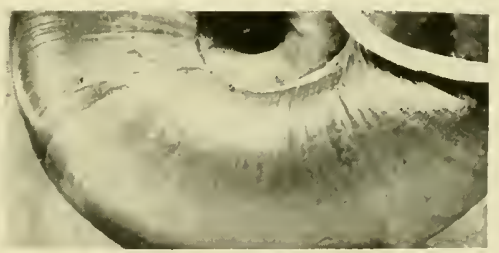

$6 \mathrm{~b}$

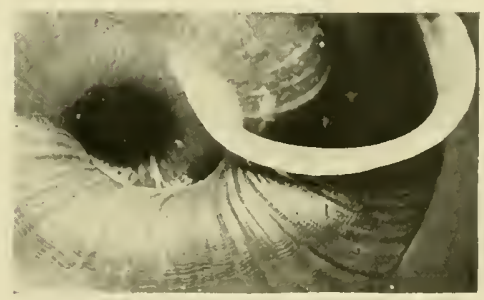

10

PILSBRY AND FERRISS: MOLLUSKS OF THE BLACK RANGE, NEW MEXICO. 



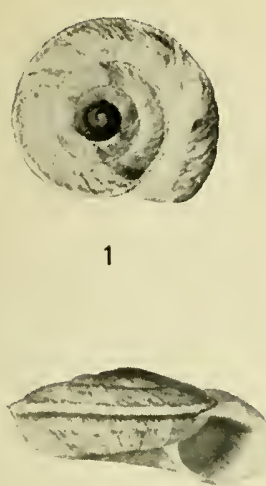

$1 \mathrm{c}$

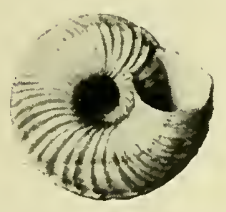

2

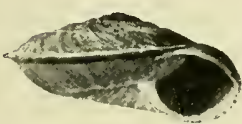

4

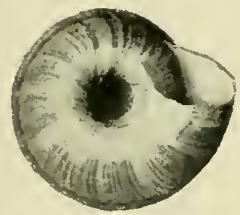

$4 a$

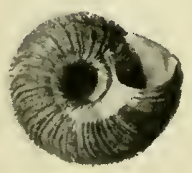

6

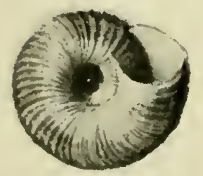

6 a

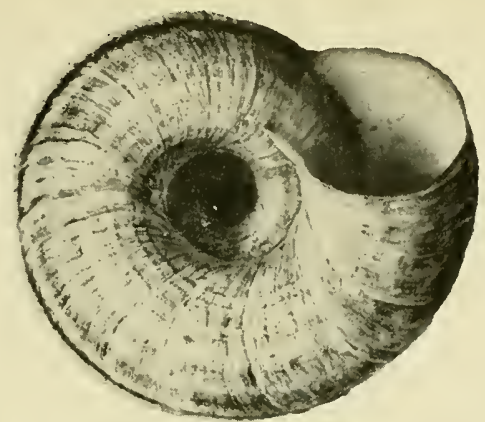

$1 a$

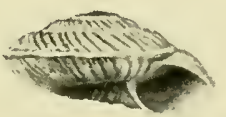

$2 a$

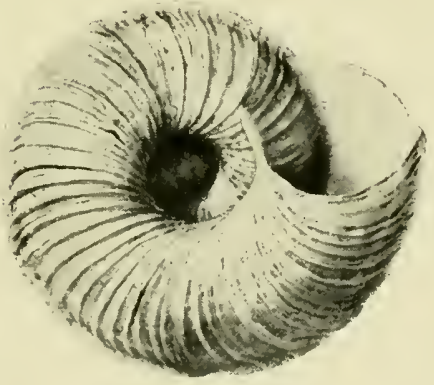

$3 b$

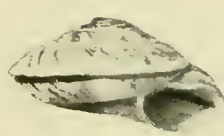

5
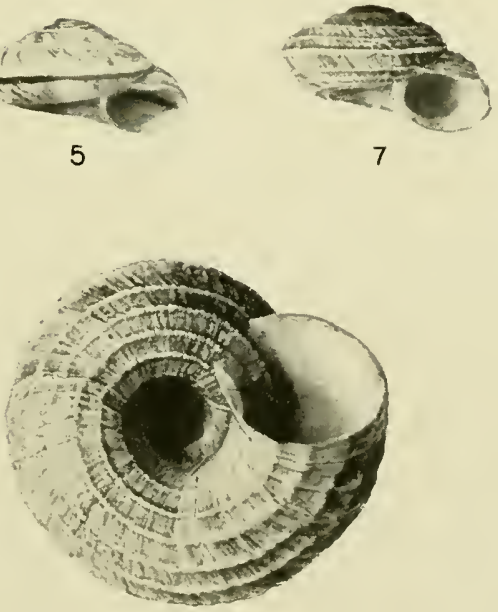

$7 a$

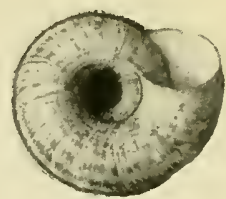

$1 \mathrm{~b}$

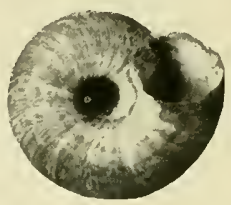

1d

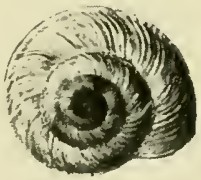

$3 a$

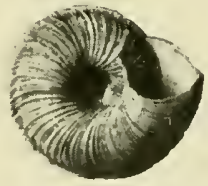

$3 c$

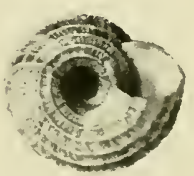

$7 b$

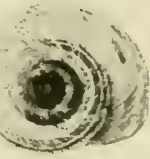

$7 \mathrm{c}$

PILSBRY AND FERRISS: MOLLUSKS OF THE BLACK RANGE, NEW MEXICO. 



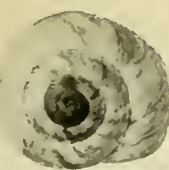

1

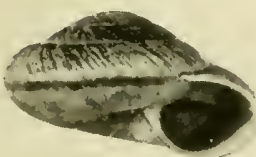

3

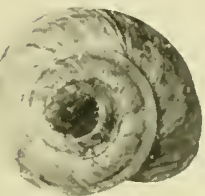

4

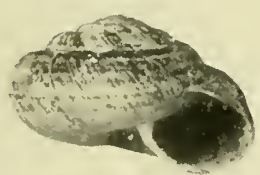

6

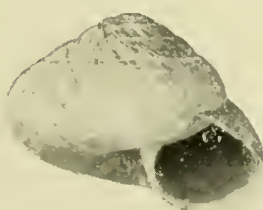

8

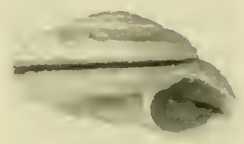

$4 a$

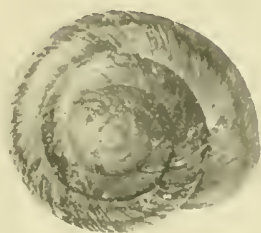

3a

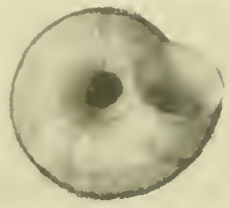

$4 b$
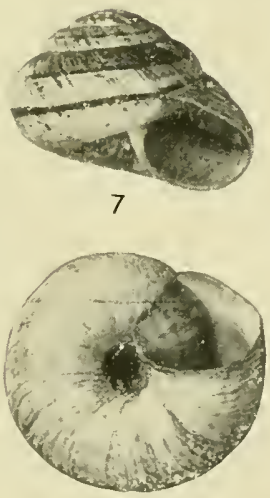

$8 a$

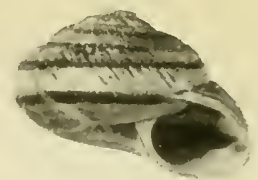

2

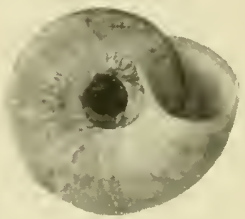

$3 b$

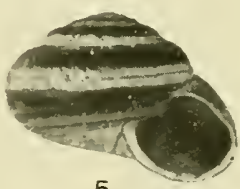

5

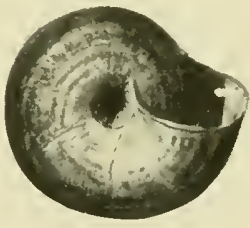

$5 a$

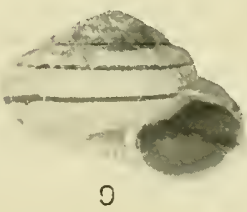

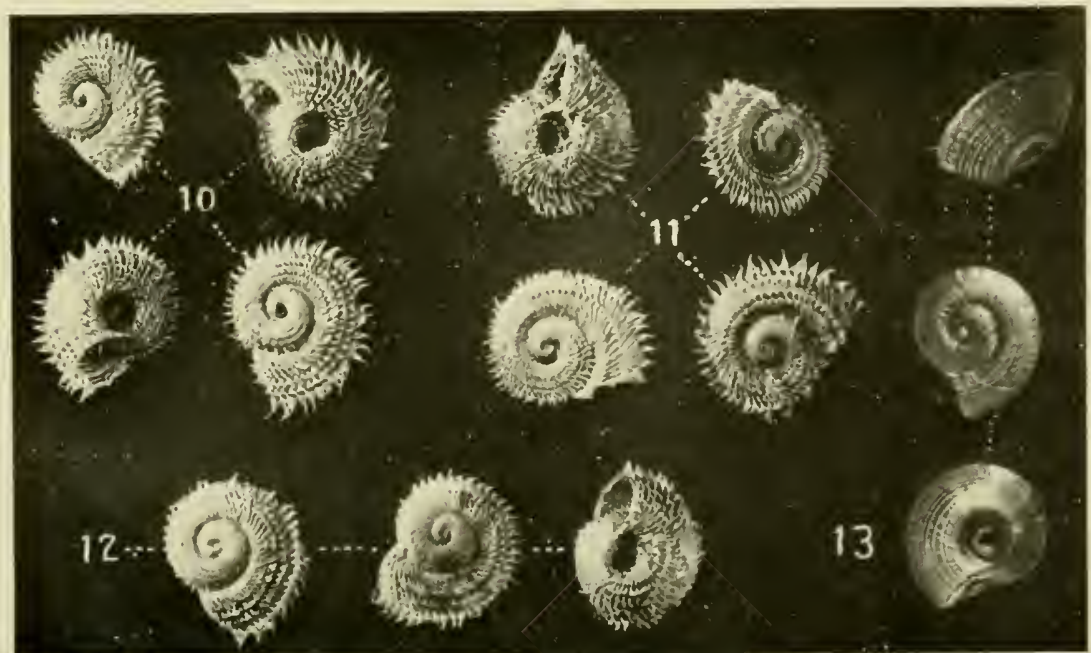

PILSBRY AND FERRISS: MOLLUSKS OF THE BLACK RANGE, NEW MEXICO. 


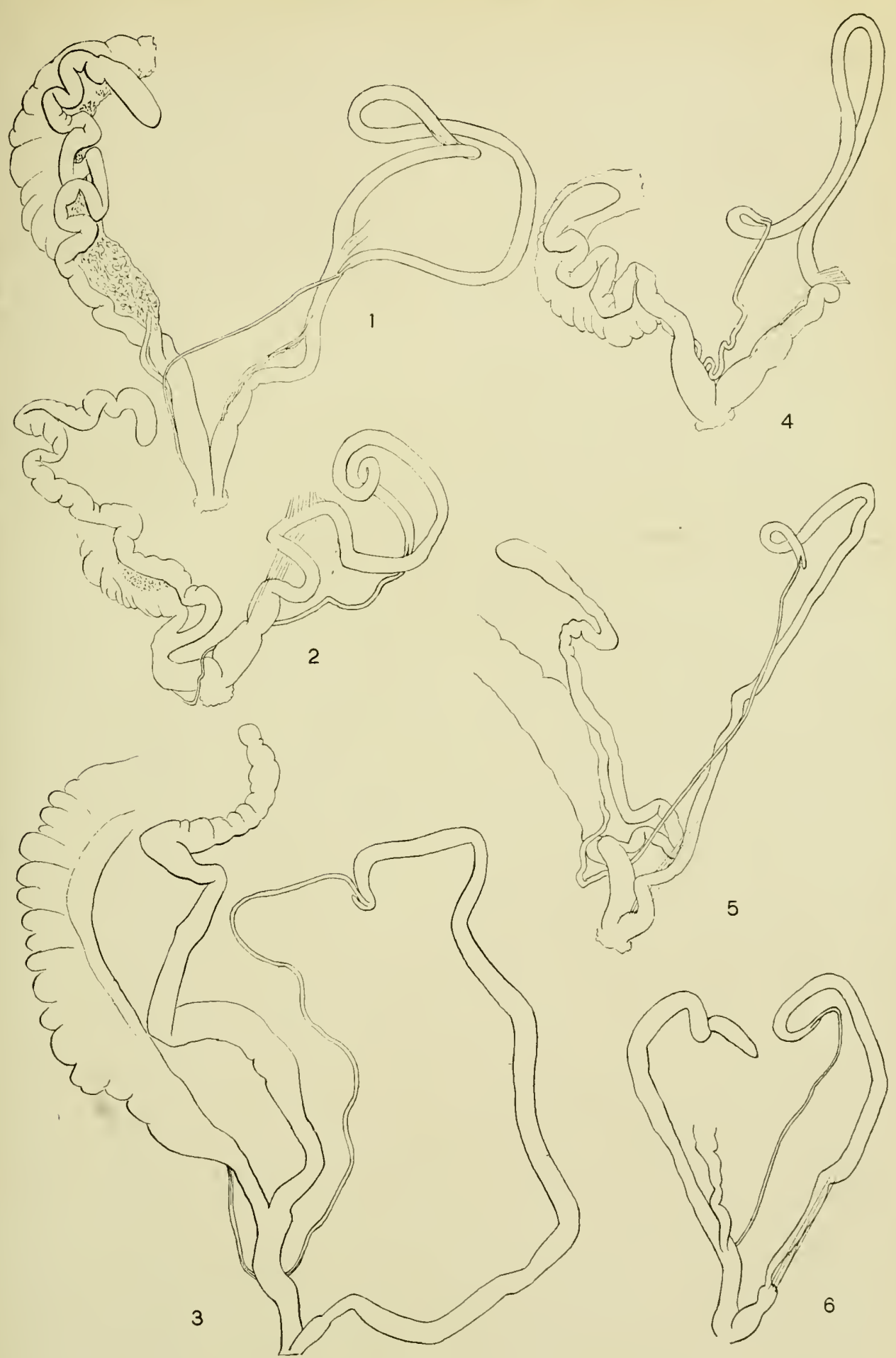

PILSBRY AND FERRISS: MOLLUSKS OF THE BLACK RANGE, NEW MEXICO. 



\title{
Mollusca of the Southwestern States-
}

\section{The Santa Catalina, Rincon, Tortillita}

\section{and Galiuro Mountains.}

X. The Mountains of the Gila Headwaters.

\author{
BY \\ Henry A. Pilsbry and James H. Ferriss.
}

From the Proceedings of The Academy of Natural Sciences of Philadelphia, November, 1918. 



$$
\text { . }
$$




\section{MOLLUSCA OF THE SOUTHWESTERN STATES-IX, THE SANTA CATALINA, RIN- CON, TORTILLITA AND GALIURO MOUNTAINS. $\mathrm{X}$, THE MOUNTAINS OF THE GILA HEADWATERS.}

BY HENRY A. PILSBRY AND JAS. II. FERRISS. ${ }^{1}$

The Santa Catalina, in Pima County, north of Tueson, is one of the large ranges of Southern Arizona, about forty-five miles in length, including its Tanque Verde and Rincon outliers, with an extreme width of twenty-five miles. Mount Lemon with an elevation of 9,150 feet is heavily forested with yellow pine, quaking asp, cork bark fir (Abies arizonica), Douglas spruce (Pseudotsuga mucronata), cypress (Cupressus arizonica), other coniferous trees, large oaks and an alder as tall as a pine. The male fern and the brake stand here four feet in height. The Douglas spruce are eight feet in diameter. There is a forest gloom at mid-day, and a ground covering indicating a timber growth of many years without interruption by fires or lumbering. Winter often brings ten feet of snow. With numerous trout streams, it has the attractions, summer and winter, of the deep forests along the Canadian border without their annoying insects.

In quantity and number of species of the smaller suails the north slope of Mount Lemon has the best record so far. The odorshooting, rough-coated Sonorella also is here in large numbers under the fallen bark of the Douglas spruce and the dead poles of the quaking asp and cork bark fir. Unlike his brethren with a polished coat, this snail seeks food and cover similar to those used by the Polygyras of timbered areas in the Mississippi valley and eastward.

The humid forest conditions of the region around Lemon Mountain prevail at Soldier Camp, Kellogg's Peak, Alder Canyon, Alder Springs. The Spud Rock Ranger Station and other high peaks of the Rincon section, except in lacking cork bark fir, also follow Mount Lemon closely in forest conditions. They have the large oaks and conifers, the quaking asp, and the heavy floor of humus underfoot, but not quite as many snails.

In the valleys of Bear Wallow and Sabino creeks, at the heart of the Santa Catalinas, the Arizonians of lower and hotter levels have

1 The field work covered by this report was by Ferriss, assisted in the Blue River region and the Mogollon Mountains by the late L. E. Daniels. 
built villages of summer cottages. It is about a full day's journey from Tucson on horseback. A small saw mill furnishes building material for this summer society, for a sanitarium now under construction and for the copper mines over the ridge at the foot of Marble Peak.

Except in the valley of the San Pedro river and the village of Oracle only a few miners, ranch men and forest rangers are to be found in all this group of ranges. There are more bears and mountain lions than people.

The southern slopes of the Catalinas, the foot hills and mesas, and the Galiuro and Tortillita ranges are not heavily forested. At best it is low, open woods or desert shrubbery, through which the granite rocks and precipices glisten in the sun. The soil is dry, though often covered with fallen leaves and growing vegetation. A few Sonorellas and some of the smaller snails may be found at all altitudes in the rock slides, the talus, on all sides of the mountain, and in any kind of rock, especially smooth and stratified rock; sometimes also under fallen timber, or in small piles of boulders.

In the dry season, among dry and hot rocks, dead shells will be the rule. Here one must dig a full eight hour day for a live one. We find a two-foot bar of half inch octagonal steel very helpful. The bar should have a two-inch chisel edge flattened out at each end, one of these turned at a right angle like a hoe. It will weigh one and three-quarter pounds; a good digger, a jimmy for rock work, and a helpful staff in steep and rough places.

Sonorella is something of a rambler, more so than Ashmunella or Oreohetix, and upon damp days scouts may be met out in the fallen leaves far from their rocky homes. Often single, dead, lie along the trails where there is no shelter in the vicinity for snail kind. In 1913, on the south side of the Santa Catalinas in the dry season, day after day but one or two living Sonorellas were found. It was the same about Brush Corral Ranger Station, on the north side, in the rocky slides of the canyons nearly on a level with the river. In one of these slides of three or more feet in depth, three hundred good "bones" were found but none alive. It was also the same kind of collecting in the Galiuros and the Tortilitas in the winter of 1917-18.

A small cleep slide of "porphyry" or shale, shaded partially with rose bushes, elder or gooseberry bushes, makes an ideal home for the Southwestern snails.

The Galiuro range, in Graham County, and the Tortillita range, in Pinal County, as yet unsurveyed, seem to have an elevation of 
about 7,000 or 8,000 feet, granite or other igneous rock prevailing, and with but a little timber. A few ledges of sharp-pointed limestone, dolomite probably, had no attraction for the snails. The entire region at present is inaccessible except to horsemen and pedestrians and these should carry their own food and shelter. We did, and lived like kings before the war.

One of us (Ferriss) collected a few days, less than a week, in the Santa Catalinas, Mount Lemon and Soldier Camp, in 1910; again much of the time from May to October in 1913, on the southern slope, around Mount Lemon, Soldier Camp, Marble Peak and on the northern mesa, about Brush Corral. Again a month was spent in 1917, at Sabino Basin, Bear Creek, and Brush Corral, the Rincon Peaks and the Galiuros. The guide, Frank Cole, on a hunting trip, brought in Sonorellas from the Tortillitas and from the Cañada del Oro section of the Santa Catalinas. Many inviting prospects in these mountains remain neglected. They surely contain species still unknown.

Life is rapid in snaildom, decay a slow process in an arid climate; and possibly these fat cemeteries in the basements of Sonorella slides merely represent the natural death rate of many years. It may be that one living inhabitant to one hundred skeletons is the right proportion. However an impression grows upon the collector as he digs in the arid foothills, that in earlier times there were periods or seasons more favorable to snail life--seasons with more moisture, more vegetation, and a cleeper humus. The steep mountain gulches with walls on either side thrown above the surrounding surface quite plainly speak of days when the floods were greater than any known in modern times. These boulder bulwarks contain potsherds and other evidence of human occupation; also Sonorellas. As collecting. grounds they are often preferable to the large slides farther up the mountain. Among these boulders, in the hot sunlight, we found the largest Sonorella. Measured crudely in the field it had a diameter of 33 millimeters.

In collecting Sonorellas and Oreohelices from arid to humid zones in the same canyon or mountain, one gets the impression that the differences of size are mainly a matter of the breed; that they are racial, rather than due to length of growing season, supply of food or climatic comforts. We naturally search ideal environments of food, shade and shelter for robust races, and expect to meet the pigmy forms in hot, dry and barren places. Often what we find is the reverse of this. On one climb in 1918, at Kitt's Peak, a liarge 
and robust Sonorella was found at a low elevation in a barrier of boulders, so dry and barren the snails would necessarily lie dormant a large part of the year. At a thousand feet higher, beside a stream of running water, came in a much smaller breed; and, 1500 feet above number two, with an ideal situation as to a moist atmosphere, food, shelter and snail comfort, lived a pigmy Sonorella of about 12 millimeters in diameter.

Again on the Kaibab Plateau in 1909, every colony of Oreohelix strigosa depressa seemed a little different from all other colonies. At Two Spring Canyon with running water all the way, the pigmies were at the higher station in a grove of quaking asp. Every colony increased in size and color brilliance at a regular pace down the canyon. Here seemed proof positive of the advantage of a longer growing season. Over the ridge in Snake Gulch the order was reversed, for the larger shells were at the top in a dry situation, and their size seemingly decreased in proportion to the mileage as we descended along a running stream. In Jacobs Canyon, running parallel to Snake Gulch, dry all the way, the large and gaudy shells were midway, the smaller and paler above and below. Food conditions may have had some influence in the development of these races but if so the evidence was not apparent. In the field we meet contradictions continually beyond our understanding, but perhaps we may have a better comprehension before the survey of the Southwest is completed.

\section{HELICID $\approx$ E.}

Sonorella odorata n. sp. Pl. 11I, figs. 1 to 4 .

The shell is depressed, umbilicate, the umbilicus contained about $7 \frac{1}{3}$ times in the diameter of shell; buffy-citrine below, somewhat lighter than isabella color above, with a chestnut brown band at the shoulder. The first half whorl has irregular radial wrinkles soon passing into a low granulation, the last embryonic whorl granular, over which there are close decurrent threads, interrupted into short dashes on the upper part of the whorl. Subsequent whorls are very minutely granular, somewhat dull, the granulation effaced at the base, which is more glossy. The last whorl shows also numerous faint spiral striae. The whorls are quite convex, the early ones increasing slowly, the last widening rapidly, rather abruptly descending close to the aperture. The aperture is elliptical-lunate; peristome is narrowly expanded throughout, dilated at the columellar insertion.

Alt. 11.4, diam. $19.5 \mathrm{~mm}$.; $4 \frac{1}{2}$ whorls (type).

$\begin{array}{lllllll} & 13.4, & \text { " } & 23.3 & \text { " } & 4 \frac{2}{3} & \text { (Station 18, 1917). } \\ \text { " } 13.2, & \text { " } & 22 & \text { " } & \text { (Station 18, 1917). }\end{array}$




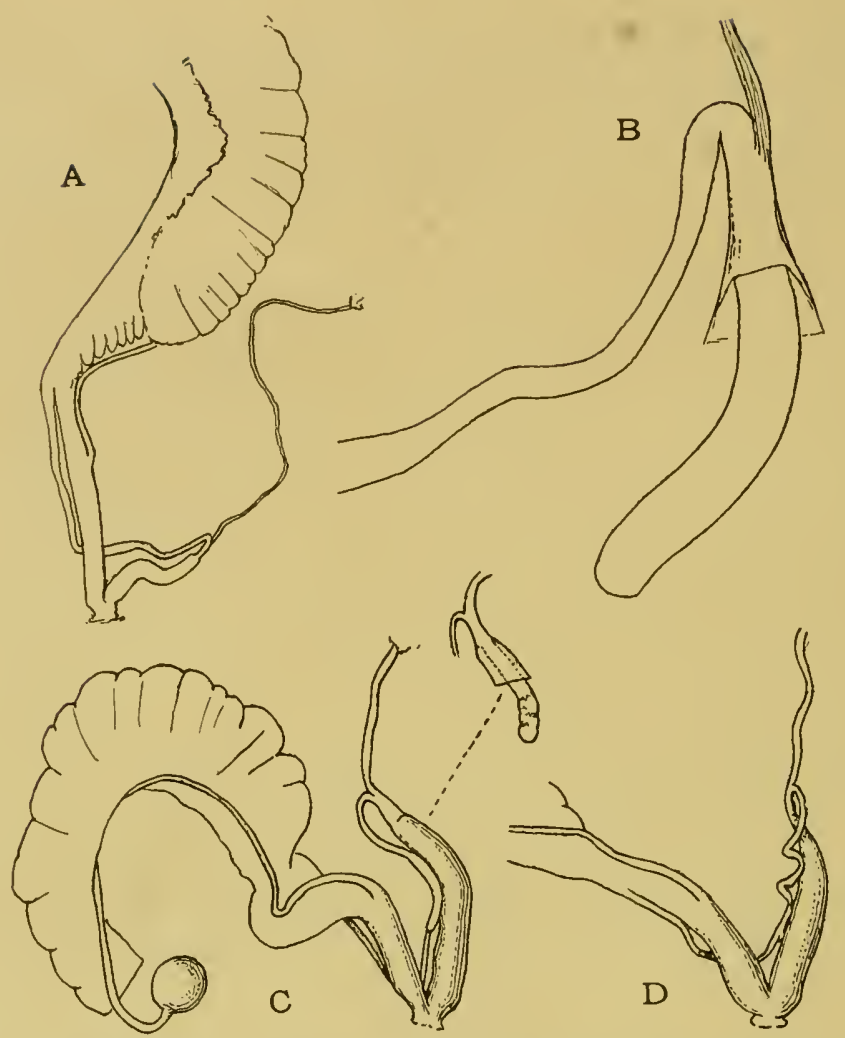

Fig. 1. Genitalia of S. odorata. $a$, No. 119,$032 ; b$, penis-napilla of same much enlarged; $c$, No. 119,035, with detail of penis-papilla; $d$, No. 119,034.

The sole is tripartite in color, the side areas being somewhat darker. The back and head are quite dark in most alcoholic specimens, black in life, the tips of the tubercles lighter.

The penis is small, containing a cylindric papilla with rounded end, about two-thirds as long as the penis. The penial retractor is inserted upon the epiphallus not far from its base. The flagellum is present as a very minute but distinct bud in most of the specimens opened, but in two it was not seen though looked for. In the specimen No. 119,032 (figs. $1 a, b$,), the male organs are evidently not fully developed, the penis and epiphallus being small and short, while the retractor muscle is correspondingly longer, making the total length about normal, the individual being of full size though not adult. Measurements of the organs in $\mathrm{mm}$. follow: 


\begin{tabular}{|c|c|c|c|c|c|c|c|c|c|}
\hline LOCALITY. & & 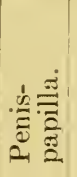 & $\frac{\stackrel{n}{\Xi}}{\stackrel{\Xi}{\Xi}}$ & 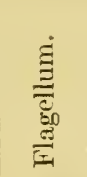 & & 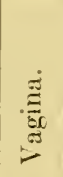 & 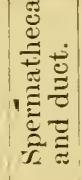 & 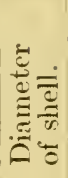 & $\frac{\grave{\Xi}}{\Xi}$ \\
\hline $\begin{array}{l}\text { Head of Alder Canyon... } \\
\text { ". } \\
\text { N.-E. side Mt. Lemon } \cdots \\
\text { " } \\
\text { S. of spring, Mt. Iemon }{ }^{2} \text { " } \\
\text { S. o. marmoris, Station } 36\end{array}$ & $\begin{array}{c}6.6 \\
6.5 \\
6 \\
6 \\
\frac{6}{3.5} \\
10.7\end{array}$ & $\begin{array}{l}4 \\
3.3 \\
4 \\
5 \\
2 \\
6.5\end{array}$ & $\begin{array}{l}7.5 \\
7.2 \\
8 \\
5 \\
8 \\
3.2 \\
8\end{array}$ & $\begin{array}{l}\text { trace } \\
0 \\
\text { trace } \\
\text { trace } \\
\text { trace } \\
0 \\
\text { dist. }\end{array}$ & $\begin{array}{l}7 \\
8.5 \\
5 \\
7 \\
6 \\
13.5 \\
\cdots\end{array}$ & $\begin{array}{l}6 \\
7 \\
4.5 \\
4 \\
5 \\
5 \\
8\end{array}$ & $\cdots$ & $\begin{array}{l}20 \\
20 \\
19 \\
24 \\
20 \\
20\end{array}$ & $\begin{array}{l}119,033 \\
119,033 \\
119,034 \\
119,035 \\
119,035 \\
119,032 \\
109,07: a\end{array}$ \\
\hline
\end{tabular}

Santa Catalinas above $7500 \mathrm{ft}$ : Mt. Lemon, Stations 5 and 6 (1911), 32 and 37 (1913), on the trail to Webber's and other places. Soldier Camp, Bear Wallow, Head of Alder Canyon (type loc., No. 119,033). Kellogg Peak, southeastern sicle.

Rincons at station 22, Spud Rock Ranger Station, and Station 20 , on the north slope.

It lives in deep humid forest in colonies, as our eastern helices do, under $\operatorname{logs}$ and bark of quaking asp and Arizona fir, sometimes by dozens. Only at Spud Rock it was found deep in rocks, also humid. It is a timber snail of the Canadian zone forest. In general aspect the shell reminds one of the Californian helices.

This is a common snail in the heavily wooded upper levels of the Santa Catalinas, taken at many stations. When picked up it emits a strong unpleasant odor recalling that of the goldenrod of Thunderhead mountain in East Tennessee (probably Solidago odora). This was first noticed at Kellogg Peak. When picked up the snail shot out two or three drops of liquid six inches or more (evidently expelled from the lung as the foot is retracted). One often smelled them before finding any. But three or four shells broken by mice or squirrels were noticed in the course of collecting, and it may be that the snail-eaters object to the smell.

By the genitalia this species is related to S. clappi of the Santa Rita range, and $S$. ferrissi of the Dragoons, though differing from both in several details. The shell is most like S. clappi. It differs from other Santa Catalina species by the minute granulation of the surface, which gives it a dull, silky luster.

The color is rather variable. At Soldier Camp (Fig. 4), Cañada

2 Specimen not fnlly mature. 
del Oro and some other places the general hue is cinnamon or cinnamon-buff, opaque, and the size small, diam. 18 to $20 \mathrm{~mm}$. The smallest adult seen measures $17 \mathrm{~mm}$. in diameter.

Specimens from the Rincons, Station 22 (1917), are pale cinnamon or greenish above, fading to a pale, bluish-gray on the base, the band with narrow, indistinct paler borders or without them. The lip is conspicuously brown-edged. The umbilicus is generally wider than in the Catalina shells. One perfect shell and another broken one in this lot are albinos, or at least the tint is very pale, and there is no band. These shells are found deep in a rock slide in a quaking asp thicket. At Station 20 (1917), on the northern slope of the Rincons, two dead but fresh shells were found in a day's search.

Sonorella odorata marmoris n. subsp. PI. III., figs. 6 to $6 b$.

The shell is more solid than $S$. odorata, opaque; cinnamon, paler around the umbilicus and on both sides of the chestnut-brown band. Last whorl is decidedly more depressed than in S. odorata, and is narrower as viewed from above. The umbilicus is wider. The aperture is much smaller.

Alt. 10.4, diam. $20 \mathrm{~mm}$.; $4 \frac{2}{3}$ whorls (type).

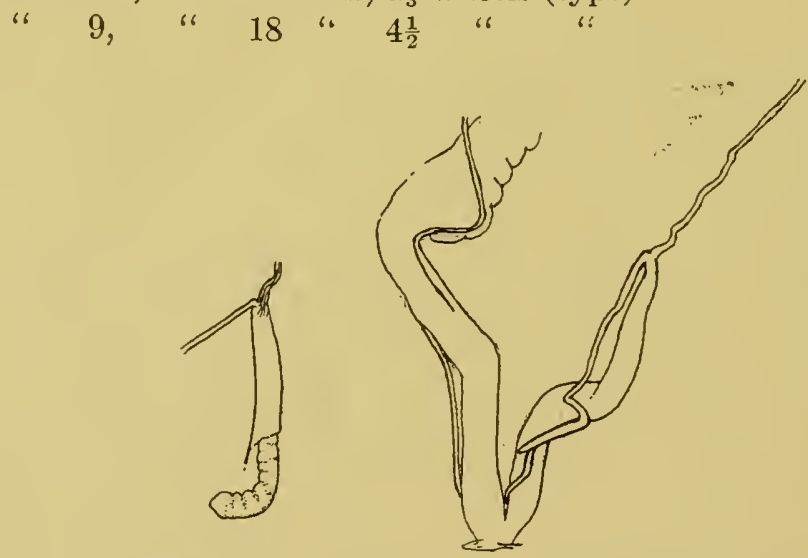

Fig. 2. Genitalia of S. o. marmoris, No. 109,079, with detail of penis-papilla.

Santa Catalina Mountains: Marble Peak, on the east side above the rock slide; old Dan's Gulch on the northwest side, type loc.; ridge running toward Mt. Lemon; Ferriss 1911 and 1913. Type No. 109,075 A. N. S. P.; paratypes 109,075a, also in Ferriss collection.

Genitalia (fig. 2) in general similar to S. odorata but the penis and papilla are decidedly longer and there is a flagellum, well developed for a Sonorella. Measurements of the organs are given in the table on page 287. 
It lives in relatively dry rock slides, with the smooth Sonorella marmorarius, high on Marble Peak and its flanks, thus differing in habits from $S$, odorata. The shell is readily separable from odorata, and perhaps it should be considered a separate species. It has the same peculiar odor.

Sonorella sabinoensis n. sp. Pl. IV, figs. 1 to $5 d$.

The shell is rather narrowly umbilicate (width of umbilicus contained 8 times in that of shell in the type specimen), rather solid; cinnamon-buff, broadly zoned with white (or whitish) on both sides of the chestnut-brown band above the periphery. The surface is glossy; embryonic whorls having the usual sculpture of the hachitana group, granular, with divaricating protractive threads below and retractive above; subsequent whorls delicately marked with growthlines. Suture descends moderately in front. The aperture is large, oblique, rotund-oval. Peristome narrowly expanded, dilated at the umbilical insertion.

Alt. 12, diam. $21.2 \mathrm{~mm}$; aperture $12 \times 13 \mathrm{~mm}$.; $4 \frac{1}{2}$ whorls.

Santa Catalina mountains, Arizona, in Sabino canyon (type loc. Station 16, 1913) and its tributaries, Sycamore canyon and Mt. Lemon Fork, from about 3000 to 6000 feet elevation. Also Rock and Vantana canyons, west of Sabino, and Bear canyon eastward.

It is a species of the dry, sun-baked rock-slides, living ones found only deep in the crevices, in the lower levels of desert vegetation. The Sabino Basin, Sycamore and Bear canyon localities are below the pine belt, in arid country, with some oak, juniper and sycamore. The species is not known to occur in the humid upper forest.

Genitalia (fig. 3, $a-d$ ) resembling those organs in S. marmorarius. The penis is thin, not swollen basally. The penis-papilla is slender and corrugated, as in the other species, and nearly as long as the penis (fig. $3 a$ ). The flagellum is either minute or wanting.

\begin{tabular}{|c|c|c|c|c|c|c|}
\hline Mus. No. & Penis. & Papilla. & $\begin{array}{l}\text { Epiphal- } \\
\text { lus. }\end{array}$ & $\begin{array}{c}\text { Flagel- } \\
\text { luin. }\end{array}$ & Vagina. & \\
\hline 109,097 & 10 & 7 & 8 & 0 & 9 & Type, fig. $3 c$. \\
\hline 109,092 & 9.5 & S & 7 & 0 & 7.3 & \\
\hline 109,094 & 10.5 & 10 & 9 & -1 & 9 & Fig. $3 d$. \\
\hline $109,0.57$ & 9 & 7 & 6 & 0.3 & S. 5 & \\
\hline 109,098 & 8.5 & S & 6.5 & 0.5 & 6.5 & Fig. $3 a, b$. \\
\hline
\end{tabular}

Shells from the type station measure from 20 to $24 \mathrm{~mm}$. diameter. The relative size of the aperture also varies within rather wide limits. In the type specimen (pl. IV, figs. 2-2b) the width of aperture is con- 
tained about 1.63 times in that of the shell, and in another locotype (pl. IV, figs. 3-3b) it is contained nearly 1.8 times. In the smaller mouthed individuals the umbilicus is somewhat larger and less covered, and the last whorl, viewed from above, is not so wide. We have tried in vain to use these characters for a separation of the series (some hundreds of shells); but while the extremes in size of aperture appear quite distinct, the distinction could not be carried through, as nearly every station supplied individuals with large, intermediate and small apertures.

The specimens from low in Sabino canyon usually have more solicl, thicker shells than those from higher; but this is not always the case.

It is a species of the arid mountains, confined to lower elevations than S. marmorarius.

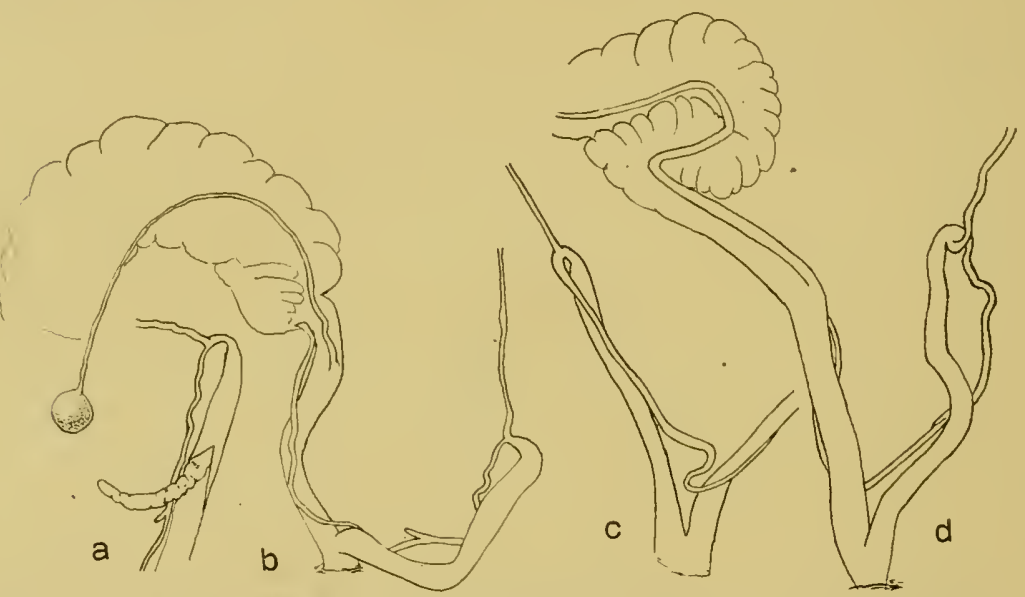

Fig. 3.. Sonorella sabinoensis, Sabino Canyen, genitalia. a, b, No. 109,098; c, No. 109,097 ; $d$, No. 109,094 .

The smallest shells, diam. $19 \mathrm{~mm}$., were found at Station 15, low in Sabino canyon (about 4,000 ft.); but others up to $25 \mathrm{~mm}$. diam. occur in the same place. The largest, $27 \mathrm{~mm}$. diam. are from Station 9, 1913, the bluffs opposite Station 15. One of this lot is figured, pl. IV, figs. 4-4b.

The degree of depression is variable in the same lot. Specimens selected from a station on Vantana canyon measure:

Alt. 14.5 diam. 26, mm. (largest).

" 13.2 " 25, " (most depressed).

" 16.4 " 24.8, " (" elevated).

" 12.2 " 20, " (smallest).

Figures 5 to $5 d$ are depressed and elevated shells from Bear canyon. 
Sonorella sabinoensis occidentalis n. subsp. Pl, V, figs. 1 to $1 b$.

The shell appears indistinguishable from S. sabinoensis.

Alt. 16, diam. 28 mm.; 5 whorls.

\begin{tabular}{|c|c|c|c|c|}
\hline 17.3 & $"$ & 27 & $"$ & \\
\hline 16 & " & 25 & " & \\
\hline 14 & $"$ & 23.7 & 6 & \\
\hline 14 & $" 6$ & 22.3 & $" 6$ & \\
\hline
\end{tabular}

This form is separated from S. sabinoensis solely on account of the difference in the penis, which is enlarged at the base in occidentalis, slender in sabinoensis. While the Pima canyon shells are distinguishable from the large-mouthed typical forms of sabinocnsis, we can find no difference in the sabinoensis with slightly smaller aperture, such as those from Sabino canyon Station 9 (which agree in genitalia with the type of sabinoensis). No specimens with the penis swollen basally were found among the numerous Sabino canyon individuals opened.

The head and back are hair brown, fading to drab on the sides, the tail and entire sole being dull chamois to dull cream-buff.

Western end of the Santa Catalinas; type No. 119,491, from Station 36, east side of Pima canyon. Also on the west side, Station 37 (Pusch Ridge); Station 43 (1917), northeast of Sutherland's ranch, in the foothills; Station 45 , in the large canyon worth of Romero canyon (eastward from Sutherland's).

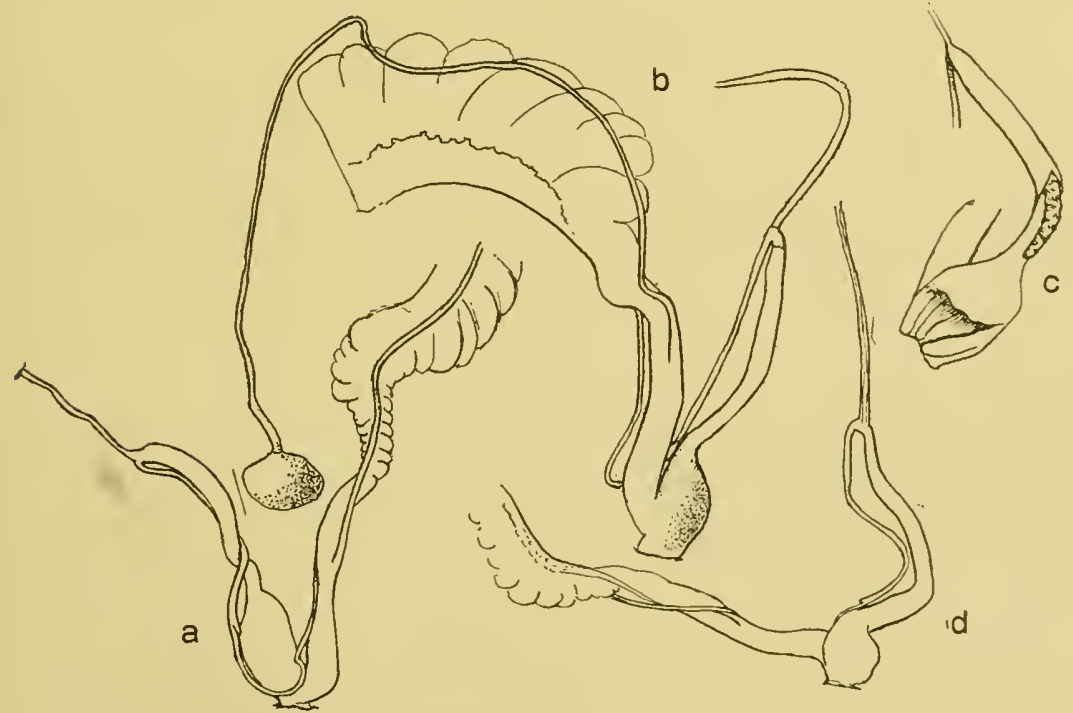

Fig. 4. Genitalia of S. s. occidentalis. a, No. 115,052. b, No. 115,045, with detail of penis and papilla at $c ; d$, No. 118,056, canyon north of Romero Canyon. 
Genitalia (Fig. 4a-d). The penis is slender except at the base where it is suddenly dilated. Internally there is a short, sinuous fleshy fold and several minor folds in the dilated part of the penis where it passes into the atrium, which also contains several fleshy ridges. The papilla is long, slender and corrugated. Penial retractor is terminal and enveloping base of the epiphallus, as usual. The epiphallus is nearly as long as penis, with a slight distal swelling in place of a flagellum. The vagina is shorter than the penis. Measurements of the organs in $\mathrm{mm}$. follow:

\begin{tabular}{|c|c|c|c|c|c|c|c|}
\hline Mus. No. & Penis. & Papila. & $\begin{array}{l}\text { Epiphal- } \\
\text { lus. }\end{array}$ & $\begin{array}{l}\text { Flagel- } \\
\text { lum. }\end{array}$ & Vagina. & $\begin{array}{l}\text { Sperma- } \\
\text { theca } \\
\text { and rluet. }\end{array}$ & Locality. \\
\hline $\begin{array}{l}118,045 \\
11,052 \\
118,056\end{array}$ & $\stackrel{10}{S} .5$ & $\begin{array}{l}8 \\
6 \\
6.5\end{array}$ & $\begin{array}{l}8 \\
7.5 \\
7.5\end{array}$ & $\underset{6}{0}$ & $\begin{array}{l}6 \\
4 \\
6\end{array}$ & $\begin{array}{l}32 \\
23\end{array}$ & $\begin{array}{l}\text { Sta. } 36 . \\
\text { Sta. } 37 . \\
\text { " } 45 .\end{array}$ \\
\hline
\end{tabular}

The series of 60 specimens from Pima canyon consist chiefly of dead shells. The average size appears to be slightly less in the specimens from the western side of the canyon, forming the eastern slope of Pusch Ridge.

There are three "dead" specimens from "Pusa Ridge" ( $=$ Pusch Ridge) in the U. S. National Museum, No. 271,011, collected by Barber. The diameter is about $22 \mathrm{~mm}$.

The specimens from the canyon north of Romero (opening northwestward), Station 45 (1917), have the same range of variation noted in Sabino canyon S. sabinoensis. There are depressed, more openly umbilicate shells, together with smaller, usually less depressed shells with relatively larger aperture and smaller umbilicus, $\frac{1}{3}$ to $\frac{1}{2}$ covered by the expansion of the columellar lip; also a few specimens transitional in these characters. 14 examined.

Alt. 15.4, diam. $27.3 \mathrm{~mm} ., 4 \frac{3}{4}$ whorls (largest).

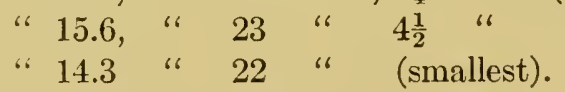

The genitalia do not differ from Pima canyon shells.

Seven shells from Station 43 (1917) measure: diam. 21, 21.5, $23.5,23.7,24,24.4,24.4 \mathrm{~mm}$.

All of the localities for this form are in the arid lower zone of the range.

Sonorella sabinoensis buehmanensis n. subsp. Pl. V, figs. 2 to 3 .

Typically the shell differs from $S$. sabinoensis by being more solid and more elevated, only very slightly paler near the shoulder band, and with nearly one whorl more in examples of the same diameter. 
Alt. 16.7, diam. $25.6 \mathrm{~mm}$; $5 \frac{1}{3}$ whorls (type; Figs. 2-2b).

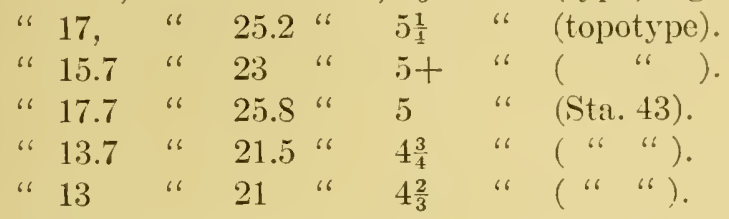

Buehman canyon, in the eastern part of the Santa Catalina Moun-" tains, the type from Station 44 (1913), near the Korn Kobb mine. Also at Stations 41, head of Sycamore gulch, tributary to Buehman canyon, 42, Buehman canyon at the Brush Corral, and station 43, Buehman canyon a mile below the Brush Corral Ranger Station.

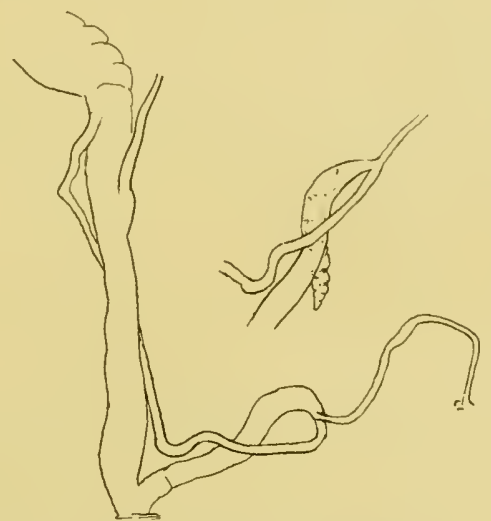

Fig. 5. Genitalia of Sonorella sabinoensis buehmancnsis, No. 109,196.

There is considerable variation in the shells from Buehman canyon, in size, degree of elevation and number of whorls; yet unless anatomical differences are found, we consider them all of one race. As yet, only the typical form has been dissected.

Specimens from Station 41 (1913), from the head of Sycamore Gulch, have the umbilicus slightly more open than in typical buchmanensis, and the borders of the shoulder-band are paler; thus approaching the larger forms of $S$. sabinoensis.

In Stations 42 and 43 the size varies widely, and the smaller specimens have only a fraction of a whorl more than sabinoensis, from which they differ by the smaller aperture. One figured (pl. I, figs. 3-3b, Station 43) measures: alt. 13.7, diam. $21 \mathrm{~mm}$. In the same lots the larger shells have a diameter of $25 \mathrm{~mm}$. or slightly more.

Like other species of the dry lower mountains, living snails are rare. In one rock slicte in Buehman Canyon, 360 fairly good "bones" were found, and only 8 living snails. 
Sonorella hesterna n. sp. Pl. $1 \mathrm{~V}$, figs. $6,6 a, 6 b$.

A long series of dead shells was taken at Station 148 (1917) in a rock slicle on the south side of the Tucson-Benson highway, near the cave on Shaw's ranch, southern foothills of the Rincons, at about 3,500 feet. They are smaller and more solid than S. rinconensis, and the umbilicus is somewhat smaller. It is more depressed and has a vider umbilicus than $S$. sabinoensis. In color and surface it resembles the latter species. The freshest shells are between cinnamon and tawny-olive, fading around the umbilicus, white on both sides of the chestnut-brown band. The suture descends rather abruptly to the aperture, but not quite so deeply as in S. hachitana.

Alt. 13.5, diam. $22.4 \mathrm{~mm}$. (type).

" 14.7 , " 25.9 "

In a series of 37 adult examples, the smallest measures $20.1 \mathrm{~mm}$. in diameter, the largest $25.9 \mathrm{~mm}$. They run as follows:

Diam. 20-20.9 mm., 4 specimens.

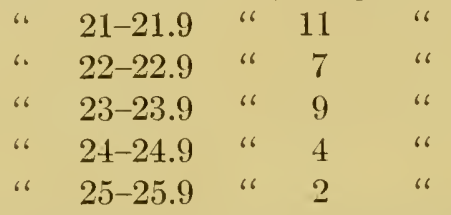

The station is an extremely arid one. It is a true desert Sonorella. The status of the form is uncertain, but it can scarcely be linked with any of the Santa Catalina or Rincon species, so that, while we do not like to describe a Sonorella without examination of the soft anatomy, there seems nothing else to do in this case. Its status may be revised when living examples come to hand.

Sonorella marmorarius n. sp. Pl. IlI, figs. 9, $9 a, 96$.

The shell is depressed, rather solid, umbilicate (the width of umbilieus contained about 7 times in that of the shell, suddenly widening at the last whorl to about double its former width); light pinkish cinnamon, paler around the umbilicus, and whitish on both sides of the chestnut-brown band above the periphery. The surface is glossy. Embryonic shell of $1 \frac{1}{2}$ whorls, the last of which is densely, irregularly granular, with indistinct protractive and retractive threads (when unworn), subsequent whorls delicately marked with growth-lines, and under the lens showing some weak spiral impressed lines in places on the upper surface of the last whorl. The suture descends rather deeply in front. Aperture is quite oblique, oval. Peristome expanded throughout, with a gray edge, somewhat thickened within, the margins generally connected by a roughened callous ridge in fully adult shells. 
Alt. 14 diam. $25 \mathrm{~mm}$; aperture $11.2 \times 13.6 \mathrm{~mm}$; $4 \frac{3}{4}$ whorls.

Marble Peak, Santa Catalina Mountains, Arizona; type loc. Station 26, 1913, quartzite slide on Marble Peak. Also found at Station 3, 1911, slide above Apache mine; Station 4, 1911, top of ridge south of the Peak; Station 38, 1913, north side of Marble Peak; "Joliet Cave," and other stations on the same mountain.

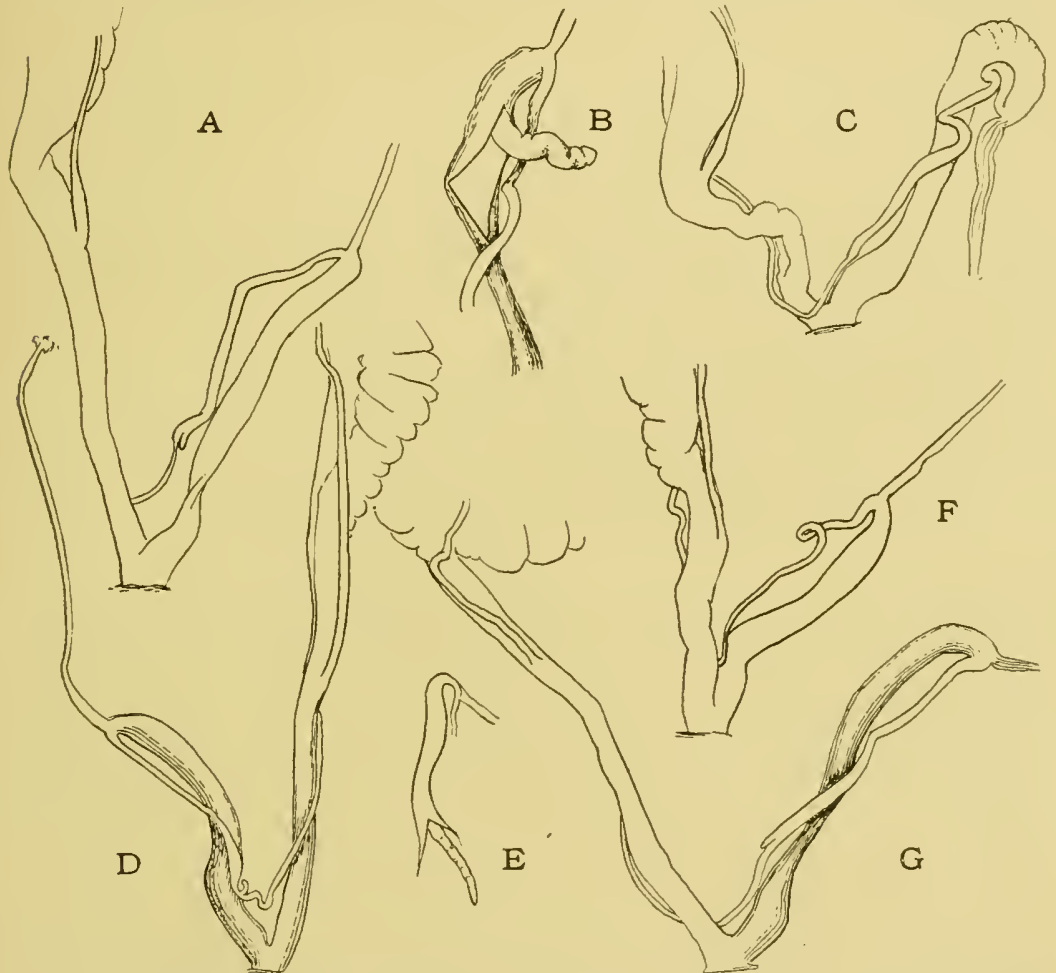

Fig. 6. Genitalia of Sonorella marmorarius, a, No. 109,077; b, c, No. 109,071; d, No. 109,$039 ;$, No. 109,0s3; $f$, No. $109,0 \$ 4 ; g$, No. 109,078.

Genitalia (Fig. $6 a-g$ ). The penis is thin-walled, very weakly or usually not noticeably enlarged near the atrium, containing a slender tapering, corrugated papilla, half to two-thirds or more the length of penis. Epiphallus somewhat shorter than penis, typically terminating in a little flagellum, but this is often rudimentary or wanting. Penial retractor long, inserted on apex of penis and base of epiphallus. The ragina is but little shorter than the penis. Lengths of the organs in $\mathrm{mm}$. follow, the specimens all from stations on Narble Peak: 


\begin{tabular}{|c|c|c|c|c|c|c|c|c|}
\hline Mus. No. & Penis. & Papilla. & $\begin{array}{l}\text { Epiphal- } \\
\text { lus. }\end{array}$ & $\begin{array}{l}\text { Flagel- } \\
\text { lum. }\end{array}$ & $\begin{array}{c}\text { Retrac- } \\
\text { tor. }\end{array}$ & Vagina. & Station. & Fig. \\
\hline 109,078 & 12.5 & 7.3 & S & -1 & & 10 & 26 & $6 \%$ \\
\hline 109,077 & 12 & s & 10 & 1 & 8 & 11 & 26 & fre. \\
\hline 119,039 & () & 6 & 7.3 & 1 & 12 & 8.5 & 4(1911). & $6 \%$. \\
\hline 119,040 & 10) & 5.5 & 7 & 0.5 & & 9.5 & $3(1911)$. & \\
\hline 109,074 & 11.5 & 10 & 9 & 1 & & 9 & & \\
\hline 109,053 & 5.5 & 7 & & $0 . \overline{5}$ & & 7 & 22 & $6 e$. \\
\hline $109,0=4$ & 9 & 7 & & 0 & 11 & 5.5 & & $f f$ \\
\hline $109,0<0$ & 12.5 & 6 & & 0 & & 7 & 39 & \\
\hline 109,071 & 11.5 & 6 & 7.3 & 0 & & 6 & Cave & $6^{1}$, \\
\hline
\end{tabular}

This species is closely related to S. hachitana (Dall) and S. compar Pils. It has the peristome more thickened within than the former and differs from $S$. compar ${ }^{3}$ by the more solid shell, more thickened peristome, ete.

The more wiclely open umbilicus distinguishes it readily from other Sonorellas of the hachitana group found in the Santa Catalinas.

Other specimens of the original lot from the type locality measure:

Alt. 15 diam. $26.3 \mathrm{~mm}$. Alt. 13.8, diam. $24 \mathrm{~mm}$.

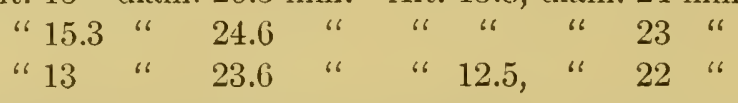

The largest examples were taken at Station 3 , two measuring: Alt. 16.4, diam. $28.2 \mathrm{~mm}$.; 5 whorls.
" 17
28
" 5

Marble Peak and Apache Camp have oak, juniper and sycamore wood on the lower slopes; the crest of the ridge, the head of the main "slide," is in the pine belt.

Sonorella marmorarius limifontis n. subsp. PI. III, figs. $5,5 a, 5 b$.

The shell is depressed, openly umbilicate (the width of umbilicus contained 7 times in that of the shell); whitish, faintly buff near the suture and on the spire, having the usual chestnut-brown band. Last whorl wide, very deeply descending in front. Surface glossy; weakly marked with growth-lines as in related species of the hachitana group, and showing weak traces of impressed spiral lines on the upper surface of the last whorl. The last whorl descends deeply and abruptly in front. The aperture is very oblique, rounded-oval. Peristome somewhat expanded, slightly thickened within.

\footnotetext{
${ }^{3}$ Sonorella comnar, new name for Sonorella ashmuni Pils., Proc. A. X. A. Phila. 1905, p. 259, pl. 17, figs. 9-14. Not S. ashmuni Bartsch.

()n eomparison with the type of S. ashmuni, this species is seen to differ conspienously by the more depressed and more openly umbilicate shelf.-H.A.I'.
} 
Alt. 13.3, diam. $22.3 \mathrm{~mm} . ; 5$ whorls.

" 14 " 23 " scarcely 5 whorls.

" 16 " 26.5 " 5 whorls.

Santa Catalina Mountains at Station 17, bluffs near Mud Springs, on Pine Canyon.

The last whorl descends more than in S. marmorarius, the aperture is more oblique, and the color of adults is paler. The immature shells have more of a cinnamon tint than the adults.

The spiral lines mentioned in the description are usually very faint, often scarcely discemible, but in the largest example they aro quite distinct. The umbilicus sometimes varies to somewhat smaller than in the type specimen.

Mud Springs, on Pine Canyon, a branch of Sabino above Sabino Basin, is a walled hole in the mud. It is on the trail from Sabino Basin to Soldicr's Camp, the elevation about 7,000 ft. It is in the pine zone. The Sonorella was found in the first rocks east of the spring along the trail. Also at the foot of a high cliff, in stratified "porphyry," in a ravine heavily wooded with cypress (Cupressus arizonica), about a mile southeast of the springs.

Sonorella marmorarius imula n. subsp. Pl. III, figs. $7,7 a$.

At Stations 17 and 19 (1917), on a limestone hill 6 miles west of Brush Corral Ranger Station, north of Alder Springs, in the northern: foothills of the Catalinas, many specimens were taken, chiefly dead, differing from typical marmorarius by the somewhat darker color, and by having about a half of a whorl more in examples of similar diameter.

Alt. 26.5, diam. $15 \mathrm{~mm}$; $5 \frac{1}{3}$ whorls.

Eighty-five specimens from Station 19, all of the adults collected, measure as follows:

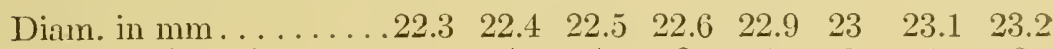
Number of specimens. . $11 \quad 1 \quad \begin{array}{lllllll}1 & 1 & 3 & 1 & 3 & 1 & 3\end{array}$

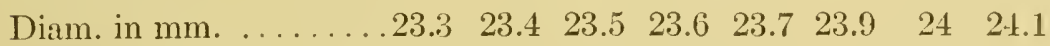

Number of specimens... $2 \begin{array}{llllllll}2 & 3 & 2 & 2 & 3 & 1 & 4 & 2\end{array}$

Diam. in $\mathrm{mm} \ldots \ldots \ldots \ldots 24.2 \quad 24.3 \quad 24.4 \quad 24.5 \quad 24.6 \quad 24.7 \quad 24.8 \quad 24.9$

Number of specimens. . $\begin{array}{lllllllll}6 & 2 & 6 & 4 & 5 & 3 & 2 & 3\end{array}$

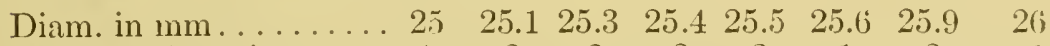

Number of specimens... $4 \begin{array}{llllllll}4 & 2 & 2 & 2 & 2 & 1 & 2 & 1\end{array}$

Diam. in mm........26.2 $26.3 \quad 26.4 \quad 26 . \overline{5}$

Number of specimens... 1110101 
As the error in measuring may be at least $0.1 \mathrm{~mm}$., it will be seen, if a curve is plotted, that the mode for diameter is at about $24.4 \mathrm{~mm}$., and the total variation $2.1 \mathrm{~mm}$. in either direction.

A specimen having the umbilicus exceptionally narrow is illustrated in pl. 4, figs. $8-8 b$. The spire is also narrower than in the typical form; yet it seems unlikely that there is more than one species in the lot.

Sonorella galiurensis n. sp. Pl. V, figs. 5 to $6 b$.

The shell is umbilicate (the width of umbilicus contained about 9 times in that of the shell), between cinnamon-brown and sayalbrown in color, fading on the base, and much paler on both sides of the broad chestnut-brown band above the periphery. Glossy; embryonic whorls closely pitted-granulate, with the usual protractive threads; subsequent whorls lightly marked with irregular growthlines. The last whorl is wide and descends somewhat in front. The peristome is narrowly expanded. The parietal callus usually has a thickened edge in fully adult shells.

Alt. 16.7, diam. 27.5 mm.; 5 whorls. (type, Sta. 30).

$\begin{array}{llllllll} & 16, & \text { " } & 27.4 & \text { " } & 5 & \text { " } & \text { (Sta. 30). } \\ & 16.4, & \text { " } & 25 & \text { " } & 5 & \text { " } & \text { (Sta. 30). } \\ & 16.7 & \text { " } & 30.5 & \text { " } & 5 & \text { " } & \text { (Sta. 34). }\end{array}$

Galiuro Mountains at the following Stations (1917):

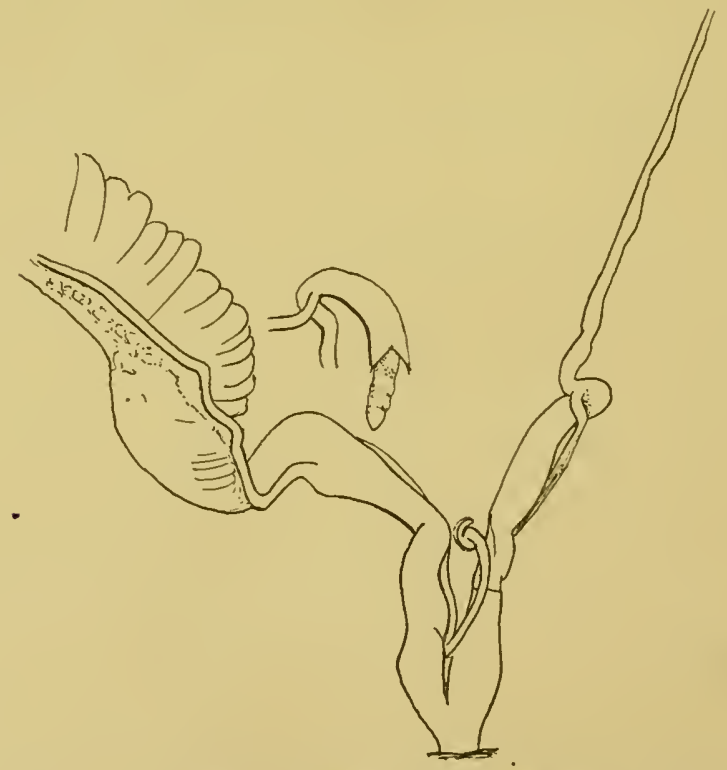

Fig. 7. Genitalia of Sonorella galiurensis, No. 118,122. 
24. Southern slope of mountains at eastern gate of John Rhodes' ranch, among boulders on mesa.

26. Rhodes' canyon.

27. Northern slope, amphitheatre on Whitlock ranch.

23. Foot of main gulch facing north, same amphitheatre.

29. Farther up same gulch.

30. "Porphyry" slide on trail $1 \frac{1}{2}$ miles south of Copper Creek Mining Camp. Type locality.

31. Camp at smelter, Copper Creek.

32. Rock slide sloping west, on trail half way between Copper Creek Camp and Table Mountain.

33. "Porphyry" slide in forks of creek 2 miles east of Table Mountain.

34. Slide near the preceding.

35. Cliffs on northeastern slope of Table Mountain.

Genitalia (fig.7). The general proportions are as in S. marmorarius. The penis has a long, very thin sheath about the basal part, not seen in marmorarius; its lower portion is somewhat swollen and has several small longitudinal folds within. Retractor muscle long. Papilla weakly annulate, about half as long as the penis. There is the usual short flagellum. The ragina about equals the penis in length.

Length of penis ......10 $\mathrm{mm}$.

papilla ....5 "

epiphallus....7 "

flagellum . . . . . . . " "

vagina $\ldots \ldots .9$ "

Museum No.........118,122.

This form is much like $S$. marmorarius. The shell is slightly more capacious and darker colored, and there is some difference in the penis. Its habitat is separated from that of marmorarius by the valley of the San Pedro River. The elevation is much less than that inhabited by $S$. marmorarius.

20 living specimens from Station 30, all taken, measure as follows:

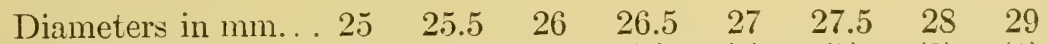

No. specimens $\ldots(1) \quad(1) \quad(2) \quad(2) \quad(3)$
17 specimens from Station 24 , a southern slope:

$\begin{array}{lllllllll}\text { Diameters. . . . . 24 } 24.5 & 25 & 26 & 26.5 & 27 & 28 & 28.5 & 30.5\end{array}$

No. specimens.... (1) (2) (3) (2) (4) (1) (2) (1) (1)

Sonorella tortillita n. sp. PI. T, figs. $4,4 a, 4 b$.

The shell is umbilicate (width of umbilicus contained about $8 \frac{1}{2}$ times in that of the shell), pinkish buff, fading to white around the umbilicus and paler near the chestnut-brown band which revolves above the periphery of the last whorl and shows very narrowly above the suture on most of the penult whorl. The surface is glossy; 
embryonic shell about $1 \frac{1}{3}$ whorls, the first half whorl having some radial wrinkles, the rest of the embryonic portion closely irregularly granulose, and having fine, rather indistinct, tangential (protractive) threarls, often visible only near the suture. Subsequent whorls have the usual fine growth-lines. The whorls increase slowly at first, the last one very wide, suture descending slightly in front. The aperture is rounded oval-lunate. Peristome is well expanded.

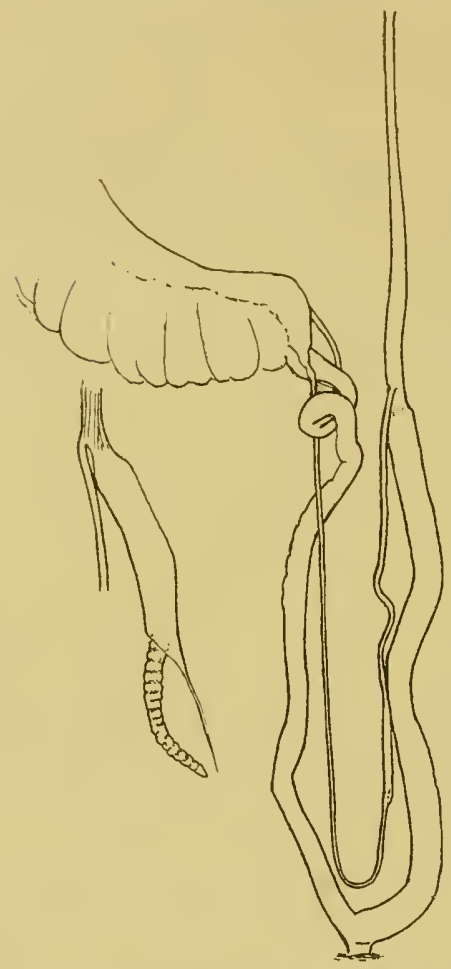

Fig. 8. Genitalia of Sonorella torpapilla. tillita with detail of the penis-

Alt. 15.5 , diam. $27 \mathrm{~mm}$; aperture alt. 14.3 , width $15 . \mathrm{S} \mathrm{mm}$.; $4 \frac{2}{3}$ whorls.

Tortillita Mountains, Pinal Co., Arizona, the type, No. 118,053, from Station 41 (1917), east side of $\mathrm{Hog}$ Canyon; also found at Station 40, west side of same canyon near the cement dam, and Station 42, south slope of mountains east of $\mathrm{Hog}$ Canyon.

Genitalia (Fig. 8). The penis is very long and rather slender, with muscular walls, containing a long, slender, corrugated, tapering papilla. The epiphallus is shorter than the penis, without a distinct flagellum, though there seems to be a rudimentary one concealed in the integument. The penial retractor is long. Length of vagina is about equal to the penis.

By the long penis and vagina this species is related to $S$. rinconensis, but in that snail these organs are far longer. S. santaritana is even more like S. tortillita in genitalia, but the shell is flatter, the whorls of smaller caliber. None of the Santa Catalina species has the vagina and penis nearly so long as in S. tortillita. The larger shells referred to $S$. sabinoensis occidentalis are closely similar.

The embryonic sculpture described is in large part effaced in the fully adult shells found. The color, too, is somewhat faded. In the young and barely full-grown examples it is decidedly darker than described. 
The largest specimen from the type locality measures 17.2x28.6 $\mathrm{mm}$.; the smallest, $12.5 \times 23.2 \mathrm{~mm}$.; very few are under $25 \mathrm{~mm}$. diameter. The largest shell in the lot from the west side of Hog Canyon measures $17.5 \times 30 \mathrm{~mm}$.

The Tortillitas are arid mountains without forest.

Sonorella rinconensis Pils. \& Ferr.

Sonorella rinconensis PilsBry \& Ferriss, Proc. A. N.s. Phila. 1909, p. 517, fig. 1, pl. 22, figs. 1-3, 5, 7.4

Rincon range: Rincon Peak and Wrong Mountain; Mt. Mica, only those from Rincon Peak dissected. This species was not encountered in the localities visited in 191\%. It inhabits elevations above $7,500 \mathrm{ft}$., occurring in granitic rocks.

Thysanophora hornii (Gabb).

Santa Catalina Mountains: Stations 3 and 9, near mouth of Sabino Canyon, 4,500 ft. Station 13, mouth of Bear Canyon, 4,500 ft. Station 40, Alder Springs, 8,000 ft. Southern foothills of Rincon Mountains near the cave, Station 191 (1918). Galiuro Mountains.

Thysanophora ingersolli (Blaud).

Santa Catalina Mountains: Mt. Lemon at Stations C, 19, 31, 34,37 , etc., at 9,000 to $9,500 \mathrm{ft}$.

Gonyodiscus cronkhitei (Ne.)

\section{ENDODONTID丑.}

Santa Catalina Mountains: Station 21, Desert Laboratory Plantation, 8,500 ft. Soldier Camp. Bear Wallow. Around Mt. Lemon at Station C, spring on west side; Station 19, Congdon's Cabin; Station 28, marshy spring; Station 37; Station 22, old Lemon trail; Station 31, aspens, new trail; Station 34, 9,000 to 9,500 ft.

Rincon Mountains: Spud Rock and Catalina saddle.

Radiodiscus millecostatus Pils. \& Ferr.

Santa Catalina Mountains: Environs of Mt. Lemon, Stations C, $19,28,30,31,34,37$ and some others, at elevation of 7,000 to $9,500 \mathrm{ft}$. Bear Wallow. Kellogg Peak. Generally distributed and locally very abundant, especially in the aspen zone.

Helicodiscus arizonensis P. \& F.

Santa Catalina Mountains: Station 1, near weir, Sabino Canyon, 4,500 ft. Station 27, Bear Wallow. Marble Peak at Station 25, $8,500 \mathrm{ft}$., and Station 26, 8,000 ft. Rincon Mountains: Spud Rock. Galiuro Mountains, Station 24 (1917).

${ }^{4}$ The reference to figures " $1-1,7$ " as given in our paper was incorrect. 
Punctum californicum Pils.

Santa Catalina Mountains: trail from Webber's to Lemon Mountain.

Vitrina alaskana Dall.

\section{VITRINID \#世.}

Santa Catalina Mountains: Station 37, north side of MI. Lemon $9,000 \mathrm{ft}$; ; trail to Webber's place.

\section{Polita indentata umbilicata (Ckll.).}

Santa Catalina Mountains: Station A, Bear Wallow Creck. IVest side Mt. Lemon at Station C. Marble Peak at Stations 25 and 26, 8,000-8,500 ft. Trail from Webber's place to Mt. Lemon. Alder Spring. Rincon Mountains at Station 21 (1917), Catalina Saddle, and Spud Rock. Galiuro Mountains, Station 24.

Striatura milium meridionalis (P.\& F.).

Santa Catalina Mountains: Station A, Bear Wallow Creek; Soldier's Camp; Station 21, Desert Laboratory plantation, 8,500 ft.; Mt. Lemon at Stations 22, 28, 31, 37, at 9,000 to 9,500 ft.; trail to Webber's Cabin; Alder Spring.

Zonitoides arborea (Say).

Santa Catalina Mountains: Station 21, Desert Laboratory plantation, 8,500 ft. Soldicr Camp. Stations 19, 22, 37 on Mt. Lemon, at about $9,000 \mathrm{ft}$. Station 25, northwest ridge of Marble Peak, S,500 ft. Rincon Mountains, Station 20 (1917).

Zonitoides minuscula alachuana (Dall).

Santa Catalina Mountains: Mt. Lemon, Bear Wallow; Kellogg Peak and Alder Spring. Rincon Mountains.

Zonitoides singleyana (Pils.).

Rincon Mountains.

Euconulus fulvus (Mull.).

Santa Catalina Mountains: Alder Springs. Soldier Camp. Station 27, Bear Wallow Creek. Mt. Lemon at Station C, 19, 22, 28, 30, 31,34 . Common up to $9,500 \mathrm{ft}$. Ridge from Marble Peak, southwest, $8,500 \mathrm{ft}$; south side of Marble Peak. Rincon Mountains.

Vallonia cyclophorella Ckll.

\section{VALLONIID正.}

Santa Catalina Mountains: Mt. Lemon at Stations 19, 22, 30, 31, 37, at about 9,000-9,500 ft. Marble Peak, quartzite slide on south sicle, $8,000 \mathrm{ft}$. 
Vallonia perspectiva Sterki.

Santa Catalina Mountains: Marble Peak, in quartzite slicle on south side, 8,000 ft., rare. Galiuro Mountains: Whitlock ranch on the northern slope.

Pupoides marginata (Say).

\section{PUPILLID $\approx$ 瓜.}

Southern foothills of Rincon Mountains near the cave, Shaw's Ranch, Station 148 (1918).

Pupilla hebes (Ancey).

Santa Catalina Mountains: Mt. Lemon, at head of the aspen gulch, and $\frac{1}{4}$ mile below, on the new trail, 9,500 ft., and on the north side, 9,000 ft. Among those from the last locality, Station 37, 6 out of 128 were albinos. Station 22, ridge near Marshall Pass. It occurred in some abundance in all the localities except Station 22.

Pupilla hebes nefas Pils. \& Ferr.

Pupilla hebes form nefas P. \&. F., Proe. A. N. S. Phila., 1910, p. 135.

Santa Catalina Mountains: Station 20, northeast side of Kellogg Peak, 8,500 ft., Station 27, Bear Wallow, 214 specimens. Soldier Camp, 63 specimens. Station 21, Desert Laboratory Station, 8,500 ft., 84 specimens. Station 22, ridge near Marshall Pass, rare. Station 29, Leaning Rock, south side Mt. Lemon, 9,500 ft., 15 specimens. Station 25, ridge of Marble Peak towards Mt. Lemon, 8,500 ft., 57 specimens. Station 26, "quartzite" slide on Mt. Lemon, \$,000 ft., 2 specimens. Station 2S, marshy spring near trail, Mt. Lemon, 1 specimen. Rincon Mountains: Spud Rock; Catalina Saddle.

$P . h$. nefas almost always has a small parietal tooth, and is usually a little longer than $P$. hebes, with between 6 and 7 whorls. It differs from $P$. syngenes by having no crest behind the lip, though there is usually a shallow, wide depression there.

In only one of the numerous stations mentioned above were hebes and nefas found together. That was Station 22, where very few shells were taken. Lots from all of the other stations, frequently copious, were either all hebes or all nefas.

Elsewhere $P$. h. nefas has been found only in two places in the Chiricahua Mountains, at elevations estimated from 7,500 to 8,000 $\mathrm{ft}$. It was not associated there with dextral hebes, which was found at another Chiricahua locality. We are now disposed to rank $P . h$. nefas as a well-marked subspecies.

Chaenaxis intuscostata (Clapp).

Southern foothills of the Rincons, near the Tueson-Benson highway, near the cave, Shaw's ranch, at about $3,500 \mathrm{ft}$. 
Gastrocopta ashmuni (Sterki).

Santa Catalina Mountains: Slicle on Marble Peak, 8,000 ft., rare.

Galiuro Mountains: Whitlock ranch, on the northern slope.

Gastrocopta cochisensis (Piis. \& Ferr.).

Santa Catalina Mountains: Alder Springs and Station 25, southwest ridge of Marble Peak, 8,500 ft. The shells were dirty when collected, like B. quadridens.

Gastrocopta dalliana (Sterki).

Santa Catalina Mountains: Station 3, mouth of Sabino Canyon, $4,500 \mathrm{ft}$.

Gastrocopta pellucida hordeacella (Pils.).

Southern foothills of Rincon Mountains near the cave, Shaw's ranch, Station 148 (1918), at about $3,500 \mathrm{ft}$.

Gastrocopta bilamellata (St. \& Clapp).

Galiuro Mountains.

Gastrocopta quadridens (Pils.).

Santa Catalina Mountains: Stations 30,31,37, and all around MIt. Lemon at 9,000 to 9,500 ft. Soldier Camp, one specimen. When found alive, the shell is rather copiously plastered with dirt, probably attached by the mucous of the animal.

Gastrocopta pilsbryanz (Sterki).

Santa Catalina Mountains: Station 3, mouth of Sabino Canyon, 4,500 ft. Alder Springs, very abundant. Station 27, Bear Wallow. Station 18, Soldier Camp, 8,500 ft. Station 21, Desert Laboratory plantation, 8,500 ft. Station 22, near Marshall Pass, old Mt. Lemon trail, 9,000 ft. Station 28, marshy spring, Mt. Lemon trail, 9,000 ft. Trail to Webber's cabin. Station 31, north side of Mt. Lemon. Station 26, quartzite slide on Marble Peak, 8,000 ft. Galiuro Mountains at Whitlock ranch. Rincon Mountains: Spud Rock.

Cochlicopa lubrica (Müll.).

\section{FERUSSACID Æ}

Santa Catalina Mountains: Station 25, ridge to peak Mt. Lemon, 8,500 ft.; Station 26, slide on Marble Peak, 8,000 ft. Rincon Mountains: Spud Rock.

Vertigo modesta insculpta Pils.

The shell is similar to $V$. modesta in contour, but differs by being closely and rather sharply striate on the intermediate whorls; the first whorl smooth, the last less striate than those preceding. There 
is a narrow but moderately high erest close behind the outer lip. The color is chestnut-brown, becoming paler towards the apex. I'hen alive both animal and shell are black. Teeth fine, a small supraparietal denticle being developed. The parietal and lower palatal folds are rather large. Length 2.6, diam. $1.35 \mathrm{~mm}$; $5 \frac{1}{2}$ whorls.

Except in external sculpture, this form resembles $V$. modesta from Alaska, figured in Proc. A. N. S. Phila. for 1900, pl. 23, fig. 2. By its sharp striation $V . m$. insculpta is quite distinct from all other large Vertigos of the Rocky Mountains, but there is a smaller form of 1 . modesta in Labrador which is striate on the spire.

It is very abundant between 9,000 and $9,500 \mathrm{ft}$. on MIt. Lemon, in and near the aspen zone, where several hundred specimens were collected.

Very beautiful albino specimens occurred in the colonies from Stations 30, 31, and 37, Mt. Lemon.

Other localities for $V$. m. insculpta are: Santa Catalina Mountains: Soldier Camp. Mt. Lemon at Stations 19, 22, 28, 30, 31, 34,37 , at 8,500 to $9,500 \mathrm{ft}$.

Vertigo coloradensis inserta Pils.

In the original V.c. basidens from Bland, New Mexico, there is one parietal tooth and the basal is at the foot of the columella, remote from the lower palatal. In the Santa Catalina series there is often a small angular lamella, and the basal fold stands close to the lower palatal.

This form replaces $V . c$. basidens in the Canadian zone of the Santal Catalinas. The type is from Bear Wallow.

Santa Catalina Mountains: Desert Laboratory plantation, 8,500 ft.; Bear Wallow Creek, 8,500 ft.; Soldier Camp. Mt. Lemon at Stations 19, 22, 28, 31, 9,000 to 9,500 ft.; Alder Springs. Rincon Mountains at Station 20.

$V$. c. inserta differs from $V$. c. arizonensis by the development of a basal fold, and all of the teeth are larger.

Recent studies of the group have convinced us that Vertigo columbiana utahensis Sterki is identical with V. coloradensis Ckll. The former name is therefore superfluous. Our record of $Y$. c. vitahensis from the Chiricahua Mountains, in these Proceedings for 1910, p. 144 , should be changed to $V$. coloradensis.

Gundlachia californica Rowell.

\section{ANCYLID平}

Santa Catalina Mountains: Sabino Canyon, at Alkali Spring, Lowell U. S. Ranger Station, on leaves of Plantinus urighti. 
Very few examples are in the Gundlachia stage; none were found in the septate stage. Many have the narrow, high, oblique shape of septates, but without septum. Many of them reached the normal size of septates, then had a resting stage during which the shell became blackened, subsequently resuming growth along the margins, forming a narrow, oblique shell somewhat like $A$. parallelus in outline. Other examples become wider, about as in $A$. rivularis, in the second period of growth. The early stages are similar in all, having the usual Ferrissia sculpture.

Those individuals in the Gundlachia stage do not appear specfically separable from $G$. californica.

Physa virgata Gld.

\section{PHYSID正.}

Small specimens which appear to belong to this species were taken in lower Sabino Canyon, with Gundlachia.

List of Collecting Stations in the Santa Catalina, Rincon, Tortillita and Galiuro Mountains.

For the Santa Catalinas and Rincons, these stations can be located and approximate elevations ascertained by reference to the U. S. Geological Survey topographic map, Tucson Quadrangle. As different sets of station numbers were unfortunately used in different years, these numbers can only be used in connection with the dates.

\section{SANTA CATALINA}

\section{Stations of 1913 (J. H. F.)}

1. Silhino Canyon, bluffs on east side of creek at water gauge dam. Elcration about $4,500 \mathrm{ft}$.

2. Same, quarter mile farther up.

3. Rock slides near camp at "Picnic Grounds," Sabino Canyon.

t. Slide north of camp, 4,800 ft.

j. Nountain east of camp.

(6. About 2 miles along trail to Soldier's Camp. 5,000 ft.

7. Spring near Ranger Staticn at mouth of Sabino Canyon (Physa and Gundiachia) $4,500 \mathrm{ft}$.

s. Mouth of Sabino, foot of bluff, west side. $4,500 \mathrm{ft}$.

9. Rocks 1 mile above camp.

10. Vantana Canyon at its mouth; a small dry canyon next west of Sabino, not named on topographic map. $C a .4,500 \mathrm{ft}$.

11. Rock Canyon, in "quartzite" bluff. This is the second small canyon west of Sabino. About 4,500 feet.

12. Vantana Canyon, west side of east mouth. Same elevation.

13. Bear Canyon, east side. 14, same, west side, near 13.

15. Mile above camp in Sabino, on inountain slope, west side. About $5,000 \mathrm{ft}$.

16. Slide below prcceding, about the same elevation.

17. First rocks below Mlud Springs, on Pine Canyon (a branch of Sabino above Sabino Basin). Mud Springs are about 9 miles south of Soldier's Camp. tbout $7,000 \mathrm{ft}$.

1S. Soldier's Camp. 
19. Congden Camp.

20. Northeastern side Fiellogg Peak.

21. Carnegie Desert Laboratory experiment station, Marshall Pass.

22. Ridge running down east side Lemon Mountain.

23. Ridge rumning south from Soldier's Camp towards Mud Springs.

24. IVest side of I Iarble Peak ridge.

25. Top of same ridge.

26. "Quartzite" slicle south side of Marble Peak (same as Station 3, 1910;

station 4,1910 , is the top of same slide).

27. Riclge south of Hinkley Camp.

28. Marshy spring on Lemon Mountain trail.

29. Leaning Rock, south side Lemon Mountain.

30. Aspen Gulch, parallel with main trail to Lemon Mountain. 31, quarter mile below 30 , where gulch is close to trail. 32 , quarter mile farther down. 33, foot of trail at the stream. Little shells very abundant at these stations and the next.

34. Cold Spring.

35. Southeast side of Marble Peak, about Apache Camp and "Joliet Carc."

36. Northwest side Marble Peak near "Old Dan's Cabin."

37. Trestfall's mine.

3. North side Marble Peak near the Daley mine.

39. Goodale's house.

40. Alder Spring, Peck Canyon (one of the head branches of Buehman Canron). Alder Spring is about 12 miles east of Soldier's Camp Ranger station; Brush Corral Ranger Station is about 8 miles farther down Buehman Canyon.

41. Buehman Canyon: "Quartzite" slide, Sycamore Spring.

42. Buehman Canyon: Forest Ranger pasture ncar lower fence, Brush Corral.

43. Buehman Canyon. Lower on the stream, towards Korn Kobb mine.

44. Buehman Canyon. Near the mine.

45. John Lyon's mountain (east of San Pedro River and Rincon Mountains, north of the Little Dragoon Mountains). The rock is granite, and only Thysanophora hornii was found.

\section{Stations of 1917 (J. H. F.). \\ (Sarta Catalina Range.)}

12. Main fork of Sabino Creek, at camp in Sabino Basin.

13. Head of Bear Creek (Gundlachia and Physa).

14. Head of Bear Canyon.

15. Northeast corner of Sahino Basin, on trail to Soldier's Camp. Boulder dykes along gulches.

16. Same as Station 12, in slikles of mountain facing north.

17. Southrest side of Sabino Basin, big mountain in the "Window Range."

18. Brush Corral, crossing of Peck Canyon, Alder Siprings.

19. Limestone mountain in foothil!s of S. Catalinas, San Pedro slope

\section{(Pincon Mlountains.)}

20. North sicle of the high Rincon peaks.

21. Saddle camp, between santa Catalinas and Rincons.

22. Ridge west of spud Rock Ranger Station, in aspens.

23. Drift debris of San Pedro River above Mamnoth.

\section{(Galiuro Mountains.)}

24. Drift of boulders near southeast gate of the forest reserve pasture.

25. In slicles, creek bank, above John Rhodes' ranch house.

26. In slides head of the same gulch as 2.).

27. In No. 4 slope in amphitheatre of the mountains on Whitlow ranch, east of sombrero Peak.

28 and 29 . Other slides in the same vicinity.

30. On trail two miles south of Copper Creek mining camps. 
31. Slide west arross gulch from smelter, Copper Creek.

32. On trail to Table MIountain about half way from last station.

3i3. West of abandoned copper eamp, creek running north, east of Table Mountain, in slide east of said creek.

$3 t$. Slides in same vieinity.

35. Cliffs, northeast rim of Table Mountain.

\section{(Western slope of Santa Catalina Range.)}

36. East side of Pima Canyon.

37. West side of Pima Canyon.

35. Drift debris of Pima Canyon.

39. Fork of the Canada del Oro near the foot of Marble Peak.

43. Northeast of Sutherland's ranch, in the foothills.

44. First large canyon north of Romero Canyon, and south of the Sutherland raneh.

4j. About one mile east of Station 44 .

(Tortillita Mountains.)

40. West side of Hog Canyon, in basin near cement dam.

41. East side of Hog Canyon, on the mountain top.

X-Mountains of the Gila Headwaters: The Blue and

White Mountains, Arizona, and the Mogollon Mountains, New Mexico.

The malacological survey of these ranges, which lie in Graham, Apache and Greenlee counties, Arizona, and Socorro county, New Mexico, was begun by one of us (Ferriss) in 1913, and continued by Ferriss and L. E. Daniels in 1914 . In 1900 Dr. E. O. Wooten, well known for his work on New Mexican botany, made a ten-day trip in the Mogollons, in course of which he crossed the range from Willow Creek to Mogollon and ascended the eastern flank of Mogollon Peak to almost 9,000 feet. The type of Ashmunella mogollonensis was collected on this occasion. So far as we know, no other mollusks had been taken in the region of the Gila headwaters prior to the collections here described.

A few mollusks collected between the San Pedro River and Clifton, Arizona, are included, as they are geographically intermediate between the regions considered in articles IX and $\mathrm{X}$.

Early in September, 1913, Ferriss left Tucson with Frank Cole, the guide of tourists and naturalists, for MIt. Thomas in southern Apache county, 11,496 feet above sea level. Traveling by wagon, brief stops were made in the Graham Mountains and upper end of the Peloncillo range. At Clifton the wagon was stored, saddle horses and pack mules secured, and the trail followed to Metcalf.

From Clifton to the Double Circle ranch on Eagle Creek it is rough country, mostly forested, and with sufficient rock for snail cover, but the snails do not like it. The trail here ran northwesterly 
for about 35 miles, then directly north 16 miles on Eagle Creek to the southern rim of the Blue Mountains. Pupas and Vallonias were found at Honeymoon Ranger Station, and Oreohelix a mile or two farther on, fifty miles from Clifton.

The rim of the Blue has a wall of broken granite. We found Ashmunella mogollonensis and a grayish form of Oreohelix cooperi, the latter also in the quaking asp and cork-bark fir groves of the vicinity.

The route lay northwesterly again, across the K. P. cienaga, down Corduroy and Fish Creeks and across Black River, to Reservation Creek in Apache Co. This high plateau has a continuous forest of the largest yellow pine, blue spruce, Douglas spruce, thickets of quaking asp and alder. Pupx and Oreohelix were the principal snails. Few were found on the dome-like summit of Mt. Thomas.

Along Black river Oreohelices, from pale to nearly black, from high to low, were in every rock pile.

On the return trip the Raspbery trail from the rim of the Blue Mountain to Cosper's ranch on the Blue river was taken. Down the Blue and San Francisco rivers Ashmunella, Sonorella and Oreohelix were found in the slides investigated, but the journey was a hurried one. This ground was thoroughly covered in the journey of 1914 .

An account of the journey of 1913 may be found in Nautilus for January, 1919.

On the expedition of 1914, Ferriss was accompanied by Mr. L. E. Daniels. ${ }^{5}$ Part of the route taken in 1913 was retraced-from Clifton, Graham Co., Arizona, up the San Francisco and Blue Rivers to Cosper's ranch, a distance of about 50 miles. From this point they continued up the Blue River, northeast, to its head, and to Luna, Socorro Co., New Mexico. From Luna the party turned southeast, across the San Francisco Mountains (which lie south of Luna), and by way of Alma to the Mogollon Mountains. Some account of this trip was given in Nautilus XXVIII, February, 1915. pp. 109-113. The Ashmunellas collected were described and figured in Nautilus XXIX, June, July and August, 1915, to which the reader is referred for these matters. A map showing the collecting stations in the Mogollons may be found on page 331 .

\footnotetext{
5 We have to record the death of Mr. Daniels, October 23, 191s. He was a companion of both authors on collecting trips of some months' duration, and it is a real sorrow that he will no longer share the labors of the trail or the cher of the evening eamp fire.
} 
The San Francisco and the Blue rivers have been seriouslytorn up by floods in recent years, but many of the snails remain. Nearly all the farmers have been swept out. Oreohelices, Sonorellas or Ashmunellas exist in every favorable situation from Clifton to Bob Cat on the interstate boundary, except in a few short stretches of these rivers where the snails scem to have a dislike for the soil, the chemistry of the rocks, or something not traced. This is about fifty miles in a straight line, and thus very long miles.

Again on the Luna road to Alma, in New Mexico, Oreohelix was found on the crest of the San Francisco Mountains, and the largest colony, with many albinos, came from the Rio Saliz, a small stream draining the San Francisco Mountains eastward into the San Francisco River.

The Mogollons might be called a federation of sharp peaks. It is not a high plateau like the White and Blue mountain region, yet the forest conditions and tree associations are almost identical. On the Bursam wagon road from Mogollon to Willow Creek, ascending to 9,000 feet, and usually running along the north slope of the peaks, the conditions for snails are ideal. Ashmunella mogellonensis and Oreohelix cooperi were soon picked whenever logs or stones were turned in this (for snail hunters) two-day journey. At two points Oreohelix barbata was found with the other two species. Afterward, when the canyons facing west and south were explored the smaller Ashmunellas were found in colonies with the three above mentioned. Sonorella has not yet been found in the Mogollon range. In the extreme southern part of Arizona (Chiricahua range) the large toothless Ashmunellas are in colonies with the smaller toothed forms and Oreohelix barbata with them. Also a Sonorella and sometimes Holospira. Three species of Sonorella have been found in one slide; but the gencral Arizona rule still remains one species of the genera of Helices to a colony.

The banks of the canyons running west, in the Mogollons, were abrupt, and the south bank furnished shade and cover. In Big Dry Canyon, rumning directly south, the banks were so abrupt and close together that snails were living on both sides of the stream, and in the greatest abundance within our experience.

The wide differences in the Ashmunellas of the Mogollons and the presence of the Chiricahua Oreohelix barbata seem to indicate an alluring future for Mogollon eonchology. We believe that the deeper canyons, penetrating farther into the large mountains, had greater riches than Big Dry, lying in between them. Here too in the 
canyon streams live the mountain trout, friendly and well conclitioned, but they are not the cut-throat trout of the Colorado.

On the whole the Mogollons, in scenery and camping delights, are not far behind the White and Blue Mountain region of eastern Arizona. Silver City is the nearest and most convenient railway station, and moreover it lies in a region unexplored by the snail fraternity.

One more killing was made on the return to Clifton, a colony of Sonorellas at Steeple Rock, Sept. 14. Thus this event of $191+$ had a continuous run of two months and seven days.

Aside from the minute Canadian Zone snails which have a wide distribution at high levels, and the minutix of the desert foothills such as Thysanophora hornii, Succinea arara, the small Zonitoides, etc., there are several forms showing close affinity between the San Francisco-Mogollon region and the Chiricahua Range. The species Sonorella binneyi, Ashmunella chiricahuana and Orohelix barbata of the Chiricahuas are represented here by S. binneyi franciscana, A. mogollonensis and $O$. barbata. The toothed Ashmunellas are of nearly related species, and the same group of forms extends farther east in New Mexico to the Black Range. None of the species mentioned are found in the northern or Dos Cabezas part of the Chiricahua range, their habitats being from 80 to over 100 miles south of the regions now under consideration. The intervening region is at the present time too dry for the existence of these snails.

\section{HELICIS, $\AA$.}

Sonorella grahamensis n. sp. PI. VI, figs. $7, \tau a, \tau$.

The shell is umbilicate (the width of umbilicus contained about $S_{\frac{1}{2}}^{1}$ times in the diameter of shell), very thin, tawny-olive, paler at the base, with the usual band; not very glossy; under the lens showing the usual weak growth-lines, and both above and below there are numerous spiral impressed lines. Whorls slowly increasing at first, the last rapidly widening, descending in front. Aperture roundedoval, quite oblique. Peristome is thin, very little expanded.

Alt. 10, diam. $19 \mathrm{~mm}$.; umbilicus $2.2 \mathrm{~mm}$.; $4 \frac{1}{2}$ whorls.

Genitalia (fig. 9). The penis has a well developed sheath at the base, and contains a long, tapering papilla. The penial retractor is inserted at the base of epiphallus and apex of penis as in the hachitana group. There is a short flagellum. The organs measure:

Length of penis $9 \mathrm{~mm}$.; papilla 7 ; epiphallus 6 ; flagellum 0.5 ; penial retractor 4.7 ; vagina 7 ; spermatheca and duct $19 \mathrm{~mm}$. 


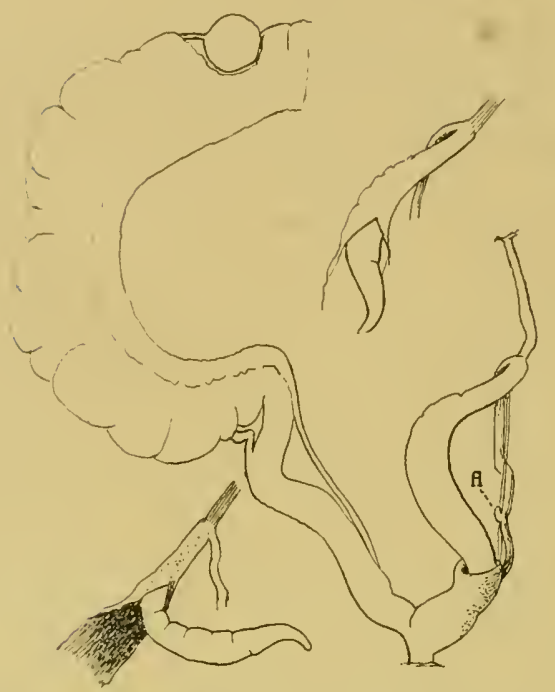

Fig. 9. Genitalia of S. grahamensis, with two details of the penis-papilla. Type specimen.

It. Graham, in the Pinaleno Range, Graham Co., Arizona, type No. 109,101 A. N. S. P., collected by J. H. Ferriss, 10-14-1913.

Graham Mountain is composed of crumbling granite (similar to that of Nine-mile Water Hole in the Dos Cabezas range), and is very dry on both north and south sides. On top there is yellow pine and quaking asp forest. Camp was made in Stockton Pass, and a couple of hours' collecting done at Mud Spring, on the summit. Besides Sonorella and Oreohelix, Vitrina alaskana was abundant, and two young Vallonias were found. The Pinaleno Range lies in line with the Chiricahua system, though separated by a rather wide mesa, in which the Southern Pacific R. R. runs, from the northern end of the Dos Cabezas Mountains.

S. grahamensis is not closely related to any other species known to us. The delicate, spirally striate shell and the rather fusiform penis-papilla are characteristic.

Micrarionta praesidii n. sp. Pl. VI, figs. $8,8 a, s 3$.

The shell is depressed, umbilicate (the width of umbilicus contained about 5.7 times in the diameter), thin. The "dead" shell is grayish white above, pale ecru-drab below, with some radial white streaks, and at the shoulder a narrow, faintly traced gray band which becomes cimnamon towards the aperture. Under a lens fine gray spiral lines are seen in places on the base. The initial half whorl is smooth; 
next whorl has hyphen-like tubercles parallel with the suture, not closely placed; subsequent whorls have faint growth-lines only; there is no trace of spiral strice.

The whorls are rather strongly convex, at first slowly increasing, the last very wide, rather deeply descending in front. The aperture is strongly oblique, nearly circular, faintly washed with ochraceous within. The peristome is sharp, very little expanded except at the columellar insertion where it is broadly dilated; terminations connected by a rather long, quite thin parietal callus.

Alt. 8.5 , diam. $16 \mathrm{~mm}$; umbilicus $2.8 \mathrm{~mm}$; $4 \frac{1}{2}$ whorls.

Fort Grant, at foot of the Graham Range, Graham Co., Arizona, the type, No. 58,121 A. N. S. P., collected by Dr. George H. Horn.

By the sculpture of the embryonic shell, as well as the general appearance, this snail resembles Micrarionta hutsoni Clapp, which is smaller, more depressed, with a larger umbilicus. It is somewhat intermediate in form, between hutsoni and indioensis. If it really belongs to Micrarionta, and there is no mistake about the locality, it is widely separated from its congeners.

The single specimen has been in the collection for many years. It had been labelled $H$. strigosa Gld.

Dr. Horn, the distinguished coleopterist, was stationed at Fort Grant sometime after 1863. He collected a number of shells in that vicinity, which were described by $\mathrm{W}$. M. Cabb in the American Journal of Conchology for October, 1866, pp. 330, 331, as follows:

Helix hornii Gabb. [Thysanophora hornii].

$H$. strigosa Gld. "The lirgest specimen I have seen of the species" [= Sonorella $\mathrm{sp}$. undet.].

H. minuscula [Zonitoides minuscula alachuana.'].

Pupa (Modicella) arizonensis Gabb [= Pupoides marginata var.].

Pupa hordacea Gabb [Pupoides hordacea!.

The locality is given as "Fort Grant, at the junction of the Arivapa and San Pedro Rivers;" but that junction is really a long day's travel-fully fifty miles-westward; yet it may have been the nearest definite landmark to be found on maps of the time.

The "H. strigosa" mentioned by Gabb is a Sonorella $25 \mathrm{~mm}$. in diameter, of the s. hachitana group. The upper part of the peristome is broken away, and the shell is bleached; we do not recognize the species.

Of the Zonitoides several live specimens are preserved. They probably came from around a spring. All of the other shells mentioned are such as live among rocks in arid foothills. The speci- 
men of Pupa hordacea seems to have been given to Mr. Binney; the other species taken by Dr. Horn are in the collection of the Academy.

As Dr. Horn was also at Gila Bend, Yuma and other places in western Arizona, the possibility of an erroneous locality label for the specimen of $M$. praesidii is to be considered. That specimen was not mentioned in Gabb's paper, but he would doubtless have considered it a small " $H$. strigosa".

Sonorella rooseveltiana (Berry). Pl. VI, figs. $9,9 a, 9 b$.

Nautilus XXXI, July, 1917, p. 14.

Roosevelt, Gila Co., Arizona, $2200 \mathrm{ft}$. clevation. Figures of the type, supplied by Dr. Berry, are here given for comparison with the forms of adjacent counties. They are 1.6 natural size, the diameter being $16.5 \mathrm{~mm}$.

S. rooseveltiana appears to belong to the hachitana group, but the single specimen dissected was quite immature. It is, we believe, the only mollusk reported from Gila County.

Sonorella delicatan. sp. Pl. VI, figs. 6, 6x, 63 .

The shell is umbilicate (umbilicus contained slightly over 6 times in diameter of shell), thin, somewhat translucent, light ochraceousbuff with several pale or whitish oblique streaks on the last whorl, and a cinnamon-brown band above the periphery. Glossy, having the usual weak irregular growth-lines. The embryonic whorls are nearly smooth, but short, protractive threads may be seen near the suture.

The last whorl is wide and descends rather slowly in front. The aperture is strongly oblique, rounded-oval. Peristome thin, expanded, with a dull brown edge.

Alt. 10.5 , diam. $18.3 \mathrm{~mm}$.; $4 \frac{1}{2}$ whorls.

Genitalia (fig. 10) remarkable for the small size of the male organs. The length of penis is about one-fifth the diameter of the shell, very slender, having a stout basal sheath, and containing a short, cylindric papilla. The epiphallus is longer than the penis, terminating in a short flagellum.

Length of penis $\quad 3.5 \mathrm{~mm}$.

$\begin{array}{lll}\text { papilla } & 1.2 & \text { " } \\ \text { epiphallus } & 4.5 & \text { " } \\ \text { flagellum } & 0.4 & \text { " } \\ \text { vagina } & 5.5 & \text { " }\end{array}$

Northern end of the Peloncillo Range, about 6 miles south of the Gila River, on the toll road between Solomonsville and Clifton, 
Graham Co., Arizona; in a "malpais" rock slide, about 4,800 ft. elevation, type No. 109,110 A. N. S. P. paratypes in Ferriss Coll.; collected by J. H. Ferriss, 11-14-1913.

The shell recalls $S$. bowiensis Pils., differing by the wider last whorl, smaller aperture and somewhat smaller umbilicus; also much less distinct sculpture of the embryonic whorls. The genitalia, examined in several individuals, differ by the very small size of the male organs, relatively even smaller than in S. hachitana and its

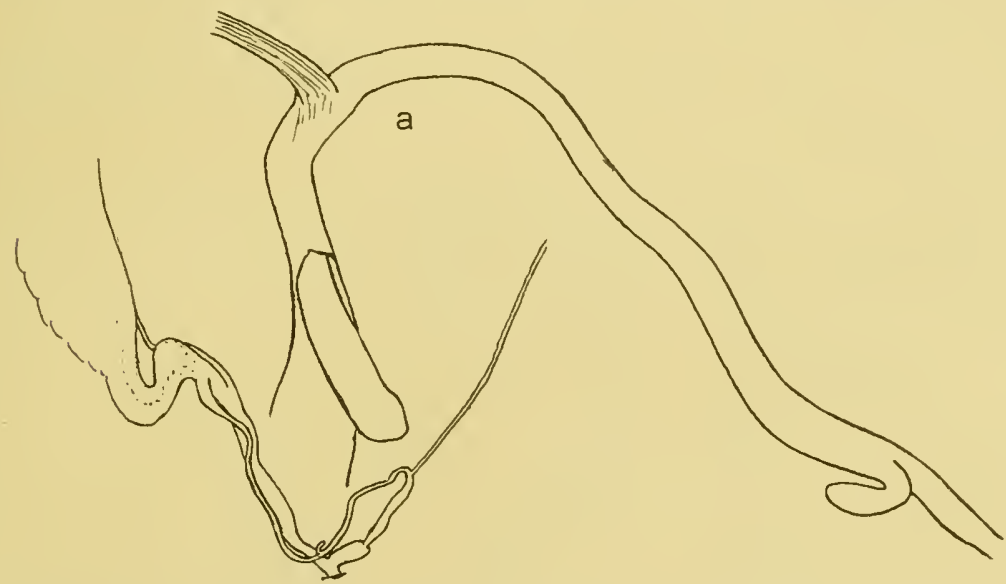

Fig. 10. Genitalia of $S$. delicata. a, outline of penis-papilla, epiphallus and flagellum.

immediate relatives. It differs from these by the cylindric penispapilla with bluntly conic end. The genitalia of S. walkeri P. \& F., of the Santa Ritas, have considerable similarity.

The living animal has an odor like S. odorata in the Santa Catalinas. Sonorella cærulifluminis n. sp. Pl. VI, figs. 1 to t.

The shell is depressed, umbilicate, the umbilicus contained about 8 times in the total diameter, somewhat translucent, nearly isabella color, having a chestnut-brown band at the shoulder, showing above the suture on the penult and usually half of the next earlier whorl, and without white bordering bands, though the shell may be slightly paler there. It is somewhat translucent throughout. Surface glossy. Embryonic portion of $1 \frac{1}{2}$ whorls, at first with some raclial ripples, then irregularly pitted-granulose, with weak oblique threads as in others of the S. hachitana group. First post-embryonic whorl is weakly striate and minutely papillose; later whorls with sculpture of delicate, irregular growth-lines only. The whorls are moderately 
convex, the last descending slowly in front. The aperture is rounded oval-lunate, large. Peristome expands a little and is dilated at the columellar insertion.

Alt. 14.6 , diam. $25 \mathrm{~mm}$; alt. of aperture 12.3 , width $14.3 \mathrm{~mm}$; $4 \frac{1}{2}$ whorls (type, Station 18 ).

Blue and San Francisco Rivers, Graham Co., Arizona, the type (No. 119,048 A. N. S. P.) from Station 18 (1914), San Francisco River 6 miles above its confluence with the Blue River. Found also at Stations 5, 8, 10, 15, 16, 17, 19, 20 (1914), and 89, 91 (1913); from Ash Canyon, 6 miles above Clifton, to the mouth of Sardine Creek on the Blue River. The higher of these colonies are at little more than $4,000 \mathrm{ft}$.

While closely related to $S$. hachitana, it differs from that by the absence of white bands bordering the shoulder-band, and of a white umbilical area, by the suture descending less deeply and not so abruptly in front, and by the smooth penis-papilla.
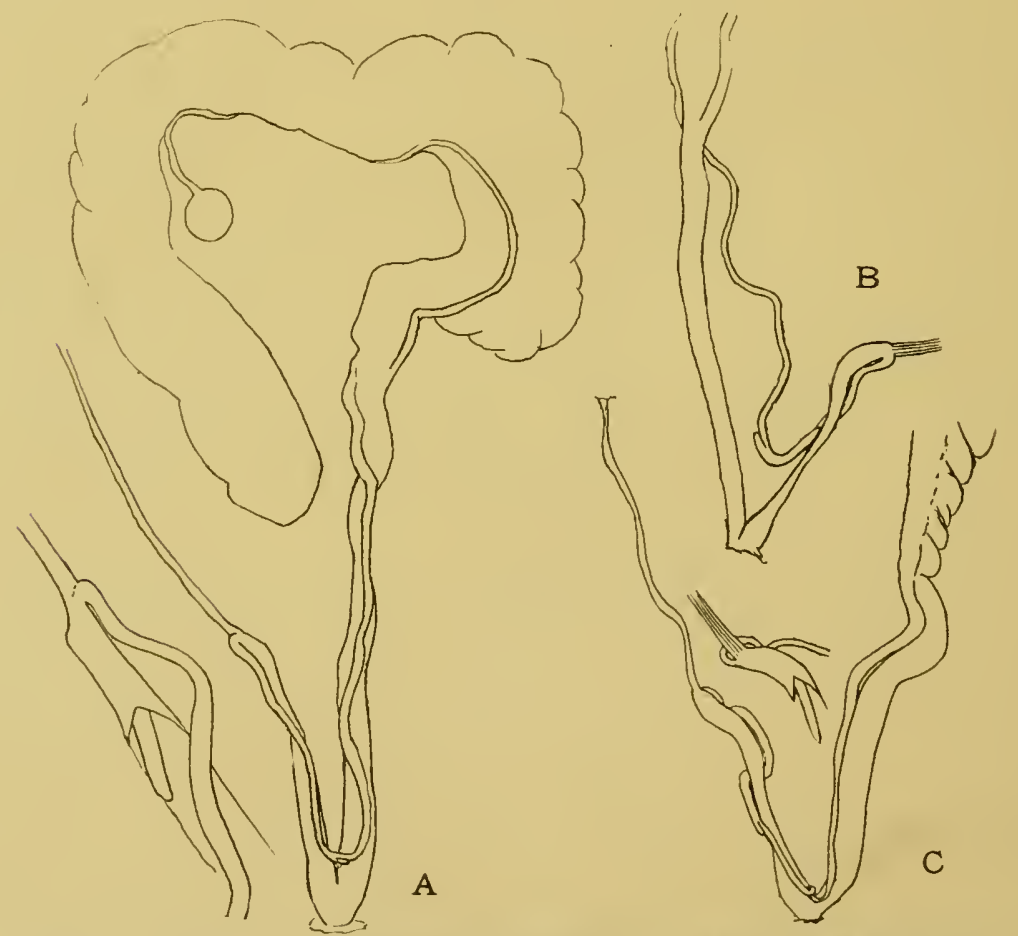

Fig. 11. Genitalia of Sonorella comulifluminis. a, No. 119,04S, Station 1S, typical, with enlarged detail of penis-papilla; $b$, No. 119,0 42 , Station 19; $c$, Station 10, Xo. 119,046. 
The head and back are blackish brown, fading downward and backward to dark grayish brown, the tail paler. The sole has lateral bands somewhat darker than the central field (No. 119,048).

Genitalia (fig. 11) generally similar to S. hachitana. The penis is very slender, its retractor muscle longer; penis-papilla slender, smooth, with tapering end. A short flagellum is present. The epiphallus is nearly as long as the penis. The vagina is generally longer than the penis.

In one specimen dissected, Station 20 (fig. 12a), the penis is about a third longer, its papilla very long, three times the usual length or more. The flagellum also is much longer. Such differences would usually be thought specific, yet I have not found any differences in the shells from this locality.

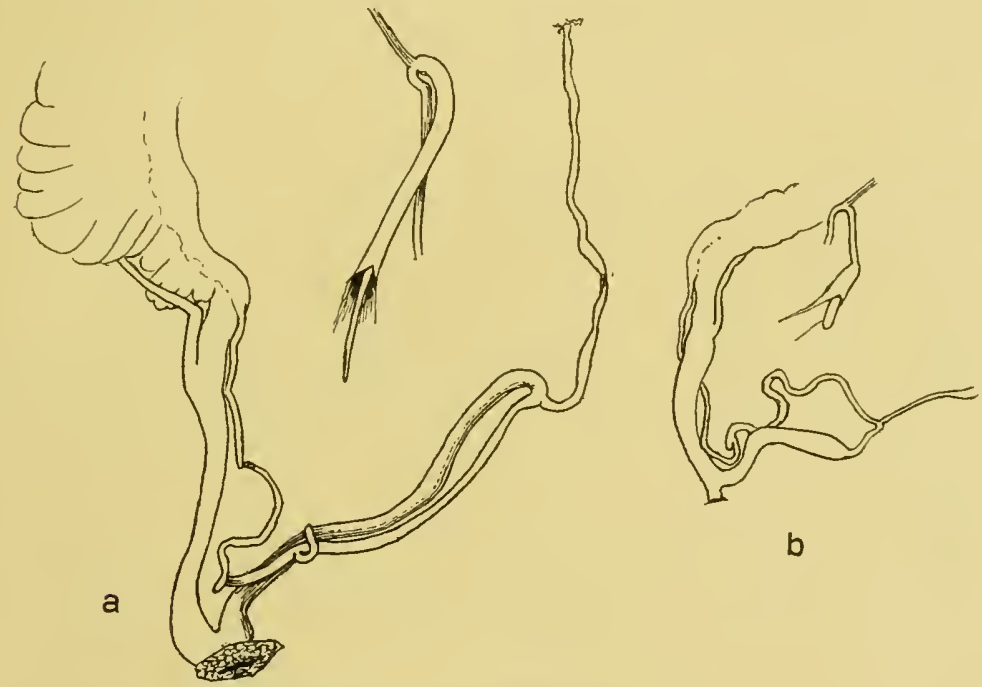

Fig. 12. a, Genitalia of $S$. coerulifuminis lar., 119,017, from Station 20, Blue River. $b, S$. binneyi franciscana No. 119,044 .

Measurements of genitalia of S. carulifuminis.

\begin{tabular}{|c|c|c|c|c|}
\hline Collecting Station.... & 18 & 19 & 16 & 20 \\
\hline Penis............. & 8.5 & 7.5 & 7 & 12 \\
\hline Penis-papilla....... & 3 & 3.5 & 4 & 11 \\
\hline Epiphallus........ & 8 & 6 & 7 & 8.7 \\
\hline Flagellum......... & 0.6 & 0.7 & 0.5 & 2 \\
\hline Retractor......... & . & . & 10 & 13 \\
\hline Vagina........... & 15 & 14 & 8 & 9.5 \\
\hline Museum No....... & 119,048 & 119,042 & $119,0 \pm 6$ & $119,0+7$ \\
\hline
\end{tabular}


The size of the shell is rather variable, the extremes of diameter in a series from Station 17 being 20 and $24.6 \mathrm{~mm}$. The largest specimen noticed measures $26.4 \mathrm{~mm}$. An inclividual without a dark band is photographed in fig. 4. It is from Station 19, Blue River, at the mouth of Pigeon Creek. Two other shells from this station are illustrated in figs. $2,2 a$ and $3,3 a$.

Sonorella binneyi franciscana n. subsp. Pl. VI, fiegs, $5,5 \pi, 5$ h.

The shell is umbilicate (width of umbilicus contained 9 to 10 times in that of shell), light pinkish cinnamon with some paler or white oblique streaks and indistinctly paler on both sides of a chestnut-brown band above the periphery. This band shows above the suture of the last half of the penult whorl. The surface is glossy; embryonic shell of about $1 \frac{1}{2}$ whorls, the first half having some radial ripples, the next whorl minutely granulate, having oblique, curved threads, protractive below, retractive above; the later whorls with fine, unequal growth-lines. The whorls are convex, slowly increasing at first, the last rapidly widening, descending a little in front. The aperture is unusually large, shortly oval-lunate. The peristome is very narrowly expanded, straightened and dilated towards the columellar insertion.

Alt. 11.6 , diam. $19 \mathrm{~mm}$., aperture $9.8 \times 11.5 \mathrm{~mm}$; $4 \frac{1}{2}$ whorls.

San Francisco River, Graham Co., Arizona; type locality, Station 92 (1913), above Sardine Creek. Also taken at Station 93 in the same vicinity, and at Station 13 (1914), 2 miles above Harper's. Ferriss and Daniels.

The head and back are dark grayish brown shading into dark vinaceous drab downward and backward, the tail light colored.

Genitalia (Fig. 12b). The penis contains a cylindric papilla with blunt, rounded end. The epiphallus is about twice as long as the penis, and bears a small flagellum. The penial retractor inserts on the epiphallus some distance (over $\frac{3}{4} \mathrm{~mm}$.) above the penis. The vagina is nearly or about as long as the penis. Measurements follow:

\begin{tabular}{|c|c|c|c|}
\hline Station. & 13 & 13 & 93 \\
\hline Length of penis & 5 & 6 & $7 \mathrm{~mm}$. \\
\hline papilla ............ & 2 & 2.3 & $3.5 “$ \\
\hline epiphallus ......... & 10.5 & 10 & 10.5 " \\
\hline flagellum ......... & 0.5 & 0.7 & small \\
\hline penial retractor..... & 3.3 & . & . \\
\hline vagina........... & 4.7 & 5 & $5.5 \mathrm{~mm}$. \\
\hline $\operatorname{eun} \mathrm{N}_{0} . . . . . . . . . .$. & 119,044 & 119,044 & 109,413 \\
\hline
\end{tabular}


binneyi P. \& F., of the southern Chiricahuas. The blunt penispapilla, and especially the insertion of the penial retractor on the epiphallus some distance beyond the apex of the penis, are alike in both. There are, however, some differences in the proportions of the organs, the epiphallus and penis-papilla being longer relative to the penis in $S . b$. franciscana, and the last whorl of franciscana is a little wider, viewed from above.

The diameter, in specimens seen, is from 17 to $19.3 \mathrm{~mm}$.

Ashmunella pilsbryana Ferriss.

Ashmunella pilsbryana Ferriss, Nautilus XXVII, 1914, p. 109.

A shmunella pilsbryana Ferriss \& Pilsbry, Nautilus XXIX, 1915, p. 42, pl. 2, fig. 3.

Arizona: Along the San Francisco River, from near Harper's Ranch to 2 miles above the mouth of the Blue River, Graham and Greenlee Counties, Arizona.

Ashmunella mogollonensis (Pils.).

Ashmunella chiricahuana mogollonensis Pilsbry, Proc. A. N. S. Phila., 1905, 1). 252 , pl. 16, figs. 101,102 .

Ashmunclla mogolionensis PrLsery, Nautilus XXIX, 1915, p. 42. PilsBry et Ferriss, Proc. A. N. S. Phila., 19i7, p. 93, pl. 7 , fig. 10 (shell), and pl. 10, fig. 3 (genitalia).

Professor E. O. Wooten, who discovered this snail, crossed the Mogollon Range from Willow to Silver Creeks, along what is now called the Bursam road. He also made an excursion from the West Fork of the Gila towards Mogollon Peak, reaching a point about $1 \frac{1}{2}$ miles due east of the Peak, in the forks of Whitewater Creek, at about $9,000 \mathrm{ft}$. It was probably here that he obtained the type of A. mogollonensis, though it is also common along Silver Creek and the Bursam Road.

Specimens were taken along Silver Creek and the Bursam Road at Stations $38,42,43,44,45$, from about 7,500 to $9,000 \mathrm{ft}$. eleration, and at Station 46, Little Turkey Creek, at about 9,000 ft.

It is rather variable in size, specimens from Station 38 measuring from 16.5 to $21 \mathrm{~mm}$. diameter, those from Station 46 from 17 to 19 $\mathrm{mm}$. Other localities in the Mogollons are Station 51, head of Mineral Creek, where there are some beautiful albino shells, and 70 , 76, 79, on Dry Creek, the shells mostly large.

In Arizona it was taken in 1913 at Stations 59, 84, 86, all on or near the rim of the Blue Mountains, at 5,500 to 12,000 feet. The shells average larger than in the Mogollons, very few being under $20 \mathrm{~mm}$. in diameter. Specimens from Station 59 measure: 
Alt. 11.5 diam. $22.8 \mathrm{~mm} .5 \frac{3}{4}$ whorls.

$\begin{array}{ccccccc}\text { " } & 11 & \text { " } & 21 & \text { " } & 5 \frac{3}{4} & \text { " } \\ & 8.5 & \text { " } & 18.3 & \text { " } & 5 \frac{1}{3} & \text { " }\end{array}$

Extremes of size, Station 86.

Alt. 11 diam. $22.8 \mathrm{~mm} .5 \frac{3}{4}$ whorls.

" 10 " 19.5 " $5 \frac{3}{4}$ "

A. mogollonensis differs from A. chiricahuana by the very small and short penis, scarcely differentiated from the epiphallus; the absence of a penial retractor muscle; and the more capacious spermatheca, which is sacculate distally in some individuals. There are also differences in the proportions of the organs, but whether constant or not ean be determined only by measuring a long series. In both the epiphallus is very long. The shells ean be distinguished by the minute but deeply engraved spiral lines of $A$. mogollonensis.

Other species of Ashmunella from the Mogollon Mountains were described in Nautilus XXIX, 1915, as follows:

Ashmunella tetrodon Pils. \& Ferr. Dry Creek.

Ashmunella tetrodon mutator Pils. \& Ferr. Dry Creek.

Ashmunella tetrodon inermis Pils. \& Ferr. Dry Creek.

Ashmunella danielsi Pils. \& Ferr. Cave Spring Canyon.

Ashmunella danielsi dispar Pils. \& Ferr. Little Whitewater Creek.

Oreohelix cooperi (W. G. B.). P!. VIl, figs. 1 to $6 . x$.

Mogollon Mountains, Socorro Co., New Mexico: Willow Creek, Stations $46-48$, at from about 8,300 to nearly $9,000 \mathrm{ft}$.; Silver Creek and along the Bursam Road (above Mogollon), at about 7,500 to

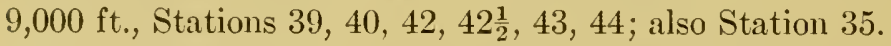

The specimens from these localities closely resemble those figured by us from the Black Range, N. M. (in these Proceedings for 1917, pl. 9, figs. 5-9), but there is greater variation in contour, as in pl. VII, figs. 6, $6 a$ from Station $42 \frac{1}{2}$, near the crest of the range, measuring

Alt. 13, diam. $21 \mathrm{~mm}$.

" 16.5 , " 20 "

The commonest form is like that shown in pl. 9, fig. 7 of our paper of 1917 ; the size generally from 21 to $23 \mathrm{~mm}$. diam. A large shell from Station 48 measures, alt. 16.4, diam. $23.3 \mathrm{~mm}$. At Stations 39 and 40 they are smaller, diam. 18 to $20 \mathrm{~mm}$. The size is independent of elevation, as there are larger shells both above and below these stations in the Willow Creek region.

In Arizona the same "Black Range form" of cooperi was found on the southern slope of the Blue Mountains, Station 59 (1913), 
in Cosper's pasture, Station 58 (pl. VII, fig. 1) and farther northward in the southern part of Apache Co., on Mt. Thomas, White Mountains, at Station 75 (1913). In all of these stations there are the same capacious whorls and frequently very high spire noted in the Mogollons.

All of the preceding inhabit high elerations, and all were found under logs and leaves in heavy timber, as in the Black Range of New Mexico. The following lots were all among rocks (pl. VII, figs. 2-5b).

Farther down the Blue River (in Greenlee Co., Arizona), the species was found as far as Station 23, east side of the river 2 miles above the mouth of Grant Creek (pl. VII, figs. 5-5b). While there is abundant intergradation with the shells of higher elevations just noticed, the majority of the shells are more openly umbilicate. Many have the spire very high, but this is variable in all the lots. Three examples from Station 23 figured measure:

Alt. 16, diam. $26.5 \mathrm{~mm}$., umbilicus $4.7 \mathrm{~mm}$.

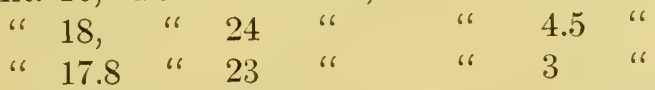

The shells from Station 25 are almost as large; those from Stations 26 to 32 (going up the river) are smaller. Specimens from Station 29, 1 mile above Blue River Ranger Station (pl. VII, figs. 2-2b) measure:

$\begin{array}{ccccc}\text { Alt. } 17, & \text { diam. } & 22.3 & \mathrm{~mm} \\ \text { " } & 18 & \text { " } & 22.2 & \text { " } \\ \text { " } & 15 & \text { " } & 22 & \text { " } \\ \text { " } & 15.6, & \text { " } & 18 & \text { " }\end{array}$

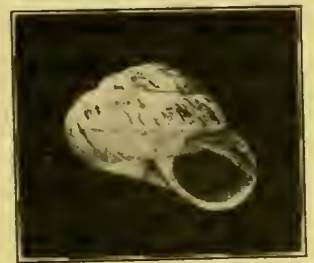

Fig. 13. Oreohelix cooperi, albino, Station 29.

There are some beautiful albino specimens in this lot (fig. 13). Other examples are figured (pl. VII, figs. 3, 3a) from Station $2 \overline{7}$. near the Blue River Ranger Station, where the shells are very dark colored. One measures, alt. 13, diam. 20.5, umbilicus $5 \mathrm{~mm}$.

A series from Station 36, Mt. Lisa, Lisa Creek, Socorro Co., N. M., 20 miles north of Alma, is similar to those of Station 29, also with not a few albino shells. 
The Blue River series shows all gradations of shape between very high shells, those of the typical cooperi contour, and an openly umbilicate shell with whorls of small caliber. The sculpture varies from that of Black Range cooperi to more effaced, the striation and spirals weak.

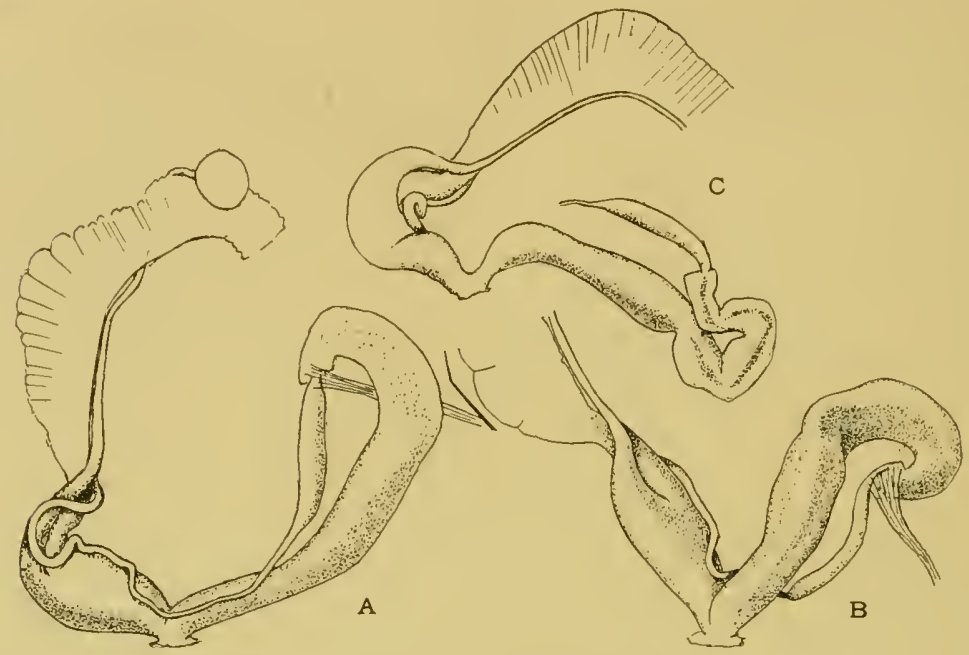

Fig. 14. Genitalia of Oreohelix cooperi. a, Cosper's pasture; $b$, Blue River, Station 26; $c$, form apache, Black River, Station 81 .

The genitalia (figs. $14 a, b, c$ ) agree with those organs in 0 . cooperi from the Black Range, N. M., figured in these Proceedings for 1917, p. 101, fig. 5. The internally ribbed portion of the penis forms more than half of the total length of that organ, as in all forms of $O$. cooperi. Measurements in $\mathrm{mm}$. follow. Numerous other specimens opened but not measured were seen to agree with those illustrated. They are distinguishable at sight from all forms of $O$. strigosa.

\begin{tabular}{|c|c|c|c|c|c|c|}
\hline Station. & Penis. & $\begin{array}{l}\text { Internally } \\
\text { ribbed part } \\
\text { of penis. }\end{array}$ & $\begin{array}{l}\text { Epiphal- } \\
\text { lus. }\end{array}$ & Vagina. & $\begin{array}{l}\text { Diam. of } \\
\text { Shell. }\end{array}$ & $\begin{array}{c}\text { Museum } \\
\text { No. }\end{array}$ \\
\hline $\begin{array}{l}26(1914) . \\
5 S(1913) \\
35(1914) \\
36(1914) \\
23(1914) . \\
76(1913) \\
\$ 1(1913) . \\
81(1913) .\end{array}$ & $\begin{array}{l}16 \\
17 \\
13 \\
13 \\
18 \\
19 \\
18 \\
17.5\end{array}$ & $\begin{array}{c}9 \\
10 \\
7.5 \\
8 \\
10 \\
10.5 \\
9.5 \\
8\end{array}$ & $\begin{array}{c}6 \\
7 \\
\cdots \\
\cdots \\
6 \\
\cdots \\
6.3\end{array}$ & $\begin{array}{c}6 \\
5 \\
\cdots \\
7 \\
7.5 \\
\ldots\end{array}$ & $\begin{array}{c}23 \\
21 \\
20 \\
21 \\
24 \\
23 \\
23 \\
\ldots\end{array}$ & $\begin{array}{l}119,151 \\
109,173 \\
119,152 \\
119,153 \\
119,150 \\
109,184 \\
109,180 \\
109,180\end{array}$ \\
\hline
\end{tabular}

Preparations are figured from Stations 26, Blue River (fig. 14b), 5\$, Cosper's pasture (fig. 14a) and 81, Black River (fig. 14). The sperimen dissected from station 36 is an albino. 
O. cooperi form apache, new form (pl. VII, figs. 7 to $8 a$ ). Rather large size, dark or very dark coloring and subobsolete sculpture (the spirals being especially weak) characterize the shells taken along the Black River and Fish Creek, in Apache County, Arizona. The shell is generally quite depressed and as openly umbilicate as the forms of O. strigosa. The diameter is usually from 22 to $26 \mathrm{~mm}$. Few have the spire very high, and none are as high as many of the Blue River shells.

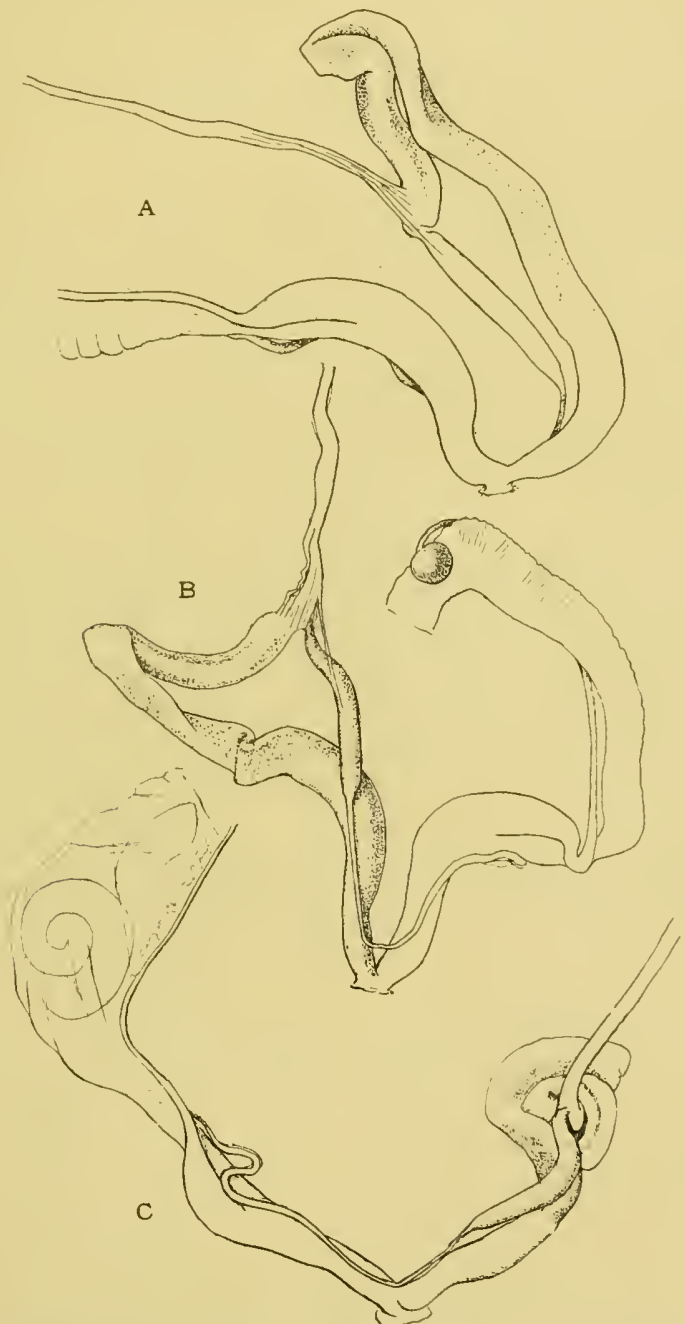

Fig. 15. Reproductive organs of Oreohelix strigosa meridionalis, the middle figure drawn from the type specimen. 
Alt. 15, diam. $24 \mathrm{~mm}$., umbilicus $4.5 \mathrm{~mm}$.

Type No. 109,184, from Station 76 (1913), Black River 2 miles above Fish Creek. It was taken also at Stations 53, 60-62, 64, 66, $68,69,71,72,76-81,83$ of the expedition of 1913.

On account of the form and sculpture of this large series, so unlike the usual forms of cooperi, it appears best to name it. The Blue River series varies from the apache type to the normal cooperi form. Indeed, specimens could be selected from the Mogollon series agreeing with apache, though they are quite exceptional there. The genitalia are either practically typical cooperi, as at Station 76 , or the costate part of the penis may be relatively a trifle longer, as at Station 81 (fig. 14c).

Oreohelix strigosa meridionalis n. subsp. Pl. VII, fig. 9.

The shell is depressed and very openly umbilicate, the last whorl subangular above the aperture; otherwise resembling $O$. c. apache. Striation weak, subobsolete spiral lines only very faintly developed.

Alt. 14.4, diam. $24.5 \mathrm{~mm}$.; umbilicus $6 \mathrm{~mm}$. wide; $5 \frac{1}{2}$ whorls.

Y Salt House branch of Eagle Creek, Graham Co., Arizona; type No. 109,186 A. N. S. P. Also taken on the Black River near the horseshoe bend.

By the shells alone we would hardly separate this form from $O$. cooperi apache; yet the genitalia were found to be like $O$. s. depressa.

The genitalia (fig. 15) agree with those of $O . s$. depressa and various allied forms except that the organs are longer in shells of similar diameter; yet in Colorado depressa this is a rather variable character, and it is somewhat affected by the conditions of preservation. The penis is very long, its internally costate portion hardly one-third of the entire length, having about 4 principal ribs within; the internally papillose portion flattened, weakly ribbed within, sometimes having a trilobed section distally. Measurements of the organs in mm. follow:

\begin{tabular}{|c|c|c|c|c|c|c|c|}
\hline $\begin{array}{l}\text { Station } \\
\text { (1913). }\end{array}$ & Penis. & $\begin{array}{c}\text { Internally } \\
\text { costate } \\
\text { portion. }\end{array}$ & $\begin{array}{c}\text { Epi- } \\
\text { phallus. }\end{array}$ & Vagina. & $\begin{array}{l}\text { Diameter } \\
\text { of shell. }\end{array}$ & Fig. & $\begin{array}{c}\text { Museum } \\
\text { No. }\end{array}$ \\
\hline $\begin{array}{l}56 \\
71\end{array}$ & $\begin{array}{l}33 \\
31 \\
19.5 \\
28\end{array}$ & $\begin{array}{r}9 \\
10 \\
6 \\
7.5\end{array}$ & $\begin{array}{r}10 \\
8 \\
5 \\
6\end{array}$ & $\begin{array}{c}9 \\
10 \\
6.5 \\
8\end{array}$ & $\begin{array}{l}24 \\
\ldots \ldots \\
21.5\end{array}$ & $\begin{array}{l}15 b \\
15 a \\
1 \ddot{15 c}\end{array}$ & $\begin{array}{l}109,186 \\
109,177 \\
109,179 \\
109,190\end{array}$ \\
\hline
\end{tabular}

$O$. $s$. meridionalis differs from $O$. $s$. depressa by the distinetly smoother shell. 
Oreohelix barbata Pils.

The occurrence of this species in the Mogollons was a surprise, as it was described from the Cave Creek region of the Chiricahuas, far to the south. It does not inhabit the dryer northern half of the Chiricahua range, and its distribution is therefore conspicuously discontinuous. It evidently changes much more slowly than the Ashmunellas, though some little differentiation may be seen as noted below.

In Dry Creek, it was taken in the slides with Ashmunella, at Stations $62,64,68,70,72,75,77,78$ and 79 . In most of these colonies it reaches large size, even larger than in the Chiricahuas. Two examples from Station 79 measure: height 8 , diam. $16 \mathrm{~mm}$., and height 9 , diam. $15.4 \mathrm{~mm}$. Usually there are several circular fringes on the last whorl above the periphery, and more on the base than in Chiricahua examples. In the latter, fringes above are exceptional. Counting that at the periphery, there are usually 8 to 11 spiral wreath in Dry Creek barbata, 6 to 10 in Chiricahuan specimens. In some lots the cuticular appendages are mostly or quite lost in the adult stage. Some consist partly of smaller individuals; and at Stations 64 and 75 all are small, 11-12 $\mathrm{mm}$. in diameter.

Cave Spring Canyon, Station 57. Very small, about $10 \mathrm{~mm}$. diameter, and agreeing well with $0 . b$. minima P. \& F. (Proc. A. N. S. Phila. 1910, p. 94, fig. 15) from Rucker Canyon, Chiricahuas. There is probably no direct relationship, each being presumably a diminutive race of the normal larger forms of their respective ranges. These small forms show decadience by the deep descent of the last whorl to the aperture.

Willow Creek, Station 46. This is on the eastern slope of the Mogollon watershed. The size is small, diameter about $11 \mathrm{~mm}$. Cuticular appendages usually deciduous.

Thysanophora hornii (Gabb).

Arizona: Station 45 (1913), John Lyon's Mountain, north of the Little Dragoons. Blue River, Station 18 (1914), and Little Blue River, Greenlee Co.

New Mexico: Station 76, Dry Creek, west side of the Mogollon Mountains.

Thysanophora ingersolli (Bld.).

Arizona: Reservation Creek, 9,500 ft.; Fish Creek; Horseshoe bend of Black River, and 2 miles above, at 9-10,000 ft. Apache Co. Cosper's pasture, Graham_Co. 
New Mexico: Stations 38, 42, 45, 51, 57 in the Mogollon Mountains, abundant.

\section{ENDODONTID丑.}

Gonyodiscus cronkhitei (Nc.).

Arizona: Cosper's pasture, 11,000 ft., and rim of the Blue Mountains, 12,000 ft., Graham Co.; Blue River, Station 29 (1914), Greenlee Co. White Mountain Camp at Mt. Thomas, 13,500 ft., Apache Co.

New Mexico: Stations 36, 42, 45, 46, 57 in the Mogollon Mountains, abundant.

Radiodiscus millecostatus Pils. \& Ferr.

Arizona: Little Blue River, Greenlee Co.; Cosper's pasture and Station 59, head of "hot air trail" rim of Blue Mountains, 12,000 ft., Graham Co.; Reservation Creek, Apache Co.

New Mexico: Station 45, Willow Creek, Mogollon Mountains. Helicodiscus arizonensis (P. \& F.).

Arizona: Cosper's ranch, on the Blue River, $5,060 \mathrm{ft}$.

New Mexico: Stations 36, 42, 55, 57, Mogollon Mountains.

Punctum conspectum (Bld.).

Arizona: Station 75 (1913), Thomas Peak, Apache Co.

New Mexico: Willow Creek, Mogollon Mountains, at Station 45 (1914).

These shells appear to be somewhat more glossy than the Californians compared, the spiral striation better developed, and the riblets irregularly developed; yet we would hesitate to separate the specimens from this widely spread west coast species. ${ }^{6}$

\section{Punctum pygmaeum (Drap.).}

Arizona: Station 70 (1913), Black River near the Horseshoe bend; somewhat abundant. This is the first record of the species for Arizona.

\section{ZONITID丑.}

Polita hammonis electrina (Gld.).

Arizona: Station 80 (1913), Black River. One example. There are no spiral striæ.

Polita indentata umbilicata (Ckil.).

Arizona: Blue River at Cosper's ranch, 5,060 ft., and Stations

${ }^{6} \mathrm{~A}$ form of this species was collected in great numbers about bushes in a meadow at the west end of Oswego, Clackamas Co., Oregon, by Mr. John A. Allen in 1913 and 1914. It differs from typical $P$. conspectum by the larger size and decidedly higher, conic spire, and may be called Punctum conspectum alleni. The type measures, alt. 1.7, diam. $2.3 \mathrm{~mm}$. (No. 111,413 a, A. N.S.P.). A specimen of $P$. conspctum received from Bland measures, alt. 1.25, diam.2.1 mm.-H. A.P. 
18, 29 (1914); Little Blue; rim of Blue Mountains, 12,000 ft.; also in Apache Co. on Fish Creek, 10,500 ft.

New Mexico: Stations 38, 42, 46, 55, Mogollon Mountains.

Striatura milium meridionalis (P.\&. F.).

Arizona: Cosper's pasture, 11,000 ft., Graham Co.; Black River and Reservation Creek, 9,500 ft., Apache Co.

New Mexico: Station 57, south fork of Whitewater Creek, Mogollon Mountains.

Zonitoides arborea (Say).

Arizona: Station 29, Blue River; Cosper's pasture and rim of the Blue Mountains, Graham Co.; Reservation Creek and Fish Creek, Apache Co. Up to $12,000 \mathrm{ft}$.

New Mexico: Stations 38, 42, 46, 50, in the Mogollon Mountains.

Zonitoides minuscula alachuana (Dall)

Arizona: Graham Mountain, Graham Co.; Station 6, foot of Copper King Mountain. Reservation Creek, Apache Co.

New Mexico: Big Dry Creek, Mogollon Mountains.

Zonitoides singleyana (Pils.).

Arizona: Station 6 (1914), foot of Copper King Mountain, 1 mile below Harper's, Graham Co.

Euconulus fulvus (Müll.).

Arizona: Station 58, Cosper's pasture, 59, rim of Blue Mountains, Graham Co.; Reservation Creek and Station 75, White Mountain Camp, $13,500 \mathrm{ft}$.

New Mexico: Stations 38, 42, 45, 46, 47, 50, 53, in the Mogollon Mountains.

Vitrina alaskana Dall.

\section{VITRINID丑.}

Arizona: Rim of Blue Mountains, 12,000 ft., Graham Co.; Reservation Creek, Apache Co., 9,000 ft.

New Mexico: Stations 45, 46, Willow Creek, Mogollon Mountains.

\section{VALLONIID $\mathbb{E}$.}

Vallonia, perspectiva Sterki.

Arizona: Graham Mountains; Cosper's ranch of the Blue River, $5,060 \mathrm{ft}$.; Ole Hagen's ranch on Eagle Creek. Abundant.

New Mexico: Station 38, Silver Creek above Mogollon, and 57, south branch Whitewater Creek; also Big Dry Creek, Mogollon Mountains.

\section{Vallonia cyclophorella Ckll.}

Arizona: Cosper's pasture and rim of Blue Mountains, Graham Co.; Reservation Creek, Apache Co. 9,500 to 12,000 ft. 
Cochlicopa iubrica, (Müll.).

Arizona: Craham Mountain; Little Blue River; Cosper's on the Blue River; rim of Blue Mountains, Graham Co.; Fish Creek, Apache Co.

New Mexico: Stations 38, 42, 46, Mogollon Mountains. Pupilla blandi pithodes Pils. \& Ferr.

Arizona: Reservation Creek, and head of Black River, Apache Co.; Cosper's pasture, Graham Co. New Mexico: Stations 38, $45,46,47,53$ Willow Creek, Mogollon Mountains, at about 9,500$10,000 \mathrm{ft}$.

This is the same race found in great abundance along the summit of the Black Range, N. M. It is larger, especially wider, than typical $P$. blandi, the crest is weaker the striation stronger. The lip is but little thickened within, and the three teeth are well developed. It is of a walnut-brown color.

Length 3.7 , diam. $1.7 \mathrm{~mm}$; $7 \frac{1}{2}$ whorls.

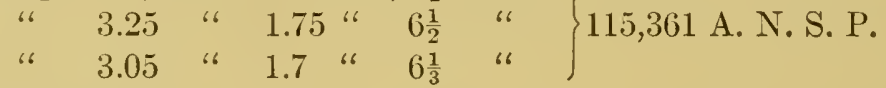

Pupilla hebes (Incey).

Arizona: Cosper's pasture and rim of Blue Mountains, Stations 58, 59, Graham Co.; Reservation Creek, Apache Co. 9,500 to 12,000 feet.

Gastrocopta ashmuni (Sterki).

Arizona: Cosper's ranch on the Blue River, 5,060 ft.; Ole Hagen's ranch, Eagle Creek. Very few found.

New Mexico: \& Stations in the Mogollon range.

Gastrocopta dalliana (Sterki).

Arizona: Station 6 (1914), foot of Copper King Mountain, near Harper's place; Ole Hagen's, Eagle Creek, Graham Co.

Gastrocopta quadridens Pils.

New Mexico: Stations 42 and 47, Silver and Willow Creeks, Mogollon Mountains.

Gastrocopta pilsbryana (N'terki).

Arizona: Graham Mountains; Ole Hagen's on Eagle Creek; Cosper's ranch, Blue River; Little Blue River; Cosper's pasture; Horseshoe of Black River; Fish Creek. From about 5,000 to 11,000 ft.

New Mexico: Stations 38, 45, 47, 50, on Silver, Willow, Turkey and Big Dry Creeks, Mogollon Mountains. It is generally distributed over the wooded country covered in this report. 
Vertigo ovata Say.

Arizona: Station 6, foot of Copper King Mountain, 1 mile below Harper's place, Graham Co.

Vertigo concinnula Ckll.

New Mexico: Stations 38, 42, 45, 50, 53 (1914), on Silver, Willow and Turkey Creeks, Mogollon Mountains, Socorro Co.

Vertigo coloradensis arizonensis P. \& V.

Arizona: Red Sack, Graham Mountains; Horseshoe bencl of Black River, Apache Co.

New Mexico: Station 38, Silver Creek, 53, Willow Creek, 50, Turkey Creek, 57, south fork Whitewater Creek, Mogollon Mountains.

Vertigo modesta .nsculpta Pils.

Arizona: Cosper's pasture and rim of Blue Mountains; Graham Co.; Reservation Creek, White Mountains, Apache Co.

Columella alticola (Ingersoll).

New Mexico: Station 45, Willow Creek, Mogollon Mountains. SUCCINEID $\nexists$ 死.

Succinea avara Say.

Arizona: Cienega near Solomonsville, Graham Co.

New Mexico: Station 46, Willow Creek, Mogollon Mountains.

Physa virgata Gld.

\section{PHYSID丑.}

Arizona: Stations 19 and 20, Blue River.

Physa sp. undet.

Arizona: Reservation Creek, near the Big Spring, Apache Co. With only immature specimens and broken adults an identification is clifficult.

Anodonta dejecta Lewis.

\section{UNIONID $Æ$.}

Arizona: Black River, southern border of Apache Co.

"Subfossil" valves of this species are found in the banks of the Santa Cruz river at Tueson.

Collecting Stations of J. H. Ferriss in Graham, Greenlee and Apache Counties, Arizona, in 1913.

47. Near Mud Springs, trail on summit of Big Graham Mountains.

48. Tank 10 miles south of Solomonsville (Physa only).

49. Swampy place 7 miles south of Solomonsville (Physa only).

50. Rock slide on the right side of the toll road, 6 miles south of Coronado. Peloncillo Range.

51. Eagle Creek.

52. Eagle Creek, 3 miles above the fork, east bank. 
53-54. Eagle Creek, 5 miles above the forks.

55. Eagle Creek, 5 miles above the forks, west side.

56. Y Salt House branch (west fork) of Eagle Creek, 1/2 mile above Hot Air Salt House.

57. 4 miles above mouth of $\mathrm{Y}$ salt house branch on Hot Air trail.

58. Cosper's pasture, top of the Blue Mountains, 12,000 ft.

59. Southern rim of the Blue Mountains.

60. Fish Creek, beaver dam camp. Apache Co.

61-65. Rock slides along Fish Creek.

66-72. Black River, near Horseshoe bend.

73. Reservation Creek, 2 miles below Big Springs.

74. Camp 4 miles below Big Springs (Physa and Pisidium).

75. Head of Black River, camp 2 miles below summit of Thomas Peak (summit 13,500 ft.). White MIts., Apache Co., Ariz.

76-\$3. Black River, 2 miles above Fish Creek.

84. I Salt House trail, rim of Blue Mountains, $12,000 \mathrm{ft}$.

S5. Below the same.

86. Raspberry or East Eagle trail, 3 miles above Cosper's place on the Blue River.

87-S8. Between Cosper's and the Little Blue River.

S9. Mouth of the Little Blue River, $4,000 \mathrm{ft}$.

90. Spring 3 miles below mouth of Little Blue (Physa).

91. Sardine Creek 1 mile above mouth.

92. San Francisco River opposite Sardine Creek.

93. Rock slide on the east bank of San Francisco River, 3 miles below Station 92.

Collecting Stations of J. H. Ferriss and L. E. Daniels in Graham and Greenlee Counties, Arizona, and Socorro County, New Miexico, 1914. List compiled by Daniels.

4. Gila River drift at Guthrie, Arizona. (Stations on the San Francisco River.)

5. Ash Canyon one mile below Harper's on the "Frisco" (San Francisco) River, six miles above Clifton, Arizona.

6. One mile below Harper's, west side of Frisco River, foot of Copper King Mountain.

7, S. Ash Canyon, above Station 5.

9. Branch of Ash Canyon below Station 5, one mile below Harper's.

10. Ash Canyon opposite Station 5, one mile below Harper's.

11. Top of Copper King Mountain, N. W. of Colorado Mine. 6 miles above Clifton. Elevation 4,500 ft.

12. Top of Copper Iring Mountain, west of Colorado Mine. $4,500 \mathrm{ft}$.

13. Slicle on cast bank of Frisco River, two miles above Harper's ranch and eight miles above Clifton.

14. Frisco River, two miles above mouth of Blue River.

(Stations on the immediate banks of the Blue River, Greenlee Co., Arizona.)

15. Four miles up from the mouth of the Blue River.

16. Five miles up the Blue River.

17, 18. Six miles up the Blue River.

19. Blue River at mouth of Pigeon Creek.

20. One mile down the Blue River from Base Line Ranger Station, east bank.

21. Little Blue River; same as Station S9 (1913).

22. "The Chimneys," three miles above Cosper's Ranch. Elevation 5,553 ft.

23. East side of Blue River one half mile below Grant Creek. $6000 \mathrm{ft}$.

24. One mile above Grant Creek, east side of Blue River.

25. Near Geo. Thompson's Ranch, three miles below Blue Post Office.

26. One mile above Blue Post Office. Elevation 6,100 ft.

27,28 . Near Blue Ranger Station.

29. One mile above Blue Ranger Station. (Twenty-one miles south of Luna, New Mexico, and 65 miles north of Clifton, Arizona.)

30. East side of Blue River, nearly at the top of the mountain.

31. Blue River south of the saw mill. 
(Stations in New Mexico.)

32. East side of Blue River, one mile north of saw mill.

33. East side of Blue River, three miles north of saw mill.

34. Mill Hollow, near top of hill, San Francisco Mountain, 8,500 ft.; about 8 miles southwest from Luna.

35. Near the Alma Wagon Road, 10 miles from Luna, in a rock slide surrounded by poplars. Crest of San Francisco Mountains.

36. Saliz Mountain, east side of Saliz Creek, 20 miles north of Alma, elevation $7,000 \mathrm{ft}$.

\section{(Stations in the Mogollon Range.)}

List compiled by Ferriss. Approximate positions are shown in fig. 16.

37-41. Along Silver Creek above Mogollon City.

42. Near saw mill, head of Silver Creek.

43, 44. Bursam Road, between Silver and Willow Creeks.

45-49. Willow Creek.

50. Turkey Creek.

51, 52. Head of Mineral Creek.

53, 54. Head of Willow Creek.

55. Little Whitewater Creek.

56-58. South Fork of Little Whitewater.

59. Cave on Spring Creek.

60-80. Big Dry Creek.

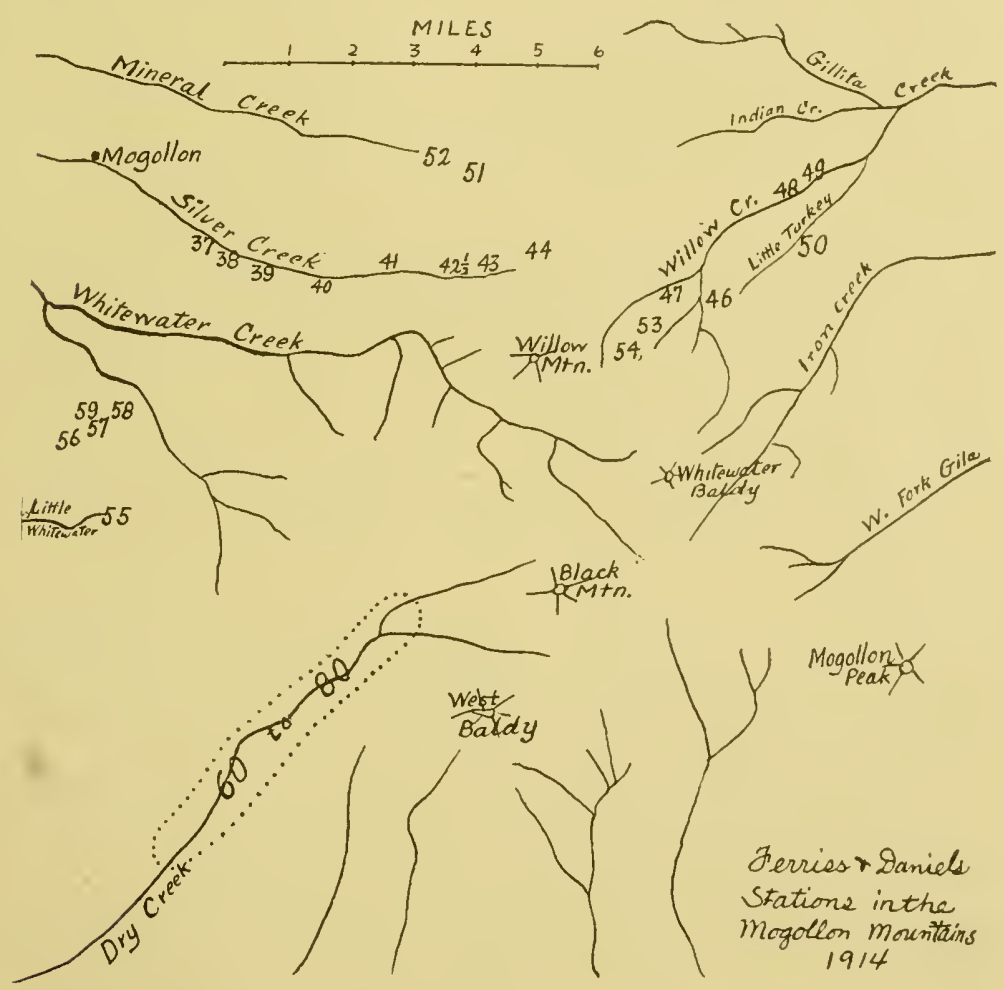

Fig. 16. Part of the Mogollon Mountains, Socorro Co., N. M. Canyons traced from U. S. Geological Survey Topographic Map, Mogollon Quadrangle, and reduced $1 / 2$. 


\section{Explanation of Plates III to VII.}

Plate III.-Figs. 1a, 1b, 2.-Sonorella odorata n. sp. Station 18 (1917), a gulch 75 yards east of Alder Spring. No. 119,501.

Figs. 3, 3a, 3b.-Sonorella odorata n. sp., type. Head of Alder Canyon. No. 119,033 .

Fig. 4.-Sonorella odorata n. sp. Form with narrow umbilicus. Station 18 (1913), Soldier Camp. No. 119,499.

Figs. 5-5b. -Sonorella marmorarius limifontis n. subsp., type. Station 17 (1913), bluffs near Mud Spring. No. 119,500.

Figs. 6, 6a, 6h.-Sonorella odorata marmoris n. subsp., type. Station 36 (1913), Old Dan Gulch, northwestern side of Marble Peak. No. 109,075.

Figs. 7, 7a.-Sonorclla marmorarius imula n. subsp., type. Station 17 (1917), limestone hill, 6 miles northwest of Brush Corral, in the northern foothills. No. 119,503 .

Figs. 8-8b.-Sonorella mormorarius imula n. subsp. Station 19 (1917), same limestone hill. No. 119,502.

Figs. 9-9b.-Sonorella marmorarius n. sp., type. Station 26 (1913), Marble Peak. No. 109,078.

Plate IV.-Figs. 1-1b.-Sonorella sabinoensis n. sp. Half mile west of eamp near mouth of Sabino canyon. No. 109,094.

Figs. 2-2b.-Sonorella sabinoensis n. sp., type. Station 16, mouth of Sabino Canyon. No. 109,097.

Figs. 3-3b.-Sonorella sabinoensis n. sp. Station 16 (1913). No. 119,487.

Figs. 4-4b.-Sonorella sabinoensis n. sp. Station 9, 2 miles above camp near mouth of Sabino Canyon. No. 119,4SS.

Figs. $5,5 a$, and $5 b-5 d$. Sonorella sabinoensis n. sp. Bear Canyon, Station 13 (1913). Depressed and elevated individuals. No. 119,490.

Figs. 6-6b. Sonorella hesterna n. sp., type. Station 148 (1917), Shaw ranch, southern foothills of the Rincons. No. 119,489.

Plate V.-Flys. 1-1b.-Sonorella sabinoensis occidentalis n. subsp., type. Station 36 (1917), south side of Pima Canyon. No. 119,491.

Figs. 2-2b. - Sonorella sabinoensis buehmanensis n. subsp., type. Station 44 (1913), Buehman Canyon near Korn Kobb mine. No. 109,198.

Figs. 3-3b.-Sonorella sabinoensis buehmanensis n. sp. Station 43 (1913), Buehman Canyon. No. 119,492.

Figs. 4-4b. - Sonorella tortillita n. sp. Station 41 (1917), east side of Hog Canyon, Tortillita Mountains. No. 118,053.

Figs. 5-5b. - Sonorella galiurensis, n. sp. Station 30 (1917). Trail 11/2 miles south of Copper Creek mining camp, Galiuro Mountains. Top and face views of type, base of a paratype. No. 119,493.

Figs. 6-6b.- Sonorella galiurensis n. sp. These views of a topotype. No. $119,493 a$.

Plate VI.-Figs. 1-1b. Sonorella carulifuminis n. sp., type. Station 18 (1914), west side of Blue River 6 miles above mouth. No. 119,048.

Figs. 2, 2a, 3, 3a.-Sonorella corulifluminis n. sp. Station 19, Blue River at mouth of Pigeon Creek. No. 119,042.

Fig. 4.-Sonorella carulifluminis n. sp. An albino specimen from the same station. No. 119,316

Fig. 5.-Sonorella binneyi franciscana n. subsp., type. Station 92 (1913), east side of San Francisco River above Sardine Creek. No. 119,052.

Figs. 6-6b.-Sonorella delicata n. sp. Type. No. 109,110.

Figs. 7-7b.-Sonorella grahamensis n. sp. Type. No. 109,101.

Figs. S-Sb.-Micrarionta prosidii $\mathrm{n}$. sp. Type. No. 58,121.

Figs. 9-9b.-Sonorella rooseveltiana Berry. Type $\times 1.6$. No. 3733 Berry collection. 
Plate VII.-Fig. 1.-Station 58 (1913), Oreohelix cooperi (W. G. B.). Cosper's pasture, rim of Blue Mountains. No. 109,173.

Figs. 2-2b-O. cooperi. Station 29 (1914), west side Blue River, 1 mile above Blue River Ranger Station, Arizona. No. 119,178.

Figs. 3, 3a.-O. cooperi. Station 27, near preceding station. No. 119,179. Fig. 4.- - cooperi. Station 32, east side Blue River, N. M. No. 119,497. Figs. 5-5b.-O. cooperi. Station 23, east side Blue River. No. 2.

Figs. 5-5b.-0. cooperi. Station 23, east side Blue River, 2 miles below mouth of Grant Creek, Arizona. No. 119,150.

Figs. 6, 6a. O. cooperi. Station 421/2, Bursam Road, head of Silver Creek, Mogollon Mts., \&,000 ft. No. 119,498.

Fig. 7.- O. cooperi apache n. subsp., type. Station 76 (1913), Black River, 2 miles above Fish Creek. No. 109,184.

Figs. 8, 8a.-O. cooperi apache. Station 53 (1914). Black River. No. $109,183$.

Fig. 9.-Oreohelix strigosa meridionalis n. subsp., type. Y Salt House Fork of Eagle Creek. No. 109,186. 



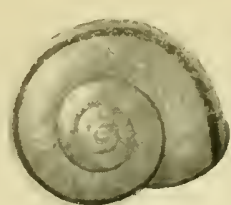

1

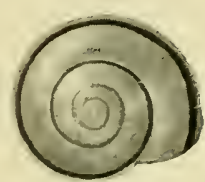

3

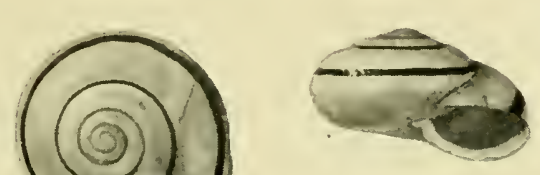

$5 a$

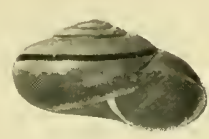

$3 a$

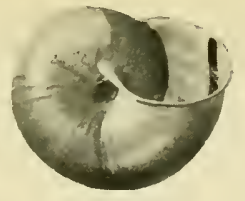

1b

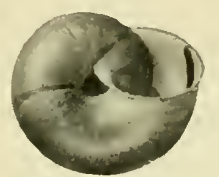

$3 b$

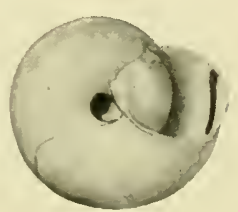

$5 b$

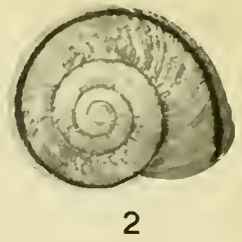

5

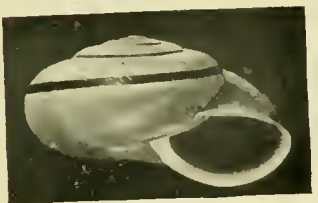

7

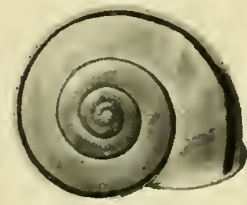

8
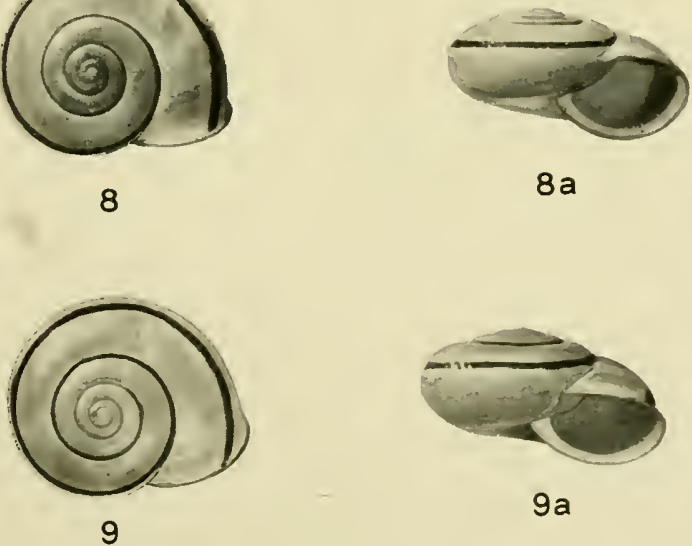

$8 a$

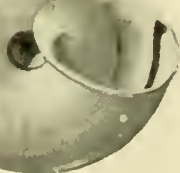

$7 a$

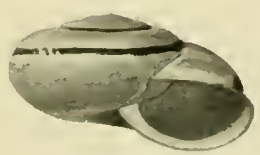

$9 a$

$6 b$
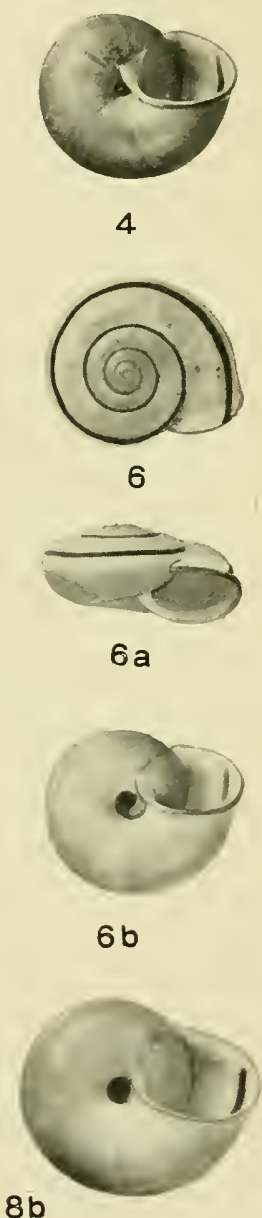

$6 a$
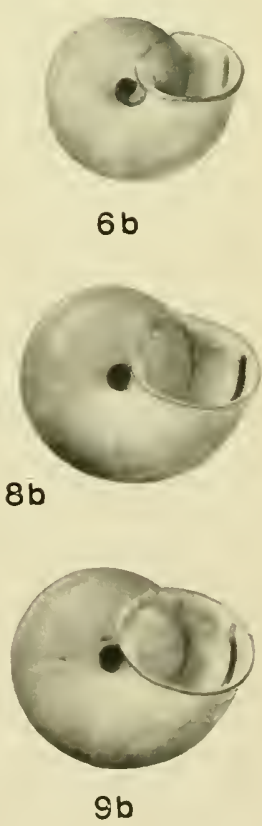

PILSBRY AND FERRISS: SOUTHWESTERN MOLLUSCA. 



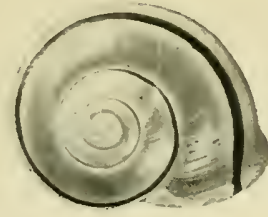

1

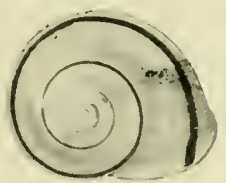

2

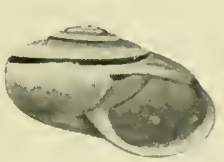

$2 a$

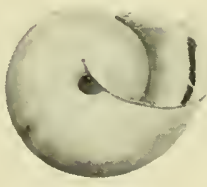

$2 b$

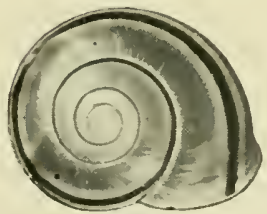

$5 b$

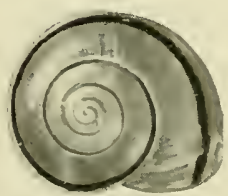

6

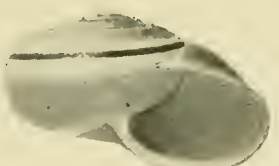

$1 a$

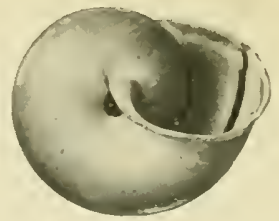

$1 b$

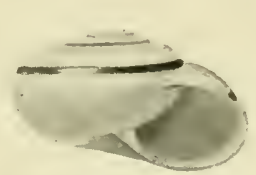

$3 a$

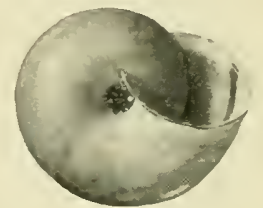

$3 b$

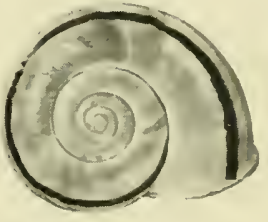

4

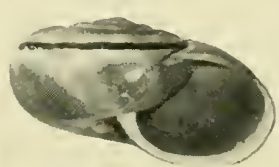

$4 a$
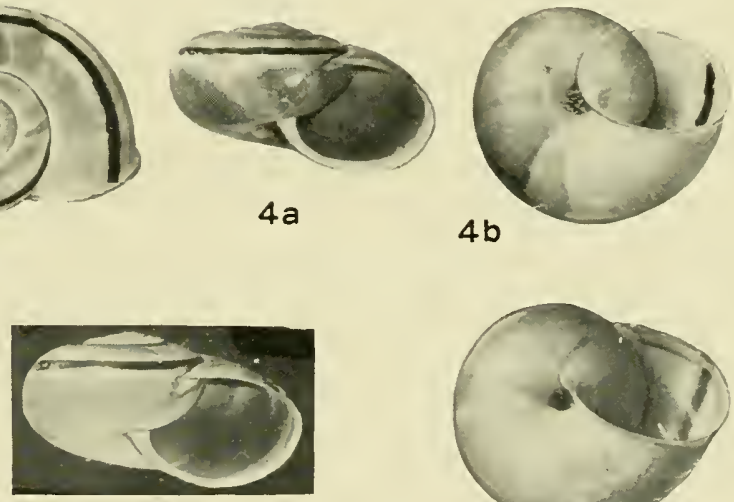

5
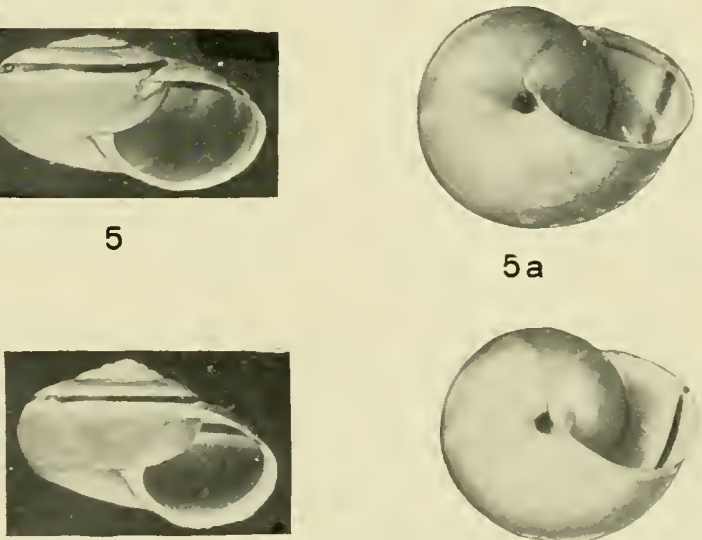

$5 c$

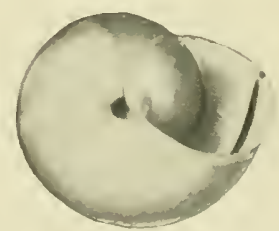

$5 d$

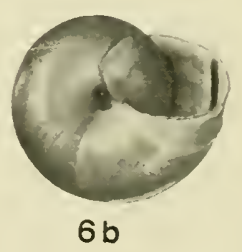

PILSBRY AND FERRISS: SOUTHWESTERN MOLLUSCA. 


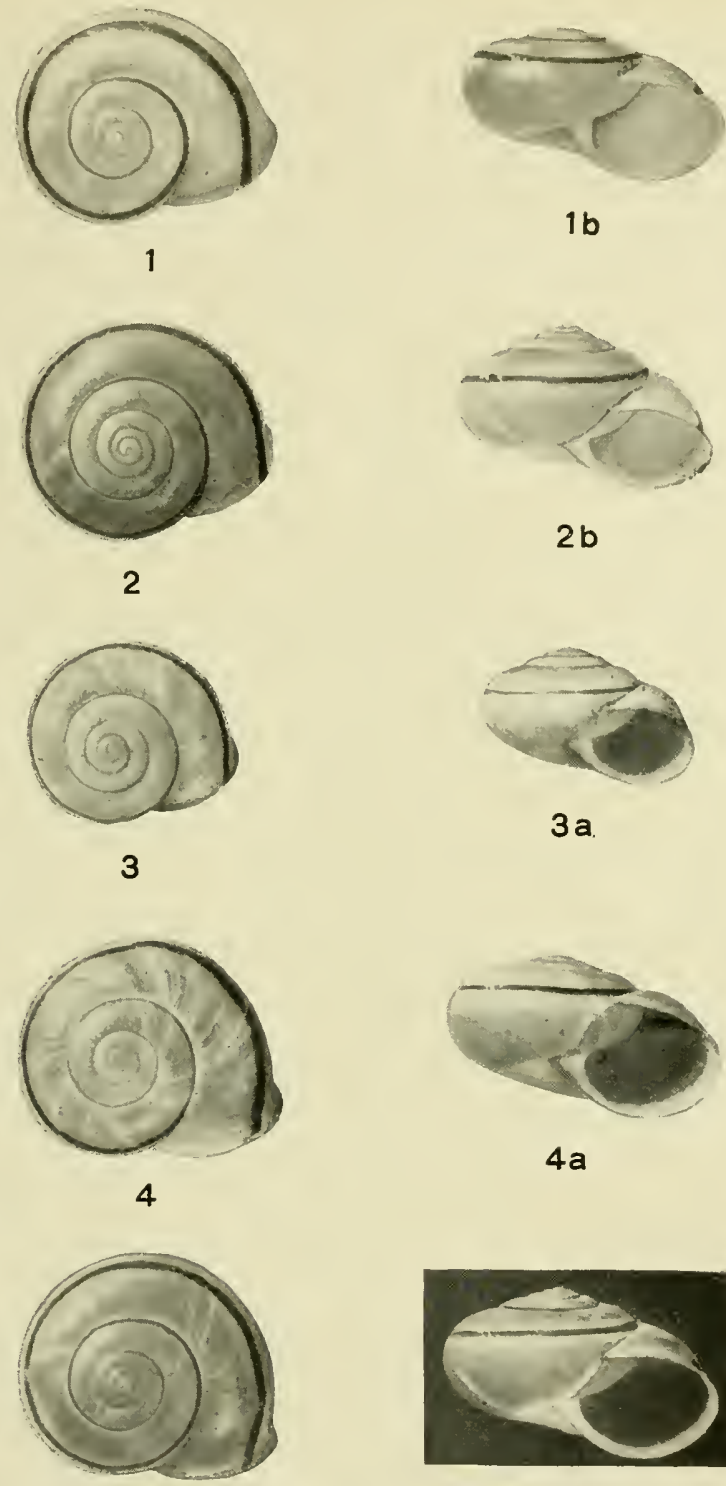

5

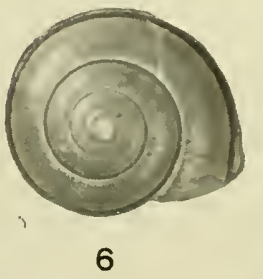

16
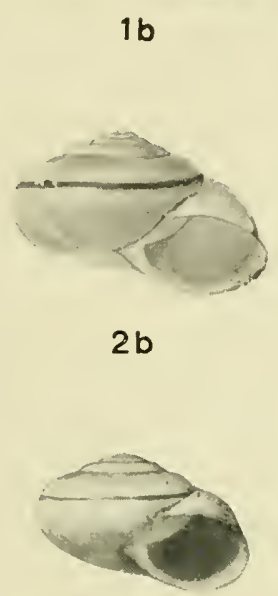

$3 a$

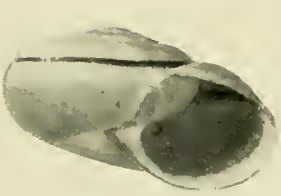

$4 a$

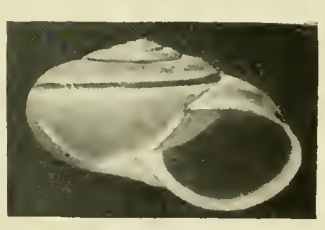

$5 a$

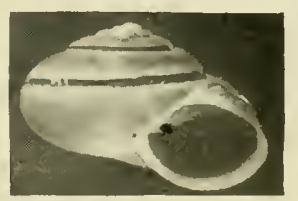

$6 a$

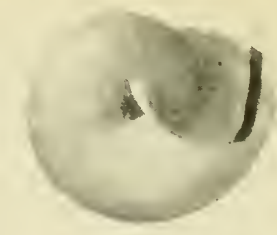

$1 a$
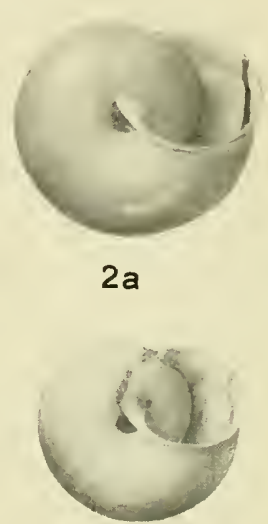

$3 b$
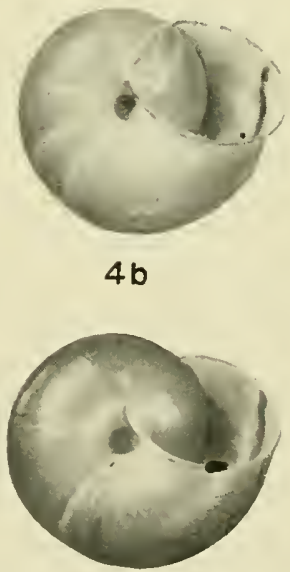

$5 b$

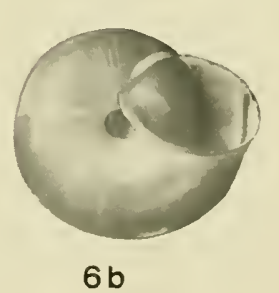

PILSBRY AND FERRISS: SOUTHWESTERN MOLLUSCA. 


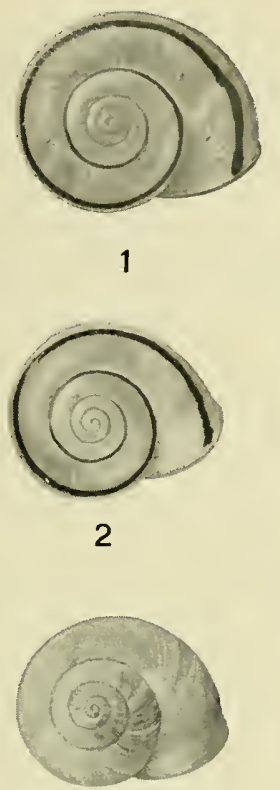

4

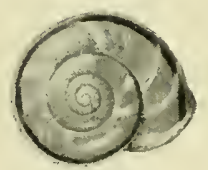

6

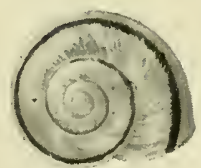

7

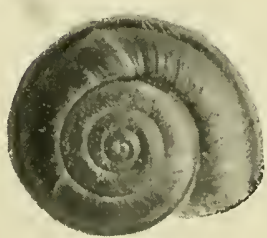

9

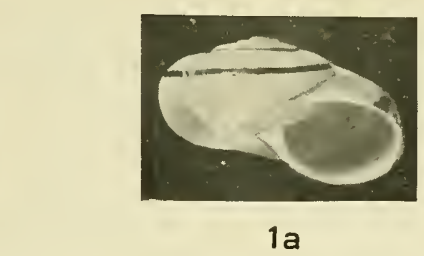

$1 a$

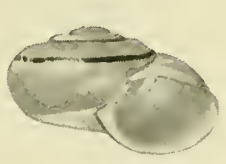

$2 a$

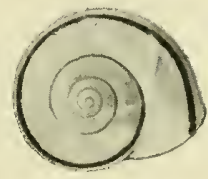

5

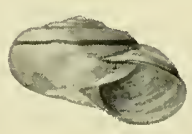

$6 a$

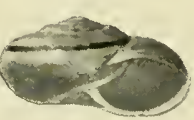

$7 a$
$5 a$

$9 a$
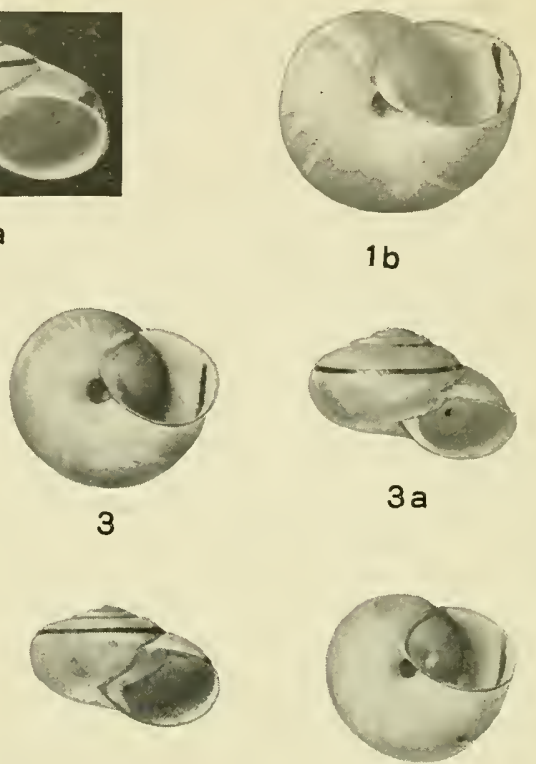

$5 b$

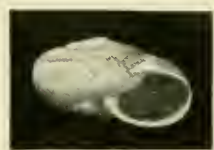

8

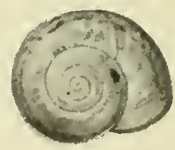

$8 a$

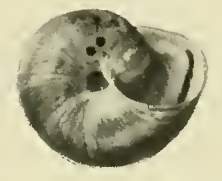

$7 b$

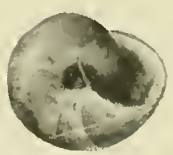

$8 b$

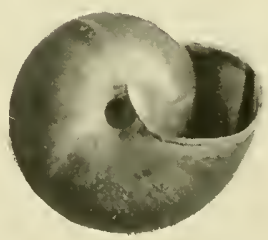

$9 b$

PILSBRY AND FERRISS: SOUTHWESTERN NOLLUSCA. 



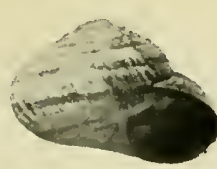

1
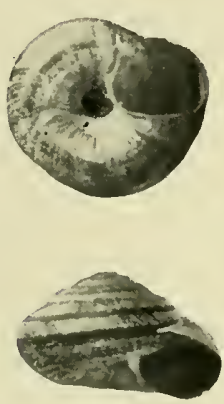

3
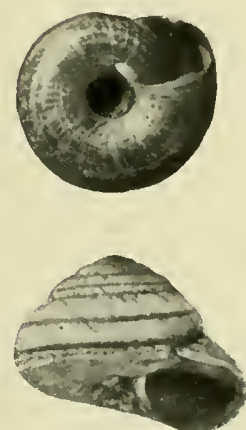

$5 a$
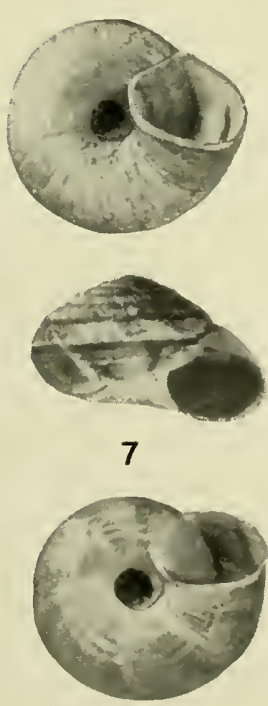

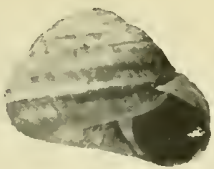

2
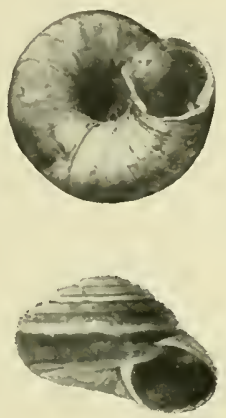

$3 a$
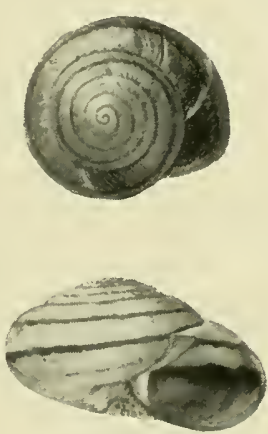

$5 b$
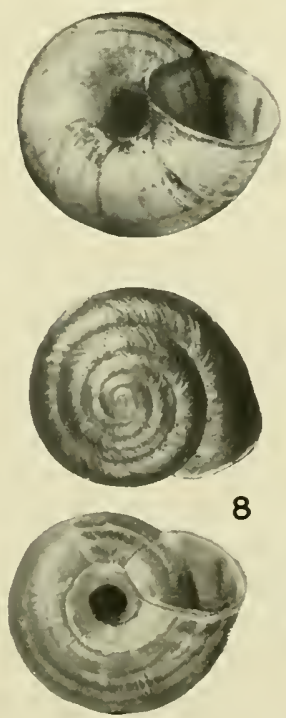

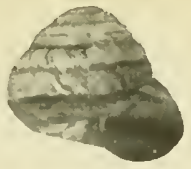

$2 a$
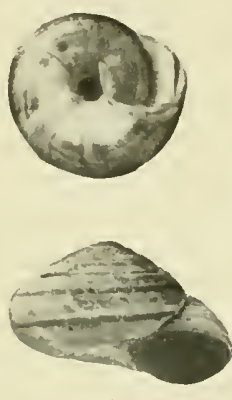

4
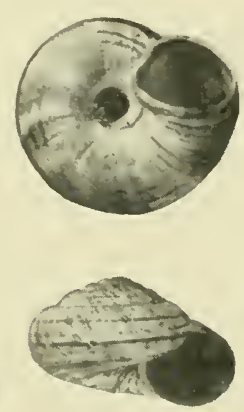

6
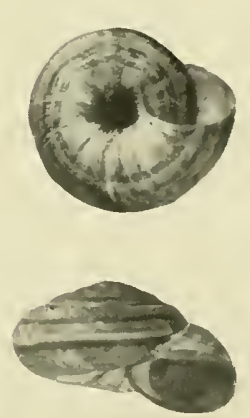

$8 a$

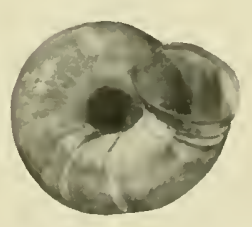

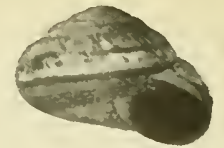

$2 b$
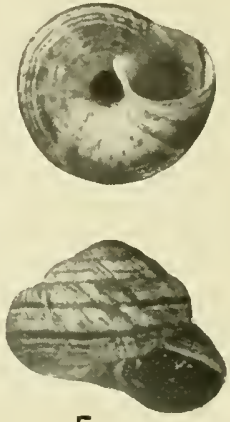

5
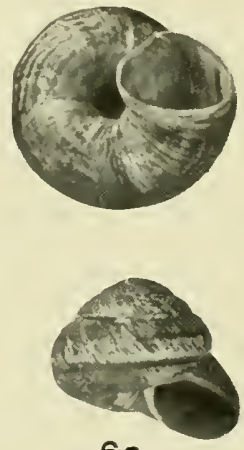

$6 a$
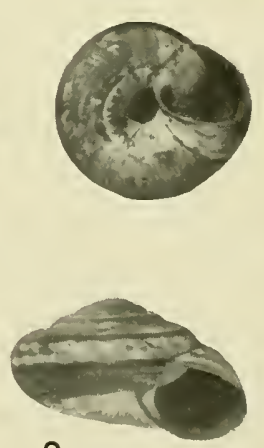

9

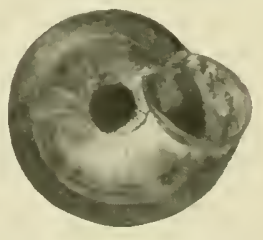

PILSBRY AND FERRISS: SOUTHWESTERN MOLLUSCA. 





\title{
MOLLUSCA OF THE SOUTHWESTERN STATES, XI-FROM THE TUCSON RANGE TO AJO, AND MOUNTAIN RANGES BETWEEN THE SAN PEDRO AND SANTA CRUZ RIVERS, ARIZONA.
}

\author{
By Henry A. Pilsbry and James H. Ferriss.
}

We continue here the examination of mollusks of the desert mountains of the southwest carried on in former papers of this series. The accumulation of data on more or less similar faunas of the many mountain ranges of this region is, from the nature of the task, somewhat monotonous; yet such work is absolutely essential to an understanding of the problems of distribution and evolution. A study of the distribution and migrations of such desert genera as Sonorella, which we have under way, cannot be made until reasonably full local data are available.

The rccords following relate almost wholly to the faunas of Pima County and the western border of Cochise County, Arizona. The explorations were made by one of us (J. H. F.) in 1917-18, continued in company with the late Mr. A. A. Hinkley, in 1919.

Types of the new species and subspecies are in the museum of the Academy. Paratypes of all are in the Ferriss collection. to Ajo.

I. List of stations and of mollusks collected from the Tueson Range west

II. List of stations and of mollusks collected in the Empire, Whetstone, Mustang, Huachuca, Santa Rita, Patagonia, San Cayento, Tumacacori and Pajaritos Ranges.

III. Notes and descriptions of Sonorella, Orcohelix, Bulimulus and Holospira.

IV. On Micrarionta rouelli (Newc.) and M. newcombi, new species.

I. List of Stations and of Mollusks Collected from the Tucson Range to Ajo.

To the eastern man, Tucson seems to be upon the rim of the world, more so than San Diego. At Tucson it is Ajo, 150 miles westward, that is the land's end and thus fascinating to explorers and miners. Contemplating the journey to Ajo, a little run was made out in that direction to the Tucson range about Christmas time, 1917, to try a new machine and to take a look at the road. Camp was made that afternoon at Pictured Rocks, a pass about the middle of the range, an hour from the city. The next day, C'hristmas, Frank Cole, our guide, hunter, cook and boss, brought in a wild pig, and Sonorella bones were found. The pig was baked with 
sweet potatoes, and there were hot biscuits, jam and peaches on Christmas day.

The next day living Sonorellas were found at four stations. A diamond rattler, mountain sheep, black-tailed deer and small game were in evidence, here under the shadow of the chief city of the state, more than in any range visited in 1917-18.

The Christmas reconnoiter was satisfactory. A few days were needed to finish up the Tucson hills and again we camped there. This programme was repeated a number of times, and the west side of the range during the months of January and February was well explored from Catt mountain on the south end to Relitto village on the north, about 35 miles.

During the last week of February the newly paved county road was taken to Ajo. The machine ran as though on air. Some twenty-two miles west of the city, on the Robles ranch, small buttes of limestone capped by lava appear, not over 100 or 150 feet above the desert floor; but we turned aside for a couple of miles and investigated. Sonorellas were very plentiful and alive. Heretofore the highest peaks of Arizona, at least from 8,000 to 10,000 feet, have been our idea of snail prosperity. The species is a small form of $S$. ambigua, here at the eastern limit of its range.

This discovery caused a deflection to the nearby Roskruge range where further good fortune awaited us, Sonorella berryi, and others; and it was the 7th of March before we were again on the road to Ajo. These mountains are on the right of the county road, but the Coyote range on the left seemed much higher than when viewed from the Baboquivari peaks. Thus another deflection, and our tents were pitched in the main canyon, or cove of the Coyotes facing eastward. Here was a half section or more of level land, well-forested with mesquite and paloverde, long known for its ranch houses, mines, and good water. Four domes of granite tower on the southwest. There are thick groves of oak, and a wealth of snails and ferns, one of the most pleasing places in this region (see maps, Text-figs. 5 and 6 ).

Sonorella ambigua grows larger in the Coyotes than elsewhere. It is also the prevalent Sonorella in Bobb's Butte and the southern Roskruges, where $S$. berryi and an interesting small race of $S$. $t u$ mamocensis were taken in single colonies.

On the 22nd of March the Coyotes, Kitt's Peak and a spur of the Baboquivaris were left behind. Water was taken on at Indian 
Oasis, where the National Government, a Preshyterian mission, and the traders have a beautiful village. All west of the Tueson Range to the western limit of Pima county belongs to the Papago Indians, a tribe rich in horses and cattle, and in good health. It is the desert proper, but well covered with mesquite, paloverde and the giant cactus. Columns of the latter run up fifty to sixty feet occasionally, and the ribs are largely used by Indians and Mexicans in fencing and house building. The forests of giant cacti are sometimes thirty miles wide. The desert trees made good firewood and fencing but do not grow larger in this region than apple trees of the east. Little real timber is seen west of Kitt's Peak.

Low parts of the desert are selected for farming, and the Indians have many acres of corn and wheat under cultivation. If the rains come they get a fair crop. There were not as many species of native plants westward of Tucson as eastward, but there were changes and new societies, hour after hour. The organ cactus (Cereus thurberi), here near its northern limit, we saw for the first time, also the crucifix tree and another species of the paloverde group. The organ cactus grows only fifteen or twenty feet high and branches freely, or rather, the stems spread at the surface of the soil. It is only about eight inches in diameter, but has the same rib construction as the giant cactus.

The hills and low mountains of the region west of the Tucson range, as well as a large part of the Tucson range itself, are capped with eruptive rock, "malpais" and basalt. This gray volcanic rock is oxidized by the weather, polished by the sand blast, thus the hills take on a dark bronze color. Among the broken fragments or blocks of this flow a prehistoric people left trenches and fortresses, plainly constructed for defensive purposes. Thus trench warfare is not as new as some may beheve, for the Indiars now living here do not know who built these fortifications. The graves of this people were also on the hillsides, built above-ground of lava blocks and timbered, and in this climate much of the wood is still sound. On top, the level spaces had squares and circles cleared in the lava for dwellings. In picture-writings their stories are recorded upon the larger volcanic blocks and cliffs.

Sonorellas in every hill was the rule until near the Big Ajo range. Then a light-colored powder appeared on the lava, and a week passed without finding a shell, except a few of the small fry found in drift. One hundred and one miles west of Tucson the fine desert Son- 
orella, S. ambigua, was found in the low hills, but not beyond there. It is one of the wide-ranging snails, found also far southward, on the Mexican boundary, and extending west of any other Sonorella.

Sonorellas were the only large species obtained from Tucson to Ajo. Chatenaxis and Thysanophora hornii were common, but other small shells few in number. Desert Sonorellas, large as they are, give the pursuer a hard race. In dry weather they retire to the deepest regions of their talus world, and to the farthest comers, and stay there in cool weather, wet or dry. Only a steady downpour on a warm day awakens long sleep and the attachment to smooth stones. But in numerous instances Sonorella has been surprised in the world above, in rainy weather, wandering among the fresh vegetation and fallen leaves. There again they are discovered with much difficulty. In the egg-laying periods they often gather plentifully among stones near fresh vegetation at the lower edge of the slide. In some instances they seemed to herd their young. Perhaps but a few times in their history do they partake of a square meal. And, where is their harvest field, in the stone pile, or in the vegetation above?

Ajo is now one of the great mining centers of Arizona, and at the time of our visit was but a little over a year old in this reputation, though an old eamp in the history of the state. The prospect of novelty and entertainment was pleasing, but the snailing proved disheartening. Later, information was gathered that a colony of shells had been seen in the Big Ajo Mountains southward, at a walnut grove and spring. Also that there were shells in the Mesquite Range on the Mexican border. The large Growler Range west of Ajo city looked promising from a distance, but the Mexican bandits were active at that time along the western boundary.

There were also hills of promise on the road back. The Pisenomo route Tuesonward was taken, and shells found in the south end of the Quijotoa Range, and in the southern foot hills of the Cababi Range. Again Sonorella ambigua; also Chenaxis, and various Pupillidæ.

Sonorellas have a wide range in station, from decaying logs in the deep moist woods of the Catalinas, to the hot side of dry desert hills. At our eamp near the Palo Alto Cattle Company's ranch house, at the foot of Kitt's Peak, a small desert hill not over fifty fect high sheltered a colony of Sonorellas. Near the summit of Kitt's peak a colony of small Sonorellas, S. xanthenes, had chosen 
heavy shade and a deep forest cover; in similar situations Polygyra albolabris, palliata and thyroidus are found in the east.

April 8th, our expedition to Ajo was again under roof at Tueson. Many may make that journey in quicker time, but few will see as much between the two eities. In interest every day was filled to its full capacity. ${ }^{1}$

Collections were made at the following stations in 1917-1918:

(1-11. Baboquivari Range. See map, Text-fig. 8, on page 83.)

1. Sycamore canyon, east bank of north fork, 100 yards above the fork, in stratified porphyry.

2. 100 yards above station 1 , west bank of north fork, in a slide.

3. Half mile above station 2 on same fork; large slide opposite eaverns.

5. South slope of small hill north of camp, in a small pile of porphyry.

6. High peak west of north from camp, slope overlooking Otero eanyon.

7. Tumble of porphyry eliffs, head of ridge.

8. Near Station 7.

9. Head of Otero canyon.

10. High mountain 4 miles west of Station 9 .

11. Opposite Station 3.

Stations 12 to 45 and 48, in the Santa Catalina, Rineon, Galiuro and Tortillita Ranges, have been enumerated in these Procendngs for 1918 , pp. 307,308 .)

46. Silver Bell Range: slides on a quartzite hill northeast of the mine headquarters.

47. Sierrita Range: largest canyon on the northeast, in bank of gulch and porphyry slides above.

\section{(5S-90. Tucson Range)}

53. Half a mile northwest of Pictured Rocks.

54. About 4 miles north of Station 53, one of several slides facing west, on the west side of the Range.

55. Slide facing west, on the next mountain north.

56. Slide facing south, same mountain.

57. Table mountain, half a mile east of Station 54 .

58. About 3 miles south of Pictured Rocks, opposite Yuma mine ("Mountain Sheep Camp").

59. About 5 miles north of Mt. Sheep Camp, in a quartzite outlier west of the range, and a twin outlier of lime butte.

\footnotetext{
${ }^{1}$ Besides the well-known works of Lumholz and MacDougal, upon the Papago country, there has recently been issued a valuable paper by liirk Bryan, "Frosion and sedimentation in the Papago country, Arizona, with a sketch of the geology." U. S. Geol. Survey, Bulletịn 730-13. 192:.
} 
60. Half a mile above Station 58, porphyry slide.

61. Slide west of 60 , across the gulch and higher.

62. Old miners' camp at foot of hill whereon are Stations 58, 60,61 .

63. (This and the following up to 85 , are in and about the amphitheater, p. 71, diagram, Text fig. 4). Small slicle at point of mountain at southwest point of amphitheater, about 3 miles south of Silver Bell road gap (Nelson's ranch).

64. North slope of same in boulders of gulch, foot of peak.

65. Bed of dry wash below 65 .

66. Near top of range, above 64 .

67. Between two highest peaks, in gulch boulders at a low level.

68. A short distance further up than 67. ite.

69. Silver Bell Pass, north side of the highway, reddish quartz-

70. South side of the same.

71. Northwest side of quartzite butte, opposite Station 59.

72. North end of the range opposite Rillito village 1 mile, north side of peak.

73. 200 yards east of the same (bones very abundant).

74. Base of mountain, below Station 66, in a gulch bank slide.

75. 200 yards up same gulch.

76. Foot of next peak east.

77. Below 76, in boulders.

78. South side of the peak at the north end of the range, opposite Stations 72, 73 .

79. Quarter mile east of same.

80. Mountain at northwest point of amphitheater, near top, in a quartzite slide on the south side.

81. Cliffs above Station 68. \&c.

82. Dry wash at Twin Cacti camp.

83. West point of amphitheater, south side, in boulders.

84. Higher up, under shoulder of the peak, eliffs.

85. Southeast end of flat-topped mountain, in a slide.

86. Catt Mountain, northwest side, above spring and herder's cabin.

87. North side of a mountain on south side of the amphitheater (Limekiln Camp).

89. 2 miles southeast of Mile-wide Copper Co. camp.

90. Southwest slope of same mountain as No. 87 .

(Robles Hills, an eastern outlier of the Roskruge Range).

91, 92. At the dolomite quarry.

93. Northeast side of the same hill, the malpais slide.

94. North side of middle hill.

95. East side same hill; in malpais. 


\section{(Roskruge Range).}

96. Small spur ruming north and south, west of Little Robles ranch house.

97. Boulder bank in a mountain $1 \frac{1}{2}$ miles east of ranch house, main range, in a wash on the north side of the first high peak.

98. Rocky cliff, higher and further east.

99. Half mile further east, higher (Raining; 58 Sonorellas alive) This is 2 miles east of Little Robles ranch house.

100. Half mile further east.

101. Little Robles spur, a small knob between the two peaks. furthest north.

102. Next to the last peak north, slide on the north side.

103. Malpais slides, small hill near forks of the road on the north side, east side of the range.

104. Black table-top mountain on east side of the range, south side.

105. East side of the same, overlooking Indian village of Cocoraque.

106. South end of range: Bobb's Butte, a ligh peak north of the Ajo road, in a malpais slide on the east side, in the north side of a wash.

107. South side of a talus field 1/1 mile long, 100 yards wide, further up.

108. Half way up the slide.

109. Near middle of the slide, which is divided by a strip of ereosote bushes.

110. Small black hill three miles east of north of Bobb's Butte, in malpais slicle.

(Coyote Mountains. See Text-figs. 5, 6.)

111. Near head of piped springs, in eliffs.

112. Boulder walls of gulches about the mining camp.

113. Wall, northeast of canyon.

114. Cliffs in rincon between Baboquivari and Coyote ranges and Kitt's Peak at spring of Chief Pablo la Jaro.

115. North wall of main canyon, near 113.

116. Mining camp, below Station 112.

117. Cliffs of creek near former Sycamore Forest Ranger Station, now a cattle camp, rincon of Chief Pablo.

118. Foot of the middle dome, southwestern rim of main canyon.

119. Santa Rosa Ranch, in the valley between the Roskruge and Comobabi Ranges; in bank of wash west of the ranch house.

(120-124, 14\%. Kitt's Peak, at the North End of the Baboquivaris and West of the Coyotes, and its Environs.)

120. Base of small outlier northwest of Kitt's Peak.

121. Kitt's Peak, middle one of three large canyons on the north side, in boulders near foot of mountain. 
122. About a mile further up, on a stream of living water.

123. Foot of cliffs near the head of the above stream, about $1,500 \mathrm{ft}$. from summit, under scattered rocks among oak brush, sticks and leaves.

124. In a low hill north of road to the ranch house.

\section{(125-131. Along the Comovo Route to Ajo.)}

125. Small hills south of the road, about 12 miles west of Indian Oasis.

126. Small hills south of the road, about 3 miles west of Comovo Church.

127. Small group of hills 10 miles from Wall's Wells, 101 miles from Tueson. Indian pictographs in the point near the road.

128. Wash at Wall's Wells, Ajo Mountains.

129. South of Station 127.

130. Between 127 and 129 .

131. On the desert midway between Wall's Wells and Quijotoa Range.

\section{(132-136. Quijotoa Mountains.)}

132. Midway between Poso Blanco and Covered Wells.

133. East side and south end of Rangeold mines (Logan), in gulch slides.

134. South mountain east side, near base, bank of gulch.

135. Foot of slide higher up mountain, in dark malpais.

136. Half mile north in deep gulch, slide of light-gray malpais.

(137-146. Cababi Hills. See map, Text-fig. 7, on page 81.)

137. Southwestern foothills: a small hill on the plain in the west side of the group.

138. West side of eastern hill of group.

139. A small hill near the wash.

140. East side of eastern hill; the locality where Frank Cole collected in 1914.

141. A large hill south of the Indian village, east of the road.

142. Two outlying hills west of the road to the village.

143. North side of the eastern hill.

144. North of wash at our camp.

145, 146. West and east sides of a valley southwest of camp, southern foothills.

147. Small granitic hill, about $50 \mathrm{ft}$. high, half mile west of Palo Alto cow camp, near Kitt's Peak.

Tuscon Range. The following are species or localities additional to those reported in these Procendings for 1915, pp. 399, 400 :

Sonorella tumamocensis P. \& F. Stations \$6, 87, 90.

Sonorella sabinoensis tucsonica P. \& F. Generally distributed.

Sonorella sabinoensis deflecta P. \& F. Station 59.

Sonorella baboquivariensis depressa P. \& F. Stations 58, 60, 61. 
Thysanophora hornii (Gabb). Stations 53, 62, 87, 89.

Gonjodiscus cronkhitei (Nc.) Tumamoc Hill.

Helicodiscus arizonensis P. \& F. Station 5.3.

Pupoides marginatus (Say). Stations 65, 82.

Chaenaxis tuba (Pils.). Stations 53, 62, 82.

Chaenaxis intuscostata (Clapp). Stations 87, 89.

Gastrocopta bilamellata (St. \& Clapp). Stations 82, 87.

We have not succeeded in tracing Sonorella arizonensis Dall, based on a unique bleached shell found in the Santa Cruz River, Tucson.

Sierritas and Silver Belit Range west to Ajo yielded the following species:

Sonorella ambigna P. \& F. Coyotes and Robles Hills to 101 miles west of Tucson. Nariz Mits. on the Mexican Boundary.

Sonorella xanthenes P. \& F. Iritt's Peak.

Sonorella baboquivariensis depressa P. \& F. Sierritas, Baboquivaris.

Sonorella berryi P. \& F. Station 103, Roskruge Mts.

Sonorella sitiens comobabicnsis P. \& F. Cababi MIts., near Indian Oasis, south end Quijotoa Mts.

Sonorella tumamocensis var. Silver Bell MIts., Station 46; Roskruges, Station 110.

Thysamophora hornii (Gabb). Station 136, Quijotoas, and 132, Covered Wells.

Pupoides marginatus (Say). Station 128, Wall's IVells, Ajo Range; 132, Covered IVells.

Chanaxis intuscostata (Clapp). Station 136, Quijotoa Range.

Chanaxis tuba (Pils.). Station 92, Robles Hills.

Gastrocopta pellucida hordeacella (Pils.). Station 128, Wall's Wells, Ajo Range.

Gastrocopta bilamellata (S. \& C.). Station 12S, Wall's Wells, Ajo Range; 132, Covered Wells.

Gastrocopta perversa (St.). Station 203, south side Sierritas.

Gastrocopta ashmuni (St.). Station 203, south side Sierritas.

Succinea avara Say. Station 128, Wall's Wells, Ajo Range, and Station 131, plain between Ajo and Quijotoa Mts.

II. List of Stations and of Mollusks Collected in the Empire, Whetstone, Mustang, Huachuca, Sañta Rita, Patagonia, San Cayento, Tumacacori and Pajaritos Ranges.

A general account of the winter and spring campaign of 1919, by one of us (J. H. F.), may be found in The Nautilus, XXYIII, pp. 37-44. Descriptions of some of the species taken are given in the same volume, pp. 19-21. 
Collecting Stations, 1918. (J. H. F.)

\section{(149-152. Empire Range.)}

149. North sicle of large peak $1 \frac{1}{2}$ miles north of Total Wreck mine. Limestone.

150. Road to Forty-nine mining camp, north slope of mountain $1 / 2$ mile south of camp, in a gulch running north.

151. Gulch west, starting west then turning north. Limestone and porphyry.

152. Southwest side of largest peak, 2 miles north of Forty-nine mining camp, north of road; at foot of $300 \mathrm{ft}$. cliff.

\section{(153-159. Mustang Range.)}

153. North side tower, east peak.

154. West end range on north side south hill, $3 \mathrm{~d}$ peak from west.

155. Same ridge higher up the mountain.

156. Next slide north of 155 .

157. North side of 4 th peak.

158. East side of tower, east peak.

159. Top and northwest side of east peak.

$$
\text { Stations of 1918. (J. H. F. And A. A. Hinkley.) }
$$

200. Southerland ranch, Santa Catalinas.

201. South side of Black Mt., San Xavier del Bac.

202. Sierrita Mts., canyon facing east, about $4500 \mathrm{ft}$. Same as Station 47 (1917-18).

203. Sierritas: road to Harris ranch, south side.

204. Sierritas, south side, about $6500 \mathrm{ft}$. Dead Sonorella only. 2041/2. Tumacácori Mts., amphitheater facing east immediately south of Tumacácori Peak, about $4000 \mathrm{ft}$., in tailings of an old mine, 3 miles west of old mission.

205. Santa Cruz River (Physa).

206. Allen Mts. in Josephine canyon (southwestern foothills of the Santa Ritas).

207. East of the largest peaks of the San Cayetano range (in the southwestern foothills of the Santa Ritas ending at Calabasas).

208. Northeast side Tumacácori Peak about half way up, in south banks of the arroyo.

209. North bank of the same.

210. South bank of same, just below north peak of canyon.

211. Same amphitheatre as Station 2041/2 near the head of stream.

212. Next to canyon wall at the head of same.

213. The lowest of the prominent knobs leading down the next slope of the main peak of the S. Cayetanos. Stations 213 to 217 are in the northwest side of the S. Cayetanos.

214. North end highest peak of S. Cayetanos.

215. Near the preceding. 
216. North slope of same peak in slide of white porphyry. (Same slide as Station 207, but higher.)

217. South side same ridge.

218. Half a mile south of the above.

219. Near the preceding.

220. Pajaritos Range: Calabasas canyon, Garcia National Forest, about a mile above Oro Blanco road.

221. A short distance further up canyon on west side.

222. Larger slides near 221.

223. Pina Blanca canyon $1 / 2$ mile above Oro Blanco road, slide on east bank.

224-229. Successively further up the stream.

230. Same vicinity as 229 .

231. Quarter mile east of Cassin's gate on Oro Blanco road, in the Tumacácori Mts.

232. Montana Peak.

233. Montana mine reservoir (Physa).

234. Tumacácori Mts., 5 miles north of Pina Blanca, in a small canyon running east and west, opposite main gulch from Tumacácori Mts. (living Bulimulus in slide).

235. Large slicle, same hill.

236. Slide $1 / 2$ mile below camp in Pina Blanca.

238. Bear canyon, Pajaritos Mts., mile below Oro Blanco road.

239. Cassin's reservoir (Physa).

240. Opposite 236.

241. Creek 2 miles north of Nogales-Tueson road (Physa).

242. Northwest branch of Pina Blanca canyon.

243. Southern peak of San Cayetano Mts., 2 miles above Calabasas, west bank of Sonoita Creek.

244. South side of a small knob, in porphyry.

245. Further north. Albino Sonorella in this and the preceding colonies.

246. Further north.

247. The furthest south of the larger peaks.

248. Near 247.

249. Edge of the mountain. Stations 243-249 are on the south side of the Cayetano Range.

250. Northwest slope of mountain, in mass of loose rock about 40 acres in extent. This station is about 2 miles from Station 217 , both well over towards the west side of the S. Cayetano Range.

251. Small hill east side of Sonoita Creek.

\section{(252-264. Patagonia Mountains.)}

252. West side of Mt. Washington, Patagonia Mits., in hills west of main canyon and of the road to Duquesne.

253. Boulder island of the main canyon ruming west on Mt. Washington; about $4500 \mathrm{ft}$.

254. Half mile above, among boulders. 
255. Half mile below peak.

256. Hills east of peak.

257. Red Mountain, Patagonia Mts., north side (Red Mountain Copper Co.).

258. North side of Duquesne road near summit of pass, in a long porphyry slide.

259. South side of road and ravine.

260. 2 miles east of Duquesne road to Mexico in ravine bank, large rocks.

261. Branch of ravine rumning east from Bald Mt., near Duquesne.

262. On the road, above bridge over perhaps the same stream.

263. Base of the top rock of Bald Mountain, south side.

264. Near foot of Bald Mt., south side.

265. Mouth of cave on Bald Mt. (Pupillidæ).

266. Crevices, Bald Mt. peak, sloping eastward (Pupilliclæ).

267. Near cave, west side Bald Mountain, (Pupillidæ, etc.).

268. Manila mine, northwest end of Huachuca Range, (Type locality of Holospira ferrissi).

269. Peak east of the cave (Pupillidæ).

270. Hill southeast of cave in the red rock.

271. Deep canyon, 1 mile north of the Manila mine hill, dolomite cliff facing northwest.

272. Cliff facing south.

273. North of 272 , cliff of granite facing northwest.

274. In cliffs on the south side of the canyon.

275. Peak of foot-hill one mile east of the camp.

276. I arge peak in the Canelo hills, east of the HuachucaDuquesne road.

277. Smaller hill, north.

278. Stream near Canelo P.O. (Lymncea and Physa).

279. Lyle canyon, south side Huachuca Range, near the head, about $7,000 \mathrm{ft}$.

280. Near the mouth of Lyle canyon, about 6,000 ft.

281. High lill two and one-half miles southwest of Manila camp.

282. West side of same peak.

283. I'iatt's reservoir (once known as Igo's), quarter mile from Manila camp (Pisidium, etc.).

284. Dan Mathew's ranch, Mustang Mountains, slope of limestone peak facing south, in the heart of the range.

285. Slope of lime facing east.

286. High cliff facing north (Station 153 of 1918).

287. Limestone hill east of 286 .

288. North side of hill north of the Mustang Range (Chonaxis).

289. Limestone hills west of the Duquesne road, Canelo Hills, four stations, numbers 289-292, commencing nearest the road.

292. Three miles west of the road, the last station of this series. 
293. Whetstone Range, two miles north of Two-Peak mining camp, in a long, porphyry slide facing east.

294. Near 270 in the Huachucas.

295. Tombstone reservoir in Carr canyon, Huachucas, slide east of stream.

296. West side of the stream.

297. Heart of Garden canyon.

298. Cliffs of Brown canyon, south of concentrator.

299. Cliffs farther west.

300. Lime ridge forming NIV. boundary of Carr canyon.

301. Second gulch east and south side of Miller canyon above

Tombstone water-works dwelling.

302. North slope of divide overlooking Ramsey canyon.

303. North slope of next peak NIV. of Station 293, Whetstone Range.

304. Peak north of 303 , facing north, and the highest cleft peak. $3041 / 2$. Same peak as 293, slope facing north.

305. Steep northern slope of trail to above stations, mile from camp.

306. Western dome of the Mustangs.

307. Western gulch of Carr canyon, Huachucas, near the cliffs.

308. Spring near marble quarry in Ash canyon (Pisidium, etc.).

309. East fork of double gulch southeast of spring, on Ash Mountain.

310. Same gulch near top of the mountain.

311. West fork of same gulch.

312. South of Foot's cabin, in limestone ridge, Montezuma canyon.

313. Farthest eastern peak, south side of canyon near Ed. Ratcliff ranch, small cliff on side hill.

314. Slides near the cliffs.

315. Gulch west of 314 .

316. Copper canyon, a mile above ranger station.

317. Ida canyon, a mile from Happy Jack cave.

318. Copper canyon, a half mile above Station 316.

319. Small mountain in forks of Copper canyon, near the mines.

320. Nountain north of State of Texas mine camp, in Montezuma canyon.

321. Northwest side of mountain west of this camp.

322. On lime hill in pass to Copper canyon, slide of porphyry.

323. Slide of porphyry southeast of pass.

324. Mountain slide north of Ed. Ratcliff ranch, near spring.

325. East side of peak northeast of State of Texas mining camp.

326. Gulch southwest of camp, in lime, Ash canyon.

327. Deep double gulch, west of last rock-fronted mountain on south side of Montezuma canyon.

328. Large conglomerate precipice one mile southwest of camp.

329. North side of canyon from camp. 
330. Opposite side of mountain from Station 229 (the Ash canyon side).

331. Third mountain south of marble quarry in Carr canyon.

332. Largest mountain west of Dan Mathew's ranch house in the Mustangs; main gulch of north slope.

333. Next gulch eastward.

334. Small hill in the pass to Elgin.

Santa Rita Mountains.-Iate in December, 1917, Rosemont and Createrville, on the eastern slope, were found to be dry collecting. Miners have removed much of the timber. Living Sonorellas were rare, and the dead ones very dead. This is in the oak, walnut and sycamore zone. A couple of miles south of Rosemont a crossing was made westward on a spur of porphyry, looking down upon Helvetia. Slides were numerous, large and deep. Dead Sonorellas of two species were found, and one alive.

At Createrville a limestone ridge south of the placer diggings, four miles south of the village, was given a hard half-day's work. $\mathrm{Mr}$. Cole, our guide, in his mining days was a superintendent here, knew the ridges and led the way. Under large blocks of stone and deep in the earth we found a few "bones" of Sonorella, but none alive. The short list follows:

Sonorella walkeri aguacalientensis P. \& F. Allen MIts., in Josephine canyon, Station 206 (1919).

Sonorella linearis P. \& F. Station 49, 50 (1917).

Sonorella hesterna P.\& F. (?). Station 49-52 (1917).

Thysanophora hornii (Gabb). Station 48 (1917), Rosemont.

Polita indentata umbilicata (Clkll.). Station 48 (1917), Rosemont. Gastrocopta ashmuni (Sterki). Station 48 (1917), Rosemont.

The Empire Mountains are small, the highest peak about $5500 \mathrm{ft}$., lying in eastern Pima Co. between the Whetstones and the northern end of the Santa Rita Range. They are mapped on the Patagonia Quadrangle. Camping on this range, across the valley from the Santa Ritas, Sonorella and Holospira were located in a high peak at the north end of the range, about two miles north of the Total Wreck mine. Again they were found in peaks on the south side of a branch road to the Forty-Nine mining camp. Also north of this road a mile or more, at the foot of a prominent precipice. Very few were alive.

Sonorella binneyi imperialis P. \& F. Station 151; a few bones at 150 .

Sonorella tryoniana P. \& F. Stations 149, 152. 
Thysanophora hornii (Gabb). Stations 149, 150.

Holospira whetstonensis P. \& F., small form. Station 149.

Polita indentata umbilicata (Ckll.) Stations 150, 151.

Chaenaxis tuba (Pils.). Station 149.

Chaenaxis intuscostata (Clapp). Station 150.

Gastrocopta perversa (Sterki). Station 149.

The Whetstone Mountains form a short range on the boundary between Pima and Cochise counties, north of the Huachueas, connected therewith by the $4500 \mathrm{ft}$. contour. The highest peak reaches $7684 \mathrm{ft}$. The range forms part of the Coronado Forest Reserve, and is mapped on the Benson Quadrangle, U. S. G. S. topographic maps.

A brief visit was made by one of us (J. H. F.) in 1914, and a few shells of Sonorella cotis were obtained. In the spring of 1919, with $\mathrm{A}$. A. Hinkley, two trips were made from our Huachuea camp without finding a shell. On the third trip, a long slide facing east was diseovered, ${ }^{2}$ eontaining many dead Sonorellas. Shells were subsequently found in the following stations:

Sonorella cotis P. \& F. Stations 3 (1914), 293, 304, 3041/2 (1919).

Sonorella insignis P. \& F. Stations 304, 3041/2, 305.

Oreohelix concentrata huachucana (Pils.). Stations 286, 303, 304, $304 \frac{1}{2}$.

Holospira whetstonensis P. \& F. Stations 293, 304, 305.

Gastrocopta ashmuni (Sterki). Station 293.

Gastrocopta a. minor (Sterki). Station 303.

Gastrocopta dalliana (Sterki). Stations 303, 293.

Gastrocopta pilsbryana (Sterki). Station 293.

Gastrocopta pellucida hordeacella (Pils.) Stations 293, 303.

Vallonia perspectiva Sterki. Station 303.

The Mustang Mountains are a small group, only about 4 miles long, between the Huachucas and Whetstones, within the eastern border of Pima Co. The highest peak is $6315 \mathrm{ft}$. elevation. Mapped on the Benson Quadrangle. The prevalence of limestone makes these mountains particularly favorable for Holospira.

First visited by J. H. F. in 1918, going down from the Empire Range. Across a beautiful prairie country settled up by dry farmers, twenty miles or more southeas.t the highway to Patagonia and Fort Huachuca passes between the Whetstone and the Mustang Mountains. Here was limestone again in both ranges. Sonorellas and Holospiras were plentiful at the Dome of the Mustangs (Sta-

\footnotetext{
${ }^{2}$ Nautilus, XXXIII, p. 42.
} 
tion 159) and two hills to the west, all that we investigated; but the limestone of the Whetstones was hard, sharp pointed, and had no snails, large or small. Subfossil Oreohelix were found in the clay banks of the Mustang gulches. Like the Empire Range, the Mustangs have a few stunted oaks and an abundance of foot-hill shrubs.

Sonorella mustang P.\& F. Commonly distributed.

Oreohelix concentrata huachucana (Pils.). Fossil only.

Holospira arizonensis mustang P. \& F.

Holospira ferrissi monoptyx P. \& F. Station 285.

Holospira whetstonensis arata P. \& F. Stations 159 and 153 (1918).

Polita indentata umbilicata (Ckll.). (Station 153 (1918).

Pupilla syngenes (Pils.). Station 286.

Chanaxis tuba (P. \& F.). Stations 288, 306.

Gastrocopta perversa (St.). Station 286.

Gastrocopta p. sana (Pils.). Station 306.

(rastrocopta ashmumi (St.). Stations 288, 306, 332.

Gastrocopta a. minor (St.). Station 288.

Gastrocopta a. imperfecta P. \& F. Station 286.

Gastrocopta dalliana (St.). Stations 286, 332.

Gastrocopta pellucida hordeacella (Pils.). Stations 286, 288, 306, 323.

Huachuca Mountians.-Our former work on this range $^{3}$ was supplemented in the spring of 1919 by an examination of Montezuma and Copper canyons, at the southeastern end of the range, and further collections in other parts by J. H. F. and A. A. Hinkley.

Ashmunella varicifera (Anc.). Montezuma canyon, Stations 314, 321, 327 (1919). Limestone hill in pass to Copper canyon, Station 322. Copper canyon, Station 316. Ash Mountain, Stations $310,311$.

A shmunella levettei heterodonta Pils. Ida canyon, Station 317.

Ashmunella levettei angigyra Pils. Station 270, hill southeast of cave, Bald Mt. Station 280, near mouth of Lyle canyon.

Sonorella (see section III of this paper).

Holospira ferrissi Pils. Northwestern end. See below.

Zonitoides minuscula (Binn.) Station 295, Carr canyon.

Striatura milium meridionalis P. \& F. Stations 295, Carr canyon, and 323, Montezuma canyon.

Pupilla syngenes (Pils.) Station 299, western cliffs of Brown canyon.

Chaenaxis intuscostata brevicostata Pils. Station 300, limestone ridge, northwest boundary of Carr canyon.

Gastrocopta pellucida hordeacella (Pils.) Stations 268, 294, 300. Gastrocopta perversa (St.). Stations 269, 270, 294, 300, 311, 268.

\footnotetext{
${ }^{3}$ P'roc. A. N. S. Phila., 1909, pp. 495-516.
} 
Gastrocopta perversa sana Pils. Stations 269, 270, 326 .

Gastrocopta ashmuni (St.). Stations 270, 297, 323.

Gastrocopta ashmuni minor (St.). Stations 294, 297.

Gastrocopta ashmuni imperfecta, n. subsp. Stations 270, 297, 303 and 311. The columellar lamella is simply curved within, and outwardly remains horizontal, as in $G$. cochisensis, not passing into the position of an infraparietal lamella. The free peristome, very large angulo-parietal lamella and the very deeply immersed lowerpalatal fold remain as in $G$. ashmuni.

Gastrocopta cochisensis (P. \& F.). Station 299, Brown canyon.

Gastrocopta dalliana (St.). Stations 270, 294, 297, 311.

Gastrocopta pilsbryana (St.). Stations 295, 297, 299.

Tertigo coloradensis inserta Pils. Stations 295, 296, rare.

Tertigo hinkleyi Pils. Station 296 e, Carr canyon.

The Canelo Hills are a long range with the higher erests up to about $5900 \mathrm{ft}$. They lie between the northern ends of the Huachuca and Patagonia ranges, united with both by the $5000 \mathrm{ft}$. contour, and more deeply separated from the southeastern Santa Ritas by the valley of Sonoita Creek. They are mapped on the Patagonia and Nogales Quadrangles.

Sonorella elizabethe P. \& F. Station 276.

Holospira ferrissi caneloensis P. \& F. Stations 289-292.

Gastrocopta ashmuni minor (St.). Station 289.

Gastrocopta dalliana (St.). Station 289.

Gastrocopta pellucida hordeacella (Pils.). Station 289.

The Patagonia Range is about 15 miles long, running up to over $7000 \mathrm{ft}$. The southern foothills extend across the Mexican boundary. Mapped on the Nogales Quadrangle. Visited by J. H. F. and A. A. Hinkley in midwinter, 1919, when there was considerable snow, hence not many species were taken. J. H. F. and E. H. Ashmun had collected a few shells in the northwestern foothills and at Sanford many years ago.

Sonorella patagonica P. \& L. Southern part, ahout Washington. Sonorella tryoniana P. \& F. Northern end.

Gastrocopta periersa (Sterki). Station 265.

Gastrocopta dalliana (Sterki). Station 265.

The San Cayetano Mountains lie east of the Santa Cruz River and north of Sonoita Creek, near the southern end of the Santa Ritas. Collection made by J. H. F. and A. A. Hinkley, 1919.

Sonorella hinkleyi P. \& F. Mainly in the southern part.

Sonorella hinkleyi cayetanensis P. \& F. Northern part. 
The Tumacaconi Mountains are west of the Santa Cruz River, and pass southward into the Pajaritos. Visited by J. H. F. and A. A. Hinkley in 1919.

Sonorella hinkleyi tumacacori P. \& F. Tumacácori Peak and next mountain southward.

Zonitoides minuscula alachuana (Dall). Station 205.

Zonitoides singleyana (Pils.).

Gastrocopta ashmuni (Sterki). Station 235.

Gastrocopta dalliana (Sterki). Station 235, 236. drift.

Gastrocopia cristata (P. \& V.). Station 205, Santa Cruz, River

Gastrocopta pellucida hordeacella (Pils.). Station 205, Santa Cruz River drift.

Pajaritos Mountains.-These rolling hills extend across the Mexican boundary west of Nogales. Visited by J. H. F. and A. A. Hinkley early in 1919. It is the only known locality in Arizona for Bulimulus.

Sonorella walkeri montana P. \& F. Stations 231, 232, 238.

Sonorella sitiens P. \& F. Numerous stations.

Bulimulus nigromontanus Dall. Pina Blanca canyon, and 5 miles north in the Tumacácori Range.

Gastrocopta dalliana (Sterki). Station 237.

\section{Notes and Descriptions of Sonorella, Oreohelix, Bulimulus and Holospira.}

\section{HELICIDAE}

The species of Sonorella may be grouped as follows:

$a^{\prime}$. Length of penis decidedly exceeding the diameter of the shell.

$b^{1}$. Penis-papilla long, thick-walled, perforated by a minute duct; epiphallus shorter than the penis.

$c^{1}$. Penis large, simply bent or but little folded in preserved examples, the stout papilla from about half to nearly as long as penis. Group of S. virilis.

$c^{2}$. Penis slender, both it and the vagina disposed in folds. Group of S. rinconensis.

$b^{2}$. Penis-papilla short (contained $4 \frac{1}{2}-5$ times in penis), hollow, with an enclosed tube; epiphallus longer than penis. Group of S. dalli.

$a^{2}$. Length of the penis less than the diameter of the shell.

$b^{1}$. Penis-papilla usually stout and cylindric, or enlarging toward the blunt or conic distal end.

$c^{1}$. Vagina much longer than the penis. Group of S. granulatissima. 
$c^{2}$. Vagina not much longer than the penis, often shorter. Group of S. ambigua.

$b^{2}$. Penis slender, the papilla slender, gradually tapering to the distal end. Group of S. hachitana.

\section{Group of S. hachitana.}

Sonorella hachitana (Dall)

A series of 21 specimens in the National Museum, no. 130005, is from the top of two peaks of the Carrizalillo Hills, near Carrizalillo Spring, New Mexico, collected by Dr. Mearns when on the International Boundary Survey. They have the deeply descending last whorl of hachitana, and differ from that species in little except the smaller size, from 18.5 to $21 \mathrm{~mm}$. diameter. It is apparently a small local form of hachitana, and of interest because it is at the eastern limit of the genus as now known.

Sonorella elizabethæ Pils. \& Ferr. Plate I, fig. 1; plate IV, figs. 1, 1 .

Nantilus vol. 33, July 1919, p. 20.

Canelo Hills: Station 276, a large peak east of the HuachucaDuquesne road. Type no. A. N. S. P.

Closely related to $S$. hachitana, but the shell is constantly smaller and the male organs longer. The penis is decidedly over onethird the diameter of shell and longer than the vagina (in hachitana between one-third and one-fourth the diameter of shell, and shorter than vagina). It is very slender, with a short, stout basal sheath. Penis-papilla slender, tapering, over half the length of penis. Flagellum minute. The organs in two specimens from Station 276 measure.

Penis.......... $8.0 \mathrm{~mm}$.

Epiphallus....5.5 and $6 \mathrm{~mm}$.

Penis-papilla......5.0 mm. Vagina........

The shells vary in diameter from 16.7 to $20.7 \mathrm{~mm}$.

Sonorella mustang Pils. \& Ferr. Plate I, figs. 2; plate IV, figs. 5.

Nautilus vol. 33, July, 1919, p. 20.

Mustang Mountains, on the Pima-Cochise Co. line, at Stations 153, 155-159 (1918), and 284, 286, 332-334, 336 (1919). Type from Station 332 (1919).

The shell resembles $S$. hachitana closely, differing by being slightly less depressed, the umbilicus somewhat smaller, the last whorl descending less in front, and the aperture larger.

It is glossy, light pinkish cinnamon, fading to whitish around the umbilicus and on both sides of the chestnut-brown band above the periphery, which is visible above the suture on $1 \frac{1}{2}$ to 2 whorls. The first whorl has minute, irregular, radial wrinkles partly anas- 
tomosing on the first half whorl, then very fine, forwardly-descending threads over them, about as in S. hachitana.

Height 15.3, diam. $26.5 \mathrm{~mm}$. ; harely 5 whorls. Station 332. Type.

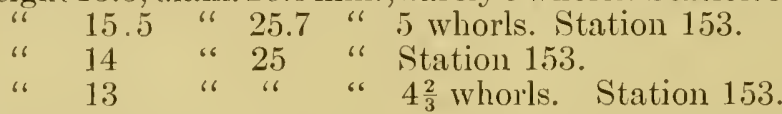

Genitalia (Plate IV, fig. 5) of the hachitana type, but characterized by the much greater length of all of the male organs, which are decidedly longer than in $S$. $h$. flora, which has a shell at least as large as $S$. mustang.

The penis is slender, having a sheath which is thick and museular near the base. Its papilla is about two-thirds the length of penis, tapering and slender. The flagellum is unusually long; beyond the flagellum the vas deferens is somewhat enlarged, as in the related forms. The lengths of the organs are as follows:

Penis $15.5 \mathrm{~mm}$., Penial retractor $11.5 \mathrm{~mm}$., Penis-papilla 10.5 mm., Fpiphallus $8.0 \mathrm{~mm}$., Flagellum $2.0 \mathrm{~mm}$., Vagina $13.5 \mathrm{~mm}$., Museum No. 44048. Station 286.

The jaw has 6 strong ribs.

Though not much differentiated from $S$. hachitana in the shell, this form appears to be specifically distinet by the genitalia. The penis is about three times as long as in S. coris, while the epiphallus is about the same as in that species.

Common throughout the Mustang range. It was taken alive in abundance at Stations 153, 155, 156 (1918) and Station 332 (1919). At Station 336 (1919) only a few fossil examples were found. Fossil or "subfossil" shells were abundant at Station 153 (1918). These shells are rather small, between 19 and $22 \mathrm{~mm}$. in diameter, with 4 to $4 \frac{3}{4}$ whorls.

A few beautiful albino shells were taken at Station 284.

Sonorella cotis Pils. \& Ferr. Plate I, figs. 5, 6; plate IV, figs. 3, 9.

Nautilus vol. 33, July, 1919, p. 20.

Whetstone Range. Type 130994 from Station 3 (1914).

The typical small form only was taken in 1914, the type locality being station 3 (1914), a mile up from the Ranger Station. The diameter is from 20 to $22 \mathrm{~mm}$. In the genitalia (Plate IV, fig. 9, paratype) this form resembles $S$. sabinoensis occidentalis. The penis is small, slender, becoming abruptly swollen near the base, the swollen part containing several large pilasters. The papilla is very slender, with slight traces of annulation. Vas deferens is enlarged in the lower part, as in S. walkeri. The organs measure:

Penis..........4.8 mm. Flagellum...... $0.5 \mathrm{~mm}$.

Penis-papilla......3.0" Vagina.........10.5 "

Epiphallus.......7.0" Museum No......119038. 
The pallial region (Plate IV, fig. 3) shows a kidney more than half as long as the lung the proportion being 15 to $26 \mathrm{~mm}$. The pericardium is $4.5 \mathrm{~mm}$. long. The veins of the anterior portion of the lung are sparsely bordered with brown dots.

In 1919 it was collected at Stations 293, 304 and $304 \frac{1}{2}$. While some typical $S$. cotis were taken, most of the shells are larger, up to $25 \mathrm{~mm}$. diam., and not definitely distinguishable from S. mustang; also very close to S. walkeri. No animals were preserved, so that we cannot eompare the genitalia of this large form, which is temporarily left with $S$. cotis, as there seems to be some intergradation in size.

Sonorella patagonica Pils. \& Ferr. Plate I, figs. 7-10; plate IV, figs. 2, 4, 6, 7, S.

Sonorella patagonica P. \& F., Nautilus vol. 33, July, 1919, p. 20.

Patagonia Mountains, in the southern part, Stations 253, 254, 255, 258, 259 to 262, 264, the type from Station 254 .

The shell is very similar to $S$. papagorum, but in the type and many other specimens (but not in all) there are impressed spiral lines on the last whorl below the suture. The embryonic shell shows forwardly-deseending threads, hachitana pattern, eharaeters not observed in S. papagorum.

Height 12.8 , diam. 22 mm.; $4 \frac{3}{4}$ whorls. Type, No. 43722.

Genitalia similar to those organs in S. papagorum, but the organs are somewhat longer; flagellum generally better developed, and the vas deferens is somewhat enlarged near the flagellum. Penial papilla is slender, tapering, corrugated (but in one example, No. 43719, from Station 260, it is smooth). Measurements of the organs in $\mathrm{mm}$. follow.

$\begin{array}{lccccccc}\text { Museum No. } & 43721 & 43722 & 43720 & 4715 & 43718 & 43733 & 43719 \\ \text { Penis } & 9.3 & 8.7 & 8.5 & 7.0 & 7.0 & 6.5 & 6.5 \\ \text { Penis-papilla } & 6.3 & 6.0 & \ldots & 5.0 & 5.5 & \ldots & 5.5 \\ \text { Epiphallus } & 7.8 & 8.0 & \ldots & 8.5 & \ldots & 6.5 & 5.7 \\ \text { Flagellum } & 0.5 & 0.5 & 1.0 & \text { minute } & \ldots & 0.7 & 1.0 \\ \text { Vagina } & 11.0 & 9.0 & 8.5 & 8.0 & 8.0 & 8.0 & 7.5 \\ \text { Station } & 258 & 254 & 252 & 253 & 255 & 260 & 260\end{array}$

While this form has considerable resemblance to $S$. hachitana in genitalia, the shell differs, being less depressed, with the last whorl descending less.

The size is rather variable. Thus one lot, no. 43720, from Station 252 , includes specimens measuring from height 11.5, diam. 18.3 $\mathrm{mm}$., to $15 \times 23.7 \mathrm{~mm}$., together with intergrading sizes. 
Sonorella walkeri aguacalientensis P. \& F.

Allen Mountains, Station 206 (1919), a small group of hills in Josephine canyon, in the southwestern foothills of the Santa Ritas, towards the Cayetano Mountains.

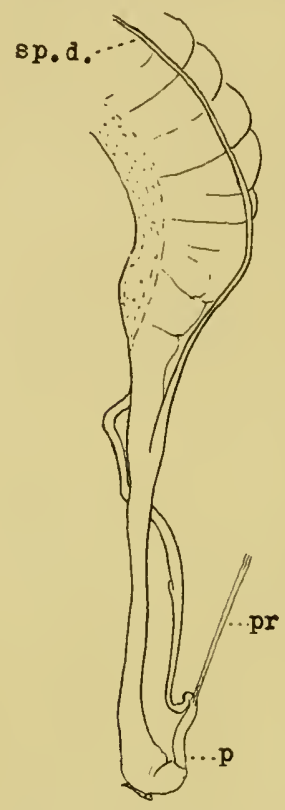

Fig. 1 - Sonorella walkeri montana. 43724. p. penis, $p r$. penial retractor, $s p . d$. duct of spermatheca.

Museum No........43724. Station.......... 232.

Fine, large specimens, about $25.5 \mathrm{~mm}$. in diameter, were taken. The reproductive organs measure in length:

Penis........................ mm.

Penis-papilla.................. "

Epiphallus...............5.0 "

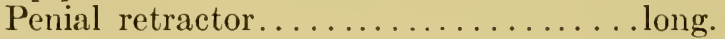

Flagellum.................. vestigial

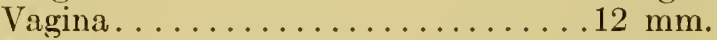

Museum No. . . . . . . . . . . . . . . . 43729.

Sonorella walkeri montana Pils. \& Ferr. Plate. I, fig. 11.

Sonorella montana P. \& F., Nautilus vol. 33, July, 1919, p. 19.

The shell in this handsome form is not distinguishable from that of S. walkeri: but montana differs somewhat by the still smaller male organs. The penis is extremely small, having a short, stout basal sheath and long retractor muscle. The flagellum is reduced to a mere bud; beyond it the vas deferens is enlarged. The base of the vagina is enlarged. Specimens from Stations 232 and 238 agree. Measurements of the organs follow:

Penis...................... $2.5 \mathrm{~mm}$.

Penis-papilla.................. 1.3

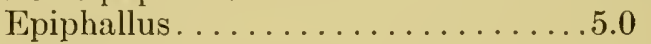

Vagina. . . . . . . . . . . . $9.4 \mathrm{~mm}$.

The preserved animal is nearly white.

Pajaritos range at Station 232, Montana Peak, near the mine; 238, Bear canyon in Bear Valley; and 231, half mile northeast of Cassin's gate in the pass, highway to Oro Blanco.

Sonorella linearis n. sp. Plate I, fig. 12.

Northern end of the Santa Rita Range, the type from Station 50 (1917), on the western side of the saddle, overlooking Helvetia. Also Rosemont, Stations 48 and 49, abundant at the latter. At Stations 49 and 50 it was associated with $S$. hesterna.

The shell is umbilicate (the umbilicus contained about seven times in the diameter), dilute cimnamon, the base whitish, with a 
chestnut-brown band with very indistinct pale borders, somewhat glossy, with fine, weak growth lines, and below the suture on the last whorl a group of incised spiral lines (weak on some specimens, but probably always present). Whorls increase rather slowly, the last slowly descending in front. The peristome is very slightly expanded.

Height 11, diam. 17.3, umbilicus $2.5 \mathrm{~mm}$; $4 \frac{1}{2}$ whorls. Type. " 10, " $17.5 \mathrm{~mm}$. Station 49.

Soft anatomy unknown.

S. clappi in the Santa Ritas has some resemblance to this species, but the last whorl is wider and the surface granulose. It appears distinct from known species of other ranges by the size, small umbilicus and especially the sculpture. Numerous dead specimens, part of them in good condition, were taken at Station 49 .

Until specimens can be dissected the position of this species in the genus cannot be determined.

\section{Sonorella sabinoensis tucsonica $\mathrm{n}$. subsp.}

Tucson Range, the commonest species, generally distributed. Stations $63,64,66,74,75,77,80-83$ in one valley, "wild pig amphitheatre"; $72,73,79$ are the small form from the northwest end of the range. Also at Stations 54, 56, 57.

The shell is similar to $S$. sabinoensis except that the umbilicus is a little larger in specimens of equal size; as in that species, the last whorl, seen from above, is quite wide. It differs from $S$. papagorum by the sculpture of the embryonic whorls, which is distinct, as in sabinoensis, while in papagorum it is extremely weak, the surface appearing more polished. The color is distinctly darker than papagorum, wood-brown or almost fawn color, with a usually broad chestnut-brown band with pale borders. The last whorl descends very little in front.

Height 15.7, diam. $27 \mathrm{~mm} ., 4 \frac{1}{2}$ whorls. Type. Station 81 .

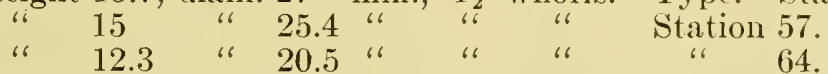

The genitalia are similar to $S$. sabinoensis, characterized by a rather long penis, in those measured from slightly over $\frac{1}{3}$ to nearly $\frac{1}{2}$ the diameter of shell. The slender, slightly tapering penispapilla is also long, generally wrinkled somewhat, but in one specimen (Station 64) it was smooth. The flagellum is small, or in a specimen from Station 57, wanting. The penis and vagina are longer than in $S$. papagorum, but of the same type. Measurements follow: 
No.

Penis

Penis-papilla

Epiphallus

Flagellum

Vagina

Diam. of shell

Station

118070
9.5
6
6
small
7
27
81

118047
10
7
8
very small
11
23.5
54

118063
9
8
7.5
1
9.5
21
64

118046

7.5

wanting

25

In No. 118070 and 118047 the basal sheath of penis is but little larger than the distal part of the penis. In 118063,118067 and 118049 it is quite thick, as in S. sabinoensis occidentalis.

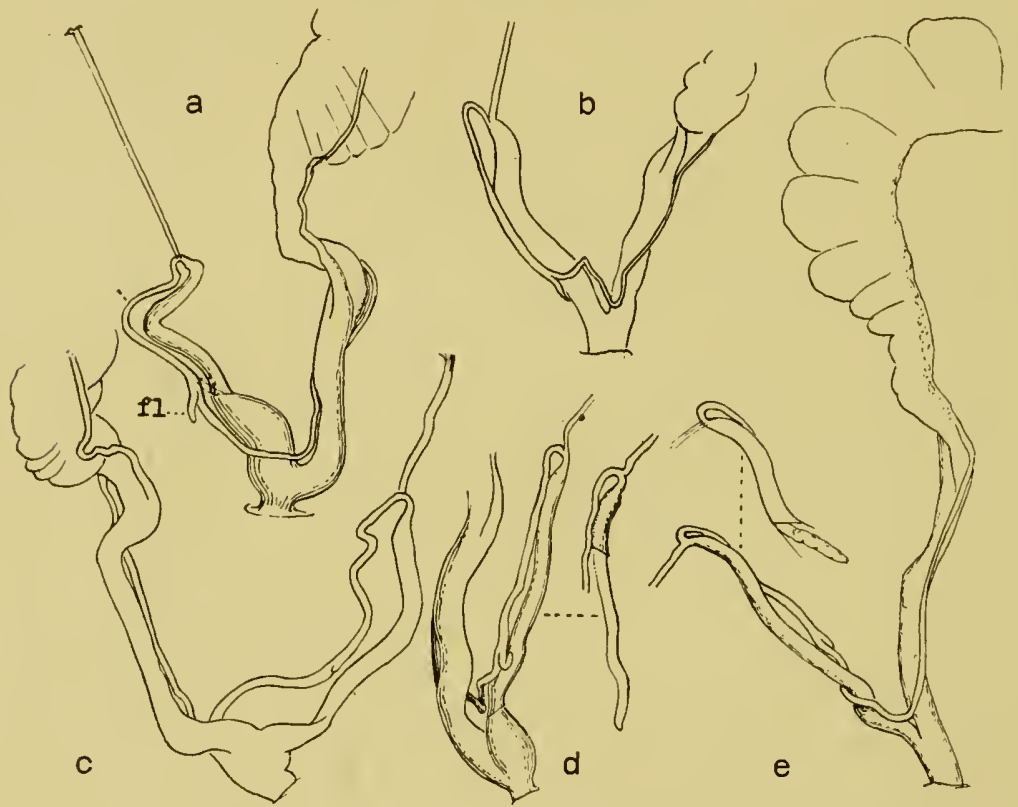

Fig. 2.-Sonorella sabinoensis tucsonica. Lower ducts of the genitalia, a, No. 118067 , station 72. b, S. s. deflecta, No. 118050 , station 59. c. S. s. tucsonica, No. 118047 , station 54 . d, 118063 , station 64 . e, 118070 , station 81 . fl., flagellum. All in the Tueson Range.

The shell is highly variable in size and in degree of depression of the spire. The largest specimens, from Station 81, were found less than half a mile from the smallest measured above, Station 64 , in the same valley.

At the north end of the Tueson Range, Stations 72, 73, 79, all of the specimens are small and clark, diam. 20 to $21.5 \mathrm{~mm}$. In the 
genitalia they do not differ from the smaller examples from "Wild Pig Amphitheatre" (fig. 4). Measurements follow.

$\begin{array}{lccc}\text { Museum No. } & 118067 & 118049 & 118050 \text { (deflecta). } \\ \text { Penis } & 9 & 7.5 & 7 \mathrm{~mm} \text {. } \\ \text { Penis-papilla } & 6 & 4 & 4.5 \\ \text { Epiphallus } & 7 & 4 & 6.5 \\ \text { Flagellum } & 1 & \ldots & 1 \\ \text { Penial retractor } & 7.5 & \ldots & \ldots \\ \text { Vagina } & 6 & 5 & 5.5 \\ \text { Station } & 72 & 79 & 59\end{array}$

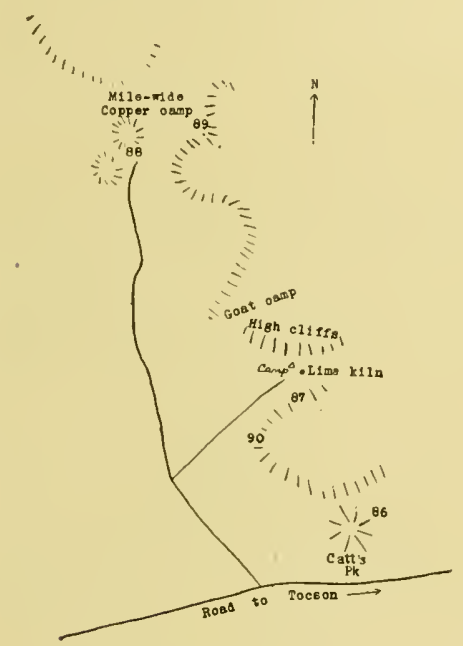

Fig. 3.-Southern end of the Tucson Range.

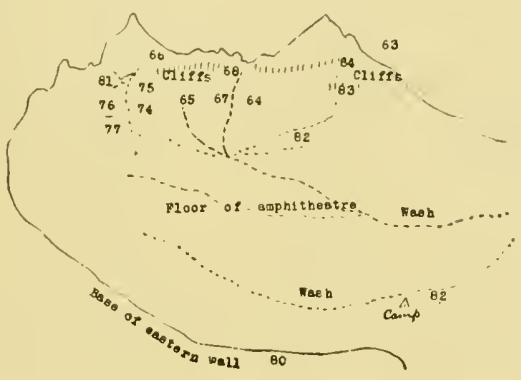

Fig. 4.-Diagram of "Wild Pig Amphitheatre," Tucson Range, looking south, showing approximate locations of collecting stations 63 to 85 . Length about 1 mile.

Sonorella sabinoensis deflecta $n$. subsp.

An equally small form was taken at station 59, about 5 miles north of Sheep camp, in a quartzite outlier of the range westward and a twin outlier of Lime Butte. In form these shells are more depressed than S. s. tucsonica, the whorls are smaller in caliber, the aperture smaller. The last whorl descends rather deeply in front, while in tucsonica it descends but little. 'The color is paler' than in the small tucsonica from the northern end of the Tucson Range. The genitalia (fig. 2b) appear not to differ. Measurements given above under No. 118050 .

Height 12, diam. $19.6 \mathrm{~mm}$; $4 \frac{1}{2}$ whorls.

Type no. 118050 a, from Station 59 (1918). One specimen in the long series seen lacks the dark shoulder band. 
Sonorella xanthenes n. sp. Piate I, fig. 13; plate VII, fig. 11.

Kitts Peak, near the top, Station 123, at foot of cliffs near the head of stream, under scattered rocks among sticks and leaves in oak brush. Type no. 118094 A.N.S.P. collected by J. H. Ferriss, 1918. Paratypes in coll. Ferriss.

The shell is rather thin, has a moderately raised spire and rather small umbilicus contained about $8 \frac{1}{2}$ times in the diameter; it is dull cinnamon-buff, paler on the base, with a narrow chestnut-brown band above the periphery. Surface smooth except for light growth lines, having little gloss. The last whorl descends moderately in front. The peristome is thin, narrowly expanded, dilated at the columellar insertion and impinging slightly on the umbilicus. Parietal callus very thin.

Height 8.4, diam. 13. mm.; $4 \frac{1}{3}$ whorls. Type.

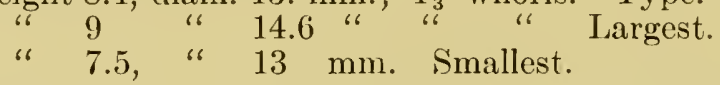

The penis contains a relatively long, smooth, slightly tapering papilla, acute at the end. The epiphallus is very slender, much longer than the penis, is a little swollen near the end and bears no flagellum. The penial retractor inserts on the epiphallus some distance from the penis. The vagina is decidedly shorter than the penis.

Length of penis $\ldots . .7 .7 \mathrm{~mm}$ " Length of epiphallus $\quad \underset{\text { papilla }}{8} \mathrm{~mm}$.

This is one of the smallest species of Sonorella, about the size of the smallest specimens of $S$. coloradoensis. It differs from the latter in the slender, acute penis-papilla and long epiphallus, among other characters.

\section{Group of Sonorella ambigua.}

This group comprises a number of minor sections or series, such as (1) the series of $S$. binneyi, in which the last whorl is very wide, with S. binneyi, S. bowiensis, S. tryoniana, S. baboquivariensis; and (2) the series of forms with spirally grooved penis-papilla, comprising S. tumamocensis, S. eremita, S. hinkleyi and S. hesterna.

Sonorella ambigua P. \& 1 . Plate 2, figs. 1-4; plate V. figs. 1-10, 12; plate VI, figs. 1-5. Sonorella ashmuni ambigua P. \& F., Proc. A. N. S. Phila., 1915, p. 411.

Abundant in the Cababi Hills, Stations 137-141, 143-146 (1918). Station 143, north side of the eastern hill of the group, is the type locality, being Cole's original station.

The large series does not show much variation, all being between 20.5 and $24 \mathrm{~mm}$. in diameter. It is a handsome, glossy form, light 
ochraceous buff with a slight cimnamon cast, whitish on the base, very little or not whitish alongside of the chestnut-brown band. There is generally no spiral striation, but sometimes the faintest traces may be seen below the last suture. The last whorl is wide and descends somewhat abruptly in front. The peristome expands, and in fully adult shells there is a slight thickening within. Parietal callus is very thin. Growth lines weak. The tip of the apex is smooth, followed by a few radial wrinkles, then some small papillæ near the suture. The rest of the embryonic shell has but little sculpture; small radial wrinkles below the suture are more or less noticeable, but no protractive or retractive threads.

The genitalia were examined in specimens from stations 137,138 , 146. The large penis is long, half the diameter of the shell or slightly more, sheathed at the base, and contains a large papilla, which is between half and two-thirds as long as penis, truncate or rounded at the end, where it is generally a little enlarged, and more or less wrinkled and dented. The penial retractor is less than half as long as penis, inserted on the epiphallus where the latter enlarges basally. ${ }^{4}$ There is a very small flagellum. Measurements follow.

Museum No.

Length of penis

" " papilla

" " "epiphalius

" " "retractor

" " vagina

" "sp. and dluct

Station

Pl. V, fig.

118108
12.5
8
9
5
12
$\ldots$.

118103
12.
8.5
9
5
$\cdots$
146

2

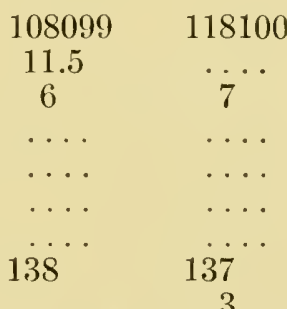

3

The form described and figured as S. ashmuni capax P. \& F. taken by Frank Cole in the Cababi Hills, 1915, was not rediscovered in 1918. It is larger than any of the long series of ambigua taken, and the embryonic shell distinctly shows many protractive threads, of which we see no trace in $S$. ambigua. It is probably specifically distinct from the latter.

The rather large caliber of the long penis and of the blunt papilla, generally larger at the end than further up, the penis longer than the epiphallus, are diagnostic of S. ambigua. 'The wrinkling of the papilla, doubtless due to contraction in alcohol, still in some degree depends upon its structure, and it varies to a certain extent in specimens from different mountain ranges. Unfortunately, no

${ }^{4}$ In measuring penis and epiphallus, care must be taken not to include the thick basal part of the latter, below the insertion of the retractor, as part of the penis. The latter terminates at the root of the papilla, even when there is no distinct contraction above that point. 
fresh specimens have been dissected. It must be remembered that all of the figures and descriptions are from alcoholic preparations.

Besides the typical form of $S$. ambigua, from the southern hills of the Cababi group, we recognize this species in various forms from the Roskruge and Coyote Ranges, their outliers, and several ranges westward.

Roskruge Range Forus.-The shell characters vary from typical to forms with stronger parietal callus. The penis-papilla, while typical in shape, is not much wrinkled, generally showing some longitudinal or irregular and but slightly raised wrinkles towards the distal end (Plate V, figs. 5-7). Measurements of the organs follow:

$\begin{array}{lrrccc}\text { Museum No. } & 118081 & 118077 & 118079 & 118078 \\ \text { Length of penis } & 11 & 14 & 10.5 & 14 & 14.5 \\ \text { "، " papilla } & 5 & 7 & 9 & 11.5 & 10 \\ \text { " " epiphallus } & 10 & 7 & 11.5 & 8 & 12 \\ \text { " " vagina } & 9 & \ldots & \ldots \ldots & 7 & 10.5 \\ \text { Spermatheca and cluci } & 20 & \ldots & \ldots \ldots & \ldots \ldots & \ldots \\ \text { Station } & 7 & 100 & 101 & 106 \\ \text { Plate V, fig. } & 7 & 5 & 6 & \end{array}$

Bobb's Butte, at the south end of the range, north of the Ajo road, different places in a malpais slide on the east side, Stations 106-109 (1918). The size is more variable than in the Cababi Hills, 19.5 to $25 \mathrm{~mm}$. diam. in one lot, Station 107. Some examples are quite typical in form, but there is often a tendency towards depression of the spire, which is sometimes nearly flat. The parietal callus is generally thicker than in the typical locality, often with a thickened edge.

The genitalia of a specimen from Station 106 (Plate V, fig. 4) are are as in ambigua except that the penis-papilla shows only a few pale, slightly raised wrinkles near the distal end.

East side of the Roskruge Range in the neighborhood of Little Robles Ranch, Stations 96-102. The species was taken in abundance at some stations, such as 99 and 102 . The specimens vary from completely typical in shell characters to forms with a moderate or heavy parietal callus, as noted above for Bobls's Butte. Size variable, the largest and smallest in several lots measuring:-

$\begin{array}{crrrrr}\text { Height } 15.3 \text {, diam. } & 25.5 \mathrm{~mm} \text {. Station } & 98 . \\ \text { " } & 13 & 21.5 & \text { " } & \text { " } & 98 . \\ \text { " } & 13.4 \text { " " } & 22.4 & \text { " } & \text { " } & 102 .\end{array}$ 

Height $\begin{array}{r}14.6 \\ 12.3\end{array}$ diam. $24.3 \mathrm{~mm}$ ". Station 104.

At Station 99, a half mile west of 98 and higher, 2 miles east of Little Robles Ranch house, the diameter runs from 19 to $22.3 \mathrm{~mm}$., and the penis-papilla is shorter than usual and smooth, Plate $V$, fig. 7 .

Specimens from the Black Table-top mountain in the eastern edge of the Roskruge Range, Station 104 on the south side and Station 105, east side, overlooking the Indian village of Cocorague are typical in form, rumning from 21 to $24 \mathrm{~mm}$. diameter.

RoBles Hills, outliers of the Roskruge Range eastward. Stations 91-95, at the dolomite quarry and northeast side of same hill, and north and east sides of middle hill, all in malpais. Shells rather small, compact, rather solid, the parietal callus generally thickened with a thickened edge.

Height 11.8, diam. 20 mm., $4 \frac{1}{2}$ whorls. Station 92 .

" 11.5 , " 13.3 , " 18.7 " 22.3 " Station 92.

Genitalia (Plate V, fig. 10, Station 93) typical except that the penis-papilla is deeply wrinkle-pitted, as in Coyote group forms. Measurements follow:

Museum No.................. 118080

Length of penis . . . . . . . . . . . . . .

" "papilla................... 8.5 "

" "

" " " " venial retractor. . . .

" "spermatheea and duct ........

Station.....................93

Plate V, fig. . .................. 10

118084

$12.3 \mathrm{~mm}$.

7 "

8 " "

6 " 6

9.5 "

22 "

104

12

Coyote Range-Collections were made in the main canyon opening east, bounded on three sides by high granite walls and four dome-like peaks on the southwestern wall. At the western head there are springs, piped to the abandoned Zechendorf ranch. The Cavalla mining camp is at the west spring. Stations 111-113, $115,116,118$, and the Rehn and Lutz station, are in this canyon. Stations 114 and 117 are in the rincon between the Baboquivari and Coyote mountains and Kitt's Peak, as shown on the sketches, figs. 5 and 6.

The special characteristics of Coyote specimens of S. ambigua are the large size of the shell and, in alcoholic specimens, the deeply, 


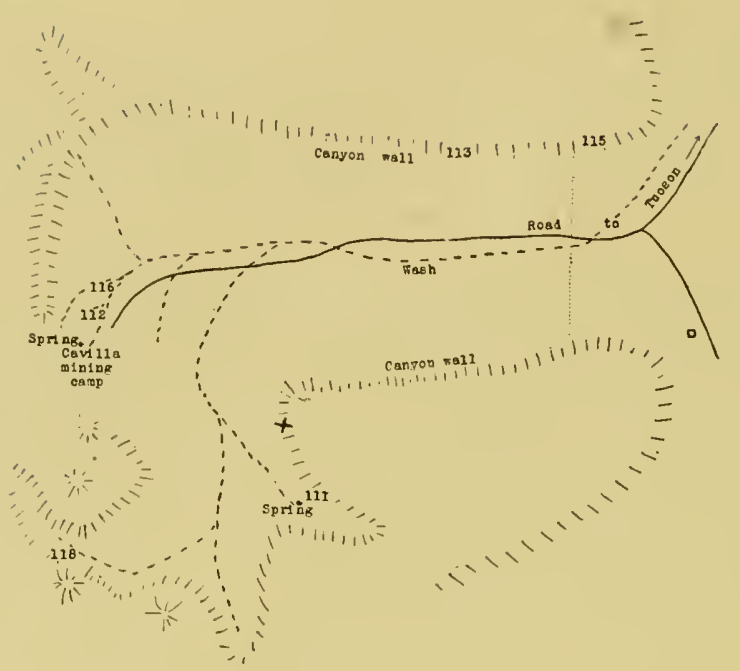

Fig. 5.-Main canyon of the Coyote mountains.

copiously, wrinkle-pitted penis-papilla, abruptly terminated and about $\frac{3}{4}$ as long as the penis, as shown in Plate. VI, fig. 3 . The organs in two large specimens measure:

Museum No..................... 118093

Length of penis. . . . . . . . . . . . . . . .

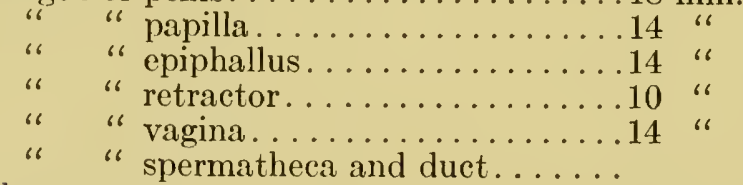

Plate. VI, fig. . . . . . . . . . . . . 4

118054
$17.5 \mathrm{~mm}$.
13
10
16.5 "
19
1

At Stations 114, 118, 119 the shells are rather thin, very large, glossy, last whorl of unusual width, parietal callus thin. Height 16.3, diam. $27.3 \mathrm{~mm} ., 4 \frac{1}{2}$ whorls (Plate. II. figs. 1, 2, Station 118). Others from the same station are not more than $25.5 \mathrm{~mm}$. diameter. These large shells closely resemble $S$. a. capax except in the embryonic shell, which is that of $S$. ambigua.

In other Stations, 112, 113, 115, 116, the shells are smaller, often somewhat more solid. Often the spire is much depressed, as noted in Bobb's Butte specimens. Height 15, diam. $26.5 \mathrm{~mm}$., Station 112. Height 12, diam. $21 \mathrm{~mm}$., Station 112. It is these smaller shells which form a perfect series connecting the large forms with typical S. ambigua. 


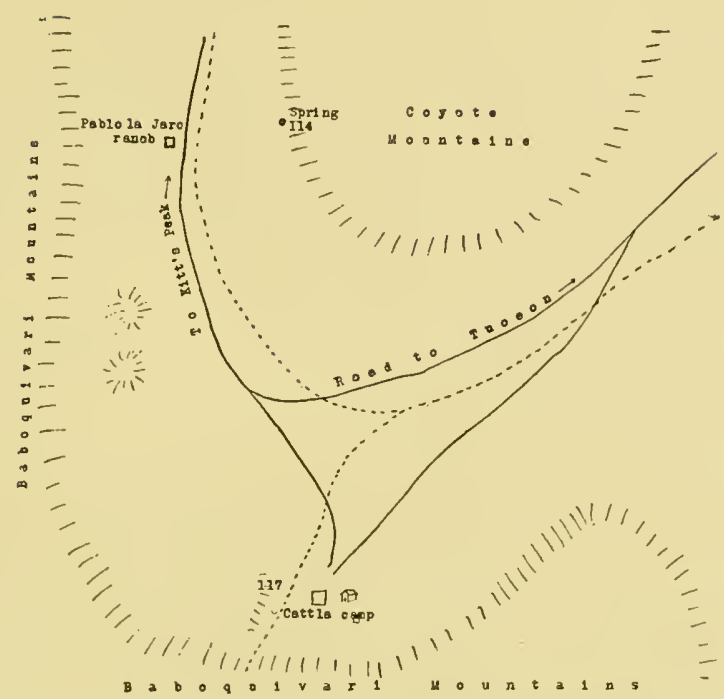

Fig. 6.-Rincon between the Baboquivari and Coyote mountains.

This species appears to have been first taken in the Coyotes by E. A. Goldman of the Biological Survey, whose specimens are 215129 U. S. N. M., 4 dead shells, one in good condition. It was next found by J. A. G. Rehn, who took numerous examples in the main canyon of the Coyotes at between 3600 and $3750 \mathrm{ft}$., on August 5, 1916, in company with F. E. Lutz. His station is marked $\mathrm{X}$ in fig. 5 .

KitT's PEAK AND ENvirons.-Stations 120-124, 147 for this species are in this region, located as follows:

120. Base of a small outlier northwest of Kitt's Peak.

121. Middle one of three large canyons on the north side, among bowlders near foot of the mountain.

122. About a mile up the canyon from 121, on a stream of living water.

123. Near head of the stream at foot of cliffs, at about $5500 \mathrm{ft}$. elevation, under scattered rocks in oak brush, sticks and leaves. The type station for $S$. xanthenes.

124. In a low hill, north of road, foot of Kitt's Peak.

147. Small hill about $50 \mathrm{ft}$. high, near Palo Alto cow camp.

At Station 122 some individuals reach a large size, 23 to 26.5 $\mathrm{mm}$. diam. Small ones only were found at 123 , the highest station, 18.5 to $22 \mathrm{~mm}$. diam. The few taken at 147 are similar. At the 
other stations the sizes are intermediate. Altogether, they resemble closely the Coyote group specimens.

In 1916, Rehn and Iutz took specimens in rocky foothills, 3700-3725 ft. elevation, 2 miles north by east of Kitt's Peak.

A specimen from Station 120 has the penis of $S$. ambigua, but the papilla appears smooth (Plate $\mathrm{V}$, figs. 8, 9). Flagellum wanting or very minute.

Length of penis $\quad 11.5 \mathrm{~mm}$.

Length of epiphallus $9 \mathrm{~mm}$.

The shells are typical ambigua. Elevated and depressed examples are figured, pl. II, figs. 3,4 .

Comovo RoAd to AJo.-The last Sonorella station westward, in the expedition of 1918, was at a small group of hills where the signboard reads "Tucson 101 miles." Beyond that the basaltic rocks were covered with white dust, perhaps alkali, or the granite faces were sharp and dry. ${ }^{5}$ Station 127 , small hills with Indian pictographs on the point nearest the road; 129 is back of the pictured rocks, west side, and south of 127 . Station 130 was made between the preceding hills and the Quijotoa Range.

Specimens from Stations 127 and 130 are typical S. ambigua in shell characters, but they average rather large, the range being from 21 to $26 \mathrm{~mm}$. diameter.

The penis-papilla is rounded at the end, not slightly enlarged distally as usual in ambigua. It is slightly wrinkled or smooth. The flagellum is short or rather long, $1.8 \mathrm{~mm}$. in one example.

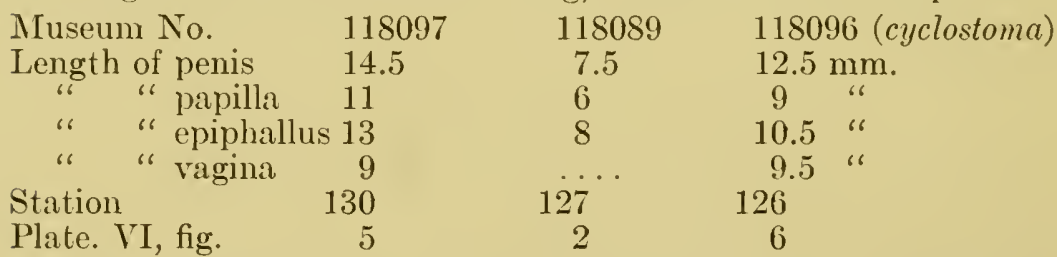

Nariz Mountains - At Monument 163 of the International Boundary, at the summit of the mountain, Dr. Mearns took two dead specimens agreeing perfectly with $S$. ambigua. They measure 20.5 and $21.1 \mathrm{~mm}$. diameter, No. 187479 U. S. N. M.

Sonorella ambigua cyclostoma n. subsp. Plate 2, figs. 5-7.

Station 126 (1918). Small hills south of Comovo road to Ajo about 3 miles west of Comovo Church. Type no. $118096 a$.

${ }^{5}$ Nautilus XXII, 3-9. 
Specimens from Station 126 are a peculiar form in which the caliber of the whorls is somewhat reduced and the aperture is less oval, nearly round. The lip margins converge more than in ambigua, and are united by a callus in old individuals. Umbilicus rather large, contained 6 times in the diameter. Embryonic shell as in S. ambigua. The peristome is well expanded and somewhat thickened within. Height 12, diam. $21 \mathrm{~mm}$; $4 \frac{1}{2}$ whorls.

Genitalia (Plate. VI, fig. 6) as in some specimens of S. ambigua, the penis-papilla smooth. Measurements are given on p. 78 . The animal, in alcohol, is light brownish vinaceous, duskier on the back, as in S. ambigua.

Sonorella sitiens Pils. \& Ferr. Plate VI, figs. 7, 9.

Proc. A. N. S. Phila. 1915,p. 407.

This species, originally described from Las Gijas, further north and west, was found everywhere in Pina Blanca canyon, Pajaritos Range. This canyon is above Oro Blanco, and heads over the border in Mexico. Stations 223, 224, 225, 229, 230, 236, 240, 242 (1919). Also in Clark's mine canyon, Station 237.

Three specimens from Stations 224 and 229 were dissected. They have the essential features of the Gija range type,-a very short, thick cylindric penial papilla and no flagellum; but in these examples the papilla is not corrugated, probably a condition of preservation. It is apparently less contracted, being the fraction of a millimeter longer. In a specimen from Clark's mine canyon it is $2 \mathrm{~mm}$. long. The organs of 3 specimens measure in length as follows:

Museum No..............44740

Length of penis................ 4.5

" "papilla............. " 1.3

" "

" "vagina........... "

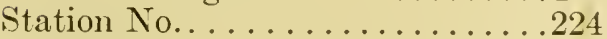

Pl. VI, fig............... . .
43734

6

1.4

5

5

229
43723

$5 \mathrm{~mm}$.

266

7 "

6 "

237

7

Specimens of the shell from Station 237 measure: Height 10.7, diam. $18.5 \mathrm{~mm}$; height 13, diam. $20.7 \mathrm{~mm}$.

Sonorella sitiens montezuma Pils. \& Ferr. Plate II, fig., 8; pl. VI, fig. 10.

Sonorella montezuma P. \&. F., Nautilus, vol. 33, July 1919, p. 20.

Huachuca range in Montezuma canyon and the pass into Copper canyon, often abundant, Stations 312-315, 320, 321, 323-325, 327 , all of 1919 . Type no. 130583 from Station 327. 
The shell is rather iarrowly umbilicate, dilute cinnamon tinted, fading to whitish around the umbilicus and on both sides of the chestnut-brown band. Surface somewhat glossy, with sculpture of weak growth lines only. Embryonic shell, after the initial smooth tip, minutely wrinkled radially, the wrinkles irregular, becoming interrupted and weaker after the first half whorl. Last whorl wide, rounded peripherally, moderately descending in front. Aperture rounded, nearly as high as wide, the peristome sharp, very slightly expanded, having a distinct thickening within.

Height 9, diam. $15 \mathrm{~mm}$.; $4 \frac{1}{2}$ whorls. Type, Station 327 .

Diam. 14 to $17 \mathrm{~mm}$. Station 324 .

The penis is longer than the vagina, has a sheath nearly half its length, and contains a very short, thick, cylindric papilla with shortly conic end. The epiphallus is enlarged where it enters penis. A very short flagellum is present. Lengths of the organs follow.

Museum No. . . . . . . . . . . . . . . . . 130628

Penis............................. 6.0

Penis-papilla. . . . . . . . . . . . . . 2.5

Epiphallus..................... 6.0

Vagina........................ 6.0

Spermatheca and duct.............. 16.0

130698

By the shape of the penis papilla, the sculpture of the embryonic shell, etc., this race closely resembles $S$. sitiens; but the male organs are larger than in that, though the shell is much smaller. It differs from $S$. parva by the more rounded periphery and the very different genitalia.

Sonorella sitiens comobabiensis P. \& F. Plate VI, fig. 11.

Originally described from the Comobabi Range; also reported from the Cababi Hills. The specimens we formerly referred to S. vespertina, from the Qui-i-tomoc Hills, appear on reexamination to be rather large S. s. comobabiensis. All of these were collected by the botanist J. C. Blumer.

In 1918, it was taken at Station 125, a small hill south of the Ajo road, 12 miles west of Indian Oasis; and at Stations 133, 134, 135 and 136, in the southern end of the Quijotoa Range.

Specimens from Station 133 dissected show the peculiarly short, thick penis-papilla characteristic of $S$. sitiens alone; but both penis and papilla are longer than in typical sitiens, and the penial retractor muscle is inserted on the summit of the penis, not as in typical sitiens and S. s. montezuma, distinctly on the epiphallus.

Length of penis 10 , of papilla $2 \mathrm{~mm}$. (Plate VI, fig. 11). 


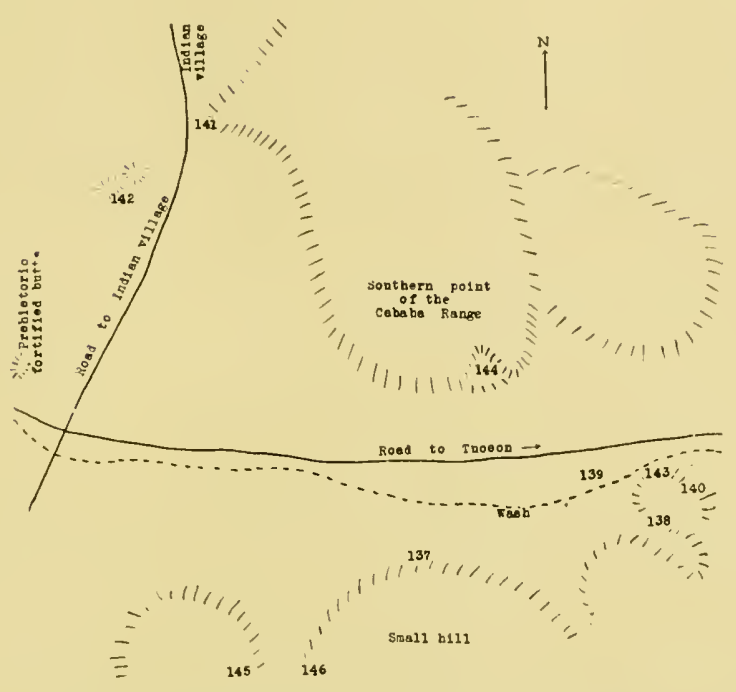

Fig. 7.- Southern end of the Cababi Range.

It was also taken at Stations 141 and 142, Cababi Hills, in a large hill south of the Indian village, east of the road, and in two outliers west of the road from the Indian village.

Localities of this group lie 50 to 75 miles northwest of the type locality of $S$. sitiens.

Sonorella baboquivariensis P. \& F. Plate II, figs. 9, 10.

Specimens dissected in 1915, were from intermediate stations in the range of the species as then mapped. In order to test the constancy of the character then emphasized, the enlarged, acornshaped end of the penis-papilla, several others have been opened, from extreme points explored in our first visit, Stations 21 and $27 .{ }^{6}$ Both show the peculiar papilla; in those from Station 27, "Sycamore" canyon, it is strongly developed, Plate VII, fig. 2 ; in two from Station 21, Mt. Mildred, Plate VII, fig. 3, it is blunter but still characteristic. Measurements of the organs in No. 1115.57, Station 27, follow :

Length of penis...... $7 \mathrm{~mm}$. Vagina......

$$
\text { " " } " \text { papilla...... } 2.7 \text { " }
$$$$
\text { Flagellum. . . . . . } 1
$$

${ }^{6}$ These stations are marked on the map, Proc. A. N. S. Phila., 1915, p. 413. 
A week in October, 1917, camp was pitched upon the same spot in Sycamore canyon in the Baboquivaris occupied by us in 1910 . A. IV. Roberts, of much assistance to us at that time, feeling the need of venison, was the host, and thus it was designed as a hunting party; but the collections were good. The Forest Reserve has been vacated by the $U$. S. Government, and Frank Cole, the ranger, withdrawn. Much of the timber seen in 1910 has disappeared, and the streams have less water, yet the snails seemed more plentiful than before. Perhaps the rodents have departed; very few were seen. On no other range were so many snails found alive. Fifteen to sixty was the rule at every station.

A form of S. baboquivariensis was taken at Station 117 (1918), in the rincon of (hief Pablo, in the cliffs of the creek near a cow camp, formerly the Sycamore Forest Ranger station (marked on map, fig. 6, p. 77 ). The shells vary in size from 16.4 to $20.3 \mathrm{~mm}$. cliam. The umbilicus is generally slightly wider than in typical S. baboquivariensis, but there is no constant difference.

The genitalia (Plate VII, figs. 12,13) differ chiefly by the absence of an enlargement of the end of the penis-papilla, which is rather thick as in baboquivariensis, but slightly longer. The papilla is shaped as in $S$. $b$. depressa but is much larger, especially thicker. The epiphallus is very slender and long, but was not gotten out entire, the specimens being very hard. Vagina is short. Three specimens of no. 118085 were dissected. The organs of two measure: Penis....................... Papilla......................... " 4.3 "

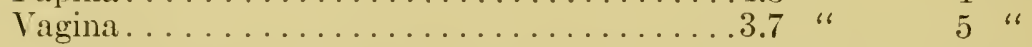

On account of the difference in the papilla, this should be segregated as a race if the character proves constant.

Sonorella baboquivariensis depressa P. \& F. Plate II, fig. 11; pl. VII, figs. 5-7, 9, 10.

In October, 1917, one of us (J. H. F.) visited the last canyon northward of those shown in our sketch map of 1915, p. 413, known as "Sycamore" or "Brown's" canyon The stations of this visit are plotted in text fig. 8, representing a northward extension of the former map.

The shells vary from the typical baboquivariensis form (Station 2) to smaller forms with the umbilicus somewhat less covered, and either narrow, as in baboquivariensis, or much wider, as in the form called S. b. depressa. Two from Station 5 measure:

Plate II, fig. 9. Height 11.8, diam. $19.2 \mathrm{~mm}$., umbilicus $2.5 \mathrm{~mm}$. Plate II, fig. 10. Height 10, diam. $16.2 \mathrm{~mm}$., umbilicus $1.8 \mathrm{~mm}$. 


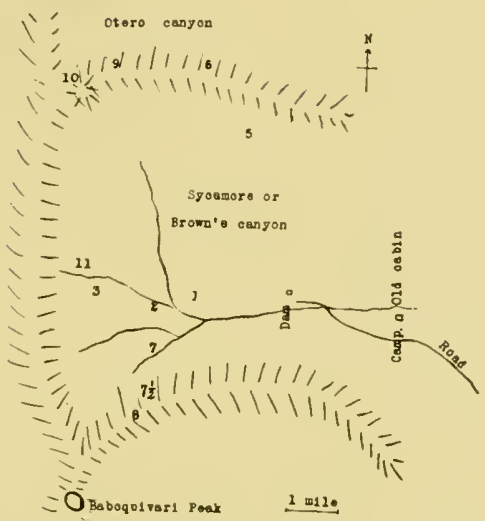

Fig. 8.-Sketch map of a section of the Baboquivari Range, showing collecting stations, 1917.

Specimens from Stations 3,5-11 are similar.

In all of these lots dissected (Stations 2, 5, 10) the penis-papilla differs from that of typical baboquivariensis by its far more slender shape, with a bluntly tapering end, not at all enlarged and glandi. form as it is in baboquivariensis. This may indicate that the form defined as depressa is specifically distinct; yet as the shell characters appear to intergrade, we leave this Sycamore canyon form as a subspecies. It inhabits the region immediately north of baboquivariensis.

Measurements of the genitalia follow:

Museum No............117527

Penis............. 7

Papilla............ 3.3

Epiphallus......... 7

Flagellum.......... long

Vagina............ 8

Stations (1917) ...... 5

Pl. VII, fig. . . . . . . 7

117527

3

7.3

2

6.5

5

9
$117522 \quad 117519$

58

$2 \quad 3.5$

69

$\because-1$

10 $\quad \cdots$

$10 \quad 5$

In the Sierrita Mountains collections were made at Station 47 (1917) and 202 (1919), in a canyon facing east, at about $4500 \mathrm{ft.}$, and at Station 204 (1919), on the south side of a mountain facing Harris ranch, at about $6000 \mathrm{ft}$. more or less. The shells resemble closely those from Sycamore canyon, and the genitalia, particularly the form of the slender penis-papilla, are identical with that race, in two dissected from Station 202. Length of penis 6.3, papilla 1.7, epiphallus 8 , flagellum 1, vagina" $7 \mathrm{~mm}$. 
In the Tucson Range, specimens were taken at Stations 58, 60 and 61 . As the original aecount of depressa was quite short, a fuller description is here given of a specimen from Station 58, pl. II, fig. 11.

The shell is very thin, depressed, with a narrow umbilicus contained 9-10 times in the diameter. Between cinnamon-buff and light pinkish-einnamon color, fading towards whitish on the base, with a ehestnut-brown band above the periphery and more or less showing on the penult whorl, and having very indistinct, narrow pale borders. The surface is glossy, the last 2 whorls marked with fine smooth, growth lines under a lens; next earlier whorl having the lines irregular; after the nearly smooth first half whorl the embryonic whorls are minutely, elosely but weakly rugose radially, and in the most perfeet examples there are rather widely spaced protractive threads, as in S. binneyi. The spire is rather low; last whorl is very wide, viewed from above; it descends slowly and but little in front. The aperture is unusually large, peristome thin, distinctly but very narrowly expanded throughout, dilated at the columellar insertion, where it overhangs a small part of the umbilicus. Parietal callus arehes forward somewhat, and bounded by a light raised line.

Height. 11.5, diam. 19.3, diam. umbilieus $2 \mathrm{~mm}$., $4 \frac{1}{2}$ whorls. " 10 , " 17.0 " 17.5 "

Genitalia (Plate VII, figs. 4, 5, 8) eharacterized by the rather slender penis with stout basal sheath, and containing a rather short, smooth, slender, blunt-ended papilla, contained 3 times, more or less, in the length of penis. Flagellum short. The vagina is slightly shorter than the penis in specimens disseeted (Stations 59 and 61). Dimensions follow:

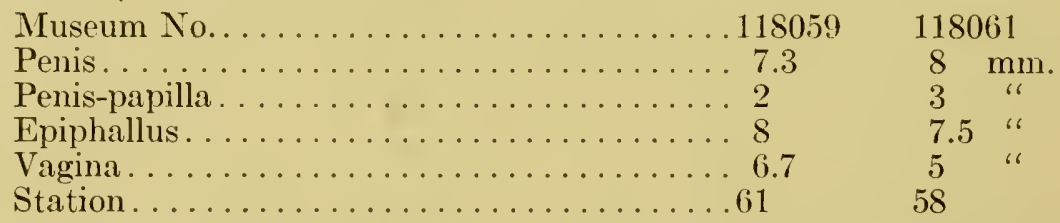

It differs from $S$. binneyi by the more fragile shell and slightly larger aperture.

We at first thought that this might be S. arizonensis Dall, but that species, well figured by Bartsch, has not so large an aperture, a deeidedly higher spire and less depressed body-whorl, and it is said to have "rather well-marked ineremental lines and microscopic vermicular markings"; the latter are eertainly wanting in the present form, but may perhaps be due to the dead condition of the single specimen of arizonensis found. 
Sonorella binneyi imperialis n. subsp. Plate 2, fig. 12; pl. VII, fig. 1.

Empire Range, Station 151 (1918); a few "bones" at Station 150.

The shell is decidedly more depressed than $S$. binneyi, rather narrowly umbilicate (umbilicus about one-ninth to one-tenth the diameter), thin, dilute cinnamon above, shading into white beneath, with a chestnut-brown band rather indistinctly whitishbordered. There are some narrow whitish growth-arrest streaks. Surface glossy, with light, fine growth lines. Embryonic shell, after the smooth initial part, radially anastomosing-crinkled, then with slowly protractive threads over fine radial crinkling, and on the last part of the first whorl, retractive threads. The spire is small. The last whorl increases very rapidly and is unusually wide, as viewed from above. In front it descends a little and slowly. The aperture is large, its width decidedly more than half the diameter. Lip thin, very slightly expanded, outwardly and basally, dilated at the columellar insertion, partly covering the umbilicus.

Height 11.3, diam. $19.5 \mathrm{~mm}$.; $4 \frac{1}{2}$ whorls.

By its large aperture, texture, lip and apical sculpture this species resembles $S$. baboquivariensis $P$. \& F., but in that species the aperture is even larger and the umbilicus more covered; moreover, the penis papilla is noticeably different, though otherwise the genitalia are rather similar. It differs from the typical Chiricahuan $S$. binneyi chiefly by being more depressed. The genitalia of this species show affinity to $S$. bowiensis and $S$. bartschi-species in which the umbilicus is decidedly larger.

The few living ones and numerous "bones" show very little variation in size, nearly all being from 19 to $20 \mathrm{~mm}$. in diameter.

S. binneyi, while it has a remarkably wide range for a Sonorella, appears everywhere to be very local. In the Chiricahuas it is known from a single canyon in the southern part of the range. The form we called franciscana has a very limited area, separated from the Chiricahuan locality by valleys and by ranges where we know that binneyi does not occur. S. b. franciscana differs from the original lot by having a somewhat longer epiphallus, a difference of no great weight, and perhaps it is not really distinguishable from typical S. binneyi. The Empire Range form, S. b. imperialis, lives about 90 miles northwest of the type locality, several intervening ranges which we have explored being without the species. It has a more depressed shell than typical binneyi, and the penispapilla is thicker. Finally in the Tucson Range, still further west, we have an allied form, S. baboquivariensis depressa, in which the penis-papilla is very slender. 
Sonorella tryoniana n. n.

Sonorella rowelli (Newc.), Pilsbry, Proc. A. N. S. Phila., 1902, p. 511; Nautilus XVI, p. 32. Pilsbry \& Ferriss, Proc. A. N. S. Phila., 1905, p. 261 , pl. 1S, figs. $33-35$; pl. 20, figs. $13,14,20$. Not Helix rowelli Newcomb.

Sanfords, Pima Co., on the bank of Sonoita creek under leaves and logs, near the water, J. H. Ferriss, type and paratype No. 83273 A. N.S. P. Also a short distance eastward in the northern end of the Patagonia mountains, J. H. F., 1902, and E. H. Ashmun, 1898. Empire mountains at Stations 149 and 152 (1918), J. H. Ferriss.

This small species, related to the Chiricahuan S. bowiensis and S. binneyi, was long thought to be Newcomb's $H$. rowelli. That species, however, proves to be a Micrarionta (Eremarionta), from southwestern Arizona.

$S$. tryoniana is much like $S$. bowiensis, but in that species the margins of the lip converge more, leaving a shorter parietal callus.

At Sanfords this species was found on the bank of the creek near the water under leaves and logs.

The specimens from far northward, in the Empire Mountains, appear to be practically typical tryoniana. Among the species of these mountains, this shell resembles $S$. binneyi imperialis in color and texture, but it is smaller, the last whorl is not so wide, the umbilicus is decidedly larger (contained between $6 \frac{1}{2}$ and 7 times in the diameter), and the aperture is relatively smaller, though of similar shape. Surface very glossy, lightly striate, without spiral lines or granulation. Height 9.4, diam. 15.7, umbilicus $2.3 \mathrm{~mm}$.; $4 \frac{1}{2}$ whorls.

Living examples were taken at Station 149, but those preserved unfortunately became dry, and the sketch, Plate VIII, fig. 6, and the measurements obtained by soaking it up, are given for what they may be worth. The penis-papilla is cylindric with a blunt, rounded end.

Length of penis $3.5 \mathrm{~mm}$.; papilla $1.5 \mathrm{~mm}$.; vagina $4 \mathrm{~mm}$.

Sonorella berryi n. sp. Plate II, fig. 13.

Station 103 (1918), in malpais slides on a small hill north of the road near the forks, on the east side of the Roskruge Range. Type no. 131001 A. N. S. P.

The shell is depressed-globose, thin, narrowly and half-covered umbilieate, translucent, white, with a chestnut-brown band above the periphery and narrowly showing on the penult whorl, and a pinkish-buff band below the suture, spreading about half way to 
the chestnut band. Surface rather glossy, smooth except for very fine growth lines. Embryonic shell smooth at the tip, then finely radially rugose towards the end of the first whorl (showing a few widely spaced protractive threads in some, especially young, examples). The last whorl is very wide and descends a little and slowly in front. The aperture is very large. Peristome thin, expanded, reflected half over the umbilicus. Parietal callus thin. Height 12.3, diam. $18.3 \mathrm{~mm}$; $4 \frac{1}{2}$ whorls. Type. Height 12, diam. $18.7 \mathrm{~mm}$. Height 11.5, diam. $17.3 \mathrm{~mm}$.

Genitalia (Plate V, fig. 11) about as in S. binneyi P. \& F., so far as can be judged from a dried specimen, soaked up.

About 60 living specimens of this handsome little Sonorella were taken. While it is related to baboquivariensis depressa, of the Baboquivari, Sierrita and Tucson Ranges, it differs by the smaller, more covered umbilicus, the still larger aperture, the less depressed shape, and in coloration, which is uniform in the long series taken.

In the genitalia it resembles $S$. binneyi franciscana in having the epiphallus longer than in Tuscon Range specimens of depressa. Unfortunately the single animal saved became dry and had to be soaked up, hence the following measurements may require some revision when fresh ones are obtained.

Length of penis $6.7 \mathrm{~mm}$.; length of papilla $2.5 \mathrm{~mm}$; length of vagina $7.5 \mathrm{~mm}$.

Named for S. Stillman Berry, who has done good work on the Californian desert snails.

Sonorella odorata P. \& F. Plate VI, fig. 8.

Genitalia of a specimen from Station 22 (1917), in the aspen zone, Spud Rock Ranger Station, Rincon Mts., are here figured to show variation in form of the penis-papilla, which is somewhat enlarged distally.

Length of penis ....6 mm. Length of epiphallus. $10 \mathrm{~mm}$.

Sonorella hinkleyi P. \& F. Plate III, figs, 1, 4.

Nautilus vol. 33, July 1919, p. 19.

San Cayetano Mountains, in the southern part, at Stations 243 to 251 (1919), the types from Station 243, the southernmost peak of the Cayetano foothills 2 miles above Calabasas, on the western branch of Sonoita Creek. The highest stations at about $7500 \mathrm{ft}$. elevation.

The shell is small, moderately solid, depressed, the umbilicus contained about 5 times in the diameter; between light pinkish- 
cimnamon and pinkish-buff, the base paler, a chestnut-brown band above the periphery. The surface is slightly glossy. Embryonic whorls radially crinkled, the second with very irregular tangential (protractive) threads on its peripheral half; subsequent whorls with weak lines of growth only. The spire is low, whorls convex, the last wide, descending a little in front. The aperture is rounded, peristome slightly expanded.

Alt. 8, diam. $15.7 \mathrm{~mm}$.; $4 \frac{1}{3}$ whorls. Type, station $243 \frac{1}{2}$. Alt. 10, diam. $17 \mathrm{lmm}$. Station 243.

The penis is rather long with a basal sheath nearly a third of its length; the papilla cylindric with conic end and weak spiral plication. Epiphallus about as long as penis, the long penial retractor inserted upon it. No flagellum. The vagina is longer than the penis, and at the distal third there is an annular swelling, the wall there being thickened and muscular, with an internal annular ridge. Above this the internal wall has fine, irregular, longitudinal threads. Measurements of the organs in $\mathrm{mm}$. follow.

Museum No... . . . . . . . . . . . . 43735

Penis. . . . . . . . . . . . .

Penis-papilla ............... 4

Epiphallus...................

Vagina........................

Station..........................

43726

$10 \mathrm{~mm}$.

3.3 "

9.5 "

11

244

A small, depressed nearly smooth species. At Station 244, in a porphyry slide on a small knob, southern side of the southern peak of the Cayetanos, most of the specimens taken are albinos, the shell white throughout. There were 452 albinos to 24 banded specimens (Plate III, fig. 4).

Sonorella hinkleyi cayetanensis Pils. \& Ferr. Plate III, fig. 5.

Sonorella cayetanensis P. \& F., Nautilus vol. 33, July 1919, p. 19.

Cayetano Mountains: Station 216, in a slide of white porphyry on north side of double peak, near the top, type loc. Also Stations $207,212,215,217$, from the foothills up.

The shell is thin, light, umbilicus contained about 8 times in the diameter, dilute cinnamon, fading to whitish around the umbilicus and on both sides of the chestnut-brown supraperipheral band. The latter shows only narrowly on the penult whorl. Surface glossy, lightly striate. Faint traces of protractive and retractive threads are visible on the latter part of the embryonic shell in young examples. The whorls increase rather slowly to the last, which is about double the width of the penult and descends very little in front. The thin peristome is narrowly expanded, insertions of the margins rather widely apart. Height 11.7, diam. 21 mm. ; nearly $4 \frac{3}{4}$ whorls. 
Genitalia much as in S. hinkleyi. The long peris contains a spirally plicate papilla somewhat over one-third the total length, its end conic. The equally long epiphallus terminates in a very short flagellum. The vagina is longer than the penis, and has an annular muscular swelling at its distal fourth. The organs measure in length:

Penis.......... $13.5 \mathrm{~mm}$.

Penis-papilla. . . . . 5.0 "

Epiphallus........13.5 "

Vagina.........20 $\mathrm{mm}$

Museum No.......43737.

Station ........... 216 .

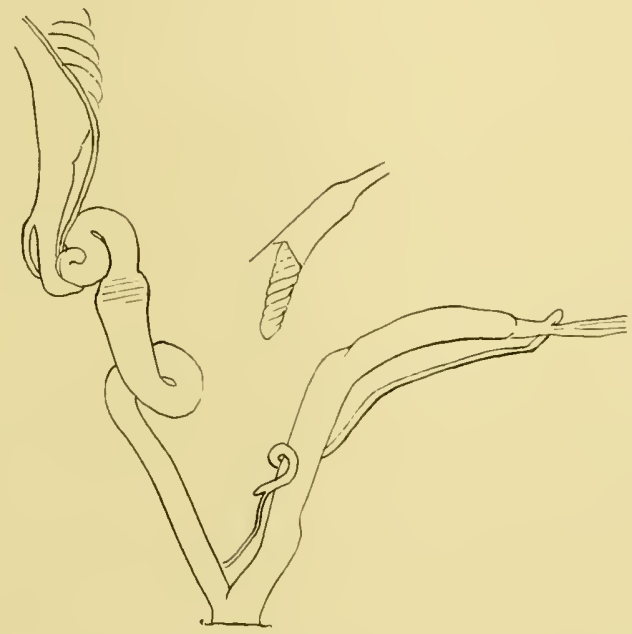

Fig. 9.-Sonorella h. cayetanensis, No. 43737, Station 216.

This form from the northern end of the Cayetano range is anatomically very close to S. hinkleyi, which inhabits the southern end of the same range, and is distinguished by the smaller size and more solid texture of the shell. However, there are some specimens, such as those from Station 219 (1919) which appear intermediate, and we therefore reduce cayetanensis to subspecific rank.

Sonorclla hinkleyi tumacacori. Plate III, fig. 2 ; pi. VIII, figs, 4, 5.

Sonorella tumacácori P. \&. F., Nautilus vol. 33, July, 1919, p. 19.

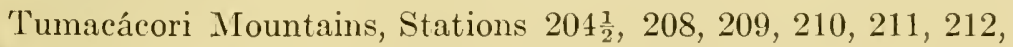
all on Tumacácori Peak and the next mountain southward.

Except by the somewhat greater length of the reproductive organs, the decidedly stronger node or swelling on the vagina, the short penial retractor and less closely twisted penis papilla, this form cliffers very little from $S$. hinkleyi, of which we now consider 
it a local race. The localities of species and race are separated by the Santa Cruz river valley.

The shell varies in size. Height 9, diam. $17 \mathrm{~mm}$., $4 \frac{1}{2}$ whorls. Station 210. Height 11, diam. $18.5 \mathrm{~mm}$., $4 \frac{1}{2}$ whorls. Station $204 \frac{1}{2}$.

The long penis has a sheath about one-third its length. The papilla is weakly spirally plieate, cylindric with long conic end. There is an extremely short flagellum. The penial retractor is very short, inserted near the base of the epiphallus. The vagina is much longer than the penis, and has a strong muscular annular swelling near its upper end, where it is folded upon itself.

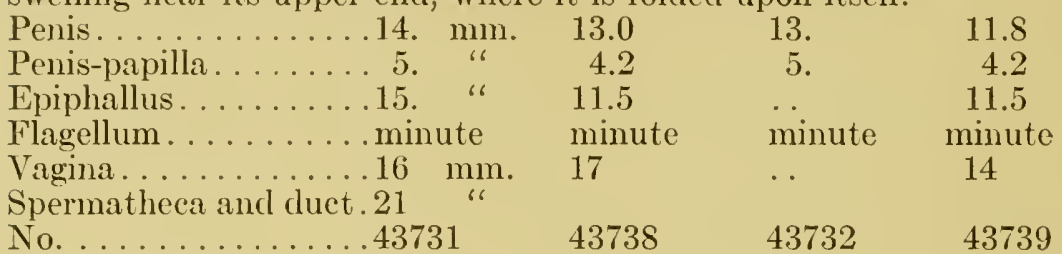

Sonorella hesterna P. \& F. Plate VIII, figs. 8, 9.

Northern end of the Santa Rita Mountains: Station 49 (1917), near Rosemont; 50, west side saddle of Santa Ritas, overlooking Helvetia; 51, Helvetia; 52, Greaterville; all in the eastern part of Pima County.

We provisionally refer a series of specimens from the northern and eastern Santa Ritas to this species from the southern foothills of the Rincons, which was described without anatomical charaeterization.

It is very closely related to $S$. hinkleyi and particularly to $S . h$. cayetanensis, the genitalia being of the same general character, but the shell is more solid. The penis-papilla is strongly plicate spir. ally, with a conic end. There is a muscular swelling or node on the vagina. Flagellum minute, vestigial. The organs measure in length:

Penis.......... $13.0 \mathrm{~mm}$.

Penis-papilla . . . . . 3. 3.7 "

Vagina............ $17 \mathrm{~mm}$.

Epiphallus..........15.0"

Museum No. .......118058.

Station........... 50 .

It remains to be seen whether $S$. hesterna from the type locality has the same anatomical features; it may possibly prove to be more like hachitana or walkeri.

Sonorella tumamocensis Pils. \& Ferr. Plate VII, fig. 14.

Tucson Range, Stations 86, Cat Mountain, 87, 90, Limekiln camp. Silver Bell mining eamp (north of the Roskruge Range). 
Malpais slides in a small black hill 3 miles east of north of Bobb's Butte, southern end of the Roskruge Range, Station 110.

A specimen from near the Desert Laboratory, Tumamoc Hill, was dissected and the penis is drawn in Plate VII, fig. 14. It agrees well with the original lot, except that the spiral grooves of the penis-papilla are less closely wound. The penis and epiphallus are each $9 \mathrm{~mm}$. long, papilla $4 \mathrm{~mm}$., in a shell $8.5 \times 15.7 \mathrm{~mm}$. There is no flagellum.

At Station 87 the specimens vary from 18 to $20.5 \mathrm{~mm}$. diameter, becoming larger than any from the type locality. None have been dissected from the Tucson Range proper, west of Tumamoc Hill, or from the Silver Bell, but except in attaining larger size they appear to be identical.

At Station 110, southern foothills of the Roskruge Range, the specimens are much like the smallest examples of typical S. tumamocensis, diam. 14 to $16.2 \mathrm{~mm}$. They are more depressed than the larger Tucson Range shells, somewhat translucent. The animals had been dried, but by the use of potash one was soaked up. The genitalia (Plate VII, fig. 15) do not differ materially from tumamocensis, except that the papilla appears to be smooth and shaped as in $S$. binneyi, not tapering and spirally grooved as in tumamocensis. There is a very small flagellum.

$\begin{array}{llll}\text { Length of penis } & 12 \mathrm{~mm} \text {. } \quad \text { Length of epiphallus } \\ 7.5 \mathrm{~mm} \text {. }\end{array}$

Little stress can be attached to such details in a specimen so poorly preserved. Evidently a further investigation of the anatomy of these several forms referred to tumamocensis must be made.

The shells at station 110 show considerable variation in size of the umbilicus:

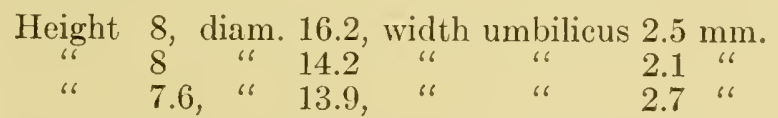

Similar variation occurs in the type locality, where also most specimens are larger.

These specimens from Station 110 are very much like S. ferrissi, but the last whorl is more depressed in the latter.

Huachucan Sonorellas.-The Huachucas have a more raried fauna of Sonorellas than any other range yet explored, the five species known anatomically belonging to four of the groups founded 
on anatomical structure. The shells are greatly varied in size and form, and two species $S$. dalli and $S$. parva, possess rudimentary "teeth." We here figure a specimen of

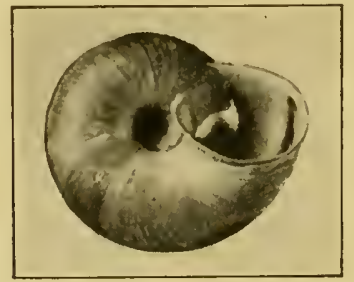

Fig. 10.-Sonorella dalli of another species of about $20 \mathrm{~mm}$. diamshowing parietal teeth. the former having these teeth well cleveloped (Text-fig. 10).

Besides these species, there are two others not yet dissected. S. huachucana was taken in 1904. It was originally described as a subspecies of the Chiricahuan S. virilis. Somewhat faded bones of another species of about $20 \mathrm{~mm}$. diameter, with smooth (not granulose) surface was taken in 1919 at Station 270 , at the northern end of the range. As it belongs to a group of very weakly differentiated species, we do not attempt to name these specimens, which certainly differ speeifically from any described Huachucan species.

Key to Huachucan Sonorellas by Characters of the Genitalia.

a. Penis long (about $40 \mathrm{~mm}$. in a shell $27 \mathrm{~mm}$. diam.), containing a short papilla (about $\frac{1}{5}$ length of penis); epiphallus long (49-60 mm.); flagellum present. S. dalli Bartsch. $a^{1}$. Penis long (about $20-25 \mathrm{~mm}$. in a shell of about $16 \mathrm{~mm}$. diam.), containing a long, longitudinally costulate papilla; epiphallus shorter than penis; no flagellum. S. parva Pils.

$a^{2}$. Penis shorter, about equalling the diameter of shell or much less, containing a thick, cylindric papilla.

b. Papilla less than half the length of penis; vagina shorter than penis; epiphallus thickened where it passes into penis.

S. sitiens montezuma $\mathrm{P}$. \& F.

$b^{1}$. Papilla more than half the length of penis; epiphallus not enlarging where it enters penis; vagina much longer than the penis.

c. Upper part of vagina muscular, swollen, usually fusiform; penis 5 to $7.5 \mathrm{~mm}$., papilla 3.3 to $5 \mathrm{~mm}$. long.

S. granulatissima Pils.

$c^{1}$. Vagina rather slender throughout, with a small fleshy node midway or at the upper third; penis 12 to $19 \mathrm{~mm}$., papilla 9 to $13 \mathrm{~mm}$. long.

S. danielsi P. \& F.

Sonorella danielsi P. \& F.

This is a common shell in Ash canyon, Stations 310, 311, 330 (1919), Montezuma and Copper canyons, no. 314, 316, 318-320, 322-324, 327-329, all 1919. Its known range is thus extended considerably. 
The color is not yellow as in the types, but a brown tint. In the soft anatomy, specimens from stations $310,311,314$ agree fully with the typical form. One from 319 dissected has the vagina like granulatissima (P.A.N.S. 1909, pl. 21, fig. 4), but the penis and papilla are long, as in danielsi. Measurements of the organs follow.

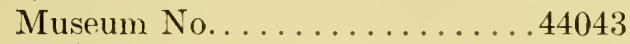

Penis. . . . . . . . . . . . . 10

Penis-papilla . . . . . . . . . . . . .

Epiphallus................ 10

Penial retractor............ 9

Vagina......................... 16

Station......................

$\begin{array}{ll}44041 & 44035 \\ 10 & 11.5 \\ 7 & 8.5 \\ \ldots & \ldots \\ 13 & 18 \\ 311 & 319\end{array}$

The large, club-shaped, abruptly truncate penis-papilla has a wrinkled-areolate surface, not very well shown in the figures published in 1909, but best in Plate 21, fig. 7 .

Specimens of S. danielsi in the National Museum, No. 124479a, are labelled "Tucson, Arizona, Cox, Lea Collection." We have noticer the Huachucan Ashmunella from the same source in these Procendings for 1909 , p. 496 . It is a form, A. varicifera, which inhabits the southern Huachucas, the habitat also of S. danielsi. The latter is known from over 25 stations in this region, but neither species has been taken by us further northwest in the Huachucas, or in any other range. There can therefore be little doubt that the Cox specimens of Ashmunella and Sonorella labelled "Tucson" came from somewhere in the neighborhood of Ash canyon, Huachucas.

Sonorella parva Pils. Plate VIII, figs. 2, 3.

Sonorella granulatissima parva Pils., Proc. A. N. S. Phila., 1905, p. 264, pl. 18, figs. 45-47; 1909, p. 501, pl. 19, figs. 10-12.

The exact locality of the original lot was not noted; they were picked up between Fort Huachuca and the Manila mine, near the latter, and agree perfectly with those taken at Station 274 (1919). It was found also at Stations 270 and 281 (1919). All of these are in the western foothills of the northwestern end of the Huachuca range.

Sculpture: after the smooth apex, there are some radial wrinkles to the end of the initial half whorl; the whorl following is very minutely, densely, evenly reticulate-pitted; in oblique light in certain places faint traces of fine, close oblique lines may sometimes be made out. The following neanic whorls are microscopically densely granulose, as in S. granulatissima, but on the last whorl this granulation becomes very weak or almost disappears. 
The last whorl is bluntly subangular in front, or at least somewhat compressed there; it descends rather deeply to the aperture. Aperture is strongly oblique, rounded, somewhat wider than high, the margins approaching. There is sometimes a very low, oblique callus pad or "tooth" on the parietal wall, further in and nearer the periphery than is usual in helices. This tooth is visible in all adult shells from station 281 , but secms to be only occasional in other lots. It is present but excessively wcak in the figured type, but is well developed in a paratype.

The soft anatomy, examined in specimens from Stations 270, 274 and 281, shows that this form is not nearly related to S. granulatissima. The animal is plumbeous black above; sole with a wide isabella colored central area, sharply defined, and dusky side areas. Genital organs are relatively large. The penis is long with a short sheath, thin-walled, containing a long fleshy papilla having numerous slender longitudinal ridges, the end abruptly truncate. Penial retractor short, on the epiphallus, which is twisted around the retractor, the basal part thickened. No flagellum. The vagina is long.

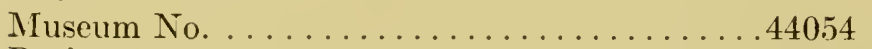

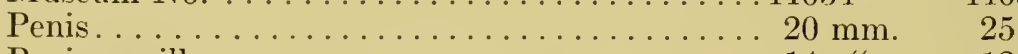

Penis-papilla.......................... 14 " 12

Epiphallus......................

Penial retractor.................. 8 " 8

Vagina...................... 16 " 21

The peculiar sculpture of the penis-papilla is unique in the genus. The "tooth" on the parietal wall is a very unusual feature in Sonorella, but occurs also, and more strongly developed, in S. dalli.

Sonorella insignis Pils. \& Ferr. Plate III, fig. 3.

Nautilus, vol. 33, July 1919, p. 21.

Whetstone Mountains, Stations 304, $304 \frac{1}{2}$ and 305 (1919). Living specimens were taken only at the type Station 304.

The shell is much depressed, openly umbilicate (the umbilicus about one-fifth the total diameter), solid, opaque, whitish stained with light pinkish-cinnamon above and in places on the base, banded with chestnut-brown, the band broad, situated well above the periphery. Surface with little gloss, having coarse, unevenly developed, very low plications in the direction of growth lines, and mainly confined to the last whorl; under the microscope traces of rather coarse, well separated spiral impressed lines may be deciphered in some places on the upper surface. No protractive threads are visible on the embryonic shell in the adult or nearly adult shells. The last whorl descends rather deeply to the aperture, which is oval with converging margins, very slightly expanded. 
Height 9.5, diam. 20.5 mm.; $4 \frac{1}{2}$ whorls. Type.

$$
\begin{array}{cccccc}
\text { " } & 8.8, & \text { " } & 19 & \text { " } & \text { Topotype. }
\end{array}
$$

Genitalia (Plate VIII, fig. 1, type) characterized by the long male organs. The large penis papilla is $\frac{3}{4}$ the length of the penis, with a bluntly conic end. The penis is slender basally, enclosed in a short sheath. Flagellum very small but distinct. Vagina shorter than penis. Lengths of organs as follows:

Penis..........16.5 mm. Epiphallus.......24 mm.

Penis papilla......12.0" Vagina.........10"

Penial retractor... 8.5 " Spermatheca and duct 25 "

The jaw has 4 or 5 ribs.

This species is readily known by its depressed shape and coarse sculpture. It is not closely related to any described form, but by the very large penis and papilla appears to belong to the group of S. virilis.

A very old specimen has a distinctly calloused parietal wall, much as in some Oreohelices.

\section{Oreohelix concentrata huachucana Pils.}

Whetstone Mountains, Stations 286, 303, 304, 304 $\frac{1}{2}$ (1919).

The Whetstone form is generally more depressed and more widely umbilicate than is usual in the Huachucas, but some Huachucan

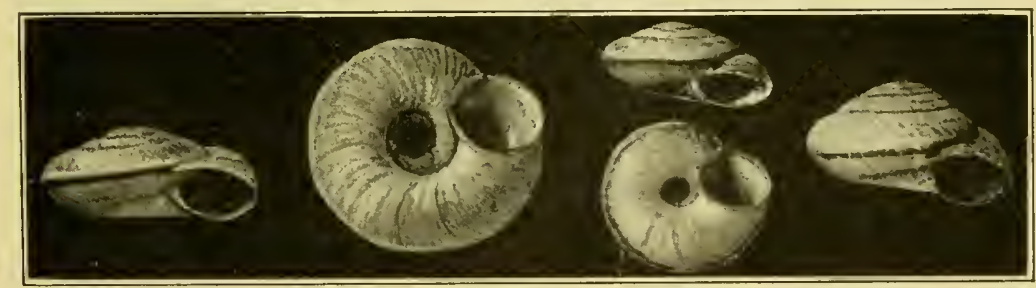

A $\quad$ B

$\mathrm{C}$

D

Fig. 11.-Oreohelix concentrata huachucana. Whetstone mountains, $a, b, c$, station $304_{2}^{1} ; d$, station 286 .

examples are entirely similar, and some from the Whetstones are elevated. They are always angular or keeled in front or throughout.

\begin{tabular}{|c|c|c|c|c|c|c|}
\hline Height & 13.3, & diam. & 22 & $\mathrm{~mm}$. & Station & 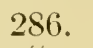 \\
\hline & 10.3 & " & 18 & " & " & "، \\
\hline " & 13.3, & " & 25 & $"$ & " & 303. \\
\hline " & 12.3, & " & 24.5 & " & $"$ & $304 \frac{1}{2}$. \\
\hline " & 12.5 & " & 22.7 & " & "، & \\
\hline " & 9.3 & " & 20.4 & " & " & "، \\
\hline " & 8.7 & " & 17.3 & "6 & " & "6 \\
\hline
\end{tabular}
Fully adult specimens measure: 
In the Mustang Mountains only fossil specimens were found. Those from Station 157 (1918) measure 20-22 mm. diameter, have a moderately raised spire, and are practically typical of the subspecies. At Station 153 (1918) the shells arc smaller, 15 to $19 \mathrm{~mm}$. diameter.

\section{BULIMULIDE.}

Bulimulus nigromontanus Dall. 1'late I, figs. 3, 4.

Pajaritos Mountains in Pina Blanca canyon, Stations 225, 236. Also 5 miles north of Moor Ranger Station, Pina Blanca, in a small canyon running east, opposite the main gulch from the Tumacácori Mountains, in a slide on the north slope of a hill of crumbling porphyry, Ferriss and Hinkley, 1919.

Except in having a somewhat smaller umbilicus, these specimens appear to agree with the description of $B$. nigromontanus, which came from Black Mountain, 12 miles south of Monument 77 of the International Boundary, on the right bank of the San Bernardino River, in Sonora. The localities now recorded carry the species about 130 miles further west. It is a species new to the United States list.

\section{UROCOPTIDE.}

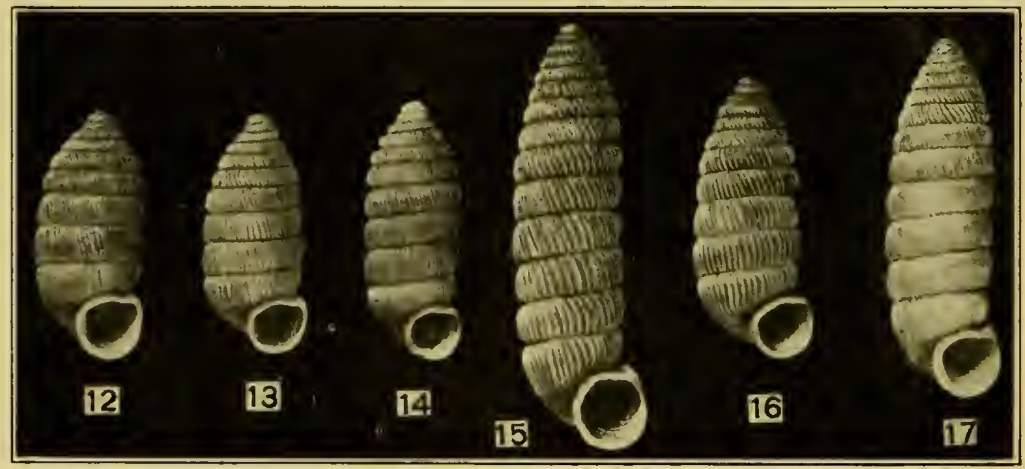

Fig. 12.-Holospira ferrissi careloensis. Fig. 13.-H. f. monoptyx. Fig. 14. -H. p. fluctivaga, Fig. 15.-H. whetstonensis. Fig. 16-H. u. arata. Fig. 17.-H. arizonensis mustang. In each case the type is figured.

Holospira ferrissi Yils.

This was taken at Station 268, Manila mine, at the northwest end of the Huachucas, the type locality. Also Station 275 , foothill a mile east. Many, but not all, specimens have 3 internal lamellæ, and the whorls are ribbed throughout. Ten topotypes opened have lamellæ as follows: 
Axial lamella only ................... specimens

Axial and hasal. . . . . . .

Axial, basal and parietal . . . . . .

Form 2.-At Station 271, a deep canyon 1 mile north of the Manila mine hill, at a dolomite cliff facing northwest, two lots were obtained. These generally have the riblets weak on the penult or on two whorls, and the lamellæ within are reduced. 15 opened from one lot and 11 from another have lamellæ thus:

$\begin{array}{lcc}\text { Axial only . . . . . . . of specimens } & \text { No. of specimens } \\ \text { Axial and basal . . . . . } & 40 & 10 \\ \text { Axial, basal and parietal } & 1 & 1\end{array}$

These specinens average somewhat larger than the typical lot of ferrissi.

An identical form was taken at Station 306 on the western dome of the Mustangs. Most of the specimens opened had a columellar lamella only, but one had 3 lamellæ.

Holospira ferrissi caneloensis n. subsp. Text-fig. 12.

Canelo Hills: limestone hills west of the Duquesme road at Stations 289 to 292 , the latter three miles west of the road and the furthest from it. Type 131010 A. N. S. and paratypes in Ferriss collection from Station 289.

The shell has the short contour and small size of typical ferrissi, but the sculpture is slightly finer, and becomes obsolete on the antepenult to last whorls, strengthened again on the last half whorl. The three internal lamellæ are strongly developed.

Length 8, diam. $3.5 \mathrm{~nm} ., 10$ whorls. Type.

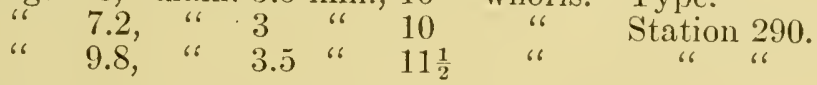

Three internal lamellæ are present in all opened of the type lot, but at Station 292 some of the apparently quite adult shells had only the axial lamella.

Holospira ferrissi monoptyx n. subsp. Text-fig. 13.

Mustang Mountains, in a limestone slope facing east, near Dan Mathew's ranch. Type No. 131009 A. N. S., paratypes in coll. Ferriss.

The shell has the short, compact shape of ferrissi, but differs by having the costulation weaker on the penult and face of last whorl, and in numerous specimens opened there is but one lamella, a strong axial. 
Length 8 diam. 3.3 mm., $10 \frac{1}{2}$ whorls. Type.

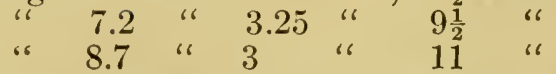

This form resembles $H . f$. caneloensis, and certain specimens are not distinguishable; but in numerous examples opened, none had any lamellæ other than the axial.

Holospira ferrissi fluctivaga n. subsp. Text-fig. 14.

Debris of the San Pedro River near Mammoth, Pinal Co., Ferriss, 1917. Type 131008.

The shell is cylindric with a short, conic, somewhat mucronate summit; much like $H$. ferrissi, from which it differs by having the later whorls decidedly more convex. There are about 8 riblets in $1 \mathrm{~mm}$. on the penult whorl. In the back and right side of the penult whorl there is a very strong and long parietal lamella, a strong, blunt axial, and a rather low basal fold.

Length 8.3 , diam. $3.15 \mathrm{~mm}$.; $10 \frac{3}{4}$ whorls.

It stands close to $H . f$. sanctcerucis, but differs by the greater convexity of the whorls of the cylindric portion of the shell.

A broken specimen of this species was in the shell debris collected by Pilsbry on the San Pedro, near Benson, in 1910. It measures, length 7.3 , diam. $2.8 \mathrm{~mm}$., $10 \frac{1}{4}$ whorls.

Holospira arizonensis mustang $n$. subsp. Text-fig 17.

Mustang Range, Pima Co., Arizona: north side of tower, eastern peak, Station 153 (1918); also the following Stations of 1919:286, the same as 153 of $1918 ; 287$, a limestone hill east of $286 ; 332$, main gulch of north slope of the largest mountains west of Dan Mathew's ranch house, and 333, the next gulch eastward. Type No. 131003 A. N.S. P., and paratype in Ferriss coll. from Station 153 .

Related to $H$. arizonensis mularis, but more slender; summit usually somewhat more slowly tapering; back of the last whorl more coarsely and more irregularly ribbed. Axis having a stout, blunt lamella. Smaller than typical $H$. arizonensis.

Length 12, diam. $3.5 \mathrm{~mm}$.; $13 \frac{1}{2}$ whorls. Type.

Holospira whetstonensis n. sp. Text-fig. 15.

Whetstone Mountains at Stations 293, 304, 305. Type 131007.

The shell is imperforate, long, cylindric with a rather tapering terminal cone about one-fourth the total length; light flesh colored. Sculpture of strong riblets throughout after the two smooth apical whorls; riblets narrower than the intervals, 40 on the penult whorl in the type specimen. The whorls of the cone are strongly convex, 
later whorls moderately so, with a well impressed suture. The last whorl is flattened laterally, sloping to the base, is contracted and very shortly free in front. The small aperture is rounded with part of the upper margin straightened. Internally there are one to three lamellæ. The type having an axial lamella only.

Length 14.2 , diam. $3.7 \mathrm{~mm}$., $14 \frac{1}{2}$ whorls. Type.

This species resembles $H$. cionella and $H$. chiricahuana. The latter has a longer terminal taper, passing imperceptibly into the cylindric part. $H$. cionella is a smaller species with finer sculpture. Out of 7 specimens from the type locality opened, 2 have an axial lamella only, 4 have axial and basal, and one has axial, basal and parietal. Several opened from the other two stations have the axial lamella alone.

The specimens from Station 293 are similar to those from 304, the type station; but at 305 the shells are smaller, extremes measuring:

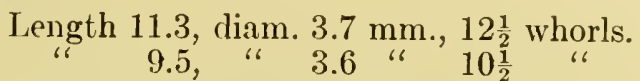

A few opened have a axial lamella only.

Also taken in the Empire Mountains, Station 149 (1918), on the north side of a large limestone peak $1 \frac{1}{2}$ miles northwest of the Total Wreck mine. Specimens small, about as at Station 293, above; only an axial lamella.

Holospira whetstonensis arata n. subsp. Text-fig. 16.

Mustang Mountains, Stations 159 (1918), type loc., and 153 (1918), both on the eastern dome of the range. Type 131005.

The shell is smaller, especially shorter than whetstonensis, with a shorter neck, but having similar strongly cut riblets, coarser than in $H$. ferrissi; the terminal cone longer than in ferrissi. There is an axial lamella lateral in position.

Length 9.3, diam. 3.5 mm., $11 \frac{1}{2}$ whorls. Type.

\begin{tabular}{|c|c|c|c|c|c|}
\hline 9.8 & 6 & 3.3 & " & Topotype. & - 180 \\
\hline 8.5 & 6 & 3.2 & " & & \\
\hline 10.9 & “ & 3.2 & " & 12 whorls. & Station 153. \\
\hline 9.4 & "6 & 3.7 & " & $10 \frac{1}{2}$ & 年 \\
\hline
\end{tabular}

IV. On Micrarionta Rowelli (Newc.) and M. Newcombi, n. sp.

Micrarionta rowelli (Newc.). Plate III, figs. 7 (type), 6.

Helix rowelli Newcomb, Proc. California Acad. Sci. III, 1S65, p. 181. Binney and Bland, Land and Fresh-water Shells of N. A., I, p. 1S5, upper fig. 326 ; not the description or lower figure. 
This species was, we belicve, the first land snail deseribed from Arizona. Neweomb's type appears to have come from Frick, or at least he is given as authority for the loeality "Arizona." Whether Frick was a fortyniner who reached California by the Old Yuma Trail through Mexico and Arizona, we do not know. We know that he lived in Oahu for some years, and collected shells there; but no details of his life could be obtained.

Bimmey, in 1869, confused Newcomb's shell with Helix lohrii Gabb, a very different shell. His deseription appears to be composite, and only his upper figure is certainly identifiable as rowelli. The lower figure differs in lacking the parietal callus and in being larger. Fiseher and Crosse followed Binney in this mistake.

In 1882, Henry Prime reported "Ampelita" rowelli from the Salt River Mountains, 7 miles south of Phoenix, Arizona, "determined by Dr. Newcomb." We have seen some of these shells, which have a general resemblance to $M$. rowelli, but are really bleached Sonorella "bones" of an undescribed species. In 1905, one of us (H. A. P.) thought to recognize Newcomb's species in certain small Sonorellas from Sanfords and the adjacent foothills of the Patagonia Mountains, Arizona. On comparison with the type specimen, it is seen that these shells are different, and the new name Sonorella tryoniana has been proposed for them.

The type-speeimen of $M$. rovelli, No. 27517 of the Neweomb collection, Cornell University, is represented in Pate III, fig. 7. It is bleached white, but shows a narrow gray band above the periphery. The surface is glossy, finely, weakly striate. On the antepenult whorl the striæ are slightly irregular, indistinctly broken into long granules. The apex is now broken, but the last part of the embryonic shell remains. It shows a sculpture entirely similar to that of $M$. wolcottiana, $M$. hutsoni and others, - granules lengthened in a spiral direction. The whorls are rather strongly convex, the last one very wide, and deseending rather deeply in front. Aperture is very shortly oval, nearly as high as widle, the peristome expanded, a little thickened within, the margins connected by a strong parietal callus. Height 8.8 , diam. 16; diam. umbilicus 2.8 $\mathrm{mm}$. Aperture $8 \mathrm{~mm}$. high, 9 wide.

In the U. S. National Museum there are two examples (one much broken) of a Micrarionta (Plate III, fig. 6), No. 187478, labelled as colleeted at Tinajas Altas by Maj. E. A. Mearns, Feb. 21, 1894. They agree so fully with Neweomb's type of $M$. rowelli that we 
believe that the habitat of that species can now be fixed. Mearns was in camp at Tinajas Altas, at the east base of the Crila Mountains, from February 14 to 23,1894 , and made a careful explorat ion. ${ }^{7}$ These famous natural rock tanks, which furnish an almost unfailing supply of good water, were an important camping place on the old I uma Trail to California, ${ }^{8}$ and probably are where Frick obtaineu the type of Helix rowelli. In the absence of other information, we propose that Tinajas Altas be considered the type locality.

$M$. rowelli stands close to $M$. hutsoni, but the aperture is more rounded, less oval, and the parietal callus is decidedly longer.

The Mearns example measures: height 8 , diam. $16.3 \mathrm{~mm}$., and is figured on Plate III, fig. 6. The parietal callus is not so heary as in Newcomb's type, which is evidently an old shell.

Micrarionta newcombi n. sp. Plate III, fig. S.

The shell is strongly depressed, openly umbilicate (the umbilicus contained 4 times in the diameter), thin, whitish (dead), with a narrow brown band above the periphery. Surface smoothish, with faint growth strix only. Embryonic whorls showing no seulpture (somewhat worn). Whorls convex, rather slowly increasing. Aperture rounded-lunate. Peristome sharp, the specimen not fully mature.

Height 8, diam. 15.5, width of umbilicus $3.9 \mathrm{~mm} ., 4 \frac{1}{2}$ whorls.

A single specimen of this species was in the Newcomb collection with the type of $M$. rowelli; presumably from the same locality. It is not fully mature, yet should be easily recognized by the strongly depressed shape and large umbilicus, unlike any other known species of the region. It is more depressed and more openly umbilicate than $M$. rixfordi, which appears to be related.

Type in the Newcomb collection, Cornell University.

${ }^{7}$ Mammals of the Mexican Boundary of the United States, Bull. 56 U. S. X. M., 1907, pp. 21, 122, pl. 13, fig. 1 .

8 The Old Yuma Trail. National Geographic Magazine, XII, 1901, p1. 129143 , map on p. 132. 


\section{Explanation of Plates I-VIII.}

Plate I.-Fig. 1.-Sonorella elizabethae P. \& F. Station 276, Canelo Hills, Arizona. Type. No. 130991.

2. Sonorella mustang P. \& F. Station 153, Mustang Range. Type. No. 130992.

3, 4. Bulimulus nigromontanus Dall. Station 225, Pina Blanca canyon, Arizona. No. 43748.

5. Sonorella cotis P. \& F. Whetstone Range. Type. No. 130994.

6. Sonorella cotis P.\& F. Station 293, Whetstone Range. No. 130995.

7. Sonorella patagonica P. \& F. Station 260, Patagonia Mts., Arizona. No. 43719.

8. Sonorella patagonica P. \& F. Station 254, Patagonia Mts. Type. No. 43722 .

9, 10. Sonorella patagonica P. \& F. Station 252, Patagonia Mts. No. 43720 .

11. Sonorella walkeri montana P. \& F. Type. No. 43724.

12. Sonorclla linearis P. \& F. Type. No. 130996.

13. Sonorclla xanthenes P. \& F. Type. No. 118095.

Plate II-Fig. 1-2.-Sonorella ambigua P. \& F. Station 118, Coyote Mts. No. 130997.

2, 4. Sonorella ambigua P.\& F. Station 120, outlier of Kitt's Peak. No. 130998.

5-7. Sonorella ambigua cyclostcma P. \& F. Type (fig. 6) and paratypes. No. $118096 a$.

8. Sonorella sitiens montezuma P. \& F. Type. No. 130583.

9 , 10. Sonorella baboquivariensis P. \& F. Bases of two specimens from station 5, Sycamore canyon, Baboquivari Mts.

11. Sonorclla baboquivariensis depressa P.\& F. Station 58, Tucson Range. No. 130999.

12. Sonorella binneyi imperialis P. \& F. Type. No. 131000.

13. Sonorella berryi P. \& F. Type. No. 131001.

Plate III.-Fig. 1.-Sonorella hinkleyi P. \& F. Type. No. 43735.

2. Sonorella hinkleyi tumacacori P. \& F. Type. No. 131002.

3. Sonorella insignis P. \& F. Type. No. 44040.

4. Sonorella hinkleyi P. \& F. Albino from Station 244. No. 43726.

5. Sonorella cayctanensis P. \& F. Type. No. 43737.

6. Micrarionta rowelli (Newc.). Enlarged views of specimen from Tinajas Altas. No. 187478 U. S. N. M.

7. Micrarionta rowelli (Newc.). Type. Natural size and enlarged. No. 27517 Cornell Univ. Coll.

S. Micrarionta newcombi P. \& F. Type. Enlarged. Cornell Univ. Coll.

Plate IV.-Fig. 1-1a.-Sonorella elizabethae P.\& F. No. 130577. Station 276, Canelo Hills.

2. Sonorella patagonica P. \& F. No. 43721. Station 258, Patagonia Mts.

3. Sonorella cotis P. \& F. No. 119038. Station 3 (1914), Whetstone Mts.

4. Sonorella patagonica P. \&.F. No. 43715. Station 253, Mt. Washington.

5. Sonorella mustang P. \& F. No. 44048. Station 286, Mustang Mits.

6. Sonorella patagonica P. \& F. No. 43719. Station 260, Patagonia Mts.

7. Sonorella patagonica P. \& F. No. 43719. Station 260, Patagonia Mts.

S. Sonorella patagonica P. \& F. No. 43722. Type. Station 254, Washington Mit., Patagonias. 
9. Sonorella cotis P. \& F. No. 11903S. Station 3 (1914). Whetstone Mts.

Plate V.-Fig. 1.-Sonorella ambigua P. \& F. No. 11810s. Station 146, Cababi Hills.

2. Sonorella ambigua P. \& F. No. 118103. Station 146, Cababi Hills,

3. Sonorella ambigua P. \& F. No. 118100. Station 137, Cababi Hills.

4. Sonorella ambigua P. \& F. No. 118078. Station 106. Bobb's Butte.

5. Sonorella ambigua P. \& F. No. 118077. Station 100, Roskruge Range.

6. Sonorella ambigua P. \& F. No. 118079. Station 101, Roskruge Range.

7. Sonorella ambigua P.\& F. No.118081. Station 99, Roskruge Range. 8, 9. Sonorella ambigua P. \& F. No. 118098. Station 120, outlier, N.-W. of Kitt's Peak. Penis and the same opened showing papilla.

10. Sonorella ambigua P. \& F. No. 118080 . Station 93, Robles Hills.

11. Sonorella berryi P.\& F. No. 118086. Station 103, Roskruge Range. From a dry specimen, soaked up.

12. Sonorella ambigua P. \& F. No. 118084. Station 104, Table Top Mts., Roskruge Range.

Plate VI.-Fig. 1.-Sonorella ambigua P. \& F. No. 118054.

2. Sonorella ambigua P. \& F. No. 118089. Station 127, Pictured rocks, 101 miles west of Tucson.

3-4. Sonorella ambigua P. \& F. No. 118093. Station 118, Coyote Mts.

5. Sonorella ambigua P.\& F. No. 118097. Station 130, Pictured rocks.

6. Sonorella ambigua cyclostoma P. \& F. No. 118096. Station 126, 3 miles west of Comovo church.

7. Sonorella sitiens P. \& F. No. 43723. Station 237, Clark's mine canyon, Pajaritos.

8. Sonorella odorata P. \& F. No. 130844. Station 22 (1917), Spud Rock Ranger Station, east side Rincon Mts.

9. Sonorella sitiens P. \& F. No. 43740. Station 224. Pina Blanca canyon

10. Sonorella sitiens montezuma P. \& F. No. 130628. Station 323.

11. Sonorella sitiens comobabiensis P. \& F. No. 118102. Station 133, S. end E. side of Quijotoa Range.

Plate VII.-Fig. 1.-Sonorella binneyi imperialis P. \& F. No. 118111. Station 151, Empire Mts.

2. Sonorella baboquivariensis P. \& F. No. 111557. Station 27 (1910), Baboquivari Mts.

3. Sonorella baboquivariensis P. \& F. No. 111551. Station 21 (1910), Baboquivari Mts.

4. Sonorella b. depressa P. \& F. No. 118059. Station 61, Tucson Range.

5. Sonorella baboquivarienis depressa P. \& F. No. 117519. Station 2, Baboquivari Mts.

6. Sonorella baboquivariensis P. \& F. No. 117528. Station 3.

7. Sonorella b. depressa P. \& F. No. 117527. Station 5, Baboquivari Mts.

8. Sonorella b. depressa P.\& F. No. 118061. Station 58, Tueson Range.

9. Sonorella b. depressa P. \& F. No. 117527. Station 5, Baboquivari Mts.

10. Sonorella b. depressa P. \& F. No. 117522. Station 10, Baboquivari Mts.

11. Sonorella xanthenes P.\& F. No. 118095. Tritt's Peak.

12. Sonorella baboquivariensis var. 118085. Station 117 (1918), rincon of chief Pablo. 
13. Sonorella baboquivariensis var. No. 1180S5. Station 117 (1918).

14. Sonorella tumamoecnsis P. \& F. No. 117524. Desert Laboratory, Tueson.

15. Sonorella tumamocensis P. \&. F. variety. No. 118090. Station 110, Roskruge Range.

Plate VIII.-Fig. 1.-Sonorella insignis P. \& F. No. 44010. Station 304 Whetstone Mts.

2-3. Sonorella parva (Pils). No. 44054. Station 270, Huachuca Range. 4. Sonorella hinkleyi tumacacori P. \& F. No. 43731. Station 209, Tumacúcori Mts.

5. Sonorella hinkleyi P.\& F. No.43726. Station 244, Cayetano Range.

6. Sonorella tryoniana P. \& F. No. 118104. Station 149, Empire Range.

7. Sonorella linkleyi P. \& F. No. 43735. Station 2431, S. peak Cayetano Mts.

8. Sonorella hesterna P. \& F. No. 118058. Station 50, N. end Santa Rita Range.

9. Sonorella hesterna P. \& F. penis papilla. The direction of coil was Inadvertently reversed by the camera lucida. 


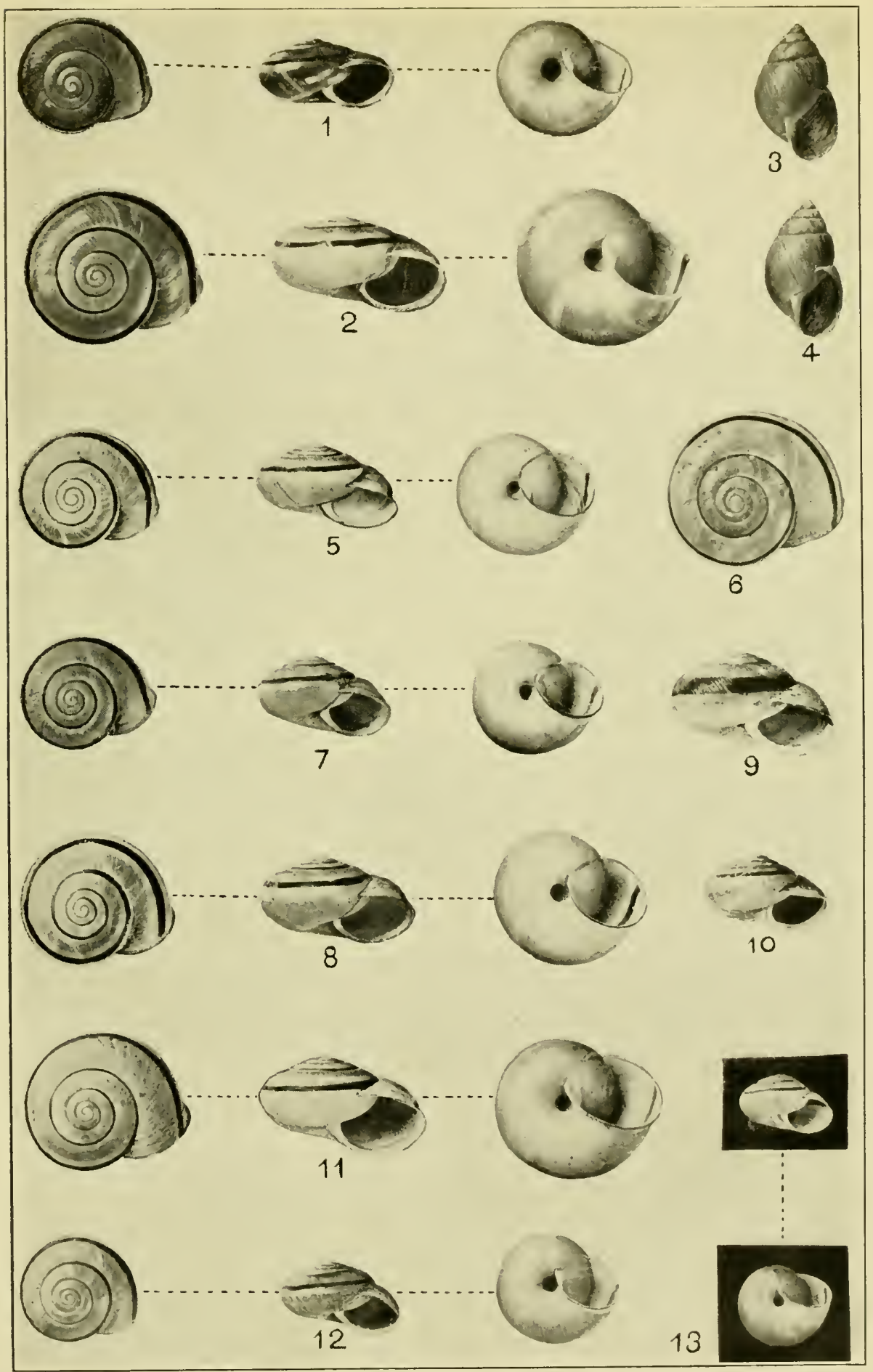

PILSBRY AND FERRISS: MOLLUSCA OF SOUTHWESTERN STATES,--XI. 



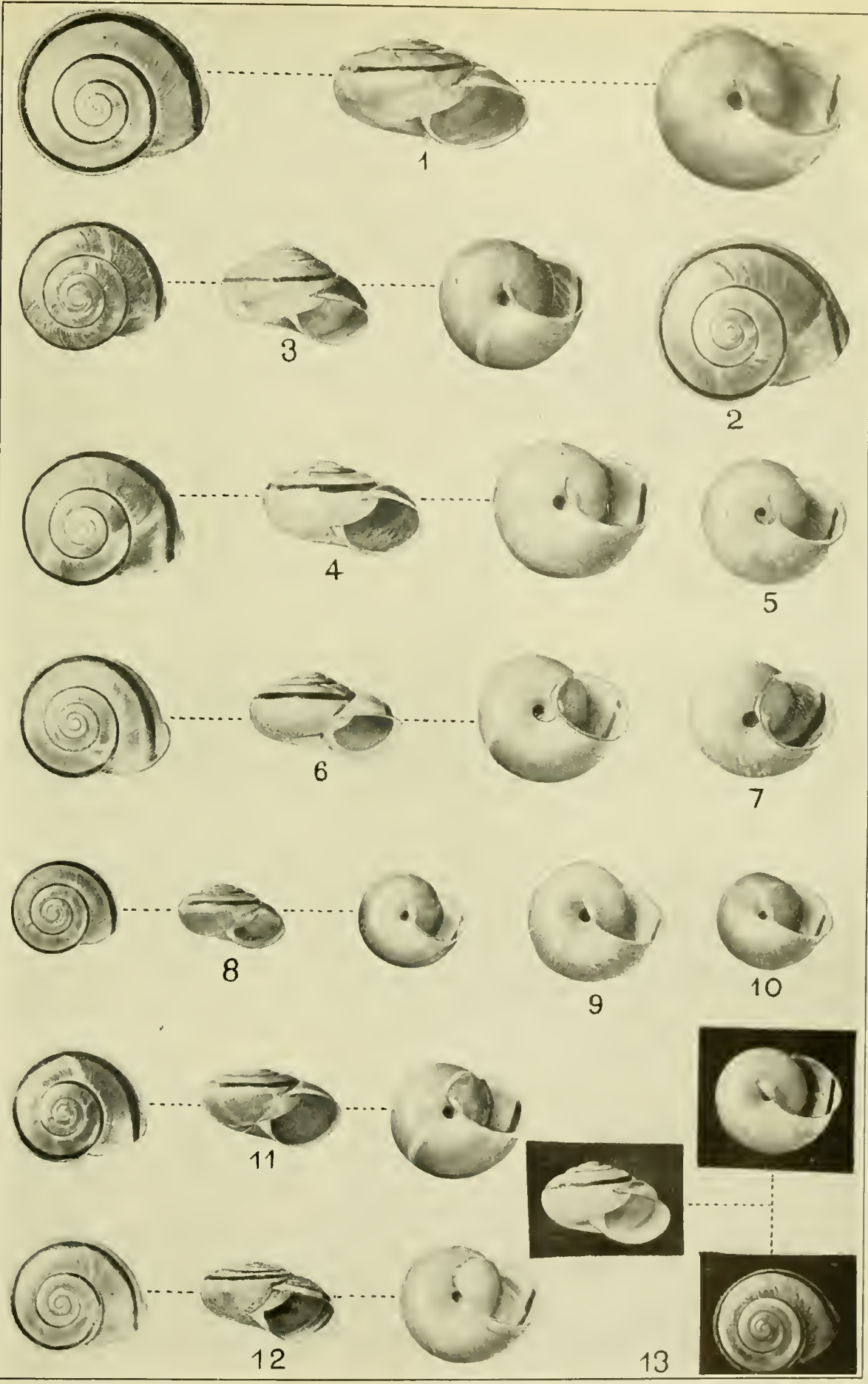

PILSBRY AND FERRISS: MOLLUSCA OF SOUTHWESTERN STATES,-XI. 



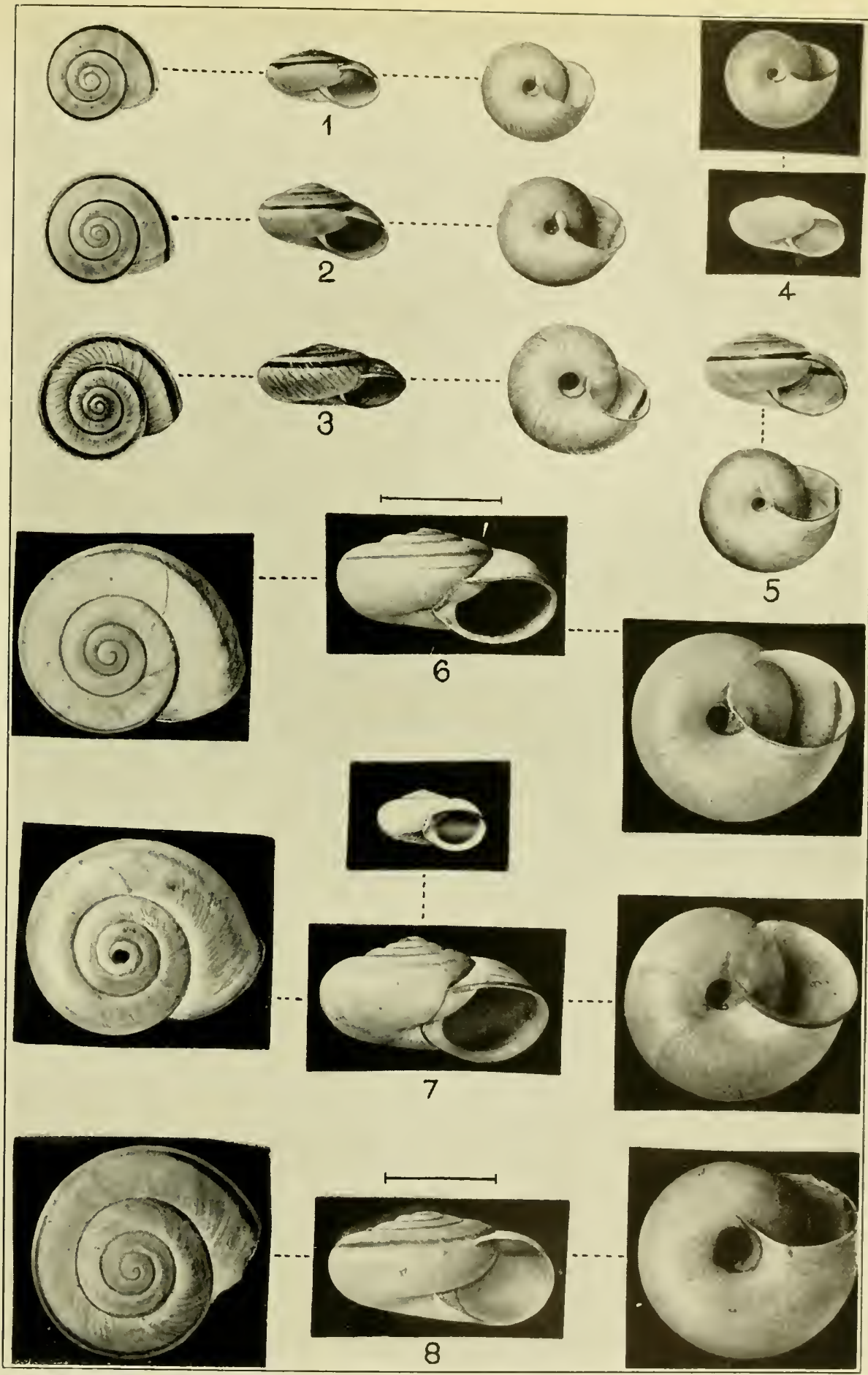

PILSBRY AND FERRISS: MOLLUSCA OF SOUTHWESTERN STATES,- XI. 

PROC. ACAD. NAT. SCI. PHILA. 1923.

PLATE IV.

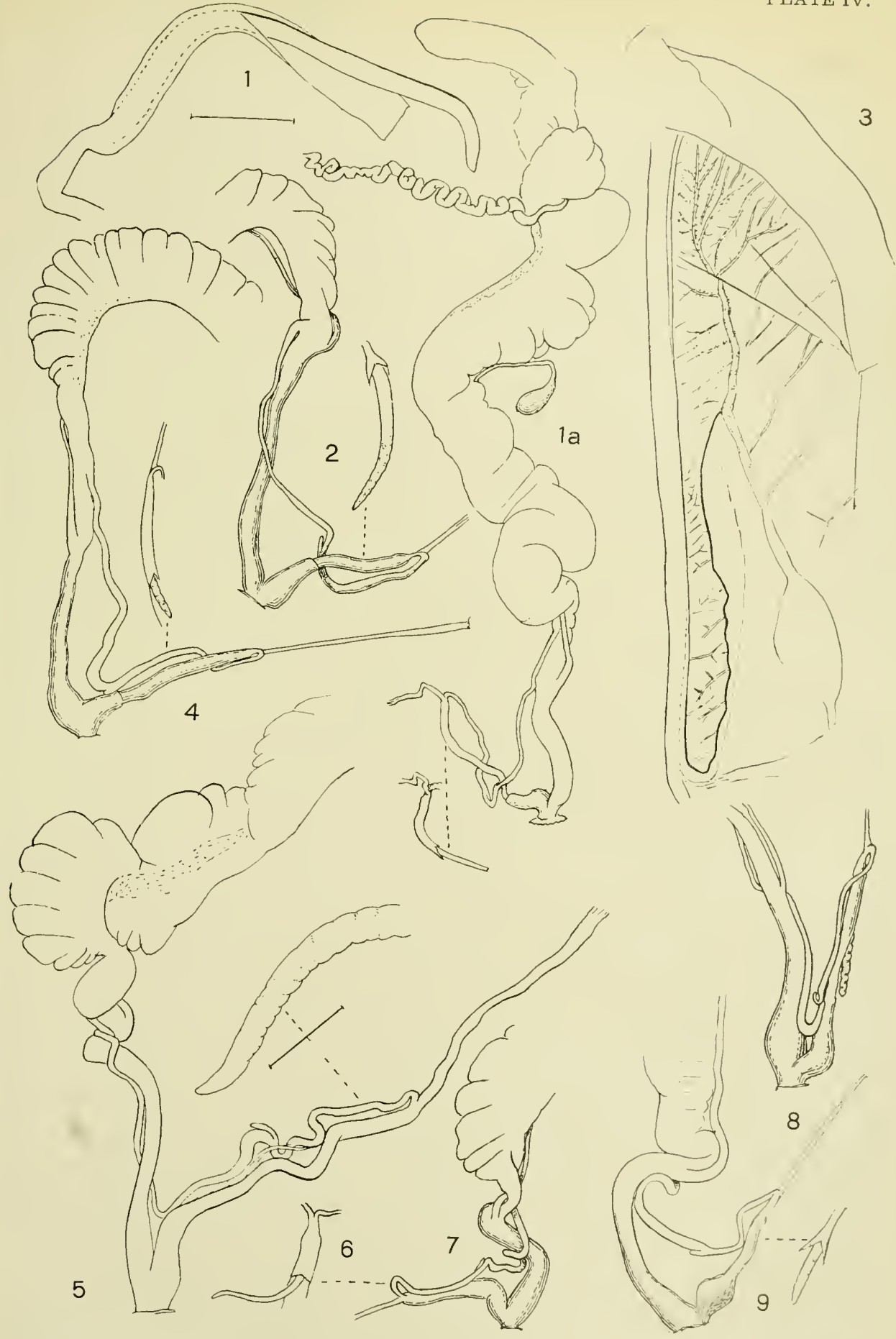

PILSBRY AND FERRISS: MOLLUSCA OF SOUTHWESTERN STATES, XI. 



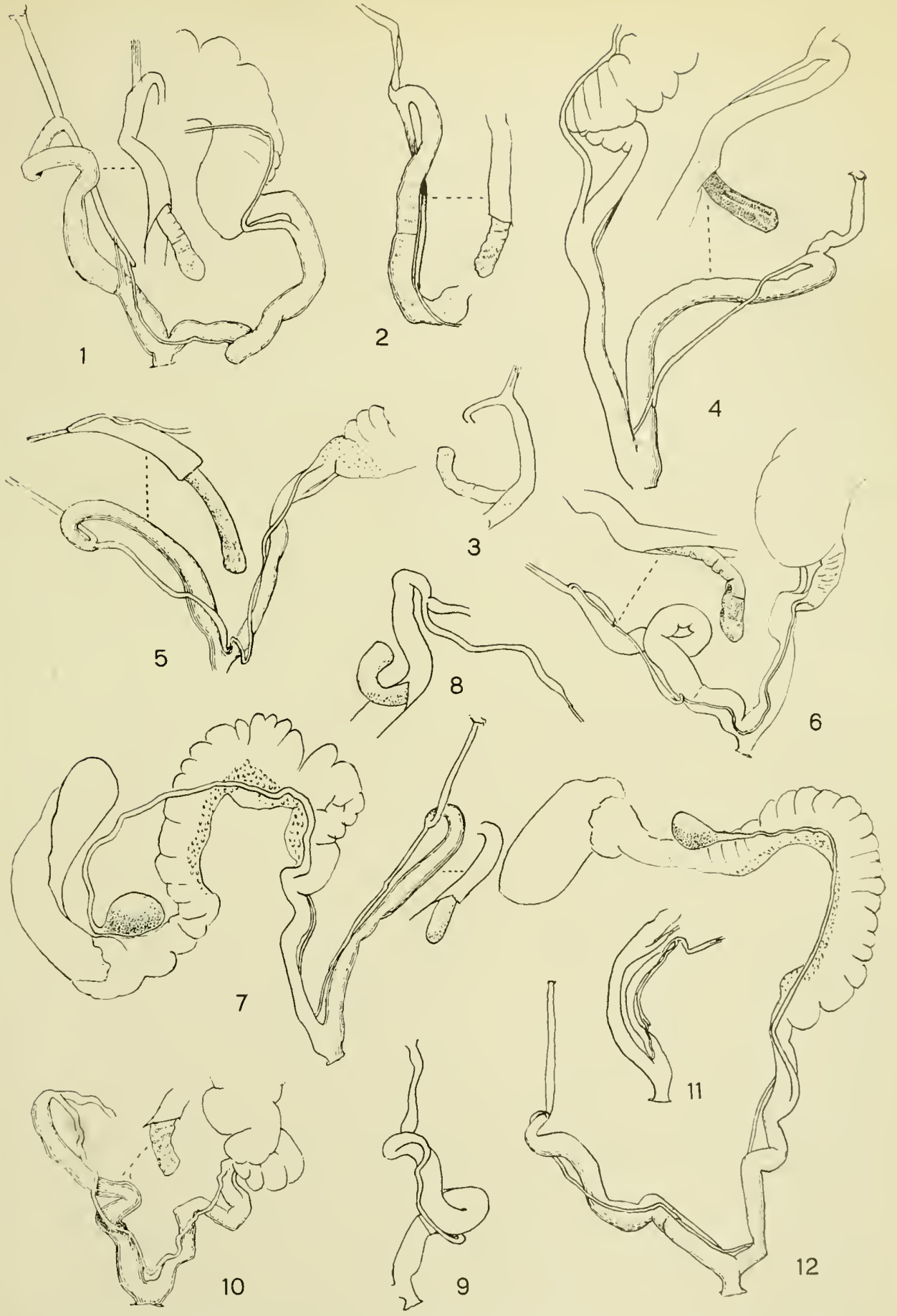

PILSBRY AND FERRISS: MOLLUSCA OF SOUTHWESTERN STATES.-XI. 

PROC. ACAD. NAT. SCI. PHILA, 1923.

PLATE VI.

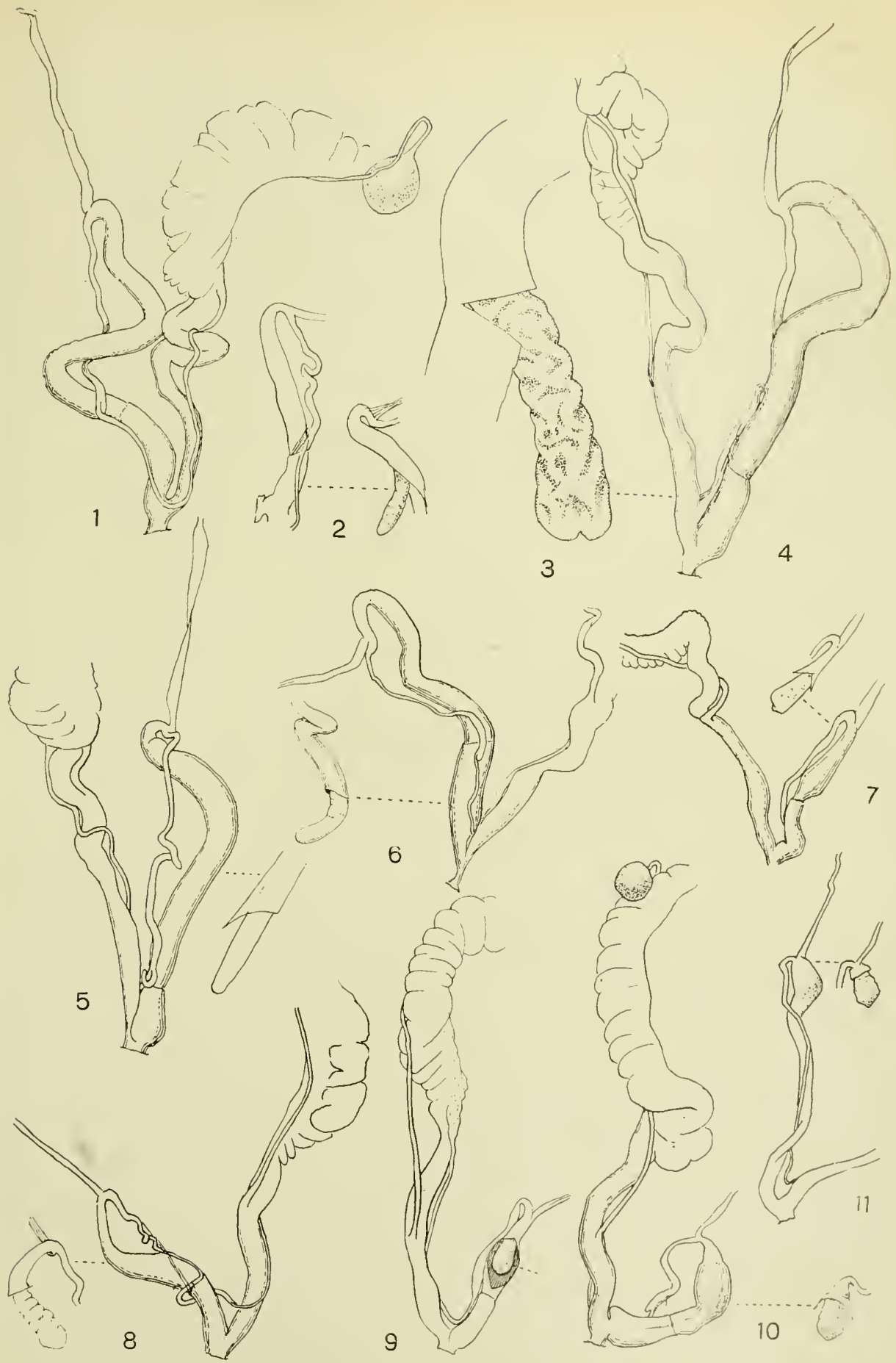

PILSBRY AND FERRISS: MOLLUSCA OF SOUTHWESTERN STATES,-XI. 

PROC. ACAD, NAT. SCI. PHILA. 1923.

PLATE VII.

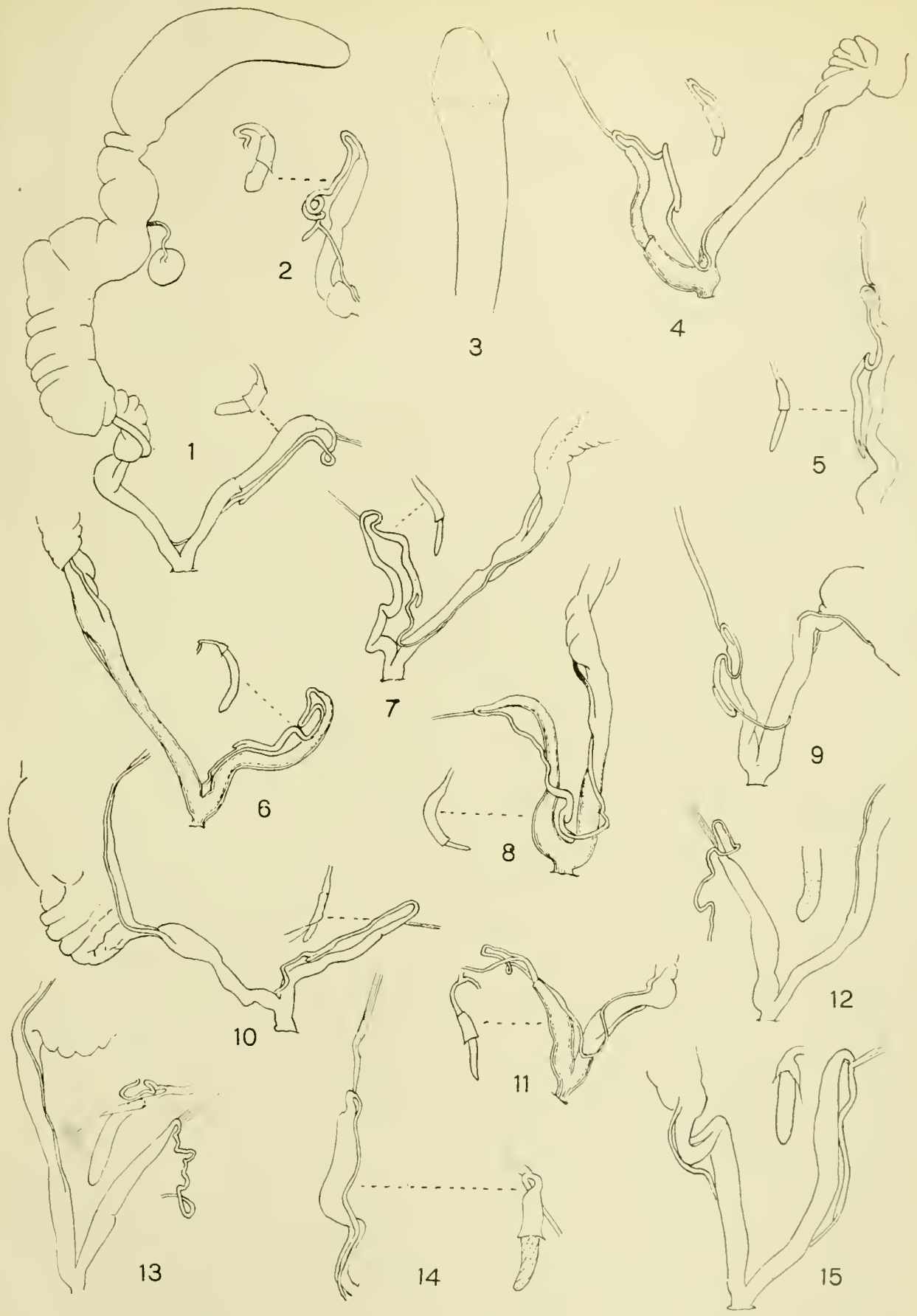

PILSBRY AND FERRISS: MOLLUSCA OF SOUTHWESTERN STATES,-XI. 

PROC. ACAD. NAT. SCI. PHILA. 1923.
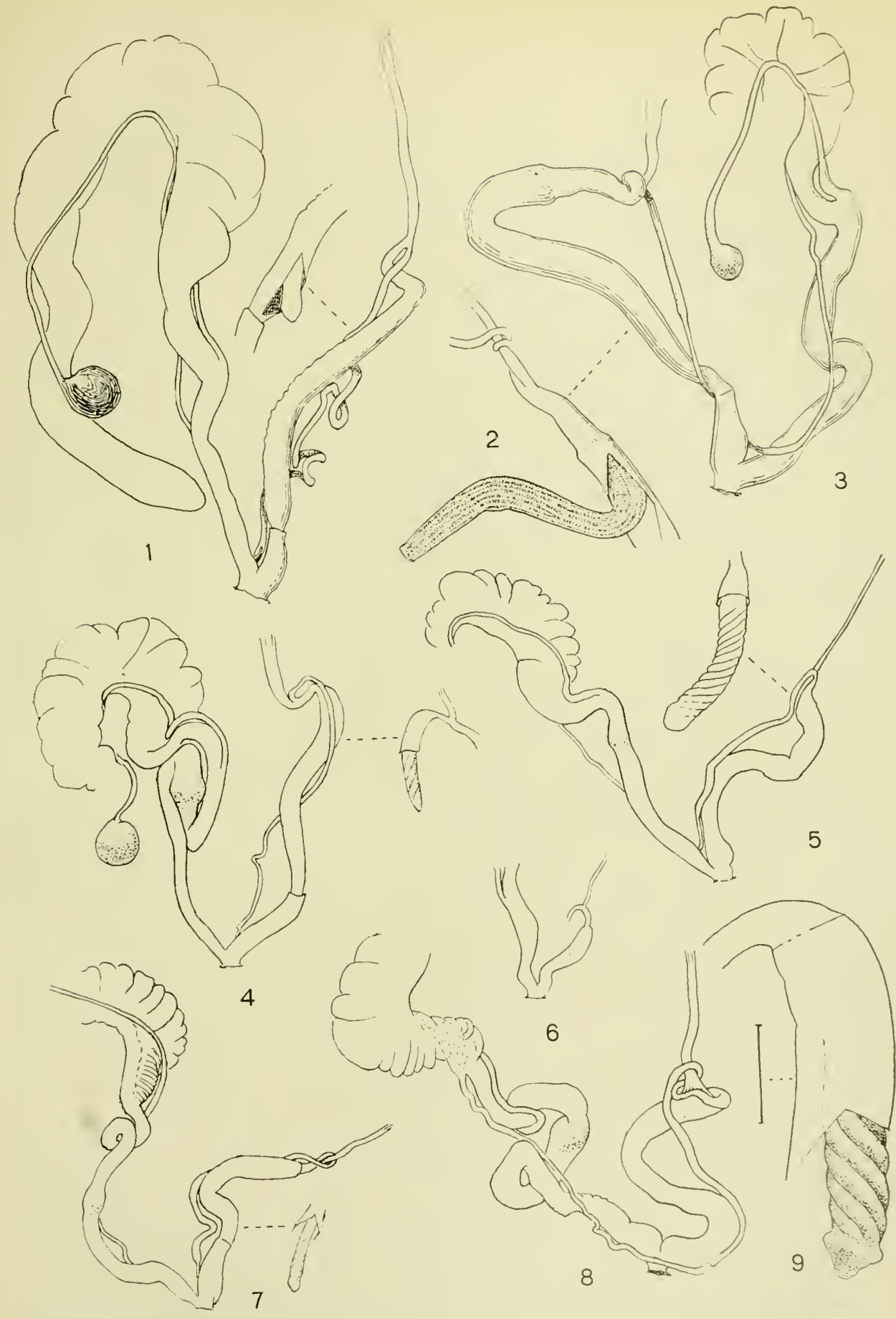

PILSBRY AND FERRISS: MOLLUSCA OF SOUTHWESTERN STATES,- XI. 









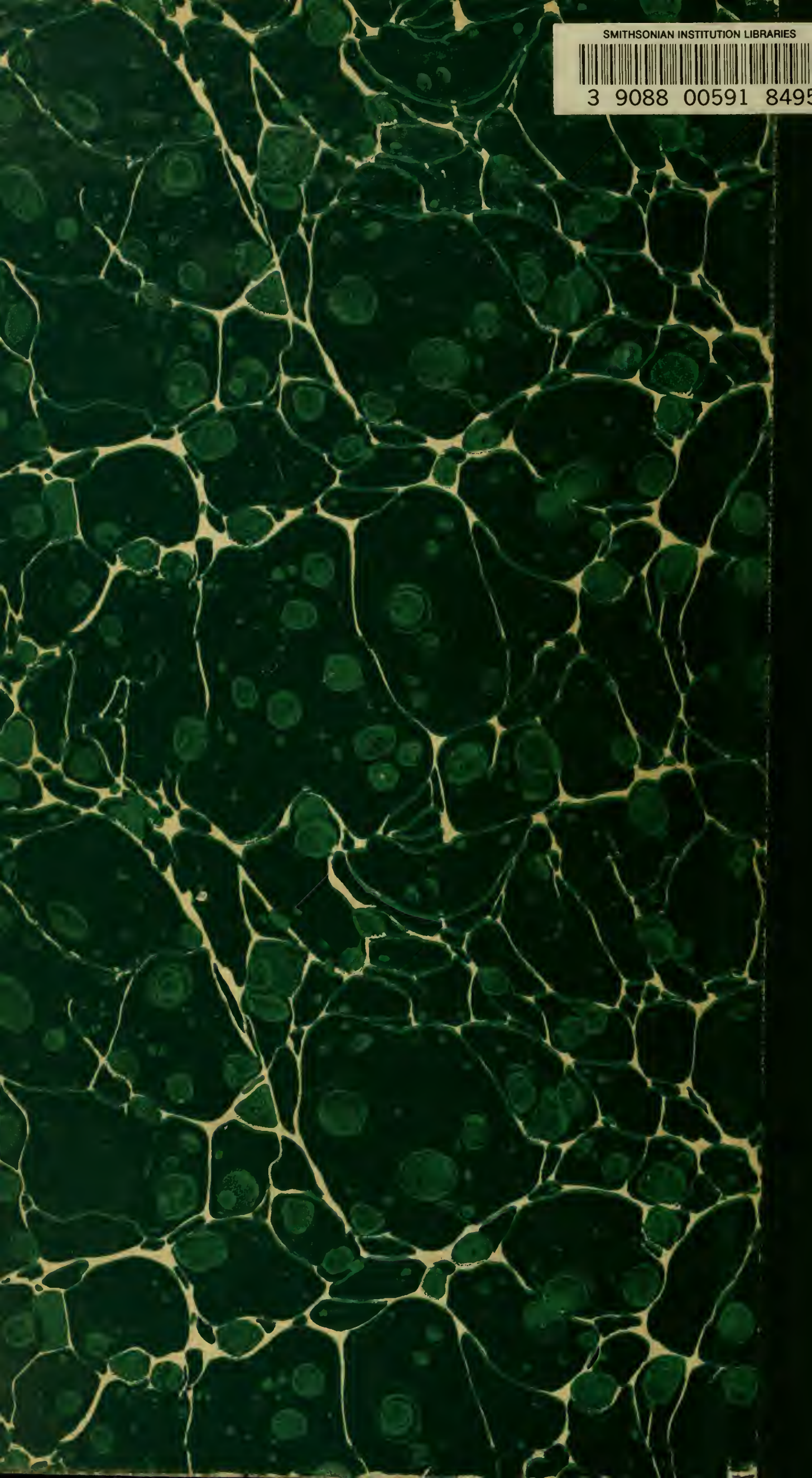

